ÖSTERREICHISCHE AKADEMIE DER WISSENSCHAFTEN PHILOSOPHISCH-HISTORISCHE KLASSE DENKSCHRIFTEN, 529. BAND

VERÖFFENTLICHUNGEN ZUM

SCHRIFT- UND BUCHWESEN DES MITTELALTERS

REIHE IV, BAND 9

URSULA STAMPFER - CLAUDIA SCHRETTER-PICKER

\title{
DIE MITTELALTERLICHEN HANDSCHRIFTEN IN DER BIBLIOTHEK DES AUGUSTINER CHORHERRENSTIFTES NEUSTIFT
}

\author{
UNTER MITARBEIT VON \\ PETRA AUSSERLECHNER, GIULIA GABRIELLI, \\ PATRIK KENNEL, GABRIELA KOMPATSCHER GUFLER, \\ WALTER NEUHAUSER, ANNA PINTER, \\ SUSANNE RISCHPLER, MARIA STIEGLECKER, \\ LAV ŠUBARIĆ
}


Ursula Stampfer - Claudia Schretter-Picker

DIE MITTELALTERLICHEN HANDSCHRIFTEN

IN DER BIBLIOTHEK DES

AUGUSTINER CHORHERRENSTIFTES NEUSTIFT 
ÖSTERREICHISCHE AKADEMIE DER WISSENSCHAFTEN

PHILOSOPHISCH-HISTORISCHE KLASSE

DENKSCHRIFTEN, 529. BAND

\author{
VERÖFFENTLICHUNGEN ZUM \\ SCHRIFT- UND BUCHWESEN DES MITTELALTERS \\ HERAUSGEGEBEN VON WALTER POHL
}

REIHE IV

MONOGRAPHIEN

HERAUSGEGEBEN VON

CHRISTINE GLASSNER UND MARIA THEISEN

BAND 9 
URSULA STAMPFER - CLAUDIA SCHRETTER-PICKER

\author{
DIE MITTELALTERLICHEN \\ HANDSCHRIFTEN \\ IN DER BIBLIOTHEK DES \\ AUGUSTINER CHORHERRENSTIFTES \\ NEUSTIFT
}

\author{
UNTER MITARBEIT VON \\ PETRA AUSSERLECHNER, GIULIA GABRIELLI, \\ PATRIK KENNEL, GABRIELA KOMPATSCHER GUFLER, \\ WALTER NEUHAUSER, ANNA PINTER, \\ SUSANNE RISCHPLER, MARIA STIEGLECKER, \\ LAV ŠUBARIĆ
}


Angenommen durch die Publikationskommission der philosophisch-historischen Klasse der ÖAW: Michael Alram, Bert G. Fragner, Andre Gingrich, Hermann Hunger, Sigrid Jalkotzy-Deger, Renate Pillinger, Franz Rainer, Oliver Jens Schmitt, Danuta Shanzer, Peter Wiesinger, Waldemar Zacharasiewicz

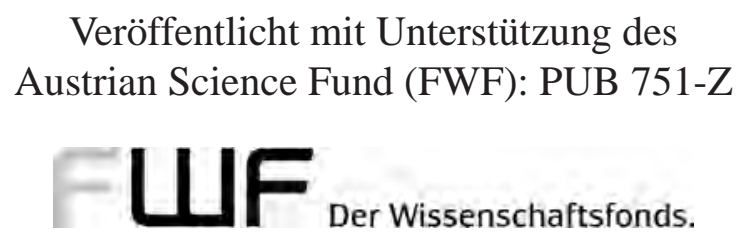

Open Access: Wo nicht anders festgehalten, ist diese Publikation lizenziert unter der Creative Commons Lizenz Namensnennung 4.0

Open access: Except where otherwise noted, this work is licensed

under a Creative Commons Attribution 4.0 Unported License. To view a copy of this licence, visit http://creativecommons.org/licenses/by/4.0/

Bibliografische Information der Deutschen Bibliothek

Die Deutsche Bibliothek verzeichnet diese Publikation in der Deutschen Nationalbibliografie, detaillierte bibliografische Daten sind im Internet über $<$ http://dnb.ddb.de $>$ abrufbar.

Diese Publikation wurde einem anonymen, internationalen Begutachtungsverfahren unterzogen.

This publication was subject to international and anonymous peer review.

Peer review is an essential part of the Austrian Academy of Sciences Press evaluation process. Before any book can be accepted for publication, it is assessed by international specialists and ultimately must be approved by the Austrian Academy of Sciences Publication Committee.

Die verwendete Papiersorte in dieser Publikation ist DIN EN ISO 9706 zertifiziert und erfüllt die Voraussetzung für eine dauerhafte Archivierung von schriftlichem Kulturgut.

Bestimmte Rechte vorbehalten.

ISBN 978-3-7001-8625-0

Copyright (C) Österreichische Akademie der Wissenschaften, Wien 2021

Satz: Auer Grafik Buch Web, 1050 Wien

Druck: Prime Rate, Budapest

https://epub.oeaw.ac.at/8625-0

https://verlag.oeaw.ac.at

Made in Europe 


\section{Inhaltsübersicht}

1. DIE STIFTSBIBLIOTHEK VON NEUSTIFT: GESCHICHTE DER BIBLIOTHEK UND DES BESTANDES

2. ÜBERSICHT ÜBER DEN HANDSCHRIFTENBESTAND ………..................................... 29

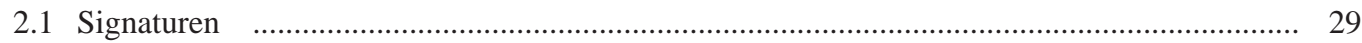

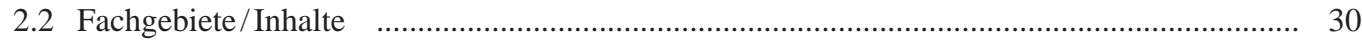

2.3 Zeitliche Verteilung ...................................................................................................... 31

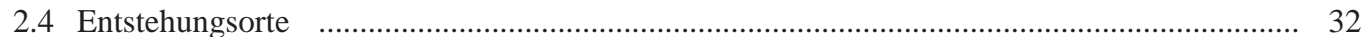

2.5 Schriften und Schreiberhände $\quad$......................................................................................... 33

2.6 Beschreibstoffe ............................................................................................................ 33

2.7 Sprachliche Verteilung ………………………………………………………......... 34

2.8 Provenienzen und Besitzeinträge ....................................................................................... 34

3. BESONDERHEITEN DER ERSCHLIESSUNG UND IHRE ERGEBNISSE ......................... 37

3.1 Wasserzeichen ……………………………………………………………….... 37

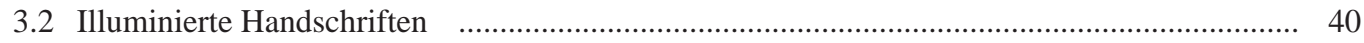

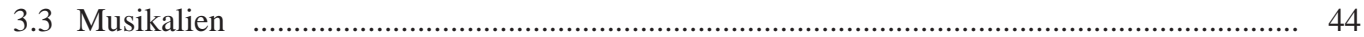

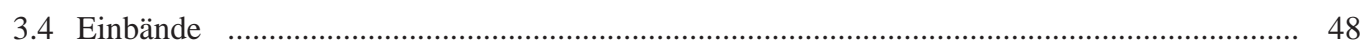

4. BISHERIGE ERSCHLIESSUNG DES HANDSCHRIFTENBESTANDES ........................... 55

5. ZUR ANLAGE DES KATALOGS _....................................................................... 57

5.1 Zur Erschließungsmethode ............................................................................................. 57

5.2 Zur Anlage der Handschriftenbeschreibungen ................................................................. 58 


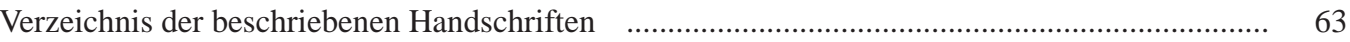

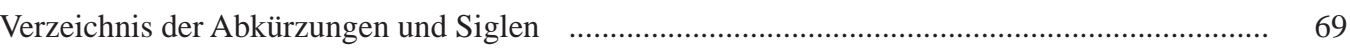

Verzeichnis der abgekürzt zitierten Literatur $\quad$........................................................................... 71

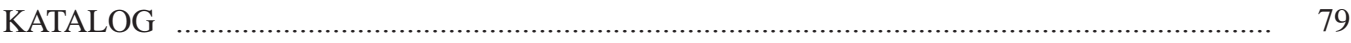

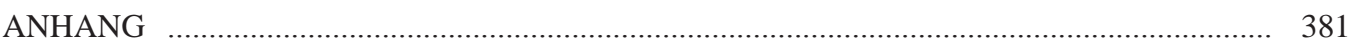

Verzeichnis der heute noch an der ULB Tirol befindlichen, zu Beginn des 19. Jahrhunderts aus Neustift dorthin gebrachten Handschriften

Konkordanz Signaturen der Stiftsbibliothek Neustift - Projektnummern der

Hill Monastic Manuscript Library ............................................................................................ 390

Verzeichnis der Heiligenfeste in den Missalien, Gradualien, Antiphonarien und Brevieren ....... 392

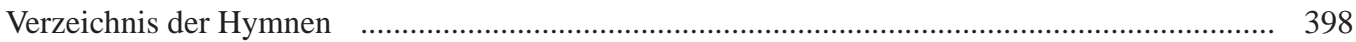

Verzeichnis der Reimoffizien ............................................................................................. 405

Verzeichnis der Sequenzen $\quad$.................................................................................................. 406

Verzeichnis und Abbildungen der Abreibungen ....................................................................... 411

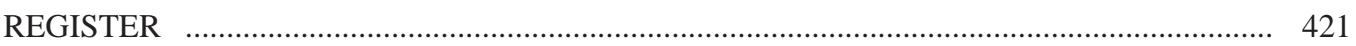

Textanfänge (Incipit) ............................................................................................................ 423

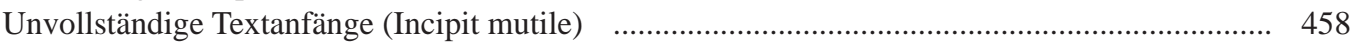

Verfasser und Werktitel ................................................................................................ 461

Vorbesitzer, Benützer, Auftraggeber, Widmungsträger und Käufer $\quad$............................................ 470

Schreiber, Schreiberverse und -sprüche .......................................................................... 471

Entstehungszeiten (Datierungen) ....................................................................................... 472

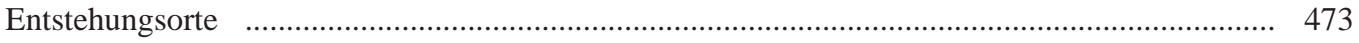




\section{Vorwort}

Die vorliegende Publikation ist das Ergebnis eines von der Autonomen Provinz Bozen-Südtirol, Abteilung Bildungsförderung, Universität und Forschung geförderten Forschungsprojektes (1. Wettbewerbsausschreibung für Projekte im Bereich der wissenschaftlichen Forschung der Autonomen Provinz Bozen-Südtirol). Zwischen 2011 und 2014 konnten in diesem Kooperationsprojekt zwischen der Philosophisch-Theologischen Hochschule Brixen und der Universitäts- und Landesbibliothek Tirol (im Folgenden „ULB Tirol“) in Innsbruck die mittelalterlichen Handschriften in der Bibliothek des Augustiner Chorherrenstiftes Neustift und in der Bibliothek des Priesterseminars in Brixen bearbeitet werden. ${ }^{1}$ Die geografische Nähe des Klosters Neustift zum Brixner Priesterseminar und die Wurzeln bzw. Entwicklungen der beiden Institutionen bedingen vielfache wechselseitige Beziehungen, die sich nicht zuletzt in ihren Büchersammlungen niederschlagen. Aus diesem Grund schien eine parallele Bearbeitung der beiden Bestände äußerst sinnvoll. So konnten die Bezüge klar herausgearbeitet und wertvolle Synergieeffekte erzielt werden. In den vorliegenden Beschreibungen der Neustifter Handschriften sind daher auch immer wieder Verweise auf die Bestände des Priesterseminars zu finden.

Seit der vorübergehenden Auflösung des Stiftes in der Zeit der Zugehörigkeit Tirols zu Bayern (1806-1814) befindet sich ein Teil der Neustifter Handschriften in den Beständen der ULB Tirol. Da sie dort bereits erschlossen wurden², konnte durch das Projekt eine „virtuelle“ Zusammenführung der heute getrennten Bestände ermöglicht werden.

Zum Gelingen des Katalogs haben zahlreiche Personen und Institutionen entscheidend beigetragen: An erster Stelle geht der Dank an die Autonome Provinz Bozen-Südtirol für ihre großzügige finanzielle Förderung.

Nicht möglich gewesen wäre das Projekt ohne das Vertrauen von Prälat Prof. Dr. Franz Georg Untergaßmair, Altabt des Stiftes Neustift, der den Bearbeiterinnen und Bearbeitern ungehinderten Zutritt zu den wertvollsten Schätzen der Stiftsbibliothek gewährte und sie im Kloster gastfreundlich aufnahm. Herzlich gedankt sei auch dem ehemaligen Stiftsdechant und Stiftsarchivar Herrn Dr. Theobald Innerhofer (gest. 2012), der das Unternehmen mit großem Interesse und sachkundiger Hilfe begleitete. Ebenso danken wir dem ehemaligen Stiftsbibliothekar Herrn Dipl.-Rpfl. Mag. Rüdiger Weinstrauch für seine vielfältige fachliche und persönliche Unterstützung. Ein Dank gebührt auch dem Prälaten Mag. Eduard Fischnaller (seit 2015), der nach Abschluss der Erschließungsarbeiten die Kosten für die in Zusammenarbeit mit der Universitätsbibliothek Bozen durchgeführte Digitalisierung des Handschriftenbestandes übernahm.

Für die Bereitschaft, das Gesamtprojekt zur Erschließung des Bestandes in der Stiftsbibliothek Neustift und in der Priesterseminarbibliothek in Brixen an der Philosophisch-Theologischen Hochschule Brixen organisatorisch ansiedeln zu dürfen, sei besonders dem ehemaligen Regens des Priester-

Der Katalog zu den mittelalterlichen Handschriften des Brixner Priesterseminars ist in Vorbereitung.

2 Das seitens des Fonds zur Förderung der wissenschaftlichen Forschung in Österreich (FWF) geförderte Langzeitprojekt zur Erschließung der Handschriften der ULB Tirol in Innsbruck konnte 2017 abgeschlossen werden. Unter der Leitung von Walter Neuhauser (gest. 2016) erschienen seit 1987 insgesamt zehn Teilbände, die auch die ehemaligen Neustifter Bestände mitberücksichtigen; vgl. Anm. 100. 
seminars und seit 2011 Bischof der Diözese Bozen-Brixen, Prof. Dr. Ivo Muser, den Bibliotheksdirektoren, Prof. Dr. Arnold Stiglmair und seinem Nachfolger Prof. Dr. Ulrich Fistill, sowie dem Verwalter Dr. Thomas Schraffl gedankt. Dank gilt auch Mag. Claudia Kaser und ihrem Team der Bibliothek der Philosophisch-Theologischen Hochschule für die Möglichkeit, dort arbeiten und recherchieren zu dürfen.

Gedankt sei der Leopold-Franzens-Universität Innsbruck und dem ehemaligen Rektor Univ.-Prof. Dr. Karlheinz Töchterle, der diesem Projektunternehmen von Anfang an positiv gegenüberstand und so die Funktion der ULB Tirol als Kooperationspartner ermöglichte.

Den Mitarbeitenden in der Verwaltung beider Institutionen ein herzliches Danke für ihre Begleitung bei der Projektanbahnung und -abwicklung.

Die ULB Tirol mit ihrem früheren Direktor HR Dr. Martin Wieser (bis 2014) begrüßte nicht nur die Initiative zur Erschließung dieses Komplementärbestandes zu den in Innsbruck verwahrten Handschriften Neustifter Provenienz. Er stellte dem Projekt auch über die Projektmittel hinausgehende personelle, infrastrukturelle und finanzielle Ressourcen zur Verfügung. Ihm und seinen Nachfolgerinnen im Amt, Dr. Elisabeth Frasnelli (2014-2015) und HR Mag. Eva Ramminger (seit 2016), sowie dem interimistischen Leiter HR Dr. Klaus Niedermair (2015-2016), sei für ihr stetes Wohlwollen und ihre Unterstützung gedankt.

Der Abteilung für Sondersammlungen mit ihrem Abteilungsleiter OR Mag. Peter Zerlauth gebührt nicht nur für die Bereitstellung der dortigen Infrastruktur und die Schaffung idealer Arbeitsbedingungen, sondern auch für mannigfache Hilfestellungen und das stete Entgegenkommen ein großer Dank, ebenso dem ehemaligen Mitarbeiter Michael Springer für seine Unterstützung.

Ein abschließender Dank gilt der Direktorin der Universitätsbibliothek Bozen, Mag. Gerda Winkler, die die Digitalisierung der Neustifter Bestände unter der Ägide ihrer Mitarbeiterin Mag. Dr. Ursula Stampfer (2017-2020) begrüßte und förderte.

Die Projektleitung oblag Mag. Dr. Ursula Stampfer, die hierfür mit Projektmitteln von der Philosophisch-Theologischen Hochschule in Brixen angestellt wurde. Für die ULB Tirol als Projektpartner wurde MMag. Dr. Claudia Schretter-Picker im Rahmen ihrer Tätigkeit an der dortigen Abteilung für Sondersammlungen die Verantwortung übertragen. Beide übernahmen neben der Projektadministration und Qualitätssicherung auch die Beschreibung von Handschriften sowie die Redaktion bzw. die Vorbereitung der Drucklegung. An der Beschreibung der Handschriften arbeiteten mehrere Fachkräfte mit unterschiedlichem Beschäftigungsausmaß und unterschiedlicher Anstellungsdauer mit, angesiedelt jeweils an der Abteilung für Sondersammlungen der ULB Tirol (in alphabetischer Reihenfolge): Mag. Petra Ausserlechner (2011, philosophisch-theologische Handschriften), Mag. Patrik Kennel (2013-2014, historisch-juristische Handschriften), MMag. Anna Pinter (2013-2014, philosophisch-theologische sowie philologische Handschriften, Redaktion). Die kunsthistorische Analyse und Auswertung übernahm Dr. Susanne Rischpler im Rahmen eines Werkvertrags (2012-2014). Mit der Erstellung der Register wurde MMag. Sissy Mederle im Rahmen eines Werkvertrages (2013-2014) betraut, die Überarbeitung und Vereinheitlichung wurde durch die Projektleiterinnen vorgenommen. Die Erstellung der Anhänge sowie die Durchreibungen der Einbände besorgte Mag. Dr. Ursula Stampfer, fallweise mit Unterstützung von PraktikantInnen. Ein Dank geht an Gionata Brusa MA und Mag. Vera-Maria Kathrein für die kritische Durchsicht der liturgischen Handschriften.

Zurückgegriffen werden konnte auch auf die Unterstützung „von außen“, nämlich von Spezialisten, die bei der Bearbeitung ohne Kosten für das Projektbudget aktiv mitwirkten. Ihnen sei herzlichst gedankt: Ao. Univ.-Prof. Mag. Dr. Gabriela Kompatscher Gufler (philologische Handschriften) sowie Ass.-Prof. Mag. Dr. Lav Šubarić (naturwissenschaftliche Handschriften) vom Institut für Klassische Philologie und Neulateinische Studien der Universität Innsbruck bzw. vom Ludwig-Boltzmann-Institut für Neulateinische Studien in Innsbruck. Dr. Giulia Gabrielli (Freie Universität Bozen, Fakultät für Bildungswissenschaften Brixen) widmete sich musikwissenschaftlichen Fragen. Die betaradiografischen Aufnahmen und die Bestimmung der Wasserzeichen besorgte Mag. Dr. Maria Stieglecker MAS im 
Rahmen ihrer Tätigkeit an der Abteilung Schrift- und Buchwesen des Mittelalters am Institut für Mittelalterforschung der Österreichischen Akademie der Wissenschaften (im Folgenden „ÖAW“).

Großer Dank gebührt HR Mag. Dr. Walter Neuhauser (gest. 2016), früherer Direktor der ULB Tirol und ehemaliger Leiter des 2017 abgeschlossenen Langzeitprojektes zur Erschließung der Handschriften der ULB Tirol. Mit Interesse verfolgte und förderte er den Fortgang der Arbeit und gab im Hinblick auf konkrete Fragen zum Handschriftenbestand der Stiftsbibliothek Neustift und zur Kodikologie im Allgemeinen wichtige Anregungen und unverzichtbare Hinweise. Darüber hinaus brachte er sich in die praktische Erschließungsarbeit vor Ort und an der Abteilung für Sondersammlungen durch die Übernahme von Beschreibungen maßgeblich ein. Ihm sei auch für die kritische Durchsicht der Katalogisate herzlich gedankt.

Bei fachspezifischen Einzelfragen konnten die Bearbeiterinnen und Bearbeiter auf die Hilfe zahlreicher Kolleginnen und Kollegen sowie Experten (vgl. entsprechende Hinweise bei den einzelnen Katalogisaten) zählen, wofür wir ihnen sehr zu Dank verpflichtet sind.

Zudem bedanken wir uns bei den Verantwortlichen der Handschriftenabteilungen anderer Bibliotheken, insbesondere der Kathedralbibliothek der Erzdiözese Esztergom-Budapest, der Österreichischen Nationalbibliothek (im Folgenden „ÖNB“) in Wien und der Bayerischen Staatsbibliothek (im Folgenden „BSB“) in München, die durch die Gewährung guter Arbeitsbedingungen den Fortgang der Katalogisierung förderten.

Für die Durchsicht des Manuskriptes und wertvolle Anregungen und Hinweise im Rahmen eines Werkvertrages (2014) ist Dr. Alois Haidinger und Dr. Franz Lackner herzlich zu danken. Für die Letztdurchsicht des Manuskripts im Rahmen ihrer Tätigkeit an der Abteilung für Sondersammlungen der ULB Tirol gilt MMag. Magdalena Rufin Dank. Ein Dank gebührt MMag. Anna Pinter für das umsichtige Lektorat.

Die erhobenen Daten wurden bereits während der Erschließung über das von Dr. Alois Haidinger entwickelte und von DI Emanuel Wenger und Mag. Dr. Christine Glaßner betreute Handschriftenportal www.manuscripta.at zugänglich gemacht. Ihnen sei für die gute Zusammenarbeit und das stete Entgegenkommen herzlich gedankt. Im Sinne des Open Access sind die Daten des gedruckten Katalogs über dieses Portal abrufbar. Ebendort werden auch die dank der großzügigen Finanzierung seitens des Klosters Neustift von den beiden Werkvertragsnehmerinnen Edith Kapeller BA MA MA und Mag. Julia Schön MA erstellten Digitalisate zur Verfügung gestellt. Für Unterstützung bei der Abwicklung der Digitalisierung ist dem Bibliothekar der Klosterneuburger Stiftsbibliothek MMag. Dr. Martin Haltrich zu danken. In Zusammenarbeit zwischen der Universitätsbibliothek Bozen und der Universität Venedig (Prof. Paolo Eleuteri) ist auch eine Dateneingabe in die italienische Datenbank www.nuovabibliotecamanoscritta.it geplant.

Besonderer Dank gilt der ÖAW, insbesondere dem Direktor des Instituts für Mittelalterforschung, Univ.-Prof. Mag. Dr. Walter Pohl, der Leiterin der Abteilung für Schrift- und Buchwesen des Mittelalters, Mag. Dr. Christine Glaßner, dem Obmann der Publikationskommission, Univ.-Prof. Dr. Hermann Hunger, sowie dem Verlag unter der Leitung von Dipl.-Medienberater Thomas Jentzsch für die Aufnahme dieser Publikation in die Reihe der „Denkschriften“.

Ursula Stampfer und Claudia Schretter-Picker Völs am Schlern/Innsbruck, im Frühjahr 2021 



\section{TEIL I: EINLEITUNG}





\title{
1. Die Stiftsbibliothek von Neustift
}

\section{Geschichte der Bibliothek und des Bestandes}

\author{
Ursula Stampfer
}

„Neustift besitzt eine große Kirche mit kostbarem Ornat und eine gute Bücherei.“ So charakterisiert der Augsburger Dominikaner Felix Faber 1483 das Augustiner Chorherrenstift Neustift bei Brixen, als er auf seinem Weg ins Heilige Land dort Halt macht. ${ }^{3}$ Auch der Besucher von heute ist von der lichtdurchfluteten und mit Fresken reich ausgestatteten Kirche sowie vom großen Bibliothekssaal tief beeindruckt.

In der Tat stellt die Neustifter Bibliothek seit dem späten Mittelalter die bedeutendste Tiroler Klosterbibliothek dar, und dies, obwohl sie im Zuge der Bauernkriege, aufgrund mehrerer Brände und durch die vorübergehende Klosteraufhebung zu Beginn des 19. Jahrhunderts große Verluste erfahren hat. Angesichts dieser Bedeutung der Büchersammlung mag es erstaunen, dass bis ins 18. Jahrhundert kaum schriftliche Quellen - weder zum Bestand selbst noch zum Ort, wo die Bücher aufbewahrt wurden - vorliegen und der reiche Schatz an mittelalterlichen Handschriften bis dato noch keiner systematischen wissenschaftlichen Erschließung unterzogen wurde.

Als Hartmann, Propst des Augustiner Chorherrenstiftes Klosterneuburg bei Wien, 1140 zum Bischof von Brixen geweiht wurde, sollte er die Reformbestrebungen seines Vorgängers Reginbert fortsetzen und dem Brixner Klerus zu neuem Aufschwung verhelfen. Allerdings verpflichtete er nicht die Domherren selbst zu einem Leben nach der Augustinusregel, sondern errichtete mit Unterstützung des Ministerialen Reginbert von Säben und dessen Frau Christina am Kreuzungspunkt zweier wichtiger Reise- und Pilgerrouten, nur wenige Kilometer von seinem Bischofssitz entfernt, ein neues Kloster: Neustift. ${ }^{4}$

Bücher zählten zweifelsohne zur Grundausstattung des Klosters: Für die Feier der Liturgie, das Gebet sowie die Verwaltung war eine Büchersammlung im Haus unabdingbar. Über die Anfänge der Bibliothek sind wir allerdings nicht unterrichtet. Es ist wohl anzunehmen, dass bereits mit den ersten

3 J. Garber, Die Reisen des Felix Faber durch Tirol in den Jahren 1483 und 1484 (Schlern-Schriften 3). Innsbruck 1923, 9. Vgl. C. D. HassLeR (Hrsg.), Fratris Felicis Fabri Evagatorium in Terrae Sanctae, Arabiae et Aegipti peregrinationem I. Stuttgardiae 1843, 70: „Est enim monasterium valde solemne et multum abundans [...]. Ecclesiam habet magnam cum pretioso ornatu, et librariam bonam“.

4 Zur Geschichte des Stiftes siehe u.a. Th. (H.) InNerhofer, Das Augustiner-Chorherrenstift Neustift, in: H. Obermair, K. Brandstätter, E. Curcel (Hrsg.), Dom- und Kollegiatstifte in der Region Tirol - Südtirol Trentino in Mittelalter und Neuzeit. Collegialità ecclesiastica nella regione trentino-tirolese dal medioevo all'età moderna (Schlern-Schriften 329). Innsbruck 2006, 223-238 (mit weiterführender Literatur); 850 Jahre Augustiner Chorherrenstift Neustift, hrsg. vom Augustiner Chorherrenstift Neustift. Brixen 1992; Th. (H.) InNERHOFER (Red.), 850 Jahre Chorherrenstift Neustift. 1. Südtiroler Landesausstellung. Stift Neustift 30. Mai bis 31. Oktober 1992. Katalog. Brixen 1992; Ders., Die Grundherrschaft des Chorherrenstiftes Neustift bis um 1500. 2 Bde. Diss. Innsbruck 1971; J. Huber (Hrsg.), Aus der Chronik des Stiftes Neustift bei Brixen. Neustift 1956; M. Schrott, Aus der Baugeschichte des Stiftes, in: A. Sparber, M. Schrott (Hrsg.), Aus der Neustifter Klosterchronik. Brixen 1930, 13-59; A. Sparber, Abriß der Geschichte des Chorherrenstiftes Neustift bei Brixen. Brixen 1920. 
Augustiner Chorherren, die von Klosterneuburg nach Neustift übersiedelten, Bücher ins neue Stift gelangten. Zudem dürften sowohl der Gründer als auch die Stifter selbst die Klostergemeinschaft mit Büchern ausgestattet haben. Mit dem Ausbau der Klosteranlage sowie der Gründung einer Schule, zunächst nur für den stiftsinternen Nachwuchs gedacht, doch schon bald auch für andere Kinder zugänglich ${ }^{5}$, waren weitere Bücher notwendig.

Vielfach von den Chorherren selbst geschrieben, teilweise käuflich erworben bzw. bei Lohnschreibern in Auftrag gegeben, teilweise als Geschenke dem Stift überlassen, nahm die Anzahl der Bücher sicherlich rasch zu. ${ }^{6}$ So übergab Berthold, Hospitaler am Heilig-Kreuz-Spital im nahegelegenen Brixen, Propst Nikolaus I. (1346-1359) und dem Konvent von Neustift am dritten Fastensonntag 1353 (24. Februar) vier Bücher mit kanonistischem Inhalt: Primo Decretum cum glosa Bartholomei ordinaria. Item Decretales sextum librum et Clementinas cum suo apparatu. Item Summam Gantfredi et librum feodorum. ${ }^{7}$ Im Gegenzug erhielt er Begräbnisrecht im Stift, zudem sollte sein Jahrtag wie der eines Konventualen begangen werden. 1383 wurde Hainricus de Uberwisen, plebanus in Lawant, ein Jahrtag sicut unius prelati in oratorio et refectorio als Dank für drei Bücher zugesichert. ${ }^{8}$

Mit dem zunehmenden wirtschaftlichen Erstarken des Stiftes ging im 15. Jahrhundert auch eine kulturelle Blütezeit einher. Mehr als 500 Höfe, vorwiegend im Pustertal und im Eisacktal gelegen, zinsten dem Stift ${ }^{9}$ und ermöglichten bauliche Änderungen und die Anschaffung von bedeutenden Kunstwerken. Zahlreiche Altäre, Tafelbilder und Fresken von namhaften Künstlern wie Michael und Friedrich Pacher, Leonhard von Brixen und Marx Reichlich, aber auch die reich mit Miniaturen geschmückten Handschriften aus dem stiftseigenen Skriptorium legen hiervon Zeugnis ab. Eine Schreibstube hat wohl seit jeher im Stift bestanden ${ }^{10}$, aber erst im 15. Jahrhundert sollte sich ihr guter Ruf verbreiten.

$5 \quad$ Die Anfänge der Schule in Neustift liegen im Dunkeln, als eigentlicher Gründer der Klosterschule gilt gemeinhin Propst Konrad von Rodank (1178-1200), der vorher als scholasticus am Brixner Dom wirkte. Doch bereits um 1150 übertrug ein Adeliger aus Latzfons dem Stift Güter in Lajen als Dank für die Ausbildung und Ordensaufnahme seines Sohnes. 1281 übergab der Adelige Rupert Maulrapp aus Kastelruth dem Stift einen Hof für die Ausbildung seiner beiden Söhne; nur einer trat anschließend in den Orden ein. Vgl. hierzu TH. (H.) InNERHofer, M. Peintner, E. Delmonego, H. Torggler, Neustift. Von der Klosterschule zum Schülerheim. Brixen 2007, 6-7.

$6 \quad$ Vgl hierzu auch B. KieferL, Die Stiftsbibliothek in Neustift. Geschichtliche Notizen, zur Feier der dortigen Abtweihe. Brixener Chronik Jg. 26 Nr. 10 (25. Jänner 1913) 2-3, Nr. 13 (1. Februar 1913) 1-2, Nr. 24 (27. Februar 1913) 1-3, Nr. 30 (13. März 1913) 1-2; Jg. 27 Nr. 24 (26. Februar 1914) 1-2. Der einstige Stiftsbibliothekar veröffentlichte in vier Teilen eine sehr anschauliche und lebendige Darstellung der Geschichte der Stiftsbibliothek. Dieser Darstellung folgt Waltraud Lamprecht im ersten Teil ihrer Diplomarbeit über das Historische Werden der Stiftsbibliothek von Neustift, vgl. W. LAMPRECht, Die Stiftsbibliothek von Neustift mit besonderer Berücksichtigung der Sektion der deutschen Literatur, Tesi di laurea. Padova, Verona 1980-1981, 6-36.

7 Neustift, Stiftsarchiv, WW 59; vgl. auch TH. MaIRHOFER, Urkundenbuch des Augustiner-Chorherrenstiftes Neustift in Tirol (Fontes Rerum Austriacarum/Österreichische Geschichts-Quellen II, 34). Wien 1871, 264-265. Drei dieser genannten Handschriften befinden sich bis heute in Neustift: Cod. 7, 99 und 253.

$8 \quad$ Neustift, Stiftsarchiv, WW 66; vgl. auch MaIRHOFER, Urkundenbuch (wie Anm. 7) 372. In dieser auf den 15. Dezember 1383 datierten Urkunde werden folgende Titel genannt: Summam confessorum maiorem in sollempni volumine; item abreviata libri Sentenciarum cum glossa et postillas perennes de tempore per totum annum. Eine eindeutige Identifizierung der genannten Titel im heute erhaltenen Handschriftenbestand ist nicht möglich. Der erste Eintrag dürfte wohl als „Summa de poenitentia“ oder „Summa confessorum“ des Raimundus de Pennaforte zu identifzieren sein (möglicherweise T. I von Cod. 614).

9 INNERHOFER, Grundherrschaft (wie Anm. 4).

$10 \mathrm{Zu}$ den Anfängen des stiftseigenen Skriptoriums liegen keine Quellen vor. In der Debatte über den genauen Entstehungsort des berühmten Codex Buranus (München, BSB, Clm 4660) wird seit geraumer Zeit auch immer wieder das Kloster Neustift angeführt. Zuletzt war insbesondere Peter Godman (gest. 2018) davon überzeugt, dass die Liedersammlung um $1230 \mathrm{im}$ Augustiner Chorherrenstift Neustift aufgeschrieben wurde. Vgl. hierzu u. a. G. STEer, „Carmina Burana“ in Südtirol. Zur Herkunft des clm 4660. Zeitschrift für deutsches Altertum und deutsche Literatur 112/1 (1983) 1-37; J. DrumbL, Studien zum Codex Buranus. Aevum 77/2 (2003) 323-356; P. Godman, Rethinking the Carmina Burana (I): The Medieval Context and Modern Reception of the Codex Buranus. Journal of Medieval and Early Modern Studies 45/2 (2015) 245-286; Ders., 
In diese Zeit fällt auch die erste auf uns gekommene Information über einen Bibliotheksraum: Propst Ulrich II. Weingartner (1427-1439) ließ im Jahr 1431 einen „doppelten Bibliotheksraum“ errichten $^{11}$, der wohl einerseits als Aufbewahrungsort für die Bücher, andererseits als Archiv dienen sollte. ${ }^{12}$ Über den genauen Standort und die Größe des Baus sind wir nicht unterrichtet.

Im Juli 1438 reiste der Augustiner Chorherr Friedrich Zollner aus dem Stift Langenzenn bei Nürnberg $^{13}$, mit dem Neustift seit 1421 geistlich verbrüdert war ${ }^{14}$, nach Neustift. Zur Förderung des geistlichen Lebens (propter spiritualis vite maiorem fructum ut prefatum est cupiensque saluti anime sue limpidius providere indulsi) hatte Propst Petrus von Langenzenn gemeinsam mit dem Rat seiner Kapitularen beschlossen, ihn in ein Augustiner Chorherrenstift seiner Wahl (ad locum regularem sibi deputatum) ziehen zu lassen. ${ }^{15}$ Warum die Wahl Zollners ausgerechnet auf jenes südlich des Brenners fiel, lässt sich heute lediglich vermuten. Sie war aber mit Sicherheit nicht dem Zufall überlassen - nicht umsonst war die Gebetsbrüderschaft mit Neustift im Juni desselben Jahres erneuert worden. ${ }^{16}$ Ein Grund mag möglicherweise ein vorbildhaftes religiöses Leben der Neustifter Chorherren gewesen sein ${ }^{17}$; als hochbegabter Schreiber hatte Zollner zudem wohl auch von dem blühenden kulturellen Leben in Neustift und von der dortigen Schreibstube gehört ${ }^{18}$ und wollte sich vielleicht ebendort weiterbilden bzw. einbringen. Zollner sollte schließlich dem Neustifter Skriptorium ein bleibendes Denkmal setzen: Im Auftrag des Propstes Nikolaus III. Scheiber (1439-1449) schrieb er zwei umfangreiche Gradualbände in Großfolio-Format. Auf etwa 600 Blatt hielt er Text und Melodie sämtlicher Wechselgesänge der Messen im Laufe eines Kirchenjahres fest, wobei der erste Band dem Temporale und der zweite Band dem Sanctorale vorbehalten ist. Die Rubriken wurden wohl vom Schreiber und somit von Friedrich Zollner selbst ausgeführt, die Fleuronnée-Initialen und der reiche dekorative und figürliche Buchschmuck, der sich durch große Detailfreude auszeichnet, stammen von mehreren Buchmalern (nähere Details siehe Beitrag von Susanne Rischpler). Der üppige Einsatz von Blattgold verlieh der liturgischen Handschrift den bis heute faszinierenden festlichen Charakter.

Dieses aufwändige Werk entstand in den Jahren 1439 bis $1446^{19}$ und somit in einer Zeit, als sich zumindest zeitweise - auch Oswald von Wolkenstein in Neustift aufhielt. Er war im November 1411 wegen seiner und seiner Familie Verdienste als Pfründner im Stift aufgenommen worden und hatte lebens-

Rethinking the Carmina Burana (II). The Child, the Jew, and the Drama. Viator. Medieval and Renaissance Studies 47/1 (2016) 107-122.

11 A. Sparber, Abriß (wie Anm. 4) 43.

12 Dies wird nicht zuletzt dadurch deutlich, dass in jener Zeit das Archiv neu geordnet wurde und die Urkunden mit Signaturen und Kurzregesten versehen wurden.

13 H. Miekisch, Das Augustinerchorherrenstift Neunkirchen am Brand. Seine Geschichte und seine Bedeutung für die Verbreitung der Raudnitzer Reform, Diss. Bamberg 2005; S. HABel, Das Augustiner-Chorherrenstift in Langenzenn von 1409 bis 1533. Horb a. N. 2004.

14 HABEL, Langenzenn (wie Anm. 13) 59. Die in Neustift erhalten gebliebenen Rotula (insgesamt fünf, davon lediglich zwei vollständig) belegen, dass Langenzenn regelmäßig von Neustifter Rotelboten aufgesucht wurde (vgl. Rotula aus den Jahren 1515, 1516/17, 1525, siehe Neustift, Stiftsarchiv, XX 58.5).

15 Neustift, Stiftsarchiv, XX 21.1. Das Schreiben des Propstes Petrus von Langenzenn datiert auf den 13. Juli 1438.

16 Neustift, Stiftsarchiv, XX 21 (1438 Juni 19).

17 Im Gegensatz zu vielen anderen Klöstern gab das religiöse Leben im Augustiner Chorherrenstift Neustift Mitte des 15. Jahrhunderts Kardinal Nikolaus von Kues offensichtlich keinen Anlass zur Kritik, im Gegensatz: Er beauftragte den damaligen Propst Kaspar Aigner (1449-1467), dem er erstmals wohl beim Konzil in Basel begegnet sein dürfte, mit der Visitation mehrerer Klöster; vgl. H. HaLlauer, Nikolaus von Kues und das Chorherrenstift Neustift, in: L. CARLen, F. SteinEGGER (Hrsg.), Festschrift Nikolaus Grass zum 60. Geburtstag dargebracht von Fachgenossen, Freunden und Schülern, Bd. 1. Innsbruck, München 1974, 309-324, hier insbes. 309-310.

18 Dies kann wohl als Indiz für die dank des Rotelbotensystems bestens funktionierende Kommunikation zwischen den Klöstern gesehen werden; vgl. E. P. Pallhuber, Der Neustifter Rotelbote, in: 850 Jahre Augustiner Chorherrenstift Neustift (wie Anm. 4) 104-111; M. SснRotт, Die Conföderationen Neustifts mit anderen Klöstern. Unum Congregati. Mitteilungen der Österreichischen Chorherrenkongregation 4 (1958) 127-158.

19 Im Jahr 1439 wurde Nikolaus Scheiber zum Propst gewählt, der im Kolophon als Auftraggeber genannt wird; 1446 verstarb Friedrich Zollner. Der erste Gradualband wurde im Jahr 1442 abgeschlossen, vgl. Graduale Neocellense I, B1. 325r-v. 
langes Wohnrecht in einem Haus in unmittelbarer Nähe zur Margarethenkirche sowie Begräbnisrecht erhalten. ${ }^{20}$ Während er zunächst nur kurze Rastzeiten als Durchreisender in Neustift eingelegt zu haben scheint, dürfte er sich ab Mitte der 1430er Jahre bis zu seinem Tod am 2. August 1445 wiederholt und länger dort aufgehalten haben. Die Frage, ob die beiden großformatigen Pergamenthandschriften, in denen er seine Lieder aufzeichnen ließ - die ältere (Hs. A) ist auf $1425^{21}$, die jüngere (Hs. B) auf $1432^{22}$ datiert -, im Neustifter Skriptorium entstanden bzw. in irgendeinem Zusammenhang mit diesem zu sehen sind, wird immer wieder aufgeworfen, konnte aber bislang noch nicht eindeutig beantwortet werden. ${ }^{23}$

Einen anschaulichen Einblick in die Neustifter Schreibstube in ebendieser Blütezeit bietet ein Rezept zur Herstellung von Tinte ${ }^{24}$, überliefert am Ende einer Handschrift über die Fassmessung aus dem Jahr 1443:25

Item zu ainer mass heffenwassers vier lot gallis, das zerstossent/klain und wann er wol gestossen sey so nempt das heffenwasser un[d]/giessent es daran und lannd das stan funf tag und wann die funf/tag vergangen sind so siedent es dann ain viertail ainer stund/und weil es dann warm ist, so nempt V lot galitzenstain, daz/zerstossent ze mel und tund es darein und ain lot gumi, daz/zerstossent auch und virvent es dar ein, die weil es warm sey/und lannd die dintten stan vier tag. So ist sy gut und schwartz. ${ }^{26}$

Nur wenige Jahre später sollte der Buchdruck die Herstellung und Verbreitung von Büchern revolutionieren und die Neustifter Bibliothek stark verändern. Wohl dank der verkehrstechnisch äuBerst günstigen Lage, aber nicht zuletzt auch dank der guten Vernetzung mit anderen Klöstern im süddeutschen Raum ${ }^{27}$, die sicherlich bei der Beschaffung von Informationen über Neuerscheinungen hilfreich war, konnte Neustift bereits in der zweiten Hälfte des 15. Jahrhunderts eine Vielzahl an gedruckten Büchern erwerben: Nicht weniger als 820 Inkunabeln waren Ende des 18. Jahrhunderts in der Stiftsbibliothek vorhanden. ${ }^{28}$ Rechnungen über Bücherkäufe sind leider kaum auf uns gekommen,

20 A. Schwов, „... er ezze mit vns obgenantem Brobst Niklasen ... auz vnser schussel“. Beziehungen Oswalds von Wolkenstein zum Propst und Konvent von Neustift, in: 850 Jahre Augustiner Chorherrenstift Neustift (wie Anm. 4) 252-266.

21 Wien, ÖNB, Cod. Vind. 2777.

22 Innsbruck, ULB Tirol, ohne Sign. (Wolkenstein-Hs.); vgl. Katalog ULB Tirol I (wie Anm. 100) 47-50.

23 Vgl. hierzu u.a. W. Neuhauser, Wissenschaftspflege in Neustift im Mittelalter im Spiegel der Handschriften, in: Ders. (Hrsg.), Beiträge zur Handschriftenkunde und mittelalterlichen Bibliotheksgeschichte. Referate der 7. Tagung österreichischer Handschriftenbearbeiter in Innsbruck/Neustift (Südtirol), Juni 1979 (Innsbrucker Beiträge zur Kulturwissenschaft 47). Innsbruck 1980, 78-79. Unter www.manuscripta. at (Innsbruck, ULB Tirol, Cod. s.n.) ist eine ausführliche aktuelle Bibliografie zur Handschrift B des Oswald von Wolkenstein zu finden, in der Digitalen Bibliothek der ULB Tirol (https://diglib.uibk.ac.at/ulbtirolhds/ content/titleinfo/5914060) ein Volldigitalisat.

24 Eine Auswahlbibliografie zu Tinten- und Farbrezepten des späten Mittelalters ist unter https://mittelalter. hypotheses.org/11576 zu finden (wie alle anderen im Folgenden angeführten Links im April 2021 geprüft).

25 Innsbruck, ULB Tirol, Cod. 593. Entstanden wohl im Wiener Raum, dürfte die Handschrift schon bald Eingang in die Neustifter Bibliothek gefunden haben, vgl. hierzu Katalog ULB Tirol VI (wie Anm. 100) 366-368; K. Girstmair, U. STAmpFER, Rätselhafte mathematische Tabellen - der Innsbrucker Codex 593. Codices manuscripti 78/79 (2011) 11-22; G. STORECK, Zahlentafeln in der Fassmessung des 15. Jahrhunderts, in: R. Gebhardt (Hrsg.), Arithmetik, Geometrie und Algebra der frühen Neuzeit. Tagungsband zum wissenschaftlichen Kolloquium „Arithmetik, Geometrie und Algebra der frühen Neuzeit“"vom 11.-13. April 2014 in der Berg- und Adam-Ries Stadt Annaberg-Buchholz (Schriften des Adam-Ries-Bundes AnnabergBuchholz 23). Annaberg-Buchholz 2014, 129-143.

26 Innsbruck, ULB Tirol, Cod. 593, B1. 23v.

27 Laut den erhalten gebliebenen Rotula war Kloster Neustift zu Beginn des 16. Jahrhunderts mit 91 Klöstern und Stiften in Gebetsbrüderschaft verbunden, vgl. Anm. 18.

28 F. X. Grass, Verzeichnis typographischer Denkmäler aus dem fünfzehenten Jahrhundert, welche sich in der Bibliothek des regulirten Korherrenstiftes des heil. Augustin zu Neustift in Tyrol befinden. Brixen 1798. Vgl. auch G. ManzInI, Gli incunaboli della Biblioteca del Convento di Novacella secondo il Catalogo Settecentesco di F. S. Grass. Archivio per l'Alto Adige 47 (1953) 299-317; F. Morandini, Studi sugli incunaboli della biblioteca di Novacella. Archivio per l'Alto Adige 40 (1945) 324-345. Die Inkunabeln wurden 1809 nach Innsbruck gebracht und werden bis heute mehrheitlich dort aufbewahrt; heute befinden sich in der Bibliothek in Neustift nur mehr 33 Wiegendrucke. 
lediglich für den Erwerb einiger Bücher unter Propst Leonhard Pacher (1467-1482) ist eine Notiz mit dem Titel Exposita per Leonhardum prepositum pro libris ornamentis et clenodiis ${ }^{29}$ erhalten. ${ }^{30}$

Neben diesem käuflichen Erwerb von Büchern wurden aber bestimmte Texte weiterhin in der stiftseigenen Schreibstube von Hand geschrieben. Spezielle, an den lokalen Ritus und persönliche Bedürfnisse angepasste Mess- und Gebetbücher mussten auch im 16. Jahrhundert händisch hergestellt werden. So enthält Cod. 405, ein um 1501 entstandenes Brevier, das großteils mit dem 1482 in Venedig gedruckten Breviarium Salisburgense ${ }^{31}$ übereinstimmt, zusätzlich Suffragien von Neustift und von dem Augustiner Chorherrenstift Waldsee. ${ }^{32}$ In beiden Klöstern war Lukas Härber als Propst tätig. ${ }^{33}$ Einem gedruckten Brevier nach Salzburger Ritus wurde auf Veranlassung des Brixner Bischofs Georg Golser 1487 ein Anhang beigefügt, damit es in Neustift verwendet werden konnte (Innsbruck, ULB Tirol, Ink. 156 F 20). Ergänzt wurden einige Feste im Sanctorale (u. a. die Feste Ingenuin und Albuin, Monika, Kassian), Angaben zu liturgischen Besonderheiten für Neustift (u. a. Abänderungen von Festrängen bei bestimmten Heiligen) sowie spezielle Suffragien. ${ }^{34}$ Weiterhin handschriftlich festgehalten wurden auch vor Ort entstandene, oft persönliche Sammlungen von Texten bzw. Kompilationen von Textausschnitten. Als Beispiele seien hier das 1509 datierte knappe Lehrbuch der Kosmografie mit anschließenden Exzerpten aus antiken Autoren (Innsbruck, ULB Tirol, Cod. 1015), das man möglicherweise für den Schulunterricht benötigte, sowie die von Propst Hieronymus Piesendorfer (1542-1561) 1535/36 verfasste Sermonessammlung (Innsbruck, ULB Tirol, Cod. 1031) genannt.

Als besonders begabter Schreiber jener Zeit ragt der Chorherr Stefan Stet(t)ner (gest. 12. Dezember 1526$)^{35}$ heraus. Neben seinem bekanntesten Werk, einem Missale, das er 1524 für bzw. im Auftrag von Propst Augustin Posch (1519-1527) geschrieben hat, sind ein Neustifter Rituale aus dem Jahr 1507 (Cod. 194) und ein Sermo (Innsbruck, ULB Tirol, Cod. 718, dat. 1510) erhalten geblieben. Mit großer

$29 \quad$ Neustift, Stiftsarchiv, Cod. 19, Bl. 190r.

30 Insgesamt sind 19 Werke aufgelistet, die ein breites Interessensspektrum erkennen lassen. Schriften der Kirchenväter Augustinus (De civitate Dei) und Laktanz sind ebenso genannt wie die beiden Hauptwerke des römischen Geschichtsschreibers Flavius Iosephus (Antiquitates Iudaices und De bello Iudaico) und das pflanzenkundliche Werk Ruralia commoda von Petrus de Crescentiis. An der ULB Tirol befinden sich mehrere Wiegendrucke von Augustinus’ „De civitate Dei“: GW 2879 (Venedig: Nicolas Jenson, 2. Oktober 1475), GW 2880 (Venedig: Gabriele di Petro, 1475), GW 2883 (Strassburg: Johann Mentelin, nicht nach 1468), GW 2887 (Basel: Johann Amerbach, 13. Februar 1489). Auch die Werke des Flavius Iosephus (GW M15160 Augsburg: Johann Schüssler, 28. Juni und 23. August 1470) sowie ein Exemplar der „Ruralia commoda“ (GW 7820 - Augsburg: Johann Schüssler, 16. Februar 1471) werden an der ULB Tirol aufbewahrt. Daneben finden sich auch eine Sermonessammlung, wohl die „Sermones aurei de sanctis“, von Leonardus de Utino (GW M17891 - Nürnberg: Anton Koberger, 22. Jänner 1478; an der ULB Tirol vorhanden) und die weit verbreitete „Summa de casibus conscientiae“ des Bartholomaeus de Sancto Concordio. Bei Letzterer ist sogar eine Jahreszahl beigefügt: 74. Es ist also anzunehmen, dass es sich um die Ausgabe, die am 17. Jänner 1474 von Arnold ter Hoernen in Köln gedruckt wurde (GW 3451), handelt. Ein Exemplar dieser Ausgabe ist weder in Neustift noch an der ULB Tirol erhalten; in Innsbruck wird ein Exemplar GW 3453 (Augsburg: Günther Zainer, 1475) und eines GW 3455 (Speyer: Peter Drach d. Ä., nicht nach 1479) aufbewahrt. In dasselbe Jahr datiert auch ein nicht näher definierter kleiner, aus dem Griechischen ins Lateinische übersetzter Traktat, der gemeinsam mit einem großformatigen Buch mit dem Titel Planctus ecclesie um 35 Gulden erworben wurde. Letzteres Werk ist möglicherweise zu identifizieren als „Planctus ruinae ecclesiae“ von Iohannes Fabri; allerdings sind laut GW nur Ausgaben in Quartformat erhalten; weder für Neustift noch für die ULB Tirol ist eine entsprechende Ausgabe nachgewiesen. Weitere 20 Gulden waren vonnöten, ad eundem illigandum et corpora faciendum, also um das Buch binden zu lassen.

31 Breviarium Salisburgense. Venedig: Nikolaus von Frankfurt, 1482 (GW 5442).

32 Vgl. u. a. M. BARczYK, P. Schurer, Kirche und Stift St. Peter zu Waldsee (Veröffentlichungen des Stadtarchivs Bad Waldsee B/3). Bad Waldsee 1979 sowie Eintrag „Augustiner Chorherrenstift Waldsee“ in der Datenbank „Klöster in Baden-Württemberg“ (https://www.kloester-bw.de/index.php).

33 Vgl. P. A. BЕСК, Lukas Härber, Probst von Waldsee und Neustift: ein Beitrag zur Geschichte des Chorherrenstifts Waldsee. Diözesan-Archiv von Schwaben 18 (1900) 97-101.

34 Vgl. Katalog ULB Tirol X (wie Anm. 100) 469-472.

35 A. Giner, Chorherrenverzeichnis 1142-1942, in: A. Giner (unter Mitwirkung von A. Sparber, M. Schrott) (Hrsg.), Festschrift zum 800jährigen Jubiläum des Stiftes Novacella. Brixen 1942, Anhang 1-61, hier 12. 
Wahrscheinlichkeit stammen auch ein Evangelistar und Lektionar (Cod. 190) aus seiner Hand. Die Frage, ob Stetner auch als Buchmaler tätig war, wie wohl aufgrund der Signatur in Cod. 194 auf Bl. 70v, das eine ganzseitige Miniatur zeigt, in der Literatur diskutiert wurde ${ }^{36}$, kann mit ziemlicher Sicherheit verneint werden.

Die kulturelle Blütezeit in Neustift erlebte am 12. Mai 1525 ein jähes Ende: Aufständische Bauern aus der Umgebung, angeführt von Michael Gaismair, plünderten das Stift und richteten, wie der Chronist und Hofrichter von Neustift Georg Kirchmair von Ragen berichtet, großen Schaden an Prief vnd $P_{\text {Puechern }}{ }^{37}$ an. Den Bauern gelang es zwar nicht, die gesuchten Urbare mit den darin festgehaltenen Abgabenverpflichtungen an sich zu reißen, doch hinterließen sie eine Spur der Verwüstung: ... in summa alle pücher was [?] geschriben gewest ist aus allen cästn, truchn, stubn sonderlich canzlei stübl schuldbrief alles zerissen, auf den hof tragen, zerhackt, zerschnidten, zerissen, zerstochn auf die spieß und hellpardt gelegt und gegeneinannder geworfen .... ${ }^{38}$ Welche Dokumente und Bücher ihnen tatsächlich in die Hände fielen und zerstört wurden, entzieht sich unserer Kenntnis. Überliefert wird, dass das sogenannte Posch-Missale (Cod. 100) nur deswegen nicht zerstört worden sei, da es Stetner als Pfarrer von Natz im dortigen Widum und nicht im Stift aufbewahrt hatte. Als Beweis hierfür wird gemeinhin die Datierung auf der ganzseitigen Miniatur auf B1. Iv angeführt: 1526. Das Messbuch habe demnach ein Jahr lang im Widum von Natz gelegen, ehe es - wohl von einem nicht näher bekannten Wanderminiator - detailreich und aufwändig illuminiert wurde.

Der Aufstand konnte zwar nach drei Tagen niedergeschlagen werden, aber das Stift erholte sich nur langsam von diesem Einfall und den Plünderungen. In der zweiten Hälfte des 16. Jahrhunderts ließen die Pröpste Augustin II. Schabl (1569-1581) und seine Nachfolger Augustin III. Distelfink (1589-1589) sowie Jakob Fischer (1589-1621) zahlreiche Handschriften und Bücher neu binden. Ob dies in Zusammenhang mit den Verwüstungen während des Bauernaufstandes zu sehen oder einer Neuaufstellung geschuldet ist, bleibt offen. Unter den von Propst Augustin Distelbrink getätigten Ausgaben finden sich auch mehrere Buchkäufe bei einem Buchführer namens Albrecht in Brixen ${ }^{39}$ sowie Entgelte für überreichte Widmungsschriften. ${ }^{40}$ Besondere Erwähnung verdient ein Eintrag vom 10. März 1588, zumal er anschaulich belegt, dass auch gegen Ende des 16. Jahrhunderts besondere Werke weiterhin selbst hergestellt wurden: Am 10. dem Steffan Wenzl khauffmann zu Braunegg der mir das pergamen, auch rot unnd plabe farben zu unser mespuech hergeben hat ime völlig bezalt $33 \mathrm{fl}$. $56 \mathrm{kr}^{41}$ Ein Messbuch auf Pergament aus jener Zeit ist nicht auf uns gekommen - auch dies wohl einerseits ein Beispiel, wie bruchstückhaft unsere Kenntnisse über die Neustifter Schreibstube und deren Erzeugnisse sind, andererseits aber auch ein Beleg dafür, dass das handgeschriebene Buch auch nach Erfindung des Buchdrucks keineswegs seine Berechtigung verloren hatte. ${ }^{42}$ Gerade für den gemein-

$36 \quad$ Vgl. hierzu das Katalogisat zu Cod. 194 im vorliegenden Band.

37 Zit. nach Tн. G. v. Karajan (Hrsg.), Johannes Tichtels Tagebuch, Sigmunds von Herberstein Selbstbiographie, Johannes Cuspinians Tagebuch, Georg Kirchmairs Denkwürdigkeiten (Fontes Rerum Austriacarum/Österreichische Geschichts-Quellen I, 1). Graz 1855, 472.

38 Zit. nach K. PAtтis, Neustift zur Zeit des Bauernaufstandes. Wirtschaftliche, soziale und religiöse Hintergründe. Brixen 2012, 35

39 Neustift, Stiftsarchiv, Cod. 26, S. 22 (2. Juli 1585): Von Albrecht Puechfüerer zu Brichsen die thayll jurii khauff 5 fl.; S. 76 (8. Jänner 1587): Am 8 dits dem Albrecht buechfüerer zu Brixen fur etlich büecher bezalth $3 f$. $12 \mathrm{kr}$. Im September desselben Jahres folgte noch der Kauf einer Postille, eines Gebetbuches und einer lanornung (?), vgl. ebda, S. 86, 88.

40 Neustift, Stiftsarchiv, Cod. 26, S. 3 (6. März 1585): Den herrn Donat alda zu Brichsen, der zu meiner consecration ministriern helffen, auch etlicher carmina halber die er mir dediciert und druckht hat verehrt 5 fl.; S. 33 (17. September 1588): Ainem studenten der mir carmine dediciert geben $30 \mathrm{kr}$.

41 Neustift, Stiftsarchiv, Cod. 26, S. 101

42 Sehr deutlich wird auf die weiterhin große Bedeutung des handschriftlichen Buches auch in einer Neustifter Bibliotheksordnung, überliefert als Abschrift im frühen 18. Jahrhundert durch den Chorherrn Petrus Ephensteiner, hingewiesen: ,Trotz der Erfindung des Buchdrucks soll man im Kloster das Bücherschreiben als eine echt monastische Aufgabe beibehalten und dabei mehr auf Lesbarkeit und Dauerhaftigkeit der Schriften als auf äußeren Glanz bedacht sein." Die Bibliotheksordnung befindet sich im Stiftsarchiv, allerdings ohne 
schaftlichen Chorgesang erfüllte möglicherweise aufgrund des notwendigen Formats in Übergröße bisweilen ein Codex besser die Bedürfnisse als ein Druck, dessen Format aus technischen Gründen limitiert war. Zudem galt das Bücherschreiben auch weiterhin als besondere Form des „Gottes Dienstes“. Insbesondere bei liturgischen Büchern machten auch nach der Einführung des einheitlichen Römischen Ritus lokale Besonderheiten eine manuelle Anfertigung erforderlich. So datiert das mit einer Höhe von $82 \mathrm{~cm}$ und einer Breite von $55 \mathrm{~cm}$ größte erhalten gebliebene Choralbuch in die 1620er Jahre. ${ }^{43}$ Laut Chorherrenverzeichnis hat auch Michael Schwarzkröll (1628-1674) ,einige Choralbücher geschr[ieben]“44, vom Chorherrn Gregor Oberpla(t)zer (1643-1701) ist ein zweibändiges Werk in Großfolio-Format mit aufwändig gestalteten Initialen erhalten. ${ }^{45}$

Die seit der zweiten Hälfte des 16. Jahrhunderts zunehmende wissenschaftliche Betätigung der Chorherren ${ }^{46}$ sowie die Errichtung einer stiftseigenen theologisch-akademischen Hauslehranstalt mit dem Ziel der Verbesserung der Ausbildung von Novizen und Klerikern als Folge des Trienter Konzils trugen zweifelsohne zu einem großen Bücherzuwachs bei. „Bereits seit dem 16. Jahrhundert war hier ein umfangreicher Bestand an theologischen Büchern und Lehrwerken für die Bibliothek angeschafft worden, zum Teil das Beste, das aus den Druckereien in Nürnberg, Basel, Rom und Lyon zu haben war. “47 Besondere Verdienste um die Hauslehranstalt erwarb sich Propst Markus Hauser (1621-1665). Er holte zahlreiche gelehrte Ordensmänner aus anderen Klöstern nach Neustift, darunter auch den Jesuiten Adam Weber. Innerhalb kurzer Zeit hatte Neustift als Studienort einen so guten Ruf, dass viele Kleriker aus anderen Klöstern dorthin kamen. Von dieser Zeit und dem hohen Niveau der Hauslehranstalt, die bis 1807 Bestand haben sollte, legen die erhalten gebliebenen Thesenblätter, die anlässlich des Examens und der Defensio hergestellt und verteilt wurden, beredtes Zeugnis ab. ${ }^{48}$ Zahlreiche Werke, darunter der 1517 in Nürnberg bei Johann Schönsperger d. Ä. gedruckte und reich illustrierte „Theuerdank“ (Barockbibliothek, Sign. 5) ${ }^{49}$, gelangten als Geschenke in die Neustifter Bibliothek, zudem wurden Bibliotheken von Verstorbenen den Stiftssammlungen einverleibt. Sämtliche Bücher des Grafen Ulrich von Enzenberg wurden z. B. nach seinem Ableben aufgrund der verwandtschaftlichen Beziehungen zu Propst Fortunat Troyer (1678-1707) in die Neustifter Bibliothek eingereiht. ${ }^{50}$

Seit dem 17. Jahrhundert, als aufgrund des großen Bücherzuwachses und insbesondere der vermehrten Benutzung der Bibliothek eine verstärkte Sorge um die Buchpflege, die Ordnung und Aufstellung sowie um eine systematische Erwerbung vonnöten war, sind auch Namen der Stiftsbibliothekare von Neustift bekannt. Es ist zwar davon auszugehen, dass das Offizium seit jeher besetzt war - schließlich fand der Umgang mit Büchern sogar Eingang in die Ordensregel des hl. Augustinus (V, 9-10) -,

Hinweis auf Petrus Ephensteiner. Zur Zuordnung samt Abschrift vgl. M. PeinTner, Die geistesgeschichtliche Bedeutung der Stiftsbibliothek, in: 850 Jahre Augustiner Chorherrenstift Neustift (wie Anm. 4) 127.

43 M. PeintNer, Schreibkunst, Studium und Musikleben im mittelalterlichen Kloster. Eine Darstellung am Beispiel der Musikgeschichte des Augustiner-Chorherrenstifts Neustift, in: K. DreXel, M. FinK (Hrsg.), Musikgeschichte Tirols I: Von den Anfängen bis zur Frühen Neuzeit (Schlern-Schriften 315). Innsbruck 2001, 353-380, hier 372.

44 Chorherrenverzeichnis (wie Anm. 35) 20.

45 Peintner, Die geistesgeschichtliche Bedeutung der Stiftsbibliothek (wie Anm. 42) 112-133, hier 128.

46 Während für das 15. und 16. Jahrhundert nur vereinzelt Nachrichten von Neustifter Chorherren an Universitäten erhalten sind, lassen sich seit 1600 mehrere Neustifter Kleriker an den Universitäten Dillingen, Ingolstadt und Salzburg nachweisen; vgl. TH. (H). INNERHOFER, 850 Jahre Erziehung und Unterricht, in: 850 Jahre Augustiner Chorherrenstift Neustift (wie Anm. 4) 154-167, hier 160.

47 F. Brendle, Die Augustiner-Chorherren, in: F. Jürgensmeier, R. E. Schwerdtfeger (Hrsg.), Orden und Klöster im Zeitalter von Reformation und Katholischer Reform 1500-1700, Bd. 3 (Katholisches Leben und Kirchenreform im Zeitalter der Glaubensspaltung 67). Münster 2007, 39-64, hier 60.

48 INNERHOFER, 850 Jahre Erziehung (wie Anm. 46) 162.

49 Der „Theuerdank“ soll dem Stift von Erzherzog Maximilian III. von Österreich als Dank für die Aufnahme des Hofes in Neustift während der Fleckfieberepidemie in Innsbruck im Herbst 1611 überreicht worden sein.

50 C. Schretter-Picker, L. Šubarić, U. Stampfer, W. Neuhauser, Barocke Buchkultur im Tiroler Raum, in: E. Klecker, Ch. Gastgeber (Hrsg.), Buchkultur des Barock (Geschichte der Buchkultur VII). Graz 2015, 295-382, hier 347. 
doch war das Amt des bibliothecarius vorab meist mit anderen Aufgaben verbunden ${ }^{51}$ und erlangte erst durch die deutliche Vergrößerung der Bestände an Bedeutung, sodass dies auch vermehrt in Quellen vermerkt wurde. So hatten Martin Warell (1665), der insbesondere als Stiftsarchivar und durch die von ihm veranlasste, bis heute gültige Ordnung des Archivbestandes Bekanntheit erlangte ${ }^{52}$, Christoph Achmüller (1679), Anton Steiger (1687-1693), Markus von Sayburg (1706), Matthias Alban (1709), Hieronymus Kon (1735), Dominikus Pussieger (1735), Bartholomaeus Perathoner (1735), Martin Raith (1741), Caspar Mayr (1742), Philipp Neri Puell (1758), Johannes Chrysostomus Pertinger (1764, 1769), Alois von Lidl (1767), Stanislaus Pertinger (1782), Franz Xaver Grass (1787, 1828), Lorenz Hueber (1798), Ferdinand Steiner (1799) und Gaudenz Amort (1800) dieses Offizium inne. ${ }^{53}$

Der enorme Bücherzuwachs machte eine Vergrößerung der Bibliotheksräumlichkeiten bzw. eine Neuorganisation der Sammlung bald unumgänglich. Der Wunsch nach Repräsentation und der Anspruch, barockes Selbstbewusstsein zur Schau zu stellen, erforderten einen Neubau an prominenter Stelle. Propst Leopold de Zanna (1767-1787) ließ im Süden des Stiftshofes anstelle des domus capellanorum $^{54}$ einen dreigeschossigen Bau aufführen, der der reichen Büchersammlung des Stiftes angemessene Räumlichkeiten bot und den Stiftshof nach Süden hin abschloss. Der Baumeister Antonio Giuseppe Sartori aus Sacco bei Rovereto, der als einer der besten Tiroler Architekten seiner Zeit galt, folgte dem Beispiel zahlreicher anderer Stifte und errichtete in den Jahren 1771 bis 1778 einen doppelstöckigen Saal mit umlaufender Galerie, die man durch zwei wie kleine Türmchen in den Ecken gestaltete Wendeltreppen erreicht - in den anderen beiden befinden sich Drehschränke. Der $11 \times 23 \mathrm{~m}$ große Saal wurde von Hans Mussack aus Sistrans bei Innsbruck mit reichen Stuckaturen in Weiß und Gold versehen, die ihm einen äußerst festlichen Charakter verleihen. Dazu tragen auch die aufwändigen Portale mit Intarsien und der Natursteinboden in Weiß, Schwarz und Rot mit Mittelrosette wesentlich bei. Die 42 Bücherschränke, jeweils mit einem geschnitzten Aufsatz für die Titel der unterschiedlichen Sachbereiche versehen, sind an die Wände zwischen den Fenstern gestellt, im Raum selbst befanden sich lediglich zwei lange Schranktische, die Platz für besonders große Bücher und möglicherweise wissenschaftliches Instrumentarium wie Globen boten. Der Saal konnte so für Veranstaltungen wie öffentliche Disputationes und repräsentative Zwecke genutzt werden. Insgesamt fanden im Saal, der auf jeder Längsseite von zehn Fenstern großzügig belichtet wird, ca. 20.000 Bände Platz. Der räumlichen Gliederung entsprechend waren die verschiedenen theologischen Disziplinen im Untergeschoss und die Werke aus dem Bereich der Humanwissenschaften auf der Galerie deutlich voneinander getrennt. Die Aufstellung nach Größen und die weitestgehende Vereinheitlichung der Einbände - vielfach wurden die alten Einbände auch lediglich mit einem neuen Rücken aus braunem Kalbsleder mit einer Titelaufschrift in Gold versehen - sorgten für einen geschlossenen Eindruck und betonten den Repräsentationsanspruch.

$51 \quad$ So ist der als Archivar und wohl auch Bibliothekar tätige Chorherr Johannes Librarius (gest. 1467), der um 1465 das „Memoriale benefactorum“ verfasst hat, auch als Johannes Cellerarius nachgewiesen, vgl. A. DörRER, Johannes Librarius, in: Die deutsche Literatur des Mittelalters. Verfasserlexikon, begründet von W. Stammler, hrsg. von K. Ruh (u. a.), IV. Berlin, New York 1983, Sp. 672-673; J. Riedmann, F. Schaffenrath, Geschichtsschreibung, in: M. Korenjak, F. Schaffenrath, L. Šubarić, K. Töchterle (Hrsg.), Tyrolis Latina. Geschichte der lateinischen Literatur in Tirol I: Von den Anfängen bis zur Gründung der Universität Innsbruck. Wien, Köln, Weimar 2012, 105-122, hier 115-117.

52 L. Šubarić, F. Schaffenrath, P. Kennel, Geschichtsschreibung, in: M. Korenjak, F. Schaffenrath, L. Šubarić, K. TöchterLe (Hrsg.), Tyrolis Latina. Geschichte der lateinischen Literatur in Tirol II: Von der Gründung der Universität Innsbruck bis heute. Wien, Köln, Weimar 2012, 726-777, hier 727-728.

53 Vgl. Chorherrenverzeichnis (wie Anm. 35) 13-37.

54 Nachdem Propst Hieronymus Rottenpuecher 1667 das damalige Schulhaus im Mittelhof hatte abreißen lassen, waren in diesem Kaplanhaus das Schulzimmer und die Lehrerwohnung untergebracht; vgl. INNERHOFER u. a., Von der Klosterschule (wie Anm. 5) 15-17; A. Sparber, Aus der inneren Geschichte unseres Klosters, in: Festschrift zum 800jährigen Jubiläum (wie Anm. 35) 69-139, hier 115; B. RuTz, Die Chorknaben zu Neustift. Ein Beitrag zur Geschichte der Schule und der Musik in Tirol. Innsbruck 1911 (Separatdruck aus Neue Tiroler Stimmen), 22. 
Kurze Zeit nach Fertigstellung dieses Saales besuchte Adalbert Blumenschein ${ }^{55}$, der in der zweiten Hälfte des 18. Jahrhunderts Bibliotheksreisen durch ganz Europa unternahm, Kloster Neustift. Seinen Reisebeschreibungen ist zu entnehmen: „Dieses von justerwehnter Stadt [Brixen] nur eine Stunde entlegene dennen Canonic. Regularib. S. Augustini angehörige Stüfte besizet eine sehr gute Bibliotheck. Das Behältniß der Bücher ist ganz neu erbauet. Sie steht in einem viereckigtem zimlich breiten, jedoch von einer nicht sonderlichen Höhe aufgeführten Saale, welcher von beiden Seiten unter dem an der Wand herumlaufend holzernen Gange durch zehn grosse, und oberhalb durch eben so viele kleinere Fenster ungemein hell erleuchtet wird. Die flache Oberdecke ist zwar nicht gemalen, jedoch mit sehr schön vergoldeter Stukatorarbeit nach der neuesten Art gezieret. Die Repositorien sind weis angestrichen, und mit Firniß überzohen, sodann die Leisten, und Ausschnitte ebenfals gut übergoldet, und weilen auch überhin die Bücher meist französisch gebunden, so läßt Solches vortreflich. Dieses Behältniß hat nun seinen Ein= und Ausgang sowohl von der Probstey, als von dem Convent. “"56 Als Arbeitsund Studierräume waren unmittelbar an den großzügigen Saal angeschlossene Räume und Kabinette vorgesehen, die zudem noch reichlich Platz für weitere Bücher boten. „Belangend nun den hiesig ganzen Bücherschaz zusammen, so schäz ich Sölchen ungefähr etwas über 8000: Bände, dann 20000: wie mir Sölcher von dennen hiesigen Geistlichen angegeben worden, ist in der Thatt zu viel.“57

Die Einrichtung von kleineren Nebenräumen entsprach auch der Forderung, die bereits in einer älteren Neustifter Bibliotheksordnung, erhalten als Abschrift des Chorherrn Petrus Ephensteiner (1691-1739), nachzulesen ist: „Neben der Hauptbibliothek soll auch eine Handbibliothek da sein, damit jene Werke, die häufig gebraucht werden, auch stets zur Verfügung stehen." ${ }^{\text {(58 }}$

In diesem Schreiben werden auch die Aufgaben eines Bibliothekars genau festgehalten: „Der Bibliothekar hat die Bücher vor allem vor Feuchtigkeit und Regen zu schützen. An schönen Tagen soll die Bibliothek fleißig gelüftet werden. Die Bücher sollen nach ihrem Inhalt in verschiedenen Schränken einen bestimmten Standort haben. Der Bibliothekar soll ein Verzeichnis haben, in dem die vorhandenen Werke eingetragen sind, und er soll dem Prälaten Rechenschaft geben, so derselbe diese verlangt. Jedes einzelne Buch soll seinen Titel tragen und am Ende einen Index. Desgleichen sind die Erwerbsdaten einzutragen und der Vermerk: Bibliotheca Collegii B.M.V. ad gratias Neocellae. " ${ }^{\text {"59 }}$ In der Tat wurde der Großteil der Druckwerke und Handschriften in Neustift mit einem Bucheignerzeichen, in Holzschnitttechnik gefertigt, ausgestattet; am häufigsten vertreten ist ein Exlibris mit Zierrahmen und dem Vermerk Bibliothecae Novacellensis samt einem $T$ (Tau-Kreuz), dem Wappenzeichen des Stiftes ${ }^{60}$ In den Handschriften sind meist auch noch ältere, handschriftliche Eintragungen zu finden: Der Großteil der Besitzvermerke stammt aus dem 15. Jahrhundert und weist stets einen ähnlichen Wortlaut auf. ${ }^{61}$

Als zentrale Aufgabe des Bibliothekars wird des Weiteren die Erstellung von Bibliotheksverzeichnissen und Katalogen zur besseren Orientierung und zur Übersicht über die Bestände genannt. Aus früheren Zeiten sind keine Verzeichnisse oder Listen überliefert, erst der Neustifter Bibliothekar und

55 Vgl. G. Osti, Adalbert Blumenschein: 1'uomo e l'opera. Atti della Accademia Roveretana degli Agiati 250 (2000), ser. VII, vol. X, A, 269-337.

56 Zit. nach W. Neunauser, Blumenscheins Bibliotheksreisen durch Tirol (Nordtirol und Südtirol). Atti della Accademia Roveretana degli Agiati 250 (2000), ser. VII, vol. X, A, 339-415, hier 347.

57 Ebda. Anschließend folgt eine kurze Beschreibung der vorhandenen Handschriften (Blumenschein hält allerdings gleich zu Beginn fest: „Von alten MSS: ist zwar alda nichts Sonderliches vorfindig“) sowie der Inkunabeln (,Von dennen gedruckten Wercken aber aus dem XV: Jahrh: sind mehr dann 300: Stück zugegen“).

58 Vgl. Anm. 42.

59 Vgl. ebda.

${ }^{60}$ Zum Stiftswappen vgl. F.-H. v. Hye, Wappen in Tirol: Zeugen der Geschichte. Handbuch der Tiroler Heraldik (Schlern-Schriften 321). Innsbruck 2004, 169-171; H. G. STRöHL, Die Wappen der Ordensstifte in Tirol und Vorarlberg. Kunst und Kunsthandwerk XV/4 (1912) 193-196.

61 Vgl. Anm. 120 und 122. 
Orientalist Franz Xaver Grass (1758-1833) verfasste Ende des 18. Jahrhunderts gleich mehrere derartige Verzeichnisse. Es waren dies die ersten gedruckten Bibliotheksverzeichnisse im Tiroler Raum. ${ }^{62}$

Nur wenige Jahre nach Fertigstellung der neuen Bibliothek, die der reichen Neustifter Büchersammlung einen angemessenen Raum bot, folgte eine schwere Zeit, die dem Stift stark zusetzte. Kloster Neustift blieb zwar von den Josephinischen Klosteraufhebungen verschont, doch wurde es während der drei Koalitionskriege gegen Frankreich (1792-1805) zwischenzeitlich als Lazarett benutzt und hatte immer wieder umfangreiche Einquartierungen von Truppen beider Kriegsparteien zu erdulden ${ }^{63}$ und drückende Abgaben zu leisten. Nachdem Tirol schließlich 1806 den Bayern zugesprochen worden war, folgte am 17. September 1807 die Aufhebung aller noch bestehenden tirolischen Klöster und Stifte. Sämtliche Kostbarkeiten, Kunstgegenstände und Bücher mussten abgeliefert werden, die Stiftsgüter wurden veräußert bzw. verpachtet. Bereits im November desselben Jahres wurden die ersten wertvollen Paramente, das Haus- und Kirchensilber sowie andere Pretiosen von Neustift nach Innsbruck geschickt. ${ }^{64}$ Auch das gotische Chorpult wurde aus Neustift entfernt. ${ }^{65}$ Für die Bücher sollte hingegen, ebenso wie für die Tafelbilder und Gemälde, vor Ort eine Auswahl getroffen werden. Der kurfürstliche „Bilder-Galerie-Inspector“ Johann Georg von Dillis reiste daher im Sommer 1808 aus München an, um in Neustift und anderen Klöstern besonders wertvolle Bilder für den Abtransport auszusuchen (u. a. den Kirchenväter-Altar von Michael Pacher); bei der Auswahl der Druckwerke und Handschriften sollte Franz Xaver Grass behilflich sein. Als dieser sich jedoch weigerte - „offenbar blutete ihm darob das Herz"66 -, wurde hiermit der Chorherr Hermann Mader beauftragt. Wegen der umfassenden, kurz vorher von Grass erstellten Kataloge konnten aber keine Raritäten und Kostbarkeiten der Bibliothek übergangen werden. Ein genaues Verzeichnis über die ausgewählten Bücher wurde allerdings im Gegensatz zu anderen Klöstern ${ }^{67}$ nicht erstellt. Nicht weniger als 60 alte Zentner (ca. 3 Tonnen) Bücher, darunter zahlreiche Handschriften und Inkunabeln, bzw. 20 Kisten wurden schließlich am 7. und 8. April 1809 an die Universitätsbibliothek nach Innsbruck überstellt. Ob einige Bücher auch in die Hofbibliothek nach München oder anderswohin gelangten, lässt sich aufgrund des Fehlens einer genauen Liste nicht mit Sicherheit feststellen. Eine entsprechende Überprüfung vor Ort ist noch ausständig. Zudem wurden die reiche Mineralien- und Elfenbeinsammlung, das Münzkabinett und allerlei sonstige Besonderheiten, die sich - einer Kunst- und Wunderkammer gleich - im Vorraum der Bibliothek befunden hatten, aus dem Stift entfernt.

62 F. X. Grass, Raritas Librorum In Bibliotheca Novacellensi Canonicorum Regularium S. Augustini Delitescentium Luci Publicae Exposita ... Brixinae 1777; Ders., Verzeichniß typographischer Denkmäler aus dem fünfzehenten Jahrhundert, welche sich in der Bibliothek des regulirten Korherrnstiftes des heil. Augustin zu Neustift in Tyrol befinden. Brixen 1789; Ders., Verzeichniß einiger Büchermerkwürdigkeiten aus den sechzehenten und siebenzehenten Jahrhunderten, welche sich in der Bibliothek des regulirten Korherrenstiftes des heil. Augustin zu Neustift in Tyrol befinden. Brixen 1790; Ders., Nachtrag zu den typographischen Denkmälern aus dem fünfzehenden und Büchermerkwürdigkeiten aus dem sechzehenden und siebenzehenden Jahrhunderte, welche sich in der Bibliothek des regulirten Korherrenstiftes des heil. Augustin zu Neustift in Tyrol befinden. Brixen 1791.

63 A. Sparber, Aufhebung und Wiederherstellung des Stiftes (1807-1816), in: J. Huber (Hrsg.), Aus der Chronik des Chorherrenstiftes Neustift bei Brixen. Neustift 1956, 66-105, hier 67.

64 Ebda 73-78.

65 Ein Foto des Chorpultes findet sich in: Festschrift zum 800jährigen Jubiläum (wie Anm. 35) Bild 47. Es ist in privatem Besitz und befindet sich heute als Dauerleihgabe im Bayerischen Nationalmuseum in München.

66 Sparber, Aus der inneren Geschichte (wie Anm. 54) 115. Laut Sparber konnte sich Grass „wegen Arbeitsüberbürdung, nämlich als Pfarrer von Natz“ entschuldigen (SPARBER, Aufhebung [wie Anm. 63] 89).

67 Als Beispiel sei hier der an der ULB Tirol aufbewahrte 80 Blatt starke Übergabekatalog der Kartause Schnals aus dem Jahr 1784 genannt (Innsbruck, ULB Tirol, Cod. 915). 
Als das Stift am 12. Jänner 1816 mit kaiserlichem Edikt wiedererrichtet wurde ${ }^{68}$, hat man wenig später auch die Rückführung der Bücher angeordnet. ${ }^{69}$ Gerade weil an die Wiedererrichtung u.a. die Bedingung geknüpft war, dass die Neustifter Chorherren Lehrtätigkeit auszuüben bzw. sämtliche Lehrkräfte für das k. k. Gymnasium in Brixen zu stellen hatten ${ }^{70}$, war man um eine möglichst rasche Rückführung bemüht. Sie gestaltete sich jedoch als äußerst schwierig. Obwohl Propst Leopold Erlacher (1790-1832) wiederholt [...] um Zurückgabe der seinem Stifte angehörigen bey der Bibliothek allhier befindlichen Bücher ${ }^{71}$ gebeten und sogar bei der „Landes Stelle“ vorgesprochen hatte, tat der damalige Bibliothekar an der Universitätsbibliothek, Johann Bertholdi ${ }^{72}$, alles, um die Rückstellung hinauszuzögern bzw. um nicht den gesamten Bestand zurückgeben zu müssen. Er soll erklärt haben, der Kaiser könne nicht mehr zurückgeben, was der König von Bayern einmal der Universitätsbibliothek geschenkt habe. ${ }^{73}$ Schließlich bot Propst Erlacher an, die bereits der k. k. Lycealbibliothek eingereihten Bücher dortzubelassen - wohl in der Hoffnung, so die anderen schneller zu erhalten; doch selbst die Anweisung der Tiroler Landesregierung an Bertholdi, dem Bevollmächtigten des Herrn Prälaten zu Neustift ungesäumt alle Werke des Stiftes Neustift zu übergeben, welche noch nicht den Katalogen eingereiht worden und zur klösterlichen Lektüre geeignet sind ${ }^{74}$, blieb ohne Wirkung. Wie ein Schreiben des Landeshauptmanns von Tirol, Ferdinand von Bissingen-Nippenburg, an Bertholdi vom Mai 1818 deutlich macht, erklärte sich Propst Erlacher vielmehr zu einem neuerlichen Geschenk bereit und verzichtete auf die typographischen Denkmäler aus seiner Bibliothek; alle anderen Bücher sollten aber sobald möglich ${ }^{75}$ ausgehändigt werden. Dass die Rückstellung immer noch nicht erfolgt sei, habe laut Bertholdi aber daran gelegen, dass der Propst die Bücher nicht habe abholen lassen. ${ }^{76}$ Es sollten schließlich noch mehr als zehn Jahre vergehen, ehe die Bücher dann auch tatsächlich im August 1833 auf Betreiben des Propstes Ludwig Mair (1832-1851) und vor allem nach Einschreiten des Guberniums ${ }^{77}$

68 Vgl. Wien, Haus-, Hof- und Staatsarchiv, Kabinettsarchiv, Staatsrat, Protokolle und Indizes, 241 Protokoll 1815: [...] Ich will die vier Stifter der Prämonstratenser zu Wilten, der Zisterzienser in Stams, der regulirten Chorherrn zu Neustift u. Benediktiner in Marienberg beibehalten, und genehmige die in dieser Hinsicht gemachten Anträge der Z: O: Hofkommission mit dem Beisatze, daß diese Stifter stets bemüht seyn sollen, einen an Talenten, Fleiß und Sitten sich auszeichnenden, wohlgebildeten Nachwuchs zu bekommen, um ihn außer der Seelsorge, vorzugsweise auch bei den öffentlichen Lehr- und Erziehungsanstalten mit Beruhigung verwenden zu können [...], dat. Mailand, 12. Jänner 1816 (freundlicher Hinweis David Fliri, Wien).

69 Vgl. Innsbruck, ULB Tirol, Direktionsakt 1816, Nr. 204, 22. Februar 1816.

70 Sparber, Aufhebung (wie Anm. 63) 95.

71 Innsbruck, ULB Tirol, Direktionsakt 1817, Nr. 209, 13. Februar 1817.

72 Johann Bertholdi war 1806 als Bibliothekar von der bayerischen Regierung eingesetzt und 1814 von der österreichischen in seinem Amt bestätigt worden (vgl. W. NeuHAuSER, Die Geschichte der Handschriftensammlung der UB Innsbruck, in: Ders. [Hrsg.], Handschriftenkunde [wie Anm. 23] 51-72, 64; A. HitTMair, Geschichte der k. k. Universitätsbibliothek in Innsbruck, Innsbruck 1910 [Sonderabdruck aus: Zeitschrift des Ferdinandeums für Tirol und Vorarlberg 3/54], 73-74).

73 Zit. nach HitTMair, Geschichte (wie Anm. 72) 85.

74 Innsbruck, ULB Tirol, Direktionsakt 1817, Nr. 218, 4. Dezember 1817.

75 Innsbruck, ULB Tirol, Direktionsakt 1818, Nr. 220, 14. Mai 1818.

76 Innsbruck, ULB Tirol, Direktionsakt 1819, Nr. 227, 30. Juni 1819 (Antwortschreiben auf eine Aufforderung von Seiten der Landesverwaltung vom 27. Mai 1819, der Landesstelle [wohl Studienhofkommission] ein Verzeichnis der an die Stifte zurückgegebenen Bücher vorzulegen).

77 Die Landesstelle kann keinen Anstand nehmen, dem Stifte Neustift jene Bücher zurückstellen zu lassen, welche sich von diesem Stifte in der hiesigen Universitätsbibliothek befinden und dermalen fortan von eben diesem Stifte noch angesprochen werden. Der Umstand, daß diese Werke bereits in die Kataloge eingereiht, und daß sie der Universitätsbibliothek wichtig sind, kann ebenso wenig, als die seit dem Jahre 1817 verzögerte Hinausgabe dieser Bücher als entscheidend, oder hemmend angesehen werden, ob aber die inzwischen eingetretenen Verfügungen mit den Duplikaten an der hiesigen Universitätsbibliothek nicht etwa eine, und welche Schwierigkeit in Ausführung dieser Rückgabe begründen, wird sich durch die weitere Verhandlung zeigen. Der Herr Universitätsbibliothekär erhält daher den Auftrag, alsobald, als es die Jahreszeit erlaubt, anzuzeigen, ob sich die im schriftlichen Verzeichniße, welches vom Stifte Neustift bei Gelegenheit der Inventur am 16. Juli v. J. vorgelegt, und welches dem Herrn Universitätsbibliothekär mit Gubernialdekret vom 4ten v. M. Zahl 28167 übergeben wurde, aufgeführten Bücher noch alle vorfinden, und wohin die etwa abgängigen gekommen seyen. 
wieder nach Neustift gebracht wurden - nicht ohne vorher noch mehrmals um die Überlassung einiger Bücher zu bitten. ${ }^{78}$ Bitten, denen das Stift auch nachkam. ${ }^{79}$

Als Vincenzo Tizzani, General-Prokurator des Augustiner Chorherrenordens, 1842 anlässlich des 700-Jahr-Jubiläums nach Neustift reiste und die dortige Bibliothek besichtigte, fand er dort wieder eine stattliche Zahl an Büchern vor: „Sie ist reich an Büchern, welche nach dem Inhalte geordnet sind: die religiösen Inhaltes bilden bei Weitem den wichtigsten Theil. [...] Der Bibliothek fehlt der Catalog, der aber nächstens wird verfertiget werden. Die Zahl der Bücher möchte die Nummer 9000 erreichen. “" ${ }^{\text {"00 }}$

Während die „typographischen Denkmäler des 15. Jahrhunderts“, d.h. die Inkunabeln, bereits 1819 der Universitätsbibliothek als Geschenk überlassen wurden - was auch im Schriftwechsel 1833 immer wieder Erwähnung fand -, werden die mittelalterlichen Handschriften nie eigens genannt. Erst als nach dem Ersten Weltkrieg Südtirol Italien zugesprochen wurde, gewann die Frage nach der Rückgabe von Kulturgütern erneut an Bedeutung. Der Friedensvertrag von Saint-Germain-en-Laye vom 10. September 1919 sah klare Bestimmungen hierfür vor. ${ }^{81}$ Die Republik Österreich verpflichtete sich, sämtliche Kunstgegenstände und expressis verbis auch Handschriften, die in Verletzung des Rechtes

Damit erlediget man vorläufig den Bericht des k. k. Herrn Universitätsbibliothekärs vom 19. v. Mts Zahl 47. Innsbruck am 11. Jänner 1833 (Innsbruck, ULB Tirol, Direktionsakt 1833, Nr. 345-67).

78 Da die im anliegenden Verzeichnisse aufgeführten juridischen und die wenigen am Ende erscheinenden medizinischen nebst ein paar andern Werke, meist rein theoretischen Gehaltes dem löbl. Stifte keinen beträchtlichen praktischen Nutzen gewähren zu können vermuthen lassen, hier aber an der Universität den h. Professoren zum Nachschlagen besonders in Bezug auf das römische Recht dessen Gehaltes die meisten sind ersprießliche dienste förderhin thun würden, so glaubt der gehorsamst Unterzeichnete anliegendes Verzeichniß ohne unbescheiden zu erscheinen mit der bitte begleiten zu dürfen die hochwürdige Vorstehung des löblichen Stiftes Neustift, wolle diese Werke der hiesigen Bibliothek gefälligst belassen und dagegen erwarten, daß der gehorsamt Unterzeichnete alle übrigen noch vorhandenen Werke (mit Ausnahme der schon im Jahre 1819 vom H. sel. Prälaten durch die hohe Landesstelle der hiesigen Bibliothek großmüthig cedirten typographischen Denkmählern des 15. Jahrhunderts in Bälde mit aller Gewissenhaftigkeit ausfolgen werde. Betreffend den so genannten Teyerdank erlaubt sich der gehorsamst Unterzeichnete noch die Bemerkung, daß der selbe bekanntlich nur einen affectations Werth habe und wirklich wie das Verzeichniß sagt defect ist, hier aber aus dem Grund behaltenswerth wäre, weil die hiesige Bibliothek noch einen hat der defect ist und beyde zusammen einen ganzen bilden. Die schönen Beyspiele der übrigen hochverehrlichen Stifte unserer Provinz die so gefällig waren zum Vortheile der öffentlich guten Sache viele ihrer Werke dazulassen (das lobliche Stift Stams hat die seinen hier befindlichen der Univers. Bibliothek samt und sonders geschenkt) und das vom h. sel. Prälaten des Stiftes Neustift durch Abtrettung der schon genannten typogr. Denkmahler erzeigte Wohlwollen des Stiftes Neustift lassen auch dermahl keine fehlbitte befürchten. Innsbruck, den 19. Mai 1833 (Innsbruck, ULB Tirol, Direktionsakt 1833, Nr. 114). In einem Nachtrag vom 25. Mai desselben Jahres zu jenem Schreiben ersucht Bibliothekar Bertholdi die Stiftsleitung nochmals um völlige Resignation für jene Bücher und Werke, die in dem vorigen Schreiben beigelegten Verzeichnis offenbar angemerkt wurden, um eine neue Stöhrung in der nun zu Stande zu bringenden Stellung und Signatur wie auch in die anzufertigenden neuen Cataloge zu vermeiden. Eine nächste Bitte, weitere Bücher der Universitätsbibliothek zu überlassen und diese in einem beigelegten Verzeichnis anzuzeigen (wie aus einem anderen Schreiben hervorgeht, ist dieses Verzeichnis sieben Bogen stark), folgt bereits am 14. Juni 1833; begründet wird dieses Ansuchen damit, weil viele von den zu übersendenden die einzigen waren, die wir in dieser Art oder aus diesem und jenem fache besassen (Innsbruck, ULB Tirol, Direktionsakt 1833, Nr. 126). Vgl. auch Brief des Bibliothekars Scherer an das Landesgubernium für Tirol und Vorarlberg vom 15. Juni 1833 (Innsbruck, ULB Tirol, Direktionsakt 1833, Nr. 127).

79 Als Dank für die Zusage, der Universitätsbibliothek jene Bücher zu überlassen, welche dem Stifte minder nothwendig seyn dürften, schlägt Bibliothekar Scherer vor, den offensichtlich in Innsbruck beschädigten „Theuerdank" auf Kosten der Landesstelle ergänzen zu lassen (Innsbruck, ULB Tirol, Direktionsakt 1833, Nr. 135, 8. Juli 1833)

80 V. Tizzani, Reise nach Neustift zur Saecularfeier im Jahre 1842 und ein Ausflug auf den großen S. Bernhard. Terni 1846, 22.

81 Y. Huguenin-Bergenat, Kulturgüter bei Staatensukzession. Die internationalen Verträge Österreichs nach dem Zerfall der österreichisch-ungarischen Monarchie im Spiegel des aktuellen Völkerrechts (Schriften zum Kulturgüterschutz/Cultural Property Studies). Berlin 2010, 113-122 (Art. 195 und 196). 
der Provinzen Italiens fortgebracht worden sind ${ }^{82}$ zurückzugeben. Zur Umsetzung dieser Vorgabe sollten ehestmöglich Verhandlungen wegen Abschlusses eines gütlichen Uebereinkommens ${ }^{83}$ aufgenommen werden. Die Ausführungskonvention vom 4. Mai 1920 sah schließlich vor, dass Österreich „alle Kulturgüter samt den Archiven“ zurückerstatte, die „nach dem 1. Januar 1790 von den abgetretenen Gebieten nach Österreich gelangt waren“ und „,nach ihrem Ursprung (origine) zum historischen und kulturellen Besitz (patrimoine historique et intellectuel) Italiens oder der abgetretenen Gebiete gehörten". ${ }^{84}$

Gerade dieser Aspekt des Lokalbezugs und der historischen Bedeutung traf auch auf die Neustifter Handschriften zu. Im Namen der Neustifter Stiftsvorstehung richtete daher der Augustiner Chorherr Anselm Sparber am 5. November 1920 schließlich an den Direktor der Universitätsbibliothek Innsbruck die Frage, ob es nicht möglich wäre, die eine und andere historische Handschrift, welche für die Geschichte Neustifts von besonderer Bedeutung ist, speziell Cod. 931 [...] zurückzuerhalten. Wie Ihnen wohl bekannt ist, finden sich in der Universitätsbibliothek ziemlich einige Handschriften, die von Neustift stammen, darunter auch historische. Von kompetenter italienischer Seite ist der Stiftsvorstehung nahegelegt worden, sie möchte die Rückgabe aller Handschriften fordern und betreiben. Doch davon will die Stiftsvorstehung nichts wissen. Vielmehr bin ich ersucht worden, den Vorschlag zu machen, ob nicht auf gütigem Wege etwas zu erreichen sei. Aus diesem und anderen Gründen gedenke ich um Neujahr hinauszufahren. Ich erlaube mir aber jetzt schon die Anfrage höflichst zu richten, ob irgendwelche Aussicht auf Erfolg vorhanden ist und ob Sie eine Eingabe in das österreichische Unterrichtsministerium befürworten würden. Es würde sich um Handschriften handeln, die für Neustift lokalgeschichtlich von großem Werte oder fast unentbehrlich sind. ${ }^{85}$ Diese Bitte bzw. diese Ansprüche stießen allerdings auf wenig Entgegenkommen auf österreichischer Seite. Hans Tietze, dem als Referent für museale Angelegenheiten im Unterrichtsministerium die Verteidigung des österreichischen Kunstbesitzes gegen Ansprüche von anderen Staaten oblag, teilte einem nicht näher benannten Kollegen mit, daß von den aus den abgetretenen Gebieten stammenden Gegenständen nur jene auszufolgen sind, die nach ihrem Ursprung (origine) zum historischen und kulturellen Besitz Italiens oder der an dasselbe abgetretene Provinzen gehören. Daher sei eine Abgabe der Inkunabeln nicht notwendig, denn unzweifelhaft ist für die Zugehörigkeit eines Inkunabels [!] der typographische Gesichtspunkt maßgebend. Das ist nach der ganzen Inkunabelforschung unzweideutig. Ganz genau dasselbe gilt von den Handschriften. Handschriften, die in Deutschland oder überhaupt außerhalb von Südtirol entstanden sind, können nicht beansprucht werden. ${ }^{86}$ Aus diesem Grund bat er als Unterlage für die weiteren Verhandlungen um eine Liste mit möglichst genauen Angaben. In einem weiteren Schreiben regte er die Möglichkeit eines Tausches an: Hier frage ich Sie nun, ob Sie es für diskutabel hielten, ein [!] ganz freien Ausgleich vorzuschlagen, z. B. für Ihre Handschrift $100^{87}$, Ihre Handschrift $87^{88}$ anzubieten. Es ist natürlich schwer zwei derartig unvergleichliche Dinge gegen einander abzuschätzen, zumal ja auch der Seneca alte Tiroler Beziehungen besitzt. Immerhin aber könnte es geltend gemacht werden, daß es sich hier um eine charakteristische italienische Arbeit handelt. Während Nr. 100 doch in der Tat die

Innsbruck, ULB Tirol, Direktionsakt 1920 ad Nr. 135, 2.

83 Ebda 3.

84 Huguenin-Bergenat, Kulturgüter (wie Anm. 81) 128.

85 Innsbruck, ULB Tirol, Direktionsakt 1920, Nr. 135.

86 Innsbruck, ULB Tirol, Direktionsakt 1921, Restitution, Fasz. 2 (Wien, 26. Februar 1921). Einen entsprechenden Hinweis betreffend die Abgabepflicht an Italien im Frühjahr 1921 findet sich auch in: Wien, Haus-, Hof- und Staatsarchiv, SB Registratur Archivbevollmächtigter, Zahl 28/1921. Freundlicher Hinweis David Fliri, Wien. 87 Heute Neustift, Stiftsbibl., Cod. 100 („Posch-Missale“).

88 Heute Innsbruck, ULB Tirol, Cod. 87. Diese Pergamenthandschrift enthält die „Tragoediae“ des Seneca und wurde Ende des 14. Jahrhunderts in Bologna geschrieben. Ein Bezug zu Neustift ist nicht gegeben; die Handschrift war im Besitz des Salzburger Fürsterzbischofs Wolf Dietrich von Reichenau (1559-1617), fand anschließend Eingang in die sogenannte Wappenturmbibliothek in Innsbruck und gelangte von dort in die ULB Tirol; vgl. Katalog ULB Tirol I (wie Anm. 100) 237-241 sowie Abb. 6 und 36. 
bedeutendste Tiroler Miniaturmalerei ist. ${ }^{89} \mathrm{Ob}$ dieser Vorschlag dem Direktor des Ufficio regionale per i Monumenti, le Belle Arti e le Antichità (ab Dezember 1923 Soprintendenza) Giuseppe Gerola dann auch tatsächlich unterbreitet wurde, ist nicht bekannt. Er kam jedenfalls nicht zustande. Bereits zwei Wochen später folgte ein Schreiben Tietzes an eben diesen Kollegen, dass es ihm gelungen sei, den größten Teil der deutschen Handschriften und sämtliche Inkunabeln [...] für Innsbruck zu retten. Die Italiener haben verzichtet auf die Nummern 59, 82, 164, 169, 170, 172, 175, 176, 596, 598, 842, 922, 157, 159, 763, 1015. ${ }^{90}$ Glücklicherweise befinden sich darunter die Rechts-Handschriften, auf die Sie ja das größte Gewicht gelegt haben. Dagegen ist es mir leider nicht gelungen, die Handschrift 100 frei zu bekommen, weil ja die Beziehungen zu Neustift zu offensichtliche sind. ${ }^{91}$ Eine Einigung mit dem italienischen Staat dürfte bereits kurze Zeit später erfolgt sein. Am 29. August desselben Jahres wurden die Handschriften entsprechend einem Auftrage des Unterrichtsamtes Ettore Modigliani (Soprintendente alle Gallerie, ai Musei Medievali e Moderni e agli Oggetti d'arte di Milano) und Giuseppe Gerola übergeben ${ }^{92}$ und gelangten als Staatsbesitz an die Soprintendenza alle Belle Arti nach Trient. ${ }^{93}$ Fast acht Jahre sollte es dauern, ehe am 7. August 1929 schließlich 100 Handschriften a titolo di semplice deposito temporaneo nach Neustift zurückkehrten ${ }^{94}$; bereits zwei Jahre später wurde um eine Dauerleihgabe ersucht. Das Stift verpflichtete sich, sie mit größter Sorgfalt aufzubewahren und sie gegen

89 Innsbruck, ULB Tirol, Direktionsakt 1921, Restitution, Fasz. 3 (Wien, 3. März 1920 [korrigiert zu 21]).

90 Diese hier genannten Handschriften werden bis heute in der ULB Tirol in Innsbruck aufbewahrt; vgl. die Liste im Anhang.

91 Innsbruck, ULB Tirol, Direktionsakt 1921, Restitution, Fasz. 1 (Wien, 14. März 1921). Das Präsidium der Tiroler Landesregierung wurde am 22. März darüber informiert. Am 7. April teilte Ludwig Sprung, Direktor der Universitätsbibliothek Innsbruck, dem Prälaten von Neustift mit, dass von Seite der italienischen Regierung durch den Herrn Kommissär Dr. Gerola ursprünglich sämtliche aus Neustift stammenden Handschriften und Bücher beansprucht wurden, weil die italienischen Vertreter die Giltigkeit der Schenkung vom 18. Juli 1833 nicht anerkennen. Unserem Einspruche und den Bemühungen der österreichischen Vertreter in Wien ist es gelungen, aus diesem für uns äusserst wertvollen Bestande durch Verzicht der italienischen Komissäre alle Drucke und von den Handschriften die Nr. 59, 82, 157, 159, 170, 172, 175, 176, 596, 598, 763, 842, 922 \& 1015, ausserdem die nach Herkunft zweifelhaften Nr. 111, 255, 324, 593, 607, 642, 692, 693, 717, 718, 723, 765, 799, 800, 829, 988 für unsere Anstalt zu retten. Alle übrigen, darunter auch alle auf Neustift selbst bezüglichen sollen an einem noch unbestimmten Termine abgeliefert werden. Es ist natürlich für das Kloster und das Land von grosser Wichtigkeit, dass diese Handschriften nicht verschleppt werden, sondern wieder im Kloster selbst oder wenigstens in einem deutschen Südtirolerort ihre Aufbewahrung finden (Neustift, Stiftsarchiv, ohne Sign., 7. April 1921).

92 Schreiben des Direktors der Universitätsbibliothek Innsbruck Ludwig Sprung an den Prälaten von Neustift, 30. August 1921 (Neustift, Stiftsarchiv, ohne Sign.). In ebendiesem Schreiben äußert der Bibliotheksdirektor auch den Wunsch, dass es Ihren Bemühungen gelingen wird, diese Handschriften dem Kloster und damit dem deutschen Besitzstande Südtirols zu retten.

93 Vgl. Schreiben des Propstes Bernhard Haller an das Commissariato Generale Civile, Uffizio Belle Arti, 5. September 1921 (Archiv des Amtes für Bau- und Kunstdenkmäler Bozen, Abteilung Denkmalpflege, Fasz. Neustift). Der Propst bat darum, die Handschriften nach Neustift zu überstellen.

94 Neustift, Stiftsarchiv, ohne Sign., „Verbale“ (ohne Datum). Eine Kopie dieses Verbale war dem Schreiben vom 2. August 1929 (Oggetto: Deposito di manoscritti) beigelegt und musste unterschrieben zur Übergabe nach Trient mitgebracht werden (vgl. Neustift, Stiftsarchiv, ohne Sign.). Im Verbale sind 99 Handschriften maschinschriftlich aufgelistet, Cod. 1015 ist handschriftlich ergänzt. Bereits seit Juli stand die Soprintendenza mit dem Konvent in regem Austausch, um die Voraussetzungen für eine Übergabe zu schaffen. Am 23. Juli wurde nach Trient berichtet, dass in jüngster Zeit nicht weniger als 10.000 Lire für die Bibliothek aufgewendet wurden und u. a. das Dach der Bibliothek erneuert worden sei. Diesem Entschluss sind Überlegungen vorausgegangen, die Handschriften im Staatsarchiv Bozen oder im Diözesanmuseum in Brixen unterzubringen. Propst Bernhard Haller wies in mehreren Schreiben an Giuseppe Gerola darauf hin, dass Neustift über geeignete Räumlichkeiten zur Aufbewahrung der Handschriften verfüge und aufgrund anderer im Stift vorhandener Handschriften eine Zusammenführung sinnvoll sei. Zudem unterstrich er die Bedeutung der Handschriften für die Geschichte des Stiftes. Warum nicht alle an der Universitätsbibliothek Innsbruck aufbewahrten Handschriften mit eindeutig Neustifter Provenienz abgegeben werden mussten, sondern das Unterrichtsministerium nicht nur auf die oben genannten Signaturen, sondern auch noch auf weitere Handschriften verzichtete (vgl. Liste im Anhang), bleibt offen. 
Diebstahl, Feuchtigkeit und Feuer zu schützen. Eine weitere Neustifter Handschrift, Cod. 142, wurde erst 1931 definitiv von Trient nach Neustift überstellt ${ }^{95}$; Cod. 1015, dessen Signatur dem Verzeichnis zu einem späteren Zeitpunkt handschriftlich hinzugefügt wurde, ist in Innsbruck verblieben. ${ }^{96}$

Genau diese Handschriften stehen im Zentrum des vorliegenden Katalogs; ausgenommen sind lediglich die Archivhandschriften, die offensichtlich 1807 ebenfalls nach Innsbruck gebracht worden waren und dort eine Bibliothekssignatur erhalten hatten, sowie Handschriften aus späteren Jahrhunderten. Dazu zählen:

Cod. 121: Proprium sanctorum ... ab norma Romani Breviarii accomodatum ${ }^{97}$ [17. Jh.]

Cod. 501: Urbario [14. Jh.]

Cod. 503: Calendarium [Kalendar mit Eintragung von Jahrtagen, Märkten, Gerichtstagen und diversen Anweisungen aus dem Jahr 1511 mit späteren Nachträgen]

Cod. 643: Partecipazione di morte di P.P. [Bitte des Klosters Neustift an die konföderierten Klöster, verstorbene Priester in den Nekrolog einzutragen; 45 Klöster haben ihr Willfahren dieser Bitte vermerkt, 1618]

Cod. 689: Johanis Stroza Oratio [17. Jh.]

Cod. 836: Rendite di Novacella 1441 [Urbar, 13. Jh. mit späteren Nachträgen]

Cod. 836: Urbario [15. Jh. mit späteren Nachträgen]

Cod. 839: Urbario [Abschrift der Privilegien Neustifts, Hinweise zu Jahrtagen von Stiftern, Stiftungen, 15. Jh.]

Cod. 845: Nomina Praepositorum novacellensium [Übersicht über die Pröpste von Neustift von 1143 bis 1689 mit Darstellung ihrer Wappen, 17. Jh.]

Cod. 857: Relation [Sammlung von Akten aus der Zeit Propst Augustin Schabls, 1569-1571, zusammengestellt 1572]

Cod. 924: Urbario [15. Jh.]

Cod. 927: Officium [Urbar, 14. Jh.]

Cod. 930: Elenco degli Abati di Novacella [Übersicht über die Pröpste von Neustift, 18. Jh.]

Cod. 931: Epitome de gestis Praelatorum Novacellensium [umfangreiches Werk zu den einzelnen Pröpsten, Propst Fortunat Troyer gewidmet, 1693]

Cod. 1012: Regula [Bulla papae Nicolai IV. „Supra Montem“, 1. Viertel 16. Jh.]

Zusätzlich zu den 85 aus Innsbruck wieder nach Neustift zurückgebrachten Bibliothekshandschriften sind im vorliegenden Katalog weitere sieben Codices berücksichtigt, die zu Beginn des 19. Jahrhunderts nicht nach Innsbruck gebracht worden sind. Hierzu zählen drei Handschriften ohne Signatur: das sogenannte Neustifter Wappenbuch und die zwei großformatigen Gradualbände aus dem 15. Jahrhundert; zwei Handschriften mit einer Bibliothekssignatur (Numerus currens, wohl aus dem

95 Die Signatur Cod. 142 ist in der dem unter Anm. 94 erwähnten „Verbale“ beigelegten Liste „Codici del Convento di Novacella“ handschriftlich ergänzt. Die Handschrift war bereits zu einem früheren Zeitpunkt als Leihgabe nach Neustift geschickt worden. Anselm Sparber verlieh sie an Leo Santifaller, der sie schließlich beim Staatsarchiv in Bozen zurückgab, vgl. Schriftwechsel zwischen Giuseppe Gerola und Antonio Zieger, Direktor des Staatsarchivs von Bozen, 23. und 24. März 1931. Im März 1931 gelangte sie wieder an die Soprintendenza all'arte medioevale e moderna Trento; Gerola sicherte daraufhin dem Stift zu, sie bei nächster Gelegenheit und zu den gleichen Bedingungen wie die anderen nach Neustift zu bringen, vgl. Schreiben vom 31. März 1931 (Archiv des Amtes für Bau- und Kunstdenkmäler Bozen, Abteilung Denkmalpflege, Fasz. Neustift).

96 Innsbruck, ULB Tirol, Cod. 1015 (Cosmographia. Scriptores geographiae. Neustift 1509); vgl. Katalog ULB Tirol X (wie Anm. 100) 188-189.

${ }_{97}$ Die Bezeichnungen sind allesamt dem Anhang des „Verbale“ entnommen (siehe Anm. 94), in eckigen Klammern wurden Informationen, vorwiegend entnommen aus dem Zettelkatalog „Die historischen Handschriften des Archivs bzw. der Bibliothek des Augustiner-Chorherrenstiftes Neustift" (online verfügbar unter http://www.ksbm.oeaw.ac.at/kataloge/IT/5000/histHss/histHss.pdf), ergänzt. 
späten 19. Jahrhundert stammend): Sign. 14820 (Rituale), Sign. 15063 (Antiphonarium); sowie zwei Handschriften, die erst in jüngster Zeit mit Nummern versehen wurden: ein Graduale und Antiphonarium, das ursprünglich die Bibliothekssignatur Sign. $14819^{98}$ aufwies und um 1970 die Bezeichnung Nr. 139 erhielt, sowie ein weiteres Graduale und Antiphonarium, geschrieben von der gleichen Hand wie Nr. 139, das erst um das Jahr 2000 mit Nr. 940 versehen wurde. ${ }^{99}$

Keine Berücksichtigung finden hingegen jene Neustifter Handschriften, die heute an der ULB Tirol aufbewahrt werden; vgl. hierzu Anhang. Sie wurden bereits im Rahmen des Projektes zur Erschließung des dortigen Handschriftenbestandes bearbeitet. ${ }^{100}$

98 Für die Freilegung der Bibliothekssignatur aus der Zeit um 1910 und weitere Auskünfte geht ein Dank an Stiftsarchivar Simon Terzer.

99 Vgl. hierzu „Übersicht über den Handschriftenbestand“, Abschnitt „Signaturen“.

100 Beim österreichischen Bibliothekartag in Eisenstadt 1972 brach der damalige Direktor der Handschriften- und Inkunabelsammlung der ÖNB Otto Mazal (1932-2008) eine Lanze für den Beginn von Generalkatalogen nach dem Vorbild der Deutschen Forschungsgemeinschaft (DFG) und rief eine Arbeitsgruppe ins Leben, die die genauen Beschreibungsrichtlinien festsetzen sollte. Nach intensiven Diskussionen und Arbeitstagungen in Kremsmünster (1973) und Zwettl (1974) lagen die Richtlinien 1975 in gedruckter Form vor; bereits kurze Zeit später wurde mit der entsprechenden Erschließung an der ULB Tirol unter der Leitung von Walter Neuhauser begonnen. Seither wurden, dem Numerus currens folgend, die gesamten dort aufbewahrten Handschriften nach diesen Richtlinien erschlossen. Die Beschreibungen liegen in insgesamt zehn Bänden vor: Katalog der Handschriften der Universitätsbibliothek bzw. Universitäts- und Landesbibliothek Tirol in Innsbruck, unter der Leitung von W. Neuhauser. T. 1: Cod. 1-100, bearb. von W. Neuhauser; T. 2: Cod. 101-200, bearb. von W. Neuhauser; T. 3: Cod. 201-300, bearb. von G. Kompatscher; T. 4: Cod. 301400, bearb. von W. Neuhauser, L. Šubarić; T. 5: Cod. 401-500, bearb. von D. Mairhofer, W. Neuhauser, M. Rossini, C. Schretter; T. 6: Cod. 501-600, bearb. von D. Mairhofer, W. Neuhauser, C. Schretter, U. Stampfer; T. 7: Cod. 601-700, bearb. von P. Ausserlechner, W. Neuhauser, C. Schretter, U. Stampfer; T. 8: Cod. 701-800, bearb. von P. Ausserlechner, W. Neuhauser, A. Ohlenschläger, C. Schretter, U. Stampfer; T. 9: Cod. 801-950, bearb. von P. Ausserlechner, H. Gritsch, P. Kennel, W. Neuhauser, A. Ohlenschläger, C. Schretter-Picker, U. Stampfer; T. 10: Cod. 951-1198, bearb. von H. Gritsch, P. Kennel, W. Neuhauser, R. Neyer, A. Ohlenschläger, A. Pinter, C. Schretter-Picker (Denkschriften der ÖAW, phil.-hist. Kl. 192, 214, 271, 327, 365, 375, 414, 456, 479, 489 = Veröffentlichungen der Kommission für Schrift- und Buchwesen des Mittelalters II, 4, 1-10). Wien 1987, 1991, 1999, 2005, 2008, 2009, 2011, 2014, 2015, 2017. Seit 2009 werden die Ergebnisse zudem auch in die von der ÖAW betreuten Datenbank www.manuscripta.at eingepflegt. Dort sind auch die in Neustift verwahrten Handschriften zu finden, sodass nunmehr zumindest eine virtuelle Zusammenführung des einstigen Bestandes gewährleistet ist. Zum Projekt der Handschriftenerschließung in Tirol vgl. u.a. W. NeuHauser, Generalkataloge zu Handschriften österreichischer Bibliotheken, in: K. Niedermair (Hrsg.), Die neue Bibliothek. Anspruch und Wirklichkeit. 31. Österreichischer Bibliothekartag Innsbruck 2011 (Schriften der Vereinigung Österreichischer Bibliothekarinnen und Bibliothekare 11). Graz, Feldkirch 2012, 38-43. 


\title{
2. Übersicht über den Handschriftenbestand
}

\author{
Ursula Stampfer
}

Insgesamt werden heute in Neustift 92 mittelalterliche Bibliothekshandschriften ${ }^{101}$ aufbewahrt. Zudem sind noch zahlreiche Archiv- sowie neuzeitliche Handschriften erhalten. Die einzelnen Bestände sind weder von ihrer Aufstellung noch hinsichtlich ihrer Signaturen klar voneinander abgegrenzt; jeweils mehrere unterschiedliche Signatursysteme kommen zum Tragen.

An der ULB Tirol werden weitere 40 Handschriften aufbewahrt, die zu Beginn des 19. Jahrhunderts von Neustift nach Innsbruck gebracht wurden (siehe oben). Bei zusätzlich 37 Handschriften kann nicht eindeutig festgestellt werden, ob sie aus Neustift nach Innsbruck gelangten. Für zwei andere Handschriften kann hingegen davon ausgegangen werden, dass sie einst zur Neustifter Bibliothek gehörten, aber bereits zu einem früheren Zeitpunkt ausgeschieden wurden.

Im Folgenden richtet sich der Fokus auf den heute in der Stiftsbibliothek Neustift aufbewahrten Bestand; eine Zusammenschau des gesamten ursprünglichen Neustifter Bestandes stellt derzeit noch ein Desiderat dar.

\subsection{Signaturen}

Nach der vorübergehenden Klosteraufhebung wurden nicht nur mittelalterliche Bibliothekshandschriften, sondern auch Teile der Archiv- und neuzeitlichen Handschriften nach Innsbruck gebracht und der Universitätsbibliothek einverleibt. All diese tragen heute jene Signaturen, die sie im Zuge der Neuaufstellung des Buchbestandes im 19. Jahrhundert ebendort erhielten. Die zahlreichen Handschriften, die aufgrund der kirchenpolitischen Maßnahmen im ausgehenden 18. und beginnenden 19. Jahrhundert aus unterschiedlichen Klöstern nach Innsbruck gebracht worden waren ${ }^{102}$, wurden hier aber nicht nach Provenienz aufgestellt und sind deshalb auf den gesamten Handschriftenbestand verteilt. Unter Direktor Martin Scherer (1832-1857) erhielten alle an der Universitätsbibliothek Innsbruck aufbewahrten Drucke und Handschriften eine mehrteilige Standortsignatur; zudem wurde für die Handschriften eine laufende Inventarnummer vergeben. Während die Standortsignaturen unter Friedrich Leithe (18681874) abgeändert wurden, behielten die Handschriften den Numerus currens bei, der sowohl am Spiegel des Vorderdeckels als auch auf einem gelben Papierschildchen am Rücken vermerkt wurde. ${ }^{103}$ Daher reichen die Signaturnummern der heute in Neustift aufbewahrten Handschriften von 4 bis 1012;

$101 \quad$ Als Grenze zwischen mittelalterlichen und neuzeitlichen Handschriften wurde die Mitte des 16. Jahrhunderts festgesetzt, da der überwiegende Teil der Handschriften bis zu jenem Zeitpunkt mittelalterlichen Charakter aufweist.

102 Zur Geschichte der Handschriftensammlung an der ULB Tirol siehe insbes. W. Neuhauser, C. SchretterPicker, P. Zerlauth, P. Kennel, Das Alte Buch an der UlB Tirol. Erbe und Auftrag, in: K. Niedermair, D. Schuler (Hrsg.), Die Bibliothek in der Zukunft: regional - global. Lesen, Studieren und Forschen im Wandel. Festschrift für Hofrat Dr. Martin Wieser. Innsbruck 2015, 245-276; NeUHAUSER, Geschichte (wie Anm. 72); HitTMair, Geschichte (wie Anm. 72).

103 Zu diesen Signaturen vgl. Katalog ULB Tirol I (wie Anm. 100) 20-21. 
die durch die Abgabe der Bücher an Italien nach dem Ersten Weltkrieg hervorgerufenen Lücken in der Signaturenreihe der Innsbrucker Handschriften wurden nicht geschlossen. ${ }^{104}$

Drei Handschriften, Sign. 14819, 14820 und 15063, weisen eine Signatur in Tinte auf naturfarbenem Papierschildchen am unteren Rücken auf. Diese Signaturen stammen aus der Zeit um 1910, als sämtliche im barocken Bibliothekssaal aufgestellten Bücher mit einem Numerus currens versehen wurden. ${ }^{105}$ Sie zeigen sehr anschaulich auf, dass einst Drucke und Handschriften - zumindest in Teilen gemischt eingereiht waren. ${ }^{106}$

Aus wesentlich jüngerer Zeit stammen die Signatur Nr. 940 sowie die Neu-Nummerierung von Sign. 14819 mit Nr. 139. Sowohl 940 als auch 139 würden sich zwar gut in die Innsbrucker Signaturenreihe einfügen, doch sind sie dort bereits anderweitig vergeben. ${ }^{107}$ Warum gerade diese beiden Nummern für die von derselben Hand geschriebenen Handschriften gewählt wurden, bleibt offen. Die Nummer 139 wurde vom Stiftsbibliothekar H. Martin Peintner vor 1972 in Rot auf einem weißen Etikett am unteren Buchrücken festgehalten. ${ }^{108}$ Das Signaturschild mit der Nummer 940 in schwarzer Tinte stammt aus der Zeit um 2000 und wurde von H. Theobald Innerhofer auf den wohl kurz vorher neu gestalteten Bibliotheksband aufgeklebt. Spuren einer älteren Signatur sind hier keine auszumachen.

Die beiden großformatigen Gradualbände aus der Mitte des 15. Jahrhunderts sowie das sogenannte Neustifter Wappenbuch weisen hingegen gar keine Signaturen auf. Der Grund hierfür liegt möglicherweise darin, dass sie ursprünglich nicht in der Bibliothek aufbewahrt wurden. Für die Gradualbände, in denen Bleistiftnotizen auf eine Verwendung bis ins späte 19./frühe 20. Jahrhundert schließen lassen, darf wohl die Kirche bzw. die Sakristei als Aufbewahrungsort angenommen werden.

Von einer Vergabe von neuen, alle mittelalterlichen Handschriften zu einer Einheit zusammenfassenden Signaturen wurde aufgrund der in bisherigen Publikationen üblichen Verwendung der „Innsbrucker Signaturen“" abgesehen. Auch die in jüngerer Zeit in Neustift vergebenen Signaturen wurden beibehalten.

\subsection{Fachgebiete/Inhalte}

Erwartungsgemäß sind die meisten überlieferten Werke theologischen Inhalts (61): Missalien, Gradualien, Ritualien und Antiphonarien, Bibeln bzw. Bibelauszüge, Psalmenkommentare, Gebetbücher sowie Ordensliteratur, d.h. Ordensregeln und deren Auslegungen, Berichte sowie Texte zur Ordensund Hausgeschichte, zahlreiche Predigtsammlungen, homiletische Traktate, Texte von Kirchenvätern und Schriften aszetischen sowie dogmatischen Inhalts.

104 Vgl. hierzu Katalog ULB Tirol I-X (siehe Anm. 100): Bei allen abgetretenen Handschriften bzw. deren Signaturen wurde ein entsprechender Eintrag vorgenommen.

$105 \mathrm{Zu}$ diesen Signaturen ist ein Zettelkatalog in Karteikartenformat erhalten, geschrieben vorrangig von zwei Händen mit einzelnen späteren Ergänzungen. Hand 2 hat mehrere Karteikarten am unteren Blattrand datiert (Juli 1911).

106 Heute befinden sich im Bibliothekssaal ausschließlich Drucke. Auch die Karteikarten mit Einträgen zu handgeschriebenen Büchern werden heute separat aufbewahrt. Wo sich die zahlreichen, vorwiegend aus dem 17. und 18. Jahrhundert stammenden hierin genannten Choralhandschriften befinden, ist nicht bekannt. Das Musikarchiv war zum Zeitpunkt der Recherchearbeit nicht zugänglich.

107 Innsbruck, ULB Tirol, Cod. 139: Thomas de Aquino, Albertus de Diessen, entstanden in Süddeutschland und Schnals (?) um 1425/35 (Letztbesitzer: Schnals); vgl. Katalog ULB Tirol II (wie Anm. 100) 108-109. Innsbruck, ULB Tirol, Cod. 940: Iacobus de Voragine, Entstehungsort unbestimmt, 14. (u. a. 1372) und 15. Jh. (Letztbesitzer: Schnals); vgl. Katalog ULB Tirol IX (wie Anm. 100) 351-354.

108 Die Signatur stimmt mit der Nummer im maschinschriftlichen „Verzeichnis der Handschriften. Aus der Bibliothek des Klosters Neustift b. Brixen. Zusammengestellt von Prof. Martin Peintner - Bibliothekar. 1972“ überein. Das Verzeichnis listet insgesamt 504 Handschriften auf; der Großteil stammt aus dem 18. und 19. Jahrhundert, einige datieren in die erste Hälfte des 20. Jahrhunderts. 
Die restlichen Handschriften bieten einen Querschnitt durch den Bildungskanon jener Zeit und zeigen einen breit gefächerten Bibliotheksbestand, ohne besondere Schwerpunkte. Juristische bzw. insbesondere kanonistische Texte (9), vielfach begleitet von bekannten Glossen, sind ebenso vorhanden wie medizinische und naturwissenschaftliche Abhandlungen (6). Die schöngeistige Literatur ist trotz des seit dem 13. Jahrhundert in Neustift belegten Schulbetriebs eher spärlich vertreten (12), Grammatiken u. ä. fehlen zur Gänze. Für den Unterricht vorgesehen waren möglicherweise auch die zwei in einem Band vereinten musiktheoretischen Traktate samt Schemata zu Tonschlüssen, denen astronomische Texte beigefügt sind. Drei Handschriften sind schließlich den Historica zuzuordnen, darunter auch ein Wappenbuch.

Ein ergänzender grober Überblick über die Inhalte der heute in Innsbruck aufbewahrten Neustifter Handschriften findet sich im Anhang.

\subsection{Zeitliche Verteilung}

Die Handschriften datieren vom 10. Jahrhundert bis ins Jahr 1524 bzw. 1526: Während die Schrift dieses jüngsten im vorliegenden Katalog berücksichtigten Codex noch eindeutig der mittelalterlichen Tradition verpflichtet ist, weist die Buchmalerei bereits in die Renaissance. So beschließt diese Handschrift das mittelalterliche Skriptorium von Neustift.

Auffallend ist die geringe Anzahl an frühen Handschriften - auch die an der ULB Tirol aufbewahrten Neustifter Handschriften datieren von der zweiten Hälfte des 14. bis ins 16. Jahrhundert; sie ist aber angesichts der zahlreich erhaltenen Fragmente ${ }^{109} \mathrm{zu}$ relativieren. Es ist vielmehr davon auszugehen, dass die Buchbestände aus der Gründungszeit des Klosters lediglich nicht die Zeiten überdauert haben und durch neuere Handschriften und später Inkunabeln bzw. gedruckte Werke ersetzt werden konnten. Hierzu zählen u. a. die im Mittelalter weit verbreiteten Lehrbücher wie die „Ars maior“ und die „Ars minor“ des Aelius Donatus oder das „Doctrinale“ des Alexander de Villa Dei. Reste von Letzterem sind als Fälze in Cod. 52 wiederverwendet worden.

Der überwiegende Teil der erhalten gebliebenen Handschriften stammt aus dem 15. Jahrhundert. Sie legen einerseits ein anschauliches Zeugnis über die wirtschaftliche und kulturelle Blütezeit des Stiftes in jener Zeit ab, machen andererseits aber auch deutlich, dass auch nach der Erfindung des Buchdruckes weiterhin Bücher handschriftlich angefertigt wurden. Der gleichzeitige Ankauf von mehr als 800 Inkunabeln zeigt auf, dass anstelle eines Entweder-oder vielmehr ein Sowohl-als-auch der Realität entsprach.

$\begin{array}{ll}\text { 10. Jh. } & 495 \\ \text { 12. Jh. } & 154,282,315,327,360,483 \\ \text { 12./13. Jh. } & 20,293,485 \\ \text { 13. Jh. } & 19,86,107 \\ \text { 13./14. Jh. } & 156,171,605 \\ \text { 14. Jh. } & 7,52 \text { (u. a. dat. 1396), } 31,99,161,162,168,253,308,532,606 \\ \text { 14./15. Jh. } & 83 \text { (dat. } 1400), 158,163,182 \text { (dat. } 1400), 183\end{array}$

109 Zahlreiche abgelöste Fragmente werden in einer eigenen Mappe im Stift Neustift aufbewahrt; andere wurden als Makulatureinbände für Drucke, aber auch für Archivhandschriften und Placita wiederverwendet. Im Rahmen eines Projektes der Freien Universität Bozen unter der Leitung von Giulia Gabrielli werden die Neustifter Fragmente in der Stiftsbibliothek und an der ULB Tirol von Gionata Brusa und Giovanni Varelli erfasst. Die abgelösten Neustifter Fragmente an der ULB Tirol fanden in einem vom Jubiläumsfonds der Österreichischen Nationalbank geförderten Projekt („,Die abgelösten Fragmente der ULB Tirol und ihre digitale Erschließung“, 2018-2020) unter der Leitung von Martin Wagendorfer und der Mitarbeit von Claudia Sojer (Universität Innsbruck, München) Berücksichtigung. Die Ergebnisse werden über https://fragmentarium.ms bereitgestellt. Vgl. die weiterführenden Informationen auf der Homepage der Abteilung für Sondersammlungen der ULB Tirol: https://www.uibk.ac.at/ulb/sondersammlungen/2.1.1.2-fragmente.html. 
15. Jh. 4, 48, 53 (u. a. dat. 1452), 76, 77 (dat. 1465), 78, 106, 123, 125, 142 (u. a. dat. 1459), 145 (dat. 1427), 146, 153, 155 (u. a. dat. 1463), 160, 165 (u. a. dat. 1407), 166, 167 (dat. 1419), 173, 174 (u. a. dat. 1472), 177, 181, 196, 200, 204, 217, 252, 353, 397, 440, 447 (dat. 1414), 453, 550 (u. a. dat. 1465), 578 (dat. 1480), 579 (dat. 1491), 597, 614 (u. a. dat. 1419), 617 (u. a. dat. 1455, 1467), 654 (dat. 1496), 748, 754, 756 (dat. 1479), 780, Sign. 15063, Nr. 139 (olim Sign. 14819) (u. a. dat. 1495, 1496), Nr. 940 (u. a. dat. 1490, 1493), Neustifter Wappenbuch, Graduale Neocellense I (dat. 1442), Graduale Neocellense II

15./16. Jh. 190,755

16. Jh. $\quad 85,100$ (dat. 1524-1526), 142 (u.a. dat. 1521), 194 (dat. 1507), 405 (dat. 1501), 691, 694, 726 (dat. 1523), 776 (u. a. dat. 1502), Sign. 14820

\subsection{Entstehungsorte}

Die Entstehungsorte der Handschriften reichen von Nordfrankreich bis nach Oberitalien, wobei der Schwerpunkt auf dem Süddeutschen Raum im Allgemeinen und Tirol im Speziellen liegt. Elf Handschriften weisen eindeutige Hinweise auf eine Herstellung in Neustift selbst auf, bei weiteren acht kann diese mit großer Wahrscheinlichkeit angenommen werden, drei andere Handschriften lassen eine Produktion im stiftseigenen Skriptorium vermuten. Zusätzlich dürften sieben Handschriften im Raum Brixen bzw. im Umfeld des Stiftes entstanden sein, so z. B. jene liturgischen Bücher, die eindeutig auf eine Verwendung in einer der inkorporierten Pfarreien Neustifts schließen lassen. Dazu zählt u. a. das Teilmissale aus dem 12. Jahrhundert (Cod. 154), das aufgrund der Hervorhebung des Festes der hl. Margaretha (in Verbindung mit Matthias und Matthäus) nach Margen bei Terenten weist, oder das Graduale und Antiphonarium aus dem späten 15. Jahrhundert (Nr. 940), das in der Kirche St. Ulrich in Ilstern (Pfarrei St. Sigmund/Kiens) verwendet worden sein dürfte.

Nicht zuletzt dank der genauen Analyse der Wasserzeichen konnten mehrere Handschriften nach Wien bzw. in den Wiener Raum lokalisiert werden. Seit jeher bestanden zwischen Kloster Neustift und dem Augustiner Chorherrenstift Klosterneuburg bei Wien enge Beziehungen, die sich auch auf den Bücherbesitz auswirkten. ${ }^{110}$ Zudem trug wohl auch das Studium einiger Neustifter Chorherren an der 1365 gegründeten Universität Wien hierzu bei ${ }^{111}$ : Sie dürften Bücher in Wien kopiert oder erworben und schließlich nach Neustift mitgebracht haben. Bei diesen Büchern handelt es sich vorwiegend um auf Papier geschriebene Gebrauchshandschriften, die kaum Buchschmuck aufweisen. Sorgfältiger und aufwändiger gestaltet sind hingegen jene Handschriften, die wohl im Umfeld der Universität Bologna entstanden sind. Eine besondere Erwähnung verdient hierbei Cod. 217 („,Satyrae“ des Iuvenal und des Persius Flaccus), der durchgehend palimpsestiert ist: Mithilfe einer Quarzlampe konnte ein ursprünglich quer zum heutigen Schriftspiegel eingetragenes formularartiges Register festgestellt werden, das wohl einem stationarius zur Dokumentation des Verleihs der Pecien diente. Die Tradition solcher Pecienhandschriften, d. h. unter Aufsicht von einer Kommission von Universitätsprofessoren (peciarii) hergestellte und von der Universität als Lehrmittel anerkannte „Normexemplare“ in ungebundenen Lagen, die anschließend von stationarii zum Zweck weiterer Abschriften verliehen wurden, ist vorwiegend für die Universitäten Paris und Bologna belegt. ${ }^{112}$

$\overline{110}$ W. NeuHauser, Buchgeschichtliche Beziehungen zwischen dem Wiener Raum und Tirol im Mittelalter, in: C. Schretter, P. Zerlauth (Hrsg.), In libris. Beiträge zur Buch- und Bibliotheksgeschichte Tirols von Walter Neuhauser (Schlern-Schriften 351). Innsbruck 2010, 405-424.

111 Neuhauser, Wissenschaftspflege (wie Anm. 23) 93-94. Bei L. Santifaller, Verzeichnis der Deutschtiroler an der Wiener Universität im Mittelalter. Tiroler Heimat N.F. 1 (1928) 258-272 werden nur drei Studenten aus Neustift angeführt (260); aus Brixen studierten zwischen 1365 und 1499 nicht weniger als 116 Studenten in Wien.

112 G. Murano, Opere diffuse per exemplar e pecia (Textes et Études du Moyen Âge 29). Turnhout 2005; K. Christ, Petia. Ein Kapitel mittelalterlicher Buchgeschichte. Zeitschrift für Bibliothekswesen 55 (1938) 1-44; J. DestreZ, La „pecia“ dans les manuscrits universitaires du XIIIe et du XIVe siècle, Paris 1935. 


\subsection{Schriften und Schreiberhände}

Den unterschiedlichen Entstehungszeiten und -orten sowie den diversen Verwendungszwecken entsprechend lassen sich in den vorliegenden Handschriften zahlreiche verschiedene Schriftarten nachweisen. ${ }^{113}$

Nur wenige Schreiberhände sind namentlich bekannt. Aus dem ersten Viertel des 15. Jahrhunderts begegnen der nicht näher fassbare Nicolaus Frechen, Hainricus Chirchmair, der möglicherweise aus dem Benediktinerkloster Mallersdorf in der Diözese Regensburg stammt (de Malhenstorff), sowie der kaiserliche Notar Albert Weinkern aus Rosenheim, der um 1420 offensichtlich im Tiroler Raum wirkte. Von ihm stammt auch die Handschrift Brixen, Priesterseminarbibliothek, Cod. D.19 (dat. 1421) sowie München, BSB, Clm 8375 (dat. Innsbruck 1418). Zudem ist er als notarius publicus 1426 in Stift Wilten nachgewiesen. ${ }^{114}$ In der Mitte des Jahrhunderts schrieb der bereits erwähnte Augustiner Chorherr Friedrich Zollner das umfangreiche Graduale, wie er selbst im Kolophon des ersten Bandes festhielt. Möglicherweise wies ebendieser Zollner auch in der zweiten Hälfte des 15. und zu Beginn des 16. Jahrhunderts tätige Neustifter Chorherren wie Erasmus Lämpl, Stephan Stet(t)ner und Franciscus Prensteiner in die Kunst des Schreibens ein. Erwähnung verdienen auch Georg Hölzl aus Mattighofen im oberösterreichischen Innviertel, der im Auftrag des Stadtrichters und bischöflichen Zöllners in Klausen Kaspar Neuhauser 1496 ein zweibändiges Gebetbuch schrieb, sowie der aus Passau stammende Heinrich Edling(er). Er ist als Schreiber zweier Gradualien und Antiphonarien aus der Zeit um 1495/96 belegt, die schließlich in zwei inkorporierten Stiftspfarreien Verwendung fanden.

\subsection{Beschreibstoffe}

42 der insgesamt 92 Handschriften sind auf Pergament geschrieben, 48 auf Papier und zwei Codices sind Mischhandschriften. Das Pergament ist sehr unterschiedlich, teilweise sehr dick, teilweise ist es sehr fein bearbeitet und geglättet. Bei unterschiedlicher Bearbeitung der beiden Seiten - Kennzeichen des sogenannten südlichen Pergaments ${ }^{115}$ - wurde beim Binden immer sorgfältig auf eine regelmäßige Abfolge geachtet. Besonders bei den älteren Handschriften sind vermehrt auch Knochenlöcher und Nahtstellen festzustellen.

Die Frage, ob das bei den Handschriften verwendete Pergament teilweise auch in Neustift selbst hergestellt wurde, muss offenbleiben. In der Mitte des 13. Jahrhunderts ist ein erster pergamenarius in Brixen belegt. ${ }^{116}$

Sämtliche Papierhandschriften wurden von Maria Stieglecker auf ihre Wasserzeichen hin genau untersucht (siehe Abschnitt 3.1), woraus sich wertvolle Hinweise zur Lokalisierung und Datierung ergaben.

113 Zur Entwicklung der Schrift im Brixner Raum von der Karolingischen Schrift bis in die zweite Hälfte des 16. Jahrhunderts mit Beispielen aus Neustift siehe L. Santifaller, Bozner Schreibschriften der Neuzeit 1500-1851. Beiträge zur Paläographie (Schriften des Instituts für Grenz- und Auslanddeutschtum an der Universität Marburg 7). Jena 1930, 19-36.

114 MAIRHOFER, Urkundenbuch (wie Anm. 7) 514

115 Beim „nördlichen Pergament“ wurden hingegen die Haar- und Fleischseite gleichmäßig bearbeitet. Zu beiden Pergamenten vgl. L. Santifaller, Beiträge zur Geschichte der Beschreibstoffe im Mittelalter. Mit besonderer Berücksichtigung der päpstlichen Kurie, T. 1: Untersuchungen (Mitteilungen des Instituts für Österreichische Geschichtsforschung, Erg.-Bd. 16, 1). Graz, Köln 1953, 80-82; DERs., Vom Schrift- und Schreibwesen unserer Heimat im Altertum und im Mittelalter. Der Schlern 13 (1932) 178-191, hier 187; Ders., Über südliches und nördliches Pergament. Der Schlern 13 (1932) 458- 463.

116 Santifaller, Vom Schrift- und Schreibwesen unserer Heimat (wie Anm. 115) 187. 


\subsection{Sprachliche Verteilung}

Von den 92 in Neustift befindlichen mittelalterlichen Handschriften ist lediglich in einer einzigen ein Teil in deutscher Sprache verfasst. Cod. 146 umfasst auf den ersten fünf Blättern die Regel des hl. Augustinus auf Deutsch, die mitten in Kapitel 7 abbricht; anschließend folgen zwei verschiedene Auslegungen und Erläuterungen der Ordensregel in lateinischer Sprache. Alle anderen Werke sind zur Gänze in lateinischer Sprache geschrieben. Auch unter den in Innsbruck aufbewahrten Neustifter Handschriften finden sich nur wenige volkssprachliche Texte, darunter ein „Spiegel deutscher Leute“ (Innsbruck, ULB Tirol, Cod. 922) und zwei „Schwabenspiegel“ (Innsbruck, ULB Tirol, Cod. 169 und 842), von denen einer möglicherweise in Neustift selbst um 1410/20 abgeschrieben wurde. Die zur selben Zeit möglicherweise ebenso in Neustift entstandene Sammlung an Auszügen und Sentenzen aus den „Pluemen der Tugend“ des Hans Vintler (Innsbruck, ULB Tirol, Cod. 961) für Predigtzwecke macht deutlich, dass die deutsche Sprache auch im geistlichen Umfeld zunehmend an Bedeutung gewann. Dasselbe Format und denselben Einband weist auch die sogenannte „Innsbrucker-Neustifter Spielehandschrift“ (Innsbruck, ULB Tirol, Cod. 960, dat. 1391) auf; sie enthält ein Maria-Himmelfahrts-Spiel, ein Osterspiel und ein Fronleichnamsspiel in Deutsch und bezeugt die lange Tradition der geistlichen Spiele in Neustift. Zumal aber in diesen Texten keine tirolischen Spracheigenheiten und -färbungen zu erkennen sind, ist nicht anzunehmen, dass die Handschrift auch vor Ort entstanden ist. ${ }^{117}$ Aufgrund der eingetragenen Todesnotiz zu Oswald von Wolkenstein 1445 wurde sie aber spätestens seit damals im Stift aufbewahrt. ${ }^{118}$ Aus dem letzten Drittel des 15. Jahrhunderts stammt schließlich auch ein umfangreiches deutschsprachiges Evangelistar (Innsbruck, ULB Tirol, Cod. 765, dat. 1472), aus dem 16. Jahrhundert hat sich eine volkssprachliche Fronleichnamspredigt (Innsbruck, ULB Tirol, Cod. 47) erhalten.

\subsection{Provenienzen und Besitzeinträge}

Bei vielen Neustifter Handschriften lässt sich nicht genau feststellen, wann und auf welchem Weg sie Eingang in die Stiftsbibliothek gefunden haben. Nur zwei Codices weisen einen expliziten Schenkungsvermerk auf ${ }^{119}$; für eine Handschrift (Cod. 4) ist eine testamentarische Überlassung nach dem Tod des einstigen Besitzers festgeschrieben. Für weitere vier Handschriften konnte eine Schenkung dank einer erhaltenen Urkunde im Stiftsarchiv nachgewiesen werden.

Die ersten handschriftlichen Besitzeinträge von Seiten des Stiftes reichen ins 15. Jahrhundert zurück: Elf Handschriften weisen entsprechende Hinweise auf, teilweise sogar in zweifacher Ausführung; ihr Wortlaut ist stets ähnlich: Iste liber est monasterii sancte Marie vulgo in Novacella. ${ }^{120}$ Dem Schriftvergleich nach kann vermutet werden, dass sie wohl von einer einzigen Hand eingetragen wurden,

117 Der Entstehungsort der Handschrift ist umstritten; eine Entstehung in Thüringen (Schmalkalden) ist wahrscheinlich, vgl. Katalog ULB Tirol X (wie Anm. 100) 64-68 mit ausführlicher Bibliografie.

118 Dieselbe Notiz findet sich auch in der sogenannten Sterzinger Miszellaneen-Handschrift, die heute im Stadtarchiv Sterzing aufbewahrt wird und deren Entstehungsort ebenso nicht eindeutig geklärt ist.

119 Cod. 123, Bl. Vv und Cod. 748, B1. IIIv. Mit dieser Schenkung dürfte vermutlich auch die Übergabe von Cod. 453 einhergegangen sein.

120 Cod. 52, HDS; Cod. 748, B1. 219r. Andere Besitzeinträge lauten: Iste liber est monasterii sancte Marie vulgo ad Novamcellam (Cod. 52, B1. 2r; Cod. 107, B1. 1r; Cod. 155, Bl. 164v; Cod. 485, B1. 66v); Iste liber est monasterii sancte Marie ad Novamcellam (Cod. 78, Bl. 119v); Iste liber est monasterii sancte Marie ad Novamcellam prope Brixinam (Cod. 83, Bl. 56r); Iste liber est monasterii sancte Marie ad gracias alias ad Novamcellam dicti (Cod. 158, Bl. IIr); Iste liber est monasterii sancte Marie virginis ad gracias alias ad Novamcellam dicti (Cod. 617, B1. Ir); Iste liber est monasterii sancte Marie in Novacella (Cod. 617, B1. 281v); Iste liber est monasterii sancte Marie vulgo ad Novamcellam Brixinensis dyocesis (Cod. 453, VDS); Iste liber est monasterii sancte Marie in Novacella extra civitatem Brixinensem sita (Cod. 200, B1. 377rb). 
möglicherweise von Johannes Librarius (gest. 1467) ${ }^{121}$, dessen Beiname auf eine bibliothekarische Tätigkeit schließen lässt.

Weitere handschriftliche Einträge reichen ins späte 17. bzw. frühe 18. Jahrhundert, als die Zugehörigkeit ad Collegium Neocell. betont wurde. Insgesamt 13 Handschriften weisen einen entsprechenden Eintrag auf. ${ }^{122}$ Auch hier fällt der durchwegs ähnliche Wortlaut auf; mit Ausnahme von zwei Handschriften ${ }^{123}$ dürften die Einträge von einer Hand gemacht worden sein.

Wohl im späten 18. Jahrhundert und damit nach der Neugestaltung des Bibliothekssaals wurde in fast allen Neustifter Handschriften am Spiegel des Vorderdeckels ein Bucheignerzeichen eingeklebt: Der Großteil der Exlibris weist einen Zierrahmen auf und führt im Genitivus possessivus die Bibliothecae Novacellensis als Besitzerin an, darunter ist ein schlichtes Tau-Kreuz zu erkennen, das Wappenzeichen des Stiftes. Dieses Exlibris in Holzschnitttechnik, das sich auch in zahlreichen Drucken nachweisen lässt, ist ebenso wenig wie das zweite nachweisbare Bucheignerzeichen in Holzschnitttechnik datiert. Letzteres zeichnet sich durch eine schlichte Rahmung aus, der Text sowie das Wappenzeichen sind identisch, und dürfte wohl ein paar Jahrzehnte später in Verwendung gekommen sein.

Einige wenige Handschriften weisen einen zusätzlichen Besitzvermerk in Form eines Neustifter Rundstempels am Beginn der Handschrift auf. In jenen Codices, die nach Innsbruck gebracht worden waren, wurde zudem meist ein Rundstempel der dortigen Universitätsbibliothek angebracht; bei der Rückkehr nach Italien drückte auch die „Soprintendenza alle belle arti per la Venezia Tridentina“ ihren Stempel hinein. Leider wurden die Stempel nicht immer mit ausreichender Sorgfalt angebracht, sodass sie vereinzelt auch Texte abdecken.

121 Vgl. Anm. 51.

122 Collegii Neocell. (Cod. 53, B1. 1r; Cod. 158, B1. IIIr; Cod. 177, B1. 1r; Cod. 405, B1. Iar; Cod. 440, B1. 1r; Cod. 453, B1. 1r; Cod. 550, B1. 1r); Ad Collegium Neocell. (Cod. 52, B1. 2r; Cod. 204, B1. 1r; Cod. 253, B1. 1r); Collegii Novacellensis (Cod. 4, Bl. 1r; Cod. 397, Bl. 1r); Ad Bibliothecam Neocell. (Cod. 748, B1. 1r). 123 Die Einträge in Cod. 4 und 397 lassen eine zweite Hand vermuten. 



\section{Besonderheiten der Erschließung und ihre Ergebnisse}

\subsection{Wasserzeichen}

\section{Maria Stieglecker}

Für die Erfassung der Wasserzeichen in den Papierhandschriften der Stiftsbibliothek Neustift wurde die Vorgehensweise gewählt, die seit den 1970er Jahren an der ÖAW entwickelt wurde und sich bereits bei mehreren Handschriftenerschließungsprojekten bewährt hat. ${ }^{124}$ Ziel einer solch genauen Analyse ist, den wahrscheinlichen Beschreibzeitraum des Papiers zu ermitteln, Hinweise auf den Beschreibort zu finden und mögliche Beziehungen zwischen einzelnen Handschriften oder Handschriftengruppen aufzuzeigen.

Um aussagekräftige Ergebnisse zu erzielen, werden sämtliche Blätter einer Handschrift auf ihre Wasserzeichen hin durchgesehen und ihre Standorte festgehalten, d.h. die Verteilung der verwendeten Papiersorten festgestellt. Diese genaue Durchsicht erweist sich als notwendig, da immer wieder einzelne Blätter, etwa bei einer Neubindung, nachträglich eingefügt oder älteres Restpapier, das über Jahre im Skriptorium liegengeblieben war, in Einzelbögen oder ganzen Lagen untergemischt worden ist. Wird eine nur stichprobenartige Durchsicht nach Wasserzeichen vorgenommen, kann solches Papier zu einer Verfälschung der Datierung führen. ${ }^{125}$ Weiters kann über die Verteilungsübersicht des verwendeten Papiers die Zusammensetzung einer Handschrift verifiziert werden, da ein Papierwechsel häufig den Beginn einer neuen kodikologischen Einheit markiert. ${ }^{126}$ Von jeder Gruppe identischer Wasserzeichen eines Manuskripts bzw. eines seiner Teile wurde je nach den gegebenen Möglichkeiten eine Betaradiografie-Aufnahme, eine Abreibung oder ein Digitalfoto angefertigt. Diese Abbildungen der Papiermarken und die zu den Trägerhandschriften erhobenen Daten wie Provenienz, Datierung oder Lokalisierung wurden in die Datenbank „WZMA - Wasserzeichen des Mittelalters“127 eingepflegt, wodurch eine gegenseitige Inbezugsetzung aller in WZMA erfassten Papiermarken ermöglicht wird. Die digitale Aufbereitung der Bilder und Daten erlaubt die dynamische Verknüpfung verwandter

124 A. Haidinger, Datieren mittelalterlicher Handschriften mittels ihrer Wasserzeichen. Anzeiger der phil.-hist. Klasse der ÖAW 139 (2004) 5-27.

125 Als Beispiel sei Cod. 155 genannt, eine Sammelhandschrift, deren Entstehungszeitraum mit „um 1463“ einzuordnen ist, wie auch der Wasserzeichenbefund bestätigt. Nur wenige Blätter fallen aus der Reihe: Im Septernio B1. 51-64 zeigen die inneren fünf Doppelblätter Wasserzeichen, die auf einen Beschriftungszeitraum um 1425/1435 schließen lassen. Hier kam allerdings kein Restpapier zum Einsatz, sondern es wurden wohl einige Blätter aus einer früher angelegten Handschrift eingebunden. Untermauert wird dies durch die Feststellung, dass der betroffene Text (B1. 51ra-105r) bis auf die genannten Doppelblätter von einer Hand geschrieben wurde.

126 Cod. 52 zum Beispiel besteht aus zwei Teilen, wobei Teil II mit 1396 datiert ist und Teil I nach Wasserzeichenbefund mit Ende 14. Jahrhunderts eingeordnet wird. Dieser Teil weist ein Wasserzeichenpaar Ochsenkopf mit Blume auf, während in Teil II ein dazu unterschiedliches Paar Ochsenkopf mit Blume zu finden ist sowie ein Paar Ochsenkopf ohne Beizeichen und zwei Paare Glocken.

$127 \quad$ www.wzma.at 
Wasserzeichen, sodass auf jeweils aktuellem Stand ersichtlich ist, für welche Handschriften Papier aus derselben Produktionscharge verwendet wurde. ${ }^{128}$

Für verlässliche Untersuchungen von Wasserzeichen im Hinblick auf Aussagen zum Verwendungszeitraum bestimmter Papiere ist eine repräsentative Menge an Vergleichsmaterial vonnöten. Erst aus mehreren unterschiedlichen datierten Quellen vorliegende identische Wasserzeichen erlauben eine sichere zeitliche Einordnung undatierten Materials. ${ }^{129}$

Umfangreiche Untersuchungen zu Wasserzeichen in Papierhandschriften, die sich zum einen in Sammlungen in Nord- und Südtirol befinden, zum anderen in Bibliotheken und Archiven in Wien und Niederösterreich, zeigen, dass in den jeweiligen Regionen unterschiedliches Importpapier aus Italien gehandelt und verwendet wurde. Eine Beobachtung, die durch die Analyse des Neustifter Bestandes bestätigt wird. Weiteres Material steuert hier die Sammlung Piccard ${ }^{130}$ bei, die Tausende von Wasserzeichen aus Tiroler Archivalien nachweist. ${ }^{131}$ Gerade die Auswertung von Wasserzeichen in Archivalien aus dem Bereich der Verwaltung und Wirtschaftsaufzeichnungen tragen maßgeblich dazu bei, Fragen zu Datierung und Lokalisierung zu klären. Ihrem Verwendungszweck nach weisen sie in der Regel Datierungen auf und liefern über ihre lokale Verwendung und Aufbewahrung Hinweise auf Beschreiborte.

Der dabei gesammelte bzw. über die Sammlung Piccard zur Verfügung stehende große Pool an Vergleichsmaterial erbrachte erwartungsgemäß viele Treffer für die Papiermarken der Neustifter Handschriften. Sehr genau konnte z. B. der wahrscheinliche Beschreibzeitraum für Cod. 78 und 177 nachgewiesen werden, bei denen das verwendete Papier zwei Paare des Motivs Mohrenkopf mit Varianten zeigt. Allein in der Sammlung Piccard ergeben sich für diese Marken 56 Treffer, die folgende Datierungen aufweisen: $1 \times 1427,7 \times 1429,18 \times 1430,11 \times 1431,8 \times 1432,4 \times 1433$ und $1 \times 1435$. In der Bibliothek des Stiftes Wilten findet sich ebenfalls eine Handschrift, deren Papier beide Paare zeigt: der mit der Datierung 1431 versehene Cod. 320205 (Teil IV). Jeweils eines der genannten Wasserzeichenpaare findet sich in einer ganzen Reihe weiterer Handschriften verschiedener Sammlungen, so in den

${ }_{128}$ Die Sammlung WZMA enthält nach derzeitigem Stand knapp 19.000 Wasserzeichenbelege, hauptsächlich aus Handschriften und Archivalien, die sich in Bibliotheken und Sammlungen im Raum Wien/Niederösterreich sowie im geografischen Raum Tirol (Nord- und Südtirol) befinden. Im Zuge von Handschriftenerschließungsprojekten erfolgen laufend Ergänzungen. Eine Liste von Sammlungen, für deren Bestände bereits Wasserzeichen erhoben wurden, bietet der Reiter „Sammlungen“ auf www.wzma.at. Als Partner in das EU-Projekt „Bernstein“ (eContentPlus, 2006-2009) eingebunden, kann die Sammlung auch über das Portal „Bernstein - The Memory of Paper“ (www.memoryofpaper.eu) angesteuert werden.

129 Nach Gerhard Piccard wie Theodor Gerardy wäre von einem Beschriftungszeitraum des Papiers innerhalb von vier Jahren ab Produktion auszugehen. Statistische Auswertungen für die Sammlung WZMA haben allerdings ergeben, dass Papier mit identischen Wasserzeichen durchaus auch über einen Zeitraum von sechs bis zehn Jahren - weniger häufig auch über eine noch größere Zeitspanne - Verwendung fand. Je mehr Vergleichsmaterial aber vorliegt, umso eher können „Ausreißer“ erkannt und für eine Datierung vernachlässigt werden; d. h. es kann ein Zeitraum festgestellt werden, in dem das Papier vorwiegend beschrieben worden ist; vgl. HaIDINGER, Datieren mittelalterlicher Handschriften 17-20.

130 Die von Gerhard Piccard (1909-1989) angelegte Wasserzeichensammlung umfasst etwa 92.000 Karteikarten und wird am Hauptstaatsarchiv Stuttgart (Bestand J 340, Wasserzeichensammlung Piccard) verwahrt. Knapp zwei Drittel der Sammlung wurde über die 17 „Findbücher“ (1961-1997) in gedruckter Form zugänglich gemacht, in den Jahren 2003-2006 wurde die Sammlung digital aufbereitet und als Onlinefindmittel zur Verfügung gestellt, mittlerweile ist dieser Piccard-Online in das „WZIS - Wasserzeichen-Informationssystem“ (https://www.wasserzeichen-online.de/wzis/struktur.php) integriert; vgl. etwa P. RÜCKERT, E. FRAUENKNECHT (Hrsg.), Wasserzeichen und Filigranologie. Beiträge einer Tagung zum 100. Geburtstag von Gerhard Piccard (1909-1908). Stuttgart 2011.

131 G. Piccard, Piccard Wasserzeichen. Veröffentlichungen der Staatlichen Archivverwaltung Baden-Württemberg. Sonderreihe: Die Wasserzeichenkartei Piccard im Hauptstaatsarchiv Stuttgart. 17 Findbücher in 25 Bänden. Stuttgart 1961-1997; Piccard: Hauptstaatsarchiv Stuttgart, Bestand J 340, Wasserzeichensammlung Piccard. Online zugänglich unter https://www.wasserzeichen-online.de/wzis/struktur.php; M. STIEGLECKER, Wasserzeichen des Mittelalters (WZMA) und Piccard-Online. Vom gegenseitigen Nutzen, in: Wasserzeichen und Filigranologie (wie Anm. 130) 79-89, hier 80-81. 
Bibliotheken des Priesterseminars Brixen in Cod. A.1 (dat. 1432/1433) und B.16 (4. Jz. 15. Jh.) sowie in der ULB Tirol in Innsbruck in Cod. 228 (Vorsatzbl., um 1430/1432), Cod. 234 (Teil VI, um 1430/1431), Cod. 236 (Teil I, dat. 1429), Cod. 437 (Teil II, dat. 1432), Cod. 451 (dat. 1431), Cod. 481 (dat. 1431), Cod. 522 (Teil IV, um 1430/1432), Cod. 548 (dat. 1424132), Cod. 666 (Teil III, dat. 1433) und Cod. 763 (Teil VII, um 1429/1433). Diese Handschriften aus Sammlungen in Nord- und Südtirol weisen zum Teil Lokalisierungen auf, die sämtlich auf den Raum Tirol weisen: $4 \times$ Schnals, je $1 \times$ Neustift (?), Hall, Salern und Stams. Auch ein Drittel der oben genannten Verweise in der Sammlung Piccard zeigt Beschreiborte im Raum Tirol auf. In einigen Beständen des Raumes Wien/Niederösterreich sowie Salzburg finden sich ebenfalls Handschriften mit verwandten Wasserzeichen, deren Beschreiborte allerdings unbekannt bzw. mit Fragezeichen versehen sind: Klosterneuburg, Stiftsbibliothek, CCl 300 (dat. 1431) und Cod. 683 (Teil V, um 1430), Wien, Schottenstift, Archiv HS 28 (Teil V, 4./5. Jz. 15. Jh.) und Archiv HS 377 (Teil I, dat. 1431), Wien, ÖNB, Cod. 5319 (dat. 1431-1432) und Michaelbeuern, Stiftsbibliothek, Man. cart. 65 (2. Viertel 15. Jh.). Dieses umfangreiche Vergleichsmaterial lässt den Schluss zu, dass die Neustifter Handschriften Cod. 78 und 177 nach Wasserzeichenbefund mit „um 1431/1433“ einzuordnen sind.

Über Papier und Wasserzeichen der Neustifter Handschriften können Beziehungen des Stiftes zu Klosterneuburg bei Wien deutlich werden. Durch die bereits erfolgte Erfassung der Wasserzeichen mittelalterlicher Papierhandschriften etwa des Stiftes Klosterneuburg oder des Schottenstiftes in Wien ist hier gleichfalls eine breite Grundlage zur Recherche geboten. Als Beispiel sei der Neustifter Cod. 53 genannt: Papier mit Wasserzeichen der Motive Dreiberg mit Kreuz, Waage und Waage im Kreis, wie es für diese Handschrift verwendet wurde, findet sich ebenso in verschiedenen Handschriften bzw. Handschriftenteilen und Archivalien des Stiftes Klosterneuburg sowie weiterer Sammlungen im Raum Wien/ Niederösterreich. Allein in der Stiftsbibliothek Klosterneuburg ist Papier mit diesen Marken in 20 Handschriften nachzuweisen, im Stiftsarchiv in zwei Grundbüchern und in zwei Rechnungsbüchern. Diese Archivalien sowie eine der Handschriften sind eindeutig nach Klosterneuburg lokalisiert, bei zwei weiteren ist Wien als Entstehungsort im Kolophon genannt. In 20 weiteren Handschriften bzw. Handschriftenteilen der Sammlungen Schottenstift Wien, ÖNB, Haus-, Hof- und Staatsarchiv Wien, Benediktinerstift Melk und ULB Tirol wird als eindeutige Lokalisierung je einmal Wien und Gaming angegeben, je dreimal Wien sowie Niederösterreich als wahrscheinlicher Beschreibort. Damit kann für Cod. 53 ebenfalls eine Entstehung im Wiener Raum angenommen werden. ${ }^{133}$

Beziehungen zwischen Handschriften können sich auch in der Materialität widerspiegeln, wie die beiden Neustifter Manuskripte Cod. 453 und 748 zeigen. Bei beiden handelt es sich um medizinische Sammelhandschriften, die als Geschenk des Präbendars und Klosterarztes Bertoldus de Saxonia in den Besitz des Stiftes gelangten. Ein und derselbe Schreiber (möglicherweise Bertoldus de Saxonia selbst) ist über weite Strecken sowohl in Cod. 453 wie in Cod. 748 nachzuweisen: In Cod. 748 ist er als Hauptschreiber für die Teile I-III zu nennen, in Cod. 453 für die Teile II-IV. Für kleinere Texte, Notizen, Ergänzungen und Zählungen findet sich ein weiterer Schreiber sowohl für Teil I von Cod. 748 wie für Teil I von Cod. 453. Über Besitzer, Inhalt und Schreiber zeigt sich also eine Verschränkung der beiden Handschriften, gleichzeitig aber auch über das verwendete Material. Papier mit identischen Wasserzeichen des Motivs Dreiberg mit Kreuz wurde für die Teile I und III des Cod. 748 und Teil IV des Cod. 453 herangezogen. Ein Wasserzeichenpaar Horn findet sich in identischer Form in Cod. 748, Teil II und Cod. 453, Teil III. Jeweils in Teil III beider Handschriften zeigt das Papier ein weiteres Zeichenpaar Dreiberg mit Kreuz, in Teil III von Cod. 748 sowie in Teil II von Cod. 453 ein Paar Horn.

132 Hier handelt es sich um ein nachträglich eingefügtes Einzelblatt, das besagtes Mohrenkopf-Wasserzeichen aufweist. Die Datierung dieses Codex kann damit für die Analyse vernachlässigt werden.

133 M. Stieglecker, Verborgene Zeichen. Handschriftenbeschreibung und Wasserzeichenanalyse, in: B. SÁra (Hrsg.), Quelle \& Deutung I. Beiträge der paläographischen Tagung Quelle und Deutung I am 27. November 2013. Budapest 2014, 29-52, hier 46-48 (auch online verfügbar unter honlap.eotvos.elte.hu/wp-content/ uploads/2016/02/quelle.pdf). 
Insgesamt wurden 50 Papierhandschriften des Bestandes Neustift auf ihre Wasserzeichen hin untersucht und 383 Abbildungen von Papiermarken in die Wasserzeichen-Datenbank WZMA eingebunden. Mit diesen konnten für 47 bisher nur vage datierte Handschriften bzw. Handschriftenteile des Bestandes wesentliche Hinweise auf deren wahrscheinlichen Beschriftungszeitraum gegeben werden, weiters wurden die Datierungen der datierten Manuskripte über den Wasserzeichenbefund bestätigt. Auf der anderen Seite steht mit diesen Eingaben in WZMA für filigranologische Forschungen wieder mehr Vergleichsmaterial zur Verfügung, sodass zur Entstehungsgeschichte von Manuskripten im Tiroler Raum künftig immer genauere Ergebnisse zu erwarten sind. Systematische Analysen zu weiteren Beständen in der Region, seien es Handschriften, Inkunabeln oder Archivalien, böten hier Möglichkeiten, neben Fragen zu Datierung und Lokalisierung undatierter Papiere auch fundierte Aussagen auf papiergeschichtliche Fragestellungen etwa im Hinblick auf Handelswege und die Verbreitung bestimmter Papiersorten ${ }^{134}$ zu treffen.

\subsection{Illuminierte Handschriften}

\section{Susanne Rischpler}

Der Bestand der Neustifter illuminierten Handschriften ist erstklassig, einige Stücke (siehe unten) sind als kostbare Zimelien einzustufen. Gut ein Viertel der Handschriften beinhaltet höherrangigen Buchschmuck. Daher wurde der Buchschmuckerschließung ${ }^{135}$ im vorliegenden Katalog gebührend Augenmerk und Raum gewidmet - ohne jedoch den einfacheren Dekor zu vernachlässigen. Innerhalb der Katalogisate wird die Buchzier jeweils im Abschnitt A (Ausstattung) behandelt. Besteht eine Handschrift aus mehreren Teilen, so wird im gegebenen Fall der Buchschmuck eines jeden Teils gesondert betrachtet. Die Erschließung orientiert sich an der Methode der „Mitteleuropäischen Schulen“ in der Katalogreihe zu den „Illuminierten Handschriften und Inkunabeln der Österreichischen Nationalbibliothek“. ${ }^{136}$ Die Erfassung des Buchschmucks erfolgt nach hierarchischen Gesichtspunkten: Zuerst

134 Vgl. hierzu etwa M. ZAAR-GörgEns, Champagne - Bar - Lothringen. Papierproduktion und Papierabsatz vom 14. bis zum Ende des 16. Jahrhunderts. Trier 2004; R. Graziaplena, Paper Trade and Diffusion in Late Medieval Europe. A First Approach, in: R. Graziaplena (Hrsg.), Paper as a Medium of Cultural Heritage. Archaeology and Conservation (26 $6^{\text {th }}$ IPH-Congress. Rome, Verona, August $30^{\text {th }}-$ September $\left.6^{\text {th }} 2002\right)$. Roma 2004, 343-354; M. StiEglecker, Papier in Tirol und Niederösterreich, in: Papers of the XXXII International Congress of Paper Historians: Fabriano - Amalfi 21-27 September 2014. Waimes 2018, 233-239.

$\mathrm{Zu}$ Einsatzmöglichkeiten der Wasserzeichenforschung, zu Papiergeschichte oder Aufnahmeverfahren vgl. Ochsenkopf und Meerjungfrau. Papiergeschichte und Wasserzeichen vom Mittelalter bis zur Neuzeit. Begleitbuch und Katalog zur Ausstellung des Landesarchives Baden-Württemberg, Hauptstaatsarchiv Stuttgart und der Österreichischen Akademie der Wissenschaften, Kommission für Schrift- und Buchwesen des Mittelalters, Wien. Stuttgart und Wien 32009 (auch als PDF auf www.wzma.at unter „Materialien“ einzusehen).

135 Ohne die umstandslose Unterstützung und den wertvollen fachlichen Rat der Kollegenschaft wäre die Buchschmuckerschließung nicht zu leisten gewesen. Mein herzlicher Dank gilt daher Ursula Stampfer und Claudia Schretter-Picker sowie Ulrike Bauer-Eberhardt (München, BSB), Regina Cermann (Wien, ÖAW), Giulia Gabrielli (Freie Universität Bozen), Katharina Hranitzky (Wien, Kunsthistorisches Institut), Edith Madas (Budapest, Országos Széchényi Könyvtár), Walter Neuhauser (gest. 2016), Karl-Georg Pfändtner (Augsburg, Staats- und Stadtbibliothek), Martin Roland (Wien, ÖAW) und Michaela Schuller-Juckes (Wien, Kunsthistorisches Institut). Nicht zuletzt danke ich der Bibliotheksstiftung Otto Pächt, Wien, für den Zugang zu ihrem reichen Bilderfundus.

136 Bislang erschienen, jeweils in Wien (als Bände 10-14 der Reihe „Die Illuminierten Handschriften und Inkunabeln der Österreichischen Nationalbibliothek“): Mitteleuropäische Schulen I (ca. 1250-1350), 1997; Mitteleuropäische Schulen II (ca. 1350-1410): Österreich, Deutschland, Schweiz, 2002; Mitteleuropäische Schulen III (ca. 1350-1400): Böhmen, Mähren, Schlesien, Ungarn (mit Ausnahme der Hofwerkstätten Wenzels IV. und deren Umkreis), 2004; Mitteleuropäische Schulen IV (ca. 1380-1400). Hofwerkstätten König Wenzels IV. und deren Umkreis, 2014; Mitteleuropäische Schulen V (ca. 1410-1450): Wien und Niederösterreich, 2012. 
werden die übliche Ausstattung und der niederrangige Dekor, wie Überschriften, Paragraphzeichen, Zeilenfüllsel, Zeigehände und Lombarden summarisch angeführt, dann wird, soweit vorhanden, der höherrangige Dekor ausführlich beschrieben, wobei sowohl für den ornamentalen als auch für den figürlichen Schmuck die stilistischen Charakteristika herausgearbeitet werden. Darüber hinaus wird gegebenenfalls auf stilistische und ikonografische Zusammenhänge (Vergleichsbeispiele) hingewiesen. Wenn sich aus der stilistischen und ikonografischen Einordnung stichhaltige datierungs- und/oder lokalisierungsrelevante Fingerzeige ergeben, fließen diese in den Katalogisatkopf der jeweiligen Beschreibung ein.

Lediglich eine der insgesamt 92 in den Katalog aufgenommenen Handschriften (Cod. 578) trägt keinen nennenswerten Buchschmuck. 66 Codices weisen niederrangigen Buchschmuck auf. Zu diesem Ausstattungsniveau gehören neben der Rubrizierung, zu der von Überschriften bis hin zu Paragraphzeichen alle farblichen Hervorhebungen zählen, beispielsweise Zeilenschlussfüllungen, aufwändigere Zeigehände sowie verzierte Cadellen und Lombarden. Auch diese werden sorgsam erfasst, da sie immer wieder zur Gruppierung und Identifizierung von Schreibern, Rubrikatoren, Lombardenmalern und auch Illuminatoren beitragen können.

25 Handschriften sind mit höherrangigem Buchschmuck verziert, der von sorgfältig ausgeführten Fleuronnée-Lombarden und -Initialen, über kolorierte Federzeichnungen, ornamentale und figürliche Deckfarbeninitialen bis hin zu ganzseitigen Miniaturen reicht. Da sie sehr qualitätvoll bzw. ausgesprochen reich mit ornamentalem wie mit figürlichem Schmuck ausgestattet sind, werden folgende Codices ausführlicher behandelt: das Missale des Propstes Hieronymus Posch (Cod. 100), das „Speculum humanae salvationis“ (Cod. 166), das Rituale Cod. 194, das Lektionar Cod. 196, das Ordinarium missae Cod.252, das zweibändige Stundenbuch des Klausner Stadtrichters Kaspar Neuhauser (Cod. 353 und 654), das Brevier des Propstes Lukas Härber von Ringelsperg (Cod. 405), das Rituale Sign. 14820 sowie die beiden Bände des berühmten Neustifter Graduales (ohne Sign.). Die meisten dieser Handschriften wurden im Jahr 1905 von Hermann Julius Hermann erstmals unter kunsthistorischen Gesichtspunkten erfasst. ${ }^{137}$

Ein gutes Viertel und damit die meisten der in der Neustifter Bibliothek aufbewahrten illuminierten Handschriften stammen wohl aus Neustift selbst oder aus Brixen, das Gros davon entstand im 15. und 16. Jahrhundert. So sind bis auf das „Speculum humanae salvationis“, das zu Beginn des 15. Jahrhunderts im süddeutschen Raum geschaffen worden sein dürfte, auch alle Zimelien mit Sicherheit oder größerer Wahrscheinlichkeit nach Neustift zu lokalisieren, wo sie an der Wende vom Spätmittelalter zur Frühen Neuzeit geschrieben und ausgeschmückt wurden.

Durch die Untersuchung des Buchschmucks konnten in nicht wenigen Fällen die Datierung und auch die Lokalisierung der Handschriften präzisiert werden: Die Miszellanhandschrift Cod. 76 enthält zwar nur eine größere Initiale, doch trägt diese dazu dabei, den entsprechenden Handschriftenteil nach Neustift zu lokalisieren und in die Mitte des 15. Jahrhunderts zu datieren, da die Initiale von der Hand des Hauptflorators der Neustifter Gradualien stammt. Mit Hilfe des Fleuronnées lassen sich Handschriften zudem gruppieren, wodurch wiederum Datierungen ermöglicht werden. So haben u. a. die teilweise datierten Neustifter Liturgica Cod. 405 und 194 sowie die Sammelhandschrift Cod. 142 (Datierungen von 1501 bis 1521) eine Floratorenhand gemeinsam, deren Hauptwerk, das bis auf spätere Zusätze undatierte Rituale Sign. 14820, somit in das erste Fünftel des 16. Jahrhunderts gegeben werden kann.

137 H. J. Hermann, Die illuminierten Handschriften in Tirol (Beschreibendes Verzeichnis der illuminierten Handschriften in Österreich 1). Leipzig 1905. Hermann beschreibt ausführlich die damals noch in der Universitätsbibliothek Innsbruck befindlichen Cod. 4, 76, 99, 100, 166, 194, 196, 217, 252 und 654 sowie die beiden in Neustift verbliebenen Gradualbände (die genauen bibliografischen Verweise zu Hermann siehe im vorliegenden Katalog jeweils im Literaturabschnitt der Beschreibungen). 
Um die Mitte des 15. Jahrhunderts wird das buchmalerische Geschehen durch das Großprojekt der beiden Gradualbände beherrscht, die sehr wahrscheinlich vor Ort in Neustift entstehen. Das Vorhaben bindet die Mitarbeiter aller Ausstattungsebenen für längere Zeit, sie können ihre Fähigkeiten entfalten und werden dann gerne für weitere illuminatorische Tätigkeiten herangezogen - sowohl in Neustift selbst als auch in Brixen. So ordern die Brixner Bischöfe der Zeit, Johannes Röttel (1444-1450) und wohl auch Nikolaus Cusanus (1450-1464), Liturgica, die sie von Mitarbeitern der Gradualbände ausstatten lassen. Schöne Beispiele, die Zeugnis für die enge Verbindung von Neustift und Brixen in dieser Phase ablegen, sind die Missalien Cod. C.1 und F.8 der Brixner Priesterseminarbibliothek, in denen sich Illuminationen von der Hand des Servatius, eines der Deckfarbenmaler der Neustifter Gradualien, finden. Der von Bischof Röttel in Auftrag gegebene Cod. C.1 ist 1447 datiert, entstand also, nachdem bereits ein Großteil der Ausstattungsarbeiten an den Gradualbänden abgeschlossen gewesen sein dürfte. Des Weiteren schmückte auch der zweite Deckfarbenmaler der Neustifter Gradualien bischöfliche Liturgica aus, und zwar das Brevier Cod. E.21 und das Missale Cod. F.4 der Brixner Priesterseminarbibliothek, die keine expliziten Datierungen tragen, sich aber dank der Zusammenhänge im Buchschmuck kurz vor die Mitte des 15. Jahrhunderts datieren lassen. Diese bereits vor der aktuellen Katalogisierung bekannten Verbindungen auf der illuminatorischen Ebene machten deutlich, dass nur eine eng verzahnte Erschließung der Handschriftenbestände in Neustift und in der Brixner Priesterseminarbibliothek eine sinnvolle sein konnte: So zeigt sich nicht nur das 1480 datierte Brevier des Erasmus Pugsinger (Priesterseminarbibliothek, Cod. T.3) im Deckfarbenschmuck, der naturalistische, goldverzierte Blütenzweige variiert, mit dem Lektionar Cod. 196 verwandt und stützt dessen Datierung, sondern auch das Brixner Graduale Cod. F.5, für das sich somit zumindest eine Datierung ans Ende des 15. Jahrhundert rechtfertigen lässt. Auch die annähernd 3000 Initialen und Cadellen, die der Hauptflorator der Neustifter Gradualien mit seinem akkuraten Fleuronnée verzierte und mit unzähligen charakteristischen Profilköpfen besetzte, übten einen starken Einfluss aus, z. B. auf das Cadellen-Fleuronnée im Brixner Missale Cod. C.1 oder noch in der um einige Jahrzehnte jüngeren Neustifter Bruno de Segni-Handschrift Cod. 190. Berührungspunkte ergeben sich auch auf der Ebene der Lombarden. Im ersten Band des Neuhauser-Stundenbuchs (Cod. 353), das im Deckfarbendekor einige Affinitäten zur Neustifter Buchmalerei zeigt, beweist der Lombardenschmuck Verbindungen zu den aufwändiger ausgeführten Lombarden in den Brixner Pontifikalien Cod. C.8 und Cod. F.6. Da Cod. 353 durch seinen 1496 datierten zweiten Band mit Sicherheit um oder kurz nach 1496 einzuordnen ist, kann so für die beiden Brixner Codices eine Datierung ans Ende des 15. Jahrhunderts ins Auge gefasst werden.

Ein Ergebnis der kunsthistorischen Untersuchung des Neustifter Bestandes, das es hervorzuheben gilt, ist die Entdeckung des Servatius, bei dem es sich mit sehr großer Wahrscheinlichkeit um die erste Illuminatorenhand der Neustifter Gradualien handelt. Dieser Buchmaler führte auch Fleuronnée aus, ist aber nicht mit dem Hauptflorator der Gradualien gleichzusetzen, der wahrscheinlich gemeinsam mit Friedrich Zollner, dem Schreiber, Rubrikator und Notenmaler der Gradualien, nach Neustift kam. Eigentlich muss man im Fall des Servatius von einer Wiederentdeckung sprechen. Er war in Vergessenheit geraten, obwohl er seine mit einem Bildnis verknüpfte Signatur Servacius Lichtensteyn de Prussia im zweiten Gradualband hinterlassen hatte und in der Literatur bereits sporadisch als Illuminator genannt worden war. Während der Schreiber Friedrich Zollner, der in der Literatur immer wieder irrigerweise als Illuminator vereinnahmt wurde, nachweislich aus Langenzenn bei Nürnberg kam ${ }^{138}$, kann man von Servatius nur vermuten, auf welchen Pfaden er nach Neustift gelangte. Mutmaßlich war er ein wandernder Buchmaler. Es ist folglich offensichtlich, dass man für das Gradualienprojekt leistungsfähige und begabte Buchkünstler - sowohl Kleriker wie den Augustiner Chorherrn Zollner als auch Laien wie

138 Zur Gebetsbrüderschaft zwischen den Augustiner Chorherrenstiften Neustift und Langenzenn vgl. Anm. 14 und 18. 
Servatius - von außerhalb heranzog. ${ }^{139}$ Diese Vorgehensweise war nicht unüblich. Als beispielsweise in der ersten Hälfte der 1420er Jahre im niederösterreichischen Klosterneuburg ein vierbändiges Antiphonar in Angriff genommen wurde, holte man sich ebenfalls externe Kräfte, was in diesem Fall durch die Eintragungen in den Klosterneuburger Rechnungsbüchern gut belegt ist. ${ }^{140}$

Der umfangreiche Neustifter Handschriftenbestand des 15. und 16. Jahrhunderts birgt nicht zuletzt anschauliche Beispiele für den Umgang mit Vorlagen in einem Skriptorium dieser Zeit. Eine wichtige Rolle spielte dabei das bereits genannte Lektionar Cod. 196, welches sich aus einem Epistolar und einem unvollständigen Evangelistar zusammensetzt. Da es möglich war, den fehlenden Beginn des Evangelistarteils, der sich seit dem 19. Jahrhundert in der Kathedralbibliothek von Esztergom (Ungarn) befindet, in die Untersuchung einzubeziehen ${ }^{141}$, konnte klar herausgearbeitet werden, dass Epistolar und Evangelistar von je einem Buchmaler ausgeschmückt worden waren, die auf einen gemeinsamen Vorlagenfundus - eventuell ein Musterbuch - zurückgegriffen haben. ${ }^{142}$ Diese Vorlagen wurden in Neustift so gut gehütet, dass sie noch in der Renaissancezeit wirksam werden konnten. Daher inspirierte Cod. 196 nicht nur in den 1490er Jahren die Seitenranddekorationen in den zusammengehörigen Brevierbänden Cod. 353 und 654 (dat. 1496), sondern lieferte noch in den 1520er Jahren Modelle für das exquisite Posch-Missale - und zwar vom Randschmuck mit seinen naturalistisch anmutenden Pflanzendarstellungen bis hin zu den Kompositionen figürlicher Initialen. Selbstverständlich diente in dieser Zeit auch Gedrucktes als Grundlage für gemalten Buchschmuck. So wurden für den Großteil der Vollbilder im Brevierband Cod. 654 vermutlich die Illustrationen einer knapp zehn Jahre zuvor erschienenen Inkunabel als Grundlagen benutzt, wobei man auch die dreiregistrige Unterteilung der Bildfelder übernahm. ${ }^{143}$ Von einer Inkunabel mit gemaltem Buchschmuck wurden wiederum Cod. 196 und der in Esztergom befindliche Handschriftenteil beeinflusst, und zwar in Bezug auf Maltechnik und Motivrepertoire. Der Schmuck dieser Inkunabelbibel dürfte seinerseits in der Nachfolge des Innicher Missales stehen, das sich im Verlauf der Buchschmuckerschließung in Neustift und Brixen als ein weiteres maßgebliches Werk für die Buchmalerei in Neustift-Brixen und Umgebung herauskristallisierte. ${ }^{144}$ Daher sind weitere Projekte zur Erschließung von Handschriftenbeständen sowie zur Erforschung von Inkunabelbeständen in (Süd-)Tiroler Bibliotheken nur zu begrüßen, da sie mit Sicherheit dazu beitragen werden, die Buchschmuckbezüge zwischen den erhaltenen Handschriften im Tiroler Raum zu erhellen.

139 Zu Servatius (und zu Zollner) siehe S. Rischpler, „Servacius Lichtensteyn de Prussia“, in: J. F. Hamburger, M. TheISEN (Hrsg.), Unter Druck. Mitteleuropäische Buchmalerei im 15. Jahrhundert. Tagungsband zum internationalen Kolloquium in Wien, ÖAW, 13.-17.1.2016 (Buchmalerei des 15. Jahrhunderts in Mitteleuropa 15). Petersberg 2018, 41-52.

140 Vgl. S. RischPLeR, Der Illuminator Michael. Purkersdorf 2009 (Codices Manuscripti. Supplementum 1) 18-19, 46-49 (Nr. 1), 94.

141 An dieser Stelle sei Edith Madas (Budapest, Országos Széchényi Könyvtár) nochmals für ihre freundliche Hilfe gedankt, die sowohl die Zusammensicht des Cod. 196 mit Esztergom, Kathedralbibliothek, Ms. II.2 als auch des Neustifter Cod. 146 mit Esztergom, Kathedralbibliothek, Ms. II.516 ermöglichte.

142 Auch im Datierungskontext ist das Lektionar Cod. 196 von Interesse: In dem in Esztergom befindlichen Handschriftenteil begegnet, eingeschrieben in eine figürliche Deckfarbeninitiale, eine Jahreszahl, die für die Datierung der Gesamthandschrift richtungsweisend sein dürfte (Esztergom, Kathedralbibliothek, Ms. II.2, B1. 5v: Darbringung im Tempel; an der Wand über den Gesetzestafeln die Jahreszahl 1482; die 2 abgerieben).

143 Itinerarium seu peregrinatio BMV: lat., Johann Reger, Ulm, ca. 1487/88, GW M15415 oder dt., Johann Schobser, Augsburg, 1489, GW M15419 (jeweils mit Links zu Volldigitalisaten).

144 Inkunabelbibel: Wien, ÖNB, Ink. 3.C.6; Johann Mentelin, Straßburg, vor dem 27. Juni 1466 bzw. um 1470, GW 4295 (http://data.onb.ac.at/rec/AC07662248, auf dieser Seite Link zum Volldigitalisat); zu dieser Bibel vgl. M. Roland, Buchmalerei der Gotik, in: P. Naredi-Rainer, L. Madersbacher (Hrsg.), Kunst in Tirol I (Kunstgeschichtliche Studien - Innsbruck N. F. 3). Innsbruck, Wien, Bozen 2007, 267-294, 291-292, Kat. 188. - Missale: Innichen, Kollegiatstift, ohne Sign., zu dieser Handschrift, die wohl in der 2. Hälfte der 1450er Jahre entstanden ist, siehe HermanN, Die illuminierten Handschriften (wie Anm. 137) 75-78, Nr. 81; E. KÜHEBACHER, Kirche und Museum des Stiftes Innichen. Bozen 1993, Nr. 163, Abb. 116, 117a-g; Roland, Gotik 275 Anm. 79, Abb. 17. 


\subsection{Musikalien}

\section{Giulia Gabrielli}

Musik spielte in Neustift seit jeher eine große Rolle. Choralbücher, Musikarchivalien sowie die von 1390 bis in die Neuzeit nachweisbaren geistlichen Spiele dokumentieren den hohen Stellenwert der Musik im Kloster. Ins Jahr 1466 reicht die erste urkundliche Erwähnung eines Orgelspiels in der Stiftskirche zurück. ${ }^{145}$ Auch wenn zunächst wohl noch als curiositatis vanitas abgetan, bildet die Orgel seither einen wichtigen Bestandteil der Kirche. Unter Propst Markus Hauser waren sogar vier Orgeln in der Kirche aufgestellt. ${ }^{146}$

Eine besondere Bedeutung kommt seit den Anfängen dem Choralgesang zu, der maßgeblich zur feierlichen Gestaltung der Liturgie beitrug. Die bis heute erhaltenen liturgischen Handschriften mit Notation dürften, wie nicht zuletzt auch die zahlreichen Fragmente belegen, wohl nur den Rest einer ursprünglich weit umfangreicheren Sammlung an Musikhandschriften bilden. Dennoch machen sie die große Musiktradition im Augustiner Chorherrenstift deutlich.

„Es sind dort gereifte und ehrerbietige Männer, und ich glaube, ich hab nie einen genaueren und besseren Chorgesang als in diesem Kloster gehört. “147 Der Dominikaner Felix Faber betonte in seinem Reisetagebuch aus den Jahren 1483/84 nicht nur den reichen Bücherbestand von Neustift, sondern hob insbesondere auch die Qualität des liturgischen Gesangs hervor. Eine intensive musikalische Tätigkeit und die Produktion von Musikhandschriften zeichnen das Stift vermutlich schon seit den ersten Jahrhunderten seines Bestehens aus. Dies bezeugen u. a. Persönlichkeiten, die in Neustift lebten oder dort zu Besuch waren. Propst Albert (1298-1314) wird im „Memoriale benefactorum Novacellensium“ als metrista perfectus, musicus subtilis bezeichnet. ${ }^{148}$ Derselben Chronik zufolge hat Albert auch liturgi-

145 A. und M. Reichling, Orgelgeschichte der Stiftskirche zu Neustift bei Brixen, in: Festschrift. Orgelweihe der Neuen Metzler-Orgel. Stiftskirche Neustift. Sonntag, 18. Mai 2014. Neustift 2014, 31-43, hier 31.

146 Ebda 33.

147 „Sunt ibi viri maturi et observantiales: numquam videtur mihi me audivisse tam regularem et bonum chori cantum, sicut in hoc monasterium.“ Vgl. Anm. 3.

148 Johannes Librarius, Memoriale benefactorum Novacellensium, Hs. aus dem Jahr 1463, ursprünglich in Neustift verwahrt, heute verloren. Eine Transkription des auf Albert bezogenen Abschnitts ist enthalten in: A. DörRer, Bozner Bürgerspiele. Alpendeutsche Prang- und Kranzfeste, Bd. 1. Leipzig 1941, 142. Vgl. auch M. Frei, Das Memoriale benefactorum des Augustiner-Chorherrenstiftes Neustift verfasst von Johannes Librarius, Diss. Wien 1960. Albert von Neustift wird für gewöhnlich die Urheberschaft der marianischen Sequenz Ave cella novae legis zugeschrieben, in deren erstem Vers angeblich die alte Bezeichnung des Klosters, „cella nova“, anklingt. In der Chronik des Johannes Librarius findet sich jedoch kein Hinweis auf bestimmte von Albert verfasste Werke, ebensowenig auf diese Sequenz. Eine Zuschreibung der marianischen Sequenz an Propst Albert erfolgte erstmals durch Anton Dörrer (vgl. DöRRER, Bozner Bürgerspiele 142). Er stützte sich dabei auf die Aussage des Kanonikers und Historikers Max Schrott, dass er diese Sequenz in einer Handschrift des 14. Jahrhunderts aus Neustift gefunden und den Gleichklang zwischen der ersten Strophe und dem Namen des Stiftes bemerkt habe. Diese hypothetische Zuschreibung an Propst Albert wurde auch in der späteren Literatur übernommen, vgl. u. a. A. DöRRER, Albert von Neustift (Albertus Novacellensis), in: Verfasserlexikon (wie Anm. 51) V, 21-22; L. Oberrauch, Musik, in: Tyrolis Latina (wie Anm. 51) 143-146, hier 144. Derzeit ist es nicht möglich, die von Max Schrott genannte Handschrift aus dem 14. Jahrhundert zu identifizieren. Die einzigen beiden im Augustiner Chorherrenstift Neustift gefundenen Zeugen für die Sequenz sind ein Fragment aus dem 14. Jahrhundert, das für den Einband von Cod. 440 verwendet wurde und am Rand zu einem Totenoffizium den Text der Sequenz enthält (siehe Beschreibung im Katalog), und die Version mit Notation im zweiten Band des Zollner-Graduales aus dem 15. Jahrhundert (B1. 217v). Jedenfalls auszuschließen ist die von Oberrauch vorgeschlagene Übereinstimmung der von Schrott genannten Handschrift mit Cod. 710 der ULB Tirol, da diese höchstwahrscheinlich aus Wilten stammt und sich kein Bezug zu Neustift herstellen lässt; vgl. Katalog ULB Tirol VIII (wie Anm. 100) 60-65; Sт. ENGeLs, Einstimmige liturgische Handschriften des Mittelalters in Tirol, in: Musikgeschichte Tirols I (wie Anm. 43) 119-322, insbes. 293-296. 
sche und musikalische Handschriften kompiliert. ${ }^{149}$

Im Hinblick auf die weltliche Musiktradition in Neustift darf die enge Beziehung des Minnesängers Oswald von Wolkenstein zu Neustift nicht unerwähnt bleiben. Möglicherweise ließ er im damals sehr renommierten Skriptorium des Stiftes die zwei Liederhandschriften herstellen, die sich heute in Wien und in Innsbruck befinden. ${ }^{150}$ In der ULB Tirol wird außerdem noch eine weitere berühmte Musikhandschrift des 15. Jahrhunderts aus Neustift verwahrt, nämlich Cod. 457. Die Handschrift überliefert eine umfangreiche Sammlung einfacher polyphoner liturgischer Musik; aufgrund der großen Bedeutung des enthaltenen Repertoires war die Handschrift in den vergangenen Jahrzehnten Gegenstand intensiver wissenschaftlicher Untersuchungen. ${ }^{151}$

Ein ganz anderes Schicksal erlebten die fünf mittelalterlichen Handschriften mit Kompositionen in Cantus planus, Cantus fractus und einfacher Polyphonie, die noch heute in der Stiftsbibliothek zu finden sind. Sie sind wichtige Zeugnisse für die Geschichte des liturgischen Gesangs in Neustift. Alle fünf Handschriften stammen aus dem 15. Jahrhundert - von den älteren Musikhandschriften ist keine vollständig erhalten geblieben; daneben existiert eine große Anzahl an Fragmenten, die erst vor Kurzem systematisch untersucht und beschrieben wurden. ${ }^{152}$ Die Musikhandschriften aus Neustift werden im vorliegenden Katalog zum ersten Mal vollständig und systematisch beschrieben. ${ }^{153}$ Drei davon Nr. 139 (olim Sign. 14819) und die beiden Bände des Zollner-Graduales - waren in der Forschung bereits bekannt, während zwei - Nr. 940 und Sign. 15063 - erstmals genauer untersucht werden konnten. Alle fünf Handschriften enthalten musikalische Werke aus dem sogenannten Gregorianischen Repertorium in gotischer Choralnotation auf Vierliniensystem. Es handelt sich um zwei großformatige Choralbücher mit reichem Dekor, die gemeinsam das sogenannte Zollner-Graduale bilden und die über Jahrhunderte hinweg in der Stiftskirche verwendet wurden, sowie um drei kleinere und weniger ausgeschmückte, von denen zwei womöglich für Kirchen in der Umgebung erstellt wurden.

Die zwei großformatigen Bände des Graduale stellen wohl die berühmtesten in Neustift verwahrten Handschriften dar. Es ist anzunehmen, dass die Chorsänger, von denen Felix Faber in den 1480er Jahren so begeistert war, aus ebendiesen, etwa 40 Jahre zuvor geschriebenen Handschriften gesungen haben. Wie bereits an anderer Stelle ausführlich dargelegt, entstanden die zwei Bände zwischen 1439 und 1446 und wurden vom Augustiner Chorherrn Friedrich Zollner aus dem Kloster Langenzenn geschrieben (siehe hierzu Abschnitt 3.2). In den reichen Buchschmuck, gestaltet von mehreren Händen, werden bisweilen auch Textzeilen und Notation eingebunden. So sind z. B. in der Initiale R von Resurrexit (Introitus zum Ostersonntag, Graduale Neocellense I, Bl. 156v) drei Schriftrollen mit den Initien der drei Ostergesänge dargestellt, einer davon zweistimmig. ${ }^{154}$

149 Claret in libris missalibus quibusdam [...] et libris cantualibus („Memoriale benefactorum Novacellensium“, zit. nach Dörrer, Bozner Bürgerspiele [wie Anm. 148] 142). Es ist jedoch keine liturgisch-musikalische Handschrift aus der Zeit Alberts vollständig erhalten geblieben.

150 Die erste (Cod. A) befindet sich in Wien, ÖNB (Cod. Vind. 2777), die zweite (Cod. B) in der ULB Tirol (Wolkenstein, o. S.).

151 Vgl. Katalog ULB Tirol V (wie Anm. 100) 358-375, mit ausführlicher Bibliografie.

152 Die Katalogisierung erfolgte im Rahmen eines von der Freien Universität Bozen finanzierten Forschungsprojekts unter der Leitung von Giulia Gabrielli, vgl. Anm. 109.

153 Aufgrund der erschwerten Zugänglichkeit berücksichtigte Praßl in seiner Arbeit über die Sequenzen der österreichischen Augustiner 1987 die Neustifter Musikhandschriften nicht (F. K. PrassL, Psallat ecclesia mater. Studien zu Repertoire und Verwendung von Sequenzen in der Liturgie österreichischer Augustinerchorherren vom 12. bis zum 16. Jahrhundert, Diss. Graz 1987). Jüngere Untersuchungen wie jene von PeinTner, Schreibkunst (wie Anm. 43), insbes. 366-368, und von Engels, Einstimmige liturgische Handschriften (wie Anm. 148) behandeln nur Teile des vorhandenen Materials.

154 Es handelt sich um den Hymnus Salve festa dies, die marianische Antiphon Regina celi und den zweistimmigen Tropus Alle[uia] Dei filius. 
Die detaillierte Erforschung des musikalischen Inhalts der beiden Handschriften steht noch am Anfang. ${ }^{155}$ Doch bereits bei einer ersten genauen Durchsicht fallen einige seltene oder gar einzigartige Kompositionen auf. Es handelt sich hierbei in erster Linie um Tropen, also Ergänzungen textlicher und/ oder melodischer Art, mit dem Ziel, Inhalt und Bedeutung der kanonisierten Stücke zu aktualisieren und weit verbreiteten Kompositionen lokale oder identitätsstiftende Merkmale zu geben. Gerade für das 15. Jahrhundert sind insbesondere im süddeutschen Raum eine Fülle solcher Tropen bekannt. ${ }^{156}$ Im Neustifter Graduale finden sich derartige Ergänzungen bei den Festen bzw. liturgischen Formularen für die wichtigsten Heiligen des Stiftes: für den Ordensvater Augustinus und für die Gottesmutter Maria. Die Initien eines Tropus zum Introitus Statuit ei beim Fest des hl. Augustinus (Graduale Neocellense II, B1. 175r) sind in keiner anderen Quelle belegt (Initien: Augustinus* - Hic est manu* - Ut pro nobis* Hic est cleri*). Auch die Alleluia-Komposition in derselben Messe (Alleluia Protege pastor bone, Bl. 175r) hat großen Seltenheitswert, ihre Melodie ist auch im Graduale Magnum von ca. 1490 aus dem Augustiner Chorherrenstift Seckau überliefert. ${ }^{157}$ Die Beziehungen zwischen Neustift und Seckau reichen bis zur Gründung jenes Stifts zurück: Bischof Hartmann von Brixen, Gründer von Kloster Neustift, nahm in seinem Todesjahr 1164 die Weihe der Stiftskirche von Seckau vor. ${ }^{158}$ Möglicherweise ist gerade das Vorhandensein derselben Komposition in beiden Augustiner Chorherrenstiften ein Zeichen für den engen Kontakt der Stifte auch noch im 15. Jahrhundert. Auch die Tropen zum Introitus Gaudeamus für die Feste der Himmelfahrt Mariens (Graduale Neocellense II, B1. 171v, Inc.: Quia virgo*) und Mariä Geburt (Graduale Neocellense II, Bl. 186r, Inc.: Nata summa*) stellen Unikate dar. Wie auch beim Fest des hl. Augustinus enthält die Handschrift nur die Textanfänge der Tropen, wohl ein Zeichen dafür, dass Text und Melodie bekannt waren und von den Sängern aus dem Gedächtnis vorgetragen wurden. Ebenso einzigartig ist der kurze Tropus zum Agnus Dei O dulcis Iesu Christe mit rhythmischer Notation, der gleich in beiden Bänden vorkommt (Graduale Neocellense I, Bl. 305v und II, Bl. 288r).

Weiters fällt die große Fülle an Sequenzen auf, die im Graduale überliefert werden - auch dies ein typisches Merkmal der deutschen Quellen des späten 15. Jahrhunderts. Die über 90 Sequenzen in beiden Bänden entsprechen im Wesentlichen den in zeitgenössischen österreichischen Augustiner Chorherren-Handschriften enthaltenen Sequenzen-Reihen und weisen signifikante Überschneidungen mit dem Repertorium von Seckau auf. ${ }^{159}$ Hervorzuheben sind zwei Sequenzen für die Brixner Diözesanpatrone: Innoventur hac in die (Graduale Neocellense II, B1. 107v) für das Fest der hl. Ingenuin und Albuin und Gloriosa fulget dies für jenes des hl. Kassian (Graduale Neocellense II, Bl. 274v-274br). Die erste Sequenz wurde eigens für diese Heiligen komponiert und wird auch in anderen Handschriften der Diözese Brixen überliefert ${ }^{160}$, im Repertorium anderer österreichischer Augustiner Chorherrenstifte ist sie hingegen nicht zu finden. Die zweite, Gloriosa fulget dies, taucht in ebendiesem Repertorium

155 Eine erste Untersuchung der Neustifter Tropen wurde von der Verfasserin für ihren Vortrag „Tropes in cantus planus sources from South Tyrol“, gehalten beim $20^{\text {th }}$ International Musicological Society Congress, Study Group Cantus Planus, Venice, July $28^{\text {th }}-$ August $1^{\text {st }}$ 2014, durchgeführt. Der Beitrag wird im Tagungsband publiziert: J. Borders u. a. (Hrsg.), Cantus planus. Venice meeting 2014 (im Druck).

156 Zur Verbreitung und $\mathrm{zu}$ den charakteristischen Merkmalen der Tropen aus jüngeren Quellen im deutschsprachigen Raum sowie über die verschiedenen Quellenarten siehe A. HAUG, Troparia tardiva. Repertorium später Tropenquellen aus dem deutschsprachigen Raum (Monumenta monodica Medii Aevi. Subsidia 1). Kassel 1995, insbes. 3-10.

157 Graz, UB, Hs. 17, Bl. 188v. Die Handschrift ist unter http://143.50.26.142/digbib/handschriften/Ms.00010199/Ms.0017/index12.html einsehbar.

158 Vgl. A. Sparber, Leben und Wirken des seligen Hartmann, Bischofs von Brixen (1140-1164). Wien 1957, 82. Eine Verbrüderung des Augustiner Chorherrenstiftes Seckau mit Neustift ist seit 1331 belegt (vgl. PAllhuber, Der Neustifter Rotelbote [wie Anm. 18] 111).

159 Diese und die beiden folgenden Beobachtungen basieren auf dem Vergleich mit Quellen und Repertorien aus Prassl, Psallat ecclesia mater (wie Anm. 153).

160 G. GabrielLi, Katalog der in Bozen und Brixen verwahrten Musikhandschriften im Cantus planus und Cantus fractus, Diss. Graz 2015, 369, 483. 
auf. ${ }^{161}$ Dort ist allerdings die Verwendung dieser üblicherweise für die Bekenner verwendeten Sequenz ${ }^{162}$ für das Fest der Translatio mehrerer Heiliger, insbesondere des hl. Rupertus, Virgilius, Nicolaus, Valentinus und Augustinus, belegt. Im Neustifter Graduale ist Gloriosa fulget dies gleich in zwei Versionen enthalten: für eben diese beiden Feste (Graduale Neocellense II, Bl. 272v-274v) und unmittelbar darauffolgend wie erwähnt für das Fest des hl. Kassian. Hier zeigt sie sich in einer wesentlich ausgefeilteren Form als in der vorangehenden Variante, reich mit Melismen verziert und mehreren Textvarianten; die auf den vorhergehenden Blättern angeführten Strophen 4 und 5 sind hier nun weggelassen.

Am Rand - vermutlich Ende des 18. Jahrhunderts - ergänzte Anmerkungen und Hinweise für die praktische Umsetzung lassen darauf schließen, dass das Graduale wohl über einen sehr langen Zeitraum in Neustift in Gebrauch war. An zahlreichen Stellen wurden die Melodien außerdem durch das Weglassen von Melismen verändert; diese wurden mit Papierstreifen überklebt oder mittels grafischer Zeichen wie senkrechte Striche in Rot oder Schwarz gestrichen. Die Herstellung von Choralbüchern wurde auch in neuzeitlicher Zeit in Neustift fortgesetzt, wie zahlreiche erhaltene Handschriften belegen. ${ }^{163}$

Die beiden Papierhandschriften Nr. 139 (olim Sign. 14819) und Nr. 940 stammen von einer Hand und wurden Ende des 15. Jahrhunderts von Heinricus Edlinger geschrieben; beide enthalten ein Antiphonar sowie ein Graduale. Nr. 139 (olim Sign. 14819) wurde bereits von Stefan Engels genau erforscht: ${ }^{164}$ Die Handschrift enthält u.a. Beispiele für Cantus fractus in gotischer Choralnotation. Nr. 940 ist hingegen in der Forschung noch weitgehend unbekannt. Die Handschrift weist dieselben Merkmale und denselben Inhalt wie Nr. 139 (olim Sign. 14819) auf, möglicherweise diente sie als Vorlage für Nr. 139.

Beide Handschriften dürften für zwei Kirchen in der (Neustift inkorporierten) Pfarre St. Sigmund/ Kiens im Pustertal hergestellt und zu einem nicht näher bestimmbaren späteren Zeitpunkt in die Stiftsbibliothek Neustift überstellt worden sein. ${ }^{165}$

Wie bei den beiden obgenannten Antiphonarien-Gradualien ist auch bei Sign. 15063 nicht sicher, ob die Handschrift in Neustift verwendet wurde, da sie weder einen Stempel noch ein Exlibris der Stiftsbibliothek aufweist. Wie bereits bei einer ersten Analyse festgestellt werden kann, ist dieser Codex aus musikwissenschaftlicher Sicht äußerst interessant. Leider ist der ursprüngliche Inhalt an zahlreichen Stellen verloren gegangen, da viele Blätter radiert und zu einem späteren Zeitpunkt überschrieben wurden. In jenem Teil, der aus dem 15. Jahrhundert stammt, überliefert die Handschrift zahlreiche rhythmische Offizien und Tropen, darunter einen zweistimmigen Tropus zum Benedicamus Procedentem sponsum de thalamo, der auch im bereits genannten Cod. 457 der ULB Tirol vorkommt. Der Stil der sogenannten einfachen Polyphonie scheint sich über lange Zeit in Neustift gehalten zu haben: den handschriftlichen Quellen zufolge bis zur Schwelle zum 19. Jahrhundert. So taucht in einem Psalterium-Hymnar von 1779, das in der Stiftsbibliothek verwahrt wird, ein „Hymnus secundatus“ auf: Die Hauptmelodie wird von einer in Quarten und Quinten tieferen Stimme begleitet. ${ }^{166}$

161 Diese Verwendung ist in Augustiner Chorherren-Handschriften aus Salzburg, Vorau und Seckau belegt; vgl. Prassl, Psallat ecclesia mater (wie Anm. 153) 359 passim. Die von Praß1 untersuchten Sequenzen sind auch online unter www.cantusplanus.at verfügbar, zu finden in der Rubrik der Sequenzen in der Liturgie österreichischer Augustiner Chorherren: http://www.cantusplanus.at/de-at/austriaca/prassl/index.php.

162 Siehe AH 54, Nr. 89

163 Siehe z.B. Cod. 136, Choralhandschrift auf Pergament aus dem Jahr 1762: Sie überliefert eine Reihe von Alleluia-Versen, Gradualien und marianischen Sequenzen, die in der Liturgie eindeutig bis ins späte 18. Jahrhundert gesungen wurden. Ein weiteres Beispiel für die lange Pflege der althergebrachten Gesänge ist zweifellos der genannte „Hymnus secundatus“ im Psalterium-Hymnar von 1779.

164 EnGELS, Einstimmige liturgische Handschriften (wie Anm. 148) 309-310.

165 Für weitere Informationen hierzu siehe die Beschreibungen der beiden Handschriften im nachfolgenden Katalogteil.

166 Es handelt sich um den Hymnus Iam lucis, in dem eine zweite, in Rot notierte Stimme die in Schwarz notierte Hauptstimme begleitet, ähnlich einem Orgelpunkt (Neustift, Stiftsbibl., Cod. 129,6). 
Eine weitere Besonderheit dieses Antiphonars stellen die Reihen der Antiphonen zum Magnificat und zum Benedictus für die Sonntage nach Pfingsten dar. Diese stimmen mit der Klosterneuburger Reihe überein. ${ }^{167}$ Die Reihe der Responsorien zur Nokturn des Totenoffiziums (Bl. 185v-192v) ist hingegen nirgendwo sonst belegt ${ }^{168}$, auch nicht in Brixen, und spiegelt daher offensichtlich eine besondere, möglicherweise lokale Tradition wider.

Sign. 15063 enthält am 5. Februar außerdem das Offizium der Brixner Diözesanheiligen Ingenuin und Albuin. Der Text des Offiziums entspricht jenem in den handschriftlichen und gedruckten Brevieren der Diözese Brixen, die hier bezeugte Version mit Notation ist hingegen die zweitälteste und die erste mit diastematischer Notation. ${ }^{169}$ Die Antiphon zum Magnificat der ersten Vesper Adest dies celebris hat denselben Textanfang wie die Antiphon zum Magnificat des Offiziums für den hl. Augustinus, die in mehreren Handschriften des 13. Jahrhunderts auftaucht, und könnte uns möglicherweise einen Hinweis auf einen Zusammenhang zwischen diesem Offizium und dem Augustiner Chorherrenstift Neustift geben.

Gerade hinsichtlich diverser Zusammenhänge und Beziehungen sind dank musikwissenschaftlicher Detailuntersuchungen in den kommenden Jahren noch Neuerkenntnisse zu erwarten.

\subsection{Einbände}

\section{Ursula Stampfer}

In der Stiftsbibliothek Neustift sind unterschiedlich gestaltete Einbände auf uns gekommen, die einen Einblick in die Geschichte und Entwicklung des Buchbinderhandwerks erlauben. Zudem lässt sich bestätigen, dass der Einband nicht zwingend mit der Entstehungszeit des Textes übereinstimmen muss bzw. aus diversen Gründen im Laufe der Jahrhunderte ersetzt und erneuert wurde. Für einen möglichst vollständigen Überblick über die Einbände bzw. die Buchbindekunst wäre es notwendig, nicht nur die Einbände der überlieferten Handschriften, sondern auch jene der Archivhandschriften sowie der Inkunabeln zu untersuchen und die Archivalien nach allfälligen Hinweisen auf Stempel- und Rollenkäufe sowie Buchbinder genauestens zu sichten. Die Einbände spiegeln die abwechslungsreiche Geschichte der Neustifter Handschriften wider. Sie legen Zeugnis ab von der Buchpflege in der Romanik, Gotik und insbesondere in der Renaissance, zeigen auf, wie sich die Änderung der räumlichen Verhältnisse in der zweiten Hälfte des 18. Jahrhunderts auch auf die einzelnen Bücher auswirkte, und veranschaulichen die Restaurierpraxis im ausgehenden 20. Jahrhundert.

Nur mehr ein kleiner Teil der Codices weist heute noch den ursprünglichen Einband auf. 13 Handschriften werden von einem gotischen Ledereinband, teilweise schmucklos, teilweise mit Streicheisenlinien, teilweise mit Blinddruck verziert, geschützt. Die sieben Renaissance-Einbände sind mehrfach bereits eine Zweitbindung bzw. nicht unmittelbar nach Fertigstellung der Handschrift entstanden. Im Gegensatz zu Archivhandschriften und Urbaren ist nur ein einziger den Bibliothekshandschriften zugeordneter Codex mit einem Makulatureinband versehen: die „Vita Hartmanni““ aus der Zeit um 1200. Ein Codex ist in einen roten Samteinband eingebunden, der wohl aus dem 17. Jahrhundert stammen

167 Vgl. die Datenbank „Post-Pentecost Cantica Antiphons“ (https://www.uni-regensburg.de/Fakultaeten/phil_ Fak_I/Musikwissenschaft/cantus/). Zur engen Beziehung zwischen den beiden Augustiner Chorherrenstiften Neustift und Klosterneuburg bei Wien siehe allgemeine Einleitung (Abschnitt 1).

168 Vgl. K. Оттоsen, The responsories and versicles of the Latin Office of the Dead. Aarhus 1993. Hier werden zu dieser Responsorien-Reihe keine Parallelen aufgezeigt.

169 Das älteste Offizium mit Notation ist im „Calendarium Wintheri“ aus Brixen (Bozen, Staatsarchiv, Cod. 147) erhalten: Die darin enthaltenen Melodien sind allerdings nicht erschließbar, da sie in linienlosen, deutschen adiastematischen Neumen angegeben sind. Eine genaue Beschreibung der Handschrift findet sich in: G. Gabrielli, I manoscritti liturgico-musicali di Bolzano (secoli XIII-XIX) (Bibliotheca Mediaevalis 3). Lucca 2015, 3-8. 
dürfte. Der weitaus größte Teil der Handschriften (64) zeigt heute einen Bibliothekseinband im Stile eines Halbfranzeinbandes aus der Zeit um 1780, samt Titelaufschrift in Golddruck am Rücken. Dass das sogenannte Posch-Missale wohl im selben Zeitraum mit einem schlichten Kalbsledereinband gebunden und Vorder- und Hinterdeckel nicht wie bei den anderen mit einem schwarz-braun gesprenkelten Papier überzogen wurden, hängt wohl mit dessen bereits damals erkannter Bedeutung zusammen. Im Zuge von Restaurierungen erhielten vier Handschriften in der zweiten Hälfte des 20. Jahrhunderts einen neuen Einband.

Die älteste heute in der Stiftsbibliothek aufbewahrte Handschrift (Cod. 495) stammt aus dem 10. Jahrhundert und ist mit einem schlichten Einband, der wohl nur kurze Zeit nach Abschluss des Textes angefertigt worden sein dürfte, versehen: Holzdeckel, die mit einem schmucklosen, im Laufe der Jahrhunderte stark nachgedunkeltem Schweinsleder überzogen sind. Eine genaue Datierung und Lokalisierung des Einbands ist aufgrund mangelnder Sekundärhinweise nicht möglich. Die Titelaufschrift am Vorderdeckel aus dem 12. Jahrhundert sowie die noch erhaltenen hervorstehenden Dorne der einstigen Schließen machen deutlich, dass das Buch ursprünglich liegend aufbewahrt wurde. Der blau gefärbte Rücken mit einer weißen Titelaufschrift - es lässt sich nicht feststellen, wann dieser Eingriff erfolgte ${ }^{170}$ - bezeugt nicht nur die spätere Aufstellung in Regalen, sondern auch eine einstige Zugehörigkeit zu einer Teilbibliothek. Solche blau gefärbten Rücken weisen nicht nur einige weitere Handschriften auf (Cod. 142, 194, 440, 726 und Nr. 139 [olim Sign. 14819] sowie Innsbruck, ULB Tirol, Cod. 688, 731), sondern mehr als 300 Druckwerke. Wozu diese Blaufärbung diente, ist bis dato noch nicht geklärt. Möglicherweise waren diese Bücher zu einer bestimmten Zeit Teil einer Art „Spezialbibliothek“" im Haus; nicht zuletzt aufgrund der Tatsache, dass sich unter diesen Bänden auch das „Liber anniversariorum Neocellensis“, das „Necrologium Neocellense“ sowie ein besonders schön ausgeschmücktes Neustifter Rituale befinden, könnte man an eine Aufstellung in der Prälatur denken. Die zweite, wohl etwas ältere Form der besonderen Rückengestaltung, nämlich ein an den Bünden und im zweiten Rückenfeld schwarz gefärbter Rücken ${ }^{171}$, lässt sich bei den Handschriften nicht nachweisen.

Bei den erhalten gebliebenen gotischen Einbänden aus dem 15. Jahrhundert ist der Lederbezug, der bisweilen rot gefärbt ist, vielfach nur sehr spärlich mit Blindlinien verziert. Einige Einbände weisen aber auch eine reiche Dekoration mit Einzelstempeln auf, die meist in von mehrfachen Streicheisenlinien umrandeten Feldern platziert sind. Diese Stempel, diverse Blüten, Lilien, Adler, Einhorn, Spruchbänder Maria u. a., konnten bislang keinem konkreten Buchbinder bzw. keiner Werkstatt zugeordnet werden; eine Lokalisierung in den süddeutschen, wenn nicht gar Tiroler Raum ist anzunehmen. Eine genauere Erforschung derselben, verbunden mit einer umfangreichen Archivrecherche bleibt bis auf Weiteres noch ein Desiderat. Reicher verziert sind lediglich die Einbände zweier Handschriften mit liturgischem Inhalt. Die Antiphonarien und Gradualien (Nr. 139 [olim Sign. 14819] und Nr. 940) wurden in den 1490er Jahren von Heinrich Edlinger geschrieben, wohl im direkten Umfeld des Augustiner Chorherrenstiftes, ebendort dürfte auch die Bindung zu lokalisieren sein. Hierfür spricht insbesondere der Einzelstempel Osterlamm mit Fahne in Kreis, der auch beim Einband von Cod. 11 des Stiftsarchivs Verwendung fand (dat. 1580: Rechnungsbuch des Propstes Augustin Schabl), dort in Kombination mit Rollen (Neuhauser R 48 und R 56, Gruppe $7^{172}$ ), die eindeutig nach Neustift weisen. Der Einzelstempel dürfte also möglicherweise zu einem Formenschatz gehört haben, der im Kloster selbst aufbewahrt und

170 Diese Färbung dürfte mit einer Neuaufstellung einhergegangen sein, die möglicherweise im Zuge der Errichtung der akademisch-theologischen Hauslehranstalt in der zweiten Hälfte des 17. Jahrhunderts, der Neugestaltung der Prälatur in der ersten Hälfte des 18. Jahrhunderts oder der Neugestaltung der Stiftsbibliothek in der zweiten Hälfte des 18. Jahrhunderts erfolgte.

171 NeuHAuser, Wissenschaftspflege (wie Anm. 23) 98.

172 W. Neuhauser, Die Rolleneinbände des Buchdruckers und Buchbinders Gallus Dingenauer: Meister G-D, in: G. Colin (Hrsg.), De libris compactis: miscellanea (Studia Bibliothecae Wittockianae 1). Bruxelles 1984, 133-249, hier 196-199. 
den jeweiligen Buchbindern für Auftragsarbeiten ${ }^{173}$ zur Verfügung gestellt wurde. Wenn wir mit der Annahme, dass Nr. 139 (olim Sign. 14819) und Nr. 940 Ende des 15./Anfang des 16. Jahrhunderts, also kurz nach Erstellung des Textes gebunden wurden, richtigliegen, so wäre dieser Stempel fast 100 Jahre im Einsatz gewesen.

Zwei weitere Einbände aus dem 15. Jahrhundert verdienen eine besondere Erwähnung: Cod. 4, der ein Repertorium beider Rechte von Iohannes Calderinus enthält und vom Brixner Domherrn Johann Ebner ${ }^{174}$ nach seinem Tod 1461 dem Stift überlassen wurde, weist am Hinterdeckel oben mittig die Spur eines ursprünglich dort befestigten runden Beschlags auf. Es ist also anzunehmen, dass es sich hierbei ursprünglich um ein Kettenbuch handelte. ${ }^{175}$

Völlig anderer Natur ist hingegen der Einband der um 1200 entstandenen „Vita beati Hartmanni“ (Cod. 293), die im 15. Jahrhundert neu gebunden und mit einer - ansonsten in Neustift insbesondere für Archivhandschriften üblichen - Makulatur umschlagen wurde: Das beidseitig beschriebene und mit gotischer Choralnotation versehene Pergament-Doppelblatt aus einem Antiphonar, aufgrund der Schrift ins 14. Jahrhundert zu datieren, das offensichtlich seiner ursprünglichen Verwendung entledigt worden war, ist über dünne Pappdeckel gespannt.

Während die erhaltenen gotischen Einbände größtenteils wohl zeitnah zur Herstellung bzw. zum Erwerb der Handschriften entstanden, belegt das Gros der Einbände aus späterer Zeit eine Welle an Neubindungen, die wohl in engem Zusammenhang mit dem steigenden Interesse an Büchern und Bibliotheken in Tirol in der zweiten Hälfte des 16. Jahrhunderts steht. ${ }^{176}$ Durch das Aufblühen des Buchhandels im Allgemeinen und den verstärkten Bücherkauf durch Klöster im Zuge der Gegenreformation erhielten nicht nur die Buchhändler, sondern insbesondere auch die Buchbinder vermehrt Aufträge. Die Einbände aus jener Zeit sind reich mit Einzelstempeln, Rollen und Platten verziert, teilweise in Blinddruck, teilweise in Golddruck, bei mehreren Büchern ist auch der Schnitt golden gefärbt und punziert. Eine systematische Erforschung sämtlicher in Tirol wirkender spätmittelalterlicher und frühneuzeitlicher Buchbinder und deren Werkstätten ist zwar noch ausständig, doch dank der grundlegenden Arbeit von Walter Neuhauser zu den im Tiroler Raum auffindbaren Einbänden aus der zweiten Hälfte des

173 Bislang konnte kein Hinweis auf einen stationären Buchbinder im 15. und beginnenden 16. Jahrhundert in Neustift gefunden werden; man kann wohl von Wanderbuchbindern ausgehen.

174 Möglicherweise identisch mit Johannes Ebner aus Krems, der 1414 an der Universität Wien immatrikuliert war; vgl. L. SANTIFALLER, Das Brixner Domkapitel in seiner persönlichen Zusammensetzung im Mittelalter (Schlern-Schriften 7). Innsbruck 1924, 298-299; Die Matrikel der Universiät Wien I: 1377-1450, bearb. von F. Gall (Publikationen des Instituts für Österreichische Geschichtsforschung VI, 1). Graz, Köln 1956, 104.

175 In Neustift lassen sich ansonsten keine Hinweise auf Kettenbücher finden. Ob diese gerade im Umfeld von Schultätigkeit weit verbreitete Sicherungspraxis tatsächlich in Neustift nicht üblich war oder ob sich lediglich keine entsprechenden Einbände erhalten haben, muss offenbleiben. Möglicherweise belegt gerade der Einband, dass Cod. 4 aus dem Besitz eines Brixner Domherrn ursprünglich an der seit dem 10. Jahrhundert urkundlich belegten Domschule Brixen verwendet worden war.

176 Hier sei insbesondere an den bibliophilen Erzherzog Ferdinand II. (1529-1595) und dessen umfangreiche Bibliothek auf Schloss Ambras erinnert; vgl. I. PURŠ, Die Bibliothek Erzherzog Ferdinands II. auf Schloss Ambras, in: S. HAAG, V. SAndBichler (Hrsg.), Ferdinand II. 450 Jahre Tiroler Landesfürst. Jubiläumsausstellung. Innsbruck, Wien 2017, 99-106; Das Inventarium der Ambraser Sammlungen aus dem Jahre 1621. T. 2: Bibliothek, hrsg. und kommentiert von A. AuER, in: Jahrbuch des Kunsthistorischen Museums Wien, Bd. 2. Wien 2001, 281-345; A. Auer, E. Irblich, Natur und Kunst. Handschriften und Alben aus der Ambraser Sammlung Erzherzog Ferdinands II. (1529-1595). Ausstellungskatalog. Wien 1995. Als Landesfürst kam ihm sicherlich Vorbildfunktion zu; in der zweiten Hälfte des 16. Jahrhunderts entstanden vermehrt private Bibliotheken. Über die wohl umfangreichste verfügte die Familie der Freiherren von Wolkenstein-Rodenegg; vgl. U. StAMPFER, Adelige Lesekultur um 1600 am Beispiel der WolkensteinRodenegg, in: G. Pfeifer, K. Andermann (Hrsg.), Die Wolkensteiner. Facetten des Tiroler Adels in Spätmittelalter und Neuzeit (Veröffentlichungen des Südtiroler Landesarchivs 30). Innsbruck 2009, 323-334; A. DörRer, Die Bibliothek des Freiherrn Christoph von Wolkenstein auf Schloss Rodenegg. Ein adeliges Gegenstück zur landesfürstlichen Ambraser Sammlung. Zentralblatt für Bibliothekswesen 57 (1940) 18-43; Ders., Tirolisches aus der Bücherei des Freiherrn Christoph von Wolkenstein auf Rodenegg, in: Tirolensia zum 80. Geburtstag Konrad Fischnaler's (Schlern-Schriften 30). Innsbruck 1935, 21-26. 
16. Jahrhunderts und der Erfassung von Schmuckformen ${ }^{177}$ können mehrere der Neustifter Einbände bereits bekannten Buchbindern bzw. Buchbindewerkstätten zugewiesen werden. In Neustift namentlich fassbar ist allerdings bis dato nur Narziß Schuechl. Er stammte aus Augsburg, dürfte kurz nach 1560 nach Innsbruck gekommen sein und wurde ebendort am 18. März 1568 als Bürger aufgenommen. Über sein Leben sind wir nur spärlich unterrichtet; über seine Tätigkeit als Buchbinder informieren uns die erhalten gebliebenen Einbände für die Bibliothek des Jesuitenkollegs in Innsbruck, das Prämonstratenser Chorherrenstift Wilten, das Zisterzienserstift Stams, die Franziskanerklöster in Innsbruck und in Schwaz sowie für Privatpersonen. Man kann also auf eine gute Auftragslage schließen. Einträge im Raitbuch ${ }^{178}$ des Neustifter Propstes Augustin Distelfink (1585-1589) belegen, dass er in der Zeit von 1585 bis 1589 auch mehrere Bücher für das Augustiner Chorherrenstift eingebunden hat. ${ }^{179}$ Zumal er in den Rechnungen als Narzischg puechbinter zu Brichsen bezeichnet wird, ist anzunehmen, dass er sich immer wieder für längere Zeit in der Bischofsstadt aufhielt und dort über eine eigene Buchbinderwerkstätte verfügte. ${ }^{180}$ Auf der Basis der bereits erschlossenen und im Detail untersuchten Handschriften im Tiroler Raum, insbesondere der Stiftsbibliothek Wilten, der Priesterseminarbibliothek Brixen und der ULB Tirol, sind ausgehend von den verwendeten Stempeln und Rollen - sie sind allesamt nicht signiert - Rückschlüsse auf seine Arbeiten möglich. Die bei den Einbänden der Cod. 353, 654, 726, Sign. 15063 sowie des ersten Bandes des Neustifter Gradualbuches (bei Band 2 ist der Einband zur Gänze Ende des 20. Jahrhunderts erneuert worden) verwendeten Rollen und Platten lassen sich der von Neuhauser definierten Gruppe 1 und 2 sowie 7 zuordnen, die miteinander sehr eng verknüpft sind. ${ }^{181}$ Trotz Schwierigkeiten bei der Abgrenzung der einzelnen Gruppen untereinander können all diese Dekorelemente mit größter Wahrscheinlichkeit Schuechl bzw. seiner Werkstatt zugewiesen werden. Aufgrund der großen Ähnlichkeit des Einbandes von Cod. 405 mit jenen von Cod. 353 und 654 (vgl. insbesondere auch die Schließen) kann auch jener Band Schuechl und seiner Werkstatt zugeordnet werden. Während die Einbände der Gruppe 1/2 laut Neuhauser in den Zeitraum 1568-70 datieren, stammen jene mit Dekorelementen aus Gruppe 7 aus der Zeit zwischen ca. 1570 und nach 1600.

177 Neuhauser, Dingenauer (wie Anm. 172). Im Kontext von Tiroler Bucheinbänden dürfen zudem folgende Arbeiten nicht unerwähnt bleiben; sie wurden hinsichtlich des vorliegenden Neustifter Bestandes konsultiert, es konnten allerdings keine Übereinstimmungen festgestellt werden: W. NeuHAuser, Eriber. Ein Beitrag zum süddeutschen und Tiroler Bucheinband des 15. Jahrhunderts, in: A. De Coster, C. Sorgeloos (Hrsg.), Bibliophilies et reliures. Mélanges offerts à Michel Wittock. Bruxelles 2006, 317-373; E. RAMmingER, Augsburger Rolleneinbände des 16. Jh.s an der Universitätsbibliothek Innsbruck, bibliothekarische Hausarbeit. Innsbruck 1987 (maschinschr.); S. SEPP, Spätgotische Kölner Einbände aus der ehemaligen Haller Jesuitenbibliothek in der Universitätsbibliothek Innsbruck. Codices manuscripti 6 (1980) 89-111; W. NeuHAusER, Erfurter Blindstempeleinbände an der Universitätsbibliothek Innsbruck. Codices manuscripti 5 (1979) 8-24; O. MAZAL, Gotische Einbände aus der Kartause Schnals. Gutenberg-Jahrbuch (1973) 423-428.

178 Neustift, Stiftsarchiv, Cod. 26.

179 1585: 27. Mai: Dem Narzischg puechbinter zu Brichsen fur das rodl püechl und zway andere püecher einzubinden bezalt $1 \mathrm{fl} 20 \mathrm{kr}$; 22. August: Den Narzischgg puechpintter zway postille lassen einpinden geben $2 \mathrm{fl}$. 1586: 10. August: Am 10 dito dem Narcis puechpinter zu Brixen umb willen etlich püecher einzubinden bezalldt 3 fl. $28 \mathrm{kr}$.

1587: 25. Jänner: Am 25 dits dem puechpinter zu Brixen das er 15 tag bei mir hat eingepunden darvir bezalt ich ime $4 \mathrm{fl}$.

1588: 13. Jänner: Am 13. dem buechpinter zu Brixen, dem maister Narziß, der mir im gotshauß etlich corpuecher unnd anndrer puecher eingebunden hat, fur 32 tag bezalt $8 \mathrm{fl}$. $52 \mathrm{kr}$; 12. Mai: Dem Narciß puechpinter fur 2 misell unnd ain corporaetaschen zu uberziechen zalt 4 fl $30 \mathrm{kr}$; 18. September: Am 18. dem Narciß buechpindter fur ain prefier einzupindten geben $24 \mathrm{kr}$.; 9. November: Eodem die dem Narciß puechpindter zu Brixen das er mir im gotshau $\beta$ hat 7 tag einpundten bezalt ain tag $16 \mathrm{kr}-1 \mathrm{fl} .52 \mathrm{kr}$.

180 Die bisherige Annahme, dass er erst 1588 seine Werkstätte nach Brixen verlegt habe, dürfte hiermit entkräftet sein; möglicherweise ist Narziß Schuechl in jenem Jahr lediglich vollständig nach Brixen übersiedelt. Vgl. NeuHAuser, Dingenauer (wie Anm. 172) 156; F. WALDNER, Quellenstudie zur Geschichte der Typographie in Tirol. Innsbruck 1888, 103.

181 Sowohl Gruppe 2 als auch Gruppe 7 sind wohl als Fortsetzung der Gruppe 1 anzusehen (NeuHauser, Dingenauer [wie Anm. 172] 196-197). 
Als für Neustift wohl bedeutendste Rolle ist jene hervorzuheben, die das Stiftswappen, aufgeteilt auf drei einander abwechselnde Einzelmedaillons (vier Spitzen der Herren von Säben, Tau-Kreuz und Patriarchenkreuz), zeigt. Möglicherweise wurde diese Wappenrolle, die sich auch am Einband des Placitum aus dem Jahr 1579 sowie am Rechnungsbuch von Propst Augustin Schabl (1569-1581) befindet, von eben jenem Propst in Auftrag gegeben. ${ }^{182}$ Ein Wappensupralibros, das einen Erzengel (Michael?) mit einem Schild mit zwei aufsteigenden Löwen und damit den Wappenschild dieses Propstes zeigt (Neuhauser P 3), belegt anschaulich die bibliophile Haltung Schabls. Mit dieser Platte sind die beiden Gebetbücher des Klausner Stadtrichters Kaspar Neuhauser geschmückt (Cod. 353, 654), die zu einem nicht näher definierten Zeitpunkt in den Besitz des Klosters übergingen und unter Propst Schabl neu gebunden wurden. In der ULB Tirol lassen sich zudem weitere drei Bände mit dieser Platte nachweisen (Ink. 106 E 1, Ink. 106 E 2: Breviarium Salisburgense, Pars hiemalis und Pars aestivalis. Nürnberg: Georg Stuchs 1497 [GW 5444]; Sign. 100306: H. Pantaleon, Teutscher Nation Heldenbuch ... erstlich ... in Latein zusammen gezogen ... jetzmalen aber von dem ersten authore selbs verteütschet ... Basel: Nicolaus Brylinger, 1567-1570). ${ }^{183}$ Während das Wappensupralibros selbstredend später keine Verwendung mehr fand, taucht die Wappenrolle auch noch auf einem Druck aus dem Jahr 1609 auf. ${ }^{184}$

Diese lebhafte (Neu-)Bindetätigkeit Ende des 16./Anfang des 17. Jahrhunderts lässt sich auch in anderen Klöstern beobachten: So wurden im Prämonstratenserstift Wilten zwischen ca. 1590 und 1610 von Leonhard Schuechl - möglicherweise ein Sohn von Narziß Schuechl - zahlreiche Handschriften und Inkunabeln neu gebunden. ${ }^{185}$

Bei den allermeisten Handschriften wurde in der zweiten Hälfte des 18. Jahrhunderts der mittelalterliche oder frühneuzeitliche Einband entfernt und der Einheitlichkeit wegen durch einen schlichten Bibliothekseinband ersetzt. Diese Neubindungen stehen zweifelsohne allesamt im Zusammenhang mit dem Neubau des Bibliothekssaales und der Neuaufstellung der Bibliothek unter Propst Leopold de Zanna. Auch zahlreiche Druckwerke wurden mit demselben Einband versehen; vielfach wurden hierbei aber die ursprünglichen Deckel beibehalten und lediglich der Rücken erneuert, um so dem Bibliothekssaal ein möglichst harmonisches Bild zu verleihen. Dieser Halbfranz- bzw. Halbledereinband zeichnet sich durch Pappdeckel, die mit schwarz gesprenkeltem braunem Papier überzogen sind, sowie einen braunen Lederrücken aus. Mit demselben braunen Leder sind auch die Ecken jeweils verstärkt. Die einfachen Bünde am Rücken werden von schlichten Bordüren in Golddruck gesäumt, in den Feldern zwischen den Bünden ist M. S. (Manuscriptum) in Golddruck festgehalten, zudem ist meist ein Werktitel oder vereinzelt auch der Autor des Textes angegeben. Werke von geringerem Umfang, wie z. B. Cod. 578, 579, 597, 691, 694, 754, 755, 756 und 780, wurden hingegen mit demselben Papier, mit dem bei anderen Bänden die Pappe umschlagen wurde, lediglich broschiert. Auffallend ist die Tatsache, dass im Rahmen dieser Neubindungen mehrere Sammelbände in ihre Einzelbestandteile aufgelöst wurden, von denen jeder einen entsprechenden Halbfranzeinband erhielt. ${ }^{186}$ Aus den Rechnungsbüchern des

182 Aufgrund dieser beiden Archivhandschriften, die wohl kaum eine Neubindung wenige Jahre nach der Erstellung erfahren haben dürften, ist die von Neuhauser geäußerte These, dass die Wappenrolle auf eine Bindung unter Propst Jakob Fischer (1589-1621) schließen ließe, wohl kaum haltbar. Die Tatsache, dass das Tau-Kreuz am unteren Ende einen Sporn habe - laut Neuhauser ein Hinweis darauf, dass die Rolle in jene Zeit zu datieren sei, zumal Propst Fischer der letzte war, unter dem das Tau-Kreuz diese Form aufwies (vgl. Neuhauser, Wissenschaftspflege [wie Anm. 23] 99) - spricht meines Erachtens nicht gegen eine frühere Datierung.

183 Neuhauser, Dingenauer (wie Anm. 172) 214

184 NeuHauser, Wissenschaftspflege (wie Anm. 23) 99.

185 NeuHauser, Dingenauer (wie Anm. 172) 141, 160, 189.

186 So bildeten die ursprünglich selbständigen Handschriften aus dem 14. und 15. Jahrhundert Cod. 158, 83, 82, 183, 161, 182 und 162 sowie Cod. 157, 159, 168, 163, 181 und 164 (in eben dieser Reihenfolge) seit dem 15. Jahrhundert bis dahin jeweils eine Einheit. Heute werden Teile dieser einstigen Sammelhandschriften mit durchgehender Foliierung und gemeinsamem Inhaltsverzeichnis aus dem 15. Jahrhundert in der Stiftsbibliothek Neustift, andere an der ULB Tirol (Cod. 82 sowie Cod. 157, 159 und 164) aufbewahrt. Diese Bände führen die Notwendigkeit bzw. Sinnhaftigkeit einer virtuellen Rekonstruktion einstiger Bestände deutlich vor Augen. 
Propstes $^{187}$ geht hervor, dass diese Neubindungen bereits Anfang der Sechzigerjahre des 18. Jahrhunderts begonnen wurden ${ }^{188}$ und sich bis ins Jahr $1778^{189}$, also eben jenes Jahr, in dem auch der Neubau des Bibliothekssaales abgeschlossen werden konnte, fortsetzten. Im Zuge dieser Neubindungen dürfte auch das Exlibris der Stiftsbibliothek in Holzdrucktechnik mit Zierrahmen, das bis heute viele Handschriften und Drucke schmückt, eingeklebt worden sein. Insgesamt hat der bzw. haben die Buchbinder in diesen Jahren 464 Gulden, 59 Kreuzer verdient. Wer diese Arbeiten durchgeführt hat, ist leider nicht erwähnt; zumal sie aber Eingang in die Rechnungsbücher gefunden haben, kann davon ausgegangen werden, dass kein Chorherr bzw. Klostermitglied diese Neubindungen vorgenommen hat. Warum nicht ausnahmslos alle Einbände erneuert bzw. umgestaltet wurden, muss offenbleiben; eine mögliche Erklärung könnte der Aufbewahrungsort sein. Die Handschriften, die auch heute noch einen mittelalterlichen oder frühneuzeitlichen Einband aufweisen, sind großteils liturgischen Inhalts und wurden möglicherweise nicht im neuen Bibliothekssaal aufgestellt, sondern wurden im näheren Umfeld der Kirche aufbewahrt. Cod. 142, der neben der Ordensregel des hl. Augustinus und der Auslegung derselben durch Hugo de Sancto Victore das Anniversarium und Necrologium des Stiftes enthält, dürfte hingegen im Archiv geblieben sein und daher seinen schlichten Renaissance-Einband behalten haben.

Sieben Handschriften erhielten im Rahmen einer Neubindung bzw. Restaurierung in den vergangenen Jahrzehnten (wohl um 1980) ${ }^{190}$ einen völlig neuen Einband. Wie den - meist am Spiegel des Hinterdeckels - aufgeklebten Etiketten zu entnehmen ist, wurden Cod. 453, 483, 532, 550 ${ }^{191}, 614$ und der zweite Band des Zollner-Graduales in der Restaurierwerkstätte des Benediktinerinnenstiftes Santa Maria di Rosano in Rignano sull'Arno bei Florenz neu gebunden. Cod. 776 enthält kein Etikett; der eingebundene schmale Papierstreifen mit italienischer Beschriftung lässt vermuten, dass auch er seinen neuen Einband in einer italienischen Restaurierwerkstätte erhielt. Auch der erste Gradualband und Cod. 123 wurden in Santa Maria di Rosano neu gebunden und deren Einbände unter Verwendung des ursprünglichen Lederbezugs restauriert.

In den letzten Jahren wurden die Restaurierungen im Sinne einer bestmöglichen Konservierung der Handschriften fortgesetzt. Die Arbeiten wurden von Buchrestauratoren aus Süd- und Nordtirol durchgeführt. ${ }^{192}$

$187 \quad$ Neustift, Stiftsarchiv, Cod. 24.

188 Der erste entsprechende Eintrag reicht in den Juni 1761 zurück: an büchern pro Bibliotheca item büchbindern 92 fl. (Neustift, Stiftsarchiv, Cod. 24, S. 141).

189 Neustift, Stiftsarchiv, Cod. 24, S. 188 ist unter Ausgaben in Jenner 1778 vermerkt: dem büchbündter laut conto $102 \mathrm{fl}$., $9 \mathrm{kr}$.

190 Ein Restaurierbericht konnte leider für keine dieser Handschriften ausfindig gemacht werden.

191 Die ursprünglichen, wohl aus dem 15. Jahrhundert stammenden, mit einem rot gefärbten Leder überzogenen Holzdeckel sind erhalten und werden getrennt aufbewahrt (ursprünglich im Stiftsarchiv, heute liegen sie bei den Fragmenten). Ein Dank geht an Simon Terzer für die Übermittlung von Bildmaterial. Auf beiden Holzdeckeln ist innen jeweils der Abklatsch einer Urkunde zu sehen. Auf dem ursprünglichen Vorderdeckel - darauf lassen die an der Universitätsbibliothek in Innsbruck notierten Signaturen (in Tinte 550 und $I I$ [...] sowie in Bleistift II $\overline{3}$ D 8) schließen - ist der Abklatsch einer quer eingeklebten, 22zeiligen, seitlich rechts beschnittenen Urkunde mit klarem Brixenbezug zu erkennen, u. a. ist von der Pfarre St. Michael die Rede. Besonders interessant ist die Nennung des Domherrn Johannes Ebner (siehe Anm. 174), der dem Kloster Neustift nach seinem Tod 1461 eine Handschrift (Cod. 4) testamentarisch überlassen hat. Auch in der 33zeiligen Urkunde am ursprünglichen Hinterdeckel begegnet uns Johannes Ebner. Ob dies ein Hinweis darauf ist, dass die Handschrift auf demselben Weg wie Cod. 4 Eingang in die Neustifter Stiftsbibliothek gefunden hat, muss offenbleiben.

192 Sofern Informationen zu Restaurierungen vorliegen, wurde dies in den Katalogisaten vermerkt. 



\title{
4. Bisherige Erschließung des Handschriftenbestandes
}

\author{
Ursula Stampfer
}

Die vorliegende Publikation stellt die erste systematische Erfassung und wissenschaftliche ErschlieBung sämtlicher in Neustift aufbewahrter mittelalterlicher Handschriften dar. Bislang lag lediglich ein nach Signaturen geordneter Zettelkatalog vor, der an der ULB Tirol unter Direktor Friedrich Leithe (1868-1874) bzw. Ludwig von Hörmann (1882-1902) erstellt wurde. Bei der damaligen Beschreibung der Handschriften stützte man sich nur auf die in ihnen selbst enthaltenen Daten und unternahm keine weiteren Literaturrecherchen u. ä. zur Identifizierung von Texten, sodass die Angaben vielfach sehr ungenau und unvollständig sind. ${ }^{193}$ Wohl im Zuge der Rückgabe von knapp 100 Handschriften an Italien wurden aus dem Konvolut an Beschreibungskärtchen aller Handschriften an der ULB Tirol die Katalogisate zu den Neustifter Beständen zu einer separaten Einheit zusammengefasst. Sie wurden zu einem späteren Zeitpunkt - handschriftlich findet sich die Ergänzung [1973] - nochmals in die Hand genommen und um einige maschinschriftliche Karteikärtchen zu den Archivhandschriften des Stiftes ergänzt. Bei den Buchhandschriften selbst wurden nur sehr wenige Ergänzungen gemacht; u. a. wurde vermerkt, ob ein Mikrofilm vorliegt oder nicht. Ein handschriftlicher Hinweis fehlt am linken oberen Blattrand bei jenen Handschriften, die an der ULB Tirol verblieben sind, lässt darauf schließen, dass diese Addenda des Zettelkatalogs in Neustift erfolgt sein dürften. Kopien des Zettelkatalogs mit dem Titel „Die historischen Handschriften des Archivs bzw. der Bibliothek des Augustiner Chorherrenstiftes Neustift" befinden sich heute sowohl in der Stiftsbibliothek Neustift als auch an der ULB Tirol; unter https://manuscripta.at/kataloge/IT/5000/histHss/histHss.pdf kann er zudem online eingesehen werden.

H. Martin Peintner erstellte 1972 einen Zettelkatalog zu jenen Handschriften, die aus Platzgründen nicht wie die wertvollen hist. Codices im Archiv aufbewahrt werden konnten. Die in diesem maschinschriftlichen Verzeichnis aufgelisteten Handschriften sind - mit Ausnahme von Nr. 139 (olim Sign. 14819) - allesamt jüngeren Datums.

H. Theobald Innerhofer erstellte ein Verzeichnis aller im Archiv aufbewahrten Bibliotheks- und Archivhandschriften; seine Ausführungen zu den Bibliothekshandschriften reichen aber nicht über die Notizen des früheren Zettelkatalogs hinaus.

Ein wissenschaftlicher Katalog lag lediglich für die illuminierten Handschriften vor: Der Wiener Kunsthistoriker Hermann Julius Hermann (1869-1953) veröffentlichte 1905 eine umfassende Arbeit zu den illuminierten Handschriften in Tirol (siehe Anm. 137 und Literatur). Die Neustifter Bestände, damals noch großteils in Innsbruck verwahrt, sind zum Teil unter den dortigen Beständen, zum Teil im Kapitel zu Neustift selbst zu finden. In den folgenden Jahren folgten mehrere Einzelstudien zu ausgewählten Handschriften; seit jeher ziehen insbesondere die reich mit Buchmalerei ausgestatteten Werke die Aufmerksamkeit der Forschung auf sich. In jüngerer Zeit verfasste vor allem H. Martin Peintner mehrere Publikationen zum Neustifter Skriptorium. 1979 fand schließlich die siebte Tagung der österreichischen Handschriftenbearbeiter teilweise in Neustift statt - wohl ein deutliches Zeichen für die Bedeutung, die der dortigen Handschriftensammlung einerseits im Allgemeinen, andererseits aber wohl auch als zentralem Komplementärbestand zu den Innsbrucker Handschriften im Speziellen

$193 \quad$ Katalog ULB Tirol I (wie Anm. 100) 21. 
beigemessen wird. Letztere wurden seit Mitte der 1970er Jahre systematisch nach den Richtlinien der ÖAW tiefenerschlossen, in Neustift sollten noch mehr als drei Jahrzehnte vergehen, ehe die wissenschaftliche Katalogisierung in Angriff genommen werden konnte.

Viele Initialen und Miniaturen von Neustifter Handschriften sind in diversen Publikationen abgebildet. Die erste systematische Aufnahme sämtlicher mittelalterlicher Handschriften wurde durch Mitarbeiter der Hill Monastic Manuscript Library (HMML) in Collegeville (Minnesota) in den 1960er Jahren durchgeführt; Kopien der Mikrofilme liegen im Stift. Kurze Zeit später erfolgte eine weitere Mikroverfilmung durch das staatliche Denkmalamt in Verona; auch hiervon werden Kopien in Neustift aufbewahrt.

Nach Abschluss der Katalogisierungstätigkeit ließ das Stift alle im vorliegenden Katalog berücksichtigten Handschriften digitalisieren. Die Digitalisate sind unter www.manuscripta.at einsehbar.

Die datierten und/oder mit einer Schreibernennung versehenen Neustifter Handschriften finden zudem Berücksichtigung im Band zu den „Manoscritti datati della provincia di Bolzano“. Dieser Katalog ist derzeit in Vorbereitung und wird in der Reihe „Manoscritti datati d'Italia“ erscheinen. ${ }^{194}$

194 Vgl. hierzu http://www.manoscrittidatati.it. Basierend auf den Diplomarbeiten von Cristina Stefani (I manoscritti datati della Provincia di Bolzano. Bolzano, Biblioteca del Monastero di Muri-Gries. Bressanone, Biblioteca del Seminario Maggiore. Novacella, Archivio dell’Abbazia di S. Maria, Tesi di laurea. Trento 1995-1996) und Sissi Mattiazzi (Un esempio di biblioteca francescana: la Biblioteca dei Frati Minori di Bolzano, Tesi di laurea. Padova 2011-2012) werden hierin von Leonardo Granata und Ursula Stampfer sämtliche datierte Handschriften in Südtiroler Bibliotheken erfasst. 


\title{
5. Zur Anlage des Katalogs
}

\author{
Claudia Schretter-Picker
}

\subsection{Zur Erschließungsmethode}

Mit der vorliegenden Publikation wird im Rahmen der im Umfeld der Abteilung Schrift- und Buchwesen, Institut für Mittelalterforschung, der ÖAW angesiedelten Projekte zur wissenschaftlichen Erschließung von Handschriften eine bisher nur in Ansätzen erprobte Methode der Handschriftenbeschreibung intensiviert, nämlich die der arbeitsteiligen Bearbeitung der einzelnen Handschriften. Damit soll dem Umstand Rechnung getragen werden, dass es sich beim vorliegenden Handschriftenbestand der Neustifter Stiftsbibliothek um einen Komplementärbestand zu den bereits bearbeiteten Handschriften Neustifter Provenienz in der ULB Tirol handelt. Erst eine intensive, bestandsübergreifende Untersuchung der verschiedenen Aspekte der jeweiligen Handschrift - Zusammensetzung, Beschreibstoff, Schrift, Einband, Ausstattung, Notation, Geschichte, Inhalt - liefert die Basis für die virtuelle Zusammenführung dieses heute getrennten Bestandes. Für die im Neustifter Bestand reichlich vertretenen Handschriften mit höherrangigem Buchschmuck erschien eine nach den Richtlinien und der Terminologie für die Handschriftenbeschreibung in Österreich erfolgende nur knappe Beschreibung als nicht zielführend, zumal ein Spezialkatalog der illuminierten Handschriften für den Tiroler Raum nicht in absehbarer Zeit zu erwarten ist. Auch die Handschriften mit Notation lohnen eine intensivere Betrachtung. Trotz des hohen zeitlichen, personellen und finanziellen Aufwandes wurde also nicht nur an der Methode der Tiefenerschließung festgehalten, sondern diese durch leichte Adaptionen sogar intensiviert. Der dadurch lukrierte Mehrwert wurde in den Gutachten und Evaluationen zum Antrag für die Finanzierung dieses Erschließungsprojektes durchwegs positiv bemerkt und die Methodik begrüßt.

Noch vor der eigentlichen Katalogisierungsarbeit waren bereits die Daten zu allen Neustifter Handschriften aus dem Alten Zettelkatalog an der ULB Tirol und den Anhängen der bereits erschienenen gedruckten Kataloge zu den heute an der ULB Tirol befindlichen Neustifter Handschriften gesammelt worden. Diese betrafen einerseits summarische Angaben zum Inhalt der Handschriften, aber auch Hinweise auf Beschreibstoffe, Format und Datierung.

In einem zweiten Schritt wurden Verweise zu den jeweiligen Handschriften aus Handschriftenrepertorien und Sekundärliteratur gesammelt.

Danach erfolgte eine Autopsie aller Handschriften, wobei in rudimentärer Form Informationen zu äußeren und inhaltlichen Merkmalen erfasst wurden. Diese wurden mit den bereits vorhandenen Daten kumuliert und für die Weiterbearbeitung vorbereitet. Auf dieser Basis konnten Handschriftengruppen gebildet werden, differenziert nach Beschreibstoff, Datierung, Ausstattungselementen, Notation sowie inhaltlichen Kriterien. Damit war die Voraussetzung für eine arbeitsteilige Bearbeitung des Bestandes durch ein Team von Spezialistinnen und Spezialisten geschaffen.

Um den hohen Ansprüchen der detaillierten Beschreibungsrichtlinien Genüge leisten zu können und dennoch zeitökonomische Bedingungen zu erfüllen, wurde die Beschreibung der äußeren Merkmale der Handschriften zunächst durch Autopsie vorgenommen. Die zeitaufwändige Identifikation der 
Texte und der Nachweis von Parallelüberlieferungen erfolgten teils anhand von Mikrofilmen und teils mit Arbeitsdigitalisaten in Forschungseinrichtungen, ergänzt durch Einsichtnahme der Bestände vor Ort. Unabdingbar war hierfür die Infrastruktur der Abteilung für Sondersammlungen der ULB Tirol (Arbeitsplätze, PCs und Laptops, gedruckte und elektronische Hilfsmittel, UV-Lampe, Leuchtfolie zur Analyse der Wasserzeichen usw.), aber auch der Bibliothek des Priesterseminars in der PhilosophischTheologischen Hochschule Brixen.

\subsection{Zur Anlage der Handschriftenbeschreibungen}

Die Beschreibungen halten sich grundsätzlich an die „Richtlinien und Terminologie für die Handschriftenbeschreibung in Österreich" der Kommission für Schrift- und Buchwesen (seit 2012 Institut für Mittelalterforschung, Abteilung Schrift- und Buchwesen) der ÖAW in Wien. ${ }^{195}$ Durch praktische Gepflogenheiten und technische Neuerungen notwendig gewordene Zusatzbestimmungen, die im Zuge des Austausches mit anderen HandschriftenbearbeiterInnen besprochen bzw. schriftlich niedergelegt wurden ${ }^{196}$, fanden auch in dieser Arbeit ihren Niederschlag. Bei einzelnen Fragestellungen waren die Kataloge der Handschriften der ULB Tirol sowie der Katalog der mittelalterlichen Handschriften der Bibliothek des Prämonstratenser Chorherrenstiftes Wilten in Innsbruck richtungsweisend. ${ }^{197}$ Zudem wurde den oben dargelegten methodischen Überlegungen Rechnung getragen und die Richtlinien dahingehend adaptiert (siehe unten).

Der Bibliothekssignatur als Kopfzeile folgt der Autor bzw. der anonyme Sachtitel, wobei bei umfangreicheren Textsammlungen ein fingierter Gesamttitel verwendet wird. Die Schlagzeile enthält relevante Daten zu Material, Umfang (gezählte Blätter), Maße des Buchblocks, Entstehungsort und Datierung der Handschrift.

Die Beschreibung des Äußeren gliedert sich in mehrere Bereiche, gekennzeichnet durch folgende Siglen:

B Beschreibstoff, Zustand und Zusammensetzung der Handschrift

S Schrift

N Notation

A Ausstattung

E Einband

G Geschichte der Handschrift

L Literatur

Die Beschreibung des Äußeren bezieht sich in der Regel auf die Handschrift als Ganzes. Aufgrund der heterogenen Teile bei Sammelhandschriften wird dementsprechend eine allgemeine, die gesamte

195 O. MAZAL, Richtlinien und Terminologie für die Handschriftenbeschreibung, in: Ders. (Hrsg.), Handschriftenbeschreibung in Österreich. Referate, Beratungen und Ergebnisse der Arbeitstagungen in Kremsmünster (1973) und Zwettl (1974) (Denkschriften der ÖAW, phil.-hist. Kl. 122 = Veröffentlichungen der Kommission für Schrift- und Buchwesen des Mittelalters II, 1). Wien 1975, 135-172.

196 Vgl. G. HAYer, Richtlinien oder Dogma? Ein Beitrag zur Diskussion über die Richtlinien für die Handschriftenbeschreibung in Österreich, in: I. REIfFENSTEIN (Hrsg.), Beiträge zur Überlieferung und Beschreibung deutscher Texte des Mittelalters. Referate der 8. Arbeitstagung österreichischer HandschriftenBearbeiter vom 25.-28.11.1981 in Rief bei Salzburg (Göppinger Arbeiten zur Germanistik 402). Göppingen 1983, 213-227; A. Derolez, Die Handschriftenbeschreibung und die Bibliotheks- und Buchgeschichte des Mittelalters, in: A. RAPP, M. ЕмBACH (Hrsg.), Rekonstruktion und Erschließung mittelalterlicher Bibliotheken (Beiträge zu den historischen Kulturwissenschaften 1). Berlin 2008, 105-118, hier 116-117.

197 Wie Anm. 100; G. Kompatscher Gufler, D. Mairhofer, C. Schretter, Katalog der mittelalterlichen Handschriften der Bibliothek des Prämonstratenser Chorherren Stiftes Wilten. Redigiert von P. AusSERLECHNER (Denkschriften der ÖAW, phil.-hist. Kl. 425 = Veröffentlichungen der Kommission für Schrift- und Buchwesen des Mittelalters II, 10). Wien 2012. 
Handschrift betreffende Beschreibung des Äußeren an den Anfang gestellt; die einzelnen Teile werden mit speziellen Beschreibungen versehen.

Abschnitt B verzeichnet Angaben zu Beschreibstoff, Erhaltungszustand, Zusammensetzung der Handschrift nach der Chroust'schen Lagenformel, Eigentümlichkeiten des Buchblocks, Existenz von Kustoden bzw. Reklamanten, Foliierung bzw. Paginierung sowie Textverlust. Die Angabe zu den Wasserzeichen reduziert sich auf einen Verweis auf die stetig erweiterte Internetplattform www.wzma.at. Verwandte Wasserzeichen werden nur im begründeten Anlassfall angeführt. Abreibungen sowie Betaradiografie-Aufnahmen der nachgewiesenen Wasserzeichen sind neben www.wzma.at auch über www.manuscripta.at ansteuerbar.

Im Abschnitt S werden Informationen zur Schrift festgehalten: Schriftraum, Spaltenzahl, Zeilenzahl, Linierung, Schriftart, Schreiber, Schriftwechsel, Datierung. Da es sich bei den behandelten Handschriften um einen Teilbestand handelt, konnten im Zuge detaillierter Untersuchungen des Komplementärbestandes an der ULB Tirol Querverbindungen zu anderen Handschriften hergestellt werden. Die noch ausständige Untersuchung auch des archivalischen Materials in der Stiftsbibliothek bzw. im Stiftsarchiv in Neustift lässt weitere Erkenntnisse zu den Schreibern erwarten. Ebenso können Spuren zum Skriptorium des Augustiner Chorherrenstiftes Klosterneuburg noch weiter nachverfolgt werden. Hierfür soll dieser Katalog als Basis dienen. Die paläografische Terminologie folgt - mit leichten Adaptierungen - den Richtlinien Mazals. ${ }^{198}$

Die bei den vorliegenden Beschreibungen erstmals angeführte Sigle N bezieht sich auf Informationen zur Notation: Gestaltung, Notensysteme, Textzeilen, Art der Notation, Datierung und Lokalisierung, Besonderheiten. Die ausführlichen Beschreibungen der liturgischen Handschriften richten sich nach dem Vorbild der Innsbrucker Katalogbände. Abweichend davon werden die in den Missalien und Brevieren enthaltenen Sequenzen und Hymnen sowie die in den Sanktoralteilen enthaltenen Offizien in eigenen Tabellen übersichtlich dargestellt.

Die Sigle A enthält Angaben zur Ausstattung der Handschrift. Aufgenommen wird sowohl einfacher Dekor als auch höherrangiger Buchschmuck (s. Einleitung 3.2 Illuminierte Handschriften).

Im Abschnitt E folgt eine Beschreibung des Einbandes. Angeführt werden Hinweise auf Material des Deckels und des Bezuges, Stil, Technik der Verzierung, Entstehungsort und Entstehungszeit. Aufgrund der meist vorgenommenen Ablösung der ursprünglichen Einbände und Neubindung in Form von einfachen Halbfranz-Bibliothekseinbänden ist es leider nicht mehr möglich, eine umfassende Auswertung der ursprünglichen Einbandtypen zu geben. Trotzdem wurde versucht, Querverbindungen zwischen den wenigen noch erhaltenen ursprünglichen Einbänden in Neustift und in anderen Tiroler Bibliotheken herzustellen und daraus buch- und bibliothekshistorisch relevante Schlüsse zu ziehen. Abbildungen der Einbände bzw. Abreibungen aller Einbandstempel und -rollen finden sich unter www.manuscripta.at bzw. im Abbildungsteil im Anhang.

Abschnitt $\mathrm{G}$ fasst Hinweise auf die Geschichte der Handschrift zusammen und nennt alle Angaben über Vorbesitzer sowie Benützung der Handschrift. Damit soll versucht werden, die Handschrift in ihren bibliotheksgeschichtlichen Kontext zu betten und Zusammenhänge herzustellen. Um die historischen Fakten deutlich darzustellen, werden alle entsprechenden Angaben im Wortlaut in möglichst chronologischer Reihenfolge wiedergegeben. Berücksichtigt werden u.a. Besitzeinträge (soweit zu ermitteln, auch getilgte), Kauf-, Schenkungsvermerke, Supralibros sowie Exlibris und alte Signaturen.

Unter der Sigle L wird die gesamte Literatur, in der die Handschrift bzw. einzelne Teile daraus behandelt oder zumindest erwähnt bzw. zitiert sind, chronologisch geordnet aufgelistet. Auch Editionen,

198 Zur Frage der Nomenklatur vgl. K. SchNeIDER, Paläographie und Handschriftenkunde für Germanisten. Eine Einführung. Tübingen 1999, 28 Anm. 46; DIES., Gotische Schriften in deutscher Sprache 1, 12-13; A. Fingernagel, Die Buchschriften des 12. Jahrhunderts, in: Ders. (Hrsg.), Romanik (Geschichte der Buchkultur 4/1). Graz 2007, 89-90; A. Derolez, The Palaeography of Gothic Manuscript Books. Cambridge 2003, 57; H. FoErster, Abriss der lateinischen Paläographie. Erweiterte 3. Auflage von T. Frenz. Stuttgart 2004, 217; J. Autenrieth, Probleme der Lokalisierung und Datierung von spätkarolingischen Schriften (10. und 11. Jahrhundert). Codicologia 4 (1978) 68. 
denen die betreffende Handschrift zugrunde liegt oder in deren Handschriftenlisten sie genannt ist, finden Berücksichtigung. Bibliografische Vollständigkeit wurde angestrebt, kann jedoch nicht zugesichert werden. Mehrfach genannte Werke werden in Kurzform wiedergegeben und sind im Verzeichnis der abgekürzt zitierten Literatur aufgelistet. Relevante Publikationen ohne Nennung der Handschrift sind an entsprechender Stelle der Inhaltsbeschreibung angegeben.

Im Anschluss an die Beschreibung des Äußeren folgt die Beschreibung des Inhalts. Einzelne Texte werden mit arabischen Ziffern durchnummeriert. In runden Klammern wird der Standort angegeben. Der Autor wird, wenn möglich, in normierter Form angeführt. Ist er in der Handschrift selbst nicht genannt, wird er in Spitzklammern gesetzt. Der Anführung des Titels folgen in Klammern der Nachweis des Textes in Standardeditionen oder zumindest in einem älteren Druck, Nachweise in gängigen Repertorien, Werks- bzw. Handschriftenverzeichnissen. Titel, Incipit und Explicit werden in der Regel nur dann angegeben, wenn sie im Wortlaut stark von den genannten Ausgaben abweichen oder keine gängige Edition vorliegt. Auch Schreibervermerke und Kleintexte werden berücksichtigt. Überschriften und Schlussschriften werden nur vermerkt, sofern sie nähere Angaben zum Text, z. B. die Zuschreibung zu einem anderen als dem ermittelten Autor, beinhalten. Die wiedergegebenen Textstellen werden im Wortlaut der Handschrift kursiv aufgenommen; im Initienregister finden sie sich in normalisierter Form. Eindeutige Abkürzungen werden ohne eigenen Ausweis aufgelöst. Auf etwaige Glossen ist hingewiesen. Die noch in situ befindlichen Fragmente werden sowohl äußerlich als auch inhaltlich beschrieben. Zusammengehörige Fragmente in einer Handschrift werden an der Stelle ihres Erstvorkommens zusammengefasst. Von einer Beschreibung der abgelösten, (noch) nicht zugewiesenen Fragmente wurde abgesehen. ${ }^{199}$ Bisweilen folgen der inhaltlichen Beschreibung Hinweise zum Text, zur Textgeschichte, auf weiterführende Literatur oder zu Parallelüberlieferungen, vorwiegend im süddeutschen Raum. Kataloge mit Beschreibungen der zum Vergleich herangezogenen Handschriften werden nicht eigens ausgewiesen. Auch EDV-gestützte Hilfsmittel und Internetdatenbanken werden nicht eigens zitiert.

Die Handhabung der Beschreibungen soll durch mehrere Register, Verzeichnisse und Übersichten erleichtert werden.

Hinweise, Ergänzungen und Korrekturen zu den vorliegenden Beschreibungen sowie bibliografische Addenda werden im Webportal www.manuscripta.at berücksichtigt.

199 Die Fragmente werden derzeit im Rahmen anderer Projekte erschlossen, vgl. Anm. 109. 
TEIL II: KATALOGTEIL 



\section{Verzeichnis der beschriebenen Handschriften}

Cod. 4

IOHANNES CALDERINUS. ARNOLDUS DE GEILHOVEN

Pap. II, 432 Bl. $410 \times 285$. Oberitalien (Bologna?), Anfang 15. Jh.

Cod. 7

GUILELMUS DURANTIS. IOHANNES ANDREAE

Perg. I, 164, I* Bl. $410 \times 275$. Bologna, 1. H. 14. Jh.

Cod. 19

PETRUS LOMBARDUS

Perg. I, 108, I* Bl. $385 \times 270$. Nordfrankreich (Raum Paris), 13. Jh.

Cod. 20

VETUS TESTAMENTUM

Perg. I, 168, I* Bl. $380 \times 280$. Entstehungsort unbestimmt, 12./13. Jh.

Cod. 31

ALDOBRANDINUS DE TOSCANELLA. EXPOSITIO SUPER AVE MARIA. GODEFRIDUS

HERILACENSIS

Perg. I, 130, I* Bl. $320 \times 240$. Süddeutscher Raum (?), 14. Jh.

Cod. 38

THOMAS DE AQUINO

Perg. I, 272, I* Bl. $345 \times 260$. Süddeutscher Raum (?), 15. Jh.

Cod. 52

THEOLOGISCHE SAMMELHANDSCHRIFT

Pap. 273 Bl. $290 \times$ 205. Süddeutscher Raum (Tirol?), T. I: Ende 14. Jh., T. II: 1396.

Cod. 53

THOMAS EBENDORFER

Pap. I, 348 Bl. $285 \times 210$. Wiener Raum (?), Mitte 15. Jh. (u. a. 1452).

Cod. 76

SAMMELHANDSCHRIFT

Perg./Pap. I, 75, I* Bl. $270 \times$ 205. T. I: Neustift, Mitte 15. Jh., T. II: St. Dorothea (Wien) und Neustift, 6. Jz. 15. Jh.

Cod. 77

THOMAS DE AQUINO. PETRUS BLESENSIS

Pap. I, 120, I* Bl. $275 \times 200$. Basel, 1465.

Cod. 78

PEREGRINUS OPPOLIENSIS

Pap. I, 120, I* Bl. $280 \times 205$. Raum Brixen (Neustift?), um 1430/33.

Cod. 83

GREGORIUS MAGNUS

Pap. I, 59, I* Bl. 285× 205. Süddeutscher Raum, 1400 . 
Cod. 85

TRACTATUS DE SACRAMENTIS

Pap. I, 107, I* Bl. $290 \times 205$. Wohl Neustift, Anfang 16. Jh.

Cod. 86

THOMAS DE AQUINO

Perg. I, 40, I* Bl. $300 \times 205$. Frankreich (?), wohl Mitte 13. Jh.

Cod. 99

CLEMENS V. IOHANNES ANDREAE. IOHANNES XXII

Perg. I, 33, I* Bl. $400 \times 270$. Bologna, 1. H. 14. Jh.

\section{Cod. 100}

MISSALE (FESTIVUM)

Perg. 104 Bl. $380 \times 295$. Neustift, 1524-1526.

Cod. 106

IOHANNES IANUENSIS

Perg. I, 110, I* Bl. $365 \times 285$. Süddeutscher Raum (?), 1. H. 15. Jh.

Cod. 107

COMPILATIONES ANTIQUAE I-III

Perg. I, 81, I* Bl. 355×230. Nordfrankreich (Raum Paris), zw. 1210 und 1234.

Cod. 123

BERNARDUS DE GORDONIO. MEDIZINISCHE TRAKTATE

Pap. IV, 227, I* Bl. 315×215. Süddeutscher Raum, 6. Jz. 15. Jh.

Cod. 125

THEOLOGISCHE SAMMELHANDSCHRIFT

Pap. I, 313, I* Bl. $310 \times 220$. Süddeutscher Raum, 6. Jz. 15. Jh.

Cod. 142

REGULA S. AUGUSTINI. HUGO DE SANCTO VICTORE (?). LIBER ANNIVERSARIORUM NEOCELLENSIS. NECROLOGIUM NEOCELLENSE

Perg. I, 173, I* Bl. $300 \times 230$. Neustift, T. I: 1521, T. II: 1459 .

Cod. 145

BARTHOLOMAEUS A SANCTO CONCORDIO

Pap. I, 314, I* Bl. $300 \times 215$. Süddeutscher Raum (Tirol?), 1427.

Cod. 146

REGEL DES HL. AUGUSTINUS. HUGO DE SANCTO VICTORE (?). HUMBERTUS DE ROMANIS Perg. I, 160, I* Bl. $290 \times 220$. Süddeutscher Raum (T. I: Neustift?), 1. H. 15. Jh. (vor 1445).

Cod. 153

IOHANNES HEROLT (DISCIPULUS)

Pap. I, 168, I* Bl. 270× 205. Wiener Raum, 4. Jz. 15. Jh.

Cod. 154

MISSALE SPECIALE (TEILMISSALE)

Perg. I, 47, I* Bl. $295 \times 195$. Umfeld Neustift, 12. Jh. (mit Nachträgen 13. Jh.).

Cod. 155

SAMMELHANDSCHRIFT

Pap. I, 164, I* Bl. $290 \times 205$. Umfeld Neustift (u. a. Pfalzen), 7. Jz. 15. Jh. (u. a. 1463).

Cod. 156

HUGO DE SANCTO CARO

Perg. I, 88, I* Bl. 290×210. Nordfrankreich (Raum Paris), um 1300.

Cod. 158

AUGUSTINUS

Pap. III, 69, I* Bl. $285 \times 205$. Süddeutscher Raum, um 1400 . 
Cod. 160

LAURENTIUS RUSIUS

Pap. I, 55, I* Bl. $290 \times 210$. Süddeutscher Raum, Mitte 15. Jh.

Cod. 161

IOHANNES DE DAMBACH. ORIGENES. EXPOSITIO ORATIONIS DOMINICAE

Pap. I, 12, I* Bl. $285 \times 205$. Süddeutscher Raum, Ende 14. Jh.

Cod. 162

SERMONES IN DEDICATIONE ECCLESIAE

Pap. I, 10, I* Bl. $290 \times 205$. Süddeutscher Raum, Ende 14. Jh.

Cod. 163

ARISTOTELES

Pap. I, 79, I* Bl. $290 \times 220$. Wien, T. I: um 1389 und um 1443, T. II: Ende 14. Jh.

Cod. 165

THEOLOGISCHE SAMMELHANDSCHRIFT

Pap. I, 148, I* Bl. $295 \times 205$. Süddeutscher Raum, 1. Jz. 15. Jh. (T. III: 1407).

Cod. 166

SPECULUM HUMANAE SALVATIONIS

Pap. II, 58, I* Bl. $295 \times 210$. Süddeutscher Raum, 1. Jz. 15. Jh.

Cod. 167

ADAM DE ALDERSBACH

Pap. I, 72, I* Bl. $290 \times 205$. Süddeutscher Raum, 1419.

Cod. 168

ARISTOTELES

Pap. I, 46, I* Bl. $290 \times 220$. Wien, 9. Jz. 14. Jh.

Cod. 171

THOMAS CANTIMPRATENSIS. THEOLOGISCHE TRAKTATE

Perg. I, 91, I* Bl. $285 \times 210$. Süddeutscher Raum, Ende 13./Anfang 14. Jh.

Cod. 173

MAURUS SERVIUS HONORATUS

Pap./Perg. I, 172, I* Bl. $260 \times 215$. Italien, 2. Drittel 15. Jh.

Cod. 174

SERMONES DE TEMPORE

Pap. I, 225, I* Bl. $280 \times 200$. Tirol (?), um 1470 (u. a. 1472).

Cod. 177

FLORES DE SANCTIS ET DE TEMPORE

Pap. I, 153, I* Bl. $280 \times 210$. Tirol (Neustift?), um 1430/33.

Cod. 181

ALANUS AB INSULIS

Pap. I, 60, I* Bl. 285×210. Wiener Raum, um 1410.

Cod. 182

PS.-EUSEBIUS

Pap. I, 16, I* Bl. 285×205. Süddeutscher Raum, 1400.

Cod. 183

HENRICUS SUSO

Pap. I, 48, I* Bl. $285 \times 205$. Süddeutscher Raum, um 1400 .

Cod. 190

BRUNO DE SEGNI

Perg. I, 68, I* Bl. $315 \times 250$. Neustift (?), 2. H. 15./Anfang 16. Jh.

Cod. 194

RITUALE NEOCELLENSE

Perg. I, 67 Bl. 305×225. Neustift, 1507. 


\section{Cod. 196}

LECTIONARIUM MISSAE NEOCELLENSE

Perg. I, 26 Bl. $315 \times 250$. Neustift, Ende 15. Jh. (vor 1482?).

Cod. 200

ROBERTUS HOLCOT

Pap. I, 390, I* Bl. $310 \times 215$. Wiener Raum (?), um 1415/20.

Cod. 204

VETUS TESTAMENTUM

Pap. 307 Bl. $310 \times 200$. Tirol (?), um 1470 .

Cod. 217

DECIMUS IUNIUS IUVENALIS. AULUS PERSIUS FLACCUS

Perg. I, 56, I* Bl. $310 \times 200$. Bologna, 1. H. 15. Jh.

Cod. 252

ORDINARIUM MISSAE

Perg. 46 Bl. $340 \times 245$. Neustift (?), letztes Viertel 15. Jh.

Cod. 253

GODEFRIDUS DE TRANO. TANCREDUS BONONIENSIS. RAIMUNDUS DE PENNAFORTE

Perg. 88 Bl. $380 \times 265$. Oberitalien (Bologna?), 1. H. 14. Jh.

Cod. 282

BERNARDUS CLARAEVALLENSIS

Perg. I, 25, I* Bl. $240 \times 165$. Entstehungsort unbestimmt, 2. H. 12. Jh.

Cod. 293

VITA BEATI HARTMANNI EPISCOPI (BRIXINENSIS)

Perg. 23, II* Bl. $260 \times 170$. Neustift, 12./13. Jh.

Cod. 308

THEOLOGISCHE SAMMELHANDSCHRIFT

Perg. I, 228, I* Bl. $220 \times 150$. Süddeutsch-österreichischer Raum, 14. Jh.

Cod. 315

ISAIAS MIT GLOSSA ORDINARIA

Perg. I, 88, I* Bl. 235×170. Entstehungsort unbestimmt, 12. Jh.

Cod. 327

GALFREDUS DE VINOSALVO

Perg. I, 21, I* Bl. $220 \times 150$. Frankreich (?), 13. Jh.

Cod. 353

LIBER HORARUM, Bd. 1 (zusammengehörend mit Cod. 654)

Perg. VI, 194 Bl. $160 \times 120$. Raum Brixen, um 1496 .

Cod. 360

CONRADUS HIRSAUGIENSIS

Perg. I, 26, I* Bl. $165 \times 110$. Entstehungsort unbestimmt, 12. Jh.

Cod. 397

IOHANNES DE TURRECREMATA

Perg. I, 88, I* Bl. $140 \times 105$. Süddeutscher Raum (?), 2. H. 15. Jh.

Cod. 405

BREVIARIUM SALISBURGENSE

Perg. VII, 236 Bl. $135 \times 100$. Wohl Neustift, um 1500 (u. a. 1501).

Cod. 440

MARSILIUS DE INGHEN. IOHANNES BURIDANUS

Pap. I, 414 Bl. $280 \times 205$. Tirol (?), um 1450 .

Cod. 447

KANONISTISCHE SAMMELHANDSCHRIFT, u. a. ALBERTUS DE BRIXIA

Pap. 208, X* Bl. $295 \times 215$. Süddeutscher Raum, 1414. 
Cod. 453

MEDIZINISCHE SAMMELHANDSCHRIFT

Pap. III, 234, I* Bl. $295 \times 210$. T. I: Wiener Raum, um 1455-1460, T. II-IV: Wiener Raum (?), um 1440.

\section{Cod. 483}

HONORIUS AUGUSTODUNENSIS

Perg. I, 76, I* Bl. $255 \times 170$. Entstehungsort unbestimmt, 2. H. 12. Jh.

Cod. 485

HUGO DE SANCTO VICTORE

Perg. I, 66, I* Bl. $240 \times 180$. Entstehungsort unbestimmt, um 1200.

\section{Cod. 495}

GREGORIUS MAGNUS

Perg. 202 Bl. $210 \times 140 / 145$. Entstehungsort unbestimmt, 10. Jh.

Cod. 532

SAMMELHANDSCHRIFT

Perg. I, 145, I* Bl. $150 \times 110$. Entstehungsort unbestimmt, 14. Jh.

Cod. 550

GUIDO DE MONTE ROCHERII. GUILELMUS DURANTIS

Pap. I, 446, III* Bl. $295 \times 210$. T. I: Wiener Raum, 6. Jz. 15. Jh., T. II: Raum Brixen (u. a. Villanders), 7. Jz. 15. Jh. (u. a. 1465).

\section{Cod. 578}

RAPHAEL VOLGOSIUS

Pap. I, 10, I* Bl. $295 \times 210$. Brixen, 1480 .

Cod. 579

PUBLIUS OVIDIUS NASO

Pap. 14 Bl. $300 \times 210$. Wiener Raum oder Tirol (?), 1491 .

Cod. 597

SERMONES. AUGUSTINUS FAVARONI

Pap. 58 Bl. $270 \times 210$. Wiener Raum, um 1464/65.

\section{Cod. 605}

PETRUS HISPANUS. DE MODIS SIGNIFICANDI

Perg. I, 8, I* Bl. $185 \times 135$. Entstehungsort unbestimmt, Ende 13./Anfang 14. Jh.

\section{Cod. 606}

TRACTATUS DE CONFESSIONE

Perg. I, 6, I* Bl. $220 \times 155$. Entstehungsort unbestimmt, 14. Jh.

\section{Cod. 614}

JURISTISCHE SAMMELHANDSCHRIFT

Pap. I, 290, I* Bl. $210 \times 145$. Tirol, T. I: 7./8. Jz. 14. Jh, T. II: 1. Viertel 15. Jh. (u. a. 1419), T. III: 1. Jz. 15. Jh., T. IV: 4. Jz. 15. Jh.

\section{Cod. 617}

\section{SAMMELHANDSCHRIFT}

Pap. I, 282 Bl. $220 \times 145$. Tirol (u. a. Neustift), T. I, II, IV: 7. Jz. 15. Jh. (u. a. 1467), T. III: 6. Jz. 15. Jh. (u. a. 1455).

\section{Cod. 654}

LIBER HORARUM, Bd. 2 (zusammengehörend mit Cod. 353)

Perg. II, 207, I* Bl. $165 \times 120$. Raum Brixen, 1496 .

\section{Cod. 691}

ARGUMENTA LIBRORUM DICTYS CRETENSIS

Pap. 5 Bl. $210 \times 145$. Neustift (?), Anfang 16. Jh.

Cod. 694

PAULUS URSINUS

Pap. 27 Bl. $205 \times 150$. Tirol, 1523. 
Cod. 726

RITUALE NEOCELLENSE

Pap. III, 78, I* Bl. $120 \times 100$. Neustift, 1523 (mit Zusätzen 16. und 17. Jh.).

Cod. 748

MEDIZINISCHE SAMMELHANDSCHRIFT

Pap. III, 220 Bl. 290 × 215. T. I-III: Wiener Raum (?), um 1440, T. IV: Schwäbisch-Schweizer Raum, um 1430.

Cod. 754

THEOLOGISCHE SAMMELHANDSCHRIFT, u. a. IOHANNES GERSON

Pap. 26 Bl. $280 \times 195$. Tirol, 3. Viertel 15. Jh.

Cod. 755

THEOLOGISCHE SAMMELHANDSCHRIFT

Pap. 12 Bl. $270 \times 200$. Neustift oder Wiener Raum (?), 6. Jz. 15. Jh., 1481 (?) und 16. Jh.

Cod. 756

MATTHIAS ENGELSCHALK

Pap. 53 Bl. $275 \times 200$. Süddeutscher Raum, 1479 .

Cod. 776

MUSIKALISCH-ASTRONOMISCHE SAMMELHANDSCHRIFT

Pap. I, 71, I* Bl. $210 \times 155$. Neustift (?), Anfang 16. Jh. (u. a. 1502).

Cod. 780

GAIUS SALLUSTIUS CRISPUS

Pap. 86 Bl. $210 \times 145$. Oberitalien (?), Ende 15. Jh.

Sign. 14820

RITUALE NEOCELLENSE

Perg. X, 85, II* Bl. $300 \times 230$. Neustift, Anfang 16. Jh. (mit Zusätzen, u. a. 1578).

Sign. 15063

ANTIPHONARIUM

Perg. 197 Bl. $355 \times 255$. Wohl Neustift, 2. H. 15. Jh. (mit späteren Zusätzen).

Nr. 139 (olim Sign. 14819)

GRADUALE. ANTIPHONARIUM

Pap. 231 Bl. 315×215. Umfeld Neustift, Ende 15. Jh. (T. I: 1495/96).

Nr. 940

GRADUALE. ANTIPHONARIUM

Pap. I, 229, I* Bl. 310×220. Umfeld Neustift, 1490/93.

ohne Sign.

NEUSTIFTER WAPPENBUCH

Perg. I, 88, I* Bl. $245 \times 180$. Sterzing (?), 1548-1552.

ohne Sign.

GRADUALE NEOCELLENSE I

Perg. II, 289, I* Bl. $725 \times 505$. Neustift, 1442.

ohne Sign.

GRADUALE NEOCELLENSE II

Perg. I, 317, I* Bl. $700 \times 500$. Neustift, Mitte 15. Jh. (zw. 1442 und 1446). 


\section{Verzeichnis der Abkürzungen und Siglen}

Vorbemerkung: Abkürzungen von biblischen Büchern nach der Biblia sacra iuxta vulgatam versionem (Ed. R. Weber, B. Fischer. Stuttgartiae ${ }^{33} 1983$, XXXI), Abkürzungen von Festbezeichnungen weitgehend nach Schneyer (s. Literaturverzeichnis), Abkürzungen als Teile von Handschriftensignaturen meist ohne Auflösung.

$\begin{array}{ll}\text { A } & \text { Ausstattung der Handschrift } \\ \text { Abb. } & \text { Abbildung } \\ \text { Abh. } & \text { Abhandlung(en) } \\ \text { Abt. } & \text { Abteilung } \\ \text { Anm. } & \text { Anmerkung } \\ \text { ap. } & \text { apostolus, apostoli } \\ \text { App. } & \text { Appendix } \\ \text { art. } & \text { articulus } \\ \text { B } & \text { Beschreibstoff und } \\ & \text { Zusammensetzung der } \\ \text { Bd., Bde } & \text { Handschrift } \\ \text { bearb. } & \text { Band, Bände } \\ \text { bes. } & \text { bearbeitet } \\ \text { Bibl. } & \text { besonders } \\ & \text { Bibliothek, Bibliotheca, } \\ \text { Bl. } & \text { Biblioteca, Bibliothèque } \\ \text { BMV } & \text { Blatt, Blätter } \\ \text { BN } & \text { Beata Maria Virgo } \\ \text { BSB } & \text { Bibliothèque Nationale } \\ \text { bzw. } & \text { Bayerische Staatsbibliothek } \\ \text { C. } & \text { beziehungsweise } \\ \text { ca. } & \text { Causa } \\ \text { cap. } & \text { circa } \\ \text { CC } & \text { capitulum, Kapitel } \\ \text { CCl } & \text { Codex Cremifanensis } \\ \text { Clm } & \text { Codex Claustroneoburgensis } \\ \text { Cod. } & \text { Codex Latinus Monacensis } \\ \text { d. h. } & \text { Codex, Codices } \\ \text { dat. } & \text { das heißt } \\ \text { ders., dies. } & \text { datiert } \\ \text { Dipl.-Arb. } & \text { derselbe, dieselbe } \\ \text { Diss. } & \text { Diplomarbeit } \\ \text { dist. } & \text { Dissertation } \\ \text { dnca } & \text { distinctio } \\ \text { dni } & \text { dominica } \\ \text { Doppelbl. } & \text { domini } \\ \text { dt. } & \text { Doppelblatt, -blätter } \\ \text { E } & \text { deutsch } \\ \text { ebda } & \text { Einband } \\ \text { Ed. } & \text { Editio(n) } \\ & \end{array}$

$\begin{array}{ll}\text { ed. } & \text { edidit, ediderunt, editio } \\ \text { ehem. } & \text { ehemals, ehemalig } \\ \text { Einzelbl. } & \text { Einzelblatt, -blätter } \\ \text { ep. } & \text { epistola } \\ \text { etc. } & \text { et cetera } \\ \text { ev. } & \text { evangelista } \\ \text { evtl. } & \text { eventuell } \\ \text { Expl. } & \text { Explicit } \\ \text { fasc. } & \text { fasciculus } \\ \text { fer. } & \text { feria } \\ \text { ff. } & \text { (und) folgende } \\ \text { Forts. } & \text { Fortsetzung } \\ \text { fr. } & \text { frater } \\ \text { Fragm. } & \text { Fragment } \\ \text { G } & \text { Geschichte } \\ \text { Gegenbl. } & \text { Gegenblatt, -blätter } \\ \text { gest. } & \text { gestorben } \\ \text { H. } & \text { Hälfte } \\ \text { HD } & \text { Hinterdeckel } \\ \text { hl. } & \text { heilig(e) } \\ \text { hrsg. } & \text { herausgegeben } \\ \text { Hrsg. } & \text { Herausgeber } \\ \text { Hs. } & \text { Handschrift, Handschriften } \\ \text { i. m. } & \text { in margine } \\ \text { Inc. } & \text { Incipit } \\ \text { Ink. } & \text { Inkunabel } \\ \text { insbes. } & \text { insbesondere } \\ \text { Jh. } & \text { Jahrhundert } \\ \text { Jz. } & \text { Jahrzehnt } \\ \text { korr. } & \text { korrigiert } \\ \text { L } & \text { Literatur } \\ \text { lat. } & \text { lateinisch } \\ \text { LB } & \text { Landesbibliothek } \\ \text { lib. } & \text { liber, libri } \\ \text { Lit. } & \text { Literatur } \\ \text { mm } & \text { Millimeter } \\ \text { Ms. } & \text { Manuskript } \\ \text { mut. } & \text { (Titel, Incipit, Explicit) } \\ \text { N } & \text { mutile } \\ \text { Nachsatzbl. } & \text { Notation } \\ & \text { Nachsatzblatt, -blätter } \\ & \end{array}$




$\begin{array}{llll}\text { ND } & \text { Nachdruck } & \text { Sp. } & \text { Spalte } \\ \text { N. F. } & \text { Neue Folge } & \text { Ss. } & \text { sanctissimus } \\ \text { Nr. } & \text { Nummer } & \text { Staatsbibl. } & \text { Staatsbibliothek } \\ \text { o. } & \text { ohne } & \text { Stadtbibl. } & \text { Stadtbibliothek } \\ \text { ÖAW } & \text { Österreichische Akademie der } & \text { Stiftsbibl. } & \text { Stiftsbibliothek } \\ & \text { Wissenschaften } & \text { Str. } & \text { Strophe } \\ \text { ÖNB } & \text { Österreichische } & \text { Suppl. } & \text { Supplement } \\ & \text { Nationalbibliothek } & \text { T. } & \text { Teil } \\ \text { Pap. } & \text { Papier } & \text { Taf. } & \text { Tafel } \\ \text { Perg. } & \text { Pergament } & \text { Tit. } & \text { Titel } \\ \text { phil.-hist. Kl. } & \text { philosophisch-historische } & \text { tit. } & \text { titulus } \\ & \text { Klasse } & \text { tract. } & \text { tractatus } \\ \text { Ps.- } & \text { Pseudo- } & \text { tw. } & \text { teilweise } \\ \text { qu. } & \text { quaestio } & \text { u. a. } & \text { und andere(s), unter anderem } \\ \text { Quadrages. } & \text { Quadragesima } & \text { u. ö. } & \text { und öfter } \\ \text { quaestiunc. } & \text { quaestiuncula } & \text { UB } & \text { Universitätsbibliothek } \\ \text { Quinquages. } & \text { Quinquagesima } & \text { ULB } & \text { Universitäts- und } \\ \text { r } & \text { recto } & & \text { Landesbibliothek } \\ \text { S } & \text { Schrift } & \text { urspr. } & \text { ursprünglich } \\ \text { S. } & \text { Seite } & \text { V. } & \text { Vers } \\ \text { s. } & \text { sanctus } & \text { v } & \text { verso } \\ \text { s. } & \text { siehe } & \text { v. a. } & \text { vor allem } \\ \text { s. d. } & \text { siehe dort } & \text { Vaticana } & \text { Bibliotheca Apostolica } \\ \text { s. o. } & \text { siehe oben } & & \text { Vaticana } \\ \text { s. u. } & \text { siehe unten } & \text { VD } & \text { Vorderdeckel } \\ \text { s. v. } & \text { sub verbo } & \text { vgl. } & \text { vergleiche } \\ \text { SB } & \text { Sitzungsberichte } & \text { Vorsatzbl. } & \text { Vorsatzblatt, -blätter } \\ \text { Septuages. } & \text { Septuagesima } & \text { Wiss. Stadtbibl. } & \text { Wissenschaftliche Stadtbibliothek } \\ \text { Ser. } & \text { Serie, series } & \text { Z. } & \text { Zeile } \\ \text { Sexages. } & \text { Sexagesima } & \text { z. B. } & \text { zum Beispiel } \\ \text { Sign. } & \text { Signatur } & \text { zum Teil } \\ \text { sog. } & \text { sogenannt } & \text { zwischen } \\ & & & \\ & & & \end{array}$

Auflösung der Siglen der Bearbeiterinnen und Bearbeiter:
A. P.: Anna Pinter
C. S.: Claudia Schretter-Picker
G. G.: Giulia Gabrielli
G. K.: Gabriela Kompatscher Gufler
L. Š.: Lav Šubarić
M. S.: Maria Stieglecker
P. A.: Petra Ausserlechner
P. K.: Patrik Kennel
S. R.: Susanne Rischpler
U. S.: Ursula Stampfer
W. N.: Walter Neuhauser 


\section{Verzeichnis der abgekürzt zitierten Literatur}

850 Jahre Augustiner Chorherrenstift Neustift

850 Jahre Neustift. Katalog

$\mathrm{AH}$

Atz

Baroffio

Beier

Bernhard, ed. LeclercqRochais

BGOC, Bernard

BHL

BHM

Bloomfield

Bloomfield, Suppl.

Bosse

BS

CAO

CCCM
850 Jahre Augustiner Chorherrenstift Neustift, hrsg. vom Augustiner Chorherrenstift Neustift. Brixen 1992.

Th. (H.) InNERhofer (Red.), 850 Jahre Chorherrenstift Neustift. 1. Südtiroler Landesausstellung. Stift Neustift 30. Mai bis 31. Oktober 1992. Katalog. Brixen 1992.

Analecta hymnica medii aevi. Ed. G. M. Dreves, C. Blume. 55 Bde. Leipzig 18861922, ND Frankfurt 1961. 2 Registerbde. Bern, München 1978.

K. Aтz, Kunstgeschichte von Tirol und Vorarlberg. Innsbruck ${ }^{2} 1909$.

G. BAROFFIO, Iter Liturgicum Italicum. Editio maior. Stroncone 2011.

Сн. BEIER, Die illuminierten Handschriften und Inkunabeln der Universitätsbibliothek Graz. Die illuminierten Handschriften 1400 bis 1550. Textband, Tafel- und Registerband (Denkschriften der Österreichischen Akademie der Wissenschaften, phil.-hist. Klasse 390/Institut für Kunstgeschichte der Universität Wien = Veröffentlichungen der Kommission für Schrift- und Buchwesen des Mittelalters V, 1). Wien 2010.

Bernardus Claraevallensis, S. Bernardi Opera. Ed. J. Leclerce, H. M. Rochais. 8 Bde. Romae 1957-1977.

Bibliographie générale de l’Ordre Cistercienne. Saint Bernard (Documentation cistercienne 21, Fasc. hors Série 1-19). Rochefort 1979-1983.

Bibliotheca hagiographica Latina antiquae et mediae aetatis (Subsidia hagiographica 6-7). 2 Bde. Bruxelles 1898-1901.

B. LAMBERT, Bibliotheca Hieronymiana manuscripta (Instrumenta patristica 4). 4 Bde. Steenbrugis 1969-1972.

M. W. Bloomfield (u. a.), Incipits of Latin works on the virtues and vices, 1100-1500 A. D. Including a section of Incipits of works on the Pater Noster (The Mediaeval Academy of America Publication 88). Cambridge, Mass. 1979.

R. Newhauser, I. Bejczy, A Supplement to Morton W. Bloomfield et al. Incipits of Latin works on the virtues and vices 1100-1500 a. D. (Instrumenta patristica et mediaevalia 50). Turnhout 2008.

D. Bosse, Untersuchung einstimmiger mittelalterlicher Melodien zum „Gloria in excelsis Deo“, Diss. Erlangen 1955.

Biblia sacra iuxta Latinam vulgatam versionem ... cura et studio monachorum s. Benedicti commissionis pontificiae ... bzw. monachorum abbatiae pontificiae sancti Hieronymii in urbe ordinis s. Benedicti edita. 18 Bde. Roma 1926-1995.

Corpus antiphonalium officii. Ed. R.-J. HeSBERT (Rerum ecclesiasticarum documenta, Series maior, Fontes 7-12). 6 Bde. Roma 1963-1979.

Corpus Christianorum. Continuatio mediaevalis. Bd. 1ff. Turnholti 1967ff. 
CCCPG

CCSL

Chev.

CIC, ed. Friedberg

Colophons

Corpus orationum

CPL

СРPM

CSEL

Distelbrink

Dolezalek

Engels

Fiegl, Missale

Fiegl, Prachthandschrift

Furtenbach-Kalb

Giner

Glorieux

Glorieux, Oeuvres

Goy

Gozzi
Corpus Christianorum. Clavis Patrum Graecorum. Bd. 1ff. Turnholti 1974ff.

Corpus Christianorum. Series Latina. Bd. 1ff. Turnholti 1953ff.

U. Chevalier, Repertorium hymnologicum (Subsidia hagiographica 4). 6 Bde. Louvain, Bruxelles 1892-1921.

Corpus iuris canonici. Editio Lipsiensis secunda. Instruxit Ae. Friedberg. 2 Bde. Lipsiae 1879-1881, ND Graz 1955.

Colophons de manuscrits occidentaux des origines au XVIe siècle. Ed. Bénédictins du Bouveret (Spicilegii Friburgensis Subsidia 2-7). 6 Bde. Fribourg 1965-1982.

Corpus orationum (CCSL 160 und 160 A ff.). Bd. 1ff. Turnholti 1992ff.

E. Dekkers, E. GaAr, Clavis Patrum Latinorum (Sacris erudiri 3). Steenbrugis ${ }^{2} 1961$.

Clavis Patristica Pseudoepigraphorum Medii Aevi. 2 Bde. Turnholti 1990-1994.

Corpus scriptorum ecclesiasticorum Latinorum ed. consilio Academiae Lit. Caesareae Vindobonensis. Bd. 1ff. Vindobonae 1866ff.

B. Distelbrink, Bonaventurae scripta authentica, dubia vel spuria critice recensita (Subsidia scientifica Franciscalia 5). Roma 1975.

G. Dolezalek, Verzeichnis der Handschriften zum römischen Recht bis 1600. 4 Bde. Frankfurt 1972.

ST. ENGELS, Einstimmige liturgische Handschriften des Mittelalters in Tirol, in: K. Drexel, M. Fink (Hrsg.), Musikgeschichte Tirols I: Von den Anfängen bis zur Frühen Neuzeit (Schlern-Schriften 315). Innsbruck 2001, 219-322.

H. FIEGL, Zur künstlerischen Ausstattung des Missale für Propst Augustin I. Posch (1519-1527), Cod. 100, im Augustiner Chorherrenstift Neustift, Brixen, Dipl.-Arb. Wien 1998.

H. FIEGL, Eine Prachthandschrift aus dem Kloster Neustift in Südtirol. Ein vergleichbares Gestaltungsprinzip zum Gebetbuch für Kaiser Maximilian I. von Albrecht Dürer, MS. L. impre. München, Bayerische Staatsbibliothek, im Posch-Missale, Cod. 100, Kloster Neustift/Brixen. Der Schlern 73 (1999) 747-758.

S. Furtenbach, H. Kalb, Die Erschließung kanonistischer und legistischer Handschriften in Nord- und Südtirol, in: W. NeuHauser (Hrsg.), Beiträge zur Handschriftenkunde und mittelalterlichen Bibliotheksgeschichte (Innsbrucker Beiträge zur Kulturwissenschaft, Sonderh. 47). Innsbruck 1980, 17-26.

A. Giner, Chorherrenverzeichnis 1142-1942, in: A. Giner (unter Mitwirkung von A. Sparber, M. Schrott) (Hrsg.), Festschrift zum 800jährigen Jubiläum des Stiftes Novacella. Brixen 1942, Anhang 1-61.

P. Glorieux, Répertoire des maîtres en théologie de Paris au XIII ${ }^{\mathrm{e}}$ siècle (Études de philosophie médiévale 17-18). 2 Bde. Paris 1933.

P. GloRieux, Jean Gerson. Oeuvres complètes. 10 Bde. Paris 1960-1973.

R. Goy, Die Überlieferung der Werke Hugos von St. Viktor (Monographien zur Geschichte des Mittelalters 14). Stuttgart 1976.

M. Gozzi, Musikgeschichte der Region Trient bis 1600, in: K. Drexel, M. FinK (Hrsg.), Musikgeschichte Tirols I: Von den Anfängen bis zur Frühen Neuzeit (SchlernSchriften 315). Innsbruck 2001, 467-593. 
Grabmann

Grabmann, Aristoteles

Graesse

Gschwend

GW

H bzw. HC

Hamesse

Hauréau bzw. Hauréau, App.

HC

Hermann

Hofmann-Brandt

Jungmann

Kaeppeli bzw. Kaeppeli-Panella

Katalog ULB Tirol I-X

Klapper II
M. Grabmann, Die Werke des hl. Thomas von Aquin, Eine literarhistorische Untersuchung und Einführung (Beiträge zur Geschichte der Philosophie und Theologie des Mittelalters 32, 1-2). Münster ${ }^{3} 1949$.

M. Grabmann, Forschungen über die lateinischen Aristotelesübersetzungen des XIII. Jahrhunderts (Beiträge zur Geschichte der Philosophie des Mittelalters 17, 5-6). Münster 1916.

Jacobi a Voragine Legenda Aurea vulgo Historia lombardica dicta. Ad optimorum librorum fidem recensuit TH. GRAESSE. Lipsiae 1850.

K. Gschwend, Die Depositio und Elevatio crucis im Raum der alten Diözese Brixen. Ein Beitrag zur Geschichte der Grablegung am Karfreitag und der Auferstehungsfeier am Ostermorgen. Sarnen 1965.

Gesamtkatalog der Wiegendrucke. Bd. 1ff. Leipzig $1925 \mathrm{ff}$.

H. HAIN, Repertorium bibliographicum in quo libri omnes ab arte typographica inventa usque ad annum MD typis expressi ordine alphabetico recensentur. 4 Bde. Stuttgartiae 1826-1838. Mit Supplementen von Copinger (s. d.).

J. HAMESSE, Repertorium initiorum manuscriptorum Latinorum medii aevi (Textes et études du moyen âge 42). Bd. 1ff. Louvain-La-Neuve $2007 \mathrm{ff}$.

B. HAURÉAu, Initia operum scriptorum Latinorum medii potissimum aevi ex codicibus manuscriptis et libris impressis alphabetice digessit... 6 Bde, 2 Bde Appendices. Turnholti 1973-1974.

Hain-Copinger s. H (Hain).

H. J. Hermann, Die illuminierten Handschriften in Tirol (Beschreibendes Verzeichnis der illuminierten Handschriften in Österreich 1). Leipzig 1905.

H. Hofmann-Brandt, Die Tropen zu den Responsorien des Officiums. 2 Bde. Erlangen 1971.

J. A. Jungmann, Missarum sollemnia. Eine genetische Erklärung der römischen Messe. 2 Bde. Wien ${ }^{4} 1958$.

TH. Kaeppeli, Scriptores ordinis Praedicatorum medii aevi. 4 Bde (Bd. 4: Тн. Kaeppeli-E. Panella). Romae 1970-1993.

W. Neuhauser (Leitung), Katalog der Handschriften der Universitätsbibliothek bzw. der Universitäts- und Landesbibliothek Tirol in Innsbruck, T. 1: Cod. 1-100, bearb. von W. Neuhauser; T. 2: Cod. 101-200, bearb. von W. Neuhauser; T. 3: Cod. 201300, bearb. von G. Kompatscher; T. 4: Cod. 301-400, bearb. von W. Neuhauser, L. Šubarić; T. 5: Cod. 401-500, bearb. von D. Mairhofer, W. Neuhauser, M. Rossini, C. Schretter; T. 6: Cod. 501-600, bearb. von D. Mairhofer, W. Neuhauser, C. Schretter, U. Stampfer; T. 7: Cod. 601-700, bearb. von P. Ausserlechner, W. Neuhauser, C. Schretter, U. Stampfer; T. 8: Cod. 701-800, bearb. von P. Ausserlechner, W. Neuhauser, A. Ohlenschläger, C. Schretter, U. Stampfer; T. 9: Cod. 801-950, bearb. von P. Ausserlechner, H. Gritsch, P. Kennel, W. Neuhauser, A. Ohlenschläger, C. Schretter-Picker, U. Stampfer; T. 10: Cod. 951-1198, bearb. von H. Gritsch, P. Kennel, W. Neuhauser, R. Neyer, A. Ohlenschläger, A. Pinter, C. Schretter-Picker (Denkschriften der Österreichischen Akademie der Wissenschaften, phil.-hist. Kl. 192, 214, 271, 327, 365, 375, 414, 456, 479, 489 = Veröffentlichungen der Kommission für Schrift- und Buchwesen des Mittelalters II, 4, 1-10). Wien 1987, 1991, 1999, 2005, 2008, 2009, 2011, 2014, 2015, 2017. T. 1-3 mit Beiheft Handschriften mit Datierungen und undatierten Schreibervermerken.

J. KLAPPER, Schriften Johanns von Neumarkt II: Hieronymus. Die unechten Briefe des Eusebius, Augustinus, Cyrill. Zum Lobe der Heiligen (Vom Mittelalter zur Reformation 6, 2). Berlin 1932. 
Kristeller

Kustatscher

Kustatscher-Korenjak

Kuttner

Lacombe

Laußermayer

Leclercq-Rochais

Lipphardt

LMLO

Madre

Mairhofer

MeSch II

MeSch VI

MGH

Miazga

MIÖG
P. O. KRISTELLER, Iter Italicum I. London 1963 bzw. VI 1992.

E. Kustatscher, Die Städte des Hochstifts Brixen im Spätmittelalter. Verfassungs- und Sozialgeschichte von Brixen, Bruneck und Klausen im Spiegel der Personengeschichte (1200-1550). 2 Bde (Veröffentlichungen des Südtiroler Landesarchivs 25). Innsbruck 2007.

E. Kustatscher, M. Korenjak, Kirchliches Schrifttum, in: M. Korenjak, F. Schaffenrath, L. Šubarić, K. Töchterle (Hrsg.), Tyrolis Latina. Geschichte der lateinischen Literatur in Tirol I: Von den Anfängen bis zur Gründung der Universität Innsbruck. Wien, Köln, Weimar 2012, 147-166.

St. Kuttner, Repertorium der Kanonistik 1140-1234 (Studi e testi 71). Città del Vaticano 1937, ND Roma 1972.

G. Lacombe u.a., Aristoteles Latinus (Corpus philosophorum medii aevi). Pars prior. Roma 1939. Ed. Nova. Bruges, Paris 1957. Pars posterior. Cantabrigiae 1955. Supplementa altera. Bruges, Paris 1961.

M. Th. Laussermayer, Die Entwicklung der Buchmalerei in Tirol, Diss. Innsbruck 1965.

s. Bernhard, ed. LeClercQ-Rochais.

W. LiPPHARDT, Lateinische Osterfeiern und Osterspiele (Ausgaben deutscher Literatur des XV. bis XVIII. Jahrhunderts. Reihe Drama 5). 6 Bde. Berlin 1975-1981.

A. Hughes, Late Medieval Liturgical Offices. Resources for Electronic Research 1: Texts (Subsidia Mediaevalia 23). Toronto 1994.

A. MADRE, Nikolaus von Dinkelsbühl. Leben und Schriften (Beiträge zur Geschichte der Philosophie und Theologie des Mittelalters 40, 4). Münster 1965.

Tн. Mairhofer, Urkundenbuch des Augustiner-Chorherrenstiftes Neustift in Tirol (Fontes rerum Austriacarum II, 34). Wien 1871.

Dieilluminierten Handschriftenund Inkunabeln derÖsterreichischen Nationalbibliothek 11: Mitteleuropäische Schulen II (ca. 1350-1410). Österreich, Deutschland, Schweiz. Bearb. von A. Fingernagel, K. Hranitzky, V. Pirker-Aurenhammer, M. Roland, F. Simader. Textband, Tafel- und Registerband (Denkschriften der Österreichische Akademie der Wissenschaften, phil.-hist. Kl. 305 = Veröffentlichungen der Kommission für Schrift- und Buchwesen des Mittelalters I, 11). Wien 2002.

Die illuminierten Handschriften und Inkunabeln der Österreichischen Nationalbibliothek 15: Mitteleuropäische Schulen VI (ca. 1410-1450). Österreich (ohne Wien und Niederösterreich), Deutschland, Schweiz. Bearb. von CH. BeIER, R. Cermann, A. Fingernagel, K. Hranitzky, K.-G. Pfändtner, V. Pirker-Aurenhammer, M. Roland, S. Rischpler, M. Schuller-Juckes, F. Simader; unter Mitarbeit von M. Elsigan und M. Stieglecker. Textband, Tafel- und Registerband (Denkschriften der Österreichischen Akademie der Wissenschaften, phil.-hist. Kl. = Veröffentlichungen der Kommission für Schrift- und Buchwesen des Mittelalters I, 15). Wien (in Druckvorbereitung).

Monumenta Germaniae historica. Bd. 1ff. Hannover $1826 \mathrm{ff}$.

T. Miazga, Die Melodien des einstimmigen Credo der römisch-katholischen lateinischen Kirche. Eine Untersuchung der Melodien in den handschriftlichen Überlieferungen mit besonderer Berücksichtigung der polnischen Handschriften. Graz 1976.

Mitteilungen des Instituts für Österreichische Geschichtsforschung. Wien 1880ff. 
Mone

MTU

Neuhauser, In libris

Neuhauser, Musikgeschichtliche Quellen

Neuhauser, Neustift

Neuhauser,

Rolleneinbände

Peintner, Buchmalerei

Peintner, Stiftsbibliothek

Peintner, Schreibkunst

PL

Préfaces

Rasmo

Rischpler

Roland, Gotik

Roland, Renaissance

SB Wien

Schneyer
F. J. Mone, Lateinische Hymnen des Mittelalters aus Handschriften. 3 Bde. Freiburg i. Br. 1853-1855, ND Aalen 1964.

Münchener Texte und Untersuchungen zur deutschen Literatur des Mittelalters. München 1961ff.

C. Schretter-Picker, P. Zerlauth (Hrsg.), In libris. Beiträge zur Buch- und Bibliotheksgeschichte Tirols von Walter Neuhauser (Schlern-Schriften 351). Innsbruck 2010.

W. NeuHauser, Musikgeschichtliche Quellen in Klöstern, Bibliotheken und Archiven, in: K. DreXel, M. FinK (Hrsg.), Musikgeschichte Tirols I: Von den Anfängen bis zur Frühen Neuzeit (Schlern-Schriften 315). Innsbruck 2001, 145-217 (auch in: Neuhauser, In libris 425-494).

W. Neuhauser, Wissenschaftspflege in Neustift im Spiegel der Handschriften, in: W. Neuhauser (Hrsg.), Beiträge zur Handschriftenkunde und mittelalterlichen Bibliotheksgeschichte (Innsbrucker Beiträge zur Kulturwissenschaft, Sonderh. 47). Innsbruck 1980, 73-104 (auch in: Neuhauser, In libris 97-128).

W. Neuhauser, Die Rolleneinbände des Buchdruckers und Buchbinders Gallus Dingenauer: Meister G-D, in: G. Coun (Hrsg.), De libris compactis: miscellanea (Studia Bibliothecae Wittockianae 1). Bruxelles 1984, 133-249.

M. Peintner, H. Walder (Photos), Neustifter Buchmalerei. Klosterschule und Schreibstube des Augustiner-Chorherrenstiftes. Bozen 1984.

M. Peintner, Die geistesgeschichtliche Bedeutung der Stiftsbibliothek, in: 850 Jahre Chorherrenstift Neustift, hrsg. vom Augustiner Chorherrenstift Neustift. Brixen 1992, 112-133.

M. Peintner, Schreibkunst, Studium und Musikleben im mittelalterlichen Kloster. Eine Darstellung am Beispiel der Musikgeschichte des Augustiner-Chorherrenstiftes Neustift, in: K. Drexel, M. FinK (Hrsg.), Musikgeschichte Tirols I: Von den Anfängen bis zur Frühen Neuzeit (Schlern-Schriften 315). Innsbruck 2001, 353-380.

Patrologiae Cursus completus... accurante J. P. Migne. Series Latina. 221 Bde. Lutetiae Parisiorum 1844-1864.

D. De Bruyne, Préfaces de la Bible latine. Namur 1920.

N. Rasmo, Mittelalterliche Kunst Südtirols. Ausstellungskatalog. Bozen 1949.

S. Rischpler, „Servacius Lichtensteyn de Prussia“, in: J. F. Hamburger, M. THEISEN (Hrsg.), Unter Druck. Mitteleuropäische Buchmalerei im 15. Jahrhundert. Tagungsband zum internationalen Kolloquium in Wien, Österreichische Akademie der Wissenschaften, 13.-17. 1. 2016 (Buchmalerei des 15. Jahrhunderts in Mitteleuropa 15). Petersberg 2018, 41-52.

M. Roland, Buchmalerei der Gotik, in: P. Naredi-Rainer, L. Madersbacher (Hrsg.), Kunst in Tirol I (Kunstgeschichtliche Studien - Innsbruck N. F. 3). Innsbruck, Wien, Bozen 2007, 267-294.

M. Roland, Die Buchmalerei der Renaissance, in: P. NARedi-Rainer, L. Madersbacher (Hrsg.), Kunst in Tirol I (Kunstgeschichtliche Studien - Innsbruck N. F. 3). Innsbruck, Wien, Bozen 2007, 633-646.

Sitzungsberichte der phil.-hist. Kl. der Österreichischen Akademie der Wissenschaften. Wien 1848ff.

J. B. SchNeYer, Repertorium der lateinischen Sermones des Mittelalters für die Zeit von 1150-1350 (Beiträge zur Geschichte der Philosophie und Theologie des Mittelalters 43). 11 Bde. Münster 1969-1990. 
Schulte GQ

Shooner

Sources chrétiennes

Sparber

Steer

Stefani

Stegmüller RB

Stegmüller RS (1937)

Stegmüller RS

Thorndike-Kibre

Verfasserlexikon $^{2}$

Walther, Initia

Walther, Proverbia

Weber

Welter

Wilhelm I bzw. II

Wretschko-Sprung

ZRG

Zumkeller
J. F. Schulte, Die Geschichte der Quellen und Literatur des Canonischen Rechts von Gratian bis auf die Gegenwart. 2 Bde. Stuttgart 1875-1877.

H. V. Shooner, Codices manuscripti operum Thomae de Aquino (Editores operum $d$. Thomae de Aquino 2ff.). Romae $1967 \mathrm{ff}$.

Sources chrétiennes. Bd. 1ff. Paris 1941ff.

A. Sparber, Über Neustifter Geschichtsquellen, in: R. von Klebelsberg (Hrsg.), Festschrift zu Ehren Emil von Ottenthals (Schlern-Schriften 9). Innsbruck 1925, 219227.

G. STEER „Carmina Burana“ in Südtirol. Zur Herkunft des clm 4660. Zeitschrift für deutsches Altertum und deutsche Literatur 12 (1983) 1-37.

C. Stefani, I manoscritti datati della Provincia di Bolzano. Bolzano, Biblioteca del Monastero di Muri-Gries. Bressanone, Biblioteca del Seminario Maggiore. Novacella, Archivio dell’Abbazia di S. Maria, Tesi di laurea. Trento 1995-96.

F. StegmüLLER, Repertorium biblicum medii aevi. 11 Bde. Matriti 1950-1980.

F. Stegmüller, Repertorium initiorum plurimorum in Sententias Petri Lombardi Commentariorum. Römische Quartalschrift 45 (1937) 85-360.

F. StegmülLer, Repertorium commentariorum in Sententias Petri Lombardi. 2 Bde. Würzburg 1947.

L. Thorndike, P. Kibre, A Catalogue of Incipits of mediaeval scientific writings in Latin (The Mediaeval Academy of America Publication 29). Cambridge, Mass. ${ }^{2} 1963$.

Die deutsche Literatur des Mittelalters. Verfasserlexikon. Begründet von W. STAmmLER. Hrsg. von K. RuH u. a. 14 Bde. Berlin, New York 1978-2008.

H. WALTHER, Initia carminum ac versuum medii aevi posterioris Latinorum (Carmina medii aevi posterioris Latina 1). Göttingen 1959.

H. Walther, Proverbia sententiaeque Latinitatis medii aevi (Carmina medii aevi posterioris Latina II). 6 Bde. Göttingen 1963-1967.

D. WeBer, Die handschriftliche Überlieferung der Werke des Heiligen Augustinus VI, 1-2 (Sitzungsberichte der Österreichischen Akademie der Wissenschaften, phil.hist. Kl. 601 = Veröffentlichungen der Kommission zur Herausgabe des Corpus der lateinischen Kirchenväter H. 11-12). Wien 1993.

J. Th. Welter, L'exemplum dans la littérature religieuse et didactique du Moyen Age. Paris, Toulouse 1927 ND Genève 1973, 2012.

F. Wilhelm, Die historischen Handschriften der Universitätsbibliothek Innsbruck. Mitteilungen des Österreichischen Vereins für Bibliothekswesen 5 (1901) 61-66, 135138, 209-212; 6 (1902) 34-39, 67-74, 106-110.

A. Wretschko, L. Sprung, Die Rechtshandschriften der Universitätsbibliothek in Innsbruck. Innsbruck 1904.

Zeitschrift (der Savigny-Stiftung) für Rechtsgeschichte. Wien, Köln, Graz 1861ff.

A. ZumkelLer, Manuskripte von Werken der Autoren des Augustiner-Eremitenordens in mitteleuropäischen Bibliotheken (Cassiciacum 20). Würzburg 1966. 


\section{Verzeichnis ausgewiesener Datenbanken}

Cantus

Krämer, Scriptores

PL-Database

Schneyer II

WZMA
Cantus: A database for Latin Ecclesiastical Chant. Indices of chants in selected manuscripts and early printed sources of the liturgical Office. Waterloo.

S. KRÄMER, Scriptores possessoresque codicum medii aevi. Datenbank von Schreibern und Besitzern mittelalterlicher Handschriften. Augsburg 2003-2012.

Patrologia Latina Database. Release 4. Cambridge 1993-1995.

Repertorium der lateinischen Sermones des Mittelalters für die Zeit von 1350-1500. Nach den Vorarbeiten von J. B. Schneyer hrsg. von J. Hödl und W. Knoch. Münster 2001.

Wasserzeichen des Mittelalters. Österreichische Akademie der Wissenschaften. www.wzma.at

Sämtliche Weblinks wurden zuletzt im April 2021 überprüft. 

KATALOG 



\section{Cod. 4}

\section{IOHANNES CALDERINUS. ARNOLDUS DE GEILHOVEN}

Pap. II, 432 Bl. $410 \times 285$. Oberitalien (Bologna?), Anfang 15. Jh.

B: $\quad$ Pap. leicht gewellt, vereinzelt kleine Löcher und Risse, tw. verschmutzt, vereinzelt Tintenkleckse, am oberen Blattrand Spuren eines Wasserschadens, insbes. am Beginn und am Schluss (mit Beschädigung der Malerei). Zw. Bl. 46 und 47 (am Falz) Spuren von gepressten pflanzlichen Blättern. Nachweise und Bilder der Wasserzeichen s. WZMA. Datierung nach Wasserzeichenbefund. Lagen: $\mathrm{I}^{\mathrm{II}}$ (Vorsatzlage, Perg.) + 11. $\mathrm{V}^{110}+\mathrm{IV}^{118}+$ $6 . V^{178}+(I V+2)^{188}+24 . V^{428}+(I I I-2)^{432}$. Bl. I urspr. als Spiegel auf dem VD aufgeklebt, Bl. II stark beschnitten $(110 / 115 \times 280)$. Bl. 179 und 188 eingehängte Einzelbl. Gegenbl. zu Bl. 429 und 430 herausgeschnitten (ohne Textverlust). Lagenreklamanten. Am unteren Blattrand mittig Kennzeichnung der Blätter der ersten Lagenhälfte mit Kleinbuchstaben in alphabetischer Reihenfolge (auf $z$ folgt $a a$ ), vielfach stark be- bzw. weggeschnitten, am rechten unteren Blattrand vereinzelt Zählung der Blätter der ersten Lagenhälfte in arabischen Ziffern erhalten. Am oberen Blattrand Foliierung 19. Jh. durch die ULB Tirol; Fehler in der Zählung: 215 ausgelassen, 280 doppelt angeführt. Rote Ledersignakel.

S: $\quad$ Schriftraum 260/270 $\times 180 / 185$. Zwei Spalten, von einfachen Bleistift- bzw. Blindlinien gerahmt, zu 52-65 Zeilen. Bastarda: Rudolph Claghewinter de Saxonia (Bl. 431vb), vgl. Krämer, Scriptores. Am Blattrand Korrekturen, zahlreiche Glossen, meist von anderer Hand, vereinzelt gerahmt. Außerhalb des Schriftraumes Notazeichen.

A: Abwechselnd rote und blaue Paragraphzeichen; diverse Verweiszeichen (oft drei Punkte mit kommaartigem Fadenausläufer); des Öfteren tintenfarbene Randmarkierungen, u. a. Bl. 62rb Doppellinie, aus der ein Dreieck (mit Bögchenrand) ragt, in das ein kleiner Kreis eingetragen ist; Lagenreklamanten von je vier Dreipunktmotiven gerahmt; ab Bl. 17r zahlreiche flüchtige Zeigehände (mit Ärmelansatz); Bl. 17rb, 70va-b (jeweils am Kolumnenrand) Profilgesichter. In der Regel zwei- und dreizeilige Lombarden, abwechselnd in Rot und Blau; die blauen Lombarden mit rotem, die roten Lombarden mit violettem Fleuronnée. Repräsentanten.

Fleuronnée: in den Binnenfeldern und als Besatz charakteristische saitenartige Parallelstriche, besetzt mit kleinen Perlen oder henkelartigen Klammern; schwungvoll zurückgebogene Fadenausläufer, tw. lockere (bzw. ondulierende) Bündelfäden und florale Endmotive (kleine Häkchenblüten, Bl. 373vb „Ähre“). Fleuronnée-Initialen jeweils zu Beginn der Lemmata, Paragraphzeichen jeweils zur Bezeichnung der Unterabschnitte eines Lemmas.

Deckfarbenschmuck: 24 neun- bis 17-zeilige ornamentale Initialen mit kurzen Ranken (nur Bl. 1r mit dreiseitigem Rankenwerk) am Beginn der Praefatio und der einzelnen Buchstaben dieses alphabetisch gegliederten Repertoriums; Bl. 1r ein Wappen; Bl. 1r Freifläche (ca. $185 \times 110)$ für einleitende Miniatur (Dedikationsbild?), nicht ausgeführt.

Die Ornamentalinitialen (Bl. 1ra, 1va [spaltenbreit], 43ra, 49vb, 105vb, 134vb, 171va, 184vb, 187rb, 193va, 233vb, 234va, 251vb, 278va, 288vb, 299ra, 350rb, 353ra, 369rb, 398vb, 410vb, 430va, 431va, 431vb [bes. beschädigt]) mit blattvergoldeten, schwarz konturierten Außengründen. Buchstabenkörper häufig in abgestuften Rosa- und Lilatönen (auch Grau), gerne mit feinperligem „Erbsenschotenmotiv“ (dieses tw. auch an Blättern) als Randdekor, seltener über Kreuz geschlungene Bänder (z. B. Bl. 1ra) als Ziermotiv. In den Binnenfeldern zumeist Blattformationen auf blauem oder karminrosafarbenem Grund, dieser mit feinen, weißen, tw. spiralig eingerollten Blättchenranken mit kugeligen Endhäkchen; feiner weißer Lineardekor auch auf Buchstabenkörpern und Ranken. Die kraft- und schwungvoll gewundenen Ranken entwachsen den Buchstabenkörpern, drehen sich an den Enden fallweise ein und/oder laufen in tintenfarbene Fäden aus; diese zuweilen schwer von den immer wieder sichtbaren Vorzeichnungslinien zu unterscheiden (z.B. Bl. 184vb); selten bilden die Rankenäste spitze Haken aus (z.B. Bl. 369rb); Rankenblätter mit feiner Strichelung in dunklerer Lokalfarbe abschattiert; als Dekor dicht gestreute, meist freie, schwarz konturierte Goldpunkte mit relativ langem Stiel, der an kleinem Haken bzw. Punkt ansetzt; im Rankenwerk der 
Einleitungsseite auch Goldfelder. Kräftiges, die Grundfarben Rot, Blau und Grün vielfältig nuancierendes Kolorit; neben Blattgold (auf hellrosafarbenem Bolus) auch Pinselgold verwendet.

Bl. 1r mittig auf dem Bas-de-page Wappen (in einem aus vier Bögen und vier Spitzen zusammengesetzten Vierpassrahmen; auf grünem, von schwarzen Blättchenranken überzogenem Grund): in Gold ein abgerissener schwarzer Greifenkopf, umgeben von drei achtstrahligen schwarzen Sternen; Wappen bislang unidentifiziert.

Deckfarbenschmuck wie im Falle von Brixen, Priesterseminarbibl., Cod. C.6 durch das Spätwerk des 1349 bis 1403 nachweisbaren Niccolò di Giacomo da Bologna beeinflusst (s. M. Roland, Fleuronnée als Bindeglied. Das Brevier des Ludwig von Teck und die Fleuronnée-Gruppe St. Dorothea II, in: M. Haltrich, M. Stieglecker [Hrsg.], Code(x). Festgabe zum 65. Geburtstag von Alois Haidinger [Codices Manuscripti. Suppl. 2]. Purkersdorf 2010, 104-131, hier 109-110, insbes. Abb. 29), was zeitlich gut mit dem Wasserzeichenbefund zusammengeht. Bei Niccolò di Giacomo ähnlicher Aufbau von Einleitungsseiten (Wappen, in Medaillon, auf dem Bas-de-page in symmetrisches Rankengefüge eingegliedert), ebenfalls großzügig verwendete freie Goldpunkte mit schwarzer Kontur und Stiel sowie Verzicht auf Tierdrolerien. Das Fleuronnée ebenfalls italienisch.

E: $\quad$ Schmuckloser gotischer Einband: weißes Schweinsleder über Holz. Tirol (?), 2. H. 15. Jh.

Leder zerkratzt und fleckig, Holz tw. freiliegend. Am VD und HD Spuren von je fünf rautenförmigen Beschlägen. Am VD oben mittig Spuren eines Titelschildes. Am HD oben mittig Spur eines runden Beschlags, urspr. wohl Kettenbuch. Reste von zwei Leder-Metall-Schließen, verziert mit achtblättriger Rosette (wie Neustift, Stiftsbibl., Cod. 440). Kanten gerade, Unterkanten stark abgerieben. Rücken: vier Doppelbünde. Im ersten Feld aufgeklebtes Papierschild M: S: sowie Repertorium Iuris, im zweiten Signaturschild (s. bei G), im untersten Spuren eines urspr. aufgeklebten Signaturschildes (?). Kapitale mit naturfarbenem Spagat umstochen, oberes Kapital beschädigt. Urspr. Spiegel des VD Pergamentblatt, heute gelöst (s. bei B), auf überlappendem Leder des Einbandes Signaturen und Bleistiftnotiz, auf Holz Exlibris aufgeklebt (s. bei G), Spiegel des HD leeres Pergamentblatt.

G: Bl. IIv Vermerk über die testamentarische Überlassung an das Kloster Neustift durch den Domherrn Johann Ebner (möglicherweise gebürtig aus Krems, seit 1442 als Brixner Domherr belegt, vgl. Santifaller, Brixner Domkapitel 298, Nr. 55) mit Hinweis auf seinen Tod am 3. August 1460 (laut Santifaller Todesdatum allerdings 3. August 1461): Iste liber legatus est monasterio sancte Marie virginis ad gracias alias Novacella communiter nuncupata prope Brixinam per venerabilem virum magistrum Iohannem Ebner canonicum Brixinensem ob salutem anime sue. Qui obiit anno domini $M^{\circ} C C C C^{\circ} L X^{\circ}$ die $3^{a}$ Augusti. Cuius anima requiescat in pace. Amen. Ähnlich lautende Vermerke B1. 234r (Iste liber pertinet monasterio sancte Marie in Novacella prope Brixinam datus a magistro Iohanne Ebner $A^{\circ}$ domini etc. $603^{a}$ die Augusti) und $\mathrm{Bl}$. 431va (Iste liber legatus est monasterio Novacellensi prope Brixinam per venerabilem virum quondam magistrum Iohannem Ebner canonicum Brixinensem pro remedio anime sue $A^{\circ} 1460$ die $3^{a}$ Augusti). Bl. 1r Besitzvermerk 17. Jh. Collegii Novacellensis. Auf der Innenseite des VD Exlibris der Stiftsbibl. Neustift 18. Jh. 1809 anlässlich der vorübergehenden Aufhebung des Klosters Neustift der ULB Tirol übergeben. Auf der Innenseite des VD alte Signaturen der ULB Tirol II $\overline{1}$ B 3 (Tinte) und Nr. 4 (Tinte) sowie Bleistiftnotiz (Vide Grundzettel). Am Rücken gelbes Signaturschild der ULB Tirol 4. Bl. 1r Stempel der ULB Tirol 19. Jh. 1921 aufgrund des Friedensvertrages von St. Germain an den italienischen Staat abgegeben und von diesem 1929 dem Kloster Neustift als Dauerleihgabe überlassen. Bl. 1r Stempel der Soprintendenza Tridentina 20. Jh.

L: $\quad$ Wilhelm I 136, II 108, 110. - Wretschko-Sprung 13. - Hermann 123, Nr. 144. - L. Santifaller, Das Brixner Domkapitel in seiner persönlichen Zusammensetzung im Mittelalter (Schlern-Schriften 7). Innsbruck 1924, 298, Nr. 55 (ohne Nennung der Sign.). - Neuhauser, Neustift 88. - Colophons Nr. 16308. - Katalog ULB Tirol I 59, 281. - Stefani 122-123. - Peintner, Stiftsbibliothek 122. - Krämer, Scriptores, s. v. „Claghewinter, Rudolphus“.

(Ir) leer.

(Iv) Federproben: Zwei Verse eines italienischen Strambotto, 15. Jh. (vgl. V. Cian, Ballate e strambotti del sec. XV. tratti da un codice Trevisano. Giornale storico della letteratura italiana 4 [1884] 1-55, hier 53).

zamay non spiero de veder vendeta/de quella falsa lengua maledeta.

(IIr) leer.

(IIv) Vermerk über die testamentarische Überlassung (s. bei G). Bleistiftnotiz (19. Jh.): Kummt nächstens zur vollständigen behandlung. 
(1ra-431vb) 〈IoHANNES CALDERINUs〉: Repertorium utriusque iuris (Druck: GW 5904), mit Praefatio von Arnoldus de Geilhoven: Remissorium utriusque iuris (CCCM 212, XII).

(1r) Tit. (18. Jh.): Anno (gestrichen: 1460) Repertorium iuris scriptum.

(1ra) Praefatio (tw. Druck: A. Rivier, Dr. Arnold Gheyloven, aus Rotterdam, Verfasser eines Remissorium juris utriusque und anderer juristischer Schriften. ZRG Germanistische Abt. 11 [1873] 454-455). Inc.: Memoriam esse thesaurum inventorum eleganter ait Cycero in Rethoricis ad Herenium libro tercio ... - Expl.: ... fundere penes omnium conditorem. Qui trinus et unus vivit et regnat in secula benedictus Amen.

(1va) Text. Inc.: A hec dictio. A Interdum includit ut $C$ de ... - Expl.: ... Zenotasium quid nota ff de rerum divisione $\S$ intactum et cetera. Laus tibi Christe. Explicit.

Die Verfasserfrage lässt sich für den Haupttext nicht eindeutig klären. Der Text wird in der Parallelüberlieferung tw. Iohannes Calderinus, tw. Arnoldus de Geilhoven zugeschrieben. Das Incipit (Bl. 1va) stimmt mit Schulte GQ II 249-250 (Iohannes Calderinus, Repertorium utriusque iuris) überein. Bei F. Schulte, Die canonistischen Handschriften der Bibliotheken in Prag. Mit drei Tafeln. Abh. der böhmischen Gesellschaft der Wissenschaften VI/2 (1868) 77, Nr. 190 wird dasselbe Inc. Arnoldus de Geilhoven zugeschrieben.

Lit.: Schulte GQ II 249-250 und 438-439.

(414ra-b) leer bis auf Notiz: reverte folium scribitur (?): per Io. An. de fide instru.

(431vb) Schreibervermerk: Scriptum per me Rodulphum (!) Claghewinter de Saxonia.

(431v) Bleistiftnotiz (19. Jh.): Vide abietiv zu behandeln.

$(432 \mathrm{r}-\mathrm{v})$ leer.

A. P./U.S.

\section{Cod. 7}

\section{GUILELMUS DURANTIS. IOHANNES ANDREAE}

Perg. I, 164, I* Bl. $410 \times 275$. Bologna, 1. H. 14. Jh.

B: $\quad$ Zwei Teile: I (I, 1-143[144]), II (144[145]-163[164], I*). Am oberen Blattrand Foliierung 19. Jh. durch die ULB Tirol; Fehler in der Zählung: 52 doppelt angeführt.

E: $\quad$ Neuzeitlicher Bibliothekseinband: schwarz gesprenkeltes braunes Pap. über Pappe. Neustift, 2. H. 18. Jh. Pap. tw. stark abgerieben, insbes. an den unteren Kanten. Ecken mit braunem Leder verstärkt. Rücken: braunes Leder, fünf einfache Bünde, von Goldbordüren gesäumt. Im ersten Feld Golddruck M: S:, im zweiten Golddruck IUS CANONIC. GLOSAT., im dritten Signaturschild (s. bei G). Spiegel Pap. 18. Jh. Am Spiegel des VD Exlibris, Signaturen und Bleistiftnotizen (s. bei G), Spiegel des HD leer.

G: $\quad$ Die Hs. dürfte wohl zu jenen vier Hs. kirchenrechtlichen Inhalts zählen, die 1353 als Geschenk des Herrn Berthold, Hospitaler zu Brixen, in den Besitz des Stiftes gelangten (vgl. Neustift, Stiftsarchiv, WW 59; Mairhofer 264-265; Peintner, Stiftsbibliothek 118; Peintner, Schreibkunst 377). Am Spiegel des VD Exlibris der Stiftsbibl. Neustift 18. Jh. 1809 anlässlich der vorübergehenden Aufhebung des Klosters Neustift der ULB Tirol übergeben. Am Spiegel des VD alte Signaturen der ULB Tirol II $\overline{1} J 11$ (?, radiert), II $\overline{2}$ A 7 (gestrichen), II 1 B 6 (Bleistift), Nr. 7 (Tinte) und Bleistiftnotizen (Vide Grundzettel) sowie (wird paläograf. behandelt und vollständig katalog.). Am Rücken gelbes Signaturschild der ULB Tirol 7. Bl. 1r Stempel der ULB Tirol 19. Jh. 1921 aufgrund des Friedensvertrages von St. Germain an den italienischen Staat abgegeben und von diesem 1929 dem Kloster Neustift als Dauerleihgabe überlassen. Bl. 1r Stempel der Soprintendenza Tridentina 20. Jh.

L: $\quad$ Wilhelm I 136. - Wretschko-Sprung 13. - Rasmo 20 (Nr. 13-14) und Abb. 11-13 (ohne Nennung der Sign.). - Furtenbach-Kalb 21. - Neuhauser, Neustift 88. - Peintner, Buchmalerei 33, 41 und 42. - Katalog ULB Tirol I 62, 281. - Peintner, Stiftsbibliothek 118. - M. Bollati, Kat.-Nr. 13: Dekretalien, in: A. De Marchi, 
T. Franco, S. Spada Pintarelli (Hrsg.), Trecento. Gotische Maler in Bozen. Ausstellungskatalog. Bozen 2000, 105-107. - Peintner, Schreibkunst 377.

$$
\text { I (I, 1-143[144]) }
$$

B: Haar- und Fleischseite deutlich unterscheidbar, tw. fleckig. Vereinzelt Nahtspuren. Bl. 141 zw. den zwei Spalten in der Blattmitte ein Stück Perg. herausgeschnitten (wohl ohne Buchschmuck). Am Blattrand leicht gewellt. Lagen: (I-1) (Vorsatzbl., Pap. 18. Jh.) + (V-III) ${ }^{4}+14 \cdot V^{143(144)}$. Gegenbl. zum Vorsatzbl. als Spiegel auf dem VD aufgeklebt. Die äußersten drei Doppelbl. der ersten Lage verloren (Textverlust). Meist Lagenreklamanten, gerahmt und mit einfachen Ausläufern versehen. Zw. Bl. 63 und 64 dürfte mindestens eine Lage fehlen (Textverlust). Am oberen Blattrand Einteilung der Bücher (1-4), im ersten Buch mit zusätzlicher Angabe der Partes; bei den ersten zwei Büchern urspr. Einteilung (primi, secundi) durchgestrichen und durch Zahlen ersetzt.

S: $\quad$ Schriftraum 325/345×185. Zwei Spalten, von Tintenlinien gerahmt, zu 87-93 Zeilen auf Tintenlinierung. Zirkelstiche. Textualis formata (Littera Bononiensis). Vereinzelt Korrekturen und Ergänzungen am Schriftrand tw. von gleicher, tw. von späterer Hand. Zahlreiche Orientierungshilfen in Vierpassform am Blattrand (s. bei A).

A: Rote Überschriften, tw. nicht ausgeführt, vereinzelt von späterer Hand in Schwarz am Schriftrand ergänzt; die Vierpassrahmen (s. bei S) mit Fibrillen und gestrichelten Rändern (z. B. Bl. 5vb, 89va), von dieser Hand auch winzige Vorschreibungen auf den Seitenrändern (z. B. Bl. 134va) und Zeilenfüllsel (Bl. 32rb am Kolumnenende verzierte „Kugeln“, durch Reihen von o- bzw. c-förmigen, vom Schreiber ausgeführten Gliedern zu einer Art Kette verbunden); abwechselnd rote und blaue Paragraphzeichen; in Tintenfarbe: Randmarkierungen (z.B. Bl. 112va Vertikallinien im Wechsel mit Gruppen kleiner Perlen), Lagenreklamanten mit Rahmen und Fibrillen (z. B. Bl. 14v) sowie flüchtige Zeigehände (z. B. Bl. 25ra). Repräsentanten.

$\mathrm{Zu}$ Beginn von Unterabschnitten zwei- bis fünf-, meist dreizeilige Lombarden, abwechselnd in Rot und Blau (zuweilen mit Tendenz zu Violett), umfasst und ergänzt von einem großen, gegenfarbigen Paragraphzeichen mit langem, an der Kolumne anliegendem Ausläufer; Lombarde und Paragraphzeichen jeweils in der Gegenfarbe mit Fleuronnée besetzt, das wiederum in der Gegenfarbe gepunktet, gekernt und/oder gestrichelt sein kann; nur selten an einem der Bestandteile das Fleuronnée weggelassen (z. B. Bl. 45v). Charakteristisch, im Binnenfeld und als Besatz, das Motiv der Fadenspirale; in ihrem Zentrum fallweise eine (aus vollfarbigem Grund ausgesparte) Dreierformation aus Knospenkopf und zwei Perlen; häufig auch aus dem Binnenfeldgrund ausgesparte, langstielige Knospen. Als Besatz Perlen: klein und mit Abstand aufgereiht oder größer und eng aneinandergesetzt (tw. gepunktet bzw. besetzt mit kleinen Perlen); häufig einfache, etwas unsicher geführte Fadenausläufer mit volutenartig eingerollten Enden. Bl. 29va, 29vb und 30rb der FleuronnéeBesatz der Paragraphzeichen (hier mit Zickzack-Aussparungen) wohl von anderer Hand, s. v. a. die Fadenausläuferbündel.

Bl. $5 v-10 v$ zumeist in Initialnähe von späterer Hand ergänzte Federzeichnungen (stark verblasst; abgerieben?), häufig Figuren (z. B. Bl. 10v im Interkolumnium stehender Mönch?), die mit der Initiale interagieren können (z. B. Bl. 5va links unten sitzender Mann, der Ausläuferblätter berührt).

Deckfarbenschmuck: zu Beginn der Kapitel in der Regel dreizeilige (auch zwei- bis fünfzeilige) figürliche Initialen, tw. mit Serifen- oder mittig am Initialfeld ansetzendem Dekorblatt; nur wenige kurze Ranken; bei I-Initialen ersetzen die Büsten (s. u.) den Buchstaben (z. B. Bl. 96vb1); im vierten Buch auch einige Ornamentalinitialen zu Kapitelbeginn (mit einfachem Dekor, z.B. Bl. 87va); zu Beginn des 2. und 4. Buches je eine spaltenbreite Miniatur (24-29 bzw. 22-25 Zeilen hoch), jeweils unmittelbar gefolgt von einer größeren Einleitungsinitiale (acht bzw. 13 Zeilen hoch, jeweils mit kürzerer Blattranke und zwei Goldpunkten); eine größere Initiale auch zu Beginn von De sponsalibus et matrimoniis (Bl. 141vb2, siebenzeilig, ein Ausläuferblatt). - Die Initialen mit blattvergoldeten, schwarz umrandeten, meist quadratischen Außengründen, Buchstabenkörper häufig rosa(rot), seltener grau(grün), mit feinem weißen Liniendekor, ebenso die blauen Binnenfelder; die seltenen kurzen Ranken (nur zu Beginn des Werks) mit tintenfarbenen Fadenausläufern sowie konturierten (und gestielten) Goldpunkten. In den kleinen Binnenfeldern zumeist männliche Büsten oder Köpfe (Inkarnat-Abschattierung mit Grau), fallweise (aber nicht unbedingt mit Textbezug) als Kleriker gekennzeichnet, beispielsweise tonsurierter Mönch (z. B. Bl. 75ra3) oder Bischof mit Mitra (z. B. Bl. 141vb2); bei I-Initialen neigen sich die Figuren zuweilen aus den Initialfeldern heraus (z. B. Bl. 79va: Figur präsentiert Schriftstück, Beischrift libellus) oder entsteigen ihnen (z.B. Bl. 76rb4). Textbezug z. B. Bl. 131va (De donationibus): Büste eines Mannes, der (Geld-)Beutel emporhält (durchscheinende Konturlinie belegt, dass Haltearm nicht zur urspr. Konzeption gehörte).

Bl. 32va Miniatur: Gerichtsszene zw. zwei turmartigen Gebäuden (mit Bauzier und Einblicken in Kuppelräume) mit zentral auf einem einfachen Steinsitz thronendem König als Richter, flankiert von je drei 
Männern (u. a. Kleriker mit grauer Kutte und Gelehrter mit purpurroter Kappe), die Schriftstücke präsentieren; König wendet sich (mit Redegestus?) dem grauhaarigen Mann zu seiner Rechten zu; zu seinen Füßen purpurrotes Fußpolster, hinter ihm goldene Wand (Blattgold tw. abgeplatzt, hellrosafarbener Bolus und Vorzeichnung sichtbar), über die hellblaues, reich gefälteltes Tuch herabhängt. - Die anschließende Initiale zeigt bärtigen Mann mit erhobener Rechter.

Bl. 66ra Marienkrönung: Hinter dem breiten, reich verzierten Steinthron, auf dem Christus seine Mutter krönt, fünf Engel (mit spitzen Flügeln), die goldenes Ehrentuch entfalten; Thron flankiert von zwei stehenden Engeln mit goldenen Stäben; Christus hält weißen Herrscherstab in der Linken; goldfarbenes Fußpolster; Initialfeldandeutung durch purpurnen, blau umrandeten Hintergrund in Spaltenbreite. - In zugehöriger Initiale Schöpfung Adams, der nackt, den Kopf auf seine Linke gestützt, auf schräg ansteigender Felsformation liegt; anatomische Unsicherheiten (Ansatz des linken Arms). Gott, der außerhalb des hochrechteckigen Initialfelds steht, neigt sich Adam zu.

Bl. 141vb2 Büste eines graubärtigen Bischofs mit rotem Mantel über weißem Gewand und goldverzierter Mitra.

M. Bollati hat den Deckfarbendekor des Cod. 7 dem „Maestro del B 18“ (alias „Secondo Maestro di San Domenico“) zugeschrieben, was für T. I zutrifft. Der „Maestro del B 18“ lässt sich in den ersten Jahrzehnten des 14. Jh. v. a. in Bologna nachweisen; zu diesem Illuminator s. auch S. L'Engle, Master of B18, the Roermond Volumen Parvum and the Early Fourtheenth Century Illumination in Bologna. Codices Manuscripti 52/53 (2005) 1-20. - Das Fleuronnée in T. I ist oberitalienisch.

S. R.

$(\mathrm{Ir}-\mathrm{v})$ leer.

1 (1ra-143vb) 〈Guilelmus Durantis〉: Speculum iudiciale, unvollständig (Druck: GW 9148-9161. Basel 1574 u. ö.).

(1ra-32rb) Lib. 1. Inc. mut.: Item quod est frater ...] paternam pietatem non agnoscat ... Quid si aliquis interfecit patrem vel tutorem meum ... (= Particula 2, cap. De accusatore) - Expl.: ... Qualiter autem libelli super salariis concipiantur dicetur I. in T. de magistris.

(1ra-2rb) Particula 2, beginnend in cap. De accusatore.

(2rb-10va) Particula 3. Mit Fehlstelle zw. Bl. 4vb und 5ra (innerhalb cap. De procuratore). (4vb) Expl. mut.: ... hoc fallit in contractu matrimonii Extra De conver. i[ - (5ra) Inc. mut.: ] quod non quia tantum consequitur per directam ...

(10va-32rb) Particula 4.

(32va-63vb) Lib. 2. Inc.: Sancti spiritus gracia suffragante de personis ... - Expl. mut.: ... et actio quando inepte proponitur ut f. de [ (= cap. Forma proponendi exceptionem peremptoriam) (64ra-65vb) Lib. 3. Inc. mut. (cap. De notoriis criminibus): ] et probatur extra de regula veniens prope prin. Sequitur de manifesto videre ... - Expl.. ... in popularibus de hoc Extra De purg. can. c. tuarum. (= Ende Pars 3)

(66ra-143vb) Lib. 4. Inc.: Formavit Deus hominem ad ymaginem et similitudinem suam ... Expl. mut.: ... prefate ecclesie et quam tanquam suam [ (Reklamante: ancillam) (= cap. De natis ex libero ventre)

Lit.: Schulte GQ II 148-152; K. W. Nörr, Die Literatur zum gemeinen Zivilprozeß, in: H. Coing (Hrsg.), Handbuch der Quellen und Literatur der neueren europäischen Privatrechtsgeschichte I. München 1973, 394.

$$
\text { II (144[145]-163[164], I*) }
$$

B: Haar- und Fleischseite deutlich unterscheidbar, tw. fleckig, am Blattrand leicht gewellt. Lagen: 2.V ${ }^{163(164)}+$ (I-1) ${ }^{I^{*}}$ (Nachsatzbl., Pap. 18. Jh.). Gegenbl. zum Nachsatzbl. als Spiegel auf dem HD aufgeklebt. Die Blätter der ersten Lagenhälfte der ersten Lage mit roten Strichen am seitlichen Blattrand gezählt.

S: $\quad$ Schriftraum $340 \times 195$. Zwei Spalten, von Tintenlinien gerahmt, zu 85 Zeilen auf Tintenlinierung. Zirkelstiche. Textualis formata (Littera Bononiensis). Korrekturen und Ergänzungen am Schriftrand tw. von gleicher, tw. von anderer Hand. 
A: Abwechselnd rote und blaue Paragraphzeichen, tw. mit Zackenverzierung (z.B. Bl. 152r). Tintenfarbene Randmarkierungen (z.B. Bl. 163rb), feine Unterstreichungen und flüchtige Zeigehände (z. B. Bl. 149ra). Repräsentanten, Überschriften nicht ausgeführt.

Zu Beginn von Unterabschnitten dreizeilige Lombarden, abwechselnd in Rot und Dunkelblau mit Fleuronnée in der Gegenfarbe. Charakteristische saitenartige Vertikallinien, besetzt mit kleinen, tw. gestielten und gepunkteten Halbkreisen; Parallellinien als Konturierung, auch Fadenausläufer parallel geführt und gestaffelt in einfachen Voluten endend.

Deckfarbenschmuck: zu Kapitelbeginn vierzeilige figürliche bzw. ornamentale Initialen (die schwarzen Konturlinien der goldenen Initialfelder spitz ausgezogen) mit wenigen Ausläuferblättern. Viele Parallelen zum Deckfarbendekor in T. I, aber nicht von derselben Hand stammend; die Büsten differenzierter mit welligem Haar, geraden Nasen und - speziell in der Profilansicht - stark betonten Augen (z. B. B1. 155va), die Ornamentalinitialen (Blattformationen, z. B. Bl. 145rb, 148va) etwas aufwändiger ausgeführt.

Der Deckfarbendekor in T. II ist sehr wahrscheinlich dem „Maestro della Crocifissione D“ zuzuschreiben, der beispielsweise auch in dem um 1340 entstandenen Decretum Gratiani München, BSB, Clm 23552 mit dem „Maestro del B 18“ sowie dem „Illustratore“ zusammenarbeitete; hierzu: G. del Monaco, I manoscritti miniati dell'Illustratore nella cultura figurativa del secondo quarto del XIV secolo, Diss. Bologna 2012, 62, 216-221 (Nr. 19), http://amsdottorato.unibo.it/5083/1/Tesi_del_Monaco.pdf; zu Clm 23352 s. auch U. Bauer-Eberhardt, Die illuminierten Handschriften italienischer Herkunft in der Bayerischen Staatsbibliothek 1: Vom 10. bis zur Mitte des 14. Jahrhunderts (Katalog der illuminierten Handschriften der Bayerischen Staatsbibliothek in München VI, 1: Text- und Tafelband). Wiesbaden 2011, 234-238 (Nr. 213). - Das Fleuronnée in T. II ist oberitalienisch.

2 (144ra-163vb) 〈IOHANNES ANDREAE〉: Novella super librum sextum Decretalium, unvollständig (hier abgeglichen mit Druck: Venedig 1612).

Inc. mut. (cap. De haereticis): ] simul citant cui obedire teneatur pro ordinario facit quia eius iurisdiccio firmior et antiquior cui specialis non derogat ... - Expl. mut.: ... quia tamen beneficia inter[pretamur (cap. De sententia excommunicationis)

Lit.: Schulte GQ II 218-219; K. W. Nörr, Die Literatur zum gemeinen Zivilprozeß, in: H. Coing (Hrsg.), Handbuch der Quellen und Literatur der neueren europäischen Privatrechtsgeschichte I. München 1973, 378.

$\left(I^{*} \mathrm{r}-\mathrm{v}\right)$ leer.

P. A./U. S.

\section{Cod. 19}

\section{PETRUS LOMBARDUS}

Perg. I, 108, I* Bl. $385 \times 270$. Nordfrankreich (Raum Paris), 13. Jh.

B: Dickes, an den Rändern abgegriffenes Perg., an den Rändern tw. beschnitten, vereinzelt bis zum Textrand mit geringem Textverlust, vereinzelt Nahtspuren. Bl. 38 keilförmig dreieckiges Pergamentstück herausgeschnitten. Lagen: (I-1) (Vorsatzbl., Pap. 18. Jh.) + II $+4 . I^{4}{ }^{36}+(I V-1)^{43}+(V I-1)^{54}+$ IV $^{62}+\mathrm{III}^{68}+5 . \mathrm{IV}^{108}$ $+(\mathrm{I}-1)^{\mathrm{I}^{* *}}$ (Nachsatzbl., Pap. 18. Jh.). Gegenbl. zum Vor- bzw. Nachsatzbl. als Spiegel auf dem VD bzw. HD aufgeklebt. Erste Lage unvollständig (Textverlust), urspr. wohl Quaternio. Es fehlen das Doppelbl. zw. Bl. 1 und 2 bzw. Bl. 3 und 4 sowie das Doppelbl. in der Lagenmitte zw. Bl. 2 und 3 (s. bei Inhalt). Gegenbl. zu Bl. 42 und 53 herausgeschnitten (ohne Textverlust). Sexternio Bl. 44-54 (vgl. bei S) nachträgliche Einfügung nach Verlust von ein oder zwei Quaternionen. Nach Bl. 108 fehlt mindestens eine Lage (Textverlust). Lagenreklamanten. Am oberen Blattrand tw. Schriftreste (weggeschnitten, Zählung der Psalmen in römischen Zahlen). Am oberen Blattrand Foliierung 19. Jh. durch die ULB Tirol.

S: $\quad$ Schriftraum $255 \times 155$. Zwei Spalten, seitlich von zweifachen Tintenlinien gerahmt, zu meist 67-70 Zeilen auf Tintenlinierung. Zirkelstiche am äußeren und inneren Blattrand. Textualis (Perlschrift), Bibeltext und Kommentar in unterschiedlicher Größe. Bl. 38ra-54vb Kommentar von anderer Hand in kleinerer Schrift 13. Jh. (Einfügung mit dünnerer Feder nach herausgeschnittenem Blatt zw. Bl. 37 und 38 bis Ende des Sex- 
ternio Bl. 54). Am seitlichen und unteren Blattrand zahlreiche Interlinear- und Randglossen von verschiedenen Händen 13. Jh. sowie neuzeitliche Randglossen (Bleistift, stark verblasst, z. B. Bl. 39r).

A: Rote Unterstreichungen, am Beginn der Kommentarabschnitte rote und blaue Satzmajuskeln in Lombardenform, am Beginn der Psalmen und der Psalmenverse einzeilige, abwechselnd rote und blaue Lombarden mit Palmettenfleuronnée in der Gegenfarbe. Bl. 17vb (2), 37ra, 52rb, 55ra (2), 69va, 69vb vierzeilige (B1. 55ra 1 sechszeilige) Initialen in Deckfarbenmalerei der nordfranzösischen Schule: rosafarbener oder blauer Buchstabenkörper, gefüllt mit verschiedenfarbigen geometrischen Ornamenten oder Fabelwesen auf blauem oder blattvergoldetem Grund mit Ausläufern in Blattgold, Rosa und Blau. Blattgold, tw. abgeplatzt (z. B. Bl. 17vb) auf hellem Bolus.

S. R.

E: $\quad$ Neuzeitlicher Bibliothekseinband: schwarz gesprenkeltes braunes Pap. über Pappe. Neustift, 2. H. 18. Jh. Pap. fleckig und zerkratzt. Am VD und HD Ecken mit braunem Leder verstärkt. Rücken: braunes Leder, fünf einfache Bünde, von Goldbordüren gesäumt. Im ersten Feld Golddruck M: S:, im zweiten Golddruck COME. IN PSALT. DAVID in Goldrahmung, im dritten Signaturschild (s. bei G). Spiegel Pap. 18. Jh. Am Spiegel des VD Exlibris, Signaturen und Bleistiftnotiz (s. bei G), Spiegel des HD leer.

G: Zeitpunkt und Art der Erwerbung durch Neustift unbekannt. Am Spiegel des VD Exlibris der Stiftsbibl. Neustift 18. Jh. 1809 anlässlich der vorübergehenden Aufhebung des Klosters Neustift der ULB Tirol übergeben. Am Spiegel des VD alte Signaturen der ULB Tirol II $\overline{1}$ C 6 (Bleistift) und Nr. 19 (Tinte) sowie Bleistiftnotiz (Vide Grundzettel). Am Rücken gelbes Signaturschild der ULB Tirol 19. Bl. 1r Stempel der ULB Tirol 19. Jh. 1921 aufgrund des Friedensvertrages von St. Germain an den italienischen Staat abgegeben und von diesem 1929 dem Kloster Neustift als Dauerleihgabe überlassen. Bl. 1r Stempel der Soprintendenza Tridentina 20. Jh.

L: $\quad$ Stegmüller RB Nr. 10030. - Steer 36. - Katalog ULB Tirol I 99, 281.

(Ir-v) leer.

(1ra-108vb) Petrus Lombardus: Commentarii in Psalmos, unvollständig: Ps 48-145 (PL 191, 465B-1271A).

(1ra) Inc. mut.: ] cur timebo. Tercio dicitur que impiis et iustis reddenda sunt ibi ... (= Schluss des Kommentars zum Tit. von Ps 48. PL 191, 465B).

(1ra) Beginn von Ps 48. Text. Inc.: Audite hec omnes gentes auribus percipite omnes qui habitatis orbem ...

Kommentar. Inc.: Audite hec que dicturus sum. Hic attentos facit omnes Gregorius id est omnes iniqui, hec iam hodie ... (PL 191, 465B).

Zw. Bl. 1vb und 2ra Verlust eines Blattes, Schluss von Ps 48 und Beginn von Ps 49 fehlen.

(2ra-vb) Ps 49,17-50,7.

Zw. Bl. 2vb und 3ra Verlust eines Doppelbl. (Lagenmitte), Schluss von Ps 50, Ps 51 und Beginn von Ps 52 fehlen.

(3ra-vb) Ps 52,6-54,8.

Zw. Bl. 3vb und 4ra Verlust eines Blattes, Ps 54,9-21 fehlt.

(4ra-108vb) Ps 54,21-145,4.

Bei den herausgeschnittenen Gegenbl. zu Bl. 42 (zw. Bl. 37 und 38) und 53 (zw. Bl. 44 und 45) kein Textverlust. Sexternio Bl. 44-54 von anderer Hand (Text und Kommentar) als Ersatz für zwei Sexternionen, ohne Textlücke. Im Ternio Bl. 63-68 keine Textlücke.

(108vb) Expl. mut.: ... quam in diversos seculi ambitus tendebant (= Kommentar). Beatus cuius Deus Iacob adiutor [ (Ps 145,4. PL 191, 1271A).

$\left(\mathrm{I}^{*} \mathrm{r}-\mathrm{v}\right)$ leer. 


\section{Cod. 20}

\section{VETUS TESTAMENTUM}

Perg. I, 168, I* Bl. $380 \times 280$. Entstehungsort unbestimmt, 12./13. Jh.

B: $\quad$ Dickes Perg., tw. fleckig und löchrig, vereinzelt Nahtspuren, Bl. 121 und 125 seitlich stark beschnitten (380 $\times$ ca. 235 bzw. 230). Lagen: (I-1) ${ }^{\mathrm{I}}$ (Vorsatzbl., Pap. 18. Jh.) $+\mathrm{III}^{6}+\mathrm{IV}^{14}+(\mathrm{IV}+1)^{23}+(\mathrm{IV}+1)^{32}+17 . \mathrm{IV}^{168}+$ $(\mathrm{I}-1)^{\mathrm{I} *}$ (Nachsatzbl., Pap. 18. Jh.). Gegenbl. zum Vor- bzw. Nachsatzbl. als Spiegel auf dem VD bzw. HD aufgeklebt. Bl. 23 und 24 eingehängte Einzelbl. Bl. 48v (Ende der Lage 6) und 112v (Ende der Lage 14) Reklamanten, letztere stark beschnitten. Am oberen Blattrand zeitgenössische Foliierung in arabischen Ziffern 105-273 (Tinte), tw. beschnitten; Fehler in der Zählung: 111 ausgelassen. Am unteren Blattrand Foliierung 20. Jh. (Bleistift, hier berücksichtigt). Am oberen Blattrand Einteilung der Bücher von unterschiedlichen Händen.

S: $\quad$ 1) Bl. 1r-24v: Schriftraum $295 \times 195$. Zwei Spalten, seitlich von zweifachen Bleistiftlinien gerahmt, zu 43 bzw. 44 Zeilen auf Bleistiftlinierung. Zirkelstiche. Karolingisch-gotische Mischschrift 12. Jh. Am Blattrand Kapitelzählung und Nota-Hinweise von späterer Hand.

2) Bl. 25r-96v: Schriftraum 290/300 × 175/190. Zwei Spalten, von zweifachen bis an den Blattrand reichenden Tintenlinien gerahmt, zu 45-47 Zeilen auf Tintenlinierung. Zirkelstiche. Textualis 13. Jh.

3) Bl. 97r-168v: Schriftraum $300 \times 190$. Zwei Spalten, von Tinten- bzw. Bleistiftlinien gerahmt, zu 43 Zeilen auf Tinten- bzw. Bleistiftlinierung. Textualis 13. Jh. von zwei Händen: 1) Bl. 97ra-120rb; 2) Bl. 120va168vb. Vereinzelt Randbemerkungen von späteren Händen. Bl. 14r, 79r und 101r Randglossen 14. Jh.

A: $\quad$ Bl. 1ra-22vb schwarze (Bl. 2rb grüne, 3ra rote) einzeilige Lombarden, Bl. 7v-9r Textgliederung durch rote Buchstaben am Rand sowie Bl. 1v und 2r Angabe des Buches am oberen Blattrand in Rot und Grün. Bl. 3v flüchtige Federzeichnung eines Königs (Salomon) mit Zepter sowie rot ergänzter Krone und Zeigehand. Weitere Zeigehände B1. 3v und 4r. Bl. 1va und 13ra elf- bzw. 17zeilige kopfstempelartig gespaltene Initialen in Rot, Blau und Grün mit routiniertem rot-blauem Palmettenfleuronnée, das in der Binnenfeldorganisation wenig Symmetrietendenzen zeigt; Bl. 12vb fünfzeilige rot gezeichnete und blau akzentuierte Rankeninitiale (mit Spangen) auf grünem Grund; Buchstabenkörper gespalten und blau gefüllt; die Rankenvoluten im Binnenfeld umschließen oben eine spitze, unten eine kelchförmig-gerundete Blüte; leicht bewegte, wenig schraffierte Rankenblätter. - Die Rankeninitiale und die beiden Fleuronnée-Initialen wohl von einer Hand 13. Jh.

Bl. 25ra-119rb rote Auszeichnungsstriche und Überschriften, selten Durchstreichungen. Vereinzelt Zeigehände (B1. 102v, 103v). Ein- bis dreizeilige (wein-)rote Lombarden und einige größere rote Initialen (bis zu 16zeilig, Bl. 25ra) mit Punktverdickungen und tw. kritzeligen geometrischen Aussparungen und Füllranken, jeweils mit Palmettenfleuronnée (auch als Besatz) in (hellerem) Blau, recht flüchtig und etwas disparat, aber wohl von einer Hand (13. Jh.); selten rotes Fleuronnée (z. B. Bl. 26r) von anderer Hand (auch 13. Jh.). In den Binnenfeldern der Lombarden u. a. Spiralen, bei den größeren Initialen einfache Ranken (Bl. 25ra), lanzettförmige Blätter (Bl. 38ra) und Palmetten; charakteristisch die fischgrätenartig angeordneten, stärkeren (Besatz-)Fäden mit kugeligen Köpfchen (Bl. 44ra, 66vb). Bl. 87va, 91ra, 93rb und 100rb sechs- bis achtzeilige rote Initialen mit Spangen am Buchstabenkörper und/oder Rosetten im Binnenfeld, die von Palmettenkränzen umgeben sein können; Bl. 93rb blauer Außengrund, Bl. 100rb größere, feiner ausgeführte Palmetten als Besatz. Bl. 50rb von einer anderen, ungeübteren Hand zehnzeilige Initiale E, u. a. mit ungelenkem, schwarz-rotem (Wappen-)Adler im oberen, gelblich gefärbten Binnenfeld; unklar, ob auch die zwölfzeilige hellrot(-blaue) Initiale Bl. 78rb, die in der Art einer Rankeninitiale angelegt ist, von dieser Hand stammt; Bl. 50rb und 78rb ebenfalls 13. Jh.

Fleuronnée bis einschließlich Bl. 119rb, dann nur mehr rote Überschriften und einige rote Lombarden bis Bl. 146ra. Repräsentanten.

Michaela Schuller-Juckes, Wien, sei für ihre Hinweise herzlich gedankt.

E: Neuzeitlicher Bibliothekseinband: schwarz gesprenkeltes braunes Pap. über Pappe. Neustift, 2. H. 18. Jh. Pap. tw. stark abgerieben, insbes. an den unteren Kanten. Ecken mit braunem Leder verstärkt. Rücken: braunes Leder, fünf einfache Bünde, mit Goldbordüren gerahmt. Im ersten Feld Golddruck M: S:, im zweiten Golddruck S: S: Biblia Incipiens a III. Libro Regum in Goldrahmung, im dritten Signaturschild (s. bei G). Spiegel Pap. 18. Jh. Am Spiegel des VD Signaturen und Bleistiftnotiz (s. bei G), Spiegel des HD leer.

G: Zeitpunkt und Art der Erwerbung durch Neustift unbekannt. 1809 anlässlich der vorübergehenden Aufhebung des Klosters Neustift der ULB Tirol übergeben. Am Spiegel des VD alte Signatur der ULB Tirol II $\overline{1}$ 
C 16 (Bleistift) sowie Nr. 20 (Tinte) und Bleistiftnotiz (Vide Grundzettel). Am Rücken gelbes Signaturschild der ULB Tirol 20. Bl. Iv Abklatsch des Stempels der ULB Tirol 19. Jh. 1921 aufgrund des Friedensvertrages von St. Germain an den italienischen Staat abgegeben und von diesem 1929 dem Kloster Neustift als Dauerleihgabe überlassen. Bl. 1r Stempel der Soprintendenza Tridentina 20. Jh.

L: $\quad$ Steer 36. - Katalog ULB Tirol I 99, 281 - Baroffio 324, Nr. 16708.

(Ir-v) leer.

(1ra-168vb) Vetus Testamentum, unvollständig.

Am Ende der einzelnen Bücher meist Angabe einer Versanzahl.

(1ra) 2. Regum. Inc. mut.: ] de manu Egyptii et interfecit eum hasta sua. Hec fecit Banaias filius ... (2 Rg 23,21). - (1va) 3. Regum. - (13ra) 4. Regum. - (24vb) leer.

(25ra) IUdices. - (36rb) Ruth.

(38ra) Hieronymus: Prologus in librum Iudith (BS VIII 213-214. Préfaces 35, Nr. 2. - Stegmüller RB Nr. 335). - (38ra) Iudith.

(43vb) Hieronymus: Prologus in librum Esther (BS IX 3-4. Préfaces 36, Nr. 3 und 4. - Stegmüller RB Nr. 341 und 343). - (44ra) EstHER.

(49va) 1. MACCABAEORUM. - (66rb) 2. Maccabaeorum.

(77rb) Hieronymus: Prologus in libros Salomonis (BS IX 3-5. Préfaces 118, Nr. 1. - Stegmüller RB Nr. 457).

(77va) 〈Hieronymus〉: Prologus in libros Salomonis (BS IX 7-9. Préfaces 119-120, Nr. 3: Commentarius in Eccl. - Stegmüller RB Nr. 456).

(77vb) Hieronymus: Prologus in libros Salomonis (BS XI 6. Préfaces 118-119, Nr. 2. - Stegmüller RB Nr. 455).

(78ra) Proverbia. - (87va) Ecclesiastes. - (91ra) Canticum canticorum. - (92vb) SAPientia.

(99va-b) Hieronymus: Prologus in librum Ecclesiastici (BS XII 145-147. - Stegmüller RB Nr. 26). (99vb) Sirach (Ecclesiasticus) mit cap. 52.

(119va) Hieronymus: Prologus in librum Esdrae (BS VIII 3-7. Préfaces 33-34, Nr. 1. - Stegmüller RB Nr. 330). - (120ra) 1. Esdras. - (123vb) 2. Esdras (Nehemias). In der Hs. als Nehemias, unterteilt in zwei Bücher: (123vb) 1. Nehemias = 2. Esdras 1-7,69. (126va) 2. Nehemias = 2. Esdras 7,70-13,31. (129va) Hieronymus: Prologus in librum Iob (BS IX 69-74. Préfaces 38, Nr. 1. - Stegmüller RB Nr. 344). - (130ra) Ioв.

(140va) Hieronymus: Prologus in librum Tobiae (BS VIII 155-156. Préfaces 35, Nr. 1. - Stegmüller RB Nr. 332). - (140vb) ToBias.

(145ra) Hieronymus: Prologus in libros Paralipomenon (BS II 546-547. Préfaces 30-31, Nr. 1. - Stegmüller RB Nr. 328).

(145va) Hieronymus: Prologus in libros Paralipomenon (Préfaces 31-32, Nr. 2. - Stegmüller RB Nr. 327).

(146ra) 1. Paralipomenon. - (158rb) 2. Paralipomenon. (168vb) Expl. mut.: ... Steteruntque viri quos [ (2 Par 28,15)

$\left(\mathrm{I}^{*} \mathrm{r}-\mathrm{v}\right)$ leer. 


\section{Cod. 31}

\section{ALDOBRANDINUS DE TOSCANELLA. EXPOSITIO SUPER AVE MARIA. GODEFRIDUS HERILACENSIS}

Perg. I, 130, I* Bl. $320 \times 240$. Süddeutscher Raum (?), 14. Jh.

B: $\quad$ Perg. tw. eingerissen, löchrig, vereinzelt Nahtspuren, Haar- und Fleischseite deutlich unterscheidbar. Lagen: $(\mathrm{I}-1)^{\mathrm{I}}$ (Vorsatzbl. Pap. 18. Jh. $)+10 \cdot \mathrm{IV}^{80}+(\mathrm{IV}+2)^{91(90)}+5 \cdot \mathrm{IV}^{131(130)}+(\mathrm{I}-1)^{\mathrm{I}^{*}}$ (Nachsatzbl. Pap. 18. Jh.). Gegenbl. zum Vor- bzw. Nachsatzbl. als Spiegel auf dem VD bzw. HD aufgeklebt. Am oberen Blattrand Foliierung 19. Jh. durch die ULB Tirol; Fehler in der Zählung: 85 ausgelassen. Bl. 90 und 91 eingehängte Einzelbl., urspr. Teil einer eigenen Lage, zw. Bl. 90 und 91 fehlt mindestens ein Blatt (Textverlust). Nach Bl. 131 fehlt mindestens eine Lage (Textverlust). Lagenreklamanten, tw. gerahmt oder unterstrichen.

S: $\quad$ Schriftraum $250 \times 185$. Zwei Spalten, von Tintenlinien gerahmt, zu einheitlich 33 Zeilen auf Tintenlinierung. Zirkelstiche. Textualis. Korrekturen und Nachträge von späterer Hand.

A: $\quad$ Rote Auszeichnungsstriche und Paragraphzeichen. Abwechselnd rote und blaue ein- bis vier-, meist zweizeilige Lombarden mit einfachem Fleuronnée in der Gegenfarbe. Bl. 1ra und 49ra jeweils fünfzeilige blaue Initiale mit kopfstempelförmigen Aussparungen und etwas ungelenkem rotem Knospenfleuronnée im Binnenfeld, Bl. 1ra als Besatz Perlenpyramiden, Bl. 92ra fünfzeilige rot-blaue Initiale mit kopfstempelförmigen Aussparungen und einfachem rotem Fleuronnée im Binnenfeld; Ähnlichkeit mit der zweiten Floratorenhand in Cod. 38 (dat. allerdings ins 15. Jh.).

S. R.

E: $\quad$ Neuzeitlicher Bibliothekseinband: schwarz gesprenkeltes braunes Pap. über Pappe. Neustift, 2. H. 18. Jh. Pap. leicht abgerieben. Ecken mit braunem Leder verstärkt. Rücken: braunes Leder, vier einfache Bünde, von Goldbordüren gesäumt. Im ersten Feld Golddruck M: S: und Signaturschild (s. bei G), im zweiten Golddruck EXPOSIT. IN CREDO AVE MAR. ET PATER NOSTER in Goldrahmung. Schnitt rot gesprenkelt. Spiegel Pap. 18. Jh. Am Spiegel des VD Exlibris und Signaturen (s. bei G), Spiegel des HD leer.

G: $\quad$ Bl. 1r (stark beschnitten) sowie Bl. 48vb Besitzvermerk 15. Jh.: Iste liber est monasterii sancte Marie in Novacella T 13. Am Spiegel des VD Exlibris der Stiftsbibl. Neustift 18. Jh. 1809 anlässlich der vorübergehenden Aufhebung des Klosters Neustift der ULB Tirol übergeben. Am Spiegel des VD alte Signaturen der ULB Tirol II 1 D 9 (Tinte, Bleistift) sowie Nr. 31 (Tinte). Am Rücken gelbes Signaturschild der ULB Tirol 31. Bl. 1r Stempel der ULB Tirol 19. Jh. 1921 aufgrund des Friedensvertrages von St. Germain an den italienischen Staat abgegeben und von diesem 1929 dem Kloster Neustift als Dauerleihgabe überlassen. Bl. 1r Stempel der Soprintendenza Tridentina 20. Jh.

L: $\quad$ E. Bauer (Hrsg.), Paternoster-Auslegung, zugeschrieben Jakob von Jüterbog, verdeutscht von Heinrich Haller (Lunder germanistische Forschungen 39). Lund, Kopenhagen 1966, 17, 66-67, 83 u. ö. - B.-G. Guyot, A propos de quelques commentaires sur le Pater noster. Revue des Sources philosophiques et théologiques 53 (1969) 245-255, hier 248-250. - Kaeppeli Nr. 133. - Stegmüller RB Nr. 1105 und 3886. - Bloomfield Nr. 8085. - Katalog ULB Tirol I 118, 282. - E. Bauer (Hrsg.), Godefridus Herilacensis „Expositio super orationem dominicam“ in der Übersetzung Heinrich Hallers (Analecta Cartusiana 263). Salzburg 2008, 7*_8*. - Kustatscher-Korenjak 158.

$(\mathrm{Ir}-\mathrm{v})$ leer.

1 (1ra-48rb) 〈Aldobrandinus de Toscanella〉: Scala fidei (Schneyer 1, 250, Nr. 350. Kaeppeli Nr. 133. Stegmüller RB Nr. 1105. Distelbrink Nr. 197).

(48va-b) leer bis auf Besitzvermerk (s. bei G).

2 (49ra-91vb) Expositio suPER Ave Maria, unvollständig.

(49ra) Inc.: Ave [Maria] gratia plena dominus tecum (Lc 1,28) benedicta tu in mulieribus (Lc 1,42). Dixit angelus ad virginem de celo missus. Et benedictus fructus ventris tui. Adicit Elyzabeth spiritu prophetico inspirata ... - Expl.: ... tercio de salutacionis compendio. Primo igitur dicendum est de angeli officio o (?).

(49vb) Inc.: Missus est Gabriel angelus a Deo. Luc. 1 (26). In hoc verbo Gabriel angelus sacramenti regalis conscius ac Dei fore virginis paranymphus describitur ... - Expl.: ... decuit ipsum 
secreciori consilio pertractari. Et sic patent octo ministeria que Gabriel exhibuit circa virginis uterum fecundandum.

(54ra) Inc.: Secundo idem angelus octo officia exercuit cir[ca] filium virginis declarandum. Primum erat officium docendi unum Ioseph dubitantem ... - Expl.: ... volavit unus ad me de Seraphyn etc. Postquam dictum est de angeli officio dicendum est de virginis vocabulo.

(55va) Inc.: Nomen virginis Maria. Luc. 1 (27). Nulla res potest amari nec laudari nisi prius cognoscetur dicente Augustinus (!) de trinitate ... - Expl.: ... visione preclara fruicione beata intencione eterna.

(58rb) Inc.: Nomen virginis Maria. Luc. 1 (27). De dulcissimo nomine ipsius Marie adhuc amplius videamus. Est notandum quod nomen huius dulcissime virginis est a Deo revelatum ...Expl.: ... huius nomen gloriosum wlgatum est in omni terra et in omni regione celestium et infernorum.

(60va) Inc.: Nomen virginis Maria. Luc. 1 (27). De nomine huius ineffabilis virginis adhuc est plus dicendum. Et est notandum quod hec virgo postquam Christum concepit reperitur in scriptura ... - Expl.. ... que cum sit omnibus superior servicio se subiecit omni.

(65va) Inc.: Nomen virginis Maria (Lc 1,27). Prius dictum est de nomine. Nunc dicendum est de hoc vocabulo Maria. Et est notandum quod IIII or genera volatilium solent nidos suos ornare ... Expl.: ... Postquam dictum est de angeli officio et de virginis vocabulo. Nunc dicendum est de salutacionis conpendio.

(67rb) Inc.: Ave gratia plena dominus tecum. Luc. 1 (28). Si quis princeps vel rex vel magnus dominus vult destinare nuncium vel legatum ad summum principem vel regem vel dominum magnum pro magna et ardua causa ... - Expl.: ... Non diligamus verbo nec lingua scilicet tantum sed opere et veritate.

(69ra) Inc.: Gracia plena (Lc 1,28). Dictum est prius quomodo dulcissima virgo Maria est gloriose salutata in hoc verbo Ave. Nunc dicendum est quomodo graciose est adornata ... Expl.: ... que in Maria clarius et plus Christianus quam in aliquo homine refulserunt.

(71va) Inc.: Gracia plena (Lc 1,28). Notandum quod sicut sunt VII utilitates sive efficacie quas gracia confert anime de quibus dictum est in sermone precedenti dicendum est ... - Expl.: ... habebit amicum regem. Quam amiciciam nobis concedat.

(73rb) Inc.: Gracia plena (Lc 1,28). Prius dictum est quod gracia habet VII efficacias quas in anima facit et quod sunt septem preparaciones quibus homo ad graciam se disponit ... - Expl.: ... sive possumus sive habemus ad quam gloriam nos perducat.

(75vb) Inc.: Gracia plena (Lc 1,28). Prius dictum est quomodo Maria fuit graciose salutata quod notabatur in hoc verbo Ave ... - Expl.: ... denique necessitatis amplissimo miseretur affectu.

(79vb) Inc.: Dominus tecum. Luc. 1 (28). Secundum ordinem naturalem in mundo corpora magis conformia in natura sint magis propinqua in situ ... - Expl.: ... Iste ergo est dominus qui fuit tecum o Maria.

(82ra) Inc.: Dominus tecum (Lc 1,28). O Maria dominus tecum te associans tecum te custodiens tecum te glorificans ... - Expl.: ... mecum fac ut amor tuus semper sit mecum.

(84va) Inc.: Benedicta tu in mulieribus. Luc. 1 (42). Illud digne commendatur quod in se consideratum bonum apparet et aliis comparatum excellit ... - Expl.: ... pronunciando et dicendo Magnificat anima mea domino.

(89rb) Inc.: Benedicta tu in mulieribus (Lc 1,42). Si volumus amplius scire quod multipliciter est sanctissima virgo domina Maria benedicta inspiciamus ... - Expl. mut.: ... Et quod bona domine Marie sunt precellentiora omnia et in Christo singulariter bene[ (= Rom, Vaticana, Cod. Vat. lat. 1287, S. 42a, Z. 7)

(91ra) (Lc 1,42). Inc. mut.: ] est in multis pro nobis constituta ... (= Rom, Vaticana, Cod. Vat. lat. 1287, S. 42a, Z. 9 von unten) - Expl. mut.: ... Domina Maria eciam corpus infantis suaviter attractat quia quicquid facit circa hominem totum est suavitas et pietas [ (= Rom, Vaticana, Cod. Vat. lat. 1287, S. 43a, Z. 3 von unten) 
Parallelüberlieferung: Klosterneuburg, Stiftsbibl., CCl 774, Bl. 150r-172v (unvollständig, Text nur bis Neustift, Stiftsbibl., Bl. 77v, Z. 22, erhalten); ab Bl. 49vb: Rom, Vaticana, Cod. Vat. lat. 1287, S. 1.

$\mathrm{Zu}$ einer möglichen Zuweisung an Siboto von Wien vgl. Ch. Jörg, Untersuchungen zur Büchersammlung Friedrichs von Amberg. Ein Beitrag zur franziskanischen Geistesgeschichte des Spätmittelalters. Zeitschrift für Schweizerische Kirchengeschichte/Revue d'histoire ecclésiastique suisse 69 (1975) 1-264, hier 95-96.

3 (92ra-131vb) 〈Godefridus Herilacensis〉 (= Ps.-Iacobus de Paradiso): Expositio super orationem dominicam, unvollständig (Ed. Bauer, Paternoster-Auslegung 84-226. - L. Meier, Die Werke des Erfurter Kartäusers Jakob von Jüterborg in ihrer handschriftlichen Überlieferung [Beiträge zur Geschichte der Philosophie und Theologie des Mittelalters 37, 5]. Münster/W. 1955, Nr. 24. Stegmüller RB Nr. 2608, 3886, vgl. auch Nr. 1551, 11642. Bloomfield Nr. 8085 bzw. 8203).

Expl. mut.: ... proximo tuo nocenti te et tunc deprecanti tibi peccata tua solventur. Hom[o homini servat (Sir 28,2-3).

Parallelüberlieferung: u. a. Innsbruck, ULB Tirol, Cod. 24, Bl. 120ra, Cod. 365, Bl. 1ra, Cod. 705, Bl. 11va; Klosterneuburg, Stiftsbibl., CCl 293, Bl. 216ra.

Zur Verfasserfrage s. Bauer, Paternoster-Auslegung 66-67, Guyot, Commentaires und Bauer, Godefridus Herilacensis 7*-9*.

Wie Innsbruck, ULB Tirol, Cod. 24 zählt Neustift, Stiftsbibl., Cod. 31 zu den Hs., die die längere Textversion überliefern (CV-traité-Typus, s. Guyot, Commentaires 248-249).

$\left(\mathrm{I}^{*} \mathrm{r}-\mathrm{v}\right)$ leer.

A. $\mathbf{P}$.

\section{Cod. 38}

\section{THOMAS DE AQUINO}

Perg. I, 272, I* Bl. $345 \times 260$. Süddeutscher Raum (?), 15. Jh.

B: $\quad$ Dickes Perg., vereinzelt Löcher und Nahtspuren, tw. unregelmäßig. Bl. 127v stark verschmutzt. Lagen: (I-1) (Vorsatzbl., Pap. 18. Jh.) + 34.IV ${ }^{269(272)}+(\mathrm{I}-1)^{\mathrm{I*}}$ (Nachsatzbl., Pap. 18. Jh.). Gegenbl. zum Vor- bzw. Nachsatzbl. als Spiegel auf dem VD bzw. HD aufgeklebt. Am Beginn und am Ende fehlt jeweils wohl mindestens eine Lage (Textverlust). Am oberen Blattrand Foliierung 19. Jh. durch die ULB Tirol; Fehler in der Zählung: 115, 161 und 171 doppelt angeführt.

S: $\quad$ Schriftraum 240/250 $\times 180 / 185$. Zwei Spalten, von vielfach bis an den Blattrand reichenden Tintenlinien gerahmt, zu 38-40 Zeilen. Zirkelstiche. Bastarda, Textanfänge in Textualis formata (Textura).

A: Rote Auszeichnungsstriche, Unterstreichungen, Rahmungen, Über- und Schlussschriften sowie B1. 1r-2r, 7r-12r, 139ra, 141ra, 144v, 171rb, 261ra, 268ra am oberen Blattrand Angaben der jeweiligen Quaestio. Vereinzelt auch blaue Überschriften (Bl. 70vb). Rote und blaue Paragraphzeichen. Vereinzelt Zeigehände mit Ärmeldraperie (z. B. Bl. 142ra). Rote und blaue ein- bzw. zweizeilige Lombarden, tw. mit Punktverdikkungen, Fadenausläufern (tw. in Achterschlinge gelegt, tw. gestrichelt), (kopfstempelförmigen) Aussparungen und Knospenfleuronnée in der Gegenfarbe; Bl. 81r und 89r gelblich-braune (verblasste?) Lombarden und Paragraphzeichen. Oberlängen in der ersten bzw. Unterlängen in der letzten Zeile bisweilen cadellenartige Dehnungen, tw. mit Blattwerk und Knospenfleuronnée gefüllt, vereinzelt in Schwarz und Rot. B1. 21rb Ausläufer mit bärtigem Profilkopf, B1. 25ra u. a. mit plastisch herausgearbeitetem Kopf. Am oberen Blattrand Dehnungen vereinzelt beschnitten. Bl. 144va vierzeilige blaue Initiale $P$ mit rotem Initialfeld, das mit silbernem Knospenfleuronnée bemalt ist; B1. 161 I $\mathrm{rb}$ zweizeilige blaue Lombarde mit dunkelrotem und braunem Fleuronnée, Perlenpyramiden als Besatz. Repräsentanten.

Fleuronnée von zwei Händen, die sich Pars 1 und 2 aufgeteilt haben; die zweite Hand vgl. Cod. 31 (Entstehungszeit der Hs. 14. Jh.). 
E: $\quad$ Neuzeitlicher Bibliothekseinband: schwarz gesprenkeltes braunes Pap. über Pappe. Neustift, 2. H. 18. Jh. Pap. tw. abgerieben und beschädigt. Ecken mit braunem Leder verstärkt. Rücken: braunes Leder, oben schadhaft, fünf einfache Bünde, mit Goldbordüren gerahmt. Im ersten Feld Golddruck $M$ : S:, im zweiten SUMA ANGELICI PARS II DE INCARNATIONE in Goldrahmung, im dritten Feld Signaturschild (s. bei G). Schnitt rot gefärbt. Spiegel Pap. 18. Jh. Am Spiegel des VD Exlibris und Signaturen (s. bei G), Spiegel des HD leer.

G: Zeitpunkt und Art der Erwerbung durch Neustift unbekannt. Am Spiegel des VD Exlibris der Stiftsbibl. Neustift 18. Jh. 1809 anlässlich der vorübergehenden Aufhebung des Klosters Neustift der ULB Tirol übergeben. Am Spiegel des VD alte Signaturen der ULB Tirol II $\overline{2} G 13$ (gestrichen, korr. zu 12) (radiert, Tinte), II 1 E 6 (Bleistift) sowie Nr. 38 (Tinte). Am Rücken gelbes Signaturschild der ULB Tirol 38. Bl. 1r Stempel der ULB Tirol 19 Jh. 1921 aufgrund des Friedensvertrages von St. Germain an den italienischen Staat abgegeben und von diesem 1929 dem Kloster Neustift als Dauerleihgabe überlassen. Bl. 1r Stempel der Soprintendenza Tridentina 20. Jh.

L: $\quad$ Shooner II 51. - Katalog ULB Tirol I 130, 282.

(Ir-v) leer.

(1ra-269vb) Thomas de Aquino: Summa theologica, Pars 3. Quaestiones de incarnatione dni, unvollständig: Beginn und Schluss fehlen (Ed. Thomas de Aquino, Opera omnia iussu impensaque Leonis XIII. P. M. edita. Bd. 11. Romae 1903, hier ab 134).

(1ra) Pars 1 (qu. 1-59), unvollständig: hier ab qu. 8, art. 6.

Inc. mut.: ] non procedit ab ore vestro sed si quis bonus est ad edificacionem fidei ut det graciam audientibus. Ergo videtur quod eciam alii quam Christo competat esse ecclesie capud. Propterea Christus ex eo quod preest ecclesie non solum dicit capud ... - Expl.. ... quia unus et idem est Deus et homo dominus Ihesus Christus de cuius incarnacionis misterio ad presens dicta sufficiant (gestrichen: Explicit tercia pars sancti Thome).

Schlussschrift: Explicit prima pars huius tercie partis ffratris Thome de Aquino scilicet de salvatore nostro et misterio incarnacionis.

(144rb) Pars 2 (qu. 60-90), unvollständig: hier bis qu. 85, art. 4.

Tit.: Incipit secunda pars eiusdem tercie partis Summe Thome que est de sacramentis. - Incipit (gestrichen: quarta) secunda pars (gestrichen: Summe s. Thome). - Inc.: Post consideracionem eorum que pertinent ad misteria verbi incarnati considerandum est de ecclesie sacramentis ... - Expl. mut.: ... in libro de memoria sed penitencia est de preterito ut dictum est ergo penitencia est in memoria sicut in subiecto. Preterea nihil agit [

$\left(\mathrm{I}^{*} \mathrm{r}-\mathrm{v}\right)$ leer.

A. P./U. S.

\section{Cod. 52}

\section{THEOLOGISCHE SAMMELHANDSCHRIFT}

Pap. 273 Bl. $290 \times$ 205. Süddeutscher Raum (Tirol?), T. I: Ende 14. Jh., T. II: 1396.

B: $\quad$ Zwei Teile: I (1-39), II (40-273). Am oberen Blattrand Foliierung 19. Jh. durch die ULB Tirol.

E: Schmuckloser gotischer Einband: rot gefärbtes Leder über dickem Holz. Süddeutscher Raum (Tirol?), Ende 14./Anfang 15. Jh.

Leder stark abgerieben und zerkratzt, Holz an den Ecken tw. freiliegend. VD und HD gleich: Spuren von je fünf kleinen runden Beschlägen. Am VD oben mittig aufgeklebtes Papiertitelschild Ysidorus de summo bono. Item questiones sentenciarum Boneventure secundi et quarti librorum. Item similitudines rerum XI, daneben und darunter Reste von Titelaufschriften (Tinte auf Leder), u. a. Ysidorus de summo bono, auf stark abgeriebenem Leder XI. Urspr. zwei Langriemen-Stoff-Metall-Schließen, heute nur mehr obere erhalten. Kanten abgeschrägt und gerade. Rücken: vier Doppelbünde, im ersten Feld aufgeklebtes Papierschild $M: S$ : 1396, im zweiten Papierschild Ysidori Theologia, im dritten Signaturschild (s. bei G), im fünften Papier- 
schild aufgeklebt (ohne Beschriftung). Kapitale mit Lederband umstochen. Am Spiegel des VD Verse und Notizen (s. bei Inhalt), Exlibris und Signaturen (s. bei G), am Spiegel des HD Besitzvermerk (s. bei G) und Federproben. In den Ecken sowie in der Mitte zur Verstärkung jeweils beschriebene Pergamentstücke aufgeklebt, tw. mit Notation.

G: $\quad$ Bl. 2r Besitzvermerk 15. Jh. Iste liber est monasterii s. Marie v[irginis] ad Novacellam. Am Spiegel des HD Besitzvermerk 15. Jh. Iste liber est s. Marie v[irginis] in Novacella. Bl. 2r Besitzvermerk 18. Jh. Ad Collegium Neocell[ensem]. Am Spiegel des VD Exlibris der Stiftsbibl. Neustift 18. Jh. 1809 anlässlich der vorübergehenden Aufhebung des Klosters Neustift der ULB Tirol übergeben. Am Spiegel des VD alte Signaturen der ULB Tirol II 1 F. 9 (Tinte, Bleistift) und Nr. 52 (Tinte). Am Rücken gelbes Signaturschild der ULB Tirol 52. Bl. 1r Stempel der ULB Tirol 19. Jh. 1921 aufgrund des Friedensvertrages von St. Germain an den italienischen Staat abgegeben und von diesem 1929 dem Kloster Neustift als Dauerleihgabe überlassen. Bl. 1r Stempel der Soprintendenza Tridentina 20. Jh.

L: $\quad$ Katalog ULB Tirol I 161, 282. - Stefani 94.

$$
\text { I (1-39) }
$$

B: $\quad$ Pap. bes. am unteren Blattrand tw. verschmutzt (u. a. Tintenflecken), Bl. 1 beinahe lose. Bilder und Nachweise der Wasserzeichen s. WZMA. Datierung nach Wasserzeichenbefund. Identische Wasserzeichen: u. a. Innsbruck, ULB Tirol, Cod. 589, T. I (dat. 1395). Lagen: (II-1) (Vorsatzbl.) + 3.VI ${ }^{39}$. Gegenbl. zu Bl. 3 als Spiegel auf dem VD aufgeklebt. In den Lagenmitten beidseitig beschriebene Pergamentfälze. Am Ende der zweiten und dritten Lage Kustoden in arabischen Ziffern.

S: $\quad$ Schriftraum 195/210×130. Zwei Spalten, von Tintenlinien gerahmt, zu 35-40 Zeilen. Bastarda von zwei Händen: 1) Bl. 2va-3rb und 38vb-39vb; 2) Bl. 4ra-38va.

A: Rote Auszeichnungsstriche, Unter- und Durchstreichungen, Über- und Schlussschriften sowie Angabe des jeweiligen Buches am oberen Blattrand. B1. 4ra rote Zeigehand. Ein- bis dreizeilige rote Lombarden, bisweilen mit Punktverdickungen und einfachen Fadenausläufern. Rote Tinte bisweilen verschmiert. Bl. 4ra in Rot und Tintenfarbe kopfstempelförmig gespaltene P-Initiale (Höhe ca. 80 mm). Repräsentanten.

1 (VDS-1ra) Notizen und Verse.

1) Notiz (zentriert, rot).

Lib[...]. - Nota. - In annuncciacione (!) dominica Deus homo factus est et die eodem passus, Ioseph venditus, Isaac ymolatus, Adam formatus, casus demonum, Iohannes Baptista decollatus, Petrus a vinculis solutus Abel interfectus Iacobus passus infernus spoliatus latro in paradisum locatus offe[...] Melch[isedech?]. Abrahe.

2) Versus de sanctis Iohanne Baptista et Iohanne ev. (in zwei Spalten).

Nota. - Inc.: De duobus filiis summe deitatis (recte: veritatis)/Quos dedit ecclesie pater pietatis/Quos eorum habeat plus auctoritatis ... - Expl.: ... [...] valeat videatur clare. Parallelüberlieferung: Heidelberg, UB, Pal. lat. 965, Bl. 241va.

3) Federprobe am unteren Blattrand.

4) Notiz zu den Unterschieden zw. der griechischen und der lateinischen Kirche.

Nota. - Inc.: In hoc differunt Greci a Latinis quia Greci similiter omnes dicunt ... - Expl.: ... dicunt tum calice stagni argenti vel auri debere agi quia lignum est multum porosum.

Darunter gestrichen: traditor autem dedit eis signa dicens quam [...] scilicet.

$(1 \mathrm{rb}-\mathrm{v})$ leer.

(2r) Besitzvermerk und Stempel (s. bei G). Notiz zum Inhalt (18. Jh.) Theologia. Isidori (gestrichen: libri) Anno 1396.

2 (2va-38va) Exzerpte aus Isidorus Hispalensis: De summo bono seu Sententiarum Lib. 1-3 (PL 83, 653-738 bzw. CCSL 111, 7-330. - CPL Nr. 1199. Bloomfield Nr. 4873, 4888 und 5854 sowie Bloomfield, Suppl. Nr. 5854). 
(2va-3rb) Register. Tit.: Incipit (gestrichen: dominica se[...]; darüber, ebenso gestrichen: dictamina [?]) registrum super librum Ysydori De summo bono.

(3v) leer.

(4ra) Prolog. Inc.: Premissis in nomine Christi librorum tabulis sive capitulorum tytulis secuntur ex eis ... - Expl.: ... forme verborum autorum (!) ydemptitate.

(4ra) Text. Inc.: Solus Deus dicitur immortalis quia solus est incommutabilis nam et omnia (recte: anima) moritur dum de ore autem (recte: deserente) Deo de bono in malum mutatur ... - Expl.: ... de quibus bene per prophetam dicitur Ducunt in bono dies suos et in puncto ad inferna descendunt etc.

Schreibervers: Finis adest operis mercedem posco laboris etc. (Colophons Nr. 21270).

Schlussschrift: Explicit Ysidorus de summo bo[no].

(4ra-13ra) Lib. 1. - (13ra-24rb) Lib. 2. - (24rb-38va) Lib. 3.

Parallelüberlieferung dieser Exzerpte: u. a. Innsbruck, ULB Tirol, Cod. 120, Bl. 1r; Cod. 262, Bl. 1v; Cod. 410, Bl. 38v; Cod. 449, Bl. 202ra und Cod. 608, Bl. 1ra.

3 (38vb-39ra) Exzerpte (u. a. aus Flavius Iosephus: De antiquitatibus und De bello Iudaico, HieRonymus: Epistola ad Helvidium, Thomas de Aquino: Catena aurea in Lucam), in drei Kapitel gegliedert.

3.1 (38vb) Inc.: Ab Adam usque ad diluvium duo milia VI centi etc. Iosephus primo libro Antiquitatum migraverunt $X$ tribus de Iudea ... - Expl.: ... meam terram rediit liberatus a servicio Babilorum Iosephus I libro de Iudaico bello.

3.2 (38vb-39ra) Inc.: Nulla obstetrix nulla muliercularum sedulitas intercessit ipsa pannis involvit infantem ... - Expl.: ... pre filiis hominum et matris obediens et moribus facetus.

3.3 (39ra) Tit.: De baptismo. - Inc.: In fontibus ecclesiarum non in privatis domibus debet baptisma concedi ... - Expl. mut.: ... puniri. In Clementinis de supremo (?) presenti [

4 (39rb-vb) 〈IACOBUS DE VoRAGINE : Legenda aurea sanctorum, sive Lombardica historia, cap. 35: De ieiunio quattuor temporum (Ed. Graesse).

Anschließend Schluss von cap. 34: De Quadragesima: Quare autem non observamus nostrum ieiunium ... ut digni valeamus comedere agnum vite.

Schlussschrift: Amen dicat omnis homo.

$$
\text { II (40-273) }
$$

B: $\quad$ B1. $46 \mathrm{v}-47 \mathrm{r}$ Tintenflecken. Bilder und Nachweise der Wasserzeichen s. WZMA. Wasserzeichenbefund mit Datierung übereinstimmend. Lagen: $\mathrm{II}^{43}+5 \cdot \mathrm{VI}^{103}+(\mathrm{VI}+\mathrm{III})^{121}+6 \cdot \mathrm{VI}^{193}+2 \cdot \mathrm{V}^{213}+5 . \mathrm{VI}^{273}$. In Lage 7 Ternio eingebunden (Bl. 106-111). In den Lagenmitten beidseitig beschriebene Pergamentfälze. Am Lagenende Kustoden in arabischen Ziffern, bei letzter Lage auf dem ersten Blatt. Bl. 44-105 am oberen Blattrand mittig zeitgenössische Foliierung in roten arabischen Ziffern.

S: $\quad$ Schriftraum $210 \times 130 / 140$. Zwei Spalten, von Tintenlinien gerahmt, zu 30-36 Zeilen. Bastarda, dat. 1396 (Bl. 270vb). Bl. 43v (Register) dreispaltig mit jeweils eigener zusätzlicher Spalte für die Blattzahlen, jeweils von zweifachen roten Tintenlinien begrenzt.

A: $\quad$ Rote Auszeichnungsstriche, Paragraphzeichen, Unterstreichungen, Überschriften. Bl. 204rb-264rb am Blattrand Hervorhebung einzelner Lemmata in Rot. B1. 264vb Zeigehand. Ein- bis vierzeilige (B1. 202ra fünfzeilige) rote Lombarden, tw. mit Punktverdickungen, Bl. 44ra dreizeilig mit einfachem Dekor im Binnenfeld (rot) und als Besatz (tintenfarben); B1. 112ra fünfzeilige rot-tintenfarbene Lombarde (als kopfstempelförmig gespaltene Lombarde angelegt, tintenbrauner Buchstabenteil $C$ einfach darübergemalt). Bl. 110v-111r (Register) jeweils seitenhohes Kürzel $D^{I}$ (für „Distinctio“) und Abschnittsbuchstaben in Rot. 
(40r-43r) leer.

5 (43v-105vb) BonaVentura (〈BonaVentura ABbreviatus 〉): Super II Sententiarum (Stegmüller RS Nr. 142, II. Distelbrink Nr. 187. G. E. Mohan, Initia operum Franciscalium. Franciscan Studies 37 [1977] 313*-314*).

(43v) Register mit Blattzahlangabe. Tit.: Incipit registrum capitulorum secundi libri Sentenciarum sequentis secundum numerum.

(44ra) Text. Tit. (am oberen Blattrand): Liber Sentenciarum secundus. Tit. (am Textbeginn): Questiones Boneventure de lapsu. - Inc.: Queritur utrum angelus in primo instanti creacionis fuerit malus actu proprie voluntatis ... - Expl.: ... nichil intelligere possunt de salute beatorum etc. Expliciunt.

(106r-110r) leer.

6 (110v-201ra)〈Humbertus de Prulliaco»: Extractiones super IV librum Sententiarum Petri Lombardi (Stegmüller RS Nr. 380, IV. Vgl. Glorieux Nr. 365c).

(110v-111r) Register. Tit.: Incipitur particio distinccionum super $4^{m}$ librum Sentenciarum.

(111v) leer.

(112r) Text. Inc.: Circa quartum librum Sentenciarum primo queritur quid sit sacramentum. Dicendum quod sacramentum quattuor modis solet describi vel definiri. Primo sic sacramentum est sacre rei signum ... - Expl.: ... ad gaudia eos secum trahit eterna. Ad que nos perducat Ihesus Christus Amen.

Schlussschrift: Expliciunt extracciones super quartum librum Sentenciarum continentes veritatem etc.

(201rb-vb) nur Rahmung.

7 (202ra-270vb) 〈IACobus de Lausanna〉: Compendium moralitatum (Kaeppeli Nr. 2090. Bloomfield Nr. 82. Glorieux Nr. 345aa. Stegmüller RB Nr. 3887. Thorndike-Kibre 9. Walther, Initia Nr. 70. Welter 349 Anm. 38).

Inc.: Abicit mundus pauperes et honorat divites. Nota Augustinus dicit super quod corvus est illius nature quod pullos suos ... - Expl.. ... propter carnem quia pennas virtutum non habent etc. Schlussschrift mit Datierung: Explicit liber iste. Sit laus et gloria Christo Amen. Anno domini $1396^{\circ}$ in vigilia assumpcionis s. Marie etc. (14. August 1396).

(271r-273v) leer.

8 (HDS) Besitzvermerk (s. bei G). Fragmente (s. bei E). Federproben: homo natus - de peccatoribus quare de C. circa principium - dileccio creature impedit dileccioni di[cit] Augustinus ponit Extra De aceto quare de d.

9 (Fälze) Fragmente aus 〈AleXander DE VIlla Dei〉: Doctrinale (Ed. Reichling [Monumenta Germaniae paedagogica XII]. Berlin 1893, 7-178). Mit Interlinearglossen.

Perg., Textualis formata (Textura) Anfang 14. Jh. auf Tintenlinierung. Interlinearglossen in Textualis cursiva von zeitgenössischer Hand. Rote Auszeichnungsstriche, Paragraphzeichen und Initialen.

Enthält u. a.: Victrices turbe victricia tela tulere (V. 693). - Si brevis est e vel i producitur atque facit di (V. 723). - Dat lepus hic tenet intercus genus omne vetusque (V. 663). - Hoc monasilla (!) dant ut thus [sed dicitur] hec grus (V. 665). - preteriens in vi dat itum nullumve supinum (V. 741). - dant duo bos impos corapos custosque sacerdos (V. 651). - in triplici genere decet adiectiva notare (V. 683). - ag- vel cognosco dat itum sepelire sepultum (V. 763). - mons pons fons hic dant Mars dens cal[s quoque] (V. 675). - continue iuncta si non lex non tenet [ista] (V. 727).

U.S. 


\section{Cod. 53}

\section{THOMAS EBENDORFER}

Pap. I, 348 Bl. $285 \times 210$. Wiener Raum (?), Mitte 15. Jh. (u. a. 1452).

B: Pap. am Beginn und am Schluss des Buchblocks fleckig, bes. bei erster Lage unterer Blattrand eingerissen, Bl. 74 beinahe lose. Blattränder bisweilen eingerissen, Riss Bl. 218 mit Papierstreifen geflickt. Bilder und Nachweise der Wasserzeichen s. WZMA. Wasserzeichenbefund mit Datierung übereinstimmend. Identische Wasserzeichen: u. a. Klosterneuburg, Stiftsbibl., CCl 407, T. I ([Wien], dat. 1455); Wien, ÖNB, Cod. 3719 (dat. 1453). Lagen: $1^{1}+29 . V^{348}$. Vorsatzbl. eingehängtes Einzelbl., beschriebener Pergamentfalz auf Bl. Iv und Bl. 13r aufgeklebt. In den Lagenmitten Pergamentfälze, tw. beschrieben (tw. in dt., tw. in lat. Sprache). Lagenreklamanten, tw. stark beschnitten, vereinzelt rot gerahmt. Bl. 110-290 am Lagenbeginn bisweilen Reste von Kustoden in römischen Zahlen in Rot, stark beschnitten. Am oberen Blattrand Foliierung durch die ULB Tirol 19. Jh.; Fehler in der Zählung: 12 ausgelassen, 325 doppelt angeführt.

S: $\quad$ Schriftraum 190/205 × 140/175. Zwei Spalten, von feinen Tinten-, Bl. 254r-275r von Blindlinien gerahmt, zu 40-49 Zeilen. Bastarda von drei Händen: 1) Bl. 1ra-253vb, dat. 1452 (Bl. 237ra); 2) Bl. 254ra-301vb; 3) Bl. 302ra-348rb.

A: Rote Auszeichnungsstriche, Durch- und Unterstreichungen, Rahmungen und Kapitelzählungen am Blattrand. Zwei- bis siebenzeilige rote Lombarden, tw. mit Punktverdickungen, einfachen Ausläufern und etwas Fleuronnée (B1. 205ra mit schwarzem Knospenfleuronnée). B1. 57va und 58rb drei- bzw. vierzeilige blaue Lombarde mit einfachem rotem Fleuronnée. Bl. 1ra zwölfzeilige rote Initiale mit kopfstempelförmiger Aussparung. Am Blattrand vereinzelt rote Federzeichnungen (u. a. B1. 152ra Vogelkopf im Profil [von geübter Hand], Bl. 285ra Christuskopf mit Nimbus). Ab Bl. 338rb Initialen nicht ausgeführt, Bl. 66v-73v keine Rubrizierung. Zahlreiche rote und schwarze Zeigehände. Am oberen Blattrand auf dem Verso jeweils Fest bzw. Sonntag angegeben, auf dem Recto die jeweilige Sermozahl (ausgenommen Bl. 106v und 107r), tw. von Titel im Fließtext abweichend. Repräsentanten.

E: Gotischer Einband: rot gefärbtes Schafleder über Holz mit Blindlinien. Neustift, Mitte 15. Jh.

Leder an den Kanten und insbes. am HD stark beschädigt. Rücken im 18. Jh. mit braunem Leder überklebt. Am VD und HD je zwei aus einfachen Streicheisenlinien gebildete Rahmen. Mittelfeld durch einfache Streicheisenlinien diagonal unterteilt. Spuren von je drei, urspr. wohl fünf runden Beschlägen und von zwei Langriemen-Leder-Metall-Schließen. Am VD oben aufgeklebtes Pergamenttitelschild mit Aufschrift (in Textura 15. Jh.) Haselbach de tempore gemali (!), darunter Reste eines aufgeklebten Pergamentschildes. Am HD oben Bohrloch, urspr. Kettenbuch. Kanten leicht abgeschrägt und gerade. Rücken: braunes Leder, drei Doppelbünde, von Goldbordüren gesäumt. Im ersten Feld Signaturschild (s. bei G), im zweiten Golddruck M. S. HASELBACH SERMONES in Goldrahmung. Kapitale mit Leder umstochen. Am Spiegel des VD Signaturen und Exlibris (s. bei G), am Spiegel des HD aufgeklebter beschriebener Pergamentfalz (s. bei Inhalt) und Tintenkleckse.

G: Zeitpunkt und Art der Erwerbung durch Neustift unbekannt. Bl. 1r Besitzvermerk 18. Jh. Collegii Neocell. Am Spiegel des VD Exlibris der Stiftsbibl. Neustift 18. Jh. 1809 anlässlich der vorübergehenden Aufhebung des Klosters Neustift der ULB Tirol übergeben. Am Spiegel des VD alte Signaturen der ULB Tirol II $\overline{1} F$ 10 (Bleistift) und Nr. 53 (Tinte). Am Rücken gelbes Signaturschild der ULB Tirol 53. 1921 aufgrund des Friedensvertrages von St. Germain an den italienischen Staat abgegeben und von diesem 1929 dem Kloster Neustift als Dauerleihgabe überlassen. Bl. Ir Stempel der Soprintendenza Tridentina 20. Jh.

L: $\quad$ Katalog ULB Tirol I 61, 282. - M. Stieglecker, Verborgene Zeichen. Handschriftenbeschreibung und Wasserzeichenanalyse, in: B. Sara (Hrsg.), Quelle \& Deutung I. Beiträge der Tagung Quelle und Deutung I am 27. November 2013. Budapest 2014, 29-52, hier 44-48. - Dies., Hidden signs: how to capture watermarks, in: P. Ó Macháin (Hrsg.), Paper and the Paper Manuscript. A context for the transmission of the Gaelic literature. Cló Torna 2019, 44-54, hier 53.

Thomas Ebendorfer (Haselbach): Sermones de tempore de evangeliis, pars hiemalis (Schneyer II Nr. 135-185. A. Lhotsky, Thomas Ebendorfer. Ein österreichischer Geschichtsschreiber, Theologe und Diplomat des 15. Jahrhunderts [Schriften der MGH 15]. Stuttgart 1975 [unveränderter ND der Ausgabe von 1957] 75, Nr. 38). Sermones jeweils zweigeteilt, Tit. und Inc. beider Teile, Expl. nur des gesamten Sermo aufgenommen. Die Schneyer-Nr. bezieht sich, falls nicht anders angegeben, auf den gesamten Sermo.

(Ir-v) leer bis auf Stempel (s. bei G). 
(1r) am oberen Blattrand Tit.: Incipiunt sermones dominicales hyemales egregii doctoris magistri Thome Haselbach magistri arcium ac sacre pagine professoris et primo prima dominica in adventu domini etc. primus sermo prime dominice.

Von späterer Hand 18. Jh.: Thomce Haselbach.

(1ra) Dnca 1. adv. (Schneyer II Nr. 135). Inc.: Cum appropinquasset Ihesus Ierosolimis et venisset Bethfage ad montem Oliveti tunc misit duos discipulos etc. Mt. 21 (1). Hodie sancta mater ecclesia incipit celebrare adventum domini et hanc observanciam recepit a sanctis patribus ... - (1va) Tit.: Secundus sermo prime dominice. - Inc.: Dicite filie Syon Ecce rex tuus venit tibi manswetus etc. ubi supra (Mt 21,5) et originaliter Zacharie $9^{\text {no }}$ capitulo (9). Secundum doctores adventus domini agitur per quattuor ebdomadas ad denotandum quod est quadruplex adventus filii Dei ... - Expl... ... ut eternis solemnitatibus mereamur interesse Amen.

(6va) Dnca 2. adv. Tit.: Dominica secunda in adventu domini. Sermo primus (Schneyer II Nr. 136). Inc.: Erunt signa in sole luna et stellis in terra pressura Luc. $21^{\circ}(25)$. Christus dominus per scripturas nobis valde incutit timorem de extremo iudicio ... - (7ra) Tit.: Sermo (gestrichen: secundo) secunde dominice. - Inc.: Erunt signa in sole luna et stellis etc. Luc. $21^{\circ}$ ubi supra (25). In presenti ewangelio monet nos dominus quatenus preparemus nos ad istam ultimam racionem quam oportet nos facere in extremo iudicio ... - Expl.: ... et mereamur intrare gaudia sanctorum Amen. - (11rb) Tit.: Sermo $3^{\text {us }} 2^{e}$ dominice (Schneyer II Nr. 137). - Inc.: Erunt signa in sole luna et stellis etc. Luc. 21 ${ }^{\circ}$ (25). Quod multum terribile sit extremum iudicium videtur posse trahi ex hiis que in proximo sermone dixi ... - (13ra) Tit.: Sermo quartus $2^{e}$ dominice. - Inc.: Arescentibus hominibus pre timore et expectacione que supervenient universo orbi (Lc 21,26). In precedenti sermone dixi de signis adventus diei iudicii ... - Expl.: ... et tunc veniet dies domini scilicet iudicii de quo in sequenti sermone. - (19rb) Tit.: Sermo quintus $2^{e}$ dominice (Schneyer II Nr. 138). - Inc.: Et tunc videbunt filium hominis venientem in nube cum potestate magna et maiestate Luc. $22^{\circ}(21,27)$. Sicut valde consultum est servo procuratori alicuius potentis domini qui numquam racionem fecit ... - (20ra) Tit.: Sermo sextus secunde dominice. - Inc.: Et tunc videbunt filium hominis venientem in nube etc. ubi supra (Lc 21,27). In istis verbis describit salvator adventum suum ad iudicium extremum ... - Expl.. ... Ite maledicti etc. et e contrario de bonis Amen.

(25vb) Dnca 3. adv. Tit.: Dominica $3^{a}$ in adventu domini (gestrichen: Primus) sermo (Schneyer II Nr. 140). - Inc.: Cum audisset Iohannes in vinculis opera Christi mittens duos de discipulis suis ait illi etc. Mt. $11^{\circ}$ (2). Ex quo inter cetera multum provocat ad virtutes et virtuosorum hominum laudabilis conversacio ... - (26ra) Tit.: (gestrichen: Secundus) sermo tercie dominice in adventu domini. - Inc.: Cum audisset Iohannes in vinculis etc. ubi supra (Mt 11,2). Pro intellectu notandum quod secundum magistrum historiarum Iohannes arguebat Herodem propter Herodiadem quam a fratre suo receperat ... - Expl.: ... spinas et tribulos (korr. aus tribuualos) mundane cupiditatis extirpat (!). Miserunt Iudei ab Ierosolimis sacerdotes et levitas ad Iohannem ut interrogarent eum Tu quis es Ioh. $1^{\circ}$ capitulo (19).

(30ra) Dnca 4. adv. Tit.: Incipit prohemium quarte dominice (Schneyer II Nr. 141). - Inc.: Miserunt Iudei a Ierosolimis sacerdotes et levitas ad Iohannem ut interrogarent eum Tu quis es Iohannis $1^{\circ} \mathrm{ca}-$ pitulo (19). (am Rand ergänzt: Et in ewangelio hodierno sicut scriptura) sacra Veteris et Novi Testamenti perswadet fideles ut diligant et amplexentur humilitatem ... - (30va) Tit.: Dominica quarta sermo. - Inc.: Miserunt Iudei a Ierosolimis sacerdotes et levitas etc. ubi supra (Io 1,19). Secundum Originem Iudei videntes prope esse tempus adventus Messie ... - Expl.: ... et quam tardus ad bona et pronus ad mala etc. etc.

(43rb) In nativitate dni. Tit. (am oberen Blattrand): In nocte nativitatis Christi. Sermo primus. - Inc.: Exiitt (!) edictum a Cesare Augusto ut describeretur universus orbis Luc. 2 (1). Sicut omnipotens Deus verax est in premissis Ita et misericors ... - (43va) Inc.: Exiit edictum a Cesare Augusto ubi supra (Lc 2,1). Nota Octavianus imperator dictus est Augustus primus quia regnum Romanorum notabiliter auxit ... - Expl.. ... eciam quia stetit inter lapidantes. - (47va) Tit. (am oberen Blattrand): In nativitate domini nostri Ihesu Cristi. Sermo secundus. - Inc.: Exiit edictum a Cesare Augusto ut describeretur universus orbis Luc. 2 (1). Sicut dicit Bernardus in sermone de epyphania Priusquam appareret Dei 
humanitas latebat ... - (47vb) Inc.: Exiit edictum a Cesare Augusto (Lc 2,1). Secundum hystoriam post mortem Iulii Cesaris qui a poetis conmendatur ... - Expl.: ... ut cum angelis eternaliter sibi decantemus (gestrichen: post) laudes in patria Amen.

(52rb) De s. Stephano. Tit.: Sequitur sermo in die s. Stephani (am oberen Blattrand: In aurora diei nativitatis Christi. Alius sermo). - Inc.: Pastores loquebantur ad invicem Transeamus usque Betlehem et videamus hoc verbum quod factum est etc. Luc. 2 (15). Hodierne diei gaudiosa festivitas nos ammonet et accendit aliquid de temporali Christi ... - (52vb) Tit.: In die s. Stephani. - Inc.: Pastores loquebantur etc. (Lc 2,15). Notandum quod Octavianus imperator 42 anno imperii sui quia 57 annis regnavit et versus finem valde pacifice ... - Expl.. ... ad Bethlehem celestem lapides torrentes contra eum gaudenter suscepit.

(57va) Dnca infra octav. nativitatis dni (Schneyer II Nr. 142). - Inc.: Erat Ioseph et Maria mater Ihesu mirantes super hiis que dicebantur de illo etc. Luc. 2 (33). Augustinus in quodam sermone de Christi nativitate qui incipit Adiuvet nos humilimos ... - (58rb) Inc.: Erat Ioseph et Maria mater Ihesu mirantes etc. (Lc 2,33). Ewangelium presens tangit primo de parentibus salvatoris id est patre et matre ... Expl.: ... sed a casu similiter eveniunt etc.

(63ra) In circumcisione dni. - Inc.: Postquam consumati sunt dies octo ut circumscideretur (!) puer vocatum est nomen eius Ihesus etc. Luc. $2^{\circ}$ capitulo (21). Ex quo tota Christi vita et conversacio nostra est instruccio ... - (63va) Inc.: Postquam consumati sunt dies octo ubi supra (Lc 2,21). Sciendum quod Deus creavit primos parentes iustos iusticia naturali id est sine omni obliquitate ... - Expl.. ... omnes filii Israhel incircumscisi (!) sunt corde etc.

(66rb) In epiphania dni. Inc.: Cum natus esset Ihesus in Betlehem Iude (!) etc. Mt. $2^{\circ}$ (1). Omnipotens Deus ex supereffluenti non ex operibus iusticie que fecimus ... - Expl. abweichend: ... discessimus ad hec parlamenta revocamur plura ibidem. - (70va) Tit. (am oberen Blattrand): In epiphania domini. Sermo secundus. - Inc.: [C] um natus esset Ihesus in Betlehem Iude (!) etc. Mti $2^{\circ}$ (1). Sicut Deus disposuit omnia sapienter sic fidei incrementum et suam humanitatem ... - (71ra) Inc.: [C]um natus esset Ihesus vide supra (Mt 2,1). Pro intellectu littere notandum ut narrat Iosephus 13 libro Antiquitatum capitulo 14 regnum Iudeorum fuit interceptum 481 annis et duos menses a captivitate ... - Expl.. ... in aliis terris sunt eciam alia signa usque hodie mansura etc.

(76ra) Dnca 1. post epiph. dni (Schneyer II Nr. 143). Inc.: Cum factus esset Ihesus annorum 12 etc. Luce $2^{\circ}$ (42). Cristus dominus ne dum etate virili sed eciam in puericia sua se nobis ita exhibet ut ostendat quanta caritate nos diligat ... - (76va) Inc.: Cum factus esset Ihesus annorum duodecim ascendentibus illis in Ierusalem secundum conswetudinem etc. (Lc 2,42). Augustinus dicit in De consensu ewangelistarum et magistri hystoriarum quod Herode mortuo ... - Expl.. ... assiduat illi flagella ut letetur in novissimo suo et plura de hoc ibidem etc. - (80va) Tit.: Dominica de eodem sermo (Schneyer II Nr. 144). - Inc.: Puer Ihesus proficiebat sapiencia etate et gracia apud Deum et homines. Luce $2^{\circ}$ (52). Quando diligenter consideramus inestimabilia divine bonitatis beneficia nobis exhibita ... (81rb) Inc.: Puer Ihesus proficiebat etate etc. capitulo et loco ubi supra (Lc 2,52). Presens ewangelium tangit statum Christi tempore puericie circa 12 annum ... - Expl.: ... quibus parata sunt celestia per Christum dominum qui vivit et regnat in seculorum secula Amen etc.

(84vb) Dnca 2. post epiph. dni. Tit. (am oberen Blattrand): Dominica secunda post epiphaniam. Sermo primus (Schneyer II Nr. 145). - Inc.: Nupcie facte sunt in Chana Galilee Iohannis $2^{\circ}$ capitulo (1). Propter multiplicacionem humani generis Deus specialiter instituit matrimonium ... - (85rb) Inc.: Nupcie facte sunt in Chana Galilee etc. ut supra (Io 2,1). Hic possit queri de tempore et loco et sic de aliis. Ad illud respondet ewangelista Iohannes $2^{\circ} \ldots$ - Expl.: ... et allegat magister in quarta distinccione versus finem. - (89vb) Tit. (am oberen Blattrand): Dominica secunda post epiphaniam. Sermo secundus. - Inc.: [N]upcie facte sunt in Chana Galilee Iohannis $2^{\circ}(1)$. De prima parte ewangelii dicendum est sed referendo ad nupcias corporales de quibus loquitur specialiter ewangelium ... - Expl.: ... observare volens matrimonium contrahere vide Holkoth super Sapiencie etc. - (92rb) Tit. (am oberen Blattrand): Dominica secunda post epiphaniam. Sermo tercius (Schneyer II Nr. 146). - Inc.: [N] upcie facte sunt in Chana Galilee etc. Iohannis $2^{\circ}(1)$. Quamvis in nupciis homines soleant convivia 
tenere hec autem caute tenenda sunt in Dei timore ... - (92vb) Inc.: [N]upcie facte sunt in Chana Galilee ut supra (Io 2,1). Prima pars presentis ewangelii congruit multum presenti tempore in quo celebrantur nupcie et matrimonia ... - Expl.: ... de tempore quo nupcie sunt celebrande vide supra etc. (96va) Dnca 3. post epiph. dni. Tit. (am oberen Blattrand): Dominica tercia post epiphaniam. Sermo primus (Schneyer II Nr. 148). - Inc.: [C]um autem descendisset Ihesus de monte secute sunt turbe multe. Et ecce leprosus etc. Mti octavo (1). Cristus dominus volens omnem dubitacionem de sua divinitate a nobis excludere ... - (97ra) Inc.: [C]um autem Ihesus descendisset de monte etc. (Mt 8,1) Secundum Chrysostomum omelia 24 super Mattheum Ne forte diceret populus aput se ... - Expl.: ... ut eterna premiati gloria ista mala divina gracia adiuvante vincamus Amen. - (110va) Tit.: Dominica $3^{a}$ post epyphaniam (Schneyer II Nr. 147). - Inc.: Cum autem descendisset Ihesus de monte Ecce leprosus veniens adorabat eum. Mt. $8^{\text {us }}$ (1). Ecclesia instituit quod per totum annum cantantur et predicantur Christi miracula ... - (110vb) Inc.: [C]um autem descendisset Ihesus de monte ubi supra Mt. $8^{\text {vo }}$ capitulo (1). Quia postillacio verborum ewangelii satis patet ex alio sermone facto de eodem. Ideo solummodo dicendum erit ... - Expl.: ... dicente domino Vade sicut credidisti fiat tibi adiuvante domino nostro Ihesu Christo benedicto in secula etc.

(114va) Dnca 4. post epiph. dni (Schneyer II Nr. 149). Inc.: Ascendente Ihesu in naviculam secuti sunt eum discipuli eius etc. Mt. $8^{\text {vo }}$ (23). Licet mundus iste primo appareat valde amicus tranquillus et pacificus hominibus ... - (115ra) Inc.: Ascendente Ihesu in naviculam etc. ubi supra Mt. $8^{\text {vo }}$ capitulo (23). Cristus dominus tempore quo suam predicacionem incepit semper operatus est ... - Expl. ... hic placeamus sibi in via ut secum mereamur congregari in patria etc. etc.

(119va) Dnca 5. post epiph. dni (Schneyer II Nr. 151). Inc.: In illo tempore respondens Ihesus dixit Confiteor tibi pater domine celi et terre quia abscondisti hec a sapientibus et prudentibus etc. Mt. $11^{\circ}$ (25). Dominus Deus non invitat solum cottidie per suos nunccios predicatores sed eciam per se ipsum ... - (119vb) Inc.: Respondens Ihesus dixit Confitebor tibi, pater, domine celi et terre etc. Mt. 11 (25). Hic post postillacionem ewangelii alias habitam dicam solum de illa parte Venite ad me ... Expl.: ... quo quisque Deo appropinquat hic in via per graciam et in eterna beatitudine per gloriam Amen. Sequitur.

(124ra) Dnca in Septuages. (Schneyer II Nr. 152). Inc.: Simile est regnum celorum homini patrifamilias qui exiit mane conducere operarios in vineam suam etc. Mt. 20 c. (1). Dominus Deus creavit hominem (gestrichen: [...]ro, am Rand ergänzt: ymo) et totum mundum propter suam bonitatem ... - (124va) Inc.: Simile est regnum celorum homini patrifamilias etc. capitulo ubi supra (Mt 20,1). Chrysostomus super Mattheum omelia 28 Homo Christus paterfamilias cui celi et (gestrichen: fr) pater (recte: terra) una est domus familia ... - Expl.: ... pervenire mereamur ad requiem perpetuam prestante domino Ihesu Christo benedicto in secula seculorum etc.

(129va) Tit.: Alius sermo in LXX ${ }^{\text {ma }}$ (Schneyer II Nr. 153). - Inc.: Simile est regnum homini patrifamilias etc. Mt. 20 (1). Sicut patrifamilias placet servus qui parate exequitur suam voluntatem ... - (130ra) Inc.: Simile est regnum celorum homini patrifamilias qui exiit etc. capitulo ubi supra (Mt 20,1). Salvator Christus in presenti ewangelio movet singulos homines ad considerandum sua propria opera ... Expl.: ... ubi murmurabunt sine fine eis in maiorem confusionem et penam etc.

(134ra) Dnca in Sexages. (Schneyer II Nr. 155). Inc.: Cum turba plurima conveniret et de civitatibus properarent ad Ihesum dixit per similitudinem Exiit qui seminat seminare semen suum etc. Luce 8 (4). Beatus Bernardus in sermone De Quadragesima dicit quod septem sunt impedimenta ... - (134va) Inc.: Cum turba plurima conveniret convenirent (!) et de civitatibus properarent ad Ihesum etc. capitulo ubi supra $($ Lc 8,4). Presens ewangelium mea non indiget exposicione quia summa veritas ... - Expl.: ... eris potestatem habens supra decem civitates. - (138va) Tit.: Alius sermo in Sexagesima (Schneyer II Nr. 156). - Inc.: Cum turba plurima conveniret et de civitatibus properaret ad Ihesum dixit per similitudinem Exiit qui seminat seminare semen suum. Luc. 8 (4). Vera (am Rand ergänzt: paciencia) quanta bona et quantas utilitates afferat homini possumus ex diversis scripturis sacris colligere ... - (139ra) Inc.: Cum turba plurima etc. capitulo ubi supra (Lc 8,4). In presenti ewangelio dominus ostendit multorum auditorum Christi devocionem ... - Expl.: ... per quod et reduci ad regnum promeruit 2 Regum 
16. - (142rb) Tit.: Alius sermo in $L X^{a}$ (Schneyer II Nr. 154). - Inc.: Cum turba plurima conveniret, de civitatibus properarent ad Ihesum dixit per similitudinem Exiit qui seminat seminare semen suum etc. Luc. 8 (4). Salvator noster Christus dominus sepius verbis suis nos amonet (!) non solum mala fugere ... - (142vb) Inc.: Cum turba plurima ubi supra (Lc 8,4). Secundum Bedam Satorem istum nullum melius quam Dei filium intelligere possumus ... - Expl.: ... per levam autem vita presens designatur per dexteram vere futura (am Rand ergänzt: ut dicit Gregorius).

(145vb) Dnca in Quinquages. (Schneyer II Nr. 157). Inc.: Assumpsit Ihesus duodecim discipulos suos et ait illis Ecce ascendimus Ierosolimam et consumabuntur (!) omnia etc. Luce 18 (31). Celestis medicus quamvis vocatus ab infirmo homine propter originale peccatum ... - (146rb) Tit.: Sermo in Quinquagesima. - Inc.: Assumpsit Ihesus duodecim discipulos et ait illis Ecce ascendimus Ierosolimam etc. Luce 18 (31). In presenti ewangelio ponuntur duo principalia. Primum de Christi passione ... - Expl.: ... et tecum finaliter permanere in patria prestante eodem domino nostro Ihesu Christo benedicto in secula Amen. - (151va) Tit.: In Quinquagesima (Schneyer II Nr. 158). - Inc.: Assumpsit Ihesus duodecim discipulos suos et ait illis Ecce ascendimus Ierosolimam et consumabuntur omnia que scripta sunt per prophetas etc. Luce 18 (31). Secundum scripturas sanctorum homo per peccatum fit instabilis et mutabilis et despectus ... - (152ra) Inc.: Assumpsit Ihesus duodecim discipulos suos et ait illis Ecce ascendimus etc. (Lc 18,31). Hoc ewangelium facit memoriam de Christi passione et secundum Wilhelmum Duranti ... - Expl.: ... Respice fides tua te salvum fecit etc. Quam salutem.

(156rb) Dnca 5. post epiph. dni. Tit. (am oberen Blattrand): Dominica quinta post epiphaniam domini. Sermo secundus (Schneyer II Nr. 1501). - Inc.: Confiteor tibi pater domine celi et terre etc. Mt. $11^{\text {mo }}$ (25). Sicut inter virtutes morales que pertinentes sunt ad mores exteriores precipue precipua est gratitudo ... - (156vb) Inc.: Confiteor tibi etc. (Mt 11,25). Quia Christus multa signa fecit in civitatibus Iudeorum ipsi nichilominus in sua pertinacia permanserunt ... - Expl.: ... ipsum amoris brachio sustentabat et ideo ipsum non onerabat.

(159ra) Dnca 1. in Quadrages. Tit.: Dominica prima in Quadragesima (am Rand ergänzt: Sermo primus) (Schneyer II Nr. 159). - Inc.: Ductus est Ihesus in desertum a spiritu ut temptaretur a dyabolo etc. Mt. 4 (1). Ex quo omnia tempora tempus (am Rand ergänzt: suum) habent ut dicit sapiens Ecclesiastes $3^{\circ}$ Est tempus flendi ... - (159vb) Tit.: Dominica Invocavit. - Inc.: Ductus est Ihesus in desertum ubi supra (Mt 4,1). Ex quo sequitur assumpsit eum dyabolus etc. Dubitatur a quo spiritu ductus sit in desertum ... - Expl.: ... sed facit eciam cum temptacione proventum de quibus patebit in loco suo etc. (164ra) Tit.: Alius sermo in dominica prima XL $L^{m e}$ (am Rand ergänzt: Sermo ${ }^{u s}$ ) (Schneyer II Nr. 161). Inc.: Ductus est Ihesus in desertum a spiritu ut temptaretur a dyabolo etc. Mt. 4 (1). Totam vitam nostram plenam fecit Deus temptacionibus et eciam racionabiliter Deus permittit electos suos temptari ... - (164va) Inc.: Ductus est Ihesus in desertum a spiritu ut temptaretur a dyabolo (Mt 4,1). Glossa dicit Christus non permisit se temptari nisi post baptismum ... - Expl.: ... et Gregorius dicit Illos iure pulsare negligit (!) quos iure possidere quieto se sentit. - (169rb) Tit.: Alius sermo in prima dominica $X L^{\text {me }}$ (am Rand ergänzt: Sermo tercius) (Schneyer II Nr. 162). - Inc.: Ductus est Ihesus in desertum a spiritu ut temptaretur a dyabolo Mt. 4 (1). Sicut in bello corporali securius pugnatur et cicius obtinetur triumphus contra hostes ... - (170ra) Inc.: Ductus est Ihesus in desertum etc. ubi supra (Mt 4,1). Tota summa huius ewangelii est quod Christus voluntarie ivit ad desertum locum ... - Expl.: ... quibus ipsum vincere poterimus prestante domino nostro Ihesu Christo Amen. - (174ra) Tit.: Dominica prima in $X L^{m a}$ (am Rand ergänzt: Sermo quartus) (Schneyer II Nr. 160). - Inc.: Ductus est Ihesus in desertum a spiritu ut temptaretur a dyabolo Mt. 4 (1). Sicut dicit Gregorius omelia $2^{a}$ super ewangelia Miracula domini et salvatoris nostri sic accipienda sunt ... - (174va) Inc.: Ductus est Ihesus in desertum a spiritu ut temptaretur a dyabolo etc. ubi supra (Mt 4,1). Pro intellectu dubitatur quale fuit illud desertum ad litteram ...- Expl.. ... apparet ex textu littere quod sic quia dicitur Tunc assumpsit eum. - (176vb) Tit.: Alius sermo de ieiunio et utilitate eius (Schneyer II Nr. 163. Lhotsky 83, Nr. 103).Inc.: Et cum ieiunasset 40 diebus et 40 noctibus postea esuriit Mt. 4 (2). Sancti patres primitivi Christiane ecclesie instituerunt ieiunium fidelibus observandum ... - Expl.: ... quia non potuerunt sed quia non voluerunt etc. Sequitur. - (185va) Tit. (am oberen Blattrand): Alius sermo de ieiunio 
(Lhotsky 83, Nr. 104). - Inc.: Crisostomus omelia $16^{a}$ super Mt. dicit Omnium malorum tria et forciora sunt tria mala ... - Expl.: ... et fratres in tota medietate claustri non quiescere permitteret. - (191ra) Tit. (am oberen Blattrand): De ieunio sermo tercius (Lhotsky 83, Nr. 105). - Inc.: Nunc igitur de gula videndum est isto tempore sacro quia (gestrichen: quod) secundum Gregorium ... - Expl.. ... quod iam modus est (gestrichen: esse, am Rand ergänzt: semper est peccatum) peccatum etc. - (197vb) Tit. (am oberen Blattrand): Alius bonus sermo. De confessione et penitencia et consimilibus (Lhotsky 84, Nr. 107). - Inc.: Quia ut ait Ambrosius in sermone de $40^{m a}$ Ecce nunc tempus acceptabile est in quo confessio a morte animam liberat ... - Expl.: ... est magis de uno quam de alio conterendum hec de contricione breviter sint dicta etc. - (205ra) Tit. (am oberen Blattrand): De confessione et penitencia. Sermo secundus (Lhotsky 84, Nr. 108). - Inc.: Nunc ergo de confessione videndum est ad quam homo obligatur qui peccavit mortaliter ex Dei institucione et precepto Iohannis 20 (22) ubi confessionem instituit quando dixit apostolis Accipite spiritum sanctum ... - Expl.: ... ut prodigalitas avariciam ut vere impleatur illud abyssus abyssum invocat etc. De satisfaccione supra dictum est. - (209rb) Tit. (am oberen Blattrand): De rebus male acquisitis (Lhotsky 84, Nr. 109, in zwei Teile unterteilt). - Inc.: Videte ne furtivus sit reddite eum [...] dominis suis quia non licet vobis edere ex furto aliquid aut contingere (Tb 2,13). Verba sunt beati Thobie ad vocem edi cuiusdam balantis caprarum ... - (227ra) Inc.: Dicto de restitucione fienda dampnificatis in rebus exterioribus nunc restat dicere de restitucione fienda in bonis anime et corporis ... - Expl.: ... secundum arbitrium boni viri precipue ad intensas ad medicos etc. De restitucione si placet vide S. T. Scotum in scriptis magistri Nicolai de Dinckelspühel multa invenies si placet recurre illuc. - (227vb) Tit. (am oberen Blattrand): Sermo de penitencia (Lhotsky 84, Nr. 106, in zwei Teile unterteilt). - Inc.: Facite dignos fructus penitencie (Mt 3,8 und Lc 3,8). Ita hortatur nos predicator penitencie beatus Iohannes Baptista in deserto predicans baptismum penitencie Mt. 3 et Luce 3 quod specialiter nobis dicitur hoc sacratissimo ieiuniorum tempore legimus ... - (232va) Inc.: Novissime audistis quomodo in hoc sacratissimo tempore matamur (!) ad penitenciam ... - Expl.: ... cum sacerdos dicit quidquid boni feceris sit tibi in remissionem peccatorum tuorum.

(236vb) Dnca 2. in Quadrag. (Schneyer II Nr. 164). Inc.: Egressus Ihesus secessit in partes Tiri et Sydonis etc. Mt. 15 (21). Inter cetera que reconciliant peccatorem Deo postquam in peccatum mortale corruit est recognicio ... - (237ra) Datierung in Rot: 1452. - (237rb) Tit.: Sermo in dominica Reminiscere. - Inc.: Egressus Ihesus secessit in partes Tiri et Sydonis Mt. 15 (21). Pro intellectu notandum sicut habetur Mt. 14 Postquam Christus transfretavit per mare Tyberiadis venit Capharnaum ... - Expl.: ... quia quod ipsi apostoli non impetraverunt et obtinuerunt ipsa impetrat.

(238va) Dnca 3. in Quadrag. (Schneyer II Nr. 165). Inc.: Erat Ihesus eiciens demonium et illud erat mutum etc. Luc. $11^{\text {mo }}$ (14). Secundum quod dicit Beda in omelia de Christi transfiguracione ut patet Mt. 17 Salvator humani generis Christus dominus ... - (239ra) Tit.: Dominica tercia in XL ${ }^{\text {ma }}$ (am Rand ergänzt: Oculi). - Inc.: Erat Ihesus eiciens demonium etc. ubi supra (Lc 11,14). Demones enim frequenter plus solito ante et circa Christi adventum obsidebant homines ... - Expl.: ... Tu solus nosci corda filiorum hominum etc. Et exposicionem textus sequentis in sermone (gestrichen: sequenti complebo) sequenti usque ad finem complebo. - (240ra) (Schneyer II Nr. 166). Inc.: Erat Ihesus eiciens demonium et illud erat mutum etc. Luce $11^{\circ}(14)$. Quam detestabile sit vicium invidie et fugiendum patet propter multa mala ... - (240va) Inc.: Erat Ihesus eiciens demonium ubi supra (Lc 11,14). Crisostomus et Theophilus dicunt et habetur Mt. 12 Ille demoniacus erat mutus ... - Expl.. ... corpore per carnis assumpcionem et sic de aliis est. Idem Beda dicit in omelia.

(242rb) Dnca 4. in Quadrag. (Schneyer II Nr. 167). Inc.: Abiit Ihesus trans mare Galilee quod est Tyberiadis et sequebatur eum multitudo magna etc. Iohannis 6 (1). Licet secundum Augustinum in quodam sermone ad fratres Non debeamus loqui sublimia ... - (242vb) Inc.: Abiit Ihesus trans mare Galilee ubi supra (Io 6,1). In hoc ewangelio considerantur triplices persone scilicet Christus discipuli et turbe ... Expl.: ... sobrie pie et caste vivendo celestis sapiencie mereamur dulcedine recreari Amen.

(246ra) Dnca 1. in passione dni (Schneyer II Nr. 168). Inc.: Dixit Ihesus turbis Iudeorum et principibus sacerdotum Quis ex vobis arguet me de peccato si veritatem dico quare non creditis michi etc. Iohannis 8 (46). Quod quilibet homo et maxime Christianus debeat fugere lites et contenciones ... - (246va) 
Inc.: Quis ex vobis arguet me de peccato etc. ubi supra (Io 8,46). Christus dominus frequenter in suis sermonibus arguit Iudeis super peccatis suis ... - Expl.: ... sustinendi precipue verbales ut patet in presenti ewangelio etc.

(249ra) Dnca 2. in passione dni (Schneyer II Nr. 169). Inc.: Cum appropinquasset Iesus Ierosolimis et venit Bethfage ad montem Oliveti etc. Mt. 21 (1). Consuetudo est regum terre ut quando volunt aliqua seriosa bellica exercere ... - (249va) Inc.: Cum appropinquasset Iesus Ierosolimis etc. ubi supra (Mt 21,1). Pro intellectu littere notandum quod Iohannis 12 dicitur Quando Iudei iam ex consilio Cayphe ... - Expl.: ... quod 6ta die separabatur ante pascha in eadem ymolandum pro peccatis mundi. (251va) Fer. 5. in coena dni (Schneyer II Nr. 171). Inc.: Sic comedetis illum renes vestros accingetis calciamenta vestra habebitis in pedibus tenentes baculos manibus et comedetis festinanter etc. Exodi 12 (11). Hec verba licet ad litteram sint dicta de agno pascali cuius ymolacione ... - (252ra) Inc.: Sic comedetis illum renes vestros accingetis calciamenta vestra habebitis in pedibus etc. ut supra (Ex. 12,11). Nunc igitur iuxta premissa sicut dixi ad contemplacionem ... - Expl.: ... qui habet peccatum mortale de quo non est contritus sufficienter etc. - (257vb) Tit.: Alius sermo in cena domini (Schneyer II Nr. 172). - Inc.: Hoc facite in meam commemoracionem $1^{\circ}$ Cor. 11 (24). In hodierna epistola dominus noster Ihesus Cristus de hoc mundo per passionem suam acerbissimam ... - (258rb) Inc.: Hoc facite in meam commemoracionem ubi supra (1 Cor 11,24). Sacramentum mei corporis sumite quo ad fideles et conficite quo ad presbiteros ... - Expl.: ... meritum fidei evacuetur si tamen instaret martirium sentiret. - (265ra) Tit.: Alius sermo in cena domini (Schneyer II Nr. 173). - Inc.: Ante diem festum pasche sciens Ihesus quia venit hora eius etc. Ioh. 13 (1). Crisostomus super Iohannem tractans illud Ioh. 10. Facta sunt encenia ... - (265va) Inc.: Ante diem festum pasce sciens Ihesus quia venit hora eius etc. ubi supra (Io 13,1) Sicut auris non potest saciari auditu nec oculus ... - Expl.: ... ut te digne collaudare nunc et in eternum per interminabilia secula Amen. - (272rb) Tit.: Alius sermo de cena et passione Christi. - Inc.: Sciens Ihesus quia venit hora eius ut transeat ex hoc mundo ad patrem Ioh. 13 (1). Dominus Ihesus Christus et magister noster preciosum nostre redempcionis precium ... - (272va) Inc.: Sciens Ihesus etc. (Io 13,1). Quia in tentivum (!) passionis Christi et occasio fuit prodicio ... Expl. erweitert (mit Innsbruck, ULB Tirol, Cod. 421, Bl. 372va übereinstimmend): ... non studuerit condolere ut ait Gregorius ... tibi appropinquare et tecum in gloria habitare concedere digneris Amen. (280rb) Fer. 6. in parasceve (Schneyer II Nr. 174). Inc.: Egressus Ihesus cum discipulis suis trans torrentem Cedron ubi erat ortus etc. Ioh. 18 (1). Sapiens Ecclesiastes 3 (1 und 4) dicit quod omnia tempora tempus habent. Est tempus flendi et tempus ridendi ... - (281ra) Inc.: Igitur locuturus hodie nunc amplius de dira Christi morte et innocenti passione ... - Expl. erweitert: ... et omnibus diebus vite nostre in gloria habitare. Sed dubitaret forte aliquis Iterum salvator noster mori voluit ... et celesti tuo patri in conspectum glorie tue me miserum commendare in te enim vere credo te confiteor unde tu domine etc.

(299ra) Dnca resurrectionis dni (am Rand ergänzt: Sermo primus) (Schneyer II Nr. 175). Inc.: Maria Magdalene et Maria Iacobi et Salomee emerunt aromata ut venientes ungerent Ihesum. Mr 16 et ultimis (1). Presens Novi Testamenti precipua festivitas inter ceteras venerabilis toto orbe terrarum ... - (299vb) Inc.: Maria (gestrichen: Iacobi, am Rand ergänzt: Magdalene) et Maria Iacobi et Salomee (Mc 16,1). Hee due fuerunt ultime sorores ex parte matris cum virgine gloriosa ... - Expl.: ... et impetravit orando coram ymaginem virginis. Vide Ieronimi in legenda ipsius etc. - (304vb) Tit. (am oberen Blattrand): In die sancto pasche. Sermo secundus (Schneyer II Nr. 176). - Inc.: [M]aria Magdalene etc. Marci ultimo (16,1). Divina scriptura istam habet proprietatem quod in una sui parte fideles ammonet lacrimari ... - Expl. abweichend: ... ad plenam pietatis graciam te adiuvante pervenire mereamur etc. - (310ra) Tit. (am oberen Blattrand): In die sancto pasche. Sermo tercius (Schneyer II Nr. 177). - Inc.: [S] urrexit non est hic Marci 16 (6). Quando dignitatem festorum tocius anni clarius inspicimus invenimus quod ipsa presens pascalis sollempnitas ... - Expl.: ... de eius utero quando natus fuit in mundo. Rogemus etc. - (313vb) Tit. (am oberen Blattrand): In die sancto pasche. Sermo quartus (Schneyer II Nr. 178). - Inc.: [E]xpurgate vetus fermentum etc. prime Corinthorum $5^{\circ}$ (7). Hodiernam pascalem videlicet festivitatem inter ceteras festivitates Christi precipuam ... - Expl.: ... ab omni mortis impetu tuum defendas populum etc. 
(318rb) Dnca 1. post pascha. Tit. (am oberen Blattrand): In octava pasche. Sermo primus (Schneyer II Nr. 179). - Inc.: Accipite spiritum sanctum quorum remiseritis peccata Ioh. 20 (22). Salvator noster Christus dominus sicut omnia in sua passione ostendit ut declararet suam humanitatem ... - Expl.. ... quia tu Deus protector noster es et solus gloriosus super omnem terram etc.

(322rb) Tit. (am oberen Blattrand): In octava pasche. Sermo secundus (Bibelzitat wie Schneyer II Nr. 180). - Inc.: Cum ergo sero factum esset die illa una sabatorum etc. Ioh. 20 capitulo (19). Hodie divina dies resurreccionis colitur in quo (!) perfecta requies designatur ... - Expl.: ... et vitam eternam possidere quam etc.

(325ra) Dnca 2. post pascha (Schneyer II Nr. 181). Inc.: Ego sum pastor bonus. Bonus pastor animam suam dat pro ovibus suis Ioh. X (11). Licet multe sunt cause in particulari quare lites et turbaciones surgunt inter homines in mundo ... - Expl.: ... vide in $2^{\circ}$ sermone post octavam Penthecostes scilicet Homo quidam erat dives.

(328va) Dnca 3. post pascha (Schneyer II Nr. 182). Inc.: [M]odicum et iam non videbitis me etc. Ioh. 16 (16). Imminente hora qua Christus dominus voluit pro nobis crucis passionem et mortem pati ... Expl.: ... quod numquam aufferetur ab eis quod nobis prestare dignetur etc.

(333rb) Dnca 4. post pascha (Schneyer II Nr. 183). Inc.: Vado ad eum qui me misit Ioh. 16 capitulo (5). Divina disposicione et providencia ab eterno Deus piissimus disposuit postquam Iudaycus populus ... - Expl.: ... Nescitis, quia amicicia huius mundi inimica est Deo etc.

(338rb) Dnca 5. post pascha (Schneyer II Nr. 184). Inc.: [A]men Amen dico vobis. Si quid pecieritis patrem in nomine meo dabit vobis Ioh. 16 (23). Quamvis multis modis homo serviat Deo et pro peccatis suis satisfaciat ... - Expl.: ... et hoc eciam post 6 menses factum est ut patet ibidem etc.

(344rb) Dnca 6. post pascha (Schneyer II Nr. 185). Inc.: [C]um venerit paraclitus quem ego mittam vobis a patre etc. Ioh. 15 (26). Misericors pater qui est prope est omnibus invocantibus eum in veritate quia nos orphanos non relinquit ... - Expl.: ... ut oportet assistere coram eo etc.

(346vb) Tit. (am oberen Blattrand): Sermo de sanctis infra pascha. - Inc.: [S]tabunt iusti in magna constancia etc. Sap. 5 (1). Circa quem textum est dicendum an sancti in eterna beatitudine quam habebunt post resurreccionem sedebunt vel stabunt ... - Expl.. ... Et hec misericordia propria est Deo Iohannes dicimus in Collecta Omnipotens sempiterne Deus cui proprium misereri semper et parcere etc.

Parallelüberlieferung: u. a. Innsbruck, ULB Tirol, Cod. 421, passim (Vorbesitzer Neustift), mit geringfügigen Abweichungen in der Anordnung. Gegenüber Cod. 53 fehlen die Sermones Bl. 156rb, 313vb, 322rb, 338rb, 344rb und 346vb.

Zur Überlieferung s. Lhotsky 75.

(348rb-vb) leer.

(HDS) Aufgeklebtes Fragment einer URKunde des Bischofs von Brixen an Johannes, scholasticus aus Isny (de Ysnina).

Perg. ca. 35×280, am seitlichen Rand jeweils mit Leder des Einbands überklebt. Erhaltener Schriftraum ca. $20 \times 250$. Drei Zeilen. Urkundenschrift (Trecento II), Brixen 2. H. 14. Jh.

Inc. mut.: ] episcopus Brixinensis dilecto nobis in Christo Iohanni scolastici (!) de Ysnina salutem in domino. Ecclesiam parrochialem sancti [...]usina nostre diocesis ad collacionem nostram pleno ... Expl. mut.: ... eius dimissionem tibi conferimus et de eadem providemus [

U.S. 


\section{Cod. 76}

\section{SAMMELHANDSCHRIFT}

Perg./Pap. I, 75, I* Bl. $270 \times 205$. T. I: Neustift, Mitte 15. Jh., T. II: St. Dorothea (Wien) und Neustift, 6. Jz. 15. Jh.

B: $\quad$ Zwei Teile: I (I, 1-16), II (17-74[75], I*). Foliierungen: 1) Älteste Foliierung (vor Zusammenbinden der zwei Teile) am oberen rechten Blattrand, tw. beschnitten 1-56, beginnend mit Kapitel 1 der Statuten (Bl. 19r). 2) Zweite Foliierung am unteren rechten Blattrand, tw. beschnitten bzw. überklebt 1-13, beginnend mit dem Prolog der Statuten (Bl. 17r). 3) Dritte Foliierung (im Zuge des Zusammenbindens 1457?) am rechten Blattrand mittig 1-74, beginnend mit der Regula s. Augustini (Bl. 1r). 4) Jüngste Foliierung 19. Jh. durch die ULB Tirol am rechten oberen Blattrand (hier berücksichtigt), entsprechend der dritten Foliierung; Fehler in der Zählung: 71 doppelt angeführt.

E: $\quad$ Neuzeitlicher Bibliothekseinband: schwarz gesprenkeltes braunes Pap. über Pappe. Neustift, 2. H. 18. Jh. Am VD und HD Ecken mit braunem Leder verstärkt. Rücken: braunes Leder, drei einfache Bünde, von Goldbordüren gesäumt. Im zweiten Feld Golddruck M. S. REGUL. S. AUGU. CUM COME. in Goldrahmung, im dritten Signaturschild (s. bei G). Spiegel sowie Vor- und Nachsatzbl. Pap. 18. Jh. Am Spiegel des VD Signaturen und Bleistiftnotiz (Vide Grundzettel), Spiegel des HD leer.

G: Zumindest T. II der Hs. wurde von Nikolaus, Propst des Augustiner Chorherrenstiftes St. Dorothea in Wien, im Zuge seiner Visitation des Klosters Neustift zurückgelassen und dort wohl von seiner Hand mit Visitationsinstrument (dat. Neustift, 18. Juli 1457) u. a. ergänzt. Abschrift vom Augustiner Chorherrn Petrus Ephensteiner 1728 in Neustift, Stiftsbibl., Cod. 29, S. 115-239. Hs. 1809 anlässlich der vorübergehenden Aufhebung des Klosters Neustift der ULB Tirol übergeben. Am VDS alte Signaturen der ULB Tirol II $\overline{1} H$ 8 (Tinte, Bleistift, ältere radierte Signatur überschrieben), daneben N. 76/(2) (Tinte, Bleistift). Am Rücken gelbes Signaturschild der ULB Tirol 76. Bl. 1r Stempel der ULB Tirol 19. Jh. 1921 aufgrund des Friedensvertrages von St. Germain an den italienischen Staat abgegeben und von diesem 1929 dem Kloster Neustift als Dauerleihgabe überlassen. Bl. 1r Stempel der Soprintendenza Tridentina 20. Jh.

L: $\quad$ Wretschko-Sprung 14-15. - Hermann 145, Nr. 162. - Sparber 227. - Kristeller I 439. - Neuhauser, Neustift 82. - Katalog ULB Tirol I 227, 282. - Peintner, Stiftsbibliothek 122. - Twenty-Fifth Saint Louis Conference on Manuscript Studies: Abstracts of Papers. Manuscripta 42 (1998) 139-157, hier 152. - H. Fasching, Die Wiener Konstitutionen für Regulierte Augustiner Chorherren in Österreich im 15. Jahrhundert (Beiträge zur Kirchengeschichte Niederösterreichs 16, Geschichtliche Beilagen zum St. Pöltner Diözesanarchiv 33). St. Pölten 2008, 87-94 (Sigle N). - Baroffio 324, Nr. 16709. - Rischpler 50.

$$
\text { I (I, 1-16) }
$$

B: $\quad$ Perg., vereinzelt löchrig, Bl. 16 genäht. Lagen: (I-1) (Vorsatzbl., Pap. 18. Jh.) + 2.IV ${ }^{16}$. Gegenbl. zum Vorsatzbl. als Spiegel auf dem VD aufgeklebt. Bl. 11r neuzeitliches gelbes Papiersignakel der ULB Tirol.

S: $\quad$ 1) Bl. 1r-10v: Schriftraum $180 \times 90$, von Tintenlinien begrenzt, zu 20 Zeilen. Kalligraphische Bastarda. Am Blattrand tw. Notizen von späterer Hand.

2) B1. 11r-15v: Schriftraum $215 \times 130$, von Bleistiftlinien seitlich begrenzt, zu 25 Zeilen, tw. auf Bleistiftlinierung. Textualis. Am Blattrand bisweilen Notizen von späterer Hand.

A: 1) Bl. 1r-10v: Rote Auszeichnungsstriche. Bl. 1r sechszeilige Fleuronnée-Initiale: blauer Buchstabenkörper mit ausgesparten Halbpalmetten, die mit feinem Tintenstrich und roter Kreuzschraffur herausgearbeitet sind; im Binnenfeld auf rotem Grund Ähre aus gestrichelten, spitzknospenartigen Halbpalmetten (an den Stiel zurückgeklappt); als Besatz Halbpalmetten, durch Zackenlinien verbunden und mit Doppelstrichen verziert. Von der Hand des Hauptflorators der Neustifter Gradualien (Graduale Neocellense I, dat. 1442; Graduale Neocellense II, zw. 1442 und 1446).

2) Bl. 11r-15v: Rote Auszeichnungsstriche, Unterstreichungen, Paragraphzeichen, Überschriften. Bl. 12r Zeigehand. Satzmajuskeln tw. cadellenartig verziert. Bl. 11r zweizeilige rote Lombarde mit blütenförmiger Aussparung, Binnenfeld rot ausgemalt. 
$(\mathrm{Ir}-\mathrm{v})$ leer.

1 (1r-10v) Regula s. Augustini (PL 32, 1377-1384. Regula recepta = Ordo monasterii, Satz $1+$ Praeceptum [CPL Nr. 1839b]. Vgl. L. Verheijen, La règle de saint Augustin 1 [Études augustiniennes 15,1]. Paris 1967, 417-437).

2 (11r-15v) QuAestio SOLLEMnis.

Tit.: Questio solempnis cuiusdam doctoris theologie coram papa Eugenio et cardinalibus de religiosis quando professus mortaliter aut venialiter peccat. - Inc.: Utrum religiosus professus et divina precepta cum substancialibus regule conservans ... - Expl.. ... Quam nobis consequi concedat Ihesus Christus benedictus Amen. $(16 \mathrm{r}-\mathrm{v})$ leer.

$$
\text { II (17-74[75], I*) }
$$

B: $\quad$ Bl. 17 Perg. (Falz zw. Bl. 27 und 28). Bl. 18-74 Pap., tw. an den Rändern verstärkt. Bilder und Nachweise der Wasserzeichen s. WZMA. Datierung nach Wasserzeichenbefund. Identische Wasserzeichen: u. a. Innsbruck, ULB Tirol, Cod. 199 (dat. 1458/59); Klosterneuburg, Stiftsbibl., CCl 147 (dat. 1464). Lagen (unsicher): $(\mathrm{III}+5)^{27}+2 . \mathrm{VI}^{51}+4^{55}+(\mathrm{V}-2+2)^{65}+(\mathrm{III}+3)^{73(74)}+1^{74(75)}+(\mathrm{I}-1)^{\mathrm{I}^{*}}($ Nachsatzbl., Pap. 18. Jh). Bl. 1719, 26, 27, 52-57, 66-68, 74 eingefügte Einzelbl. Gegenbl. zum Nachsatzbl. als Spiegel auf dem HD aufgeklebt. Bl. 17r neuzeitliches gelbes Papiersignakel. Bl. 63v tw. mit Papierblatt (korr. Text?) überklebt.

S: $\quad$ B1. $17 \mathrm{r}-18 \mathrm{v}$ Schriftraum $225 \times 130$, von Blind- bzw. Tintenlinien begrenzt, zu 38 Zeilen, Bl. 19r-73v Schriftraum $215 \times 115$, zumeist von Tintenlinien begrenzt. Bastarda von drei Händen: 1) Bl. 17r-26r, Z. 2 und Z. 6-33, Bl. 27r-54v und Bl. 63v, Z. 23-Bl. 73v. Schreiber möglicherweise Nikolaus, Propst von St. Dorothea, in Neustift 1457 (Bl. 66r Datierung der abgeschriebenen Visitationsurkunde Neustift, 1457 Juli 18); 2) Bl. 26r, Z. 3-5 und Z. 34-Bl. 26v; 3) Bl. 55r-63v, Z. 22.

Bl. 74r Nachtrag: Schriftraum $115 \times 165$. Antiquakursive, Mitte 17. Jh. (1653?). Am Blattrand bisweilen Notizen von späteren Händen, tw. dt.

A: Rubrizierung wohl von einer Hand: Rote Auszeichnungsstriche, Unter- bzw. Durchstreichungen, Überschriften, ein- bzw. zweizeilige Lombarden, tw. mit roter Deckfarbe gefüllt oder einfach verziert. B1. 71 $\mathrm{Ir}$ Cadelle mit Profilkopf in Federzeichnung. Repräsentanten.

3 (17r-53v) sog. „Wiener Statuten“: Statuta canonicorum regularium sub episcopis Pataviensibus Georgio et Leonhardo (1389-1451) ordinata pro monasteriis BMV in Dürnstein et s. Dorothea (Wien) (Ed. Fasching 149-454).

(17r) Prolog. Tit.: Incipit prologus in statuta canonicorum regularium. - Inc.: Cum ex primo et principali nostre regule precepto teneamur habere cor unum et animam unam ... - Expl.: ... et doctorum sigillis communita.

(17v) Register.

(19r) Haupttext, bestehend aus 59 Kapiteln. Tit. (cap. 1): De recepcione noviciorum et pena dancium aut recipiencium aliquid pro ingressu de absolucione a censuris et preparacione ad confessionem generalem et de rebus eorum. Capitulum primum. - Inc.: Quando aliquis se cupit ad communem vitam transferre ... - Expl.: ... ut in scrutinio facile reperiantur. Explicit.

Die anlässlich der Visitation von 1457 eingeführten sog. „Wiener Statuten“ wurden im Augustiner Chorherrenstift Neustift wahrscheinlich bis ins 18. Jh. verwendet. Wohl als anonyme Privatarbeit wurden sie in abgeänderter Form 1695 bei Paul Nikolaus Führer in Brixen gedruckt: „Statuta Religiosa, Canonicis Regularibus Lateranensibus Collegii Neocellensis S. Mariae Ad Gratias observanda“" (vgl. Fasching 100-101).

Zur breiten hs. Überlieferung vgl. Fasching 52-53. Text wie: Herzogenburg, Stiftsbibl., Cod. 12 (Prov. Augustiner Chorherrenstift Dürnstein). Abschrift in: Neustift, Stiftsbibl., Cod. 29 (dat. 1728), S. 117-194, „Libellus primus“. 
4 (53v-63v) LiBELLuS OFFICIORUM (Ed. Fasching 457-542).

(53v) Prolog. Tit.: Incipit prologus in libellum officiorum. - Inc.: Preterea quam divinum officium concernunt ... - Expl.: ... vel contemptum.

(54r) Register.

(54r) Haupttext, bestehend aus 16 Kapiteln. Tit.: Incipit libellus officiorum de prelato et eius conversacione. - Inc.: Prelatus monasterii qui tam verbo quam exemplo fratribus sibi commissis preesse debet ... - Expl.: ... pater noster cum totidem ave Maria.

Zur breiten hs. Überlieferung vgl. Fasching 52-53, Abschrift in: Neustift, Stiftsbibl., Cod. 29 (dat. 1728), S. 194-208, „Libellus secundus“.

(63v-65v) De plebanis (Ed. Fasching 554-557).

Tit.: Sequitur capitulum de plebanis quales debeant esse. - Inc.: Plebani quia post prelatum maioribus quam ceteri fratres sunt periculis expositi ... - Expl.: ... non valeat induci.

Schlussschrift: Expliciunt statuta.

Parallelüberlieferung: Herzogenburg, Stiftsbibl., Cod. 12 (Prov. Augustiner Chorherrenstift Dürnstein); Abschrift in: Neustift, Stiftsbibl., Cod. 29 (dat. 1728), S. 215-218, „Libellus secundus", cap. 17.

6 (66r-71v) Abschrift des Visitationsinstruments des Augustiner Chorherrenstiftes Neustift durch Nikolaus, Propst von St. Dorothea in Wien, der von Nicolaus Cusanus im Zuge der Melker Reform als Visitator nach Neustift entsandt wurde.

Tit.: Sequitur carta in monasterio Novacellensi relicta per reverendissimum patrem dominum Nicolaum praepositum s. Dorothee Vienne in visitatione 1457. - Inc.: In nomine domini Amen. Splendor paterne glorie...

Datierung: Datum in sepe dicto monasterio Novecelle die lune decimaoctava mensis Iulii anno domini millesimo quadringentesimo quinquagesimo septimo.

Originale Pergamenturkunde (Neustift, Stiftsarchiv, VV 50) mit Wachssiegel des Propstes Nikolaus von St. Dorothea an Hanfschnur, dat. Neustift, 1457 Juli 18, bestätigt vom Brixner Bischof Nikolaus Cusanus.

Abschrift in: Neustift, Stiftsbibl., Cod. 29 (dat. 1728), S. 219-228.

$7 \quad\left(71^{\mathrm{I}} \mathrm{r}-72 \mathrm{v}\right)$ Abschrift einer Cedula für das Augustiner Chorherrenstift Neustift, verfasst von Nikolaus, Propst von St. Dorothea in Wien, im Rahmen seiner Visitation des Klosters Neustift 1457 (Ed. Fasching 686-689).

Tit.: Sequitur copia cedule per dominum prepositum sancte Dorothee hic relicte. - Inc.: Sicut tactum est in carta quadam hoc in loco reperta ...

Originale Pergamenturkunde nicht mehr erhalten.

Abschrift in: Neustift, Stiftsbibl., Cod. 29 (dat. 1728), S. 228-231.

8 (73r-v) ÜBer die Pfründnerschaft im Kloster, dt. (Ed. Fasching 572-573).

Tit.: De donatis. - Inc.: Wer begert zu ainem donatum aufgenommen werden, der sol vor wissen, daz er nit zu müssichait und rue ... - Expl.: ... nyemands icht darumb gepunden noch schuldig. Abschrift in: Neustift, Stiftsbibl., Cod. 29 (dat. 1728), S. 231-233.

9 (74r) Kapitelbeschluss von 1653, betreffend die Vigil des Augustinustages in Neustift und die Frage der Abstinenz.

Inc.: Anno salutis MDCLIII septimo Kalendis Septembris ad maiorem Dei gloriam S. P. N. Augustini honorem ...

Abschrift in: Neustift, Stiftsbibl., Cod. 29 (dat. 1728), S. 234.

$(74 \mathrm{v})$ leer.

$\left(I^{*} \mathrm{r}-\mathrm{v}\right)$ leer. 
Zu Nikolaus de Corona (Kronstadt, Siebenbürgen), Propst von St. Dorothea in Wien (14281458), und der Visitation in Neustift vgl. u. a. F. Röhrig, Wien - St. Dorothea, in: F. Röhrig (Hrsg.), Die ehemaligen Stifte der Augustiner-Chorherren in Österreich und Südtirol (Österreichisches Chorherrenbuch. Die Klöster der Augustiner-Chorherren in der ehemaligen Österreichisch-ungarischen Monarchie 1). Klosterneuburg 2005, 664-665; Fasching 19-24. Zu seiner Visitationstätigkeit vgl. auch M. Niederkorn-Bruck, Die Melker Reform im Spiegel der Visitationen (MIÖG Erg.-Bd. 30). Wien 1994.

C.S.

\section{Cod. 77}

\section{THOMAS DE AQUINO. PETRUS BLESENSIS}

Pap. I, 120, I* Bl. $275 \times 200$. Basel, 1465.

B: Pap. bes. am Beginn und am Schluss fleckig. Nachweise und Bilder der Wasserzeichen s. WZMA. Wasserzeichenbefund mit Datierung übereinstimmend. Lagen: $(\mathrm{I}-1)^{\mathrm{I}}$ (Vorsatzbl. 18. Jh.) $+10 . \mathrm{VI}^{119(120)}+(\mathrm{I}-1)^{\mathrm{I}^{*}}$ (Nachsatzbl. 18. Jh.). Gegenbl. zum Vor- bzw. Nachsatzbl. als Spiegel auf dem VD bzw. HD aufgeklebt. Lage 3 und 4 vertauscht (s. bei Inhalt). Am oberen Blattrand Foliierung 19. Jh. durch die ULB Tirol; Fehler in der Zählung: 47 doppelt angeführt. Bl. 107 und 113 Reste von neuzeitlichen gelben Papiersignakeln der ULB Tirol.

S: $\quad$ Schriftraum 240/245 $\times 155 / 160$. Zwei Spalten, Bl. 1r-47'v von Bleistift- bzw. Blindlinien gerahmt, Bl. 48r119v von feinen Tintenlinien gerahmt, zu 51-61 Zeilen. Flüchtige Bastarda, dat. 1465 (Bl. 106vb, 112vb [Basel, 9. September.], 119va [13. September]). Am Blattrand Zählung der einzelnen Quaestiones, tw. beschnitten.

A: Rote Auszeichnungsstriche, Paragraphzeichen (ähnlich Zeilenanschlusszeichen) und Unterstreichungen. $\mathrm{Bl}$. 1ra sechszeilige rote Initiale mit ausgesparter vierblättriger Blüte, Bl. 113ra fünfzeilige Initiale nicht ausgeführt. Bl. 27v-36v, 47v-47'v, 50v-59r, 68v-71v, 74v-95v, 101v-107v, 108v-119v keine Rubrizierung.

E: $\quad$ Neuzeitlicher Bibliothekseinband: schwarz gesprenkeltes braunes Pap. über Pappe. Neustift, 2. H. 18. Jh. Am VD und HD Ecken mit braunem Leder verstärkt. Rücken: braunes Leder, vier einfache Bünde, von Goldbordüren gesäumt. Im ersten Feld Golddruck M: S:, im zweiten Golddruck OPERA THEOLOGICA in Goldrahmung, darunter Signaturschild (s. bei G). Schnitt rot gesprenkelt. Am Spiegel des VD Signaturen, Exlibris und Bleistiftnotiz (s. bei G), Spiegel des HD leer.

G: Zeitpunkt und Art der Erwerbung durch Neustift unbekannt. Am Spiegel des VD Exlibris der Stiftsbibl. Neustift 18. Jh. 1809 anlässlich der vorübergehenden Aufhebung des Klosters Neustift der ULB Tirol übergeben. Am Spiegel des VD alte Signaturen der ULB Tirol II 1 K 9 (Bleistift) und Nr. 77/(1) (Tinte, Bleistift) sowie Bleistiftnotiz (Thomas de Aquino Vide Grundzettel). Am Rücken gelbes Signaturschild der ULB Tirol 77(1). Bl. 1r Stempel der ULB Tirol 19. Jh. 1921 aufgrund des Friedensvertrages von St. Germain an den italienischen Staat abgegeben und von diesem 1929 dem Kloster Neustift als Dauerleihgabe überlassen. Bl. 1r Stempel der Soprintendenza Tridentina 20. Jh.

L: $\quad$ Katalog ULB Tirol I 227, 283. - Stefani 95.

(Ir-v) leer.

1 (1ra-112vb) Traktat in enger Anlehnung an: Thomas de Aquino: Super librum quartum Sententiarum (Vgl. Druck: u. a. GW M46385. Ed. Opera omnia XI. Paris 1847. - Glorieux Nr. 14f4. Grabmann 286-290. Shooner Nr. 1126, 10).

Gegenüber Druck bisweilen abweichend und gekürzt, Reihenfolge der Quaestiunculae vereinzelt abgeändert, Expositiones textus am Ende der einzelnen Distinctiones nicht immer enthalten, Kommentare jeweils an die einzelnen Quaestiones und Quaestiunculae direkt anschließend. Lage 3 und 4 (Bl. 25-47) im Zuge der Neubindung vertauscht, daher Forts. von Bl. 24vb (Dist. 9) auf 
Bl. 37ra, Forts. von Bl. 47vb (Dist. 14) auf Bl. 25ra, Forts. von Bl. 36vb (Dist. 16) auf Bl. 48ra (kein Textverlust).

(1ra-106vb) Text. Inc.: Circa distinccionem sacramenti (!) queritur utrum hec distinccio sit bona. Sacramentum est invisibilis gracie visibilis forma ut ymaginem gerat et causa existat. Resspondo (!) quod sic quia completissime racionem sacramenti designat ... (Dist. 1, qu. 1, art. 1, quaestiunc. 3) ... Queritur utrum hec sit bona. Sacramentum est sacre rei signum respondeo quod sic quia sacramentum secundum proprietatem vocabuli videtur ... (Dist. 1, qu. 1, art. 1, quaestiunc. 1) ... - Expl.: ... de quibus penis nos liberet et ad gaudium nos perducat qui sine fine regnat Amen.

Enthält: (1ra) Dist. 1. - (4vb) Dist. 2. - (6vb) Dist. 3. - (8va) Dist. 4. - (11va) Dist. 5. - (13ra) Dist. 6. - (15rb) Dist. 7. - (17ra) Dist. 8. - (23ra) Dist. 9. - (25ra) Forts. Dist. 14. - (28rb) Dist. 15. (36rb) Dist. 16. - (37ra) Forts. Dist. 9. - (38ra) Dist. 10. - (39va) Dist. 11. - (43ra) Dist. 12. (46rb) Dist. 13. - (47vb) Dist. 14. - (48ra) Forts. Dist. 16. - (49vb) Dist. 17. - (54vb) Dist. 18. (57va) Dist. 19. - (59ra) Dist. 20. - (60vb) Dist. 21. - (62rb) Dist. 22. - (63va) Dist. 23. - (64vb) Dist. 24. - (66vb) Dist. 25. - (68ra) Dist. 26. - (68va) Dist. 27. - (69va) Dist. 28. - (69vb) Dist. 29. - (70ra) Dist. 30. - (70va) Dist. 31. - (71ra) Dist. 32. - (71va) Dist. 33. - (73rb) Dist. 34. (74rb) Dist. 35. - (74va) Dist. 36. - (75ra) Dist. 37. - (75rb) Dist. 38. - (77vb) Dist. 39. - (78ra) Dist. 40. - (79ra) Dist. 41. - (80ra) Dist. 42. - (80vb) Dist. 43. - (82rb) Dist. 44. - (88ra) Dist. 45. - (90va) Dist. 46. - (92vb) Dist. 47. - (94vb) Dist. 48. - (95vb) Dist. 49. - (104va) Dist. 50. (106vb) Schlussschrift: Et sic est finis Questionum fratris Thome de Aquino ordinis Predicatorum super quartum Sentenciarum anno domini 1465.

(106vb-112vb) Register, geordnet nach Distinctiones und Quaestiones.

(112vb) Schlussschrift: Expliciunt Questiones super quartum Sentenciarum cum earum registro magistri Thome de Aquino cum solis solucionibus dimissis de gerentibus. In Basilea anno domini MCCCC ${ }^{\circ} \mathrm{LXV}$ (gestrichen: in die) secunda feria in die Kunigundis (9. September 1465).

2 (113ra-119va) Petrus Blesensis: Compendium in Iob (PL 207, 795C-826B. - Stegmüller RB Nr. 6431). Dem Kommentar ist ein Widmungsbrief an König Heinrich II. Plantagenêt vorangestellt.

Schlussschrift: Finitum est Idus Septembris anno domini LXV. Deo gracias (13. September 1465).

(119vb) nur Rahmung.

$\left(\mathrm{I}^{*} \mathrm{r}-\mathrm{v}\right)$ leer.

A. P./U. S.

\section{Cod. 78}

\section{PEREGRINUS OPPOLIENSIS}

Pap. I, 120, I* Bl. $280 \times 205$. Raum Brixen (Neustift?), um 1430/33.

B: Pap. etwas fleckig, Bl. 119v stark verschmutzt. Bilder und Nachweise der Wasserzeichen s. WZMA. Datierung nach Wasserzeichenbefund. Identische Wasserzeichen: u. a. Neustift, Stiftsbibl., Cod. 177; Wilten, Stiftsbibl., Cod. 3202 05, T. IV (dat. 1431); Innsbruck, ULB Tirol, Cod. 437, T. II (Stams, dat. 1432), Cod. 666, T. III (Schnals, dat. 1433). Lagen: $(\mathrm{I}-1)^{\mathrm{I}}$ (Vorsatzbl. 18. Jh. $)+10 . \mathrm{VI}^{119(120)}+(\mathrm{I}-1)^{\mathrm{I}^{*}}($ Nachsatzbl. 18. Jh.). Gegenbl. zum Vor- bzw. Nachsatzbl. als Spiegel auf dem VD bzw. HD aufgeklebt. Am oberen Blattrand Foliierung 19. Jh. durch die ULB Tirol; Fehler in der Zählung: 115 doppelt angeführt.

S: $\quad$ Schriftraum $185 / 200 \times 120 / 130$. Zwei Spalten, von feinen Tintenlinien gerahmt, zu 35-43 Zeilen. Zirkelstiche. Bastarda von zwei Händen: 1) Bl. 1ra-60vb; 2) Bl. 61ra-119rb. Oberlängen der Buchstaben der ersten Zeile bisweilen gelängt. Vereinzelt Randnotizen und Kapitelzählung von späterer Hand. 
A: Rote Auszeichnungsstriche, Unterstreichungen, Überschriften und Schlussschrift. Rubrizierung (insbes. Titel) bisweilen nicht ausgeführt. Zeigehände. Zwei- bzw. dreizeilige rote Lombarden, tw. mit Punktverdickungen, tw. mit einfach verzierten Ausläufern. Ab Bl. 61 Repräsentanten. Bl. 1ra sechszeilige rote Lombarde mit leicht verziertem Ausläufer.

E: $\quad$ Neuzeitlicher Bibliothekseinband: schwarz gesprenkeltes braunes Pap. über Pappe. Neustift, 2. H. 18. Jh. Am VD und HD Ecken mit braunem Leder verstärkt. Rücken: braunes Leder, vier einfache Bünde, mit Goldbordüren gerahmt. Im zweiten Feld Golddruck M. S. DE TEMP. 1460 (Datierung?) in Goldrahmung, im dritten Signaturschild (s. bei G). Schnitt rot gefärbt. Am Spiegel des VD Signaturen und Bleistiftnotiz (s. bei G), Spiegel des HD leer.

G: $\quad$ Bl. 119v Besitzvermerk 15. Jh. Iste liber est monasterii s. Marie ad Novacellam. 1809 anlässlich der vorübergehenden Aufhebung des Klosters Neustift der ULB Tirol übergeben. Am Spiegel des VD alte Signaturen der ULB Tirol II $1 \mathrm{~K} 10$ (Bleistift) und Nr. 78 (Tinte) sowie Bleistiftnotiz (Vide Grundzettel). Am Rücken gelbes Signaturschild der ULB Tirol 78. Bl. 1r Stempel der ULB Tirol 19. Jh. 1921 aufgrund des Friedensvertrages von St. Germain an den italienischen Staat abgegeben und von diesem 1929 dem Kloster Neustift als Dauerleihgabe überlassen. Bl. 1r Stempel der Soprintendenza Tridentina 20. Jh.

L: $\quad$ Katalog ULB Tirol I 227, 283.

$(\mathrm{Ir}-\mathrm{v})$ leer.

(1ra-119rb)〈Peregrinus Oppoliensis〉: Sermones de sanctis (Schneyer 4, 558-572). Tit.: Incipiunt sermones de sanctis per circulum anni.

(1ra) De s. Andrea (Nr. 195). (1vb) Nr. 196. (3ra) Nr. 197. - (4rb) De s. Nicolao (Nr. 198). Inc.: Benediccionem omnium gencium dedit illi. Sap. (Sir 44,25). In verbis istis ostendit nobis spiritus sanctus quedam signa in beato Nicolao propter que signa obtinuit benediccionem omnium gencium ... (4vb) Nr. 199. (6rb) Nr. 200. - (7ra) De s. Lucia (Nr. 201). - (7vb) De s. Thoma ap. (Nr. 202). Expl.: ... in castitate Deo spiritum reddiderunt.

(8vb) Inc.: Affer manum tuam et mitte in latus meum (Io 20,27). Benigni homines habent modum dum vident aliquem ex caris amicis suis cecidisse in aliquam passionem solent eos instruere ... - Expl.: ... sine mortalibus peccatis existentibus.

Parallelüberlieferung: Neustift, Stiftsbibl., Cod. 617, B1. 136r (Entstehungsort: Neustift, 1455); Innsbruck, ULB Tirol, Cod. 71, Bl. 21rb (Vorbesitzer: Wilten, Entstehungsort: Tirol, 15. Jh.), Cod. 207, Bl. 5va (Vorbesitzer: Schnals, Entstehungsort: Österreich, dat. 1440, Schreiber: Christianus de Engelprecz).

(10va) De s. Stephano (Nr. 203). (11rb) Nr. 204. (12ra) Nr. 205. Expl.. ... venit ad amplexus domini (wie Innsbruck, ULB Tirol, Cod. 207, Bl. 7rb). (12va) Nr. 111 (Expl. auch Nr. 205, wie Innsbruck, ULB Tirol, Cod. 207, Bl. 7va). - (13vb) De s. Iohanne ap. (Nr. 113). Expl.: ... recedente autem luce fovea plena manna reperitur sicut plenius supra dictum est (Expl. vgl. Innsbruck, ULB Tirol, Cod. 71, Bl. 26vb und Cod. 207, Bl. 8ra). (15ra) Nr. 206. (15vb) Nr. 207. Expl. (erweitert): ... sed perseveravit in fide Christi ut vicissitudinem Christi amicicie proposse redderet etc. (Expl. wie Innsbruck, ULB Tirol, Cod. 71, Bl. 29va und Cod. 207, Bl. 9va). - (16va) De s. Innocentibus (Nr. 208). (17rb) Nr. 209. Expl.: ... carnifices guttura eorum gladio figebant ridebant. Sic et tu $2 \mathrm{~m}$ et $3 \mathrm{~m}$ collige supra etc. (vgl. Innsbruck, ULB Tirol, Cod. 71, Bl. 31rb und Cod. 207, Bl. 10rb). (18ra) Nr. 210. Expl.: ... pro eo quod non correxit eum a iuventute sua (Expl. vgl. Innsbruck, ULB Tirol, Cod. 207, Bl. 10va).

(18rb) De s. Thoma martyre (Nr. 211). - (19rb) De s. Fabiano et Sebastiano (Nr. 212). - (19vb) De s. Agnete (Nr. 213). - (20vb) In conversione s. Pauli (Nr. 214). (22rb) Nr. 215. (23va) Nr. 216. Expl.: ... quod lac fluxit pro sangwine de corpore suo (Expl. vgl. Innsbruck, ULB Tirol, Cod. 71, Bl. 39vb und Cod. 207, B1. 15ra). - (25rb) In purificatione BMV (Nr. 217). (26rb) Nr. 218. (27va) Nr. 219.

(29rb) Tit.: Idem sermo. - Inc.: Ecce ego mitto angelum meum qui preparabit viam ante faciem tuam. Malach. $3^{\circ}$ (1). In verbis istis $4^{\text {or }}$ (Innsbruck, ULB Tirol, Cod. 207, Bl. 18ra: quinque) notantur. Primum est quod dominus dicit Ecce ego mitto angelum meum etc. $2 \mathrm{~m}$ est quod dicit ... - Expl.: ... ut nos cum illo et ipse nobiscum usque in finem perseveret.

Parallelüberlieferung: Innsbruck, ULB Tirol, Cod. 71, Bl. 45va und Cod. 207, Bl. 18ra. 
(30va) In cathedra s. Petri (Nr. 220). (31va) Nr. 221. (32vb) Nr. 124. Expl.. ... ipsum imitari. Exaltavit et eum in virtute miraculorum. Hic dic miracula. - (33ra) De s. Matthia (Nr. 222). (35ra) (Bibelzitat und Expl. wie Nr. 223). Inc.: Tu domine qui nosti corda hominum etc. Actus $(1,24)$. Hodie in ecclesia agitur de duabus personis scilicet de Iuda qui est de honore suo detrusus ... (36ra) Nr. 224. - (37ra) De s. Gregorio (Nr. 126). Expl.: ... semper sum circa te. Ecce quanta felicitas (Expl. wie Innsbruck, ULB Tirol, Cod. 207, Bl. 22vb). (38ra) Nr. 225. - (38vb) De s. Benedicto (Nr. 127). Expl.: ... dominus parvulos amplexatus est et eos ad se vocari facit prosequere sicut vis (vgl. Expl. Nr. 226). - (39vb) In annuntiatione BMV (Nr. 227). (42ra) Nr. 228. (43va) Nr. 229. (44vb) Nr. 230. Expl.: ... Hic dic exemplum de muliere et puero require supra. (45ra) Nr. 232. Expl.: ... ut mediante gracia sua perveniamus ad gaudia eterna etc. (Expl. wie Innsbruck, ULB Tirol, Cod. 207, Bl. 27rb). (46vb) Nr. 233. - (48vb) De s. Ambrosio (Nr. 129). Expl.: ... quid sic factum est et sic patet quomodo exaltatus est in presenti (Expl. wie Innsbruck, ULB Tirol, Cod. 207, Bl. 29rb). - (49vb) De s. Georgio (Nr. 234). (51va) Nr. 235. - (52vb) De s. Marco (Nr. 132). Expl.: ... quia potest nos iuvare corpore et anima (Expl. wie Innsbruck, ULB Tirol, Cod. 207, Bl. 30vb). (53vb) Nr. 236. - (55rb) De s. Philippo et Iacobo (Nr. 134). Expl.: ... peccatores in magna constancia. (56ra) Nr. 238. - (57va) In inventione s. crucis (Nr. 239). Expl.: ... vestitus regia veste. Sic etc. (Expl. wie Innsbruck, ULB Tirol, Cod. 207, Bl. 32rb). (58vb) Nr. 136. (60ra) Nr. 240. - (61rb) De s. Iohanne ante Portam Latinam (Nr. 241). (61vb) Nr. 242. Expl.: ... ubi pax ibi Deus et ubi Deus ibi omne bonum etc. - (62rb) De s. Barnaba (Nr. 140). Expl.: ... et eum ibidem protinus combusserunt. Et sic amiciciam Dei est consecutus etc. - (63rb) De s. Vito (Nr. 243). Expl.: ... ne per accidiam separaretur ab eo. - (64ra) De s. Iohanne Baptista (Nr. 142). Expl.: ... totus mundus est consolatus.

(64vb) Tit.: De eodem. - Inc.: Tu puer propheta altissimi vocaberis preibis enim ante faciem domini parare vias eius (Lc 1,76). Nota quod est triplex via. Prima in mundum, 2a per mundum, 3a extra mundum. Prima via in mundo (!) est lamentabilis ... - Expl.: ... Propterea circumdatus es laqueis etc. (65va) De s. Petro et Paulo (Nr. 248). Expl.: ... in omni vita sua nichil aliud operatus est nisi quod laboravit oravit et predicavit. - (67ra) De s. Margareta (Nr. 252). - (68ra) De s. Maria Magdalena (Nr. 253). (69ra) Nr. 255.

(69vb) Ohne Tit. Inc.: Ponam arcum meum in nubibus celi et erit signum federis mei. Gen. 9 (13). Hec verba possunt exponi de beata Maria Magdalena que intelligitur per arcum celestem propter tria. Primo racione materie ... - Expl.: ... quantum optimam partem celestis glorie elegit dicitur illuminata (vgl. 〈Aldobrandinus de Cavalcantibus〉 [=〈Ps.-Thomas de Aquino〉]: Sermo 53: De s. Maria Magdalena [Druck: S. E. Fretté, Thomae Aquinatis Opera Omnia 29. Parisiis 1876, 317]. - Vgl. Schneyer 8, 620, Nr. 36).

(70ra) De s. Iacobo (Nr. 257). Expl.: ... potestis calicem bibere. Responderunt audacter Possumus. (71ra) Nr. 259. - (72ra) De s. Petro ad vincula (Nr. 149). Expl.: ... et regni eius non erit finis. (73ra) Nr. 262. - (73va) De s. Laurentio (Nr. 263). Expl.: ... et hoc spontanee quia voluntarie ibat ad supplicia dic legendam. (74ra) Nr. 264. (75ra) Nr. 150. Expl.: ... Imperatorem tunc obisse et unam aurem fractam esse in testimonium. - (75vb) In assumptione BMV (Nr. 151). Expl.: ... et multis retulit que vidit et audivit et sic multi crediderunt etc. (77rb) Nr. 265. (78va) Nr. 266. (79va) Nr. 267.

(80ra) Ohne Tit. Inc.: Vidi alterum angelum descendentem de celo amictum nube et yris in capite eius et facies eius sicut sol Apoc. $(10,1)$. In verbis istis tria notantur de sancto (gestrichen: Barth, am Rand korr. zu: Bernhardo). Primo sanctitas vite cum dicitur Vidi alterum angelum descendentem de celo amictum nube. Primus enim angelus fuit beatus Benedictus ... - Expl.: ... in peccatis vivificavit suis miraculis sicut in vita sua legitur etc.

(80vb) De s. Bartholomaeo (Nr. 268). (81rb) Nr. 269. Expl.: ... quattuor seris scilicet pudore confitendi spe longioris vite timore pene et desperacione etc. (82vb) Nr. 270. (83vb) Nr. 271. (85ra) De s. Augustino (Nr. 272). - (86rb) In decollatione s. Iohannis Baptistae (Nr. 273). (87rb) Nr. 274. Expl.: ... dyabolus decollavit eum etc. - (87vb) In nativitate BMV (Nr. 275). (88vb) Nr. 276. (89vb) Nr. 155. Expl.: ... et cognoscamus et amemus eum ut ab ipso numquam seperemur (!) etc. (91rb) Nr. 277. Inc.: Nova lux oriri visa est honor et tripudium aput omnes populos urbis (!) et provincias Hester V (recte: 
8,16-17). Quia nativitatem beate Marie agimus ideo gaudere debemus quia ipsa est stella ... - (92vb) In exaltatione s. crucis (Nr. 278). (94ra) Nr. 156. Expl.: ... ut te eriperet de faucibus leonum infernalium id est demonium. - (95rb) De s. Matthaeo (Nr. 279). (96va) Nr. 280.

(97vb) Tit.: De sancto Mauricio. - Inc.: Absterget Deus omnem lacrimam etc. Apoc. (7,17 und 21,4). Ad mimitacionem (!) sanctorum flere debemus et nos quinque de causis ... - Expl.: ... Lacrimis meis stratum meum rigabam etc.

(98va) De s. Michaele et de s. angelis (Nr. 284). Inc.: Omnes sunt aministratorii spiritus in ministerium missi propter eos qui hereditatem capiunt salutis gloria id est hominis quibus promittitur vita eterna Heb. II (recte: 1,14). Modus est nobilium et aliorum honestorum virorum quod ad filiorum suorum custodiam et instruccionem ponunt suos servos ... (99va) Nr. 285.

(100va) Inc.: Omnes sunt aministratorii spiritus etc. Heb. II ${ }^{\circ}$ (recte: 1,14$)$. Hodie agimus festum omnium angelorum et hoc propter plures causas. Primo quia singulariter omnes honorare non possumus. Isto die omnes honoremus ... - Expl.: ... et inter choros martirum collocavit etc.

Parallelüberlieferung: Innsbruck, ULB Tirol, Cod. 207, Bl. 63va.

(101va) De s. Michaele et de s. angelis (Nr. 286). (103rb) Nr. 287. - (104rb) De s. Hieronymo (Nr. 288). (104vb) De s. Luca (Nr. 289). Expl.: ... et mortuos sedebit sicut ipse dominus ait In generacione etc. (Expl. vgl. Innsbruck, ULB Tirol, Cod. 207, Bl. 66ra). - (105vb) De s. Ursula et de undecim milibus virginum (Nr. 290). - (106va) De s. Simone et Iuda (Nr. 291). (107rb) Nr. 292. (108ra) Nr. 293. (108vb) Tit.: De eodem (Schneyer: De omnibus Sanctis, Nr. 294). (109va) De omnibus Sanctis (Nr. 295). (110ra) Nr. 296. - (110vb) In commemoratione omnium fidelium defunctorum (Nr. 298). (111va) Nr. 299.

(112ra) Ohne Tit. Inc. vgl. «Sifridus Niger〉 (Schneyer 5, 432, Nr. 49) bzw. anonymer Sermo (Schneyer 9, 535, Nr. 59, zu Stuttgart, LB, theol. fol. 332). Inc.: Mittite partes eis qui non preparaverunt sibi.

(2) Esdre (8,10). Consuetudo in mundo est quando aliquis usque in mortem in carcere cruciatur mittit ad amicos suos de quibus maxime confidit ... - Expl.: ... illis qui sunt in purgatorio.

Parallelüberlieferung: Innsbruck, ULB Tirol, Cod. 207, Bl. 75rb.

(113rb) Ohne Tit. Inc.: Miseremini mei etc. Iob 19 (21). Notandum monere penitencie portando debemus fratres nostros exemplo Christi qui penam peccatorum portavit ... - Expl.: ... valuerunt oraciones omnium adiutorum pro eis facere etc.

Parallelüberlieferung: Innsbruck, ULB Tirol, Cod. 207, Bl. 76rb.

(113va) In commemoratione omnium fidelium defunctorum (Nr. 300). Expl.: ... Qui coronat te in misericordia etc. - (114ra) De s. Martino (Nr. 301). (115ra) Nr. 174. Expl.: ... martir sanguine fuit tamen voluntate. (115Ira) Nr. 302. - (115Iva) De s. Elisabetha (Nr. 303). (116rb) Nr. 304. - (117ra) De s. Clemente (Nr. 305). - (117va) De s. Catharina (Nr. 306). (118va) Nr. 307. Expl.: ... ut quicumque in memoria mei scriptam passionem meam habuerit etc. Rogemus.

(119rb) Schlussschrift: Deo gracias.

(119va-b) nur Rahmung und Besitzvermerk (s. bei G).

$\left(\mathrm{I}^{*} \mathrm{r}-\mathrm{v}\right)$ leer.

U.S. 


\section{Cod. 83}

\section{GREGORIUS MAGNUS}

Pap. I, 59, I* Bl. $285 \times 205$. Süddeutscher Raum, 1400 .

B: $\quad$ Bl. 1 beinahe lose. Buchblock nachträglich beschnitten. Bilder und Nachweise der Wasserzeichen s. WZMA. Wasserzeichenbefund mit Datierung übereinstimmend. Identische Wasserzeichen: Neustift, Stiftsbibl., Cod. 158 und Cod. 183. Lagen: (I-1) ${ }^{\mathrm{I}}$ (Vorsatzbl. 18. Jh.) $+(\mathrm{V}-1)^{9}+2 \cdot \mathrm{VI}^{33}+\mathrm{VII}^{47}+\mathrm{VI}^{59}+(\mathrm{I}-1)^{\mathrm{I}^{*}}$ (Nachsatzbl. 18. Jh.). Gegenbl. zum Vor- bzw. Nachsatzbl. als Spiegel auf dem VD bzw. HD aufgeklebt. Gegenbl. zu Bl. 1 herausgerissen (ohne Textverlust). Am Ende der Lagen 2-4 Reklamanten, tw. stark beschnitten. Am oberen Blattrand Foliierung 15. Jh. 70-128, Hinweis auf ehem. Sammelhandschrift (s. bei G). Fehler in der Zählung: 77 statt 70 (wohl Fehler in der Schreibung). Am oberen Blattrand Foliierung 19. Jh. durch die ULB Tirol (hier berücksichtigt). Bl. 52 Rest eines neuzeitlichen gelben Papiersignakels der ULB Tirol.

S: $\quad$ Schriftraum $215 \times 140 / 150$. Zwei Spalten, von feinen Tintenlinien gerahmt, zu 34-49 Zeilen. Zirkelstiche. Bastarda von zwei Händen: 1) Bl. 1ra-52rb, dat. 1400 (Bl. 52rb), mit unterschiedlichem Duktus (= Schreiber Cod. 158); 2) Bl. 52va-55vb (wohl von gleicher Hand wie Foliierung und Besitzvermerk Bl. 56r).

A: Rote Auszeichnungsstriche, Paragraphzeichen und Unterstreichungen. Bl. 1r-51v am oberen Blattrand Angabe des jeweiligen Buches in Rot. Zweizeilige rote Lombarden, tw. mit Punktverdickungen. Bl. 1ra siebenzeilige rot-tintenfarbene kopfstempelförmig gespaltene Lombarde $Q$ mit etwas ausgeschmücktem Caudaausläufer, B1. 10ra und rb jeweils vierzeilige rot-tintenfarbene Initiale mit kopfstempelförmigen Aussparungen. Bl. 52v-55v nur Lombarden und Überschriften in Rot. Repräsentanten.

E: $\quad$ Neuzeitlicher Bibliothekseinband: schwarz gesprenkeltes braunes Pap. über Pappe. Neustift, 2. H. 18. Jh. Am VD und HD Ecken mit braunem Leder verstärkt. Rücken: braunes Leder, vier einfache Bünde, mit Goldbordüren gerahmt. Im zweiten Feld Golddruck M. S. DIAL. S. GREG. in Goldrahmung, im dritten Signaturschild (s. bei G). Schnitt rot gesprenkelt. Spiegel Pap. 18. Jh. Am Spiegel des VD Signaturen und Bleistiftnotiz (s. bei G), Spiegel des HD leer.

G: $\quad$ Bl. 56r Besitzvermerk 15. Jh. Iste liber est monasterii s. Marie ad Novacellam prope Brixinam.

Nach dem Inhaltsverzeichnis in Neustift, Stiftsbibl., Cod. 158, Bl. Ir gehört Cod. 83 zu einer Gruppe von urspr. tw. selbständigen Hs. des 14. und 15. Jh., die im 15. Jh. in Neustift zu einem Sammelband vereinigt wurden (s. auch Foliierung). Im Zuge der Neuaufstellung der Neustifter Bibliothek in der 2. H. 18. Jh. wurde die Sammelhandschrift (wie dies auch bei anderen Handschriften und Inkunabeln gemacht wurde) in sieben Einzelhandschriften aufgelöst; jeder Einzelband erhielt den für Neustift typischen Halbledereinband. Zur urspr. Hs. zählen folgende Signaturen (in der urspr. Reihenfolge):

Cod. 158: Augustinus. Foliierung 15. Jh. 1-69.

Cod. 83: Theologische Sammelhandschrift, dat. 1400. Foliierung 15. Jh. 70-128.

Cod. 82: Henricus de Langenstein: De contractibus. De contemptu mundi. Foliierung 15. Jh. 129-165.

Cod. 183: Heinrich Seuse: Horologium sapientiae. Foliierung 15. Jh. 166-203.

Cod. 161: Iohannes de Dambach. Origenes. Foliierung 15. Jh. 204-215.

Cod. 182: Ps.-Eusebius, dat. 1400. Foliierung 15. Jh. 216-231.

Cod. 162: Sermones de dedicatione. Foliierung 15. Jh. 232-241.

Von diesen sieben Hs. befindet sich heute eine an der ULB Tirol in Innsbruck (Cod. 82), die restlichen sechs werden hingegen in der Stiftsbibl. Neustift aufbewahrt.

1809 anlässlich der vorübergehenden Aufhebung des Klosters Neustift der ULB Tirol übergeben. Am Spiegel des VD alte Signaturen der ULB Tirol II 1 H 15 (Bleistift) und Nr. 83/(1) (Tinte, Bleistift) sowie Bleistiftnotiz (Vide Grundzettel). Am Rücken gelbes Signaturschild der ULB Tirol 83/(1). 1921 aufgrund des Friedensvertrages von St. Germain an den italienischen Staat abgegeben und von diesem 1929 dem Kloster Neustift als Dauerleihgabe überlassen. Bl. 1r Stempel der Soprintendenza Tridentina 20. Jh.

L: $\quad$ Katalog ULB Tirol I 236, 283. - Stefani 96.

$(\mathrm{Ir}-\mathrm{v})$ leer.

1 (1ra-52rb) Gregorius Magnus: Dialogi = Dialogorum libri IV de vita et miraculis patrum Italicorum (PL 77, 149-429 [Lib. 1, 3 und 4] bzw. PL 66, 126-204 [Lib. 2]. Ed. U. Moricca [Fonti per la storia d'Italia 57]. Roma 1924. Ed. A. de Vogüé [Sources chrétiennes 260]. Paris 1979 [Lib. 1-3] und [Sources chrétiennes 265]. Paris 1980 [Lib. 4]. - CPL Nr. 1713). 
(1ra) Lib. 1. - (10ra) Kapitelübersicht zu Lib. 2. - (10rb) Lib. 2 = Vita s. Benedicti abbatis. - (22vb) Kapitelübersicht zu Lib. 3. - (23rb) Lib. 3. - (38ra) Kapitelübersicht zu Lib. 4. - (38vb) Lib. 4. (52rb) Datierung: Millesimo quadringentesimo anno in vigilia sancti Ypoliti martiris (12. August 1400).

2 (52va-55va) 〈Ps.-Augustinus $\rangle(=\langle$ Ps.-Bernardus Claraevallensis $\rangle=\langle$ Ps.-Hieronymus $\rangle=$ 〈Ps.-Aegidius Romanus〉): Speculum peccatoris (PL 40, 983-992. - Bloomfield Nr. 4918. R. Rudolf, Ars moriendi. Von der Kunst des heilsamen Lebens und Sterbens [Forschungen zur Volkskunde 39]. Köln, Graz 1957, 14 Anm. 12. Weber I 174, Nr. 14; II 112. Zumkeller Nr. 65). Tit.: Speculum peccatoris.

3 (55va-b) 〈BERNARdinUS SENENSIS〉 (?): Speculum peccatorum sive amatorum mundi, unvollständig (Druck: GW 3889-3892. S. Bernardini Senensis Opera III. Venetiis 1745, 437-440, hier 437. - Bloomfield Nr. 6443. Th. Hohmann, Initienregister der Werke Heinrichs von Langenstein. Traditio 32 [1976] 399-426, hier Nr. 266).

Tit.: Sermo per quondam Karthusiensem editus. (rot:) Sermo de conteptu (!) mundi et dicitur speculum amatorum mundi. - Expl. mut.: ... spaciosa via que ducit ad perdicionem ubi est perdicio nature et glorie [

Zur Verfasserfrage (auch Nicolaus de Dinkelsbühl, Iodocus de Heilprunna und Henricus de Langenstein zugeschrieben) s. Madre 297 (mit Angabe der Überlieferung).

(56r) Besitzvermerk (s. bei G).

(56v-59v) nur Rahmung.

$(\mathrm{I} * \mathrm{r}-\mathrm{v})$ leer.

U.S.

\section{Cod. 85}

\section{TRACTATUS DE SACRAMENTIS}

Pap. I, 107, I* Bl. $290 \times 205$. Wohl Neustift, Anfang 16. Jh.

B: $\quad$ Bilder und Nachweise der Wasserzeichen s. WZMA. Datierung nach Wasserzeichenbefund. Lagen: (I-1) (Vorsatzbl. 18. Jh.) $+\mathrm{V}^{10}+(\mathrm{VII}+1)^{25}+(\mathrm{VI}+1)^{38}+\mathrm{V}^{48}+(\mathrm{VI}+1)^{61}+\mathrm{VI}^{73}+\mathrm{VII}^{87}+\mathrm{VI}^{99}+\mathrm{IV}^{(107)}+(\mathrm{I}-1)^{\mathrm{I}^{*}}$ (Nachsatzbl. 18. Jh.). Gegenbl. zum Vor- bzw. Nachsatzbl. als Spiegel auf dem VD bzw. HD aufgeklebt. Bl. 11, 38 und 49 Einzelbl. Am oberen Blattrand Foliierung 19. Jh. durch die ULB Tirol.

S: Schriftraum 215/225 $\times 120 / 125$, tw. von feinen Tinten-, tw. von Blindlinien gerahmt, zu 35-42 Zeilen. Humanistische Kursive.

A: $\quad$ Äußerst spärliche Rubrizierung: vereinzelte Auszeichnungsstriche; wenige zwei- bzw. dreizeilige Lombarden mit Punktverdickungen, tw. mit cadellenartigen Ausläufern. Repräsentanten.

Bl. 1r P-Lombarde mit kopfstempelartigem Besatz und in gestrichelte Achterschlingen gelegtem, mit freien Kreisen sowie Fibrillen dekoriertem Ausläufer (vgl. Cod. 194, Bl. 22r und Cod. 405, Bl. 160v).

E: $\quad$ Neuzeitlicher Bibliothekseinband: schwarz gesprenkeltes braunes Pap. über Pappe, Neustift, 2. H. 18. Jh. Pap. tw. abgerieben. Am VD und HD Ecken mit braunem Leder verstärkt. Rücken: braunes Leder, vier einfache Bünde, von Goldbordüren gesäumt. Im ersten Feld Golddruck M: S:, im zweiten Golddruck DE SACRAMENTIS in Goldrahmung, im dritten Signaturschild (s. bei G). Kapitale mit naturfarbenem und grünem Zwirn umstochen. Schnitt rot gesprenkelt. Spiegel Pap. 18. Jh. Am Spiegel des VD Exlibris, Signaturen und Bleistiftnotiz (s. bei G), Spiegel des HD leer.

G: $\quad$ Am Spiegel des VD Exlibris der Stiftsbibl. Neustift 18. Jh. 1809 anlässlich der vorübergehenden Aufhebung des Klosters Neustift der ULB Tirol übergeben. Am Spiegel des VD alte Signaturen der ULB Tirol II $\overline{4} D 11$ (?, radiert, Tinte), II 1 H 17 (Bleistift) und N. 85 (Tinte) sowie Bleistiftnotiz (Vide Grundzettel). Am Rücken gelbes Signaturschild der ULB Tirol 85. Bl. 1r Stempel der ULB Tirol 19. Jh. 1921 aufgrund des Friedens- 
vertrages von St. Germain an den italienischen Staat abgegeben und von diesem 1929 dem Kloster Neustift als Dauerleihgabe überlassen. Bl. 1r Stempel der Soprintendenza Tridentina 20. Jh.

L: $\quad$ Katalog ULB Tirol I 237, 283.

(Ir-v) leer.

(1r-106v) Tractatus de Sacramentis.

Inc.: Piissimus salvator Ihesus Christus tociusque consolator Deus omnis sue pietatis tantam humani generis imperitiam et ignaviam necnon infirmitatis ... - Expl.: ... et partim potest haberi ex dictis hic. $(107 \mathrm{r}-\mathrm{v})$ nur Rahmung.

$\left(I^{*} \mathrm{r}-\mathrm{v}\right)$ leer.

P. A.

\section{Cod. 86}

\section{THOMAS DE AQUINO}

Perg. I, 40, I* Bl. $300 \times 205$. Frankreich (?), wohl Mitte 13. Jh.

B: $\quad$ Feines Perg., Haar- und Fleischseite deutlich unterscheidbar. Bl. 26 Loch mit Nahtspuren, B1. 4 Nahtspur. Bl. 38 und 39 am oberen und unteren inneren Blattrand jeweils ein kleines Pergamentstück herausgeschnitten (ohne Textverlust). Lagen: (I-1) ${ }^{\mathrm{I}}$ (Vorsatzbl., Pap. 18. Jh.) $+2 . \mathrm{VI}^{24}+\mathrm{V}^{33(34)}+3 . \mathrm{I}^{39(40)}+(\mathrm{I}-1)^{\mathrm{I}^{*}}(\mathrm{Nach}-$ satzbl., Pap. 18. Jh.). Gegenbl. zum Vor- bzw. Nachsatzbl. als Spiegel auf dem VD bzw. HD aufgeklebt. Urspr. wohl durchwegs Sexternionen: Bei Lage 3 fehlt das äußerste Doppelbl.; nach Lage 3 fehlen wohl mehrere Lagen, von Lage 4-6 jeweils nur ein Doppelbl. erhalten (jeweils Textverlust). Bl. 35v Reklamante, beschnitten. Am oberen Blattrand Foliierung 19. Jh. durch die ULB Tirol; Fehler in der Zählung: 30 doppelt angeführt.

S: $\quad$ Schriftraum $215 \times 140$. Zwei Spalten, von feinen Bleistift- bzw. Blindlinien gerahmt, zu einheitlich 50 Zeilen auf Bleistift- bzw. Blindlinierung. Am oberen und ab Bl. 3r zusätzlich am unteren Blattrand jeweils eine von Bleistift- bzw. Blindlinien gerahmte Zeile. Zirkelstiche. Textualis.

A: $\quad$ Rote Auszeichnungsstriche; auf dem oberen Seitenrand der Rectos jeweils die Nummerierung der Textabschnitte in roten und blauen römischen Zahlen (auf dem Verso jeweils ein rotes $D^{I}$ für „Distinctio“); rote und blaue Paragraphzeichen; Verweiszeichen; rote Unterstreichungen. Zweizeilige rote und blaue Initialen mit Fleuronnée in der Gegenfarbe.

$\mathrm{Zu}$ Beginn der Distinctiones fünf- bis achtzeilige Initialen (Bl. 1 ra, 9ra, 11vb, 15va, 19ra, 20rb, 22rb, 24rb, 26va, 29rb, 32va) mit rot-blauem Fleuronnée von derselben Hand. Nur die Eingangsinitiale Bl. 1ra in den Schriftspiegel integriert, alle anderen Initialen (auch die kleineren) fast vollständig auf den Seitenrand bzw. ins Interkolumnium gerückt. Buchstabenkörper geometrisch, oft kopfstempelförmig rot-blau (Bl. 1 ra einfarbig blau) gespalten. Fleuronnée meist in der Gegenfarbe gepunktet und gekernt; Kerne oft mit kleinen geschwungenen Fadenausläufern (z.B. Bl. 20rb). In den Binnenfeldern überwiegend Voluten, die selten (z.B. Bl. 1ra) Palmetten, Knospen und lilienartige Dreiblätter einschließen. Als Besatz oft Perlen-Dreiergruppen und Fäden, die sich häufig haarnadelförmig zurückbiegen; diese Fadenformationen (mit verbindenden Perlengruppen aneinandergereiht) bei kleineren Initialen auch als Ausläufer, die an den Enden mitunter (z. B. Bl. 35va) Fadensterne sowie kleinere dazwischengeschaltete Perlen und Doppelstriche als Dekor aufweisen. Bei größeren Initialen Fleuronnée-Leisten, die v. a. mit abwechselnd roten und blauen Kreissegmenten besetzt sind, welche in orthogonal abstehenden Fibrillen enden; als Endmotive überwiegend Perlengruppen; Bl. 32va Fleuronnée-Leiste zudem von einer Reihe kleiner Perlen begleitet (dieses Motiv auch an den Ausläufern kleinerer Initialen, z. B. Bl. 24rb).

Das Fleuronnée könnte in Frankreich entstanden sein. Es zeigt einige Charakteristika der Pariser Produktion aus dem 2. Viertel 13. Jh. mit Tendenz zur Jahrhundertmitte (vgl. P. Stirnemann, Fils de la vierge. L'initiale à filigranes parisiennes 1140-1314. Revue de l'art 90 [1990] 58-73, hier 67-68, insbes. Cat. 25-31 mit Abb.). 
E: $\quad$ Neuzeitlicher Bibliothekseinband: schwarz gesprenkeltes braunes Pap. über Pappe. Neustift, 2. H. 18. Jh. Insbes. am VD Pap. und Pappe tw. stark abgerieben und beschädigt. Am VD und HD Ecken mit braunem Leder verstärkt, tw. beschädigt. Rücken: braunes Leder, oben beschädigt, vier einfache Bünde, von Goldbordüren gesäumt. Im ersten Feld Golddruck M: S:, im zweiten S. THOMÆ in Goldrahmung, im dritten PARS SUMÆ, ebenso in Goldrahmung, im vierten Signaturschild (s. bei G). Schnitt rot gesprenkelt. Spiegel Pap. 18. Jh. Am Spiegel des VD Exlibris, Signaturen und Bleistiftnotiz (s. bei G), Spiegel des HD leer.

G: $\quad$ Am Spiegel des VD Exlibris der Stiftsbibl. Neustift 18. Jh. 1809 anlässlich der vorübergehenden Aufhebung des Klosters Neustift der ULB Tirol übergeben. Am Spiegel des VD alte Signaturen der ULB Tirol II $\overline{5}$ (?) C 7 (Tinte, radiert), II 1 H 18 (Bleistift) und N. 86 sowie Bleistiftnotiz (Vide Grundzettel). Am Rücken gelbes Signaturschild der ULB Tirol 86. Bl. 1r Stempel der ULB Tirol 19. Jh. 1921 aufgrund des Friedensvertrages von St. Germain an den italienischen Staat abgegeben und von diesem 1929 dem Kloster Neustift als Dauerleihgabe überlassen. Bl. 1r Stempel der Soprintendenza Tridentina 20. Jh.

L: $\quad$ Shooner II 53. - Katalog ULB Tirol I 237, 283. - Steer 36.

$(\mathrm{Ir}-\mathrm{v})$ leer.

(1ra-39vb) Thomas de Aquino: Super librum secundum Sententiarum, unvollständig (Druck: u. a. GW M46376. Ed. R. P. Madonnet. Parisiis 1929. - Glorieux Nr. 14f². Grabmann 286-290. Stegmüller RS Nr. 846, II. Stegmüller RS [1937] Nr. 1597. Shooner Nr. 1104).

(1r) Tit.: Incipit super secundum fratris Thome.

Dist. 1-6, 8-9 vollständig. Zahlreiche Fehlstellen: Dist. 7, 10, 22, 25, 41, 42 und 44 nur tw. erhalten. Dist. 11-21, 23-24, 26-40 und 43 fehlen zur Gänze. Reihenfolge tw. abweichend: Dist. 22 und 25 nachgereiht, Dist. 42 nach Dist. 44.

(1ra) Prolog. Inc.: Spiritus eius ornavit celos et obstetricante manu eius eductus est coluber tortuosus Iob XXVI (13). Creaturarum consideratio pertinet ad theologos et philosophos ...

(1rb) Dist. 1. - (9ra) Dist. 2. - (11vb) Dist. 3. - (19ra) Dist. 4. - (20rb) Dist. 5. - (22rb) Dist. 6.

(24rb) Dist. 7. (24vb) Expl. mut.: ... nec mala voluntate carere possunt nec pena sed [ - (25ra) Inc. mut.: ] cognicio rei nisi per speciem eius sed species eventus futuri non potest ...

(26va) Dist. 8. - (29rb) Dist. 9.

(32va) Dist. 10. (33vb) Expl. mut.: ... non mediantibus principatibus qui hoc per se exequuntur [

(34ra) Dist. 41. Inc. mut.: ] enigma vel obscuritas sive imperfectio ... - (34vb) Expl. mut.: ... vocat irascibile et concupiscibile que sunt [

(35ra) Dist. 44. Inc. mut.: ] esse scilicet secundum quid aliquas prelationes a Deo non esse ... - (35vb) Expl. mut.: ... est medium inter timorem et audaciam scilicet considerat in omnibus [ (am unteren Blattrand Reklamante: actibus)

(36ra) Dist. 42. Inc. mut.: ] dicitur in Deum peccare ... - (37vb) Expl. mut.: ... maiori vel minori contemptu potest facere et huius ratio [

(38ra) Dist. 22. Inc. mut.: ] secundo an excuset peccatum. Ad primum sic proceditur ... - (38vb) Expl. mut.: ... que quis scire tenetur alias non quia etiam ha[bere

(39ra) Dist. 25. Inc. mut.: ] malum quia li[berum] ar[bitrium] per se in bonum ordinatum est ... (39vb) Expl. mut.: ... et per modum istum omnes actus humani sunt [

$(\mathrm{I} * \mathrm{r}-\mathrm{v})$ leer. 


\section{Cod. 99}

\section{CLEMENS V. IOHANNES ANDREAE. IOHANNES XXII.}

Perg. I, 33, I* Bl. $400 \times 270$. Bologna, 1. H. 14. Jh.

B: $\quad$ Urspr. helles, an den Rändern abgegriffenes Perg., Haar- und Fleischseite deutlich unterscheidbar. Lagen: $1^{1}$ (Vorsatzbl., Pap. 18. Jh.) $+\mathrm{IV}^{8}+2 . \mathrm{V}^{28}+(\mathrm{III}-1)^{33}+1^{1^{*}}$ (Nachsatzbl., Pap. 18. Jh.). Gegenbl. zu Bl. 29 herausgeschnitten (Textverlust). Am Beginn und am Schluss fehlt jeweils wohl mindestens eine Lage (Textverlust). Am oberen Blattrand Foliierung 19. Jh. durch die ULB Tirol. Bl. 33 Rest eines neuzeitlichen gelben Papiersignakels der ULB Tirol.

S: $\quad$ Schriftraum $255 \times 155$. Zwei Spalten, von kaum wahrnehmbaren Bleistiftlinien gerahmt (Text bis Bl. 31ra von Kommentar umgeben). Text mit wechselnder Zeilenzahl, Kommentar zu meist 72-80 Zeilen auf Bleistiftlinierung. Bl. 31v-32r Schriftraum (nur Text) $280 \times 155$. Zwei Spalten, von kaum wahrnehmbaren Bleistiftlinien gerahmt, zu 55 Zeilen. Bl. 32v-33v Schriftraum (nur Text) $320 \times 200$. Zwei Spalten, von kaum wahrnehmbaren Bleistiftlinien gerahmt, zu 82 Zeilen. Textualis formata (Littera Bononiensis), Text und Kommentar in unterschiedlicher Schriftgröße. Randglossen am seitlichen und unteren Blattrand (Gliederung mit Kleinbuchstaben) von verschiedenen Händen in Notula 15. Jh.

A: $\quad$ Rote Überschriften, abwechselnd rote und blaue Paragraphzeichen (mit betont langgezogenem Oberstrich); Bl. 30va-32rb rote Auszeichnungsstriche, Paragraphzeichen und Zeilenfüllsel; in Tintenfarbe diverse Verweiszeichen, Randmarkierungen und Zeigehände (von verschiedenen Händen). Ein- und dreizeilige rote und blaue Lombarden mit Fleuronnée in der Gegenfarbe. Repräsentanten.

Fleuronnée: in den Binnenfeldern (und als Besatz) charakteristische saitenartige Parallelstriche, verziert mit kleinen Perlen und kleinbogig geränderten Blättchen; gelegentlich kurze Fadenausläufer; Bl. 33vb zu Beginn der Extravagantes 16-zeilige rote I-Initiale mit bogenförmigen Aussparungen und blauem Fleuronnée; ebda die Explicit-Zeile der Summula mit wenig schwarzem Fleuronnée.

Deckfarbenschmuck: in den Clementinen zu Beginn der Tituli vierzeilige figürliche Initialen, in der Glossa ordinaria vierzeilige ornamentale Initialen, jeweils mit wenigen Ausläuferblättern bzw. kurzen Ranken; am Anfang der Summula (Bl. 32va) zehnzeilige figürliche Initiale mit etwas mehr Rankenwerk.

Blattvergoldete, schwarz konturierte Außengründe; Buchstabenkörper mit farblich abgesetzten Knotenmotiven. Die Ranken(-Blätter) entspringen den Serifen oder setzen mittig und symmetrisch auseinanderwachsend am Initialfeld an (Tropfenmotive in den Gabelungen), Adern und Schattierungen der Rankenblätter mit dunklerer Lokalfarbe deutlich herausgearbeitet, als Dekor schwarz konturierte Goldpunkte (mit feinen tintenfarbenen Fadenfortsätzen). Lebhafte Farbigkeit: neben Rosa, Rot, mehreren Grün- und Blautönen, Cremeweiß in Kombination mit senffarbigem Ocker und Grauviolett bis hin zu kräftigerem Violett; häufig feiner weißer Liniendekor. In den Binnenfeldern der Ornamentalinitialen zumeist Blattmotive (u. a. an Rankengabelungen erinnernd, Bl. 17rb); die figürlichen Initialen zeigen männliche Büsten (Ausnahmen: Bl. 12va, zum Tit. De baptismo et eius effectu, Rundgesicht, das wohl in Stein gemeißelt sein soll; Bl. 16ra, zum Tit. De magistris, statt I-Initiale ca. achtzeilige Halbfigur eines Bischofs, dessen Körper nach unten in Rankenblätter ausläuft), tw. als Kleriker oder Gelehrte charakterisiert (auch mit Textbezug, z.B. Bl. 5rb: Mönch, De statu monachorum et canonicorum regularium, Lib. 3, tit. 10, cap. 1); Gesichter mit horizontalen Augenbrauen und kleinen, dicklippigen Mündern, Inkarnat mit Grau abschattiert.

Bl. 32va Unterrichtsszene (mit Autorbildnis): Der Lehrende (wohl Iohannes Andreae) in blauem Gewand mit rotem, pelzbesetztem Mantel (und ebensolcher Kappe) etwas erhöht auf einem Holzstuhl mit Querbrett, auf dem ein geöffnetes Buch und Schreibutensilien liegen; mit den dünnen Fingern der Rechten hält er ein Schreibgerät und wendet sich im Profil dem Auditorium (Mönchen?) zu.

Der Deckfarbenschmuck entstand im 3. Jz. 14. Jh. in Bologna (freundliche Auskunft Ulrike Bauer-Eberhardt, München). In der Gestaltung der Hände (stäbchenartige Finger) sowie der Mund- und Augenpartien besteht eine gewisse Ähnlichkeit mit denjenigen Figuren im Volumen parvum Bordeaux, Bibliothèque municipale, ms. 355.1, die einem Buchmaler aus dem Kontext des „Maestro del 1328“ zugeschrieben werden (G. del Monaco, I manoscritti miniati dell'Illustratore nella cultura figurativa del secondo quarto del XIV secolo, Diss. Bologna 2012, 159-162 [Nr. 3], http://amsdottorato.unibo.it/5083/: In dieser ca. 1335 datierten Hs. begegnen neben der bewussten Hand aus dem Umfeld des „Maestro del 1328“ auch der „Illustratore“ und der „Maestro dell’Authenticum di Bordeaux“). - Das Fleuronnée ist oberitalienisch.

S. R.

E: $\quad$ Neuzeitlicher Bibliothekseinband: schwarz gesprenkeltes braunes Pap. über Pappe. Neustift, 2. H. 18. Jh. Pap. abgerieben und beschädigt. Ecken mit braunem Leder verstärkt. Rücken: braunes Leder, fünf einfache Bünde, von Goldbordüren gesäumt. Im ersten Feld Golddruck M: S:, im zweiten Golddruck CLEMENTIN. 
(stark zerstört) in Goldrahmung, im dritten Signaturschild (s. bei G). Schnitt rot gesprenkelt. Spiegel Pap. 18. Jh. Am Spiegel des VD Exlibris, Signaturen und Bleistiftnotiz (s. bei G), Spiegel des HD leer.

G: Die Hs. zählt wohl zu jenen vier Hs. kirchenrechtlichen Inhalts, die 1353 als Geschenk des Herrn Berthold, Hospitaler zu Brixen, in den Besitz des Stiftes gelangten (vgl. Neustift, Stiftsarchiv, WW 59. Mairhofer 264-265; Peintner, Stiftsbibliothek 118; Peintner, Schreibkunst 377-378). Am Spiegel des VD Exlibris der Stiftsbibl. Neustift 18. Jh. 1809 anlässlich der vorübergehenden Aufhebung des Klosters Neustift der ULB Tirol übergeben. Am Spiegel des VD alte Signaturen der ULB Tirol II $\overline{2}$ [...] 6 (?, Tinte, radiert), II 2 C 3 (Bleistift); Nr. 99 (Tinte) und Bleistiftnotiz (Vide Grundzettel). Am Rücken gelbes Signaturschild der ULB Tirol 99. Bl. 1r Stempel der ULB Tirol 19. Jh. 1921 aufgrund des Friedensvertrages von St. Germain an den italienischen Staat abgegeben und von diesem dem Kloster Neustift als Dauerleihgabe überlassen. Bl. 1r Stempel der Soprintendenza Tridentina 20. Jh.

L: Wretschko-Sprung 15. - Hermann 155, Nr. 110. - B. Pagnin, La „littera Bononiensis“, studio paleografico. Atti del Reale Istituto Veneto di scienze, lettere ed arti 93/2 (1933/34) 1593-1665, Nr. 24. - FurtenbachKalb 20. - Neuhauser, Neustift 88. - Katalog ULB Tirol I 279, 283. - J. Tarrant, The manuscripts of the Constitutiones Clementinae I: Admont to Munich. ZRG Kanonistische Abt. 70 (1984) 109 und II: Napoli to Zwettl. ZRG Kanonistische Abt. 71 (1985) 80. - Peintner, Stiftsbibliothek 118-119. - Peintner, Schreibkunst 377-378.

(Ir-v) leer.

1 (1ra-32rb) 〈CLEMENS V.»: Constitutiones (Clementinen), unvollständig: enthält nur Lib. 3, tit. 8, cap. 2 bis Schluss (CIC, ed. Friedberg II 1162-1200. - Tarrant II 80). Mit der Glossa ordinaria des IOHANNES ANDREAE (Druck: u. a. GW 7101).

(1ra-32rb) Text. Inc. mut.: ] quasi torrens pregravemur negociis curis excitemur innumeris cogitacionibus ... (CIC, ed. Friedberg II 1162, Z. 12) - Expl.: ... Si quis autem hec actemptare (!) presumpserit indignacione omnipotentis Dei et beatorum Petri et Pauli apostolorum eius se noverit incursurum.

(1ra-31ra) Kommentar. Inc. mut.: ]usurarum excommunicatum publice nominatum interdictum et tempus interdicti numquid una vel quadruplici excommunicacione ligabitur ... (Druck: GW 7101, Sign. E3 Anm. n) - Expl.: ... cum ad illam redibimus per intercessionem virginis gloriose nos collocet cum electis Amen.

2 (32va-33vb) Iohannes Andreae: Summula quarti libri Decretalium (Summa de sponsalibus et matrimonio) = Überarbeitung von 〈IOHANNES DE ANGUISSOLA»: Summa de sponsalibus et matrimoniis (Druck: GW 1754. - Tarrant II 80).

Inc.: Cristi nomen invocans ad honorem ipsius et reverentissimi patris domini Bononiensis archidiaconi qui divinam potenciam imitatus de me nichil fecit aliquid ... - Expl.. ... et non ad propositum unde quid dicunt vide per te. Iohannes Andree. Explicit Summula quarti libri Decretalium Iohannis Andree.

3 (33vb) Iohannes XXII.: Extravagantes, unvollständig: Tit. 14, cap. 3 (Avignon, 1322 Dezember 8) (Druck: u. a. Lyon 1559, 114-118. CIC, ed. Friedberg II 1225-1226, Z. 6. J. Tarrant, Extravagantes Iohannis XXII. [Monumenta iuris canonici B 6]. Città del Vaticano 1983, Nr. 18, 228-234). Beginn gegenüber Ed. und Druck leicht abweichend, jedoch in Übereinstimmung mit Variante RVC, s. Tarrant 134 bzw. 228, Apparat. Cod. 99 bei Tarrant nicht genannt.

Inc.: Iohannes episcopus servus servorum Dei. Ad perpetuam rei memoriam valitura canonum. Non est dubium pertinere cum statuta a se vel predecessoribus suis edita obesse percipit pocius quam prodesse ne ulterius adesse valeant providere. Dudum si quidem felicis recordacionis Nicolaus papa IIIus predecessor noster attente prospiciens ... - Expl. mut.: ... quam si res illas cum illo quo carere se dicunt domino optinent [

Lit.: Schulte GQ II 133 und 214.

$\left(\mathrm{I} *_{\mathrm{r}-\mathrm{v})}\right.$ leer.

W. N. 


\section{Cod. 100}

\section{MISSALE (FESTIVUM)}

Perg. 104 Bl. $380 \times 295$. Neustift, 1524-1526.

B: $\quad$ Hs. 2017 restauriert: gereinigt, loses Bl. 99 wieder eingebunden, lockere Lagen stabilisiert (vgl. Restaurierprotokoll). Haar- und Fleischseite deutlich unterscheidbar, bisweilen etwas gewellt, einzelne Löcher (B1. 22, 40) und Nahtspuren (Bl. 37). Bl. 73rb Initiale herausgeschnitten (s. bei A). Lagen: 6.IV ${ }^{48}+\mathrm{I}^{50}+6 . \mathrm{IV}^{98}+$ $(I V-2)^{104}$. Gegenbl. zu B1. 99 und 100 herausgeschnitten (ohne Textverlust). Bei den meisten figürlichen Initialen Klebespuren und tw. Stoffreste von einstigen Schutztüchlein. Reste von dunklen Ledersignakeln. Am oberen Blattrand Foliierung 19. Jh. durch die ULB Tirol.

S: $\quad$ Schriftraum $270 / 275 \times 195 / 200$. Zwei Spalten, seitlich von Tintenlinien begrenzt, zu einheitlich 28 Zeilen. Bl. 52r-61r (Canon missae) Schriftraum 265/275×195/200, von Tintenlinien gerahmt, zu einheitlich 15 Zeilen auf feiner Tintenlinierung. Zirkelstiche. Textualis formata (Textura), dat. 1524 (Bl. 38rb, 50rb, 50v, 93rb, 94va, 104ra). Schreiber: Stephan Stetner (Bl. 38rb, 93rb, 94va, 104ra), vgl. Krämer, Scriptores.

N: $\quad$ Bl. 38v-47v sowie Bl. 56v-57r Schriftraum 260/265×200. Seitlich von Tintenlinien gerahmt, links jeweils mit eigener Spalte für den Notenschlüssel. Jeweils neun Notensysteme sowie Textzeilen. Gotische Choralnotation mit f-Schlüssel auf vier roten Linien. Kustoden und rote Gliederungsstriche.

A: $\quad$ Rote Auszeichnungsstriche, Überschriften, Durchstreichungen und Benediktionskreuze (rote Tatzen- und Kolbenkreuze, z.B. Bl. 56r). Bei den Datierungen und/oder Stetners Namensnennungen bzw. Initialen (s. bei S) jeweils fünf tintenfarbene Ziermotive bzw. Trennzeichen aus drei kleinen Kreisen in Dreiecksanordnung mit kurzem, kommaartigem Fadenausläufer (Bl. 104ra zusätzlich Kreuz, vielleicht von späterer Hand als Sterbekreuz für den am 12. Dezember 1526 verstorbenen Stetner?); in den Binnenfeldern der Majuskeln gelegentlich feine Doppelschrägstriche, tw. mit einseitigem Bogenbesatz. Rote und blaue ein- bis vierzeilige Lombarden mit Punktverdickungen und kürzeren Ausläufern; einige aufwändigere (I-)Lombarden, deren Ausläufer in Achterschlaufen enden (z. B. Bl. 5va, 6va; sehr ähnliche Lombarden in Sign. 14820, vgl. z. B. Cod. 100, Bl. 5va mit Sign. 14820, Bl. 82v6, aber wohl nicht von einer Hand); v. a. die größeren Lombarden mit Fleuronnée: rote Lombarden mit hellblauem oder grünem, blaue Lombarden zumeist mit Fleuronnée in Rottönen, seltener in Grün und Lila. Repräsentanten.

Fleuronnée: in den Binnenfeldern charakteristische zierliche Spiralranken (oft mit Punktenden), häufiger auch Blättchenmotive, Rautengitter und dachziegelartig angeordnete Bögen. Konturlinien. Wenige kurze Fadenausläufer, dafür die längeren Lombardenausläufer konturiert und mit Fleuronnée (v. a. Fibrillen) verziert; in den Ausläuferschlingen zuweilen Blattmedaillons; charakteristisch auch der Strahlenbesatz an kleinen Kreisen und Punktverdickungen (sowohl ins Binnenfeld als auch nach außen gerichtet); als Besatz außerdem Fibrillen, auch in Kombination mit Spiralen; derartige Fibrillen sowie kleine strahlenbesetzte Kreise auch in den Deckfarben-Randleisten. - Lombarden mit figürlichem Federzeichnungsdekor (Auswahl): Maskarons (Bl. 35rb1, 97va) und maskaronartige Köpfe (Bl. 17rb1, 101vb); heraldische Vögel (Bl. 21ra Adler mit gespreizten Flügeln, 26rb doppelköpfiger Adler, 37rb3 aufflatternder Greif?); diverse Köpfe und Büsten, u. a. Bl. 46v Haupt Christi im Strahlenkranz, 40r Engelsbüste, 25vb zwei Greisenköpfe im Profil einander zugewandt, der linke mit geöffnetem Mund; Bl. 48va zwei Fangen spielende Putti. Maskarons und Haupt Christi sehr fein ausgeführt.

Deckfarbenschmuck: sechs ornamentale und 23 figürliche Initialen, jeweils mit Randschmuck, ein Kussbildchen sowie zwei Vollbilder mit Randdekor; insgesamt sieben Wappen mit kartuschenartigen Schilden.

Die Ornamentalinitialen vorrangig im Winterteil des Temporale, im Ordinarium missae und in den Praefationes (Bl. 2ra, 38v, 39r, 40v, 41v, 42r), siebenzeilig bzw. zwei Notenzeilen hoch, Randschmuck v. a. Typ 2 und 3 (s. u.). Auch die grob ausgeschnittene Initiale Bl. 73rb (Mariä Empfängnis) könnte eine ornamentale Initiale gewesen sein (nur fünfzeilig, kurze Ranken, insbes. Typ 2; muss vor 1905 ausgeschnitten worden sein, da Verlust bei Hermann 162 vermerkt).

Die figürlichen Initialen im Temporale und Sanctorale (Bl. 3ra, 5rb, 7ra, 8rb, 9vb, 11va, 17rb, 43v, 45v, 52r, 62ra, 63va, 68va, 70rb, 71va, 76ra, 77rb, 79rb, 80vb, 83rb, 85ra, 86va, 88rb) in der Regel sechs- und siebenzeilig.

Rahmen der Ornamentalinitialen einfarbig oder aus grünen, blauen, rosafarbenen oder roten Abschnitten zusammengesetzt; dieser Rahmentyp selten bei figürlichen Initialen, die zumeist von breiteren, blattvergoldeten Rahmen umgeben sind (Konturierung und Profilierung mit schwarzen und weißen Linien); nur die Ornamentalinitiale Bl. 42r mit (einfach punziertem) goldenem Rahmen. Breitere unverzierte Goldrahmen auch bei den Vollbildern. - Buchstabenkörper häufig aus Renaissancemotiven wie Kandelabern, Säulen, Fruchtschalen und -körben, Festons, Rüstungsteilen (Brustpanzern), Blattmasken, Fabelwesen (v. a. Drachen) und Puttenköpfen (geflügelt) aufgebaut, bei den Ornamentalinitialen gerne in Lila- und Violetttönen koloriert, 
bei den figürlichen Initialen oft in Gold mit schwarzen Kontur- und Binnenlinien, Schraffuren auch in Weiß; darüber hinaus glatte goldene Buchstabenkörper mit minutiösem, in weißlichem Malmittel ausgeführtem Dekor, s. Te-igitur-Initiale Bl. 52r (auf dem Schaft z. B. zartes Flügelpaar); nur wenige Buchstabenkörper, die in spätmittelalterlicher Manier mit ondulierenden Blattranken gefüllt sind. - Initialfelder der Ornamentalinitialen blattvergoldet (bis auf Bl. 42r: blaugrundig) und mit Rautengittern aus Punktlinien (gefüllt mit Blütenpunzen) überzogen; bei den figürlichen Initialen B1. 7ra, 8rb, 9vb, 17rb, 52r, 62ra, 68va, 70rb, 76ra und 80vb jeweils Miniatur im Initialfeld, Buchstabenkörper davorgesetzt (nur Bl. 70rb Initialbuchstabe auf den Rahmen appliziert); wenn das Bild im Binnenfeld platziert und die Initiale von einem farbigen Außengrund (meist kobaltblau oder dunkelrot; Bl. 83rb Wolkenhimmel) umgeben ist, dann können Rahmen und Buchstabenkörper Schatten auf den Farbgrund werfen.

Variationsreicher und üppiger Randschmuck, der nur eine Ecke des Schriftspiegels umschließt, aber auch zwei bis vier Seitenränder bedecken kann; vier Haupttypen: 1. kandelaberartige Randleisten, die meist auf Sockeln, Säulen, vasenartigen Gefäßen etc. ruhen und sich aus Renaissancemotiven (s. o. bei Buchstabenkörpern, zusätzlich bukranienartige Blattmasken, Waffen, heraldisch anmutende Flügelpaare, Musikinstrumente, Schmuckstücke; zu figürlichen Komponenten s. u. Detailbeschreibungen) im Wechsel mit floralen Elementen (Blüten und breite Blätter mit volutenartig eingerollten Spitzen) symmetrisch aufbauen; die einzelnen Abschnitte der Achsenstäbe leicht kolbenförmig. V. a. am Beginn der Hs. (bis Bl. 8r), beim Kanonbild und am Anfang des Messkanons, meist auf beiden Vertikalrändern des Folios; die äußeren Kandelaberleisten, die gesamte Marginalfläche nutzend, breiter angelegt und häufig mit einem Fruchtkorb bekrönt; 2. dünnastige, gerne symmetrisch angelegte Spiralranken mit bunten, fein gezackten Blättern, Fantasieblüten, Goldscheibchen und charakteristischen Perlreihen u. a. als Fruchtstand; z. B. Bl. 2r, rechter Seitenrand; 3. farbenfreudige Akanthusranken, oft gerade geführt, mit Eck- bzw. Endschlingen, die mit (punziertem) Blattgold gefüllt sind; wie bei den Kandelaberleisten Tendenz zu symmetrischem Aufbau; als Ziermotiv goldene Manschetten; nur dieser Rankentyp setzt, oft aus floralen Manschetten entspringend, direkt und mittig am Initialrahmen an (lediglich bei der Oster-Initiale B1. 62ra spätmittelalterliche Gestaltungsweise: Ranken entwachsen den Serifen des Buchstabenkörpers, der hier zudem mit Blattwerk gefüllt ist, s. o.); als Beispiel s. Bl. 11v; 4. naturalistische (Blüten-)Zweige, die botanisch identifizierbar sind (s.u. Detailbeschreibungen); verziert mit Fibrillen und (punzierten) Goldfeldern; Kombination von naturalistischen Zweigen und stilisierter Goldzier als Charakteristikum anzusehen; diese Zweige häufiger bei figürlichen als bei ornamentalen Initialen. - Die Typen 2, 3 und 4, die auch als Mischformen auftreten können, zusätzlich mit Drolerien belebt (s. u. Detailbeschreibungen). Zudem detailfreudige Bas-de-page-Illuminationen (s.u. Detailbeschreibungen), bei denen wie bei den Drolerien eine Vorliebe für Jagdszenen festzustellen ist.

Auf die Tätigkeit einer Meisterhand (und wenigstens einer Assistenzhand) dürften u. a. folgende Figuren mit bes. differenziert gemalten Gesichtszügen, Haaren und Gewändern hinweisen (ausführlich zur Händescheidung unter sorgfältiger Berücksichtigung stilistisch-technischer Charakteristika s. Fiegl, Missale 118-120, die durchaus drei Miniatorenhände für möglich hält): Bl. 1v die drei Hauptfiguren, dabei Augustin Posch mit Porträtcharakter und das Mariengewand mit bes. nuancierter Draperie; Bl. 51v alle drei Figuren der Kreuzigungsgruppe; Bl. 52ra Abraham; Bl. 58v Antlitz Christi auf dem Schweißtuch (man beachte zudem die Drapierung des Tuches und die Gestaltung der Engelsgewänder) und B1. 70rb Gottvater. Auch die Basde-page-Szenen B1. 52r und 79r, bei denen die Auswirkungen des Windes nicht nur durch wehende Haare spürbar gemacht werden, sowie die Finesse der Epiphanie-Initiale Bl. 8r sind bemerkenswert. Generelle Charakteristika: Figuren in allen Körperhaltungen anatomisch sehr gekonnt dargestellt, nur Kniepositionen etwas unsicher (z.B. Augustin Posch, Bl. 1v). Heiligenscheine häufig als goldene, schwarz konturierte Scheiben, die bei Figuren in Rückenansicht tellerartig am Hinterkopf sitzen (z. B. Bl. 63va); Engel und Putti mit buntfarbigen Flügeln. Gebauschte, reich gefältelte und fallweise abflatternde Gewänder. Sehr sichere (Zentral-)Perspektive, nur wenige Ungereimtheiten (z.B. Bl. 7ra Thronlehne nicht in Fluchtlinie, Altarmensa zu aufsichtig; Bl. 68va Kapitelle der rechten Säulenreihe verschoben); Vorliebe für tonnengewölbte Räume; gekonnter Einsatz von Hell und Dunkel bis hin zu subtilen Schattenwürfen (z. B. Bl. 52r Schatten des Feuerholzes auf der Altarfront und B1. 86v Schatten des Hirschkäfers auf dem Bas-de-page) und trompel'œil-artigen Schattenwürfen an Initialen (s. o.). Kleinteilige Darstellung von Mauerwerk (z. B. unregelmäßige Struktur der Ruinenmauern Bl. 8rb) und Marmor (Altäre). Naturgetreue Gestaltung von Böden mit Steinen, Grasbüscheln, Wegen etc. Als Hintergründe in den Miniaturen gerne Landschaftsausblicke mit Gebirgspanoramen, Burgen oder Stadtveduten (s. v. a. Kanonblatt B1. 51v), Himmel mit nuancierten Wolkenstrukturen (z. B. B1. 52ra, hier auch die aus dem Feuer aufsteigenden Rauchschwaden sehr gekonnt). Strahlendes Kolorit (s. auch Hermann 156) u. a. Kobaltblau, Violett mit Tendenz zu Pink und Orangegelb (dieses nicht zuletzt für Judasgewand im Letzten Abendmahl, Bl. 17rb); die Assistenzhand (bei Figuren- und Landschaftsdarstellungen) mit stärkerem Farbauftrag als die Meisterhand (Fiegl, Missale 119); reiche Verwendung von Blattgold auf beigefarbenem Bolus (sichtbar z. B. B1. 52r T-Initiale). Einfache Punzierungen: Punktlinien und kleine Kreise, die zu Rosetten zusammengesetzt sein können.

Figürliche Initialen und erwähnenswerter Randschmuck (auch auf Folios mit ornamentalen Initialen): 
B1. 2r [Ornamentalinitiale] - Auf dem oberen Seitenrand Neustifter Wappen: in Rot goldenes Tau-Kreuz. Bas-de-page: mittig ein Kandelaber, Ranken (Typ 2, mit Puttenköpfchen), in deren Schutz vier Putti, begleitet von einem springenden Hund, derbe Späße treiben. Drolerien: Eichhörnchen, drei Vögel.

Bl. 3ra Geburt Christi: Maria und Josef beten kniend das auf dem Boden (auf einem roten Tuch) liegende nackte Kind an, das die Händchen nach Maria ausstreckt; neben Josef, der eine Kerze hält, Ochs und Esel; am Himmel vier Putti, die von einem Notenblatt singen; im Hintergrund auf einem Mauerrest ein rötlicher Säulenstumpf. - Bas-de-page: Ranken (Typ 2), davor Putto auf der Hirschjagd, der im Laufen ein Jagdhorn bläst und von einem angeleinten und zwei frei laufenden Hunden, die den Hirsch attackieren, unterstützt wird. In der rechten Kanderlaberleiste zwei Posaunenengel. Drolerien: Kröte, drei Vögel.

Bl. 5rb Jesuskind in hauchfeiner Strahlenmandorla auf hellblauer Wolke stehend (linker Fuß leicht angehoben), in der Linken die Weltkugel, Zeigefinger der Rechten erhoben. - Bas-de-page: mittig Putto, der auf einem Sockel stehend einen Kandelaber balanciert, Ranken (Typ 2), unter deren Bögen zwei Hirsche liegen. In der rechten Kandelaberleiste Wappen: vor zwei gekreuzten Säbeln blauer Schild (von goldenem Rautengitter überzogen), darauf goldener Zweig mit Blättern (Hermann 158: Erdbeerblatt); unter der bekrönenden Fruchtschale Gruppe von sieben Putti, die von einem Notenblatt singen.

Bl. 7ra Beschneidung Christi: In einem sakralen Raum (im Hintergrund die Gesetzestafeln auf einem Altar) auf einem thronartigen Sitz ein greiser Priester, der das Jesuskind auf dem Schoß hält, das vom Mochel beschnitten wird; daneben Assistenzgruppe, angeführt von Maria und Josef; Boden u.a. mit Adlerfliesen belegt. - Bas-de-page: Drei Putti mit Jagdhörnern, Speer bzw. Stange und Fangnetz jagen, begleitet von vier frei laufenden Hunden, ein Hasenpaar, dem ein Igel voranläuft, auf dessen Stacheln Früchte stecken. Die Kandelaberleiste links ruht auf männlicher Büste mit Tatzen; im oberen Bereich der Leiste Neustifter Wappen: in Rot goldenes Tau-Kreuz. Rechte Randleiste: oben Blütenranke, unten Weinstock: Reben mit blauen Trauben ranken sich um rote Stange, an der eine kleine Sichel klemmt. Drolerien (Weinstock): zwei blau-gelbliche Vögel, zwei Biber.

B1. 8rb Anbetung der Heiligen Drei Könige: In einer Ruinen-Szenerie sitzt Maria mit dem nackten Kind auf dem Schoß, das nach der Kiste mit Gold greift, welche ihm der greise, vor ihm kniende König darbringt; dahinter die beiden anderen Könige mit ihren Gaben und Gefolge; am Himmel der Stern der Weisen. Bas-de-page: Soldat mit weiß-blauer Fahne; Ranken (Typ 2) mit vier Drolerievögeln, u. a. Wiedehopf und grüner Papagei. In der linken, von einem geflügelten Puttenkopf bekrönten Randleiste kleines Bildnis der sich erstechenden Lucretia. Die rechte Randleiste ruht auf kniendem Schildträger (mit Brustpanzer), darüber vor gekreuzten Waffen ein Rundschild mit männlichem Profilkopf, des Weiteren ein kniender Putto mit zwei Füllhörnern und an der Spitze ein Bildchen des dornengekrönten Christus (auf blauem Grund, in Architekturrahmen)

Bl. 9vb Darbringung Christi im Tempel: Vor einem mit einem feinen Tuch bedeckten Altar, auf dem sich die Gesetzestafeln erheben, reicht Maria das Kind dem Priester (mit Goldmitra); neben Maria stehen Josef und eine Frau mit zwei Opfertauben, hinter dem Priester drei jüdische Greise. - Unterhalb der Initiale Rankentyp 3 (und 2), daneben naturalistischer Zweig mit gelben Blüten, auf dem linken Seitenrand Blütenranke (vgl. Bl. 7r) und darüber weiterer naturalistischer Zweig mit länglichen, roten Blüten. Drolerien: Vogel und roter Käfer.

Bl. 11va Einzug in Jerusalem: Jesus reitet segnend auf der Eselin dem Stadttor zu, vor dem Männer mit Palmzweigen stehen; hinter ihm die Apostel, vor ihm breitet ein Mann in kostbarem Gewand einen roten Mantel aus; das Gesicht Jesu abgerieben. - In den Ranken (Typ 3) ein Marder, der einen rosafarbenen Vogel anfaucht, der sich nach seinem Jäger umwendet.

Bl. 17rb Letztes Abendmahl: Jesus und seine Jünger an einem mit feinem, weißem Tuch gedeckten Tisch; Johannes kauert auf dem Schoß Jesu, der dem gegenüber sitzenden Judas (mit rotem Beutel in der Linken) einen Bissen reicht; im Vordergrund schenkt ein Jünger Wein aus einer Zinnkanne in einen Becher, neben ihm auf dem Fliesenboden Kupferbecken mit einer weiteren Kanne; im Hintergrund großes Fenster mit Architekturrahmung. - Als Randzier rote Disteln und Weinranke, die in Rankentyp 3 endet. Drolerien: fasanenartiger, blau-gelb-roter Vogel; blaue Libelle.

B1. 38v [Ornamentalinitiale] - Rankentyp 3 mit Dompfaff.

B1. 39r [Ornamentalinitiale] - Rankentyp 3 mit zwei Vögeln sowie ein Zweig kleiner, roter Nelken, darin eine Henne mit ihren Küken.

B1. 40v [Ornamentalinitiale] - Rankentyp 3 mit Uhu (auf einem Bein stehend, mit gespreizten Flügeln), der von drei Vögeln attackiert wird.

B1. 41v [Ornamentalinitiale] - Rankentyp 3 mit Maikäfer, bräunlichem Falter, Fliege und zwei Vögeln.

B1. 42r [Ornamentalinitiale] - Rankentyp 3, auf dem Bas-de-page in Blütenzweig (vgl. Bl. 7r) auslaufend; graubrauner Falter.

Bl. 43v Sitzendes Äffchen an einer Leine, das sich in Rundspiegel betrachtet. - Rankentyp 3 mit Libelle und Elster. 
B1. 45v Halbfigur des segnenden Christus mit Weltkugel in der Linken, auf blassblauer Wolke, umgeben von gelb-pinkfarbener Aureole. - Als Randzier Wiesensalbei- und Butterblumenzweig, ineinander gehakt, mit grau-gelbem Vogel.

Bl. 52r Opferung Isaaks: Isaak kniet betend auf einem Altar, neben ihm auf der Mensa brennt rauchend ein Feuer. Abraham berührt mit der Linken die Schulter seines Sohnes, wobei sein ausgestreckter Arm vom TSchaft fast verdeckt wird, und erhebt mit der Rechten das Schwert, woran ihn ein herbeifliegender Engel hindert; zw. Engel und Abraham der im Gesträuch verfangene Widder. - Auf dem Bas-de-page zugehörige Szene: In einer liebevoll gestalteten Seeuferlandschaft schreiten Abraham (mit Fackeln) und Isaak (mit Holzbündel), begleitet von einem Hund, gegen den Wind an, der ihre Kleider und Haare wehen lässt, Bäumchen umbiegt und Vögel über den Himmel jagt. Mittig auf dem oberen Seitenrand detailliert ausgeführte Blattmaske mit Ranken (Typ 2), die große Ähnlichkeit zu dem mit der Feder gezeichneten Maskaron Bl. 97va aufweist. Die linke Kandelaberleiste wird von einem knienden, grauhaarigen Mann mit Rüstung getragen, am Fuß der rechten Kanderlaberleiste zwei musizierende Satyrn (abgegriffen, s. bei B).

Bl. 62ra Auferstehung Christi: Der Auferstandene (mit Wundmalen) steht im Kontrapost mit wallendem, rotem Mantel, Siegesfahne und Strahlennimbus segnend auf dem geschlossenen Sarkophag. Davor stützt sich einer der schlafenden Soldaten auf einen großen, hölzernen Humpen. Die Strahlen der im Hintergrund über der Hochgebirgskette aufgehenden Sonne korrespondieren mit dem Heiligenschein Christi. - Zentral auf dem Bas-de-page Pfau, der ein Rad schlägt, links neben ihm Pfauhenne und herbeifliegender Fasan (vor Ästchen mit zart lilafarbenen Blüten); rechts neben dem Pfau Zweige mit Feigen, unter denen ein Putto schläft und zwei Affen herabgefallene Früchte aufsammeln und fressen; davor eine Maus. Auf dem rechten Seitenrand Ranke aus folgenden Abschnitten: unten Eichenzweig, von dem ein Putto mit umgehängter Tasche Eicheln pflückt; in diesen Zweig eingehakt stachelige Heckenrosenranke, in der ein Laute spielender Putto sitzt; an diese Ranke eine Blütenranke (vgl. Bl. 7r) mit Hilfe eines roten Bändchens angebunden, zuoberst Rabennest, aus dem ein Putto eines der Rabenküken gestohlen hat und einem weiteren Engelchen, das ihm mit einer Schale oder einem Hut entgegen klettert, reichen will, was die heranfliegende Rabenmutter zu verhindern versucht. Darüber, auf dem oberen Seitenrand, verfolgt ein Greifvogel eine Wildente. Von der Initiale ausgehend Ranken (Typ 3); darunter, auf dem linken Seitenrand, frei stehendes Maiglöckchen; zuunterst naturalistisches Zweiglein mit roten Blüten.

Bl. 63va Himmelfahrt Christi: Maria und Apostel knien um Auffahrtsberg (darauf Fußspuren Christi) und blicken zum Himmel empor, wo Beine und Gewandsaum des Auffahrenden im Strahlenkranz zu sehen sind. Beine Christi abgerieben. - Als Randzier Akelei- und Heckenrosenzweig (mit kleinen Dornen), ineinander gehakt. Drolerien: Käfer, roter Falter, stäbchenförmiges rotes Insekt und ein Vogel.

Bl. 68va Pfingsten: Maria und Apostel in einer Säulenhalle, über ihnen die Taube des hl. Geistes (von Strahlenkranz umgeben) in wolkenumsäumter, gelb-rosafarbener Aureole. - Auf dem Bas-de-page großer, von einem Putto (mit Schwert) geführter Braunbär, der den Betrachter mit gefletschten Zähnen anblickt. Auf ihm reitet ein Posaune blasender Putto mit purpurfarbenem Kopfband, das entgegengesetzt zu den an der Posaune befestigten Bändern abflattert. Musikalisch begleitet wird der Zug von zwei Putti, einer davon mit hoher Kappe, die Krummhorn und ein Streichinstrument spielen; über ihnen, in einem Bäumchen, eine Elster, am Himmel größerer schwarzer Vogel, der einem hellblauen Vögelchen nachstellt. Am Bäumchen angebunden ein Affe, hinter dem ein Feigenast emporwächst; im Vordergrund Frosch und Schildkröte. Auf dem oberen Seitenrand jagt ein Greifvogel einen Stieglitz. Um die linke obere Seitenecke legt sich ein Zweig mit kleinen blau-roten Blüten, in den eine große Iris kopfüber eingehängt ist.

Bl. 70rb Gnadenstuhl: Gottvater sitzt, mit der Taube des hl. Geistes auf der Schulter, auf einem Marmorthron und hält, seinen Blick zur Seite gerichtet, den Leichnam seines Sohnes vor sich, der den Betrachter unter halb gesenkten Lidern anzublicken scheint. - Bas-de-page: Rankentyp 2.

Bl. 71va Zwei Engel präsentieren eine große Monstranz mit Hostie. - Als Randzier naturalistischer Zweig mit roten Blüten (Mohn?) und Rankentyp 3, der in Typ 2 übergeht. Drolerien: Vogel, kleine Libelle, Fliege (?) und Maikäfer.

Bl. 73rb [Ornamentalinitiale?] - Rankentyp 2 (und 3). Drolerien: grüner Papagei und Greifvogel, der sich auf eine Wildente herabstürzt.

Bl. 76ra Verkündigung: In einem schlichten und trotz zweier Fenster relativ düsteren Raum kniet Maria mit vor der Brust gekreuzten Armen an einem hölzernen Betpult (mit Fronttürchen), auf dem ein aufgeschlagenes Buch liegt; über ihr die Taube des hl. Geistes im Strahlenkranz, neben dem Pult bauchige Bodenvase mit Maiglöckchenstrauß. Von links eilt segnend der Engel herbei, in der Linken einen Stab, um den sich das Spruchband Ave Ma[ria] gr[a]c[i]a plen[a], $d$ [ominus] te[cum] windet. - Linker Seitenrand und Bas-depage: Rankentyp 3 mit Marienkäfer, Heuschrecke und blau-rotem Vogel. Rechter Seitenrand: unten Blütenranke (vgl. Bl. 7r), darin eingehängt oben Ranke Typ 3 (und 2).

Bl. 77rb Heimsuchung: Vor einem rundbogigen Tor (darüber Fachwerk-Erker) begrüßt Elisabeth Maria. Rankentyp 3 mit Vogel, Insekt und Fuchs, der eine Blaumeise bedroht und dabei von einer Elster beschimpft wird. 
Bl. 79rb Marientod: Die verstorbene Maria sitzend, mit hoher, brennender Kerze in der Rechten in einem Himmelbett; davor drei betende bzw. lesende Apostel; ein Apostel hebt den Bettvorhang an und berührt Maria am Ellbogen, Johannes unterstützt Maria beim Halten der Totenkerze, hinter ihm Petrus mit Aspergil und geöffnetem Gebetbuch, gefolgt von den anderen Aposteln, von denen der vorderste den Weihwasserkessel trägt; über Johannes das Seelenfigürchen Mariens, das in den Himmel zu Christus emporschwebt. - Auf dem Bas-de-page zugehörige Szene des Marienbegräbnisses: Eine Soldatengruppe verfolgt die Apostel, die Maria zu Grabe tragen. Petrus wendet sich um und stellt sich den Angreifern mit ausgestreckter rechter Hand entgegen. Die Juden, die versucht haben, sich des von vier Aposteln getragenen Sargs zu bemächtigen, sind zu Boden gestürzt, während ihre abgerissenen Hände am Sargtuch (schwarz mit weißem Kreuz) hängenblieben. Johannes, dem der Wind Haar und Mantel verweht, trägt dem Zug einen hohen Palmzweig voran. Im Interkolumnium und auf dem oberen Seitenrand Rankentyp 3, auf dem rechten Rand Typ 2.

$\mathrm{Bl}$. 80vb Hl. Augustinus in prächtigem Bischofsornat, frontal auf einem wuchtigen weißen Thron sitzend, die Rechte segnend erhoben und von adorierenden Augustiner Chorherren flankiert. Die beiden vorderen Chorherren halten ihre schwarzen Kappen in den Händen, links der Propst mit grauem, schweifbesetztem Feh-Almutium. - Bas-de-page: Greifvogel stürzt sich (parallel begleitet von kleinerem Vogel im Sturzflug) auf Gans mit ihren Jungen herab, diesen voran eine Eidechse; Putto mit erhobenem Streitkolben greift von hinten Affen an, welcher aus einer Schale frisst, in der ein Putto herabgefallene Feigen sammelt. Diese werden von einem Putto in dem auf dem linken Seitenrand emporwachsenden Feigenast gepflückt, an den sich nach oben ein Blütenzweig (vgl. Bl. 7r) anschließt; darin zwei weitere Putti, von denen einer Flöte (?) spielt und trommelt, während der andere, zusammen mit einer Gans und einem Hasen (beide an den Beinen aufgehängt) kopfüber in den Ranken hängt. Auf dem oberen Seitenrand und im Interkolumnium Rankentyp 3 ; in Rankengabelung Eule, die blauen Vogel gefangen hat.

Bl. 83rb Geburt Mariens: Vor Rundbogenfenster mit Ausblick in Berge und Himmel (dieser auf dem Außengrund fortgesetzt) sitzt Anna in einem Himmelbett (davor Kasten mit Zinnkanne und -becher) und löffelt aus einem Teller, während eine kniende Magd die kleine Maria (als Wickelkind) in einem Holzzuber badet. Auf dem Bas-de-page Putti bei der Weinlese; mittig in den zarten Weinranken zwei weitere Putti, die großes Neustifter Wappen präsentieren (goldenes Tau-Kreuz auf rotem Grund, der von feinen Ranken in dunklerem Rot überzogen ist). Am rechten oberen Blattrand Rankentyp 3 mit Maikäfer, Marienkäfer und bräunlichem, schwarz geflecktem Schmetterling. In die Ranke größerer naturalistischer Zweig mit roten Blüten kopfüber eingehängt.

Bl. 85ra Kirchenweihe: Bischof im Ornat mit goldenem Krummstab und Aspergil nähert sich, gefolgt von Klerikerschar (der vorderste mit Weihwasserkessel), einer Kirchenfassade mit schmalem Rundbogentor (mit Vordach, darüber Rundfenster; zudem Dachreiter erkennbar); über der Szene weht die Kirchweihfahne. Als Randzier Rankentyp 3.

Bl. 86va Allerheiligen: Heiligenschar; in der Frontreihe erkennbar (von links nach rechts): Katharina (Schwert), Barbara (Kelch und Hostie), Petrus (Schlüssel), Paulus (Schwert und Buch), Johannes (Kelch mit Schlange), Benedikt (schwarzer Habit). - Auf dem Bas-de-page großer Hirschkäfer und zwei aufgeschreckte, von bellendem Hund begleitete Putti, die wohl versucht haben, den Käfer mit einem Beil, jetzt am Boden liegend, zu attackieren. In der linken oberen Seitenecke roter Klee, an den ein auf den linken Rand herabhängender Veilchenzweig mit einem roten Bändchen angebunden ist. Drolerie (Kleezweig): rosafarbener Falter. B1. 88rb Totenmesse(n): Tisch mit schwarzem Tuch (mit weißem Kreuz), darauf Totenschädel und brennende Kerze. - Rankentyp 3 (und 2) sowie kurze Blütenranke (vgl. Bl. 7r). Drolerie: Rabe mit Knochen im Schnabel.

Bl. 58v Kussbildchen $(55 \times 180)$ : Zwei prächtig gewandete Engel präsentieren das Schweißtuch mit dem dornenbekrönten Haupt Christi (mit delikatem Kreuznimbus).

Bl. 1v ganzseitiges Stifterbild (250×200); interpretiert man das Buch in den Händen des hl. Augustinus als das Missale, dann auch Dedikationsbild: In schlichtem Goldrahmen (8 $\mathrm{mm}$ breit), mittig unter einem auf Marmorsäulen ruhenden und von Tondi flankierten Korbbogen, vor kobaltblauem Grund (mit feinlinigem Rautengitter), die Madonna in einer Mandorla (abwechselnd gerade und ondulierende Strahlen), mit einem Stab und dem Jesuskind auf dem Arm, das sich dem auf die Knie gesunkenen Auftraggeber der Hs., dem Neustifter Propst Augustin Posch, zuneigt; dieser trägt ein mit Schweifen besetztes Feh-Almutium, über ihm ein lebhaft gewundenes, leeres Spruchband; auf der anderen Seite der Madonna steht der hl. Augustinus im Bischofsornat mit kostbarem Krummstab und einem geöffneten Buch in den behandschuhten Händen; über der Madonna zwei Putti, die eine goldene Bügelkrone halten; zu Füßen der Gruppe drei weitere Putti als Wappenhalter: links Klostergründer Herren von Säben (auf silbernem Grund fünf aufsteigende rote Spitzen, mit feinen Ranken geschmückt), in der Mitte Neustift (auf rotem Grund goldenes Tau-Kreuz), rechts Augustin Posch (auf rotem Grund goldener Dreiberg, darüber stilisierter Ast mit zwei goldenen Früchten; Hermann 157: Erdbeeren). In der rechten Bildhälfte ein gut $40 \mathrm{~mm}$ breiter Streifen beschädigt. - Bas-depage: Auf einem vasenartigen Ziersockel sitzt ein Putto, der in zwei große Hörner bläst, denen Schwäne und Ranken (Typ 2) entwachsen. Zentral auf dem oberen Seitenrand halten zwei grün-karminrosafarbene Dra- 
chen, die in Blattwerk übergehen, eine blaugrundige, goldgerahmte und von einer Fruchtschale bekrönte Kartusche mit der Jahreszahl 1526 (Goldziffern). Auf dem linken und dem rechten Seitenrand Kandelaberleisten, die rechte Leiste entwächst den Bas-de-page-Ranken; in der linken Leiste zwei Schwäne (an den henkelartigen Hälsen mit einem goldenen Band zusammengebunden und zugleich am zentralen Stab fixiert), zuoberst eine Fruchtschale mit drei Puttenköpfen.

Bl. $51 v$ ganzseitiges Kanonbild $(245 \times 195)$ : dreifigurige Kreuzigung in einfachem Goldrahmen $(50 \mathrm{~mm}$ breit). Im Boden verkeiltes Kreuz aus roh behauenen Baumstämmen, am Fuß umgeben von den Gebeinen Adams; der Gekreuzigte mit massiver Dornenkrone, beinah geschlossenen Lidern und rosafarbenem, abflatterndem Lendentuch; drei Engel fangen das den Wundmalen Christi entströmende Blut in Kelchen auf, zwei der Engel schweben dabei unter den Querarmen des Kreuzes, der dritte kniet dahinter; Maria richtet, mit gefalteten Händen, den Blick verloren zu Boden, während Johannes mit leicht geöffnetem Mund und erhobenen Händen zum Gekreuzigten aufblickt. Minutiös gestalteter Hintergrund mit Stadtvedute vor alpiner Bergkette, über der die Sonne an einem mit zarten Wolken überzogenen Himmel untergeht. In der rechten oberen Ecke Abdruck der Te-igitur-Initiale B1. 52r. - Auf dem Bas-de-page drei zugehörige Passionsszenen: Geißelung mit zwei Schergen, von denen einer Christus am Heiligenschein (!) festhält oder ihm in die Haare fassen will (Szene etwas abgerieben) und seinen Fuß fixierend auf das linke Bein Christi gestellt hat; die Geißelsäule zugleich der Sockel der linken Kandelaberleiste; daneben Dornenkrönung mit drei Schergen und Kreuztragung mit drei Soldaten, von denen einer Simon von Cyrene, der Jesus beim Tragen helfen will, an den Haaren festhält, um ihn mit einem Seil zu schlagen. Auf dem oberen Seitenrand edler Fruchtpokal, dem Ranken (Typ 2, mit Puttenköpfchen) entwachsen.

Als Vorlage für Cod. 100 diente tw. Cod. 196 (zusammen mit dem Teil Esztergom, Kathedralbibl., Ms. II.2), vgl. z. B. die Augustinus-Initialen mit den adorierenden Chorherren (B1. 80vb mit Cod. 196, B1. 31[22]r; s. Hermann 163 Anm. 2) oder die Kirchenweihe-Initialen, deren Komposition im Posch-Missale seitenverkehrt übernommen wurde (Bl. 85ra mit Cod. 196, Bl. 34[25]r; s. Hermann 163 Anm. 3); darüber hinaus etliche Parallelen im Randschmuck, v. a. bei den naturalistischen Pflanzendarstellungen; zum einen Übernahme der Kombinationen zweier naturalistischer Zweige, wobei nur minimale Veränderungen vorgenommen wurden, vgl. Bl. 63v mit Cod. 196, Bl. 34[25]v (Akelei und Heckenrosen samt Vogel und rotem Falter) oder Bl. 45v mit Ms. II.2, Bl. 11v (Wiesensalbei und Butterblume samt Vogeldrolerie), des Weiteren Übernahme des naturalistischen Zweigs und Umwandlung des Akanthusasts zu Rankentyp 3, vgl. Bl. 39r mit Cod. 196, Bl. 32[23]r (Nelken samt Glucke, Akanthus mit zwei Vogeldrolerien), und schließlich wurde häufiger aus einer Kombination von Akanthus mit naturalistischem Zweig nur letzterer übernommen, vgl. die kopfüber auf dem Seitenrand platzierten Iriszweige Bl. 68v und Ms. II.2, Bl. 5v (sehr ähnliche Iris auch Cod. 196, Bl. 10v, hier mit der Blüte nach oben). Die Adaptationen sind nicht an die Textstelle und den Initialtyp gebunden, denen die jeweilige(n) Pflanze(n) in Cod. 196 bzw. Ms. II.2 zugeordnet wurde(n). Dies lässt an ein Musterbuch des 15. Jhs. denken, das in Neustift noch im 16. Jh. vorlag. Während die PflanzenIlluminationen quasi unverändert übernommen wurden, passte man die spätmittelalterlichen Akanthusranken dem Renaissance-Geschmack an. - Zu den Vorbildern für die Gestaltung von Cod. 100 wurden vielfältige Überlegungen angestellt. H. Fiegl sieht die Ausstattung des Missales nur peripher durch die Donauschule und deren Naturauffassung beeinflusst, vielmehr durch die Motivik (v. a. des Randschmucks) und die Farbgebung der süddeutschen Buchmalerei des 1. Viertels 16. Jh. (Nürnberg und vorrangig Augsburg) sowie durch das Organisationsprinzip der Ausstattungselemente, das Albrecht Dürer für seinen Part der Ausschmückung im Gebetbuch Maximilians I. (1514 gedruckt, 1515 dekoriert) wählte (s. Fiegl, Missale 121-124; Fiegl, Prachthandschrift 752-754, passim), weshalb als führende Illuminatorenhand wohl ein süddeutscher Künstler angenommen werden kann, der nicht nur als Miniator, sondern auch als Tafelmaler tätig gewesen sein könnte (Fiegl, Missale 121). Eine weitere Inspirationsquelle dürften die verbreiteten Holzschnitte und Stiche süddeutscher Meister Anfang 16. Jh. gewesen sein (s. Hermann 163 Anm. 4). Während in der älteren Literatur noch Stephan Stetner als ausführender Künstler genannt wird (s. z. B. Hermann 156), spricht sich die neuere Forschung dagegen aus, da zumindest die Meisterhand des Cod. 100 eindeutig fortschrittlicher einzustufen ist als Stetners Arbeiten - immer vorausgesetzt, man nimmt diesen Neustifter Chorherrn in der Tat nicht nur als Schreiber, sondern auch als Buchmaler an. Eine Hypothese, die mit Vorbehalten zu sehen ist (hierzu vgl. Cod. 194). Fiegl, Prachthandschrift 748 kann sich zumindest eine untergeordnete Mitarbeit Stetners am Posch-Missale vorstellen, wobei sie Cod. 194 und 196 in ihre Überlegungen einbezieht.

E: Neuzeitlicher Bibliothekseinband: braunes Leder über Holz mit Blindlinien. Neustift, 2. H. 18. Jh. Einband und Bindung 2017 restauriert: gereinigt, Bindung und Heftung stabilisiert, Buchrücken gestärkt sowie Fehlstellen am Einbandrücken ergänzt (vgl. Restaurierprotokoll). Leder stark abgerieben, zerkratzt und beschädigt. VD und HD gleich: ein aus dreifachen Streicheisenlinien gebildeter Rahmen, zum Rücken 
hin vertikal jeweils nochmals dreifache Streicheisenlinien. Reste von zwei Leder-Metall-Schließen. Kanten gerade und nach innen hin abgeschrägt. Rücken: Leder tw. 2017 ergänzt (deutlich erkennbar), fünf einfache Bünde, von (urspr. wohl Gold-)Bordüren gesäumt. Im zweiten Feld Golddruck MISSALE in Goldrahmung, im dritten Signaturschild (s. bei G). Kapitale mit naturfarbenem und grünem Spagat umstochen sowie mit Leder umschlagen. Spiegel Pap. 18. Jh. Am Spiegel des VD Exlibris und Signaturen (s. bei G), Spiegel des HD leer.

G: Hs. von Stephan Stetner 1524 im Auftrag von Propst Augustin Posch (Propst 1519-1527) im Kloster Neustift geschrieben, Buchmalerei wohl erst zwei Jahre später abgeschlossen (s. Bl. 1v: 1526). Zahlreiche Darstellungen des Neustifter Wappens (Bl. 1v, 2r, 7r, 83r). Bl. 2r Besitzvermerk Ecclesiae Neocell. Am Spiegel des VD Exlibris der Stiftsbibl. Neustift 18. Jh. 1809 anlässlich der vorübergehenden Aufhebung des Klosters Neustift der ULB Tirol übergeben. Am Spiegel des VD Signaturen der ULB Tirol II 2 G 4 (Bleistift) und Nr. 100 (Tinte). Am Rücken gelbes Signaturschild der ULB Tirol 100. Bl. 1r und 2r Stempel der ULB Tirol, 19. Jh. 1921 aufgrund des Friedensvertrages von St. Germain an den italienischen Staat abgegeben und von diesem 1929 dem Kloster Neustift als Dauerleihgabe überlassen. Bl. 1r Stempel der Soprintendenza Tridentina 20. Jh.

L: $\quad$ F. Leithe, Die k.k. Universitätsbibliothek in Innsbruck. Neuer Anzeiger für Bibliographie und Bibliothekswissenschaft (1874) 260-266, hier 263. - Wilhelm II 110. - Hermann 155-164, Nr. 171. - Atz 1012. - B. Rutz, Illuminierte Choralhandschriften zu Neustift. Kirchenmusikalische Jahrbuch 22 (1909) 88-95, hier 90. - Gschwend 86. - Colophons Nr. 16895. - P. d'Ancona, E. Aeschlimann, Dictionnaire des miniaturistes. Mailand 1949, ND Nendeln 1969, 200. - I. Uhl, Buchmalerei. Geschichte, Technik und Ikonographie. Ettal 1971, 99-100 und Abb. 75. - T. Fabich, Die Buchmalerei der Frührenaissance in Süddeutschland. Wien 1972, 81-97, 149, Nr. 20. - W. Neuhauser, Eine unbekannte lateinische Beschwörungsformel in der sog. Neustifter-Innsbrucker-Spielehandschrift (Cod. 960 der Universitätsbibliothek Innsbruck), in: R. Muth, G. Pfohl (Hrsg.), Serta philologica Aenipontana 3 (Innsbrucker Beiträge zur Kulturwissenschaft 20). Innsbruck 1979, 221-253, hier 226 und 253. - Neuhauser, Neustift 85. - W. Salmen, Katalog der Bilder zur Musikgeschichte in Österreich 1 (Innsbrucker Beiträge zur Musikwissenschaft IV). Innsbruck 1980, Nr. 585. Katalog ULB Tirol I 279, 283-284. - Peintner, Buchmalerei 34-35, 93-115 (ohne Nennung der Sign.). - P. Spunar, Repertorium auctorum Bohemorum provectum idearum post Universitatem Pragensem conditam illustrans I (Studia Copernicana 25). Wratislaviae u. a. 1985, Nr. 120. - M. Peintner, Kloster Neustift. Augustiner Chorherren in Südtirol. Bozen 1985, 19 (ohne Nennung der Sign.). - Peintner, Stiftsbibliothek 124-126. - M. Peintner, Das Skriptorium von Neustift, in: 850 Jahre Neustift. Katalog 91-93, hier 93 (ohne Nennung der Sign.). - Th. (H.) Innerhofer, Wappen und Siegel des Konvents und der Pröpste von Neustift, in: 850 Jahre Neustift. Katalog 199-214, hier 199 (ohne Nennung der Sign.). - Stefani 97. - Fiegl, Missale. - Fiegl, Prachthandschrift. - U. Merkl, Buchmalerei in Bayern in der ersten Hälfte des 16. Jahrhunderts. Regensburg 1999, 22. - Neuhauser, Musikgeschichtliche Quellen 164, 194 (ohne Nennung der Sign.). Peintner, Schreibkunst 371, Taf. 10-12 (ohne Nennung der Sign.). - Gozzi 548, Nr. 78. - M. Roland, Buchmalerei, in: A. Rosenauer (Hrsg.), Geschichte der Bildenden Kunst in Österreich 3: Spätmittelalter und Renaissance. München u. a. 2003, 521-546, hier 534-535. - Th. (H.) Innerhofer, Das Augustiner-Chorherrenstift Neustift, in: H. Obermair, K. Brandstätter, E. Curzel (Hrsg.), Dom- und Kollegiatstifte in der Region Tirol Südtirol - Trentino in Mittelalter und Neuzeit (Schlern-Schriften 329). Innsbruck 2006, 223-238, hier 228. Roland, Renaissance 633, 635, 638, 643-644 (Kat. 334, tw. ohne Nennung der Sign.). - Baroffio 324, Nr. 16710-11. - Krämer, Scriptores, s. v. „Stetner, S.“. - D. Merlin, Due versioni melodiche del Pater Noster a Bressanone/Brixen ed una rara soluzione editoriale nel contesto dei messali a stampa all'inizio del Cinquecento, in: L. Rossi (Hrsg.), Ars Sacra 2013. Musica sacra e liturgia nelle Cappelle Musicali: testimonianze e testimoni. Giornate di studi musicologici, etnomusicologici e storici. Anagni, 21-24 marzo 2013. Roma 2017, 327-349. - U. Stampfer, Missale des Neustifter Propstes Augustin Posch, in: J. Kronbichler, H.-P. Ties (Hrsg.), Renaissance im Gebirge. Der Maler Bartlme Dill Riemenschneider und seine Zeit. Hofburg Brixen 27. Mai-31. Oktober 2017, 120-123 (Kat. 26). - J. Emprechtinger, Restaurierprotokoll, Mai 2017.

Missale (festivum) für Propst Augustin Posch („Posch-Missale“).

Mit Missale Brixinense (Druck: Basel 1511) weitgehend übereinstimmend, Anordnung abweichend: Ordo missae zw. Karsamstag und Ostersonntag eingeschoben. Rubriken bes. an den Kartagen aufgrund der Eigenliturgie tw. gegenüber Druck leicht abweichend.

Vollständige Messformulare im Temporale nur für die Hochfeste, im Sanctorale für Marienfeste, Agnes, Augustinus, Allerheiligen und Kirchweihe, zusätzlich Sakramentar für zahlreiche Heiligenfeste.

(1r) nur Rahmung.

(1v) ganzseitige Miniatur (s. bei A). 
1 (2ra-36rb) Temporale, pars hiemalis (In nativitate dni bis In vigilia paschatis). (2ra) In vigilia nativitatis dni. - (3ra) In galli cantu. Mit Sequenz (AH 53, Nr. 10). - (5rb) In die sancto. Mit Sequenz (AH 53, Nr. 15). - (7ra) In circumcisione dni. Mit Sequenz (AH 53, Nr. 16). - (8rb) In epiphania dni. Mit Sequenz (AH 53, Nr. 29). - (9vb) In purificatione BMV. Mit Sequenz (AH 53, Nr. 99). - (11va) Dnca in palmis. - (17rb) Fer. 5 in coena dni. - (20va) Fer. 6 in parasceve. (28ra) Depositio (Gschwend 86). Inc.: Quid retribuam domino pro omnibus que retribuit mihi panem celestem accipiam de mensa domini ... - (28va) Sabb. sanctus. Feuer- und Kerzenweihe mit anschließendem Exultet (im Druck nur Verweis). (29vb) Sechs Lectiones, jeweils mit anschließender Oratio: Lectio 1; Lectio 2 (im Druck nicht enthalten: Gn 22,1-19); Lectio 3 (im Druck: Lectio 2); Lectio 4 (im Druck: Lectio 3); Lectio 5 (im Druck: Lectio 4); Lectio 6 (im Druck nicht enthalten: Is 55,1-11). (34vb) Taufwasserweihe mit Orationen (mit Druck übereinstimmend) und anschließenden Gebeten, Rubriken und Hymnus unter ausdrücklicher Bezugnahme auf das Salzburger Missale: Sequitur secunda collecta continuando sub una conclusione secundum Salisburgensem. (35ra) Messe (mit Druck übereinstimmend).

2 (36va-61v) ORdo Missae.

2.1 (36va-38rb) Kyriale: Kyrie. Gloria. Credo. Agnus Dei.

(36va) Kyrie (mit Notation). Gloria (einmal ohne, einmal mit Notation). - (36vb) Agnus Dei. (37ra) Gloria mit Tropus Spiritus et alme. - (37rb) Intonation für zwei verschiedene Versionen des Credo. - (37vb) Gebete nach der Gabenbereitung. Darunter Datierung und Schreibernennung: 1524 S S.

$2.2(38 \mathrm{v}-47 \mathrm{v})$ Praefationes mit Notation.

(38v) In die nativitatis domini prefatio. - (39r) De epiphania domini Ihesu prefatio solennis. (40r) De sancta cruce sequitur prefatio dominicaliter. - (40v) In vigilia pasce prefatio de resurrectione dominicaliter sequitur. - (41v) In die sancto pasce prefatio de resurrectione domini solenniter. - (42r) Ascensionis domini prefatio solenniter. - (43r) In vigilia penthecostes prefatio dominicaliter de sanctis. - (43v) In die penthecostes prefatio solenniter. - (44v) De sancta trinitate prefatio solenniter. - (45v) De beata virgine prefatio solenniter. - (46v) Prefatio communis solenniter cantanda. - (47r) Prefatio communis ferialiter.

2.3 (47v) Forts. des Kyriale: Sanctus. Benedictus (beide ohne Notation).

2.4 (48ra-50rb) COMMUNICANTES.

(48ra) De nativitate domini Ihesu infra actionem. - De epiphania domini infra actionem. - (48rb) In cena domini infra actionem. - (48vb) In vigilia pasce infra actionem. - (49rb) In die sancto pasce infra actionem. - (49vb) Ascensionis domini infra actionem. - In vigilia et in die sancto penthecostes.

(50rb) Datierung: 1524.

2.5 (50v) GeBETSCHLÜSSE.

(50v) Conclusio ultime collecte. Et famulos tuos antistitem regem et princepes (!) nostros cum omnibus sibi commissis ... Per dominum nostrum Ihesum Christum filium tuum ... vel sic Per eundem dominum nostrum ... vel Qui cum Deo patre et spiritu sancto vivis ... Oremus. Dominus vobiscum. Per omnia secula seculorum. Pax domini sit semper vobiscum.

Darunter Datierung: 1524.

(51r) leer.

2.6 (51v) ganzseitiges KANONBILD (s. bei A).

2.7 (52r-61r) CANON MisSaE. Von Te igitur bis Doxologie.

(56v) Pater noster, unterschieden nach Fest- und Werktagen, jeweils mit Notation. (57v) Libera nos. Pax vobiscum. (58r) Agnus Dei. Kommuniongebete (gegenüber Druck tw. abweichend).

(61v) leer. 
3 (62ra-73rb) Temporale, pars aestivalis (Dnca resurrectionis dni bis In festo ss. corporis Christi). (62ra) Dnca resurrectionis dni. Mit Sequenz (AH 53, Nr. 36). - (63va) In ascensione dni. Mit Sequenz (AH 53, Nr. 67). - (65rb) Sabb. in vigilia pentecostes. (65va) Vier Lectiones (tw. nur Verweis), jeweils mit anschließender Oratio (mit Druck übereinstimmend). (67rb) Taufwasserweihe (vom Druck leicht abweichend). (67va) Messe. - (68va) Dnca pentecostes et de spiritu sancto. Mit Sequenz (AH 53, Nr. 70). - (70rb) In festo ss. trinitatis. Mit Sequenz (AH 53, Nr. 81). - (71va) In festo ss. corporis Christi. Mit Sequenz (AH 50, Nr. 385).

4 (73rb-88rb) SANCTORALE, pars hiemalis und pars aestivalis gemischt.

(73rb) In conceptione immac. BMV. Mit Sequenz (AH 54, Nr. 188). - (74rb) Agnes. Mit Sequenz (AH 55, Nr. 51). - (76ra) In annuntiatione BMV. - (77rb) In visitatione BMV. Mit Sequenz (AH 54, Nr. 193). Oratio, Secreta und Postcommunio vom Druck abweichend. - (79rb) In assumptione BMV. Mit Sequenz (AH 53, Nr. 104). - (80va) Augustinus. Mit Sequenz (AH 54, Nr. 32). Lectio (Hbr 5,1-6) vom Druck abweichend. - (82va) Hermes. Nur Oratio, Secreta, Postcommunio. - (82vb) Adrianus. Wie im Druck nur Oratio, Secreta, Postcommunio. - Corbinianus. Wie im Druck nur Oratio, Secreta, Postcommunio. - (83ra) In nativitate BMV. Mit Sequenz (AH 53, Nr. 95). - (85ra) In dedicatione ecclesiae. Mit Sequenz (AH 53, Nr. 247). Postcommunio vom Druck abweichend. - (86rb) Omnes sancti. Mit Sequenz (AH 53, Nr. 112). Communio vom Druck abweichend. - (88ra) Caesarius. Nur Oratio, Secreta und Postcommunio.

5 (88rb-93rb) Missae PRo DEFUnCtis.

(88rb) Pro fidelibus defunctis in generali. Gradualteile. - (88vb) Pro defunctis episcopis vel prelatis. Gradualteile. - (89ra) Pro episcopo. Wie im Druck nur Sakramentarteile. - (89rb) Pro uno vel pluribus sacerdotibus. Wie im Druck nur Sakramentarteile. - (89va) In depositione unius. Sakramentarteile, nicht im Druck enthalten. - (89vb) Pro uno vel pluribus fundatoribus. Sakramentarteile, nicht im Druck enthalten. - (90rb) In anniversario unius. Wie im Druck nur Sakramentarteile. - (90rb) In anniversario plurium. Sakramentarteile, nicht im Druck enthalten. (90vb) Pro benefactoribus. Sakramentarteile, nicht im Druck enthalten. - (91ra) Pro fratribus et sororibus. Wie im Druck nur Sakramentarteile. - (91va) Pro parentibus. Wie im Druck nur Sakramentarteile. - (91vb) Generalis.

Anschließend Lectiones (Reihenfolge vom Druck abweichend): (92ra) 2 Mcc 12,43-46. - (92rb) Ez 37,12-14. - (92va) Apc 14,13. 1 Cor 15,20-23.

(92va) Pro episcopis et prelatis (Reihenfolge vom Druck abweichend). Nur Lectiones: Ies. 58,10-11. Io 6,37-39. - (93ra) Io 6,53-54. Io 11,21-27.

(93rb) Datierung und Schreibernennung: 1524 S: S:

6 (93rb-104ra) SACRAMENTARIUM.

6.1 (93rb-97rb) TEMPORALE.

(93rb) Dnca 3. post epiph. dni. - (93va) Dnca 4. post epiph. dni. - (93vb) Dnca 5. post epiph. dni. - Dominica sexta. Im Druck nicht enthalten. - (94ra) Dnca in Septuages. - (94rb) Dnca in Sexages. - Dnca in Quinquages.

(94va) Datierung und Schreibernennung: 1524 S: S:

(94va) Dominica octava post trinitatis. - (94vb) Dominica nona. - (95ra) Dominica decima. (95ra) Dominica undecima. - (95rb) Dominica duodecima. - (95va) Dominica tredecima. (95vb) Dominica quartadecima. - (96ra) Dominica quindecima. Secreta und Postcommunio gegenüber Druck vertauscht. - (96ra) Dominica sedecima. - (96rb) Dominica decima septima. Secreta und Postcommunio vom Druck abweichend. - (96va) Dominica decima octava. - (96va) Dominica decima nona. - (96vb) Dominica vigesima. - (97ra) Dominica vigesima prima. (97rb) Dominica vigesima secunda. 
6.2 (97va-104ra) SANCTORALE.

(97va) Philippus et Iacobus. - (97va) Sigismundus. Vom Druck abweichend. - (97vb) In inventione s. crucis. - (98ra) Alexander et Eventius. - (98rb) Monica. Im Druck nicht enthalten. - (98va) Florianus et socii. Vom Druck abweichend. - (98vb) Iohannes ante Portam Latinam. - (99ra) Gordianus et Epimachus. - (99rb) Pancratius. - (99va) Maria ad martyres. Im Druck nicht enthalten. - (99vb) In translatione s. Albuini. - (100ra) Victor. Im Druck nicht enthalten. - (100rb) Urbanus papa. - (100va) Nicomedes. - (100vb) Marcellinus et Petrus. - (101ra) Erasmus. Secreta und Postcommunio vom Druck abweichend. - (101rb) Bonifatius et socii. Oratio und Postcommunio vom Druck abweichend. - (101va) Primus et Felicianus. - (101vb) Barnabas. Vom Druck abweichend. - (102ra) Basilides et socii. - (102rb) Vitus. - (102va) Marcus et Marcellianus. (102va) Gervasius et Prothasius. - (102vb) Achatius et socii. Vom Druck abweichend. - (103ra) Ursula et undecim milia virginum. Oratio vom Druck abweichend. - (103rb) Severinus. Vom Druck abweichend. - (103va) Crispinus et Crispinianus. Oratio vom Druck abweichend. (103vb) In translatione s. Amandi. Secreta und Postcommunio vom Druck abweichend.

(104ra) Datierung und Schreibernennung: 1524 S. Stetner.

(104rb) leer.

(104v) nur Rahmung und Linierung.

U.S.

\section{Cod. 106}

\section{IOHANNES IANUENSIS}

Perg. I, 110, I* Bl. 365 × 285. Süddeutscher Raum (?), 1. H. 15. Jh.

B: Haar- und Fleischseite deutlich unterscheidbar, wenige kleine Löcher und Nahtspuren. Lagen: (I-1) ${ }^{1}$ (Vorsatzbl., Pap. 18. Jh.) + 11. $\mathrm{V}^{110}+(\mathrm{I}-1)^{\mathrm{I}^{*}}$ (Nachsatzbl., Pap. 18. Jh.). Ab Lage 5 (mit Ausnahme von Lage 9 und 11) am Lagenanfang Kustoden in arabischen Ziffern beginnend mit 7, d. h. vor Bl. 1 fehlen wohl zwei Lagen (Textverlust). Lagenreklamanten, tw. stark be- bzw. weggeschnitten. Nach Bl. 110 fehlt mindestens eine Lage (Bl. 110v Reklamante: unde postreme, Textverlust). Am rechten unteren Blattrand vereinzelt Zählung der einzelnen Blätter jeder Lage 1-10, tw. beschnitten. Am oberen Blattrand Foliierung 19. Jh. durch die ULB Tirol. Spuren von Ledersignakeln, Bl. 68 Lederrest.

S: $\quad$ Schriftraum 280/290×185/190. Zwei Spalten, von Tintenlinien gerahmt (seitlich von zweifachen), zu 43, meist 47-48 Zeilen. Zirkelstiche. Bastarda, Initien der einzelnen Abschnitte (jeweils ein bzw. zwei Zeilen) in Auszeichnungsschrift (Textualis formata [Textura]). Am Blattrand Notazeichen, Korrekturen und Ergänzungen, tw. von anderer Hand.

A: Rote Auszeichnungsstriche und Unterstreichungen, rote und blaue Paragraphzeichen sowie einzeilige Lombarden. Bei Buchstabenwechsel (Bl. 4ra, 38va, 52vb und 68vb) jeweils mehrzeilige (30-65 mm) rote Initiale. Oberlängen in der ersten Zeile bisweilen mit cadellenartigen Ausläufern, Unterlängen in der letzten Zeile tw. gedehnt. Bl. 62v rote Zeigehand (beschnitten). Repräsentanten.

E: $\quad$ Neuzeitlicher Bibliothekseinband: schwarz gesprenkeltes braunes Pap. über Pappe. Neustift, 2. H. 18. Jh. Pap. etwas abgerieben, bes. am unteren Rand. Am VD und HD Ecken mit braunem Leder verstärkt. Am HD Pappe an der Kante beschädigt. Rücken: braunes Leder, fünf einfache Bünde, von Goldbordüren gesäumt. Im ersten Feld Golddruck M: S:, im zweiten Golddruck VOCABULARIUS in Goldrahmung, im dritten Signaturschild (s. bei G). Schnitt rot gesprenkelt. Spiegel Pap. 18. Jh. Am Spiegel des VD Exlibris, Signaturen und Bleistiftnotiz (s. bei G), Spiegel des HD leer.

G: Zeitpunkt und Art der Erwerbung durch Neustift unbekannt. Am Spiegel des VD Exlibris der Stiftsbibl. Neustift 18. Jh. 1809 anlässlich der vorübergehenden Aufhebung des Klosters Neustift der ULB Tirol übergeben. Am Spiegel des VD alte Signaturen der ULB Tirol II $\overline{3}$ [...] (radiert, Tinte), II 2 C 10 (Bleistift) und Nr. 106 (Tinte) sowie Bleistiftnotiz (Vide Grundzettel). Am Rücken gelbes Signaturschild der ULB Tirol 106. Bl. 1r Stempel der ULB Tirol 19. Jh. 1921 aufgrund des Friedensvertrages von St. Germain an den 
italienischen Staat abgegeben und von diesem 1929 dem Kloster Neustift als Dauerleihgabe überlassen. Bl. 1r Stempel der Soprintendenza Tridentina 20. Jh.

L: $\quad$ Kristeller VI 122. - Stegmüller RB Nr. 4220 Suppl. - Katalog ULB Tirol II 30, 203. - Peintner, Stiftsbibliothek 122.

$(\mathrm{Ir}-\mathrm{v})$ leer.

(1ra-110vb) 〈Iohannes IAnUEnsis〉: Catholicon sive Prosodia, Pars 5: Vocabularium, unvollständig: L (lucinia) - P (postremus) (Druck: GW 3182-3205).

Inc. mut.: ] que vulgo dicitur Rothinholus. Oracius in sermone. Licinias (!) soliti inpensa (!) prandere coemptas. Lucinium -nii ubi solet candela lucere quia dat lumen et dicitur a luce ... - Expl. mut.: ... et comparatur postremus -or -simus [

$(\mathrm{I} * \mathrm{r}-\mathrm{v})$ leer.

A. P./U.S.

\section{Cod. 107}

\section{COMPILATIONES ANTIQUAE I-III}

Perg. I, 81, I* Bl. $355 \times 230$. Nordfrankreich (Raum Paris), zw. 1210 und 1234 .

B: Haar- und Fleischseite deutlich unterscheidbar, in regelmäßiger Abfolge gebunden. Nur sehr vereinzelt kleine Löcher. Bl. 1-10 durchgehend kleines rundes (gestanztes) Loch. Bl. 5 und 6, 17-22 sowie 79-81 unteres Drittel weggeschnitten (ohne Textverlust), Bl. 80 auch letzte Zeile beschnitten. Lagen: (I-1) (Vorsatzbl., Pap. 18. Jh. $)+5 \cdot V^{50}+(\mathrm{V}-1)^{59}+2 \cdot V^{79}+2^{81}+(\mathrm{I}-1)^{\mathrm{I}^{*}}$ (Nachsatzbl., Pap. 18. Jh.). Gegenbl. zum Vor- bzw. Nachsatzbl. als Spiegel auf dem VD bzw. HD aufgeklebt. Gegenbl. zu Bl. 56 herausgeschnitten (Textverlust), zugehöriger Falz mit erhaltenen Repräsentanten jetzt zw. Bl. 55 und 56 (urspr. zw. Bl. 53 und 54). Bl. 80 und 81 eingehängte Einzelbl. B1. 81 verkehrt, d. h. verso statt recto eingebunden. Am oberen Blattrand Foliierung 19. Jh. durch die ULB Tirol.

S: $\quad$ Schriftraum $205 \times 110$. Zwei Spalten, von Bleistiftlinien gerahmt, zu 51 Zeilen auf (weit über den Schriftraum hinausreichender) Bleistiftlinierung. Zirkelstiche. Littera Parisiensis. Aus inhaltlichen rechtshistorischen Gründen wohl zw. 1210 und 1234 geschrieben.

A: $\quad$ Rote Überschriften, nur tw. ausgeführt. Lombarden und Initialen nicht ausgeführt, kein Platz freigelassen (Ausnahme: Bl. 1ra Platz für Einleitungsinitiale freigelassen, spaltenbreit, elf Zeilen hoch). Am inneren Blattrand sowie links des Schriftraums Repräsentanten für Lombarden; am inneren Blattrand Repräsentanten für Überschriften (quer zum Schriftraum).

E: $\quad$ Neuzeitlicher Bibliothekseinband: schwarz gesprenkeltes braunes Pap. über Pappe. Neustift, 2. H. 18. Jh. Am VD und HD Ecken mit braunem Leder verstärkt. Am VD rechte obere Ecke eingerissen. Rücken: braunes Leder, fünf einfache Bünde, von Goldbordüren gesäumt. Im ersten Feld Golddruck $M$ : S:, im zweiten Golddruck IUS CANONICUM in Goldrahmung, im dritten Signaturschild (s. bei G). Schnitt rot gesprenkelt. Spiegel Pap. 18. Jh. Am Spiegel des VD Exlibris und Signaturen (s. bei G), Spiegel des HD leer.

G: $\quad$ Bl. 1r Besitzvermerk 15. Jh. Iste liber est monasterii sancte Marie vel ad Novamcellam. Am Spiegel des VD Exlibris der Stiftsbibl. Neustift 18. Jh. 1809 anlässlich der vorübergehenden Aufhebung des Klosters Neustift der ULB Tirol übergeben. Am Spiegel des VD alte Signaturen der ULB Tirol II 2 C 11 (Bleistift, über ältere radierte Signatur geschrieben) und N. 107 (Tinte). Am Rücken gelbes Signaturschild der ULB Tirol 107. Bl. 1r Stempel der ULB Tirol 19. Jh. 1921 aufgrund des Friedensvertrages von St. Germain an den italienischen Staat abgegeben und von diesem 1929 dem Kloster Neustift als Dauerleihgabe überlassen. Bl. 1r Stempel der Soprintendenza Tridentina 20. Jh.

L: $\quad$ Wilhelm I 136. - Wretschko-Sprung 15. - Furtenbach-Kalb 20. - Neuhauser, Neustift 88. - Katalog ULB Tirol II 30, 203. 
$(\mathrm{Ir}-\mathrm{v})$ leer.

1 (1ra-78va) 〈Bernardus PapIEnsis»: Breviarium Extravagantium sive Compilatio prima Decretalium, unvollständig (Ed.: A. Friedberg, Quinque Compilationes antiquae. Leipzig 1882, ND Graz 1956, 1-65).

(1ra-53vb) Lib. 1-4, tit. 3, cap. 3. Inc.: [Iuste iudicate] filii hominum et nolite iudicare secundum faciem sed secundum iustum iudicium iudicate ut ostendatis vero diligere iusticiam qui iudicatis ... - Expl. mut.: ... que dispen[ (Lib. 4, tit. 4 und 5, cap. 1 fehlt)

(54ra-78va) Lib. 4, tit. 5, cap. 2-Lib. 5, tit. 37, cap. 14. Inc. mut.: ] facultas et manumittentis ...Expl.: ... non enim potest esse pastoris excusatio si lupus oves comedit et pastor nescit.

Schlussschrift: Expliciunt Decretales prime.

(78vb) nur Rahmung und Linierung.

Lit.: Schulte GQ I 78-82; Kuttner 322-344.

2 (79ra-80vb) 〈Iohannes Guallensis〉: Compilatio secunda Decretalium, unvollständig (Ed.: A. Friedberg, Quinque Compilationes antiquae. Leipzig 1882, ND Graz 1956, 66-67).

Tit.: De constitutionibus. - Inc.: [P]reterea de lege illa vel errore quem cives tuos asseris statuisse videlicet ut si quis teneret per XXX annos ... - Expl. mut.: ... cum ex quo electionis tue confirmationem accepisti [ (= Lib. 1, tit. 3, cap. 7)

Lit.: Schulte GQ I 87-91; Kuttner 345-354.

3 (81ra-vb, verkehrt eingebunden, Text beginnend bei 81va) (Petrus Beneventanus CollivaciNUS»: Compilatio tertia Decretalium, unvollständig: Lib. 5, tit. 23, cap. 8-10 (Ed.: A. Friedberg, Quinque Compilationes antiquae. Leipzig 1882, ND Graz 1956, 134).

(81va) Inc. mut.: ma]nifestam non que iudici nec que alii ... - (81rb) Expl.: ... que possint in abbatem assumi.

Lit.: Schulte GQ I 87-91; Kuttner 355-368.

$\left(\mathrm{I}^{*} \mathrm{r}-\mathrm{v}\right)$ leer.

\section{Cod. 123}

\section{BERNARDUS DE GORDONIO. MEDIZINISCHE TRAKTATE}

Pap. IV, 227, I* Bl. $315 \times 215$. Süddeutscher Raum, 6. Jz. 15. Jh.

B: Bilder und Nachweise der Wasserzeichen s. WZMA. Datierung nach Wasserzeichenbefund. Identische Wasserzeichen: u. a. Innsbruck, ULB Tirol, Cod. 586 (dat. 1459); Neustift, Stiftsbibl., Cod. 125; Brixen, Priesterseminarbibl., Cod. R.3. Urspr. Lagenformel aufgrund der Neubindung im 20. Jh. (s. bei G) nicht mehr eindeutig nachvollziehbar, urspr. wohl Sexternionen: Bl. 21v, 33v, 43v, 55v, 76v, 87v, 98v, 110v, 133v und 144v Lagenreklamanten erhalten. Gegenbl. zum Vor- und Nachsatzbl. (20. Jh.) am Spiegel des VD bzw. HD aufgeklebt. Bl. 1-166 am oberen Blattrand der Rectos zeitgenössische Foliierung in arabischen Ziffern (Register und leere Blätter ungezählt), Bl. 155, 157 und 158 fehlen (Textverlust). Ab Bl. 167 Forts. der Foliierung 19. Jh. durch die ULB Tirol. Mehrere Blätter in der Zählung (1-220) nicht berücksichtigt, später nachgetragen als $11^{a}, 35^{a-b}, 64^{a-c}, 95^{a}, 121^{a}$ und $139^{a}$.

S: $\quad$ Vorsatzlage (Bl. IIr-Vr) Schriftraum $255 \times 160$. Zwei Spalten, seitlich von Tintenlinien begrenzt, zu 66 Zeilen. Bl. 1r-220r Schriftraum wechselnd 210/240 $\times 135 / 140$, tw. von Tinten-, tw. von Bleistiftlinien gerahmt, zu 39-58 Zeilen. Bastarda von zwei Händen: 1) Bl. 1r-211r und 213r-220r; 2) Bl. IVv-Vr, 11ㄹv, 18v, 212rv sowie zahlreiche Nachträge und Ergänzungen am Blattrand (= späterer Duktus des Schreibers von Neustift, Stiftsbibl., Cod. 453, T. II-IV und Cod. 748, T. I-III, möglicherweise zu identifizieren mit Bertoldus de Saxonia, s. bei G). 
A: $\quad$ Rote Auszeichnungsstriche, vereinzelt Paragraphzeichen, Durchstreichungen, Unterstreichungen und Überschriften. Bl. 1v-10v zwei- bis vierzeilige, Bl. 32v-33v vier- bis siebenzeilige, Bl. 159r-166r drei- bzw. vierzeilige rote Lombarden. Bl. Vv und 139v Neustifter Wappen in schwarzer Tinte.

E: $\quad$ Gotischer Einband: dunkelbraunes Leder über Holz mit Blinddruck. Tirol (?), 2. H. 15. Jh.

Einband restauriert bzw. unter Verwendung des urspr. Lederbezugs am VD und HD im 20. Jh. erneuert. Urspr. Leder tw. stark abgerieben und zerkratzt. VD und HD gleich: zwei aus je zweifachen Streicheisenlinien gebildete Rahmen. Äußerer Rahmen leer, Mittelfeld durch zweifache Streicheisenlinien diagonal in mehrere Rautenfelder unterteilt; darin jeweils ein kreisförmiger Stempel (Nr. 1). Spuren von zwei Kurzriemenschließen. Kanten gerade. Rücken: Leder erneuert, fünf einfache Bünde. Im ersten Feld Signaturschild (s. bei G). Kapitale mit hellblauem und rotem Zwirn umstochen. Spiegel sowie je ein Vor- und Nachsatzbl. 20. Jh. Am Spiegel des VD zwei Fragmente (wohl Teile des urspr. Spiegels) eingeklebt: 1) mit Besitzvermerk (s. bei G); 2) mit Spruch Seneca. Nichil est homini bonum sine se bono. Am Spiegel des HD Etikett der Restaurierwerkstätte (s. bei G).

G: Geschenk des Neustifter Präbendars und Klosterarztes Bertoldus de Saxonia ans Stift (gemeinsam mit Cod. 748 und vermutlich auch dem tw. von denselben Händen geschriebenen Cod. 453): Bl. Vv Schenkungsvermerk (s. Nr. 2) mit Neustifter Wappen. Zu Bertoldus vgl. Liber anniversariorum Novae Cellae Brixinensis (MGH Necrologia Germaniae III 46): „Item magister Bertoldus de Saxonia, medicine doctor, prebendarius et phisicus huius monasterii, in vita sua multa fecit bona et libere omnia sua dedit monasterio, prout continetur in litera prebendali, quam monasterio dedit“". Besitzvermerke 15. Jh.: Am Spiegel des VD Iste liber est monasterii sancte Marie virginis in Novacella prope Brixinam, Bl. 139v Iste liber est monasterii sancte Marie virginis in Novacella mit Neustifter Wappen. Bl. 1r Besitzvermerk 18. Jh. Collegii Neocellensis. 1809 anlässlich der vorübergehenden Aufhebung des Klosters Neustift der ULB Tirol übergeben. Bl. 1r Stempel der ULB Tirol 19. Jh. 1921 aufgrund des Friedensvertrages von St. Germain an den italienischen Staat abgegeben und von diesem 1929 dem Kloster Neustift als Dauerleihgabe überlassen. Bl. 1r Stempel der Soprintendenza Tridentina 20. Jh. Am Spiegel des HD Etikett der Restaurierwerkstätte 20. Jh. (Laboratorio di restauro del libro, S. Maria di Rosano [Firenze]), kein Restaurierbericht erhalten. Bl. Ir Signatur Cod. 123 (Bleistift). Am Rücken Neustifter Signaturschild 20. Jh. 123.

L: $\quad$ Wilhelm II 110. - Neuhauser, Neustift 89. - Katalog ULB Tirol II 72, 203.

(Ir-v) leer bis auf Signatur (s. bei G).

(IIr-IVr) nur Rahmung.

(IVva-Vra) Inhaltsverzeichnis zu Nr. 3.

(Vrb) leer.

1 (Vv) SCHENKUNGSVERMERK mit Inhaltsangabe: Liber iste legatus est monasterio sancte Marie virginis ad gracias alias ad Novamcellam communiter appellati (!) a felicis recordacionis magistro Bertoldo de Saxonia arcium et medicine doctore eximio cum aliis libris et rebus pro prebenda ac remedio anime sue. Obiit 1476. Liber iste continet Lilium medicine editum a magistro Bernardo de Gordonio. Tractatum de febribus. Item alium de asmate.

2 (1r-166r) Bernardus de Gordonio: Practica seu Lilium medicinae, unvollständig (Druck: GW 4080-4084. - Thorndike-Kibre 771-772. L. E. Demaitre, Doctor Bernard de Gordon: Professor and practitioner [Pontifical Institute of Medieval Studies, Studies and Texts 51]. Toronto 1980, 185-188). Gegenüber Druck tw. leicht abgeändert, tw. gekürzt.

(1r) Hinweis am oberen Blattrand 18. Jh.: Bernardus de Gordonio. De febribus et asmate.

(1r) Tit.: Incipit liber qui dicitur Lilium medicine editus a magistro Bernardo de Gordonio in preclarissimo studio montis Pessulani.

(1r) Prolog. Inc.: [I]nterrogatus Socrates a quodam quomodo posset optime respondere seu dicere. Respondit Si nichil ... - Expl.: ... post annum XX lecture nostre anno domini $M^{\circ} C^{\circ} C^{\circ} I I I^{\circ}$ mense Iulii.

(1r) Kapitelübersicht zu Lib. 1. - (1v) Lib. 1, cap. 1-10.

(11v) nur Rahmung. 
(11 $\left.{ }^{\mathrm{a}} \mathrm{r}\right)$ Nachtrag zu Lib. 1, cap. 10, durchgestrichen. Inc. mut.: ] non omnino sunt certe pronuncciaciones neque vite neque mortis. Curacio rectificetur aer ... - Expl. mut.: ... de corde cervi 3. 1 misceantur [

Am oberen Blattrand Notiz von anderer Hand: Nichil vacat.

$\left(11^{\mathrm{a}} \mathrm{v}\right)$ Ergänzung zu cap. 11 (einzufügen Bl. 12v, Z. 5). Inc.: Curacio. Aut enim intendimus sudorem provocare aut auferre ... - Expl.: ... dyafori sicud narrat Galienus etc.

(12r) Lib. 1, cap. 11-31.

(18v) leer bis auf Nachtrag zu Lib. 1, cap. 18.

(35 $\mathrm{a}-35 \mathrm{br})$ nur Rahmung.

$\left(35^{\mathrm{b}} \mathrm{v}\right)$ Kapitelübersicht zu Lib. 2. - (36r) Lib. 2.

$\left(64 v-64{ }^{c} r\right)$ nur Rahmung.

$\left(64^{\mathrm{c}} \mathrm{v}\right)$ Kapitelübersicht zu Lib. 3. - (65r) Lib. 3.

$\left(83^{\mathrm{a}} \mathrm{v}\right)$ Kapitelübersicht zu Lib. 4. - (84r) Lib. 4, cap. 1-5 sowie 11-13 (in der Hs. als 10-12 angeführt).

(95v-95 $\mathrm{r}$ ) nur Rahmung.

$\left(95^{\mathrm{a}} \mathrm{v}\right)$ Kapitelübersicht zu Lib. 5. - (96r) Lib. 5.

$\left(121 \mathrm{v}-121^{\mathrm{a}} \mathrm{r}\right)$ nur Rahmung.

$\left(121^{\mathrm{a}} \mathrm{v}\right)$ Kapitelübersicht zu Lib. 6. - (122r) Lib. 6.

$\left(139^{\mathrm{a}} \mathrm{r}\right)$ nur Rahmung.

(139ªv) Kapitelübersicht zu Lib. 7. - (140r) Lib.7, cap. 1-20, unvollständig. (154v) Expl. mut.: ... et si corpus est mundificatum tanto melius etc. [ (Textverlust: Bl. 155 fehlt, s. bei B). (156r-v)

Cap. 21, unvollständig, bricht nach dem vorletzten Rezept ab. Expl. mut.: ... vel conficiantur cum melle et zuccharo (andere Tinte:) etc. [ (Textverlust: Bl. 157-158 fehlen, s. bei B)

(159r-166r) Lib. 4, cap. 6-10.

Lit.: L. E. Demaitre, Doctor Bernard de Gordon: Professor and practitioner (Pontifical Institute of Medieval Studies, Studies and Texts 51). Toronto 1980.

(166v-170v) nur Rahmung.

$(171 \mathrm{r}-194 \mathrm{v})$ leer.

3 (195r-211r) TRACTATUS DE FEBRIBUS.

(195r-202r) Inc.: [F]ebris secundum Avicennam quarto canonis in principio est calor extraneus accensus in corde et ab eo procedens mediantibus spiritu et sanguine ... Et talis calor extraneus quandoque est in spiritibus, quandoque in humoribus ... - Expl.. ... sed est magis tristis et magis timidus.

(202v) nur Rahmung.

(203r-211r) Inc.: [C] um de febribus flegmaticis iam tractandum est. Primo videndum est ... Expl.: ... et sparagi. Et hec de cura flegmatice, a flegmate pontico provenientis. Laus Deo.

$(211 \mathrm{v})$ leer.

4 (212r-215r) Tractatus de asmate.

Tit.: De asmate. - Inc.: Asma ut dicit Avicenna est egritudo pulmonis cum qua paciens non invenit excusacionem ab anhelitu ... Et Rasis addit tussim et quod leditur ex iacendo ... - Expl.. ... ficubus siccis pressis et ysopo et ca. ve. etc.

5 (215v-216v) Nachtrag zu Bernardus de Gordonio: Practica seu Lilium medicinae, Lib. 3, cap. 16.

Inc.: Reuma est fluxus humorum ad partes subiectas. Reumatis autem tres species ab autoribus distinguntur ... - Expl.: ... in passionibus pectoralum ad preservandum ne materia vadat ad pectus.

(217r-v) nur Rahmung. 
6 (218r-220r) Nachtrag zu Bernardus de Gordonio: Practica seu Lilium medicinae, Lib. 4, cap. 4, unvollständig: Text bricht in der Mitte der dritten Rubrica ab.

Verweis am Blattrand: Idem capitulum habetur 87. - Inc.: [T] ussis est motus naturalis ex pulmone ... - Expl.: ... simpliciter tamen loquendo tussis est motus quoniam ledit operationes aut significat lesionem cum concutiatur.

(220v) leer.

$\left(\mathrm{I}^{*} \mathrm{r}-\mathrm{v}\right)$ leer.

L. Š.

\section{Cod. 125}

\section{THEOLOGISCHE SAMMELHANDSCHRIFT}

Pap. I, 313, I* Bl. 310×220. Süddeutscher Raum, 6. Jz. 15. Jh.

B: $\quad$ Bl. 1 stark beschädigt, Fehlstellen bzw. Risse mit Pap. geklebt. Bl. 310 Loch (Textverlust), Bl. 311 loses Einzelbl., stark beschädigt (Textverlust). Nachweise und Bilder der Wasserzeichen s. WZMA. Datierung nach Wasserzeichenbefund. Identische Wasserzeichen: u. a. Neustift, Stiftsbibl., Cod. 123; Innsbruck, ULB Tirol, Cod. 758 (dat. 1455). Lagen: $(\mathrm{I}-1)^{\mathrm{I}}$ (Vorsatzbl. 18. Jh.) $+26 \cdot \mathrm{VI}^{310(312)}+1^{311(313)}+(\mathrm{I}-1)^{\mathrm{I}^{*}}($ Nachsatzbl. 18. Jh.). Gegenbl. zum Vor- bzw. Nachsatzbl. als Spiegel auf dem VD bzw. HD aufgeklebt. Bl. I und 1 etwas kleiner als restlicher Buchblock $(310 \times 210)$. In der Mitte der ersten und der letzten Lage unbeschriebener Pergamentfalz. Lagenreklamanten, Lagen 1-13 meist stark beschnitten, ab Lage 14 (Bl. 168v) gänzlich erhalten. Am oberen Blattrand Foliierung 19. Jh.; Fehler in der Zählung: 271 und 288 doppelt angeführt. Bl. 98, 125 und 205 jeweils neuzeitliches oranges Papiersignakel der ULB Tirol.

S: $\quad$ Schriftraum 210/230×130/145. Zwei Spalten, bis Bl. 24v vorwiegend von Blindlinien, anschließend von Tintenlinien gerahmt, mit wechselnder Zeilenzahl. Zirkelstiche. Bastarda von mehreren Händen: 1) Bl. 1ra97va (zu 34-40 Zeilen); 2) Bl. 98ra-125ra (zu 35-37 Zeilen); 3) Bl. 125va-160vb (zu 38-43 Zeilen); 4) Bl. 161ra-200ra (zu 50-54 Zeilen); 5) Bl. 205ra-311v (zu 44-48 Zeilen).

A: $\quad$ Rote Auszeichnungsstriche, Paragraphzeichen, Zeilenfüllsel, Unterstreichungen sowie Über- und Schlussschriften. Rote und schwarze Zeigehände. Ein- bis fünfzeilige rote Lombarden, tw. mit Punktverdickungen, tw. mit einfachen Ausläufern, sehr vereinzelt mit einfachem Knospenfleuronnée in Schwarz. Bl. 1ra fünfzeilige rote Initiale mit einfachem Knospenfleuronnée im Binnenfeld, als Besatz lange, orthogonal abstehende Fadenausläufergruppen. Repräsentanten.

E: $\quad$ Neuzeitlicher Bibliothekseinband: schwarz gesprenkeltes braunes Pap. über Pappe. Neustift, 2. H. 18. Jh. Am VD und HD Ecken mit braunem Leder verstärkt. Rücken: braunes Leder, tw. beschädigt, vier Doppelbünde, von Goldbordüren gesäumt. Im ersten Feld Golddruck M: S:, im zweiten Golddruck KAMPIGALL. (!) BIBLIA AUREA in Goldrahmung, im dritten Signaturschild (s. bei G). Kapitale mit naturfarbenem Spagat umstochen. Spiegel Pap. 18. Jh. Am Spiegel des VD Exlibris, Signaturen und Bleistiftnotiz (s. bei G), Spiegel des HD leer.

G: Zeitpunkt und Art der Erwerbung durch Neustift unbekannt. Am Spiegel des VD Exlibris der Stiftsbibl. Neustift 18. Jh. 1809 anlässlich der vorübergehenden Aufhebung des Klosters Neustift der ULB Tirol übergeben. Am Spiegel des VD alte Signaturen der ULB Tirol II $\overline{4} D 6$ G 6 (? radiert und durchgestrichen, Tinte), II 2 E 12 (Bleistift) und Nr. 125/3 (Tinte) sowie Bleistiftnotiz (Vide Grundzettel). Am Rücken gelbes Signaturschild der ULB Tirol 125/(3). Bl. 1r Stempel der ULB Tirol 19. Jh. 1921 aufgrund des Friedensvertrages von St. Germain an den italienischen Staat abgegeben und von diesem 1929 dem Kloster Neustift als Dauerleihgabe überlassen. Bl. 1r Stempel der Soprintendenza Tridentina 20. Jh.

L: $\quad$ Kaeppeli Nr. 1622. - Stegmüller RB Nr. 124,1.1 Suppl. - Zumkeller Nr. 115. - K. Walsh, Von der scholastischen Literatur zur Pastoraltheologie. Die „Augustinerschule“ im Spiegel der Stamser Handschriften, in: Studia Stamsensia (Innsbrucker historische Studien 6). Innsbruck 1984, 27-44, hier 40 Anm. 62. - Katalog ULB Tirol II 75, 204. - Peintner, Stiftsbibliothek 121. - D. E. Mairhofer, Liber Lacteus. Eine unbeachtete Mirakel- und Exempelsammlung aus dem Zisterzienserkloster Stams (Codicologia 1). Badenweiler 2009, 23 Anm. 33. 
(Ir-v) leer.

1 (1ra-97va) Antonius Rampegolus: Biblia aurea (Druck: u. a. GW M36970. - Stegmüller RB Nr. 1419. Zumkeller Nr. 115).

(1r) Tit.: Incipit Biblia aurea sancti alphabeti (ergänzt: author Antonius Kampigallus [!] ordinis Eremitarum sancti Augustini).

(1ra) Prolog. Inc.: Religiosis atque honestis viris in Christo dilectis fratribus studentibus Neapolim ... - Expl.: ... consuevit egredi a sua (!) misericordie largitate Amen.

(1va) Register. Tit.: Tabula capitulorum.

(2va) Alphabetisches Stichwortverzeichnis. Tit.: Item alia tabula.

(9ra) Text. Inc.: Abstinencia est meriti augmentativa. Sapiencie acquisitiva ... - Expl.. ... accepit epistolas ut persequeretur Christianos Act. 13. Deo gracias.

Genaue Aufschlüsselung des Inhalts s. bei Stegmüller.

$(97 \mathrm{vb})$ leer.

2 (98ra-125rb) Exzerpte aus «Guilelmus Peraldus〉: Summa de vitiis et virtutibus, De virtutibus (Druck: u. a. GW 12055. - Kaeppeli Nr. 1622B. Bloomfield Nr. 5601).

(98ra) Register. Tit.: Summa virtutum.

(98rb) Text. - (125rb) Schlussschrift: Expliciunt excerpta de summa virtutum. Deo gracias.

3 (125va-145vb) 〈Gerardus de Vliederhoven»: Cordiale quattuor novissimorum (Druck: u.a. GW 7473. - Madre 329. Bloomfield Nr. 3057).

Tit.: Sequitur Cordiale tractatus de quatuor novissimis optima materia.

Auch zugeschrieben Henricus de Hassia, Iohannes Gerson, Iacobus Gruytroede, Dionysius Carthusianus.

4 (146ra-160vb) 〈Thomas a Kempis〉: De imitatione Christi (Ed.: J. Pohl, Thomae Hemerken a Kempis ... opera omnia II. Friburgi Br. 1904. - Bloomfield Nr. 4633).

Abweichende Kapitelzählung in der Hs., da einige Kapitel nicht gezählt, vereinzelt Kapitel gekürzt bzw. ausgelassen, s. Lib. 3.

(146ra-151ra, Z. 11) Lib. 1. - (151ra, Z. 11-154va, Z. 14) Lib. 2, beginnend mit cap. 1.2 ohne Hervorhebung (Eya anima fidelis prepara ...). - (154va, Z. 15-159ra, Z. 34) Lib. 3, cap. 1-59.3. (159ra, Z. 35-160vb) Lib. 4.

5 (161ra-169va) 〈IAcobus Mediolanensis $\rangle=\langle$ Ps.-Bonaventura $\rangle$ : Stimulus amoris, Auszug (Druck: A. Ch. Peltier, S. R. E. Cardinalis S. Bonaventurae ... opera omnia XII. Parisiis 1868, 633-703. Stimulus amoris fr. Iacobi Mediolanensis. Canticum pauperis Fr. Ioannis Peckam [Bibliotheca Franciscana Medii Aevi 4]. Quaracchi ${ }^{2}$ 1949, 1-129. - Distelbrink Nr. 217-219. Bloomfield Nr. 1294).

Die Hs. enthält Pars 1, cap. 1-4; Pars 2, cap. 1, 6, 9, 10; Pars 3, cap. 1-5 des Drucks (1868).

Rubrik: Liber ille (!) qui intitulatur Stimulus amoris in dulcissimum et piissimum salvatorem nostrum in tres dividitur partes ... - Inc.: Currite gentes undique et miramini erga vos caritatem Dei ... - Expl.: ... misericors est Deus qui est benedictus et laudabilis et gloriosus in secula seculorum Amen.

Lit.: F. Eisermann, „Stimulus amoris“. Inhalt, lateinische Überlieferung, deutsche Übersetzungen, Rezeption (MTU 118). Tübingen 2001.

Vgl. Cod. 165, Bl. 132v.

6 (169va-170ra) Auszug aus «EcBertus Schonaugiensis〉: Soliloquium seu Meditationes, cap. 1-4 (PL 195, 105D-108B).

Tit.: Contemplacio Bernhardi.

Vgl. Cod. 165, Bl. 139v. 
7 (170rb-183vb) 〈Ps.-〉Eusebius CAESARIEnsis: Epistola ad beatum Damasum episcopum Portuensem et ad christianissimum Theodosium Romanorum senatorem de morte Hieronymi (PL 22, 239-282. Klapper II 10-241. - BHL Nr. 3866. BHM Nr. 903E). Abweichende Kapiteleinteilung. Tit.: Incipit libellus de vita et obitu et miraculis sancti Ieronimi et primo epistula Eusebii ad Damasium (!) et Theodonium (!) Romanorum imperatorem senatorem.

Schlussschrift: Explicit epistula Eusebii de morte sanctissimi Ieronimi presbyteri.

8 (183vb-186va) 〈Ps.->Augustinus: Epistola 18 (ad Cyrillum Hierosolymitanum episcopum de magnificentiis beati Hieronymi) (PL 22, 281-289. Klapper II 245-288. - CPL Nr. 367. BHL Nr. 3867. BHM Nr. 903A).

Tit.: Incipit epistula beati Augustini ad Cyrillum patriarchum Ierosolimitanum de beatissimo Ieronimo. Exordium epistolare de non tacendo laudes Ieronimi.

Schlussschrift: Explicit epistula Augustini ad Cirillum de glorioso Ieronimo.

9 (186va-198va) 〈Ps.->CYRILlus: Epistola ad Augustinum de miraculis Hieronymi (PL 22, 289326. - CPL Nr. 367. BHL Nr. 3868. BHM Nr. 903C) = 〈Ps.-Augustinus»: Epistola App. 19 (PL 33, 1126-1153).

Tit.: Incipit epistula Cirilli ad Augustinum de miraculis gloriosi Iheronimi.

10 (198va-200ra) Auszüge aus 〈Iohannes Andreat»: Hieronymianus (Druck: GW 1727. - BHL Nr. 3876. BHM Nr. 907).

(198va) Tit.: De quibus miraculis factis noviter in Appulia et primo quid in Troya civitate. - Inc.: Sciendum est quod moderno tempore in Appulia in provincia Capitinate ... - Expl.: ... et notabiliter fide digni.

(198vb) Tit.: De magistro Iacobo liberato. - Inc.: Magister Iacobus scutellarius commendabilis vite ... - Expl.: ... subsidium obtulit.

(199ra) Tit.: De mortuo resuscitato. - Inc.: Item magister barbatus sancti Georii ... - Expl.: ... et aduc (!) vivit.

(199ra) Tit.: De capto liberato. - Inc.: Item dum exercitus domini regis Roberti ... - Expl.: ... votum implevit.

(199rb) Tit.: De liberato ab aquis. - Inc.: Item Favinus de Slappis ... - Expl.: ... elevaverunt eundem.

(199rb) Tit.: De liberato a casu. - Inc.: Item cum quidam frater in subscripta manens ... - Expl.: ... illesus evasit.

(199rb) Tit.: De abortiva. - Inc.: Item quedam mulier in Arriano peperit ... - Expl.: ... puella revixit.

(199rb) Tit.: De falcone invento. - Inc.: Item quidam nobilis falconem unum perdiderat ... Expl.: ... falco venit.

(199rb) Tit.: De sanacione equi. - Inc.: Item miles quidam Gallicus familiaris ... - Expl.: ... votum replevit sancto Ieronimo gracias agens.

Die letzten beiden Auszüge in Wilten, Stiftsbibl., Cod. 320205 zu einem Kapitel zusammengefasst.

(199rb) Tit.: De liberacione unius pueri. - Inc.: Item Petrus frater domini Mathei de Sallerno ... Expl.: ... in eterna beati Ieronimi presentatus.

(199va) Tit.: De ceco illuminato. - Inc.: Nicolaus Iohannis mariscalchi (!) ...-Expl.: ... restitutus est visus.

(199va) Inc.: Item maiora (wie Wilten, Stiftsbibl., Cod. 3202 05, Bl. 427rb, im Druck „Maria“) de terra ... - Expl.: ... reliqui operando.

(199va) Tit.: De puero liberato a flammis. - Inc.: Item Iohannes infans cum sorore maiore ... Expl.: ... fuit illesus.

(199va) Inc.: De duabus ecclesiis noviter ... - Expl.: ... montis Deglin (?). 
(199va) Tit.: De ecclesia sub terra cooperta. - Inc.: Deserta (in Wilten, Stiftsbibl., Cod. 3202 05, B1. 427va: „De secunda“") cui inest miraculum ... - Expl.: ... concursum civium festinatur. (199vb) Tit.: Quomodo translatum est corpus suum Romam. - Inc.: In quadam legenda transmissa de Roma ... - Expl.: ... et devotissime laudavit.

(200ra) Tit.: De blasphemo privato. - Inc.: Hereticus quidam illud gloriosum corpus dicens publice ... - Expl.: ... multi heretici ad lumen fidei et gremium ecclesie sunt reversi.

(200rb-204v) nur Rahmung.

Bis auf den letzten Text dieser Hs. dieselbe Auswahl der Kapitel auch in Wilten, Stiftsbibl., Cod. 3202 05, vereinzelt Überschriften, sofern vorhanden, geringfügig abweichend.

Nr. 7-10 Texte in dieser Anordnung auch in Cod. 165, Bl. 42va-74rb.

Lit.: Schulte GQ II 217.

11 (205ra-311vb) Sibylla Tiburtina (= Liber miraculorum dictus Lacteus) (Bloomfield Nr. 1447, 3580. Stegmüller RB Nr. 124,1 und Nr. 124,1.1 Suppl.).

Ein Großteil der Exempla ist in der Legenda Aurea (hier abgeglichen mit Ed. Graesse; zuletzt ed. von G. P. Maggioni, Iacopo da Varazze. Legenda Aurea [Millenio Medievale 6, Testi 3]. Tavarnuzze [Firenze] 1998) enthalten. Die vorliegende Sammlung stimmt mit München, BSB, Clm 23420 überein; sämtliche Exempla sind, wenn auch tw. anders angeordnet, in Innsbruck, ULB Tirol, Cod. 494 (Mairhofer, Liber Lacteus) enthalten. Zahlreiche Exempla auch in Neustift, Stiftsbibl., Cod. 308.

Die Titel der einzelnen Exempla werden nur dann zitiert, wenn sie bei Mairhofer nicht aufscheinen oder von den dort angeführten Titeln abweichen. Text bisweilen von Editionen und Drucken abweichend, aber mit Mairhofer übereinstimmend. Inc. und Expl. werden nur dann angeführt, wenn sowohl von Editionen und Drucken als auch von Mairhofer abweichend.

Tit.: Incipit liber miraculorum dictus Lacteus qui dividitur in novem distinctiones.

11.1 (205ra-215ra) Dist. 1: Miracula de Iesu Christo.

(205ra) Inhaltsübersicht.

(205rb) Tit.: Quod Augustus dictus Octavianus noluit se primum adorare pro Deo et visiones Sibille de nativitate Christi (Graesse Nr. 6 [S. 44, Z. 11-31]. - Mairhofer Nr. 1). (205rb) Graesse Nr. 6 (S. 42, Z. 1-9). - Mairhofer Nr. 2. (205va) Graesse Nr. 6 (S. 43, Z. 31-S. 44, Z. 4). Mairhofer Nr. 3. (205va) Zwei Teile: Tit. 1: Quod omnes sodomite perierunt (Graesse Nr. 6 [S. 44, Z. 4-8]). Tit. 2: Idem (Graesse Nr. 6 [S. 45, Z. 34-S. 46, Z. 1]). - Mairhofer Nr. 4. (205va) Tit.: De eodem (Graesse Nr. 6 [S. 44, Z. 32-S. 45, Z. 2]. - Mairhofer Nr. 5). (205vb) Tit.: De Maria et Ioseph et asino (Graesse Nr. 6 [S. 45, Z. 8-15]. - Mairhofer Nr. 6). (205vb) Tit.: De Hugone abbate (Graesse Nr. 6 [S. 46, Z. 14-26]. - Mairhofer Nr. 7). (205vb) Tit.: De crucifixo et quodam peccatore (Graesse Nr. 6 [S. 46, Z. 26-33]. - Mairhofer Nr. 8). (206ra) Tit.: De circumcisione et nomine Ihesu (Mairhofer Nr. 9). (206rb) Mairhofer Nr. 10. (206va) Mairhofer Nr. 11. (206vb) Mairhofer Nr. 12. (207ra) Graesse Nr. 137 (130), 5. - Mairhofer Nr. 245. (207rb) Tit.: De virtutibus sancte crucis (Mairhofer Nr. 13). (207va) Graesse Nr. 137 (130), 3. - Mairhofer Nr. 14. (207vb) Graesse Nr. 137 (130), 4 (S. 608, Z. 26-S. 609, Z. 18). - Mairhofer Nr. 15. (208ra) Mairhofer Nr. 16. (208rb) Mairhofer Nr. 17. (208va) Mairhofer Nr. 18. Mairhofer Nr. 19. (209rb) Mairhofer Nr. 20. (209va) Graesse Nr. 100 (95) (S. 430, Z. 18-S. 431, Z. 31). - Mairhofer Nr. 21. (210ra) Graesse Nr. 100 (95) (S. 431, Z. 31-S.432, Z. 32). - Mairhofer Nr. 22. (210va) Mairhofer Nr. 23. (210vb) Graesse Nr. 68 (64) (S. 303, Z. 30-S. 304, Z. 7,9-20,2232). - Mairhofer Nr. 24. (211ra) Mairhofer Nr. 246. (211ra) Tit.: De iuranti per se crucem (Mairhofer Nr. 247). (211rb) Mairhofer Nr. 25. (211rb) Graesse Nr. 54 (52) (S. 242, Z. 3-32). - Mairhofer Nr. 26. (211va) Mairhofer Nr. 27. (212va) Mairhofer Nr. 28. (212va) Graesse Nr. 181 (176), 4 (S. 838, Z. 25-34). - Mairhofer Nr. 29. (212vb) Mairhofer Nr. 30. (213ra) Tit.: De milite qui sancta loca visitavit (Mairhofer Nr.34). (213rb) Mairhofer Nr. 31. (213va) Tit.: Quod dyabolus bella suscitat (Graesse Nr. 181 [176], 4 [S. 842, Z. 15-24]. - Mairhofer Nr. 35). (213va) 
〈Guilelmus Malmesburiensis〉: Gesta regum Anglorum, Lib. 2, cap. 192 (PL 179, 1172A-B. Mairhofer Nr. 36). (213vb) Tit.: De sancta trinitate et tribus guttis et gemma (Graesse Nr. 181 [176], 1 [S. 824, Z. 31-S. 825, Z. 7]. - Mairhofer Nr. 37). (214ra) Mairhofer Nr. 32.

11.2 (215ra-222ra) Dist. 2: Miracula BMV.

(215ra) Tit.: Incipit secunda distinccio in qua agitur de miraculis sancte Marie et continet XXX miracula.

(215ra) Inhaltsübersicht.

(215rb) Tit. (zum auf den Prolog folgenden Exemplum): De virtute cuiusdam cerci (!) in purificacione sancte Marie. Prolog (Mairhofer Nr. 1.2, S. 91), direkt im Anschluss Graesse Nr. 37, 2. - Mairhofer Nr. 38. (215vb) Graesse Nr. 37, 3. - Mairhofer Nr. 39. (215vb) Graesse Nr. 119 (114), 6. - Mairhofer Nr. 40. (215vb) Graesse Nr. 119 (114), 8. - Mairhofer Nr. 41. (216ra) Graesse Nr. 119 (114), 2. - Mairhofer Nr. 42. (216ra) Graesse Nr. 131 (126), 2. - Mairhofer Nr. 43. (216ra) Graesse Nr. 88 (83) (S. 367, Z. 18-S. 368, Z. 2). - Mairhofer Nr. 44. (216rb) Graesse Nr. 131 (126), 3. - Mairhofer Nr. 45. (216rb) Mairhofer Nr. 46. (216va) Graesse Nr. 131 (126), 8. - Mairhofer Nr. 47. (216va) 〈Herbertus Claraevallensis`: De miraculis, Lib. 3, cap. 14 (PL 185, 1077D-1078B. - Mairhofer Nr. 48). (216vb) Graesse Nr. 131 (126) (S. 589, Z. 39-S. 590, Z. 12). - Mairhofer Nr. 49. (217ra) Mairhofer Nr. 50. (217ra) Mairhofer Nr. 52. (217rb) Mairhofer Nr. 33. (217va) Graesse Nr. 51 (50), 2. - Mairhofer Nr. 53. (217va) Graesse Nr. 51 (50), 3. - Mairhofer Nr. 54. (218ra) Mairhofer Nr. 55. (218rb) Mairhofer Nr. 56. (218rb) Graesse Nr. 119 (114), 7. - Mairhofer Nr. 57. (218va) Graesse Nr. 119 (114), 3. - Mairhofer Nr. 58. (219ra) Graesse Nr. 119 (114), 4. - Mairhofer Nr. 59. (219va) Graesse Nr. 131 (126), 9. Mairhofer Nr. 60. (219vb) Mairhofer Nr. 61. (219vb) Graesse Nr. 119 (114), 5. - Mairhofer Nr. 62. (220ra) Graesse Nr. 131 (126), 4. - Mairhofer Nr. 63. (220rb) Graesse Nr. 131 (126), 5. - Mairhofer Nr. 64. (220rb) Mairhofer Nr. 65. (220vb) Graesse Nr. 131 (126), 6. - Mairhofer Nr. 66. (221ra) Mairhofer Nr. 67. (221rb) Mairhofer Nr. 68. (221va) Ed.: A. E. Schönbach, Studien zur Erzählungsliteratur des Mittelalters (SB Wien 144). Wien 1901, 57-59. - Mairhofer Nr. 69.

11.3 (222ra-229ra) Dist. 3: Miracula de Iohanne Baptista et sanctis apostolis atque martyribus. (222ra) Tit.: Incipit distinccio tercia in qua agitur de miraculis sancti Iohannis Baptiste et sanctorum apostolorum atque martirum etc. Sequuntur capitula. (222rb) Inhaltsübersicht.

(222va-b) Iohannes Baptista: (222va) Graesse Nr. 86 (81), 3. - Mairhofer Nr. 70. (222va) Graesse 125 (120), 2. - Mairhofer Nr. 71. (222va) Graesse Nr. 125 (120), 4. - Mairhofer Nr. 72. (222vb-223vb) Iohannes ap. et ev.: (222vb) Graesse Nr. 9, 1. - Mairhofer Nr. 73. (222vb) Graesse Nr. 9, 3-4. - Mairhofer Nr. 74. (223rb) Graesse Nr. 9, 5. - Mairhofer Nr. 75. (223va) Graesse Nr. 9, 8. - Mairhofer Nr. 76. (223vb) Graesse Nr. 9, 11. - Mairhofer Nr. 77.

(223vb-224rb) Petrus ap.: (223vb) Graesse Nr. 89 (84), 4 (S. 378, Z. 9-22). - Mairhofer Nr. 78. (224ra) Graesse Nr. 89 (84), 4 (S. 378, Z. 22-S. 379, Z. 6). - Mairhofer Nr. 79. (224ra) Graesse Nr. 89 (84), 4 (S. 379, Z. 6-14). - Mairhofer Nr. 80. (224rb) Mairhofer Nr. 81.

(224rb-225rb) Andreas ap.: (224rb) Graesse Nr. 2, 9. - Mairhofer 82. (225ra) Graesse Nr. 2, 10. - Mairhofer Nr. 83.

(225rb-226ra) Iacobus maior: (225rb) Graesse Nr. 99 (94), 4. - Mairhofer Nr. 84. (225rb) Graesse Nr. 99 (94), 5. - Mairhofer Nr. 85. (225va) Graesse Nr. 99 (94), 6. - Mairhofer Nr. 86. (225va) Graesse Nr. 99 (94), 8. - Mairhofer Nr. 87. (225vb) Graesse Nr. 99 (94), 9. - Mairhofer Nr. 88. (225vb) Graesse Nr. 99 (94), 10. - Mairhofer Nr. 89.

(226ra) Thomas ap.: Mairhofer Nr. 90.

(226va-227ra) Marcus ev.: (226va) Tit.: De beato Marco ewangelista et eius transsitu (!) ad Venetos (Graesse Nr. 59 [57], 2 [S. 267, Z. 28-S. 268, Z. 14]. - Mairhofer Nr. 91). (226vb) Graesse Nr. 59 (57), 9. - Mairhofer Nr. 92. 
(227ra-vb) Stephanus: (227ra) Graesse Nr. 8, 6. - Mairhofer Nr. 93. (227rb) Graesse Nr. 112 (107) (S. 463, Z. 30-S. 464, Z. 16). - Mairhofer Nr. 94. (227va) Graesse Nr. 112 (107) (S. 464, Z. 16-S. 465, Z. 8). - Mairhofer Nr. 95.

(227vb-228ra) Laurentius: (227vb) Graesse Nr. 117 (112), 5. - Mairhofer Nr. 96. (227vb) Graesse Nr. 117 (112), 7 (S. 495, Z. 11-32). - Mairhofer Nr. 98.

(228ra-b) Thomas Cantuariensis: (228ra) Tit.: Qualiter et ubi passus sit beatus Thomas Cantuariensis (Graesse Nr. 11, 2 [S. 68, Z. 19-30]. - Mairhofer Nr. 99). (228ra) Tit.: De sancto Thoma et cantu angelorum (Graesse Nr. 11, 3 [S. 68, Z. 30-S. 69, Z. 3]. - Mairhofer Nr. 100). (228rb) Graesse Nr. 11, 3 (S. 69, Z. 7-13). - Mairhofer Nr. 101.

(228rb) Sebastianus: Graesse Nr. 23, 4. - Mairhofer Nr. 102.

(228rb) Blasius: Tit.: De sancto Blasio et porco et lupo (Graesse Nr. 38 [S. 167, Z. 30-S. 168, Z. 16]. - Mairhofer Nr. 103).

(228va) Marcellinus: Ed.: A. Sorbelli, Corpus chronicorum Bononiensium (Rerum Italicarum scriptores. Raccolta degli storici italiani dal cinquecento al millecinquecento 28/1). Città di Castello 1905, 206, Z. 18-207, Z. 33 (Cronaca A). - Mairhofer Nr. 104.

(228vb) Mauritius: (228vb) Graesse Nr. 141 (136), 2. - Mairhofer Nr. 105. (228vb) Tit.: De sancto Mauricio et clero ambicioso (Graesse Nr. 141 [136], 5. - Mairhofer Nr. 106).

(228vb) Cosmas et Damianus: (228vb) Tit.: De sanctis Cosma et Damiano et viro et muliere (Graesse Nr. 143 [138], 3. - Mairhofer Nr. 107).

11.4 (229ra-238ra) Dist. 4: Miracula de episcopis.

(229ra) Tit.: Incipit quarta distinccio de sanctis doctoribus Augustino Gregorio Ambrosio Martino et Nicolao episcopis etc.

(229ra) Inhaltsübersicht.

(229rb-230vb) Augustinus: (229rb) Graesse Nr. 124 (119), 4 (S. 562, Z. 15-20). - Mairhofer Nr. 108. (229va) Mairhofer Nr. 109. (229vb) Graesse Nr. 124 (119), 5. - Mairhofer Nr. 110. (229vb) Graesse Nr. 124 (119), 6. - Mairhofer Nr. 111. (230ra) Graesse Nr. 124 (119), 7. Mairhofer Nr. 598. (230ra) Graesse Nr. 124 (119), 8. - Mairhofer Nr. 112. (230rb) Graesse Nr. 124 (119), 13 (S. 565, Z. 5-29). - Mairhofer Nr. 113. (230va) Graesse Nr. 124 (119), 9. Mairhofer Nr. 599. (230va) Graesse Nr. 124 (119), 10. - Mairhofer Nr. 600. (230va) Graesse Nr. 124 (119), 11. - Mairhofer Nr. 601.

(230vb-233rb) Gregorius: (230vb) Graesse Nr. 46, 2. - Mairhofer Nr. 114. (230vb) Tit.: De pueris anglicanis (Graesse Nr. 46, 3 [S. 190, Z. 1-29]. - Mairhofer Nr. 115). (231ra) Graesse Nr. 46, 4 (S. 190, Z. 39-S. 191, Z. 1 und S. 191, Z. 37-S. 192, Z. 16). - Mairhofer Nr. 116. (231rb) Graesse Nr. 46, 6 (S. 194, Z. 7-20). - Mairhofer Nr. 117. (231rb) Graesse Nr. 46, 6 (S. 194, Z. 20 39). - Mairhofer Nr. 118. (231va) Graesse Nr. 46, 11-12. - Mairhofer Nr. 119. (231va) Graesse Nr. 46, 13. - Mairhofer Nr. 120. (231vb) Graesse Nr. 46, 16. - Mairhofer Nr. 121. (232ra) Tit.: De monacho qui peculium restituit et mortuos revixit et fratres detrahentes increpavit (Graesse Nr. 46, 17. - Mairhofer Nr. 122). (232rb) Graesse Nr. 46, 1. - Mairhofer Nr. 602. (232va) Graesse Nr. 46, 4 (S. 191, Z. 10-18). - Mairhofer Nr. 603. (232va) Graesse Nr. 46, 5 (S. 193, Z. 38-S. 194, Z. 6). - Mairhofer Nr. 604. (232va) Graesse Nr. 46, 7. - Mairhofer Nr. 605. (232vb) Graesse Nr. 46, 8 (S. 195, Z. 30-S. 196, Z.1). - Mairhofer Nr. 606. (232vb) Graesse Nr. 46, 8 (S. 196, Z. 3-11). - Mairhofer Nr. 607. (233ra) Graesse Nr. 46, 14. - Mairhofer Nr. 608. (233ra) Graesse Nr. 46, 19. - Mairhofer Nr. 609.

(233rb-234vb) Ambrosius: (233rb) Graesse Nr. 57 (55), 1 (S. 250, Z. 28-S. 251, Z.13). Mairhofer Nr. 123. (233rb) Graesse Nr. 57 (55), 5. - Mairhofer Nr. 124. (233va) Graesse Nr. 57 (55), 2 (S. 251, Z. 21-32). - Mairhofer Nr. 610. (233vb) Graesse Nr. 57 (55), 2 (S. 251, Z. 32-S. 252, Z. 1). - Mairhofer Nr. 611. (233vb) Graesse Nr. 57 (55), 3 (S. 252, Z. 16-25). Mairhofer Nr. 612. (233vb) Graesse Nr. 57 (55), 4 (S. 253, Z. 4-8). - Mairhofer Nr. 613. (233vb) 
Graesse Nr. 57 (55), 4 (S. 253, Z. 14-30). - Mairhofer Nr. 614. (234ra) Graesse Nr. 57 (55), 6 (S. 255, Z. 15-21). - Mairhofer Nr. 615. (234ra) Graesse Nr. 57 (55), 7. - Mairhofer Nr. 616. (234vb-236ra) Martinus: (234vb) Graesse Nr. 166 (161) (S. 741, Z. 29-S. 742, Z. 33). - Mairhofer Nr. 125. (234vb) Graesse Nr. 166 (161) (S. 742, Z. 33-39). - Mairhofer Nr. 126. (235ra) Graesse Nr. 166 (161) (S. 743, Z. 35-S. 744, Z. 10). - Mairhofer Nr. 127. (235ra) Tit.: De humilitate sancti Martini (Graesse Nr. 166 [161] [S. 745, Z. 5-20]. - Mairhofer Nr. 128). (235rb) Graesse Nr. 166 (161) (S. 745, Z. 21-31). - Mairhofer Nr. 129. (235rb) Tit.: De largitate eius (Graesse Nr. 166 [161] [S. 746, Z. 29-S. 747, Z. 16]. - Mairhofer Nr. 130). (235va) Graesse Nr. 166 (161) (S. 749, Z. 2-14). - Mairhofer Nr. 131. (235vb) Graesse Nr. 166 (161) (S. 744, Z. 33-S. 745, Z. 5). - Mairhofer Nr. 617. (235vb) Tit.: De Severo et Martino (Graesse Nr. 166 [161] [S. 749, Z. 14-21]. - Mairhofer Nr. 618). (235vb) Tit.: De exsequiis eius et Ambrosio (Graesse Nr. 166 [161] [S. 749, Z. 22-34]. - Mairhofer Nr. 619). (236ra) Tit.: De duobus sociis ceco et contracto (Graesse Nr. 166 [161] [S. 750, Z. 7-20]. - Mairhofer Nr. 620).

(236ra-238ra) Nicolaus: (236ra) Graesse Nr. 3, 4. - Mairhofer Nr. 132. (236rb) Graesse Nr. 3, 6 (S. 25, Z. 11-24). - Mairhofer Nr. 133. (236rb) Graesse Nr. 3, 6 (S. 25, Z. 6-11 und Z. 24-S. 26, Z. 26). - Mairhofer Nr. 134. (236vb) Graesse Nr. 3, 8. - Mairhofer Nr. 135. (236vb) Tit.: De ymagine sancti Nicolai plagata (Graesse Nr. 3, 9. - Mairhofer Nr. 136). (237ra) Tit.: De quodam fatuo sapienti qui sanctum Nicolaum honoravit (Mairhofer Nr. 137). (237va) Graesse Nr. 3, 10. Mairhofer Nr. 621. (237va) Graesse Nr. 3, 11. - Mairhofer Nr. 622. (237vb) Mairhofer Nr. 623.

11.5 (238ra-259ra) Dist. 5: Miracula de confessoribus.

(238ra) Tit.: Quinta distinccio de confessoribus.

(238ra) Inhaltsübersicht.

(238va-239ra) Remigius: (238va) Tit.: De miraculo sancti Remigii episcopi (Graesse Nr. 16 [S. 96, Z. 5-15]. - Mairhofer Nr. 138). (238vb) Graesse Nr. 16 (S. 96, Z. 35-S. 97, Z. 28). Mairhofer Nr. 139.

(239ra-240va) Basilius: (239ra) Tit.: De famulo qui se dyabolo dedit et Basilio (Graesse Nr. 26, 5. - Mairhofer Nr. 140). (239vb) Tit.: Basilius (Graesse Nr. 26, 1. - Mairhofer Nr. 625). (240ra) Graesse Nr. 26,6. - Mairhofer Nr. 626. (240rb) Graesse Nr. 26, 7. - Mairhofer Nr. 627.

(240va-241vb) Iohannes elemosinarius: (240va) Graesse Nr. 27, 1 (S. 126, Z. 19-28). - Mairhofer Nr. 141. (240va) Graesse Nr. 27, 1 (S. 126, Z. 28-S. 127, Z. 1). - Mairhofer Nr. 142. (240va) Graesse Nr. 27, 3 (S. 127, Z. 1-24). - Mairhofer Nr. 143. (240vb) Tit.: De precioso operimento (Graesse Nr. 27, 8. - Mairhofer Nr. 145). (241ra) Tit.: De populo exeunti ecclesiam (Graesse Nr. 27, 11. - Mairhofer Nr. 146). (241ra) Tit. (nach Mairhofer zu Nr. 631): Quomodo homines ad pecuniam pervocabat (Graesse Nr. 27, 4. - Mairhofer Nr. 630). (241rb) Tit. (nach Mairhofer zu Nr. 630): De magna eius largitate (Graesse Nr. 27, 9. - Mairhofer Nr. 631). (241va) Graesse Nr. 27, 3. - Mairhofer Nr. 144.

(241vb) Petronella: Graesse Nr. 88 (83) (S. 368, Z. 2-12). - Mairhofer Nr. 147.

(242ra-va) Germanus: (242ra) Graesse Nr. 107 (102) (S. 448, Z. 27-S. 449, Z. 12). - Mairhofer Nr. 148. (242ra) Graesse Nr. 107 (102) (S. 449, Z. 22-30). - Mairhofer Nr. 149. (242rb) Graesse Nr. 107 (102) (S. 449, Z.30-S. 450, Z.11). - Mairhofer Nr. 150. (242rb) Graesse Nr. 107 (102) (S. 450, Z. 33-39). - Mairhofer Nr. 151. (242rb) Graesse Nr. 107 (102) (S. 451, Z. 7-16). Mairhofer Nr. 633. (242rb) Graesse Nr. 107 (102) (S. 450, Z. 11-24). - Mairhofer Nr. 632. (242va-b) Iohannes Chrysostomus: (242va) Graesse Nr. 138 (131) (S. 616, Z. 25-29). - Mairhofer Nr. 152. (242va) Graesse Nr. 138 (131) (S. 616, Z. 30-34). - Mairhofer Nr. 153. (242va) Graesse Nr. 138 (131) (S. 616, Z. 34-S. 617, Z. 5). - Mairhofer 154.

(242vb-243va) Patricius: (242vb) Graesse Nr. 50 (49) (S. 213, Z. 17-23). - Mairhofer Nr. 155. (242vb) Graesse Nr. 50 (49) (S. 213, Z. 29-S. 216, Z. 13). - Mairhofer Nr. 156. 
(243va-244ra) Paulus eremita: (243va) Graesse Nr. 15 (S. 94, Z. 9-28). - Mairhofer Nr. 157. (243vb) Graesse Nr. 15 (S. 94, Z. 28-S. 95, Z. 18). - Mairhofer Nr. 158. (244ra) Tit.: De transitu eiusdem Pauli (Graesse Nr. 15 [S. 95, Z. 18-27]. - Mairhofer Nr. 159).

(244ra-245ra) Antonius: (244ra) Graesse Nr. 21, 1 (S. 104, Z. 8-12). - Mairhofer Nr. 160. (244rb) Graesse Nr. 21,1 (S. 104, Z. 12-17). - Mairhofer Nr. 161. (244rb) Tit.: Quod demones Antonium verberaverunt (Graesse Nr. 21, 1 [S. 104, Z. 17-32]. - Mairhofer Nr. 162). (244rb) Graesse Nr. 21, 5 (S. 106, Z. 19-23). - Mairhofer Nr. 637. (244rb) Graesse Nr. 21, 3 (S. 105, Z. 22-29). - Mairhofer Nr. 634. (244va) Graesse Nr. 21, 4 (S. 106, Z. 2-11). - Mairhofer Nr. 635. (244va) Graesse Nr. 21, 5 (S. 106, Z. 10-18). - Mairhofer Nr. 636. (244va) Graesse Nr. 21, 5 (S. 106, Z. 23-27. - Mairhofer Nr. 638. (244vb) Graesse Nr. 21, 5 (S. 106, Z. 27-36). - Mairhofer Nr. 639. (244vb) Tit.: De digitorum exustione notabile (Mairhofer Nr. 242).

(245ra-b) Macarius: (245ra) Graesse Nr. 18 (S. 101, Z. 5-8). - Mairhofer Nr. 163. (245ra) Graesse Nr. 18 (S. 101, Z. 8-23). - Mairhofer Nr. 164. (245rb) Graesse Nr. 18 (S. 101, Z. 23-32). Mairhofer Nr. 165. (245rb) Tit.: Item de sancto Machario (Graesse Nr. 18 [S. 100, Z. 16-25]. Mairhofer Nr. 640). (245rb) Tit.: Quod humilitate dyabolum vicit (Graesse Nr. 18 [S. 100, Z. 25-S. 101, Z. 1]. - Mairhofer Nr. 641).

(245rb-vb) Iohannes elemosinarius: (245rb) Graesse Nr. 27, 1 (S. 127, Z. 25-39). - Mairhofer Nr. 628. (245va) Graesse Nr. 27, 2 (S. 127, Z. 39-S. 128, Z. 28). - Mairhofer Nr. 629.

(245vb-246ra) Pastor: (245vb) Graesse Nr. 175 (170) (S. 805, Z. 2-6). - Mairhofer Nr. 642. (245vb) Graesse Nr. 175 (170) (S. 805, Z. 6-11). - Mairhofer Nr. 643.

(246ra) Moyses abb.: (246ra) Graesse Nr. 177 (172) (S. 806, Z. 22-26). - Mairhofer Nr. 644. (246ra) Graesse Nr. 177 (172) (S. 806, Z. 27-S. 807, Z. 2). - Mairhofer Nr. 645. (246ra) Graesse Nr. 177 (172) (S. 807, Z. 3-10). - Mairhofer Nr. 646.

(246ra-b) Arsenius abb.: (246ra) Graesse Nr. 178 (163) (S. 808, Z. 30-37). - Mairhofer Nr. 647. (246ra) Graesse Nr. 178 (163) (S. 808, Z. 37-S. 809, Z. 7). - Mairhofer Nr. 648. (246rb) Graesse Nr. 178 (163) (S. 809, Z. 7-23). - Mairhofer Nr. 649.

(246rb-va) Agathon abb.: (246rb) Graesse Nr. 179 (174) (S. 810, Z. 11-18). - Mairhofer Nr. 650. (246rb) Graesse Nr. 179 (174) (S. 810, Z. 18-26). - Mairhofer Nr. 651.

(246va-248ra) Benedictus: (246va) Tit.: De gloriosis virtutibus Benedicti (Graesse Nr. 49 [48], 3 [S. 206, Z. 39-S. 207, Z. 24]. - Mairhofer Nr. 652). (246va) Graesse Nr. 49 (48), 4. - Mairhofer Nr. 653. (246vb) Graesse Nr. 49 (48), 7 (S. 208, Z. 37-S. 209, Z. 7). - Mairhofer Nr. 654. (246vb) Graesse Nr. 49 (48), 7 (S. 209, Z. 7-14). - Mairhofer Nr. 655. (246vb) <Ps.-Gregorius Magnus»: Dialogi, Lib. 2, cap. 12 (Ed.: F. Clark, The Pseudo-Gregorian dialogues 1. Leiden 1987. - Mairhofer Nr.656). (247ra) Graesse Nr. 49 (48), 12. - Mairhofer Nr.657. (247ra) Graesse Nr. 49 (48), 14. - Mairhofer Nr. 658. (247rb) Graesse Nr. 49 (48), 15 (S. 211, Z. $27-$ 36). - Mairhofer Nr. 659. (247rb) Tit.: De eiusdem virtutibus (Graesse Nr. 49 [48], 1 [S. 204, Z. 17-S. 205, Z. 1]. - Mairhofer Nr. 177). (247rb) Graesse Nr. 49 (48), 1 (S. 205, Z. 2-11). Mairhofer Nr. 178. (247va) Graesse Nr. 49 (48), 2. - Mairhofer Nr. 179. (247va) Graesse Nr. 49 (48), 3 (S. 206, Z. 1-14). - Mairhofer Nr. 180. (247vb) Graesse Nr. 49 (48) (S. 206, Z. 29-39). Mairhofer Nr. 181. (247vb) Graesse Nr. 49 (48) (S. 207, Z. 32-S. 208, Z. 7). - Mairhofer Nr. 182. (247vb) Graesse Nr. 49 (48), 6. - Mairhofer Nr. 183. (248ra) Graesse Nr. 49 (48), 16. - Mairhofer Nr. 184.

(248ra-251vb) Bernardus: (248ra) Graesse Nr. 120 (115) (S. 529, Z. 13-29). - Mairhofer Nr. 663. (248rb) Graesse Nr. 120 (115) (S. 529, Z. 29-S. 530, Z. 9). - Mairhofer Nr. 185. (248va) Graesse Nr. 120 (115) (S. 530, Z. 25-S. 531, Z. 10). - Mairhofer Nr. 186. (248va) Graesse Nr. 120 (115) (S. 532, Z. 22-S. 533, Z. 2). - Mairhofer Nr. 187. (248vb) Graesse Nr. 120 (115) (S. 533, Z. 2-12). - Mairhofer Nr. 188. (248vb) Graesse Nr. 120 (115) (S. 534, Z. 30-S. 535, Z. 8). - Mairhofer Nr. 189. (249ra) Tit.: De demoniaco et Bernhardo (Graesse Nr. 120 [115] [S. 535, Z. 22-S. 536, Z. 10]. - Mairhofer Nr. 190). (249rb) Tit.: Item de demone peculanti et incubo (Graesse Nr. 120 [115] [S. 536, Z. 10-26]. - Mairhofer Nr. 191). (249va) Graesse Nr. 120 
(115) (S. 536, Z. 27-S. 537, Z. 2). - Mairhofer Nr. 192. (249va) Graesse Nr. 120 (115) (S. 537, Z. 3-12). - Mairhofer Nr. 193. (249va) Graesse Nr. 120 (115) (S. 537, Z. 13-24). - Mairhofer Nr. 194. (249vb) Graesse Nr. 120 (115) (S. 537, Z. 24-33). - Mairhofer Nr. 195. (249vb) Tit. (nach Mairhofer zu Nr. 197): Quod moriens fratribus tria observanda reliquit (Graesse Nr. 120 [115] [S. 537, Z. 33-S. 538, Z. 2]. - Mairhofer Nr. 196). (249vb) Tit. (nach Mairhofer zu Nr. 196): De poculo amaro militibus propinato (Graesse Nr. 120 [115] [S. 538, Z. 2-12]. Mairhofer Nr. 197). (250ra) Graesse Nr. 120 (115) (S. 538, Z. 12-22). - Mairhofer Nr. 198. (250ra) Tit.: De virtutibus beati Bernhardi (Graesse Nr. 120 [115] [S. 528, Z. 16-22]. - Mairhofer Nr. 661). (250ra) Tit.: De obitu Bernhardi (Graesse Nr. 49 [48], 18. - Mairhofer Nr. 660). (250rb) Graesse Nr. 120 (115) (S. 534, Z. 15-30). - Mairhofer Nr. 662. (250rb) 〈HERBERTus ClaRAEVAllensis : De miraculis, Lib. 2, cap. 15 (PL 185, 1324D-1325C. - Mairhofer Nr. 664). (250va) 〈Herbertus Claraevallensis〉: De miraculis, Lib. 2, cap. 16 (PL 185, 1325C-1326C. Mairhofer Nr. 665).

(250vb) Pastor: (250vb) Graesse Nr. 175 (170) (S. 803, Z. 15-26). - Mairhofer Nr. 166. (250vb) Graesse Nr. 175 (170) (S. 804, Z. 21-27). - Mairhofer Nr. 167.

(250vb) Iohannes abb.: Graesse Nr. 176 (171) (S. 805, Z. 22-S. 806, Z. 6). - Mairhofer Nr. 168. (251ra) Moyses abb.: Graesse Nr. 177 (172) (S. 806, Z. 8-19). - Mairhofer Nr. 169.

(251ra-va) Arsenius abb.: (251ra) Graesse Nr. 178 (163) (S. 807, Z. 14-26). - Mairhofer Nr. 170. (251rb) Graesse Nr. 178 (163) (S. 807, Z. 26-S. 808, Z. 2). - Mairhofer Nr. 171. (251rb) Graesse Nr. 178 (163) (S. 808, Z. 3-22). - Mairhofer Nr. 172.

(251va) Agathon abb.: Graesse Nr. 179 (174) (S. 810, Z. 30-S. 811, Z. 3). - Mairhofer Nr. 173. (251va-252va) Hieronymus: (251va) Graesse Nr. 146 (141) (S. 654, Z. 2-25). - Mairhofer Nr. 174. (251vb) Graesse Nr. 146 (141) (S. 654, Z. 25-S. 655, Z. 19). - Mairhofer Nr. 175. (251vb) Graesse Nr. 146 (141) (S. 655, Z. 31-S. 657, Z. 13). - Mairhofer Nr. 176.

(252va) Aegidius: Graesse Nr. 130 (125) (S. 584, Z. 2-14). - Mairhofer Nr. 199.

(252va) Beda Venerabilis: Graesse Nr. 181 (176), 4 (S. 833, Z. 13-S. 834, Z. 2). - Mairhofer Nr. 200.

(252vb) Udo Magdeburgensis: Ed.: A. E. Schönbach, Studien zur Erzählungsliteratur des Mittelalters (SB Wien 144). Wien 1901, 2-9. - Mairhofer Nr. 666.

(254vb) Dionysius: Mairhofer Nr. 667.

(255va-257ra) Dominicus: (255va) Graesse Nr. 113 (108) (S. 467, Z. 10-29). - Mairhofer Nr. 201. (255va) Graesse Nr. 113 (108) (S. 468, Z. 26-S. 469, Z. 11). - Mairhofer Nr. 202. (255vb) Graesse Nr. 113 (108) (S. 469, Z. 11-18). - Mairhofer Nr. 203. (255vb) Graesse Nr. 113 (108) (S. 470, Z. 3-28). - Mairhofer Nr. 204. (256ra) Graesse Nr. 113 (108) (S. 470, Z. 28-38). Mairhofer Nr. 205. (256ra) Tit.: De converso vidente dyabolum (Graesse Nr. 113 [108] [S. 470, Z. 38-S. 471, Z. 13]. - Mairhofer Nr. 206). (256rb) Graesse Nr. 113 (108) (S. 471, Z. 13-19). Mairhofer Nr. 207. (256rb) Graesse Nr. 113 (108) (S. 473, Z. 32-S. 474, Z. 5). - Mairhofer Nr. 209. (256va) Graesse Nr. 113 (108) (S. 474, Z. 5-10). - Mairhofer Nr. 210. (256va) Graesse Nr. 113 (108) (S. 476, Z. 25-31). - Mairhofer Nr. 211. (256va) Graesse Nr. 113 (108) (S. 477, Z. 20-S. 478, Z. 18). - Mairhofer Nr. 212. (256vb) Tit.: De morte et exhortacione eius (Graesse Nr. 113 [108] [S: 478, Z. 23-31]. - Mairhofer Nr. 213). (256vb) Graesse Nr. 113 (108) (S. 482, Z. 13-S. 483, Z. 8). - Mairhofer Nr. 214.

(257ra-259ra) Franciscus: (257ra) Graesse Nr. 149 (144) (S. 663, Z. 6-22). - Mairhofer Nr. 215. (257rb) Tit.: Quod carnalis frater eum despexit (Graesse Nr. 149 [144] [S. 664, Z. 2-6]. - Mairhofer Nr. 216). (257rb) Graesse Nr. 149 (144) (S. 664, Z. 6-10 und Z. 16-20). - Mairhofer Nr. 217. (257rb) Graesse Nr. 149 (144) (S. 664, Z. 10-16). - Mairhofer Nr. 218. (257rb) Graesse Nr. 149 (144) (S. 664, Z. 20-29). - Mairhofer Nr. 219. (257va) Graesse Nr. 149 (144) (S. 664, Z. 29-35). - Mairhofer Nr. 220. (257va) Graesse Nr. 149 (144) (S. 665, Z. 15-25). - Mairhofer Nr. 221. (257va) Graesse Nr. 149 (144) (S. 665, Z. 8-15). - Mairhofer Nr. 222. (257vb) Graesse Nr. 149 (144) (S. 665, Z. 25-32). - Mairhofer Nr. 223. (257vb) Graesse Nr. 149 (144) (S. 666, 
Z. 33-S. 667, Z. 3). - Mairhofer Nr. 224. (257vb) Graesse Nr. 149 (144) (S. 666, Z. 15-33). Mairhofer Nr. 225. (258ra) Graesse Nr. 149 (144) (S. 667, Z. 4-11). - Mairhofer Nr. 226. (258ra) Graesse Nr. 149 (144) (S. 667, Z. 11-20). - Mairhofer Nr. 227. (258ra) Graesse Nr. 149 (144) (S. 667, Z. 20-26). - Mairhofer Nr. 228. (258rb) Graesse Nr. 149 (144) (S. 668, Z. 18-30). Mairhofer Nr. 229. (258rb) Graesse Nr. 149 (144) (S. 668, Z. 34-39). - Mairhofer Nr. 230. (258rb) Tit.: Quod fuit multe pietatis (Graesse Nr. 149 [144] [S. 668, Z. 39-S. 669, Z. 8]. Mairhofer Nr. 231). (258rb) Tit.: Quod vituperari desiderabat (Graesse Nr. 149 [144] [S. 669, Z. 31-36]. - Mairhofer Nr. 232).

(258va) Tit.: Quod avibus predicabat (Graesse Nr. 149 [144] [S. 670, Z. 19-27]. - Mairhofer Nr. 233). (258va) Tit.: Quod aves obedierunt ei (Graesse Nr. 149 [144] [S. 670, Z. 27-31]. Mairhofer Nr. 234). (258va) Tit.: De eodem (Graesse Nr. 149 [144] [S. 670, Z. 7-14]. - Mairhofer Nr. 235). (258va) Graesse Nr. 149 (144) (S. 670, Z. 32-S. 671, Z. 1). - Mairhofer Nr. 236. (258vb) Graesse Nr. 149 (144) (S. 671, Z. 13-25). - Mairhofer Nr. 237. (258vb) Graesse Nr. 149 (144) (S. 671, Z. 29-35). - Mairhofer Nr. 238. (258vb) Graesse Nr. 149 (144) (S. 671, Z. 39-S. 672, Z. 8). - Mairhofer Nr. 239. (259ra) Graesse Nr. 149 (144) (S. 672, Z. 10-15). Mairhofer Nr. 240. (259ra) Graesse Nr. 149 (144) (S. 673, Z. 6-15). - Mairhofer Nr. 241.

11.6 (259ra-268vb) Dist. 6: Miracula de virginibus et viduis.

(259ra) Tit.: Sequitur distinccio sexta et est de virginibus et viduis.

(259ra) Inhaltsübersicht.

(259rb-261rb) Maria Magdalena: (259rb) Graesse Nr. 96 (90), 1 und 2 (S. 409, Z. 29-S. 413, Z. 8). - Mairhofer Nr. 250. (260ra) Graesse Nr. 96 (90), 2 (S. 413, Z. 10-21). - Mairhofer Nr. 251. (260rb) Tit.: De eius felici transitu ex hoc mundo (Graesse Nr. 96 [90], 2 [S. 413, Z. 21-S. 415, Z. 2]. - Mairhofer Nr. 252). (260va) Graesse Nr. 96 (90), 2 (S. 415, Z. 3-8). Mairhofer Nr. 253. (260va) Tit.: De milite occiso et resuscitato (Graesse Nr. 96 [90], 4. - Mairhofer Nr. 254). (260vb) Graesse Nr. 96 (90), 8. - Mairhofer Nr. 256. (260vb) Graesse Nr. 96 (90), 7. - Mairhofer Nr. 255. (260vb) Graesse Nr. 96 (90), 9. - Mairhofer Nr. 257. (260vb) Graesse Nr. 96 (90), 5. - Mairhofer Nr. 258. (261ra) Graesse Nr. 96 (90), 10. - Mairhofer Nr. 259. (261ra) 〈Conradus Eberbacensis〉: Exordium magnum Cisterciense, Dist. 4, cap. 2,1-30 (PL 185, 1096D-1097B. - Mairhofer Nr. 260).

(261rb-263rb) Catharina: Tit.: De virtutibus sancte Katherine virginis et matris (Graesse Nr. 212 [209]. - Mairhofer Nr. 261). (262ra) Graesse Nr. 172 (167) (S. 795, Z. 5-9). - Mairhofer Nr. 262. (262ra) Graesse Nr. 172 (167) (S. 795, Z. 10-20). - Mairhofer Nr. 263. (262ra) Mairhofer Nr. 264. (262vb) Mairhofer Nr. 265. (263ra) Tit.: De sacerdote et cane cuius caput latrabat (Mairhofer Nr. 266).

(263rb-va) Agnes: (263rb) Graesse Nr. 24,2 (S. 116, Z. 2-8). - Mairhofer Nr. 267. (263rb) Graesse Nr. 24, 3. - Mairhofer Nr. 268. (263va) Tit.: De ymagine sancte Agnetis (Graesse Nr. 24, 4 [S. 116, Z. 16-26]. - Mairhofer Nr. 269).

(263va-b) Agatha: (263va) Graesse Nr. 39 (S. 173, Z. 4-14). - Mairhofer Nr. 270. (263va) Tit.: De velo sancte Agathe (Graesse Nr. 39 [S. 173, Z. 18-25]. - Mairhofer Nr. 271).

(263vb-264ra) Undecim milia virginum: (263vb) Graesse Nr. 158 (153), 2. - Mairhofer Nr. 272. (263vb) Graesse Nr. 158 (153), 3. - Mairhofer Nr. 273.

(264ra) Margarita: Graesse Nr. 151 (146). - Mairhofer Nr. 274.

(264rb) Thais meretrix: Graesse Nr. 152 (147) (S. 677, Z. 25-S. 679, Z. 24). - Mairhofer Nr. 275. (264vb) Tit.: De alia meretrice (Graesse Nr. 152 [147] [S. 679, Z. 24-31]. - Mairhofer Nr. 276). (265ra) Eugenia, Prothus et Iacinthus: Graesse Nr. 136 (129) (S. 602, Z. 13-S. 604, Z. 31). Mairhofer Nr. 277.

(265va-268vb) Elisabeth: (265va) Tit.: De sancta Elizabeth lantgravia et viro eius (Mairhofer Nr. 278). (268rb) Tit.: De obitu Elizabeth et eius laude (Mairhofer Nr. 279). 
11.7 (268vb-276va) Dist. 7: Miracula de defunctis.

(268vb) Tit.: Sequitur distinccio septima et est ad diversas materias introductiva ut patet intuenti. (268vb) Inhaltsübersicht.

(269ra) Omnes sancti: Graesse Nr. 162 (157) (S. 727, Z. 12-S. 728, Z. 4). - Mairhofer Nr. 280 (hier zweigeteilt: Tit. 1: De festo omnium sanctorum et eius iniciis. Tit. 2: De eodem). (269va-271rb) Commemoratio animarum: (269va) Graesse Nr. 163 (158) (S. 731, Z. 26-S. 732, Z. 9). - Mairhofer Nr. 282. (269va) Graesse Nr. 163 (158) (S. 731, Z. 4-24). - Mairhofer Nr. 281. (269vb) Graesse Nr. 163 (158) (S. 732, Z. 32-S. 733, Z. 11). - Mairhofer Nr. 284. (270ra) Graesse Nr. 163 (158) (S. 732, Z. 13-22). - Mairhofer Nr. 283. (270ra) Graesse Nr. 163 (158) (S. 733, Z. 20-25). - Mairhofer Nr. 285. (270ra) Graesse Nr. 163 (158) (S. 733, Z. 11-18). - Mairhofer Nr. 286. (270rb) Tit.: De fluvio infernali (Graesse Nr. 163 [158] [S. 733, Z. 30-S. 734, Z. 19]. Mairhofer Nr. 287). (270rb) Mairhofer Nr. 288. (270va) Graesse Nr. 163 (158) (S. 734, Z. 33-S. 735, Z. 3). - Mairhofer Nr. 289. (270vb) Graesse Nr. 163 (158) (S. 735, Z. 18-26). Mairhofer Nr. 290. (271ra) Graesse Nr. 163 (158) (S. 735, Z. 32-S. 736, Z. 8). - Mairhofer Nr. 291. (271ra) Graesse Nr. 163 (158) (S. 736, Z. 9-13). - Mairhofer Nr. 292. (271ra) Graesse Nr. 163 (158) (S. 738, Z. 34-S. 739, Z. 13). - Mairhofer Nr. 293. (271rb) Graesse Nr. 163 (158) (S. 739, Z. 19-29). - Mairhofer Nr. 294.

(271rb) Ed.: J. Klapper, Exempla aus Handschriften des Mittelalters (Sammlung mittellateinischer Texte II). Heidelberg 1911, Nr. 26, 27. - Mairhofer Nr. 295. (271va) Mairhofer Nr. 296. (271va) Mairhofer Nr. 297. (271va) Mairhofer Nr. 298. (271vb) Mairhofer Nr. 299. (271' $\left.{ }^{\mathrm{I}} \mathrm{ra}\right)$ 〈InNocentius III.`: De contemptu mundi, Lib. 3, cap. 7 (PL 217, 740A. - Mairhofer Nr. 300). (271' $\mathrm{I}$ ra) Mairhofer Nr. 301.

(271 $\left.{ }^{\mathrm{I}} \mathrm{va}-272 \mathrm{rb}\right)$ 〈Honorius AugustodunEnsis`: Speculum ecclesiae. Sermo generalis: (271 $\left.{ }^{\mathrm{I}} \mathrm{va}\right) \mathrm{Ad}$ milites (PL 172, 865A-C. - Mairhofer Nr. 302). (271 I vb) Ad pauperes (PL 172, 864C-865A. Mairhofer Nr. 303). (271 $\left.{ }^{\mathrm{I} v b}\right)$ Ad agricolas (PL 172, 866B-867B. - Mairhofer Nr. 304). (272rb) Ad coniugatos (PL 172, 870A-B. - Mairhofer Nr. 305).

(272rb) 〈Herbertus Claraevallensis»: De miraculis, Lib. 2, cap. 33 (PL 185, 1344B-D) = 〈Conradus Eberbacensis»: Exordium magnum Cisterciense, Dist. 4, cap. 35, 1-48 (PL 185, 1123B-1124A). - Mairhofer Nr. 306. (272va) 〈Herbertus Claraevallensis»: De miraculis, Lib. 2, cap. 34 (PL 185, 1344D-1345B) = 〈CONRADUS EBERBACENSIS : Exordium magnum Cisterciense, Dist. 5, cap. 2, 41-64 (PL 185, 1126D-1127B). - Mairhofer Nr. 307. (272va) 〈Herbertus Claraevallensis : De miraculis, Lib. 2, cap. 35 (PL 185, 1345C-D) = «Conradus Eberbacensis : Exordium magnum Cisterciense, Dist. 5, cap. 3, 11-44 (PL 185, 1127C-1128B). - Mairhofer Nr. 308.

(272vb-273va) «Guilelmus Malmesburiensis»: Gesta regum Anglorum: (272vb) Lib. 2, cap. 204, 1-6 (PL 179, 1188B-1189C. - Mairhofer Nr. 309). (273rb) Lib. 2, cap. 204, 7 (PL 179, 1189D-1190A. - Mairhofer Nr. 310). (273rb) Lib. 3, cap. 293, 1-2 (PL 179, 1262A-C. - Mairhofer Nr. 311).

(273va) Mairhofer Nr. 312. (273vb) Mairhofer Nr. 313. (274rb) Mairhofer Nr. 314. (274va) Mairhofer Nr. 315. (275ra) Mairhofer Nr. 316. (275rb) Mairhofer Nr. 317 (Tit. auf Bl. 275va wiederholt).

(275va-276rb) 〈Gregorius Magnus〉: Dialogi, Lib. 4: (275va) Cap. 33 (PL 77, 372C-373A. Mairhofer Nr. 318). (275vb) Cap. 40 (PL 77, 392C-393A. - Mairhofer Nr. 319). (275vb) Cap. 40 (PL 77, 393B-C. - Mairhofer Nr. 320). (276ra) Cap. 54 (PL 77, 413B-C. - Mairhofer Nr. 321). (276ra) Cap. 55 (PL 77, 416A-B. - Mairhofer Nr. 322). (276rb) Cap. 56 (PL 77, 416B-C. Mairhofer Nr. 323). (276rb) Cap. 53 (PL 77, 412C-413 A. - Mairhofer Nr. 324).

(276rb) Graesse Nr. 180 (175) (S. 816, Z. 12-33). - Mairhofer Nr. 325.

11.8 (276va-286ra) Dist. 8: Miracula de sacramentis ecclesiae.

(276va) Inhaltsübersicht. 
(276vb-278rb) Sacramentum baptismi: (276vb) Graesse Nr. 52, 2. - Mairhofer Nr. 326. (277rb) Tit.: Quod baptismus confert sanitatem corporis (Graesse Nr. 117 [112] [S. 491, Z. 1-7]; anschließend Ergänzung zur hl. Odilia, vgl. Graesse Nr. 190 [189]. - Mairhofer Nr. 327). (277rb) Graesse Nr. 181 (176), 1 (S. 824, Z. 24-28). - Mairhofer Nr. 328. (277rb) Graesse Nr. 181 (176) (S. 834, Z. 3-10). - Mairhofer Nr. 329. (277va) «Herbertus Claraevallensis»: De miraculis, Lib. 3, cap. 32 (PL 185, 1377B-1378C. - Mairhofer Nr. 330). (277vb) Mairhofer Nr. 331.

(278rb) Sacramentum confirmationis: Mairhofer Nr. 332.

(278rb-va) Unctio infirmorum: (278rb) Mairhofer Nr. 333. (278va) Mairhofer Nr. 334.

(278vb-280ra) Sacramentum eucharistiae: (278vb-279rb) 〈PASCHASIUS RADBERTUS〉: De corpore et sanguine dni, cap. 14: (278vb) PL 120, 1317B-C. - Mairhofer Nr. 335. (278vb) PL 120, 1318B-1319C. - Mairhofer Nr. 336. (279ra) PL 120, 1319D-1320D. - Mairhofer Nr. 337. (279rb) Mairhofer Nr. 338. (279va) Mairhofer Nr. 339. (279va) 〈Herbertus Claraevallensis〉: De miraculis, Lib. 1, cap. 20 (PL 185, 1296D-1297D. - Mairhofer Nr. 340). (279vb) Mairhofer Nr. 341. (279vb) 〈Herbertus Claraevallensis〉: De miraculis, Lib. 3, cap. 28-29 (PL 185, 1373D-1374D. - Mairhofer Nr. 342). (280ra) Mairhofer Nr. 343.

(280ra-284vb) Sacramentum paenitentiae et reconciliationis: (280ra) Mairhofer Nr. 344. (280rb) Mairhofer Nr. 345. (280rb) 〈GRIMLAICUS〉: Regula solitariorum, cap. 36 (PL 103, 625D-626A. Mairhofer Nr. 346). (280va) Mairhofer Nr. 347. (280va) Mairhofer Nr. 348. (280vb) Mairhofer Nr. 349. (281ra) Mairhofer Nr. 350. (281rb) Mairhofer Nr. 351. (281va) Mairhofer Nr. 352. (281vb) 〈Sigbertus Gemblacensis〉: Chronica 823 (PL 160, 157C. - Mairhofer Nr. 353). (282ra) 〈Odo de Cheriton〉, Parabolae Nr. 188 (Ed. Hervieux IV 339. - Mairhofer Nr. 354). (282ra) Mairhofer Nr. 355. (282rb) Mairhofer Nr. 356. (282va) Graesse Nr. 181 (176), 4 (S. 834, Z. $17-$ 21). - Mairhofer Nr. 357. (282va) 〈Guilelmus MalmEsBuriensis»: Gesta regum Anglorum, Lib. 2, cap. 175 (PL 179, 1146D-1147A. - Mairhofer Nr. 358). Tit. (nach Mairhofer zu Nr. 359): De quodam clerico vocali et eius constancia. (282vb) Tit. (nach Mairhofer zu Nr. 360): De clerico qui tonsuram deposuit (Mairhofer Nr. 359). (282vb) 〈Herbertus Claraevallensis〉: De miraculis, Lib. 3, cap. 13 (PL 185, 1365C-D. - Mairhofer Nr. 360). (283ra) Mairhofer Nr. 361. (283ra) Mairhofer Nr. 362. (283rb) Mairhofer Nr. 363. (283va) Mairhofer Nr. 364. (283va) «Sulpicius Severus»: Dialogi, Lib. 1, cap. 14 (PL 20, 192D-193B. - Mairhofer Nr. 365). (283vb) Tit.: De latrone qui per IIII candelas veniam meruit (Mairhofer Nr. 366). (284ra) Tit. (nach Mairhofer zu Nr. 368): De monacho quem confudit obsessus (Mairhofer Nr. 367). (284ra) Tit.: De confessione notandum (Mairhofer Nr. 368). (284ra) 〈CAESARIus HeIsterbacensis〉: Dialogus miraculorum, Dist. 3, cap. 6 (Ed. Strange I, 116-120. - Mairhofer Nr. 369). Tit.: De virgine non confessa quam dyabolus confudit. (284rb) Mairhofer Nr. 370. (284va) Mairhofer Nr. 371. (284va) Mairhofer Nr. 372. (284va) Mairhofer Nr. 373. (284va) Mairhofer Nr. 374. (284vb) Mairhofer Nr. 375.

(284vb-285va) Sacramentum matrimonii: (284vb) 〈Herbertus Claraevallensis〉: De miraculis, Lib. 3, cap. 34 (PL 185, 1379C-1381B. - Mairhofer Nr. 376). (285rb) Mairhofer Nr. 377. (285rb) Mairhofer Nr. 378. (285va) Mairhofer Nr. 379.

11.9 (286ra-311rb) Dist. 9: Miracula de factis et dictis theologorum. (286ra) Inhaltsübersicht.

(287ra) Ed.: R. Lotti, Contributi su Domenico Cavalca (c. 1270-1342), Diss. Amsterdam 1987, 231-232. - Mairhofer Nr. 390. (287ra) 〈Guilelmus MALMESBuRIEnsis〉: Gesta regum Anglorum, Lib. 2, cap. 174 (PL 179, 1146A-C. - Mairhofer Nr. 391). (287rb) Mairhofer Nr. 392. (287rb) 〈Guilelmus Malmesburiensis〉: Gesta regum Anglorum, Lib. 2, cap. 207 (PL 179, 1192A-B. Mairhofer Nr. 393). (287va) Mairhofer Nr. 394. (287vb) Mairhofer Nr. 395.

(288rb-288Ira) 〈Sulpicius Severus»: Dialogi, Lib. 1: (288rb) Cap. 15 (PL 20, 193D-194B. Mairhofer Nr. 397). (288rb) Cap. 17 (PL 20, 194D-195A. - Mairhofer Nr. 398). (288va) Cap. 18 (PL 20, 195C. - Mairhofer Nr. 399). Tit.: De incredibili obediencia novicii. (288va) Cap. 19 
(PL 20, 195D-196B. - Mairhofer Nr. 400). (288vb) Cap. 20 (PL 20, 196B-197A. - Mairhofer Nr. 401).

(288'ra) 〈Wernerus de Ellerbach〉: Deflorationes ss. patrum, Lib. 1, Sermo in rogationibus (PL 157, 968B-C. - Mairhofer Nr. 402).

(288 $\mathrm{ra}-\mathrm{ra}$ ) 〈Honorius Augustodunensis»: Speculum ecclesiae: (288 $\mathrm{ra}$ ) Dnca 1. post pent. (PL 172, 1042B-D. - Mairhofer Nr. 403). (288' rb) Dnca 20. post pent. (PL 172, 1066D-1068A. Mairhofer Nr. 404).

(288 ${ }^{\mathrm{I}} \mathrm{va}$-289rb) «GRegorius MAgnus»: XL Homiliae in Evangelia: (288 $\left.{ }^{\mathrm{I}} \mathrm{va}\right)$ Lib. 1 (PL 76, 1133C-1134B. - Mairhofer Nr. 405). (288'vb) Lib. 2 (PL 76, 1300B-D. - Mairhofer Nr. 406). (289ra) Lib. 1 (PL 76, 1158B-1159A. - Mairhofer Nr. 407).

(289rb-290vb) Ioseph: (289rb) Graesse Nr. 67 (63), 2 (S. 298, Z.15-S. 299, Z. 13). - Mairhofer Nr. 408. (289va) Graesse Nr. 67 (63), 2 (S. 299, Z. 15-S. 300, Z. 16). - Mairhofer Nr. 409. (289vb) Graesse Nr. 67 (63), 2 (S. 300, Z. 16-301, Z. 16). - Mairhofer Nr. 410. (290rb) Graesse Nr. 67 (63), 2 (S. 301, Z. 16-36). - Mairhofer Nr. 411. (290rb) Graesse Nr. 67 (63), 2 (S. 301, Z. 37-S. 302, Z. 11). - Mairhofer Nr. 412 (290va) Graesse Nr. 67 (63), 2 (S. 302, Z. 11-32). Mairhofer Nr. 413 (290va) Graesse Nr. 67 (63), 2 (S. 302, Z. 32-S. 303, Z. 9). - Mairhofer Nr. 414. (290vb) Graesse Nr. 67 (63), 2 (S. 303, Z. 9-15). - Mairhofer Nr. 415

(290vb) Iudas Ischariot: Graesse Nr. 45 (S. 184, Z. 1-S. 186, Z. 13). - Mairhofer Nr. 416.

(291va-292va) Pilatus: (291va) Graesse Nr. 53 (51) (S. 231, Z. 21-S. 232, Z. 24). - Mairhofer Nr. 417. (292ra) Graesse Nr. 53 (51) (S. 232, Z. 30-S. 233, Z. 26). - Mairhofer Nr. 418. (292rb) Graesse Nr. 53 (51) (S. 233, Z. 27-S. 234, Z. 26). - Mairhofer Nr. 419.

(292va-293rb) Nero: (292va) Graesse Nr. 89 (84), 3 (S. 376, Z. 5-22). - Mairhofer Nr. 420. (292vb) Graesse Nr. 89 (84), 3 (S. 376, Z. 25-S. 377, Z. 14). - Mairhofer Nr. 421. (293ra) Graesse Nr. 89 (84), 3 (S. 377, Z. 15-29). - Mairhofer Nr. 422.

(293rb-vb) Iulianus Apostata: (293rb) Graesse Nr. 30, 5 (S. 143, Z. 35-S. 144, Z. 11). - Mairhofer Nr. 423. (293rb) Graesse Nr. 30, 5 (S. 144, Z. 12-23). - Mairhofer Nr. 424. (293va) Graesse Nr. 125 (120), 1 (S. 571, Z. 3-8). - Mairhofer Nr. 425 (293va) Graesse Nr. 125 (120), 1 (S. 571, Z. 8-14). - Mairhofer Nr. 426. (293va) Graesse Nr. 125 (120), 1 (S. 571, Z. 14-21). - Mairhofer Nr. 427. (293vb) Graesse Nr. 125 (120), 1 (S. 571, Z. 21-28). - Mairhofer Nr. 428. (293vb) Graesse Nr. 30, 5 (S. 144, Z. 34-35). - Mairhofer Nr. 429.

(293vb-294rb) Basilius: (293vb) Graesse Nr. 30, 5 (S. 144, Z. 35-S. 145, Z. 6). - Mairhofer Nr. 430. (294ra) Graesse Nr. 30, 5 (S. 145, Z. 6-30). - Mairhofer Nr. 431.

(294rb) Graesse Nr. 181 (176), 4 (S. 838, Z. 9-15). - Mairhofer Nr. 432. (294rb) Graesse Nr. 181 (176), 4 (S. 837, Z. 31-38). - Mairhofer Nr. 433. (294rb) Graesse Nr. 181 (176), 4 (S. 837, Z. 13-21). - Mairhofer Nr. 434. (294va) Graesse Nr. 181 (176), 4 (S. 836, Z. 37-S. 837, Z. 10). Mairhofer Nr. 435. (294va) Graesse Nr. 181 (176), 4 (S. 839, Z. 1-12). - Mairhofer Nr. 436. (294vb) Mairhofer Nr. 437. (295ra) Mairhofer Nr. 438. (295rb) Graesse Nr. 181 (176), 4 (S. 840, Z. 3-841, Z. 5). - Mairhofer Nr. 439. (295va) H 12553-12557. - Mairhofer Nr. 440. (295vb) Graesse Nr. 136 (129) (S. 603, Z. 4-9). - Mairhofer Nr. 441. (295vb) Mairhofer Nr. 442. (296ra) Graesse Nr. 182 (177) (S. 846, Z. 39-S. 847, Z. 14). - Mairhofer Nr. 443. (296ra) Graesse Nr. 182 (177) (S. 854, Z. 9-17). - Mairhofer Nr. 444. (296rb) Mairhofer Nr. 445. (296rb) Mairhofer Nr. 446. (296va) 3. Esr 3,3-4,47. - Mairhofer Nr. 447.

(297rb-300ra) 〈Odo de Cheriton`: Parabolae: (297rb) Nr. 6 (Ed. Hervieux IV 267. - Mairhofer Nr. 448). (297rb) Nr. 8 (Ed. Hervieux IV 268. - Mairhofer Nr. 449). (297va) Mairhofer Nr. 450. (297va) Nr. 12 und 13 (Ed. Hervieux IV 271. - Mairhofer Nr. 451). (297va) Nr. 26 (Ed. Hervieux IV 275. - Mairhofer Nr. 452). (297va) Nr. 42 (Ed. Hervieux IV 281. - Mairhofer Nr. 453). (297vb) Nr. 45 (Ed. Hervieux IV 282. - Mairhofer Nr. 454). (297vb) Nr. 46 (Ed. Hervieux IV 282. - Mairhofer Nr. 455). (298ra) Nr. 47 (Ed. Hervieux IV 283. - Mairhofer Nr. 456). (298ra) Nr. 52 (Ed. Hervieux IV 285. - Mairhofer Nr. 457). (298ra) Mairhofer Nr. 458. (298ra) Nr. 74 (Ed. Hervieux IV 294. - Mairhofer Nr. 459). (298rb) Nr. 85 (Ed. Hervieux IV 298. - Mairhofer 
Nr. 460). (298rb) Nr. 86 (Ed. Hervieux IV 298-299. - Mairhofer Nr. 461). (298rb) Nr. 88 (Ed. Hervieux IV 299. - Mairhofer Nr. 462). (298rb) Mairhofer Nr. 463. (298va) Nr. 93 (Ed. Hervieux IV 301. - Mairhofer Nr. 464). (298va) Mairhofer Nr. 465. (298va) Nr. 102 (Ed. Hervieux IV 304. - Mairhofer Nr. 466). (298vb) Nr. 105 (Ed. Hervieux IV 305. - Mairhofer Nr. 467). (298vb) Nr. 116 und 117 (Ed. Hervieux IV 309-310. - Mairhofer Nr. 468). (299ra) Vgl. Nr. 123 (Ed. Hervieux IV 312. - Mairhofer Nr. 469). (299ra) Nr. 132 (Ed. Hervieux IV 315-316. - Mairhofer Nr. 470). (299ra) Nr. 131 (Ed. Hervieux IV 315. - Mairhofer Nr. 471). (299rb) Nr. 136 (Ed. Hervieux IV 217. - Mairhofer Nr. 472). (299va) Nr. 133 (Ed. Hervieux IV 316. - Mairhofer Nr. 473). (299va) Nr. 143 (Ed. Hervieux IV 320-321. - Mairhofer Nr. 474). Tit.: De humilitate. (299va) Nr. 144 (Ed. Hervieux IV 321. - Mairhofer Nr. 475). (299vb) Nr. 153 (Ed. Hervieux IV 325. - Mairhofer Nr. 476). (299vb) Nr. 163 (Ed. Hervieux IV 328. - Nr. 477). (299vb) Nr. 164 (Ed. Hervieux IV 328-329. - Mairhofer Nr. 478). (299vb) Nr. 157 (Ed. Hervieux IV 329-330. Mairhofer Nr. 479). (300ra) Nr. 171 (Ed. Hervieux IV 332. - Mairhofer Nr. 480).

(300ra) Mairhofer Nr. 481. (300ra) Tit.: De libertate animi (Mairhofer Nr. 482). (300rb) Mairhofer Nr. 483. (300rb) Mairhofer Nr. 484. (300rb) Graesse Nr. 180 (175) (S. 815, Z. 24-S. 816, Z. 9. - Mairhofer Nr. 485). (300va) Mairhofer Nr. 486. (300va) Mairhofer Nr. 487.

(300va-301ra) 〈Grimlaicus〉: Regula solitariorum: (300va) Cap. 44 (PL 103, 635B-C. - Mairhofer Nr. 488). (300vb) Cap. 56 (PL 103, 647D-648A. - Mairhofer Nr. 489). (300vb) Cap. 54 (PL 103, 615D. - Mairhofer Nr. 490). (301ra) Cap. 57 (PL 103, 648D. - Mairhofer Nr. 491). (301ra) Cap. 39 (PL 103, 630B. - Mairhofer Nr. 492).

(301ra) Mairhofer Nr. 493. (301rb) Mairhofer Nr. 494. (301rb) Vitae patrum, Lib. 5, Verba seniorum, libell. 16, cap. 19 (PL 73, 973B-C) = 〈GRIMLAicus`: Regula solitariorum, cap. 59 (PL 103, 654A-B). - Mairhofer Nr. 495. (301va) Mairhofer Nr. 496. (301va) Mairhofer Nr. 497. (301va) Mairhofer Nr. 498. (301va) Mairhofer Nr. 499. (301vb) Mairhofer Nr. 500. (301vb) Mairhofer Nr. 501. (301vb) Mairhofer Nr. 502. (302ra) Mairhofer Nr. 503. (302ra) 〈Gregorius MAgnus»: Dialogi, Lib. 4, cap. 11 (PL 77, 336B-337A. - Mairhofer Nr. 504). (302ra) Mairhofer Nr. 505. (302rb) Vitae patrum, Lib. 5, Verba seniorum, libell. 3, cap. 23 (PL 73, 864A-B. - Mairhofer Nr. 506). (302rb) Mairhofer Nr. 507. (302rb) Mairhofer Nr. 508. (302rb) Mairhofer Nr. 509. (302va) Mairhofer Nr. 510. (302va) Mairhofer Nr. 511. (302va) Mairhofer Nr. 512. (302vb) Vitae patrum, Lib. 5, Verba seniorum, libell. 6, cap. 18 (PL 73, 891C-D. - Mairhofer Nr. 513). (302vb) Mairhofer Nr. 514. (302vb) Mairhofer Nr. 515. (303ra) Vitae patrum, Lib. 5, Verba seniorum, libell. 6, cap. 21 (PL 73, 892B-C. - Mairhofer Nr. 516). (303ra) Mairhofer Nr. 517. (303ra) Mairhofer Nr. 518. (303rb) Vitae patrum, Lib. 5, Verba seniorum, libell. 3, cap. 14 (PL 73, 862BC. - Mairhofer Nr. 519). (303rb) Mairhofer Nr. 520. (303va) 〈Ps.-Rufinus AquiLEIENsis〉: Vitae patrum, Lib. 3, Verba seniorum, cap. 55 (PL 73, 768C-D) = 〈GRIMLAICUS〉: Regula solitariorum, cap. 39 (PL 103, 630C-D). - Mairhofer Nr. 521. (303va) 〈Hieronymus»: Epistola 107 (ad Laetam) (PL 22, 872. - Mairhofer Nr. 522). (303va) Mairhofer Nr. 523. (303vb) Mairhofer Nr. 524. (303vb) Mairhofer Nr. 525. (303vb) Mairhofer Nr. 526. (304ra) Mairhofer Nr. 527. (304ra) Mairhofer Nr. 528. (304ra) Mairhofer Nr. 529. (304rb) Vgl. Vitae patrum, Lib. 5, Verba seniorum, libell. 8, cap. 24 (PL 73, 909C. - Mairhofer Nr. 530). (304rb) Mairhofer Nr. 531. (304rb) Mairhofer Nr. 532. (304va) Mairhofer Nr. 533. (304va) 〈Petrus CANTOR»: Verbum abbreviatum, cap. 86 (PL 205, 256D-257A. - Mairhofer Nr. 534). (304va) 〈Nicolaus Pergamenus»: Dialogus creaturarum, dial. 75, 23-36 (Ed.: Th. Graesse, Die beiden ältesten lateinischen Fabelbücher des Mittelalters des Bischofs Cyrillus „Speculum sapientiae“ und des Nicolaus Pergamenus „Dialogus creaturarum“. Stuttgart 1880, 219. - Mairhofer Nr. 535). (304va) Mairhofer Nr. 536. (304vb) Mairhofer Nr. 537. (304vb) Mairhofer Nr. 538. (305ra) Mairhofer Nr. 539. (305ra) «Ps.-Rufinus Aquileiensis): Vitae patrum, Lib. 3, Verba seniorum, cap. 118 (PL 73, 782C-D. - Mairhofer Nr. 540). (305ra) Mairhofer Nr. 541. (305rb) Mairhofer Nr. 542. Tit.: Qui propriam iracundiam vindicant. (305rb) 〈Gregorius Magnus`: Dialogi, Lib. 4, cap. 19 (PL 77, 352A-B. - Mairhofer Nr. 543). (305rb) Mairhofer Nr. 544. (305va) Mairhofer Nr. 545. (305va) 〈Rufinus AquILEIENSIs : 
Historia monachorum, cap. 1 (PL 21, 394C. - Mairhofer Nr. 546). (305va) Mairhofer Nr. 547. (305va) Mairhofer Nr. 548. (305vb) Mairhofer Nr. 549. (305vb) Mairhofer Nr. 550. (305vb) 〈Ps.-Rufinus Aquileiensis〉: Vitae patrum, Lib. 3, Verba seniorum, cap. 97 (PL 73, 778A-C) = Vitae patrum, Lib. 6, Verba seniorum, libell. 3, cap. 17 (PL 73, 1013D-1014B). - Mairhofer Nr. 551. (305vb) Mairhofer Nr. 552.

(306ra) 〈InNocentius III.>: De contemptu mundi, Lib. 2: (306ra) Cap. 36 (PL 217, 731D-732A. Mairhofer Nr. 553). (306ra) Cap. 39 (PL 217, 733B. - Mairhofer Nr. 554). (306ra) Cap. 20 (PL 217, 725A. - Mairhofer Nr. 555).

(306ra) Mairhofer Nr. 556.

(306rb-vb) Vitae patrum, Lib. 5: (306rb) Libell. 14, cap. 52 (PL 73, 963B-C. - Mairhofer Nr. 557). (306rb) Mairhofer Nr. 558. (306rb) Libell. 14, cap. 72 (PL 73, 966A-B. - Mairhofer Nr. 559). (306va) Libell. 5, cap. 34 (PL 73, 882D-883A. - Mairhofer Nr. 560). (306vb) Mairhofer Nr. 561. (306vb) Libell. 3, cap. 2 (PL 73, 860C-D. - Mairhofer Nr. 562). (306vb) Libell. 17, cap. 18 (PL 73, 976B. - Mairhofer Nr. 563).

(306vb) Mairhofer Nr. 564. Tit.: De caritate. (306vb) Mairhofer Nr. 565. (307ra) «Petrus CANTOR : Verbum abbreviatum, cap. 98 (PL 205, 280A-B. - Mairhofer Nr. 566). Tit.: Quod caritas non agit properam. (307ra) Mairhofer Nr. 567. (307ra) 〈Gregorius MAGnus»: Dialogi, Lib. 1, cap. 9 (PL 77, 197B-C. - Mairhofer Nr. 568). (307rb) Mairhofer Nr. 569. (307rb) 《Rufinus AQuileIEnsis : Historia monachorum, cap. 31 (PL 21, 458B-C. - Mairhofer Nr. 570). (307rb) Mairhofer Nr. 571. (307rb) 〈Ps.-Rufinus Aquileiensis»: Vitae patrum, Lib. 3, Verba seniorum, cap. 28 (PL 73, 756 B-C) und Vitae patrum, Lib. 6, Verba seniorum, libell. 2, cap. 17 (PL 73, 1004 A. - Mairhofer Nr. 572). (307va)〈Ps.-Rufinus Aquileiensis`: Vitae patrum, Lib. 3, Verba seniorum, cap. 13 (PL 73, 745B-746B. - Mairhofer Nr. 573). (307va) Mairhofer Nr. 574. Tit.: De obsidione castri. (307va) Mairhofer Nr. 575. (307vb) Mairhofer Nr. 576. (307vb) Mairhofer Nr. 577. (307vb) Mairhofer Nr. 578. (308ra) Mairhofer Nr. 579. (308va) Mairhofer Nr. 580. $(308 \mathrm{vb})$ 〈Ps.-Rufinus Aquileiensis〉: Vitae patrum, Lib. 3, Verba seniorum, cap. 84 (PL 73, 775BC. - Mairhofer Nr. 581). (309ra) 〈Sulpicius Severus, Iohannes Cassianus〉: Vitae patrum, Lib. 4, Excerpta , cap. 43 (PL 73, 841A-C. - Mairhofer Nr. 582). (309ra) Rufinus Aquileiensis`: Historia monachorum, cap. 1 (PL 21, 399A-400A. - Mairhofer Nr. 583). (309va) 〈Rufinus AQuILEIENSIS〉: Historia monachorum, cap. 6 (PL 21, 401C-403C. - Mairhofer Nr. 584). (309vb) (Sulpicius Severus, Iohannes Cassianus $:$ Vitae patrum, Lib. 4, Excerpta, cap. 52 (PL 73, 846B-D. - Mairhofer Nr. 585).

(310ra) Vitae patrum, Lib. 5: (310ra) Libell. 4, cap. 27 (PL 73, 880C-D. - Mairhofer Nr. 586). (310ra) Libell. 5, cap. 37 (PL 73, 883D-884B. - Mairhofer Nr. 587). (310rb) Libell. 5, cap. 30 (PL 73, 881C. - Mairhofer Nr. 588). (310va) Libell. 7, cap. 41 (PL 73, 903A. - Mairhofer Nr. 589). (310va) Libell. 7, cap. 43 (PL 73, 903B-904A. - Mairhofer Nr. 590). (310vb) Libell. 10, cap. 10 (PL 73, 913C-D. - Mairhofer Nr. 591). (310vb) Libell. 14, cap. 18 (PL 73, 952A) = 〈Grimlaicus〉: Regula solitariorum, cap. 58 (PL 103, 649D-650. - Mairhofer Nr. 592).

(311ra) Vitae patrum, Lib 6: (311ra) Libell. 1, cap. 12 (PL 73, 994C-995A. - Mairhofer Nr. 593). (311ra) Libell. 1, cap. 13 (PL 73, 995A-B. - Mairhofer Nr. 594). Tit.: De fine boni hominis et mali hominis.

(311rb) 〈Ps.-Rufinus Aquileiensis〉: Vitae patrum, Lib. 3, Verba seniorum, cap. 54 (PL 73, 768BC. - Mairhofer Nr. 595). (311rb) 〈Godefridus Altissiodorensis»: Declamationes ex s. Bernardi sermonibus, cap. 25 (PL 184, 454C-455A. - Mairhofer Nr. 597).

(311rb) Schlussschrift: Et sic est finis. 
12 (311v) Miraculum de duOBus SociIs.

Inc.: Erant duo socii simul coniuncti unus quesivit alterum quis eorum remocius ambulasset. Dixit primus Fui in provincia ... - Expl.: ... et ea que congregasti cuius erunt etc.

$\left(\mathrm{I} *^{*}-\mathrm{v}\right)$ leer.

P. A./A. P.

\section{Cod. 142}

\section{REGULA S. AUGUSTINI. HUGO DE SANCTO VICTORE (?). LIBER ANNIVERSARIORUM NEOCELLENSIS. NECROLOGIUM NEOCELLENSE}

Perg. I, 173, I* Bl. $300 \times 230$. Neustift, T. I: 1521, T. II: 1459 .

B: $\quad$ Zwei Teile: I (I, 1-51) und II (52-173, I*). Am oberen Blattrand Foliierung 19. Jh. durch die ULB Tirol (hier berücksichtigt)

E: $\quad$ Renaissanceeinband: helles Leder über Holz. Neustift, 16. Jh.

Leder insbes. am HD stark abgerieben, in den Ecken Holz tw. freiliegend. VD und HD gleich: vier von dreifachen Streicheisenlinien gebildete Rahmen (von außen nach innen): Rahmen 1: Dekor aus spitz aufeinander zulaufenden dreifachen Streicheisenlinien; Rahmen 2: Ranke mit eingeschlossenen Blüten und Granatapfel (Nr. 1); Rahmen 3: Ranke mit eingeschlossenen Blüten und Granatapfel (Nr. 2); Rahmen 4: Rundbogen auf Stab (Nr. 3). Mittelfeld oben und unten horizontal durch dreifache Streicheisenlinien begrenzt, in der Mitte Einzelstempel zwölfblättrige Rosette mit zwölfblättriger Mittelblüte frei (Nr. 4), in den Ecken Einzelstempel mit floralem Dekor frei (Nr. 5). Zwei Kurzriemen-Leder-Metall-Schließen. Kanten gerade, nach innen abgeschrägt und von zweifachen Streicheisenlinien eingefasst. Rücken: blau gefärbt (wie öfters in Neustift), vier Doppelbünde. Bünde durch dreifache Streicheisenlinien begrenzt, Linien am VD und HD fortgesetzt, spitz aufeinander zulaufend. Im zweiten Feld Signaturschild (s. bei G), im fünften Spuren eines abgelösten Papierschilds, leer. Kapitale mit naturfarbenem Spagat umstochen, oben nur mehr tw. erhalten. Spiegel Pap. 18. Jh. (?). Am Spiegel des VD Exlibris, Signaturen und Bleistiftnotiz (s. bei G), Spiegel des HD leer. Unter dem Spiegel des VD Pergamentblatt, Gegenfalz zw. Bl. I und 1.

G: $\quad$ Am Spiegel des VD Exlibris der Stiftsbibl. Neustift 18. Jh. 1809 anlässlich der vorübergehenden Auflösung des Klosters Neustift der ULB Tirol übergeben. Am Spiegel des VD alte Signaturen der ULB Tirol II 2 G 4 (Bleistift) und Nr. 142 (2) (Tinte, Bleistift) sowie Bleistiftnotiz (Vide Grundzettel). Bl. 1r Stempel der ULB Tirol 19. Jh. Am Rücken gelbes Signaturschild der ULB Tirol 142/2. 1921 aufgrund des Friedensvertrages von St. Germain an den italienischen Staat abgegeben und von diesem 1929 dem Kloster Neustift als Dauerleihgabe überlassen.

L: $\quad$ Wilhelm I 136. - Wretschko-Sprung 16. - O. Redlich, Tirolische Geschichtsquellen des Mittelalters (Festschrift des Akademischen Historikerklubs in Innsbruck zur Erinnerung an das dreißigste Stiftungsfest). Innsbruck 1903, 8. - Sparber 226-227. - L. Santifaller, Calendarium Wintheri. Il più antico calendario necrologio ed urbario del capitolo della cattedrale di Bressanone. Gleno 1926, 376-391, 413. - L. Santifaller, Kalendar und Nekrolog des Kollegiatstiftes im Kreuzgang zu Bressanone aus dem 13. Jahrhundert (Beihefte zum Jahrbuch für Geschichte, Kultur und Kunst 4). Bozen 1939, 11. - MGH Necrologia Germaniae III 28-47. - J. Baur, Die Spendung der Taufe in der Brixner Diözese in der Zeit vor dem Tridentinum (Schlern-Schriften 42). Innsbruck 1938, 142. - Goy 471, Nr. 85. - Neuhauser, Neustift 81. - Th. (H.) Innerhofer, Der Grabplatz Oswalds von Wolkenstein in der Stiftskirche von Neustift. Der Schlern 58 (1984) 418-419. - Katalog ULB Tirol II 113, 204. - Katalog ULB Tirol II, Beiheft, Taf. 66 und 79. - Kristeller VI 122. - Stefani 99-100. - Peintner, Stiftsbibliothek 122.

$$
\text { I (I, 1-51) }
$$

B: $\quad$ Perg. stark abgegriffen. Lagen: (I-1) (Vorsatzbl., Pap. 18. Jh.?) $+6 . I^{48}+(I I-1)^{51}$. Gegenbl. zum Vorsatzbl. als Spiegel auf dem VD aufgeklebt. Gegenbl. zu Bl. 50 herausgeschnitten (Textverlust). Lage 1 Reklamante erhalten, beschnitten. In der Mitte des oberen Blattrandes rote Foliierung, dat. 1521 (s. bei A), in arabischen Ziffern 1-52. 
S: $\quad$ Schriftraum $225 \times 170$, Bl. $1 \mathrm{r}-6 \mathrm{v}$ einspaltig, Bl. $7 \mathrm{r}-51 \mathrm{v}$ zwei Spalten, seitlich von roten Tintenlinien begrenzt, zu 23 Zeilen. Textualis formata (Textura), dat. 1521, Rubrizierung von gleicher Hand (dat. in Rot Bl. 4r, 6v, 22va, 29rb, 43vb; Bl. 4r zusätzlich in Schwarz). Schreiber: H. R. (?) (s. bei A). Bl. 45ra, Z. 11-23 von anderer Hand. Von späterer Hand I-Striche, bisweilen in Häkchenform, und U-Striche in gebogter Form. Vereinzelt interlineare Nachträge von zeitgenössischer Hand (in Tinte).

A: Rote Auszeichnungsstriche, Trennstriche, Überschriften, Blattzählung. In den untersten Zeilen Unterlänge des Minuskelbuchstabens g bisweilen kalligraphisch gelängt. Bl. 5r Hinweiszeichen in Pfeilform (in Bleistift) von späterer Hand. Einzeilige rote Lombarden (pastos-erhabener Tintenauftrag, Bl. 30vb blaue Lombarde) mit einfachem Dekor: Punktverdickungen, Achterschlingen, Bl. 22va als Besatzmotiv mit schwarzer Tinte gezeichneter Profilkopf (mit geöffnetem Mund). Repräsentanten.

Zwei größere Initialen (B1. 1r: sechszeilig, rot-blau gespalten; B1. 7ra: fünfzeilig, blau) mit rotem Fleuronnée (charakteristische länglich-blasige Knospen) von der im 1. Fünftel 16. Jh. nachweisbaren Hand, die auch in Cod. 405 (dat. 1501, hier das Fleuronnée flüchtiger) und Cod. 194 (dat. 1507) tätig war, in beiden Bänden des Zollner-Graduales einige Initialen mit Fleuronnée (s. jeweils Ergänzungshand 2) geschmückt und Sign. 14820 zur Gänze ausgestattet hat.

Bl. 25vb und Bl. 37va signiert $H$. R. (jeweils rot, in g-Unterlänge, letzte Zeile) und fügt Bl. 37va liniavit 1521 (in Rot) hinzu (lat. „liniare“ bzw. „lineare“: „Linien ausführen, mit Linien umgeben“, s. Du Cange et al., Glossarium mediae et infimae latinitatis. Niort 1883-1887, Bd. 5, Sp. 118a bzw. 115b; „lineare“ auch „eine Handschrift ausmalen“, s. E. Habel, F. Gröbel, Mittellateinisches Glossar. Paderborn 2008, Sp. 223); von dieser Hand auch die Datierung 1521 Bl. 4r, 6v, 22va, 29rb, 43vb.; unklar, ob H. R. lediglich die Begrenzungslinien des Schriftspiegels zog (allerdings fraglich, ob diese Tätigkeit eine Signatur rechtfertigte), oder als Rubrikator (und zugleich Schreiber) anzunehmen ist; es ist eher unwahrscheinlich, dass $H$. $R$. als Florator tätig war, denn dann wäre ihm die oben genannte Handschriftengruppe zuzuschreiben, was die Frage aufwirft, warum er ein Werk mit zwei Fleuronnée-Initialen signierte, ein vollständig fleuronniertes Buch wie Sign. 14820 aber nicht.

S. R.

$(\mathrm{Ir}-\mathrm{v})$ leer.

1 (1r-6v) Regula s. Augustini (PL 32, 1377-1384. Regula recepta = Ordo monasterii, Satz $1+$ Praeceptum [CPL Nr. 1839b]. Vgl. L. Verheijen, La règle de saint Augustin 1 [Études augustiniennes 15,1]. Paris 1967, 417-437).

(1r) Tit.: Regula beati Augustini.

Daneben in Rot: 1521.

2 (7r-51v) Hugo 〈DE SAncto Victore (?)〉: Expositio in regulam beati Augustini, unvollständig: Schluss fehlt (PL 176, 881-924C. - Goy 457-478).

Tit.: Incipit glosa Hugonis super regulam beati Augustini. - Expl. mut: ... Graciarum actio patri luminum semper [

$$
\text { II }\left(52-173, I^{*}\right)
$$

B: $\quad$ Perg. stark abgegriffen, löchrig, Nahtspuren, insbes. am Blattrand stark verschmutzt. Bl. 53, 55, 65 und 67 jeweils mit angeklebtem Pergamentstreifen ergänzt. Buchblock nachträglich beschnitten (Text am oberen und seitlichen Blattrand bisweilen beschnitten). Lagen: (VII-2) ${ }^{63}+(\mathrm{VII}-3)^{74}+(\mathrm{VII}-2)^{86}+(\mathrm{VIII}-3)^{97}+$ $(\mathrm{VII}-2)^{109}+(\mathrm{VII}-2)^{121}+\mathrm{II}^{125}+5 . \mathrm{IV}^{166}+(\mathrm{III}+1)^{173}+(\mathrm{I}-1)^{\mathrm{I}^{*}}$ (Nachsatzbl., Pap. 18. Jh.?). Gegenbl. zu Bl. 54, 63, 64, 68, 74, 79, 85, 91, 97, 102, 108, 114 herausgeschnitten (ohne Textverlust). Gegenbl. zu Bl. 87 herausgeschnitten (Textverlust, vgl. Schriftrest auf Falz zw. Bl. 97 und 98). Bl. 85 von kleinerem Format (295× 190). Bl. 167 eingehängtes Einzelbl. Bl. 173 durch Pergamentmakulaturfalz verstärkt. Gegenbl. zum Nachsatzbl. als Spiegel auf dem HD aufgeklebt. Am oberen Blattrand ältere Foliierung in arabischen Ziffern 1-43 (= 53-121), nur die Blätter mit Nekrologeintragungen foliiert, die dazwischen befindlichen Blätter mit dem Text des Martyrologs unfoliiert. B1. 52r Rest eines Signakels.

S: $\quad$ B1. 52r-126v Schriftraum ca. $220 \times 160$. Zwei Spalten, von roten bzw. rot-schwarzen bzw. schwarzen Tintenlinien gerahmt, Bl. 81r, 85r-v, 93r, 98r, 110r, 122r-126v einspaltig, zu meist 27 Zeilen. Bastarda 15. Jh. mit Nachträgen von späteren Händen. 
Bl. 127r-173r Schriftraum $240 \times 180$, von roten Tintenlinien in vier Felder unterteilt, jeweils ca. $120 \times 80$ (jedes Feld für einen Tag des Nekrologs). Haupthand Bastarda, dat. 1459 (Bl. 172v). Zahlreiche Nachtragshände bis 2. H. 17. Jh. Schriftraum und Zeilenzahl mit Händen wechselnd.

A: $\quad$ Rote Auszeichnungsstriche, Trennstriche, Paragraphzeichen, Durchstreichungen, Zeilenfüllsel, Über- und Schlussschriften. Bl. 122r Laus Deo mit roter Rahmung, das L mit Ausläufer, der in Herzblättern endet. KLLigaturen in Rot, Bl. 53r mit kordelartiger Aussparung, Bl. 99r mit kritzeligem schwarzem Fleuronnée. Rote Benediktionskreuze. Ein- und zweizeilige rote Lombarden, vereinzelt mit Punktverdickungen, cadellenartigen Verzierungen und einfachem Fleuronnée in Schwarz; ab Bl. 123v lange schwarze I-Versalien, fallweise mit blassrotem Dekor. Repräsentanten.

3 (52ra-126v) LiBER ANNIVERSARIORUM NEOCELLENSIS (MGH Necrologia Germaniae III 39-47).

Heiligenfeste aufgelistet in Santifaller, Calendarium 377-391 (Cal. n. 10).

Folgende Blätter und Schriftspalten sind leer: Bl. 52ra-b, 58va-59rb, 64r, 70rb, 74rb, 75rb, 77rb, 78rb, 79rb, 80rb, 83rb, 84rb, 87rb, 88rb, 97rb, 101rb, 102rb, 103rb, 108rb, 120rb.

4 (127ra-172va) Necrologium Neocellense (MGH Necrologia Germaniae III 28-38).

(172va) Datierung (rot): Explicit memoriale fratrum et sororum nostre confraternitatis finitum anno domini 1459 in vigilia concepcionis Marie virginis (7. Dezember 1459).

(172vb) leer.

(173ra) Nachtrag. Tit.: Utriusque sexus nomina laicalem nobiscum fraternitatem habentium hic infra notata sunt ab anno virginei partus 1506.

(173rb) Datierter Nachtrag 1590: Ludovicus Ox scriba noster in fraternitatem nostram laicalem assumptus est. Anno domini 1590. Die 2 decembris anno 85 (? radiert). Obiit autem 7 die eiusdem anni et mensis.

(173rb, unten) kurze Additionsrechnung.

(173v) leer.

$\left(I^{*} r\right)$ Bleistiftnotiz 20. Jh. (Datierung?).

$\left(\mathrm{I}^{*} \mathrm{v}\right)$ leer.

\section{Cod. 145}

\section{BARTHOLOMAEUS A SANCTO CONCORDIO}

Pap. I, 314, I* Bl. $300 \times 215$. Süddeutscher Raum (Tirol?), 1427 .

B: $\quad$ Pap. bes. am oberen Blattrand gewellt, am seitlichen Rand bisweilen eingerissen und tw. fleckig, Bl. 1 Wasserschaden. Nachweise und Bilder der Wasserzeichen s. WZMA. Wasserzeichenbefund mit Datierung übereinstimmend. Identische Wasserzeichen: u. a. Innsbruck, ULB Tirol, Cod. 663, T. II, Cod. 666, T. II, Cod. 787, T. II. Lagen: (I-1) ${ }^{\mathrm{I}}$ (Vorsatzbl. 18. Jh.) $+1^{1}+26 . \mathrm{VI}^{313}+1^{314}+(\mathrm{I}-1)^{\mathrm{I}}$ (Nachsatzbl. 18. Jh.). Gegenbl. zum Vor- bzw. Nachsatzbl. als Spiegel auf dem VD bzw. HD aufgeklebt. Bl. 1 und 314 Einzelbl., wohl urspr. Vor- bzw. Nachsatzbl. Vor Bl. 1 und in den Lagenmitten von verschiedenen Händen beidseitig beschriebene und rubrizierte Pergamentfälze, längs geschnitten (vereinzelt Namen bzw. Namensanfänge erkennbar: möglicherweise aus einem Nekrolog 14. Jh.). Lagenreklamanten, tw. gerahmt, Bl. 301v weggeschnitten. Am oberen Blattrand Foliierung 19. Jh. durch die ULB Tirol.

S: $\quad$ Schriftraum 205/210×145/150. Zwei Spalten, von Tintenlinien gerahmt, zu 37-46 Zeilen. Zirkelstiche. Bastarda von einer Hand mit unterschiedlichem Duktus, dat. 1427 (Bl. 313vb). Schreiber: Nicolaus Petrus. Bl. 1r und 314r-v Einträge von zeitgenössischer Hand.

A: Rote Auszeichnungsstriche und -punkte, Paragraphzeichen (auch am seitlichen Blattrand), Rahmungen, Zeilenfüllsel, Unterstreichungen sowie Überschriften. Zwei- und drei-, vereinzelt auch vierzeilige rote Lombarden, tw. mit Punktverdickungen, vereinzelt mit einfachen Ausläufern. B1. 120va I-Versal mit eingeschriebener (weiblicher?) Figur in Schwarz. 
E: $\quad$ Neuzeitlicher Bibliothekseinband: schwarz gesprenkeltes braunes Pap. über Pappe. Neustift, 2. H. 18. Jh. Am VD und HD Ecken mit braunem Leder verstärkt. Rücken: braunes Leder, vier Doppelbünde, von Goldbordüren gesäumt. Im ersten Feld Golddruck M: S:, im zweiten Golddruck BARTHOLOMAEI A S. CONCORDIO OPERA in Goldrahmung, im dritten Signaturschild (s. bei G). Kapitale mit Leder umschlagen. Spiegel Pap. 18. Jh. Am Spiegel des VD Exlibris, Signaturen und Bleistiftnotiz (s. bei G), Spiegel des HD leer.

G: Zeitpunkt und Art der Erwerbung durch Neustift unbekannt. Am Spiegel des VD Exlibris der Stiftsbibl. Neustift 18. Jh. 1809 anlässlich der vorübergehenden Aufhebung des Klosters Neustift der ULB Tirol übergeben. Am Spiegel des VD alte Signaturen der ULB Tirol II $\overline{3}$ [...] 6 [...] (? radiert, Tinte), II 2 G 7 (Bleistift) und Nr. 145 (Tinte) sowie Bleistiftnotiz (Vide Grundzettel). Am Rücken gelbes Signaturschild der ULB Tirol 145. Bl. 1r Stempel der ULB Tirol 19. Jh. 1921 aufgrund des Friedensvertrages von St. Germain an den italienischen Staat abgegeben und von diesem 1929 dem Kloster Neustift als Dauerleihgabe überlassen. Bl. 1r Stempel der Soprintendenza Tridentina 20. Jh.

L: $\quad$ Kaeppeli Nr. 436. - Katalog ULB Tirol II 117, 204-205. - Stefani 101. - Peintner, Stiftsbibliothek 121.

(Ir-v) leer.

1 (1r) Versus de titulis librorum Decretalium (Druck: GW M23131. Vgl. Walther, Initia Nr. 18797). Die genaue Formulierung des jeweiligen Titulus ist über die Verse geschrieben.

Inc.: Summum constitue rescriptum post aliud consue ... - Expl. mut.: ... Sponsans inpubes clamdestina (!) sponsa duorum Condicio cleri quam polluit et lepro servus [ Forts. Nr. 3, Bl. 314r. Parallelüberlieferung: u. a. Innsbruck, ULB Tirol, Cod. 285, Bl. 57r; Freiburg, UB, Hs. 1283, Bl. 18v.

(1v) leer bis auf Notiz: luo vinarii (?).

2 (2ra-313vb) Bartholomaeus a Sancto Concordio: Summa de casibus conscientiae (= Summa Pisanella) (Druck: GW 3450-3457. - Kaeppeli Nr. 436. Bloomfield Nr. 5052).

(2ra) Abkürzungsverzeichnis. Tit.: In Christi nomine Amen. Iste sunt declaraciones de breviaturis positis in hac summa.

(2rb) Alphabetisches Stichwortverzeichnis.

(6ra) Text (tw. vom Druck leicht abweichend).

(101rb) Expl. mut. (Excomunicacio sexto): ... seu excomunicatis recipere [ Forts. Bl. 102va103rb. Anschließend Bl. 101va Inc. mut.: ] volentes libro sexto salvis que dicuntur in sequenti ... Bl. 102r Vermerk: ferte (!) duo follia (!) circa signum hoc = Verweis auf Forts. Bl. 103va.

(311ra) Fünf Zeilen gegenüber Druck eingefügt, durchgestrichen ... sola fama non sufficit ut (hier Einschub: est indicandus cum in pacto ...) dicatur.

(313vb) Schlussschrift: Consummatum fuit hoc opus in civitate Pizanensis per fratrem Bartholomeum de sancto Concordio ordinis fratrum Predicatorum doctorem decretorum. Anno domini $M^{\circ} 338$ die septima mensis Decembris tempore sanctissimi in Christo patris ac domini domini pape Benedicti duodecimo. Predictus autem frater Bar[tholomeus] compilator huius libri obiit anno domini $M^{\circ} C C C^{o} X L V I I$ secunda die Iulii. Cuius anima requiescat in eo qui vivit et regnat per omnia secula seculorum.

(rot umrandet:) Finitus autem est iste liber presens anno domini etc. vigesimo septimo in vigilia sancti Andree per manus Nicolai Petri hora II post meridiem vel quasi etc. (29. November 1427)

3 (314r) Forts. von Nr. 1, Bl. 1r. Inc. mut.: ] Nat cogna spiri cogna le sangwinis uxor ... - Expl.. ... peniteat sentencia ver post regulam iuris.

4 (314va-b) Diverse Kurztexte.

1) Tit.: Hec servare decet quemlibet hominem religiosum. - Inc.: Devotus sit in choro discretus in capitulo sobrius in refectorio disciplinatus in omni loco ... - Expl.: ... numquam extra se in cordis evagacione.

Parallelüberlieferung: Mainz, Wiss. Stadtbibl., Hs. I 314, Bl. 120v (hier Bernardus Claraevallensis zugeschrieben) und Hs. I 392, Bl. 205r. 
2) Tit.: Casus in quibus clericus tenetur respondere coram iudice seculari. - Inc.: Quando feudum tenet a layco de iudice c. ceterum ... - Expl.: ... debet actor defendere coram iudice seculari ff. de iudi[ce] l. si heres pre aliis (?).

3) Tit.: In istis casibus non tenetur quis confiteri proprio sacerdoti. - Inc.: Item si est hereticus. Item si publicus peccator pena usurarius concubinarius etc. ... - Expl.: ... Item si peccatum de quo vult confiteri esset commissum alteri sacerdoti etc.

Schlussschrift: Hos casus ponit sanctus Thom[as] de Aqui[no] in quarto Sentenciarum di. XVII. 4) Darunter von anderer Hand: Inc.: Quoniam apostolica sedes intendit providere negociis non personis ... - Expl. mut.: ... sed quantum ad numerum dierum tunc habet octavas ut dicit $c$. preallegatum. Quoniam (?) [

5) Tit.: Difinicio conf[irmata?] Concilii Basiliensis. - Inc.: Item ubi quis in testamento disposuit ... - Expl.: ... quod deest in defuncto igitur etc.

6) Darunter: Patronus est turpitudinis qui celat crimen uxoris Extra de iure iur. Quemadmodum [ $\left(\mathrm{I}^{*} \mathrm{r}-\mathrm{v}\right)$ leer.

U.S.

\section{Cod. 146}

\section{REGEL DES HL. AUGUSTINUS. HUGO DE SANCTO VICTORE (?). HUMBERTUS DE ROMANIS}

Perg. I, 160, I* Bl. $290 \times 220$. Süddeutscher Raum (T. I: Neustift?), 1. H. 15. Jh. (vor 1445).

B: $\quad$ Drei Teile: I (I, 1-5), II (6-12a[13]), III (13[14]-158[160], I*). Am oberen Blattrand Foliierung 19. Jh. durch die ULB Tirol; Fehler in der Zählung: 12 und 93 doppelt angeführt.

E: $\quad$ Neuzeitlicher Bibliothekseinband: schwarz gesprenkeltes braunes Pap. über Pappe. Neustift, 2. H. 18. Jh. Pap. etwas abgerieben. Am VD und HD Ecken mit braunem Leder verstärkt. Rücken: braunes Leder, vier einfache Bünde, von Goldbordüren gesäumt. Im ersten Feld Golddruck $M$ : S:, im zweiten Golddruck $E X$ PLICAT. REGULAE SANCTI AUGUSTIN. in Goldrahmung, im dritten Signaturschild (s. bei G). Spiegel Pap. 18. Jh. Am Spiegel des VD Exlibris, Signaturen und Bleistiftnotiz (s. bei G), Spiegel des HD leer.

G: $\quad$ Bl. 158vb Besitzvermerk 15. Jh., radiert Iste liber est beate virginis (?). Fehlender Quinio zw. Bl. 121 und 122 gelangte 1746 in den Besitz von Samuel Szekely; vgl. Vermerk Esztergom, Kathedralbibl., Ms. II.516, Bl. 1r: Anno 1746 die 24. Martii occasione itineris in Italiam suscepti, dum in urbe Brixiensi in Tyroli diem quietis habuissemus, eo (?) tum profectus sum ad monasterium Neo-Cellense Neustifft dictum Canonicorum Regularium S. Augustini Congregationis Lateranensis, ubi praelatus est Reverendissimus ac Perillustrissimus D. P. Antonius Steigberger, Decanus Gregorius Zeiller, Bibliothecarius Caspar Meyer. Et haec mihi Samuel Székely de Duba Locumtenenti manu propria. Wie die Lage nach Esztergom gelangte, ist nicht klar, möglicherweise - wie Ms. II.2, das einen Teil des Cod. 196 umfasst - als Geschenk von Sándor Mérey 1847; vgl. hierzu Cod. 196, Abschnitt G. Ebenso unklar bleibt, wann drei Blätter dieses einen Quinio verloren gegangen sind; vgl. T. III.

Der in Neustift verbliebene Teil wurde mit Sicherheit erst nach 1746 neu gebunden und dabei auch beschnitten: Reklamanten im Gegensatz zur heute in Esztergom aufbewahrten Lage kaum mehr sichtbar. Am Spiegel des VD Exlibris der Stiftsbibl. Neustift 18. Jh. 1809 anlässlich der vorübergehenden Aufhebung des Klosters Neustift der ULB Tirol übergeben. Am Spiegel des VD alte Signaturen der ULB Tirol II 2 G 8 (Tinte, Bleistift) und N. 146 (Tinte) sowie Bleistiftnotiz (Vide Grundzettel). Am Rücken gelbes Signaturschild der ULB Tirol 146. Bl. 1r Stempel der ULB Tirol 19. Jh. 1921 aufgrund des Friedensvertrages von St. Germain an den italienischen Staat abgegeben und von diesem 1929 dem Kloster Neustift als Dauerleihgabe überlassen. Bl. 1r Stempel der Soprintendenza Tridentina 20. Jh.

L: $\quad$ Kristeller VI 122. - Wretschko-Sprung 16. - R. Creytens, Les commentateurs dominicains de la Règle de saint Augustin du XIIIe au XVIe siècle. Archivum Fratrum Praedicatorum 33 (1963) 121-157, hier 126. Neuhauser, Neustift 85. - Katalog ULB Tirol II 117, 205. - Handschriftencensus: Neustift 146 (http://www. handschriftencensus.de/18762). - E. Madas (in Verbindung mit K. Körmendy, J. Lauf, G. Sarbak), Katalog 
der mittelalterlichen Handschriften in Esztergom. Die Bestände der Kathedralbibliothek und anderer Sammlungen (Fragmenta et codices in bibliothecis Hungariae VII-B). Deutsche Fassung unter Mitwirkung von A. Vizkelety. Esztergom, Budapest (in Druck).

$$
\text { I (I, 1-5) }
$$

B: Perg. an der rechten unteren Ecke abgegriffen. Bl. 2 am unteren Blattrand Nahtspuren. Lagen: (I-1) (Vorsatzbl., Pap. 18. Jh.) + (1+II) $)^{5}$. Gegenbl. zum Vorsatzbl. als Spiegel auf dem VD aufgeklebt. Bl. 1 eingehängtes Einzelbl., auf Bl. 2 aufgeklebt.

S: $\quad$ Schriftraum $220 \times 150$, von feinen Tintenlinien gerahmt, zu einheitlich 28 Zeilen auf feiner Tintenlinierung. Zirkelstiche. Textualis formata (Textura), in der letzten Zeile Unterlänge des Minuskelbuchstabens g bisweilen kalligraphisch gelängt. Bl. 4r am Blattrand Nachtrag von späterer Hand in Textualis cursiva, Bl. 5v vereinzelte Interlinearnachträge von späterer Hand.

A: $\quad$ Rote Auszeichnungsstriche, Paragraphzeichen, Durchstreichungen, Überschriften. Zeilenfüllsel. Zwei- und dreizeilige rote, grüne und blaue Lombarden (Bl. 2r Punktverdickungen, Bl. 5r Ausläufer) mit rotem Fleuronnée (Bl. 3v flüchtigeres blaues Fleuronnée, möglicherweise von anderer Hand). Charakteristisch im Binnenfeld und als Besatz stilisierte Halbpalmetten, als Besatz zudem Knospen im Wechsel mit Dornen; längere Fadenausläufer, die in Halbpalmetten oder Fibrillen enden können. - Affinitäten zu der in beiden Bänden des Zollner-Graduales tätigen Fleuronnée-Ergänzungshand 1, vgl. z. B. Bl. 2r mit Bl. 306v2 im zweiten Gradualband: sehr ähnlich die Halbpalmetten, die wie ein Flügelpaar angeordnet sind.

Bl. 1r vierzeilige ornamentale Deckfarbeninitiale mit breitem rotem Profilrahmen, auf dem der grüne, mit groben Blattranken gefüllte Buchstabenkörper aufliegt; blaues Binnenfeld mit weißen Federranken, deren Voluten Punktblüten umschließen.

(Ir-v) leer

1 (1r-5v) Regel Des HL. Augustinus, dt., unvollständig (vgl. CPL Nr. 1839).

Erhalten sind der Beginn von cap. 1, der Schluss von cap. 2, cap. 3-6 sowie der Beginn von cap. 7 (= letztes Kapitel).

$(1 \mathrm{r}-\mathrm{v})$ Tit.: Hye hebt sich an sand Augustins regel. - Inc.: Vor allen dingen ir lieben prüder habt got lieb dar nach den nächsten. Wan die zway gepot synd uns vorderleich gegeben ... - Expl. mut.: ... und ert in euch selbs got dez tempel ir worden seyt [

(2r-5v) Inc. mut. (Schluss cap. 2): ] so sy ye meyner bedurffen, ye saliger sy sind. Noch so sol der zarten speis girikait sy nicht uben ... - Expl. mut. (Beginn cap. 7): ... das sol man nicht sawmitlich übergeen, sunder mit fleiß und straffung sol man [

$\mathrm{Zu}$ den mhd. Übersetzungen der Augustinusregel s. G. de Smet, „Augustinerregeln“ (mhd.). Verfasserlexikon ${ }^{2}$ I 545-550.

$$
\text { II }\left(6-12^{\mathrm{a}}[13]\right)
$$

B: Perg. fleckig und am rechten unteren Blattrand tw. stark abgegriffen. Buchblock beschnitten (vgl. Randbemerkung Bl. 12r und v). Bl. 8 lose. Bl. 7 und 8 am unteren Blattrand Löcher und Nahtspuren, Bl. 12 und $12^{\mathrm{a}}$ jeweils Loch im Textfeld (ohne Fehlstelle im Text). Lagen: $(\mathrm{I}+1)^{8}+(1+\mathrm{I})^{11}+\mathrm{I}^{12 \mathrm{a}(13)}$. Bl. 8 und 9 eingehängte Einzelbl., Bl. 8 heute lose, Bl. 9 auf Bl. 10 aufgeklebt. Zw. Bl. 12 und 12 a fehlt wohl ein Doppelbl.

S: $\quad$ 1) Bl. 6r-8v und Bl. 10r-11v Schriftraum $225 \times 170$, von feinen Tintenlinien gerahmt, zu 34 Zeilen. Bl. 11r und v deutlich über begrenzten Schriftraum hinaus beschrieben. Bastarda. Am Blattrand Notizen von unterschiedlichen Händen sowie Nachträge und Forts. der Rubriken von anderer Hand, bisweilen durch unterschiedliche Symbole im Text gekennzeichnet.

2) Bl. 9r-v Schriftraum $225 \times 165$, von kräftigen Tintenlinien begrenzt, zu 34 Zeilen. Rubriken wohl von gleicher Hand. Textualis.

3) Bl. $12 \mathrm{r}-12^{\mathrm{a}} \mathrm{v}$ Schriftraum $215 \times 165$, von feinen Tintenlinien gerahmt, zu 40 Zeilen. Forts. der Rubriken am Blattrand. Textualis. 
A: $\quad$ 1) Bl. $6 r-8 v$ und $10 r-11 v$ rote Auszeichnungsstriche, Paragraphzeichen, Unterstreichungen, Interpunktionszeichen, Überschriften, Satzmajuskeln in Lombardenform, einfache Lombarden. Repräsentanten. Rubriken und Nachträge am Blattrand in Rot.

2) Bl. 9r-v rote Auszeichnungsstriche. Rubriken wohl von anderer Hand.

3) Bl. $12 r-12^{a} v$ rote Auszeichnungsstriche, Paragraphzeichen, Initialmajuskeln, dreizeilige Lombarden mit wenig Dekor (Bl. 12r im Binnenfeld Spruchband mit $V$ und $O$ ?). Repräsentanten. Rubriken. Knochenlöcher rot umrandet.

2 (6r-12v) 〈Hugo de SAncto Victore (?)〉: Expositio in regulam beati Augustini, unvollständig (PL 176, 881-924. - Goy 457-478).

(6r-7v) Inc. mut. (cap. 1): ] [D] eum ex toto corde et ex tota anima et proximum nostrum sicut nos. Necessaria est ita quia virtus concordie ... - Expl. mut.: ... unde et subditur. (rot:) Qui autem nichil habebant non ea querant in monasterio que nec foris habere potuerunt. [ (PL 176, 882B-886D).

(8r-9v) Inc. mut. (cap. 2): ] peccati superbia. Prima est enim in peccando ultima remanet in conflictu ... - Expl. mut. (cap. 3): ... hostem nutrit. Sic ergo nutrienda est ut [ (PL 176, 889A-893A).

(10r-v) Inc. mut. (cap. 6): ] esse vestimenta clericorum in quibus nichil notari possit ... - Expl. mut.: ... Non solum tacita voluntate intus concupiscencia oritur sed eciam per exteriorem [ (PL 176, 897B-899B).

(11r-v) Inc. mut. (cap. 7): ] magis ad vindictam pertinet quam ad disciplinam. Caveant ergo fratres ut neminem reprehendant ... - Expl. mut. (cap. 8): ... temperat sentenciam cum subiungit. (rot:) Tamen si vestra tolleratur infirmitas ut hoc recipiatis quod posueratis in uno tamen loco sub communibus custodibus habete quod ponitis. (vom Druck leicht abweichend:) Nullus sibi aliquid operetur sed omnia vestra in communi fiant maiori studio et frequenciori alacritate quam si vobis singuli propria faceretis [ (PL 176, 904A-906B).

(12r-v) Inc. mut. (Schluss cap. 9): ] redeundum est ad mansuetudinis lenitatem. Nam pertinax motus facile ... - Expl. mut. (cap. 10): ... accipere oracionis effectum. (rot:) Qui autem numquam vult petere veniam aut non ex animo petit sine causa est in monasterio eciam si inde non proiiciatur (!) [ (PL 176, 913C-916A).

$\left(12^{\mathrm{a}} \mathrm{r}-\mathrm{v}\right)$ Inc. mut.: (cap. 11) ] verbere et castigacione in ipso inicio peccati ... - Expl. mut.: ... Iusto non est lex posita. Ubi enim spiritus [ (PL 176, 921A-923C).

$$
\text { III (13[14]-158[160], I*) }
$$

B: Vereinzelt kleine Löcher und Nahtspuren. Bl. 19 Riss. Bl. 92 am unteren Blattrand Rechteck herausgeschnitten. Lagen: 13. $\mathrm{V}^{141(143)}+\mathrm{IV}^{149(151)}+(\mathrm{IV}+1)^{158(160)}+(\mathrm{I}-1)^{\mathrm{I}^{*}}$ (Nachsatzbl., Pap. 18. Jh.). Gegenbl. zum Nachsatzbl. als Spiegel auf dem HD aufgeklebt. Bl. 150 eingehängtes Einzelbl., auf Bl. 151 aufgeklebt. Ab Bl. 13 am oberen Blattrand mittig zeitgenössische Foliierung in arabischen Ziffern 41-195 (mit den Folioangaben im Register übereinstimmend, allerdings wird hierbei das Verso immer zum darauffolgenden [und nicht zum vorangehenden] Recto gezählt), Blätter mit Foliierung 151-160 (= Quinio) fehlen (s. bei G). Lagenreklamanten stark be- bzw. weggeschnitten.

S: $\quad$ Schriftraum $210 \times 140 / 145$. Zwei Spalten, von feinen Tintenlinien gerahmt, zu 35-39 Zeilen. Zirkelstiche. Zwei Hände: 1) Bl. 13ra-156ra: Bastarda. Auszüge aus der Regula Augustini in Auszeichnungsschrift (Textualis formata [Textura]) von gleicher Hand. Vereinzelt Nachträge am Blattrand und interlinear; 2) Bl. 156va-158vb (Register): Textualis, auf feiner Tintenlinierung. Zählung der Kapitel in Rot (tw. arabische Ziffern, tw. römische Zahlen). Von Hand der Foliierung Blattangaben (Numerus foliorum) in arabischen Ziffern in eigener Spalte (bis auf Bl. 158rb immer links der Titelangaben) später hinzugefügt. Am Blattrand vereinzelt Nachträge in Bastarda.

A: 1) Bl. 13ra-156rb rote Auszeichnungsstriche, Überschriften (Bl. 54vb und 141va mit Repräsentant am unteren Blattrand), Paragraphzeichen (vereinzelt blau, Bl. 49ra mit geschlungenem Ausläufer), Unterstreichungen. Als Orientierungshilfen Nota-Hinweise, X-förmige Zeichen, Haken, Zwei-, Drei- und Vierpunktgruppe. Zeigehände (meist flüchtig gezeichnet; auch mit Ärmeldraperie, z. B. Bl. 119rb und 146ra). Zwei- bis vierzeilige blaue, hell- und dunkelrote Lombarden (B1. 131va türkisgrün), vereinzelt mit Punktverdickungen, 
Aussparungen, einfachem schwarzem Fleuronnée (Bl. 84rb im Binnenfeld gegenständiges Halbpalmettenpaar). Lombarden mitunter nicht ausgeführt (Bl. 82ra Vorzeichnung einer C-Lombarde). Oberlängen in der ersten Zeile und Unterlängen in der untersten Zeile bisweilen gelängt und verziert; in der obersten Zeile tw. cadellenartig, häufig mit Köpfen in Federzeichnung (z. B. Bl. 87r). Einige ungelenke Bas-de-page-Federzeichnungen: Bl. 50r liegender Hund, Tierkopf mit Hörnerpaar; Bl. 114r langbeiniger rot-schwarzer Vogel mit Fisch im Schnabel; Bl. 75r männliche Büste (evtl. mit dem Stift ausgeführt, mit dem auch die auf Petrus Figuli bezogenen Vermerke Bl. 113va-119rb eingetragen wurden). Repräsentanten.

2) Bl. 156va-158vb (Register) rote Überschrift, Kapitelzählung. Zeigehände. Einzeilige abwechselnd rote und blaue Lombarden. Bl. 156va fünfzeilige blaue Lombarde mit rotem Fleuronnée (im Binnenfeld Knospenräder, als Besatz eng stehende Knospenreihen). Oberlängen in der ersten Zeile und Unterlängen in der untersten Zeile bisweilen gedehnt und (cadellenartig) verziert.

S. R.

3 (13ra-158vb) Humbertus de Romanis: Expositio regulae s. Augustini, unvollständig (Ed.: J. J. Berthier, B. Humberti de Romanis ... opera de vita regulari I. Roma 1888, ND Torino 1956, 43-633. - Kaeppeli Nr. 2016). Kapiteleinteilung in Hs. von Ed. abweichend.

Der Text beginnt mit dem Ende von cap. 44; der Schluss von cap. 151, cap. 152-162 sowie der Beginn von cap. 163 fehlen.

(13ra-121vb) Cap. 44-151 (= Ed. cap. 53-162). Inc. mut.: ] erectis quasi orans huius (darüber: di) exemplum ... - Expl. mut.: ... Quod ergo dicitur interdum quod hoc non debent facere [

Der hier fehlende Quinio (s. bei B) heute in Esztergom, Kathedralbibliothek, Ms. II 516. Allerdings sind von den urspr. fünf Doppelbl. nur mehr zwei erhalten (urspr. Foliierung: Bl. 151 und 160 sowie 154 und 157), vgl. Katalog der mittelalterlichen Handschriften in Esztergom.

(122ra-156rb) Cap. 163-198 (= Ed. cap. 174-209). Inc. mut.: ] Prima est certitudo ...

Schlussschrift (unmittelbar an Text anschließend): Hoc additur in fine ut sciatis quicumque ordinis nostri hoc inpleverit se totam regulam implesse et ad amplius non tueri Deo gracias qui vivit et regnat in secula seculorum Amen.

(156va-158vb) Register mit später hinzugefügter Blattangabe.

Tit.: In nomine domini Amen. Incipit tabula super exposicionem regule beati Augusti episcopi quam exposicionem frater Humbertus magister ordinis ad utilitatem ac peticionem fratrum ordinis Predicatorum conpilavit. - Inc.: De laudibus regule beati Augustini Capitulum primum ... Expl.: ... De hiis que valent ad remissionem habendam CLXXXXVII. De temptacionibus CLXXXXVIII.

Lit.: Creytens $120-157$.

(158vb) Besitzvermerk (s. bei G).

4 Am Blattrand vereinzelt Notizen von anderer Hand: (113vb) am unteren Blattrand radierte Notiz Anno domini $M^{\circ}$ CCCC $^{\circ}$ XLV frater Petrus Figuli Rat[isponiensis] (?) dyocesis fuit in monasterio Nova[cellensi] dioc[esis] Brixinensis.

(114ra) am unteren Blattrand radierte Notiz Anno domini $M^{\circ} C^{C} C C^{\circ}$ XLV frater.

(119rb) am unteren Blattrand radierte Notiz Figuli.

$\left(\mathrm{I}^{*} \mathrm{r}-\mathrm{v}\right)$ leer. 


\section{Cod. 153}

\section{IOHANNES HEROLT (DISCIPULUS)}

Pap. I, 168, I* Bl. $270 \times 205$. Wiener Raum, 4. Jz. 15. Jh.

B: $\quad$ Pap. z. T. stark fleckig und beschädigt: B1. 5, 49, 89 Löcher bzw. Risse, B1. 13, 27, 61, 157 eingerissen. Buchblock beschnitten. Bilder und Nachweise der Wasserzeichen s. WZMA. Datierung nach Wasserzeichenbefund. Identische Wasserzeichen: v. a. in 1437/38 datierten Hs. aus dem Wiener Raum, z. B. Wien, Schottenstift, Archiv, Hs. 280, Archiv, Hs. 280 und Hs. 381 (beide dat. 1438); Klosterneuburg, Stiftsarchiv, Grundbuch $17 / 2$ (dat. 1437). Lagen: $(\mathrm{I}-1)^{\mathrm{I}}$ (Vorsatzbl. 18. Jh.) $+(1+\mathrm{VI})^{13}+11 . \mathrm{VI}^{145}+(\mathrm{VI}-1)^{156}+\mathrm{VI}^{168}+$ $(\mathrm{I}-1)^{\mathrm{I}^{*}}$ (Nachsatzbl. 18. Jh.). Gegenbl. zum Vor- bzw. Nachsatzbl. als Spiegel auf dem VD bzw. HD aufgeklebt. Bl. 1 eingefügtes Einzelbl., auf Bl. 2 aufgeklebt, urspr. letztes Bl. einer Lage (vgl. Reklamante). Gegenbl. zu Bl. 146 herausgeschnitten (Textverlust). Erstes bzw. letztes Blatt der Lage jeweils durch einen aufgeklebten Papierfalz verstärkt. Zw. Bl. 156 und 157 Pergamentfalz. Lagenreklamanten, z. T. beschnitten. Am oberen Blattrand Foliierung 19. Jh. durch die ULB Tirol; Fehler in der Zählung: 115 doppelt angeführt, 116 ausgelassen.

S: $\quad$ Schriftraum $205 \times 145 / 150$. Zwei Spalten, von feinen Tintenlinien gerahmt, zu 37-41 Zeilen. Bastarda.

A: Rote Auszeichnungsstriche, Unterstreichungen, Über- und Schlussschriften. Zwei- bis siebenzeilige rote Lombarden, tw. mit Punktverdickungen. Repräsentanten.

E: Neuzeitlicher Bibliothekseinband: schwarz gesprenkeltes braunes Pap. über Pappe. Neustift, 2. H. 18. Jh. Am VD und HD Ecken mit braunem Leder verstärkt. Rücken: braunes Leder, vier einfache Bünde, von Goldbordüren gesäumt. Im zweiten Feld Golddruck MANUSCRIPT. in Goldrahmung, im dritten Signaturschild (s. bei G). Kapitale mit naturfarbenem und blauem Zwirn umstochen. Schnitt rot gesprenkelt. Spiegel Pap. 18. Jh. Am Spiegel des VD Signaturen und Bleistiftnotiz (s. bei G), Spiegel des HD leer.

G: Zeitpunkt und Art der Erwerbung durch Neustift unbekannt. 1809 anlässlich der vorübergehenden Aufhebung des Klosters Neustift der ULB Tirol übergeben. Am Spiegel des VD alte Signatur der ULB Tirol II 2 H 1 (Tinte, Bleistift) und Nr. 153 (Tinte) sowie Bleistiftnotiz (Vide Grundzettel). Am Rücken gelbes Signaturschild der ULB Tirol 153. Bl. 1r Stempel der ULB Tirol 19. Jh. 1921 aufgrund des Friedensvertrages von St. Germain an den italienischen Staat abgegeben und von diesem 1929 dem Kloster Neustift als Dauerleihgabe überlassen. Bl. 1r Stempel der Soprintendenza Tridentina 20. Jh.

L: $\quad$ Katalog ULB Tirol II 133, 205.

$(\mathrm{Ir}-\mathrm{v})$ leer.

1 (1ra-160vb) 〈Iohannes Herolt (Discipulus)〉: Sermones de tempore (Schneyer II Nr. 11?-91). (1ra) Vermutlich Dnca 4. adv. (Schneyer II Nr. 11?). Inc. mut.: ] miracula et in hoc apparebit ipsorum consciencia unde Gregorius ... - Expl.: ... Ite maledicti in ignem eternum qui paratus est dyabolo et angelis eius a quo nos custodiat dominus noster Iesus Christus qui vivit et regnat in secula seculorum Amen.

(1va) Tit.: Sequitur sermo de nativitate Christi undecimus bonus et utilis (Schneyer II Nr. 12). Inc.: Ecce ewangelizo vobis ... Luc. $2^{\circ}(10-11)$. Nota quod inter omnia festa letabunda tocius anni hoc festum nativitatis est tanto lecius ... - Expl.. ... non licet comedere carnes in die nativitatis Christi. Extra de observancia ieiunii (?).

(4va) Tit.: Item sermo de nativitate Christi delusoribus. Sermo XII ${ }^{\text {us }}$ bonus (Schneyer II Nr. 13). Inc.: Anuncio vobis gaudium magnum ... Luc. $2^{\circ}(10)$. Scire debetis in Christo dilectissimi quod dies hodierna ex salvatoris nostri nativitate nobis redditur gaudiosa ... - Expl.: ... animas vero in penas eternas perpetuo secum cruciandas detrudendo etc.

(7rb) Tit.: De sancto Stephano. Sermo tredecimus (Schneyer II Nr. 14, Bibelzitat abweichend, vgl. Nr. 15). - Inc.: S (!) Stephanus vidit celos apertos. Actuum $7^{\circ}$ (56). Aristoteles primo Ethicorum finis per quem omnia desiderantur et sperantur optimus est ... - Expl.: ... ubi nullus ordo sed sempiternus horror inhabitat etc.

(9rb) Tit.: Divisio sermonis huius (Schneyer II Nr. 15). - Inc.: Ecce video celos apertos (Act 7,56). Prosequendo sermonem iam inceptum tunc sciendum quod quanto celum aperitur per intensam contricionem ... - Expl.: ... et beato Stephano inmense gracie referuntur etc. 
(11va) Tit.: Sermo quindecimus de sancto Iohanne ewangelista (Schneyer II Nr. 16). - Inc.: Sequere me. Iohannis 21 (19). Verba proposita sunt a Christo beato Petro dicta et iam dicuntur cuilibet homini qui vult salvari ... - Expl.: ... quia ambo apud Deum sunt equales meriti etc.

(14ra) Tit.: De parentibus qui pueros occidunt. Sermo de Innocentibus $16^{u s} X V I^{u s}$ (Schneyer II Nr. 17). - Inc.: Mittens Herodes occidit omnes pueros ... Mt. $2^{\circ}$ (16). Ex quo hodie peragitur festum illorum puerorum innocentium qui ab iniquo Herode interfecti sunt ... - Expl.: ... Salomon dicit: Qui parcit virge odit puerum suum etc. Sequitur.

(15vb) Tit.: Dominica infra octavas nativitatis Christi. Sermo XVII ${ }^{\text {us }}$ quare parvulus factus est (Schneyer II Nr. 18). - Inc.: Puer autem crescebat ... Luc. $2^{\circ}$ (40). Ex quo in presenti ewangelio fit mencio de puero nobis recenter nato. Tunc pro presenti sermone tria sunt dicenda. Primo quare Christus parvulus factus est ... - Expl.: ... et ymaginem regina mihi tribuit etc.

(17va) Tit.: Dominica. Sermo XVIII quod impedimenta perfectus (!) sunt septem (Schneyer II Nr. 19). - Inc.: Puer autem crescebat etc. (Lc 2,40). Sicut puer Ihesus crevit corporaliter ita et nos crescere debemus spiritualiter ... - Expl.: ... iniuria esset minima tunc esset veniale.

(19rb) Tit.: In die circumcisionis domini. Sermo XIX ${ }^{\text {us }}$ bonus (Schneyer II Nr. 20). - Inc.: Postquam consummati sunt dies octo ... Luc. $2^{\circ}(21)$. Solent homines in novo anno munuscula sibi invicem dare ... - Expl.: ... ipsi dyaboli maxime repellerentur per hoc nomen Iesus etc.

(21ra) Tit.: Iuvenes debent a iuventute servire Deo. Sermo $X X^{\text {us }}$ (Schneyer II Nr. 21). - Inc.: Postquam consummati sunt dies octo etc. Luc. $2^{\circ}(21)$. Sciendum quod Christus die octavo circumcisus est et sanguinem suum fudit ... - Expl.: ... et fideliter Deo servierunt etc.

(23ra) Tit.: Sequitur sermo XXI ${ }^{u s}$ in festo epiphanie domini (Schneyer II Nr. 22). - Inc.: Ecce magi veniunt ... Mt. $2^{\circ}(1)$. Hodierne diei festivitas magna est. Unde merito dicitur apparicio ...Expl.: ... Gregorius. Mala que nos hic premunt ad Deum ire compellunt etc.

(25vb) Tit.: De eodem festo de ioco. Sermo XXII ${ }^{\text {us }}$ (Schneyer II Nr. 23). - Inc.: Videntes stellam gavisi sunt gaudio magno valde etc. (Mt 2,10). Glosa non fuit satis ewangeliste dicere gavisi sunt sed addit valde magno gaudio ... - Expl.: ... ad inferos transmissi sic et illi accidit etc.

(27va) Tit.: Dominica infra octavas epiphanie sermo XXIII ${ }^{\text {us }}$ (Schneyer II Nr. 24). - Inc.: Cum factus est Iesus annorum duodecim ... Luc. $2^{\circ}$ (42). In presenti enim ewangelio instruit Maria parentes qualiter se debeant habere ad filios ... - Expl.: ... et Deo fideliter servivit et sic salvatus est etc.

(30va) Tit.: De eadem dominica. Ffilii tenentur VI parentibus. Sermo XXIIII ${ }^{u s}$ (Schneyer II Nr. 25). - Inc.: Descendit cum eis ... Luc. $2^{\circ}$ (51). Augustinus Non solum Christi verba sunt nobis in documentum sed eciam Christi facta sunt nobis in exemplum ... - Expl.. ... vidit illum Parisius cum aliis multis pueris et hominibus etc.

(32va) Tit.: Dominica prima post octavas epiphanie. Sermo XXV $V^{\text {us }}$ (Schneyer II Nr. 26). - Inc.: Nupcie facte sunt ... Ioh. $2^{\circ}$ (1-2). Quamvis heretici miseri menciantur carnale martirium esse illicitum eorum tamen falsitas manifeste apparet ... - Expl.: ... eterna dampnatio a qua nos custodiat dominus noster Iesus Christus A.

(35va) Tit.: Sermo XXVI ${ }^{u s}$ quere a quibus non prospere succeditur in matrimonio (Schneyer II Nr. 27). - Inc.: Nupcie facte sunt in Chana Galilee etc. (Io 2,1). Ex quo ewangelium hodiernum mencionem facit de matrimonio et de nupciis in quibus Christus Deus et homo cum benedicta matre ... - Expl.: ... Quod audiens Iohannes admirans gracias Deo egit etc.

(37va) Tit.: Defectus quos Christus assumpsit. Dominica $2^{a}$. Sermo XXVII ${ }^{u s}$ (Schneyer II Nr. 28). Inc.: Cum descendisset Iesus ... Mt. 8 (1). Sciendum quod dicit Haymo Mons in quo Deus sedet celum intelligitur... - Expl. (von Schneyer II abweichend): ... efficitur servus dyaboli nec propria voluntate in $q .1$ Non est.

(39rb) Tit.: De honore sermo XXVIII ${ }^{u}$ de eadem dominica (Schneyer II Nr. 29). - Inc.: Ego veniam et curabo eum. Mt. 8 (7). In hiis verbis notatur magna humilitas Christi qui servum centurionis dignatus est visitare ... - Expl. (von Schneyer II abweichend): ... in tenebras exteriores etc. Hoc est dicendum de penis inferni. Illum sermonem quere infra 125 Q. Sequitur. 
(41va) Dnca 4. post epiph. Tit.: De temptacionibus. Sermo XXVIIII ${ }^{\text {us }}$ (Schneyer II Nr. 32). - Inc.: Motus magnus factus est ... Mt. 8 (24). Mr. 4 (vgl. Mc 4,37). Luc. 8 (vgl. Luc. 8,23). Ubi sciendum est quod per mare intelligitur presens mundus et per motum magnum ... - Expl.: ... et ita sanus frater ille discessit etc. Sequitur sermo.

(44va) Dnca 5. post epiph. Tit.: Sermo XXX $X^{\text {us }}$ quomodo boni et mali sunt permixti in hoc mundo (Schneyer II Nr. 33). - Inc.: Sinite utraque crescere ... Mt. 13 (30). Sciendum quod in celo sunt solummodo boni in inferno solummodo mali ... - Expl. (gegenüber Schneyer II erweitert, vgl. Schneyer II Nr. 34): ... ad vitam salutis. De ewangelio eodem Triticum congregate ... est dicendum de novem gaudiis celi. Istum sermonem quere infra $83 \mathrm{~K}$ exemplum.

(46vb) Tit.: Dominica quinta de humilitate. Sermo XXXI ${ }^{\text {us }}$ (Schneyer II Nr. 35). - Inc.: Discite a me quia mitis sum ... Mt. XI (29). Aristoteles In sempiternis nichil violentum. Qui ergo alte in celo vult ... - Expl.: ... Discite a me quia mitis sum et humilis corde etc.

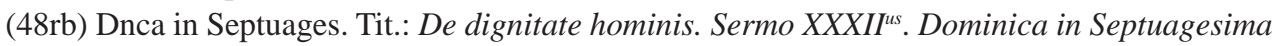
(Schneyer II Nr. 36). - Inc.: Simile est regnum celorum homini patrifamilias ... Mt. $2^{\circ}$ (recte: 20,1). Scire debetis in Christo dilectissimi quod sancta mater ecclesia katholica hodierna die duo nobis tempora representat ... - Expl.: ... quanto spiritu confortabantur tanto corpore infirmabantur etc.

(50ra) Tit.: De dignitate hominis sermo XXXII ${ }^{\text {us }}$ (!). Dominica in $L X X^{a}$ (Schneyer II Nr. 37). Inc.: Simile est regnum celorum homini patrifamilias ... Mt. XX $X^{\circ}(1)$. EX quo in presenti ewangelio fit mencio de patrefamilias qui conduxit operarios ... - Expl.. ... animam illius ancille ad celum deduxit etc.

(51vb) Tit.: Dominica in LX de creacione hominis. Sermo XXXIIII bonus (Schneyer II Nr. 38).Inc.: Exiit qui seminat ... Luc. 8 (5). Ubi sciendum quod seminator est Deus omnipotens qui exiit seminare semen suum id est genus humanum creando ... - Expl.: ... Cupio dissolvi et esse cum Christo etc.

(54ra) Tit.: Dominica in $L X^{a}$ de verbo Dei. Sermo XXXVus bonus (Schneyer II Nr. 39). - Inc.: Semen est verbum Dei. Luc. 8 (11). Est enim semen verbum Dei quod Christus de celo attulit in terra seminavit ... - Expl.: ... in locis penalibus iusticia dampnantis dampnat etc.

(55rb) Tit.: Dominica in Quinquagesima de gaudio mundano. Sermo XXXVI ${ }^{\text {us }}$ (Schneyer II Nr. 40). - Inc.: Ecce ascendimus Ierosolimam ... Luc. 18 (31-32). Mt. $2^{\circ}$ (vgl. recte Mt 20,1819). Marci 10 (vgl. Mc 10,33-34). Duo enim manifestantur in ewangelio presenti scilicet passio Christi et illuminacio cuiusdam ceci ... - Expl. (von Schneyer II abweichend): ... et facta est postmodum mulier sancta etc. Sequitur.

(58ra) Tit.: Sermo XXXVII de corea et de eadem dominica (Schneyer II Nr. 41). - Inc.: Tradetur enim gentibus ... Luc. 18 (32). Ubi sciendum quod passio Christi que in hodierno ewangelio nobis proponitur retrahere nos debet ab illicitis gaudiis huius seculi ... - Expl.: ... mundus non sit diligendus illum sermonem infra 136 ff. Secuntur sermones Quadragesime etc.

(60va) Tit.: Incipit Quadragesimale in die cinerum fiunt sex. Sermo XXXVIII ${ }^{u}$ (Schneyer II Nr. 42). - Inc.: Convertimini ad me ... Iohel $2^{\circ}$ (12). Unde Iohannes de Sancto Geminiano Videmus enim quod cum animal brutum sentit se wlneratum sollicite querit et procurat sanacionis remedium ... - Expl.: ... a quibus tandem suffocatus penam irrisionis luit etc.

(62va) Tit.: Dominica prima in Quadragesima de ieiunio. Sermo XXXVIIII ${ }^{\text {s }}$ (Schneyer II Nr. 43). - Inc.: Cum ieiunasset quadraginta diebus ... Mt. $4^{\circ}$ (2). Mr. $1^{\circ}$ (vgl. Mc 1,13). Luc. $4^{\circ}$ (vgl. Lc 4,1). Christus ieiunavit nobis in doctrinam et exemplum quia secundum Gregorium Omnis Christi actio nostra est instructio ... - Expl.: ... pane et aqua in uno peccato mortali ieiunaret etc.

(65rb) Tit.: Dominica prima in Quadragesima de septem temptacionibus. Sermo XL ${ }^{\text {us }}$ (Schneyer II Nr. 44). - Inc.: Et accedens temptator dixit ei Si filius Dei es ... Mt. $4^{\circ}$ (3). Sciendum quod Christus voluit temptari ut ostenderetur quod nos spiritualiter pugnare oporteret ... - Expl.: ... est ordo monachorum. Et statim egressus factus sum monachus etc. 
(67va) Bei Schneyer II ohne eigene Nr. (direkt an Nr. 44 anschließend). Tit.: Ffidem falsificant 24 genera hominum. Sermo XLI ${ }^{u s}$ dominica secunda. - Inc.: Mulier magna est fides tua ... Mt. $15^{\circ}$ (28). Mr. $7^{\circ}$ (vgl. Mc 7,25) etc. Aristoteles 8 Phisicorum Illud est prius quo non existente non sunt alia sed (radiert: sum?) sine fide ... - Expl. (von Schneyer II abweichend): ... et in punctu ad inferna descendunt etc.

(69ra) Tit.: Dominica tercia in Quadragesima de iuramentis. Sermo XLII ${ }^{u s}$ (Schneyer II Nr. 45). Inc.: Erat Iesus eiciens ... Luc. XI ${ }^{\circ}$ (14). Mt. $22^{\circ}$ (vgl. recte Mt 9,32-33). Mr. $3^{\circ}$ (22). Iohannes de Sancto Geminiano Videmus naturaliter quod lux habet expellere tenebras. Christus autem est lux ... - Expl.: ... et Deus sibi illud peccatum indulsit etc.

(71vb) Tit.: Dominica quarta in Quadragesima scilicet media de contricione et confessione. Sermo XLIII ${ }^{\text {us }}$ (Schneyer II Nr. 46). - Inc.: Est puer unus hic qui habet quinque panes ... Ioh. $6^{\text {to }}$ (9). Mt. 14 (vgl. Mt 14,17). Iohannes de Sancto Geminiano dicit quod totum officium presentis diei dominice continet quasi quedam nova et leta ... - Expl.: ... nomine de cetero non oblatrare etc.

(74va) Tit.: De penitencia vera et falsa. Sermo XLIIII ${ }^{u s}$ de eadem dominica (Schneyer II Nr. 47). Inc.: Penitenciam agite ... Mt. $3^{\circ}(2)$. Aristoteles $5^{\circ}$ Phisicorum Omnis motus tendit ad aliquem terminum per debita media ... - Expl.: ... quia misericordia opera eius. Et de ista materia quere exempla infra 2 N. item $14 \mathrm{ff}$. Item 43 Q.

(77ra) Tit.: Sequitur dominica de passione domini. Sermo XLV ${ }^{\text {us }}$ (Schneyer II Nr. 48). - Inc.: Tulerunt ergo lapides ... Ioh. 8 (59). Aristoteles 8 Ethicorum dicit Vera (gestrichen: iusticia) amicicia habet reamacionem. Et quia Christus vere nos dilexit ... - Expl.. ... et laudabiliter postmodum vixit et in domino quievit. Quod et nobis concedat Ihesus Christus Amen etc.

(79ra) Unmittelbar an Sermo XLV anschließend: De eadem dominica in passione domini alius sermo. Qui ex Deo est verba Dei audit. Istum sermonem quere ante $35 \mathrm{~V}$ (vgl. Schneyer II Nr. 49).

(79rb) Tit.: Dominica palmarum de indigne communicantibus. Sermo XLVI ${ }^{u s}$ (Schneyer II Nr. 50). - Inc.: Benedictus qui venit in nomine domini. Mt. 21 (9). Mr. XI (9). Luc. 19 (recte: 13,35). Ioh. 12 (13). Hodie sancta mater ecclesia duas processiones recolit ... - Expl.: ... abstinendi et emendandi vitam suam etc.

(81rb) Tit.: In cena domini de percepcione sacramenti eukaristie. XLVII ${ }^{\text {us }}$ (Schneyer II Nr. 51). Inc.: Probet autem seipsum homo ... Prima Cor. XI (28). Aristoteles $2^{\circ}$ De anima Simile a simili nutritur sicut patet in cibo digesto a quo corpus nutritur ... - Expl.: ... post confessionem et penitenciam digne communicavit.

(84ra) Unmittelbar an Sermo XLVII anschließend (Schneyer II Nr. 52). Inc.: Item pro $2^{\circ}$ sermone in hac die tria sunt dicenda. Primo quomodo $4^{\text {or }}$ genera hominum ... - Expl.: ... oravit quinque Pater noster. Hoc quere infra sermone $80 \mathrm{~V}$.

(84ra) Tit.: In die parascevensi duodecim fructus de memoria passionis Christi. Sermo XLVIII ${ }^{u s}$ (Schneyer II Nr. 53). - Inc.: O vos omnes qui transitis ... Trenorum primo (Lam 1,12). Unde Iohannes de Sancto Geminiano dicit Conveniens est ut senciat (!) membrum quod sentit caput ...Expl.: ... Interior est planctus gravior cum te tam ingratum experior etc.

(86ra) Tit.: In die parasceves de passione Christi. Sermo XLIX ${ }^{\text {us }}$ (Schneyer II Nr. 54). - Inc.: Inclinato capite emisit spiritum ... Ioh. 19 (30). Iohannes de Sancto Geminiano dicit Mors salvatoris karissimi quam hodie recolimus fuit ultima consummacio dominice passionis ... - Expl.: ... et post mortem celos introivit. Hoc et nobis prestare dignetur Iesus Christus virginis Marie filius Amen.

(89rb) Vermerk (Schneyer II Nr. 55): Item tercium sermonem de passione scilicet quomodo Christus assumpsit decem defectus humane nature. Quere ante $27^{\circ}$ sermone A.

(89rb) Weiterer Vermerk (nicht bei Schneyer II): Item exemplum bonum de passione domini de milite illo qui quinque Pater noster oravit. Quere infra sermone $80 \mathrm{~V}$. 
(89va) Tit.: Sermo in festo pasce. Sermo Lus (Schneyer II Nr. 56). - Inc.: Hec est dies q[uam] fecit dominus ... Ps. $117^{u s}$ (24). Sciendum quod presens festivitas precellit alias festivitates in sollempnitate et iocunditate ... - Expl.: ... et sic fatue redierunt ad suas sorores etc.

(91vb) Tit.: Signa digne communionis. Sermo LI ${ }^{u s}$ (Schneyer II Nr. 57). - Inc.: Mane nobiscum domine. Luc. 24 (29). Hec verba canit ecclesia per illud sacrum tempus pascale usque ad ascensionem ... - Expl.: ... Et hec est caritas sufficiens sed ducit ad nimiam gloriam.

(94va) Tit.: In festo pasce de recidivacione. Sermo LII ${ }^{u s}$ (Schneyer II Nr. 58). - Inc.: Mane nobiscum domine. Luc. 24 (29). In quibus verbis monemur ne a bono iam incepto desistamus ... Expl.: ... ceteri penitenciam egerunt ad salutem etc.

(96ra) Tit.: Item in festo pasce. Sermo LIII ${ }^{u}$ (Schneyer II Nr. 59). - Inc.: Mane nobiscum domine. Luc. 24 (29). Circa quod sciendum quod sunt sex que debent hominem retrahere ab omni peccato mortali ... - Expl. (von Schneyer II abweichend): ... et circa me perpendo et considero quomodo gaudere possum undique cum hoc seculo etc.

(99rb) Tit.: De eadem feria aliqui sunt modis stulti aliqui modis sapientes. Sermo LIIII ${ }^{\text {us }}$ (Schneyer II Nr. 60). - Inc.: O stulti et tardi corde ad credendum. Luc. 23 (recte: 24,25). Sciendum quod $2^{m}$ dictum Salomonis stultorum infinitus est numerus ... - Expl.: ... si usque hodie peccent vel peniteant etc.

(101ra) Tit.: Quarta feria pasce de laboratoribus. Sermo LV ${ }^{u s}$ (Schneyer II Nr. 61). - Inc.: Vado piscari. Ioh. $21^{\circ}$ (3). Ex quo hodie est ultima dies celebris presentis festivitatis pasce et modo homines redire debent ad pristinos labores suos ... - Expl. (von Schneyer II abweichend): ... ab eo noluit exire sed eius verba contempsit etc. Quere hoc exemplum sermone $26 \mathrm{~V}$.

(103va) Nicht bei Schneyer II, jedoch im Druck GW 12346. Tit.: Dominica in octava pasce. Sermo LVIus. Decem confert societas bona. - Inc.: Thomas autem non fuit cum eis quando venit Iesus. Ioh. 20 (24). Notandum quod beatus Thomas Christum discipulis apparentibus non vidit quia non fuit cum eis sed post octo dies eum vidit ... - Expl. (= Expl. Schneyer II Nr. 61): ... secundum alterius voluntatem et ideo maioris virtutis sunt etc.

(104va) Tit.: Sermo LVII ${ }^{u s}$ de cycatricibus wlnerum (Schneyer II Nr. 62). - Inc.: Inffer digitum tuum huc. Iohannis 20 (27). Sciendum primo quod Christus servavit cycatrices wlnerum in suo corpore glorificato ... - Expl.: ... sed dignitas et pulchritudo erit etc.

(106ra) Tit.: Sermo LVIII ${ }^{\text {us }}$ de recidivantibus de eadem dominica (Schneyer II Nr. 63). - Inc.: Respondit Thomas dixit Deus meus et dominus meus. Ioh. 20 (28). Verba predicta quilibet potest dicere qui digne in hoc sacro tempore communicavit ... - Expl.. ... octo genera hominum vix vel raro se emendant etc.

(107vb) Tit.: Dominica prima post octavas pasce de prelatis et subditis. Sermo LVIIII ${ }^{u \text { (Schneyer }}$ II Nr. 64). - Inc.: Ego sum pastor bonus. Ioh. decimo (11). Sciendum quod per pastorem in presenti ewangelio intelliguntur prelati et per oves intelliguntur subditi ... - Expl.: ... tales eciam tenentur ad restitucionem.

(109vb) Tit.: De eadem dominica (Schneyer II Nr. 65). - Ego sum pastor bonus (Io 10,11). Hic Christus seipsum commendat. Unde hic est dicendum quando quis potest se licite commendare et quando est veniale et quando est mortale hoc quere infra sermone $107 \mathrm{~K}$.

(109vb) Tit.: De eadem dominica (Schneyer II Nr. 66). - Animam meam pono pro ovibus meis (Io 10,15). Hic dicendum est de caritate Dei quam habet ad nos et eciam de caritate quam nos ad ipsum habere debemus. Istum sermonem quere infra 119 P.

(109vb) Tit.: Dominica secunda post octavas pasce quare antiqui patres tam diu vixerunt. Sermo LX $X^{\text {us }}$ (Schneyer II Nr. 67). - Inc.: Modicum et iam non videbitis me. Ioh. 16 (16). Hec verba locutus est dominus Deus et ante passionem suam post cenam ... - Expl.: ... mortuus est. Et alius dixit Certe tibi ludum dimitto etc.

(112vb) Tit.: De eadem dominica de partu mulierum. Sermo LXI ${ }^{\text {s }}$ (Schneyer II Nr. 68). - Inc.: Mulier dum parit tristiciam habet. Ioh. 16 (21). Ex quo in verbis premissis fit mentio de partu mulierum. Tunc in presenti sermone tria sunt dicenda ... - Expl.: ... quia de porco fuit nutritus. 
(115rb) Tit.: De eadem dominica (Schneyer II Nr. 69). - Vos autem contristabimini (Io 16,20). Hic est dicendum quare Deus permittit aliquos bonos homines ita acerbissime tribulari in presenti. Istum sermonem quere ante 290.

(115va) Tit.: De eodem (Schneyer II Nr. 70). - Mundus autem gaudebit (Io 16,20). Hic est dicendum quare gaudium mundi est fugiendum et quando est mortale. Istum sermonem quere ante $36 \mathrm{D}$.

(115va) Tit.: Dominica tercia post octavas pasce. Isti arguuntur a Deo qui factis ostendunt se non credere in Deum. Sermo LXII ${ }^{\text {us }}$ (Schneyer II Nr. 71). - Inc.: Arguet mundum de peccato quia non credunt in me. Ioh. 16 (8). Sciendum quod plura genera hominum sunt qui dicunt verbis se credere in Deum ... - Expl.: ... utilem ad custodiam sui ad augmentum meriti etc.

(117vb) Tit.: De eadem dominica. Sermo LXIII. De correctione (Schneyer II Nr. 72). - Inc.: Arguet mundum de peccato. Ioh. 16 (8). Sciendum quod sicut Deus arguet peccatores de suis excessibus in futuro ... - Expl.: ... in suis missis et oracionibus quia valde affligor etc.

(119vb) Tit.: De eodem (Schneyer II Nr. 73). - Arguet mundum de peccato (Io 16,8). Glosa semper quod habet. Unde hic est dicendum quomodo quis committit $7^{m}$ peccata mortalia quere infra sermone $141 \mathrm{I}$.

(119vb) Tit.: De eodem (Schneyer II Nr. 74). - Arguet mundum de iusticia (Io 16,8). Glosa semper quam non habet. Unde hic est dicendum quomodo homo debet iustus inveniri si wlt salvari. Istum sermonem quere infra $154 \mathrm{~S}$.

(119vb) Tit.: Dominica quinta scilicet rogacionum de oracione. Sermo LXIIII ${ }^{u}$ (Schneyer II Nr. 75). - Inc.: Petite et accipietis. Ioh. 16 (24). Benignitas salvatoris Dei nostri maior est in exaudiendo peticiones filiorum suorum ... - Expl.. ... quia providet illis meliora quam petunt etc. (123rb) Tit.: De eadem dominica de Pater noster. Sermo LXV ${ }^{u s}$ (Schneyer II Nr. 76). - Inc.: Petite et accipietis. Ioh. 16 (24). Ex quo dominus noster Iesus Christus in verbis premissis invitat nos ad orandum tunc hic queritur ... - Expl.: ... sed quam caritas fraternalis commendat etc.

(126ra) Tit.: In festo ascensionis. Sermo (gestrichen: $L X^{u s}$ ) LXVI ${ }^{u s}$ (Schneyer II Nr. 77). - Inc.: Postquam locutus est eis Assumptus est in celum ... Mr. 16 (19). Sciendum quod ab origine mundi non fuit tale festum in celo nec unquam usque post iudicium erit ... - Expl.. ... si vis plura dicere de baptismo quere infra sermone $77 \mathrm{~B}$.

(127ra) Tit.: De eodem festo. Signa veri Christiani. Sermo LXVII ${ }^{\text {us }}$ (Schneyer II Nr. 78). - Inc.: Signa autem eos qui crediderint. Hec sequentur. Mr. ultimis (16,17). Quamquam nesciatur de homine quoquam an salvetur vel dampnetur ... - Expl.: ... et sermonem confirmante sequentibus signis etc.

(129va) Tit.: Sermo infra octavas ascensionis de preparacione ad graciam. Sermo LXVIII ${ }^{\text {us }}$ (Schneyer II Nr. 79). - Inc.: Cum venerit paraclitus quem ego mittam vobis a patre. Ioh. 15 (26). Sicut in dominica proxima futura recolitur spiritus sancti missio ... - Expl.: ... sed in deserto deficiente eis farina receperunt manna etc.

(131vb) Tit.: De eadem dominica de excommunicacione. Sermo LXVIIII ${ }^{\text {us }}$ (Schneyer II Nr. 80). Inc.: Absque sinagogis facient vos. Ioh. 15 (recte: 16,2). Sciendum quod sicut Iudei olim tenuerunt se ad discipulos Christi scilicet separando eos a participacione et communione ipsorum ...Expl.: ... in ecclesiam posuit statim moriebatur etc.

(134va) Tit.: De festo pentecostes de spiritu sancto. Sermo LXX ${ }^{\text {us }}$ (Schneyer II Nr. 81). - Inc.: Ad eum veniemus et mansionem aput eum faciemus. Iohannis 14 (23). Sciendum quod hodierna festivitas inter alia festa dignitatem singularem obtinet ... - Expl.: ... et finem suum in bono terminavit quod et nobis concedat Ihesus Christus Amen.

(137ra) Tit.: Alius sermo de spiritu sancto et est LXXI (Schneyer II Nr. 82). - Inc.: Repleti sunt omnes spiritu sancto. Act. $2^{\text {us }}$ (4). Aristoteles $9^{\circ}$ Methaphisice Contraria non fiunt in eodem. Cum ergo spiritus sanctus intrat in cor hominis tunc mala et peccata depellit ... - Expl.: ... tria in proficientibus et tria in perfectis etc. 
(139ra) Tit.: Alius sermo quare Deus subtrahit graciam homini LXXII ${ }^{u s}$ (Schneyer II Nr. 83). Inc.: Spiritus meus super mel dulcis. Ecc ${ }^{i}$. 24 (Sir 24,27). Ex quo spiritus sanctus est fons tocius dulcedinis tunc queritur quare Deus quandoque dilectis suis subtrahit in presenti consuetam graciam ... - Expl.: ... delevit penam et culpam propterea risi etc.

(141rb) Tit.: De donis spiritus sancti. Sermo LXXIII ${ }^{\text {us }}$ (Schneyer II Nr. 84). - Inc.: Repleti sunt omnes spiritu sancto. Act. $2^{\circ}$ (4). Ex quo iam illis sacris diebus peragitur missio spiritus sancti tunc aliquid de donis spiritus sancti pro presenti sermone dicendum est ... - Expl.: ... si carnali delectacione cor maculas etc.

(144rb) Tit.: Fferia $4^{\text {ta }}$ pentecostes Deus vocat hominem multipliciter. Sermo LXXIIII ${ }^{\text {us }}$ (Schneyer II Nr. 85). - Inc.: Nemo potest venire ad me nisi pater meus traxerit eum. Ioh. 6 (44). Sciendum quod circa predicta verba tria sunt dicenda. Primo quomodo Deus trahit et vocat hominem ...Expl.: ... perseveravit in bono sine cessacione quod et nobis prestare dignetur Iesus Christus Marie filius Amen etc.

(147va) Tit.: In festo trinitatis. Sermo LXXV ${ }^{\text {us }}$ (Schneyer II Nr. 86). - Inc.: O altitudo diviciarum sapiencie et sciencie Dei ... Ro. XI (33 und 36). Sciendum quod hodie festum trinitatis institutum est ut omnes fideles agnoscant unam simplicem deitatem et trinitatem ... - Expl.: ... quam sit verum quod puer dixit recognovit etc.

(150va) Tit.: Item de trinitate de baptismo. Sermo LXXVI ${ }^{u s}$ (Schneyer II Nr. 87). - Inc.: Nisi quis renatus fuerit ex aqua ... Ioh. $3^{\circ}$ (5). Sciendum quod triplex est nativitas naturalis spiritualis et celestis ... - Expl.: ... inveniens sibi celum semper apertum.

(152va) Tit.: Item de trinitate de signis ante et post baptismum. Sermo LXXVII ${ }^{\text {us }}$ (Schneyer II Nr. 88). - Inc.: Nisi quis renatus fuerit ex aqua et spiritu sancto etc. ubi supra. (Io 3,5). Ex premissis patet quod quam cito homo moritur qui adhuc stat in innocencia baptismali ... - Expl.: ... ut excusacio de ignorancia habetur.

(154ra) Tit.: In festo corporis Christi. Sermo LXXVIII ${ }^{u s}$ (Schneyer II Nr. 89). - Inc.: Caro mea vere est cibus ... Ioh. 6 (55). Sicut dicit Aristoteles $4^{\circ}$ Ethicorum Terribilissimum omnium terribilium videtur esse mors ... - Expl.: ... quia Ihesus venit et inter hec verba migravit ad dominum etc.

(156vb) Tit.: Item sermo LXXVIIII ${ }^{u}$ de corpore Christi (Schneyer II Nr. 90). - Inc.: Caro mea vere est cibus ... Ioh. 6 (55). Sic legimus quod unigenitus Dei filius volens [ (Textverlust, s. bei B) (157ra) Forts. Inc. mut.: ] stat circa magnum sudat in toto corpore igitur magnus ignis in Christi pectore erat qui toto corpore sudavit etc. ... - Expl.: ... subito salvos facit sperantes in se etc.

(158va) Tit.: Item de corpore Christi isti manducant corpus Christi spiritualiter. Sermo LXXXus (Schneyer II Nr. 91). - Inc.: Qui manducat hunc panem vivet in eternum. Ioh. 16 (recte: 6,58). Loquendo de manducacione huius venerabilis sacramenti sciendum quod hoc sacramentum tripliciter sumitur ... - Expl.: ... quem in cimiterio sepelierunt ubique tam grande miraculum diwlgentes etc.

Schlussschrift: Explicit primus liber.

2 (161ra-b) Exemplum: Pater, filius et asinus (vgl. B. E. Perry, Aesopica: a series of texts relating to Aesop or ascribed to him or closely connected with the library tradition that bears his name I. Urbana Illinois 1952, Nr. 721. J. T. Welter, La tabula exemplorum secundum ordinem alphabeti. Recueil d'exempla compilé en France à la fin du XIIIe siècle. Paris, Toulouse 1926, Nr. 265).

Tit.: Nota exemplum. - Inc.: Item mundus assimilatur duobus viris scilicet patri et filio quorum unus scilicet pater equitabat super azinum et filius pedester ambulabat ... - Expl.: ... si est liberalis dicunt esse fatuum. Ergo non est gaudendum de martyrio temporaliter sed tantum spiritualiter etc.

$(161 \mathrm{v}-168 \mathrm{r})$ nur Rahmung.

(168v) Federprobe: Oswald.

$\left(\mathrm{I}^{*} \mathrm{r}-\mathrm{v}\right)$ leer. 


\section{Cod. 154}

\section{MISSALE SPECIALE (TEILMISSALE)}

Perg. I, 47, I* Bl. $295 \times 195$. Umfeld Neustift, 12. Jh. (mit Nachträgen 13. Jh.).

B: $\quad$ Dickes Perg. abgegriffen, fleckig, löchrig, Nahtspuren. Lagen: $1^{1}$ (Vorsatzbl., Pap. 18. Jh.) $+(I V-3)^{5}+(I V-$ $1)^{12}+4 . I V^{44}+3^{47}+1^{1^{*}}$ (Nachsatzbl., Pap. 18. Jh.). Gegenbl. zu Bl. 1 (Textverlust) und zu Bl. 9 herausgeschnitten. Zw. Bl. 3 und 4 (Lagenmitte) Verlust eines Doppelbl. (Textverlust). Bl. $45-47$ drei aufeinander geklebte Einzelbl. (ohne Textverlust) als Rest einer Lage. Schluss verloren. Ab Lage 2 am Lagenende Kustoden III-VII in römischen Zahlen, stark beschnitten. Am Beginn Verlust zweier Lagen. Aufgrund des einheitlichen Schriftraums der gesamten Hs. ist die Zugehörigkeit der ersten Lage trotz anderen Schreibers und fehlender Zählung anzunehmen. Am oberen Blattrand Foliierung 19. Jh. durch die ULB Tirol.

S: $\quad$ Bl. 1r-4r Schriftraum $215 \times 125$, seitlich von kaum sichtbaren zweifachen Tintenlinien gerahmt, zu 24 Zeilen auf kaum sichtbarer Tintenlinierung. Karolingische Minuskel. Bl. 4ra-b Seitenmitte und Zusätze am Rand von anderer Hand, wie Bl. 4va-5vb. Bl. 4va-5vb Schriftraum 215×125. Zwei Spalten, seitlich von zweifachen Tintenlinien gerahmt, zu 43-46 Zeilen auf Tintenlinierung. Textualis 13. Jh. (möglicherweise in Neustift hinzugefügt). Bl. 6r-47v Schriftraum 215×125/130, seitlich von zweifachen Tintenlinien gerahmt, zu 24 Zeilen auf Tintenlinierung. Karolingische Minuskel von anderer Hand 12. Jh.

A: Rote Unterstreichungen, Zeilenfüllsel (Bl. 5rb), Benediktionskreuze, Überschriften, Satzmajuskeln in Lombardenform und zweizeilige Lombarden. Bl. 9v fünfzeilige Initialligatur VD (= Vere dignum), Bl. 10r siebenzeilige Initiale $T$ mit flankierenden rot(-tintenfarbenen) Halbpalmetten. Zw. Bl. 9 und 10 urspr. vorhandenes Kanonbild herausgeschnitten.

E: $\quad$ Neuzeitlicher Bibliothekseinband: schwarz gesprenkeltes braunes Pap. über Pappe. Neustift, 2. H. 18. Jh. VD und HD fleckig und zerkratzt. Ecken mit braunem Leder verstärkt. Rücken: braunes Leder, fünf einfache Bünde, von Goldbordüren gesäumt. Im zweiten Feld Golddruck MISSALE in Goldrahmung, im vierten Feld gelbes Signaturschild (s. bei G). Schnitt rot gesprenkelt. Spiegel Pap. 18. Jh. Am Spiegel des VD Signaturen, Bleistiftvermerk (s. bei G) und eingeklebter Papierzettel (20. Jh.) mit kurzer Inhaltsangabe, Spiegel des HD leer.

G: Unsicher, ob in Neustift entstanden. Nachträge in Textualis 13. Jh. (Bl. 4r, untere Blatthälfte-5vb) möglicherweise in Neustift eingetragen. Hs. 1809 anlässlich der vorübergehenden Aufhebung des Klosters Neustift der ULB Tirol übergeben. Am Spiegel des VD alte Signaturen der ULB Tirol II 2 H 2 (Tinte, Bleistift) und Nr. 154 (Tinte) sowie Bleistiftvermerk (Vide Grundzettel). Am Rücken gelbes Signaturschild der ULB Tirol 154. Bl. 1r Stempel der ULB Tirol 19. Jh. 1921 aufgrund des Friedensvertrages von St. Germain an den italienischen Staat abgegeben und von diesem 1929 dem Kloster Neustift als Dauerleihgabe überlassen. Bl. 1r Stempel der Soprintendenza Tridentina 20. Jh.

L: $\quad$ Katalog ULB Tirol II 133, 205. - Baroffio 324, Nr. 16712.

Missale speciale (Teilmissale).

Die Hervorhebung der hl. Margaretha spricht für eine Verwendung in einer der Margarethenkirchen im Neustifter Seelsorgebereich, z. B. in Neustift selbst, Schabs, Völs am Schlern (Obervöls), Margen bei Terenten, bes. aber in Montal wegen der zusätzlichen Hervorhebung von Matthias und Matthäus (vgl. die Ausmalung der Kirche im 19. Jh.). Zu Montal vgl. das wohl in Neustift für Montal geschriebene „Teyser-Missale“ von 1414 (Innsbruck, ULB Tirol, Cod. 563), mit roter Hervorhebung der Kirchenpatronin Margaretha im Kalendar, s. Katalog ULB Tirol VI 197-203 und W. Neuhauser, Das sog. Teyser-Missale (Cod. 563 der Innsbrucker Universitätsbibliothek). Der Schlern 81/7 (2007) 40-47. Ohne Notation.

$(\mathrm{Ir}-\mathrm{v})$ leer.

1 (1r-4r) Sequenzen (weitgehend wie Innsbruck, ULB Tirol, Cod. 563).

(1r) In resurrectione dni (AH 53, Nr. 36, Beginn fehlt). Inc. mut.: ] manus baptizandus et perfert fraudes temptatoris fugit persequentum lapides ... (= Str. 6, V. 2).

(1v) De ascensione domini (AH 53, Nr. 67). - (1v) De s. spiritu (AH 53, Nr. 70). - (2r) De sancta trinitate (AH 53, Nr. 81). - (2v) De apostolis (AH 53, Nr. 228). - (2v) De virginibus (AH 50, 
Nr. 271). - (3r) In dedicacione ecclesie (AH 53, Nr. 247). - (3v) De sancta Maria (AH 40, Nr. 119). - (3v) Item de sancta Maria (AH 54, Nr. 192).

2 (4r) ORATIONES DE UNA VIRGINE.

Tit.: De una virgine non martire. - Inc.: Deus qui nos hodie beate virginis tue annua sollempnitate letificas ... - Secreta. Grata tibi sit domine hec oblatio plebis tue quam tibi offerimus in honore sancte $N$ virginis tue ut cunctis proficiat ad salutem. - Postcommunio. Adiuvent nos quesumus domine et hec misteria ...

3 (4r-5vb) Von späterer (Neustifter?) Hand: Officium de s. Matthaeo. Nicht mit Breviarium Romanum übereinstimmend.

Mit Antiphonen, Responsorien und Versikel. Lektionen aus der Vita s. Matthaei auctore incerto nach Rom, Vaticana, Cod. Vat. lat. 1188 (Acta Sanctorum quotquot toto orbe coluntur ... collegit J. Bollandus. Venetiis 1867, Sept. VI 221-223) und Mt 9,9. Ps 33, 63, 74 und 98.

Inc.: Regem apostolorum dominum venite adoremus ... - Expl. mut.: ... Quem etiam proficientibus eiusdem gratie crementis de communi discipulorum numero ad apostolatus gradum promonuit nec solum predicandi verum etiam scribendi evangelium illi ministerium commisit ut qui terrestrium omiserat celestium [

4 (6r-v) ORATIONES ANTE MISSAM.

(6r) (rot) Cum sacerdos deponit vestem dicat. (schwarz) Exue me domine veterem hominem ... (Jungmann I 362 Anm. 13).

(6r) Ps 84, 85, 115, 116. Pater noster.

(6r) Preces (vgl. Jungmann I 355). Ps 43,26. Ps 32,22. Ps 84,7. Ps 84,8. Ps 142,2. Ps 18,13.

Ps 101,2 (jeweils nur Textbeginn).

(6r) Oracio. Aures tue pietatis mitissime Deus inclina precibus meis ... (Jungmann I 355).

(6r) Quando manus lavat. Largire sensibus nostris omnipotens Deus... (Jungmann I 361 Anm. 8. PL 78, 245).

(6r) Ad humerale. Indue me domine vestimento salutis et circumda galea fortitudinis ... (vgl. Jungmann I 367, dort leicht abweichend zum Anlegen der Albe).

(6r) Ad albam. Indue me domine vestimento salutis et iusticię et intellectu spirituali (vgl. Jungmann I 367, leicht abweichend).

(6r) Ad zonam. Precinge domine lumbos mentis meę pater clementissime et circumcide vitia cordis mei (Jungmann I 368).

(6v) Ad stolam. Stola iusticię circumda domine cervicem meam ... (Jungmann I 371).

(6v) Ad casulam. Indue me domine ornamento humilitatis et karitatis et concede michi protectionem ... (Jungmann I 372 Anm. 66).

(6v) Ad fanonem. Da domine virtutem manibus meis ad abstergendam omnem maculam... (Jungmann I 369).

(6v) Letzte Formel. Fac me queso omnipotens Deus ita iusticia indui ... (Jungmann I 372 Anm. 68).

5 (6v-7r) Messgebete von Stufengebet bis Opferung.

6 (7v) Messgebete zur Kommunion (Friedensgebet bis Gebete nach der Kommunion).

7 (7v-8r) Orationes POST MisSAm (wie im Missale Romanum, vgl. Jungmann II 571-572).

Canticum trium puerorum (Dn 3,57-88), Ps 150, Pater noster (jeweils nur Textbeginn). Confiteantur. Sacerdotes tui. Non nobis domine non. Esto nobis domine. Domine exaudi orationem und Gebet Deus qui tribus pueris mitigasti flammas ignium concede propicius ut nos famulos tuos non exurat flamma vitiorum. 
8 (8r-9v) Praefationes. Sanctus.

(8r) De nativitate domini. - In epiphania domini. - (8v) In Quadragesima. - De resurrectione. De ascensione domini. - De s. spiritu. - (9r) De s. trinitate. - De apostolis. - De s. Maria. - (9v) Praefatio communis. Anschließend Sanctus.

9 (10r-12r) CANON missae bis Agnus Dei. Bl. 10v zwei Zeilen radiert (wohl keine weitere Heiligenaufzählung) zw. Cosme et Damiani und Et omnium sanctorum tuorum quorum meritis precibusque concedas.

$10(12 \mathrm{v}-38 \mathrm{v})$ SACRAMENTARIUM.

$10.1(12 \mathrm{v}-30 \mathrm{v})$ Temporale.

(12v) De nativitate domini. - De s. Maria infra nativitatem domini. - Dominica post nativitatem domini. - (13r) De sancto Vincentio. - De sancta Agna (!) virgine. - De sancto Mathia. - (13v) In annuntiatione s. Marie. - Dominica I. post epiphaniam. - (14r) Dominica II. - Dominica III. Dominica IIII. - (14v) Dominica V. - Dominica in LXX ${ }^{a}$. - Dominica in LX ${ }^{a} .-(15 \mathrm{r})$ Dominica in Quinquagesima. - Feria IIII. in capite ieiunii. - Ad missam. - Feria V. - (15v) Feria VI. Sabbato. - (16r) Dominica I. in Quadragesima. - Feria II. - Feria III. - (16v) Feria IIII. - Feria V. - (17r) Feria sexta. - Sabbato. - Dominica II. - (17v) Feria II. - Feria III. - Feria IIII. - (18r) Feria V. - Feria VI. - (18v) Sabbato. - Dominica III. - Feria II. - (19r) Feria III. - Feria IIII. Feria V. - (19v) Feria VI. - Sabbato. - Dominica in media Quadragesima. - (20r) Feria II. Feria III. - Feria IIII. - (20v) Feria V. - Feria VI. - (21r) Sabbato. - Dominica in passione. Feria II. - (21v) Feria III. - Feria IIII. - (22r) Feria V. - Feria VI. - Sabbato. - (22v) (Dnca in palmis fehlt) Feria secunda. - Feria III. - (23r) Feria IIII. - (Kartage fehlen) De resurrectione domini. - (23v) Dominica in octava pasche. - Dominica II. - Dominica III. - Dominica IIII. (24r) Dominica V. - De ascensione domini. - (24v) Dominica post ascensionem domini. - In sancto die pentecostes. - Dominica I. post pentecosten. - (25r) Dominica secunda. - Dominica III. - Dominica IIII. - Dominica V. - (25v) Dominica VI. - Dominica VII. - (26r) Dominica VIII. - Dominica VIIII. - Dominica X. - (26v) Dominica XI. - Dominica XII. - Dominica XIII. (27r) Dominica XIIII. - Dominica XV. - Feria IIII. IIII ${ }^{\text {or }}$ temporum. - (27v) Feria VI. - Sabbato. Ad missam. - (28r) Dominica XVI. - Dominica XVII. - Dominica XVIII. - (28v) Dominica XVIIII. - Dominica XX. - Dominica XXI. - (29r) Dominica XXII. - Dominica XXIII. - Dominica in adventu domini. - (29v) Dominica II. - Dominica III. - Feria IIII. - (30r) Feria VI. - Sabbato. (30v) Ad missam. - Proxima dominica ante nativitatem domini.

10.2 (30v-36r) Sanctorale und Missae votivae.

(30v) De sancta Margareta. - (31r) De sancto Matheo apostolo. - In dedicatione ecclesie. (31v) De sancta trinitate. - Feria II. de sapientia. - Feria III. de sancto spiritu. - (32r) Feria IIII. de angelis. - Feria V. de karitate. - Feria VI. de sancta cruce. - (32v) Sabbato de s. Maria. - De omnibus sanctis. - (33r) In basilica cuiuslibet sancti. - Pro papa vel episcopo. - (33v) Pro omni gradu ecclesie. - Pro peccatis. - Pro pluvia. - (34r) Pro serenitate. - Pro salute vivorum. - Pro tribulatione. - (34v) Pro amicis. - (35r) Pro iter agentibus. - Generalis. - (35v) Item generalis.

10.3 (36r-38v) Missae PRo DEFunCtis.

(36r) In depositione defuncti. - In anniversario. - (36v) Pro episcopo (bzw. darübergeschrieben: episcopis). - Pro sacerdote (darübergeschrieben: sacerdotibus). - Pro congregatione. - (37r) Pro uno defuncto. - Pro parentibus. - (37v) Pro femina. - Pro elemosinariis. - (38r) Pro in cimiterio. - Pro nuper defunctis. - (38v) Communis oratio.

11 (38v-47v) Lectionarium (Episteln und Evangelien). Temporale und Sanctorale gemischt. (38v) De nativitate domini [in die]. - (39v) Infra nativitatem domini de s. Maria. - (40v) De s. Vincentio. - (41r) De s. Mathia. - (41v) De annuntiatione s. Marie. - (42r) De resurrectione. (42v) De ascensione domini. - (43v) De die sancto Pentecostes. - (44r) De sancta Margareta. - 
(44v) De sancto Matheo apostolo. - (45r) In dedicatione ecclesię. - (45v) De sancta trinitate. Zwei Lesungen bzw. Evangelien. - (46v) De sancta cruce. - De sancta Maria. Mit zusätzlichem Evangelium Infra pascha (Io 19,25). - (47r) Pro peccatis. - Pro defunctis.

$(\mathrm{I} * \mathrm{r}-\mathrm{v})$ leer.

W. N.

\section{Cod. 155}

\section{SAMMELHANDSCHRIFT}

Pap. I, 164, I* Bl. $290 \times 205$. Umfeld Neustift (u. a. Pfalzen), 7. Jz. 15. Jh. (u. a. 1463).

B: $\quad$ Vereinzelte B1. stark fleckig, B1. 111 und 112 sowie gegen Ende Wasserschaden. Bilder und Nachweise der Wasserzeichen s. WZMA. Wasserzeichen mit Datierung übereinstimmend. Identische Wasserzeichen: u. a. Innsbruck, ULB Tirol, Cod. 773 (dat. 1464). Bl. 53-62 wohl Lage aus einer ca. 1425/30 angelegten Hs. (s. Wasserzeichenbefund). Lagen: (I-1) ${ }^{\mathrm{I}}$ (Vorsatzbl. 18. Jh.) $+\mathrm{VI}^{12}+(\mathrm{V}-5)^{17}+2 \cdot \mathrm{VI}^{41}+(\mathrm{V}+1-2)^{50}+(\mathrm{II}+\mathrm{V})^{64}+$ 3. $\mathrm{VI}^{100}+(\mathrm{VI}-1+1)^{112}+(\mathrm{VI}-2)^{122}+(\mathrm{VII}+2)^{138}+(\mathrm{V}-5)^{143}+(\mathrm{VI}-5)^{150}+\mathrm{VII}^{164}+(\mathrm{I}-1)^{\mathrm{I*}}($ Nachsatzbl. 18. Jh. $)$. Gegenbl. zum Vor- bzw. Nachsatzbl. als Spiegel auf dem VD bzw. HD aufgeklebt. Gegenbl. der gesamten zweiten Lage herausgeschnitten. Gegenbl. zu Bl. 43, 44, 106, 113 und 114 sowie zu Bl. 139-148 herausgeschnitten (jeweils ohne Textverlust). Bl. 42 Einzelbl., auf Bl. 43 aufgeklebt. Bl. 112, 137 und 138 eingehängte Einzelbl. Zw. Bl. 18 und 19, 84 und 85 sowie 105 und 106 jeweils ein kleines Einzelbl. eingefügt. Diese Blätter bei der Foliierung zwar berücksichtigt, doch Zahl des darauffolgenden Blattes wiederholt. Reste von alten Ledersignakeln sowie neuzeitlichen gelben Papiersignakeln der ULB Tirol.

S: $\quad$ Bl. 1ra-50ra: Schriftraum 240/265×155/160. Zwei Spalten, meist von Blindlinien, vereinzelt von feinen Tintenlinien gerahmt, zu 45-50 Zeilen auf Blindlinierung. Bastarda von einer Hand mit unterschiedlichem Duktus.

Bl. 51r-105v: Schriftraum 230/245×140/150, von Blindlinien (Bl. 53r-62v: von feinen Tintenlinien) gerahmt, zu 34-41, meist 37 Zeilen auf Blindlinierung. Bastarda von zwei Händen: 1) Bl. 51r-52r und 63r105v sowie eingehängtes Einzelbl. 106r-v mit breitem und rundem Duktus, dat. 1463 (Bl. 105r). Schreiber: Matheus Tegedener, vgl. Krämer, Scriptores; 2) Bl. 53r-62v.

Bl. 106ªra-122ra: Schriftraum 250/255×150/155. Zwei Spalten, von Blindlinien gerahmt, zu 47-50 Zeilen auf Blindlinierung. Bastarda.

Bl. 123r-140r: Schriftraum 240/255 × 145/155, von Blindlinien gerahmt, zu 47-56 Zeilen auf Blindlinierung. Bastarda mit engem und kleinem Duktus.

Bl. 141ra-150ra: Schriftraum 240/250 × 150/160. Zwei Spalten, von Blindlinien gerahmt, zu 46-53 Zeilen. Bastarda.

Bl. 151r-163v: Schriftraum 245/255×80/95, von Blindlinien gerahmt, zu 28-37 Zeilen. Gleichmäßige Bastarda. Bl. 151r-155v am rechten Textrand Kommentar von gleicher Hand.

A: Rote Auszeichnungsstriche, Paragraphzeichen, Unter- und Durchstreichungen, Rahmungen sowie tw. Randnotizen. Zwei- bis fünfzeilige rote Lombarden, z. T. mit Punktverdickungen. Rubrizierung tw. nur sehr spärlich. Bl. 48vb-50ra, 72v-100v, 101v-131r, 132r-134v Rubrizierung nicht ausgeführt (tw. Platz für Initialen und Paragraphzeichen freigelassen).

E: $\quad$ Neuzeitlicher Bibliothekseinband: schwarz gesprenkeltes braunes Pap. über Pappe. Neustift, 2. H. 18. Jh. Am VD und HD Ecken mit braunem Leder verstärkt. Rücken: braunes Leder, vier einfache Bünde, von Goldbordüren gesäumt. Im ersten Feld Golddruck M: S:, im zweiten Golddruck IUS CANON. in Goldrahmung, im dritten Signaturschild (s. bei G). Kapitale mit blauem und naturfarbenem Zwirn umstochen, freiliegend. Schnitt rot gesprenkelt. Spiegel und Vor- bzw. Nachsatzbl. Pap. 18. Jh. Am Spiegel des VD Exlibris, Signaturen und Bleistiftnotiz (s. bei G). Spiegel des HD leer.

G: $\quad$ Bl. 164v Besitzvermerk 15. Jh. Iste liber est monasterii sancte Marie vulgariter ad Novamcellam. Am Spiegel des VD Exlibris der Stiftsbibl. Neustift 18. Jh. 1809 anlässlich der vorübergehenden Aufhebung des Klosters Neustift der ULB Tirol übergeben. Am Spiegel des VD alte Signaturen der ULB Tirol II (Tinte) 2 K 3 (Bleistift), Nr. 155 (Tinte) sowie Bleistiftnotiz (Vide Grundzettel). Am Rücken gelbes Signaturschild der ULB Tirol 155. Bl. Ir Stempel der ULB Tirol 19. Jh. 1921 aufgrund des Friedensvertrages von St. Germain 
an den italienischen Staat abgegeben und von diesem 1929 dem Kloster Neustift als Dauerleihgabe überlassen. Bl. Ir Stempel der Soprintendenza Tridentina 20. Jh.

L: Wilhelm II 109. - Wretschko-Sprung 17. - H. Caplan, Mediaeval Artes praedicandi. A Hand-List und A Supplementary Hand-List (Cornell Studies in classical philology 24 und 25). Ithaca, N. Y. 1934 und 1936, Nr. 14. - Th.-M. Charland, Artes praedicandi. Contribution à l'histoire de la rhéthorique au moyen-âge (Publications de l'Institut d'études médiévales d'Ottawa 7). Paris, Ottawa 1936, 44. - Kristeller I 439. Dolezalek II o. S. - Colophons IV Nr. 13447. - Furtenbach-Kalb 21. - Neuhauser, Neustift 89. - S. Furtenbach, Ars notariatus. Ein kurialer Notariatstraktat des 15. Jahrhunderts. Österreichisches Archiv für Kirchenrecht 30 (1979) 3-22, 299-327. - Katalog ULB Tirol II 133, 205-206. - Katalog ULB Tirol II, Beiheft, Taf. 69. - Stefani 102-103. - Peintner, Stiftsbibliothek 122. - Krämer, Scriptores, s. v. „Tegedener, Matheus“.

$(\mathrm{Ir}-\mathrm{v})$ leer.

1 (1ra-6va) Franciscus de Zabarellis: De horis canonicis (Ed.: V. O. Ludwig, Ein neuaufgefundener Traktat Franz Zabarellas [Jahrbuch des Stiftes Klosterneuburg III]. Wien, Leipzig 1910, 151-178).

Inc.: Repetiturus decretalem [X.3.41.1.] presbyter que prima sub rubrica de ce[lebratione] missarum situatur et ponitur ... - Expl.: ... in c. Cum Marthe Ibi materia plenius terminatur scilicet de temp[ore] ordi[nis] et sic est finis.

Vgl. Schulte GQ II 283-285.

(6va) Direkt anschließend Schlussbemerkungen zum Traktat des Franciscus de Zabarellis (nicht in Edition enthalten): Sequitur prima conclusio. Quamvis beneficiatus per alias horas canonicas ... Item decretalem presbiter repetiit dominus Franciscus de Saberellis (am Blattrand korr.: Sarabellis) qui post ea fuit creatus in cardinalem et tunc fuit nominatus Florentius qui obiit in concilio Constantiensi.

2 (6va-15vb) SAmmLung KANONISTISCher Texte (Verweise u. a. auf Iohannes Calderinus, Raimundus de Pennaforte).

(6va) Inc.: Numquid Iudeus litigans cum Christiano iurabit de calumpnia super ewangelio videtur...

(6vb) Tit.: De adulterio et stupro. - Inc.: An maritus uxori adultere subtrahere possit debitum cohabitacionum et dotem sine iudicio ecclesie. Tua fraternitas hic tractantur iura an vir uxori adultere...

(7ra) Tit.: De pe[nitentia?] et re[missione?]. - Inc.: Tutela bona confessionis quando confitetur mulier se habere filium spurium inter legitimos. Officii mulier que partum supponit alienum vel de adulterio concepit ...

(7rb) Tit.: De uno filio inter multos alios legitimos. - Inc.: De quadam muliere dicebatur una vice casus supradictus fuisse...

(7va) Inc.: An reddituarii teneantur propriis sumptibus deferre dominis redditus et presertim ecclesiarum. Et videtur quod sic quia redditus ecclesie videntur esse dos ipsius ...

(7vb) Tit.: Casus diversi et periculosi in confessionem contingentes. - Inc.: Si uxor alicuius viri quia non potest prolem habere timens quod possessio viri ad alios devolveretur ...

(8rb) Inc.: Aliquis fuit testis in causa matrimoniali qui falsum protulit testimonium vel aliqua dixit de causa matrimoniali se scire que in veritate ignoravit ...

(8va) Inc.: Aliquis vovebat perpetuam continenciam postmodum non obstante voto ...

(8va) Inc.: Aliquis habens uxorem postmodum commisit cum filia uxoris sue adulterium ...

(8va) Inc.: Aliquis cognovit matrem et filiam vel duas sorores vel duas consaguineas mulieres ...

(8vb) Inc.: Aliquis contraxit sponsalia cum aliqua muliere et contracto matrimonio cognovit carnaliter mulierem sponse ante sponsam ...

(8vb) Inc.: Aliquis dicit confessori suo quod mulierem quam nunc habet duxit in uxorem in facie ecclesie ...

(9ra) Inc.: Aliquis segetem meam sevit tempore oportuno animo surripiendi sed nichil de ea asportavit ... 
(9ra) Inc.: Aliquis venit ad confessorem et dicit ei peccata sua et dicit se non posse abstinere a luxuria ...

(9ra) Inc.: Aliquis furiosus interfecit hominem postea factus sane mentis se hominem interfecisse confitetur ...

(9rb) Inc.: Aliquis confitetur aliquod crimen sacerdoti et episcopus excommunicat omnes huius criminis consocios ...

(9rb) Inc.: Aliquis est surdus et mutus vel ita eger quod non potest peccata sua confiteri sacerdoti ...

(9rb) Inc.: Aliquis peregrinus vel viator seu negociator vel mercator venit ad extraneum sacerdotem ...

(9rb) Inc.: Aliquis confitetur peccata sua sacerdoti et dicit quod non potest cessare ...

(9va) Inc.: Si quis revelet peccatum suum sacerdoti non ut peniteat sed ut consilium et auxilium ab eo recipiat...

(9va) Inc.: Aliquis in infirmitate petit sacerdotem et antequam ad eum venerit sacerdos ...

(9va) Inc.: Aliquis habetur pro prelato et in veritate non est prelatus audit confessiones parrochianorum illius parrochie ...

(9vb) Inc.: Mulier uxor alicuius confitetur sacerdoti se tenuisse filium proprium coram episcopo ...

(9vb) Inc.: Filius carnalis dicit confessori suo se duxisse in uxorem illam quam pater suus baptizaverit ...

(10ra) Inc.: Iohannes qui non est pater meus nec consanguineus duxit matrem meam in uxorem suam. Ipsa moritur postmodum ...

(10ra) Inc.: Est dubitacio de monialibus occulte corruptis quia in quibusdam monasteriis consuetudo est quod sole virgines...

(10rb) Tit.: De sacramento eukaristie. - Inc.: Nemo potest conficere corpus Christi nisi sacerdos qui rite fuerit ordinatus secundum claves ecclesie ...

(13ra) Tit.: De casibus diversis et periculosis in missa contingentibus. - Inc.: Presbiter potest supplere missam ab episcopo inchoatam si episcopus non poterit propter infirmitatem ...

(14rb) Inc.: Misse sunt celebrande in locis Deo consecratis vel in locis in quibus episcopus permiserit celebrare quia melius est missam non celebrare aut non audire ...

(14va) Inc.: Utrum habens confessionale a se[de] ap[ostolica] secundum formam consuetam possit sibi racione istius eligere in confessorem quemcumque sacerdotem non suspensum ...

(14vb) Inc.: Utrum racione confessionalis quod dari consuevit possit quis absolvi in casibus episcopalibus a quolibet sacerdote...

(14vb) Inc.: Utrum sacerdos in confessione eam absolvere posset cum qua peccavit fornicarie ... (15ra) Inc.: Quid agendum sit dum quis habeat aliqua peccata a quibus ille cui confiteatur non potest absolvere. Dicit beatus Tho[mas] ...

3 (15ra) Kanonistische Notiz zUR Eucharistie.

Tit.: Nota. - Inc.: I. Cor. XIIII (19) Sed eciam volo quinque verba sensu meo loqui ut et alios instruam ... Nota vir debet se abstinere ab uxore sua ante sacrum et communionem per III vel IIII vel VI dies...

$(15 v)$ leer.

4 (16ra-vb) 〈Ps.-Augustinus : Sermo 277: De reddendis decimis $=$ 〈CAESARIUS Arelatensis $\rangle$ : Sermo 33 (PL 39, 2266-2268. CC 103, 143-146. - CPL Nr. 284).

Tit.: Sermo de reddendis decimis. - Expl. (gegenüber PL und CC gekürzt): ... in illa sacrilega lavacione moriantur vel mortem corporis timeant qui de anime sue salute non curant.

5 (16vb-17va) KURZTRAKTAT ZU VERI UND FALSI PRAEDICATORES.

Inc.: Veri predicatores precipue quibus non sunt certe elemosine assignate libencius vadunt ad eos convertendos qui nondum ad fidem Christi conversi sunt quam ad illos qui iam conversi 
sunt ... - Expl.: ... ducit eos ad heresim non enim simplices sed studiosi ad here[sim] confluxerunt. Ty. (?) VI.

Darstellung der 50 Zeichen zur Identifikation von Ps.-Predigern ab B1. 17va übereinstimmend mit der Tabula de signis per quae pseudo-praedicatores discerni possunt a veris zu GuILELMUS DE SANCto Amore: Collationes catholicae et canonicae scripturae 4 (Druck: Opera omnia. Konstanz 1632, 487-490).

(17va-b) Unmittelbar anschließend Tabelle mit Auflistung Der verschiedenen OrdensGemeinSCHAFTEN.

Tit.: Ffratres mendicantes et cappam habentes et quasi omnes regulas eorum deserentes. - Inc.: Ordo fratrum Predicatorum. Ordo fratrum Minorum ... - Expl.: ... Ordo Celestinorum. In via Dei alius sic alius sic ibat sed utrum hec predicta debite fuerit et plene dubitatur a quam pluribus. Gliederung nach: Monachi. - Regulares canonici. - Ffratres degentes sub regula.

6 (18ra-45rb) BegrifFSERKLÄRungen zu den Canones. Innerhalb eines Buchstabens alphabetische Anordnung, Alphabet jedoch nicht konsequent eingehalten. Wohl Kompilation aus mehreren Rechtslexika.

(18ra) Prolog. Inc.: In nomine domini Amen. Quia in libris sacrorum Canonum et in legibus imperialibus plerumque restat difficultas vocabulorum ... - Expl.: ... per superius dictum quia omnium habere memoriam etc.

(18ra) Vocabularius. Text. Inc.: Abigeus dicitur ille qui pecora alicuius a pascuis et armentis subducit ... Abolicio est ab accusando cessacio ... - Expl.: ... Zenodochius dicitur qui zenonem alicuius civitatis procurat ... Zenodochium dicitur locus hospitum vel domus peregrinantibus ... de sanctissimis episcopis coll. IX post principium etc.

Lit.: E. Seckel, Beiträge zur Geschichte beider Rechte im Mittelalter I. Tübingen 1898, 323-335, Teiledition 358-365.

Parallelüberlieferung: u. a. München, BSB, Clm 3563, Bl. 246r.

7 (45va-48ra) Termini librorum I-V Decretalium.

Tit.: Exposiciones terminorum I li. Decretalium. - Inc.: Constitucio est ius relatum in scriptis redactum. Vel aliter est ius ubi non sequitur pena. Sed sanxio est ius ubi sequitur pena. Consultacio est in qua ... - Expl.: ... Celebracio missarum est cum missa propter vivos et mortuos cantetur. Regula dicitur virga ... est multorum constructibilium colleccio.

(45va) Lib. 1. - (46ra) Lib. 2. - (46va) Lib. 3. - (47ra) Lib. 4. - (47rb) Lib. 5.

Parallelüberlieferung: u. a. Melk, Stiftsbibl., Cod. 1894, Bl. 181r.

8 (48ra-49va) Glossar, Verzeichnis verschiedener Autoren juristischer Werke, Abkürzungsverzeichnis.

(48ra) De nominibus doctorum et primo quoad doctores sacre theologie qualiter iuvenes debent legere.

(48va) Doctores qui super decreto scripserunt sunt hii.

(48va) Hii doctores scripserunt ad Decretales.

(48vb) Abkürzungsverzeichnis in alphabetischer Reihenfolge.

9 (49vb-50ra) ARgumenta QUiBus VALET ARGUERE IN CANONICO IURE.

Tit.: Nota argumenta quibus valet arguere in canonico iure. - Inc.: Primo reprobatur superfluitas quia superflua sunt resecanda ab arte id est a iure canonico ... - Expl.. ... de pactis pactus. Quod semel est dictum manet irrevocabile verbum de proba per tuas.

Tit. und Inc. wie Augsburg, UB, Cod. II.1.4 21, Bl. 146v.

(50rb-vb) leer. 
10 (51ra-105r) Iohannes de Auerbach: Processus iudiciarius (Ed. Th. Muther. Halae 1873, 3-322). Schlussschrift mit Datierung und Schreibernennung: Terminatus est hic iudiciarius processus Hinrici Aurbach decretorum doctoris per Matheum Tegedener de Iuterbock presbiterum Brandeburgensis diocesis. In domo et habitacione reverendi patris Leonardi plebani in Phalczen (gestrichen: anno) Briccinensis diocesis anno domini MCCCCLXIII in octava corporis Cristi (16. Juni 1463). Lit.: Schulte GQ II 301-302; H. Boockmann, Aus den Handakten des Kanonisten Johannes Urbach (Auerbach). Deutsches Archiv für Erforschung des Mittelalters 28 (1972) 497-532.

11 (105v-106v) Declaratio arboris consanguinitatis (vgl. CiC, ed. Friedberg I 1429-1430). (105v) § 16-17 In linea equali colleteralium (!) quoto gradu quis distat a communi stipite toto distant inter se ...

(106r) Inc.: Aut fratres sunt ex utroque coniuncti aut non. Si ex utroque coniuncti et tunc aut soli fratres extant ... - Expl.: ... autem de here[ditate] ab intestato.

(106v) Inc.: Nota. Detur quid tunc si superest filius fratris ex uno parente coniuncti ... - Expl.: ... filiis fratris utriusque coniunctis. Idem est eciam dicendum de nepotibus.

12 (106ara-112v) Exzerpte aus «Bernardus Parmensis»: Casus longi Decretalium (Druck: GW 4092-4105).

(106 ${ }^{\mathrm{a} a}$ ) Prolog. Tit.: Prologus. - Inc.: [R]ex pacificus premissa salutacione sic pone casum in ista constitucione. Rex pacificus id est dominus noster Ihesus Christus ... - Expl.. ... sine licencia sedis apostolice speciali.

(106 ra) Text. Tit.: De summa trinitate et fide katholica firmiter credimus. - Inc.: Nota quod post simbolum apostolorum quod dicitur Credo in Deum concilia predicta fuerunt olym a sanctis patribus de summa trinitate et fide katholica contra quosdam hereticos de quibus quattuor conciliis legitur ... - Expl.: ... inferiores prelati sine diocesani consensu in ecclesiis suis non possint instituere clericos peregrinos.

(113r-114v) leer.

13 (115ra-118ra) Ars notariatus (Druck: u.a. GW 2648. Ed. Furtenbach 308-327).

Lit.: R. Stintzing, Geschichte der populären Literatur römisch-katholischen Rechts. Leipzig 1867, 297-299; L. v. Rockinger, Ueber Formelbücher vom dreizehnten bis zum sechzehnten Jahrhundert als rechtsgeschichtliche Quellen. München 1855, 66 Anm. 132; Kristeller I 439; Dolezalek II o. S.; Furtenbach 3-22, 299-327.

14 (118rb-122ra) 〈Ps.-Iohannes Andreat»: Ordo iudiciarius (Druck: u.a. GW M47346. Ed.: O. Riedner, Die geistlichen Gerichtshöfe zu Speier im Mittelalter II. Paderborn 1915, 5-48. Hamesse Nr. 3001-3002).

Anschließend (121vb): Iura hic non allegantur sed pocius obmittantur non propter ignoranciam doctorum sed propter imbecillitatem discencium ad quorum profectum hec summula conscripta est ... sed perfectum illorum quos informat.

Lit.: Schulte GQ II 225-226. Vgl. auch R. Stintzing, Geschichte der populären Literatur des römisch-kanonischen Rechts. Leipzig 1867, 202-220.

Zur Verfasserfrage s. L. v. Rockinger, Über einen ordo iudiciarius, bisher dem Johannes Andreae zugeschrieben. München 1855; L. Fowler-Magerl, Ordines iudiciarii and libelli de ordine iudiciorum (Typologie des sources de moyen âge occidental 63). Turnhout 1994, 98.

Anschließend (122ra): Inc.: Est discrecio testantisque suprema voluntas accio ... - Expl.: ... favor odia dolus. (122rb-vb) leer.

15 (123r-138r) 〈Ps.->Albertus Magnus: Secreta mulierum, mit Kommentar (Druck: GW 719759a. - Thorndike-Kibre 635). Verglichen mit GW 724, leicht abweichend. 
(123r) Kommentarprolog. Inc.: [H]omo est optimum eorum que sunt in mundo IIII Ethicorum et mundus ... - Expl.: ... et non pure naturalis sed partim medicinalis et partim naturalis.

(123r-138r) Text. Tit.: Titulus: Incipit Secreta mulierum et virorum ab Alberto Magno composita. - Inc.: [D]ilecto sibi in Christo socio et amico N. clerico de tali loco vere sapiencie et augmentum continuum vite presentis. Iste liber cuius subiectum est ens mobile contractum ad naturam secretorum mulierum ... - Expl.: ... Hiis visis dictis finem imponamus ... per infinita secula seculorum Amen.

(138r) Unmittelbar anschließend. Inc.: Nota. Coitus maxime exsiccat quia per ipsum recedit magna humiditas ... - Expl.: ... longitudo et breviacio vite in hominibus est a natura et eius constellacione et illud eciam maxime habet variari etc.

$(138 \mathrm{v})$ leer.

Lit.: L. Thorndike, A History of Magic and Experimental Science II. London 1923, 739-745, 749-750; M. Schleissner, „Secreta mulierum“. Verfasserlexikon² VIII 986-993.

16 (139r-140r) ARs PRAEDICANDi (Caplan Nr. 14. Charland 44 mit Zuschreibung an Henricus de Langenstein, vgl. Caplan 7. Th. Hohmann, Initienregister der Werke Heinrichs von Langenstein. Traditio 32 (1976) 399-426, hier Nr. 16*).

Inc.: Ars predicandi est sciencia docens de aliquovis termino vel ente aliquid dicere ... - Expl.: ... Vicia sermocionantis (!) Ignorancia predicantis Infacundia ... Digressio remota Applicacio defectuosa.

$(140 v)$ leer.

17 (141r-143v) 〈Iohannes Marchesinus»: Super Psalterio, aus: Mammotrectus super Bibliam (Druck: GW M20819. - Stegmüller RB Nr. 4776). Gegenüber Druck tw. stark gekürzt.

Inc.: Beatus vir. Pestilencie contagie (!) quod dum unum apprehendit celeriter transit ad plures quia velut incendium ... Domine quid multiplicati. Soporatus id est sopitus ... Verba mea. Patens id est apertum decidant id est cadant ... Domine ne in furore. Stratum id est lectum ... Domine Deus meus. Decidam id est cadam ... - Expl.: ... Laudate dominum de celis. ... Id est in metallis permixtis acutum sonum facientibus.

18 (144ra-150ra) Auctoritates PHILOSOPHORum.

Tit.: Auctoritates philosophorum. - Inc.: Tales dicit [A]ntiquissimum encium est Deus ingenitum et in evum. Optimum encium mundus nam opus Dei ... Solon dicit Quid est verbum Imago operum quo firmatur verbum ... Pitacus dicit Optimas esse victorias que sine sanguinis effusione fiant. Item prudentium virorum esse priusquam fiant difficilia ... - Expl.: ... Secundus philosophus dicit Athenis claruit tempore Adriani imperatoris qui philosophatus est omni tempore silentium habere ... fortuna sine sollicitudine felicitas etc. Explicit materia philosophorum sed non omnium.

Thales - Solon - Chilo - Pittacus - Bias - Cleobolus - Periander - Pythagoras - Simonides Isocrates - Crispus - Socrates - Democritus - Hippocrates - Heraclitus - Diogenes - Plato Aristoteles - Epicurus - Theophrastus - Hecaton - Cicero - Cato - Plautus - Iulius Caesar Terentius - Varro - Existus Xistus (Sixtus?) - Athenodorus - Valerius - Quintilianus Plinius - Ptolomaeus - Galenus - Symachus patricius - Secundus philosophus.

Dasselbe Inc. sowie ähnliche Auswahl an Autoren in St. Gallen, Stiftsbibl., Cod. 482, Bl. 362r. Vgl. tw. Diogenes Laertius, De vita et moribus philosophorum libri decem. Coloniae Agrippinae 1535.

(150rb-vb) leer.

19 (151r-155r) Theobaldus: Physiologus cum commento (Ed.: P. T. Eden, Theobaldi „Physiologus“ [Mittellateinische Studien und Texte 6]. Leiden, Köln 1972, 24-72. - Thorndike-Kibre 1584). 
Kommentar, vorwiegend rechts des Textes. Inc.: Iste liber Phisiologus intitulatur et dicitur a physis id est natura ... - Expl.: ... Allegoria secunda pili elephantis id est doctrina Christi que si incenduntur in aliqua domo id est homine recedunt omnia animalia venenosa.

20 (155v-163v) Avianus: Fabeln (Nr. 1-28). Mit Kommentar (nur Bl. 155v) (Druck: GW 3110. Ed. K. Lachmann. Berolini 1845). Kommentar nicht im Druck enthalten.

Inc.: [R] ustica deflenti puero iuraverat olym / Ni taceat rapido quod foret esca lupo ... - Expl.. ... Qua fieri posset cum racione nocens/Vix castigator cui semita recta negatur/Que mala mens didicit perdere vix poterit.

Kommentar (zu Fabeln Nr. 1 und 2). Inc.: Liber Aviani poete in quo primo introducit fabulam de villana et lupo ostendens in eo quod fraudulenti mulieri non est fides ... - Expl.: ... dabitur et incurrit periculum.

$(164 \mathrm{r}-\mathrm{v})$ leer.

$\left(\mathrm{I}^{*} \mathrm{r}-\mathrm{v}\right)$ leer.

P. A./A. P.

\section{Cod. 156}

\section{HUGO DE SANCTO CARO}

Perg. I, 88, I* Bl. $290 \times 210$. Nordfrankreich (Raum Paris), um 1300 .

B: $\quad$ Perg. unregelmäßig beschnitten, bes. am Beginn stark verschmutzt, tw. löchrig, Nahtspuren. Lagen: (I-1) ${ }^{\mathrm{I}}$ (Vorsatzbl., Pap. 18. Jh.) $+4 . \mathrm{V}^{40}+2 . \mathrm{IV}^{56}+2 . \mathrm{VI}^{80}+\mathrm{IV}^{88}+(\mathrm{I}-1)^{\mathrm{I}^{*}}$ (Nachsatzbl., Pap. 18. Jh.). Gegenbl. zum Vor- bzw. Nachsatzbl. als Spiegel auf dem VD bzw. HD aufgeklebt. Nach Bl. 88 fehlt mindestens eine Lage. Am Lagenanfang Kustoden in arabischen Ziffern, am Lagenende in roten bzw. schwarzen römischen Zahlen. Am oberen rechten Blattrand spätmittelalterliche Foliierung in arabischen Ziffern.

S: $\quad$ Schriftraum 200/205×135/140, von seitlich zweifachen Tintenlinien gerahmt, zu 46 (Bl. 1ra-10vb) bzw. 40 Zeilen (Bl. 11ra-88vb) auf Tintenlinierung. Bl. 1r-20v am äußeren Blattrand dritte gerahmte Spalte, tw. liniert. Zirkelstiche. Littera Parisiensis um 1300. Notizen, Nachträge, Auctoritatesangaben, gerahmte Inhaltshinweise von verschiedenen Händen.

A: $\quad$ Rote Auszeichnungsstriche, Durchstreichungen, Überschriften, Rahmungen, Notizen, zweizeilige (Bl. 1ra und 2rb dreizeilige) Lombarden mit kopfstempelförmiger Aussparung und einfachem Dekor. Repräsentanten.

E: $\quad$ Neuzeitlicher Bibliothekseinband: schwarz gesprenkeltes braunes Pap. über Pappe. Neustift, 2. H. 18. Jh. Am VD und HD Ecken mit braunem Leder verstärkt. Rücken: braunes Leder, vier einfache Bünde, von Goldbordüren gesäumt. Im ersten Feld Golddruck M: S:, im zweiten Feld Golddruck HUGO IN PROVER. in Goldrahmung, im dritten Signaturschild (s. bei G). Spiegel Pap. 18. Jh. Am Spiegel des VD Exlibris, Signaturen, Bleistiftnotiz (s. bei G). Spiegel des HD leer.

G: Zeitpunkt und Art der Erwerbung durch Neustift unbekannt. Am Spiegel des VD Exlibris der Stiftsbibl. Neustift 18. Jh. 1809 anlässlich der vorübergehenden Aufhebung des Klosters Neustift der ULB Tirol übergeben. Am Spiegel des VD alte Signaturen der ULB Tirol II 2 H 4 (Tinte, Bleistift), Nr. 156 (Tinte) sowie Bleistiftnotiz (Vide Grundzettel). Am Rücken gelbes Signaturschild der ULB Tirol 156. Bl. 1r Stempel der ULB Tirol 19. Jh. 1921 aufgrund des Friedensvertrages von St. Germain an den italienischen Staat abgegeben und von diesem 1929 dem Kloster Neustift als Dauerleihgabe überlassen. Bl. 1r Stempel der Soprintendenza Tridentina 20. Jh.

L: $\quad$ Kaeppeli Nr. 1989. - Stegmüller RB Nr. 3677 Suppl. - Steer 36. - Katalog ULB Tirol II 133, 206.

$(\mathrm{Ir}-\mathrm{v})$ leer.

$(1 \mathrm{r}-88 \mathrm{v})$ Hugo de SAncto CARo = 〈Ps.-Nicolaus de Gorran $\rangle$ : Postilla in Proverbia, unvollständig: cap. 1-25 (Druck: Opera omnia III. Venetiis 1754. - Stegmüller RB Nr. 3677 und Nr. 3677 Suppl., mit Nennung der Hs. - Kaeppeli Nr. 1989, mit Nennung der Hs.). 
Tit.: Incipiunt notule compilate a magistro Hugone fratre ordinis Predicatorum super Proverbia. - Inc.: Dicit Ecclesiasticus XXX IX b (!) occulta Proverbiorum exquirit sapiens et in absconditis parabolarum ... - Expl. mut. (cap. 25): ... invito auditore libenter refert ut dicit Ieronimus. Et ubi (!) ne esset auditor ne esset detractor. Unde super XXIIII [

$\left(\mathrm{I}^{*} \mathrm{r}-\mathrm{v}\right)$ leer.

P. K.

\section{Cod. 158}

\section{AUGUSTINUS}

Pap. III, 69, I* Bl. $285 \times 205$. Süddeutscher Raum, um 1400 .

B: Bilder und Nachweise der Wasserzeichen s. WZMA. Datierung nach Wasserzeichenbefund. Identische Wasserzeichen: Neustift, Stiftsbibl., Cod. 83 (dat. 1400) und Cod. 183. Lagen: (I-1)I (Vorsatzbl. 18. Jh.) + $(\mathrm{VI}+1)^{\mathrm{III}, 11}+2 \cdot \mathrm{VI}^{35}+\mathrm{V}^{45}+2 \cdot \mathrm{VI}^{69}+(\mathrm{I}-1)^{\mathrm{I}^{*}}$ (Nachsatzbl. 18. Jh.). Gegenbl. zum Vor- bzw. Nachsatzbl. als Spiegel auf dem VD bzw. HD aufgeklebt. Bl. II eingefügtes Einzelbl., an Bl. III angeklebt. Am Lagenende Kustoden in arabischen Ziffern. Ab Textbeginn am oberen Blattrand Foliierung 15. Jh. 1-69, Hinweis auf ehem. Sammelhandschrift (s. bei G).

S: $\quad$ Schriftraum 220/225×150. Zwei Spalten, von Tintenlinien gerahmt, zu 54-57 Zeilen. Bastarda (= Cod. 83, Schreiber 1).

A: Rote Auszeichnungsstriche, Unterstreichungen, Über- und Schlussschriften. Flüchtige Zeigehände. Fünfbis siebenzeilige rote bzw. rot-schwarz kopfstempelförmig gespaltene Lombarden, tw. mit Punktverdickungen und Ausläufern.

E: $\quad$ Neuzeitlicher Bibliothekseinband: schwarz gesprenkeltes braunes Pap. über Pappe. Neustift, 2. H. 18. Jh. Am VD und HD Ecken mit braunem Leder verstärkt. Rücken: braunes Leder, vier einfache Bünde, von Goldbordüren gesäumt. Im zweiten Feld Golddruck M. S. CONFE. S. AUGU. in Goldrahmung, im dritten Signaturschild (s. bei G). Schnitt rot gesprenkelt. Spiegel Pap. 18. Jh. Am Spiegel des VD Signaturen und Bleistiftnotiz (s. bei G), Spiegel des HD leer.

G: Bl. IIr zwei Besitzvermerke 15. Jh. Iste liber est monasterii s. Marie ad gracias alias ad Novamcellam dicti und Novacelle sowie Neustifter Wappen in Federzeichnung.

Nach dem Inhaltsverzeichnis in dieser Hs. auf B1. Ir gehört Cod. 158 zu einer Gruppe von urspr. tw. selbständigen Hs. des 14. und 15. Jh., die im 15. Jh. in Neustift zu einem Sammelband vereinigt wurden (s. auch Foliierung). Im Zuge der Neuaufstellung der Neustifter Bibliothek in der 2. H. 18. Jh. wurde die Sammelhandschrift (wie dies auch bei anderen Handschriften und Inkunabeln gemacht wurde) in sieben Einzelhandschriften aufgelöst; jeder Einzelband erhielt den für Neustift typischen Halbledereinband. Zur urspr. Hs. zählen folgende Signaturen (in der urspr. Reihenfolge):

Cod. 158: Augustinus. Foliierung 15. Jh. 1-69.

Cod. 83: Theologische Sammelhandschrift, dat. 1400. Foliierung 15. Jh. 70-128.

Cod. 82: Henricus de Langenstein: De contractibus. De contemptu mundi. Foliierung 15. Jh. 129-165.

Cod. 183: Heinrich Seuse: Horologium sapientiae. Foliierung 15. Jh. 166-203.

Cod. 161: Iohannes de Dambach. Origenes. Foliierung 15. Jh. 204-215.

Cod. 182: Ps.-Eusebius, dat. 1400. Foliierung 15. Jh. 216-231.

Cod. 162: Sermones de dedicatione. Foliierung 15. Jh. 232-241.

Von diesen sieben Hs. befindet sich heute eine an der ULB Tirol in Innsbruck (Cod. 82), die restlichen sechs werden hingegen in der Stiftsbibl. Neustift aufbewahrt.

Bl. IIIr Besitzvermerk 18. Jh. Collegii Neocell. 1809 anlässlich der vorübergehenden Aufhebung des Klosters Neustift der ULB Tirol übergeben. Am Spiegel des VD alte Signaturen der ULB Tirol II (Tinte) 2 H 6 (Bleistift) und Nr. 158 (Tinte) sowie Bleistiftnotiz (Vide Grundzettel). Am Rücken gelbes Signaturschild der ULB Tirol 158. Bl. IIr Stempel der ULB Tirol 19. Jh. 1921 aufgrund des Friedensvertrages von St. Germain an den italienischen Staat abgegeben und von diesem 1929 dem Kloster Neustift als Dauerleihgabe überlassen. Bl. IIr Stempel der Soprintendenza Tridentina 20. Jh.

L: $\quad$ Katalog ULB Tirol II 133, 206. - Peintner, Stiftsbibliothek 121. 
(Ir-v) leer.

(IIr) Besitzvermerke und Stempel (s. bei G). Federproben u. a.:

1) Raymundus. Interpretacio huius nominis phaf ponit. p pater h honoris a altissimi f filius.

2) Interpretatio huius tituli (?) monachus. (tw. gestrichen:) M manducans o omnia n nichil a amans $c$ culum h habens u vulvam s supponens (?).

3) 〈Serlon de Wilton`: Versus (Walther, Initia Nr. 10349. J. Öberg, Poèmes latins [Acta Universitatis Stockholmiensis. Studia Latina Stockholmiensia 14]. Stockholm 1965, 121, Nr. 78).

Tit.: Nota si vis. - Text (Hexameter): Linquo coax ranis cra corvis vanaque vanis / ad loycam (!) pergo que mortis non timet ergo. - Hec ille.

Inhaltsverzeichnis des Sammelbandes mit Blattangabe. Tit.: Contenta in hoc libro hic signata.

Libri tredecim Confessionum beati Augustini episcopi 1. - Quatuor libri Dyalogorum beati Gregorii pape 77. - Tractatus De contractibus m. Heinrici de Hassia in sudore wltus tui 130. - Epistola eiusdem de ymagine mundi et eius contemptu venerando domino 160. - Speculum peccatoris. Quoniam karissimi etc. 122 (!). - Horologium sapiencie. Sentite de domino in bonitate 166. - Tractatus de indulgenciis. Cum non paucorum 204. - Omelia Origenis super ewangelio. Maria stabat ad monumentum 209. Epistola Eusebii de abitu beati Ieronimi presbiteri. Patri reverendissimo 216. - Sermones quidam de dedicacione ecclesie primus venit enim filius hominis 232.

(IIv) leer.

(IIIra) Federprobe: Beginn von Augustinus, Confessiones, Lib. 1 (PL 32, 659-661, leicht abweichend): [M]agnus dominus et laudabilis nimis. [M]agnus dominus et laudabilis nimis. Magna virtus tua ...

(IIIrb) Tit.: Tredecim libri Confessionum sancti Augustini beatissimi patris nostri ad proficiendum utilissimi.

(IIIv) leer.

(1ra-60ra) Augustinus: Confessiones (PL 32, 659-868. CSEL 33, 1-388. - CPL Nr. 251).

(1ra) Lib. 1. - (4va) Lib. 2. - (7va) Lib. 3. - (9rb) Lib. 4. - (12vb) Lib. 5. - (16ra) Lib. 6. - (20rb) Lib. 7. - (24va) Lib. 8. - (28vb) Lib. 9. Bl. 33v leer mit Vermerk Hic nullus est defectus. Ohne Textverlust. (34ra) Lib. 10. - (43ra) Lib. 11. - (48rb) Lib. 12. - (53va) Lib. 13.

(60ra) Schlussschrift: Deo gracias Amen. Explicit liber Confessionum beati Augustini primo anno etc. (60rb-69vb) nur Rahmung und Foliierung.

$\left(\mathrm{I}^{*} \mathrm{r}-\mathrm{v}\right)$ leer.

U.S.

\section{Cod. 160}

\section{LAURENTIUS RUSIUS}

Pap. I, 55, I* Bl. $290 \times 210$. Süddeutscher Raum, Mitte 15. Jh.

B: $\quad$ Bilder und Nachweise der Wasserzeichen s. WZMA. Datierung nach Wasserzeichenbefund. Identische Wasserzeichen: u. a. Innsbruck, ULB Tirol, Cod. 624, T. II (dat. 1449). Lagen: (I-1) (Vorsatzbl., Pap. 18. Jh.) + $(\mathrm{VI}+1)^{13}+3 . \mathrm{VI}^{49}+6^{55}+(\mathrm{I}-1)^{\mathrm{I}^{*}}$ (Nachsatzbl., Pap. 18. Jh.). Gegenbl. zum Vor- bzw. Nachsatzbl. als Spiegel auf dem VD bzw. HD aufgeklebt. Bl. 12 sowie 50-55 eingehängte Einzelbl. Am oberen Blattrand Foliierung 19. Jh. durch die ULB Tirol.

S: $\quad$ Schriftraum $225 \times 145$, von Tintenlinien begrenzt, zu 34-38 Zeilen (Bl. 2ra-4rb auf Tintenlinierung). Bastarda.

A: Rote Auszeichnungsstriche, Paragraphzeichen, Unterstreichungen, Kapitelnennung im Register und Überschriften. Zweizeilige (Bl. 4ra vierzeilige) rote Lombarden, tw. mit Punktverdickungen, tw. mit einfachen Fadenausläufern. Bl. 1r zehn Einzelzeichnungen in Schwarz (monogrammartig) auf Blindlinierung, wohl von einer Hand. 
E: $\quad$ Neuzeitlicher Bibliothekseinband: schwarz gesprenkeltes braunes Pap. über Pappe. Neustift, 2. H. 18. Jh. Am VD und HD Ecken mit braunem Leder verstärkt. Rücken: braunes Leder, vier einfache Bünde, von Goldbordüren gesäumt. Im ersten Feld Golddruck M: S:, im zweiten bis vierten Feld Golddruck RUZZI MARESCHALCIA EQUORUM in Goldrahmung, im fünften Signaturschild (s. bei G). Schnitt rot gesprenkelt. Spiegel Pap. 18. Jh. Am Spiegel des VD Exlibris, Signaturen und Bleistiftnotiz (s. bei G), Spiegel des HD leer.

G: Zeitpunkt und Art der Erwerbung durch Neustift unbekannt. Am Spiegel des VD Exlibris der Stiftsbibl. Neustift 18. Jh. 1809 anlässlich der vorübergehenden Aufhebung des Klosters Neustift der ULB Tirol übergeben. Am Spiegel des VD alte Signaturen der ULB Tirol II 2 H 8 (Tinte, Bleistift), Nr. 160 (Tinte) sowie Bleistiftnotiz (Vide Grundzettel). Am Rücken gelbes Signaturschild der ULB Tirol 160. Bl. 1r Stempel der ULB Tirol 19. Jh. 1921 aufgrund des Friedensvertrages von St. Germain an den italienischen Staat abgegeben und von diesem 1929 dem Kloster Neustift als Dauerleihgabe überlassen. Bl. 1r Stempel der Soprintendenza Tridentina 20. Jh.

L: $\quad$ Kristeller VI 122. - Katalog ULB Tirol II 133, 206. - Peintner, Stiftsbibliothek 122.

(Ir-v) leer.

1 (1r) Zehn ZeICHNUNGEN in Schwarz (s. bei A).

2 (1r) Rezepte zur Heilung von Pferdekrankheiten.

Contra debilitatem oculorum equorum et macularum ...

Contra debilitatem capitis naturalem ...

Contra inflacionem colli equorum ...

Contra vermes in intestivis equorum ...

Quando equus patitur in pedibus defectum ...

Rappigen rossen. Quando equus patitur fissuras contra ungulam wlgariter in den fisselen ... Quando dorsum equi leditur per sellam ...

Contra scabiem equorum ...

(1v) leer.

3 (2ra-55va) Laurentius Rusius: Marescalcia (Druck: GW M39220. - Thorndike-Kibre 766. L. Schnier, Die Pferdeheilkunde des Laurentius Rusius, Diss. Berlin 1937. W. Perino, Die Pferdearzneibücher des ausgehenden Mittelalters und der beginnenden Neuzeit, Diss. München 1957, 12-14).

(2ra) Register. Tit.: Incipit tabula sive registrum.

(3vb) leer.

(4ra) Prolog. Tit.: Epistola sive prohemium. - Inc.: Reverendo in Christo patri et domino suo domino N. Dei gracia sancti Adriani dyaconi cardinalis Laurentius dictus Kytius (!) mereschaltus (!) de Urbe ... Inter cetera animalia que ad dignitatis humane solacium ...

(4rb) Text. Tit.: De natura equi. Rubrica. $2^{m}$. - Inc.: Equs (!) calide nature iudicatur sed temperate calor ostenditur per levitatem ... - Expl.. ... et mitte eum ad modum suppositorii in equi sexum aut anum. Et sic est finis Deo gratias.

(55va) Schlussschrift: Explicit liber mareschalcie equorum compositus (gestrichen: per Paulum $K$. de Monaco et sic est finis) per Laurencium dictum Ruzzum de Urbie mareschalcum et familiarem reverendi patris et domini Neapoleonis de Ursinis sancti Adriani diaconi cardinalis.

(55vb) leer.

$\left(I^{*} \mathrm{r}-\mathrm{v}\right)$ leer.

C. S. 


\title{
Cod. 161
}

\section{IOHANNES DE DAMBACH. ORIGENES. EXPOSITIO ORATIONIS DOMINICAE}

\author{
Pap. I, 12, I* Bl. $285 \times 205$. Süddeutscher Raum, Ende 14. Jh.
}

B: $\quad$ Bilder und Nachweise der Wasserzeichen s. WZMA. Datierung nach Wasserzeichenbefund. Identische Wasserzeichen: u. a. Innsbruck, ULB Tirol, Cod. 608, T. II. Lagen: (I-1) ${ }^{\mathrm{I}}$ (Vorsatzbl. 18. Jh.) $+\mathrm{VI}^{12}+(\mathrm{I}-1)^{\mathrm{I*}}$ (Nachsatzbl. 18. Jh.). Gegenbl. zum Vor- bzw. Nachsatzbl. als Spiegel auf dem VD bzw. HD aufgeklebt. Erstes und letztes Blatt des Sexternio jeweils am Vor- bzw. Nachsatzbl. angeklebt. Am oberen Blattrand Foliierung 15. Jh. 204-215, Hinweis auf ehem. Sammelhandschrift (s. bei G). Daneben Foliierung 19. Jh. durch die ULB Tirol 1-12 (hier berücksichtigt).

S: $\quad$ Schriftraum $225 \times 150 / 155$. Zwei Spalten, von Tintenlinien gerahmt, zu 43-52 Zeilen. Bastarda.

A: $\quad$ Bl. 1ra-8rb rote Auszeichnungsstriche und Unterstreichungen sowie zwei- und dreizeilige rote Lombarden. B1. 6ra rot-tintenfarbener I-Versal mit kopfstempelförmiger Aussparung, Punktverdickung und Ausläufern. Ab Bl. 8va Rubrizierung nicht ausgeführt.

E: $\quad$ Neuzeitlicher Bibliothekseinband: schwarz gesprenkeltes braunes Pap. über Pappe. Neustift, 2. H. 18. Jh. Am VD und HD Ecken mit braunem Leder verstärkt. Rücken: braunes Leder, vier einfache Bünde, von Goldbordüren gesäumt. Im zweiten Feld Golddruck M. S., im dritten Signaturschild (s. bei G). Schnitt rot gesprenkelt. Spiegel Pap. 18. Jh. Am Spiegel des VD Signaturen und Bleistiftnotiz (s. bei G), Spiegel des HD leer.

G: $\quad$ Nach dem Inhaltsverzeichnis in Neustift, Stiftsbibl., Cod. 158, Bl. Ir gehört Cod. 161 zu einer Gruppe von urspr. tw. selbständigen Hs. des 14. und 15. Jh., die im 15. Jh. in Neustift zu einem Sammelband vereinigt wurden (s. auch Foliierung). Im Zuge der Neuaufstellung der Neustifter Bibliothek in der 2. H. 18. Jh. wurde die Sammelhandschrift (wie dies auch bei anderen Hs. und Inkunabeln gemacht wurde) in sieben Einzelhandschriften aufgelöst; jeder Einzelband erhielt den für Neustift typischen Halbledereinband. Zur urspr. Hs. zählen folgende Signaturen (in der urspr. Reihenfolge):

Cod. 158: Augustinus. Foliierung 15. Jh. 1-69.

Cod. 83: Theologische Sammelhandschrift, dat. 1400. Foliierung 15. Jh. 70-128.

Cod. 82: Henricus de Langenstein: De contractibus. De contemptu mundi. Foliierung 15. Jh. 129-165.

Cod. 183: Heinrich Seuse: Horologium sapientiae. Foliierung 15. Jh. 166-203.

Cod. 161: Iohannes de Dambach. Origenes. Foliierung 15. Jh. 204-215.

Cod. 182: Ps.-Eusebius, dat. 1400. Foliierung 15. Jh. 216-231.

Cod. 162: Sermones de dedicatione. Foliierung 15. Jh. 232-241.

Von diesen sieben Hs. befindet sich heute eine an der ULB Tirol in Innsbruck (Cod. 82), die restlichen sechs werden hingegen in der Stiftsbibl. Neustift aufbewahrt.

1809 anlässlich der vorübergehenden Aufhebung des Klosters Neustift der ULB Tirol übergeben. Am Spiegel des VD alte Signaturen der ULB Tirol II 2 H 9 (Tinte, Bleistift) und N. 161/1 (Tinte) sowie Bleistiftnotiz (Vide Grundzettel). Am Rücken gelbes Signaturschild der ULB Tirol 161. Bl. 1r Stempel der ULB Tirol 19. Jh. 1921 aufgrund des Friedensvertrages von St. Germain an den italienischen Staat abgegeben und von diesem 1929 dem Kloster Neustift als Dauerleihgabe überlassen. Bl.1r Stempel der Soprintendenza Tridentina 20. Jh.

L: $\quad$ Kristeller I 439. - Kaeppeli Nr. 2262. - J. P. McCall, Chaucer and the Pseudo Origen „De Maria Magdalena“: A Preliminary Study. Speculum 46 (1971) 491-509, hier 507. - Katalog ULB Tirol II 133, 206.

$(\mathrm{Ir}-\mathrm{v})$ leer.

1 (1ra-6ra) 〈IOHANNES DE DAMBACH〉: Tractatus de indulgentiis (Kaeppeli Nr. 2262, mit Nennung der Hs.).

Inc.: Cum non paucorum erga beneficia indulgenciarum mens errabunde vagetur ... - Expl.: ... hoc eciam est de intencione beati Thome de Aquino in scripturis super quartum Sentenciarum etc. Sic est finis huius tractatus.

Zu Iohannes de Dambach s. u. a. F. J. Worstbrock, ,Johannes von Dambach (Tambach, de Tambaco, Than-, Cam-, Zam-, -bico, -buco) OP“. Verfasserlexikon² IV 571-577. 
Opera III. Parisiis 1512, 129ra-131vb. - CCCPG I Nr. 1523).

Tit. (am oberen Blattrand): Omelia Origenis super ewangelium Maria stabat ad monumentum. Inc.: In illo tempore stabat Maria ad monumentum foris plorans et reliqua (Io 20,11). Omelya Origenis. De presenti solempnitate locuturus auribus vestre caritatis dilectissimi amor venit ad memoriam ... - Expl.: ... quia vidi dominum et hoc dixit michi cui est honor et gloria cum patre et spiritu sancto in secula seculorum Amen. Explicit omelia Origenis super ewangelium Iohannis Stabat ad monumentum.

3 (8va-9va) EXPOSITIO ORATIONIS DOMINICAE.

3.1 (8va) Inc.: [S]anctus Gregorius in prologo oracionis dominice dicente Preceptis salutaribus moniti et divina institucione formati audemus dicere ... - Expl.: ... eis infirmatus est tamquam dominus servis. Nos igitur per sanguinem Christi filii adopcionis effecti audemus dicere Pater noster.

3.2 (9ra) Inc.: [H]oc opusculum dividitur in tres partes scilicet in exordium in quo benivolencia captatur tractatum ... Prima pars tangitur ibi Pater noster $2^{a}$ ibi sanctificetur $3^{a}$ in fine cum concluditur Amen. Circa primam partem est sciendum primo quod per istam partem exordialem datur nobis petendi confidencia ... - Expl.: ... et filii dilectissimi patrem in trepidacione appellare debemus quid delictum est autem que offensa quam presens.

(9vb-12vb) nur Rahmung und Foliierung.

$\left(\mathrm{I}^{*} \mathrm{r}-\mathrm{v}\right)$ leer.

P. A./U. S.

\section{Cod. 162}

\section{SERMONES IN DEDICATIONE ECCLESIAE}

Pap. I, 10, I* Bl. $290 \times 205$. Süddeutscher Raum, Ende 14. Jh.

B: Bilder und Nachweise der Wasserzeichen s. WZMA. Datierung nach Wasserzeichenbefund. Identische Wasserzeichen: u. a. Brixen, Priesterseminarbibl., Cod. A.15 und Cod. A.22. Lage: $1^{1}$ (Vorsatzbl. 18. Jh.) + $\mathrm{V}^{10}+$ $1^{1^{*}}$ (Nachsatzbl. 18. Jh.). Gegenbl. zum Vor- bzw. Nachsatzbl. als Spiegel auf dem VD bzw. HD aufgeklebt. Am Lagenanfang Kustode 22, am oberen Blattrand Foliierung 15. Jh. 232-241, Hinweise auf ehem. Sammelhandschrift (s. bei G). Daneben Foliierung 19. Jh. durch die ULB Tirol 1-10 (hier berücksichtigt).

S: $\quad$ Schriftraum $215 \times 150$. Zwei Spalten, von Tintenlinien gerahmt, zu 40-48 Zeilen. Zirkelstiche. Bastarda.

A: $\quad$ Schwarze Unter- und Durchstreichungen sowie Überschriften. Bl. 3rb einfache Federzeichnung eines Gesichtes im Profil. Platz für zwei- und dreizeilige Lombarden freigelassen, diese jedoch nicht ausgeführt. Repräsentanten.

E: $\quad$ Neuzeitlicher Bibliothekseinband: schwarz gesprenkeltes braunes Pap. über Pappe. Neustift, 2. H. 18. Jh. Am VD und HD Ecken mit braunem Leder verstärkt. Rücken: braunes Leder, vier einfache Bünde, von Goldbordüren gesäumt. Im zweiten Feld Golddruck M. S., im dritten Signaturschild (s. bei G). Schnitt rot gesprenkelt. Spiegel Pap. 18. Jh. Am Spiegel des VD Signaturen und Bleistiftnotiz (s. bei G), Spiegel des HD leer.

G: $\quad$ Nach dem Inhaltsverzeichnis in Neustift, Stiftsbibl., Cod. 158, Bl. Ir gehört Cod. 162 zu einer Gruppe von urspr. tw. selbständigen Hs. des 14. und 15. Jh., die im 15. Jh. in Neustift zu einem Sammelband vereinigt wurden (s. auch Foliierung). Im Zuge der Neuaufstellung der Neustifter Bibliothek in der 2. H. 18. Jh. wurde die Sammelhandschrift (wie dies auch bei anderen Hs. und Inkunabeln gemacht wurde) in sieben Einzelhandschriften aufgelöst; jeder Einzelband erhielt den für Neustift typischen Halbledereinband. Zur urspr. Hs. zählen folgende Signaturen (in der urspr. Reihenfolge):

Cod. 158: Augustinus. Foliierung 15. Jh. 1-69.

Cod. 83: Theologische Sammelhandschrift, dat. 1400. Foliierung 15. Jh. 70-128.

Cod. 82: Henricus de Langenstein: De contractibus. De contemptu mundi. Foliierung 15. Jh. 129-165.

Cod. 183: Heinrich Seuse: Horologium sapientiae. Foliierung 15. Jh. 166-203. 
Cod. 161: Iohannes de Dambach. Origenes. Foliierung 15. Jh. 204-215.

Cod. 182: Ps.-Eusebius, dat. 1400. Foliierung 15. Jh. 216-231.

Cod. 162: Sermones de dedicatione. Foliierung 15. Jh. 232-241.

Von diesen sieben Hs. befindet sich heute eine an der ULB Tirol in Innsbruck (Cod. 82), die restlichen sechs werden hingegen in der Stiftsbibl. Neustift aufbewahrt.

1809 anlässlich der vorübergehenden Aufhebung des Klosters Neustift der ULB Tirol übergeben. Am Spiegel des VD alte Signaturen der ULB Tirol II 2 H 10 (Tinte, Bleistift) und N. 162 (Tinte) sowie Bleistiftnotiz Vide Grundzettel. Am Rücken gelbes Signaturschild der ULB Tirol 162. Bl. 1r Stempel der ULB Tirol 19. Jh. 1921 aufgrund des Friedensvertrages von St. Germain an den italienischen Staat abgegeben und von diesem 1929 dem Kloster Neustift als Dauerleihgabe überlassen. Bl. 1r Stempel der Soprintendenza Tridentina 20. Jh.

L: $\quad$ Katalog ULB Tirol II 138, 206.

(Ir) leer.

(Iv) Bleistiftnotiz 19. Jh.: Sermones Sacri.

(1ra-10rb) SERmones in DedicAtione ECClesiae.

(1ra) Inc.: [V]enit enim filius hominis querere et salvum facere quod perierat (Lc 19,10). Ista scribit beatus Lucas et sunt verba nostri salvatoris suam dileccionem quam ad quendam humanum habuit ...Expl.: ... omnia taliter custodire ut mereamur in templum glorie tue eternaliter introire.

(1va) Tit.: Alius sermo de dedicacione templi. - Inc.: [Z]achee festinans descende (Lc 19,5). Nota quod quidam Deum recipiunt in domum suam et non in animam quidam in animam et non in domum quidam in animam et in domum quidam nec in animam nec in domum ... - Expl.: ... Iudas qui desperavit. Rogemus. Inc. mit geringen Abweichungen wie Schneyer 9, 536, Nr. 77 (zu Stuttgart, LB, theol. fol. 332).

(2rb) Tit.: Alter sermo in dedicacione. - Inc.: [B]eati qui habitant in domo tua domine (Ps 84,5). Davit (!) dicit hec verba. Notandum est quod domus domini est quadruplex scilicet domus materialis ... Expl.: ... ut mereamur recipi in domum celestem. Rogemus.

Inc. wie München, UB, fol. 133, Bl. 162va.

(2va) Tit.: In dedicacione. - Inc.: [I]ngressus Ihesus ambulabat Iericho (Lc 19,1). Iericho interpretatur luna et signat mundum propter suum defectum ... - Expl.. ... nos intrare in regnum celorum. Rogemus. Inc. wie Schneyer 8, 608, Nr. 2 (zu München, BSB, Clm 5998), Schneyer 9, 537, Nr. 86 (zu Stuttgart, LB, theol. fol. 332) oder Schneyer 9, 830, Nr. 13 (zu Vorau, Stiftsbibl., Cod. 161).

(3ra) Tit.: De eo sermone in dedicacione. - Inc.: [T]emplum hoc sanctum ingredientes rex pie exaudi nos domine. Nota tria templa placencia Deo. Primum templum est aureum secundum est eburneum tertium est lapideum ... - Expl.: ... Ite maledicti in ignem eternum. Rogemus.

(3va) Tit.: De dedicacione templi. - Inc.: [V]idit Iacob in sompnis scalam et angelos Dei descendetes (!) et ascendentes per eam (Gn 28,12). Ait vere dominus est in loco isto et ego nesciebam $(\mathrm{Gn} 28,16)$. Hiis verbis possumus quattuor notare. Primo quis sit Iacob secundo quod dormivit tercio que sit scala quarto quod angelos vidit ... - Expl.: ... bonam dedicacionem in corde suo habuit. Rogemus.

(4ra) Inc.: [E]gressus Ihesus perambulabat Iericho (Lc 19,1). Zacheus interpretatur iustus sed quia ille iustus non erat ideo dominum videre non poterat. Sunt autem tres cause quare dominum videre non poterat. Primo propter divicias ... - Expl.: ... concessit unde rogemus unum de festo Pentecosten. Refulsit sol quere in fine sermonis.

(4va) Inc.: [D]uodecim sunt signa scilicet aries thaurus ... Notandum quod in hiis duodecim signis sol perficit cursum suum ... - Expl.: ... in cuius signis sol perficit cursum simul etc.

(5rb) «CONRAdUS DE BRundelsheIm〉 (Schneyer 1, 746, Nr. 378).

(6va) Inc.: [N] ova veniens e celo nupciali thalamo. Apok. XIX (vgl. AH 51, Nr. 102, Str. 2). Nota quod sponsa Christo debet se preparare ad eius adventum quinque modis. Primo se lavando ... - Expl.. ... ut voluntatem eius faciat. Rogemus dominum ut ab hostibus protegat et ad regnum eternum perducat etc. (7rb) Inc.: [V]enit filius hominis querere et salvum facere. Luc. 19 (10). Hic sumat peccatrix anima confidenciam tripliciter. Quia Christus venit quesivit et salvum fecit venit nascendo quesivit (gestrichen: nasciendo) predicando salvum fecit moriendo ... - Expl.: ... neque secundum peccata nostra facias nobis in adultera. Rogemus. 
Inc. wie Augsburg, Staats- und Stadtbibl., $2^{\circ}$ Cod. 420, Bl. 103va.

(7va) Inc.: [E]t querebat videre Ihesum quis esset (Lc 19,3). Hec verba scribit Lucas de quodam Iudeo qui vocabatur Zacheus qui desiderabat videre filium Dei ... - Expl.: ... Gaudium vestrum nemo tollet a vobis ad quod nos perducat.

(8ra) Bibelzitat und Expl. wie 〈Aldobrandinus de Cavalcantibus〉 (Schneyer 1, 212, Nr. 836). Inc.: [T]emplum Dei sanctum est quod estis vos si quis autem templum Dei violavit disperdet illum dominus Deus (1) Chor. 3 (17). In verbis istis apostolus duo facit, ostendit enim fidelis anime sanctitatem et execratur sanctitatis violatorem ...

(8vb) Inc.: [V]idi civitatem sanctam Iherusalem. Apok. 21 (2). Dicit beatus Augustinus quod duplex est civitas ... - Expl.: ... cum dicit Vidi civitatem iusticie et iustorum.

(9ra) Inc.: Vidi civitatem sanctam etc. (Apc 21,2). Quantum ad statum penitencie ostendit autem civitatem iustorum laudabilem duplici respectu ... - Expl.: ... hic manentem civitatem festinemus ingredi in futuram civitatem ad quam nos perducat.

(9vb) 〈Martinus Oppaviensis〉 (Schneyer 4, 148, Nr. 319, vgl. auch Schneyer 9, 621, Nr. 57).

(10va-b) nur Rahmung.

$\left(I^{*} \mathrm{r}-\mathrm{v}\right)$ leer.

P. A./U.S.

\section{Cod. 163}

\section{ARISTOTELES}

Pap. I, 79, I* Bl. $290 \times 220$. Wien, T. I: um 1389 und um 1443, T. II: Ende 14. Jh.

B: $\quad$ Zwei Teile: I (I, 1-30), II (31-79, I*). Am oberen Blattrand Foliierung 19. Jh. durch die ULB Tirol.

E: Neuzeitlicher Bibliothekseinband: schwarz gesprenkeltes braunes Pap. über Pappe. Neustift, 2. H. 18. Jh. Am VD und HD Ecken mit braunem Leder verstärkt. Rücken: braunes Leder, vier einfache Bünde, von Goldbordüren gesäumt. Im zweiten Feld Golddruck M. S. DE ANIMA ANTICI (!) in Goldrahmung, im dritten Signaturschild (s. bei G). Schnitt rot gesprenkelt. Spiegel Pap. 18. Jh. Am Spiegel des VD Signaturen und Bleistiftnotiz (s. bei G), Spiegel des HD leer.

G: $\quad$ Nach dem Inhaltsverzeichnis in Innsbruck, ULB Tirol, Cod. 157, Bl. Ir gehört Cod. 163 zu einer Gruppe von urspr. selbständigen Hs. des 14. und 15. Jh., die im 15. Jh. in Neustift zu einem Sammelband vereinigt wurden. Im Zuge der Neuaufstellung der Neustifter Bibliothek in der 2. H. 18. Jh. wurde die Sammelhandschrift (wie dies auch bei anderen Hs. und Inkunabeln gemacht wurde) in sieben Einzelhandschriften aufgelöst; jeder Einzelband erhielt den für Neustift typischen Halbledereinband. Zur urspr. Hs. zählen folgende Signaturen (in der urspr. Reihenfolge):

Cod. 157: Aristoteles: Ethica Nicomachea und Oeconomica.

heute nicht mehr nachweisbar: Aristoteles: Politica.

Cod. 159: Albertus de Saxonia: Kommentar zu Cod. 157.

Cod. 168: Aristoteles: Physica, Lib. 1-5.

Cod. 163: Aristoteles: Physica, Lib. 6-8 und De anima.

Cod. 181: Alanus ab Insulis: Summa de arte praedicatoria.

Cod. 164: Anshelmus Havelburgensis. Anticimenon.

Von diesen sieben Hs. ist eine nicht mehr erhalten, drei befinden sich heute an der ULB Tirol in Innsbruck (Cod. 157, 159 und 164), drei werden in der Stiftsbibl. Neustift (Cod. 163, 168 und 181) aufbewahrt.

1809 anlässlich der vorübergehenden Aufhebung des Klosters Neustift der ULB Tirol übergeben. Am Spiegel des VD alte Signaturen der ULB Tirol II 2 H 11 (Tinte, Bleistift) und Nr. 163 (Tinte) sowie Bleistiftnotiz (Vide Grundzettel). Am Rücken gelbes Signaturschild der ULB Tirol 163. Bl. 1r Stempel der ULB Tirol 19. Jh. 1921 aufgrund des Friedensvertrages von St. Germain an den italienischen Staat abgegeben und von diesem 1929 dem Kloster Neustift als Dauerleihgabe überlassen. Bl. 1r Stempel der Soprintendenza Tridentina 20. Jh. 
L: $\quad$ Lacombe II 1023, Nr. 1495. - Neuhauser, Neustift 91-95. - Katalog ULB Tirol II 138, 206. - W. Neuhauser, Buchgeschichtliche Beziehungen zwischen dem Wiener Raum und Tirol im Mittelalter. Jahrbuch für Landeskunde von Niederösterreich N. F. 63/64 (1997/98) 57 (auch in: Neuhauser, In libris 405-424).

$$
\text { I (I, 1-30) }
$$

B: $\quad$ Bl. 2-5 und 8-10 lose. Bilder und Nachweise der Wasserzeichen s. WZMA. Bl. 1-24 Datierung nach Wasserzeichenbefund. Identische Wasserzeichen: u. a. Klosterneuburg, Stiftsbibl., CCl 477, T. II (Korneuburg, dat. 1389) und Wien, Schottenstift, Archiv, Hs. 273, T. I (Prag, dat. 1389). Bl. 25-30 wohl später eingefügt: Datierung um 1443 nach Wasserzeichenbefund. Identische Wasserzeichen: Klosterneuburg, Stiftsbibl., CCl 369 (dat. 1443). Lagen: (I-1) ${ }^{\mathrm{I}}$ (Vorsatzbl. 18. Jh.) $+2 \cdot \mathrm{VI}^{24}+\mathrm{III}^{30}$. Gegenbl. zum Vorsatzbl. als Spiegel auf dem VD aufgeklebt. Zw. Bl. 15 und 16 ungezähltes kleines Bl. (135/145×110/115) eingefügt. Bl. 1-29 am oberen Blattrand der Rectos zeitgenössische Buchzählung. Lagenreklamanten.

S: $\quad$ Text von Kommentar umgeben. Schriftraum Haupttext 160×100/105, von Tintenlinien gerahmt, zu 27-34 Zeilen. Mehrere Hände: 1) Bl. 1r-24v: Bastarda 14. Jh. von zwei sich abwechselnden Händen; 2) Bl. 25r29r Bastarda 15. Jh. Schriftraum der Kommentarfelder stark wechselnd, von Tintenlinien gerahmt, bisweilen bis zum Blattrand beschrieben: oberes Kommentarfeld $40 \mathrm{~mm}$, unteres $65 \mathrm{~mm}$ hoch, äußeres 65/70 mm (tw. beschnitten, Textverlust), inneres $30 \mathrm{~mm}$ breit. Vgl. auch Cod. 168.

A: Rote Auszeichnungsstriche, Unterstreichungen, Rahmungen sowie schwarze, rot konturierte Paragraphzeichen und Zeigehände. Zwei- bis sechszeilige rote Lombarden mit Punktverdickungen; vereinzelt zweizeilige schwarze, rot umrahmte Lombarden mit etwas Dekor. Repräsentanten.

$(\mathrm{Ir}-\mathrm{v})$ leer.

1 (1r-29r) Forts. von Cod. 168, Bl. 46v: Aristoteles: Physica, Lib. 6-8, Translatio nova durch Guilelmus de Moerbeke (Druck: u. a. GW 2336. Ed.: Aristoteles Latinus VII: Physica, Fasc. 1: Translatio vetus, ed. F. Bossier, J. Brams, rev. ed. A. Mansion. Leiden, New York 1990. - Lacombe I 52, Nr. 17 und I 126-127, Nr. 17 sowie II 1023, Nr. 1495. Thorndike-Kibre 1296). Mit umfangreichem Kommentar.

(1r-9v) Lib. 6. - (10r-14v) Lib. 7. - (15r-29r) Lib. 8.

(24v) Expl. mut.: ... infinito tempore infinitum transiit aliquis similiter autem [ $\mathrm{Bl}$. 25r-v leer ohne Textverlust. Text setzt Bl. 26r von anderer Hand unmittelbar fort. Inc. mut.: ] infinitum utique (!) in longitudine est et in tempore ...

(29r) Expl. (leicht abweichend): ... manifestum utique quod indivisibile est et impartibile et nullam habens magnitudinem Amen.

$(29 \mathrm{v}-30 \mathrm{v})$ leer.

\section{(1r-29r) KOMMENTAR.}

(1r-9v) Zu Lib. 6. Inc.: Iste est liber sextus Phisicorum, in quo philosophus determinat de divisione motus et quietis in suas partes ... - Expl.: ... sed non eedem semper et cetera autem finis sexti libri Phisicorum Deo gracias.

$(10 \mathrm{r}-14 \mathrm{v}) \mathrm{Zu}$ Lib. 7. Inc.: Omne quod movetur necesse. Iste est septimus liber Phisicorum in quo philosophus determinat de comparatione motuum ... - Expl.: ... est finis huius septimi libri de quo sit Iesus Marie filius in secula seculorum benedictus Amen.

(15r-29r) Zu Lib. 8. Inc.: Utrum autem factus. Iste est octavus liber Phisicorum in quo Aristoteles determinat de perpetuitate motus ... - Expl.: ... de rebus naturalibus in principio totius nature qui est super omnia benedictus Deus in secula Amen.

Lit.: Grabmann, Aristoteles 170-174. 


$$
\text { II }\left(31-79, I^{*}\right)
$$

B: $\quad$ Bilder und Nachweise der Wasserzeichen s. WZMA. Datierung nach Wasserzeichenbefund. Identische Wasserzeichen: u. a. Innsbruck, ULB Tirol, Cod. 221 (dat. 1390); Wien, Schottenstift, Archiv, Hs. 367 (dat. 1391) und Archiv, Hs. 362 (dat. 1400); Korneuburg, Stadtarchiv, Cod. 1756 (dat. 1396). Lagen: (VI+1) ${ }^{43}+$ 3.VI $I^{79}+(\mathrm{I}-1)^{\mathrm{I}^{*}}$ (Nachsatzbl. 18. Jh.). Gegenbl. zum Nachsatzbl. als Spiegel auf dem HD aufgeklebt. Bl. 31 zusätzlich eingefügtes halbes Bl. $(290 \times 110 / 115)$. Lagenreklamanten, tw. weggeschnitten.

S: $\quad$ Text von Kommentar umgeben (Bl. 75r-76v ohne Kommentar). Schriftraum wechselnd: Haupttext Bl. 31r75r und 78r-79v: $150 \times 85 / 95$, Bl. 75v-77v: 185/210×125/140, von zweifachen Linien gerahmt (Bl. 75v76v nur seitlich einfach begrenzt), zu 16-20 Zeilen, Bl. 75r zu 21 Zeilen, Bl. 75v zu 23 Zeilen, Bl. 76r-v zu 27 Zeilen. Vier Hände Ende 14. Jh.: 1) Bl. 32r-44r, Z. 3 Textualis cursiva; 2) Bl. 44r, Z. 4-74v Bastarda; 3) B1. 75r-76v kursive Bastarda von späterer Hand; 4) B1. 79v flüchtige Notula von späterer Hand in dunkler Tinte, geschrieben wohl in Neustift, vgl. die Eintragungen in Innsbruck, ULB Tirol, Cod. 157, 159 und 164. Randglossierung von mehreren Händen Ende 14. Jh.: 1) Bl. 31r-34v Notula; 2) Bl. 35r-36r Bastarda (spätere Hand), jeweils beginnend Notandum ...; 3) 47r-48v Bastarda (gleicher Schreiber wie Bl. 35r-36r); 4) Bl. 50v-74v Bastarda. Zusätzlich Bl. 32r-37v, 47r-49r Interlinearglossierung, danach nur vereinzelt.

A: Rote Auszeichnungsstriche, Unterstreichungen, Rahmungen sowie schwarze, rot konturierte Paragraphzeichen und Zeigehände. Ein- bis vierzeilige rote Lombarden, B1. 47r und 48v mit gegenständigen Halbpalmetten im Binnenfeld. Bl. 75r-76v ohne Rubrizierung.

2 (31r-v) Forts. des Kommentars von Bl. 32r.

(32r-76v) Aristoteles: De anima, Translatio nova durch Guilelmus de Moerbeke (Druck: GW 2343-2349. Aristotelis de anima libri tres, cum Averrois commentariis et antiqua tralatione suae integritati restituta ... Michaele Sophiano interprete. Venetiis 1562, ND Frankfurt a. M. 1962. Lacombe I 58-59, Nr. 27 und I 136-137, Nr. 27, sowie II 1023, Nr. 1495. Thorndike-Kibre 179). Mit Kommentar bis Bl. 75v und tw. Interlinearglossen.

Abweichender Beginn von Lib. 3 (71v) De parte autem anime quam cognoscit anima et sapit ... (vgl. Lacombe I 58-59)

Die im Druck 1562 als ,,antiqua tralatio” bezeichnete Übersetzung entspricht der Translatio nova bei Lacombe.

Text. Inc.: Bonorum honorabilium notitiam opinantes magis autem alteram altera aut secundum certitudinem aut ex eo ... - Expl. mut. (Lib. 3, cap. 10): ... videtur enim quod iam delectabile et simpliciter delectabile et bonum simpliciter [

(32r) Lib. 1. - (47r) Lib. 2. - (71v) Lib. 3.

(31r-34v) Kommentar 1. Inc. (Bl. 32r): Circa inicium huius libri sicud aliorum sunt aliqua generalia autem textus in tytulationem prenotanda. Primo in quali sciencia ... Forts. nach $\mathrm{Bl}$. 32r auf Bl. 31v und anschließend auf Bl. 31r, Forts. auf Bl. 32v. - Expl.: ... ut benedicam ab eis acceptemus et alium refutemus.

(35r-36r) Kommentar 2. Inc.: Notandum circa textum nonnulli priorum oppinati (!) sunt quod quando anima ingrediebatur corpus... - Expl.: ... Quidam dicunt Platonem asseruisse animam esse iterum se ipsam moventem male dicunt hec opinio nomine Platonis secundum Temocritum. (47r-48v) Kommentar 3 (zu Lib. 2). Inc.: Circa textum notandum quod philosophus in textu dicit quod erit determinandum ... - Expl.: ... Tonitruum est sonus factus in nubibus propter extinctionem inflammacionis in eisdem.

(50v-71r) Kommentar 4a (zu Lib. 2). Inc.: Doctrinarum autem anime. Capitulum $3^{m}$ in quo determinatur de potenciis anime ... - Expl.: ... racione sanatur immediate ministrat in temporali. Intenciones sensibilia ad hoc igitur deservit (!) sanacionem.

(71v-74v) Kommentar 4b (zu Lib. 3). Inc.: De parte autem anime. Iste est tercius liber parcialis in quo dicitur de aliis anime potenciis ... - Expl.: ... est posterius considerandum scilicet in $2^{\circ}$ idem in $12^{\circ}$ Methaphysice.

Lit.: Grabmann, Aristoteles 190-198.

(77r-79r) nur Rahmung. 
$3 \quad(79 v)$ Notabilia zu De anima.

Inc.: Item nota quod per quiditatem anime intellegitur summa et essencia ipsius anime ...- Expl.: ... Alio modo potest considerari prout inseparata a corpore $2^{\circ}$ de ipsa determinare potest ad mathematicam.

$\left(\mathrm{I}^{*} \mathrm{r}-\mathrm{v}\right)$ leer.

P. K./W. N.

\section{Cod. 165}

\section{THEOLOGISCHE SAMMELHANDSCHRIFT}

Pap. I, 148, I* Bl. $295 \times 205$. Süddeutscher Raum, 1. Jz. 15. Jh. (T. III: 1407).

B: $\quad$ Drei Teile: I (I, 1-74[75]), II (75[76]-113[115]), III (114[116]-146[148], I*). Bilder und Nachweise der Wasserzeichen s. WZMA. T. III dat. 1407, Wasserzeichen von T. III auch in T. I und II. Identische Wasserzeichen: u. a. Neustift, Stiftsbibl., Cod. 166. In der Mitte des oberen Blattrandes (am unteren Blattrand meist wiederholt) Foliierung 59-205 (bisweilen beschnitten), urspr. Bl. 1-58 fehlen. Am rechten oberen Blattrand Foliierung 19. Jh. durch die ULB Tirol 1-145; Fehler in der Zählung: 21, 86 und 97 doppelt angeführt, 87 ausgelassen. Neuzeitliche gelbe Papiersignakel der ULB Tirol.

E: Neuzeitlicher Bibliothekseinband: schwarz gesprenkeltes braunes Pap. über Pappe. Neustift, 2. H. 18. Jh. Am VD und HD Ecken mit Leder überzogen. Rücken: braunes Leder, drei einfache Bünde, von Goldbordüren gesäumt. Im zweiten Feld Golddruck OPUSCULA DIVERSOR. PATRUM in Goldrahmung, im dritten Signaturschild (s. bei G). Schnitt rot gesprenkelt. Spiegel Pap. 18. Jh. Am Spiegel des VD Signaturen und Bleistiftnotiz (s. bei G), Spiegel des HD leer.

G: Zeitpunkt und Art der Erwerbung durch Neustift unbekannt. Die zeitgenössische Foliierung in der Mitte des oberen Blattrandes lässt - gemeinsam mit den übereinstimmenden Wasserzeichen sowie der Größe der Hs. darauf schließen, dass Cod. 165 urspr. mit Cod. 166 vereinigt war. Gegebenenfalls wohl im Zuge der Neuaufstellung der Neustifter Bibliothek in der 2. H. 18. Jh. (wie dies auch bei anderen Hs. und Inkunabeln gemacht wurde) in Einzelhandschriften aufgelöst; jeder Einzelband erhielt den für Neustift typischen Halbledereinband.

1809 anlässlich der vorübergehenden Aufhebung des Klosters Neustift der ULB Tirol übergeben. Am Spiegel des VD alte Signaturen der ULB Tirol II 2 H 13 (Tinte, Bleistift) und N. 165/(8) (Tinte, Bleistift) sowie Bleistiftnotiz (Vide Grundzettel). Am Rücken gelbes Signaturschild der ULB Tirol 165/(8). Bl. 1r Stempel der ULB Tirol 19. Jh. 1921 aufgrund des Friedensvertrages von St. Germain an den italienischen Staat abgegeben und von diesem 1929 dem Kloster Neustift als Dauerleihgabe überlassen. Bl. 1r Stempel der Soprintendenza Tridentina 20. Jh.

L: $\quad$ Stegmüller RB Nr. 4819,4 Suppl. (zu Bl. 129-132). - Katalog ULB Tirol II 140, 206-207. - Katalog ULB Tirol II, Beiheft, Taf. 52. - F. Eisermann, „Stimulus amoris“. Inhalt, lateinische Überlieferung, deutsche Übersetzungen, Rezeption (MTU 118). Tübingen 2001, 153, 214, 224, 324, 327.

$$
\text { I (I, 1-74[75]) }
$$

B: $\quad$ Pap. fleckig. Lagen: $(\mathrm{I}-1)^{\mathrm{I}}$ (Vorsatzbl. 18. Jh. $)+4 \cdot \mathrm{VI}^{47(48)}+(\mathrm{V}+1)^{58(59)}+\mathrm{VI}^{70(71)}+\mathrm{II}^{74(75)}$. Bl. 52 eingehängtes Einzelbl. Am oberen Blattrand der Rectos Zählung der einzelnen Bücher (Abschnitt 1) bzw. Überschriften (Abschnitt 3-5), bisweilen beschnitten.

S: $\quad$ Schriftraum $230 \times 150$. Zwei Spalten, von tw. Bleistift-, tw. Blindlinien gerahmt, zu 50 (Schreiber 1) bzw. 41-42 (Schreiber 2) Zeilen. Bastarda, Anfang 15. Jh. von zwei Händen: 1) Bl. 1ra-58vb (= Cod. 166, Schreiber 1); 2) Bl. 59ra-74rb.

A: Rubrizierung von unterschiedlichen Händen: 1) Bl. 1ra-58vb; 2) Bl. 59ra-74rb. Rote Auszeichnungsstriche, Paragraphzeichen, Zeilenfüllsel, Unterstreichungen, Über- und Schlussschriften. Zeigehände. Rote Satzmajuskeln und ein- bis dreizeilige Lombarden; B1. 42va dreizeilige Initiale $P$ in roter Umrisszeichnung, schwarz konturiert und mit schwarzem Fleuronnée (Knospengarben im Binnenfeld, gepunktete Perlen als Besatz). 
1 (1ra-42ra) Gregorius Magnus: Dialogi = Dialogorum libri IV de vita et miraculis patrum Italicorum (PL 77, 149-429 [Lib. 1, 3 und 4] bzw. PL 66, 126-204 [Lib. 2]. Ed. U. Moricca [Fonti per la storia d'Italia 57]. Roma 1924. Ed. A. de Vogüé [Sources chrétiennes 260]. Paris 1979 [Buch 1-3] und [Sources chrétiennes 265]. Paris 1980 [Buch 4]. - CPL Nr. 1713).

(1ra) Lib. 1. - (8va) Kapitelübersicht zu Lib. 2. - (8vb) Lib. 2 = Vita s. Benedicti abbatis. - (16vb) Kapitelübersicht zu Lib. 3. - (17ra) Lib. 3. - (28ra) Kapitelübersicht zu Lib. 4. - (28va) Lib. 4. (42ra) Schlussschrift: Explicit Dyalogus Gregorii.

2 (42ra) Exzerpte aus «Ps.->Augustinus: Auctoritates.

Tit.: Diffinicio virtutis secundum beatum Augustinum. - Inc.: Est amor ordinatus videlicet ut amet ... - Expl.: ... alii gustum reparat, alii aliud et aliud operatur etc.

Parallelüberlieferung: u. a. Fiecht, Stiftsbibl., Hs. 15, Bl. 82r.

Darunter von späterer Hand: Qui non est dives et nescit vivere pauper/Ille modum vite nescit habere sue (Walther, Proverbia Nr. 24397. Vgl. Walther, Initia Nr. 15581).

(42rb) leer.

3 (42va-53va) 〈Ps.-〉Eusebius CAesariensis: Epistola ad beatum Damasum episcopum Portuensem et ad christianissimum Theodosium Romanorum senatorem de morte Hieronymi (PL 22, 239282. Klapper II 10-241. - BHL Nr. 3866. BHM Nr. 903E).

Tit.: Incipit epistola beati Ewsebii ad Damasium episcopum (Nachtrag: Portuensem) et Theodonium (!) Romanorum senatorem sui magistri gloriosissimi sancti Ieronimi (gestrichen: episcopi Portuensis) presbiteri.

Schlussschrift: Explicit epistola Ewsebii de morte sanctissima Ieronimi presbiteri.

4 (53va-55vb) 〈Ps.-〉Augustinus: Epistola 18 (ad Cyrillum Hierosolymitanum episcopum de magnificentiis beati Hieronymi) (PL 22, 281-289. Klapper II 245-288. - CPL Nr. 367. BHL Nr. 3867. BHM Nr. 903A).

Tit.: Incipit epistola beati Augustini ad Cyrillum patriarcham Ierosolitanum de beatissimo Ieronimo. Exordium epistolare de non tacendo laudem Ieronimi.

Schlussschrift: Explicit epistola Augustini ad Cyrilium de glorioso Ieronimo.

5 (55vb-71rb) 〈Ps.-〉CYrILlus: Epistola ad Augustinum de miraculis Hieronymi (PL 22, 289-326.CPL Nr. 367. BHL Nr. 3868. BHM Nr. 903C) = 〈Ps.-Augustinus〉: Epistola App. 19 (PL 33, 1126-1153).

Tit.: Incipit epistola Cyrilli ad Augustinum de miraculis gloriosi Ieronimi.

6 (71rb-74rb) Auszüge aus 〈IoHAnNes AndreaE»: Hieronymianus (Druck: GW 1727. - BHL Nr. 3876. BHM Nr. 907).

(71rb-73rb) Tit.: De quibusdam miraculis vel mirabilibus factis noviter in Apulia et primo quid in Troia civitate etc. - Inc.: Sciendum est quod moderno tempore in Apulia in provincia Capitimate (!) ... - Expl.: ... fidei et gremium ecclesie sunt reversi. Deo gracias.

(73va-74rb) Inc.: Hic s. Ieronimus sacerdos fuit ordine peregrinacionis ... Frater Iacobus de varietatibus legendarum ... - Expl.: ... rex Israheliticus occidente sole.

(74rb) Schlussschrift: Explicit libellus de vita et obitu et miraculis sancti Ieronimi doctoris egregii. Ergo sancte Ieronime pro me misero peccatore intercede ad Ihesum Christum qui propter nos venit (gestrichen: ad) in mundum istum etc.

(74va-b) nur Rahmung.

Zu Texten und Anordnung von T. I vgl. u. a. Wilten, Stiftsbibl., Cod. 3202 05, T. IV. Zu Nr. 3-6 vgl. Cod. 125, Bl. 170rb-200ra (bes. Nr. 10).

Lit.: Schulte GQ II 217. 


\section{II (75[76]-113[115])}

B: Pap. fleckig. Lagen: 2.VII ${ }^{101(103)}+\mathrm{VI}^{113(115)}$.

S: $\quad$ Schriftraum $230 \times 150$. Zwei Spalten, von meist Blind-, tw. Bleistiftlinien gerahmt, zu 50 Zeilen. Bastarda Anfang 15. Jh. von zwei Händen: 1) Bl. 75ra-111ra, Z. 46 (= Schreiber 1 von T. I); 2) Bl. 111ra, Z. 46Bl. 113va.

A: Rote Auszeichnungsstriche, Paragraphzeichen, Unter- bzw. Durchstreichungen, Überschriften. Zeigehände. Rote Satzmajuskeln sowie ein- bis dreizeilige Lombarden.

7 (75ra-88va) 〈Rufinus AQUILEIENSIS〉: Historia monachorum = Vitae patrum, Lib. 2 (Druck: PL 21, 387-462. Ed.: E. Schulz-Flügel, Tyrannius Rufinus, Historia monachorum sive de vita sanctorum patrum [Patristische Texte und Studien 34]. Berlin u. a. 1990, 234-387.- CPL Nr. 198p. BHL Nr. 6524).

(75ra) Tit.: In Christi nomine incipit liber de vita sanctorum patrum Heremitarum.

(75ra) Register. (75ra) Prolog.

(75va) Cap. 1: De s. Iohanne. - (78vb) Cap. 15: De Apellen presbytero et Iohanne. - (79rb) Cap. 16: De Paphnutio. - (80rb) Cap. 12: De Elia. - (80rb) Cap. 13: De Pithyrione. - (80va) Cap. 14: De patre Eulogio. - (80va) Cap. 7: De Apollonio. - (82va) Cap. 8: De Ammone. - (83ra) Cap. 9: De Coprete presbytero et patermutio. - (84va) Cap. 11: De Heleno. - (85rb) Cap. 6: De Theone. (85va) Cap. 20: De Dioscuro presbytero. - (85va) Cap. 2: De Hor. - (86ra) Cap. 5: De Oxyryncho civitate. - (86rb) Cap. 18: De Serapione presbytero. - (86va) Cap. 19: De Apollonio monacho et martyre. - (86vb) Cap. 21: De monachis in Nitria commorantibus. - (86 ra, Z. 20) Cap. 22: De loco qui dicitur Cellia. - (86'ra) De Ammonio (bis PL 21, 446B: ... puteum foderat, Bl. 86' $\mathrm{r}$ rb, Z. 23). - (86'rb, Z. 23) Cap. 24: De Didymo. - (86'rb) Cap. 30: De Ammone, primo Nitriae monacho (bis PL 21, 456C: ... sanitas redditur). - (87va) Cap. 31: De Paulo simplice. - (88ra) Cap. 32: De Piammone presbytero. - (88rb) Cap. 33: De Iohanne. - (88rb) Epilog. (88va) Schlussschrift: Explicit liber primus.

8 (88va-104vb) 〈Ps.-Rufinus Aquileiensis〉: Vitae patrum, Lib. 3 = Verba seniorum (Druck: GW M50865. PL 73, 739A-808B. - BHL Nr. 6525).

(88va) Register.

(90ra) Prolog. Tit.: Incipit liber secundus de vita sanctorum patrum prologus.

(90ra) Text. Tit.: De odio mundi.

(104vb) Schlussschrift: Explicit liber secundus.

9 (104vb-111ra) 〈Sulpicius Severus, Iohannes Cassianus : Vitae patrum, Lib. 4 = Excerpta (PL 73, 813-842A. - BHL Nr. 6526).

(104vb) Register.

(105rb) nur Rahmung.

(105va) Tit.: Liber tercius. - Expl.: ... quam dominus ab eo avertere voluit ipse sibi conscivit (= cap. 44).

(111ra, unten) Vermerk: cetera capitula require in dialogum in isto signo x in chilem non credas.

10 (111rb-113va) Notiz.

Tit.: Nota. - Inc.: In hystoria ecclesiastica habetur de institucione vite sanctorum patrum in Egypto ... - Expl. mut.: ... quasi absque tumultu populi necari [

(113vb) nur Rahmung. 


\section{III (114[116]-146[148], I*)}

B: $\quad$ Bl. 114 abgegriffen (wohl urspr. ohne Einband). Lagen: 2.VI ${ }^{137[139]}+(\mathrm{III}+3)^{146[148]}+(\mathrm{I}-1)^{\mathrm{I}^{*}}($ Nachsatzbl. 18. Jh.). Bl. 138-140 eingehängte Einzelbl.

S: $\quad$ Schriftraum $240 \times 160$, von Tintenlinien gerahmt, zu 50 Zeilen. Bl. 143v-146v: Drei Spalten, von Bleistiftlinien gerahmt. Bastarda 15. Jh. von zwei Händen: 1) Bl. 114r-143r; 2) Bl. 143v-145v, dat. Juni 1407 (Bl. 128v).

A: Rote Auszeichnungsstriche, Paragraphzeichen, Unterstreichungen, Rahmungen, Über- und Schlussschriften. Zeigehände (z. B. Bl. 126v mit Ärmelansatz). Rote zweizeilige Lombarden.

11 (114r-128v) QuAEstiones DisputaTAE DE PECCATO IN SPIRITUM SANCTUM.

Tit.: De peccato in spiritum sanctum et misericordia Dei. Darüber Schreibervers: Assit ad inceptum sancta Maria meum.

Inc.: Dubitatur numquid aliquid peccatum sic (!) tam grande ... - Expl.. ... tamquam verus amicus. Sic est finis.

(128v) Schlussschrift und Datierung: Expliciunt questiones bone disputate a diversis doctoribus in studio Pragensi anno domini millesimo quadicentesimo (!) septimo mensis Iunii etc. (Juni 1407). Daneben von späterer Hand in anderer Tinte: 1407.

Parallelüberlieferung: u. a. München, BSB, Clm 28564, Bl. 246ra.

12 (129r-131v) Determinatio doctorum universitatis Pragensis de V propositionibus magistri IOHANNIS MunTZINGER 1386 FACTA = Gutachten der Prager theologischen Fakultät im Rahmen der theologischen Streitigkeiten zw. Johannes Müntzinger und den Dominikanern in Ulm (Druck: J. G. Schelhorn, Amoenitates literariae ... VIII. Frankfurt, Leipzig 1728, 527-552. - Stegmüller RB Nr. 4819,4 Suppl., mit Nennung der Hs.).

Inc.: In exordio presentis negocii Deo scienciarum domino humiliter invocato protestamur quod circa puncta nuper in forma publice scripture de oppido Ulmensi Constantiensis diocesis transmissa ... - Expl.: ... probabile reputamus.

Lit.: A. Lang, Johann Müntzinger, ein schwäbischer Theologe und Schulmeister, in: Geisteswelt des Mittelalters. Studien und Texte. Martin Grabmann zur Vollendung des 60. Lebensjahres von Freunden und Schülern gewidmet. München 1935, 1208-1210; A. Holtorf, „Müntzinger (Münzinger), Johannes“. Verfasserlexikon² VI 794-799.

13 (131v-132r) QuAestio DE ARTiculis IOHANNIS MüNTZINGER.

Inc.: Utrum solus Deus sit adoracione latrie adorandus ... - Expl.: ... sanguinem circumcisionis non creditur resumpsisse. Sic est finis.

In Fritzlar, Dombibl., Ms. 6, Bl. 296vb-297rb Conradus de Soltau zugeschrieben.

Schlussschrift (zu Nr. 12 und 13): Expliciunt punctus magistri Iohannis Munczinger.

$14(132 \mathrm{v}-139 \mathrm{v})$ 〈Iacobus Mediolanensis〉 (=〈Ps.-Bonaventura $)$ : Stimulus amoris, Auszug (Druck: A. Ch. Peltier, S. R. E. Cardinalis S. Bonaventurae ... opera omnia XII. Parisiis 1868, 633-703. Stimulus amoris fr. Iacobi Mediolanensis. Canticum pauperis Fr. Ioannis Peckam [Bibliotheca Franciscana Medii Aevi 4]. Quaracchi 21949, 1-129. - Distelbrink Nr. 217-219. Bloomfield Nr. 1294).

Die Hs. enthält Pars 1, cap. 1-4; Pars 2, cap. 1, 3-6, 9, 10; Pars 3, cap. 1-5 des Drucks (1868). Rubrik: Liber iste qui intitulatur stimulus amoris in dulcissimum et piissimum Ihesum salvatorem nostrum in tres dividitur partes...

Inc.: Currite gentes undique et miramini erga vos caritatem Dei ... - Expl.: ... misericors est Deus qui est benedictus et laudabilis et gloriosus in secula seculorum Amen.

Schlussschrift: Explicit stimulus amoris. 
Vgl. Cod. 125, Bl. 161ra. Parallelüberlieferung (mit derselben Auswahl): Innsbruck, ULB Tirol, Cod. 140, Bl. 145va.

Lit.: F. Eisermann, „Stimulus amoris“. Inhalt, lateinische Überlieferung, deutsche Übersetzungen, Rezeption (MTU 118). Tübingen 2001 (mit Nennung der Hs.).

15 (139v-141r) 〈ECBERTus SchonaugIEnsis»: Soliloquium seu Meditationes (PL 195, 105D-114).

Tit.: Contemplacio Bernhardi.

Schlussschrift: Explicit contemplacio beati Bernhardi.

Vgl. Cod. 125, Bl. 169va.

16 (141r-143r) Augustinus: Sermo 9 de decem chordis (PL 38, 75-91. CCSL 41, 105-151. CPPM I 456).

Tit.: Augustinus de decem cordis.

17 (143va-144ra) De FORMA VIVENDI MONACHORUM (AH 33, Nr. 220).

Inc.: Christus nobis tribuit normam (!) hic vivendi/Et exemplo docuit viam gradiendi/Ut mundana vanitas possit vilipendi ... - Expl.: ... qui timent turbamen/Et a malo liberat (gestrichen: liberit) in eternum Amen.

Darunter zwei Strophen hinzugefügt (vgl. AH 33, Nr. 220, S. 207): Qui transitis monachi omnes huc venite ... Sed perlege iugiter atque meditare.

18 (144rb-vc) Claustrum animae.

Tit.: Nota quoddam claustrum spirituale. - Inc.: Manus Zorobabel fundaverunt eam $(\mathrm{Za} \mathrm{4,9)}$ scilicet animam per istum Zorobabel eam ... - Expl.: ... ad triclinium trinitatis. Quod nobis dignetur concedere anime verus sponsus Iesus Christus dominus noster qui cum patre et spiritus sanctus vivit et regnat per omnia secula seculorum Amen.

Vgl. u. a. Innsbruck, ULB Tirol, Cod. 73, Bl. 113ra.

(145ra-146vc) nur Rahmung.

$\left(\mathrm{I}^{*} \mathrm{r}-\mathrm{v}\right)$ leer.

C.S.

\section{Cod. 166}

\section{SPECULUM HUMANAE SALVATIONIS}

Pap. II, 58, I* Bl. $295 \times 210$. Süddeutscher Raum, 1. Jz. 15. Jh.

B: $\quad$ Pap. bes. am Beginn stark verschmutzt, Bl. 1 und 2 beinahe lose, Bl. 11 lose. Blätter bisweilen mit schmalen Papierfälzen zur Verstärkung umschlagen bzw. geklebt. Bl. 1 urspr. mit Papierfalz auf Bl. I aufgeklebt, heute gelöst. Bl. II (Einzelbl., $130 \times 190)$ an Bl. 1r angeklebt. Nachweise und Bilder der Wasserzeichen s. WZMA. Datierung nach Wasserzeichenbefund. Identische Wasserzeichen: u. a. Neustift, Stiftsbibl., Cod. 165 (T. III dat. 1407); Wien, Schottenstift, Archiv, Hs. 102 (dat. 1408). Lagen: (I-1) (Vorsatzbl. 18. Jh.) $+1^{\mathrm{II}}+2 . \mathrm{VI}^{24}$ $+\mathrm{V}^{34}+2 \cdot \mathrm{VI}^{58}+(\mathrm{I}-1)^{I^{* *}}($ Nachsatzbl. 18. Jh.). Gegenbl. zum Vor- bzw. Nachsatzbl. als Spiegel auf dem VD bzw. HD aufgeklebt. Am Lagenende Kustoden in arabischen Ziffern, meist beschnitten. Am unteren, tw. zusätzlich am oberen Blattrand zeitgenössische Foliierung 1-10, 35 sowie 50-58, am oberen Blattrand fehlende Foliierung im 19. Jh. durch die ULB Tirol ergänzt. Bl. 52 neuzeitliches oranges Papiersignakel der ULB Tirol.

S: $\quad$ Schriftraum 215/220 (Bl. 3-71r: 125/135) $\times$ 170/175. Oberes Drittel des Schriftraums Federzeichnungen vorbehalten. Zwei Spalten, von feinen Tinten-, ab B1. 35 meist von Blindlinien gerahmt, zu 41-51 Zeilen, wenn Federzeichnungen zu 25-28 Zeilen, bisweilen auf Tinten- bzw. Blindlinierung. Zirkelstiche. Bastarda von zwei Händen: 1) Bl. IIv-52rb (= Cod. 165, Schreiber 1); 2) Bl. 52va-56ra. Beischriften zu den Federzeichnungen wohl von den Schreibern mit unterschiedlicher Feder. 
A: Rote Auszeichnungsstriche, Paragraphzeichen, Unterstreichungen, Über- und Schlussschriften; Bildbeischriften tw. (schwarz-)rot gerahmt; Bl.3rb als Kolumnenabschluss Punktblüten auf roter Wellenlinie; B1. 14ra der thronende Pharao baldachinartig in Rot (von Beischriftenhand) umkritzelt. Ein- und zweizeilige rote Lombarden und I-Versalien, B1. 52vb-55vb fallweise mit freien Punkten. Repräsentanten.

Zu den 45 Kapiteln des Speculum humanae salvationis 192 Federzeichnungen, tw. koloriert (dazu s. u.). Typologische Ausdeutung der Vita Christi, deren Bildprogramm sich - eingeleitet von der Schöpfungsgeschichte (cap. 1-2) und abgeschlossen von den sieben Stationen des Leidens Christi sowie den sieben Schmerzen und Freuden Mariens (cap. 43-45, jeweils acht Bilder) - in 40 Vierergruppen untergliedert; pro Gruppe jeweils ein Antitypus und drei meist dem Alten Testament entnommene Typen; Antitypus jeweils über linker Spalte des Verso, sodass jede Viergruppe $2: 2$ auf einer Doppelseite zu stehen kommt und als Einheit wahrgenommen werden kann. Anfänge der typenbezogenen Textabschnitte meist durch Paragraphzeichen und Marginalvermerke (prima/secunda/tertia figura) gekennzeichnet.

Cod. 166 gehört zur sog. Deutschen Gruppe des Speculum humanae salvationis, deren Bildprogramm sich in der 1. H. 14. Jh., zeitnah zur Entstehung dieses in zahlreichen Hs., Blockbüchern und Inkunabeln erhaltenen Erbauungsbuches, entwickelte. Ausführlich zur Ikonographie MeSch II 9-17, Kat. 3 (Wien, ÖNB, Cod. 1636; M. Roland), insbes. 12-15. Bemerkungen zu Abweichungen von der gängigen Ikonographie der Deutschen Gruppe mit * gekennzeichnet.

Bildbeischriften (in Schwarz und Rot, von verschiedenen Händen) auf Typen konzentriert; nachfolgend nur zitiert, wenn sie über Namen, Dingbezeichnungen und Angaben von Bibelstellen hinausgehen; [HS]: in Beischrift Historia Scholastica explizit als Quelle genannt.

Cap. 1: Bl. 3va Engelsturz. Bl. 3vb Erschaffung Evas. Bl. 4ra Gott vermählt Adam und Eva. Bl. 4rb Versuchung Evas durch die Schlange.

Cap. 2: Bl. 4va Sündenfall. Bl. 4vb Vertreibung aus dem Paradies. Bl. 5ra Adam und Eva arbeiten (In sudore wultus tui vesceris pane tuo). Bl. 5rb Arche Noah.

Cap. 3: Bl. 5va Verkündigung der Geburt Mariens an Anna (auf dem Spruchband des Engels: Ave gracia). Bl. 5vb Traum des Königs Astyages von der Geburt des Cyrus [HS]. Bl. 6ra Verschlossener Garten und versiegelter Brunnen als schematisierte Darstellung in rotem Kreis. Bl. 6rb Bileam kämpft gegen Engel.

Cap. 4: Bl. 6va Mariengeburt: Maria stehend zw. Anna und Joachim (*Annas Bett fehlt). Bl. 6vb Wurzel Jesse. Bl. 7ra Verschlossenes Tor des Tempels (Sinnbild Mariens). Bl. 7rb Tempel Salomos.

Cap. 5: B1. 7va Darbringung Mariens im Tempel: Maria als Dreiviertelfigur auf Säule. Bl. 7vb Der goldene Tisch der Sonne in Zabulon (Mensa solis inventa a piscatoribus). Bl. 8ra Jiftach opfert seine Tochter. Bl. 8rb Semiramis in den hängenden Gärten.

Cap. 6: Bl. 8va Verlobung Mariens. Bl. 8vb Verlobung von Sara und Tobias. Bl. 9ra Turm des Baris. Bl. 9rb Turm Davids mit Schilden.

Cap. 7: Bl. 9va Verkündigung an Maria. Bl. 9vb Brennender Dornbusch (auf tafelartigem Spruchband Gottes: Audi Israel mandata). Bl. 10ra Gideon und das Vlies. Bl. 10rb Rebekka und Eliëser am Brunnen.

Cap. 8: Bl. 10va Geburt Christi. Bl. 10vb Traum des Mundschenks des Pharao. Bl. 11ra Aarons grünender Stab. Bl. 11rb Sibylle verkündet Kaiser Augustus die Geburt Christi (u. a. Quere in passionali de nativitate domini).

Cap. 9: Bl. 11va Anbetung der Heiligen Drei Könige. Bl. 11vb Die Heiligen Drei Könige erblicken den Stern (u. a. Quere in passionali de nativitate domini). Bl. 12ra Die drei Helden bringen David Wasser. Bl. 12rb Thron Salomos: Salomo als Büste auf Säulenstumpf, vor dem Thron kniet Königin von Saba (ohne Gabe). Cap. 10: Bl. 12va Darbringung Christi im Tempel. Bl. 12vb Bundeslade. Bl. 13ra Siebenarmiger Leuchter (wirkt durch Blattdekor und grüne Kolorierung wie eine Pflanze). Bl. 13rb Darbringung Samuels im Tempel. Cap. 11: Bl. 13va Flucht nach Ägypten, im Hintergrund Götzenbilder (Genesis 27 de Rebeca que Iacob consuluit ut fugent). Bl. 13vb Ägyptische Madonna [HS]. B1. 14ra Der Knabe Mose greift in die glühenden Kohlen [HS]. Bl. 14rb Traum Nebukadnezars.

Cap. 12: Bl. 14va Taufe Christi. Bl. 14vb Ehernes Meer im Tempel (von sechs Rindern getragenes Erzbecken). Bl. 15ra Naamans wird durch Bad im Jordan geheilt. Bl. 15rb Israeliten tragen Bundeslade durch den Jordan.

Cap. 13: Bl. 15va Dreimalige Versuchung Christi durch den Teufel. Bl. 15vb Daniel tötet den Drachen des Götzen Bel. Bl. 16ra David tötet Goliat. Bl. 16rb David tötet einen Löwen und einen Bären (im Hintergrund zwei kleinere Löwen).

Cap. 14: Bl. 16va Maria Magdalena trocknet die Füße Christi mit ihren Haaren. Bl. 16vb Der gefangen gesetzte und büßende König Manasses. Bl. 17ra Heimkehr des verlorenen Sohnes. Bl. 17rb Natan vor David. Cap. 15: Bl. 17va Einzug Christi in Jerusalem. Bl. 17vb Jeremia klagt auf den Mauern von Jerusalem. Bl. 18ra David mit dem Haupt Goliats wird von Michal und Saul ehrenvoll empfangen. Bl. 18rb Geißelung Eliodors.

Cap. 16: Bl. 18va Letztes Abendmahl. Bl. 18vb Mannalese. Bl. 19ra Juden braten das Paschalamm. Bl. 19rb Melchisedek und Abraham. 
Cap. 17: Bl. 19va Christus wirft die Soldaten, die ihn verhaften wollen, mit seinem Wort nieder. Bl. 19vb Simson erschlägt die Philister mit einem Eselskinnbacken. Bl. 20ra Schamgar tötet 600 Männer mit einer Pflugschar. B1. 20rb David tötet 800 Männer mit einem Hieb.

Cap. 18: Bl. 20va Gefangennahme Christi (Judaskuss, Christus heilt das von Petrus abgeschlagene Ohr des Malchus). Bl. 20vb Joab tötet Amasa. Bl. 21ra Saul attackiert David mit einem Speer. Bl. 21rb Opfer Abels und Kains; Kain erschlägt Abel.

Cap. 19: Bl. 21va Verspottung Christi. Bl. 21vb Hur wird zu Tode gespien [HS]. Bl. 22ra Noahs Schande. Bl. 22rb Verspottung (und Blendung) Simsons.

Cap. 20: Bl. 22va Geißelung Christi. Bl. 22vb Achior wird an einen Baum gebunden. Bl. 23ra Lamech wird von seinen beiden Frauen verspottet. Bl. 23rb Ijob wird von seiner Frau und vom Teufel gegeißelt.

Cap. 21: Bl. 23va Dornenkrönung. Bl. 23vb Apamene nimmt Darius die Krone weg (Concubina Appomen que abstraxxit [!] regi [darüber von anderer Hand: Zorobabel] coronam de capite). Bl. 24ra Schimi verhöhnt David. Bl. 24rb Hanun, der König der Ammoniter, entehrt den Boten Davids, indem er ihm die Kleider abschneiden lässt.

Cap. 22: Bl. 24va Kreuztragung. Bl. 24vb Isaak, das Opferholz tragend, folgt Abraham (mit Feuerschale). Bl. 25ra Gleichnis von den bösen Winzern: Weinbergarbeiter töten den Boten des Weinbergbesitzers. Bl. 25rb Die beiden Kundschafter tragen die große Traube.

Cap. 23: B1. 25va Christus wird ans Kreuz geschlagen. Bl. 25vb Tubal-Kaijn schmiedet Nägel und Jubal musiziert. B1. 26ra Jesaja wird zersägt. Bl. 26rb Joab, der König von Moab, opfert seinen Sohn auf der Stadtmauer.

Cap. 24: Bl. 26va Kreuzigung mit Maria, Johannes und den beiden Schächern. Bl. 26vb Traum Nebukadnezars vom großen Baum. Bl. 27ra Opfertod des Königs Codrus. Bl. 27rb Eliëser tötet den Elefanten.

Cap. 25: Bl. 27va Verspottung des gekreuzigten Christus. Bl. 27vb Michal, Sauls Tochter, verspottet David. B1. 28ra Abschalom wird von seinen Mördern verspottet. B1. 28rb Ewil-Merodach zerstückelt den Leichnam seines Vaters Nebukadnezar.

Cap. 26: Bl. 28va Kreuzabnahme. Bl. 28vb Josefs Rock wird Jakob gebracht. Bl. 29ra Adam und Eva betrauern den toten Abel (*mit offenen Augen). Bl. 29rb Noomi trauert mit Rut und Orpa um ihre Söhne.

Cap. 27: Bl. 29va Grablegung Christi. Bl. 29vb David folgt trauernd dem Leichnam Abners (*normalerweise vier Sargträger, von den beiden hinteren nur Köpfe zu sehen). Bl. 30ra Josef wird von seinen Brüdern in den Brunnen geworfen. Bl. 30rb Jona wird ins Meer geworfen und vom Wal verschlungen.

Cap. 28: Bl. 30va Christus in der Vorhölle (*übliche Einteilung in vier Register nur rudimentär im oberen Bereich erhalten: zwei Register, daneben Christus auf Wolke; darunter Höllenszene). Bl. 30vb Die drei Jünglinge im Feuerofen, von einem Engel getröstet. Bl. 31ra Daniel in der Löwengrube, von einem Engel gespeist. Bl. 31rb Strauß befreit sein Junges mit Schlangenblut aus einer Glasflasche.

Cap. 29: Bl. 31va Christus besiegt den Teufel. Bl. 31vb Benaja tötet einen Löwen. Bl. 32ra Simson und der Löwe. Bl. 32rb Ehud tötet Eglon (u. a. Ayoth ambidexter).

Cap. 30: Bl. 32va Maria besiegt den Teufel mit den Leidenswerkzeugen. Bl. 32vb Judit tötet Holofernes. Bl. 33ra Jaël tötet Sisera. Bl. 33rb Königin Tomyris taucht das Haupt des von ihr getöteten König Cyrus in Blut.

Cap. 31: Bl. 33va Höllenfahrt Christi: Jesus befreit die Seelen der Gerechten aus dem Höllenfeuer. Bl. 33vb Auszug aus Ägypten. B1. 34ra Gott befreit Abraham aus dem Feuer (Ur in Chaldäa). Bl. 34rb Lots Flucht aus Sodom.

Cap. 32: Bl. 34va Auferstehung Christi. Bl. 34vb Simson mit den Stadttoren von Gaza. Bl. 35ra Jona wird vom Wal ausgespien. Bl. 35rb Eckstein wird Schlussstein des Tempels (Lapis angularis factus in caput anguli).

Cap. 33: Bl. 35va Himmelfahrt Christi. Bl. 35vb Jakobs Traum von der Himmelsleiter. Bl. 36ra Gleichnis vom guten Hirten (Ovis perdita). Bl. 36rb Himmelfahrt des Elija (*Feuerwagen nicht als solcher gekennzeichnet) (u. a. Verweis auf Parallelstelle Hoc etiam legitur de Enoch Genesis x).

Cap. 34: Bl. 36va Pfingsten (Ausgießung des hl. Geistes). Bl. 36vb Turmbau zu Babel. B1. 37ra Gott erscheint Mose (Gesetzgebung auf dem Berg Sinai). Bl. 37rb Elija füllt mit seinem Gebet die Ölkrüge der armen Witwe. Cap. 35: Bl. 37va Maria mit den Leidenswerkzeugen. Bl. 37vb Hanna sorgt sich um den abwesenden Tobias: links die Eltern Hanna und Tobit, rechts Tobias, der von seinem Begleiter Rafael weggeführt wird. Bl. 38ra Gleichnis von der verlorenen Drachme. Bl. 38rb Saul vermählt Palti und Michal, obwohl diese David liebt.

Cap. 36: Bl. 38va Krönung Mariens. Bl. 38vb David bringt die Bundeslade in seinen Palast. Bl. 39ra Das Apokalyptische Weib (Mondsichel-Madonna). Bl. 39rb Salomo lässt seine Mutter Batseba zu seiner Rechten auf dem Thron Platz nehmen.

Cap. 37: Bl. 39va Maria und zwei Mönche besänftigen als Fürbitter den Zorn Gottes, symbolisiert durch Pfeile, die auf die sündigen Menschen gerichtet sind. Bl. 39vb Abigajil besänftigt Davids Zorn. Bl. 40ra Die 
Frau aus Tekoa besänftigt Davids Zorn. Bl. 40rb Eine kluge Frau besänftigt Joabs Zorn mit dem abgeschlagenen Haupt des Scheba.

Cap. 38: B1. 40va Schutzmantel-Madonna. Bl. 40vb Tharbis verteidigt die Stadt Saba [HS]. B1. 41ra Eine Frau tötet Abimelech mit einem Stein und rettet die Stadt Tebez. Bl. 41rb Michal rettet David vor seinen Verfolgern.

Cap. 39: Bl. 41va Christus zeigt Gottvater seine Wundmale. Bl. 41vb Antipater zeigt Julius Caesar seine Wunden. Bl. 42ra Maria zeigt Christus ihre Brust (*hier verhüllt) und bittet für das Volk (Maria armiger Christi). Bl. 42rb Ester vor Ahasver als Fürbitterin für die Israeliten.

Cap. 40: Bl. 42va Jüngstes Gericht. Bl. 42vb Gleichnis von den zehn Talenten. Bl. 43ra Gleichnis von den fünf klugen und den fünf törichten Jungfrauen. Bl. 43rb Das Menetekel.

Cap. 41: Bl. 43va Strafen der Verdammten in der Hölle. Bl. 43vb Rache an Davids Feinden. Bl. 44ra Gideon lässt die Ältesten von Sukkot schlagen. Bl. 44rb Untergang der Ägypter im Roten Meer (*kein Wasser zu erkennen, sollte evtl. durch rote Kolorierung dargestellt werden).

Cap. 42: Bl. 44va Maria und Christus thronend in der Mandorla. Bl. 44vb Salomo und die Königin von Saba. Bl. 45ra Gastmahl des Königs Ahasver. Bl. 45rb Gastmahl der Söhne Ijobs.

Cap. 43: Die sieben Stationen des Leidens Christi. Bl. 45va Christus mit Kreuz (und Wundmalen, Seitenwunde ist zu erkennen) erscheint einem Einsiedler. Bl. 45vb Letztes Abendmahl. Bl. 46ra Ölberg. Bl. 46rb Gefangennahme Christi (Judaskuss). Bl. 46va Christus vor Pilatus (Handwaschung). Bl. 46vb Geißelung Christi. B1. 47ra Urteil des Pilatus und Kreuztragung Christi. B1. 47rb Dreifigurige Kreuzigung. Cap. 44: Die sieben Schmerzen Mariens. Bl. 47va Mönch mit Schwert in der Brust. Bl. 47vb Darbringung Christi im Tempel. Bl. 48ra Flucht nach Ägypten (heilige Familie zu Fuß mit Engelserscheinung). Bl. 48rb Der zwölfjährige Christus bei den Schriftgelehrten; Mann mit wirrem Haar spuckt (?) Christus an (Pharisäer?). Bl. 48va Gefangennahme Christi. Bl. 48vb Dreifigurige Kreuzigung. Bl. 49ra Grablegung Christi. Bl. 49rb Maria mit den Leidenswerkzeugen

Cap. 45: Die sieben Freuden Mariens. Bl. 49va Maria erscheint einem kranken Mönch. Bl. 49vb Verkündigung (auf dem Spruchband des Engels: Ave gracia plena). Bl. 50ra Heimsuchung. Bl. 50rb Geburt Christi. Bl. 50va Anbetung der Heiligen Drei Könige. Bl. 50vb Darbringung Christi im Tempel. Bl. 51ra Maria findet Christus unter den Schriftgelehrten. Bl. 51rb Krönung Mariens.

Illustrationen jeweils rahmenlos, häufig mit Bodenandeutungen. Etwas ungelenke Figuren, zuweilen mit unproportionierten Händen; vereinzelt ungeschickte Rückenfiguren (z. B. Bl. 45vb); bis auf ältere bzw. bärtige Männer relativ einheitliche Gesichter, häufig mit deutlich eingezeichnetem Nasenrücken. Gewänder mit kritzelig eingezeichneten Faltenbahnen, die am Boden weich umbrechen. Einfache Schattierungen durch Schraffen, häufiger durch graue Flächen (B1. 20v Abschattierung durch Rot); insgesamt wenig Plastizität. Uneinheitliche Kolorierung in Rot (ab Bl. 44v auch Rotbraun), Grün, Ocker(-Gelb), ab Bl. 42v Blau(-Grau); selten Inkarnat(-Andeutungen); kolorierte und unkolorierte Abschnitte wechseln sich ab: anfangs (Bl. $3 \mathrm{v}-$ 25r, Cap. 1-22) sorgfältigerer Farbauftrag; Bl. 25v-33r (Cap. 23-30) bis auf etwas Rot für Blut bzw. Wunden unkoloriert; Bl. 33v-38r und 42v-43v (Cap. 31-35; 40) koloriert, aber bis auf Bl. 42v-43r mit weniger Aufwand; Bl. 38v-42r und 44r-51r (Cap. 36-39; 41-45) bis auf rotbraune Einsprengsel unkoloriert.

Während die ältere Forschung, u. a. Hermann, Cod. 166 nach Österreich lokalisierte, gibt Roland, Gotik 267 Anm. 18, 271 Anm. 50, der Stilentsprechungen zum Johannesmeister aus dem Atelier des Rüdiger Schopf (um 1400, Freiburg i. B.) sieht, die Hs. nach Südwestdeutschland. Die Lokalisierung bedarf allerdings noch weiterer Überprüfung.

S. R.

E: $\quad$ Neuzeitlicher Bibliothekseinband: schwarz gesprenkeltes braunes Pap. über Pappe. Neustift, 2. H. 18. Jh. Pap. tw. etwas abgerieben. Am VD und HD Ecken mit braunem Leder verstärkt. Rücken: braunes Leder, vier einfache Bünde, von Goldbordüren gesäumt. Im zweiten Feld Golddruck MANUSCRIPTA in Goldrahmung, im dritten gelbes Signaturschild (s. bei G). Schnitt rot gesprenkelt. Spiegel Pap. 18. Jh. Am Spiegel des VD Signaturen und Bleistiftnotiz (s. bei G), Spiegel des HD leer.

G: Zeitpunkt und Art der Erwerbung durch Neustift unbekannt. Die zeitgenössische Foliierung in der Mitte des oberen Blattrandes lässt - gemeinsam mit den übereinstimmenden Wasserzeichen sowie der Größe der Hs. darauf schließen, dass Cod. 166 urspr. mit Cod. 165 vereinigt war. Gegebenenfalls wohl im Zuge der Neuaufstellung der Neustifter Bibliothek in der 2. H. 18. Jh. (wie dies auch bei anderen Hs. und Inkunabeln gemacht wurde) in Einzelhandschriften aufgelöst; jeder Einzelband erhielt den für Neustift typischen Halbledereinband.

1809 anlässlich der vorübergehenden Aufhebung des Klosters Neustift der ULB Tirol übergeben. Am Spiegel des VD alte Signaturen der ULB Tirol II 2 H 14 (Tinte, Bleistift) und Nr. 166/1 (Tinte) sowie Bleistiftnotiz (Vide Grundzettel). Am Rücken gelbes Signaturschild der ULB Tirol 166. Bl. IIr Stempel der ULB Tirol 19. Jh. 1921 aufgrund des Friedensvertrages von St. Germain an den italienischen Staat abgegeben 
und von diesem 1929 dem Kloster Neustift als Dauerleihgabe überlassen. Bl. IIr sowie Bl. 1r Stempel der Soprintendenza Tridentina 20. Jh.

L: $\quad$ Wilhelm II 110. - H. Tietze, Die typologischen Bilderkreise des Mittelalters in Österreich. Wiener Jahrbuch für Kunstgeschichte 2/1 (1904) 62. - Hermann 166-169, Nr. 178. - Rasmo 26 (Nr. 48) und Abb. 44-45 (ohne Nennung der Sign.). - Peintner, Buchmalerei 37-40. - Katalog ULB Tirol II 140, 207. - Peintner, Stiftsbibliothek 118-119. - Roland, Gotik 267 Anm. 18, 271 Anm. 50.

(Ir-v) leer.

(IIr) Stempel (s. bei G).

1 (IIv) Memorialverse De ordine librorum Bibliae (Walther, Initia Nr. 19872).

Inc.: Ut seriem menti (!) teneas textus doceam te/Est Genesis primus, post Exodus ipse secundus ... - Expl.: ... Iacobus et Petrus Io[hannes] Iudas et Apokalipsis.

2 (1ra-51rb) Speculum humanae salvationis (Ed.: J. Lutz, P. Perdrizet. Mühlhausen 1907. - Stegmüller RB Nr. 11765. Bloomfield Nr. 2562 und 4579).

Gegenüber Edition vereinzelt Verse ausgelassen oder eingefügt, Wortstellung bisweilen leicht abweichend.

(1ra-3rb) Prooemium. Tit.: Incipit prohemium istius libri qui dicitur speculum humane salvacionis.

(3va-45rb) Cap. 1-42 (Ed. 4-87).

(45va-47rb) De septem stationibus passionis Iesu Christi (Ed. 88-91). Tit.: Capitulum 43m.

(47va-49rb) De septem tristitiis BMV (Ed. 92-95). Tit.: Capitulum $44^{m}$ de septem tristiciis beate virginis.

(49va-51rb) De septem gaudiis BMV (Ed. 96-99). Tit.: Capitulum $45^{m}$ de septem gaudiis beate virginis.

3 (51va-52rb) Vita s. Mariae post ascensionem Christi versificata (vgl. Druck: A. Vögtlin, Vita beatae virginis Mariae et salvatoris rhythmica [Bibliothek des Litterarischen Vereins in Stuttgart 180]. Tübingen 1888, V. 6612-6741. - Walther, Initia Nr. 7529).

(51va-52ra) Tit.: Qualis fuerit vita et conversacio virginis Marie. Incipit prologus operis sequentis. - Inc.: Hec est vita virginis Marie gloriose/Summi Dei filii matris generose ... Maria sibi regulam statuit vivendi / et sub quodam ordine Deo serviendi ... - Expl.: ... Sic per dies singulos Maria faciebat/Quibus in hoc seculo vivens permanebat.

(52ra-rb) Anschließend Mariengebet in Versen. Tit.: Oracio ad beatam virginem. - Inc.: O regina virginum fac tecum gratulari/Quos hic in exilio vides tribulari ... - Expl.: ... Gaudentesque perducere ad celi regna Amen.

Parallelüberlieferung: u. a. Graz, UB, Hs. 241, Bl. 126v und Hs. 1638, Bl. 69r.

(52rb) Schlussschrift (rot): Explicit speculum humane salvacionis/Quod docet nos venire ad locum eterne visionis.

4 (52va-56ra) Auszüge aus «Eusebius CAESARIEnsis, InTERPRETE Rufino AquiLEIEnSI〉: Ecclesiasticae Historiae (Druck: u. a. Basel 1559. Ed.: E. Schwartz, Th. Mommsen, Eusebius Werke II: Historia ecclesiastica [GCS 9/1 und 2]. Leipzig 1903 und 1908).

Tit.: Nota de destinccione (!) gentis Iudeorum. - Inc.: Quanta Iudeis acciderint gravia post post (!) temeritatem crucis in Christum scribit magister in Ecclesiastica Hystoria libro $2 c^{\circ} 6$ dicens Primo quidem temporibus Tyberii refert in urbe Roma ... - Expl.: ... sic deterriti Iudei atque gentiles locum simul et inaniter cepta relinquere.

(52va-53rb) Lib. 2.

(52va) Cap. 6. - (52vb) Cap. 7 und 11. - (53ra) Cap. 19 und 20. - (53rb) Cap. 21 (leicht gekürzt).

(53rb-55va) Lib. 3.

(53rb) Cap. 5. - (53va) Cap. 6. - (54vb) Cap. 7. - (55ra) Cap. 8.

(55va-55vb) Lib. 4, cap. 6. 
(55vb-56ra) Lib. 10 (= Rufinus Aquileiensis, Lib. 1), cap. 38-40 (Druck auch PL 21, 505A-506C, hier cap. 37-39. - Vgl. CPL Nr. 198k).

(56rb-vb) nur Rahmung.

5 (57ra) 〈Sulpicius Severus, Iohannes Cassianus»: De vitis patrum, Lib. 4 = Excerpta, cap. 45, unvollständig, durchgestrichen (PL 73, 842A).

Inc.: [Q]uid eciam de illo monacho commemorem cuius nomen quia adhuc superest ... - Expl. mut.: ... pariter in eodem monasterio commanebat [

(57rb-58vb) nur Rahmung.

$\left(\mathrm{I}{ }^{*} \mathrm{r}-\mathrm{v}\right)$ leer.

A. P./U.S.

\section{Cod. 167}

\section{ADAM DE ALDERSBACH}

Pap. I, 72, I* Bl. $290 \times 205$. Süddeutscher Raum, 1419 .

B: Pap. fleckig (Wasserschaden?), B1. 39 und 40 löchrig. Bilder und Nachweise der Wasserzeichen s. WZMA. Wasserzeichenbefund mit Datierung übereinstimmend. Verwandte Wasserzeichen: u. a. Wien, Schottenstift, Archiv, Hs. 329, T. I (dat. 1417); Klosterneuburg, Stiftsbibl., CCl 680, T. I (dat. 1419); Innsbruck, ULB Tirol, Cod. 546. Lagen: (I-1) ${ }^{\mathrm{I}}$ (Vorsatzbl. 18. Jh.) + VII ${ }^{14}+4 \cdot \mathrm{VI}^{62}+\mathrm{V}^{72}+(\mathrm{I}-1)^{\mathrm{It}^{*}}$ (Nachsatzbl. 18. Jh.). Gegenbl. zum Vor- bzw. Nachsatzbl. als Spiegel auf dem VD bzw. HD aufgeklebt. Am Ende der Lagen 4 und 5 Kustode in Rot in arabischer Ziffer, am Ende der Lage 4 stark beschnitten. Am oberen Blattrand Foliierung 19. Jh. durch die ULB Tirol.

S: $\quad$ Schriftraum $215 / 225 \times 145 / 150$. Zwei Spalten, von Tintenlinien gerahmt, ab Bl. 39 nur mehr seitlich begrenzt, zu 44-51 Zeilen. Verszeilen mit größerem Abstand (ca. drei Zeilen des begleitenden Kommentars). Bastarda, dat. 1419 (Bl. 71va). Schreiber: Nicolaus Frechen.

A: Rote Auszeichnungsstriche, Paragraphzeichen, Unterstreichungen und Überschriften. Drei- bis zehnzeilige rote Lombarden, tw. mit Punktverdickungen. B1. 1ra fünfzeilige rote Initiale mit ausgesparten Vierblattblüten. B1. 31v (ganzseitig) Arbor consanguinitatis in schwarzer und grünlich-ockerfarbener Pinselzeichnung; Baumschema entspringt aus einem Kranz von Akanthusblättern, Medaillons nicht beschriftet.

E: $\quad$ Neuzeitlicher Bibliothekseinband: schwarz gesprenkeltes braunes Pap. über Pappe. Neustift, 2. H. 18. Jh. Pap. tw. abgerieben und beschädigt. Am VD und HD Ecken mit braunem Leder verstärkt. Rücken: braunes Leder, vier einfache Bünde, von Goldbordüren gesäumt. Im ersten Feld Golddruck M: S:, im zweiten RITUALE in Goldrahmung, im dritten Signaturschild (s. bei G). Schnitt rot gesprenkelt. Spiegel Pap. 18. Jh. Am Spiegel des VD Exlibris, Signaturen und Bleistiftnotiz (s. bei G), Spiegel des HD leer.

G: $\quad$ Bl. 1r Besitzvermerk Anfang 16. Jh. Magister Nicolaus Leopoldus ex Insprugga XXX (vgl. Cod. 579; 1511 Lehrer an der Pfarrschule von St. Jakob, Innsbruck [W. Steiner, Die Lateinschule der St. Jakobspfarrkirche in Innsbruck, in: K. Drexel, M. Fink (Hrsg.), Musikgeschichte Tirols I: Von den Anfängen bis zur Frühen Neuzeit (Schlern-Schriften 315). Innsbruck 2001, 404, 501], empfängt 1513 in Brixen die niederen Weihen und erhält 1515 Kanonikat, gest. 1535 [K. Wolfsgruber, Das Brixner Domkapitel in seiner persönlichen Zusammensetzung in der Neuzeit 1500-1803 (Schlern-Schriften 80). Innsbruck 1951, 42 und 170; W. Senn, Musik und Theater am Hof zu Innsbruck. Geschichte der Hofkapelle vom 15. Jahrhundert bis zu deren Aufhebung im Jahre 1748. Innsbruck 1954, 13 und 46]). Am Spiegel des VD Exlibris der Stiftsbibl. Neustift 18. Jh. 1809 anlässlich der vorübergehenden Aufhebung des Klosters Neustift der ULB Tirol übergeben. Am Spiegel des VD alte Signaturen der ULB Tirol II 2 H 15 (Tinte, Bleistift) und N. 167 (Tinte) sowie Bleistiftnotiz (Vide Grundzettel). Am Rücken gelbes Signaturschild der ULB Tirol 167. Bl. 1r Stempel der ULB Tirol 19. Jh. 1921 aufgrund des Friedensvertrages von St. Germain an den italienischen Staat abgegeben und von diesem 1929 dem Kloster Neustift als Dauerleihgabe überlassen. Bl. 1r Stempel der Soprintendenza Tridentina 20. Jh. 
L: $\quad$ Wilhelm II 108. - Katalog ULB Tirol II 140, 207. - Katalog ULB Tirol II, Beiheft, Taf. 54. - Stefani 104. Peintner, Stiftsbibliothek 121. - Baroffio 324, Nr. 16713.

$(\mathrm{Ir}-\mathrm{v})$ leer.

1 (1ra-71vb) 〈ADAM DE AldERSBACH〉: Summula pauperum mit Kommentar und Interlinearglossen (bis B1. 66vb) (Druck der Verse: GW 212-217. - Walther, Initia Nr. 9117. Kaeppeli Nr. 3. Bloomfield Nr. 2668 und 5852. Kommentar nicht übereinstimmend).

(1ra-b) Prolog. Inc.: Secundum dictum Augustini in domo Dei id est in ecclesia quatuor sunt necessaria scilicet grammatica musica computus et ius cananicum (!). Gramatica ad scripturas sacras intelligendum musica ad laudes Dei decantandum ... - Expl.: ... Civile dicitur alio nomine imperiale et illud traditur in quattuor libris legum scilicet ius canonicum est ius regulare et traditur in duobus libris principaliter scilicet in Decretalibus et in libro Decretorum et in aliis. (1rb-71ra) Text. Inc.: In summis festis (interlinear: in diebus magne festivitatis) ad missam (interlinear: id est divinum officium) dicitur (interlinear: id est legitur) una. Tantum (interlinear: id est solummodo) collecta nisi sit (interlinear: semper talis festivitatibus) coniuncta (interlinear: approbata) diei (interlinear: semper alicuius sancti). (Forts. 2rb) In defunctorum (interlinear: id est mortuorum) collectam (interlinear: id est talem oracionem) dicere (interlinear: id est legere vel interponere) missa de sanctis poteris (interlinear: id est valebis) sed (interlinear: id est tamen) illa penultima fiat (interlinear: semper collecta id est penes id est erit ultimam) ... - Expl.: ... virgo si rapitur a pluribus et violenter unus noscat eam ... in summis festis que quatuor esse videtur (!) corpora non aliqua defunctorum tumulantur.

(1rb-71vb) Kommentar. Inc.: Hic iam est pars executiva in qua prosequitur intentum volens depellere ignoranciam deposicionis circa quid sciendum quod duplex est ignorancia scilicet ignorancia abnegacionis et ignorancia deposicionis ... - Expl.: ... In ista parte magister ponit alia documenta circa confessionem et primo facit hoc de raptu virginis ... sed communiter dicta sunt festum ascensionis et festum cordis Christi et festum omnium sanctorum et patrocinium et quodlibet alius festum beate virginis Marie et sic est finis Deo laus omnipotenti et matri eius gloriosissime virginis Marie. Laus summo genitori detur atque eius genitrici Deo gracias.

(31v) ganzseitig Arbor consanguinitatis, nicht beschriftet.

(71va) Schlussschrift mit Datierung und Schreibernennung: Anno ab incarnacione domini millesimo quarto decimo (!) et decimo nono finitus est liber iste per manus Nicolay Frechen in octava Agnetis virginis hora decima diei ante festum purificacionis Marie virginis etc. (1. Februar 1419). Lit.: Schulte GQ II 427-428; F. Valls Taberner, La „Summula Pauperum“ de Adam de Aldersbach (Span. Forschungen der Görresgesellschaft I/7). Münster 1938, 75-83.

2 (71va-b) Exzerpte aus Augustinus, Gregorius Magnus und Beda Venerabilis.

1) Tit.: Augustinus. - Inc.: In illo die quo videtur corpus Christi victus necessarius retribuitur lenia colloquia dimittantur ... - Expl.. ... a Deo remunerantur etc.

2) Tit.: Gregorius. - Inc.: O quam magnum donum et mirificum bonum de Dei misericordia quia tanta est dignitas ... - Expl.: ... unius anime a penis purgatorii liberacio etc.

3) Tit.: Beda. - Inc.: Sacerdos qui sine mortalibus est peccatis et bono proposito si non celebrat missam cum possit et habet copiam celebrandi ... - Expl.: ... et pro hoc respondebit Deo in novissimo die.

3 (71vb) Versus de REgimine sacerdotis (Walther, Initia Nr. 14519).

16 Hexameter. Inc.: Presbiter attende capias hec dogmata mente/hec tibi norma datur per quam tua vita regatur ... - Expl.: ... vivere sine mori (!) confert qui porrigit ori.

4 (71vb) De Transsubstantiatione (Walther, Initia Nr. 3214).

14 Hexameter. Tit.: Augustinus. - Inc.: Constat in altari carnem de pane creari/illa caro Deus est qui dubitat reus est ... - Expl.: ... errores hereses laicorum quando reiecit. 
5 (72r) 〈Ps.-BonAVENTURA〉: Tabula a celebrantibus missam consideranda (Druck: GW M14225. Distelbrink Nr. 225). Mit acht schematischen Darstellungen.

Inc.: Intencionis discussio - ne propter vanam gloriam ... - Expl.: ... causa excellentis/ excellentioris anime/excellentissime divinitatis Christi.

Darunter Notiz: Tangere qui gaudes meretricem qualiter audes/palmis pollutis regem tractare salutis (Walther, Proverbia Nr. 31040).

(72v) nur Rahmung.

$\left(\mathrm{I}^{*} \mathrm{r}-\mathrm{v}\right)$ leer.

P. A.

\section{Cod. 168}

\section{ARISTOTELES}

Pap. I, 46, I* Bl. $290 \times 220$. Wien, 9. Jz. 14. Jh.

B: Bilder und Nachweise der Wasserzeichen s. WZMA. Datierung nach Wasserzeichenbefund. Identische Wasserzeichen: u. a. Göttweig, Stiftsbibl., Cod. 70 (rot) (dat. 1384); Zwettl, Stiftsbibl., Cod. 224 (dat. 1389). Lagen: (I-1) ${ }^{\mathrm{I}}$ (Vorsatzbl. 18. Jh.) $+3 . \mathrm{VI}^{36}+\mathrm{V}^{46}+(\mathrm{I}-1)^{\mathrm{I}^{*}}$ (Nachsatzbl. 18. Jh.). Gegenbl. zum Vor- bzw. Nachsatzbl. als Spiegel auf dem VD bzw. HD aufgeklebt. Erstes und letztes Bl. des Quinternio von den übrigen Bl. etwas abweichend, unsicher, ob zwei einzelne Bl. oder ein Doppelbl. Lagenreklamanten. Am oberen Blattrand rechts zeitgenössische Zählung der Bücher in arabischen Ziffern, tw. durchgestrichen und neu geschrieben. Am oberen Blattrand Foliierung 19. Jh. durch die ULB Tirol.

S: $\quad$ Text von Kommentar umgeben. Schriftraum Haupttext $160 \times 95 / 110$, von Tintenlinien gerahmt, zu 27-33 Zeilen. Schriftraum Kommentarfelder stark wechselnd, von Tintenlinien gerahmt (Bl. 1-36 einfach, Bl. 37r46v tw. zweifach). Äußeres Kommentarfeld tw. beschnitten (Textverlust). Kursive Bastarda von mehreren einander abwechselnden Händen. Schreiberwechsel Bl. 2v, 3v, 5v, 10v, 12v/13r, 16v, 17r (die letzten drei Zeilen gleiche Hand wie die dazugehörige Glosse), 18v, 28r/v, 34v/35r, 35r/v, 36v/37r, 38r-39r Forts. von Bl. 36v. Bl. 35r Text in kalligraphischer Bastarda. Weitere Schreiberwechsel 39r, 40r, 41r/v, 41v/42r. Glossen weitgehend von einer Hand. Vgl. auch Cod. 163, T. I.

A: Rote Auszeichnungsstriche, Unterstreichungen, Rahmungen sowie schwarze, rot konturierte Paragraphzeichen. Zwei- und dreizeilige rote und schwarze Lombarden, tw. mit rotem (Schraffur-)Dekor, Bl. 1r, 9r, $24 \mathrm{v}$ vier- und fünfzeilige rote Lombarden, Bl. 1r mit schwarzen gegenständigen Halbpalmetten im Binnenfeld.

E: $\quad$ Neuzeitlicher Bibliothekseinband: schwarz gesprenkeltes braunes Pap. über Pappe. Neustift, 2. H. 18. Jh. Am VD und HD Ecken mit braunem Leder verstärkt. Rücken: braunes Leder, vier einfache Bünde, von Goldbordüren gesäumt. Im zweiten Feld Golddruck M. S. PHYSICA in Goldrahmung, im dritten Signaturschild (s. bei G). Schnitt rot gesprenkelt. Spiegel Pap. 18. Jh. Am Spiegel des VD Signaturen und Bleistiftnotiz (s. bei G), Spiegel des HD leer.

G: $\quad$ Nach dem Inhaltsverzeichnis in Innsbruck, ULB Tirol, Cod. 157, Bl. Ir gehört Cod. 168 zu einer Gruppe von urspr. selbständigen Hs. des 14. und 15. Jh., die im 15. Jh. in Neustift zu einem Sammelband vereinigt wurden.

Im Zuge der Neuaufstellung der Neustifter Bibliothek in der 2. H. 18. Jh. wurde die Sammelhandschrift (wie dies auch bei anderen Hs. und Inkunabeln gemacht wurde) in sieben Einzelhandschriften aufgelöst; jeder Einzelband erhielt den für Neustift typischen Halbledereinband. Zur urspr. Hs. zählen folgende Signaturen (in der urspr. Reihenfolge):

Cod. 157: Aristoteles: Ethica Nicomachea und Oeconomica. heute nicht mehr nachweisbar: Aristoteles: Politica.

Cod. 159: Albertus de Saxonia: Kommentar zu Cod. 157.

Cod. 168: Aristoteles: Physica, Lib. 1-5.

Cod. 163: Aristoteles: Physica, Lib. 6-8 und De anima.

Cod. 181: Alanus ab Insulis: Summa de arte praedicatoria.

Cod. 164: Anshelmus Havelburgensis. Anticimenon. 
Von diesen sieben Hs. ist eine nicht mehr erhalten, drei befinden sich heute an der ULB Tirol in Innsbruck (Cod. 157, 159 und 164), drei werden in der Stiftsbibl. Neustift (Cod. 163, 168 und 181) aufbewahrt. 1809 anlässlich der vorübergehenden Aufhebung des Klosters Neustift der ULB Tirol übergeben. Am Spiegel des VD alte Signaturen der ULB Tirol II 2 H 16 (Tinte, radiert), II 2 H 16 (Bleistift) und Nr. 168 (Tinte) sowie Bleistiftnotiz (Vide Grundzettel). Am Rücken gelbes Signaturschild der ULB Tirol 168. Bl. 2r Stempel der ULB Tirol 19. Jh. 1921 aufgrund des Friedensvertrages von St. Germain an den italienischen Staat abgegeben und von diesem 1929 dem Kloster Neustift als Dauerleihgabe überlassen. Bl. 2r Stempel der Soprintendenza Tridentina 20. Jh.

L: $\quad$ Lacombe II 1024 Nr. 1496. - Neuhauser, Neustift 91-95. - Katalog ULB Tirol II 140, 207. - W. Neuhauser, Buchgeschichtliche Beziehungen zwischen dem Wiener Raum und Tirol im Mittelalter. Jahrbuch für Landeskunde von Niederösterreich N. F. 63/64 (1997/98) 57 (auch in: Neuhauser, In libris 405-424).

$(\mathrm{Ir}-\mathrm{v})$ leer.

(1r) am oberen Blattrand Schreibervers, stark beschnitten: Assit ad inceptum sancta Maria meum.

(1r-46v) Aristoteles: Physica, Translatio nova durch Guilelmus de Moerbeke, Lib. 1-5 (Druck: u. a. GW 2336. Ed.: Aristoteles Latinus VII: Physica, Fasc. 1: Translatio vetus, ed. F. Bossier, J. Brams, rev. ed. A. Mansion. Leiden, New York 1990. - Lacombe I 52, Nr. 17, I 126-127, Nr. 17 und II 1024, Nr. 1496. Thorndike-Kibre 1296). Mit umfangreichem Kommentar.

Tit.: Textus VIII librorum Phisicorum. - Inc.: Quoniam quidem scire et intelligere contingit circa omnes sciencias quarum principia sunt aut cause aut elementa ... - Expl. mut. (Lib. 5, cap. 6, knapp vor Schluss): ... et de motu quidem et quoete (!) quomodo utique unus [

(1r-8v) Lib. 1. - (9r-17r) Lib. 2. - (17r-24r) Lib. 3. - (24v-39r) Lib. 4. Bl. 36v schließt propter parvitatem, $\mathrm{Bl}$. 37r (Forts. von anderer Hand): et perpetuitatem. Mutatio autem omnis a natura ... bis inpossibile est et [ $\mathrm{Bl}$. 37v leer, Bl. 38r (von gleicher Hand von Bl. 36v): Mutatio autem omnis a natura ... - (39r46v) Lib. 5. Bl. 45r-v leer. Text von Bl. 44v setzt auf Bl. 46r unmittelbar und ohne Textverlust fort.

(1r-46v) KomMENTAR.

(1r) Einleitender Kommentar zum gesamten Werk. Inc.: Dubitatur utrum sciencia naturalis est sciencia de omnibus rebus ... - Expl.: ... et que quando cum ad formationem.

(1r-8v) Zu Lib. 1. Inc.: Quoniam quidem. Iste liber intytulatur liber Phisicorum Aristotelis filii Nicometi Grecorum sapientissimi ... - Expl.: ... pateant declaranda. Et sic est finis primi libri Phisicorum etc. Deo gratias Amen etc.

(9r-17r) Zu Lib. 2. Inc.: Eorum que. Iste est liber secundus Phisicorum in quo Aristoteles determinat de $p($ !) principiis doctrine ... - Expl.: ... et sic est finis secundi de quo sit benedictus Ihesus Marie filius Amen etc.

(17r-24r) Zu Lib. 3. Inc.: Quoniam autem natura. Hic incipit $3^{\text {us }}$ liber Phisicorum (gestrichen: Et continet) in quo Aristoteles determinat de passionibus ... - Expl.: ... Et sic est finis Aristotelis $3^{i i}$ libri de quo sit benedictus Ihesus Marie filius in secula seculorum Amen Amen etc.

(24v-39r) Zu Lib. 4. Inc.: Similiter autem. Hic est quartus liber Phisicorum in quo Aristoteles determinat de passionibus ... - Expl.. ... et anima in 10 casibus.

(39r-46v) Zu Lib. 5. Inc.: Transmutatur autem. In ista parte Aristoteles ponit $5^{m}$ librum Physicorum in quo Aristoteles determinat de divisione motus ... - Expl.: ... solvit ut presens fuit soluta.

Bl. 46v (am unteren Blattrand) Reklamante zu Lib. 6: Si autem est continuum.

Forts. (Lib. 6-8) in Cod. 163, Bl. 1r-29r.

Lit.: Grabmann, Aristoteles 170-174.

$(\mathrm{I} * \mathrm{r}-\mathrm{v})$ leer.

P. K./W. N. 


\section{Cod. 171}

\section{THOMAS CANTIMPRATENSIS. THEOLOGISCHE TRAKTATE}

Perg. I, 91, I* Bl. $285 \times 210$. Süddeutscher Raum, Ende 13./Anfang 14. Jh.

B: $\quad$ Zwei Teile: I (I, 1-61), II (62-91, I*). Am oberen Blattrand durchgehende Foliierung 19. Jh. durch die ULB Tirol.

E: $\quad$ Neuzeitlicher Bibliothekseinband: schwarz gesprenkeltes braunes Pap. über Pappe. Neustift, 2. H. 18. Jh. Am VD und HD Ecken mit braunem Leder verstärkt. Rücken: braunes Leder, vier einfache Bünde, von Goldbordüren gesäumt. Im ersten Feld Golddruck M: S:, im zweiten Golddruck DE NATURA LIB. in Goldrahmung, im dritten Signaturschild (s. bei G). Schnitt rot gefärbt. Spiegel Pap. 18. Jh. Am Spiegel des VD Exlibris, Signaturen und Bleistiftnotiz (s. bei G), Spiegel des HD leer.

G: Zeitpunkt und Art der Erwerbung durch Neustift unbekannt. Am Spiegel des VD Exlibris der Stiftsbibl. Neustift 18. Jh. 1809 anlässlich der vorübergehenden Aufhebung des Klosters Neustift der ULB Tirol übergeben. Am Spiegel des VD alte Signatur der ULB Tirol II $\overline{1}$ [...] (Tinte, radiert), II 2 H 19 (Bleistift) und Nr. 171/ (1) (Tinte, Bleistift) sowie Bleistiftnotiz (Vide Grundzettel). Am Rücken gelbes Signaturschild der ULB Tirol 171/1. Bl. 1r Stempel der ULB Tirol 19. Jh. 1921 aufgrund des Friedensvertrages von St. Germain an den italienischen Staat abgegeben und von diesem 1929 dem Kloster Neustift als Dauerleihgabe überlassen. Bl. 1r Stempel der Soprintendenza Tridentina 20. Jh.

L: $\quad$ Katalog ULB Tirol II 142, 207.

$$
\text { I (I, 1-61) }
$$

B: $\quad$ Perg. tw. löchrig, Bl. 19 Riss mit rotem Zwirn genäht. Lagen: (I-1 $)^{\mathrm{I}}$ (Vorsatzbl., Pap. 18. Jh.) $+\mathrm{V}^{10}+(\mathrm{V}-4)^{16}$ $+4 . \mathrm{V}^{56}+(\mathrm{V}-5)^{61}$. Gegenbl. zum Vorsatzbl. als Spiegel auf dem VD aufgeklebt. In der zweiten Lage zwei Doppelbl. verloren (Textverlust). Nach Bl. 61 fünf leere, bis auf das letzte unlinierte Blätter am Ende der Lage weggeschnitten. Kustoden in römischen Zahlen $\left(I I I^{u s}-V I I I^{u s}\right)$ am Ende der ersten sechs Lagen. Zeitgenössische Foliierung in arabischen Ziffern am oberen Blattrand, beginnend mit 21; Fehler in der Zählung: Bl. 40v fehlerhafte Foliierung 55, korr. aus 56, auf Bl. 41r fehlerhafte Foliierung 56 neben der richtigen 65, auf Bl. 42r Foliierung 66 korr. aus 56. Textverlust am Anfang des Buchblocks (zwei Lagen).

S: $\quad$ Schriftraum $205 \times 120$. Zwei Spalten, von Tintenlinien gerahmt, zu 40 Zeilen auf Tintenlinierung. Zirkelstiche. Textualis. Gleicher Schreiber wie T. II. Vereinzelt Korrekturen des Schreibers und kurze Anmerkungen von anderen, späteren Händen am Blattrand. Bl. 61vb acht Zeilen (Schlussschrift?) radiert.

A: $\quad$ Rote Paragraphzeichen und Überschriften. Zweizeilige rote Lombarden.

$(\mathrm{Ir}-\mathrm{v})$ leer.

1 (1ra-61vb) 〈Thomas CANTIMPRATENSIs〉: Liber de natura rerum, unvollständig (Ed. H. Boese. Berlin, New York 1973, 13-377. - Thorndike-Kibre 1026).

Einzelne Kapitel gegenüber der Ed. tw. gekürzt oder erweitert, Kapiteleinteilung bisweilen abweichend, ganze Kapitel ausgelassen oder hinzugefügt.

Enthält:

(1ra-3rb) Lib. 4.

(1ra) Cap. 80. Inc. mut.: ca]ventes in secretis pariunt et occultant. Femine onagrorum ... - (1ra) Cap. 82. - Cap. 85. - (1va) Cap. 86. - Cap. 87. - (1vb) Cap. 90. - Cap. 93. - Cap. 94. - (2ra) Cap. 96. - (2rb) Cap. 98. - (2va) Cap. 101. - Cap. 103. - Cap. 97. - (2vb) Cap. 104. - (3ra) Cap. 105. (3rb) Cap. 108.

(3rb-13va) Lib. 5.

(3rb) Cap. 1. - (4ra) Cap. 2. - (4va) Cap. 4. - Cap. 6. - (4vb) Cap. 8. - Cap. 9. - (5ra) Cap. 10. (5rb) Cap. 11. - Cap. 12. - Cap. 14. - (5va) Cap. 15. - (5vb) Cap. 18. - Cap. 24. - (6ra) Cap. 26. - Cap. 27. - Cap. 28. - (6rb) Cap. 30. - (6va) Cap. 31. - Cap. 32. - (6vb) Cap. 34. - (7ra) Cap. 35. - Cap. 36. - (7va) Cap. 38. - (7vb) Cap. 39. - (8ra) Cap. 40. - Cap. 41. - (8rb) Cap. 44. - Cap. 45. (8vb) Cap. 51. - (9ra) Cap. 52. - (9rb) Cap. 53. - Cap. 55. - (9va) Cap. 57. - (9vb) 
Cap. 58. - (10va) Cap. 59. - (10vb) Cap. 60. - (11ra) Cap. 61. - Cap. 62. - (11rb) Cap. 63. - Cap. 66. - (11va) Cap. 67. - (11vb) Cap. 73. - Cap. 74. - Cap. 76. - Cap. 79. Expl. mut.: ... domesticis rebus insidiatur. Accipitri [ - (12ra) Cap. 106. Inc. mut.: ] pullorum evolancium inbecilles ... Cap. 108. - Cap. 109. - (12rb) Cap. 110. - (12va) Cap. 111. - Cap. 112. - (12vb) Cap. 114. - Cap. 113. - Cap. 116. - (13ra) Cap. 118. - Cap. 119. - (13rb) Cap. 120.

(13va-15va) Lib. 6.

(13va) Cap. 2. - (13vb) Cap. 3. - Cap. 5. - Cap. 7. - (14ra) Cap. 10. - Cap. 12. - (14rb) Cap. 13. Cap. 15. - Cap. 16. - (14va) Cap. 20. - Cap. 23. - (14vb) Cap. 27. - Cap. 30. - Cap. 33. - (15ra) Cap. 34. - Cap. 36. - Cap. 46. - (15rb) Cap. 47. - Cap. 48. - (15va) Cap. 53.

(15va-16va) Lib. 7.

(15va) Cap. 1. Expl. mut: ... aliqui non tangunt vas quo venantur nisi sit recens. Femine pisci[um - (16ra) Cap. 52. Inc. mut.: ne]mo propheta acceptus est in patria sua ... - Cap. 57. - Cap. 59. - Cap. 64. - (16rb) Cap. 70. - Cap. 72. - (16va) Cap. 77. - Cap. 83. - Cap. 88.

(16va-21vb) Lib. 8.

(16va) Cap. 1. - (17rb) Cap. 2. - Cap. 3. - (17va) Cap. 4. - (17vb) Cap. 5. - (18ra) Cap. 6. Cap. 9. - (18rb) Cap. 12. - (18rb) Cap. 13. - Cap. 14. - Cap. 15. - (18va) Cap. 16. - (19ra) Cap. 17. - Cap. 20. - (19rb) Cap. 21. - Cap. 23. - Cap. 25. - (19va) Cap. 26. - (19vb) Cap. 27. - Cap. 29. - Cap. 30. - (20rb) Cap. 31. - Cap. 32. - Cap. 33. - (20va) Cap. 34. - De serpente vulgari. Cap. 35. - Cap. 36. - Cap. 37. - (20vb) Cap. 38. - Cap. 40. - (21ra) Cap. 41. - Cap. 42. - Cap. 43. - (21rb) Cap. 45.

(21vb-26rb) Lib. 9.

(21vb) Cap. 1. - Cap. 2. - ( 23rb) Cap. 3. - Cap. 5. - (23va) Cap. 7. - (23vb) Cap. 9. - Cap. 11. Cap. 12. - (24ra) Cap. 13. - Cap. 14. - (24rb) Cap. 15. - Cap. 16. - Cap. 19. - (24va) Cap. 21. Cap. 22. - (24vb) Cap. 24. - Cap. 25. - (25ra) Cap. 28. - (25rb) Cap. 33. - Cap. 34. - Cap. 35. (25va) Cap. 43. - Cap. 45. - (25vb) Cap. 44. - Cap. 40. - Cap. 46. - Cap. 48. - (26ra) Cap. 47. - Cap. 49. - Cap. 51. - Cap. 52. - Cap. 53.

(26rb-32ra) Lib. 10.

(26rb) Cap. 5. - Cap. 6. - (26va) Cap. 7. - Cap. 8. - Cap. 12. - (26vb) Cap. 13. - Cap. 15. - (27ra) De cyconia. - Cap. 16. - (27rb) Cap. 18. - (27va) Cap. 19. - Cap. 20. - Cap. 21. - (27vb) Cap. 22. - Cap. 23. - (28ra) Cap. 25. - Cap. 26. - Cap. 24. - (28rb) Cap. 28. - Cap. 29. - (28va) De mirica. - Cap. 31. - (28vb) De mepsilo (!). - Cap. 33. - Cap. 32. - Cap. 34. - (29rb) Cap. 35. Cap. 36. - (29va) Cap. 37. - Cap. 38. - Cap. 39. - (29vb) De pyro. - (30ra) De pruna. - Cap. 40. - Cap. 41. - Cap. 42. - (30va) Cap. 43. - (30vb) Cap. 45. - De sicomoro. - De sambuco. - De sparago. - Cap. 46. - (31ra) Cap. 47. - Cap. 48. - Cap. 51. - (32ra) Cap. 52.

(32ra-36rb) Lib. 11.

(32ra) Cap. 2. - (32rb) Cap. 3. - Cap. 4. - (32va) Cap. 6. - Cap. 8. - (33rb) Cap. 9. - (33va) Cap. 10. - (33vb) Cap. 11. - Cap. 12. - (34ra) Cap. 13. - Cap. 14. - (34rb) Cap. 15. - Cap. 16. - Cap. 17. - (34va) Cap. 18. - Cap. 20. - (34vb) Cap. 21. - Cap. 22. - (35ra) Cap. 23. - Cap. 24. - Cap. 25. - (35rb) Cap. 26. - Cap. 27. - (35va) Cap. 28. - Cap. 29. - (35vb) Cap. 30. - Cap. 31. - Cap. 32. - (36ra) Cap. 33.

(36rb-41ra) Lib. 12.

(36rb) Cap. 1. - (36va) Cap. 2. - (36vb) Cap. 3. - Cap. 4. - De aristologia. - (37ra) De arthemesia. - De alleo. - De alchana. - De anisio. - (37rb) De bethonica. - De basilisco. - De celidonia. - De cynoglosa. - De cyclamine. - (37va) Cap. 5. - Cap. 6. - (37vb) De caulibus. - De cicorea. - De canna melis. - Cap. 7. - Cap. 8. - (38ra) Cap. 9. - Cap. 10. - (38rb) Cap. 11. - De eruca. - De eleboro. - Cap. 12. - (38va) De fabis. - (38vb) De grano frumenti. - De galbano. - 
Cap. 13. - (39ra) De ysopo. - De barba iovis. - De latuca. - De lylio. - Cap. 14. - (39rb) Cap. 15. - (39va) Cap. 17. - Cap. 18. - Cap. 19. - (39vb) Cap. 20. - Cap. 21. - Cap. 23. - (40ra) Cap. 24. - (40rb) De rafano. - Item de ruta. - De syler. - Cap. 25. - (40va) Cap. 26. - Cap. 27. - Cap. 28. - De squilla. - De tapsia. - (40vb) De verbena. - De vicia. - Cap. 29. - Cap. 30. - (41ra) Cap. 31. - Cap. 32.

(41ra-51ra) Lib. 14.

(41ra) Cap. 1. - (41vb) Cap. 2. - Cap. 3. - (42ra) Cap. 4. - (42rb) Cap. 5. - (42va) Cap. 6. - Cap. 7. - Cap. 8. - Cap. 9. - De amandino. - Cap. 10. - (42vb) Cap. 11. - Cap. 12. - (43ra) Cap. 13. (43rb) Cap. 14. - Cap. 15. - (43va) Cap. 16. - Cap. 17. - (43vb) Cap. 18. - Cap. 19. - Cap. 20. Cap. 21. - (44ra) Cap. 22. - Cap. 23. - De celonte. - De crisopasion. - De core. - (44rb) De demonio. - Cap. 24. - Cap. 25. - (44va) Cap. 26. - De egolito. - Cap. 27. - Cap. 28. - (44vb) Cap. 29. - De episcute. - (45ra) De exacolito. - Cap. 30. - Cap. 31. - Cap. 32. - (45rb) Cap. 33. - Cap. 34. - Cap. 35. - Cap. 36. - (45va) De gerachirea. - Cap. 37. - Cap. 38. - (45vb) Cap. 41. - Cap. 42. - Cap. 44. - (46ra) De lagapis. - Cap. 45. - (46rb) Cap. 46. - Cap. 48. - De muro. - De nichamar. - De noche. - (46va) Cap. 49. - (46vb) Cap. 50. - Cap. 51. - Cap. 52. (47ra) Cap. 53. - Cap. 54. - Cap. 55. - Cap. 56. - (47rb) De peanite. - De quirin. - De quinidros. - Cap. 57. - (47vb) Cap. 58. - (48ra) Cap. 59. - Cap. 60. - (48rb) Cap. 61. - Cap. 62. - Cap. 63. - Cap. 64. - (48va) Cap. 66. - Cap. 65. - Cap. 67. - (48vb) Cap. 68. - De terebole - De tervice. - De tercillo. - De zunicho. - (49ra) De zignites. - Cap. 69. - (49vb) Cap. 70. - (50vb) Cap. 71.

(51ra-52va) Lib. 15.

(51ra) De metallis. - Cap. 1. - (51va) Cap. 2. - (51vb) Cap. 3. - (52ra) Cap. 4. - Cap. 5. - (52rb) Cap. 6. - (52va) Cap. 7.

(52va-53rb) Lib. 13.

(52va) Cap. 6. - (52vb) Cap. 7. - Cap. 10. - Cap. 11. - Cap. 12. - Cap. 13. - Cap. 14. - Cap. 15. - (53ra) Cap. 16. - Cap. 18. - Cap. 19. - Cap. 20. - Cap. 21. - Cap. 24. - Cap. 27. - (53rb) Cap. 28. - Cap. 29. - Cap. 30.

(53rb-61rb) Lib. 1.

(53rb) Cap. 1. - (53va) Cap. 2. - (53vb) Cap. 3. - (54ra) Cap. 4. - (54rb) Cap. 5. - Cap. 6. (54va) Cap. 7. - (54vb) Cap. 8. - Cap. 9. - Cap. 10. - (55ra) Cap. 11. - Cap. 12. - (55rb) Cap. 13. - (55va) Cap. 14. - (55vb) Cap. 15. - Cap. 16. - Cap. 17. - (56ra) Cap. 18. - Cap. 19. - Cap. 20. - (56rb) Cap. 21. - Cap. 22. - (56va) Cap. 23. - Cap. 24. - Cap. 25. - (56vb) Cap. 26. - Cap. 27. - (57ra) Cap. 35. - (57va) Cap. 36. - (57vb) Cap. 37. - Cap. 38. - (58ra) Cap. 39. - Cap. 41. - (58rb) Cap. 42. - Cap. 43. - Cap. 45. - (58va) Cap. 46. - Cap. 47. - (59rb) Cap. 48. - Cap. 49. - (59va) Cap. 50. - (60ra) Cap. 51. - Cap. 52. - (60rb) Cap. 53. - Cap. 55. - (60va) Cap. 56. - Cap. 57. - (60vb) Cap. 59. - Cap. 60. - (61ra) Cap. 62. - Cap. 63. - Cap. 65.

Lit.: H. Boese, Zur Textüberlieferung von Thomas Cantimpratensis' Liber de natura rerum. Archivum Fratrum Predicatorum 39 (1969) 53-68.

$(61 v)$ leer.

$$
\text { II (62-91, I*) }
$$

B: $\quad$ Perg. tw. löchrig, Lagen: 3.V $V^{91}+(\mathrm{I}-1)^{1^{*}}$ (Nachsatzbl., Pap. 18. Jh.). Gegenbl. zum Nachsatzbl. als Spiegel auf dem HD aufgeklebt. Kustoden in römischen Zahlen am Anfang und Ende der letzten zwei Lagen $\left(I I^{u s}-I I I^{u s}\right)$. Textverlust am Ende des Buchblocks (mindestens eine Lage). Am oberen Rand der Bl. 75v, 76v-77r, 78v79v, 89v-91v Minuskel $c$.

S: $\quad$ Schriftraum $205 \times 120$. Zwei Spalten, von Tintenlinien gerahmt, zu 40 Zeilen auf Tintenlinierung. Zirkelstiche, großteils weggeschnitten. Textualis. Gleicher Schreiber wie T. I, etwas kleinerer Schriftgrad. Ver- 
einzelt Korrekturen des Schreibers und kurze Anmerkungen von anderen, späteren Händen am Blattrand. Schreiberspruch Bl. 62r sowie spätere Ergänzung Bl. 65v Textualis cursiva.

A: Rote Paragraphzeichen und Überschriften. Bl. 62r-87v rote Marginalien. Bl. 62ra-88rb zweizeilige rote Lombarden. Bl. 63ra-91vb rote lombardenförmige Satzmajuskeln. Repräsentanten am Blattrand in Schwarz oder Rot.

2 (62ra-88rb) De comparationibus BMV (Stegmüller RB Nr. 8879).

Tit. (am Blattrand): De duodecim proprietatibus. - Tit.: In isto libello continentur proprietates diversarum creaturarum similitudinarie convenientes virtutibus matris creatoris. - Inc.: Beata virgo comparatur celo. Celum enim dicitur quasi gaza eliorum id est solis domus, quia quasi in domo propria ... - Expl.: ... tuam precibus et meritis illius terre cui benedixisti.

3 (88rb-91vb) Tractatus SUPER Missus Est (Exzerpte aus Bernardus Claraevallensis), unvollständig. Tit.: Bernhardus super ewangelium. - Inc.: Missus est Gabriel angelus (Lc 1,26). Vehemencia desiderii, fervore devocionis, puritate oracionis fontem attingit pietatis ... - Expl. mut.: ... qui ipsam invocatam in necessitate non senserit affuisse et post in periculis et [ Parallelüberlieferung: Heiligenkreuz, Stiftsbibl., Cod. 112, Bl. 74r.

$\left(I^{*} \mathrm{r}-\mathrm{v}\right)$ leer.

\section{Cod. 173}

\section{MAURUS SERVIUS HONORATUS}

\section{Pap./Perg. I, 172, I* Bl. $260 \times 215$. Italien, 2. Drittel 15. Jh.}

B: $\quad$ Pap. und Perg. gemischt: In Lage 1 innerstes Doppelbl. Perg., in Lage 5, 6, 8 und 9 jeweils äußerstes und innerstes Doppelbl. Perg. Haar- und Fleischseite deutlich unterscheidbar. Pap. und Perg. tw. fleckig. Bilder und Nachweise der Wasserzeichen s. WZMA. Datierung nach Wasserzeichenbefund. Lagen: $(\mathrm{I}-1)^{\mathrm{I}}$ (Vorsatzbl., Pap. 18. Jh. $)+\mathrm{VII}^{14}+3 . \mathrm{VI}^{50}+\mathrm{VIII}^{66}+\mathrm{IX}^{84}+(\mathrm{VIII}-1)^{99}+\mathrm{VIII}^{115}+\mathrm{X}^{135}+\mathrm{VIII}^{151}+(\mathrm{X}+1)^{172}+(\mathrm{I}-1)^{\mathrm{I}^{*}}$ (Nachsatzbl., Pap. 18. Jh.). Gegenbl. zum Vor- bzw. Nachsatzbl. als Spiegel auf dem VD bzw. HD aufgeklebt. Gegenbl. zu Bl. 99 herausgeschnitten (Textverlust). Bl. 172 eingehängtes Einzelbl. (Perg.). Bl. 172 klebte wohl als Spiegel auf dem HD des urspr. Einbandes. Zw. Bl. 39 und 40 sowie zw. Bl. $111^{1}$ und 113 jeweils ein kleines Einzelbl. $(200 \times 60$ bzw. $180 \times 75)$ eingehängt. Zw. Bl. 135 und 136 fehlt mindestens eine Lage (Textverlust). Ab Lage 4 Reklamanten erhalten. Am oberen Blattrand Foliierung 19. Jh. durch die ULB Tirol; Fehler in der Zählung: 111 doppelt angeführt, 112 ausgelassen. In Abschnitt 3 am oberen Blattrand Buchzählung: Bl. 27v-33r und 39r-40r am oberen Blattrand mittig in Rot I für Buch 1 der Aeneis, ab Buch 2 mittig in arabischen Ziffern in Schwarz, vielfach be- bzw. weggeschnitten, und rechts in Rot, auf 8 folgt 10 (Buch 9 fehlt).

S: $\quad$ Schriftraum $180 / 200 \times 140 / 145$. Zwei Spalten, von tw. sehr feinen Bleistift-, tw. Blindlinien gerahmt, zu 35-37 Zeilen auf Bleistift- bzw. Blindlinierung. Zirkelstiche. Humanistische Minuskel von drei verschiedenen Händen: 1) Bl. 1ra-120va; 2) Bl. 120vb-135vb (sehr klein, kalligraphisch); 3) 136ra-170va (flüchtiger). Am Blattrand Notizen vorwiegend von zeitgenössischer, vereinzelt von späterer Hand.

A: $\quad$ Bl. 1ra-3rb rote Auszeichnungsstriche, Randmarkierungen in Form von vereinfachtem Perlenbesatz, seitliche Hervorhebungen, Marginalien und Schlussschrift. Zeigehände (z. B. Bl. 17ra, 18rb). Bl. 27ra-33rb und 39ra-40rb rote Auszeichnungsstriche und Unterstreichungen. In der gesamten Hs. Platz für mehrzeilige Initialen freigelassen, nicht ausgeführt.

E: $\quad$ Neuzeitlicher Bibliothekseinband: schwarz gesprenkeltes braunes Pap. über Pappe. Neustift, 2. H. 18. Jh. Am VD und HD Ecken mit braunem Leder verstärkt. Rücken: braunes Leder, vier einfache Bünde, von Goldbordüren gesäumt. Im zweiten Feld Golddruck M. S. SERVY EXPOSITIO IN LIBROS ENEIDOS in Goldrahmung, im dritten Signaturschild (s. bei G). Schnitt rot gesprenkelt. Spiegel Pap. 18. Jh. Am Spiegel des VD Signaturen und Bleistiftnotiz (s. bei G), Spiegel des HD leer. 
G: Zeitpunkt und Art der Erwerbung durch Neustift unbekannt. 1809 anlässlich der vorübergehenden Aufhebung des Klosters Neustift der ULB Tirol übergeben. Am Spiegel des VD alte Signaturen der ULB Tirol II 2 H 21 (Bleistift) und N. 173 (Tinte) sowie Bleistiftnotiz (Vide Grundzettel). Am Rücken gelbes Signaturschild der ULB Tirol 173. Bl. 1r Stempel der ULB Tirol 19. Jh. 1921 aufgrund des Friedensvertrages von St. Germain an den italienischen Staat abgegeben und von diesem 1929 dem Kloster Neustift als Dauerleihgabe überlassen. Bl. 1r Stempel der Soprintendenza Tridentina 20. Jh.

L: $\quad$ Wilhelm I 136. - Neuhauser, Neustift 84. - Katalog ULB Tirol II 143, 208. - Peintner, Stiftsbibliothek 122. $(\mathrm{Ir}-\mathrm{v})$ leer.

(1ra-172va) Maurus Servius Honoratus: Commentarii (Ed. G. Thilo, H. Hagen. Lipsiae 1881-1902), mit ergänzenden Notizen von späteren Händen, u. a. Zitate.

1 (1ra-3rb) Commentarius in Vergili Bucolica, unvollständig: Lib. 9,5-Lib. 10 (Thilo III 1, 109, ab Z. 14).

Inc. mut.: ] faciunt sic victos e contra[rio] voti impotes qui non possunt facere quod volunt ...

(3rb) Schlussschrift: Laus Deo.

(3va) nur Rahmung und Linierung.

2 (3vb-25ra) Commentarius in Vergili Georgica, Lib. 1-4 (Thilo III 1, 128-360).

(25rb-26vb) nur Rahmung und Linierung.

3 (27ra-170va) Commentarius in Vergilit Aeneidos, unvollständig. (27ra-84vb) Lib. 1,1-Lib. 5,42 (Thilo I 7, Z. 5-594, Z. 25). Inc. mut.: ] Ausoniis disterminat arva colonis unde apparet Antenorem non ad Italiam venisse ... - Expl. mut.: ... non fugantur semper [ (mit Reklamante: Enim)

(85ra-135vb) Lib. 5,78-Lib. 8,663 (Thilo I 601, Z. 8-II 295, Z. 27). Inc. mut.: ] gaudet purpureosque iacit flores ... - Expl. mut.: ... flamines in capite [ (mit Reklamante: habebant)

(136ra-170va) Lib. 10,475-Lib. 12 (Thilo II 441, Z. 7-650). Inc. mut.: ] poetis plerumque conceditur ... - Expl.: ... adhuc habitare nature lege poterat sic Homerus.

(170va) Schlussschrift: Explicit Servii expositio gramatici super libros Eneidos.

(170vb-171vb) nur Rahmung und Linierung.

4 (172r) FEDERPROBEn.

1) 〈Publius Papinius Statius〉: Thebais II 620 (Ed. A. Klotz, Th. Klinnert. Lipsiae ${ }^{2} 1973$ ).

Unusne viri tot cedibus unus ibit ovans [A]rgos.

2) 〈Publius Vergilius Maro»: Georgica, Lib. 1,1, unvollständig (Ed. R. A. B. Mynors. Oxonii 1990).

Quid faciat letas seg[

3) Darunter Notız: Bartholomei Cremonensis. Möglicherweise Hinweis auf Vergilausgabe des Bartolomeo da Cremona (Venetiis 1472 = GW M49740, ohne Servius-Kommentar) oder Besitzvermerk: In Frage kommt hierfür der vorgenannte Drucker. Eine Zuordnung zu Bartolomeo Sacchi (1421-1481), auch B. Platina und B. Cremonensis genannt, erscheint aufgrund eines Vergleichs der Hände wenig wahrscheinlich.

$(172 \mathrm{v})$ leer.

$\left({ }^{*} \mathrm{r}-\mathrm{v}\right)$ leer. 


\section{Cod. 174}

\section{SERMONES DE TEMPORE}

Pap. I, 225, I* Bl. $280 \times 200$. Tirol (?), um 1470 (u. a. 1472).

B: B1. 56rb Loch, B1. 156r-179v tw. fleckig und Tintenfraß. Nachweise und Bilder der Wasserzeichen s. WZMA. Datierung nach Wasserzeichenbefund. Identische Wasserzeichen: u. a. Brixen, Priesterseminarbibl., Cod. A.2; Neustift, Stiftsbibl., Cod. 204; Innsbruck, ULB Tirol, Cod. 621; Zwettl, Stiftsbibl., Cod. 205, T. II (dat. 1481). Lagen: (I-1) ${ }^{\mathrm{I}}$ Vorsatzbl., Pap. 18. Jh.) + 18.VII ${ }^{21(216)}+(\mathrm{III}+3)^{224(225)}+(\mathrm{I}-1)^{\mathrm{I}^{*}}($ Nachsatzbl., Pap. 18. Jh.). Gegenbl. zum Vor- bzw. Nachsatzbl. als Spiegel auf dem VD bzw. HD aufgeklebt. B1. 216-218 eingehängte Einzelbl. Nachsatzbl. mit Makulaturstreifen verstärkt (] et motibus carnalibus habuerit, s. auch bei E [VDS bzw. HDS]). Am oberen Blattrand zeitgenössische Foliierung 1-156, Forts. der Foliierung 19. Jh. durch die ULB Tirol, wiederum beginnend mit 156, daher Zahl 156 doppelt angeführt. Bl. 151 und 168 jeweils neuzeitliches gelbes Papiersignakel der ULB Tirol.

S: Schriftraum und Zeilenzahl mit den Händen wechselnd. Schriftraum 210/230×140/155. Zwei Spalten, Bl. 1ra-179vb von Tintenlinien, ab Bl. 180ra von Blindlinien gerahmt, zu 39-46 Zeilen, Bl. 151va-154rb auf Tintenlinierung (hier zusätzliche Spalte für Angabe der Blattzahlen), ab Bl. 203ra tw. auf Blindlinierung. Bastarda von mehreren Händen: 1) Bl. 1ra-154rb, dat. 1472 (Bl. 151rb); 2) Bl. 155ra-156vb und Bl. 162va167vb; 3) Bl. 156 ra-162rb; 4) Bl. 168ra-224va. Am seitlichen Blattrand Korrekturen bzw. Ergänzungen, tw. von anderer zeitgenössischer Hand, häufig stark beschnitten.

A: Rote Auszeichnungsstriche und Unterstreichungen, Überschriften. Kapitelzählung in tw. roten, tw. tintenfarbenen arabischen Ziffern sowie rote Anmerkungen und Hervorhebungen am Blattrand. Rote meist drei-, gelegentlich vierzeilige Lombarden, tw. mit Punktverdickungen oder kurzen Fadenausläufern, vereinzelt einfachen Aussparungen. Buchstabenschäfte am Rand des Schriftraums bisweilen gelängt, vereinzelt mit einfachem Dekor, Bl. 201va Tierdarstellung in Federzeichnung, Bl. 204ra cadellenartige, rubrizierte Oberlänge mit Profilgesicht. Repräsentanten.

E: $\quad$ Neuzeitlicher Bibliothekseinband: schwarz gesprenkeltes braunes Pap. über Pappe. Neustift, 2. H. 18. Jh. Pap. etwas abgerieben. Am VD und HD Ecken mit braunem Leder verstärkt. Rücken: braunes Leder, vier einfache Bünde, von Goldbordüren gesäumt. Im ersten Feld Golddruck M: S:, im zweiten Golddruck HOMILIA IN DOMINIC. in Goldrahmung, im dritten Signaturschild (s. bei G). Schnitt rot gesprenkelt. Spiegel Pap. 18. Jh. Am Spiegel des VD Exlibris, Signaturen und Bleistiftnotiz (s. bei G), darunter Makulaturstreifen. Spiegel des HD leer, darunter Exlibris sowie Makulaturstreifen.

G: Zeitpunkt und Art der Erwerbung durch Neustift unbekannt. Am Spiegel des VD Exlibris der Stiftsbibl. Neustift 18. Jh., dasselbe Exlibris auch verkehrt unter dem Spiegel des HD erkennbar. 1809 anlässlich der vorübergehenden Aufhebung des Klosters Neustift der ULB Tirol übergeben. Am Spiegel des VD alte Signaturen der ULB Tirol II 2 H 22 (Tinte, Bleistift) und Nr. 174/I (Tinte, Bleistift) sowie Bleistiftnotiz (Vide Grundzettel). Am Rücken gelbes Signaturschild der ULB Tirol 174/I. Bl. 1r Stempel der ULB Tirol 19. Jh. 1921 aufgrund des Friedensvertrages von St. Germain an den italienischen Staat abgegeben und von diesem 1929 dem Kloster Neustift als Dauerleihgabe überlassen. Bl. 1r Stempel der Soprintendenza Tridentina 20. Jh.

L: $\quad$ Katalog ULB Tirol II 143, 208. - Stefani 105. - Peintner, Stiftsbibliothek 121.

(Ir-v) leer.

1 (1ra-151rb) Sermones de epistolis de TEMPORE „SENSATus“.

1.1 (1ra-4rb) KonKordanz I zw. Festtag, Thema und Auswahl der Sermones für Predigten über das Evangelium.

Tit.: Tabulacio quomodo ad predicandum sit in hoc opere de ewangeliis. - Inc.: Nota. Si alicui plus placuerit predicare de ewangeliis quam de epistolis ... - Expl.. ... sic de aliis procedas de quibus autem placurit (!) predicare etc.

1.2 (4v-5r) KONKORDANZ II (gekürzt).

Tit.: Incipit recapitulacio distinccionum huius libri. - Inc.: Distinccio $1^{a}$ Christus est nobis prope quattuor modis ... - Expl.: ... 60 Oracio nostra ut exaudiatur a Deo debet esse quadruplex disposita.

(5v) leer. 
1.3 (6ra-151rb) Sermones de tempore „Sensatus“ (Schneyer 5, 358-362, Nr. 1-60). (6ra) Prolog (Nr. 1). - (6ra) Dnca 1. adv. (Nr. 2). - (8ra) Dnca 2. adv. (Nr. 3). - (9va) Dnca 3. adv. (Nr. 4). - (11rb) Dnca 4. adv. (Nr. 5). - (14vb) In vigilia nativitatis dni (Nr. 6). - (16rb) In nativitate dni (Nr. 7). - (18ra) Dnca infra octav. nativitatis dni (Nr. 8). - (20ra) Dnca 1. post epiph. dni (Nr. 9). - (21va) Dnca 2. post epiph. dni (Nr. 10). - (24ra) Dnca 3. post epiph. dni (Nr. 11). (26rb) Dnca 4. post epiph. dni (Nr. 12). - (29ra) Dnca 5. post epiph. dni (Nr. 13). - (32vb) Dnca in Septuages. (Nr. 14). - (36rb) Dnca in Sexages. (Nr. 15). - (38va) Dnca in Quinquages. (Nr. 16). (41rb) In capite ieiunii (Nr. 17). - (43ra) Dnca 1. in Quadrages. (Nr. 18). - (44vb) Dnca 2. in Quadrages. (Nr. 19). - (46va) Dnca 3. in Quadrages. (Nr. 20). - (49ra) Dnca 4. in Quadrages. (Nr. 21). - (51rb) Dnca 1. in passione dni (Nr. 22). - (53ra) Dnca in palmis (Nr. 23). - (55vb) Fer. 5. in coena dni (Nr. 24). - (58rb) Fer. 6. in parasceve (Nr. 25). Tit.: In passione domini. (60va) Dnca resurrectionis dni (Nr. 26). - (63vb) Dnca 1. post pascha (Nr. 27). - (64vb) Dnca 2. post pascha (Nr. 28). - (67vb) Dnca 3. post pascha (Nr. 29). Tit.: Dominica $2^{a}$ post dominicam pasche (!). - (70va) Dnca 4. post pascha (Nr. 30). Tit.: Dominica $3^{a}$ post pasce. - (72vb) Dnca 5. post pascha (Nr. 31). Tit.: Dominica $4^{a}$ post pascha. - (75ra) In ascensione dni (Nr. 32). - (77va) Dnca infra oct. ascensionis dni (Nr. 33). - (80rb) Dnca pentecostes et de spiritu sancto (Nr. 34). (82vb) In festo ss. trinitatis (Nr. 35). - (85va) Tit.: De corpore Christi (Nr. 36). - (87va) Dnca 2. post pent. (Nr. 37). Tit.: Dominica prima post Penthecostes.

(90vb) Tit.: De morte corporali et spirituali per totum. Dominica secunda. - Inc.: Translati sumus de morte ad vitam. $I^{a}$ Ioh. $4^{a}(3,14)$. Nos enim videmus ad sensum quod quando aliqui evaserunt mortem qui fuerunt in bello fortissimo ubi multi mortui fuerunt ad suos dilectos veniunt et dicunt ... - Expl.: ... quasi post conbustionem ab igne liberari.

Parallelüberlieferung: Innsbruck, ULB Tirol, Cod. 151, Bl. 81vb.

(93va) Dnca 3. post pent. (Nr. 38). - (97rb) Dnca 4. post pent. (Nr. 39). - (99ra) Dnca 5. post pent. (Nr. 40). - (100rb) Dnca 6. post pent. (Nr. 41). - (102rb) Dnca 7. post pent. (Nr. 42). Tit.: Dominica $7^{a}$ post (gestrichen: Penthe) Trinitatis. - (104rb) Dnca 8. post pent. (Nr. 43). - (106va) Dnca 9. post pent. (Nr. 44). - (108vb) Dnca 10. post pent. (Nr. 45). - (111rb) Dnca 11. post pent. (Nr. 46). - (114ra) Dnca 12. post pent. (Nr. 47). - (116va) Dnca 13. post pent. (Nr. 48). - (119ra) Dnca 14. post pent. (Nr. 49). - (122va) Dnca 15. post pent. (Nr. 50). - (125ra) Dnca 16. post pent. (Nr. 51). Expl.: ... qualis est sua dileccio. - (129ra) Dnca 17. post pent. (Nr. 52). - (131rb) Dnca 18. post pent. (Nr. 53). - (133rb) Dnca 19. post pent. (Nr. 55). - (135vb) Dnca 20. post pent. (Nr. 54). - (138va) Dnca 21. post pent. (Nr. 56). - (140va) Dnca 22. post pent. (Nr. 57). - (142va) Dnca 23. post pent. (Nr. 58). - (145vb) Dnca 24. post pent. (Nr. 59). - (148vb) Dnca 25. post pent. (Nr. 60)

(151rb) Datierung: 1472.

1.4 (151va-154rb) Thematisches REGISTER in alphabetischer Reihenfolge mit Blattangabe. Inc.: Activa et contemplativa vita 30. Angeli gaudent de conversione peccatoris 31... - Expl.. ... Virgines habebunt $4^{\text {or }}$ singularia in patria 127. Virtutes comparantur luci triplici racione 71. $(154 \mathrm{v})$ leer.

2 (155ra-167vb) SERMONES DE TEMPORE, größtenteils anonym.

(155ra) De annuntiatione BMV. Inc.: Ave gracia plena dominus tecum. Luc. 1 (28). Ista dies precipue maior est omnibus festivitatibus ... - Expl.: ... induit pro redempcione humani generis in cruce obligavit. Rogemus dominum ut nobis ferat eternum premium.

(156ra) Tit.: Sermo de corpore Christi. In cena domini (Schneyer 8, 419, Nr. 81).

(156'ra) 〈Ambrosius Spiera〉: Sermo Fer. 6 in parasceve (Schneyer II Nr. 97) bzw. 〈Albertus ENGELSCHALK> (Schneyer II Nr. 323). Inc.: Egressus Ihesus trans torrentem Cedron ubi erat ortus in quem introivit et ipse cum discipuli (!) suis (Io 18,1). Sicut enim tunc vos scitis, quod mos predicatorum est in principio sermonum predicatorum ad beatam virginem recurrere ... - Expl.: ... in commendacionem sue caritatis in augmentum mee devocionis et in meritum vite eterne. 
Inc. wie Graz, Franziskanerkloster, Cod. A 67/29, Bl. 100va.

(156'ra) Inc.: Egressus Ihesus trans torrentem Cedron (Io 18,1). Quando enim occurrat festum alicuius sancti tunc consuevimus eius legendam et passionem ut Laurencii Petri etc. Sic enim hodie est flendum ... - Expl.: ... eligendo flores de IIII ${ }^{\text {or }}$ ewangelistis.

Inc. vgl. Graz, Franziskanerkloster, Cod. A 67/29, Bl. 100va.

(156'ra) HisTORIA PASSIONIS DNI SECUNDUM QUATTUOR EVANGELISTAS. Inc.: Historia passionis Christi fuit per istum modum sicut tunc dicit beatus Iohannes ewangelista qui tunc passionem filii Dei scripsit ... - Expl.: ... vero Christus sepultus fuisset revertebatur virgo Maria amarissime plorans secundum Augustinum procede.

(162va) Tit.: Exhortacio in die palmarum. - Inc. (ohne Bibelthema): Hodie sancta mater ecclesia duas processiones recolit ... - Expl.: ... vicit [...] claustrum [...].

(163ra) Inc.: Sicut ovis ad occisionem ductus est. Is. 53 (7). Hodie karissimi dies celebratur insignis et festiva in tanto maioris devocionis affectu a singulis Christifidelibus est celebranda ...Expl.: ... et post hanc vitam celestem gloriam intrare et possidere meremur quod nobis concedere dignetur Ihesus Christus dominus noster qui eam nobis suo sanguine comparavit qui est benedictus in sanguine suo Amen.

Inc. wie Augsburg, UB, Cod. II. 1. fol. 48, Bl. 81rb.

(166va) Inc.: Qui manducat hunc panem vivet in eternum. Ioh. 6 (58) et in ewangelio hodierne leccionis. Magnam hodie et precipuam karissimi omnique devocione recollendam agimus solempnitatem ad cuius celebracionem venerandam venerabilis Hugo de Sancto Victore in quodam sermone ipsius sollempnitatis nos devote invitat ... - Expl.. ... ex hoc salutem consequere hic per graciam et in futuro per gloriam Amen.

3 (168ra-224vb) LiBER SERMONUM „FONS VITAE“ (Schneyer 7, 611-617, Nr. 1-65). Festangabe bei Schneyer tw. abweichend; bei Abweichungen in der Hs. jene bei Schneyer in Klammer angeführt. (168ra) Tit.: Dominica prima in adventu domini. - Inc.: Hora est iam nos de sompno surgere. Apostolus ad Romanos (13,11). Egregius predicator et apostolus invitans nos ad opera virtutum. In istis verbis tria facit. Primo allegat temporis oportunitatem ... - Expl.: ... et ipsum amicum tuum faciunt. Rogemus.

(169rb) Tit.: Sermo $2^{\text {us }}$ de eodem (Schneyer 7, Nr. 1). - (170rb) Tit.: Dominica secunda (Nr. 2). (171va) Tit.: Dominica tercia (Nr. 3). - (172rb) Tit.: Dominica quarta (gestrichen: quinta) (Dnca 3. adv., Nr. 4). - (173rb) Tit.: In nativitate domini (Nr. 5). - (174rb) Tit.: Sermo de eodem (Dnca infra octav. nativitatis dni, Nr. 6). - (175rb) Tit.: Dominica prima post epiphaniam (Nr. 7). (176vb) Tit.: Dominica secunda post epiphaniam (Nr. 8). - (177vb) Tit.: Dominica tercia (Nr. 9). - (179ra) Tit.: Dominica quarta (Nr. 10). - (180ra) Dnca 5. post epiph. dni (Nr. 11). (180vb) Dnca in Septuages. (Nr. 12). - (181va) Dnca in Sexages. (Nr. 13). - (182ra) Dnca in Quinquages. (Nr. 14). - (182va) Dnca 1. in Quadrages. (Nr. 15). - (183rb) Dnca 2. in Quadrages. (Nr. 16). - (184rb) Dnca 3. in Quadrages. (Nr. 17). - (185ra) Dnca 4. in Quadrages. (Nr. 18). (186ra) Dnca 1. in passione dni (Nr. 19). - (186vb) Dnca in palmis (Nr. 20). - (187rb) Fer. 5 in coena dni (Nr. 21). Inc.: Acccippe (!) et manducate ex hoc omnes Actis Ioh. (recte: 1 Cor 11,24). Nota quando tritulator est debilis et habet grave flagellum in manu ... Inc. wie Kremsmünster, Stiftsbibl., CC 23, Bl. 277v. - (188va) Fer. 6. in parasceve (Nr. 22). - (189rb) Nr. 23. - (189vb) In vigilia paschatis (Nr. 24). - (191ra) Dnca resurrectionis dni (Nr. 25). Expl.: ... dixit de templo corporis sui etc. Rogemus. Expl. wie Kremsmünster, Stiftsbibl., CC 23, Bl. 281v. - (191vb) Nr. 26. Expl.: ... tercia autem conversionem in bono perseverancium. Rogemus ergo dominum. Expl. wie Kremsmünster, Stiftsbibl., CC 23, Bl. 281v. - (192va) Tit.: In octava resurreccionis (Dnca 1. post pascha, Nr. 27). - (193va) Tit.: Dominica prima post octavas (Dnca 2. post pascha, Nr. 28). - (194va) Tit.: Dominica secunda (Dnca 3. post pascha, Nr. 29). - (195ra) Tit.: Dominica tercia (Dnca 4. post pascha, Nr. 30). - (196ra) Tit.: Dominica quarta (Dnca 5. post pascha, Nr. 31). Inc. bei Schneyer unsichere Lesung, in der Hs.: ... quia promptus sum ... - Expl. bei 
Schneyer unsichere Lesung, in der Hs.: ... vel tribulacio a dyabolo detestinata. - (196vb) Tit.: Dominica quinta (In Litaniis maioribus et minoribus, Nr. 32). - (197va) Tit.: In die sancto ascensionis domini (Nr. 33). - (198rb) Tit.: Dominica post ascensionem domini (Dnca 6. post pascha, Nr. 34). - (198vb) Tit.: De eodem (Nr. 35). - (199va) Tit.: De sancto Penthecostes (Nr. 36). - (200ra) Tit.: De eodem (Nr. 37). - (200vb) Ohne Festangabe bei Schneyer (Nr. 38). (201va) Tit.: De sancta trinitate (Nr. 39). - (202va) Dnca 1. post pent. (Nr. 40). - (204ra) Dnca 2. post pent. (Nr. 41). Expl.: ... et fons perpetue consolacionis. Rogemus ergo dominum. Expl. wie Kremsmünster, Stiftsbibl., CC 23, Bl. 296r. - (204va) Dnca 3. post pent. (Nr. 42).

(205va) Tit.: Dominica quarta. - Inc.: Estote misericordes sicut et pater vester misericors est. Luc. VI ${ }^{\circ}$ (36). Nota in precedenti ewangelio dominicali dicitur dicitur (!) quod publicani et peccatores ... - Expl.: ... pauperibus distribuendo centuplum accipiet in vitam eternam. Rogemus. Parallelüberlieferung: Kremsmünster, Stiftsbibl., CC 23, Bl. 297v.

(206va) Tit.: Dominica quinta (Nr. 43). - (207va) Tit.: Dominica sexta (Dnca 5. post pent., Nr. 44). Expl.: ... velox ad iram quia occisio aliquando sequitur. Rogemus. Expl. wie Kremsmünster, Stiftsbibl., CC 23, Bl. 300r. - (208rb) Tit.: Dominica VII (Dnca 6. post pent., Nr. 45). (209ra) Tit.: Dominica octava (Nr. 46). - (209va) Tit.: Dominica nona (Dnca 7. [!] post pent., Nr. 47). Expl.: ... Sic est deliciosus. Rogemus etc. Expl. wie Kremsmünster, Stiftsbibl., CC 23, Bl. 302v. - (210va) Tit.: Dominica decima (Dnca 8. post pent., Nr. 48). - (211rb) Tit.: Undecima dominica (Dnca 9. post pent., Nr. 49). - (212va) Tit.: Dominica XII (Dnca 10. post pent., Nr. 50). (213rb) Tit.: Dominica XIII (Dnca 10. post pent., Nr. 51). - (213vb) Tit.: Dominica XIIII (Dnca 11. post pent., Nr. 52). - (215ra) Tit.: Dominica XV (Dnca 12. post pent., Nr. 53). - (215va) Tit.: Dominica quartadecima (Dnca 13. post pent., Nr. 54). - (216rb) Tit.: Dominica quintadecima (Dnca 14. post pent., Nr. 55). - (217ra) Tit.: Dominica sedecima (Dnca 15. post pent., Nr. 56). (217vb) Tit.: Dominica XVII (Dnca 16. post pent., Nr. 57). - (218va) Tit.: Dominica XVIII (Dnca 17. post pent., Nr. 58). Expl.: ... manus eius contra omnes. Genesis. Rogemus ergo etc. Expl. wie Kremsmünster, Stiftsbibl., CC 23, Bl. 313v. - (219ra) Tit.: Dominica XVIIII (Dnca 18. post pent., Nr. 59). - (219va) Tit.: Vicesima dominica (Nr. 60). Expl.: ... sustinere debuit. Mt. ultimo Accipiens etc. Rogemus. Expl. vgl. Kremsmünster, Stiftsbibl., CC 23, Bl. 314r. - (220ra) Tit.: Vicesima prima (Dnca 20. post pent., Nr. 61). - (221ra) Tit.: Vicesima secunda (Dnca 21. post pent., Nr. 62). - (222ra) Tit.: Vicesima tercia (Dnca 22. post pent., Nr. 63). - Inc.: Ostendite michi numisma census. Mt. XXII ${ }^{\circ}$ (19). Nota predicatores dicuntur pastores quibus dicetur (!) Iohannes $X X I^{\circ}$ Afferte michi de piscibus ... Inc. wie Kremsmünster, Stiftsbibl., CC 23, Bl. 316v. - (223ra) Tit.: Vicesima quarta (Dnca 23. post pent., Nr. 64). - (223va) Tit.: Dominica vicesima quinta (Dnca 24. post pent., Nr. 65).

$(224 \mathrm{r}-\mathrm{v})$ leer.

$\left(\mathrm{I}^{*} \mathrm{r}-\mathrm{v}\right)$ leer.

A. P./U.S.

\section{Cod. 177}

\section{FLORES DE SANCTIS ET DE TEMPORE}

Pap. I, 153, I* Bl. $280 \times 210$. Tirol (Neustift?), um 1430/33.

B: $\quad$ Pap. tw. fleckig, bes. B1. 41-47, B1. 12 am seitlichen Blattrand eingerissen. B1. 33 am seitlichen Blattrand beschnitten. Bilder und Nachweise der Wasserzeichen s. WZMA. Datierung nach Wasserzeichenbefund. Identische Wasserzeichen: u. a. Innsbruck, ULB Tirol, Cod. 481 (dat. 1431), Cod. 437, T. II (dat. 1432), Cod. 666, T. III (dat. 1433). Lagen: (I-1) (Vorsatzbl. 18. Jh.) $+\mathrm{V}^{10}+2^{12}+2 . \mathrm{V}^{32}+1^{33}+4 . \mathrm{VI}^{81}+(\mathrm{VI}-1)^{92}+$ 5.VI ${ }^{152}+1^{153}+(\mathrm{I}-1)^{1 *}($ Nachsatzbl. 18. Jh.). Gegenbl. zum Vor- bzw. Nachsatzbl. als Spiegel auf dem VD bzw. HD aufgeklebt. Gegenbl. zu Bl. 83 herausgeschnitten (ohne Textverlust). Lage 4 und 9 mit einem 
Papierfalz umschlagen. Am oberen Blattrand Foliierung 19. Jh. durch die ULB Tirol; Fehler in der Zählung: Bl. 152 und 153 fälschlich als 252 und 253 foliiert, später korrigiert.

S: $\quad$ Schriftraum 180/200 × 130. Zwei Spalten, von Tintenlinien gerahmt, zu 33-38 Zeilen. Zirkelstiche. Bastarda von drei Händen: 1) Bl. 1ra-80va, Z. 30; 2) Bl. 80va, Z. 30-Bl. 106vb, Z. 9 und Bl. 153ra-va; 3) Bl. 106vb, Z. 10-Bl. 152vb. Randbemerkungen von späterer Hand.

A: $\quad$ Rote Auszeichnungsstriche, Unterstreichungen und Überschriften. Zeigehände. Oberlängen in der ersten Zeile bisweilen gedehnt. Drei- und vierzeilige (Bl. 1ra und 140ra achtzeilige) rote Lombarden, tw. mit ungelenken kopfstempelartigen Aussparungen, tw. mit Punktverdickungen, tw. mit minimal verzierten Ausläufern. Vereinzelt auch fünfzeilige rote Lombarden mit einfachem Knospenfleuronnée als Besatz. Repräsentanten.

E: $\quad$ Neuzeitlicher Bibliothekseinband: schwarz gesprenkeltes braunes Pap. über Pappe. Neustift, 2. H. 18. Jh. Am VD und HD Ecken mit braunem Leder verstärkt. Rücken: braunes Leder, vier einfache Bünde, von Goldbordüren gesäumt. Im zweiten Feld Golddruck M. S. FLORES 1460 in Goldrahmung, im dritten Signaturschild (s. bei G). Schnitt rot gesprenkelt. Spiegel Pap. 18. Jh. Am Spiegel des VD Signaturen und Bleistiftnotiz (s. bei G), Spiegel des HD leer.

G: Bl. 1r Besitzvermerk 18. Jh. Collegii Neocell. Anno 1460. 1809 anlässlich der vorübergehenden Aufhebung des Klosters Neustift der ULB Tirol übergeben. Am Spiegel des VD Signaturen der ULB Tirol II (Tinte) 2 K 25 (Bleistift) und Nr. 177 (Tinte) sowie Bleistiftnotiz (Vide Grundzettel). Am Rücken gelbes Signaturschild der ULB Tirol 177. Bl. 1r Stempel der ULB Tirol 19. Jh. 1921 aufgrund des Friedensvertrages von St. Germain an den italienischen Staat abgegeben und von diesem 1929 dem Kloster Neustift als Dauerleihgabe überlassen. Bl. 1r Stempel der Soprintendenza Tridentina 20. Jh.

L: $\quad$ Katalog ULB Tirol II 158, 208.

$(\mathrm{Ir}-\mathrm{v})$ leer.

(1ra-143rb) Flores (Graeculus Piper) secundum Conradum de Waldhausen bzw. Graeculus (Schneyer 1, 805-815, Nr. 149-326 bzw. Schneyer 2, 206-219, Nr. 1-174). Tit. am oberen Blattrand: Flores de sanctis et de tempore simul. Autorenschaft unsicher. Im Folgenden Sermones nach Schneyer für Conradus de Waldhausen (Schneyer 1) und Graeculus (Schneyer 2) zitiert; drei Sermones der Hs. fehlen bei Graeculus, eine bei Conradus de Waldhausen. Wenn nicht anders angegeben, wird zunächst jeweils die entsprechende Nummer in Schneyer 1, dann jene in Schneyer 2 angeführt.

(1ra) Tit.: Dominica in adventu domini prima etc. (Schneyer 1, 805, Nr. 149 für Conradus de Waldhausen bzw. Schneyer 2, 206, Nr. 1 für Graeculus). (1vb) Schneyer 1, Nr. 150 bzw. Schneyer 2, Nr. 2. (2vb) Nr. 151 bzw. Nr. 3. (4ra) Nr. 152. (5ra) Nr. 153 bzw. Expl. eher Nr. 4. (6ra) Nr. 154 bzw. Nr. 5.

(7ra) Dnca 2. adv. (Nr. 155). (7va) Tit.: Sermo tercius (Nr. 156 bzw. Nr. 6).

(8va) Tit.: Dominica tercia in adventu (Expl. eher Nr. 157 bzw. Nr. 7). (9rb) Nr. 158 bzw. eher Nr. 8. (10va) Nr. 160.

(11va) Dnca 4. adv. (Nr. 161 bzw. Nr. 10). (12rb) Nr. 162 bzw. Nr. 11. (13rb) Nr. 163 bzw. Nr. 12. (14ra) Nr. 164 bzw. Expl. eher Nr. 14.

(15ra) Tit.: In nativitate domini (Nr. 165). (16ra) Nr. 166 bzw. Nr. 15. (17rb) Nr. 167 bzw. Nr. 16 mit leicht abweichendem Inc. (18ra) Nr. 168 (nicht in Schneyer 2). (19rb) Nr. 169 (nicht in Schneyer 2). (20va) Nr. 170 bzw. Nr. 17.

(21va) Dnca infra octav. nativitatis dni (Nr. 171 bzw. Nr. 18). (22va) Nr. 173 bzw. Nr. 19 mit leicht abweichendem Inc. Expl. (= Expl. Nr. 175 bzw. Nr. 22): ... Unde Augustinus Quicumque se ad hoc nomen devote inclinaverit decem dies indulgencie consequitur. Invoca ergo hoc nomen Ihesus ut consequaris remissionem omnium peccatorum.

(23rb) In circumcisione dni. (Inc. wie Nr. 175 und 176 bzw. Nr. 21). Expl. abweichend (ähnlich Nr. 176 bzw. Nr. 21): ... Invoca nomen eius quod hodie sibi impositum est in quo quidem nomine solum salvari poteris ut dicit apostolus.

(24vb) Tit.: In epiphania domini sermo (Schneyer 1, Nr. 177). (25vb) Nr. 178 bzw. Nr. 23. (26vb) Nr. 179 (nicht in Schneyer 2). Expl.: ... nam communis est omnibus divitibus et pauperibus dare regnum celorum. Rogemus igitur puerum Ihesum Alleluia. (28ra) Nr. 180. Bibelzitat leicht abweichend (bei Schneyer Mt 2,11 beginnend mit „Apertis thesauris suis“, in der Hs. Mt 2,11 erst ab): Obtulerunt 
domino aurum ... (28vb) Nr. 181 bzw. Nr. 25.

(30ra) Dnca 1. post epiph. dni (Nr. 182 bzw. Nr. 26). (31ra) Nr. 183 bzw. Nr. 27. Expl.: ... obsequendo et amando invenit et puerum Ihesum placabilem sibi. Rogemus igitur dominum. (31vb) Schneyer 2, Nr. 28. (32va) Nr. 185 bzw. Nr. 30.

(33vb) Dnca 2. post epiph. dni (Nr. 186 bzw. Nr. 31). Expl. erweitert: ... sic per mulierem diligentem ornatur domus (= Ende Schneyer). Ergo diligere debemus uxores etc. (34rb) Nr. 187 bzw. Nr. 32.

(35va) Dnca 3. post epiph. dni (Nr. 188 bzw. Nr. 33). (36vb) Nr. 189 bzw. Nr. 34. (38rb) Nr. 190 bzw. Nr. 35.

(39rb) Dnca 4. post epiph. dni (Nr. 191 bzw. Expl. eher Nr. 36). (40vb) Expl. eher Nr. 192 bzw. Nr. 37. (42ra) Nr. 193 bzw. Expl. eher Nr. 38.

(43rb) Dnca in Septuages. (Nr. 196 bzw. Nr. 41). Am Rand Bemerkung Valde popularis et utilis ad docendum. (44ra) Nr. 197 bzw. Nr. 42.

(44vb) Dnca 5. post epiph. dni (Nr. 194 bzw. Nr. 39). Inc. jeweils leicht abweichend. Inc.: Domine, nonne bonum semen seminasti etc. Matth. (13,27). Plures sunt agri in quibus seminat ... (46ra) Nr. 195 bzw. Nr. 40.

(47rb) Dnca in Sexages. (Nr. 198 bzw. Nr. 43). (48rb) Bei Schneyer 1 nur Bibelzitat wie Nr. 199 bzw. Inc. Nr. 44. Expl.: ... Confitentur se nosce Deum factis autem negant.

(49rb) Dnca in Quinquages. (Nr. 200 bzw. Nr. 45). Expl. (jeweils leicht abweichend): ... sic et quilibet debet videre intra se qui debeat mundare. (50ra) Nr. 201 bzw. Inc. und Expl. eher Nr. 46. (51rb) Nr. 202 bzw. Expl. eher Nr. 47.

(52ra) Tit.: Feria quarta cinerum (Nr. 203 bzw. Expl. eher Nr. 49). (53ra) Nr. 204 bzw. Nr. 50. (54ra) Nr. 205 bzw. Nr. 51. (55ra) Nr. 206 bzw. Expl. eher Nr. 52.

(56va) Dnca 1. in Quadrages. (Nr. 207, Expl. eher Nr. 53). Expl.: ... ad infernum detraheris in profundum laci. (57vb) (Nr. 208 bzw. Nr. 54).

(59rb) Dnca 2. in Quadrages. (Nr. 209 bzw. Nr. 55). (60rb) Inc. von Nr. 210 leicht abweichend bzw. eher Nr. 56. (61rb) Nr. 211 bzw. Nr. 57.

(62rb) Dnca 3. in Quadrages. (Expl. eher Nr. 212 bzw. Nr. 58). (63rb) Expl. eher Nr. 213 bzw. Nr. 59. (64ra) Expl. eher Nr. 214 bzw. Nr. 60.

(64vb) Dnca 4. in Quadrages. (Nr. 215 bzw. Nr. 61). (66ra) Nr. 216 bzw. Nr. 62. (66vb) Nr. 217 bzw. Nr. 63. (67vb) Mit dt. Zusatz: ... quia numquam liberabor. Und reimet sich das merlin nit wol so iber doch der sinn gern guot. Rogemus etc.

(67vb) Dnca 1. in passione dni (Nr. 218 bzw. Nr. 64). (68vb) Nr. 219 bzw. Nr. 65. (69vb) Nr. 220 bzw. Expl. eher Nr. 66.

(70rb) Dnca in palmis (Nr. 221 bzw. Nr. 67). (71rb) Nr. 222 bzw. Nr. 68. (72rb) Nr. 223 bzw. Nr. 69.

(73rb) Tit.: In cena domini sermo (Nr. 225 bzw. Nr. 71). Expl. erweitert: ... In pedum ablucione innuitur (= Ende Schneyer) humilitas ubi dicitur quod humilitas est summa virtus. (73vb) Nr. 227.

(75rb) Tit.: Idem. Nur Bibelzitat wie Nr.226, Inc. wie Nr. 72. Inc.: Ad mensam magnam sedisti (Sir 31,12). Scito quod talia oportet te preparare qualia sunt in hostia. Quanto maior est festivitas tanto se melius homines preparare debent ... - Expl.: ... Tales non debent accipere corpus Christi. Rogemus. Parallelüberlieferung: Innsbruck, ULB Tirol, Cod. 758, Bl. 189v.

(76va) Tit.: In parascephenn (!) (Nr. 228 bzw. Nr. 73). (78rb) Nr. 230 bzw. Nr. 75.

(78vb) Tit.: In die sancto pasche (Nr. 231 bzw. Nr. 76). (80rb) Nr. 232 bzw. Expl. eher Nr. 77. (81ra) Nr. 233 bzw. Nr. 78. (82ra) Nr. 234 bzw. Nr. 79.

(82rb) Dnca resurrectionis dni, fer. 2 (Nr. 235 bzw. Nr. 80). (83vb) Nr. 236 bzw. Nr. 81. (84rb) Expl. eher Nr. 237 bzw. Nr. 82.

(85rb) Dnca resurrectionis dni, fer. 3 (Nr. 240 bzw. Nr. 83).

(86ra) Dnca 1. post pascha (Nr. 241 bzw. Nr. 84). (86va) Nr. 243 bzw. Inc. eher Nr. 85. (87rb) Nur Bibelzitat und Expl. wie Nr. 242, Inc. übereinstimmend mit Nr. 86.

(88ra) Dnca 2. post pascha (Nr. 244 bzw. Nr. 87). (88vb) Nr. 245 bzw. Nr. 88. (89va) Nr. 246 bzw. Nr. 89. (90ra) Dnca 3. post pascha (Nr. 247 bzw. Nr. 90). (91ra) Nr. 248 bzw. Nr. 91. (91vb) Nr. 249 bzw. Nr. 92. 
(92va) Dnca 4. post pascha (Nr. 251 bzw. Inc. eher Nr. 94). (93va) Nr. 252 bzw. Nr. 95. (94ra) Nr. 253 bzw. Nr. 96.

(95ra) Dnca 5. post pascha (Nr. 254 bzw. Nr. 97). (96ra) Nr. 255 bzw. Nr. 98. (96va) Expl. eher Nr. 256 bzw. Nr. 99. (97ra) Nr. 257 bzw. Nr. 100. (97vb) Nr. 259 bzw. Nr. 101.

(98va) In ascensione dni (Nr. 260 bzw. Nr. 102). (99va) Nr. 261 bzw. Nr. 103. (100va) Nr. 262 bzw. Nr. 104.

(101rb) Dnca 6. post pascha (Nr. 263 bzw. Nr. 105). (102rb) Nr. 264 bzw. Nr. 106. (103rb) Nr. 265 bzw. Nr. 107.

(104rb) Dnca pentecostes et de spiritu sancto (Nr. 266 bzw. Nr. 108). (105ra) Nr. 267 bzw. Nr. 109. (105va) Nr. 268 bzw. Nr. 110.

(106vb) In festo ss. trinitatis (Nr. 269 bzw. Expl. eher Nr. 111). (107rb) Nr. 270 bzw. Expl. eher Nr. 112. (108rb) Dnca 1. post pent. (Inc. wie Nr. 271, Expl. Nr. 272 bzw. Inc. wie Nr. 113, Expl. Nr. 114). (109va) Nr. 273 bzw. Nr. 115.

(110va) Dnca 2. post pent. (Nr. 276 bzw. Nr. 116). (111rb) Nr. 274 bzw. Nr. 117. (112rb) Nr. 275 bzw. Nr. 118.

(113ra) Dnca 3. post pent. (Nr. 277 bzw. Nr. 119). (114ra) Nr. 278 bzw. Nr. 120. (114vb) Expl. eher Nr. 279 bzw. Nr. 121.

(115vb) Dnca 4. post pent. (Nr. 280 bzw. Nr. 122). (116va) Nr. 281 bzw. Nr. 123. (117va) Inc. mit Glosse wie Nr. 282 bzw. Nr. 124.

(118rb) Dnca 5. post pent. (Nr. 283 bzw. Nr. 125). (119rb) Nr. 284 bzw. Nr. 126. (120ra) Nr. 285 bzw. Nr. 127.

(120vb) Dnca 6. post pent. (Expl. eher Nr. 286 bzw. Nr. 128). (121va) Nr. 287 bzw. Nr. 129. (122rb) Nr. 288 bzw. Nr. 130.

(123rb) Dnca 7. post pent. (Expl. eher Nr. 289 bzw. vgl. Nr. 131). (124ra) Nr. 291 bzw. Nr. 132. (124va) Nr. 290 bzw. Nr. 133.

(125va) Dnca 8. post pent. (Expl. eher Nr. 292 bzw. Nr. 134). (126rb) Expl. Nr. 293 bzw. Nr. 135. (127ra) Nr. 294 bzw. Nr. 136. Expl. leicht gekürzt: ... ceteris peccantibus tantum dat unam.

(127va) Dnca 9. post pent. (Nr. 295 bzw. Nr. 137). (128rb) Nr. 296 bzw. Nr. 138. (129ra) Nr. 297 bzw. Nr. 139 .

(129vb) Dnca 10. post pent. (Nr. 298 bzw. Nr. 140). (130va) Nr. 299 bzw. Nr. 141. (131rb) Nr. 300 bzw. Nr. 142.

(132ra) Dnca 11. post pent. (Nr. 301 bzw. Nr. 143). (133ra) Nr. 302 bzw. Nr. 144. (133vb) Nr. 303 bzw. Nr. 145.

(134rb) Dnca 12. post pent. (Nr. 304 bzw. Nr. 146). Inc. leicht abweichend: Misit digitos suos ... Mt. $4^{\circ}$ (recte: Mc 7,33). Digitos in aures surde (!) et tandem rogaverunt tam ut imponeret sibi manum ... (134vb) Nr. 305 bzw. Nr. 147.

(135va) Dnca 13. post pent. (Nr. 306 bzw. Nr. 148). (136rb) Nr. 307 bzw. Nr. 149. (137rb) Nr. 308 bzw. Nr. 150.

(137vb) Dnca 14. post pent. (Nr. 309 bzw. Nr. 151). (138rb) Nr. 310 bzw. Nr. 152.

(138vb) Dnca 15. post pent. (Nr. 311 bzw. Nr. 153). (139va) Expl. eher Nr. 312 bzw. Nr. 154. (140ra) Nr. 313 bzw. Nr. 155. (140vb) Nr. 314 bzw. Nr. 156.

(141rb) Dnca 16. post pent. (Nr. 315 bzw. Nr. 157). (142rb) Nr. 316 bzw. Nr. 158. (143ra) Nr. 317 bzw. Nr. 159.

(143rb) Dnca 17. post pent. (nur Bibelzitat und Expl. vgl. Nr. 318 bzw. Inc. wie Nr. 160). (144rb) Nr. 319 bzw. Nr. 161. (144vb) Nr. 320 bzw. Nr. 162.

(145va) Dnca 18. post pent. (Nr. 321 bzw. Expl. eher Nr. 163).

(146rb) Dnca 18. post pent. (Expl. eher Nr. 322 bzw. Nr. 164).

(147rb) Dnca 19. post pent. (Nr. 166). (148rb) Nr. 167. (148vb) Nr. 168)

(149va) Dnca 20. post pent. (Nr. 170). Expl.: ... Math. Venite benedicti patres etc. (150ra) Nr. 324 bzw. Nr. 169. 
(151ra) Dnca 21. post pent. (Nr. 171). (151vb) Nr. 325 bzw. Nr. 172. (152va) Nr. 173.

(153rb) Dnca 22. post pent. (Nr. 326 bzw. Nr. 174). Expl.: ... et submergit scriptura humilitatem eius dicens.

(153vb) leer.

$(\mathrm{I} * \mathrm{r}-\mathrm{v})$ leer.

U.S.

\section{Cod. 181}

\section{ALANUS AB INSULIS}

Pap. I, 60, I* Bl. 285×210. Wiener Raum, um 1410 .

B: $\quad$ Pap. bisweilen stark fleckig, Wasserschaden, Risse und Fehlstellen, nachträglich ergänzt, Lage 1 mit Pap. verstärkt. Zw. Lage 1 und 2 sowie in den Lagenmitten Pergamentfälze. Bilder und Nachweise der Wasserzeichen s. WZMA. Datierung nach Wasserzeichenbefund. Lagen: (I-1) (Vorsatzbl., Pap. 18. Jh.) $+5 . \mathrm{VI}^{60}+$ $(\mathrm{I}-1)^{I^{*}}$ (Nachsatzbl., Pap. 18. Jh.). Gegenbl. zum Vor- bzw. Nachsatzbl. als Spiegel auf dem VD bzw. HD aufgeklebt. Lagenreklamanten. Am Beginn von Lage 2 Kustode in arabischer Ziffer erhalten. Am oberen Blattrand Foliierung 19. Jh. durch die ULB Tirol.

S: $\quad$ Schriftraum 200/210 $\times 140 / 145$, von tw. kaum sichtbaren Bleistiftlinien begrenzt. Zeilenzahl wechselnd. Bastarda. Incipit in Auszeichnungsschrift (Textura).

A: Rote Auszeichnungsstriche, Unterstreichungen, Rahmungen der Über- und Schlussschriften. Zeigehände. In der ersten Zeile bisweilen cadellenartige Verlängerung der Schäfte einzelner Buchstaben und einfache Verzierungen (in Federzeichnung Bl. 8rb Gesicht, B1. 21ra Profilkopf). Zweizeilige rote Lombarden, tw. mit Punktverdickungen. Bl. 1ra einfache rote Initiale mit kopfstempelförmiger Aussparung und einer Ähre aus gestielten Perlen im Binnenfeld.

E: $\quad$ Neuzeitlicher Bibliothekseinband: schwarz gesprenkeltes braunes Pap. über Pappe. Neustift, 2. H. 18. Jh. Am VD und HD Ecken mit Leder verstärkt. Rücken: braunes Leder, vier einfache Bünde, von Goldbordüren gesäumt. Im zweiten Feld Golddruck M. S. ALAN. DE ARTE PRAED. in Goldrahmung, im dritten Signaturschild (s. bei G). Schnitt rot gesprenkelt. Spiegel Pap. 18. Jh. Am Spiegel des VD Signaturen und Bleistiftnotiz (s. bei G), Spiegel des HD leer.

G: $\quad$ Nach dem Inhaltsverzeichnis in Innsbruck, ULB Tirol, Cod. 157, Bl. Ir gehört Cod. 181 zu einer Gruppe von urspr. selbständigen Hs. des 14. und 15. Jh., die im 15. Jh. in Neustift zu einem Sammelband vereinigt wurden. Im Zuge der Neuaufstellung der Neustifter Bibliothek in der 2. H. 18. Jh. wurde die Sammelhandschrift (wie dies auch bei anderen Hs. und Inkunabeln gemacht wurde) in sieben Einzelhandschriften aufgelöst; jeder Einzelband erhielt den für Neustift typischen Halbledereinband. Zur urspr. Hs. zählen folgende Signaturen (in der urspr. Reihenfolge):

Cod. 157: Aristoteles: Ethica Nicomachea und Oeconomica.

heute nicht mehr nachweisbar: Aristoteles: Politica.

Cod. 159: Albertus de Saxonia: Kommentar zu Cod. 157.

Cod. 168: Aristoteles: Physica, Lib. 1-5.

Cod. 163: Aristoteles: Physica, Lib. 6-8 und De anima.

Cod. 181: Alanus ab Insulis: Summa de arte praedicatoria.

Cod. 164: Anshelmus Havelburgensis. Anticimenon.

Von diesen sieben Hs. ist eine nicht mehr erhalten, drei befinden sich heute an der ULB Tirol in Innsbruck (Cod. 157, 159 und 164), drei werden in der Stiftsbibl. Neustift (Cod. 163, 168 und 181) aufbewahrt.

1809 anlässlich der vorübergehenden Aufhebung des Klosters Neustift der ULB Tirol übergeben. Am Spiegel des VD alte Signaturen der ULB Tirol II $\overline{4}$ D 9 (Tinte, radiert), II 2 H 29 (Bleistift) und Nr. 181 (Tinte) sowie Bleistiftnotiz (Vide Grundzettel). Bl. 1r Stempel der ULB Tirol 19. Jh. 1921 aufgrund des Friedensvertrages von St. Germain an den italienischen Staat abgegeben und von diesem 1929 dem Kloster Neustift als Dauerleihgabe überlassen. Bl. 1r Stempel der Soprintendenza Tridentina 20. Jh.

L: $\quad$ Neuhauser, Neustift 91-95. - Katalog ULB Tirol II 167, 208. 
(Ir-v) leer.

(1r-60v) Alanus 〈AB Insulis〉: Summa de arte praedicatoria (PL 210, 111A-195D). Zw. cap. 30 und 31 eingeschoben $31^{m}$ De penitencia (Bl. 41rb-42ra), deshalb im Folgenden Zählung von PL abweichend. Cap. 48 fehlt.

(1r) Tit.: Incipit Alanus de arte predicandi. - Inc.: Vidit Iacobus scalam a terra usque ad celum attingentem per quam ascendebant ... - Expl.: ... et alibi. Et regnis eius non erit finis.

(41rb) Einschub. Tit.: De penitencia. - Inc.: Dominus dicit in ewangelio Penitenciam agite appropinquabit enim regnum celorum (Mt 3,2). Petrus apostolus dicit Penitenciam agite et baptizetur ... - Expl.: ... docebo iniquos vias.

(59r) Schlussschrift: Explicit summa magistri Alani de modo predicandi.

$(59 \mathrm{v}-60 \mathrm{v})$ Register.

$\left(I^{*} \mathrm{r}-\mathrm{v}\right)$ leer.

C.S.

\section{Cod. 182}

\section{PS.-EUSEBIUS}

Pap. I, 16, I* Bl. $285 \times 205$. Süddeutscher Raum, 1400 .

B: $\quad$ Bilder und Nachweise der Wasserzeichen s. WZMA. Wasserzeichenbefund mit Datierung übereinstimmend. Lagen: (I-1) (Vorsatzbl. 18. Jh.) + VIII ${ }^{16}+(\mathrm{I}-1)^{I^{*}}($ Nachsatzbl. 18. Jh.). Gegenbl. zum Vor- bzw. Nachsatzbl. als Spiegel auf dem VD bzw. HD aufgeklebt. Am Lagenanfang Kustode 21, am rechten oberen Blattrand Foliierung 15. Jh. 216-231, Hinweise auf ehem. Sammelhandschrift (s. bei G). Am oberen Blattrand mittig Foliierung 19. Jh. durch die ULB Tirol 1-16 (hier berücksichtigt).

S: $\quad$ Schriftraum 220/225 ×170/175. Zwei Spalten, von Tintenlinien gerahmt, zu 35-40 Zeilen. Bastarda, dat. 1. Oktober 1400 (Bl. 16rb).

A: $\quad$ Rote Auszeichnungsstriche, Durchstreichungen und Überschriften. Zwei- bis vierzeilige einfache rote Lombarden, selten mit kopfstempelförmigen Aussparungen.

E: $\quad$ Neuzeitlicher Bibliothekseinband: schwarz gesprenkeltes braunes Pap. über Pappe. Neustift, 2. H. 18. Jh. Am VD und HD Ecken mit braunem Leder verstärkt. Rücken: braunes Leder, vier einfache Bünde, mit Goldbordüren gesäumt. Im zweiten Feld Golddruck M. S., im dritten Signaturschild (s. bei G). Schnitt rot gesprenkelt. Spiegel Pap. 18. Jh. Am Spiegel des VD Signaturen und Bleistiftnotiz (s. bei G), Spiegel des HD leer.

G: $\quad$ Nach dem Inhaltsverzeichnis in Neustift, Stiftsbibl., Cod. 158, Bl. Ir gehört Cod. 182 zu einer Gruppe von urspr. tw. selbständigen Hs. des 14. und 15. Jh., die im 15. Jh. in Neustift zu einem Sammelband vereinigt wurden (s. auch Foliierung). Im Zuge der Neuaufstellung der Neustifter Bibliothek in der 2. H. 18. Jh. wurde die Sammelhandschrift (wie dies auch bei anderen Hs. und Inkunabeln gemacht wurde) in sieben Einzelhandschriften aufgelöst; jeder Einzelband erhielt den für Neustift typischen Halbledereinband. Zur urspr. Hs. zählen folgende Signaturen (in der urspr. Reihenfolge):

Cod. 158: Augustinus. Foliierung 15. Jh. 1-69.

Cod. 83: Theologische Sammelhandschrift, dat. 1400. Foliierung 15. Jh. 70-128.

Cod. 82: Henricus de Langenstein: De contractibus. De contemptu mundi. Foliierung 15. Jh. 129-165.

Cod. 183: Heinrich Seuse: Horologium sapientiae. Foliierung 15. Jh. 166-203.

Cod. 161: Iohannes de Dambach. Origenes. Foliierung 15. Jh. 204-215.

Cod. 182: Ps.-Eusebius, dat. 1400. Foliierung 15. Jh. 216-231.

Cod. 162: Sermones de dedicatione. Foliierung 15. Jh. 232-241.

Von diesen sieben Hs. befindet sich heute eine an der ULB Tirol in Innsbruck (Cod. 82), die restlichen sechs werden hingegen in der Stiftsbibl. Neustift aufbewahrt.

1809 anlässlich der vorübergehenden Aufhebung des Klosters Neustift der ULB Tirol übergeben. Am Spiegel des VD alte Signaturen der ULB Tirol II $\overline{4} D 12$ (Tinte, radiert), II 2 H 30 (Bleistift) und Nr. 182 (Tinte) sowie Bleistiftnotiz (Vide Grundzettel). Am Rücken gelbes Signaturschild der ULB Tirol 182. Bl. 1r 
Stempel der ULB Tirol 19. Jh. 1921 aufgrund des Friedensvertrages von St. Germain an den italienischen Staat abgegeben und von diesem 1929 dem Kloster Neustift als Dauerleihgabe überlassen. Bl. 1r Stempel der Soprintendenza Tridentina 20. Jh.

L: $\quad$ Katalog ULB Tirol II 167, 208. - Stefani 106. - Peintner, Stiftsbibliothek 121.

$(\mathrm{Ir}-\mathrm{v})$ leer.

(1ra-16rb) 〈Ps.->Eusebius Caesariensis: Epistola ad beatum Damasum episcopum Portuensem et ad christianissimum Theodosium Romanorum senatorem de morte Hieronymi (PL 22, 239-282. Klapper II 10-241. - BHL Nr. 3866. BHM Nr. 903E). Abweichende Kapiteleinteilung.

Schlussschrift mit Datierung: Explicit epistola beati Ewsebii ad Damasium Portuensem episcopum et ad Theodonium Romanorum senatorem de morte gloriosissimi confessoris Ieronimi doctoris eximii anno domini $\mathrm{M}^{\circ} \mathrm{CCC} \mathrm{C}^{\circ}$ in die sancti Remigii episcopi et confessoris etc. (1. Oktober 1400).

(16va-b) nur Rahmung. $\left(I^{*} \mathrm{r}-\mathrm{v}\right)$ leer.

P. A.

\section{Cod. 183}

\section{HENRICUS SUSO}

Pap. I, 48, I* Bl. $285 \times 205$. Süddeutscher Raum, um 1400 .

B: $\quad$ Bilder und Nachweise der Wasserzeichen s. WZMA. Datierung nach Wasserzeichenbefund. Identische Wasserzeichen: Neustift, Stiftsbibl., Cod. 83 (dat. 1400) und Cod. 158. Lagen: (I-1) ${ }^{\mathrm{I}}$ (Vorsatzbl. 18. Jh.) + 4.VI ${ }^{48}$ $+(\mathrm{I}-1)^{I^{*}}$ (Nachsatzbl. 18. Jh.). Lage 2 und 3 am Lagenende Kustoden in arabischen Ziffern erhalten. Am oberen Blattrand mittig zeitgenössische Foliierung in Rot 2-38 (Bl. 1 ungezählt, Zahl 2 doppelt angeführt, 11 ausgelassen), dann Forts. 19-24 und 35-38, darüber Korrektur Foliierung 19. Jh. durch die ULB Tirol 39-48 (hier berücksichtigt). Am oberen rechten Blattrand Foliierung 15. Jh. in Schwarz 166-203.

S: $\quad$ Schriftraum ca. $220 \times 155$. Zwei Spalten, von Tintenlinien gerahmt, zu 43-46 Zeilen. Bastarda. Am Blattrand vereinzelt Ergänzungen, Korrekturen und Kapitelzählung, tw. von gleicher, tw. von späterer Hand.

A: $\quad$ Rote Auszeichnungsstriche, Paragraphzeichen, Unterstreichungen und Überschriften. Zwei- bis vierzeilige einfache rote Lombarden (Bl. 1ra mit kopfstempelförmiger Aussparung und verziertem Ausläufer). Repräsentanten.

E: $\quad$ Neuzeitlicher Bibliothekseinband: schwarz gesprenkeltes braunes Pap. über Pappe. Neustift, 2. H. 18. Jh. Am VD und HD Ecken mit braunem Leder verstärkt. Rücken: braunes Leder, vier einfache Bünde, mit Goldbordüren gesäumt. Im zweiten Feld Golddruck M. S. HOROL. SAPIENT., im dritten Signaturschild (s. bei G). Schnitt rot gesprenkelt. Spiegel Pap. 18. Jh. Am Spiegel des VD Signaturen und Bleistiftnotiz (s. bei G), Spiegel des HD leer.

G: $\quad$ Nach dem Inhaltsverzeichnis in Neustift, Stiftsbibl., Cod. 158, Bl. Ir gehört Cod. 183 zu einer Gruppe von urspr. tw. selbständigen Hs. des 14. und 15. Jh., die im 15. Jh. in Neustift zu einem Sammelband vereinigt wurden (s. auch Foliierung). Im Zuge der Neuaufstellung der Neustifter Bibliothek in der 2. H. 18. Jh. wurde die Sammelhandschrift (wie dies auch bei anderen Hs. und Inkunabeln gemacht wurde) in sieben Einzelhandschriften aufgelöst; jeder Einzelband erhielt den für Neustift typischen Halbledereinband. Zur urspr. Hs. zählen folgende Signaturen (in der urspr. Reihenfolge):

Cod. 158: Augustinus. Foliierung 15. Jh. 1-69.

Cod. 83: Theologische Sammelhandschrift, dat. 1400. Foliierung 15. Jh. 70-128.

Cod. 82: Henricus de Langenstein: De contractibus. De contemptu mundi. Foliierung 15. Jh. 129-165.

Cod. 183: Heinrich Seuse: Horologium sapientiae. Foliierung 15. Jh. 166-203.

Cod. 161: Iohannes de Dambach. Origenes. Foliierung 15. Jh. 204-215.

Cod. 182: Ps.-Eusebius, dat. 1400. Foliierung 15. Jh. 216-231.

Cod. 162: Sermones de dedicatione. Foliierung 15. Jh. 232-241.

Von diesen sieben Hs. befindet sich heute eine an der ULB Tirol in Innsbruck (Cod. 82), die restlichen sechs werden hingegen in der Stiftsbibl. Neustift aufbewahrt. 
1809 anlässlich der vorübergehenden Aufhebung des Klosters Neustift der ULB Tirol übergeben. Am Spiegel des VD alte Signaturen der ULB Tirol II 4 D [...] (Tinte, radiert), II 2 H 31 (Bleistift) und Nr. 183 (Tinte) sowie Bleistiftnotiz (Vide Grundzettel). Am Rücken gelbes Signaturschild der ULB Tirol 183. Bl. 1r Stempel der ULB Tirol 19. Jh. 1921 aufgrund des Friedensvertrages von St. Germain an den italienischen Staat abgegeben und von diesem 1929 dem Kloster Neustift als Dauerleihgabe überlassen. Bl. 1r Stempel der Soprintendenza Tridentina 20. Jh.

L: $\quad$ P. Künzle (Hrsg.), Heinrich Seuse, Horologium sapientiae. Erste kritische Ausgabe unter Benützung der Vorarbeiten von Dominikus Planzer (Spicilegium Friburgense 23). Freiburg 1977, 162-163, Nr. 131. - Katalog ULB Tirol II 168, 208. - Kustatscher-Korenjak 154.

(Ir-v) leer.

(1ra-48vb) 〈Henricus Suso〉: Horologium sapientiae (Ed. Künzle 363-605. - Kaeppeli Nr. 1852. Bloomfield Nr. 5416).

Tit.: Horologium sapiencie.

(1ra) Prolog. - (2ra) Lib. 1. - (30vb) Lib. 2.

(48vb) Schlussschrift: Explicit horologium sapiencie fratris cuiusdam ordinis Predicatorum etc.

Darunter Tit.: Liber contemplacionis etc. (nicht auf den in dieser Hs. enthaltenen Text bezogen, wohl Tit. des urspr. darauffolgenden Textes in der ehem. Sammelhandschrift, möglicherweise Cod. 161 [Iohannes de Dambach, Tractatus de indulgentiis], oder eines urspr. vorgesehenen, nie ausgeführten Textes „De contemplatione“).

$\left(\mathrm{I}^{*} \mathrm{r}-\mathrm{v}\right)$ leer.

\section{Cod. 190}

\section{BRUNO DE SEGNI}

Perg. I, 68, I* Bl. $315 \times 250$. Neustift (?), 2. H. 15. Jh./Anfang 16. Jh.

B: $\quad$ Vereinzelt kleine Löcher und Nahtspuren. Bl. 17 Riss am seitlichen Blattrand. Die ersten drei Blätter am seitlichen und unteren Rand stark beschnitten $(275 \times 205$, urspr. möglicherweise Rankendekor?). Lagen: $(\mathrm{I}-1)^{\mathrm{I}}$ (Vorsatzbl., Pap. 18. Jh.) + III ${ }^{6}+7 . \mathrm{IV}^{62}+\mathrm{III}^{68}+(\mathrm{I}-1)^{\mathrm{I}^{*}}$ (Nachsatzbl., Pap. 18. Jh.). Gegenbl. zum Vorbzw. Nachsatzbl. am VD bzw. HD aufgeklebt. Urspr. wohl durchgehend Quaternionen: Bei der ersten und letzten Lage fehlt jeweils das äußere Doppelbl. (Textverlust), zudem nach Lage 1, 2 und 3 wohl jeweils eine Lage (Textverlust), nach Lage 4 mehrere Lagen verloren (Textverlust). Ab Lage 3 Reklamanten, Bl. 22v beschnitten. Am oberen Blattrand Foliierung 19. Jh. durch die ULB Tirol.

S: Schriftraum $245 / 250 \times 175 / 180$. Zwei Spalten, von tw. sehr feinen Tinten-, tw. Blindlinien gerahmt, zu einheitlich 44 Zeilen auf sehr feiner Tintenlinierung. Kalligraphische Bastarda.

A: $\quad$ Rote Auszeichnungsstriche, Paragraphzeichen (selten blau), Unterstreichungen (u. a. Psalmen), Zeilenfüllsel und Überschriften; ab B1. 67v keine Rubrizierung. Gelegentlich (in oberster Textzeile) cadellenartig gedehnte Oberlängen (Bl. 42vb, 44va: größer und mit schwarzem Fleuronnée verziert). Ein- bis fünfzeilige Lombarden mit Punktverdickungen, einigen Aussparungen (Zickzack, Trifolien) und (kurzen) Ausläufern (zur Farbigkeit s. u.); Bl. 14rb nicht ausgeführt. Vereinzelt Repräsentanten.

Die Anfänge der einzelnen Psalmen werden durch größere Initialen gekennzeichnet. Die Dekoration beginnt mit sechs aufwändigeren Fleuronnée-Initialen (vier- und fünfeilig, Bl. 1ra, 2rb, 3ra, 4rb, 5rb, 6rb), gefolgt von sechs fein ausgeführten Ornamentalinitialen (fünfzeilig, Bl. 7rb, 8vb, 10ra, 11vb, 13ra, 14va), um sich bis zum Ende der Hs. - nur unterbrochen von zwei weiteren Ornamentalinitialen (sechs- und fünfzeilig; Bl. 19va, 38va) - mit einer Reihe einfach verzierter Lombarden zu begnügen.

Fleuronnée-Initialen: rote und blaue Lombarden (Bl. 1ra rot-blau gespalten, Bl. 6rb graublau, wohl übermalt, mit Einritzungen: Ranke?, VP-Ligatur) mit rot-grünem, oft in der Gegenfarbe gepunktetem Fleuronnée. In den Binnenfeldern (tw. langstielige) Knospen in diversen Anordnungen, Bl. 2rb, 3ra und 4rb auf vollfarbigem grünem Grund (Grün dünn aufgetragen). Konturlinie(n), (angedeutete) Initialfelder, fallweise Zwickel-Trifolien. Als Besatz gereihte und zu Dreiergruppen zusammengefasste Knospen sowie Fibrillen; 
längere und kürzere Fadenausläufer, v.a. Bl. 1ra kammartig abstehend und dabei spitz zulaufend. Binnenfeldknospen Bl. 1ra und 6rb erinnern etwas an das Fleuronnée in Sign. 14820 (1. Fünftel 16. Jh.); Bl. 6rb Besatzknospen, die mit zwei kurzen Parallelstrichen mit den Konturlinien verbunden sind; solche Knospen auch bei der Cadelle Bl. 44va, was darauf schließen lassen könnte, dass das Fleuronnée Bl. 1ra-6rb und das Cadellenfleuronnée einer Hand zuzuschreiben sind; letzteres orientiert sich wiederum am Fleuronnée der beiden Bände des Zollner-Graduales, stammt aber wohl nicht vom einschlägigen Hauptflorator, der noch akkurater zeichnete, vgl. z.B. Bl. 44va und die Cadelle Bl. 3v (oben) im ersten Gradualband. Auf dieser Basis ergibt sich - mit der gebotenen Vorsicht - eine Fleuronnée-Datierung in die 2. H. 15. Jh. (möglicherweise mit Tendenz ins 1. Fünftel 16. Jh.).

Die rankenlosen und einfach gerahmten Deckfarbeninitialen Bl. 7rb-14va von einer Hand: Bl. 7rb Querstrich des A windet sich wie kurzes Spruchband (mit Schattenwurf auf kobaltblauem Initialfeld); Buchstabenkörper mit Füllranken, deren Blätter akkurat (mit Tendenz zur Symmetrie) ondulieren. Ungewöhnliche Initial- bzw. Binnenfeldgestaltungen: B1. 8vb liegt der Buchstabenkörper auf einer „Blätterdecke“ auf, Bl. 10ra wird er von einem weiß-blauen Band umgeben, das an Wolkenstilisierungen erinnert, Bl. 11vb, 13ra und 14va zart und zugleich plastisch herausmodellierte Binnenfeldblüten und -blätter; zierliches „Erbsenschotenmotiv" Bl. 10ra im Buchstabenkörper, 11vb in den Initialfeldblättern. Bis auf die (dunkel-)weinroten Buchstabenkörper Bl. 8vb und 10ra klare Farbigkeit. Bl. 8vb und 10ra Pinselgold im Binnenfeld. Bl. 19va und 38va wohl jeweils von anderer Hand: Bl. 19va sorgfältige Ausführung, gedeckte Farbigkeit (violettes Initialfeld mit blauer Rankenzier, auf dem der braunrot-ockergoldene Buchstabenkörper aufliegt; „Erbsenschotenmotiv" in Füllblättern) und längere Akanthusranke; Bl. 38va blaue Lombarde mit Liniendekor (s. u.) umfangen von oliv-goldenem Initialfeld, das flüchtig in Gelb und Rot dekoriert ist (im Binnenfeld Netzmuster). Die fünfzeiligen grünen Lombarden Bl. 18va und 20rb, in deren Buchstabenkörpern Blattdekor angelegt ist, evtl. für weitere Dekoration vorgesehen.

Ab Bl. 16vb Lombarden in Blau, Weinrot und Grün (dünnerer Farbauftrag) mit einfachem, meist auf dem Buchstabenkörper aufgemaltem Dekor (in der Regel linear); Bl. 25vb fünfzeilige Lombarde: Buchstabenkörper in pastosem Grün, roter Federzeichnungsdekor; Bl. 35ra sechszeilige abgeriebene Goldlombarde (Bolus sichtbar) mit rotem Fleuronnée (langstielige Knospen aus schraffiertem Binnenfeldgrund ausgespart, radial abstehende Fadenausläufer); diese Fleuronnéehand, die nicht mit dem am Beginn der Hs. tätigen Florator übereinstimmt, in flüchtigerer Manier auch B1. 57ra.

E: $\quad$ Neuzeitlicher Bibliothekseinband: schwarz gesprenkeltes braunes Pap. über Pappe. Neustift, 2. H. 18. Jh. Pap. tw. etwas abgerieben. Am VD und HD Ecken mit braunem Leder verstärkt. Rücken: braunes Leder, vier einfache Bünde, von Goldbordüren gesäumt. Im ersten Feld Golddruck $M$ : S:, im zweiten Golddruck EXPOSIT. IN PSALMO DAVIDIO (!) in Goldrahmung, im dritten Signaturschild (s. bei G). Schnitt rot gesprenkelt. Spiegel Pap. 18. Jh. Am Spiegel des VD Exlibris, Signaturen und Bleistiftnotiz (s. bei G), Spiegel des HD leer.

G: $\quad$ Am Spiegel des VD Exlibris der Stiftsbibl. Neustift 18. Jh. 1809 anlässlich der vorübergehenden Aufhebung des Klosters Neustift der ULB Tirol übergeben. Am Spiegel des VD alte Signatur der ULB Tirol II 3 E 3 (Tinte, Bleistift) und Nr. 190/(1) (Tinte, Bleistift) sowie Bleistiftnotiz (Vide Grundzettel). Am Rücken gelbes Signaturschild der ULB Tirol 190/(1). Bl. 1r am unteren Blattrand bzw. Bl. 4r Stempel der ULB Tirol 19. Jh. 1921 aufgrund des Friedensvertrages von St. Germain an den italienischen Staat abgegeben und von diesem 1929 dem Kloster Neustift als Dauerleihgabe überlassen. Bl. 1r am unteren Blattrand bzw. Bl. 4r Stempel der Soprintendenza Tridentina 20. Jh.

L: $\quad$ Stegmüller RB Nr. 1852 Suppl. - Katalog ULB Tirol II 180, 208-209. - Peintner, Stiftsbibliothek 121.

$(\mathrm{Ir}-\mathrm{v})$ leer.

1 (1ra-67ra) 〈BRUno DE SEGNI〉: Expositio in Psalmos, unvollständig (PL 164, 699B-1228C. Stegmüller RB Nr. 1852).

Beginn des Textes fehlt, Bl. 1ra Beginn des zweiten Psalms.

(1ra-6vb) Ps 2-7. Inc. mut. (PL 164, 699B): ] Et merito quidem contra eos cum quadam indignacione loquitur qui in Christum dominum ... - Expl. mut.: ... qui omnia iudicas in equitate. Iudica me domine. Tu inquit me iudica [ (PL 164, 717C)

(7ra-14vb) Ps 27-33. Inc. mut. (PL 164, 786A): ] et non edificabis eos. Isti exterminio digni sunt ... - Expl. mut.: ... Iste qui hoc dicit iam eius degustaverat [ (PL 164, 808A) 
(15ra-30vb) Ps 49-61. Inc. mut. (PL 164, 875A): ] ituri sunt qui semper celestia dilexerunt ... Expl. mut.: ... dyabolum dereliqui veni ad Christum ipse [ (PL 164, 918A)

(31ra-38vb) Ps 67-70. Inc. mut. (PL 164, 941B): ] erat cor unum et anima una et nemo dicebat aliquid ... - Expl. mut.: ... Quia dixerunt inimici mei mala mihi et qui custodiebant [ (PL 164, 964C)

(39ra-62vb) Ps 117-143. Inc. mut. (PL 164, 1142B): ] non erit. Sed illi soli dicant qui dominum timent ... - Expl. mut.: ... ex hoc in illud quia eorum [ (PL 164, 1213D)

(63ra-67ra) Ps 144-150. Inc. mut. (PL 164, 1216C): ] salvos faciet eos. Hoc est est (!) enim eorum voluntas ... - Expl.: ... Omnis spiritus laudet dominum, spiritus omnis eum benedicat nunc et in evum. Laudet ametque colat quem Rachel mater adorat. Nunc fecunda quidem sterilis sine semine pridem. Hoc pater hoc flamen hoc filius audiat. Amen.

2 (67rb-68vb) Dispositio catholicae Fidei, unvollständig (vgl. Stegmüller RB Nr. 3339-3340, 9054, 9899).

Tit.: Incipit disposicio katholice fidei quam edidit sanctus episcopus Athanasius in concilio Nicee civitatis coram multis patribus. - Inc.: Quicumque vult salvus esse ante omnia opus est ut teneat katholicam fidem ... - Expl. mut.: ... Tangere se permisit causa confirmandi katholicam fidem ut destrueret perfidiam hereticorum qui dicunt Christum non levasse carnem suam in celo et propter hoc Christus petivit cibum et ante discipulos manducavit expletis XL diebus coram discipulis [ $\mathrm{Zu}$ den Kommentaren zum Athanasianischen Glaubensbekenntnis vgl. A. E. Burn, The Athanasian Creed and its early Commentaries. Cambridge 1896.

$(\mathrm{I} * \mathrm{r}-\mathrm{v})$ leer.

A. P./U. S.

\section{Cod. 194}

\section{RITUALE NEOCELLENSE}

Perg. I, 67 Bl. $305 \times 225$. Neustift, 1507.

B: $\quad$ Dickes Perg. Buchblock nachträglich leicht beschnitten (vgl. Zahlen am oberen Blattrand). Lagen: $(\mathrm{V}-2)^{1,7}+$ $\mathrm{IV}^{15}+(\mathrm{IV}-2)^{23(21)}+\mathrm{IV}^{31(29)}+(\mathrm{IV}-1)^{38(36)}+3 \cdot \mathrm{IV}^{62(60)}+(\mathrm{IV}-1)^{70(67)}$. Gegenbl. zu Bl. I herausgeschnitten (ohne Textverlust). Gegenbl. zu Bl. 7 als Spiegel auf dem VD aufgeklebt. Gegenbl. zu Bl. 19 und 20 (urspr. Bl. 21 und 22) sowie zu Bl. 64 (urspr. Bl. 69) mit Textverlust, Gegenbl. zu Bl. 33 ohne Textverlust herausgeschnitten. Auf der Miniatur Bl. 70v am oberen und rechten Blattrand Abklatsch von Rubrizierung. Am oberen Blattrand zeitgenössische Foliierung in roten arabischen Ziffern 1-70; urspr. Bl. 20, 21 und 69 fehlen (herausgeschnitten). Zwei Pergamentsignakel.

S: $\quad$ Schriftraum $215 \times 150 / 155$. Von Blindlinien gerahmt, zu einheitlich 22 Zeilen auf Blindlinierung bzw. sieben rote Vierliniensysteme und Text. Textualis formata (Textura), dat. 1507 (B1. 70v). Schreiber (?): S. S. (= Stephan Stetner) (Bl. 70v), vgl. Krämer, Scriptores.

A: $\quad$ Rote Auszeichnungsstriche und Überschriften; wenige blaue Paragraphzeichen. In den Binnenfeldern der Majuskeln gelegentlich feine Doppelschrägstriche, tw. mit einseitigem (bedorntem) Bogenbesatz (z.B. Bl. 2v, Z. 3). Rote und blaue Benediktionskreuze in Tatzenkreuzform. Zur Wasserweihe drei blaue Zeichen (jeweils eine Notenzeile hoch), die die schriftlichen Handlungsanweisungen visuell unterstützen (vgl. Sign. 14820): Bl. 38v Kreuz (mit dreiteilig aufgespaltenen Enden und weinrotem Federzeichnungsdekor) zu hic insuffla per modum crucis sancte, Bl. 40r vierstrahliger Stern mit Goldpunkt in der Mitte zu hic proijciatur aqua in quatuor partes, Bl. 41v dreiblättrige Lilie zu suffla ter in fontem in hunc modum. Ein- bis dreizeilige (dunkel-)rote und blaue, tw. verblasste Lombarden mit Punktverdickungen, in wenigen Fällen kopfstempelartiger Besatz und in gestrichelte Achterschlingen gelegte, mit freien Kreisen sowie Fibrillen dekorierte Ausläufer (sehr ähnlich in Cod. 85 und 405, vgl. z. B. Bl. 22r mit Cod. 85, Bl. 1r bzw. Cod. 405, Bl. 160v); Bl. 66v vierzeilige kopfstempelartig in Rot und Blau gespaltene Lombarde mit Fleuronnée (im Binnenfeld rot, außen blau; zur Einordnung s. u.). Repräsentanten. 
Deckfarbenschmuck: 13 zwei- bis vierzeilige ornamentale Initialen mit kurzen Ranken, nur B1. 1r1 achtzeilig mit annähernd dreiseitig umlaufender Ranke; zwei ganzseitige Miniaturen.

Die Ornamentalinitialen (Bl. 1r1, 1r2, 1r3, 7v, 8r, 21v, 23r, 27r, 32v, 36r, 45v, 54v, 57r) mit einfachen Rahmen, häufig in der Farbe der Außengrundzwickel, diese oft mit Trifolien gefüllt; Bl. 1r1 Rahmenleisten grün (oben und unten), ockerfarben (links) und violett (rechts). Bei blauen Buchstabenkörpern, auch bei der größeren Einleitungsinitiale, Blattfüllungen nur angedeutet, bei andersfarbigen Buchstabenkörpern Füllblätter plastischer herausgearbeitet. Binnenfelder meist blattvergoldet und punziert (Rautengitter, häufig mit siebenblättrigen Blüten gefüllt, s. auch Goldgrund Bl. Iv); in Deckfarbe ausgeführte Binnenfelder (B1. 27r, 32v) mit gegenständigen Blattpaaren. Kurze, kräftig bewegte Akanthusranken (häufig Gabelungen, Überschneidungen und Verschlingungen), in der Regel aus Serifen der Buchstabenkörper entspringend, auch am Rahmen ansetzend; Blattformen wenig variiert, immer wieder tropfenförmig verdickte Blattadern; als Schmuck Goldfelder und -punkte (mit tintenfarbenem Federzeichnungsdekor); B1. 1r Marginalranken zusammengesetzt aus zwei auf dem linken Seitenrand miteinander verschlungenen Hauptpartien (an der Verknüpfungsstelle hakt sich auch der Ausläufer der mittleren Initiale ein); große Fibrillen, links unten ein naturalistisch gestalteter Astanschnitt, üppige Fantasieblüten, auf der Spitze einer solchen steht (auf dem rechten Seitenrand) ein Storch mit weit nach hinten gebogenem Hals. Bl. Iv Rahmen (Breite 21-22 mm) der Miniatur aus zusammengesteckten Stäben, deren Zwischenräume bzw. -streifen mit Blattranken (auch hier verdickte Adern) gefüllt sind; äußere Rahmenstäbe gehen an den Ecken in kurze Ranken über (vgl. Ornamentalinitialen); mittig an den Leisten Goldpunkte mit weinrotem Federzeichnungsdekor. Etwas sorgfältiger (sowohl Initiale selbst als auch Rankenwerk): Bl. 54v und v. a. Bl. 57r, bei denen im Gegensatz zu dem etwas blasseren Grün, das bei allen anderen Initialen eingesetzt wurde, Olivgrün Verwendung fand; generell begrenzte Farbpalette; ockerfarbene Partien mit Pinselgold; Blattgold auf rotem Bolus (s. Bl. 57r). Bl. Iv (236×162) Madonna. Muttergottes mit opulenter Perlenkrone sitzt auf Holzthron; das dunkelrote Ehrentuch (mit Goldmuster, das Blätter und Früchte beinhaltet) reicht über die Sitzfläche bis auf den Boden hinunter und dient Maria als Bankbelag; in der Rechten hält sie eine kleinere grüne melonen- bzw. kürbisartige Frucht, von der sich das Jesuskind, das Maria mit der linken Hand stützt, abzuwenden scheint; die Handfläche seines erhobenen, rechten Händchens weist nach vorne. Insbes. die Marienfigur unsicher proportioniert: der rundliche Kopf im Verhältnis zum Körper zu groß, der sich unter den (allerdings gekonnt herausgearbeiteten) Gewandfalten nicht recht abzeichnet, sodass die Sitzposition der Gottesmutter vage bleibt; der Thron detailreich (bis hin zur Maserung), aber perspektivisch etwas unsicher gestaltet (Fluchtlinien der Rückenlehne zu weit nach oben geführt).

B1. $70 v(258 \times 159) \mathrm{Hl}$. Augustinus. Halbfigur des Heiligen mit prächtiger Mitra, grünem Pluviale und goldfarbenen, beringten Handschuhen präsentiert in einem fensteröffnungsartig gestalteten Rahmen vor rotem Teppichgrund (mit Goldranken) ein aufgeschlagenes Buch mit dem Incipit der Augustinusregel von drei Händen: 1) Hec sunt que ut observetis, 2) precipimus in monasterio constituti, 3) post $p$ e $k$ (principalia precepta); Gesichtszüge durch kräftige schwarze Linien bezeichnet (Überarbeitung?); in die Rahmenkehlungen „Gewändefiguren“ eingestellt (auf zierlichen Säulchen, in Grisaille-Malerei): zwei bis auf ihr Lendentuch nackte, bärtige Männer; der linke hält ein Schwert über seinen Kopf, der rechte einen Stein; der Heilige an den rechten Rand der Fensteröffnung gerückt, wobei er das Buch, das nicht auf seiner linken Handfläche aufliegt, sondern darüber zu schweben scheint, in seine linke Armbeuge bettet und mit dem rechten Zeigefinger hält; auf dem Vorderrand der Fensterbrüstung Jahreszahl 1507 eingemeißelt (flankiert von Dreiblättchen), rechts davon Signatur $S$ S = Stephan Stetner; nach dem Buchstaben jeweils charakteristisches Ziermotiv bzw. Trennzeichen aus drei kleinen Kreisen in Dreiecksanordnung mit kurzem, kommaartigem Fadenausläufer); über dem Kopf des Augustinus üppiges, rot liniertes und in Achterschlingen gelegtes Schriftband mit Datierung Anno domini millesimo quingentesimo septimo (mehrfach eingestreutes Ziermotiv: Punkt bzw. kleines Quadrat, besetzt mit Häkchen und Fibrillen).

Das Fleuronnée mit länglich-blasigen Knospen und (bedornten) Besatzknospen, die in zwei kürzere Fäden auslaufen, von der im 1. Fünftel 16. Jh. nachweisbaren Hand, die auch in Cod. 405 (dat. 1501, hier das Fleuronnée flüchtiger) und Cod. 142, T. I (dat. 1521) tätig war, in beiden Bänden des Zollner-Graduales einige Initialen mit Fleuronnée (s. jeweils Ergänzungshand 2) geschmückt und Sign. 14820 zur Gänze ausgestattet hat. Diese Hand ist vermutlich auch für den ornamentalen Deckfarbendekor (einschließlich Rahmen und Ranken Bl. 1v) in der vorliegenden Hs. sowie in Cod. 405 (hier nicht so sorgfältig ausgeführt) verantwortlich. Detailliert zu dieser Hand und den Zusammenhängen zw. Fleuronnée- und Deckfarbenzier bei Sign. 14820. Die beiden sorgfältiger ausgearbeiteten Initialen Bl. 54v und 57r zeigen Affinitäten zur Epistolarhand von Cod. 196, Bl. 1r, 2r und 7v: Blattwerk im Buchstabenkörper ebenfalls mit kleinen Randeinbuchtungen und tropfenförmig verdickten Adern, $\mathrm{Bl}$. 2r zudem auch das Binnenfeld mit blütengefülltem Rautengitter punziert; darüber hinaus auch Ähnlichkeiten im Rankenwerk (Blattformen, Überschneidungen).

Bislang ging man aufgrund der Signatur Stephan Stetners in der Miniatur Bl. 70v davon aus, dass er nicht nur als Schreiber (vgl. Cod. 100 und möglicherweise auch Cod. 196), sondern auch als Buchmaler tätig gewesen sei (s. z. B. Hermann 170-171, Fiegl, Prachthandschrift 748), was an dieser Stelle nicht völlig negiert, 
aber mit der gebotenen Vorsicht erwogen werden soll. Denn in den von ihm erhaltenen Werken hat Stetner nur in Cod. 194 innerhalb einer Illumination signiert, ansonsten jeweils im Text (s. die vier Signaturen in Cod. 100). Zudem gehört seine Signatur in Cod. 194 nicht urspr. zur Jahreszahl auf der Fensterbrüstung, sondern wurde dahinter und damit zugleich unterhalb der Augustinusregel ergänzt, womit ein Bezug zum geschriebenen Text, also zu seiner Schreibertätigkeit, ausgedrückt sein könnte.

Insbesondere die Augustinus-Miniatur, deren unlängst vorgeschlagene Zuschreibung an Friedrich Pacher (s. Suckale, Suckale-Redlefsen 60-61) angezweifelt werden muss, zeigt einige Ähnlichkeiten zum Wappenhalterengel in Cod. 405; darüber hinaus lässt sich der hl. Augustinus gut mit der Figur des Reginbert in der Miniatur am Anfang der Neustifter Totenrotel von 1515 vergleichen (s. H. Miekisch, Das Augustiner-Chorherrenstift Neunkirchen am Brand. Münsterschwarzach 2014, Farbabb. S. 170).

E: $\quad$ Renaissanceeinband: helles Schweinsleder über Holz mit Blinddruck. Neustift (?), 2. H. 16. Jh.

Leder an den Stellen der einstigen Beschläge und in den Ecken beschädigt, am HD etwas abgerieben. VD und HD annähernd gleich: drei von jeweils dreifachen (außen sechsfachen) Streicheisenlinien begrenzte Rahmen. Rahmen 1: verschränkte Bögen mit floralem Dekor (Nr. 1 = ähnlich wie Neuhauser, Rolleneinbände, R 10), seitlich je eine Rolle, unten und oben je zwei spiegelsymmetrisch angeordnet. Rahmen 2: zusätzlich vertikal mit dreifachen Streicheisenlinien unterteilt, Feld leer, Rahmen gefüllt mit Rolle Sichel mit eingeschriebenem Blattmotiv abwechselnd mit floralem Dekor (Nr. 2). Rahmen 3: Rolle mit Kornblumenmotiv (Nr. 3). Spuren von vier rautenförmigen Eck- und einem viereckigen, auf die Spitze gestellten Mittelbeschlag. Zwei Kurzriemen-Leder-Metall-Schließen. Kanten gerade und nach innen abgeschrägt. Rücken: blau gefärbt (wie öfters in Neustift), vier Doppelbünde. Bünde von zwei- und dreifachen Streicheisenlinien begrenzt, Linien auf VD bzw. HD fortgesetzt, spitz aufeinander zulaufend und leicht in den ersten Rahmen hineinreichend. Im ersten Feld Rest eines aufgeklebten Papierschildes 1507, im zweiten Rest eines Papiertitelschilds $R[$ it]ua[le]/[C]o[ll]egi[i]/ Neocel., beide vor der Blaufärbung des Rückens aufgeklebt, im dritten Signaturschild (s. bei G). Kapitale mit naturfarbenem und hellbraunem Spagat umstochen. Schnitt abwechselnd rot und grün gesprenkelt. Spiegel des VD Pergamentblatt mit Exlibris, Signaturen und Bleistiftnotiz (s. bei G), Spiegel des HD leeres Papierblatt. Unter den Spiegeln zusätzliches Blatt aufgeklebt, Gegenfalz (mit Resten einer Rahmung) zw. Lage 1 und 2 bzw. 8 und 9.

G: $\quad$ Am Spiegel des VD Exlibris der Stiftsbibl. Neustift 18. Jh. 1809 anlässlich der vorübergehenden Aufhebung des Klosters Neustift der ULB Tirol übergeben. Am Spiegel des VD alte Signaturen der ULB Tirol II 3 E 7 und N. 194 sowie Bleistiftnotiz (Vide Grundzettel). Am Rücken gelbes Signaturschild der ULB Tirol 194. B1. 1r Stempel der ULB Tirol 19. Jh. 1921 aufgrund des Friedensvertrages von St. Germain an den italienischen Staat abgegeben und von diesem 1929 dem Kloster Neustift als Dauerleihgabe überlassen. Bl. Ir Stempel der Soprintendenza Tridentina 20. Jh.

L: $\quad$ Wilhelm II 110. - Hermann 170-171, Nr. 181. - Atz 1012. - Colophons Nr. 16895. - P. d’Ancona, E. Aeschlimann, Dictionnaire des miniaturistes. Milan 1949, ND Nendeln 1969, 200. - Gschwend 86-88 (ohne Nennung der Sign.). - Lipphardt III 1084-1086; VI 352, Nr. 628 (Sigle Neust³). - Neuhauser, Neustift 85. Katalog ULB Tirol II 193, 209. - Katalog ULB Tirol II, Beiheft, Taf. 77-78. - Peintner, Stiftsbibliothek 126. - Gozzi 548, Nr. 79. - R. Kay, Pontificalia. A Repertory of Latin Manuscript Pontificals and Benedictionals. Lawrence 2007, 108, Nr. 560. - Baroffio 324, Nr. 16714. - Krämer, Scriptores, s. v. „Stetner, S.“. - R. Suckale, G. Suckale-Redlefsen, Buchmalerei in Mitteleuropa und ihr historischer Kontext, in: J. F. Hamburger, R. Suckale, G. Suckale-Redlefsen (Hrsg.), Unter Druck. Mitteleuropäische Buchmalerei im Zeitalter Gutenbergs (Buchmalerei des 15. Jahrhunderts in Mitteleuropa 2). Luzern 2015, 11-66, hier 60-61. - U. Stampfer, Neustifter Rituale, in: J. Kronbichler, H.-P. Ties (Hrsg.), Renaissance im Gebirge. Der Maler Bartlme Dill Riemenschneider und seine Zeit. Hofburg Brixen 27. Mai-31. Oktober 2017, 118-119 (Kat. 25).

Rituale Neocellense. Vgl. Cod. 726 und Sign. 14820.

(Ir) leer bis auf Stempel (s. bei G).

(Iv) ganzseitige Miniatur (s. bei A).

(1r-7v) In PURIFICATIONE BMV.

(1r) Benedictio candelarum. Tit.: Purificacionis Marie cereorum benedictio post $3^{a s}$. $-(6 r)$ Processio candelarum. - (6v) Canticum Zachariae.

(7v-19v) DNCA IN PALMIS.

(7v) In die palmarum ad processionem. - (10r) Exorcismus florum et frondium. - Benedictio pal- 
marum. - (14r) Praefatio. - (16r) Aspersio et thurificatio palmarum. - (16v) Distributio palmarum. (17r) In reditu. - (18r) Adoratio crucis. - (19r) Canticum puerorum. - (19v) In reditu ante altare oratio. (19v-23r) FER. 5. IN COENA DNI.

(19v) In cena domini benedictio ignis. - Expl. mut.: ... nostris profuturum usibus novum hunc ignem sanctifica [ Bl. 20 und 21 herausgeschnitten, enthaltend Fußwaschung. Bl. 22r Inc. mut.: hu]militatis gratia Petri petens vestigia ...

(23r-32r) FER. 6. IN PARASCEVE.

(23r) Adoratio crucis. - (26r) Depositio crucis (Gschwend 86). - (27r) Vesper.

(32v-42r) IN VIGILIA PASCHATIS.

(32v) Benedictio ignis. - (34v) In reditu canitur himnus Prudencii (AH 50, Nr. 31). - (35r) Exsultet (nur Verweis). - (35r) Benedictio aquae. - (42r) Litaniae sanctorum (nur Verweis).

(42v-45r) DNCA RESURRECTIONIS DNI (Gschwend 86-88).

(45r) Benedictio aquae in vigilia Pentecostes (nur Verweis).

(45v) IN ASSUMPTIONE BMV.

(45v-54v) ORdo PAENITENTIAE.

(54v-56v) EINKLEIDUNG DER NovizEN.

Tit.: De induitione (i gestrichen) novitiorum.

(57r-64r) Profess.

(64v-66r) Ordo FÜr DIE AufNAHME von LAIEN.

Tit.: De fraternitate laicali.

(66r-68v) Totenliturgie Für die Konventualen.

(68v) Expl. mut.: ... Infra sacerdotium constituti tria orabunt psalteria cum septem vigiliis. Conversi vero trecen[ta

Bl. 69 herausgeschnitten (mit Schluss des Textes), s. bei B.

(70r) nur Rahmung und Foliierung.

(70v) ganzseitige Miniatur (s. bei A) mit zweimaliger Datierung Anno domini millesimo quingentesimo septimo (Spruchband) sowie 1507 (untere Stirnseite des Rahmens) und Schreibernennung (?) S. S.

W. N./U.S.

\section{Cod. 196}

\section{LECTIONARIUM MISSAE NEOCELLENSE}

Perg. I, 26 Bl. $315 \times 250$. Neustift, Ende 15. Jh. (vor 1482?).

B: $\quad$ Perg. am unteren Blattrand stark abgegriffen. Lagenaufbau im Zuge der Neubindung in der 2. H. 18. Jh. verändert, urspr. wohl durchgehend Quaternionen: (I-1) (Vorsatzbl., Pap. 18. Jh.) $+2 . \mathrm{IV}^{16}+(\mathrm{IV}-4)^{20}+$ $(\mathrm{VI}-10)^{32(23)}+\mathrm{II}^{35(26)}$. Gegenbl. zum Vorsatzbl. als Spiegel auf dem VD aufgeklebt. Gegenbl. zu Bl. 17-20 herausgeschnitten (wohl leer, ohne Textverlust). Von urspr. Sexternio Gegenbl. zu B1. 31 im Jahre 1746 herausgeschnitten, heute in der Kathedralbibliothek Esztergom (Ungarn) (s. bei G). Bl. 21-29 sowie Bl. 36-42 1872 an der ULB Tirol herausgeschnitten (Textverlust), s. bei G. Bl. 30 und 31 als Einzelbl. mit der letzten Lage verbunden. Am oberen Blattrand Foliierung durch die ULB Tirol 1857 (vgl. Innsbruck, ULB Tirol, Alte Titelkopie: Handschriften). Bl. 32[23]r Spur eines Ledersignakels sowie am Blattrand römisches Zahlzeichen $I$ (als Orientierungshilfe?). 
S: $\quad$ Schriftraum 210/215 $\times 145 / 155$. Von feinen Tintenlinien gerahmt, zu einheitlich 19 Zeilen auf feiner Tintenlinierung. Zirkelstiche. Textualis formata (Textura) Ende 15. Jh. (Terminus ante quem 1482?: vgl. Esztergom, Kathedralbibl., Ms. II.2, Bl. 5v, figürliche Initiale dat. 1482). Vereinzelt mit Bleistift Akzentzeichnungen (Terminus post quem 1746) und Korrekturen, Durchstreichungen.

A: $\quad$ Rote Auszeichnungsstriche, Überschriften, Akzentzeichnungen (bis Bl. 5v Striche und Wellen, Bl. 32[23]r und 33[24]r auch Häkchen) sowie Verweiszeichen (z. B. Bl. 30[21]r; Korrekturen dieser Art könnten 1531 vorgenommen worden sein, vgl. ebda die entsprechende Datierung in Rot auf der unteren Initialrahmenleiste; Ziffern der Jahreszahl mit Zwischenpunkten geschrieben, als „Zeilenfüllsel“ Doppelpunkt mit kurzer Wellenlinie); Bl. 34[25]r rote Unterstreichung; Bl. 15r jüngere dunkelrote Ranke als Zeilenfüllsel über radierter Stelle. Bl. 3r, Z. 4 und 6 schwarze Minuskeln mit roten Majuskeln überschrieben; Bl. 14v in der obersten Zeile einzeilige rote Lombarde und nachfolgendes (blassrotes) Paragraphzeichen über radierter Stelle ergänzt; von dieser späteren Hand wohl auch die Füllranke Bl. 15r sowie ab Bl. 10v immer wieder Akzentzeichnungen in blassem Rot. In den Binnenfeldern der Textualis-Majuskeln des Öfteren feine Doppelschrägstriche (z. B. Bl. 3r, Z. 1), fallweise auch mit kleinem angesetztem Bogen (z. B. Bl. 15r, Z. 2).

Deckfarbenschmuck: 33 ornamentale und acht figürliche Initialen, jeweils mit Ranken; die ornamentalen Initialen vier- bis sechszeilig, die figürlichen fünf- und sechszeilig.

Initialrahmen zumeist profiliert und rosafarben (auch blau) oder (bei etlichen figürlichen Initialen) mit Blattgold belegt und punziert; einige I-Initialen rahmenlos, die mit den in der Längsschaftmitte symmetrisch angeordneten Blattknollen wie doppelflügelige Türen mit Knäufen wirken (z. B. Bl. 19v); Großteil der Initialfelder bzw. Außengründe mit punziertem Blattgold gefüllt; $\mathrm{Bl}$. 3r und 4v silberne Initialfelder (bemalt bzw. punziert); zur Punzierung s. u.; Binnenfelder ansonsten meist blau oder karminrot ausgemalt und von feinen, gestrichelten Goldranken oder Rautengründen, Bl. 2v von maßwerkartigen Motiven in Weiß und Silber, überzogen. Die in Grün, Pinselgold, häufig Blau und Rosa, Rot und Violetttönen, seltener in GrauWeiß gehaltenen und meist von einem dünnen Konturstab eingefassten Buchstabenkörper, die mit vielfältigst variierendem Blattwerk gefüllt sind, liegen auf den Rahmen auf (Bl. 30[21] r-v der Binnenfeldgrund bis in die Rahmenzone hinein ausgedehnt); die Serifen tw. wie angeschnittene Pflanzenstängel gestaltet (z. B. Bl. 2r), vgl. Ranken; Bl. 5r Buchstabenkörper mit drei Goldringen geschmückt; der weiße Buchstabenkörper B1. 14v wohl unvollendet. Die Marginalranken bei Ornamentalinitialen meist zwei- oder dreiseitig (in Seitenecken oft in Schlingen gelegt); bei figürlichen Initialen, denen in der Regel aufwändigerer Marginaldekor zugeordnet ist, überwiegen kürzere Rankenarrangements; insgesamt filigran-anmutige Rankenanlage ohne Bestrebung, die Seitenränder abzudecken; die Äste dabei auf längeren Abschnitten schnurgerade geführt, B1. 3r grüner und rosafarbener Ast zu einem Rankenstab gewunden; zwei Grundtypen des Randdekors: stilisierte Ranken (mit abwechslungsreichen, schmalsilhouettigen Blattvarianten, zur Farbgebung s. u., und sparsam, gerne mittig auf dem Bas-de-page platzierten Fantasieblüten) und botanisch identifizierbare Blütenzweige (z. B. Bl. 8r Veilchen, Bl. 10v1 Iris, B1. 12v Kornblume); die beiden Typen oft miteinander kombiniert (Charakteristikum), naturalistische Zweige häufiger auf Folios mit figürlichen Initialen; bei beiden Typen sowohl naturalistisch anmutende Astanschnitte (z. B. B1. 2r) als auch dezenter, fallweise punzierter Golddekor: Punkte (selten mit bunten Blütenblättern besetzt, z.B. Bl. 4v), Tropfen und charakteristische (spindelförmige) Füllfelder in Rankenzwischenräumen (z. B. Bl. 2r linker Rand); Bl. 12r rosafarbener Distelzweig mit naturalistischen Blüten und stilisierten Blättern (die ihrerseits an bestacheltes Distelblattwerk erinnern). Variationsreichtum auch beim Rankenansatz: Während im Epistolar die Ranken häufig aus den Buchstabenserifen oder aus (Blatt-)Manschetten (z. B. Bl. 8r), aber auch aus dem Rahmen (bzw. Initialfeld) entspringen, an diesem angelegt (z. B. Bl. 6v) oder sogar angebunden (Bl. 2r) sein können, bleibt die Randzier im Evangelistar zuweilen ganz ohne Kontakt zur Initiale (z. B. Bl. 34v). Große Vielfalt der insges. ca. 90 Drolerien: häufig Vögel, zuweilen Insekten, z. B. Fliege (Bl. 5v neben Initiale), Biene (B1. 14v Bas-depage), Käfer (Bl. 18r oberer Seitenrand), auch Raupen, zudem lebendig inszenierte Vierbeiner, wie z. B. eine Katze, die einer Maus hinterherjagt (Bl. 14r), ein sich kratzender Hund (Bl. 12r) oder ein kauernder Hase (Bl. 9v); v. a. die Vögel wirken in Farbgebung und Haltung sehr naturnah, z. B. der Erpel, Bl. 19v, oder die Henne mit ihren Küken, Bl. 32r; zu Beginn der Hs. einige Vögel mit weit ausschreitender bzw. gegrätschter Beinposition (Bl. 2r-v, 3v); Bl. 10v auch das Osterlamm mit Siegesfahne drolerieartig in das Rankenwerk integriert.

Figuren anatomisch recht gekonnt ausgeführt; beim stehenden Jesuskind Bl. 2r der Versuch eines Kontraposts, wobei der Standbeinfuß im rechten Winkel nach außen gedreht und der Spielbeinfuß spitz nach vorne gestreckt ist, vgl. die Christusfiguren Ms. II.2, Bl. 9r und v. a. Bl. 13v; hl. Michael (Bl. 33[24]r) mit ausgeprägtem Körperschwung. In der Regel rundliche Köpfe mit rosigen Pausbacken, woraus sich eine kindliche Physiognomie ergibt; Weißhöhungen auf Stirn, Augendeckeln, oberen Wangenpartien und Nasenrücken (zuweilen auch auf den Fingern); die Chorherren Bl. 31[22]r durch (leicht) variierende Gesichtszüge und unterschiedliche Haarfarben als jüngere und ältere Männer individualisiert. Gewänder zuweilen recht gebauscht und mit feiner Strichelung schraffiert und gehöht (vgl. Strichführung bei Buchstabenkörpern, 
s. Bl. 32[23]r: Kleider, Decke, Vorhang und Buchstabenkörperfüllung); fallweise auch Goldhöhungen auf Gewandstoffen (z. B. Bl. 30[21]r). Einzelfiguren (Jesuskind, Bl. 2r; hl. Michael, Bl. 33[24]r; s. auch hl. Agnes, Ms. II.2, Bl. 4v) stehen auf grün marmorierten Böden (beim Jesuskind könnte es sich auch um ein Kissen mit ähnlichem Muster handeln) und werden von ornamentalen Gründen hinterfangen; szenische Darstellungen finden in Räumen (z. B. Huldigung an den hl. Augustinus, Bl. 31[22]r) oder Landschaften (z.B. Heimsuchung, B1. 30[21]r) statt; die himmlische Sphäre der Allerheiligen-Darstellung (Bl. 34[25]v) durch stilisierte blau-goldene Wolkenbänder wiedergegeben; Wände (aus grau-grün und violett kolorierten Mauersteinen) tw. mit detailliert gemusterten Teppichen verhängt (z. B. Bl. 32[23]r) und Böden mit gemusterten Fliesen belegt, z. B. Dekor aus Kreuzen und Kreisen, Bl. 31[22]r und Ms. II.2, Bl. 13v, oder Adler (Tiroler Adler?), Bl. 32[23]r; Fensterscheiben mit Silber, Scheibenstruktur durch Rauten aus Punktpunzenlinien bezeichnet (z. B. 31[22]r, Ms. II.2, B1. 5v); typisch bei den Landschaftsdarstellungen die Bäume mit dünnen Stämmen und summarisch zusammengefassten Blattwerkpartien (z. B. Bl. 30[21]r; Ms. II.2, Bl. 4r); auch hier naturalistische Pflanzendarstellungen (z.B. Bl. 30[21]r; Ms. II.2, Bl. 1r, 2r). Bei Architekturen bzw. Innenräumen (bis auf die Maueraufsicht Bl. 34[25]r und das Kopfteil des Bettes Bl. 32[23]r) recht sicherer Einsatz von Parallel- und Zentralperspektive.

Während die Farbgebung der Buchstabenkörper auch kräftiges Rot und Blau kennt, wurde bei den Ranken zarteres, fast transparent wirkendes Kolorit verwendet: dezentes Grün, helleres Mittelblau, Rosa (ganz selten Rot), Ocker und ins Fliederfarbene tendierendes Violett; verdunkelte Blattspitzen, an den Graten zarte Farbverläufe, auch Changieren möglich (Bl. 9v Blätter neben Initiale: gebrochenes Grün zu Altrosa); gekonnt herausgearbeitete Rundungen durch aufgesetzte Lichter, s.z. B. die Pollen der Fantasieblüte Bl. 7v. Reichliche Anwendung von Gold: Pinselgold patzig aufgetragen, Initialfeld Bl. 7v mit bes. grobem, möglicherweise nachgetragenem Pinselgolddekor in dachziegelartigen, schwarz konturierten Einzelfeldern, die zusätzlich mit bunten Punkten geschmückt sind; Blattgoldpartien gut erhalten, an den seltenen Bruchstellen (z.B. Bl. 14v) zartrosafarbener Bolus sichtbar; Bl. 30[21]r Blattgold des Heiligenscheins samt Bolus sowie Teile der Hintergrund-Bemalung abgeplatzt, Vorzeichnung sichtbar. Aufwändigere Punzierung: nicht nur Punktlinien (radial als Dekor von Heiligenscheinen und Außengrundzwickeln) oder einfache Kreise, sondern z. B. auch Blüte mit fünf spitzen Blättchen (z. B. B1. 30[21]r und Ms. II.2, B1. 6v, jeweils auf dem Initialrahmen), fünfblättrige Blüte mit gerundeten Blättchen in dachziegelartig aneinander gesetzten Punktpunzenbögen (Binnenfeld Bl. 13v) und gezahntes, von je zwei siebenblättrigen Blüten flankiertes Blättchen in doppellinigem Rautengitter (z. B. Binnenfeld Bl. 9v); auch Kombination von Punzen und kleinteiliger Bemalung möglich, z. B. Binnenfeld Bl. 10v1 (bunte Blüten) und Initialrahmen B1. 5v (blau-weiß-rote Querstriche). Bl. 2r Nacktes (beschnittenes) Jesuskind mit Heiligenschein auf grüner Bodenandeutung (Kissen?) stehend. Bl. 30[21]r Heimsuchung: Maria mit Heiligenschein und Elisabeth mit weißer Haube in hügeliger Landschaft.

Bl. 30[21]v Marientod: Maria, im Kreis der Apostel im Bett sitzend, bekommt von Johannes die Sterbekerze gereicht, daneben Petrus mit Weihwasserkessel und Aspergil; über der Szene (auf einer Wolkenkonsole) die Halbfigur Christi mit dem Seelenfigürchen Mariens.

Bl. 31[22]r Hl. Augustinus in prächtigem Bischofsornat, frontal thronend und die Rechte segnend erhoben, wird von adorierenden Augustiner Chorherren flankiert. Die beiden vorderen Chorherren halten ihre schwarzen Kappen in den Händen, links der Propst mit grauem, schweifbesetztem Feh-Almutium.

Bl. 32[23]r Geburt Mariens: Anna sitzt im Bett, das durch einen grünen Vorhang verborgen werden kann, und übergibt Maria (Wickelkind) einer Magd; vor dem Bett ein mit Wasser gefüllter Zuber, ein Schemel und ein weißes Hündchen.

Bl. 33[24]r Erzengel Michael als Seelenwäger mit erhobenem Schwert; in der linken Waagschale ein betendes Seelenfigürchen, an die rechte Schale klammert sich ein schwarzer Teufel.

Bl. 34[25]r Kirchenweihe: Vor einem schmalen Rundbogentor (mit geöffneter Holztür und Vordach, darüber Rundfenster; grüne Dachziegel) Bischof im Ornat mit goldenem Krummstab (mit transparentem, wie Vorzeichnung wirkendem Sudarium) und Aspergil; hinter ihm zwei Kleriker mit Weihwasserkessel, Buch und Weihrauchfass; über der Szene weht die Kirchweihfahne (Kreuzfahne, vgl. Fahne des Auferstandenen Ms. II.2, Bl. 9r).

B1. 34[25]v Allerheiligen: Frontal thronender und von zwei Leuchter(?)-Engeln flankierter Christus mit Kreuzstab und Weltkugel, umgeben von Maria und Heiligen, die durch Haartracht und Kopfbedeckung nach (geistlichen) Ständen differenziert sind.

Epistolar (Cod. 196, Bl. 1r-20v) und Evangelistar (Esztergom, Kathedralbibl., Ms. II.2, und Cod. 196, Bl. 30r-35[26]v, s. bei G und Inhalt) wurden jeweils vorrangig von einer Hand ausgestattet: Die sog. Evangelistarhand ist als die versiertere und daher auch für die Seiten mit figürlichen Initialen zuständige Hand auszumachen; von ihr könnte auch das Jesusfigürchen im Epistolar (Cod. 196, Bl. 2r) stammen. Bei der sog. Epistolarhand handelt es sich um einen v. a. für die Folios mit Ornamentalinitialen zuständigen Mitarbeiter, der sich stark am Formenvokabular der Evangelistarhand orientierte, wodurch sich die Unterscheidung der beiden Kräfte fallweise etwas problematisch gestaltet; allerdings dürften die ornamentalen Hintergründe und 
die Punzierungen durchwegs von der Epistolarhand stammen. In aller Regel war jede der beiden Hände aber nicht nur mit der Initiale, sondern auch mit dem weiteren Buchschmuck auf dem jeweiligen Folio befasst, gestaltete also auch die Buchstabenkörper und das Rankenwerk samt Drolerien, vgl. z. B. die Buchstabenkörperfüllungen der figürlichen Initialen Cod. 196, Bl. 2r, 33[24]r und Ms. II.2, Bl. 12v (alle Evangelistarhand), bei denen die Höhungen durch feine Strichelung herausmodelliert wurden, mit der Buchstabenkörperfüllung der Ornamentalinitiale Cod. 196, Bl. 1r (Epistolarhand), die sehr ähnliche Formen (v. a. die tropfenförmig verdickten Adern), aber eine gröbere Ausführung zeigt, oder die Irisstängel Cod. 196, Bl. 10v (Epistolarhand) und Ms. II.2, Bl. 5v (Evangelistarhand) bzw. die Hasen-Drolerien Cod. 196, Bl. 9v (Epistolarhand) und Ms. II.2, Bl. 2v (Evangelistarhand), die jeweils große Motivnähe aufweisen, aber unterschiedlich gestaltet wurden. Man kann demnach davon ausgehen, dass es einen gemeinsam benutzten Vorlagenfundus (ein Musterbuch?) gab. Die Jahreszahl 1482 auf Bl. 5v von Ms. II.2 kann zusammen mit dem 1480 datierten Brevier Brixen, Priesterseminarbibl., Cod. T.3, das starke Bezüge zu Cod. 196 zeigt, wohl als zeitlicher Anhaltspunkt für die Entstehung beider Handschriftenteile herangezogen werden, die Datierung 1531 auf Bl. 30[21]r könnte sich auf Textkorrekturen beziehen (s. o. beim niederrangigen Buchschmuck), keinesfalls auf die Wirkungszeit der noch in der spätmittelalterlichen Buchmalerei verankerten Evangelistarhand (Roland, Renaissance 635 und 640 Anm. 25: 1531 als Datierung für die gesamte Hs. angenommen). Denn wäre das Evangelistar in dieser Zeit entstanden, wiese es vermutlich Verbindungen zu Cod. 100, dem sog. Posch-Missale (1524-1526), auf, in dem interessanterweise Motive aus Cod. 196 aufgegriffen werden (s.z. B. Iris Cod. 100, Bl. 68v). Die Evangelistarhand zeigt immer wieder Unterschiede in der Ausführung von Figuren (vgl. z. B. die nicht nur in Bezug auf Gesichter, Hände und Gewänder, sondern auch bei der Darstellung von Tieren und Architektur bes. sorgfältige Einleitungsseite des Evangelistars, Ms. II.2, Bl. 1r, mit der Kirchenweihe, Cod. 196, Bl. 34[25]r). Inwieweit hierfür die das Gesamtkonzept der Hs. beherrschende Variationsfreude oder Qualitätsschwankungen verantwortlich sind oder ob man für diesen Handschriftenteil noch weitere Händescheidungen vornehmen muss, wird an anderer Stelle zu entscheiden sein.

Der qualitätvolle Dekor von Cod. 196 und Esztergom, Kathedralbibl., Ms. II.2, weist deutliche maltechnische und motivische Bezüge zu der Inkunabelbibel Wien, ÖNB, Ink. 3.C.6 auf (Straßburg: Johann Mentelin, vor dem 27. Juni 1466 bzw. um 1470; GW 4295 [mit Volldigitalisat]; zu dieser Bibel s. auch Roland, Gotik 291-292, Kat. 188 sowie Brixen, Priesterseminarbibl., Cod. C.13 und E.2), die ihrerseits durch Ranken mit tropfenförmig verdickten Blattadern und ihre naturalistischen Tierdrolerien und Blütenzweige bzw. -sträußchen in der weiteren Nachfolge des wohl in der 2. H. der 1450er Jahre entstandenen Missales der Stiftsbibl. Innichen stehen dürfte (ohne Sign.; Hermann 75-78, Nr. 81; E. Kühebacher, Kirche und Museum des Stiftes Innichen. Bozen 1993, Nr. 163, Abb. 116, 117a-g; Roland, Gotik 275 Anm. 79, Abb. 17). Beispiele für Affinitäten zw. der Wiener Inkunabel und dem vorliegenden Lektionar: luzid-delikater Farbauftrag, durch aufgesetzte Lichter gekonnt herausgearbeitete Rundungen (s.z.B. Ink. 3.C.6, Bl. 176v die Beeren unten links oder Bl. 159r die Fantasieblüte auf dem rechten Seitenrand mit dem aus vielen Kügelchen zusammengesetzten Fruchtkolben und dem „Erbsenschotenmotiv“ in den Blütenblättern; dieses Motiv übrigens nur im Evangelistar und dort auch nur einmal verwendet: Ms. II.2, Bl. 2r im Buchstabenkörper), Blätter mit verdickter Ader und (dreiteiligen) Spitzen (z. B. Bl. 53r Bas-de-page), spindelförmige, blattvergoldete Rankenzwischenräume (s. ebda) sowie naturalistische Blütenzweige (z. B. Bl. 177r Heckenrosen und Veilchen) und Vogeldrolerien (z. B. ebda Eule und Falke). Figuren und Drolerien in der Inkunabelbibel allerdings wesentlich elaborierter, zudem die Kombination von naturalistischen und stilisierten Elementen in Cod. 196 und Ms. II.2 bis hin zum Charakteristikum ausgeprägt.

S. R.

E: $\quad$ Neuzeitlicher Bibliothekseinband: braunes Leder über Pappe. Neustift, 2. H. 18. Jh.

Leder abgerieben und zerkratzt, in den Ecken tw. beschädigt, am VD links unten runder Fleck. Rücken: braunes Leder, vier einfache Bünde, von heute kaum mehr sichtbaren Goldbordüren gesäumt. Im ersten Feld Golddruck M: S:, im zweiten EPIST. ET [EVA]N. in Goldrahmung, im dritten Signaturschild (s. bei G). Spiegel Pap. 18. Jh., am Spiegel des VD Signaturen und Bleistiftnotiz (s. bei G), Spiegel des HD leer bis auf Bleistiftnotiz 19./20. Jh. 1470 (Versuch einer Datierung?).

G: Der Beginn des Evangelistars (Nativitas dni bis Petrus et Paulus, insges. 16 Blätter, 2 davon verloren) gelangte 1746 in den Besitz des Samuel Székely, vgl. Notiz Esztergom, Kathedralbibl., Ms. II.2, B1. 1r: Ex cimeliis Sam[uel] Székely de Doba cui in Collegio Neocellensi Canonic. Regular. S. Augustini Congreg. Dioecesis Brixinensis in Tyroli d. 24. Martii 1746 per Rev. Casp. Mayer Bibliothecarium d[atum] est." Über Sándor Mérey, den Obergespan des Komitats Somogy, kam das Fragment 1847 schließlich in die Kathedralbibliothek von Esztergom (vgl. Hinweis Ms. II. 2, Bl. Ir). In diesem Teil Bl. 5v die Datierung 1482 (in Cod. 196, Bl. 30r, zusätzlich die Datierung 1531), zu beiden Datierungen s. bei A.

Der durch diese Schenkung an Székely verursachte Textverlust in der Hs. in Neustift dürfte wohl dazu geführt haben, dass die entsprechenden Evangelientexte auf insges. neun Blättern handschriftlich ergänzt 
wurden und bei der Neubindung in der 2. H. 18. Jh. miteingebunden wurden. Da in dem in Neustift erhaltenen Teil mit Bleistift zahlreiche Akzente zu finden sind, in jenem in Esztergom jedoch nicht, kann davon ausgegangen werden, dass die Hs. auch nach 1746 in Neustift noch verwendet wurde.

1809 anlässlich der vorübergehenden Aufhebung des Klosters Neustift der ULB Tirol übergeben. Am Spiegel des VD Signaturen der ULB Tirol II 3 E 9 (Bleistift) und Nr. 196 (Tinte) sowie Bleistiftnotiz (Vide Grundzettel). Am Rücken gelbes Signaturschild der ULB Tirol 196. Bl. 1r Stempel der ULB Tirol 19. Jh. Bei der Foliierung an der ULB Tirol wurden auch die in der 2. H. 18. Jh. neu ergänzten Blätter mitberücksichtigt (21-29, 36-42), 1872 wurden sie aber herausgeschnitten und ausgeschieden, vgl. Notiz Innsbruck, ULB Tirol, Alte Titelkopie: Handschriften: „als fremdartige durchaus werthlose Bestandtheile eines anderen Evangeliars und Epistolars, das mit dem vorliegenden prachtvoll ausgestatteten cumulirt war, im Beisein aller Beamter ausgeschieden und in die Makulatur gegeben und bei dieser Gelegenheit der alte Abgang der Feste Weihnachten bis Peter und Paul im II Theile des vorliegenden Werkes (Evangeliar) constatirt. 12/I/72. Leithe. Foregg. Hofer. Hörmann“. 1921 aufgrund des Friedensvertrages von St. Germain an den italienischen Staat abgegeben und von diesem 1929 dem Kloster Neustift als Dauerleihgabe überlassen. Bl. 1r Stempel der Soprintendenza Tridentina 20. Jh.

L: $\quad$ Wilhelm II 110. - Hermann 171-173, Nr. 182. - Atz 1012. - I. Genthon (Hrsg,), Esztergom múemlékei, T. 1 (Magyarország müemléki topográfí́ja 1). Budapest 1948, 350-354 (ohne Nennung der Sign.). - Neuhauser, Neustift 85. - Katalog ULB Tirol II 193, 209. - Peintner, Buchmalerei 35, 116-118 (ohne Nennung der Sign.). - Ch. Giner, Leben im Kloster, in: 850 Jahre Neustift. Katalog 85-90, hier 89. - Fiegl, Missale 19-20. - Roland, Renaissance 635, 640. - Baroffio 324, Nr. 16715. - E. Madas (in Verbindung mit K. Körmendy, J. Lauf, G. Sarbak), Katalog der mittelalterlichen Handschriften in Esztergom. Die Bestände der Kathedralbibliothek und anderer Sammlungen (Fragmenta et codices in bibliothecis Hungariae VII-B). Deutsche Fassung unter Mitwirkung von A. Vizkelety. Esztergom, Budapest (in Druck).

$(\mathrm{Ir}-\mathrm{v})$ leer.

$1 \quad(1 \mathrm{r}-20 \mathrm{v})$ EPISTOLAR.

(1r) In galli cantu (Is 9,1 und 5-6).

(1v) nur Rahmung und Linierung.

(2r) In galli cantu (Tit 2,11-15). - In aurora (Is 61,1-3 und 62,11-12). (2v) (Tit 3,4-7). - (3r) Ad publicam missam (Is 52,6-10). (3v) (Hbr 1,1-12). - (4r) In nativitate sancti Stephani prothomartiri (Act 6,8-10 und 7,54-60). - (5r) Iohannis ewangeliste (Eccl. 15,1-6). - (5v) In circumcisione domini (Gal 3,23-4,2). - (6r) Epiphanie domini (Is 60,1-6). - (6v) Agnetis virginis. (Eccl. 51,1-12). - (7r) Purificacionis. (Mal 3,1-4). - (7v) Ingenuini et Albuini (Eccl. 44,1015). - (8r) Annunciacionis (Is 7,10-15). - (8v) In consecracione palmarum (Ex 15,27-16,10). (9v) In cena domini (1 Cor 11,20-32). - (10v) In festo pasce (1 Cor 5,7-8). - (10v) Feria II ${ }^{a}$ (Act 10,37-43). - (11r) Feria III ${ }^{a}$ (Act 13,16-33). - (12r) Ascensionis (Act. 1,1-11). - (12v) In die Penthecostes (Act 2,1-11). - (13v) Feria II ${ }^{a}$ (Act 10,42-48). - (14r) Feria III ${ }^{a}$ (Act 8,1417). - De sancta trinitate (Rm 11,33-36). - (14v) Corporis Christi. (1 Cor 11,23-29). - (15r) Iohannis Waptiste (Is 49,1-7). - (15v) Petri et Pauli (Act 12,1-11). - (16v) Visitacionis Marie (Ct 2,8-14). - (17r) Assumpcionis Marie (Sir 24,11-20). - (17v) Augustini episcopi (Hbr 5,16). - (18r) Nativitatis Marie (Prv 8,22-35). - (19r) Michaelis (Apc 12,7-12). - (19v) Dedicacionis eclesie (Apc 21,2-5). - (20r) Omnium sanctorum (Apc 7,2-12).

2 (30[21]r-35[26]r) EvANGELISTAR, unvollständig.

Der Beginn des Evangelistars [B1. 1r-14v] befindet sich heute in Esztergom, Kathedralbibl., Ms. II.2 (s. bei G; ausführlichere Beschreibung mit Abb. in Genthon, Esztergom 350-354):

[1r] In galli cantu. - [1v] In primo mane. - [2r] In die sancto. - [2v] In die s. Stephani. - [3r] Iohannis evangeliste. - [3v] In octava [nativitas]. - [3v] In die sancto epyphania. - [4v] In festo s. Agnetis. - [5r] Purificacio. - [6r] De patronis. - [6v] In annunciacione s. Marie. - [7v] In consecracione palmarum. - [8r] In cena domini. $-[9 \mathrm{r}]$ In die sancto pasche. $-[9 \mathrm{v}]$ Feria secunda. $-[10 \mathrm{v}]$ Feria tercia. Expl. mut.: ... nolite timere. Contur[ ( $1 \mathrm{Bl}$. fehlt, Textverlust)

[11r] In ascensione dni. Inc. mut.: ] habebunt. Et dominus quidem Ihesus postquam locutus est eis assumptus ... - [11r] In die penthecostes. - [11v] Feria II ${ }^{a} .-[12 \mathrm{r}]$ Feria III ${ }^{a} .-[12 \mathrm{v}]$ De sancta trinitate. Expl. mut. ... prohibebit de me et vos [ (1 Bl. fehlt, Textverlust) 
[13r] Vigilia Iohannis Baptistae. Inc. mut.: ] factum est autem cum sacerdotio fungeretur ... - [13v] Evangelium Liber generationis. Require nativitatis Marie. - De corpore Christi. - Iohannis Baptiste. - [14v] Petri et Pauli. Expl. mut.: ... cumque ligaveris super terram erit ligatum et in [

(30[21]r) Petrus et Paulus. Inc. mut. (Forts. von Esztergom, Kathedralbibl., Ms. II.2, Bl. 14v): ]

celis et quidcumque solveris super terram erit solutum et in celis (Mt 16,19). - (30[21]r) De visitacione sancte Marie (Lc 1,39-56). - (30[21]v) In assumpcione s. Marie (Lc 10,38-42). (31[22]r) In die Augustini (Lc 19,12-26). - (32[23]r) In nativitate s. Marie (Mt 1,1-16). (33[24]r) In festo Michahelis (Mt 18,1-10). - (34[25]r) In dedicacione ecclesie (Lc 19,1-10). (34[25]v) In festo omnium sanctorum (Mt 5,1-12).

(35[26]v) nur Rahmung und Linierung.

U.S.

\section{Cod. 200}

\section{ROBERTUS HOLCOT}

Pap. I, 390, I* Bl. $310 \times 215$. Wiener Raum (?), um 1415/20.

B: Pap. stark fleckig, vereinzelt kleinere Einrisse am unteren Blattrand. Bl. 1 unten ergänzt sowie rechte Spalte kleines Loch, Bl. 158 eingerissen. Bl. 264-267, 276-277 sowie 287 und 290 etwas kleiner als restlicher Buchblock. Hinweise und Bilder der Wasserzeichen s. WZMA. Datierung nach Wasserzeichenbefund. Identische Wasserzeichen: u. a. Wien, Schottenstift, Archiv, Hs. 101 (dat. 1416) und Archiv, Hs. 130 (dat. 1418). Lagen: (I-1) ${ }^{\mathrm{I}}$ (Vorsatzbl. 18. Jh. $)+(\mathrm{VI}-2)^{10}+7 . \mathrm{VI}^{94}+\mathrm{V}^{104}+14 . \mathrm{VI}^{271(272)}+(\mathrm{VI}-1)^{282(283)}+8 . \mathrm{VI}^{378(379)}+(\mathrm{VI}-$ $1)^{389(390)}+(\mathrm{I}-1)^{I^{*}}$ (Nachsatzbl. 18. Jh.). Gegenbl. zum Vor- bzw. Nachsatzbl. als Spiegel auf dem VD bzw. HD aufgeklebt. Gegenbl. zu Bl. 9 und 10 (Textverlust), zu Bl. 281 (ohne Textverlust, Falz erhalten), zu Bl. 379 (Textverlust) herausgeschnitten. Bl. 9 am oberen Blattrand auf Bl. 8 aufgeklebt, Bl. 10 mit Papierstreifen mit Bl. 9 sowie 11 verbunden. Am Lagenende Kustoden in Rot ausgeschrieben, Lage 1-7 zusätzlich in Schwarz als arabische Ziffer. Ab Lage 8 Reklamanten, tw. beschnitten. In den Lagenmitten unbeschriebene Pergamentfälze. Am oberen Blattrand Foliierung 19. Jh. durch die ULB Tirol; Fehler in der Zählung: 182 doppelt angeführt.

S: $\quad$ Schriftraum 215/230 × 135/150. Zwei Spalten, tw. von feinen Tintenlinien, tw. von Blindlinien gerahmt, auf dem Verso vielfach ohne Rahmung, zu 38-45 Zeilen. Zirkelstiche. Bastarda von einer Hand mit unterschiedlichem Duktus. Randbemerkungen und Korrekturen von späterer Hand.

A: $\quad$ Rote Auszeichnungsstriche, Paragraphzeichen, Unterstreichungen, Kustoden, Überschriften sowie Angabe der jeweiligen Lectio am oberen Blattrand. Bl. 1ra rote Zeigehand. Zwei- und dreizeilige rote Lombarden, tw. mit Punktverdickungen, tw. mit einfachen Ausläufern. Bl. 2va und 4va drei- bzw. zweizeilige rote Lombarde mit einfachem Fleuronnée in Schwarz (Bl. 4va: zwei gegenständige Halbpalmetten im Binnenfeld), Bl. 2va Fratze als Besatz. Repräsentanten.

E: $\quad$ Neuzeitlicher Bibliothekseinband: schwarz gesprenkeltes braunes Pap. über Pappe. Neustift, 2. H. 18. Jh. Pap. etwas abgerieben, bes. an den Kanten. Am VD und HD Ecken mit braunem Leder verstärkt. Rücken: braunes Leder, tw. beschädigt und mit Wurmlöchern, drei Doppelbünde, von Goldbordüren gesäumt. Im ersten Feld Golddruck M: S:, im zweiten Golddruck ROBERTI HOLTGOT POSTILLA SUPER LIBRO SAPIENTIE in Goldrahmung, im dritten Signaturschild (s. bei G). Kapital oben freiliegend und beschädigt. Am unteren Schnitt Aufschrift Holdgot. Spiegel Pap. 18. Jh. Am Spiegel des VD Exlibris, Signaturen und Bleistiftnotiz (s. bei G), Spiegel des HD leer.

G: $\quad$ Bl. 377rb Besitzvermerk 15. Jh. Iste liber est monasterii sancte Marie in Novacella extra civitatem Brixinensem sita. Am Spiegel des VD Exlibris der Stiftsbibl. Neustift 18. Jh. 1809 anlässlich der vorübergehenden Aufhebung des Klosters Neustift der ULB Tirol übergeben. Am Spiegel des VD alte Signaturen der ULB Tirol II $\overline{2}$ [...] (radiert), II 3 E 12 (Bleistift) und Nr. 200 (Tinte) sowie Bleistiftnotiz (Vide Grundzettel). Am Rücken gelbes Signaturschild der ULB Tirol 200. Bl. 1r Stempel der ULB Tirol 19. Jh. 1921 aufgrund des Friedensvertrages von St. Germain an den italienischen Staat abgegeben und von diesem 1929 dem Kloster Neustift als Dauerleihgabe überlassen. Bl. 1r Stempel der Soprintendenza Tridentina 20. Jh.

L: $\quad$ Stegmüller RB Nr. 7416, 7416,3, 7416,12. - Kaeppeli Nr. 3497. - Katalog ULB Tirol II 201, 209. 
$(\mathrm{Ir}-\mathrm{v})$ leer.

(1ra-389vb) Roвertus Holcot: Postilla super librum Sapientiae, unvollständig (Druck: GW 1288412890. - Stegmüller RB Nr. 7416. Kaeppeli Nr. 3497).

(1ra) Prolog. Inc. mut.: ] usitata hec enim katholicos et in scismaticos et fideles in hereticos et doctores in adulatores convertit sicut recenter nobis occurrit et nuper exprimato vidistis. Hec enim facultas est illa ancilla Agar de qua scribitur... - Expl.: ... quos precioso sanguine redemisti quod nobis ille concedat qui cum patre vivit et regnat etc.

(2va) Lectiones (insges. 212). Inc.: Diligite iusticiam qui iudicatis terram. Circa istum librum qui liber Sapiencie nuncupatur sunt in principio tria notanda ... - Expl.. ... Sapiencia deducet ad regnum perpetuum. Ad quod regnum nos perducat ille qui cum patre et filio et spiritu sancto vivit et regnat in secula seculorum. Amen. Gloria tibi sit trinitas etc.

(377rb) Schlussschrift (rot): Explicit postilla reverendi doctoris et magistri Roberti Holtgot ordinis fratrum Predicatorum super libros Sapiencie.

Darunter: Besitzvermerk (s. bei G).

$(377 v)$ leer.

(378ra-389vb) Zwei Register.

(378ra) Register der einzelnen Lectiones in alphabetischer Reihenfolge.

Tit.: Incipiunt tituli questionum in exposicionem libri Sapiencie secundum ordinem alphabeti. - Inc.: Accepcio personarum utrum sit peccatum leccione $78 \mathrm{~b} \ldots$.. Expl.: ... Ymagines utrum sint adorande et quid in eis adoretur leccione $77 \mathrm{~b}$.

(379ra) Sachregister (unvollständig, A-H) (vgl. Register am Beginn des Drucks).

Einführung: Ad evidenciam tabule sequentis que est super exposicionem libri Sapiencie. Sciendum quod in ea breviter continentur materie (am Blattrand ergänzt: naturales et) curiose questiones non tamen disputabiles ... qui est superadditus propter prompciorem modum ad inveniendum materiam Inc.: Aaron virga quomodo floruit leccione 93 b ... - Expl. mut.: ... Hospes preteriens est mundana felicitas [

$(\mathrm{I} * \mathrm{r}-\mathrm{v})$ leer.

U. S.

\section{Cod. 204}

\section{VETUS TESTAMENTUM}

Pap. 307 Bl. $310 \times 200$. Tirol (?), um 1470 .

B: $\quad$ Pap. am Beginn und am Ende des Buchblocks bes. am Rand, in der Mitte des Buchblocks im Bund verschmutzt. Bilder und Nachweise der Wasserzeichen s. WZMA. Datierung nach Wasserzeichenbefund. Identische Wasserzeichen; u. a. Innsbruck, ULB Tirol, Cod. 60 (um 1470/71); Neustift, Stiftsbibl., Cod. 174; Brixen, Priesterseminarbibl., Cod. A.2 (dat. 1472). Lagen: 25.VI ${ }^{301(300)}+(\mathrm{V}-3)^{308(307)}$. Gegenbl. zu 304 und 306 herausgerissen (ohne Textverlust), Gegenbl. zu Bl. 302 als Spiegel auf dem HD aufgeklebt. Lagenreklamanten erhalten (außer bei Lage 24 und 25), tw. rot umrandet, ab Lage 10 beschnitten. In den Lagenmitten beschriebene und rubrizierte sowie illustrierte Pergamentfälze, stark verschmutzt. Vereinzelt Reste einer Zählung der Blätter der ersten Lagenhälfte erhalten. Am oberen Blattrand Foliierung 19. Jh. durch die ULB Tirol; Fehler in der Zählung: 260 ausgelassen.

S: $\quad$ Schriftraum 210/220 × 140/145. Zwei Spalten, von Blindlinien gerahmt, zu 43-44 Zeilen auf Blindlinierung. Bastarda von zwei Händen: 1) Bl. 1ra-274ra, Z. 10; 2) Bl. 274ra, Z. 11-Bl. 306ra.

A: $\quad$ Rote Auszeichnungsstriche, Unterstreichungen, Durchstreichungen, Rahmungen sowie Über- und Schlussschriften. Bl. 1ra-274ra Buchstaben in der obersten Zeile tw. gedehnt. An den Kapitelanfängen jeweils zwei- bis siebenzeilige rote Lombarden, meist mit Punktverdickungen, tw. mit einfachen Aussparungen, vereinzelt mit verzierten Ausläufern. Am Beginn der einzelnen Bücher fünf- bis elfzeilige rote Initialen mit 
Aussparungen in Form von Blättern (Halbpalmetten), ondulierenden Ranken und Kopfstempeln, Bl. 73va und 135va Herzblätter und/oder Blüten als Besatz. Bl. 119va und 120rb einfaches Fleuronnée in Schwarz. Repräsentanten.

E: $\quad$ Gotischer Einband: dunkelbraunes Rindsleder über Holz mit Blinddruck. Tirol (?), Ende 15. Jh.

Leder stark abgerieben, Holz z. T. freiliegend. VD und HD gleich: zwei durch je dreifache Streicheisenlinien begrenzte Rahmen, jeweils gefüllt mit Einzelstempeln. Rahmen 1: Einzelstempel Drache (Vogel?) in Raute (Nr. 1), in den Ecken Einzelstempel fünfblättrige Blüte frei (Nr. 2); Rahmen 2: vertikal abwechselnd Schriftband „Maria“ (Nr. 3) und Einzelstempel Einhorn in Raute (Nr. 4), in den Ecken Einzelstempel fünfblättrige Blüte frei (Nr. 2), unten und oben zudem je ein Einzelstempel Einhorn in Raute (Nr. 4). Im Mittelfeld oben und unten je ein Einzelstempel doppelköpfiger Adler in Raute (Nr. 5), in der Mitte Spuren eines rautenförmigen Beschlags. Ebenso in den Ecken Spuren von (spitz zulaufenden) Beschlägen. Zwei Leder-MetallSchließen, die obere schadhaft, die untere vollständig erhalten. Schließe mit Schriftband (wohl „Maria“). Kanten gerade. Rücken: drei Doppelbünde, Leder oben eingerissen, unten beschädigt. In den Feldern zw. den Bünden jeweils in den Ecken Einzelstempel heraldische Lilie in Raute (Nr. 6), in der Mitte Schriftband (Nr. 3). Im ersten Feld aufgeklebtes Papierschild M: S:, im zweiten Papiertitelschild SS Biblia sowie Signaturschild (s. bei G), im fünften (= letzten) Papierschild (leer). Kapitale mit rotem und blauem bzw. naturfarbenem Zwirn umstochen. Spiegel Pap. 15. Jh. Am Spiegel des VD Signaturen sowie Bleistiftnotiz (Vide Grundzettel), Spiegel des HD leer.

G: $\quad$ Bl. 1r Besitzvermerk 18. Jh. Ad Collegium Neocell. 1809 anlässlich der vorübergehenden Aufhebung des Klosters Neustift der ULB Tirol übergeben. Am Spiegel des VD Signaturen der ULB Tirol II 3 F 1 (Bleistift) und Nr. 204 (Tinte) sowie Bleistiftnotiz (Vide Grundzettel). Am Rücken gelbes Signaturschild der ULB Tirol 204. Bl. 1r Stempel der ULB Tirol 19. Jh. 1921 aufgrund des Friedensvertrages von St. Germain an den italienischen Staat abgegeben und von diesem 1929 dem Kloster Neustift als Dauerleihgabe überlassen. Bl. 1r Stempel der Soprintendenza Tridentina 20. Jh.

L: $\quad$ Katalog ULB Tirol III 25, 335. - Peintner, Stiftsbibliothek 121. - Baroffio 324, Nr. 16716.

(1ra-306ra) Vetus Testamentum, unvollständig.

(1ra-253vb) Libri historici: Pentateuchus, Iosua, Reges, Iudices, Ruth, Iudith, Esther.

(1ra) 〈Hieronymus»: Epistola 53 (52) ad Paulinum presbyterum (BS I 3-37. Préfaces 1-7. - BHM Nr. 53. Stegmüller RB Nr. 284. CPL Nr. 620).

(5ra) 〈Hieronymus〉: Praefatio in Pentateuchum (BS I 63-69. Préfaces 7-8. - Stegmüller RB Nr. 285). (5vb) Genesis. - (33ra) Exodus. - (56va) Leviticus. - (73va) Numeri. - (97vb) Deuteronomium.

(119va) 〈Hieronymus〉: Prologus in librum Iosue (BS IV 3-8. Préfaces 22-23. - Stegmüller RB Nr. 311). (120rb) Iosue. - (135va) 1. Regum. - (157vb) 2. Regum. - (170rb) 3. Regum. - (197rb) 4. Regum. (217rb) IudicEs. - (234rb) Ruth.

(236vb) 〈Hieronymus〉: Prologus in librum Iudith (BS VIII 213-214. Préfaces 35, Nr. 2. - Stegmüller RB Nr. 335). - (236vb) Iudith.

(245va) 〈Hieronymus〉: Prologus in librum Esther (BS IX 3-4. Préfaces 36, Nr. 3 und 4. - Stegmüller RB Nr. 341 und 343). - (245vb) EsTHER.

(254ra-289vb) LiBri MacCABAEORUM.

(254ra) 1. MaccabaeOrum. - (275v) leer. - (276ra) 2. MACCABAEORUM.

(290ra-306ra) Iов.

(306ra) Schlussschrift: Et sic est finis. Tu autem domine miserere nobis.

(306rb-308v) leer. 


\title{
Cod. 217
}

\section{DECIMUS IUNIUS IUVENALIS. AULUS PERSIUS FLACCUS}

\author{
Perg. I, 56, I* Bl. $310 \times 200$. Bologna, 1. H. 15. Jh.
}

B: $\quad$ Perg. fleckig, insbes. am Blattrand Wasserflecken, löchrig, vielfach geflickt. Haar- und Fleischseite deutlich unterscheidbar. Perg. palimpsestiert (s. bei Inhalt). Auf Bl. 22v am oberen Blattrand je ein Farbstreifen in Grün (darin neuzeitlicher Eintrag uber?), Blau und Rosa (Pinselproben?). Lagen: (I-1) ${ }^{\mathrm{I}}$ (Vorsatzbl., Pap. 18. Jh.) $+\mathrm{III}^{10(6)}+\mathrm{II}^{20(10)}+2 . \mathrm{III}^{70(22)}+\mathrm{IV}^{50(30)}+\mathrm{II}^{60(34)}+\mathrm{V}^{\text {unfoliiert(44) }}+\mathrm{II}^{67(48)}+\mathrm{IV}^{80(56)}+(\mathrm{I}-1)^{\mathrm{I}^{*}}$ (Nachsatzbl., Pap. 18. Jh.). Gegenbl. zum Vor- bzw. Nachsatzbl. als Spiegel auf dem VD bzw. HD aufgeklebt. Zahlreiche Bl. fehlen (Textverlust), s. u. zeitgenössische Foliierung. Am oberen Blattrand zeitgenössische Foliierung. Heutige Bindung fehlerhaft, vgl. zeitgenössische Foliierung und Lagenreklamanten: 1-3, 8-10, 13, 11, 20, 18, 21-23, 28-30, 61-63, 68-70, 41-44, 47-50, 51-52, 59-60, zehn unfoliierte Bl., 64-67, 71-80. Am unteren Blattrand Foliierung 21. Jh. (hier berücksichtigt). Bl. 35 (Textbeginn der Satiren des Persius) neuzeitliches gelbes Papiersignakel der ULB Tirol.

S: $\quad$ Schriftraum $220 / 225 \times 125$. Von feinen (am linken Textrand jeweils zweifachen) Tintenlinien begrenzt, zu einheitlich 25 Zeilen auf Tintenlinierung. Humanistische Minuskel. Interlinear- und Marginalglossen, bisweilen radiert, von drei zeitgenössischen Händen in Humanistischer Minuskel, tw. mit kursivem Einschlag. Vereinzelt Ergänzungen am Blattrand von späterer Hand. Bleistiftnotizen 19. Jh., insbes. die Anordnung der Blätter betreffend.

A: Rubrizierung in hell- bis dunkelrosafarbener Tinte: Auszeichnungsstriche am Versbeginn (bis Bl. 2r), Überschriften, am oberen Blattrand und randseitig Nummerierungen (römische Ziffern) der Bücher und Satiren (auch in schwarzer Tinte), Randmarkierungen (z. B. Bl. 2v in der Art von vereinfachtem Perlenbesatz), Unterstreichungen, wenige Zeigehände. Repräsentanten.

$\mathrm{Zu}$ Beginn der einzelnen Satiren ein- und zweizeilige rote und blaue Lombarden mit Fleuronnée, bei roten Lombarden (stark verblasstes) rosafarbenes, bei blauen Lombarden rotes Fleuronnée (Bl. 17r einzeilige rosafarbene Lombarde mit zierstabartigem Mittelstrich). In den Binnenfeldern und als Besatz charakteristische saitenartige Parallelstriche, verziert mit kleinen Perlen; randseitig aus den durch Schräghaken in gegeneinander versetzte Abschnitte unterteilten Parallelstrichbündeln einzelne Striche zu schwungvollen Fadenausläufern verlängert, charakteristische große, nach unten weisende Schlingen mit (hakenartigem) Binnenmotiv.

Erhaltener Deckfarbenschmuck: vier rankenlose Ornamentalinitialen, sechs- und vierzeilig am Buchbeginn Bl. 1r und 35r, zweizeilig am Anfang von zwei Satiren, Bl. 9v und 27r.

Blattvergoldete Außengründe (Bl. 1r rosafarbener Bolus sichtbar) mit schwarzen Rahmenlinien, fallweise mit feinen Eckspitzen; rosafarbene Buchstabenkörper (Bl. 1r mit grünen „Anschnitten“ und roter Manschette, Bl. 35r mit Serifenblatt); in den Binnenfeldern auf blauem Grund diverse Blattformationen in Grau, Grün und kräftigem Rot; feiner weißer Lineardekor; Buchstabenkörper und Blätter mit (angedeutetem) „Erbsenschotenmotiv"; neben den Initialen auf dem Seitenrand freie Goldpunkte (mit schwarzer Konturlinie, Strahlen und kleinen Kreisen).

Das Kolorit (u. a. das Blau der Binnengründe), die feinen weißen Dekorlinien und das „Erbsenschotenmotiv" verweisen auf die italienische Buchmalerei 1. H. 15. Jh.; das Fleuronnée ebenfalls italienisch.

S. R.

E: $\quad$ Neuzeitlicher Bibliothekseinband: schwarz gesprenkeltes braunes Pap. über Pappe. Neustift, 2. H. 18. Jh. Pap. tw. stark abgerieben. Am VD und HD Ecken mit braunem Leder verstärkt. Rücken: braunes Leder, vier einfache Bünde, von Goldbordüren gesäumt. Im zweiten Feld Golddruck IUVEN. ET PERSII WITR. (!) SATY. in Goldrahmung, im dritten Signaturschild (s. bei G). Spiegel Pap. 18. Jh. Am Spiegel des VD Signaturen und Bleistiftnotizen (s. bei G), Spiegel des HD leer.

G: Zeitpunkt und Art der Erwerbung durch Neustift unbekannt. 1809 anlässlich der vorübergehenden Aufhebung des Klosters Neustift der ULB Tirol übergeben. Am Spiegel des VD alte Signaturen der ULB Tirol II $\overline{5}$ C 4 (Tinte), II 3 F 14 (Bleistift) und Nr. 217/(1) (Tinte, Bleistift) sowie Bleistiftnotizen (Vide Grundzettel) (die Textblätter des Juvenal u. Persius sind verwechselt). Am Rücken gelbes Signaturschild der ULB Tirol 217. Bl. 1r Stempel der ULB Tirol 19. Jh. 1921 aufgrund des Friedensvertrages von St. Germain an den italienischen Staat abgegeben und von diesem 1929 dem Kloster Neustift als Dauerleihgabe überlassen. Bl. 1r Stempel der Soprintendenza Tridentina 20. Jh.

L: $\quad$ Kristeller VI 122. - Wilhelm I 136. - Hermann 173, Nr. 183. - A. Zingerle, Ueber eine Innsbrucker Juvenalhandschrift mit Scholien (Kleine philologische Abhandlungen 4). Innsbruck 1887, 1-12. - A. Zingerle, 
Übersicht über philologische Handschriften aus Tirolischen Bibliotheken. Commentationes Aenipontanae 4 (1909) 1-4, hier 3, Nr. 8. - Neuhauser, Neustift 84. - Katalog ULB Tirol III 64, 335. - Peintner, Stiftsbibliothek 122. - M. Peintner, Das Skriptorium von Neustift, in: 850 Jahre Neustift. Katalog 91-93, hier 93 (ohne Nennung der Sign.).

(Ir-v) leer.

1 (1r-34v) Decimus Iunius Iuvenalis: Saturae, unvollständig (Ed. I. Willis. Stutgardiae et al. 1997). Aufgrund fehlender Blätter lückenhafter Text mit reichlichen Interlinear- und Randglossen von drei unterschiedlichen Händen. Den einzelnen Satiren sind die entsprechenden Argumenta von Guarinus Veronensis vorangestellt (Ed.: D. Manzoli, Nuovi carmi di Guarino Veronese. Verona 2000).

Am oberen Blattrand: Liber primus satyra prima.

Tit.: Iunii Iuvenalis Aquinatis poetarum satyricorum facetissimi et gravissimi liber Satyrarum suarum primus incipit.

Aufgrund der fehlerhaften Bindung ergibt sich folgende Reihenfolge:

(1r) Sat. 1, V. 1-146. Tit.: Materiam et causas satyrarum hac inspice prima. - (4v) Sat. 3, V. 3-152. - (7r) Sat. 3, V. 253-302. - (8r) Sat. 3, V. 153-202. - (9r) Sat. 5, V. 134-173. - (9v) Sat. 6, V. 1-15. Tit.: Hac (!) satyra incestas mulieres monstrat, ut omnem uxorem Ursidius devitet pectore toto. - (10r) Sat. 5, V. 26-75. - (11r) Sat. 6, V. 16-169. - (14r) Sat. 6, V. 371-521. - (17r) Sat. 12, V. 126-130. - (17r) Sat. 13, V. 1-146. Tit.: Mens cruciat pravos. Sapiens fert damna modeste. - (20r) Sat. 14, V. 97-247. - (23r) Sat. 8, V. 119-275. - (26r) Sat. 9, V. 1-45. Tit.: Concubitus diri et sodomitica probra notantur. - (27r) Sat. 10, V. 1-294. Tit.: Arguit hec hominum curas et inania vota. Von anderer Hand: Liber quartus. - (33r) Sat. 12, V. 25-125.

Zur Kommentierung Iuvenals s. auch E. M. Sanford, Renaissance Commentaries on Juvenal. Transactions and Proceedings of the American Philological Association 79 (1948) 92-112.

2 (35r-44v) Aulus Persius Flaccus: Saturae, unvollständig (Ed. W. Kissel. Berolini 2007).

Tit.: A. Persii Vultrani satyrarum libellus incipit feliciter.

(35r) Prolog (hier als Satura 1 gezählt). Schlussschrift: Explicit prima.

(35r) Sat. 1. Tit.: Incipit secunda de perversis exercitationibus poetarum. - (38r) Sat. 2. Tit.: Satira II de falsis votis. - (39v) Sat. 3. Tit.: Satyra III de inerta (!) iuvenum. - (41v) Sat. 4. Tit.: S[atura] IIII in ambitiosos cives. - (43r) Sat. 5, V. 1-99. Tit.: S[atura] V ad Corntum (!) poetam de illecbris (!) urbis.

3 (45r-53r) Forts. von Nr. 1: Decimus Iunius Iuvenalis: Saturae, unvollständig (s. o.).

(45r) Sat. 13, V. 147-249. - (47r) Sat. 14, V. 1-96. Tit.: Imbuit exemplis natos mala vita parentum. - (49r) Sat. 14, V. 248-331. - (50v) Sat. 16 (am Rand als XV gezählt), V. 1-60. Tit.: Militiae mores et commoda dinumerantur. - (51v) Sat. 15 (am Rand als XVI gezählt), V. 1-54. Tit.: Immanes ritus Aegyptius incola servat. - (53r) Sat. 15, V. 155-174.

$(53 \mathrm{v}-56 \mathrm{v})$ leer.

$\left(\mathrm{I}^{*} \mathrm{r}-\mathrm{v}\right)$ leer.

Gesamte Hs. palimpsestiert. Möglicherweise handelt es sich um ein Register für den Stationarius (wohl eines Notars) zur Dokumentation des Verleihs von Pecien; bes. auffallend ist die Verwendung der lat. Sprache. Aufgrund inhaltlicher, u. a. topographischer Hinweise im Umfeld der Universität Bologna entstanden. Giovanna Murano sei für ihre wertvollen Hinweise herzlich gedankt.

G. K./A. P. 


\section{ORDINARIUM MISSAE}

Perg. 46 Bl. $340 \times 245$. Neustift (?), letztes Viertel 15. Jh.

B: $\quad$ Dickes Perg. Lagen: $(\mathrm{IV}+1)^{9}+4 \cdot \mathrm{IV}^{41}+(\mathrm{III}-1)^{46}$. Am Beginn fehlt eine Lage (vermutlich Quaternio). Bl. 1 eingehängtes Einzelbl., Gegenfalz zu Bl. 1 zw. erster und zweiter Lage. Gegenbl. zu Bl. 42 herausgeschnitten (Textverlust). Am rechten unteren Blattrand Lagenfoliierung 1-8. Am oberen Blattrand Foliierung 19. Jh. durch die ULB Tirol. Bl. 1 Spuren eines Signakels.

S: $\quad$ Schriftraum 225/255×165/175, von Tintenlinien gerahmt, Bl. 2r zu zehn, Bl. 2v-25v (Canon Missae) zu einheitlich neun Zeilen, Bl. 26r-46v zu einheitlich 14 Zeilen auf Tintenlinierung. Zirkelstiche. Textualis formata (Textura).

A: $\quad$ Rote Auszeichnungsstriche; bei k und Q die Serifen etwas langgezogen, wodurch sie wie Unterstreichungen wirken; rote Benediktionskreuze in quadratischem Rähmchen; ein- und zweizeilige rote Lombarden. Repräsentanten.

B1. 2r Te-igitur-Initiale (insgesamt dreizeilig) mit der Vorzeichnung eines zweizeiligen T, dessen Querbalken auf den mit einem Lilienknauf bekrönten Längsschaft aufgesteckt ist.

B1. 1v ganzseitiges Kanonbild $(245 \times 175)$ : dreifigurige Kreuzigung in qualitätvoller Deckfarbenmalerei. In einem plastisch wirkenden grünen Profilrahmen (Breite $14 \mathrm{~mm}$ ) mit quadratischen, einfach punzierten Goldapplikationen an den Ecken und in der Mitte der Längsseiten, vor karminrotem, mit feinem Goldmuster (gestricheltes Rautengitter mit eingeschriebenen Ästchen) überzogenem Grund Christus an einem hohen TauKreuz mit naturgetreu herausgearbeiteter Maserung, das auf einer verhältnismäßig kleinen, von Knochen umgebenen Felsformation steht. Der Körper des Gekreuzigten anatomisch weitgehend korrekt dargestellt (s. v. a. Armmuskeln, Brustkorb sowie Knie- und Wadenpartie). Die Inkarnate korrespondieren mit dem hellen Pergamentton des Folios (das Lendentuch Christi nur wenig heller), Modellierung und Schattierung mit Weißhöhungen und Grau- bzw. Rosatönen. Während Christus die Augen geschlossen hat, blicken Maria und Johannes, die auf hügeligem, in weichem Grün koloriertem Wiesenboden (mit tw. größeren Pflanzen) stehen und sich dem Kreuz zuwenden, zu Boden. Der Gekreuzigte und Johannes mit fein gewellten Haaren; alle drei Figuren mit Goldnimben (Blattgold auf rosafarbenem Bolus, leicht beschädigt, mit Punktlinien radial punziert), bei Christus zusätzlich mit blauem Kreuz; charakteristisch die relativ langen, aber rundlich endenden Nasen. Maria hat beide Hände vor die Brust erhoben; Johannes, dessen Hände noch zarter gestaltet sind als die der Gottesmutter, hält seine Rechte an die Wange. Gekonnt herausgearbeitete Draperie durch ausgewogene Knickfalten und Konturlinien, Schattierungen in der Lokalfarbe und wenige Schraffuren. Verschmutzungen im unteren Bereich des Marienmantels, der Beine Christi und auf dem Basisfelsen. Keine Rankenrahmung, lediglich die goldenen Rahmenbeschläge jeweils mit zartem Floraldekor in Karminrosa besetzt: an den Längsseiten Dreiblätter und an den Ecken je zwei kurze, überkreuzte Ästchen mit erkennbaren Anschnitten.

Die unfigürlichen Anteile des Kanonblatts dürften von einem anderen Illuminator geschaffen worden sein als die Figuren. Während sich für diese Hand keine Entsprechungen in der Neustifter Buchmalerei nachweisen lassen, finden sich für den Ornamentalgrund der Kreuzigung und den Blättchendekor des Rahmens Vergleichsbeispiele im Epistolar des Cod. 196 (figürliche Initiale Bl. 5v dat. 1482): Bl. 14r der feine Goldästchendekor auf dem Initialfeldgrund, B1. 12v das angeschnittene, neben der Initiale in die Ranke eingehängte Ästchen und B1. 17r (links unten) die Gestaltung der rosafarbenen Rankenblättchen.

S. R.

E: $\quad$ Gotischer Einband: blau gefärbtes Wildleder über Holz mit Blindlinien. Neustift (?), Ende 15. Jh.

Leder stark abgerieben, fleckig, Holz tw. freiliegend. Zwei Schichten: tw. freiliegendes Schweinsleder, darüber blau gefärbtes Wildleder mit Blindlinien. VD und HD gleich: Gliederung durch jeweils dreifache Streicheisenlinien: ein von solchen Linien begrenzter Rahmen, Mittelfeld horizontal, vertikal und diagonal unterteilt, zudem Raute eingeschrieben. Spuren von je fünf runden Beschlägen. Zwei Leder-Metall-Schließen. Kanten gerade. Rücken: unten tw. freiliegend, Leder beschädigt, fünf Doppelbünde, jeweils durch einfache Streicheisenlinien betont. Im ersten Feld aufgeklebtes Papierschild $M$ : S:, im zweiten aufgeklebtes Papierschild, beschädigt Fragmenta Varia Miss[ale], im dritten und vierten Signaturschilder (s. bei G). Oberes Kapital mit naturfarbenem Zwirn umstochen, unteres Kapital fehlt. Spiegel Pap. 15. Jh. Am Spiegel des VD Exlibris, Signaturen und Bleistiftnotiz (s. bei G), Spiegel des HD leer.

G: $\quad$ Am Spiegel des VD Exlibris der Stiftsbibl. Neustift 18. Jh. und alte Signaturen der ULB Tirol II $\overline{1}$ (korr. aus 2) A 10 (Bleistift) und 252 (Tinte) sowie Bleistiftnotiz (Vide Grundzettel). Am Rücken Reste des gelben 
Signaturschilds der ULB Tirol. 1809 anlässlich der vorübergehenden Aufhebung des Klosters Neustift der ULB Tirol übergeben. Bl. 2r Stempel der ULB Tirol 19. Jh. 1921 aufgrund des Friedensvertrages von St. Germain an den italienischen Staat abgegeben und von diesem 1929 dem Kloster Neustift als Dauerleihgabe übergeben. Bl. 2r Stempel der Soprintendenza Tridentina 20. Jh. Am Rücken Neustifter Signaturschild 20. Jh. 252.

L: $\quad$ Wilhelm I 110. - Hermann 173, Nr. 184. - Katalog ULB Tirol III 204, 335. - Baroffio 324, Nr. 16717.

ORDINARIUM MISSAE.

Enthält Canon Missae bis Schluss der Messe, Gebete nach der Messe, Präfationen, Votivmessen und Totenmessen. Beginn (Messtexte bis Canon missae) aufgrund des Verlustes einer Lage nicht mehr enthalten. Aufgrund des zeitgenössischen Einbandes ist anzunehmen, dass es sich nicht um ein heute unvollständiges Vollmissale handelt, sondern um ein Teilmissale (Ordinarium missae), dessen Beginn (s. bei B) verloren ist. Ohne Notation.

(1r) leer.

(1v) ganzseitiges Kanonbild (s. bei A).

(2r-21v) CANON MisSAe.

(2r) Von Te igitur bis Doxologie. (12v) Pater noster. (13v) Libera nos. (14v) Pax dni. (15r) Agnus Dei. (15r-21v) Kommuniongebete. (21v) Gebet Post missam. Placeat tibi sancta trinitas hoc obsequium servitutis mee et presta ut hoc sacrificium ...

(22v) Schlussevangelium (nur Rubrik und Textbeginn) und Segen.

(22v-24v) OrATIONES POST MISSAM (vgl. Jungmann II 571-572).

Ablegung der Paramente mit Verweis auf Canticum trium puerorum und Textbeginn von Ps 150, Canticum Simeonis (Lc 2,29-32) und Vermerk (rot) Per totum cum gloria Patri antiphona (schwarz) Trium puerorum ut supra, Kyrie, Pater noster, fünf Versikel, zwei Gebete: (24r) Deus qui tribus pueris mitigasti flammas ignium ... und (24r) Acciones nostras quesumus domine aspirando preveni et adiuvando prosequere ... sowie Vermerk (24v) (rot) Tunc flectis genibus dic (schwarz) Laus patri glorie laus eius filio laus quoque sancto spiritui sit per eum Amen.

(24v) GLORIA.

(25v) CREDO.

(27r-32v) Praefationes und Communicantes.

(27r) De nativitate domini. - (27v) De epyphanie (!) domini. - (28r) In Quadragesima. - (28v) In cena domini. - (29v) De resurreccione domini. - (30r) De ascensione domini. - (30v) In festo penthecosten. - (31v) De s. trinitate. - (32r) De sancta cruce. - (32v) De beata virgine. - (32v) De apostolis. (33r) Praefacio cotidiana.

(33v-42r) Missae votivae.

(33v) In festo penthecosten. Mit Sequenz (AH 53, Nr. 70). - (38r) De sancta cruce. - (40r) Sabbato de commemoracione b. Marie. Mit Sequenz (AH 54, Nr. 218).

(42r-46v) MISSAE PRO DEFUNCTIS, unvollständig.

(42r) Officium pro defunctis. - (44v) Pro elemosinariis. - (45r) Pro famulis et famulabus. - (46r) Pro fidelibus defunctis. - (46v) Pro sacerdote. Unvollständig aufgrund des Verlustes des letzten Blattes der letzten Lage. Schließt mit Beginn der Secreta. Expl. mut.: Suscipe quesumus [

W. N. 
Cod. 253

\section{GODEFRIDUS DE TRANO. TANCREDUS BONONIENSIS. RAIMUNDUS DE PENNAFORTE}

Perg. 88 Bl. $380 \times 265$. Oberitalien (Bologna?), 1. H. 14. Jh.

B: $\quad$ Drei Teile: I (1-82), II (83-84), III (85-88). Am oberen Blattrand Foliierung 19. Jh. durch die ULB Tirol.

E: $\quad$ Gotischer Einband: braunes Leder über Holz mit Blindlinien. Oberitalien (Bologna?), 15. Jh.

Leder stark abgeschabt, tw. beschädigt, darunter liegendes Textil sichtbar. VD und HD gleich: aus dreifachen Streicheisenlinien gebildeter Rahmen. Mittelfeld durch ebensolche Linie diagonal unterteilt. Spuren eines runden Mittelbeschlags sowie von vier Eckbeschlägen (Viertelkreis). Spuren von vier Kurzriemen-LederMetall-Schließen (oben, unten, seitlich), Nägel erhalten. Am VD oben Titelaufschrift am Leder Summa Goffridi. Am HD Aufschrift E I [...]. Kanten gerade. Rücken: vier Doppelbünde. Im ersten Feld Papierschild M S, im zweiten Ius Canonicum Glossarum, im dritten Signaturschild (s. bei G). Kapitale mit naturfarbenem Spagat umstochen. Spiegel des VD und HD mit Textil überzogen, am Spiegel des VD Exlibris (s. bei G).

G: $\quad$ Die Hs. dürfte wohl zu jenen vier Hs. kirchenrechtlichen Inhalts zählen, die 1353 als Geschenk des Herrn Berthold, Hospitaler zu Brixen, in den Besitz des Stiftes gelangten (vgl. Neustift, Stiftsarchiv, WW 59. Mairhofer 364-365; Peintner, Stiftsbibliothek 118). Bl. 1r Besitzvermerk Ad Collegium Neocell. Am Spiegel des VD Exlibris der Stiftsbibl. Neustift 18. Jh. 1809 anlässlich der vorübergehenden Aufhebung des Klosters Neustift der ULB Tirol übergeben. Bl. 1r alte Signaturen der ULB Tirol II $\overline{1}$ A 11 (Bleistift) und 253/(I) (Tinte, Bleistift) sowie Bleistiftnotizen (Wird behandelt u. katalogisiert) und (Vide Grundzettel). Am Rücken gelbes Signaturschild der ULB Tirol 253/(I). Bl. 1r Stempel der ULB Tirol 19. Jh. 1921 aufgrund des Friedensvertrages von St. Germain an den italienischen Staat abgegeben und von diesem 1929 dem Kloster Neustift als Dauerleihgabe überlassen. Bl. 1r Stempel der Soprintendenza Tridentina 20. Jh.

L: $\quad$ Schulte GQ I 203, II 89. - Wilhelm I 136. - Wretschko-Sprung 17-18. - Dolezalek I o. S. - FurtenbachKalb 20. - Katalog ULB Tirol III 204, 335.

$$
\text { I (1-82) }
$$

B: Haar- und Fleischseite deutlich unterscheidbar, unregelmäßig beschnitten (mit Fehlstellen). B1. 82 von kleinerem Format $(380 \times 145 / 150)$. Lagen: 10.IV ${ }^{80}+I^{82}$. Lagenreklamanten.

S: $\quad$ Schriftraum $290 \times 205$. Zwei Spalten, von feinen, bisweilen kaum sichtbaren Bleistift- bzw. Blindlinien begrenzt, zu 59 Zeilen auf Bleistift- bzw. Blindlinierung. Zirkelstiche. Textualis. Am Blattrand Nachträge, Korrekturen und Bemerkungen von verschiedenen Händen.

A: Rote Unter- und Durchstreichungen sowie Überschriften. Zeigehände. Abwechselnd blaue und rote Paragraphzeichen sowie zwei- und dreizeilige Lombarden mit einfachem Fleuronnée und Fadenausläuferbündeln in der Gegenfarbe. Repräsentanten. Am Blattrand diverse Verweiszeichen. Am oberen Blattrand blaurote Buchbezeichnung. Bl.62v und 63r schwarze Federzeichnungen: Arbor consanguinitatis und Arbor affinitatis, jeweils mit Zierrahmen.

(1r, am oberen Blattrand) Ave Maria gratia plena dominus tecum.

1 (1ra-82ra) Godefridus 〈DE Trano〉: Summa super rubricis Decretalium (Druck: u. a. GW 10949. Stegmüller RS Nr. 245. Stegmüller RS [1937] Nr. 904).

Tit. (18. Jh.): Summa Gaffridi. De Regulis Juris.

(1ra) Prolog. Inc.: [G]losarum diversitas intelligentiam textus nec numquam obtenebrat ... Expl.: ... aliorum tales alios esse volo intellectores meorum.

(1ra) Text. Inc.: Post proemium in quo breviter edocemur ... - Expl.: ... et propterea malui repeti quam deesse.

(62v-63r) Zwei Federzeichnungen: Arbor consanguinitatis und Arbor affinitatis.

(82r) Schlussschrift: Explicit liber Deo gratia. Ave Maria gratia plena dominus tecum. Benedicta tu in mulieribus et benedictus fructus ventris tui. Gloria sit Christo per infinita secula seculorum Amen.

(82v) leer.

Lit.: Schulte GQ II 89-91. 
B: Zwei Einzelbl.: Lage: $1^{83}+1^{84}$. Fragmente, einst möglicherweise als Spiegel aufgeklebt (Rostspuren, Klebereste), Faltung und Bindung (quer zum heutigen Schriftraum) ersichtlich. Bl. 83 beschnitten $(340 \times 160)$, heute lose. Bl. $84(355 \times 210)$ beinahe lose, mit Papierstreifen oben und unten auf Falz aufgeklebt. Bl. 84ra bzw. vc beschnitten.

S: $\quad$ Erhaltener Schriftraum $165 \times 65$. Drei Spalten, von Blindlinien gerahmt, zu 46 Zeilen auf Blindlinierung. Textualis.

2 (83ra und 84ra-c) TANCREDUS 〈BonONIENSIS〉: Ordo iudicarius, unvollständig.

2.1 (83ra) Tancredus 〈Bononiensis〉: Ordo iudicarius, unvollständig: Pars 4, tit. 6, § 5-7 (Forts. von Bl. 84ra-c, ohne Textverlust) (Ed.: F. Bergmann, Pillii, Tancredi, Gratiae libri de iudiciorum ordine. Göttingen 1842, 312-314).

Inc. mut.: ]ma. sed etsi § quocumque quomodo intra diem illam poterit probare lesionem ... Expl.: ... ad rudium instructionem breviter dixisse sufficiant Amen.

Schlussschrift: Explicit liber Tancredi.

(83rb, quer zum Schriftraum) Interesse quinque sunt dampnum lucrum amissum.

(83v) FEDERPRoBEn: Ista est summa domini Acrolini ...

3 (83v) Urkundenvorlage (anonymisiert): Inc.: [V]enerabilibus in Christo patribus dominis Dei gratia archiepiscopis et episcopis sedis apostolice gratiam et communionem habentibus ... Expl.: ... munitas dant etc.

2.2 (84ra-c) Tancredus «Bononiensis»: Ordo iudicarius, unvollständig: Pars 4, tit. 5, § 14-tit. 6, § 5 (Forts. von Bl. 84va-c, ohne Textverlust) (Ed. Bergmann 300-312)

Inc. mut.: cor]rigebatur quod in ecclesia sua nolebat facere residentiam ... - Expl. mut.: ... ad restitutionem optinendam ut expresse dicit 1 illa ff ex qui cau. [

(84va-c) Pars 4, tit. 5, § 3-14 (Ed. Bergmann 288-300).

Inc. mut.: ] sibi adiudicate ut extra de sentencia et re iu. c. Bertoldus in fi. Si autem personali ... Expl. mut.: ... tenet eius appellacio ut extra de ap. pervenit de illo clerico qu[i Lit.: Schulte GQ I 203-204 und II 558; Kuttner 431-433.

$$
\text { III (85-88) }
$$

B: $\quad$ Perg. fleckig, Haar- und Fleischseite deutlich unterscheidbar, Bl. 86 Loch. Lage: II ${ }^{88}$.

S: $\quad$ Schriftraum $165 \times 65$. Drei Spalten, von Bleistiftlinien gerahmt, zu 78 bzw. 80 Zeilen auf Bleistiftlinierung. Zirkelstiche. Textualis.

A: $\quad$ Bl. 85rc-87rc rote Überschriften. Repräsentanten am Blattrand.

4 (85ra-88vc) 〈RAimundus de Pennaforte〉: Summa de matrimonio, unvollständig (Ed.: X. Ochoa, A. Diez [Universa Bibliotheca iuris I C]. Roma 1978, 901-998. - Kaeppeli Nr. 3408. Bloomfield Nr. 4943 und Bloomfield, Suppl. Nr. 4943).

(85ra-88rc) Forts. des Textes von Bl. 88rc-vc, ohne Textverlust (Tit. 2,7-25 und Conclusio). Inc. mut.: ] indicas Hermanum VII q. I Quamvis triste et C. de codicillis nec codicillos quod vero supra dictum est ... - Expl.. ... sed benigno corrigat et emmendet (= Schluss).

Schlussschrift: Explicit summa de matrimonio.

(88rc-vc) Textbeginn (Prooemium und Tit. 1-2,7):

Tit.: Incipit summa de matrimoniis. - Inc.: Quoniam frequenter in foro penitentiali dubitationes circa matrimonium ... - Expl. mut.: ... omnia que alii possunt ut est ar. III q. VIIII Indicas Hermanum. Require superius Indicas Hermanum per [...] cartulas et ibi invenies [

Darunter Schlussschrift (fälschlich): Explicit summa matrimonialis. 


\section{Cod. 282}

\section{BERNARDUS CLARAEVALLENSIS}

Perg. I, 25, I* Bl. $240 \times 165$. Entstehungsort unbestimmt, 2. H. 12. Jh.

B: $\quad$ Perg. löchrig, Nahtspuren. Lagen: (I-1) ${ }^{\mathrm{I}}$ (Vorsatzbl., Pap. 18. Jh.) $+2 . \mathrm{IV}^{16}+(1+\mathrm{IV})^{25}+(\mathrm{I}-1)^{\mathrm{I}}$ (Nachsatzbl., Pap. 18. Jh.). Gegenbl. zum Vor- bzw. Nachsatzbl. als Spiegel auf dem VD bzw. HD aufgeklebt. Am oberen Blattrand mittig zeitgenössische Foliierung in arabischen Ziffern 89-113. Vor erster Lage Textverlust. Am oberen Blattrand Foliierung 19. Jh. durch die ULB Tirol 1-25 (hier berücksichtigt). Bl. 15r neuzeitliches oranges Papiersignakel der ULB Tirol.

S: $\quad$ Schriftraum $170 \times 105$, von feinen, tw. kaum sichtbaren, seitlich zweifachen Bleistiftlinien gerahmt, zu 34 Zeilen auf Bleistiftlinierung. Zirkelstiche. Karolingisch-gotische Mischschrift. Bl. 9v und 20v Randglossen von späterer Hand, Bl. 21r Federprobe.

A: $\quad$ Rote Auszeichnungsstriche (nur B1. 1r), Über- und Schlussschriften. Vereinzelt Randzeichen. Zwei- bis fünfzeilige rote bzw. grüne Lombarden, tw. mit einfachem Dekor in der Gegenfarbe. Bl. 12r rote Satzmajuskel in Lombardenform.

E: $\quad$ Neuzeitlicher Bibliothekseinband: schwarz gesprenkeltes braunes Pap. über Pappe. Neustift, 2. H. 18. Jh. VD und HD beschädigt. Ecken mit braunem Leder verstärkt. Rücken: braunes Leder, drei einfache Bünde, von Goldbordüren gesäumt. Im ersten Feld Golddruck $M$ : $S$ : und Signaturschild (s. bei G), im zweiten und dritten Golddruck BERNARD. CLAREVALL. in Goldrahmung, im vierten Leder abgeschabt, urspr. wohl Schild aufgeklebt. Schnitt rot gesprenkelt. Spiegel Pap. 18. Jh. Am Spiegel des VD Exlibris, Signaturen und Bleistiftnotiz (s. bei G). Spiegel des HD leer.

G: Zeitpunkt und Art der Erwerbung durch Neustift unbekannt. Am Spiegel des VD Exlibris der Stiftsbibl. Neustift 18. Jh. 1809 anlässlich der vorübergehenden Aufhebung des Klosters Neustift der ULB Tirol übergeben. Am Spiegel des VD alte Signaturen der ULB Tirol II 1 C C 1 2. Ser. (Bleistift) und 282/1 (Tinte, Bleistift) sowie Bleistiftnotiz (Vide Grundzettel). Am Rücken gelbes Signaturschild der ULB Tirol 282. Bl. 1r Stempel der ULB Tirol 19. Jh. 1921 aufgrund des Friedensvertrages von St. Germain an den italienischen Staat abgegeben und von diesem 1929 dem Kloster Neustift als Dauerleihgabe überlassen. Bl. 1r Stempel der Soprintendenza Tridentina 20. Jh.

L: $\quad$ Wilhelm I 135. - Leclercq-Rochais III 7, 159. - BGOC, Bernard Nr. 4193. - E. Manning, H. Rochais, Bibliographie Générale de l’Ordre Cistercien. Saint Bernard. Documentation Cistercienne 21, fasc. hors série 10-11-12. Rochefort 1982, Nr. 4193. - Katalog ULB Tirol III 279, 335.

(Ir-v) leer.

1 (1r) Bernardus Claraevallensis: De gratia et libero arbitrio, unvollständig: cap. 14,51 (PL 182, 1029A-1030A. Ed. Leclercq-Rochais III 203. - BGOC, Bernard Nr. 4193).

(1r) Inc. mut.: ] contempnens suam velit statuere iusticie domini non sit subiectus ...

Schlussschrift: Explicit liber domini Bernhardi Clarevallensis abbatis de gratia et libero arbitrio.

2 (1r-15r) Bernardus Claraevallensis: De gradibus humilitatis et superbiae (PL 182, 939-972C. Ed. Leclercq-Rochais III 15-59. - BGOC, Bernard Nr. 4193)

3 (15r-25v) Bernardus Claraevallensis: Epistola 42 (ad Henricum Senonensem archiepiscopum: De moribus et officio episcoporum) (PL 182, 809A-834A. Ed. Leclercq-Rochais VII 100-131. BGOC, Bernard Nr. 4193).

Tit.: Epistola domni (!) Bernhardi abbatis Clarevalensis ad H. Senonensem archiepiscopum. $\left(I^{*} \mathrm{r}-\mathrm{v}\right)$ leer. 


\title{
Cod. 293
}

\section{VITA BEATI HARTMANNI EPISCOPI (BRIXINENSIS)}

\author{
Perg. 23, II* Bl. $260 \times 170$. Neustift, 12./13. Jh.
}

B: Dickes, fleckiges, tw. löchriges, an den Rändern unregelmäßig beschnittenes Perg., vereinzelt Nahtspuren. Bl. 22 untere Blatthälfte nach $15 \mathrm{~cm}$ weggeschnitten, Bl. 23 an dieser Stelle eingeschnitten. Lagen: $\mathrm{IV}^{8}+$ $(\mathrm{IV}-1+1)^{16}+(\mathrm{IV}-1)^{23}+\mathrm{II}^{\mathrm{I}^{*}}$ (Nachsatzbl. Pap.). Gegenbl. zu Bl. 11 herausgeschnitten und durch eingefügtes Blatt ersetzt (gleicher Schreiber), jetzt tw. lose (= Bl. 14). Gegenbl. zu Bl. 18 herausgeschnitten (ohne Textverlust). Am oberen Blattrand Foliierung 19. Jh. durch die ULB Tirol.

S: $\quad$ Bl. 1r-21v Schriftraum 200/210× 130, von kaum wahrnehmbaren Tintenlinien gerahmt, zu meist 27 Zeilen auf Blindlinierung. Zirkelstiche. Karolingisch-gotische Mischschrift 12. Jh. Bl. 15v Z. 19-27 möglicherweise von anderer Hand, vgl. Sparber 1940, 10. Überschrift Bl. 1r in Textualis 13. Jh., Ergänzungen am Rand von Hand des Schreibers, Randnotizen in Textualis 13. Jh. und Notula Mitte 15. Jh. (gleiche Hand wie die Zusätze in Innsbruck, ULB Tirol, Cod. 960, dort Schreiber C, vermutlich der Neustifter Stiftschronist Johannes Librarius [Kellner], s. W. Neuhauser, Beschreibung und Geschichte der Handschrift, in: E. Thurnher, W. Neuhauser (Hrsg.), Die Neustifter-Innsbrucker Spielhandschrift von 1391, Cod. 960 der Universitätsbibliothek Innsbruck [Litterae 40]. Göppingen 1975, 11). Bl. 21v Ergänzung am Schluss in Notula 15. Jh. Bl. 22 und 23 Schriftraum und Zeilenzahl wechselnd. Textualis 13. Jh. und Bastarda 15. Jh.

A: Bl. 1r-21v rote Auszeichnungsstriche, Unterstreichungen, Satzmajuskeln in Lombardenform, zwei- bzw. dreizeilige Lombarden. B1. 1r fünfzeilige rot-blaue Initiale $F$ mit blauer Füllung, weißen Aussparungen und kurzen blattförmigen rot-blauen Ausläufern. B1. 22 und 23 rote Überschriften, Unterstreichungen, Auszeichnungsstriche, Paragraphzeichen, Bl. 23r zweizeilige Lombarde $E$.

E: $\quad$ Makulatureinband: Perg. über Pappe, Neustift, 15. (?) Jh.

VD, Rücken und HD von durchgehendem Perg.-Doppelbl. überzogen. Fragment eines Antiphonale, erhalten Ausschnitte zum Ostersonntag: sieben rote Vierliniensysteme mit gotischer Choralnotation und Textzeilen, Textualis formata (Textura) 14. Jh. Rote Überschrift, Initiale $A$ und zwei Cadellen mit einfachem Fleuronnée. Am HD Stempel der Soprintendenza Tridentina. Spiegel Pap. 15 Jh. Am Spiegel des VD Exlibris, Signaturen und Bleistiftvermerk (s. bei G), Spiegel des HD leer.

G: $\quad$ Bl. 23v Besitzvermerk 15. Jh. Iste liber est monasterii s. Marie virginis in Novacella. Am Spiegel des VD Exlibris der Stiftsbibl. Neustift 18. Jh. 1809 anlässlich der vorübergehenden Aufhebung des Klosters Neustift der ULB Tirol übergeben. Am Spiegel des VD alte Signaturen der ULB Tirol II $\overline{6} B$ (?) [...] (Tinte, radiert), II $\overline{1}$ C 12 S. 2 (Bleistift) und 293 (Tinte) sowie Bleistiftvermerk (Vide Grundzettel). 1921 aufgrund des Friedensvertrages von St. Germain an den italienischen Staat abgetreten und von diesem 1929 dem Kloster Neustift als Dauerleihgabe überlassen. Am HD Stempel der Soprintendenza Tridentina 20. Jh.

L: $\quad$ H. Pez, Scriptores rerum Austriacarum I. Lipsiae 1721, 495-518 (= erste Ed., ohne Nennung der Sign.). Ph. N. Puell, Heiligmäßiger Lebenswandel des seligen Hartmanni. Brixen 1768, 180 Anm. 2 (ohne Nennung der Sign.). - H. R. v. Zeissberg, Zur Kritik der Vita B. Hartmanni episcopi Brixinensis. Archiv für österreichische Geschichte 56 (1878) 454 (mit Anführung der alten Sign. der ULB Tirol II 1 C 12 S. 2). Wilhelm I 135. - A. Sparber, Der selige Hartmann. Brixen 1911, 87 (ohne Nennung der Sign.). - Sparber 225-226. - A. Sparber, Vita beati Hartmanni episcopi Brixinensis. Einleitung und Ausgabe. Brixen (als Manuskript gedruckt) 1939. - Vita beati Hartmanni episcopi Brixinensis. Eingeleitet und ed. von A. Sparber (Schlern-Schriften 46). Innsbruck 1940. - A. Sparber, Leben und Wirken des seligen Hartmann, Bischof von Brixen (1140-1164). Wien 1957. - A. Lhotsky, Quellenkunde zur mittelalterlichen Geschichte Österreichs (MIÖG Erg.-Bd. 19). Graz, Köln 1963, 207. - Neuhauser, Neustift 81. - Steer 36. - Katalog ULB Tirol III 309, 336. - G. Kompatscher, Überblick, in: M. Korenjak, F. Schaffenrath, L. Šubarić, K. Töchterle (Hrsg.), Tyrolis Latina. Geschichte der lateinischen Literatur in Tirol I: Von den Anfängen bis zur Gründung der Universität Innsbruck. Wien, Köln, Weimar 2012, 31-52, hier 37. - Baroffio 324, Nr. 16718. - S. C. Schmölz, Die liturgische Verehrung des seligen Hartmann von Brixen, Dipl.-Arb. St. Pölten 2012, 88 („Hs. A“, ohne Nennung der Sign.).

1 (1r-21v) Vita beati Hartmanni episcopi (Brixinensis), Rec. I (Ed. Pez 495-518 [= erste Ed.]. Sparber 1940, 37-62. Schmölz 95-117).

Tit.: Prohemium in vitam beati Hartmanni episcopi. - Inc.: Fecit Moyses labrum eneum de speculis mulierum quem plenum aqua posuit ... - Expl.: ... cum ceteris sanctis ac fidelibus Christi 
dignam reverentiam recipiat. Bl. 21v nach recipiat am Schluss Ergänzung (15. Jh.) cui sit gloria et honor per infinita secula seculorum Amen.

Cod. 293 in der Überlieferung Hs. A der Rec. I. Zur Überlieferung s. Sparber (1939) bzw. (1940) 13-16. Handschriften: Hs. A (Zeissberg: A) = Neustift, Stiftsbibl., Cod. 293 (aus Neustift); Hs. B (Zeissberg: B) = Innsbruck, ULB Tirol, Cod. 216 (aus Schnals); Hs. C (Zeissberg: F) = München, BSB, Clm 11723 (aus Polling); Hs. D (Zeissberg: H) = Ed. Pez (nach einer jetzt verschollenen Hs. des Chorherrenstiftes Dürnstein); Hs. E = Klosterneuburg, Stiftsbibl., CCl 1241 (vgl. auch Schmölz 88) sowie fünf von Roschmann veranlasste Abschriften $\mathrm{Fa}-\mathrm{Fe}$, welche jeweils alle drei Viten enthalten (eine sechste von Roschmann veranlasste Hs. = nach Sparber Ff [= Klosterneuburg, Stiftsarchiv, K 105] enthält nur die Vita III). Drucke: Erstdruck in Pez 495-518, weitere Drucke s. Sparber 1911, 88 und Sparber 1939 bzw. 1940, 7-9. Zu den drei Hartmann-Viten: Vita I (Rec. I): um 1200, Verfasser wohl ein gewisser Hermannus (s. u.); Vita II (Rec. II): kürzere Fassung, unbekannter Chorherr in Neustift, 14. Jh.; Vita III: Abt Amandus Pachler von St. Peter in Salzburg, 1668, s. Sparber 1911, 86-88, Sparber 1939 bzw. 1940, 3-9.

Zur Verfasserfrage vgl. Sparber 1940, 25-33: Entstehung der Handschrift nicht wie von Pez angenommen in Klosterneuburg, sondern in Neustift (oder Brixen), so Puell 180 Anm. 2. Als Verfasser von Puell, Anhang, 5 ein Hermannus, Verwalter des von Hartmann gegründeten Spitals in Brixen, 1200-1210 Propst von Neustift angenommen, nach Sparber 1940, 26-28 käme evtl. Konrad von Rodank in Frage, ca. 1180-1200 Propst von Neustift, 1200-1216 Bischof von Brixen, 1957 schließt sich Sparber (10 Anm. 5) jedoch der Meinung von Puell an. Cod. 293 nach Sparber 1940, 13 nicht das Original, sondern eine dem Original zeitlich nahestehende Abschrift.

2 (22r) Notiz aus Kloster Baumburg (Oberbayern) über die Weihe der dortigen Kirche (15. Jh.) (Ed. Zeissberg 454-455. MGH Scriptores XVII 438).

Tit.: In monasterio Pawmburgensi Salczburgensis dyocesis ordinis sancti Augustini Canonicorum regularium sic scriptum invenitur. - Inc.: In nomine sancte et individue trinitatis et in honore sancte Marie perpetue virginis et sancte Margarethe virginis et martiris omniumque celestium virtutum consecrata est hec ecclesia anno dominice incarnacionis millesimo centesimo quinquagesimo sexto ... - Expl.. ... et a patre sanctissimo Brixinensis ecclesie Hartmanno etc.

3 (22r) Notiz Über die Weihe der Kirche zu Seckau (13. Jh.) (Ed. Zeissberg 455). Schrift nach Zeissberg 13. Jh., nach Sparber 1940, 10 eher 16. oder 17. Jh. mit Nachahmung mittelalterlicher Schreibgewohnheiten.

Inc.: Consecrata est Seccoviensis ecclesia a venerabili in Christo patre et domino Hartmanno Brixinensi episcopo circa annos (!) domini $M^{\circ} C^{o} X L^{o} \ldots$ - Expl.: ... proxima dominica post nativitatis Marie que est patrona eiusdem ecclesie.

(22v) leer.

4 (23r) Notiz Über die Verwandtschaft der hl. Maria (13. Jh.) (Hauréau II 236va).

Inc.: Ex testimoniis quatuor evangeliorum et exemplo Ieronimi contra Eheluinum (recte: Helvidium) Sancta Maria mater domini et Maria mater Iacobi Alphei et Ioseph et mater filiorum Zebedei scilicet maioris Iacobi et Iohannis evangeliste tres sorores fuerunt ... - Expl.: ... Tres ergo viros Anna habuit Ioachim, Cleopam et Salome (!).

Vgl. Leipzig, UB, Ms. 807, Bl. 166v-167r; Paris, BN, Ms. lat. 3751A, Bl. 28r. Zum Expl. vgl. Iacobus de Voragine, Legenda aurea, cap. 131 (Ed. Graesse 586).

5 (23r-v) 34 Verse ÜBer drei Heilige namens Joseph (15. Jh., von gleicher Hand wie Nr. 2).

Tit.: Versus de meritis et vita trium sanctorum nomine Ioseph. - Inc.: Omnis homo certis sciat ex causis et apertis / quod tres sunt sancti quos Ioseph nomine legi ... - Expl.. ... Illi donetur per eos quod sanctificetur. 
(23v) Besitzvermerk (von gleicher Hand wie Nr. 2 und 5) (s. bei G).

(23v) untere Blatthälfte, quer ANRUfung AN DEN HL. HarTmann: In nomine domini Iesu Christi Amen. O beate Hartmane (!) ora pro nobis ad dominum.

(23v) Darunter radierter Besitzvermerk. Salve (?) ... ego Chunradus (?) ... Brix. (?) et de Mulbach (?) ... nobilis ...

$\left(I^{*} \mathrm{r}\right)$ leer bis auf Abklatsch des Besitzvermerks auf Bl. 23v.

$\left(I^{*} \mathrm{v}-\mathrm{II}{ }^{*} \mathrm{v}\right)$ leer.

W. N.

\section{Cod. 308}

\section{THEOLOGISCHE SAMMELHANDSCHRIFT}

Perg. I, 228, I* B1. $220 \times 150$. Süddeutsch-österreichischer Raum, 14. Jh.

B: $\quad$ Perg., Haar- und Fleischseite deutlich unterscheidbar, vereinzelt verschmutzt, insbes. am Lagenende bzw. -anfang, vereinzelt kleine Löcher und Risse, einzelne Blätter zum unteren Blattrand hin unregelmäßig. Lagen: (I-1) (Vorsatzbl., Pap. 18. Jh.) $+2 . \mathrm{IV}^{16}+(\mathrm{IV}-1)^{23}+\mathrm{IV}^{31}+(\mathrm{IV}-1)^{38}+2 . \mathrm{IV}^{54}+(\mathrm{IV}-1)^{61}+\mathrm{IV}^{69}+\mathrm{III}^{75}$ $+15 . I^{195}+(\mathrm{IV}-1)^{202}+3 . \mathrm{IV}^{226}+\mathrm{I}^{228}+(\mathrm{I}-1)^{\mathrm{I}^{* *}}$ (Nachsatzbl., Pap. 18. Jh.). Gegenbl. zum Vor- bzw. Nachsatzbl. als Spiegel auf dem VD bzw. HD aufgeklebt. Gegenbl. zu Bl. 18, 36, 59 und 196 herausgeschnitten (ohne Textverlust). Lage 1-26 am Lagenende Kustoden in römischen Zahlen; ab Lage 27 (Bl. 203ff.) Reklamanten, gerahmt, be- bzw. weggeschnitten. Am oberen Blattrand Foliierung 19. Jh. durch die ULB Tirol. Bl. 110 und 228 Spuren von ehem. Signakeln.

S: $\quad$ Schriftraum 170/175 ×110. Zwei Spalten, von Tintenlinien gerahmt, zu 33-35 Zeilen auf Tintenlinierung. Zirkelstiche. Textualis. Vereinzelt Ergänzungen von derselben und von anderer zeitgenössischer Hand. Bl. 46rb, 49rb (möglicherweise J. Resch, 1716-1782, Priester und Historiker) und 219rb neuzeitliche Notizen von verschiedenen Händen.

A: Rote Auszeichnungsstriche, Trennstriche und -punkte, Unter- und Durchstreichungen, Überschriften. Bl. 1r-201v am oberen Blattrand Angabe der jeweiligen Distinctio (auf dem Verso jeweils D, auf dem Recto römische Zahl, beginnend bei IIII) in Rot, tw. von kleinen roten Kreisen gerahmt. Ab Bl. 210ra auch rote Paragraphzeichen und am Blattrand vereinzelt rote Verweiszeichen sowie Zählung der Abschnitte in roten arabischen Ziffern. In der ersten Zeile sehr selten Oberlängen gedehnt. Am Beginn jeder Distinctio (s. Inhalt) jeweils Register mit meist ein-, selten zwei- bzw. dreizeiligen roten Lombarden und Seitenangaben in roten römischen Zahlen. Zwei- bis sechszeilige rote Lombarden, tw. mit Punktverdickungen, tw. mit Ausläufern, Bl. 52r Ausläufer in drei Dornblättern endend. Bl. 13vb sechszeilige blaue Initiale mit einfachem rotem Knospenfleuronée (im Binnenfeld und als Besatz) und Fadenausläufern. B1. 35ra auf dem Bas-de-page Ausläufer mit zwei Medaillons, darin Knospenfleuronnée. B1. 225va und 228rb am unteren Blattrand Repräsentanten für Überschriften erhalten.

E: $\quad$ Neuzeitlicher Bibliothekseinband: schwarz gesprenkeltes braunes Pap. über Pappe. Neustift, 2. H. 18. Jh. Am VD und HD Pap. leicht abgerieben und zerkratzt. Ecken mit braunem Leder verstärkt. Rücken: braunes Leder, vier einfache Bünde, von Goldbordüren gesäumt. Im ersten Feld Golddruck M: S:, im zweiten Golddruck SPECULUM EXEMPLORUM in Goldrahmung, im dritten Signaturschild (s. bei G). Schnitt rot gefärbt. Spiegel Pap. 18. Jh. Am Spiegel des VD Exlibris und Signaturen (s. bei G), Spiegel des HD leer.

G: Zeitpunkt und Art der Erwerbung durch Neustift unbekannt. Am Spiegel des VD Exlibris der Stiftsbibl. Neustift 18. Jh. 1809 anlässlich der vorübergehenden Aufhebung des Klosters Neustift der ULB Tirol übergeben. Am Spiegel des VD alte Signaturen der ULB Tirol II 2 E 1 (?, Tinte, radiert), II 1 D 8 (Bleistift) und 308 (Tinte). Am Rücken gelbes Signaturschild der ULB Tirol 308. Bl. 1r Stempel der ULB Tirol 19. Jh. 1921 aufgrund des Friedensvertrages von St. Germain an den italienischen Staat abgegeben und von diesem 1929 dem Kloster Neustift als Dauerleihgabe überlassen. Bl. 1r Stempel der Soprintendenza Tridentina 20. Jh.

L: $\quad$ Stegmüller RB Nr. 10031. - Peintner, Stiftsbibliothek 118. - Katalog ULB Tirol IV 57, 471. - D. E. Mairhofer, Liber Lacteus. Eine unbeachtete Mirakel- und Exempelsammlung aus dem Zisterzienserkloster Stams [Codicologia 1]. Badenweiler 2009, 22 (ohne Nennung der Sign.). 
$(\mathrm{Ir}-\mathrm{v})$ leer.

1 (1ra-202ra) LACTEUS LIQUOR, unvollständig.

Textbeginn in Dist. 4, cap. 7. Erhalten sind insgesamt 662 Exempla, die direkt im Anschluss um weitere 28 Exempla (s. Nr. 2 und 3) ergänzt sind.

Ein Großteil der Exempla ist in der Legenda Aurea enthalten (hier abgeglichen mit Ed. Graesse; zuletzt ed. von G. P. Maggioni, Iacopo da Varazze. Legenda Aurea [Millenio Medievale 6, Testi 3]. Tavarnuzze [Firenze] 1998). Die vorliegende Sammlung stimmt trotz abweichender Anordnung der einzelnen Exempla vielfach mit Innsbruck, ULB Tirol, Cod. 494 (ausführliche Auflistung: Mairhofer, Liber Lacteus) überein. Da Cod. 308 zahlreiche zusätzliche Exempla enthält, ist er wohl einem anderen Überlieferungsstrang zuzuordnen: Eine sehr große Übereinstimmung besteht mit Heiligenkreuz, Stiftsbibl., Cod. 323, Bl. 55va-214vb (14. Jh.). Das Incipit mutile aus Cod. 308, 1ra findet sich in Heiligenkreuz, Stiftsbibl., Cod. 323 ebenfalls in Dist. 4, cap. 7 (hier Tit.: De eo qui domos sancti Laurencii abstulit). Abweichungen in Heiligenkreuz, Stiftsbibl., Cod. 323 (die Kapitelzahlen beziehen sich auf die Angaben in Cod. 308):

Dist. 4: cap. 41 in Cod. 323 nach cap. 37. - Dist. 5 (in Cod. 323 o. Tit.): Prolog aus Cod. 308, Bl. 12rb fehlt in Cod. 323. Cap. 28-32 in Cod. 323 zw. cap. 35 und 36 eingeschoben. Cap. 66-69 in Cod. 323 Tit. falsch zugeordnet. Cap. 79 und 80 in Cod. 323 ein Exempel (ohne Unterteilung). - Dist. 6 (in Cod. 323 o. Tit.): Cap. 14 und 15 vertauscht. Zw. cap. 110 und 111 in Cod. 323 ein zusätzliches Exempel. Nach dem letzten cap. aus Cod. 308 in Cod. 323, Bl. 135va 12 zusätzliche Exempla. - Dist. 7: Nach dem letzten Kapitel aus Cod. 308 in Cod. 323, Bl. 160vb ein zusätzliches Exempel. - Dist. 8: In Cod. 323, Bl. 162va Prolog. - Dist. 10: In Cod. 323, Bl. 198rb Prolog. Cap. 1-18, 28, 30, 52 und 55 nicht in Cod. 323. In Cod. 323 acht zusätzliche Exempla. Reihenfolge abweichend: sechs Exempla, cap. 27, 29, ein zusätzliches Exempel, cap. 20, 19, 23, 24, 21, 22, 25, 26, 31-45, ein zusätzliches Exempel, cap. 46-50, 53, 51, 54, 56, 57.

Insgesamt enthalten die beiden Hs. von Dist. 4, cap. 7 bis Dist. 10, cap. 57 gleich viele Exempla, allerdings weichen 22 voneinander ab. Nach Dist. 10, cap. 57 folgen in Cod. 308 weitere 176 Exempla (Mairhofer Nr. 390-416 und 447-597). Zahlreiche Exempla auch in Neustift, Stiftsbibl., Cod. 125 enthalten.

Da von Heiligenkreuz, Stiftsbibl., Cod. 323 im Gegensatz zu Innsbruck, ULB Tirol, Cod. 494 keine genaue Aufschlüsselung vorliegt, werden im Folgenden gegebenenfalls die Nummern nach Mairhofer angeführt. Die Titel der einzelnen Exempla werden nur dann zitiert, wenn sie bei Mairhofer nicht aufscheinen oder von den dort angeführten Titeln abweichen. Text bisweilen von Drucken und Editionen abweichend, aber mit Mairhofer übereinstimmend. Incipit und Explicit werden nur dann angeführt, wenn sowohl von Drucken und Editionen als auch von Mairhofer abweichend.

1.1 (1ra-12rb) Dist. 4: Miracula de martyribus.

(1ra-vb) Laurentius: (1ra) Inc. mut.: ] panem invenit sed cum vix ad unius prandii esum tribus personis sufficere videntur Laurentius artifices suos nolens deficere ... (Graesse Nr. 117 [112], 4). (1ra) Graesse Nr. 117 (112), 6. - Mairhofer Nr. 97. (1rb) Graesse Nr. 117 (112), 7 (S. 495, Z. 1132). - Mairhofer Nr. 98. (1vb) Tit.: De illis qui corpus eius viderunt (Graesse Nr. 117 [112], 7 [S. 495, Z. 33-S. 496, Z. 1]).

(1vb-3ra) Thomas Cantuariensis: (1vb) Tit.: De sancto Thoma Cantuariense (!) archiepiscopo (Graesse Nr. 11, 1 [S. 67, Z. 9-12]). Inc.: Beatus Thomas sanctitatem suam ita subtiliter occultabat ut salvo semper honestatis rigore ... (2ra) Tit.: De excellencia huius martiris (Graesse Nr. 11, 2 [S. 68, Z. 2-7]). Expl.: ... a domino servabatur. (2ra) Tit.: Qualiter ubi quando et a quibus passus fuerit (Graesse Nr. 11, 2 [S. 68, Z. 19-30]. - Mairhofer Nr. 99). (2rb) Tit.: De cantu angelorum (Graesse Nr. 11, 3 [S. 68, Z. 30-S. 69, Z. 3]. - Mairhofer Nr. 100). (2va) Graesse Nr. 11, 3 (S. 69, Z. 7-13). - Mairhofer Nr. 101. (2va) Tit.: De efficacia aque sancti Thome (Graesse Nr. 11, 
4). (2vb) Tit.: De ave docta loqui quam nisus insequebatur (Graesse Nr. 11, 5). (2vb) Tit.: De quodam quem s. Thomas dilexit (Graesse 69 [Nr. 11, 6]).

(3ra-va) Felix presbyter Romanus: (3ra) Tit.: De sancto Felice quem pueri peremerunt (Graesse Nr. 19 [S. 102, Z. 9-17]). (3ra) Tit.: Qualiter aranee ipsum abscondiverit (!) (Graesse Nr. 19 [S. 102, Z. 22-26]). - Inc.: Quadam vice cum predicans Felix predicaret et persecutor ... (3ra) Tit.: De fratre eiusdem sancti (Graesse Nr. 19 [S. 102, Z. 30-S. 103, Z. 1]). (3rb) Tit.: De paganis qui eum tenere voluerunt (Graesse Nr. 19 [S. 103, Z. 5-8]). - Inc.: Quadam autem vice venerunt gentiles ut eum tenerent... (3rb) Tit.: Quot pontifices ydolorum baptizavit (Graesse Nr. 19 [S. 103, Z. 8-18]).

(3va-b) Sebastianus: (3va) Graesse Nr. 23, 4. - Mairhofer Nr. 102. (3vb) Tit.: De maxima pestilencia Ytalie (Graesse Nr. 23, 5 [S. 113, Z. 1-12]). - Expl.: ... a Roma reliquie sunt delate.

(3vb-4rb) Ignatius: (3vb) Tit.: Epistula Ignacii ad Mariam (Graesse Nr. 36, 1 [S. 155, Z. 3-10]). - Expl.: ... ex te propter te et in te confirmeretur. (4ra) Tit.: Rescriptum gloriose virginis ad ipsum (Graesse Nr. 36, 1-2 [S. 155, Z. 10-27]). (4ra) Tit.: Quod Ignacius angelos audivit cantantes (Graesse Nr. 36, 3 [S. 155, Z. 27-30]). (4rb) Tit.: Quod Ihesu Christi nomen in corde scriptum habuit (Graesse Nr. 36, 4 [S. 157, Z. 28-36]).

(4rb-va) Blasius: (4rb) Tit.: De sancto Blasio (Graesse Nr. 38 [S. 167, Z. 26-30]). (4va) Tit.: De porco quem lupus rapuit (Graesse Nr. 38 [S. 167, Z. 30-S. 168, Z. 3 und Z. 11-16]. - Mairhofer Nr. 103).

(4va-b) Georgius: Tit.: Quod sanctus Georius (!) dux est Christianorum (Graesse Nr. 58 [56] [S. 264, Z. 26-34]).

(4vb-5rb) Marcellinus papa (Ed.: A. Sorbelli, Corpus chronicorum Bononiensium [Rerum Italicarum scriptores. Raccolta degli storici italiani dal cinquecento al millecinquecento 28/1]. Città di Castello 1905, 206, Z. 18-207, Z. 33 [Cronaca A]. - Mairhofer Nr. 104).

(5rb) Sancti Iohannes et Paulus: Tit.: De sanctis Iohanne et Paulo (Graesse Nr. 87 [82] [S. 367, Z. 5-12]).

(5rb-6ra) Christophorus: Tit.: De sancto Christoforo insigne miraculum (Graesse Nr. 100 [95] [S. 431, Z. 29-S. 432, Z. 32]. - Mairhofer Nr. 22).

(6ra-b) Mauricius et socii sui: (6ra) Graesse Nr. 141 (136), 2. - Mairhofer Nr. 105. (6rb) Tit.: De clerico ambicioso horrendum miraculum (Graesse Nr. 141 [136], 5. - Mairhofer Nr. 106).

(6rb-7ra) Cosmas et Damianus (BHL S. 298, ohne Nr.): (6rb) Tit.: De sanctis Cosme (!) et Damiano (Graesse Nr. 143 [138], 2). (6va) Tit.: De viro qui peregre proficiscens uxorem eius conmendavit (Graesse Nr. 143 [138], 3. - Mairhofer Nr. 107). (6vb) Tit.: Quod coram cuidam viro absciderunt (Graesse Nr. 143 [138], 4).

(7ra-10vb) Udo von Magdeburg: Tit.: De querela sancti Mauricii et duplici iudicio corporali et spirituali contra Udonem (Ed.: A. E. Schönbach, Studien zur Erzählungsliteratur des Mittelalters [SB Wien 144]. Wien 1901, 2-9. - Mairhofer Nr. 666).

(10vb-12rb) Dionysius (Mairhofer Nr. 667).

1.2 (12rb-43va) Dist. 5: Miracula de episcopis.

(12rb-vb) Prolog: Tit.: Incipit prologus $V^{\circ}$ distinccionis. - Inc.: Virorum illustrium presulum scilicet ac doctorum preconia (!) sacrosanctam quinte huius distinccionis series continet et declarat nugas nimirum respuens ... - Expl.: ... et veritatis predicator principalissimus hec autem de eius laude breviter dicta sufficiant.

Schlussschrift: Explicit distinccio IIII ${ }^{a}$.

(12vb-13vb) Register mit Kapitelzahlen.

(13vb-17va) Augustinus: (13vb) Tit.: De conversione beati Augustini et ymno et domini laudamus prima distinccio (Graesse Nr. 124 [119], 1 [S. 552, Z. 36- S. 553, Z. 4 und S. 554, Z. 37-S. 555, Z. 13]). (14ra) Tit.: Quod tria a beato Ambrosio didicit (Graesse Nr. 124 [119], 1 [S. 555, Z. 1925]). (14rb) Tit.: Quod laudabat mori cupientes (Graesse Nr. 124 [119], 1 [S. 557, Z. 23-33]). 
(14rb) Tit.: Quod mulieres sunt vitande (Graesse Nr. 124 [119], 1 [S. 560, Z. 39-S. 561, Z. 3]). Inc.: Refert Gregorius in registro. Legitur quod sanctus Augustinus nec cum sorore ... (14va) Tit.: Quare librum de civitate Dei composuerit (Graesse Nr. 124 [119], 1 [S. 558, Z. 24-33]). (14va) Tit.: De egro ab ipso sanato (Graesse Nr. 124 [119], 1 [S. 559, Z. 9-21]). - Inc.: Cum beatus Augustinus febribus laboraret et lecto decumberet... (14vb) Tit.: De transitu ipsius (Graesse Nr. 124 [119], 1 [S. 559, Z. 35-S. 560, Z. 4]). - Expl.: ... floruit circa annum domini CCCC ${ }^{m}$ $X L^{m}$. (14vb) Tit.: De eo quod est illuminator ecclesie (Graesse Nr. 124 [119], 4 [S. 562, Z. 1520]. - Mairhofer Nr. 108). (15ra) Tit.: De corde sancti Augustini miraculum insigne (Mairhofer Nr. 109). (15va) Tit.: De sancto Bernhardo dormiens eum vidit (Graesse Nr. 124 [119], 4 [S. 562, Z. 20-26]). (15va) Tit.: De monacho qui digitum eius dedit (Graesse Nr. 124 [119], 5. - Mairhofer Nr. 110). (15vb) Graesse Nr. 124 (119), 6. - Mairhofer Nr. 111. (16ra) Graesse Nr. 124 (119), 7. - Mairhofer Nr. 598. (16rb) Graesse Nr. 124 (119), 8. - Mairhofer Nr. 112. (16va) Tit.: De gloria et excellencia Augustini (Graesse Nr. 124 [119], 9. - Mairhofer Nr. 599). - Inc.: Fertur quoque quod dum vir quidam sancto Augustino valde devotus in spiritu raptus ... (16va) Graesse Nr. 124 (119), 10. - Mairhofer Nr. 600. (16vb) Tit.: De proposito qui eum dilexit (Graesse Nr. 124 [119], 11. - Mairhofer Nr. 601). (17ra) Tit.: De CXL viris simul sanatis (Graesse Nr. 124 [119], 13. - Mairhofer Nr. 113).

(17va-22vb) Gregorius: (17va) Graesse Nr. 46, 1. - Mairhofer Nr. 602. (17va) Graesse Nr. 46, 2. - Mairhofer Nr. 114. (17vb) Tit.: De pueris Anglicanis (Graesse Nr. 46, 3 [S. 190, Z. 1-29]. Mairhofer Nr. 115). (18rb) Graesse Nr. 46, 4 (S. 191, Z. 10-18). - Mairhofer Nr. 603. (18rb) Graesse Nr. 46, 4 (S. 190, Z. 39-S. 191, Z. 1 und S. 191, Z. 37-S. 192, Z. 16). - Mairhofer Nr. 116. (18va) Graesse Nr. 46, 5 (S. 193, Z. 39-S. 194, Z. 6). - Mairhofer Nr. 604. (18vb) Graesse Nr. 46, 6 (S. 194, Z. 7-20). - Mairhofer Nr. 117. (19ra) Graesse Nr. 46, 6 (S. 194, Z. 2039). - Mairhofer Nr. 118. (19rb) Graesse Nr. 46, 7. - Mairhofer Nr. 605. (19va) Tit.: De fletu Gregorii (Graesse Nr. 46, 10 [S. 196, Z. 31-37]). (19va) Tit.: De egritudine eius (Graesse Nr. 46, 10 [S. 197, Z. 21-29]). (19vb) Tit.: Qualiter predicta intelligenda sint (Graesse Nr. 46, 10 [S. 197, Z. 4-21]). (20ra) Tit.: De iudicio Trayani (Graesse Nr. 46, 10 [S. 196, Z. 16-26 ]). (20rb) Tit.: De eodem (Graesse Nr. 46, 10 [S. 196, Z. 27-31]). (20rb) Tit.: De imperatore Mauricio (Graesse Nr. 46, 8 [S. 195, Z. 30-S. 196, Z. 1]. - Mairhofer Nr. 606). (20va) Graesse Nr. 46, 8 (S. 196, Z. 3-11). - Mairhofer Nr. 607. (20va) Tit.: De responsione angeli (Graesse Nr. 46, 9). (20vb) Tit.: De sancto Gregorio et matrona que panes ei obtulit (Graesse Nr. 46, 11-12. Mairhofer Nr. 119). (21ra) Graesse Nr. 46, 13. - Mairhofer Nr. 120. (21rb) Graesse Nr. 46, 14. Mairhofer Nr. 608. (21rb) Tit.: Quod officia ad missas composuit (Graesse Nr. 46, 15 [S. 199, Z. 3-10]). (21va) Tit.: Epytaphium tumbe eius (Graesse Nr. 46, 15 [S. 199, Z. 10-21]). (21vb) Graesse Nr. 46, 16. - Mairhofer Nr. 121. (22rb) Graesse Nr. 46, 17. - Mairhofer Nr. 122.

(22vb-23rb) Ambrosius: (22vb) Tit.: De virtutibus beati Ambrosii (Graesse Nr. 57 [55], 1 [S. 250, Z. 16-22]). - Inc.: Ambrosius cum incunabulis in atrio pretorii esset positus et dormiret... (22vb) Tit.: Quod invitus factus est episcopus (Graesse Nr. 57 [55], 1 [S. 250, Z. 28-S. 251, Z. 13]. - Mairhofer Nr. 123).

(23rb-va) Gregorius: Graesse Nr. 46, 19. - Mairhofer Nr. 609.

(23va-26ra) Ambrosius: (23va) Graesse Nr. 57 (55), 2 (S. 251, Z. 21-32). - Mairhofer Nr. 610. (23vb) Graesse Nr. 57 (55), 2 (S. 251, Z. 32-S. 252, Z. 1). - Mairhofer Nr. 611. (24ra) Tit.: De heretico qui Dei angelum vidit (Graesse Nr. 57 [55], 2 [S. 252, Z. 12-16]). (24ra) Tit.: De auruspice qui misit demones (Graesse Nr. 57 [55], 3 [S. 252, Z. 16-25]. - Mairhofer Nr. 612). (24ra) Tit.: De quodam cuius manus aruit (Graesse Nr. 57 [55], 3 [S. 252, Z. 25-S. 253, Z. 4]). (24rb) Graesse Nr. 57 (55), 4 (S. 253, Z. 4-8). - Mairhofer Nr. 613. (24rb) Tit.: De clauso palacio ne Ambrosius intraret (Graesse Nr. 57 [55], 4 [S. 253, Z. 8-14]). (24rb) Graesse Nr. 57 (55), 4 (S. 253 Z. 14-30). - Mairhofer Nr. 614. (24va) Tit.: De flagicioso quem tradidit dyabolo (Graesse Nr. 57 [55], 4 [S. 253, Z. 30-34]). - Expl.: ... discrepare cepit. (24vb) Graesse Nr. 57 (55), 5. - Mairhofer Nr. 124. (25ra) Graesse Nr. 57 (55), 6 (S. 255, Z. 15-21). - Mairhofer Nr. 615. 
(25ra) Tit.: Nota quod in multis fuit commendabilis (Graesse Nr. 57 [55], 7-8. - Mairhofer Nr. 616).

(26ra-29va) Martinus ep.: (26ra) Tit.: De virtutibus sancti Martini (Graesse Nr. 166 [161] [S. 741, Z. 29-S. 742, Z. 33]. - Mairhofer Nr. 125). (26rb) Graesse Nr. 166 (161) (S. 742, Z. 3339). - Mairhofer Nr. 126. (26va) Graesse Nr. 166 (161) (S. 743, Z. 35-S. 744, Z. 10). - Mairhofer Nr. 127. (26vb) Tit.: Qualiter tercium mortuum suscitavit (Graesse Nr. 166 [161] [S. 744, Z. 1016]). (26vb) Tit.: Quod ei obediebant insensibilia (Graesse Nr. 166 [161] [S. 744, Z. 16-25]). Expl. erweitert: ... magna successit qui conversus fidem suscepit. (27ra) Tit.: Quod ei obediebant vegetabilia (Graesse Nr. 166 [161] [S. 744, Z. 25-33]). (27ra) Tit.: Quod ei obediebant animalia (Graesse Nr. 166 [161] [S. 744, Z. 33-S. 745, Z. 5]. - Mairhofer Nr. 617). (27rb) Tit.: Quod multe fuerit humilitatis beatus Martinus (Graesse Nr. 166 [161] [S. 745, Z. 5-20]. - Mairhofer Nr. 128). (27va) Graesse Nr. 166 (161) (S. 745, Z. 21-31). - Mairhofer Nr. 129. (27va) Tit.: Multe fuit paciencie (Graesse Nr. 166 [161] [S. 745, Z. 31-S. 746, Z. 4]). (27vb) Tit.: Multe fuit compassionis (Graesse Nr. 166 [161] [S. 746, Z. 24-29]). (27vb) Tit.: Multe fuit largitatis (Graesse Nr. 166 [161] [S. 746, Z. 29-S. 747, Z. 16]. - Mairhofer Nr. 130). (28rb) Tit.: Multe fuit potestatis (Graesse Nr. 166 [161] [S. 747, Z. 17-26]). - Inc.: Multe fuit potestatis erga demones pellendos non solum ex hominibus ... - Expl.: ... ad armentum suum revertitur. (28rb) Tit.: Multe fuit subtilitatis (Graesse Nr. 166 [161] [S. 747, Z. 26-S. 748, Z. 6]). - Inc.: Multe subtilitatis fuit erga demones cognoscendos. Quadam vice dyabolus in forma regis purpura ... (28va) Tit.: Quod moriens dyabolum vidit (Graesse Nr. 166 [161] [S. 748, Z. 6-35]). - Inc.: Cum Martinus pergeret ad Condacensem (!) dyocesin causa sedande discordie vidit mergos in flumine (gestrichen: piscem) piscibus insidiantes ... (28vb) Graesse Nr. 166 (161) (S. 749, Z. 2-14). - Mairhofer Nr. 131. (29ra) Graesse Nr. 166 (161) (S. 749, Z. 14-21). Inc. gegenüber Ed. leicht abweichend, übereinstimmend mit Mairhofer Nr. 618. (29rb) Tit.: De eius exequiis et beato Ambrosio (Graesse Nr. 166 [161] [S. 749, Z. 22-34]. - Mairhofer Nr. 619). - Inc.: Sanctus Ambrosius eo die missam celebrans super altare ... (29rb) Graesse Nr. 166 (161) (S. 750, Z. 7-20). - Mairhofer Nr. 620.

(29va-33va) Nicolaus: (29va) Tit.: De virtutibus sancti Nycolay (Graesse Nr. 3, 1 [S. 23, Z. 2-16]). (29vb) Tit.: Quod nautis in periculo subvenit (Graesse Nr. 3, 3 [S. 23, Z. 9-S. 24, Z. 36). (30ra) Tit.: Quod famem a suis repulit (Graesse Nr. 3, 4. - Mairhofer Nr. 132). (30ra) Graesse Nr. 3, 6 (S. 25, Z. 11-24). - Mairhofer Nr. 133. (30rb) Graesse Nr. 3, 6 (S. 25, Z. 6-11 und Z. 24-26). Mairhofer Nr. 134. (31ra) Graesse Nr. 3, 8. - Mairhofer Nr. 135. (31rb) Tit.: De ymagine beati Nycolai (Graesse Nr. 3, 9. - Mairhofer Nr. 136). (31va) Graesse Nr. 3, 10. - Mairhofer Nr. 621. (31vb) Tit.: De cypho aureo et de quodam nobili (Graesse Nr. 3, 11. - Mairhofer Nr. 622). (32ra) Tit.: De divite sibi devoto (Graesse Nr. 3, 12). (32rb) Mairhofer Nr. 623. (32vb) Tit.: De quodam fatuo sapiente iocosum (Mairhofer Nr. 137).

(33rb-va) Pelagius papa: Tit.: De quodam priore ab eo plagato (Graesse Nr. 181 [176], 4 [S. 841, Z. 32-S. 842, Z. 12]).

(33va-34va) Remigius: (33va) Graesse Nr. 16 (S. 96, Z. 5-16). - Mairhofer Nr. 138. Expl.: ... autem omnia per ordinem facta sunt. (33vb) Tit.: De vino augmentato (Graesse Nr. 16 [S. 96, Z. 18-25]). - Inc.: Quodam tempore cum Remigius factus est Remensis archiepiscopus et in domo cuiusdam ... (33vb) Tit.: Quod Clodoneum (!) regem baptizavit (Graesse Nr. 16 [S. 96, Z. 25-35]). (34ra) Graesse Nr. 16 (S. 96, Z. 35-S. 97, Z. 28). - Mairhofer Nr. 139.

(34va-b) Hilarius: Graesse Nr. 17 (S. 98, Z. 7-8 und S. 99 Z. 3-24). - Mairhofer Nr. 624.

(34vb-37va) Basilius: (34vb) Graesse Nr. 26, 1 (S. 121, Z. 1-7). - Mairhofer Nr. 625. (34vb) Tit.: De heremita qui eum despexit (Graesse Nr. 26, 1 [S. 121, Z. 7-20]. - Mairhofer Nr. 625 [Forts.]). (35ra) Tit.: De quodam alio et cauda catte (Graesse Nr. 26, 2). (35ra) Tit.: De magnimitate Basilii in corripiendo (Graesse Nr. 26, 3). - Expl. erweitert: ... ecclesia catholicis sicut in tripartita hystoria dicitur. (35va) Tit.: De famulo qui se dedit dyabolo (Graesse Nr. 26, 5. - 
Mairhofer Nr. 140). (36vb) Graesse Nr. 26, 6. - Mairhofer Nr. 626. (37rb) Graesse Nr. 26, 7. Mairhofer Nr. 627.

(37va-40rb) Iohannes Elemosinarius: (37va) Graesse Nr. 27, 1 (S. 126, Z. 19-28). - Mairhofer Nr. 141. (37va) Graesse Nr. 27, 1 (S. 126, Z. 28-S. 127, Z. 1). - Mairhofer Nr. 142. (37vb) Graesse Nr. 27, 1 (S. 127, Z. 1-24). - Mairhofer Nr. 143. (38ra) Graesse Nr. 27, 1 (S. 127, Z. 25-39). Mairhofer Nr. 628. (38rb) Graesse Nr. 27, 2 (S. 127, Z. 39-S. 128, Z. 28). - Mairhofer Nr. 629. (38va) Tit.: De monacho qui cum meretricibus pernoctebat (Graesse Nr. 27, 3. - Mairhofer Nr. 144). (39rb) Graesse Nr. 27, 4. - Mairhofer Nr. 630. (39rb) Tit.: De quodam tabernario et suo nepote (Graesse Nr. 27, 6). (39va) Tit.: De precioso coopertorio cuiusdam divitis (Graesse Nr. 27, 8. - Mairhofer Nr. 145). (39vb) Graesse Nr. 27, 9. - Mairhofer Nr. 631. (40ra) Tit.: De magna eius paciencia (Graesse Nr. 27, 10). (40ra) Graesse Nr. 27, 11. - Mairhofer Nr. 146. (40ra) Tit.: De iuvene qui rapuit monialem (Graesse Nr. 27, 12 [S. 132, Z. 5-13]).

(40rb-va) Leo papa: Graesse Nr. 88 (83) (S. 368, Z. 2-12). - Mairhofer Nr. 147.

(40va-41rb) Germanus ep.: (40va) Graesse Nr. 107 (102) (S. 448, Z. 27-S. 449, Z. 12). Mairhofer Nr. 148. (40va) Graesse Nr. 107 (102) (S. 449, Z. 22-30). - Mairhofer Nr. 149. (40vb) Graesse Nr. 107 (102) (S. 449, Z. 30-S. 450, Z. 11). - Mairhofer Nr. 150. (40vb) Graesse Nr. 107 (102) (S. 450, Z. 11-24). - Mairhofer Nr. 632. (41ra) Graesse Nr. 107 (102) (S. 450, Z. 33-39). Mairhofer Nr. 151. (41rb) Graesse Nr. 107 (102) (S. 451, Z. 7-16). - Mairhofer Nr. 633.

(41rb-va) Lupus: (41rb) Tit.: De sancto Lupo Senonensi archiepiscopo (Graesse Nr. 128 [123] [S. 579, Z. 7-12]). - Inc.: Cum sancto Lupo Senonensi archiepiscopo omnes qui de curia ... (41va) Tit.: De eius convivio et vini defectu (Graesse Nr. 128 [123] [S. 579, Z. 3-7]). - Expl. erweitert: ... pre foribus nunciavit et dixit Ecce quam verum est. Date et dabitur vobis etc. (41va) Tit.: Quod dyabolum inclusit (Graesse Nr. 128 [123] [S. 580, Z. 4-9]).

(41va-42ra) Iohannes Chrysostomus: (41va) Graesse Nr. 138 (131) (S. 616, Z. 25-29). - Mairhofer Nr. 152. (41vb) Graesse Nr. 138 (131) (S. 616, Z. 30-34). - Mairhofer Nr. 153. (41vb) Graesse Nr. 138 (131) (S. 616, Z. 34-S. 617, Z. 5). - Mairhofer Nr. 154. (42ra) Tit.: De monacho sancto in episcopum electo (Graesse 138 [131] [S. 618, Z. 11-17]). - Inc.: Eo tempore in Lamon sanctissimus monachus ...

(42ra-43va) Patricius: (42ra) Graesse Nr. 50 (49) (S. 213, Z. 17-23). - Mairhofer Nr. 155. (42ra) Tit.: Quod sanctus Patricius omnes cruces adorabat (Graesse Nr. 50 [49] [S. 213, Z. 23-29]). Expl.: ... fecit eam inde tolli. (42rb) Graesse Nr. 50 (49) (S. 213, Z. 29-S. 216, Z. 13). - Mairhofer Nr. 156.

(43va) Schlussschrift: Explicit distinccio $V^{a}$.

1.3 (43va-72vb) Dist. 6: Miracula de monachis.

(43va-44vb) Register mit Kapitelzahlen.

(44vb-45va) Paulus eremita: (44vb) Graesse Nr. 15 (S. 94, Z. 9-28). - Mairhofer Nr. 157. (45ra) Graesse Nr. 15 (S. 94, Z. 28-S. 95, Z. 18). - Mairhofer Nr. 158. (45va) Tit.: De eius transitu ad celos (Graesse Nr. 15 [S. 95, Z. 18-27]. - Mairhofer Nr. 159).

(45va-47rb) Antonius: (45va) Tit.: De virtutibus sancti Anthonii (Graesse Nr. 21, 1 [S. 104, Z. 8-12). - Mairhofer Nr. 160. (45va) Graesse Nr. 21, 1 (S. 104, Z. 12-17). - Mairhofer Nr. 161. (45vb) Graesse Nr. 21, 1 (S. 104, Z. 17-32). - Mairhofer Nr. 162. (46ra) Tit.: Quod martirium desideravit (Graesse Nr. 21, 1 [S. 104, Z. 32-S. 105, Z. 1]). (46ra) Tit.: De disco argenteo (Graesse Nr. 21, 2 [S. 105, Z. 1-8]). (46ra) Tit.: De laqueis dyaboli (Graesse Nr. 21, 2 [S. 105, Z. 9-12]). - Inc.: Quadam vice cum in spiritu temptatus esset totum mundum laqueis sese invicem ... (46rb) Tit.: Quod dyabolum vidit (Graesse Nr. 21, 3 [S. 105, Z. 18-22]). (46rb) Graesse Nr. 21, 3 (S. 105, Z. 22-29). - Mairhofer Nr. 634. (46rb) Tit.: Quod cum fratribus quinque gaudebat (Graesse Nr. 21, 3 [S. 105, Z. 29-36]). (46rb) am unteren Blattrand Notiz (16. Jh.?), radiert: 1544 [...] IIII [...] jar. (46va) Graesse Nr. 21,4 (S. 106, Z. 2-10). - Mairhofer Nr. 635. (46va) Graesse Nr. 21, 5 (S. 106, Z. 19-23). - Mairhofer Nr. 637. (46vb) Graesse Nr. 21, 5 
(S. 106, Z. 10-18). - Mairhofer Nr. 636. (46vb) Tit.: Quod angelus eum docuit (Graesse Nr. 21, 5 [S. 106, Z. 23-27]. - Mairhofer Nr. 638). (46vb) Graesse Nr. 21, 5 (S. 106, Z. 27-36). Mairhofer Nr. 639.

(47ra-b) Tit.: De verbo salutis et suco (Graesse Nr. 21, 6 [S. 107, Z. 20-28]).

(47rb-48ra) Macarius: (47rb) Tit.: De sancto Machario et eius miraculis (Graesse Nr. 18 [S. 100, Z. 16-25]. - Mairhofer Nr. 640). (47rb) Tit.: Quod humilitate dyabolum vicit (Graesse Nr. 18 [S. 100, Z. 25-S. 101, Z. 1]. - Mairhofer Nr. 641). (47va) Tit.: Quod corpus suum afflixit (Graesse Nr. 18 [S. 101, Z. 5-8]. - Mairhofer Nr. 163). - Inc.: Dum temptaciones dyaboli ipsum nimio molestarent ... (47va) Graesse Nr. 18 (S. 101, Z. 8-23). - Mairhofer Nr. 164. (47vb) Tit.: De capite pagani (Graesse Nr. 18 [S. 101, Z. 23-32]. - Mairhofer Nr. 165). (47vb) Tit.: Quod dyabolus harundines collegit (Graesse Nr. 18 [S. 101, Z. 32-36]). (48ra) Tit.: De fratre qui multis prodesse voluit (Graesse Nr. 18 [S. 101, Z. 36-S. 102, Z. 4]). (48ra) Tit.: De culice (!) et reprehensione (Graesse Nr. 18 [S. 102, Z. 4-7]).

(48ra-vb) Pastor: (48ra) Tit.: De abbate Pastore (Graesse Nr. 175 [170] [S. 803, Z. 15-26]. Mairhofer Nr. 166). (48rb) Graesse Nr. 175 (170) (S. 804, Z. 21-27). - Mairhofer Nr. 167. (48rb) Tit.: Quod ira saluti sit contraria (Graesse Nr. 175 [170] [S. 804, Z. 27-31]). (48va) Tit.: Qualis debeat esse monachus (Graesse Nr. 175 [170] [S. 804, Z. 31-37]). (48va) Tit.: Notabile de cogitacionibus (Graesse Nr. 175 [170] [S. 805, Z. 2-6]. - Mairhofer Nr. 642). (48va) Graesse Nr. 175 (170) (S. 805, Z. 6-11). - Mairhofer Nr. 643.

(48vb-49ra) Iohannes abb.: (48vb) Tit.: De abbate Iohanne (Graesse Nr. 176 [171] [S. 805, Z. 13-22]). - Inc.: Iohannes abbas cum quendam qui per XL annos in heremo habitaverat interrogasset ... (48vb) Graesse Nr. 176 (171) (S. 805, Z. 22-S. 806, Z. 6). - Mairhofer Nr. 168. (49ra-va) Moyses abb.: (49ra) Graesse Nr. 177 (172) (S. 806, Z. 8-19). - Mairhofer Nr. 169. (49rb) Tit.: Notandum (Graesse Nr. 177 [172] [S. 806, Z. 19-22]). (49rb) Graesse Nr. 177 (172) (S. 806, Z. 22-26). - Mairhofer Nr. 644. (49rb) Graesse Nr. 177 (172) (S. 806, Z. 27-S. 807, Z. 2). - Mairhofer Nr. 645. (49va) Graesse Nr. 177 (172) (S. 807, Z. 3-10). - Mairhofer Nr. 646. (49va-50vb) Arsenius abb.: (49va) Tit.: Quod taciturnitas est salutis inicium (Graesse Nr. 178 [163] [S. 807, Z. 11-14]). (49vb) Graesse Nr. 178 (163) (S. 807, Z. 14-26). - Mairhofer Nr. 170. (49vb) Graesse Nr. 178 (163) (S. 807, Z. 26-S. 808, Z. 2). - Mairhofer Nr. 171. (50ra) Graesse Nr. 178 (163) (S. 808, Z. 3-22). - Mairhofer Nr. 172. (50rb) Tit.: Item unde supra (Graesse Nr. 178 [163] [S. 808, Z. 22-26]). (50rb) Tit.: Quod corpus mulieris ignis est (Graesse Nr. 178 [163] [S. 808, Z. 26-30]). (50rb) Tit.: De gracia lacrimarum (Graesse Nr. 178 [163] [S. 808, Z. 30-37]. - Mairhofer Nr. 647). (50va) Graesse Nr. 178 (163) (S. 808, Z. 37-S. 809, Z. 7). Mairhofer Nr. 648. (50va) Graesse Nr. 178 (163) (S. 809, Z. 7-23). - Mairhofer Nr. 649.

(50vb-51va) Agathon abb.: (50vb) Tit.: De sancto qui lapidem per triennium in ore portavit (Graesse Nr. 179 [174] [S. 809, Z. 27-S. 810, Z. 1]). - Expl.: ... cum leditur foras egreditur. (51ra) Tit.: Quod maximus labor est orare (Graesse 179 [174] [S. 810, Z. 1-6]). (51ra) Tit.: Quod iracundi Deo non placent (Graesse 179 [174] [S. 810, Z. 6-10]). (51ra) Graesse Nr. 179 (174) (S. 810, Z. 11-18). - Mairhofer Nr. 650. (51rb) Graesse Nr. 179 (174) (S. 810, Z. 18-26). Mairhofer Nr. 651. (51rb) Tit.: De iniuria non retinenda (Graesse 179 [174] [S. 810, Z. 28-30]). (51rb) Graesse Nr. 179 (174) (S. 810, Z. 30-S. 811, Z. 3). - Mairhofer Nr. 173.

(51va-53ra) Ieronimus: (51va) Graesse 146 (141) (S. 654, Z. 1-25). - Mairhofer Nr. 174. (51vb) Graesse 146 (141) (S. 654, Z. 25-S. 655, Z. 19). - Mairhofer Nr. 175. (52ra) Tit.: Quod in Bethleem habitabat (Graesse 146 [141] [S.655, Z. 19-31]). (52rb) Graesse 146 (141) (S. 655, Z. 31-S. 657, Z. 13). - Mairhofer Nr. 176.

(53ra-57va) Benedictus: (53ra) Graesse 49 (48), 1 (S. 204, Z. 17-205). - Mairhofer Nr. 177. (53rb) Graesse 49 (48), 1 (S. 205, Z. 2-11). - Mairhofer Nr. 178. (53rb) Graesse Nr. 49 (48), 2. - Mairhofer Nr. 179. (53va) Graesse Nr. 49 (48), 3 (S. 206, Z. 1-14). - Mairhofer Nr. 180. (53vb) Tit.: De ferro quod in profundum cecidit (Graesse 49 [48], 3 [S. 206, Z. 25-29]). (53vb) Graesse Nr. 49 (48), 3 (S. 206, Z. 29-39). - Mairhofer Nr. 181. (54ra) Tit.: De corvo et pane 
infecto (Graesse 49 [48], 3 [S. 206, Z. 39-S. 207, Z. 24]. - Mairhofer Nr. 652). (54va) Tit.: Quod dyabolus contra eum seviebat (Graesse Nr. 49 [48], 3 [S. 207, Z. 27-32]). - Inc.: Quadam vice antiquus hostis corporalibus eius ... (54va) Graesse Nr. 49 (48), 3 (S. 207, Z. 32-S. 208, Z. 7). Mairhofer Nr. 182. (54vb) Graesse Nr. 49 (48), 4. - Mairhofer Nr. 653. (55ra) Tit.: Quod spiritum prophecie habuit (Graesse Nr. 49 [48], 5). (55ra) Graesse Nr. 49 (48), 6. - Mairhofer Nr. 183. (55rb) Graesse Nr. 49 (48), 7 (S. 208, Z. 37-S. 209, Z. 7). - Mairhofer Nr. 654. (55va) Graesse 49 (48), 7 (S. 209, Z. 7-14). - Mairhofer Nr. 655. (55va) Tit.: De monachis monasterium construentibus (Graesse 49 [48], 11). - Expl.: ... audistis omnia ordinate. (55vb) <Ps.-Gregorius Magnus>: Dialogi, Lib. 2, cap. 12 (Ed.: F. Clark, The Pseudo-Gregorian dialogues 1. Leiden 1987. - Mairhofer Nr. 656). (56ra) Graesse Nr. 49 (48), 12. - Mairhofer Nr. 657. (56rb) Tit.: De fratre qui sine licencia exivit (Graesse Nr. 49 [48], 13. - Mairhofer Nr. 243). (56rb) Graesse Nr. 49 (48), 14. - Mairhofer Nr. 658. (56va) Graesse Nr. 49 (48), 15. - Vgl. Mairhofer Nr. 659. (56vb) Graesse Nr. 49 (48), 16. - Mairhofer Nr. 184. (57ra) Tit.: Quod totum mundum simul et semel vidit (Graesse Nr. 49 [48], 17). (57rb) Graesse Nr. 49 (48), 18. - Mairhofer Nr. 660.

(57va-64rb) Bernardus: (57va) Tit.: De virtutibus beati Bernhardi doctoris egregii (Graesse Nr. 120 [115] [S. 528, Z. 16-22]. - Mairhofer Nr. 661). (57va) Tit.: De dolore capitis eius in puericia (Graesse Nr. 120 [115] [S. 528, Z. 23-27]). (57vb) Tit.: Quod puer Ihesus ei apparuit (Graesse Nr. 120 [115] [S. 528, Z. 27-32]). (57vb) Tit.: De puella que in lectum eius cecidit (Graesse Nr. 120 [115] [S. 529, Z. 7-13]). (57vb) Graesse Nr. 120 (115) (S. 529, Z. 13-29). Mairhofer Nr. 663. (58rb) Graesse Nr. 120 (115) (S. 529, Z. 29-S. 530, Z. 9). - Mairhofer Nr. 185. (58va) Tit.: De ingressu eius in Cystercium (Graesse Nr. 120 [115] [S. 530, Z. 9-19]). (58vb) Tit.: De mira eius conversione sacione (!) (Graesse Nr. 120 [115] [S. 530, Z. 19-25]). (58vb) Graesse Nr. 120 (115) (S. 530, Z. 25-S. 531, Z. 10). - Mairhofer Nr. 186. (59ra) Tit.: De eius studiis (Graesse Nr. 120 [115] [S. 531, Z. 10-13]). (59rb) Tit.: De eius mundicia corporali (Graesse Nr. 120 [115] [S. 531, Z. 19-23]). (59rb) Tit.: De canonico qui ad maxillam eum percussit (Graesse Nr. 120 [115] [S. 532, Z. 4-17]). - Inc.: Quidam canonicus ad eum venit et ut ad monachum eum reciperet ... (59va) Graesse Nr. 120 (115) (S. 532, Z. 22-S. 533, Z. 2). - Mairhofer Nr. 187. (59vb) Graesse Nr. 120 (115) (S. 533, Z. 2-12). - Mairhofer Nr. 188. (60ra) Tit.: Quod fratres pro eo oraverunt (Graesse Nr. 120 [115] [S. 533, Z. 14-18]). - Expl. erweitert: ... sinite me abire. Noviciis autem intrare volentibus dicere consueverat. Si ad ea que intus sunt festinatis hic foris dimittite corpora que a seculo attulistis. Soli spiritus ingrediantur caro autem non prodest quicquam. (60rb) Tit.: Quod tota die iuxta lacum pergens eum non vidit (Graesse Nr. 120 [115] [S. 533, Z. 24-S. 534, Z. 7]). (60va) Tit.: De temptacione eius cum predicaret qualiter eum vicit (Graesse Nr. 120 [115] [S. 534, Z. 7-14]). (60va) Graesse Nr. 120 (115) (S. 534, Z. 15-30). - Mairhofer Nr. 662. (60vb) 〈Herbertus Claraevallensis»: De miraculis, Lib. 2, cap. 15 (PL 185, 1324D-1325C. - Mairhofer Nr. 664). (61rb)〈Herbertus ClaraeVALLENSIS : De miraculis, Lib. 2, cap. 16 (PL 185, 1325C-1326C. - Mairhofer Nr. 665). (61vb) Graesse Nr. 120 (115) (S. 534, Z. 30-S. 535, Z. 8). - Mairhofer Nr. 189. (62ra) Tit.: De epistula quam sub divo scripsit (Graesse Nr. 120 [115] [S. 535, Z. 8-17]). - Inc.: Frater Ruodbertus eius monachus et secundum carnem ... (62ra) Tit.: De multis quas excommunicavit (Graesse Nr. 120 [115] [S. 535, Z. 17-20]). (62rb) Tit.: De obsessa quam liberavit (Graesse Nr. 120 [115] [S. 535, Z. 20-S. 536, Z. 10]). - Mairhofer Nr. 190. (62vb) Graesse Nr. 120 (115) (S. 536, Z. 10-26). Mairhofer Nr. 191. (63ra) Graesse Nr. 120 (115) (S. 536, Z. 27-S. 537, Z. 2). - Mairhofer Nr. 192. (63rb) Graesse Nr. 120 (115) (S. 537, Z. 3-12). - Mairhofer Nr. 193. (63va) Graesse Nr. 120 (115) (S. 537, Z. 13-24). - Mairhofer Nr. 194. (63va) Graesse Nr. 120 (115) (S. 537, Z. 24-33). - Mairhofer Nr. 195. (63vb) Graesse Nr. 120 (115) (S. 537, Z. 33-S. 538, Z. 2). Mairhofer Nr. 196. (63vb) Graesse Nr. 120 (115) (S. 538, Z. 2-12). - Mairhofer Nr. 197. (64ra) Graesse Nr. 120 (115) (S. 538, Z. 12-22). - Mairhofer Nr. 198.

(64rb-va) Aegidius: Tit.: De sancto Egidio abbate et Karulo imperatore (Graesse Nr. 130 [125] [S. 584, Z. 2-14]. - Mairhofer Nr. 199). 
(64va-b) Pelagius papa: Graesse Nr. 181 (176), 4 (S. 833, Z. 13-S. 834, Z. 2). - Mairhofer Nr. 200.

(64vb-68rb) Dominicus: (64vb) Graesse Nr. 113 (108) (S. 467, Z. 10-29). - Mairhofer Nr. 201. (65ra) Graesse Nr. 113 (108) (S. 468, Z. 26-S. 469, Z. 11). - Mairhofer Nr. 202. (65va) Tit.: Quod Petrus baculum Paulus sibi librum tradidit (Graesse Nr. 113 [108] [S. 469, Z. 11-18]. Mairhofer Nr. 203). (65va) Graesse Nr. 113 (108) (S. 470, Z. 3-28). - Mairhofer Nr. 204. (66ra) Graesse Nr. 113 (108) (S. 470, Z. 28-38). - Mairhofer Nr. 205. (66rb) Graesse Nr. 113 (108) (S. 470, Z. 38-S. 471, Z. 13). - Mairhofer Nr. 206. (66rb) Graesse Nr. 113 (108) (S. 471, Z. 13 19). - Mairhofer Nr. 207. (66va) Graesse Nr. 113 (108) (S. 471, Z. 28-39). - Mairhofer Nr. 208. (66vb) Tit.: De iuvenibus ignotis qui ei panes detulerunt (Graesse Nr. 113 [108] [S. 473, Z. 32-S. 474, Z. 5]. - Mairhofer Nr. 209). (66vb) Graesse Nr. 113 (108) (S. 474, Z. 5-10). Mairhofer Nr. 210. (67ra) Graesse Nr. 113 (108) (S. 476, Z. 25-31). - Mairhofer Nr. 211. (67ra) Graesse Nr. 113 (108) (S. 477, Z. 20-S. 478, Z. 18). - Mairhofer Nr. 212. (67vb) Graesse Nr. 113 (108) (S. 478, Z. 19-35). - Mairhofer Nr. 213. (67vb) Tit.: Quod gratus Deo locus est in quo corpus viri Dei requiescit (Graesse Nr. 113 [108] [S. 482, Z. 13-S. 483, Z. 8]. - Mairhofer Nr. 214).

(68rb-72vb) Franciscus: (68rb) Graesse Nr. 149 (144) (S. 663, Z. 6-22). - Mairhofer Nr. 215. (68va) Tit.: Quod carnalis frater suus eum derisit (Graesse Nr. 149 [144] [S. 664, Z. 2-6]. Mairhofer Nr. 216). (68vb) Graesse Nr. 149 (144) (S. 664, Z. 6-10 und 16-20). - Mairhofer Nr. 217. (68vb) Tit.: Quod ei adheserunt (Graesse Nr. 149 [144] [S. 664, Z. 10-16]. - Mairhofer Nr. 218). (69ra) Tit.: De ypocrita (Graesse Nr. 149 [144] [S. 664, Z. 20-29]. - Mairhofer Nr. 219). (69rb) Graesse Nr. 149 (144) (S. 664, Z. 29-35). - Mairhofer Nr. 220. (69rb) Graesse Nr. 149 (144) (S. 665, Z. 15-25). - Mairhofer Nr. 221. (69va) Graesse Nr. 149 (144) (S. 665, Z. 8-15). Mairhofer Nr. 222. (69va) Graesse Nr. 149 (144) (S. 665, Z. 25-32). - Mairhofer Nr. 223. (69vb) Graesse Nr. 149 (144) (S. 666, Z. 33-S. 667, Z. 3). - Mairhofer Nr. 224. (70ra) Graesse Nr. 149 (144) (S. 666 Z. 15-33). - Mairhofer Nr. 225. (70rb) Tit.: Quod demones provocavit (Graesse Nr. 149 [144] [S. 667, Z. 4-11]. - Mairhofer Nr. 226). (70va) Tit.: De eius excellenti gloria (Graesse Nr. 149 [144] [S. 667, Z. 11-20]. - Mairhofer Nr. 227). (70va) Tit.: Quod stigmata Christi habuit (Graesse Nr. 149 [144] [S. 667, Z. 20-26]. - Mairhofer Nr. 228). (70vb) Graesse Nr. 149 (144) (S. 668, Z. 18-30). - Mairhofer Nr. 229. (70vb) Graesse Nr. 149 (144) (S. 668, Z. 34-39). - Mairhofer Nr. 230. (71ra) Graesse Nr. 149 (144) (S. 668, Z. 39-S. 669, Z. 8). Mairhofer Nr. 231. (71rb) Graesse Nr. 149 (144) (S. 669, Z. 31-36). - Mairhofer Nr. 232. (71rb) Graesse Nr. 149 (144) (S. 670, Z. 19-27). - Mairhofer Nr. 233. (71va) Graesse Nr. 149 (144) (S. 670, Z. 27-31). - Mairhofer Nr. 234. (71va) Graesse Nr. 149 (144) (S. 670, Z. 7-14). Mairhofer Nr. 235. (71vb) Graesse Nr. 149 (144) (S. 670, Z. 32-S. 671, Z. 1). - Mairhofer Nr. 236. (71vb) Graesse Nr. 149 (144) (S. 671, Z. 13-25). - Mairhofer Nr. 237. (72ra) Graesse Nr. 149 (144) (S. 671, Z. 29-35). - Mairhofer Nr. 238. (72rb) Graesse Nr. 149 (144) (S. 671, Z. 39-S. 672, Z. 8). - Mairhofer Nr. 239. (72rb) Tit.: Quod celos ascendit (Graesse Nr. 149 [144] [S. 672, Z. 10-15]. - Mairhofer Nr. 240). (72va) Graesse Nr. 149 (144) (S. 673, Z. 6-15). Mairhofer Nr. 241.

(72vb) Schlussschrift: Explicit distinccio VI.

1.4 (72vb-92ra) Dist. 7: Miracula de sanctis virginibus.

(72vb-73ra) Register mit Kapitelzahlen.

(73ra-76vb) Maria Magdalena: (73ra) Graesse Nr. 96 (90), 1-2 (S. 409, Z. 29-S. 413, Z. 8). Mairhofer Nr. 250. (74vb) Graesse Nr. 96 (90), 2 (S. 413, Z. 10-21). - Mairhofer Nr. 251. (75ra) Graesse Nr. 96 (90), 2 (S. 413, Z. 21-S. 415, Z. 2). - Mairhofer Nr. 252. (75vb) Graesse Nr. 96 (90), 2 (S. 415, Z. 3-8). - Mairhofer Nr. 253. (75vb) Tit.: De quodam milite occiso sibique devoto (Graesse Nr. 96 [90], 4. - Mairhofer Nr. 254). (76ra) Graesse Nr. 96 (90), 7. - Mairhofer Nr. 255. (76ra) Graesse Nr. 96 (90), 8. - Mairhofer Nr. 256. (76ra) Graesse Nr. 96 (90), 9. - Mairhofer 
Nr. 257. (76rb) Graesse Nr. 96 (90), 5. - Mairhofer Nr. 258. (76rb) Graesse Nr. 96 (90), 10. Mairhofer Nr. 259. (76va) 〈CONRAdus EberbaCEnsis〉: Exordium magnum Cisterciense, Dist. 4, cap. 2,1-30 (PL 185, 1096D-1097B. - Mairhofer Nr. 260).

(76vb-78vb) Catharina: (76vb) Tit.: De virtutibus beatissime Katherine virginis et martiris (Graesse Nr. 212 [209]. - Mairhofer Nr. 261). (78rb) Graesse 172 (167) (S. 795, Z. 5-9). - Mairhofer Nr. 262. (78va) Graesse 172 (167) (S. 795, Z. 10-20). - Mairhofer Nr. 263. (78vb) Mairhofer Nr. 264. (80rb) Mairhofer Nr. 265. (80vb) Mairhofer Nr. 266.

(81rb-va) Agnes: (81rb) Graesse Nr. 24, 1 (S. 116, Z. 2-8). - Mairhofer Nr. 267. (81rb) Graesse Nr. 24, 3. - Mairhofer Nr. 268. (81va) Tit.: De ymagine beate Agnetis (Graesse Nr. 24, 4 [S. 116, Z. 16-26]. - Mairhofer Nr. 269).

(81va-82ra) Agatha: (81va) Tit.: De virtutibus beate Agathe (Graesse Nr. 39 [S. 173, Z. 4-14]. Mairhofer Nr. 270). (81vb) Graesse Nr. 39 (S. 173, Z. 18-25). - Mairhofer Nr. 271.

(82ra-va) De undecim milibus virginum: (82ra) Graesse Nr. 158 (153), 2. - Mairhofer Nr. 272. (82rb) Graesse Nr. 158 (153), 3. - Mairhofer Nr. 273.

(82va-83ra) Margarita: Graesse Nr. 151 (146). - Mairhofer Nr. 274.

(83ra-84va) Thais meretrix: (83ra) Graesse Nr. 152 (147) (S. 677, Z. 25-S. 679, Z. 24). Mairhofer Nr. 275. (84rb) Graesse Nr. 152 (147) (S. 679, Z. 24-31). - Mairhofer Nr. 276. Expl. erweitert: ... Illa autem confusa recessit et postea penitencia ducta tandem conversa est ad dominum.

(84va-85va) Prothus et Iacinthus: Graesse Nr. 136 (129) (S. 602, Z. 14, Z. 17-S. 604, Z. 31). Mairhofer Nr. 277.

(85vb-92ra) Elisabeth: (85vb) Mairhofer Nr. 278. (91ra) Mairhofer Nr. 279.

(92ra) Schlussschrift: Explicit distinccio VII ${ }^{a}$.

1.5 (92ra-109va) Dist. 8: Miracula de defunctis.

(92ra-vb) Register mit Kapitelzahlen.

(92vb-93rb) De omnibus sanctis. Tit.: De festo omnium sanctorum et memoria mortuorum qualiter ortum habuerunt (Graesse Nr. 162 [157] [S. 727, Z. 12-S. 728, Z. 4]). Inc. gegenüber Ed. leicht abweichend, übereinstimmend mit Mairhofer Nr. 280.

(93rb-97rb) De commemoratione animarum: (93rb) Graesse Nr. 163 (158) (S. 731, Z. 4-24). Mairhofer Nr. 281. (93vb) Graesse Nr. 163 (158) (S. 731, Z. 26-S. 732, Z. 9). - Mairhofer Nr. 282. (94ra) Graesse Nr. 163 (158) (S. 732, Z. 13-22). - Mairhofer Nr. 283. (94rb) Graesse Nr. 163 (158) (S. 732, Z. 34-S. 733, Z.11). - Mairhofer Nr. 284. (94va) Tit.: De mortuis qui vivum defenderunt (Graesse Nr. 163 [158] [S. 733, Z. 20-25]. - Mairhofer Nr. 285). (94vb) Graesse Nr. 163 (158) (S. 733, Z. 11-18). - Mairhofer Nr. 286. (94vb) Graesse Nr. 163 (158) (S. 733, Z. 30-S. 734, Z. 19). - Mairhofer Nr. 287. (95rb) Mairhofer Nr. 288. (95vb) Graesse Nr. 163 (158) (S. 734, Z. 33-S. 735, Z. 3). - Mairhofer Nr. 289. (96ra) Graesse Nr. 163 (158) (S. 735, Z. 18-26). - Mairhofer Nr. 290. (96rb) Graesse Nr. 163 (158) (S. 735, Z. 32-S. 736, Z. 8). - Mairhofer Nr. 291. (96va) Graesse Nr. 163 (158) (S. 736, Z. 9-13). - Mairhofer Nr. 292. (96vb) Graesse Nr. 163 (158) (S. 738, Z. 34-S.739, Z. 13). - Mairhofer Nr. 293. (97ra) Graesse Nr. 163 (158) (S. 739, Z. 19-29). - Mairhofer Nr. 294. (97rb) Ed.: J. Klapper, Exempla aus Handschriften des Mittelalters (Sammlung mittellateinischer Texte II). Heidelberg 1911, Nr. 26, 27. - Mairhofer Nr. 295.

(97va) Mairhofer Nr. 296. (97va) Mairhofer Nr. 297. (97vb) Mairhofer Nr. 298. (98ra) Tit.: De duobus fratribus sacerdotibus horribile (Mairhofer Nr. 299). (98vb) 〈INNOcENTIUs III.»: De contemptu mundi, Lib. 3, cap. 7 (PL 217, 740A. - Mairhofer Nr. 300). (99ra) Mairhofer Nr. 301. (99vb-101rb) 〈Honorius AugustodunEnsis»: Speculum ecclesiae. Sermo generalis: (99vb) Ad milites (PL 172, 865A-C. - Mairhofer Nr. 302). (100ra) Ad pauperes (PL 172, 864C-865A. Mairhofer Nr. 303). (100rb) Ad agricolas (PL 172, 866B-867B. - Mairhofer Nr. 304). (101ra) Ad coniugatos (PL 172, 870A-B. - Mairhofer Nr. 305). 
(101rb-vb) 〈Herbertus Claraevallensis $\rangle$ : De miraculis = 〈Conradus Eberbacensis : Exordium magnum Cisterciense: (101rb) Lib. 2, cap. 33 (PL 185, 1344B-D) = Dist. 4, cap. 35, 1-48 (PL 185, 1123B-1124A). - Mairhofer Nr. 306. (101va) Lib. 2, cap. 34 (PL 185, 1344D-1345B) = Dist. 5, cap. 2, 41-64 (PL 185, 1126D-1127B). - Mairhofer Nr. 307. (101vb) Lib. 2, cap. 35 $($ PL 185, 1345C-D) = Dist. 5, cap. 3, 11-44 (PL 185, 1127C-1128B). - Mairhofer Nr. 308. (102ra-103va) «Guilelmus Malmesburiensis`: Gesta regum Anglorum: (102ra) Lib. 2, cap. 204, 1-6 (PL 179, 1188B-1189C. - Mairhofer Nr. 309). (103ra) Lib. 2, cap. 204, 7 (PL 179, 1189D-1190A. - Mairhofer Nr. 310). (103ra) Lib. 3, cap. 293, 1-2 (PL 179, 1262A-C. - Mairhofer Nr. 311).

(103va) Mairhofer Nr. 312. (104ra) Mairhofer Nr. 313. (105ra) Mairhofer Nr. 314. (105va) Mairhofer Nr. 315. (106va) Tit.: De clerico qui nepotem suum de monasterio extraxit (Mairhofer Nr. 316). (107rb) Mairhofer Nr. 317.

(107va-109ra) 〈Gregorius Magnus〉: Dialogi, Lib. 4: (107va) Cap. 33 (PL 77, 372C-373A. Mairhofer Nr. 318). (107vb) Cap. 40 (PL 77, 392C-393A. - Mairhofer Nr. 319). (108ra) Cap. 40 (PL 77, 393B-C. - Mairhofer Nr. 320). (108rb) Cap. 54 (PL 77, 413B-C. - Mairhofer Nr. 321). (108va) Cap. 55 (PL 77, 416A-B. - Mairhofer Nr. 322). (108vb) Cap. 56 (PL 77, 416B-C. Mairhofer Nr. 323). (108vb) Cap. 53 (PL 77, 412C-413A. - Mairhofer Nr. 324).

(109ra) Graesse Nr. 180 (175) (S. 816, Z. 12-33). - Mairhofer Nr. 325.

(109va) Schlussschrift: Explicit distinccio octava.

1.6 (109va-131ra) Dist. 9: Miracula de sacramentis ecclesiae.

(109va) Tit.: Incipit distinccio nona que agit per ordinem de sacramentis ecclesie et continet miracula LIIII ${ }^{\text {or }}$.

(109va-110rb) Register mit Kapitelzahlen.

(110rb-111va) Sacramentum baptismi: (110rb) Graesse Nr. 52, 2. - Mairhofer Nr. 326. (111rb) Graesse Nr. 117 (112) (S. 491, Z. 1-7); anschließend Ergänzung zur hl. Odilia, vgl. Graesse Nr. 190 (189). - Mairhofer Nr. 327. (111va) Graesse Nr. 181 (176), 1 (S. 824, Z. 24-28). Mairhofer Nr. 328. (111va) Graesse Nr. 181 (176) (S. 834, Z. 3-10). - Mairhofer Nr. 329. (111va) 〈Herbertus Claraevallensis〉: De miraculis, Lib. 3, cap. 32 (PL 185, 1377B-1378C. - Mairhofer Nr. 330). (112va) Mairhofer Nr. 331.

(113ra) Sacramentum confirmationis: Mairhofer Nr. 332.

(113va-114rb) Unctio infirmorum: (113va) Mairhofer Nr. 333. (114ra) Mairhofer Nr. 334.

(114rb-117ra) Sacramentum eucharistiae:

(114rb-116ra) 〈Paschasius RadBertus〉: De corpore et sanguine dni, cap. 14: (114rb) PL 120, 1317B-C. - Mairhofer Nr. 335. (114rb) PL 120, 1318B-1319C. - Mairhofer Nr. 336. (115ra) PL 120, 1319D-1320D. - Mairhofer Nr. 337. (115va) Mairhofer Nr. 338. (115vb) Mairhofer Nr. 339. (116ra) 〈Herbertus Claraevallensis»: De miraculis, Lib. 1, cap. 20 (PL 185, 1296D-1297D. - Mairhofer Nr. 340). (116va) Tit.: De quodam sacerdote inmundo et corpore Christi indigno terribile signum (Mairhofer Nr. 341). (116vb) 〈Herbertus Claraevallensis〉: De miraculis, Lib. 3, cap. 28-29 (PL 185, 1373D-1374D. - Mairhofer Nr. 342). (117ra) Mairhofer Nr. 343.

(117ra-126rb) Sacramentum paenitentiae et reconciliationis: (117ra) Mairhofer Nr. 344. (117vb) Mairhofer Nr. 345. (118ra) 〈GRIMLAICUs〉: Regula solitariorum, cap. 36 (PL 103, 625D-626A. Mairhofer Nr. 346). (118rb) Mairhofer Nr. 347. (118va) Mairhofer Nr. 348. (119ra) Mairhofer Nr. 349. (119va) Mairhofer Nr. 350. (120ra) Mairhofer Nr. 351. (120va) Mairhofer Nr. 352. (121va) 〈Sigbertus Gemblacensis〉: Chronica 823 (PL 160, 157C. - Mairhofer Nr. 353). (121va) 〈Odo de Cheriton〉, Parabolae 188 (Ed. Hervieux IV 339. - Mairhofer Nr. 354). (121vb) Mairhofer Nr. 355. (122vb) Mairhofer Nr. 356. (122vb) Graesse Nr. 181 (176), 4 (S. 834, Z. 17-21). Mairhofer Nr.357. (123ra) 〈Guilelmus Malmesburiensis»: Gesta regum Anglorum, Lib. 2, cap. 175 (PL 179, 1146D-1147A. - Mairhofer Nr. 358). (123vb) Tit.: De quodam dyacono 
qui tonsuram deposuit (Mairhofer Nr. 359). (123vb) 〈Herbertus Claraevallensis〉: De miraculis, Lib. 3, cap. 13 (PL 185, 1365C-D. - Mairhofer Nr. 360). (123vb) Mairhofer Nr. 361. (124rb) Mairhofer Nr. 362. (124vb) Mairhofer Nr. 363. (125rb) Mairhofer Nr. 364. (125va) «SulPicius Severus»: Dialogi, Lib. 1, cap. 14 (PL 20, 192D-193B. - Mairhofer Nr. 365). (126ra) Tit.: De latrone qui veniam meruit propter IIII ${ }^{\text {or }}$ candelas (Mairhofer Nr. 366). (126rb) Mairhofer Nr. 367. (126vb) Tit.: De obsesso qui monachum non confessum confudit (Mairhofer Nr. 368). (126vb) 〈CAesarius Heisterbacensis〉: Dialogus miraculorum, Dist. 3, cap. 6. Tit.: Item aliud de eodem (Ed. Strange I, 116-120. - Mairhofer Nr. 369). (127rb) Tit.: Quod confessio non tantum anime sed eciam corpori prodest (Mairhofer Nr. 370). (127va) Mairhofer Nr. 371. (127va) Mairhofer Nr. 372. (127vb) Mairhofer Nr. 373. (127vb) Mairhofer Nr. 374. Expl.: ... sine confessione et viatico exspiravit. (128ra) Mairhofer Nr. 375.

(128rb-131ra) Sacramentum matrimonii: (128rb) 〈Herbertus Claraevallensis〉: De miraculis, Lib. 3, cap. 34 (PL 185, 1379C-1381B. - Mairhofer Nr. 376). (129rb) Mairhofer Nr. 377. (129va) Mairhofer Nr. 378. Expl.: ... angelorum consorcia in celestibus meruerunt. (130ra) Mairhofer Nr. 379.

(131ra) Schlussschrift: Explicit distinccio $I X^{a}$.

1.7 (131ra-187vb) Dist. 10: Miracula de factis et dictis theologorum.

(131ra) Tit.: Incipit distinccio $X^{a}$ que agit de diversis videlicet factis et dictis theologorum et continent (!) sub compendio capitula $C C^{a}$ et $X X^{a}$ valde utilia necnon et delectabilia (Mairhofer Bl. 118vb).

(131ra-133va) Register mit Kapitelzahlen.

(133va) Ed.: R. Lotti, Contributi su Domenico Cavalca (c. 1270-1342), Diss. Amsterdam 1987, 231-232. - Mairhofer Nr. 390. (133vb) 〈Guilelmus MalmesBuRIEnsis〉: Gesta regum Anglorum, Lib. 2, cap. 174 (PL 179, 1146A-C. - Mairhofer Nr. 391). (134rb) Mairhofer Nr. 392. (134va) 〈Guilelmus Malmesburiensis`: Gesta regum Anglorum, Lib. 2, cap. 207 (PL 179, 1192A-B. Mairhofer Nr. 393). (134va) Mairhofer Nr. 394. (135va) Mairhofer Nr. 395. (136rb) 〈Guilelmus Malmesburiensis>: Gesta regum Anglorum, Lib. 2, cap. 192 (PL 179, 1172A-B. - Mairhofer Nr. 396).

(136vb-138rb) 〈Sulpicius Severus〉: Dialogi, Lib. 1: (136vb) Cap. 15 (PL 20, 193D-194B. Mairhofer Nr. 397). (137ra) Cap. 17 (PL 20, 194D-195A. - Mairhofer Nr. 398). (137rb) Cap. 18 (PL 20, 195C. - Mairhofer Nr. 399). (137vb) Cap. 19 (PL 20, 195D-196B. - Mairhofer Nr. 400). (138ra) Cap. 20 (PL 20, 196B-197A. - Mairhofer Nr. 401).

(138rb) 〈Wernerus de Ellerbach〉: Deflorationes ss. patrum, Lib. 1, Sermo in rogationibus (PL 157, 968B-C. - Mairhofer Nr. 402).

(138va-139va) 〈Honorius Augustodunensis»: Speculum ecclesiae: (138va) Dnca 1. post pent. (PL 172, 1042B-D. - Mairhofer Nr. 403). (139ra) Dnca 20. post pent. (PL 172, 1066D-1068A. Mairhofer Nr. 404).

(139va-141ra) 〈Gregorius Magnus»: XL Homiliae in Evangelia: (139va) Lib. 1 (PL 76, 1133C-1134B. - Mairhofer Nr. 405). (140ra) Lib. 2 (PL 76, 1300B-D. - Mairhofer Nr. 406). (140rb) Lib. 1 (PL 76, 1158B-1159A. - Mairhofer Nr. 407).

(141ra-144va) Ioseph: (141ra) Graesse Nr. 67 (63), 2 (S. 298, Z.15-S. 299, Z. 13). - Mairhofer Nr. 408. (141vb) Graesse Nr. 67 (63), 2 (S. 299, Z. 15-S. 300, Z. 16). - Mairhofer Nr. 409. (142rb) Graesse Nr. 67 (63), 2 (S. 300, Z. 16-301, Z. 16). - Mairhofer Nr. 410. (143ra) Graesse Nr. 67 (63), 2 (S. 301, Z. 16-36). - Mairhofer Nr. 411. (143rb) Graesse Nr. 67 (63), 2 (S. 301, Z. 37-S. 302, Z. 11). - Mairhofer Nr. 412. (143vb) Graesse Nr. 67 (63), 2 (S. 302, Z. 11-32). Mairhofer Nr. 413. (144ra) Graesse Nr. 67 (63), 2 (S. 302, Z. 32-S. 303, Z. 9). - Mairhofer Nr. 414. (144rb) Graesse Nr. 67 (63), 2 (S. 303, Z. 9-15). - Mairhofer Nr. 415.

(144va) Iudas Iscariot: Graesse Nr. 45 (S. 184, Z. 1-S. 186, Z. 13). - Mairhofer Nr. 416. 
(145vb-147vb) Pilatus: (145vb) Graesse Nr. 53 (51) (S. 231, Z. 21-S. 232, Z. 24). - Mairhofer Nr. 417. (146va) Graesse Nr. 53 (51) (S. 232, Z. 30-233, Z. 26). - Mairhofer Nr. 418. (147ra) Graesse Nr. 53 (51) (S. 233, Z. 27-S. 234, Z. 26). - Mairhofer Nr. 419.

(147vb-148vb) Nero: (147vb) Graesse Nr. 89 (84), 3 (S. 376, Z. 5-22). - Mairhofer Nr. 420. (148ra) Graesse Nr. 89 (84), 3 (S. 376, Z. 25-377, Z. 14). - Mairhofer Nr. 421. (148va) Graesse Nr. 89 (84), 3 (S. 377, Z. 15-29). - Mairhofer Nr. 422.

(148vb-150ra) Iulianus Apostata: (148vb) Graesse Nr. 30, 5 (S. 143, Z. 35-S. 144, Z. 11). Mairhofer Nr. 423. (149ra) Graesse Nr. 30, 5 (S. 144, Z. 12-23). - Mairhofer Nr. 424. (149rb) Graesse Nr. 125 (120), 1 (S. 571, Z. 3-8). - Mairhofer Nr. 425. (149rb) Graesse Nr. 125 (120), 1 (S. 571, Z. 8-14). - Mairhofer Nr. 426. (149va) Graesse Nr. 125 (120), 1 (S. 571, Z. 14-21). Mairhofer Nr. 427. (149va) Graesse Nr. 125 (120), 1 (S. 571, Z. 21-28). - Mairhofer Nr. 428. (149vb) Graesse Nr. 30, 5 (S. 144, Z. 34-35). - Mairhofer Nr. 429. Inc.: In odium quoque Christianorum Iulianus templum ...

(150ra-va) Basilius: (150ra) Graesse Nr. 30, 5 (S. 144, Z. 35-S. 145, Z. 6). - Mairhofer Nr. 430. (150ra) Graesse Nr. 30, 5 (S. 145, Z. 6-30). - Mairhofer Nr. 431.

(150va) Graesse Nr. 181 (176), 4 (S. 838, Z. 9-15). - Mairhofer Nr. 432. (150va) Graesse Nr. 181 (176), 4 (S. 837, Z. 31-38). - Mairhofer Nr. 433. (150vb) Graesse Nr. 181 (176), 4 (S. 837, Z. 13-21). - Mairhofer Nr. 434. (151ra) Graesse Nr. 181 (176), 4 (S. 836, Z. 37-S. 837, Z. 10). Mairhofer Nr. 435. (151rb) Graesse Nr. 181 (176), 4 (S. 839, Z. 1-12). - Mairhofer Nr. 436. (151va) Mairhofer Nr. 437. (152ra) Mairhofer Nr. 438. (152rb) Graesse Nr. 181 (176), 4 (S. 840, Z. 3-841, Z. 5). - Mairhofer Nr. 439. (153rb) Mairhofer Nr. 440. (153vb) Graesse Nr. 136 (129) (S. 603, Z. 4-9). - Mairhofer Nr. 441. (153vb) Mairhofer Nr. 442. (154ra) Graesse Nr. 182 (177) (S. 846, Z. 39-S. 847, Z. 14). - Mairhofer Nr. 443. (154rb) Graesse Nr. 182 (177) (S. 854, Z. 9-17). - Mairhofer Nr. 444. (154rb) Mairhofer Nr. 445. (154va) Mairhofer Nr. 446. (154vb) 3. Esr 3,3-4,47. - Mairhofer Nr. 447. (156rb) Tit.: De $X V^{m}$ signis ante diem iudicii (Graesse Nr. 1 [S. 6, Z. 35-7, Z. 24]). - Expl.: ... resurgent omnes et tunc apparebit filius hominis in aere. (156va-162rb) «Odo de Cheriton`: Parabolae: (156va) Nr. 6 (Ed. Hervieux IV 267. - Mairhofer Nr. 448). (156vb) Nr. 8 (Ed. Hervieux IV 268. - Mairhofer Nr. 449). (157ra) Mairhofer Nr. 450. (157ra) Nr. 12 und 13 (Ed. Hervieux IV 271. - Mairhofer Nr. 451). (157rb) Nr. 26 (Ed. Hervieux IV 275. - Mairhofer Nr. 452). Expl.: ... cadaver illius cuius fetorem abhorrens. (157rb) Nr. 42 (Ed. Hervieux IV 281. - Mairhofer Nr. 453). (157va) Nr. 45 (Ed. Hervieux IV 282. - Mairhofer Nr. 454). (157va) Nr. 46 (Ed. Hervieux IV 282. - Mairhofer Nr. 455). Expl.: ... da exemplum. (157vb) Nr. 47 (Ed. Hervieux IV 283. - Mairhofer Nr. 456). (158ra) Nr. 52 (Ed. Hervieux IV 285. - Mairhofer Nr. 457). (158ra) Mairhofer Nr. 458. (158rb) Nr. 74 (Ed. Hervieux IV 294. Mairhofer Nr. 459). Expl.: ... comedo. Hoc ordo. (158va) Nr. 84 (Ed. Hervieux IV 298. - Mairhofer Nr. 460). (158va) Nr. 86 (Ed. Hervieux IV 298-299. - Mairhofer Nr. 461). (158vb) Nr. 88 (Ed. Hervieux IV 299. - Mairhofer Nr. 462). (158vb) Mairhofer Nr. 463. (159ra) Nr. 93 (Ed. Hervieux IV 301. - Mairhofer Nr. 464). (159ra) Mairhofer Nr. 465. (159rb) Nr. 102 (Ed. Hervieux IV 304. - Mairhofer Nr. 466). (159va) Nr. 105 (Ed. Hervieux IV 305. - Mairhofer Nr. 467). (160vb) Nr. 116 und 117 (Ed. Hervieux IV 309-310. - Mairhofer Nr. 468). (160ra) Nr. 128. Tit.: Quod verus religiosus laudes et vituperia vilipendit (Ed. Hervieux IV 313-314). (160ra) Vgl. Nr. 123 (Ed. Hervieux IV 312. - Mairhofer Nr. 469). (160ra) Nr. 132 (Ed. Hervieux IV 315316. - Mairhofer Nr. 470). (160rb) Nr. 131 (Ed. Hervieux IV 315. - Mairhofer Nr. 471). (160va) Nr. 136 (Ed. Hervieux IV 217. - Mairhofer Nr. 472). (161ra) Nr. 133 (Ed. Hervieux IV 316. Mairhofer Nr. 473). (161ra) Nr. 143 (Ed. Hervieux IV 320-321. - Mairhofer Nr. 474). (161rb) Nr. 144. Tit.: Qui hic contempnitur in celo consolatur (Ed. Hervieux IV 321. - Mairhofer Nr. 475). (161va) Nr. 153. Tit.: De cupiditate, luxuria et superbia (Ed. Hervieux IV 325. Mairhofer Nr. 476). (161va) Nr. 163 (Ed. Hervieux IV 328. - Mairhofer Nr. 477). (161vb) Nr. 164 (Ed. Hervieux IV 328-329. - Mairhofer Nr. 478). (161vb) Nr. 157 (Ed. Hervieux IV 
329-330. - Mairhofer Nr. 479). (162ra) Nr. 171. Tit.: De utilitate infirmitatis (Ed. Hervieux IV 332. - Mairhofer Nr. 480).

(162rb) Mairhofer Nr. 481. (162rb) Mairhofer Nr. 482. (162va) Mairhofer Nr. 483. (162va) Mairhofer Nr. 484. (162vb) Graesse Nr. 180 (175) (S. 815, Z. 24-S. 816, Z. 9). - Mairhofer Nr. 485. (163ra) Mairhofer Nr. 486. (163rb) Mairhofer Nr. 487.

(163rb-164vb) 〈Grimlaicus〉: Regula solitariorum: (163rb) Cap. 44 (PL 103, 635B-C. - Mairhofer Nr. 488). (163va) Cap. 56 (PL 103, 847D-648A. - Mairhofer Nr. 489). (163vb) Cap. 54 (PL 103, 615D. - Mairhofer Nr. 490). Expl.. ... perimunt et vanam gloriam ostendunt. (164ra) Cap. 57 (PL 103, 648D. - Mairhofer Nr. 491). (164ra) Cap. 39 (PL 103, 630B. - Mairhofer Nr. 492). (164rb) Mairhofer Nr. 493. (164va) Mairhofer Nr. 494.

(164va) Vitae patrum, Lib. 5, Verba seniorum, libell. 16, cap. 19 (PL 73, 973B-C) $=$ «GRIMLAICUS): Regula solitariorum, cap. 59 (PL 103, 654A-B. - Mairhofer Nr. 495).

(164vb) Mairhofer Nr. 496. (164vb) Mairhofer Nr. 497. Expl.. ... et obiit in conversacione bona. (165ra) Tit.: Quod efficaciora sunt exempla (Mairhofer Nr. 498). (165rb) Mairhofer Nr. 499. (165va) Mairhofer Nr. 500. (165va) Mairhofer Nr. 501. (165vb) Mairhofer Nr. 502. (166ra) Mairhofer Nr. 503. (166rb) 〈Gregorius Magnus`: Dialogi, Lib. 4, cap. 11 (PL 77, 336B-337A. Mairhofer Nr. 504). (166va) Mairhofer Nr. 505. (166va) Vitae patrum, Lib. 5, Verba seniorum, libell. 3, cap. 23 (PL 73, 864A-B. - Mairhofer Nr. 506). (166va) Mairhofer Nr. 507. (166vb) Mairhofer Nr. 508. (166vb) Tit.: Quod nichil nobis manet nisi quod pauperibus damus (Mairhofer Nr. 509). (167ra) Mairhofer Nr. 510. (167rb) Mairhofer Nr. 511. (167rb) Mairhofer Nr. 512. (167va) Vitae patrum, Lib. 5, Verba seniorum, libell. 6, cap. 18 (PL 73, 891C-D. - Mairhofer Nr. 513). (167vb) Mairhofer Nr. 514. (167vb) Mairhofer Nr. 515. (168ra) Vitae patrum, Lib. 5, Verba seniorum, libell. 6, cap. 21 (PL 73, 892B-C. - Mairhofer Nr. 516). (168rb) Mairhofer Nr. 517. (168va) Mairhofer Nr. 518. (168vb) Vitae patrum, Lib. 5, Verba seniorum, libell. 3, cap. 14 (PL 73, 862B-C. - Mairhofer Nr. 519). (168vb) Mairhofer Nr. 520. (169ra) «Ps.-Rufinus AQuileIENSIS»: Vitae patrum, Lib. 3, Verba seniorum, cap. 55 (PL 73, 768C-D) = «Grimlaicus $:$ Regula solitariorum, cap. 39 (PL 103, 630C-D). - Mairhofer Nr. 521. (169rb) 〈Hieronymus»: Epistola 107 (ad Laetam) (PL 22, 872. - Mairhofer Nr. 522). (169rb) Mairhofer Nr. 523. (169va) Mairhofer Nr. 524. (169vb) Mairhofer Nr. 525. (169vb) Mairhofer Nr. 526. (170rb) Mairhofer Nr. 527. (170rb) Mairhofer Nr. 528. (170va) Mairhofer Nr. 529. (170vb) Vgl. Vitae patrum, Lib. 5, Verba seniorum, libell. 8, cap. 24 (PL 73, 909C. - Mairhofer Nr. 530). (170vb) Mairhofer Nr. 531. (171ra) Mairhofer Nr. 532. (171rb) Mairhofer Nr. 533. (171rb) (Petrus CantoR»: Verbum abbreviatum, cap. 86 (PL 205, 256D-257A. - Mairhofer Nr. 534). (171va) «NICoLAus Pergamenus): Dialogus creaturarum, dial. 75, 23-36 (Ed.: Th. Graesse, Die beiden ältesten lateinischen Fabelbücher des Mittelalters des Bischofs Cyrillus „Speculum sapientiae“ und des Nicolaus Pergamenus „Dialogus creaturarum“. Stuttgart 1880, 219. - Mairhofer Nr. 535). (171va) Mairhofer Nr. 536. (171vb) Mairhofer Nr. 537. (172ra) Mairhofer Nr. 538. (172rb) Mairhofer Nr. 539. (172va) (Ps.-Rufinus Aquileiensis`: Vitae patrum, Lib. 3, Verba seniorum, cap. 118 (PL 73, 782C-D. - Mairhofer Nr. 540). (172vb) Mairhofer Nr. 541. (172vb) Mairhofer Nr. 542. (173ra) 〈Gregorius Magnus»: Dialogi, Lib. 4, cap. 19 (PL 77, 352A-B. - Mairhofer Nr. 543). (173ra) Mairhofer Nr. 544. (173va) Mairhofer Nr. 545. (173va) «Rufinus Aquileiensis`: Historia monachorum, cap. 1 (PL 21, 394C. - Mairhofer Nr. 546). (173vb) Mairhofer Nr. 547. (173vb) Mairhofer Nr. 548. (174ra) Mairhofer Nr. 549. (174ra) Mairhofer Nr. 550. (174rb) 〈Ps.-Rufinus AQuILEIENSIS): Vitae patrum, Lib. 3, Verba seniorum, cap. 97 (PL 73, 778A-C) und Vitae patrum, Lib. 6, Verba seniorum, libell. 3, cap. 17 (PL 73, 1013D-1014B. - Mairhofer Nr. 551). (174va) Mairhofer Nr. 552.

(174va-175ra) 〈InNocentius III.): De contemptu mundi, Lib. 2: (174va) Cap. 36 (PL 217, 731D-732A. - Mairhofer Nr. 553). (174vb) Cap. 39 (PL 217, 733B. - Mairhofer Nr. 554). (175ra) Cap. 20 (PL 217, 725A. - Mairhofer Nr. 555). (175ra) Mairhofer Nr. 556. 
(175rb-176va) Vitae patrum, Lib. 5, Verba seniorum: (175rb) Libell. 14, cap. 52 (PL 73, 963BC. - Mairhofer Nr. 557). (175va) Mairhofer Nr. 558. (175va) Libell. 14, cap. 72 (PL 73, 966AB. - Mairhofer Nr. 559). (176ra) Libell. 5, cap. 34 (PL 73, 882D-883A. - Mairhofer Nr. 560). (176rb) Mairhofer Nr. 561. (176rb) Libell. 3, cap. 2 (PL 73, 860C-D. - Mairhofer Nr. 562). (176va) Libell. 17, cap. 18 (PL 73, 976B. - Mairhofer Nr. 563).

(176va) Mairhofer Nr. 564. (176vb) Mairhofer Nr. 565. (177ra)〈Petrus Cantor»: Verbum abbreviatum, cap. 98 (PL 205, 280A-B. - Mairhofer Nr. 566). (177ra) Mairhofer Nr. 567. (177rb) 〈Gregorius Magnus`: Dialogi, Lib. 1, cap. 9 (PL 77, 197B-C. - Mairhofer Nr. 568). (177va) Mairhofer Nr. 569. (177va) 〈Rufinus AQuileiensis»: Historia monachorum, cap. 31 (PL 21, 458B-C. - Mairhofer Nr. 570). (177vb) Mairhofer Nr. 571.

(178ra-182ra) 〈Ps.-Rufinus Aquileiensis»: Vitae patrum: (178ra) Lib. 3, cap. 28 (PL 73, 756B-C) und Lib. 6, Verba seniorum, libell. 2, cap. 17 (PL 73, 1004A. - Mairhofer Nr. 572). (178ra) Lib. 3, cap. 13 (PL 73, 745B-746B. - Mairhofer Nr. 573). (178rb) Mairhofer Nr. 574. (178va) Mairhofer Nr. 575. (178va) Mairhofer Nr. 576. (178vb) Mairhofer Nr. 577. (178vb) Mairhofer Nr. 578. (179vb) Mairhofer Nr. 579. (180va) Mairhofer Nr. 580. (181rb) Lib. 3, cap. 84 (PL 73, 775B-C. - Mairhofer Nr. 581). (181vb) 〈Sulpicius Severus, Iohannes Cassianus : Vitae patrum, Lib. 4, Excerpta, cap. 43 (PL 73, 841A-C. - Mairhofer Nr. 582).

(182ra-183vb) 〈Rufinus Aquileiensis〉: Historia monachorum: (182ra) Cap. 1 (PL 21, 399A-400A. - Mairhofer Nr. 583). (182vb) Cap. 6 (PL 21, 401C-403C. - Mairhofer Nr. 584). (183vb-187va) Vitae patrum: (183vb) «Sulpicius Severus, Iohannes Cassianus : Lib. 4, Excerpta, cap. 52 (PL 73, 846B-D. - Mairhofer Nr. 585). (184ra) Lib. 5, Verba seniorum, libell. 4, cap. 27 (PL 73, 880C-D. - Mairhofer Nr. 586). (184va) Lib. 5, Verba seniorum, libell. 5, cap. 37 (PL 73, 883D-884B. - Mairhofer Nr. 587). (185ra) Lib. 5, Verba seniorum, libell. 5, cap. 30 (PL 73, 881C. - Mairhofer Nr. 588). (185ra) Lib. 5, Verba seniorum, libell. 7, cap. 41 (PL 73, 903A. Mairhofer Nr. 589). (185rb) Lib. 5, Verba seniorum, libell. 7, cap. 43 (PL 73, 903B-904A. Mairhofer Nr. 590). (185vb) Lib. 5, Verba seniorum, libell. 10, cap. 10 (PL 73, 913C-D. Mairhofer Nr. 591). (186ra) Lib. 5, Verba seniorum, libell. 14, cap. 18 (PL 73, 952A) = 〈GRIMLAICUS〉: Regula solitariorum, cap. 58 (PL 103, 649D-650A). - Mairhofer Nr. 592. (186rb) Lib. 6, Verba seniorum, libell. 1, cap. 12 (PL 73, 994C-995A. - Mairhofer Nr. 593). (186vb) Lib. 6, Verba seniorum, libell. 1, cap. 13 (PL 73, 995A-B. - Mairhofer Nr. 594). (187ra)〈Ps.Rufinus Aquileiensis〉: Vitae patrum, Lib. 3, Verba seniorum, cap. 54 (PL 73, 768B-C. - Mairhofer Nr. 595). (187ra) Lib. 3, Verba seniorum, cap. 55 (PL 73, 768D. - Mairhofer Nr. 596).

(187va) «Godefridus Altissiodorensis»: Declamationes ex s. Bernardi sermonibus, cap. 25 (PL 184, 454C-455A. - Mairhofer Nr. 597).

(187vb) Schlussschrift: Hic explicit liber qui dicitur Lacteus liquor. Post hec incipiunt alia exempla que non videbantur superius contineri.

Lit.: Zur Verfasserfrage und Überlieferung s. Mairhofer 9-74. Zur Lacteus liquor-Sammlung am Beispiel von Heiligenkreuz, Stiftsbibl., Cod. 323 vgl. Welter 279-281.

2 (187vb-201rb) 27 weitere Exempla: Miracula DE DIVERSIS.

Unmittelbar an Lacteus liquor anschließend und nach der Angabe am oberen Blattrand zu Dist. 10 gehörend.

(187vb) Tit.: De sancto Thoma martyre et sua domina sancta Maria. - Inc.: Sanctus Thomas Cantuariensis bone yndolis adolescens cum adhuc in scolis ... - Expl... .. de medio sunt subtracti. (188va) Tit.: De sancto Udalrico episcopo et tribus bursis dyalogus. - Inc.: Sanctus Udalricus presul Augustensis cum quandam ecclesiam sue diocesis dedicare vellet ... - Expl.: ... signa ex corde ostendere.

(189ra) Visio Philiberti, 1. Fassung (Ed.: L. Zatočil, Die Visio Fulberti nach einer bislang unbeachteten Brünner Handschrift aus dem Ende des 14. Jahrhunderts. Sborník praci filosofické fakulty Brněnské University D. Řada literárněvědná 21 (1974) 39-47. - Walther, Initia Nr. 11894). 
Tit.: Conflictus corporis et anime. - Inc.: Noctis sub silencio tempore brumali deditus ... - Expl.: ... et me Christi manibus totum commendavi.

Lit.: N. F. Palmer, „Visio Philiberti“. Verfasserlexikon² X 412-418.

(191rb) Tit.: De quodam milite suspenso et virtute corporis Christi. - Inc.: Miles quidam aput Ffridricum imperatorem in multis est accusatus ... - Expl.: ... miraculum divulgantes.

$(191 \mathrm{vb})$ Tit.: De virtute confessionis et quodam iuvene qui apostatavit (enthalten in: J. Major, Magnum speculum exemplorum. Circino aureo 1611, 44-45 [Nr. III]).

(192vb) Tit.: Quod infirmitas cum paciencia mitigat penam purgatorii. - Inc.: Monachus quidam vite laudabilis sed corpore debilis fuit ... - Expl.: ... admodum superius est relatum.

(193ra) Tit.: De quodam magno latrone et virtute penitencie. - Inc.: Legitur quod in dyocesi Tridentina quidam latro fuerat famosus ... - Expl.: ... virginis devotissime ieiunare.

(194ra) Tit.: De sancto Bernhardo et monacho suo qui habuit multos pueros (enthalten in: J. Major, Magnum speculum exemplorum. Circino aureo 1611, 46 [Nr. VI]).

(194va) Tit.: De quodam usurario qui vidit duos nigros equos et de dyabolo. - Inc.: Usurarius quidam cum crux in quibusdam partibus predicaretur cum ceteris cecus non ex devocione sed ex importuna circumstancium ammonicione ... - Expl.: ... et viatico est defunctus et sepultus in inferno.

(195rb) Tit.: De usurario et eius corde inexplebili. - Inc.: Usurarius quidam dives nimis diversarum ... - Expl.: ... postmodum aliis enarravit.

(196rb) Tit.: De sancto Thoma et milite. - Inc.: Miles quidam beatum Thomam apostolum ardenter diligebat ... - Expl.. ... sponso valedixit.

(197ra) Tit.: Miraculum de decima. - Inc.: Miles quidam in dandis decimis suis tante erat iusticie ut ei summum esset studium ... - Expl.: ... uberiores fructus fecit.

Parallelüberlieferung: Innsbruck, ULB Tirol, Cod. 285, Bl. 107r.

(197rb) Tit.: De quodam converso et malo consilio dyaboli. - Inc.: Conversus quidam in quodam cenobio cum monachis loquendo ... - Expl.: ... et anima confundatur.

(197vb) Tit.: De sancto Severino et purgatorio. - Inc.: Legitur de sancto Severino quod vivens mortuos suscitavit ymo omnem infirmitatem ... - Exp.: ... post hec disparuit.

(198rb) Tit.: De dyabolo et globo igneo. - Inc.: Fuit quidam vir lascivus valde contigit eum ... Expl.: ... possum moveri pede.

(198va-200va) 〈Gregorius Magnus〉: Dialogi (CPL Nr. 1713).

(198va) Lib. 3, cap. 38 (PL 77, 316A-317A). Tit.: De sancto Eutico et de mundo fugiendo. (198vb) Lib. 3, cap. 4 (PL 77, 224C-225A). Tit.: De diversis vocibus dyaboli propter superbiam. - (199ra) Lib. 3, cap. 5 (PL 77, 225C-228B). Tit.: De ceco episcopo et veneno. - (199rb) Lib. 3, cap. 10 (PL 77, 236B-237A). Tit.: Quod elementa Deo et sanctis obediunt homines vero non. - (199rb) Lib. 3, cap. 11 (PL 77, 237A-B). Tit.: De virtute hospitalitatis. - (199va) Lib. 4, cap. 36 (PL 77, 381C). Tit.: De suppliciis inferni. - (199vb) Lib. 4, cap. 32 (PL 77, 372C-373A). Tit.: De cuiusdam morte subitanea. - (200ra) Lib. 3, cap. 14 (PL 77, 218B-C). Tit.: Qui detrahunt aliena et hereditabunt vermes et serpentes. - (200ra) Lib. 3, cap. 15 (PL 77, 253C-D). Tit.: De serpentibus qui propter oracio (!) mortui sunt et propter oracionem aves deportaverunt. (200rb) Lib. 3, cap. 16 (PL 77, 257B-D). Tit.: De dyabolo qui per formam serpentis apostatare studuit quendam sanctum.

(200va) Tit.: De risione dyabolorum pro uno calcio. - Inc.: Legitur de sancto Udalrico cum vellet causa devocionis ... - Expl.. ... peccatum mortale evasit.

(200vb) Tit.: De rustico paupere et morte. - Inc.: Fuit quidam rusticus qui cum iret ... - Expl.: ... maioribus sanctis in celo.

(201rb) Schlussschrift: Expliciunt miracula de diversis. 
3 (201va-202ra) MiraKel.

(201va-b) Tit.: Prolacio. - Inc.: Primo debemus querere Christum cum plena cordis conversione ... - Expl.: ... pereunt omnia prius facta.

(201vb-202ra) Tit.: Miraculum. - Inc.: Exemplum legitur quod quidam pauper manibus laborabat ... - Expl.: ... gracias Deo retulit. Confidamus ergo fratres in solo Deo.

Parallelüberlieferung: Schlägl, Stiftsbibl., Cod. 202, Bl. 228v.

(202rb-vb) nur Rahmung und Linierung.

4 (203ra-210ra) ÜBERSETzung vom Lat. ins Dt. einzelner Wörter des Psalteriums, der Cantica, des Pater noster, des Credo, des Te Deum, des Symbolum Athanasianum und des Ave Maria. Jeweils Anfang der einzelnen Psalmen und Gebete angeführt, anschließend ausgewählte Wörter übersetzt (lat. Wörter in Schwarz, dt. Übersetzung in Rot, meist darüber, vereinzelt daneben).

Tit.: Vlgarizacio (!) aliquorum vocabulorum psalterii. - Inc.: Beatus vir qui non abiit/Pestilencie (darüber:) Der Su ehte ... - Expl.: ... Alvo. Pauch. Coadunare. zů fügen.

5 (210ra-225va) Tractatus DE DECEM PRAECEPTIS.

(210ra) Prolog. Tit.: De incredulitate hominum prologus. - Inc.: Audi Israel Deus tuus unus est (Dt 6,4). Sunt autem septem genera hominum qui Deum non colunt sed ydola adorant. Primus genus est de quibus ... - Expl.: ... regnum Dei non videbunt.

(211rb) Text. Inc.: Non sumas nomen Dei tui invanum. Augustinus. Nomen Dei sumit invanum qui semper turpia verba profert ex corde. Unde legitur in dyalogo Gregorii ... - Expl.: ... vel incendunt vel depredantur, hos neque episcopus absolvere nisi gracia apostolici etc.

Traktat endet hier nach dem siebten Gebot.

Parallelüberlieferung: Innsbruck, ULB Tirol, Cod. 230, Bl. 155ra (bis Bl. 162rb übereinstimmend) (219ra-b) am unteren Blattrand Ergänzung von anderer Hand: Exemplum de quodam rege qui habuit duos camerarios valde invidos ... et hoc fecit propter invidiam ut suo socio ambo oculi eruerentur.

6 (225va-228rb) Sentenzen zum Dies Sabbati verschiedener Auctoritates, u.a. Hieronymus, Augustinus, Gregorius, Seneca, Beda Venerabilis, Malachias, Ambrosius, Eusebius.

Tit.: Auctoritates sanctorum de diversis sentenciis. - Inc.: Memento ut sanctifices diem sabbati. Per sabbatum intelligimus sollempnitates sanctorum in quibus quam plurimum homines vacant commessacionibus et ebrietatibus ... - Expl.: ... Bernhardus. Recole primordia tua hec pudorem addunt. Attende media illa dolorem ingerunt. Memorare novissima illa mecum incuciunt. Cogita unde veneris et erubesce ubi sis et ingemisce et contremisce quo vadis.

7 (228rb-vb) Verse zu Stationen im Leben Mariens und Jesu (vgl. Walther, Initia Nr. 6444).

1) De annunciacione versus. - Fert paranynphus ave quo mundus solvitur ave.

2) De salutacione Marie et Elizabet. - Scandit montana pia virgo stupet veterana.

3) De nativitate domini. - Sic mundo pactum solvit verbo caro factum.

4) Christus pastoribus nunciatur. - Grex cum pastore pacis letatur amore.

5) Adoratur a magys. - Dona ferunt proceres colitur quibus inclitus heres. Edocti fato dant reges munera nato.

6) De purificacione sancte Marie. - Sistitur hic domino redimendus turture bino.

7) De occisione parvulorum. - Plebs ab ymatu parit Herodis cruciatu.

8) De fuga in Egyptum. - Dum mors grassatur puero fuga tuta paratur.

9) De sessione Ihesu. - Inter doctores populi sedet et seniores.

10) De baptismo Christi. - Iordanis sacri subit hic baptisma lavatri./Contactu mundas nobis Deus conficit undas.

11) De mutacione aque et (radiert, korr. zu in) vinum. - Hic contra morem vini gerit unda saporem.

12) De vocacione Petri et Andree. - Hos vocat in primis Pelagi salvator ab ymis.

13) De cura leprosi. - Mundat leprosum tangens sub lege perosum. 
14) De filio regali. - Regulus obnatum stat supplex febre gravatum.

15) Convertit Samaritanam apud puteum. - Fons vite lassus solus sitit essibus assus.

16) De sedacione tempestatis maris. - (am unteren Blattrand eingefügt: Pupe saporatus iubet obmutescere natus.) Imperat sic ventis Pelagi silet unda furentis.

8 (228vb) Kurztraktat über die Legende der 30 Denare, unvollständig.

Tit.: Nota. Translacionem denariorum pro quibus venditus fuit Ihesus. - Inc.: Primus qui hic fuit Ninius idem fabricator fuit Thare ille dedit Abram. Abram dedit Ysmahelitis ... - Expl. mut.: ... et XV custodientibus sepulchrum [

$\left(\mathrm{I}^{*} \mathrm{r}-\mathrm{v}\right)$ leer.

A. $\mathbf{P}$.

\section{Cod. 315}

\section{ISAIAS mit GLOSSA ORDINARIA}

Perg. I, 88, I* Bl. $235 \times 170$. Entstehungsort unbestimmt, 12. Jh.

B: $\quad$ Perg. unregelmäßig beschnitten, tw. löchrig, Nahtspuren, tw. fleckig. Lagen: (I-1)I (Vorsatzbl., Pap. 18. Jh.) + 11.IV ${ }^{88}+(\mathrm{I}-1)^{\mathrm{I}^{*}}$ (Nachsatzbl., Pap. 18. Jh.). Gegenbl. zum Vor- bzw. Nachsatzbl. als Spiegel auf dem VD bzw. HD aufgeklebt. Vor der ersten Lage fehlen wohl sechs Quaternionen mit Textverlust (Bl. 1-46), nach der letzten Lage ebenfalls Textverlust. Am Lagenende Kustoden, stark beschnitten. Am rechten oberen Blattrand Foliierung 15. Jh. in arabischen Ziffern 47-92 (Zahl 88 ausgelassen), entspricht Bl. 1-45 der Foliierung 19. Jh. durch die ULB Tirol in arabischen Ziffern 1-88 (hier berücksichtigt).

S: Schriftraum $160 \times 135 / 140$. Drei Spalten von unterschiedlicher Breite, durch zweifache Tintenlinien voneinander abgegrenzt. Haupttext zu 13-14 Zeilen auf Tintenlinierung. Zirkelstiche. Karolingisch-gotische Minuskel wohl von einer Hand. Rand- und Interlinearglossen. Am äußeren Rand vereinzelt Notizen von anderer Hand.

A: $\quad$ Schwarze Paragraphzeichen. Bl. 76r und 77v rote Paragraphzeichen, Auszeichnungsstriche und Kapitelangaben.

E: $\quad$ Neuzeitlicher Bibliothekseinband: schwarz gesprenkeltes braunes Pap. über Pappe. Neustift, 2. H.18. Jh. Ecken mit braunem Leder verstärkt. Rücken: braunes Leder, vier einfache Bünde, von Goldbordüren gesäumt. Im ersten Feld Golddruck M: S:, im zweiten Golddruck JSAIÆ ONUS ÆGYP., im dritten Signaturschild (s. bei G). Spiegel Pap. 18. Jh. Am Spiegel des VD Exlibris und Signaturen (s. bei G), Spiegel des HD leer.

G: Zeitpunkt und Art der Erwerbung durch Neustift unbekannt. Am Spiegel des VD Exlibris der Stiftsbibl. Neustift 18. Jh. 1809 anlässlich der vorübergehenden Aufhebung des Klosters Neustift der ULB Tirol übergeben. Am Spiegel des VD alte Signaturen der ULB Tirol II $\overline{2} D 14$ (?) (Tinte, radiert), II $\overline{1} D 15$ (Bleistift) und 315 (Tinte). Am Rücken gelbes Signaturschild der ULB Tirol 315. Bl. 1r Stempel der ULB Tirol 19. Jh. 1921 aufgrund des Friedensvertrages von St. Germain an den italienischen Staat abgegeben und von diesem 1929 dem Kloster Neustift als Dauerleihgabe überlassen. Bl. 1r Stempel der Soprintendenza Tridentina 20. Jh.

L: $\quad$ Katalog ULB Tirol IV 90, 471.

(Ir-v) leer.

IsAiAs mit Glossa ORDINARIA, unvollständig: Is 18,7-59,13 (Druck: GW 4282. PL 113, 1260B-1302A).

(1r) am oberen Blattrand Vermerk (18. Jh.): Caput 19 Jsaie incipit hic à verbis: Onus Egypti.

(1r) Inc. mut.: ]tuum montem Syon. Onus Egypti. Ecce dominus ascendet super nubem levem ... - Expl. mut.: ... et loquemur calumpniam et transgressionem. Concepimus et [

Zur Frage der Verfasserschaft der Glossa ordinaria s. L. Smith, The Glossa Ordinaria. The Making of a Medieval Bible Commentary. Leiden 2009.

$\left(I^{*} \mathrm{r}-\mathrm{v}\right)$ leer. 


\section{Cod. 327}

\section{GALFREDUS DE VINOSALVO}

Perg. I, 21, I* Bl. $220 \times 150$. Frankreich (?), 13. Jh.

B: $\quad$ Perg. fleckig, Haar- und Fleischseite deutlich unterscheidbar. Lagen: (I-1) (Vorsatzbl., Pap. 18. Jh.) + (IV$1)^{7}+(\mathrm{IV}-\mathrm{I})^{13}+(\mathrm{IV}-\mathrm{III})^{15}+(\mathrm{IV}-\mathrm{I})^{21}+(\mathrm{I}-1)^{\mathrm{I}^{*}}($ Nachsatzbl., Pap. $18 \mathrm{Jh}$.$) . Gegenbl. zum Vor- bzw. Nachsatzbl.$ als Spiegel auf dem VD bzw. HD aufgeklebt. Urspr. wohl durchgehend Quaternionen: Bei Lage 1 fehlt Gegenbl. zu Bl. 1, bei Lage 2 fehlt ein Doppelbl. in Lagenmitte, bei Lage 3 fehlen äußerstes Doppelbl. sowie zwei Doppelbl. in Lagenmitte, bei Lage 4 fehlt ein Doppelbl. in Lagenmitte (Textverlust). Nach Bl. 21 fehlt mindestens ein Unio (Textverlust). Bl. 13v Reklamante. Am oberen Blattrand Foliierung 19. Jh. durch die ULB Tirol.

S: $\quad$ Schriftraum $160 \times 80$, von tw. kaum sichtbaren Bleistiftlinien gerahmt, zu 36 Zeilen auf tw. kaum sichtbarer Bleistiftlinierung. Textualis. Am Blattrand und interlinear Kommentare und Notizen von zeitgenössischer Hand.

A: $\quad$ Rote Auszeichnungsstriche, Durchstreichungen, Über- und Schlussschriften sowie ein- und zweizeilige einfache Lombarden, tw. mit Punktverdickungen. Bl. 1r Initiale $P$ (42 mm hoch) mit rot-blau kopfstempelförmig gespaltenem Buchstabenkörper und rotem Palmettenfleuronnée.

E: $\quad$ Neuzeitlicher Bibliothekseinband: schwarz gesprenkeltes braunes Pap. über Pappe. Neustift, 2. H. 18. Jh. Am VD und HD Ecken mit braunem Leder verstärkt. Rücken: braunes Leder, drei einfache Bünde, von Streicheisenlinien begrenzt. Im zweiten Feld Signaturschild (s. bei G). Spiegel Pap. 18. Jh. Am Spiegel des VD Exlibris und Signaturen (s. bei G), Spiegel des HD leer.

G: Zeitpunkt und Art der Erwerbung durch Neustift unbekannt. Am Spiegel des VD Exlibris der Stiftsbibl. Neustift 18. Jh. 1809 anlässlich der vorübergehenden Aufhebung des Klosters Neustift der ULB Tirol übergeben. Am Spiegel des VD alte Signaturen II $\overline{1}$ D 9 S. 2 (Tinte, Bleistift), darunter ältere radierte Signatur (erhalten: II , Tinte) sowie 327 (Tinte). Am Rücken gelbes Signaturschild der ULB Tirol 327. Bl. 1r Stempel der ULB Tirol 19. Jh. 1921 aufgrund des Friedensvertrages von St. Germain an den italienischen Staat abgegeben und von diesem 1929 dem Kloster Neustift als Dauerleihgabe überlassen. Bl. 1r Stempel der Soprintendenza Tridentina 20. Jh.

L: $\quad$ Kristeller VI 122. - Wilhelm I 135. - D. Schaller, J. Stohlmann, Nachträge zu Hans Walther, Initia carminum ac versuum medi aevi. Mittellateinisches Jahrbuch 2 (1971) 293-314, hier 300. - W. Schmidt, Untersuchungen zum „Geta“ des Vitalis Blesensis. Ratingen u. a. 1975, 10. - A. Paeske, Der „Geta“ des Vitalis von Blois. Köln 1976, 44. - Steer 36. - Katalog ULB Tirol IV 137, 471. - M. C. Woods, Classroom Commentaries. Teaching the Poetria nova across Medieval and Renaissance Europe. Columbus 2010, 144-145, 299.

$(\mathrm{Ir}-\mathrm{v})$ leer.

1 (1r-19v) Galfredus de Vinosalvo: Poetria nova, unvollständig (Druck: P. Leyser, Historia poetarum et poematum medii aevi. Halae 1721, 862-978. E. Faral, Les arts poetiques du XIIe et du XIIIe siècle [Bibliothèque de l'École des Hautes Études 238]. Paris 1924, 197-262).

(1r) Tit.: Incipit poetria magistri Ganfredi.

(1r-7v) Inc.: Papa stupor mundi si dixero papa nocenti ... - Expl. mut. (V. 478): ... puduit minus in peregrinis [ V. 515-526 bereits urspr. ausgelassen, Nachtrag der Verse und Hinweis vom selben Schreiber auf Bl. 19v.

(8r-10v) Inc. mut. (V. 563): ] preformet capitis (!) nature ... - Expl. mut. (V. 775): ... labra flamme [

(11r-13v) Inc. mut. (V. 915): ] consiliis cinctus odiis ... - Expl. mut. (V. 1130): ... virtus optima rerum [

(14r-v) Inc. mut. (V. 1276): ] In serie dicta ... - Expl. mut. (V. 1347): ... mortale remordeat, istud [

(15r-v) Inc. mut. (V. 1498): ] Qui cecidit seseque potens ... - Expl. mut. (V. 1568): ... placuerunt federa pacis [

(16r-18v) Inc.: mut.: (V. 1709): ] Vocum que flecti nequeunt ... - Expl. mut. (V. 1923): ... perhorret hyatus [ 
(19r-v) Inc. mut. (V. 2066): ] Iam mare transcurri ... - Expl.: ... de iure mereris.

(19v) Anschließend nachgetragen V. 515-526: Si vetus exemplum non sufficit ecce novellum ... Cordis ad exemplar regis formata Richardi.

Vgl. Hinweis am Blattrand: Explicit hic liber sit scriptor crimine liber (Colophons Nr. 21008. Vgl. W. Wattenbach, Das Schriftwesen im Mittelalter. Leipzig ${ }^{3} 1896,509$ und 522). Hoc exemplum apostrophe debet sequi vel postponi illi exemplo. Ancillatur item etc.

(19v) Schreibervers: Finito libro grates Christo referamus. Darunter Schlussschrift: Explicit poetria novella Ganfredi.

Lit.: Guizzardo da Bologna, Recollecte super Poetria magistri Gualfredi, a cura di D. Losappio

(Gli umanisti 3). Verona 2013; Woods 144-145, 299, mit Hinweis auf die Verwandtschaft des Kommentars von Cod. 327 mit Rom, Vaticana, Cod. Ottob. Lat. 3291.

2 (20ra-21vb) 〈Vitalis Blesensis〉: Geta, unvollständig (Ed. Paeske, mit Nennung der Hs. F. Bertini, La comedia elegiaca latina in Francia nel secolo XII. Genova 1973, 90-120. - Walther, Initia Nr. 7272).

Tit.: Incipit Geta. - Inc.: Grecorum studia nimiumque diuque secutus ... - Expl. mut. (V. 444): ... Si quecumque loquor omnia falsa forent [

$\left(\mathrm{I}{ }^{*} \mathrm{r}-\mathrm{v}\right)$ leer.

P. K.

\title{
Cod. 353
}

\section{LIBER HORARUM, Bd. 1 (zusammengehörend mit Cod. 654)}

\author{
Perg. VI, 194 Bl. $160 \times 120$. Raum Brixen, um 1496 .
}

B: $\quad$ Regelmäßiges Perg., vereinzelt kleine Löcher und Nahtspuren. Lagen: $(\mathrm{IV}-2)^{\mathrm{VI}}+2 \cdot \mathrm{V}^{20}+\mathrm{IV}^{28}+10 . \mathrm{V}^{128}+$ $\mathrm{IV}^{136}+5 . \mathrm{V}^{187(186)}+(\mathrm{V}-2)^{195(194)}$. Gegenbl. zu Bl. I (wohl ohne Textverlust) und Bl. II (Textverlust) sowie zu B1. 188 und 189 (Textverlust), zudem wohl auch einstiges Nachsatzbl. herausgerissen bzw. -geschnitten. Am Ende der Lagen 3 und 5-8 stark beschnittene Reklamanten. Um die zweite Lage schmaler Pergamentfalz geschlagen. Am oberen Blattrand zeitgenössische rote Foliierung in arabischen Ziffern 1-195 (hier berücksichtigt); Fehler in der Zählung: 153 doppelt angeführt, 164 und 168 ausgelassen. Vorgebundenes Kalendar von späterer Hand in römischen Zahlen foliiert I-VI. Inhaltsverzeichnis (Bl. Iv) mit Folioangaben bezieht sich auf Cod. 353 (= Bd. 1) und 654 (= Bd. 2, hier ohne Folioangaben).

S: $\quad$ Bl. 1r-195v Schriftraum $110 \times 70$, von jeweils zweifachen roten Tintenlinien gerahmt, zu 18-20, größtenteils 19 Zeilen auf feiner Bleistift-, tw. Blindlinierung. Zirkelstiche. Kalligraphische Bastarda (auffällig gelängte Initialmajuskeln, Unterlängen und Kürzungsstriche, bisweilen i-Punkte in Kreisform). Schreiber: Georg Hölzl aus Mattighofen, um 1496, vgl. Cod. 654 (Bl. 202r: dat. 1496).

Kalendar Bl. IIr-VIv Schriftraum $115 \times 75 / 85$. Zwei Spalten, von roten Tintenlinien gerahmt. Inhaltsverzeichnis Bl. Ir-v Schriftraum $115 \times 75$, von jeweils zweifachen roten Tintenlinien gerahmt, Folioangaben im Inhaltsverzeichnis von Hand der Foliierung (wie Cod. 654). Kalligraphische Bastarda. Schreiber: Georg Hölzl aus Mattighofen. Nachträge von späterer Hand.

A: Rote Auszeichnungsstriche, (Zwischen-)Überschriften, Interpunktionszeichen, Unterstreichungen; wenige, relativ große rote und blaue Paragraphzeichen. Bl. Ir am Textbeginn größere rote Cadelle; Bl. 102r schwarze Cadelle mit Federzeichnungsdekor. Ein- bis sechszeilige Lombarden (als KL-Ligaturen zweizeilig), abwechselnd hell-/dunkelrot und blau, mit Punktverdickungen bzw. gestielten Punkten; B1. 10v aufwändige dreizeilige blaue Lombarde mit markanten Punktverdickungen, freiem Punkt und in Achterschlingen gelegten Ausläufern, gut vergleichbar mit den Lombarden in Brixen, Priesterseminarbibl., Cod. C.8 (ab Bl. 157r), F.5, F.6 (z. B. Bl. 2v: wohl von demselben Lombardenmaler) und F.7; Bl. 94v Lombarde nicht ausgeführt. Repräsentanten.

Deckfarbenschmuck: neun drei- bis sechszeilige Ornamentalinitialen mit Ranken, acht ganzseitige (Schriftspiegelgröße) rankenlose Miniaturen. 
Zu den Charakteristika der ornamentalen Initialen (Bl. 1r, 40r, 55r, 71r, 94r, 116r, 131r, 165r, 184r) s. Cod. 654; in Cod. 353 im Verhältnis mehr blattvergoldete Binnenfelder und Buchstabenkörper als in Cod. 654, zu den Punzierungen s. u.; bei goldenen Buchstabenkörpern die Blattkonturen in Rot eingetragen; Bl. 40r Buchstabenkörper (Deckfarbe) mit Kreisen gefüllt. - Randschmuck: Akanthusranken (Charakteristika s. Cod. 654) und einige naturalistische Zweige, die recht grob gemalt sind: Bl. 94r roter Klee, 165r Eichenzweige (mit Eicheln), 184r Weinranken; nur eine Drolerie (Bl. 1r): Dompfaff, der auf einem Bein steht.

Zu den Charakteristika der Miniaturen (u. a. Figurenbildung, Hintergründe, Kolorit) s. Cod. 654.

Bl. 39v Schmerzensmann: Christus, dessen Körper von Blutstropfen bedeckt ist, präsentiert stehend seine Wundmale; zwei flankierende Engel halten seinen roten Mantel (innen grün) auf; kobaltblauer Hintergrund (s. u. bei Punzierungen).

Bl. 54v Letztes Abendmahl an einem runden Tisch; Johannes kauert auf dem Schoß Jesu; Judas, aus dessen Mund ein Teufelsfigürchen entweicht, mit rotbraunem Haar, ockergelbem Gewand und rotem Geldbeutel an der Seite; Hintergrund: Fenster (mit gemauertem Fensterkreuz), Landschaftsausblick. Vgl. kleinformatigere und daher einfachere Komposition in Cod. 654, Bl. 163v.

B1. 70v Dreifigurige Kreuzigung: am Fuß des grob gemaserten Kreuzes Steinhaufen und Gebeine Adams; Gekreuzigter mit gelbgrünem Lendentuch (vgl. Cod. 654, Bl. 15v und 165r oben); Kreuzestitel INRI (mit stark eingerollten Enden) auf das Kreuz aufgesteckt. Maria, die ihren Mantel vor dem Leib rafft, richtet den Blick verloren zu Boden, während Johannes mit gefalteten Händen in die Ferne blickt; Hintergrund: Stadtvedute (u. a. türmchenbesetzte Kirchenfassade), Fluss oder See und Bergkette.

B1. 93v Pietà flankiert von Maria Magdalena (neben ihr das Salbgefäß) und Johannes; auf Marias Herz weist großes Schwert als Zeichen ihres Schmerzes; Hintergrund: Kreuz (mit aufgestecktem Kreuzestitel), an dessen Querbalkenenden Geißel und Rute hängen, mittig Dornenkrone; Leidenswerkzeuge jeweils mit Blutstropfen benetzt.

B1. 115v Gnadenstuhl: Gottvater sitzt auf einer (Holz-?)Bank, hinter der zwei Engel ein blaues, mit goldenen Ähren übersätes Tuch hochhalten, und präsentiert mit zur Seite gerichtetem Blick das Kruzifix; darüber (auf einem in Rot eingezeichneten, stilisierten Wolkenband) Taube des hl. Geistes auf Goldgrund (Punzierung s. u.); Wasserschaden (?), s. insbes. über der rechten Schulter Gottvaters.

B1. 130v Mondsichel-Madonna: Maria, über die zwei Engelchen eine Bügelkrone halten, steht auf hellblauem Sichelmond mit Gesicht (nach unten gerichtet). Das Jesuskind, das den linken Arm um den Hals seiner Mutter gelegt hat, präsentiert mit der Rechten einen roten Apfel (?); Mutter und Kind blicken einander an. Blattvergoldeter Hintergrund (Punzierung s. u.), Wiesengrund mit Maiglöckchen und rotblütiger Pflanze im Vordergrund.

Bl. 163v Mariä Himmelfahrt: Apostel (zuvorderst Rückenfigur, deren Heiligenschein tellerartig am Hinterkopf sitzt) in einem Talkessel, u. a. mit hochgewachsenen Maiglöckchen; über ihnen wird Maria (mit gefalteten Händen) von fünf Engeln, die einen Kranz um sie bilden, in den Himmel getragen; einer der Engel dient ihr als Fußstütze, direkt über ihrem Kopf rot-goldene Wolke, die Strahlen aussendet.

B1. 183v Verkündigung: Maria kniet betend an einem Pult, während der Engel (mit Pfauenflügeln und Spruchband AVE GRACIA PLEN[A]) segnend vor ihr niederkniet; hoch über ihnen zwei Fenster (überschnitten von einem blau ausgemalten Rippengewölbe, vgl. Cod. 654, Bl. 51v), das rechte vergittert, im linken Büste des segnenden Gottvaters, von dem goldene Strahlen ausgehen, auf welchen das nimbierte, Kreuz tragende Jesuskind und die Taube des hl. Geistes zu Maria hinabgleiten.

Punzierungen: 1) Binnenfelder: Bl. 1r und 184r Rautengitter aus winzigen Quadraten, Bl. 1r mit fünfblättrigen Blüten (aus kleinen Kreisen) gefüllt, Gitterschnittpunkte zudem mit vierblättrigen roten und blauen Blüten besetzt; Bl. 184r Rautengitter mit sechsblättrigen Blüten (aus kleinen Quadraten) gefüllt; hier auch die blattvergoldete Rankenschlinge punziert (Rautengitter mit Kreisen). - 2) Hintergründe von Miniaturen: Bl. 39v kobaltblaue Deckfarbe mit wie in einen Blattgoldgrund eingepunztem Rautengitter, darin sechsblättrige Blüten; B1. 115v Goldgrund mit größeren sechs- und kleineren fünfzackigen Sternen bzw. Sternblüten (auch auf Nimben); Bl. 130v Goldgrund mit größeren sechsblättrigen Blüten, die abwechselnd rot und blau ausgemalt sind, sowie kleineren fünfzackigen Sternen bzw. Sternblüten.

Der eher grobe Deckfarbenschmuck stammt von der Hand, die auch Cod. 654 ausgestattet hat, in Cod. 353 allerdings etwas sorgfältiger und detaillierter (z. B. bei der Gestaltung der Fußböden, Gewänder, Möbel- und Architekturzier) zu Werk gegangen ist. Zur Einordnung s. bei Cod. 654.

E: $\quad$ Renaissance-Einband: braunes Leder auf Holz mit Golddruck. Neustift, zw. 1569 und 1581 (identisch mit Cod. 654). Werkstatt: Narziß Schuechl.

Einband 2014 restauriert (vgl. Restaurierbericht, drei kleine abgelöste Makulaturfragmente beigelegt). VD und HD gleich: ein von je zweifachen Streicheisenlinien in Gold begrenzter Rahmen: Rolle Enthauptung des Johannes, Eherne Schlange, Kreuzigung, Auferstehung (Nr. 1 = Neuhauser, Rolleneinbände, R 29). Im Mit- 
telfeld des VD Plattenstempel mit Darstellung eines Erzengels (Michael?) mit Wappenschild von Propst Augustin Schabl (Propst 1569-1581) mit zwei steigenden geflügelten Löwen (Nr. 2 = Neuhauser P 3). Darüber Inschrift Augustinus praepositus Novcecelle. Im Mittelfeld des HD in den Ecken Einzelstempel mit floralem Dekor aus Vase wachsend (Nr. 3), in der Mitte Einzelstempel Kreuzigung Christi (Nr. 4). Zwei Leder-Metall-Schließen, beim Materialwechsel sich stark verjüngend. Kanten gerade und nach innen hin abgeschrägt und durch einfache Streicheisenlinie eingefasst. Rücken: vier Doppelbünde, von zweifachen goldenen Linien gesäumt, Linien am VD und HD fortgesetzt, spitz aufeinander zulaufend. In den Feldern Zw. den Bünden jeweils florale Rolle (Nr. 5 = Neuhauser, Rolleneinbände, R 26). Im zweiten Feld Signaturschild (s. bei G). Kapitale mit gelbem und rotem Zwirn umstochen. Schnitt goldfarben und punziert. Spiegel des VD Perg. mit Exlibris, Signaturen und Stempel (s. bei G), Spiegel des HD leeres Papierblatt.

G: Hs. im Auftrag des Kaspar Neuhauser, bischöflicher Zöllner (1490/92) und Stadtrichter (1494-1501) in Klausen (vgl. Kustatscher I 300-302 und II 646; K. Brandstätter, Städtische Verwaltung und Bürgerschaft in Klausen im 15. Jh. Der Schlern 73 [1999] 442, 718), 1496 von Georg Hölzl geschrieben. Hs. spätestens seit der Zeit des Propstes Augustin Schabl (1569-1581) in Neustift. Am Spiegel des VD Exlibris der Stiftsbibl. Neustift 18. Jh. 1809 anlässlich der vorübergehenden Aufhebung des Klosters Neustift der ULB Tirol übergeben. Am Spiegel des VD alte Signaturen der ULB Tirol II $\overline{1}$ E 14 (Tinte, Bleistift) sowie 353 (Tinte). Am Rücken gelbes Signaturschild der ULB Tirol 353. Bl. Ir Stempel der ULB Tirol 19. Jh. 1921 aufgrund des Friedensvertrages von St. Germain an den italienischen Staat abgegeben und von diesem 1929 dem Kloster Neustift als Dauerleihgabe überlassen. Am Spiegel des VD Stempel der Soprintendenza Tridentina 20. Jh. Restaurierbericht 2014 von A. Al Shami.

L: $\quad$ Wilhelm I 135 und II 110. - Chev. Nr. 30585 und 30053 (ohne Nennung der Sign.). - AH 30, Nr. 8; 30, Nr. 12; 30, Nr. 52 und 31, Nr. 5. - Laußermayer 301-302, 309-310. - Neuhauser, Neustift 85. - Peintner, Buchmalerei, 16, 34, 84-86, 88-90 (ohne Nennung der Sign.). - Katalog ULB Tirol IV 217, 471. - Kustatscher I 302 (ohne Nennung der Sign.). - Kustatscher-Korenjak 157 (ohne Nennung der Sign.).

Liber Horarum, Bd. 1.

(Ir-v) Titel samt Inhaltsverzeichnis.

Tit.: Subscripti cursus sparsim hincinde in devocionum libellis inventi summa cum diligencia hic in unum sunt collecti ut quivis excitandam devocionem prout suus afficitur animus ad manum habeat quo se orando convertat: aut scilicet ad trinitatem beatissimam aut ad eternam sapienciam ad corpus Christi ad ipsius passionem vel eius animam ad spiritum sanctum vel beatissimam virginem Mariam ad beatos angelos vel omnes Dei sanctos aut pro misericordia inpetrandam pro peccatis propriis vel fidelibus defunctis cum septem penitencialibus psalmis cum mortuorum vigiliis et accessu altaris prout secundum ordinem huiusmodi cum numero foliorum hic sunt intitulati.

Darunter in Schwarz Auflistung aller Kapitel samt Angabe der Blattzahl. Aufgelistet werden auch jene Kapitel, die in Cod. 654 zu finden sind, allerdings ohne Angabe einer Blattzahl. Inc.: Cursus de proprio angelo folio 1 ... - Expl.: ... Vespere mortuorum folio.

1 (IIra-VIv) KaLENDAR, unvollständig (bis 22. Dezember).

Besonderheiten, die auf eine Entstehung in der Diözese Brixen hinweisen: Ingenuinus et Albuinus (5. Februar), Translatio s. Albuini (13. Mai), Dedicatio ecclesiae Brixinensis (31. Juli), Cassianus (13. August).

(IIIra) Nachtrag am 15. März von späterer Hand zum Tod des Nikolaus Neuhauser, Kirchpropst (1483/84), Bürgermeister (1488) und Stadtrichter (1492) in Klausen (s. bei G): Anno domini 1496 obit Nicolaus Neünhausser pater meus dilectus.

(IVrb) Nachtrag am 20. Juni von späterer Hand zum Tod des Bischofs Georg Golser: Anno domini 1489 obit Icorius (!) Golser episcopus Prixinensis dominus meus generosus.

Fehlstelle: Nach Bl. VI zwei Blätter herausgerissen (s. bei B), auf erstem Blatt urspr. Forts. und Abschluss des Kalendars, tw. erhalten.

2 (1r-12v) CuRsus de PROPRIO ANGelo. Hymnen (AH 50, Nr. 146, Strophen auf die einzelnen Tageszeiten aufgeteilt, Str. 4 mehrfach), Antiphonen (De s. Michaele).

Tit.: Incipit cursus de proprio angelo qui dicendus est dominica die. 
(1r) Invitatorium mit Ps 95. - (2r) Matutin. Hymnus. - (2v) Ps 8,5-9. - Antiphon (CAO Nr. 1491). - (3r) Leccio prima. Inc.: Stetit angelus iuxta aram templi habens thuribulum aureum in manu sua ... (vgl. Apc 8,3). - Expl.: ... salus honor virtus et potestas omnipotenti Deo. Tu autem. - Responsorium mit Versikel. - Te Deum.

(4r) Laudes. Ps 148,1-5. - (4v) Antiphon (CAO Nr. 2102). - Capitula. - Hymnus. - (5r) Psalmus (recte: Lc 1,68-79). - (5v) Antiphon (CAO Nr. 1472). - Oracio. Deus qui summa providencia humano generi supernorum spirituum presidia subministras ...

(5v) Prim. Hymnus. - (6r) Ps 97,7-10. - Antiphona. Emitte angelum de celis ut me perducat in paradisum exultacionis alleluia. - Capitulum. - (6v) Responsorium mit Versikel. - Oracio. Omnipotens et misericors Deus qui hominem ad imaginem tuam formasti et ei angelum corporis et anime custodem ...

(7r) Terz. Hymnus. - Ps 103, 20-22. - (7v) Antiphona. Emitte angelum de celis ut me perducat in paradisum exultacionis alleluia. - Capitulum. - Responsorium mit Versikel. - Oracio. Omnipotens et misericors Deus qui electos spiritus celestium gaudiorum ...

(8r) Sext. Hymnus. - Ps 104,1-4. - (8v) Antiphona. Emitte angelum de celis ut me perducat in paradisum exultacionis alleluia. - Capitulum. - Responsorium mit Versikel. - (9r) Oracio. Deus qui nos miseros peccatores perire non sinis presta quesumus ut angelum michi deputatum ...

(9r) Non. Hymnus. - (9v) Ps 143,10-12. - Antiphona. Emitte angelum de celis ut me perducat in paradisum exultacionis alleluia. - Capitulum. - Responsorium mit Versikel. - (10r) Oracio. Perpetuum nobis domine tue miseracionis presta subsidium ...

(10r) Vesper. Ps 138,1-3. - Antiphon (CAO Nr. 3757). - (10v) Capitulum. - Hymnus. (11r) Canticum Mariae (nur Verweis) mit Antiphon (CAO Nr. 3755). - Oracio. Omnipotens sempiterne Deus qui angelum tuum antequam nasceretur homo et ego nascerer ad custodiendum ...

(11v) Komplet. Ps 91,10-12. - Antiphona. Emitte angelum de celis ut me perducat in paradisum exultacionis alleluia. - Hymnus. - (12r) Capitulum mit Versikel. - Canticum Simeonis (nur Verweis) mit Antiphon (CAO Nr. 3592). - (12v) Oracio. Deus qui fidelium tuorum deprecacionem semper exaudis presta michi indigno peccatori ...

3 (13r-25v) Cursus de aeterna sapientia (Druck: u. a. H. Porro, Vita e morte della sig. Cornelia Lampugnana ... Pavia 1624, 215-240. Henricus Suso zugewiesen, vgl. P. Künzle, Heinrich Seuses Horologium Sapientiae. Erste kritische Ausgabe unter Benützung der Vorarbeiten von D. Planzer OP [Spicilegium Friburgense 23]. Freiburg 1977, 606ff.). Hymnen (Mone I 329 Nr. 258). Tit.: Cursus de eterna sapiencia feria secunda dicendus.

(13r) Invitatorium mit Verweis auf Ps 95. - Matutin. Hymnus. - (13v) Ps 66,1-4. - Antiphon (CAO Nr. 4810) mit Versikel. - (14r) Benediccio. Precibus et meritis sanctissime sue matris salvat et protegat ... - Leccio prima. Inc.: Sapiencia eterna splendor glorie et substancia patris qui universa de nichilo creasti ... - Expl.. ... sed tu in me et ego in te indissolubili vinculo amoris eternaliter maneamus. Tu autem. - (14v) Responsorium mit Versikel. - Leccio secunda. Inc.: Ihesu mi dulcissime felicissima sapiencia verbum patris principium et finis alpha et o omnium encium ... - Expl.: ... sed permaneat morte forcior noster amor in evum. - (15r) Responsorium mit Versikel. - (15v) Leccio tercia. Inc.: O refugium meum o liberator meus per immensum amorem qui te in patibulo crucis amarissimam mortem pro me subire coegit ... - Expl.. ... et ad conspectum glorie tue pervenire concedas. Tu autem. - (16r) Responsorium mit Versikel.

(16r) Laudes. Ps 117. - (16v) Antiphon (CAO Nr. 4811). - Capitulum. - Hymnus. - (17r) Ps. (recte: Lc 1,68-79). - (17v) Antiphon (CAO Nr. 4081). - (18r) Oracio. Deus qui per coeternam sapienciam hominem cum non esset condidisti ...

(18r) Prim. Hymnus. - (18v) Ps 143,8-10. - Antiphona. Ego diligentes me diligo et qui mane vigilaverint ad me invenient me. - Capitulum. - (19r) Responsorium mit Versikel. - (19r) Oracio. Corda nostra quesumus domine eterne sapiencie splendor illustret ... 
(19r) Terz. Hymnus. - Ps 143,10-12. - (20r) Antiphona. Filii concupisce sapienciam conserva iusticiam et prebebit eam dominus tibi. - Capitulum. - Responsorium mit Versikel. - Oracio. Deus qui per coeternam sapientiam hominem cum non esset condidisti ...

(20v) Sext. Hymnus. - (21r) Ps 33,20-22. - Antiphon (CAO Nr. 2418). - Capitulum. - Responsorium mit Versikel. - (21v) Oracio. Exaudi nos misericors Deus et mentibus nostris sapiencie tue lumen ostende ...

(21v) Non. Hymnus. - (22r) Ps 51,12-14. - Antiphon (CAO Nr. 2418). - Capitulum. - (22v) Responsorium mit Versikel. - Oracio. Infunde quesumus domine Deus tue cordibus lumen sapiencie...

(22v) Vesper. Ps 111,9-10. - (23r) Antiphon (CAO Nr. 4153). - Capitulum. - Responsorium mit Versikel. - Hymnus. - (23v) Versikel. - Magnificat (nur Verweis). - Antiphon (CAO Nr. 4050). Oracio. Deus qui per coeternam sapienciam hominem cum non esset condidisti ...

(24r) Komplet. Ps 13,4-6. - Antiphon (CAO Nr. 2576). - (24v) Capitulum. - Responsorium mit Versikel. - Hymnus. - (25r) Canticum Simeonis (nur Verweis). - Antiphon (Cantus Nr. 203570). (25v) Oracio. Fragilitatem nostram quesumus domine benignus respice et saporem nobis eterne sapiencie...

4 (26r-39r) CURSuS DE SANCTO SPIRITU. Hymnen (falls nicht anders ausgewiesen AH 50, Nr. 144).

Tit.: Cursus de sancto spiritu tercia feria dicendus.

(26r) Invitatorium mit Verweis auf Ps 95. - Matutin. Hymnus (AH 54, Nr. 153). - (26v) Ps 1. (27r) Anhtiphon (CAO Nr. 5327). - Benediccio. Confortare et corroborare in bonis operibus ...(27v) Leccio (2 Cor 13,13). - Responsorium mit Versikel.

(27v) Laudes. Ps 93. - (28r) Antiphon (CAO Nr. 5005). - Capitulum. - Hymnus (Chev. Nr. 2340). - (29r) Ps. (recte: Lc 1,68-79). - (29v) Antiphon (CAO Nr. 4920). - Oracio. Concede quesumus omnipotens Deus sanctum nos spiritum vocis promereri ... - (30r) Antiphon De sancta trinitate (CAO Nr. 5119). - Oracio. Omnipotens sempiterne Deus qui dedisti famulis tuis in confessione vere fidei eterne trinitatis gloriam agnoscere ... - (30v) Antiphon De beata virgine (CAO Nr. 1563). - Oracio. Deus qui virginalem aulam beate Marie virginis in qua habitares eligere dignatus es ... - (31r) Antiphon De omnibus sanctis (CAO Nr. 4726). - Oracio. Protege domine populum tuum et apostolorum tuorum Petri et Pauli et omnium aliorum ... - Oracio. Omnes sancti tui quesumus domine nos ubique letificent et adiuvent ut dum eorum merita recolimus patrocinia senciamus ...

(31v) Prim. Hymnus. - (32r) Ps 54,3-9. - (32v) Antiphon (CAO Nr. 5327). - Capitulum. - Responsorium mit Versikel. - (33r) Oracio. Cordibus nostris quesumus domine spiritum sanctum ... (33r) Terz. Hymnus. - (33v) Ps 70. - (34r) Antiphon (CAO Nr. 5327). - Capitulum. - Responsorium mit Versikel. - Oracio etc. Mentes nostras quesumus domine spiritus sanctus reparet ...

(34r) Sext. - (34v) Hymnus. - Ps 87. - (35r) Antiphon (CAO Nr. 5327). - Capitulum. - Responsorium mit Versikel. - Oracio. Deus cui omne cor patet et omnis voluntas loquitur et quem nullum latet secretum ...

(35v) Non. Hymnus. - Ps 124. - (36r) Antiphon (CAO Nr. 5327) (nur Verweis). - Capitulum. Responsorium mit Versikel. - Oracio. Illo nos igne spiritus sanctus inflammet quem dominus noster Ihesus Cristus ...

(36v) Vesper. Ps 128,1-5. - Antiphon (CAO Nr. 5327). - Capitulum. - (37r) Responsorium mit Versikel. - Hymnus. - (37v) Magnificat (nur Verweis). - Antiphon (CAO Nr. 4902). - (38r) Oracio. Deus qui corda fidelium sancti spiritus illustracione docuisti ...

(38r) Komplet. Ps 129. - (38v) Antiphon (CAO Nr. 5327) (nur Verweis). - Hymnus (nur Verweis). - Capitulum. - (39r) Canticum Simeonis (nur Verweis). - Antiphon (CAO Nr. 5005). Oracio. Sancti spiritus corda nostra mundet infusio ...

(39v) ganzseitige Miniatur (s. bei A). 
5 (40r-54r) CURSUS DE MISERICORDIA DNI. Hymnen (Chev. Nr. 30585. AH 30, Nr. 12).

Tit.: Cursus de misericordia domini quarta feria dicendus.

(40r) Invitatorium mit Verweis auf Ps 95. - Matutin. Hymnus. - (40v) Ps 25,6-9. - (41r) Benediccio. Ostende nobis domine misericordiam tuam et salutare tuum da nobis ... - Leccio prima (Sap 11,23-26). - Responsorium mit Versikel. - (41v) Leccio secunda (Sir 36,1-5). - (42r) Responsorium mit Versikel. - Leccio tercia (Dn 3,31,29,30,41-43). - (42v) Responsorium mit Versikel. - Te Deum. Inc.: Te Deum laudamus te dominum misericordissimum confitemur tuam maximam misericordiam semper imploramus ... - Expl.: miserere miserere miserere nostri Ihesu benigne: qui passus es pro nobis clementer in cruce Amen.

(44r) Laudes. Ps 25,15-18. - (44v) Antiphon (vgl. CAO Nr. 3816). - Capitulum. - Hymnus. (45r) Canticum Zachariae. - (45v) Antiphona. Cum vidisset dominus viduam misericordia motus super illam dixit et noli flere. - Oracio. Deus qui omnipotenciam tuam parcendo maxime et miserando manifestas multiplica super nos misericordiam tuam ...

(46r) Prim. Hymnus. - Ps 51,3-5. - (46v) Antiphona. Euntes discite quid est misericordiam volo et non sacrificium: non enim veni vocare iustos sed peccatores dicit dominus. - Capitulum. - Responsorium mit Versikel. - (47r) Oracio. Subveniat nobis domine misericordia tua ut ab imminentibus peccatorum nostrorum periculis ...

(47r) Terz. Hymnus. - (47v) Ps 119,75-78. - (48r) Antiphon CAO Nr. 2368). - Capitulum. - Responsorium mit Versikel. - Oracio. Pateant aures misericordie tue domine precibus supplicancium et ut petentibus desiderata ...

(48v) Sext. Hymnus. - Ps 69,14-17. - (49r) Antiphon (CAO Nr. 3873). - Capitulum. - (49v) Responsorium mit Versikel. - Oracio. Adesto supplicacionibus nostris omnipotens Deus et quibus fiduciam sperande pietatis indulges ...

(49v) Non. Hymnus. - (50r) Ps 103, 8-11. - Antiphon (CAO Nr. 3770). - (50v) Capitulum. Responsorium mit Versikel. - Oracio. Tua nos domine Deus misericordia ab omni surrepcione vetustatis ...

(51r) Vesper. Ps 123, 1-3. - Antiphon (CAO Nr. 4695). - Capitulum. - (51v) Responsorium mit Versikel. - Hymnus. (52r) Magnificat (nur Verweis). - Antiphona. Cum adhuc longe esset filius vidit illum pater suus et misericordia motus est occurrens cecidit super collum eius et osculatus est eum. - Oracio. Omnipotens sempiterne Deus qui ex abundancia pietatis tue et merita supplicum excedis ...

(52r) Komplet. - (52v) Ps 86,3-7. - Antiphona. Procedens servus dominum rogabat dicens pacienciam habem me et omnia reddam tibi miserttus autem dominus servi illius dimisit eum et debitum dimisit ei. - Hymnus. - (53r) Capitulum. - Responsorium mit Versikel. - (53v) Canticum Simeonis. - Preces. Ego dixi miserere mei domine. Sana animam meam quia peccavi tibi. Convertere domine ... - (54r) Oracio. Protector noster in te sperancium Deus sine quo nichil est validum ...

(54v) ganzseitige Miniatur (s. bei A).

6 (55r-70r) CuRsus de CORPORE Christi.

Tit.: Cursus de corpore Christi quinta feria dicendus.

(55r) Invitatorium mit Verweis auf Ps 95. - Matutin. Hymnus (AH 50, Nr. 388). - (55v) Ps 16. (56v) Antiphon (Cantus Nr. 200833). - Benediccio. Corporis et sanguinis domini nostri Ihesu Cristi sacramentum sit ... - Leccio prima. Inc.: Immensa divine largitatis beneficia exhibita populo Christiano inestimabilem ei conferunt dignitatem ... - Expl.: ... servitute a peccatis omnibus mundaremur. Tu autem. - Responsorium mit Versikel. - (57v) Leccio secunda. Inc.: Et ut tanti beneficii iugis in nobis maneret memoria corpus suum in cibum ... - Expl.: ... de accidentibus iudicant sibi notis. Tu autem. - (58r) Responsorium mit Versikel. - (58v) Leccio tercia. Inc.: Nullum eciam sacramentum est isto salubrius quo purgantur peccata ... - Expl.: ... Deo graciarum debite acciones. Tu autem. - (59v) Responsorium mit Versikel. - Te Deum (nur Verweis). 
(59v) Laudes. Ps 20,2-7. - (60r) Antiphon (Cantus Nr. 203078). - Capitulum. - Hymnus (AH 50, Nr. 395). - (60v) Canticum Zachariae (nur Verweis). - Antiphon (CAO Nr. 2594). - Oracio. Deus qui nobis sub sacramento mirabili passionis tue memoriam reliquisti tribue ...

(61r) Prim. Hymnus (Chev. Nr. 23597). - (61v) Ps 23. - (62r) Antiphon (Cantus Nr. 203765). Capitulum. - Responsorium mit Versikel. - Oracio. Reminiscere miseracionum tuarum quesumus domine et famulos tuos ...

(62v) Terz. Hymnus (Chev. Nr. 23749). - (63r) Ps 78,23-30. - Antiphon (Cantus Nr. 200280). (63v) Capitulum. - Responsorium mit Versikel. - Oracio. Deus qui ecclesiam tuam preciosi corporis et sanguinis domini nostri Ihesu Christi misterio ...

(64r) Sext. Hymnus (Chev. Nr. 7807). - Ps 81, 9-17. - (64v) Antiphon (Cantus Nr. 200786). (65r) Capitulum. - Responsorium mit Versikel. - Oracio. Propitiare nobis quesumus omnipotens pater per unigeniti tui corpus et sanguinem ...

(65r) Non. Hymnus (Chev. Nr. 33769). - (65v) Ps 84,2-5. - (66r) Antiphon (Cantus Nr. 201674). Capitulum. - Responsorium - Oracio. Domine Ihesu Christe fili Dei vivi qui pro nobis in cruce moriens dulcissimi lateris ...

(66v) Vesper. Ps 128. (67r) Antiphon (Cantus Nr. 204661). - Capitulum. - Responsorium mit Versikel. - Hymnus (vgl. Chev. Nr. 27686). - (68r) Magnificat (nur Verweis). - Antiphon (Cantus Nr. 203576). - Oracio. Domine Ihesu Christe qui in ultima cena tradidisti discipulis tuis ...

(68r) Komplet. - (68v) Ps 4,6-9. - (69r) Antiphon (Cantus Nr. 200020). - Hymnus (Chev. Nr. 28563). - (69v) Capitulum. - Canticum Simeonis. - Antiphon (Cantus Nr. 203492). - (70r) Oracio. Deus cuius unigenitus tuus pro nobis usque ad mortem obediens ...

(70v) ganzseitige Miniatur (s. bei A).

7 (71r-93r) CuRsus de PASSIONE DNI. Hymnen (AH 50, Nr. 382).

Tit.: Cursus de passione domini sexta feria dicendus.

(71r) Invitatorium mit Ps 95. - Matutin.- (71v) Hymnus. - (72r) Ps 2. - (73r) Antiphona. Insurrexerunt in me viri absque misericordia et non pepercerunt anime mee. - Benedictio. Gloriosa passio Christi perducat nos ad gaudia paradisi ... - (73v) Leccio prima (Io 19,1-3). - Responsorium mit Versikel. - (74r) Leccio secunda (Io 19, 16-17). - Responsorium mit Versikel. Leccio tercia (Io 19, 28-30). - Responsorium mit Versikel. - (74v) Te Deum.

(75r) Laudes. Ymnus (recte: Ps 13). - (75v) Antiphon (CAO Nr. 1913). - Capitulum. - (76r) Hymnus. - (76v) Canticum Zachariae. - (77r) Antiphon (CAO Nr. 4395). - Oracio. Domine Ihesu Christe fili Dei vivi qui hora matutina stans ligatus ... - (77v) Alia oracio. O virgo virginum sanctissima Dei genitrix Maria propter gravamen et tormentum quo torquebatur ...

(78r) Prim. Hymnus. - Ps 43. - (78v) Antiphon (CAO Nr. 2833). - Capitulum. - Responsorium mit Versikel. - (79r) Oracio. Domine Ihesu Criste fili Dei vivi qui hora diei prima permisisti te duci in consilio Iudeorum ... - (79v) Alia oracio. O virgo virginum predulcissima mater Maria quando vidisti filium tuum ...

(80r) Terz. Hymnus. - (80v) Ps 64. - (81r) Antiphon (CAO Nr. 2422). - Capitulum. - Responsorium mit Versikel. - (81v) Oracio. Domine Ihesu Criste fili Dei vivi qui hora diei tercia fuisti ab Herode illusus ... - Alia oracio. O virgo virginum beatissima virgo Maria propter angustias et cruciam inaque cor tuum sustinuit ...

(82v) Sext. Hymnus. - Ps 116,10-19. (83r) Antiphon (CAO Nr. 4343). - Capitulum. - (83v) Responsorium mit Versikel. - Oracio. Domine Ihesu Criste qui hora diei sexta ante crucem fuisti denudatus ... - (84r) Alia oracio. O virgo virginum clementissima mater Maria propter doloris gladium qui pertransivit animam tuam ...

(84v) Non. Hymnus. - Ps 142. (85v) Antiphon (CAO Nr. 1970). - Capitulum. - Responsorium mit Versikel. - Oracio. Domine Ihesu Christe fili Dei vivi qui hora diei nona pendens in cruce et clamans voce magna te derelictum dixisti ... - (86r) Alia oracio. O virgo virginum sanctissima regina propter gravamen et tormentum quo torquebatur spiritus tuus iuxta crucem ... 
(87r) Vesper. Ps 30. - (88r) Antiphona. Dignum es domine Deus noster accipere librum et solvere singnacula (!) eius quoniam occisus es et redimisti nos Deus noster. - Capitulum. - Responsorium mit Versikel. - (88v) Hymnus. - (89r) Magnificat (nur Verweis). - Antiphona. Recessit pastor noster bonus fons aque vive qui posuit animam suam pro ovibus suis et pro grege suo mori dignatus est. - Oracio. Domine Ihesu Criste fili Dei vivi qui hora vesperarum cenasti cum discipulis tuis turbatus spiritu unum ex eis te traditurum ... - (89v) Alia oracio. O virgo virginum castissima Dei genitrix Maria propter planctum acerbi eiulatus ...

(90r) Komplet. Ps 88. - (91v) Antiphon (CAO Nr. 4295). - Hymnus. - Capitulum. - (92r) Canticum Simeonis (nur Verweis). - Antiphon (CAO Nr. 4690). - Oracio. Domine Ihesu Christe fili Dei vivi qui hora completorii sepultus es et a mulieribus planctus es et lamentatus ... - (92v) Alia oracio. $O$ virgo virginum gloriosissima mater Maria propter gemitus et suspiria indicibiliaque lamenta quibus afficiebaris...

(93v) ganzseitige Miniatur (s. bei A).

8 (94r-115r) Cursus de compassione BMV, Papst Johannes XXII. zugeschrieben (vgl. Bl. 114v). (Druck: u. a. Thesaurus cursuum devotissimorum ... collectus ab G. B. Pontano. Prag 1600, 185219).

Tit.: Cursus de compassione Marie virginis sabatho dicendus.

(94r) Invitatorium. - Psalmus (AH 31, Nr. 158). - Matutin. - (94v) Hymnus (Chev. Nr. 8483). (95r) Ps 88,2-10. - Antiphona. Nocte qua Ihesus capitur absque somno fuisti que soporatis ceteris flens pervigil mansisti. - Ps 88, 5-7. - (95v) Antiphona. Hec nox merorifera tunc fit et amara matri quando capitur proles eius cara. - Ps 88,8-10. - (96r) Antiphona. Erat mater virgo pia plorans foris atriter regem mundi furibundi dum tractarent viliter. - Benediccio. Salutifera lamentacio Christi conferat nobis gaudia paradise ... - Leccio prima (Mone II Nr. 441). - (96v) Responsorium mit Versikel. - Leccio secunda. Inc.: De cruce quando dominus ad cumulum portatur confestim ei genitrix portantes ... - Expl.: ... rigans lacrimis madefecit. Tu autem. - (97r) Responsorium mit Versikel. - Leccio tercia (Mone II Nr. 443). - (97v) Te Deum.

(98r) Laudes. Ps 22,2-16. - (98v) Antiphona. Virgo regis celici genitrix iugiter preconiis honoretur dignis. - Ps 22,5-7. - (99r) Antiphona. Nunquam mater pertulit tam anxios dolores ut Maria filii considerans livores. - Ps 22,8-12. - Antiphona. Nulla novit genitrix angustias tam duras plagas cum aspiceret et captis puncturas. - (99v) Ps 22,12-14. - Antiphona. Rubens color vertitur matris in palorem dum conspicit filii crurorem. - Ps 22,15-16. - (100r) Antiphona. Desperata creditur que culpam non commisit eius natus moriens dum spiritum emisit. - Capitulum. - Hymnus (AH 4, Nr. 87). - (100v) Canticum Zachariae. - (101v) Antiphona. Tanquam latro capitur funibus constrictus Christus virgis ceditur alapis afflictus ... - Oracio. Domine Ihesu Christe clementissime qui pro nobis peccatoribus mortem subiens temporalem nec materno dolori ... Alia oracio. Domine Ihesu Christe fili virginis et matris Marie qui hora matutinali pro salute humani generis ex Maria ...

(102v) Prim. Hymnus (Chev. Nr. 9578). - (103r) Ps 22,17-19. - Antiphona. Quantam putas matris mesticiam cum sentiret nati tristiciam non est dolor ... - Capitulum. - (103v) Responsorium mit Versikel. - Oracio. Domine Ihesu Christe qui pro nobis peccatoribus in cruce agonizans ... (104r) Oracio. Domine Ihesu Christe fili virginis Marie salus mundi qui hora diei prima Pylato presidi fuisti presentatus ...

(104v) Terz. Hymnus (Chev. Nr. 12570). - Ps 55,3-5. - (105r) Antiphona. Agnus mitis tormenta paciens: heli clamat pro nobis moriens ... - Capitulum. - Responsorium mit Versikel. - (105v) Oracio. Domine Ihesu Christe qui pro nobis peccatoribus in cruce agonizans ... - Oracio. Domine Ihesu Criste fili virginis Marie salus mundi qui hora diei tercia coram Pylato preside purpura indutus fuisti ...

(106r) Sext. Hymnus (Chev. Nr. 17058). - (106v) Ps 59,2-4. - Antiphona. Clamor Christi matrem angustiat nullus planctus plangentem faciat ... - Capitulum. - Responsorium mit Versikel. - 
(107r) Oracio (Verweis auf vorangegangenes Gebet). - Alia oracio. Domine Ihesu Christe fili virginis Marie salus mundi qui hora diei sexta in cruce alta clavis durissimis affixus fuisti ...

$(107 v)$ Non. Ymnus. Rerum Deus tenax vigor Christus in cruce moritur sed pena fit acerbior cum reus non compatitur ... - (108r) Ps 69,20-21. - Antiphona. Postquam hoc diversorum est clausum virgo filium liquit qui fecit seculum flendo sequens discipulum. - (108v) Capitulum. - Responsorium mit Versikel. - Oracio (Verweis auf vorangegangenes Gebet). - Alia oracio. Domine Ihesu Christe fili virginis Marie salus mundi qui hora diei nona crucifixus manibus et pedibus verberibus et flagellis ...

(109r) Vesper. Ps 69,2-3. - Antiphona. Omnis etas defleat mortem redemptoris virgini condoleat matri salvatoris. - Ps 69,4-5. - (109v) Antiphona. Virgo cum aspiceret natum in cruce mori: suo nullus similis dolor est dolori. - Ps 69,6-7. - Antiphona. Matris quis angustias poterat auferre cum in cruce filium cerneret clavari. - Ps 35,11-13. - (110r) Antiphona. Queso mihi misero virginum regina teccum (!) flendo lacrimas humiles propina. - Ps 109,1-4. - Antiphona. Fac ut ita defleam mortem tui nati partemque possideam regni reparati. - Capitulum. - (110v) Responsorium mit Versikel. - Hymnus (Mone II 142, Nr. 439). - (111r) Magnificat (nur Verweis). - Antiphona. Expirante filio mortem mater indicat stat in plebis medio penas mortis publicat ... Oracio. Domine Ihesu Christe virginis fili dulcissime qui cum proditore cenasti ... - (111v) Alia oracio. Domine Ihesu Christe fili virginis Marie salus mundi qui hora diei vespertina pressuris innumeris nimis fatigatus ...

(112r) Komplet. Ps 41,8-11. - (112v) Antiphona. Recolamus virginis gloriose luctus cum in templum dominus vinctus fuit ductus. - Capitulum. - Responsorium mit Versikel. - (113r) Ymnus. Tu lucis ante terminum Christe sepulcro clauderis te plorat virgo virginum Deus humani generis ... - (113v) Canticum Simeonis (nur Verweis). - Antiphona. Tuam pertransivit animam virgo carens crimine Symeonis gladuis omni cum gravamine qui devote dixerat ... - Oracio. Salvator clementissime qui inter opprobria que tulisti pie matris anxietatibus compassus fuisti ... - (114r) Alia oracio. Christe rex clementissime fili Marie qui inter plurima opprobria sanctissimum spiritum emittendo patri tuo ... - Antiphona. De beata virgine Salve regina. - Oracio. Interveniat quesumus domine Ihesu Christe pro nobis apud tuam ineffabilem clemenciam nunc et in hora mortis nostre ...

(114v-115r) Schlussschrift: Has horas composuit papa Iohannes XXII et donavit omnibus vere penitentibus confessis et contritis eas devote dicentibus quadraginta annos indulgenciarum et quatuor carenas. Anschließend (in Schwarz): Et sequitur cursus de sancta trinitate in secundo folio etc.

(115v) ganzseitige Miniatur (s. bei A).

9 (116r-130r) CURSUS DE SANCTA TRINITATE.

Tit.: Cursus de sancta trinitate qui es trinus et unus miserere nobis.

(116r) Invitatorium mit Verweis auf Ps. 95. - Matutin. Hymnus (Chev. Nr. 487. AH 51, Nr. 96). (116v) Ps 8. - (117r) Antiphona. Benedictus es Deus patrum nostrorum laudabilis et gloriosus et superexaltatus in secula. - Benediccio. Te invocamus te adoramus te laudamus beata trinitas miserere nobis ... - (117v) Leccio prima. Inc.: Adesto Deus unus omnipotens pater et filius et spiritus sanctus te unum in substancia trinum ... - Expl.: ... tibi graciarum accio in secula. Tu autem domine. - Responsorium mit Versikel. - (118r) Leccio secunda. Inc.: Deus gracias tibi vera una trinitas: una et trina unitas te sanctam trinitatem ... - Expl.. ... omnium creaturarum tibi laus tibi gloria tibi graciarum accio in secula. Tu autem. - Responsorium mit Versikel. - (118v) Inc.: Credimus te Deum patrem a temetipso non ab alio nec factum nec creatum nec genitum te filium ... - Expl. ... Libera nos salva nos iustifica nos o beata trinitas. Tu autem domine. - Responsorium mit Versikel.

(119r) Laudes. Ps 100. - (119v) Antiphona. O beata trinitas et benedicta et gloriosa unitas pater et filius et spiritus sanctus tibi laus tibi Gloria tibi graciarum accio. - Capitulum. - Hymnus 
(Chev. Nr. 13381. AH 31, Nr. 5) - (120r) Canticum Zachariae. - (121r) Antiphon (CAO Nr. 1707). - Oracio. Omnipotens sempiterne Deus qui dedisti famulis tuis in confessione vere fidei eterne trinitatis gloriam agnoscere ...

(121r) Prim. Hymnus (Chev. Nr. 13150. AH 51, Nr. 40 und 2, Nr. 17). - (121v) Ps 24. - (122r) Antiphon (CAO Nr. 2948). - Capitulum. - Responsorium mit Versikel. - (122v) Oracio. Sancta trinitas unus et omnipotens Deus nos quesumus a peccatorum nostrorum maculis ...

(123r) Terz. Hymnus (Chev. Nr. 13150. AH 51, Nr. 40 und 2, Nr. 17). - Ps 67. - (123v) Antiphon (CAO Nr. 3601). - Capitulum. - Responsorium mit Versikel. - (124r) Oracio. Omnipotens sempiterne Deus qui in unitate permanes et in trinitate semper consistis ...

(124r) Sext. Hymnus (nur Verweis: Chev. Nr. 13150. AH 51, Nr. 40 und 2, Nr. 17). - Ps 117. (124v) Antiphon (CAO Nr. 2947). - Capitulum. - Responsorium mit Versikel. - (125r) Oracio. Domine sancte pater omnipotens sempiterne Deus famulos tuos maiestati tue subiectos per unicum filium tuum ...

(125r) Non. Hymnus (nur Verweis: Chev. Nr. 13150. AH 51, Nr. 40 und 2, Nr. 17). - Ps 113. (125v) Antiphon (CAO Nr. 3600). - Capitulum. - (126r) Responsorium mit Versikel. - Oracio. Concede quesumus omnipotens Deus ut sicut in nomine patris et filii divini generis intelligimus ... (126r) Vesper. Ps 147,1-11. - (127r) Antiphon (CAO Nr. 5120). - Capitulum. - Responsorium mit Versikel. - (127v) Hymnus (Chev. Nr. 487. AH 51, Nr. 96). - (128r) Magnificat (nur Verweis). Antiphon (CAO Nr. 5117). - (128r) Oracio. Filium tuum omnipotens pater ante secula gemitum invocantes exoramus ...

(128v) Komplet. Ps 150. - (129r) Antiphon (CAO Nr. 4086). - Capitulum. - Responsorium mit Versikel. - Hymnus (Chev. Nr. 10968. AH 52, Nr. 117, 5). - (129v) Canticum Simeonis (nur Verweis). - Antiphona. Sancta trinitas unus Deus omnipotens exaudi clemens supplices tuos et solve vincula peccatorum nostrorum ... - (130r) Oracio. Exaudi nos domine sancte pater omnipotens eterne Deus invocacionem omnipotentis filii tui ...

(130v) ganzseitige Miniatur (s. bei A).

10 (131r-163r) CuRsus COMMUNIS DE BMV.

Tit.: Cursus de communi de beata Maria virgine.

(131r) Invitatorium mit Verweis auf Ps. 95. - Matutin. Hymnus (Chev. Nr. 16347. AH 50, Nr. 72). - (131v) Ps 8. - (132r) Antiphon (CAO Nr. 1709). - Ps 19. - (133v) Antiphon (CAO Nr. 4942). - Ps 24. - (134r) Antiphon (CAO Nr. 1438). - Benediccio. Precibus et meritis beatissime Marie virginis et omnium sanctorum perducat nos dominus ad regna celorum ... - (134v) Leccio prima (Sir 24,11-13). - Responsorium mit Versikel. - (135r) Leccio secunda (Sir 24,1516). - Responsorium mit Versikel. - Leccio tercia (Sir 24,17-20). - (135v) Responsorium mit Versikel. - Te Deum (nur Verweis).

(136r) Laudes. Ps 93. - (136v) Antiphon (CAO Nr. 1503). - Ps 100. - (137r) Antiphon (CAO Nr. 3707). - Ps 63. - (137v) Ps 67. - (138r) Antiphon (CAO Nr. 3261). - Psalmus (recte: Dn 3,57-88). (139v) Antiphon (CAO Nr. 1705). - Ps 148. - (140v) Ps 149.- (141r) Ps 150. - Antiphon (CAO Nr. 4418). - (141v) Capitulum. - Hymnus (Chev. Nr. 16347. AH 50, Nr. 72, 6-8). Psalmus (recte: Lc 1,68-79). - (142v) Antiphon (CAO Nr. 4029). - (143r) Oracio. Concede nos famulos tuos quesumus domine Deus noster perpetua mentis et corporis sanitate gaudere ... Compassio: Hora matutina Marie nuncciatur ... (vgl. AH 30, Nr. 46 und Walther Nr. 10794). (143v) Oracio. Domine Ihesu Christe fili Dei vivi qui dixisti nolo mortem peccatoris sed ut magis convertatur et vivat queso pone amaram mortem ...

(143v) Prim. Hymnus (AH 32, Nr. 130). - (144r) Ps 117. - Ps 120. - (144v) Ps 121. - (145r) Ps 122. - (145v) Antiphon (CAO Nr. 3707). - Capitulum. - (146r) Responsorium mit Versikel. Oracio. Deus qui salutis eterne beate Marie virginitate fecunda humano genere premia prestitisti ... - (146v) Oracio. Domine Ihesu Criste fili Dei vivi qui dixisti ... (identisch mit Bl. 143v). 
(147r) Terz. Hymnus (AH 32, Nr. 130). - Ps 123. - (147v) Ps 124. - (148r) Ps 125. - Antiphon (CAO Nr. 1570). - Capitulum. - (149r) Oracio. Concede misericors Deus fragilitati nostre presidium ut qui sancte Dei genitricis Marie memoriam ... - Oracio. De omnibus sanctis. Deus qui nos concedis omnium sanctorum memoriam agere ... - (149v) Oracio. Domine Ihesu Criste fili Dei vivi qui dixisti ... (identisch mit Bl. 143v).

(149v) Sext. Hymnus (AH 32, Nr. 130). - (150r) Ps 126. - (150v) Ps 127. - (151r) Ps 128. - Antiphon (CAO Nr. 4699). - (151v) Capitulum. - Responsorium mit Versikel. - Oracio. Famulorum tuorum quesumus domine delictis ignosce ut qui tibi placere ... - (152r) Oracio. Domine Ihesu Christe fili Dei vivi qui dixisti ... (identisch mit Bl. 143v).

(152r) Non. Hymnus (AH 32, Nr. 130). - (152v) Ps 129. - (153r) Ps 130. - (153v) Ps 131. (153'r) Antiphon (CAO Nr. 5040). - Capitulum. - Responsorium mit Versikel. - Oracio. Porrige nobis Deus dexteram tuam et per intercessionem sanctissimi Dei genitricis Marie auxilium nobis superne virtutis impende ... - $\left(153^{\mathrm{I}} \mathrm{v}\right)$ Oracio. Domine Ihesu Criste fili Dei vivi qui dixisti ... (identisch mit Bl. 143v).

(153v) Vesper. Ps 110. - (154v) Antiphon (CAO Nr. 2547). - Ps 113. - (155r) Antiphon (CAO Nr. 4937). - Ps 122. - (155v) Antiphon (CAO Nr. 2855). - Ps 127. - (156r) Antiphon (CAO Nr. 2641). - Ps 147,12-20. - (156v) Antiphon (CAO Nr. 2887). - Capitulum. - Responsorium mit Versikel. - (157r) Hymnus (AH 2, Nr. 29). - (157v) Magnificat (nur Verweis). - Antiphon (CAO Nr. 1542). - Oracio. Supplicacionem servorum tuorum Deus miserator exaudi ut qui in commemoracione sancte Dei genitricis et virginis Marie congregamur eius intercessionibus ... (158r) Oracio. Domine Ihesu Christe fili Dei vivi qui dixisti ... (identisch mit Bl. 143v).

(158r) Komplet. - (158v) Ps 132. - (159v) Ps 133. - Ps 134. - (160r) Antiphon (CAO Nr. 5040). Capitulum. - Responsorium mit Versikel. - (160v) Hymnus (Chev. Nr. 6346). - (161r) Canticum Simeonis (nur Verweis). - Antiphon (CAO Nr. 2952). - Oracio. Quesumus omnipotens Deus ut beate et gloriose semperque virginis Dei genitricis Marie intercessio gloriosa nos ab omni malo protegat ... - (161v) Conclusio. Has horas canonicas Maria mater pia tue laudi refero cordis simphonia ... - Oracio etc. Ave gloriosa Maria mater Cristi virgo pia pone misericordiam et compassionem ... - (162r) Oracio devotissima de compassione gloriose virginis Marie etc. Stabat mater dolorosa iuxta crucem lacrimosa dum pendebat filius ... - (163r) Oracio. Interveniat pro nobis domine Ihesu Criste nunc et in hora nostre mortis apud tuam clementiam gloriosa Dei genitrix virgo Maria ...

(163v) ganzseitige Miniatur (s. bei A).

11 (165r-183r) Cursus de septem gaudis Mariae virginis. Hymnen (AH 30, Nr. 52).

Tit.: Cursus de septem gaudiis Marie virginis.

(165r) Invitatorium mit Verweis auf Ps. 95. - Matutin. Hymnus. - (165v) Ps 43. - (166r) Antiphona. Gaude celum trinitatis celans Dei filium planta virens puritatis iocundum ferens lilium tu regina virginum tu lux plena luminum ... - Benediccio. Precibus et meritis beate Marie virginis liberet nos filius eius ab omnibus malis ... - (166v) Leccio etc. Inc.: Gaude felix mater cum tibi per angelum Dei filius nuncciatur cum pudicus alvus tuus spiritu sancto fecundatur ... - Expl.: ... angeli leticiam iusti graciam et peccatores veniam inveniunt in eternum. Tu autem. - (167r) Responsorium. - (167v) Te Deum Marianum. (Chev. Nr. 20158. Walther, Initia Nr. 19052). (169v) Laudes. - (170r) Ps 117. - Antiphona. Gaude virgo virginum virga Yesse celeste ortans florem ... - Capitulum. - (170v) Hymnus. - (171r) Canticum Zachariae. - (171v) Antiphona. Gaude virgo stirps Davitica flos fecundus fructus iocunditatis ... - (172r) Oracio. Letifica et adiuva qui sumus omnipotens et misericors Deus dominice anuncciacionis et concepcionis gaudia recolentes...

(172v) Prim. Hymnus. - (173r) Ps 87. - (173v) Antiphona. Gaudet celum letantur sidera caste matris exultant viscera ... - Capitulum. - Responsorium mit Versikel. - (174r) Oracio. In men- 
tibus nostris quesumus domine tue gratie lumen infunde ut qui conceptum et natum de virgine Deum verum et hominem confitemur ...

(174r) Terz. - (174v) Hymnus. - (175r) Psalmus (recte: Ies. 12). - (175v) Antiphona. Gaudet mater et filia novo regis preconio plaudit celorum curia celesti nato parvulo ... - Capitulum. Responsorium mit Versikel. - (176r) Oracio. Deus qui novo stelle signo novum filium regibus ostendisti presta quesumus ut intercedente benedicta et gloriosa semper virgine ...

(176r) Sext. Hymnus. - (176v) Ps 18,47-50. - (177r) Antiphon (CAO Nr. 4597). - Capitulum. Responsorium mit Versikel. - Oracio. O domine Ihesu Criste fili Dei vivi benedicti qui pro nobis peccatoribus agonisans in cruce predilectam matrem ...

(177v) Non. Hymnus. - (178r) Ps 68,33-36. - Antiphona. O regina supernorum summo gaude gaudio psallat chorus angelorum cum regis fit ascensio dulcis cantus ... - (178v) Capitulum. Responsorium mit Versikel. - Oracio. Festina quesumus domine Ihesu festina ne tardaveris et auxilium nobis superne virtutis impende ...

(179r) Vesper. Ps 51,12-16. - (179v) Antiphona. Ihesu bone permissum spiritum peccatori dimitte debitum pie matris attendens meritum dirum ...- Capitulum. - Hymnus. (180v) Magnificat (nur Verweis). - Antiphona. Clemens virgo mater pia cor inflamma frigidisisque nobis recta via ... - Oracio. Deus qui benedicte et gloriose semper virginis genetricis filii tui Marie corpus et animam sancti spiritus illustracionem perfecisti ...

(180v) Komplet. Ps 45,10-14. - (181r) Antiphona. O decus innocencie flos virginitatis mater regis gloriose templum trinitatis regina clemencie ... - Capitulum. - (181v) Responsorium mit Versikel. - Hymnus. - (182r) Canticum Simeonis (nur Verweis). - Antiphona. O mater egregia tutrix orphanorum portus spes fiducia facta peccatorum ... - (182v) Oracio. Deus qui beatissimam semper virginem Mariam in conceptu et partu virginitate servata triplici gaudio ... - Sequitur quedam prosa de omnibus septem gaudiis beate virginis Marie. Gaude virgo que de celis iuxta vocem Gabrielis concepisti filium. Gaude mater Ihesu Christi quia virgo peperisti creatorem omnium ...

(183v) ganzseitige Miniatur (s. bei A).

12 (184r-195v) Cursus de anima Christi, unvollständig. Hymnen (AH 30, Nr. 8).

Tit.: Cursus de anima Christi ut sequitur.

(184r) Invitatorium mit Verweis auf Ps. 95. - Matutin. Hymnus. - (184v) Ps 34,2-6. - Antiphon (CAO Nr. 4418). - (185r) Benedictio. Exaudi domine preces servi tui ad te clamantis qui in trinitate perfecta vivis et regnas Deus ... - Leccio. Inc.: Domini Ihesu felix anima divinitati personaliter unita humane infirmitatis defectus habuit mihi tristis fuit ... - Expl.: ... et in eius lucem splendoremque tenens cum ipso principaliter unus (!) spiritus est facta. Tu autem. - (185v) Responsorium mit Versikel. - Te Deum.

(185v) Laudes. Ps 63,6-12. - (186r) Antiphon (CAO Nr. 3261). - (186v) Capitulum. - Hymnus. - (187r) Canticum Zachariae (nur Verweis). - Antiphon (CAO Nr. 5454). - Oracio. Celesti quesumus domine lumine semper et ubique nos preveni rationalis ...

(187v) Prim. Hymnus. - Ps 30,2-6. - (188r) Antiphon (CAO Nr. 2547). - Capitulum. - Responsorium mit Versikel. - (188v) Oracio. Illumina quesumus domine populum tuum et splendore passionum carismatum et glorie racionalis ac beatissime anime unigeniti filii tui domini nostri Ihesu Cristi ...

(188v) Terz. Hymnus. - (189r) Ps 86,1-6. - (189v) Antiphon (CAO Nr. 2855). - Capitulum. Responsorium mit Versikel. - Oracio. Presta quesumus omnipotens Deus ut passionum carismatum et glorie racionalis ac beatifice anime unigeniti filii tui domini nostri Ihesu Cristi ...

(190r) Sext. Hymnus. - Ps 119,81-84. - (190v) Antiphon (CAO Nr. 4343). - Capitulum. - Responsorium mit Versikel. - Oracio. Domine Ihesu Criste qui dum hora sexta pro redempcione mundi crucis ascendisses lignum ... 
(191r) Non. Hymnus. - (191v) Ps 31,6-9. - Antiphon (CAO Nr. 2641). - Capitulum. - (192r) Responsorium mit Versikel. - Oracio. Accepta sit quesumus domine in conspectu tuo nostra devocio ut passionum carismatum et glorie rationalis ac beatissime anime ...

(192r) Vesper. Ps 84,2-5. - (192v) Antiphon (CAO Nr. 2887). - Capitulum. - Responsorium mit Versikel. - (193r) Hymnus. - (193v) Magnificat (nur Verweis). - Antiphon (CAO Nr. 5162). Oracio. Domine Deus virtutum qui collapsa restauras et restaurata conservas ...

(194r) Komplet. Ps 16,7-11. - (194v) Antiphon (CAO Nr. 5329). - Capitulum. - (195r) Responsorium mit Versikel. - Hymnus. - (195v) Canticum Simeonis. - Antiphon (CAO Nr. 5325). Oracio [

U. S.

\section{Cod. 360}

\section{CONRADUS HIRSAUGIENSIS}

Perg. I, 26, I* Bl. $165 \times 110$. Entstehungsort unbestimmt, 12. Jh.

B: $\quad$ Perg. tw. stark fleckig, vereinzelt kleine Löcher. Lagen: (I-1) ${ }^{\mathrm{I}}$ (Vorsatzbl., Pap. 18. Jh.) $+3 . \mathrm{IV}^{24}+\mathrm{I}^{26}+(\mathrm{I}-1)^{\mathrm{I}^{*}}$ (Nachsatzbl., Pap. 18. Jh.). Gegenbl. zum Vor- bzw. Nachsatzbl. als Spiegel auf dem VD bzw. HD aufgeklebt. Letzte Lage möglicherweise urspr. ebenso Quaternio, in dessen Lagenmitte Blätter herausgenommen wurden (s. bei Inhalt). Am oberen Blattrand Foliierung 19 Jh. durch die ULB Tirol.

S: $\quad$ Schriftraum $135 \times 70 / 80$, von kaum sichtbaren Bleistiftlinien gerahmt, zu 22 (Bl. 1r-8r, Schreiber 1-3) und 32 (Bl. 8v-25v, Schreiber 4-9) Zeilen auf kaum sichtbarer Bleistiftlinierung. Zirkelstiche, zumeist beschnitten. Karolingisch-gotische Mischschrift von mehreren Händen: 1) Bl. 1r, Z. 1-3; 2) Bl. 1r, Z. 4-Bl. 7v, Z. 13; 3) Bl. 7v, Z. 14-Bl. 8r; 4) Bl. 8v-10r, Z. 8; 5) Bl. 10r, Z. 9-Bl. 14r, Z. 13; 6) Bl. 14r, Z. 14-Bl. 16v; 7) Bl. 17r; 8) Bl. 17v-24v; 9) Bl. 25r-v; 10) Bl. 26r-v. Bl. 17v-24r Marginalbuchstaben zur Kennzeichnung der Sprechereinsätze. Vereinzelte Marginal- (tw. beschnitten) und Interlinearglossen.

A: $\quad$ Bl. $1 \mathrm{r}-7 \mathrm{v}$ rote ein- bis dreizeilige Lombarden, B1. 7v mit einfachem Dekor im Binnenfeld.

E: Neuzeitlicher Bibliothekseinband: schwarz gesprenkeltes braunes Pap. über Pappe. Neustift, 2. H. 18. Jh. Am VD und HD Ecken mit braunem Leder verstärkt. Rücken: braunes Leder, vier einfache Bünde, von Goldbordüren gesäumt. Im zweiten Feld Golddruck M. S. VAR. MAT. in Goldrahmung, im dritten Signaturschild (s. bei G). Schnitt rot gefärbt. Spiegel Pap. 18. Jh. Am Spiegel des VD Signaturen und Spuren einer Bleistiftnotiz (s. bei G), Spiegel des HD leer.

G: Zeitpunkt und Art der Erwerbung durch Neustift unbekannt. 1809 anlässlich der vorübergehenden Aufhebung des Klosters Neustift der ULB Tirol übergeben. Am Spiegel des VD alte Signaturen der ULB Tirol II 1 F 2 (?) (Tinte, radiert), II $\overline{1}$ E 4 S. 2 (Bleistift) und 360 (Tinte) sowie Spuren einer Bleistiftnotiz. Am Rücken gelbes Signaturschild der ULB Tirol 360. Bl. 1r Stempel der ULB Tirol 19. Jh. 1921 aufgrund des Friedensvertrages von St. Germain an den italienischen Staat abgegeben und von diesem 1929 dem Kloster Neustift als Dauerleihgabe überlassen. Bl. Ir Stempel der Soprintendenza Tridentina 20. Jh.

L: $\quad$ P. Lehmann, Literaturgeschichte im Mittelalter I. Germanisch-Romanische Monatsschrift 4 (1912) 572. - R. B. C. Huygens, Conrad de Hirsau, Dialogus super auctores. Latomus 17 (1955) 5. - K. Langosch, Überlieferungsgeschichte der mittellateinischen Literatur, in: Geschichte der Textüberlieferung II. Zürich 1964, 184 Anm. 351. - R. B. C. Huygens, Accessus ad auctores. Bernard d'Utrecht. Conrad d'Hirsau, Dialogus super auctores. Édition critique entièrement revue et augmentée. Leiden 1970, 10. - L. G. Whitbread, Conrad von Hirsau as literary critic. Speculum 47 (1972) 234-245, 235. - Neuhauser, Neustift 84. - V. Brown, A twelfth-century Virgilian miscellany-commentary of German origin (Vatican, Ms. Pal. Lat. 1695), in: S. Krämer, M. Bernhard, Scire litteras. Forschungen zum mittelalterlichen Geistesleben (Abh. der Bayerischen Akademie der Wissenschaften, phil.-hist. Kl. N. F. 99). München 1988, 73-86, hier 74. - Katalog ULB Tirol IV 252, 472. - R. Marchionni, Dialogo sugli autori. Corrado di Hirsau. Introduzione, testo, traduzione e note di commento (Annali dell'Università di Napoli „L'Orientale“ [AION]. Dipartimento di studi del mondo classico e del mediterraneo antico. Sezione filologico-letteraria, Quaderni 12). Pisa, Roma 2008, insbes. 30-31. 
(Ir-v) leer bis auf Stempel (s. bei G).

1 (1r-25v) 〈CONRAdus Hirsaugiensis»: Dialogus super auctores, unvollständig (Ed. Huygens 1970, 71-131 [basierend auf Neustift, Stiftsbibl., Cod. 360 und Würzburg, UB, M. p. th. f. 53]).

Inc.: Quia video te diu vacare ocio silentio ... - Expl. mut. (V. 1506): ... in quorum ponderoso sensu et litera proprietate magna prolata [

Zur Textüberlieferung: Huygens 1970, 10-17.

2 (26r) 〈Ps.-Beda Venerabilis〉: Termini quartae decimae lunae regulares (Memorialverse zur Berechnung des Osterfestes) (MGH Poetae IV 670-671. PL 90, 708B und 802A).

Inc.: None Aprilis norunt quinos ...

Lit.: B. Bischoff, Ostertagtexte und Intervalltafeln, in: Ders., Mittelalterliche Studien. Ausgewählte Aufsätze zur Schriftkunde und Literaturgeschichte II. Stuttgart 1967, 192-227, hier 192.

3 (26r) Notizen:

1) durchgestrichene und radierte Noтız (unleserlich).

2) verblasst: Isti sunt filii [...] Iohannes bonus et Lafrancus filius Ambrosii est Albertus Zicerius ...

4 (26v) Tafel zUR Berechnung des Osterfestes mit erläuternden Versus de termino Paschae (19 Zeilen) (D. Schaller, E. Könsgen, Initia carminum Latinorum saeculo undecimo antiquiorum. Göttingen 1977, Nr. 208. A. Cordoliani, Contribution à la littérature du comput ecclésiastique au moyen âge. Studi medievali Ser. 3, 1/1 [1960] 112 und 2/1 [1961] 182. Walther, Initia Nr. 444). Am oberen Blattrand Bezeichnung der Spalten der Tabelle.

Inc. Versus: Ad XVI numerum quintum dato primum ... - Expl.: ... Tandem cum binis XXVI dato trinis.

Lit.: B. Bischoff, Ostertagtexte und Intervalltafeln, in: Ders., Mittelalterliche Studien. Ausgewählte Aufsätze zur Schriftkunde und Literaturgeschichte II. Stuttgart 1967, 192-227.

Darunter komputistische Notizen.

$(\mathrm{I} * \mathrm{r}-\mathrm{v})$ leer.

P. K.

\section{Cod. 397}

\section{IOHANNES DE TURRECREMATA}

Perg. I, 88, I* Bl. $140 \times 105$. Süddeutscher Raum (?), 2. H. 15. Jh.

B: $\quad$ Dickes Perg. Lagen: $(\mathrm{I}-1)^{\mathrm{I}}$ (Vorsatzbl. $)+11 . \mathrm{IV}^{88}+(\mathrm{IV}-7)^{\mathrm{I}^{*}}$ (Nachsatzbl.). Gegenbl. zum Vorsatzbl. als Spiegel auf dem VD aufgeklebt. Sechs Blätter der letzten Lage herausgeschnitten: Gegenbl. zum herausgeschnittenen zweiten Blatt erhalten (= Nachsatzbl.), Gegenbl. zum herausgeschnittenen ersten Blatt als Spiegel auf dem HD aufgeklebt. In der ersten Lagenhälfte jeweils Kustoden, beschnitten. Am oberen Blattrand Foliierung 19. Jh. durch die ULB Tirol.

S: $\quad$ Schriftraum $90 \times 65$, von feinen, kaum sichtbaren Tintenlinien seitlich gerahmt, zu 14 Zeilen auf feiner Tintenlinierung. Textualis.

A: $\quad$ Rote Überschriften und Schlussschrift. In der ersten Zeile Oberlängen von Buchstaben bisweilen mit cadellenartigen Ausläufern. Platz für zwei- bzw. dreizeilige Lombarden freigelassen, die später (Barockzeit?) nachgetragen wurden (z. B. $M$ Bl. 34v). Repräsentanten.

E: $\quad$ Gotischer Einband: braunes Leder über Holz mit Blinddruck. Süddeutscher Raum, 2. H. 15. Jh. 
Leder abgerieben und tw. beschädigt, insbes. an den Ecken, am Rücken oben und unten eingerissen. VD: zwei von jeweils dreifachen Streicheisenlinien gebildete Rahmen. Rahmen 1: Rolle mit Vase, Wappenschild und Engel, tw. stark abgerieben (Nr. 1); Rahmen 2: Einzelstempel Schriftband „Maria“ (Nr. 2), die Ecken der Rahmenbegrenzungen durch dreifache Streicheisenlinien miteinander verbunden. Im Mittelfeld Rolle zwei Quadrate konkav nebeneinander, gefüllt mit Fünfpunktblüte (Nr. 3). HD: zwei von jeweils dreifachen Streicheisenlinien gebildete Rahmen. Rahmen 1: Rolle mit ornamentalem Blattwerk in geometrischer Anordnung (Nr. 4); Rahmen 2 (innere Begrenzungslinien bis an die äußeren verlängert): seitlich je ein Schriftband „Maria“ (Nr. 2), oben und unten leer. Im Mittelfeld Rolle (Nr. 1). Zwei Leder-Metall-Schließen. Kanten gerade. Rücken: drei Doppelbünde. Im ersten Feld Papierschild M. S. (Tinte), im zweiten Papiertitelschild Turrecremata Meditatio[...] (Tinte), im dritten Signaturschild (s. bei G), im vierten leeres Papierschild. Kapitale mit grün-rosa Garn umstochen. Spiegel Perg. Am Spiegel des VD Exlibris, Signaturen (s. bei G) sowie Notiz (s. bei Inhalt), am Spiegel des HD Gebet und Federproben (s. bei Inhalt).

G: Zeitpunkt und Art der Erwerbung durch Neustift unbekannt. Bl. 1r Besitzvermerk 18. Jh. Collegii Novacellensis. Am Spiegel des VD Exlibris der Stiftsbibl. Neustift 18. Jh. 1809 anlässlich der vorübergehenden Aufhebung des Klosters Neustift der ULB Tirol übergeben. Am Spiegel des VD alte Signaturen der ULB Tirol II $\overline{1}$ F 18 (Bleistift) und 397 (Tinte). Am Rücken gelbes Signaturschild der ULB Tirol 397. Bl. 1r Stempel der ULB Tirol 19. Jh. 1921 aufgrund des Friedensvertrages von St. Germain an den italienischen Staat abgegeben und von diesem 1929 dem Kloster Neustift als Dauerleihgabe überlassen. Bl. Ir Stempel der Soprintendenza Tridentina 20. Jh.

L: $\quad$ Kristeller I 439. - C. F. Bühler, Rezension zu Kristeller I, Speculum. A Journal of Mediaeval Studies 39 (1964) 712-713, hier 712 (dazu J. N. Garvin, Scriptorium 19 [1965] 307, B 545). - Kaeppeli Nr. 2736. Katalog ULB Tirol IV 446, 472.

(VDS) NotIz. Si vixeris secundum carnem/morieris morte aeterna.

(Ir-v) leer bis auf Stempel (s. bei G).

(1r-88v) Iohannes de Turrecremata: Meditationes (Druck: u. a. GW M48257. Faksimile-Ausgabe des Erstdrucks von 1467 nach dem Exemplar der Stadtbibliothek Nürnberg, ed. H. Zirnbauer. Wiesbaden 1968. - Kaeppeli Nr. 2736, mit Nennung der Hs.).

(1r) Tit.: Meditationes reverendissimi patris domini Iohannis de Turrecremata sacrosancte Romane ecclesie cardinalis posite et depicte de ipsius mandato in ecclesie ambitu sancte Marie de Minerva Rome.

(1r) Tit.: De Dei potentia sapiencia ac benignitate. Meditatio prima. - Inc.: O admiranda et laudanda tue dispensationis gratia omnipotentissime domine Deus. Quia enim in natura tua ab homine videri non poteras ut hominem noticie tue participem faceres opus fecisti ... - Expl.: ... continue habere recommissos.

(88v) Schlussschrift: Finite sunt contemplaciones reverendissimi patris domini Iohannis de Turrecrema. Deo gracias.

(I*r) Federprobe: Pater noster qui es in coelis (übermalt).

(I*v-HDS) MARIENGeBet, dt.

Tit. verblasst. Inc.: Maria du hochgelobter Namen ein Khönigin des Himels ... - Expl.: ... embpfangen.

Darunter Federproben.

C. S. 


\title{
Cod. 405
}

\section{BREVIARIUM SALISBURGENSE}

\author{
Perg. VII, 236 Bl. $135 \times 100$. Wohl Neustift, um 1500 (u. a. 1501).
}

B: Hs. im 20. Jh. neu gebunden (sehr eng), hierbei zahlreiche Fälze von sehr starrem Perg. eingefügt, daher einzelne Blätter heute schadhaft und beinahe gelöst (kein Restaurierbericht erhalten). Lagen: (I-1) ${ }^{\mathrm{Ia}}+(\mathrm{IV}-2)^{\mathrm{VII}}+$ $2 \cdot \mathrm{V}^{20}+\mathrm{IV}^{28}+\mathrm{V}^{38}+\mathrm{IV}^{46}+8 \cdot \mathrm{V}^{126}+2 \cdot \mathrm{IV}^{142}+9 \cdot \mathrm{V}^{221(232)}+(\mathrm{V}-6)^{225(236)}$. Gegenbl. zu Bl. I als Spiegel auf dem VD aufgeklebt, heute weitgehend gelöst. Gegenbl. zu Bl. I und II herausgeschnitten (ohne Textverlust). Gegenbl. zu Bl. 222 als Spiegel auf dem HD aufgeklebt, Gegenbl. zu Bl. 222-225 sowie ein Doppelbl. herausgeschnitten (jeweils ohne Textverlust). Um Bl. 1 und 10, Bl. 88 und 95, Bl. 130 und 131, Bl. 136 und 141, Bl. 183 und 190, Bl. 195 und 199, Bl. 205 und 208, Bl. 213 und 220, Bl. 216 und 217 jeweils schmaler Falz geschlagen. Am oberen Blattrand Foliierung 19. Jh. durch die ULB Tirol; Fehler in der Zählung: auf 177 folgt 167, daher 167-177 doppelt angeführt. Bl. 1, 106, 126, 150, 170 Spuren bzw. Reste von Signakeln.

S: Schriftraum $105 / 110 \times 75$, von feinen Tintenlinien seitlich begrenzt, zu einheitlich 24 Zeilen auf Blindlinierung. Bastarda. Heiligenlitanei Bl. 130r-131r: Zwei Spalten, von feinen Tintenlinien gerahmt. Kalendar Bl. Ir-VIv: Schriftraum $115 \times 80$, mit Tintenlinien in fünf Spalten unterteilt, Tintenlinierung. Bastarda von gleicher Hand. Bl. 225r-v Nachtrag Textualis 16. Jh. Bl. 225r Datierung 1501, unklar, ob auf Haupttext oder auf Nachtrag bezogen.

A: Rote Auszeichnungsstriche (vereinzelt), Überschriften. Satzmajuskeln mit tw. gelängten Schäften und cadellenartigen Verzierungen. Ein- bis vierzeilige (dunkel-)rote und blaue Lombarden (als KL-Ligaturen ca. zweizeilig, in der Litanei Bl. 130r-131r S[ancte]-Schleifen) mit Punktverdickungen sowie fallweise mit kopfstempelartigem Besatz und Ausläufern, die in gestrichelte Achterschlingen (Bl. 214v und 161v Spiralranken, Bl. 161r Flechtknoten) gelegt und u. a. mit freien Kreisen und Fibrillen dekoriert sein können; sehr ähnliche Lombardenausläufer in Cod. 85 und 194 (vgl. z. B. Bl. 160v mit Cod. 85, Bl. 1r bzw. Cod. 194, B1. 22r); einige der Lombarden (v. a. Bl. 204v-222r, drei- und vierzeilig) mit Fleuronnée in der Gegenfarbe. Repräsentanten.

Flüchtiges Fleuronnée; in den Binnenfeldern längliche, zuweilen (leicht) blasige Knospen in verschiedenen Formationen sowie gegenständige (halbpalmettenartige) Blattpaare, Bl. 124r mit tropfenförmiger Mittelader, gefüllt mit kleinen Kreisen („Erbsenschotenmotiv“); Konturlinien; als Besatz u. a. Perlen und Knospen, charakteristisch eine Kombination aus zumeist drei Knospen (tw. bedornt), die in zwei kürzere Fäden auslaufen können; kurze, schwungvolle Ausläufer; B1. 204v Profilgesicht mit wulstiger Stirn und Nase; zur Einordnung s. u.

Deckfarbenschmuck: 24 drei- bis sechszeilige Ornamentalinitialen, gut die Hälfte mit (sehr) kurzen Ranken, v. a. die kleineren Initialen rankenlos; zwei Wappen; drei ganzseitige Miniaturen.

Die ornamentalen Initialen (Bl. 1r, 2r, 14v, 19v, 31v, 41v, 51v, 66r, 77v, 92v, 106r, 119r, 136r, 163v, 169v, $169^{\mathrm{I}} \mathrm{r}, 176^{\mathrm{I}} \mathrm{r}, 185 \mathrm{v}, 199 \mathrm{r}, 206 \mathrm{v}, 208 \mathrm{v}, 216 \mathrm{v}, 211 \mathrm{r}, 221 \mathrm{r}$ ) von unterschiedlicher Qualität, die kleineren Initialen bes. nachlässig gemalt (z. B. Bl. 14v), aber wohl alle von einer Hand. Quadratische Initialfelder mit plumpen Rahmen(linien). Buchstabenkörper gerne blau; weiße und v. a. (ocker-)gelbe Höhungen; einfache Blattfüllungen, u. a. mit kopfstempelartigen Aussparungen (eigentlich nur Stempelknäufe); Bl. 77v Stufenband. Binnenfelder (auch Außengründe) häufig blattvergoldet, teils punziert (mit Blüten gefüllte Rautengitter), teils mit flüchtigem, gelblichem (Linien-)Dekor bemalt; in dieser Art auch der Buchstabenkörper Bl. 185v auf dem Goldgrund aufgebracht. Einige Buchstabenkörper gehen in kurze Ausläufer über; zudem recht derbe Akanthusranken (mit und ohne Kontakt zur Initiale), die unterschiedliche Blattformen zeigen (u. a. mit tropfenförmig verdickten Adern); Bl. 2r (und 106r) etwas aufwändigere Ranken mit Fantasieblüten; Bl. 216v separate Ranke mit naturalistisch gestaltetem Anschnitt; als Dekor Goldfelder (Bl. 106r in Eckschlinge) und -punkte mit rotem Dekor, u. a. freie Kreise und Fibrillen (vgl. Fleuronnée).

Urspr. VDSv $(100 \times 66)$ Hl. Rochus mit Pilgerstab und -hut schlägt seinen Rock zurück, um Pestwunde am Oberschenkel zu zeigen; daneben an einem Baumstamm (?) der von Pfeilen durchbohrte hl. Sebastian (mit Lendentuch und erhobenem rechtem Arm). Beine des hl. Rochus tw. vom Grün des Wiesengrundes überdeckt; Pfeile des hl. Sebastian abgeblättert oder abgekratzt.

Bl. I I v $(102 \times 72)$ Engel (Dreiviertelfigur) präsentiert zwei Wappenschilde; links Propst Lukas Härber von Ringelsperg (Wappenschild geviert, Feld 1: auf rotem Grund goldenes Tau-Kreuz, Feld 2: auf blauem Grund drei diagonale Goldpfeile, Feld 3: auf blauem Grund goldener, gewundener Kranz, Feld 4: auf rotem Grund zwei überkreuzte goldene Schlüssel); rechts Neustifter Wappen (auf rotem, von zarten, gelblichen Ranken überzogenem Grund goldenes Tau-Kreuz); der Engel mit hohem Stirnkreuz und Flügeln, die über ihm einen Bogen andeuten, stützt die Wappen auf einer Steinbrüstung auf. HDS $(104 \times 68)$ Hl. Barbara mit Kelch (darüber Hostie, die abgeblättert zu sein scheint). 
Das Fleuronnée von der im 1. Fünftel 16. Jh. nachweisbaren Hand, die auch in Cod. 194 (dat. 1507) und Cod. 142, T. I (dat. 1521) tätig war, in beiden Bänden des Zollner-Graduales einige Initialen mit Fleuronnée (s. jeweils Ergänzungshand 2) geschmückt und Sign. 14820 zur Gänze ausgestattet hat. Diese Hand ist vermutlich auch für den ornamentalen Deckfarbendekor in der vorliegenden Hs. sowie in Cod. 194 verantwortlich; dieser Dekor und das Fleuronnée in Cod. 405 allerdings flüchtiger ausgeführt. Detailliert zu dieser Hand und den Zusammenhängen zw. Fleuronnée- und Deckfarbenzier s. bei Sign. 14820.

Die Heiligenminiaturen stammen von einer Hand: bunte, breite Rahmungen; Goldgründe, auf denen mit gelblichem Malmittel Spiralranken und Heiligenscheine (bei hl. Katharina auch Krone) eingetragen sind; simple Bodengestaltungen; stimmige Figurenanatomie, ovale Gesichter mit hoher Stirnpartie, großflächigen Oberlidern und gerader Nase; Haarwellen der hl. Katharina mit breitem Pinsel in regelmäßigen Schwüngen gestaltet; Gewanddraperien mit einfachen, aber sicheren (Schraffur-)Linien definiert. - Wappenhalterengel Bl. I ${ }^{a}$ V von anderer Hand: Rahmen in ockerfarbenem Pinselgold, Hintergrund kobaltblau (mit dünnlinigem weißem Muster), flankiert von breiteren Goldstreifen (punziert mit zwölfblättrigen Blüten); Engel mit pausbäckigem Gesicht, zwei unterschiedlich geschnittenen Augen und wolligem Haar; sein zart rosafarbenes Gewand mit routiniert ausgeführten Faltenbahnen, zudem gekonnte Schattenwürfe, die der Komposition Tiefe verleihen. Der Engel zeigt einige Ähnlichkeiten zur Miniatur des hl. Augustinus im 1507 geschaffenen Cod. 194; vgl. z. B. die Faltenbildung des Engelskleides und des Untergewands des hl. Augustinus; darüber hinaus stehen Engel und Augustinus hinter einer Fensterbrüstung; Ausführung der Miniaturen in Cod. 194 jedoch wesentlich aufwändiger und subtiler.

E: Renaissance-Einband: braun gefärbtes Leder über Holz mit Blind- und Golddruck. Neustift, 2. H. 16. Jh. Werkstatt: Narziß Schuechl.

Leder tw. leicht abgerieben, am VD Bünde tw. freiliegend, unteres und oberes Häubchen tw. eingerissen. Holz des VD und HD leicht gewölbt. VD und HD gleich: am äußersten Rand durch dreifache Streicheisenlinien (tw. auf Kante) eingefasst. Durch ebensolche Linien Einkerbungen in der Mitte des oberen, unteren und seitlichen Randes betont. Ein durch je dreifache Streicheisenlinien begrenzter Rahmen: Rolle mit in stilisierten Blättern auslaufender Volute in Golddruck (Nr. 1 = Neuhauser, Rolleneinbände, R 24). Im Mittelfeld mit zweifachen Goldlinien eingeschriebene Raute, in der Mitte rautenförmiger floraler Einzelstempel frei (Nr. 2), in den Ecken jeweils Einzelstempel gebündeltes Dreiblatt in Quadratform (Nr. 3). Am VD zusätzlich Einzelstempel kleine fünfblättrige Blüte frei (Nr. 4). Spuren bzw. Rest von zwei Leder-MetallSchließen, beim Materialwechsel sich stark verjüngend, urspr. wohl gleiche Schließen wie Cod. 353 und 654. Kanten gerade und nach innen abgeschrägt, sowohl am Spiegel des VD als auch am HD durch einfache Streicheisenlinie eingefasst. Rücken: drei Doppelbünde, oben und unten je ein einfacher Bund, durch Streicheisenlinien begrenzt bzw. bei Doppelbünden unterteilt, Begrenzung der Bünde am VD und HD fortgesetzt, spitz aufeinander zulaufend. In den Feldern zw. den Doppelbünden jeweils Einzelstempel gebündeltes Dreiblatt in Quadratform (Nr. 3), in den Feldern zw. Einzel- und Doppelbund Einzelstempel florales Dekor in Rhombusform (Nr. 5). An den Längsseiten des Rückens jeweils acht Einzelstempel achtblättrige Blüte frei (Nr. 6). Am oberen und unteren Rücken jeweils Rest eines aufgeklebten Papiertitelschilds, oben Psalte[rium] zu lesen. Unterhalb des ersten Doppelbundes Signaturschild (s. bei G). Kapitale mit gelbem und blauem bzw. tw. grünem Zwirn umstochen (Neubindung). Schnitt golden gefärbt, reich punziert mit pyramidal aufgebauten Kreisen, z. T. mit Binnenkreisen, und floralem Dekor. Urspr. Spiegel des VD heute größtenteils gelöst (s. bei Inhalt), auf dem Recto deutliche Klebespuren, heute Stempel, auf dem Verso Miniatur in Deckfarbenmalerei (s. bei A) sowie Signaturen (s. bei G). Unterhalb des urspr. Spiegels des VD beschriebenes Papierblatt aufgeklebt (s. bei Inhalt), darüber Exlibris (s. bei G). Am Spiegel des HD Miniatur in Deckfarbenmalerei (s. bei A).

G: Aufgrund der Wappendarstellung auf Bl. I ${ }^{\mathrm{a}} \mathrm{v}$ Hs. wohl im Auftrag von bzw. für Propst Lukas Härber von Ringelsperg (Propst 1483-1503) um 1500 entstanden, möglicherweise in Zusammenhang mit dem handschriftlichen Adligat von ULB Tirol, 156 F 20 (s. bei Inhalt). Auch die Suffragien auf Bl. 216r-223r weisen auf Propst Lukas Härber hin (später zusätzlich Propst des Augustiner Chorherrenstiftes Waldsee, vgl. P. A. Beck, Lukas Härber, Probst von Waldsee und Neustift: ein Beitrag zur Geschichte des Chorherrenstiftes Waldsee. Diözesan-Archiv von Schwaben 18 [1900] 97-101). Bl. Iªr Besitzvermerk 18. Jh. Collegii Neocell. Am heutigen Spiegel des VD Exlibris der Stiftsbibl. Neustift 18. Jh. 1809 anlässlich der vorübergehenden Aufhebung des Klosters Neustift der ULB Tirol übergeben. Am Verso des urspr. Spiegels des VD alte Signaturen der ULB Tirol II $\overline{1}$ F 6. S. 2 (Tinte, Bleistift) und 405 (Tinte), am Recto des urspr. Spiegels des VD Stempel der ULB Tirol 19. Jh. Am Rücken gelbes Signaturschild der ULB Tirol 405. 1921 aufgrund des Friedensvertrages von St. Germain an den italienischen Staat abgegeben und von diesem 1929 dem Kloster Neustift als Dauerleihgabe überlassen. Am Recto des urspr. Spiegels des VD Stempel der Soprintendenza Tridentina 20. Jh. 
L: $\quad$ Wilhelm II 110. - Laußermayer 310. - Chev. II Nr. 14718 (ohne Nennung der Sign.) - AH 4, Nr. 397 und 398; AH 23, Nr. 139; AH 51, Nr. 107. - Neuhauser, Neustift 85. - Katalog ULB Tirol V 84, 673. - Stefani 107. - Kustatscher-Korenjak 158. - Baroffio 324, Nr. 16719-20.

(VDS) Fragment aus einem philosophischen Traktat.

Pap. $130 \times 85$, quer zum Buchblock eingeklebt. Erhaltener Schriftraum $85 \times 100$. Von feinen Tintenlinien seitlich begrenzt, 20 Zeilen erhalten, von Exlibris der Stiftsbibl. Neustift überklebt. Humanistische Minuskel 16. Jh.

Inc. mut.: ] Item agitur scilicet qui [...] non est generacione [...] non est ... - Expl. mut.: ... super totam preposicionem [...] so[...] videt non hominem et ut sic est communis (?) [...] solum feratur super [

(urspr. VDSr) Stempel (s. bei G).

(urspr. VDSv) Signaturen (s. bei G). Ganzseitige Miniatur (s. bei A).

(I ${ }^{\mathrm{a} r}$ ) leer bis auf Besitzvermerk (s. bei G).

$\left(\mathrm{I}^{\mathrm{a}} \mathrm{v}\right)$ ganzseitige Miniatur (s. bei A).

(Ir-225v) Breviarium Salisburgense.

Mit Breviarium Salisburgense (Druck: Venedig 1482 = GW 5442 = ULB Tirol, Ink. 156 F 20 [Kalendar mit handschriftlichen, auf Neustift bezogenen Ergänzungen]) weitgehend übereinstimmend, Anordnung abweichend. Die der Innsbrucker Inkunabel beigebundene Handschrift weist nach Neustift (vgl. insbes. Bl. 9v-10v); nicht zuletzt die übereinstimmende Reihenfolge der Suffragien sowie die Datierung (vgl. jeweils Cod. 405, Bl. 221r-v und ULB Tirol, Ink. 156 F 20, Bl. 10v) erlauben die Annahme, dass Cod. 405 in Zusammenhang mit der Inkunabel samt Handschrift steht (vgl. auch Katalog X 469472); möglicherweise ist der handschriftliche Nachtrag in ULB Tirol, Ink. 156 F 20 mit Datierung von 1501 (Verbrüderung der beiden Augustiner Chorherrenstifte Waldsee und Neustift) auch erst zugleich mit Cod. 405 entstanden. In Cod. 405 weisen zudem Suffragien nach Stift Waldsee (s. bei G).

1 (Ir-VIv) KaLENDAR.

Enthält in drei Spalten den Römischen Kalender, die Tagesbuchstaben und die Festbezeichnungen.

Zudem Nennung der Anzahl der Lesungen, der Festgrade und Tierkreiszeichen.

Die Hervorhebung in Rot von Ingenuin und Albuin, Kassian sowie der Dedicatio ecclesiae Brixinensis verweisen auf die Diözese Brixen.

2 (1r-124v) PSALTERIUM FERIATUM.

Psalterium mit Antiphonen, Versikel, Capitula, Orationen und Benediktionen, gegliedert nach Tagzeiten sowie nach Wochentagen bzw. dies dominici und feriales unterschieden. Zudem jeweils unterschieden zw. Sommer- und Winterteil.

(1r) Tit.: Incipit psalterium secundum usum ecclesie Salczburgensis.

(1r-92r) Matutin und Laudes.

(1r) Dominicis diebus. - (19v) Fer. 2. - (31r) Fer. 3. - (41r) Fer. 4. - (51r) Fer. 5. - (66r) Fer. 6. (77v) Sabbatum.

(92v) Prim. - (100r) Terz. - (102r) Sext. - (104r) Non. - (106r) Vesper. - (122r) Komplet.

3 (124r-129v) Preces ad OMNes horas.

(124r) Tit.: Sequuntur preces ad omnes horas per totum annum.

(124r-125v) Matutin. - (124r) Ad matutinas in Quadragesima preces. Ps 51 (nur Verweis). (125r) Rubrik: Oracio ferialis vel de tempore. Finita oracione ad omnes horas dicatur super populum. Ps 51 (nur Verweis). Oracio. Omnipotens sempiterne Deus mestorum consolacio laborancium fortitudo ... Ps 6, 120, 121 (jeweils nur Verweise).

(125v-129r) Prim. - (125v) Ad primas in Quadragesima preces. - (126r) Rubrik: Hic incipe preces quotidianas ad primam per circulum anni. Zunächst Preces für die hohen Feiertage, ab Bl. 127r für die Werktage: Rubrik: Hucusque ad summa festa et ad binos dicuntur preces pretacte. Ad primam. - (127v) Rubrik: Conclude cum versiculo et collecta ut supra in matutinis. 
Ps 32, 122, 123 (jeweils nur Verweis). - (127v) Fünf abschließende Orationes mit vorangehender Rubrik: Ad primas per totum annum oracio.

1) Domine Deus pater omnipotens qui nos ad principium huius diei pervenire fecisti ... Mit Zusätzen: Ad capitulum dicatur. Iube domine benedicere. Eterna Dei sapiencia illuminare dignetur sensus corda et corpora nostra ...

2) Sancta Dei genitrix perpetua virgo Maria cum omnibus sanctis et electis diei intercedere dignare ... Mit Zusätzen: Ter dicatur Gloria Kyrie Pater noster. Ps 90,16-17.

3) Dirigere sanctificare et regere digneris domine sancte pater omnipotens eterne Deus ... Mit Zusätzen: Ad festum et binos. Ps 117.

4) Actiones nostras quesumus domine aspirando preveni et adiuvando prosequere ... Mit $\mathrm{Zu}-$ sätzen: Ad IX et tres lecciones dicitur. Ps 130 (nur Verweis). Kyrie. Pater noster.

5) Rubrik: Ad IX lecciones oracio. - Absolve quesumus domine animam fratrum et sororum parentum et benefactorum nostrorum et omnium fidelium defunctorum ...

(128v) Rubrik: De sanctis trium leccionum et in pura feria precum dicuntur tres collecte:

1) Beati Petri apostoli tui quesumus domine intercessione nos protege et animas famulorum tuorum sacerdotum sanctorum tuorum iunge ...

2) Deus venie largitor et humane salutis amator quesumus clemenciam tuam ...

3) Fidelium Deus omnium conditor et redemptor animabus famulorum famularumque tuarum omnium fidelium ...

(129r) Rubrik: In die animarum, in adventu domini et in Quadragesima feriatis diebus dicantur hi quinque psalmi: Ps 5, 6, 116, 1-9, 116, 10-19, 130 (jeweils nur Verweis).

(129r) Rubrik: In adventu dicantur tres collecte ut supra. In Quadragesima quinque ut supra:

1) Beati Petri ut supra.

2) Deus indulgenciarum domine da fidelibus tuis quorum anniversarium deposicionis diem et memoriam agimus ...

3) Deus venie largitor ut supra. Deus cuius misericordie non est numerus suscipe propicius preces humilitatis nostre...

4) Fidelium Deus ut supra.

(129r) Benedictio: Adiutorium nostrum in nomine domini ...

(129v) Terz, Sext und Non. Preces ad tercias, sextas et nonas.

(129v) Vesper und Komplet. Ad vesperas preces ut ad matutinas. - Ad completorium preces. Zunächst Preces für die hohen Feiertage, anschließend für die Werktage: (129v) Rubrik: Hucusque ad festa et binos ut supra in primis. Anschließend Oracio. Deus qui diem diem (!) discernis a nocte ...

(129v) Abschließende Rubrik: Nota per annum extra Quadragesimam dicantur ad horas preces.

4 (130ra-132v) LiTANIA.

(132v) Rubrik: In Quadragesima additur psalmus Levavi oculos meos in (= Ps 121) cum Gloria patri.

5 (132v-135r) Preces votivae.

(132v) Preces. Oremus pro omni gradu ecclesie. Sacerdotes tui induantur iusticia ... - (132v)

Oratio: Pietate tua quesumus domine nostrorum absolve vincula peccatorum ...

(133r) Rubrik: In angariis dicantur he 14 collecte.

1) Pro omni gradu ecclesie oracio. Omnipotens sempiterne Deus respicere dignare super apostolicam dignitatem ...

2) Pro episcopo. Omnipotens sempiterne Deus qui facis mirabilia magna solus ...

3) Pro regibus et principibus. Omnipotens sempiterne Deus qui celestia simul et terrena moderaris...

4) Pro congregacione. Defende quesumus domine Deus beata Maria semper virgine ...

5) Pro concordia oracio. Deus largitor pacis et amator charitatis da famulis tuis ... 
6) Pro iter agentibus. Deus qui diligentibus te misericordiam tuam semper impendis et a servientibus tibi in nulla...

7) Pro inimicis oracio. Deus pacis charitatisque amator et custos da omnibus ...

8) Pro penitentibus. Omnipotens et misericos (!) Deus qui omnem animam confitentem et penitentem ...

9) Pro elemosinariis. Deus qui post baptismi sacramentum secundam abolicionem peccatorum elemosinis ...

10) Pro quacumque tribulacione. Omnipotens sempiterne Deus mestorum consolacio laborancium fortitudo ...

11) Pro familiaribus. Deus qui charitatis dona per graciam sancti spiritus cordibus fidelium infundis ...

12) Pro temptacione cogitacionum. Deus cui omne cor patet et omnis voluntas loquitur et quem nullum latet secretum ...

13) Pro peticione lacrimarum. Omnipotens mitissime Deus qui sicienti populo fontem ...

14) Pro vivis et defunctis. Omnipotens sempiterne Deus qui vivorum dominaris simul et mortuorum omniumque ...

(135r) Magnificat (Luc 1,46-55). - (135v) Pater noster. Credo.

$6 \quad(135 \mathrm{v}-163 r)$ HYMNAR.

(135v-148r) TEMPORALE.

Tit.: Sequuntur hymni per totum annum. Et primo de tempore.

(148r-163r) SANCTORALE.

Mit Druck weitgehend übereinstimmend: in der Hs. De confessoribus Ingenuino et Albuino (AH 23, Nr. 139, mit Nennung der Hs.) samt Laudes (AH 51, Nr. 107, mit Nennung der Hs.) sowie De sancta Monica matre Augustini (AH 4, Nr. 397, mit Nennung der Hs.) samt Nokturn (AH 4, Nr. 398, mit Nennung der Hs.) und Laudes (AH 19, Nr. 391) ergänzt.

Tit.: Sequuntur nunc hympni de sanctis.

$7 \quad(163 v-198 v)$ COMMUNE SANCTORUM.

Mit Druck weitgehend übereinstimmend, Hymnen im Druck im Gegensatz zur Hs. im Hymnar enthalten, Lektionen gegenüber Druck gekürzt.

Tit.: Incipit commune sanctorum et primo apostolorum.

(163v) In festis apostolorum. - (169v) De pluribus martiribus. - (169'r) In festo unius martiris. (176r $\mathrm{r})$ De confessore et pontifice. - (185v) De simplici confessore. - (189r) De pluribus confessoribus. - (191r) De virgine et martire. - (195r) De virgine non martire. - (197r) De pluribus virginibus et martiribus.

8 (198v-206v) Vigiliae MORTUORUM.

(198v) Tit.: Sequuntur vigilie mortuorum.

$9 \quad(206 v-207 v)$ Quindecim Gradus.

(206v) Tit.: Sequuntur XV gradus. - Ad primum nocturnum. Ps 120-124 (jeweils Verweis). Anschließend Versikel und Oratio: Absolve domine quesumus animas famulorum famularumque tuarum ab omni vinculo delictorum ... - (207r) Secundus nocturnus pro congregacione. Ps 125129 (jeweils Verweis). Anschließend Versikel und Oratio: Deus cui proprium est misereri semper et parcere suscipe deprecacionem ... - Tercius nocturnus pro familiaribus. Ps 130-134 (jeweils Verweis). Anschließend Versikel und Oratio: Pretende domine fidelibus tuis dexteram celestis auxilii ...

$10(207 v-208 v)$ Orationes DE SS. TRINITATE.

(207v) Tit.: Sequitur trina oracio. - Invitatorium mit Psalm Deus in adiutorium und Psalm Ad te domine levavi (jeweils nur Verweis). 
(207v) Ad patrem. Domine Deus pater omnipotens qui consubstancialem et coeternum tibi ante omnia secula ineffabiliter ...

(207v) Ad filium. Domine Ihesu Christe fili Dei vivi qui es verus et omnipotens Deus splendor et imago patris vita eterna ...

(208r) Ad spiritum. Domine sancte spiritus qui coeternus coequalis et consubstancialis patri filioque existens ab eis inenarrabiliter ...

(208r) Graciarum actio ad trinitatem. Gracias tibi ago omnipotens Deus qui me dignatus es custodire in hac nocte...

11 (208v-216r) Cursus BMV.

(208v) Tit.: Sequitur cursus beate Marie virginis.

Bei jeder Tagzeit zudem Einschub De passione Christi.

(208v) Invitatorium mit Verweis auf Ps 95. - Matutin. Hymnus (AH 50, Nr. 72, Str. 1-5), anschließend: Maria mater gracie mater misericordie tu nos ab hoste protege in hora mortis suscipe ... - (209r) Antiphonen und Psalmen (jeweils nur Verweise) je nach Tagen verschieden: In dominica die, $2^{a}$ et $5^{a}$ feriis: Antiphonen (CAO Nr. 1709, Nr. 4942, 1438); Ps 8, 19, 24. Tercia et sexta feria: Antiphonen (CAO Nr. 4987, Nr. 1282, 4936); Ps 45, 46, 87. Quarta feria et sabbato: Antiphonen (CAO 2924, 2217, 4332); Ps 96-98.

$(209 v)$ Benediccio. Sancta Dei genitrix sit nobis auxiliatrix. - Leccio $1^{a}$. Inc.: O beata et gloriosa virgo Maria quis digne tibi valeat iura graciarum ... - Expl.: ... que solo tuo commercio recuperandi aditum invenit. Tu autem. - Benediccio. Nos cum prole pia benedicat virgo Maria. - Leccio $2^{a}$. Inc.: Accipe itaque quascumque exiles quascumque meritis tuis impares graciarum acciones ... - Expl.: ... et reporta nobis antidotum reconciliacionis. Tu autem. - (210r) Benediccio. Ad gaudia supernorum perducat nos regina celorum. - Leccio $3^{a}$. Inc.: Sit per te excusabile quod per te gerimus ... - Expl.: ... eiusdem iudicis et redemptoris. Tu. (Zu den Lesungen vgl. Fulbertus Carnotensis: Sermo IX [PL 141, 338]).

(210r) Laudes. Ps 93 (nur Verweis). - (210v) Antiphon (CAO Nr. 1503). - Capitulum. - Hymnus (AH 2, Nr. 27, Str. 5-7). - Ps Benedictus (nur Verweis). - Antiphon (CAO Nr. 5041). - (211r) Oracio. Deus qui de beate Marie virginis utero verbum tuum angelo annunciante carnem suscipere voluisti ... - In adventu domini oracio. Adiuvet nos quesumus domine beate Marie semper virginis intercessio veneranda ...

(211r) De passione Christi hora matutina. Hymnus (AH 30, Nr. 13, Str. 1). - Oracio. Domine Ihesu Christe absolve me per sanctam captivitatem tuam ob omnibus viciis ...

(211v) Ablassgebet: Anima Christi. Quicumque sequentem oracionem dixerit habet tria milia criminalium et XX milia venialium dierum indulgenciam.

(211v) Prim. Hymnus (AH 32, Nr. 130, Str. 1-2 und 5). - (212r) Ps 120-122 (jeweils nur Verweis). - Antiphon (CAO Nr. 4591). - Capitulum. - Oracio. Deus qui salutis eterne beate Marie virginitate fecunda humano generi premia prestisti ...

(212r) De passione domini ad primas. Hymnus (AH 30, Nr. 13, Str. 2). - (212v) Oracio. Domine Ihesu Christe qui ante iudices ligatis manibus stare voluisti ...

(212v) Terz. Hymnus (nur Verweis: AH 32, Nr. 130). - Ps 123-125 (jeweils nur Verweise). Antiphon (CAO Nr. 5040). - Capitulum. - Oracio. Concede nos famulos tuos quesumus domine Deus noster perpetua mentis et corporis sanitate gaudere ...

(213r) De passione domini ad tercias. Hymnus (AH 30, Nr. 13, Str. 3). - Oracio. Domine Ihesu Christe sanctifica me per spineam coronam et per sacra vulnera ...

(213r) Sext. Hymnus (nur Verweis: AH 32, Nr. 130). - Ps 126-128 (jeweils nur Verweise). Antiphon (CAO Nr. 4705). - Capitulum. - (213v) Oracio. Omnipotens sempiterne Deus famulos tuos dextera potencie tue a cunctis protege periculis ... 
(213v) De passione domini ad sextas. Hymnus (AH 30, Nr. 13, Str. 4 [leicht abweichend]). Oracio. Domine Ihesu Christe rogo te per amaram extensionem omnium membrorum et nervorum tuorum ...

(213v) Non. - (214r) Hymnus (nur Verweis: AH 32, Nr. 130). - Ps 129-131 (jeweils nur Verweise). - Antiphon (CAO Nr. 1357). - Capitulum. - Oracio. Protege domine famulos tuos subsidiis pacis et beate Marie virginis patrociniis confidentes ...

(214r) De passione domini ad nonas. Hymnus (AH 30, Nr. 13, Str. 5). - Oracio. Domine Ihesu Christe qui propter me mortem pati voluisti ...

(214v) Vesper. Ave Maria. - Antiphon (CAO Nr. 2547). - Ps 110 (nur Verweis). - Antiphon (CAO Nr. 4937). - Ps 113 (nur Verweis). - Antiphon (CAO Nr. 2855). - Ps 122 (nur Verweis). Antiphon (CAO Nr. 2641). - Ps 127 (nur Verweis). - Antiphon (CAO Nr. 2887). - Ps 147,12 (nur Verweis). - Capitulum. - Ymnus. Ave maris (nur Verweis: De annunciacione supra in hymnario quere). - (215r) Antiphon (CAO Nr. 4703.3). - Oracio. Famulorum tuorum quesumus domine delictis ignosce ut qui tibi placere...

(215r) De passione domini ad vesperas. Hymnus (AH 30, Nr. 13, Str. 6). - Oracio. Domine Ihesu Christe qui proprio sanguine tuo mundum redemisti redime me ab omnibus peccatis et negligenciis ...

(215v) Komplet. Ps 132 (nur Verweis). - Antiphon (CAO Nr. 1862). - Hymnus (nur Verweis: AH 32, Nr. 130). - Capitulum. - Antiphon (CAO Nr. 2952). - Psalmus (recte: Lc 2,29-32). - Oracio. Concede misericors Deus fragilitati nostre presidium ut qui sancte Dei genitricis Marie ...

(215v) De passione domini ad completorium. Hymnus (AH 30, Nr. 13, Str. 7). - (216r) Oracio. $O$ dies eterne nunquam deficiens et sol nunquam occidens qui circa solis occasum sepultus suscepisti...

12 (216r-223r) SuFFrAGia.

12.1 (216r-217v) Suffragia des Augustiner Chorherrenstiftes Waldsee.

(216r) Tit.: Sequuntur suffragia contraria ad vesperas et ad matutinas secundum modum monasterii s. Petri in Walsee.

Den einzelnen Gebeten der Suffragien jeweils eine Antiphon und ein Versikel vorangestellt. (216v) De s. trinitate. Omnipotens sempiterne Deus qui dedisti famulis tuis in confessione vere fidei eterne trinitatis gloriam agnoscere ... - De sancta cruce. Deus qui crucem sanctam ascendisti et mundi tenebras illuminasti ... - De beata virgine. Beate et gloriose semperque virginis Dei genitricis Marie quesumus omnipotens Deus intercessio gloriosa nos protegat ... - (217r) De angelis. Deus qui miro ordine angelorum ministeria hominumque dispensas concede propicius ... De s. Iohanne Baptista. Presta quesumus omnipotens Deus ut familia tua per viam salutis incedat et beati Iohannis precursoris ... - De apostolis Petro et Paulo. Apostolicis nos quesumus domine beatorum apostolorum Petri et Pauli et aliorum apostolorum adtolle presidiis ... - (217v) De s. Iohanne ewangelista. Ecclesiam tuam quesumus domine benignus illustra et (!) beati Iohannis apostoli tui et evangeliste illuminata doctrinis ... - De s. Augustino. Adesto supplicacionibus nostris quesumus omnipotens Deus et quibus fiduciam sperande pietatis indulges ... - De omnibus sanctis. Da nobis domine continua omnium sanctorum tuorum veneracione letari ...

12.2 (218r-220v) SufFragia AD Placitum. (218r) Tit.: Sequuntur nunc alia suffragia ad placitum. Vor den einzelnen Orationen jeweils ein Versikel.

(218r) De s. Maria virgine. Concede nos famulos tuos quesumus domine Deus noster perpetua mentis et corporis sanitate gaudere ... - De s. Iohanne Baptista (nur Verweis). - De sancto Petro. Deus qui apostolo Petro collatis clavibus ... - De apostolis Petro et Paulo. Protege domine populum tuum et apostolorum tuorum Petri et Pauli patrocinio confidentem ... - De s. Augustino. Deus amator omnium bonorum qui sanctissimum Augustinum confessorem ... - (218v) Alia oracio. Adesto suplica[tionibus] (nur Verweis). - De s. Iohanne ewangelista. Ecclesiam tuam que- 
sumus ... - De s. Iohanne Baptista. Concede quesumus omnipotens Deus ut quod beati Iohannis Baptiste solemnia colimus ... - De s. Maria Magdalena. Deus qui beatam Mariam Magdalenam dominice resurreccionis gaudium sanctis apostolis innotescere voluisti ... - De omnibus sanctis. Omnipotens sempiterne Deus qui nos omnium sanctorum tuorum merita sub una tribuisti celebritate ... - Alia oracio. Da nobis quesumus domine continua omnium sanctorum tuorum veneracione letari ... - (219r) De sancta Margaretha. Deus qui beatam virginem Margaretham ad celos per martirii palmam pervenire fecisti ... - De s. spiritu. Deus qui corda fidelium sancti spiritus illustracione docuisti ... - De angelis (nur Verweis). - De s. Katherina. Deus qui dedisti legem Moysi in summitate montis Synai et in eodem loco per sanctos angelos ... - De s. Nicolao. Deus qui beatum Nicolaum pontificem tuum innumeris decorasti miraculis ... - De s. cruce (nur Verweis) - De s. Dyonisio. Presta quesumus omnipotens Deus ut qui gloriosos martires Dyonisium socios quam (!) eius fortes in sua confessione cognovimus ... - (219v) De s. Laurencio. Da nobis quesumus omnipotens Deus viciorum nostrorum flammas extinguere ... - De s. Andrea. Maiestatem tuam domine suppliciter exoramus ut sicut ecclesie tue beatus Andreas ... - De s. Luca ewangelista. Interveniat pro nobis quesumus Deus sanctus tuus Lucas ewangelista qui crucis mortificacionem ...--De corpore Christi. Deus qui nobis (gestrichen: per) sub sacramento mirabili passionis tue memoriam reliquisti tribue ... - (220r) Pro pace. Deus a quo sancta desideria recta consilia et iusta sunt opera ... - Generalis oracio. A cunctis nos quesumus domine mentis et corporis defende periculis et intercedente gloriosa virgine Dei genitrice ... - Oracio pro defunctis. Avete omnium fidelium anime in pace Christi requiescite quos redemit suo precioso sanguine ... - (220v) Alia oracio pro defunctis. Sancte Deus sancte fortis sancte et immortalis Deus miserere animabus omnium fidelium defunctorum ... - Alia oracio. Domine Ihesu Christe fili Dei vivi mundi creator et redemptor qui dixisti ...

12.3 (221r-223r) Suffragia des Augustiner Chorherrenstiftes Neustift.

(218r) Tit.: Sequuntur alia suffragia secundum chorum monasterii s. Marie in Novacella.

Den einzelnen Orationen der Suffragien jeweils eine Antiphon und ein Versikel vorangestellt. Suffragien jeweils nach Tagen und Tagzeiten unterschieden.

(221r) Et primo sabbatis noctibus ad vesperas. De sancta trinitate. Omnipotens sempiterne Deus qui dedisti famulis tuis in confessione vere fidei eterne trinitatis gloriam agnoscere ... - De sancta cruce. Deus qui unigeniti filii tui precioso sanguine vivifice crucis vexillum sanctifficare (!) voluisti ... - De beata virgine. Famulorum tuorum quesumus domine delictis ignosce ut qui tibi placere ... - (221v) De sancto Augustino. Excita quesumus domine in ecclesia tua spiritum cui beatus Augustinus confessor tuus et pontifex servivit ... - De omnibus sanctis. Maiestatem tuam domine supplices exoramus ut sicut nos iugiter omnium sanctorum ...

(221v) Dominicis diebus ad matutinas. De s. trinitate (nur Verweis). - De s. cruce. Adesto nobis domine Deus noster et quos sancte crucis letari fecisti ... - (222r) De beata virgine. Protege domine famulos tuos subsidiis pacis et beate Marie virginis patrociniis confidentes ... - De s. Augustino. Deus qui populo tuo beatum Augustinum eterne salutis ministrum constituisti ... De omnibus sanctis (nur Verweis).

(222r) Per ebdomadam suffragia. Orationes durchwegs identisch mit obigen, lediglich Antiphonen und Versikel sind verändert. De beata virgine. - (222v) De sancto Augustino. - De omnibus sanctis.

(223r) Suffragia ad matutinas per ebdomadam. Orationes durchwegs identisch mit obigen, lediglich Antiphonen sind verändert. De beata virgine. - De sancto Augustino. - De omnibus sanctis.

13 (223v-224r) ACCESSUS ALTARIs (vgl. Jungmann I 354-355).

Tit.: Sequitur accessus altaris. Ymnus. Veni creator (nur Verweis). - Ps 84-86, 116,10, 130 (jeweils nur Verweise). - Capitulum. - Preces. Ego dixi domine miserere mei. Sana animam meam quia ...-Anschließend fünf Orationes: Aures tue pietatis mitissime Deus inclina precibus meis ... - Deus cui omne cor patet et omnis voluntas loquitur ... - (224r) Deus qui corda 
fide[lium] (nur Beginn). - Auge in nobis domine fidem rectam spem firmam caritatemque perfectam ... - Omnipotens sempiterne Deus dirige actus nostros in beneplacito tuo ...

14 (224r-v) Zwei Orationes ANTE MISSAM.

Tit.: Sequitur ante missam oracio.

1) Pulcherrime Ihesu Christe rogo te per illam sacratissimam effusionem preciosissimi sanguinis tui quo sumus redempti...

2) Domine Ihesu Christe qui in cruce suspensus es pro nostra redempcione tuum dulcissimum spiritum in manus Dei patris ...

15 (225r-v) ReCESSUS ALTARIs. Nachtrag (möglicherweise dat. 1501, s. bei S) (vgl. Jungmann II 572). (225r) Tit.: Sequitur recessus altaris. Canticum trium puerorum (Dn 3,57-88), Ps 150, Canticum Simeonis (Lc 2,29-32) (jeweils nur Textbeginn). Mit Antiphon. - Preces. Confiteantur tibi domine omnia opera tua ... Exultabunt sancti in gloria ... Non nobis domine non ... Domine exaudi orationem. Anschließend drei Orationes: Deus qui tribus pueris mitigasti flammas ignium, concede propicius ... - Acciones nostras quesumus domine aspirando preveni et adiuvando prosequere ... - (225v) Da nobis quesumus domine vitiorum nostrorum flammas extinguere ...

(HDS) ganzseitige Miniatur (s. bei A).

U.S.

\section{Cod. 440}

\section{MARSILIUS DE INGHEN. IOHANNES BURIDANUS}

Pap. I, 414 Bl. $280 \times 205$. Tirol (?), um 1450 .

B: $\quad$ Pap. tw. fleckig, insbes. am Schnitt und ab B1. 413. B1. 13 lose. Bilder und Nachweise der Wasserzeichen s. WZMA. Datierung nach Wasserzeichenbefund. Identische Wasserzeichen: u. a. Klosterneuburg, Stiftsbibl., CCl 341, CCl 404, CCl 409. Lagen: $I^{1}$ (Vorsatzbl. $)+7 . V^{84}+(\mathrm{VI}-8)^{88}+14 . \mathrm{VI}^{266(256)}+(\mathrm{VI}-10)^{268(258)}+$ 13.VI ${ }^{424(414)}$. Die letzten acht bzw. zehn Blätter der Lagen 8 bzw. 23 herausgeschnitten (ohne Textverlust). In den Lagenmitten tw. Pergamentfälze (bisweilen zweispaltig beschrieben und rubriziert). Lagenreklamanten, tw. be- bzw. weggeschnitten. Am oberen Blattrand Foliierung 19. Jh. durch die ULB Tirol; Fehler in der Zählung: 143-152 ausgelassen. Bl. 88 und 268 neuzeitliche orange Papiersignakel der ULB Tirol.

S: $\quad$ Schriftraum 195/225 $\times 145 / 155$. Zwei Spalten, von Tinten- bzw. Bleistiftlinien gerahmt, zu 40-51 Zeilen. Zirkelstiche. Bastarda von drei Händen: 1) Bl. 1ra-88ra; 2) Bl. 89ra-268ra; 3) Bl. 269ra-423vb. Bei Schreiber 1 und 3 Textbeginn in Textualis formata (Textura).

A: Platz für Überschriften (bei Schreiber 2), Lombarden (bei Schreiber 3) und Initialen freigelassen, nicht ausgeführt.

E: $\quad$ Halbledereinband: weißes Schweinsleder über dickem Holz mit Blinddruck.Tirol (?), 2. H. 15. Jh. Lederüberzug am VD und HD etwa bis Mitte des Buchdeckels reichend. Leder am VD stark abgenützt und beschädigt. Am VD und HD von vierfachen Streicheisenlinien gebildeter Rahmen, Mittelfeld durch ebensolche Linien diagonal unterteilt, Begrenzungsdreiecke gefüllt mit zahlreichen Einzelstempeln. Stempel am VD nicht mehr erkennbar, am HD: kleine Siebenpunktblüte (Nr. 1); Schriftband „Maria“ (Nr. 2); Doppeladler mit Krone in Tropfenform (Nr. 3); Rosette mit zweifachem Blütenkranz frei (Nr. 4); Kielbogen mit Blüte frei (Nr. 5); nach links blickender Steinbock in Rhombus (Nr. 6). Zwei Leder-Metall-Schließen, verziert mit Schriftzug und achtblättriger Rosette (wie Neustift, Stiftsbibl., Cod. 4), oberes Schließband mit aufgeklebtem beschriebenem Papiertitelschild Marsilius. Kanten gerade. Rücken: blau gefärbt (wie öfters in Neustift), Fitzbünde, dazwischen drei Doppelbünde, Felder mit zweifachen Streicheisenlinien diagonal unterteilt. Im ersten Feld Papiertitelschild M: S: Marsilius de Passionibus, im zweiten Signaturschild (s. bei G), im vierten blau gefärbtes Papierschild (Reparatur?). Spiegel des VD und HD urspr. jeweils wohl Pergamentfragment, jetzt nicht mehr erhalten und nur noch Abklatsch sichtbar (liturgischer Text: Vigiliae Mortuorum, Lectio 
VI-IX, Responsorien und Versikel; urspr. am VD aufgeklebtes Pergamentblatt heute gelöst; s. bei Inhalt), am VD zusätzlich Exlibris.

G: Zeitpunkt und Art der Erwerbung durch Neustift unbekannt. Die Wasserzeichen weisen in den Wiener Raum; verwandte Wasserzeichen u. a. auch in Innsbruck, ULB Tirol, Cod. 749, geschrieben in Schnals und Innichen. Bl. 1r Besitzvermerk 18. Jh. Collegii Neocell. Am Spiegel des VD Exlibris der Stiftsbibl. Neustift 18. Jh. 1809 anlässlich der vorübergehenden Aufhebung des Klosters Neustift der ULB Tirol übergeben. Bl. Ir alte Signaturen der ULB Tirol II $\overline{3}$ B 11 (Tinte, radiert), II $\overline{2}$ B 12 (Bleistift) und 440 (Tinte). Am Rücken gelbes Signaturschild der ULB Tirol 440 (mit Klebestreifen fixiert). Bl. 1r Stempel der ULB Tirol 19. Jh. 1921 aufgrund des Friedensvertrages von St. Germain an den italienischen Staat abgegeben und von diesem 1929 dem Kloster Neustift als Dauerleihgabe überlassen. Bl. 1r Stempel der Soprintendenza Tridentina 20. Jh.

L: $\quad$ Ch. H. Lohr, Medieval latin Aristotle commentaries. Traditio 27 (1971) 332. - M. Markowski, Katalog dzieł Marsyliusza z Inghen z ewidencją rękopisów (Katalog der Werke des Marsilius von Inghen mit der Evidenz der Handschriften). Studia Mediewistyczne 25, 2 (1988) 39-135, hier 108 und 122. - Kristeller I 439. - Katalog ULB Tirol V 297, 673.

(urspr. VDS, heute abgelöst) Fragment aus einem Breviarium (BRIXINENSE?).

Perg. ca. $277 \times 210$, urspr. als Spiegel auf dem VD aufgeklebt (Klebespuren am Verso), an den Blatträndern beschnitten. Schriftraum: $228 \times 180$, von Tintenlinien gerahmt (am Recto links von zweifachen Linien). Am Recto einspaltig, am Verso zwei Spalten, zu 28 Zeilen auf Tintenlinierung mit zahlreichen Ergänzungen am Blattrand. Textura 14. Jh., Ergänzungen großteils wohl von derselben Hand, vereinzelt von späterer Hand. Rote Auszeichnungsstriche, Durchstreichungen, Paragraphzeichen und Überschriften. Rote ein- und zweizeilige Lombarden. Am oberen Blattrand links Signatur 440 (Tinte).

1) Recto: Enthält Gebete und Psalmhinweise aus dem Officium pro defunctis. Tit.: In deposicione alicuius defuncti. - Inc.: Commendo domine in misericordiam tue divinitatis maiestatis ac magnificencie ... - Expl. mut.: ... Sancte Stephane cum omnibus martiribus veni in adiutorium anime eius et animabus [

Am Blattrand Sequenzen. Am oberen Blattrand Inc. mut.: ] per quem videmus signa in populo. (rot) Sequencia sancte Marie. (AH 54, Nr. 237).

Am linken Blattrand zwei Sequenzen (AH 54, Nr. 227; AH 32, Nr. 24), wobei die zweite am unteren Blattrand fortgesetzt wird.

2) Verso (schlecht lesbar): Lectio VI-IX (Dn 12, 2-3; 1 Cor 15, 22-23; 1 Cor 15, 51-52; 1 Th 5, 2-5) mit Responsorien. Am oberen, rechten und unteren Blattrand Sequenzen (u. a. unten AH 55, Nr. 232). Die Lesungen entsprechen der Gruppe 9 bei Ottosen (K. Ottosen, The Responsories and Versicles of the Latin Office of the Dead. Aarhus 1993, 85-87), weit verbreitet im deutschsprachigen Raum und auch in anderen Brixner Handschriften für die Vigiliae Minores belegt. Auch die Reihe der Responsorien (68-28-40-38) ist weit verbreitet; aus der Bamberger Tradition stammend lässt sie sich im gesamten deutschsprachigen Raum nachweisen, auch in Brixen. Hervorzuheben ist aber die Tatsache, dass das letzte Responsorium Libera me durchgestrichen und in Rot mit jenem aus den Vigiliae mortuorum sollemnes kommenden Deus aeterne (= Ottosen 18) ersetzt wurde. Dieses Responsorium begegnet in der einzig in Sign. 15063 überlieferten Responsorienreihe 70-44-47-58-83-76-1-18-38 an achter Stelle (freundlicher Hinweis Gionata Brusa).

(Ir) nur Signaturen (s. bei G).

(Iv) leer.

1 (1ra-88ra) MARsiLIUS 〈DE InGHEN〉: Quaestiones parvorum naturalium Aristotelis (Lohr 331-332, Nr. 15).

Tit. (18. Jh., am oberen Blattrand, vom Schreiber des Besitzvermerkes auf derselben Seite): De passionibus Magistri Marsilii. Darüber ältere Angabe: magistri Marsilii.

Inc.: [U]trum de passionibus et operacionibus animatorum ponenda sit sciencia distincta a sciencia de anima de animalibus et a sciencia de plantis ... - Expl.: ... circa hanc materiam de quo sit Deus in secula seculorum benedictus Amen. 
Schlussschrift: Expliciunt Questiones parvorum naturalium reverendi magistri Marsilii. (88rb-vb) nur Rahmung.

2 (89ra-268ra) Quaestiones Secundum Iohannem Buridanum Super libros Ethicorum Aristotelis I-V, unvollständig (Lohr 179-181, Nr. 42).

(89ra-91rb) Prolog. Inc. mut. (Platz für Textbeginn freigelassen, nicht ausgeführt): ] Aristoteles $2^{\circ}$ Ethicorum cum dicit eam esse non contemplacionis gracia. Iste est prologus quem promittit (!) magister Buridanus libris Ethicorum quo primo innuit primam conclusionem ... - Expl.: ... malefacere sed tamen non stat eum permanere eum moralem philosophum et eum malefacere. Sequitur questio utrum de virtutibus sit sciencia etc.

(91rb-268ra) Text. Inc.: In conclusione prima dicitur quod de virtutibus potest esse sciencia arguitur virtus non est sciencialis ... - Expl. mut.: ... qui bonus deliquit et bonus qui Aristoteles $2^{\circ}$ probatur [ (Lib. V, qu. 14)

Incipit und Explicit der Buchanfänge gedruckt in M. Markowski, Buridanica quae in codicibus manu scriptis bibliothecarum Monacensium asservantur. Wroclaw et al. 1981, 119-120, Nr. 15. Parallelüberlieferung: München, UB, $4^{\circ}$ Cod. ms. 685, Bl. 1r. (268rb-vb) nur Rahmung.

3 (269ra-346rb) 〈IOHANNES BuRIDANUS〉: Quaestiones super libros Meteororum Aristotelis, unvollständig (Lohr 172, Nr. 21-22).

(269ra-318vb) Lib. 1. Inc. mut. (qu. 2): ] deficientem et respondent totum ad temperamentum sanitatis ... - Expl.: ... ita profunde descendit venit enim mineam de alio loco ad illum et hec sufficiant de illa materia.

(319ra-346rb) Lib. 2. Inc.: [I]am de mari composita fuerunt multa super primum librum. Sed adhuc super secundum queritur de perpetuitate vel generacione maris scilicet utrum fuerit perpetuum ... - Expl.: ... violenta et impetuosa. Soluciones aliarum racionum satis haberi possunt ex predeterminacionis etc.

Schlussschrift: Et sic est finis libri Meteorum.

(346va-b) nur Rahmung.

(347ra-411rb) Lib. 3.

(347ra) Prolog. Inc.: [R]estat querere aliqua circa $3^{m}$ librum et verum est quod ab antiquo solemus illum totalem librum dividere in $4^{\text {or }}$ parciales ... - Expl.: ... circa $3^{m}$ librum queremus utrum etc.

(347ra) Text. Inc.: Queritur primo utrum et Nephie et Typhones descendunt ad terram ex nubibus ... - Expl.: ... de aliis. Et sic est finis questionum primi $2^{i}$ et $3^{i}$ librorum Metheororum reverendi magistri Iohannis Buridani etc.

(387va-b) nur Rahmung (ohne Textverlust).

(411va-423vb) Lib. 4. Inc.: [C]irca quartum Metherorum (!). Utrum tamen $4^{\text {or }}$ sunt qualitates prime scilicet caliditas frigiditas siccitas et humiditas. Et arguitur primo quod non quia ...Expl.: ... quia non uritur ab igne dicimus quod tale animal habitat in igne etc. et tamen de isto. Schlussschrift: Et sic est finis.

(424r-v) nur Rahmung.

A. P./U. S. 


\section{Cod. 447}

\section{KANONISTISCHE SAMMELHANDSCHRIFT, u. a. ALBERTUS DE BRIXIA}

Pap. 208, X* Bl. $295 \times 215$. Süddeutscher Raum, 1414.

B: Am seitlichen Blattrand Wasserschaden, vereinzelt kleine Löcher, Blätter der ersten Lage am Vorderschnitt tw. leicht eingerissen. Bl. 1 und 12 lose, Bl. 133 und 134 Riss. Wasserzeichen s. WZMA. Wasserzeichenbefund mit Datierung übereinstimmend. Lagen: $5 . \mathrm{VI}^{60}+\mathrm{V}^{70}+3 . \mathrm{VI}^{106}+\mathrm{V}^{116}+3 . \mathrm{VI}^{152}+\mathrm{V}^{162}+3 . \mathrm{VI}^{198}+\mathrm{V}^{208}+$ $\mathrm{V}^{\mathrm{X}^{*}}$. Bl. $\mathrm{X}^{*}$ klebte urspr. als Spiegel auf dem HD (Rostspuren). Lagenreklamanten, meist stark be- bzw. weggeschnitten, sowie Kustoden in schwarzen oder roten arabischen Ziffern, tw. beschnitten. Am unteren Blattrand Zählung der Blätter der ersten Lagenhälfte, bisweilen beschnitten. In den Lagenmitten Pergamentfälze, meist unbeschrieben, in fünfter und neunter Lage beschrieben in karolingischer Minuskel in Rot: quis descendit de celo filius / hominis qui est in celo (Io 3,13) bzw. Quis accendit lucernam (Lc 11,33). Um die letzte Lage Pergamentfalz. Bl. 1r-13v, 20r-v, 41v-43r, 50r, 52v, 71r, 83r, 86v, 127v, 163r, 205r am oberen Blattrand Angabe des jeweiligen Buches in Rot, am seitlichen Blattrand Kapitelzählung mit Buchstaben. Am oberen Blattrand zeitgenössische Foliierung in roten arabischen Ziffern von 1-208, anschließend Foliierung 19. Jh. in römischen Zahlen I-VIIII durch die ULB Tirol. Letztes Blatt (X*) ungezählt. Spuren von nicht mehr vorhandenen Signakeln.

S: $\quad$ Schriftraum 215/220 × 150. Zwei Spalten, von Tintenlinien gerahmt, zu 38-43 Zeilen. Bastarda, dat. 29. Juli 1414 (Bl. 206vb bzw. Bl. IX*ra). Schreiber: Hainricus Chirchmair de Malhenstorff (Bl. 206vb) (möglicherweise Kloster Mallersdorf OSB, Diözese Regensburg). Bl. IX*ra Nachtrag von späterer Hand in Notula. Bl. $X^{*}$ r: Schriftraum $235 \times 165$, einspaltig (ohne Rücksicht auf die vorhandene Rahmung), zu 58 Zeilen. B1. 207ra-208vb sowie X*r flüchtigere Bastarda von zeitgenössischer Hand. Ergänzungen am unteren Blattrand von späterer Hand.

A: Rote Auszeichnungsstriche, selten Paragraphzeichen, Durch- und Unterstreichungen, Rahmungen sowie Über- und Schlussschriften. Zweizeilige rote Lombarden, vereinzelt mit Punktverdickungen. Bl. 1ra vierzeilige rot-schwarze Initiale, bogenförmig gespalten, mit flüchtigem, rotem Dekor im Binnenfeld. Bl. 207ra208vb sowie Bl. X*r keine Rubrizierung. Bl. 43va und 44ra am unteren Blattrand Repräsentanten, tw. beschnitten.

E: Gotischer Einband: rot gefärbtes Schafsleder über dickem Holz mit Blindlinien. Süddeutscher Raum, 1. H. 15. Jh.

Leder stark abgerieben, am VD und HD eingerissen. Holz des HD vertikal gebrochen. VD und HD gleich: ein von zweifachen Streicheisenlinien gebildeter Rahmen, Mittelfeld durch zweifache Streicheisenlinien diagonal und in der Mitte waagrecht unterteilt. In der Mitte sowie an den Ecken Spuren von fünf runden Beschlägen. Reste von zwei Langriemen-Leder-Metall-Schließen. Kanten gerade. Rücken: drei Doppelbünde. Im ersten Feld aufgeklebtes Papiertitelschild M: S: 1414 Liber de Officio, im zweiten Signaturschild (s. bei G), im vierten aufgeklebtes Papierschild, leer. Kapitale mit rot gefärbtem Leder umstochen. Am Spiegel des VD Signaturen, Exlibris (s. bei G) sowie Abklatsch eines wohl abgelösten beschriebenen Blattes, Spiegel des HD leer.

G: Zeitpunkt und Art der Erwerbung durch Neustift unbekannt. Bl. 1r Exlibris der Stiftsbibl. Neustift 18. Jh. 1809 anlässlich der vorübergehenden Aufhebung des Klosters Neustift der ULB Tirol übergeben. Bl. 1r alte Signatur der ULB Tirol II $\overline{4} C 22$ (?) (Tinte, radiert), am Spiegel des VD weitere Signaturen der ULB Tirol II $\overline{2}$ C 6 (Bleistift) und 447 (Tinte). Am Rücken gelbes Signaturschild der ULB Tirol 447. Bl. 1r Stempel der ULB Tirol 19. Jh. 1921 aufgrund des Friedensvertrages von St. Germain an den italienischen Staat abgegeben und von diesem 1929 dem Kloster Neustift als Dauerleihgabe überlassen. Bl. 1r Stempel der Soprintendenza Tridentina 20. Jh.

L: $\quad$ Wilhelm II 107. - Stegmüller RS Nr. 368. - Kaeppeli Nr. 98. - Stefani 108. - Peintner, Stiftsbibliothek 121. - Katalog ULB Tirol V 330, 673.

1 (1ra-206vb) 〈Albertus de BriXiA〉: Summa de officio sacerdotis (Kaeppeli Nr. 98. Bloomfield Nr. 5053, vgl. Nr. 5045).

Tit. (am oberen Blattrand von anderer Hand ergänzt): Incipit. De fide, caritate, iusticia, temperancia. Tytulus libri est summa de officio sacerdotis.

Inc.: Quoniam ut ait Ieronimus sacerdotis officium est respondere de lege et ut dominus dicit per Malachiam prophetam Labia sacerdotis custodiunt sacramentum et legem ... - Expl.: ... faciens nos filios suos adoptivos per unigenitum filium dominum nostrum Ihesum Christum qui cum patre 
et spiritu sancto eternaliter est Deus unus et verus ipsi Deo sit honor et gloria qui vivit in eternum et regnat per omnia secula seculorum Amen. Deo gracias etc.

(1ra) Lib. 1. - (42va) Lib. 2. - (78ra) Lib. 3.

Schlussschrift mit Schreibernennung und Datierung: Finitus est liber iste per manus Hainrici Chirchmair de Malhenstorff dominica Ecce Deus adiuvat Anno domini $M^{\circ}$ quadringentesimo quartodecimo etc. (29. Juli 1414).

Lit.: Schulte GQ II 424; M. Grabmann, Mittelalterliches Geistesleben. Abhandlungen zur Geschichte der Scholastik und Mystik III. München 1956, 323-351: Albert v. Brescia und sein Werk „De officio sacerdotis“ (tw. Textabdruck); Ders., Albert von Brescia OP (gest. 1314) und sein Werk „De officio sacerdotis“. Ein Beitrag zur Geschichte der seelsorgerlichen Verwertung der Summa theologica des hl. Thomas in der älteren italienischen Dominikaner- und Thomistenschule. Divus Thomas (Friburgensis) 18 (1940) 5-38.

2 (207ra-208ra) DE USURA.

Inc.: Utrum usura mortaliter culpabilis sit penes intencionem principaliter mensuralis (!). Arguitur quod non quia usura attenditur penes pactum mutui inter diversas personas contractum ergo non penes intencionem principaliter ... - Expl.: ... quod scriptura sacra et cetera sancta affert. Inc. wie Prag, Národní knihovna České republiky, IX B 7, B1. 372v-373v (Expl. mut.).

3 (208ra-vb) De REEMPTIONIBUs.

Inc.: Casus talis est. Quedam domus religiose quarum fratres non manducant emerunt pensiones annuas perpetuas ipsis oportunas ... - Expl.: ... prudentes esse conamur.

Mit Gutachten von (208ra) Hainricus de Duren advocatus in curia Coloniensi; (208rb) Henricus Stuger de Bonna (!), decretorum doctor; Iohannes Wirborgensis, decretorum doctor; Iohannes de Novo Lapide, legum doctor; Iohannes de Cerno, legum doctor; (208va) Theodericus de Monasterio, sacro (!) theologie professor Colonie; Iacobus de Susato ordinis Predicatorum sacre pagine professor; Nicolaus de Spiria, sacre theologie professor fratrum ordinis Camelitarum (!); Iohannes Ban., legum doctor prepositus ecclesie sancti Georgii Coloniensis; Petrus cardinalis Cameracensis; Iohannes de Gersano, cancellarius Parysiensis; cardinalis Florus; (208vb) archiepiscopus Ianuensis; Angelus rector ecclesie sancti purati Utinensis dyocesis decretorum doctor.

Parallelüberlieferung: Frankfurt, Staats- und Universitätsbibl., Fragm. lat. IV 2; Nürnberg, Stadtbibl., Cent. VI 11, Bl. 359r.

Darunter: Sequitur confirmacio bulle super hiis dictis in fine libri.

$4 \quad$ (I*ra-IX*ra) Register zu Nr. 1.

Mit Blattangabe (rechts) und Kapitelzählung (links).

(IX*ra) Schlussschrift mit Datierung: Et sic est finis etc. anno etc. XIIII ${ }^{\circ}$.

5 (IX*ra) Nota de BAPTISMO.

Inc.: Queritur quis effectus baptismi. Respondetur secundum Thomam in $4^{\circ}$ Pueri quidem in baptismo mundantur ... - Expl.: ... et parentes confirmati.

(IXrb-v) leer.

6 (X*r) Martinus V.: Bulla „Regimini universalis“, Rom, 1425 Juli 2 (Extrav. Com. Lib. 3, tit. 5, cap. 1. CIC, ed. Friedberg II 1269-1271).

$\left(\mathrm{X}^{*} \mathrm{v}\right)$ nur Rahmung. 


\section{Cod. 453}

\section{MEDIZINISCHE SAMMELHANDSCHRIFT}

Pap. III, 234, I* Bl. $295 \times 210$. T. I: Wiener Raum, um 1455-1460, T. II-IV: Wiener Raum (?), um 1440.

B: $\quad$ Vier Teile: I (III, 1-58), II (59-142), III (143-186), IV (187-234, I*). Am oberen Blattrand Foliierung 19. Jh. durch die ULB Tirol.

E: $\quad$ Schmuckloser Einband: dunkelbraunes Leder über Holz. S. Maria di Rosano (Firenze), Ende 20. Jh. Einband sowie Bindung im Zuge der Restaurierung erneuert. Kanten gerade. Rücken: drei Doppelbünde. Im ersten Feld Spuren eines aufgeklebten Signaturschildes, im vierten Signaturschild (s. bei G). Kapitale mit hellblauem und rotem Zwirn umstochen. Spiegel Pap. 20. Jh. Am Spiegel des VD Fragment mit Besitzvermerk (s. bei G) sowie Fragment mit Notiz (s. bei Inhalt) eingeklebt. Am Spiegel des HD Etikett der Restaurierwerkstätte (s. bei G). Bl. IIIv Titelschild (möglicherweise einst am urspr. Einband aufgeklebt) Tegni Galieni. Libri afforismorum.

G: Wohl Geschenk des Neustifter Präbendars und Klosterarztes Bertoldus de Saxonia ans Stift (gemeinsam mit Cod. 123 und vermutlich auch dem tw. von denselben Händen geschriebenen Cod. 748, vgl. Schenkungsvermerk in Cod. 748, Bl. IIIv und Cod. 123, Bl. Vv). Auf dem Titelschild (eingeklebt auf Bl. IIv) unter dem Titel in roter Tinte T9, möglicherweise alte (Neustifter?) Signatur oder Besitzvermerk. Am Spiegel des VD eingeklebtes Fragment mit Besitzvermerk 15. Jh. Iste liber est monasterii sancte Marie virginis ad Novamcellam Brixinensis dyocesis. Bl. 143r Besitzvermerk 15. Jh. Iste liber est monasterii sancte Marie virginis in Novacella. Bl. 1r Besitzvermerk 18. Jh. Collegii Neocell. 1809 anlässlich der vorübergehenden Aufhebung des Klosters Neustift der ULB Tirol übergeben. Bl. 1r Stempel der ULB Tirol 19. Jh. 1921 aufgrund des Friedensvertrages von St. Germain an den italienischen Staat abgegeben und von diesem 1929 dem Kloster Neustift als Dauerleihgabe überlassen. Bl. 1r Stempel der Soprintendenza Tridentina 20. Jh. Am Spiegel des HD Etikett der Restaurierwerkstätte 20. Jh. (Laboratorio di restauro del libro S. Maria di Rosano), kein Restaurierbericht vorhanden. Bl. Ir Signatur 20. Jh. Ms 453 (Bleistift). Am Rücken Signaturschild 20. Jh. 453.

L: $\quad$ Kristeller I 439. - P. Kibre, Hippocrates Latinus. Repertorium of Hippocratic writings in the Latin Middle Ages. New York ${ }^{2}$ 1985, II 277 und III 269. - Katalog ULB Tirol V 348, 674.

$$
\text { I (III, 1-58) }
$$

B: $\quad$ Pap. tw. fleckig, insbes. Bl. 1r. Bilder und Nachweise der Wasserzeichen s. WZMA. Datierung nach Wasserzeichenbefund. Identische Wasserzeichen: u.a. Klosterneuburg, Stiftsbibl., CCl 187 (dat. 1458); Wien, ÖNB, Cod. 3901 (dat. 1461). Lagen: (I-1) ${ }^{\mathrm{I}}$ (Vorsatzbl. 20. Jh.) + III (Vorsatzbl. 15. Jh.) + 4.VI ${ }^{48}+\mathrm{V}^{58}$. Gegenbl. zum Vorsatzbl. als Spiegel auf dem VD aufgeklebt. Bl. 12v Lagenreklamante erhalten. Bl. 39r-53r am oberen rechten Blattrand der Rectos Zählung der Textabschnitte (prima particula Amphorismorum [!], $2^{a}$ particula etc.).

S: $\quad$ Bl. 1r-33r Schriftraum $180 \times 110$, von Tintenlinien gerahmt, zu 23-25 Zeilen. Bl. 33v-34v Schriftraum $245 \times 150$, von Tintenlinien gerahmt, zu 70-74 Zeilen. Bl. 35r-53r Schriftraum 200×120/125, von Tintenlinien gerahmt (Bl. 50v-53r nur seitlich begrenzt). Bl. 35r-38v zu 37-38, Bl. 39r-46v zu 24-27, Bl. 47r-53r zu 23 Zeilen. Bl. 53v-58v Schriftraum 230/240×160. Zwei Spalten, von Tintenlinien gerahmt, zu 50-59 (Bl. 53v-54v zu 72) Zeilen. Bastarda von drei Händen: 1) Bl. 1r-46v; 2) Bl. 47r-53r; 3) Bl. 53v-54v und Zählung der Textabschnitte auf Bl. 39r-53r (= späterer Duktus des Schreibers von T. II-IV, von Neustift, Stiftsbibl., Cod. 748, T. I-III und von Neustift, Stiftsbibl., Cod. 123, Schreiber 2, möglicherweise zu identifizieren mit Bertoldus de Saxonia, s. bei G).

A: Rote Auszeichnungsstriche, Paragraphzeichen, Unterstreichungen, Überschriften. Ein- und zweizeilige (Bl. 35r: dreizeilige) rote Lombarden, meist mit Punktverdickungen. Bl. 1r sowie Bl. 39r-46v Platz für einzeilige Lombarden freigelassen, nicht ausgeführt. Repräsentanten. Bl. 53va-54va keine Rubrizierung.

1 (VDS, aufgeklebtes Schildchen) Besitzvermerk (s. bei G). Notız: Prima pronosticorum: ffinis laudabilis medicine existit cum actor futura in singulis propendit quamvis omnes minime curare possit. Quod si posset non iam futuri previsor sed divinis prophetis nobilior diceretur. (Ir-IIIr) leer bis auf Signatur (s. bei G). 
(IIIv) Titelschild (s. bei E) sowie Notiz zum Inhalt 18. Jh. Regni (!) Galieni et Joannis Damasceni Aphorismi.

2 (1r-33r) Galenus: Ars parva seu Microtegni, tr. Gerardi Cremonensis (Druck: GW 2678-2683. Thorndike-Kibre 1585), mit Interlinear- und Marginalglossen, tw. mit Paraphrase (ThorndikeKibre 700).

Tit.: Incipit Tegni Galieni de corporibus sanis egris et neutris et signis sanis egris et neutris. (1r) Prolog. Inc.: [T]res sunt omnes doctrine que ordine habentur. Prima quidem ex finis nocione ... - Expl.: ... sed explicacionem demonstratorum dicentur nunc (rot:) de significacione medicine.

(1v) Text. Inc.: Medicina est sciencia sanorum egrorum et neutrorum ... - Expl.. ... scribens et quot sint et qualia determinabo in hiis oracionem.

Glosse. Inc.: Nota secundum Averroim quod medicina est de subiecto cuius subiecti racio in medicina salvatur ... - Paraphrase. Inc.: In omnibus doctrinis que secundum ordinem currunt incessus sunt secundum rerum ordines. Una earum est que fit secundum ...

3 (33v-34v) Divisiones libri Tegni Galieni.

Inc.: Tres sunt omnes doctrine que ordine habentur etc. Istius libri qui Tegni id est pars (!) parva dicitur ... - Expl.: ... in tradicione istius libri visus est observasse.

Schlussschrift: Expliciunt divisiones libri Tegni Galieni.

4 (35r-38v) Iohannes 〈Mesue〉: Liber aphorismorum (Ed.: D. Jacquart, G. Troupeau, Yûhannâ ibn Mâsawayh [Jean Mesue], Le livre des axiomes médicaux [Aphorismi]. Genève, Paris 1980, 107-223. - Thorndike-Kibre 824).

Tit.: Incipit Liber afforismorum Iohannis Damasceni.

5 (39r-53r) 〈HipPocRates»: Aphorismi (Thorndike-Kibre 1704. Kibre, Hippocrates Latinus II, Nr. III, mit Nennung der Hs.), tr. anonyma (P. Kibre, Hippocrates Latinus II, Nr. III,3). Mit Interlinear- und Marginalglossen B1. 39r-42r.

Text. Inc.: [V]ita brevis ars vero longa tempus acutum experimentum vero fallax iudicium autem difficile ... - Expl.: ... quanto magis dabuntur tanto plus peyorabuntur.

Glosse. Inc.: Continuo oportet in medicina libros afforistica brevitate collaciones componere ...

$6 \quad$ (53va-54va) QuAESTIONES.

(53va) Inc.: Utrum in omni tempore morbi possit fieri evacuatio in febre putrida. Quod sic auctoritate illius afforismi. Inchoantibus morbis etc. ... - Expl.: ... melius et perfectius complebitur cum adiutorio artis.

(54va) Inc.: Utrum corpus discrasiatum ex generacione et tempore debeat reduci ad temperamentum ... - Expl.: ... que requirit calefaciencia vel subtiliancia vel incidencia.

(54vb-58vb) leer.

$$
\text { II (59-142) }
$$

B: $\quad$ Pap. tw. leicht fleckig. Bilder der Wasserzeichen s. WZMA. Datierung nach Wasserzeichenbefund. Identische Wasserzeichen: Neustift, Stiftsbibl., Cod. 748, T. III. Lagen: 7.VI ${ }^{142}$. Ab Bl. 71r jeweils am Lagenbeginn am oberen Blattrand mittig Kustoden, tw. ausgeschrieben, tw. in arabischen Ziffern, beschnitten und tw. radiert (3-6, 7us). Am oberen Blattrand rechts Zählung der Textabschnitte (beginnend Bl. 60r mit prima particula) und mittig Foliierung innerhalb der einzelnen Abschnitte.

S: $\quad$ Schriftraum 240/250 × 155/160. Zwei Spalten, seitlich von Tintenlinien begrenzt, zu 50-59 Zeilen. Bastarda (= Schreiber von T. III und IV, von Neustift, Stiftsbibl., Cod. 748, T. I-III und von Neustift, Stiftsbibl., Cod. 123, Schreiber 2, möglicherweise zu identifizieren mit Bertoldus de Saxonia, s. bei G). Abschnittsanfänge in Textualis formata (Textura).

A: Rote Auszeichnungsstriche, Paragraphzeichen und Durchstreichungen. Abschnittsanfänge gerahmt. 
7 (59ra-134ra) 〈IAcobus ForliviEnsis`: Expositio in Hippocratis Aphorismos (Druck: GW M10637. Thorndike-Kibre 1087. Kibre, Hippocrates Latinus III 269).

Inc.: [V]ita brevis ars vero longa tempus acutum. Pretermissis quibusdam superfluis inquisicionibus in principio huius libri ... - Expl.. ... causam scilicet frigiditatem et humiditatem. Ideo non procedit contra dicta.

(134rb) nur Rahmung.

(134v-142v) leer.

$$
\text { III (143-186) }
$$

B: $\quad$ Bilder und Nachweise der Wasserzeichen s. WZMA. Datierung nach Wasserzeichenbefund. Identische Wasserzeichen: u. a. Klosterneuburg, Stiftsbibl., CCl 534, T. I (dat. 1439); Neustift, Stiftsbibl., Cod. 748, T. III. Lagen: $2 . \mathrm{VI}^{166}+2 . \mathrm{V}^{186}$. Ab Bl. 143r am Lagenbeginn am oberen Blattrand mittig Kustoden (primus-4). Bl. 143r-165r am oberen rechten Blattrand der Rectos Kennzeichnung des ersten Textabschnittes (prima).

S: $\quad$ Schriftraum 225/240 $\times 155 / 160$. Zwei Spalten, seitlich von (tw. zweifachen) Tintenlinien begrenzt, zu 52-58 Zeilen. Zirkelstiche. Bastarda (= Schreiber von T. II und IV, von Neustift, Stiftsbibl., Cod. 748, T. I-III und von Neustift, Stiftsbibl., Cod. 123, Schreiber 2, möglicherweise zu identifizieren mit Bertoldus de Saxonia, s. bei G). Beginn der Quaestiones in Textualis formata (Textura).

A: Rote Auszeichnungsstriche, Paragraphzeichen und Durchstreichungen. Überschriften gerahmt.

8 (143ra-183ra) Quaestiones in Hippocratis Aphorismos, unvollständig (Kibre, Hippocrates Latinus III 269). Text bricht in Particula 6 ab.

Tit.: Circa primam afforismorum. In exercitantibus ad summum. - Inc.: Utrum sit possibile humorem vel humores nostri corporis peccare solum in quali. Et arguitur quod non. Primo sic quilibet humor peccans ... - Expl. mut.: ... quia non video secundum primam reversionem quomodo responderetur [

(183rb-186vb) nur Rahmung.

$$
\text { IV }\left(187-234, I^{*}\right)
$$

B: Pap. fleckig, tw. Tintenkleckse. Bilder und Nachweise der Wasserzeichen s. WZMA. Datierung nach Wasserzeichenbefund. Verwandte Wasserzeichen: Neustift, Stiftsbibl., Cod. 748, T. I. Lagen: $(V I+1)^{199}+2$ VI $^{223}$ $+(\mathrm{VI}-1)^{234}+(\mathrm{I}-1)^{I^{*}}$ (Nachsatzbl. 20. Jh.). Gegenbl. zum Nachsatzbl. als Spiegel auf dem HD aufgeklebt. Bl. 190 kleineres eingehängtes Einzelbl. $(230 \times 210)$. Ab Bl. 200 am Lagenbeginn am oberen Blattrand mittig Kustoden (2-4)

S: $\quad$ Schriftraum $230 / 235 \times 155 / 160$. Zwei Spalten, seitlich von Tintenlinien begrenzt, zu 52-55 Zeilen. Zirkelstiche. Bastarda (= Schreiber von T. II und III, von Neustift, Stiftsbibl., Cod. 748, T. I-III und von Neustift, Stiftsbibl., Cod. 123, Schreiber 2, möglicherweise zu identifizieren mit Bertoldus de Saxonia, s. bei G). Bl. 187ra-b und 191ra Beginn der Quaestiones in Textualis formata (Textura).

A: Rote Auszeichnungsstriche, Paragraphzeichen und Durchstreichungen. Überschriften gerahmt.

9 (187ra-232rb) 〈IAcoBus Forliviensis〉: Quaestiones primi tegni Galeni (Druck: GW M10647. Thorndike-Kibre 1676).

Inc.: [U]trum tantum tres sint omnes doctrine ordinarie. Arguitur quod non. Primo quot sunt questiones tot sunt sciencie vel doctrine ... - Expl.: ... sex rerum non naturalium amministracio sub qua eciam acta anime continentur.

(232va-234vb) nur Rahmung.

$(\mathrm{I} * \mathrm{r}-\mathrm{v})$ leer. 


\section{Cod. 483}

\section{HONORIUS AUGUSTODUNENSIS}

Perg. I, 76, I* Bl. $255 \times 170$. Entstehungsort unbestimmt, 2. H. 12. Jh.

B: $\quad$ Perg. von unterschiedlicher Qualität, leicht fleckig, abgegriffen, vereinzelt Löcher und Nahtspuren. Lagen (Neubindung 20. Jh.): (I-1) (Vorsatzbl., Pap. 20. Jh.) $+\mathrm{II}^{4}+\mathrm{IV}^{12}+\mathrm{III}^{18}+2 . \mathrm{I}^{22}+\mathrm{IV}^{30}+\mathrm{II}^{34}+2 . \mathrm{I}^{38}+3 . \mathrm{IV}^{62}+$ $\mathrm{I}^{64}+\mathrm{IV}^{72}+\mathrm{II}^{76}+(\mathrm{I}-1)^{\mathrm{I} *}$ (Nachsatzbl., Pap. 20. Jh.). Gegenbl. zum Vor- bzw. Nachsatzbl. als Spiegel auf dem VD bzw. HD aufgeklebt. Urspr. wohl durchwegs Quaternionen, zahlreiche Fehlstellen (s. bei Inhalt): zw. Bl. 2 und 3 (Lage 1) fehlen innere Doppelbl., zw. Bl. 12 und 13 sowie Bl. 18 und 19 (Lage 3) äußerstes Doppelbl., zw. Bl. 20 und 21 (Lage 4) äußere Doppelbl., zw. Bl. 21 und 22 (Lage 5) innere Doppelbl., zw. Bl. 32 und 33 (Lage 7) innere Doppelbl., zw. Bl. 34 und 35 sowie 35 und 36 (Lage 8) innere und äußere Doppelbl., zw. Bl. 36 und 37 sowie 38 und 39 (Lage 9) äußere Doppelbl., zw. Bl. 63 und 64 (Lage 13) innere Doppelbl. Fehlbindung: urspr. Lagen I-VI (Bl. 13-36) heute nach urspr. Lage VII (Bl. 5-12) eingebunden, vgl. Kustode Bl. 12v VII ${ }^{u s}$, Lage 3 (Bl. 13-18) Blattzählung am rechten Rand von zeitgenössischer Hand 2-7 sowie Inhalt. Am oberen Blattrand Foliierung 19. Jh. durch die ULB Tirol.

S: $\quad$ Schriftraum $205 / 215 \times 130 / 145$, von seitlich zweifachen Blind- bzw. Bleistiftlinien gerahmt. Zirkelstiche. B1. 1r-38v zu einheitlich 33 Zeilen, ab B1. 39r zu einheitlich 30 Zeilen auf Blind- bzw. Bleistiftlinierung. Karolingische Minuskel mit unterschiedlichem Duktus von zwei Händen: 1) Bl. 1r-38r; 2) Bl. 38v-76v. Bisweilen Tinte radiert und verblasst. Vereinzelt Randnotizen, tw. von späterer Hand.

A: Rote Paragraphzeichen (vereinzelt) und Überschriften. Bl. 19v und 22r Zeigehände. Ein- und zweizeilige rote Lombarden, vereinzelt mit Punktverdickungen und Ausläufern. Ab Bl. 39r Repräsentanten am seitlichen Blattrand, quer zum Schriftraum.

E: Bibliothekseinband: dunkelrot gefärbtes Leder über Holz. Rignano sull’Arno (Prov. Firenze), um 1980. Einband und Bindung im Zuge der Restaurierung erneuert. Kanten gerade. Rücken: fünf Doppelbünde. Im ersten Feld Spuren eines Signaturschildes, im fünften weißes Signaturschild (s. bei G). Kapitale mit naturfarbenem und gelbem Garn umstochen. Spiegel Pap. 20. Jh., leer bis auf Etikett der Restaurierwerkstätte am HD (s. bei G).

G: Zeitpunkt und Art der Erwerbung durch Neustift unbekannt. 1809 anlässlich der vorübergehenden Aufhebung des Klosters Neustift der ULB Tirol übergeben. Bl. 1r Stempel der ULB Tirol 19. Jh. 1921 aufgrund des Friedensvertrages von St. Germain an den italienischen Staat abgegeben und von diesem 1929 dem Kloster Neustift als Dauerleihgabe überlassen. Bl. 1r Stempel der Soprintendenza Tridentina 20. Jh. Am Spiegel des HD Nachweis der Restaurierwerkstätte 20. Jh. (Laboratorio di restauro del libro S. Maria di Rosano), kein Restaurierbericht vorhanden. Bl. Ir Signatur 20. Jh. Ms. 483. Am Rücken Signaturschild 20. Jh. 483.

L: $\quad$ R. Foreville, J. Leclercq, Un débat sur le sacerdoce des moines au XIIe siècle, in: Analecta monastica IV (Studia Anselmiana 41). Roma 1957, 8-118. - Katalog ULB Tirol V 542, 674.

(Ir-v) leer bis auf Signatur (s. bei G).

(1r-76v) 〈Honorius AugustodunEnsis〉: Gemma animae, unvollständig (PL 172, 541-753).

Anordnung in Hs. vielfach vom Druck abweichend (möglicherweise aufgrund Neubindung), Kapiteleinteilung und Überschriften tw. abweichend, Kapitel vereinzelt leicht gekürzt, bisweilen zusätzliche Einschübe.

(1r-2v) Lib. 2, cap. 1-15 (PL 172, 615D-620D). Inc. mut.: ] exercitus in militiam congregatur. Signa militibus per turbas (!) dantur ... - Expl. mut.: ... in bonis in locum exul[tationis adducet

(3r-8v) Lib. 2, cap. 50-68 (PL 172, 629C-642C). Inc. mut.: ] etiam Benedictus in eadem significatione ... (8v-12v) Lib. 3, cap. 1-30 (PL 172, 641D-650C). Expl. mut.: ... Unde in illo tempore alleluia cantatur [ Mit Auslassung in cap. 22 (De tribus nuptiis ...), s. Bl. 67r-v.

(13r-18v) Lib. 1, cap. 3-38 (PL 172, 544A-555D). Inc. mut.: ] subiugat. Oppressos a diabolo liberans ... - Expl. mut.: ... duo typum Enoch et Helye preferunt qui Iudaicum [

(19r-20v) Lib. 1, cap. 63-73 (PL 172, 563C-567A). Inc. mut.: ] sumit significans angelum qui Christo resurgente lapidem ... - Expl. mut.: ... ad monasterium redimus quasi ad locum certa[minis

(21r-v) Lib. 1, cap. 46-51 (PL 172, 557D-559D). Inc. mut.: vir]gine nascitur et per multas passiones in candorem resurrectionis ... - Expl. mut.: ... scriptis vocibus premonstraverunt [ 
(22r-32v) Lib 1, cap. 84-149 (PL 172, 570C-590C). Inc. mut.: ] Missa legatio dicitur Totum tempus quo Christus mundum intravit ... - Expl. mut.: ... diversi libri sacre scripture. Secretum quod claustri gerit [ Mit Einschub zw. cap. 114 und 115 (Bl. 28r): Inc.: Licet laico plus in die ... - Expl.: ... aliis sacerdotibus licet.

(33r-34v) Lib. 1, cap. 174-187 (PL 172, 597D-601D). Inc. mut.: ] Dei dicuntur quia ex precepto Dei in servitium Dei offeruntur ... - Expl. mut.: ... cum Christiani relicta lege Dei paganos spurcis [

(35r-v) Lib. 1, cap. 58-63 (PL 172, 561D-563C). Inc. mut.: ] ecclesia conficitur et capiti Christo coniungitur ... - Expl. mut.: ... diaconus calicem tenet dum papa sanguinem [

(36r-v) Lib. 1, cap. 73-79 (PL 172, 567A-568D). Inc. mut.: certa]minis tendimus. Scrinium cum reliquiis portamus contra demones...

(37r-38r) Lib. 4, cap. 2-13 (PL 172, 690C-693C). Inc. mut.: ] rubrum id est per baptismum vel per desertum id est penitentiam ...

(38r-v) Lib. 3, cap. 33-38 (PL 172, 651C-652B). Expl. mut.: Nabuchodonosor est diabolus. [ Mit Einschub nach cap. 37: Inc.: Nabuchodonosor quippe rex Babilonis bellica manu Ierusalem destruxit ... Expl.: ... duplex gaudium habuerunt.

(39r-v) Lib. 3, cap. 46-50 (PL 172, 657A-658D). Inc. mut.: ] adhuc super corda Iudeorum positum et ideo non valent videre splendidum legis sensum ...

(39v-40r) Lib. 4, cap. 14 (PL 172, 693C-694B).

(40r-55r) Lib. 3, cap. 51-149 (PL 172, 658D--684D). Mit zwei Einschüben: 1) (53v) zw. cap. 145 und 146: Inc.: Responsorium de ascensione nostri domini ... - Expl.: ... ad eum super sydera. 2) (54r-v) in cap. 146: Inc.: Ut in aliis vero dominicis. Propter baptismalia sacramenta in tribus personis ...Expl.: ... remissio peccatorum percipitur. Quod in hac nocte vel in omnibus summis festivitatibus ad vesperam ...

(55r-60v) Lib. 4, cap. 15-40 (PL 172, 694B-703C).

(60v) Lib. 3, cap. 150 (PL 172, 684D-685A).

(60v-63v) Lib. 4, cap. 41-53 (PL 172, 703D-708C). Expl. mut.: ... David pro populo alleluia vero in te [

(64r-67r) Lib. 4, cap. 74-89 (PL 172, 718D-724D). Inc. mut.: ] tabernaculorum celebratio ordinati enim ...

(67r-v) Lib. 3, cap. 22 (PL 172, 648D-649A). Inc. (verkürzt, s. Auslassung Bl. 12r): De tribus nuptiis legitur in evangelio ...

(67v-76v) Lib. 4, cap. 90-118 (PL 172, 724D-738B). Mit drei Einschüben: 1) (72r-v) in cap. 115: Inc.: Omnibus martyribus prefertur. Sic etiam de loco vel eventu Felicis ... - Expl.: ... eos coronatos nominabant. Sic de ceteris notandum. 2) (72v-73v) in cap. 116: Inc.: Imperatoris susceptio est triumphi imitatio. Tryumphus namque regis exhibebatur ... - Expl.: ... prima propter ornatum secunda est quasi literatura laicorum tercia quia sunt admonitiones clericorum. 3) (76r) kurz vor Ende von cap. 118: Inc.: Mos paganorum versus est in religionem Christianorum ... - Expl.: ... quia cottidie sollempnia missarum celebrantur.

(76v, direkt anschließend, ohne Hervorhebung) Versus DE ORNAMENTIS FILIARUm IERUSALEM.

Inc.: Ecce filie Ierusalem quas delicias vobis preparavi ... - Expl.: ... ipse vestris nuptiis interesse mereatur. Amen.

Parallelüberlieferung: u. a. Düsseldorf, ULB, Ms. B 73, Bl. 94vb, Ms. B 167, Bl. 189va; Berlin, Staatsbibl., Preußischer Kulturbesitz, Ms. theol. lat. fol. 348, Bl. 133r; Graz, UB, Hs. 804, Bl. 76v.

$(\mathrm{I} * \mathrm{r}-\mathrm{v})$ leer.

A.P./U.S. 


\section{Cod. 485}

\section{HUGO DE SANCTO VICTORE}

Perg. I, 66, I* B1. $240 \times 180$. Entstehungsort unbestimmt, um 1200 .

B: $\quad$ Dickes Perg., vereinzelt Löcher und Nahtspuren, Bl. 65v und 66r Wasserflecken. Lagen: (I-1) ${ }^{\mathrm{I}}$ (Vorsatzbl., Pap. 18. Jh. $)+(I V-I)^{6}+7 . I^{62}+I^{66}+(I-1)^{I^{*}}$ (Nachsatzbl., Pap. 18. Jh.). Gegenbl. zum Vor- bzw. Nachsatzbl. als Spiegel auf dem VD bzw. HD aufgeklebt. Lage 9 (= heute Lage 1) unvollständig: urspr. wohl Quaternio, äußerstes Doppelbl. fehlt (vor B1. 1 und nach B1. 6 Textverlust). Am Lagenende Kustoden in römischen Zahlen, zumeist beschnitten. Lage 2 (Bl. 14v) Kustode $X^{u s}$, Lage 7 (Bl. 54v) Kustode $X V^{u s}$ : Am Beginn fehlen daher wohl acht Lagen. Am oberen Blattrand Foliierung 19. Jh. durch die ULB Tirol.

S: Schriftraum $185 / 195 \times 125$, von zweifachen Blindlinien gerahmt, zu 26 Zeilen auf Blindlinierung. Zirkelstiche. Karolingisch-gotische Mischschrift. Bl. 33v-35r am Blattrand Notizen von späterer Hand.

A: Rote Überschriften sowie Kapitelzählung am Blattrand. Meist zwei-, vereinzelt auch ein- bis siebenzeilige rote Initialmajuskeln. Repräsentanten.

E: Neuzeitlicher Bibliothekseinband: schwarz gesprenkeltes braunes Pap. über Pappe. Neustift, 2. H. 18. Jh. Pap. etwas abgerieben. Am VD und HD Ecken mit braunem Leder verstärkt. Rücken: braunes Leder, vier einfache Bünde, von Goldbordüren gesäumt. Im ersten Feld Golddruck $M: S:$, im zweiten Golddruck $D E$ LAPSU HOMINIS ET SACRAM in Goldrahmung, im dritten Signaturschild (s. bei G). Spiegel Pap. 18. Jh. Am Spiegel des VD Exlibris und Signaturen (s. bei G), Spiegel des HD leer.

G: $\quad$ B1. 66r Besitzvermerk 15. Jh. Iste liber est sancte Marie in Novacella. B1. 66v Besitzvermerk 15. Jh. Iste liber est monasterii s. Marie ad Novacellam. Am Spiegel des VD Exlibris der Stiftsbibl. Neustift 18. Jh. 1809 anlässlich der vorübergehenden Aufhebung des Klosters Neustift der ULB Tirol übergeben. Am Spiegel des VD alte Signaturen der ULB Tirol II $\overline{4} D 25$ (?, Tinte, radiert), $\overline{2} D 14$ S. 2. (Bleistift) und 485 (Tinte). Am Rücken gelbes Signaturschild der ULB Tirol 485. Bl. 1r Stempel der ULB Tirol 19. Jh. 1921 aufgrund des Friedensvertrages von St. Germain an den italienischen Staat abgegeben und von diesem 1929 dem Kloster Neustift als Dauerleihgabe überlassen. Bl. 1r Stempel der Soprintendenza Tridentina 20. Jh.

L: $\quad$ Katalog ULB Tirol V 547, 674.

$(\mathrm{Ir}-\mathrm{v})$ leer.

(1r-66v) 〈Hugo de SAncto Victore»: De sacramentis, Lib. 1, unvollständig (PL 176, 271D-364A. Ed.

R. Berndt, Hugonis de Sancto Victore. De sacramentis Christianae fidei [Corpus Victorinum. Textus historici 1]. Monasterii Westfalorum 2008, 147-269).

(1r-11r) Pars 6 (Kapitelzählung in Hs. vom Druck abweichend), unvollständig.

(1r-6v) Inc. mut. (cap. 14): revela]cionem plurimum addendum fuit. Modum vero divine cognicionis quam primus ille homo habuisse creditur explicare difficile est excepto eo quod diximus ... - Expl. mut. (cap. 26): ... in rebus occultis ea que magis probabi[lia

(7r) Inc. mut. (cap. 29): ] quam commodum obedientis adtenderet. Itaque ut homo super hanc vitam ... (11r) Pars 7. - (24r) Pars 8. - (32v) Pars 9. - (40r) Pars 10. - (51v) Pars 11. - (54v) Pars 12. $(\mathrm{I} * \mathrm{r}-\mathrm{v})$ leer. 


\section{Cod. 495}

\section{GREGORIUS MAGNUS}

Perg. 202 Bl. $210 \times 140 / 145$. Entstehungsort unbestimmt, 10. Jh.

B: $\quad$ Perg. von unterschiedlicher Qualität, fleckig (Feuchtigkeitsschäden) und abgegriffen, löchrig, Blattränder tw. eingeschnitten. Lagen: 8.IV ${ }^{64}+(\mathrm{III}+2)^{72}+(\mathrm{II}+4)^{80}+(\mathrm{III}+2)^{88}+2 \cdot \mathrm{IV}^{104}+(\mathrm{III}+2)^{112}+\mathrm{IV}^{120}+\mathrm{V}^{130}+\mathrm{IV}^{138}$ $+(\mathrm{III}+2)^{146}+\mathrm{IV}^{154}+(\mathrm{V}-2)^{162}+5 . \mathrm{IV}^{202}$. Bl. 68, 69, 74, 75, 78, 79, 84, 85, 108, 109, 142 und 143 eingefügte Einzelbl., Gegenbl. zu Bl. 156 und 157 herausgeschnitten (ohne Textverlust). Am oberen Blattrand Foliierung 19. Jh. durch die ULB Tirol; Fehler in der Zählung: Bl. 155 fälschlich als 195 angeführt.

S: $\quad$ Schriftraum $160 \times 100 / 110$, seitlich von zweifachen Blindlinien begrenzt, zu 20, Bl. 133-136, 140-157 und 162 zu 19 Zeilen auf Blindlinierung. Zirkelstiche. Karolingische Minuskel in unterschiedlicher Federdicke, wohl von mehreren einander abwechselnden Händen. Bl. 18r, 39r am unteren Blattrand Ergänzungen von der Hand des Schreibers. Bl. 1r Überschrift und Initium in Capitalis rustica.

A: Rote Kapitelzählungen, Über- und Schlussschriften, Nennung der Dialogpersonen (tw. mit Repräsentanten). Satzmajuskeln in Lombardenform sowie einzeilige, am Beginn der Bücher dreizeilige rote Initialmajuskeln.

E: Schmuckloser romanischer Einband: stark gedunkeltes, fleckiges Schweinsleder über Holz. Entstehungsort unbestimmt, 11. Jh.

Am VD schwarze Titelaufschrift in Textualis formata (Textura) 12. Jh. Dyalogus Gregorii de Sunaburg. Spuren zweier Schließen, am VD Dorne erhalten. Kanten leicht abgeschrägt und gerade. Rücken: blau gefärbt (wie öfters in Neustift), zwei Fitzbünde und zwei Doppelbünde. Im ersten Feld weiße Aufschrift Gregorii Dialogi MS., im zweiten Signaturschild (s. bei G), im vierten aufgeklebtes Papierschild, leer. Kapitale mit Spagat umstochen. Spiegel des VD und HD: gedunkelte, beschriebene, jedoch nicht mehr lesbare Pergamentstreifen, tw. vom eingeschlagenen Rückenleder überdeckt, am Spiegel des VD Exlibris und Signaturen (s. bei G).

G: $\quad$ Aufgrund der Titelaufschrift am VD ab dem 12. Jh. im Besitz des Benediktinerinnenstifts Sonnenburg im Pustertal. Zeitpunkt und Art der Erwerbung durch Neustift unklar. Am Spiegel des VD Exlibris der Stiftsbibl. Neustift 18. Jh. 1809 anlässlich der vorübergehenden Aufhebung des Klosters Neustift der ULB Tirol übergeben. Am Spiegel des VD alte Signaturen der ULB Tirol II 1 B 17 (Tinte, radiert) und II $\overline{2}$ E 10 (Bleistift). Am Rücken gelbes Signaturschild der ULB Tirol 495. Bl. 1r Stempel der ULB Tirol 19. Jh. 1921 aufgrund des Friedensvertrages von St. Germain an den italienischen Staat abgegeben und von diesem 1929 dem Kloster Neustift als Dauerleihgabe überlassen. Bl. 1r Stempel der Soprintendenza Tridentina 20. Jh.

L: $\quad$ Katalog ULB Tirol V 610, 674.

GREGORIUS MAGNus: Dialogi = Dialogorum libri IV de vita et miraculis patrum Italicorum, unvollständig (PL 77, 149-429 [Lib. 1, 3 und 4] bzw. PL 66, 126-204 [Lib. 2]. Ed. U. Moricca [Fonti per la storia d'Italia 57]. Roma 1924. Ed. A. de Vogüé [Sources chrétiennes 260]. Paris 1979 [Buch 1-3] und [Sources chrétiennes 265]. Paris 1980 [Buch 4]. - CPL Nr. 1713).

(1r) Tit.: Dialogorum Gregorii Papae urbis Romae libri Numero quatuor de miraculis Patrum Italicorum.

(1r) Prolog. - (4r) Kapitelübersicht zu Lib 1. - (4r) Lib. 1. - (43v) Kapitelübersicht zu Lib. 2. - (45r) Lib. 2. Bl. 76v/77r (Lagenmitte) Unterbrechung ohne Textverlust (PL 66, 184B6-8): Seitenbeginn Bl. 76v: ad monasterium omnipotentis Dei famulum repperit. Quia (Rest der Zeile leer), auf neuer Zeile: a creditore suo (Rest der Seite leer), Forts. Bl. 77r: pro duodecim solidis graviter affligeretur intimavit ...

(88v) Lib. 3. - (147r) Lib. 4. Expl. mut. (stark zerstört, Schrift endet am Seitenende): ... ad exitum veniens non pertimescat Quando etsi iam novit quod egit [ (PL 77, 405C3 in cap. 45)

W. N. 


\section{Cod. 532}

\section{SAMMELHANDSCHRIFT}

Perg. I, 145, I* Bl. $150 \times 110$. Entstehungsort unbestimmt, 14. Jh.

B: $\quad$ Perg. tw. genäht, Fehlstellen im Zuge der Restaurierung 20. Jh. ergänzt (s. bei G). Lagen: (I-1) ${ }^{\mathrm{I}}$ (Vorsatzbl., Pap. 20. Jh.) $+15 . I^{120}+I^{124}+2 . I^{140}+(I I I-1)^{145}+(I-1)^{I^{*}}$ (Nachsatzbl., Pap. 20. Jh.). Gegenbl. zum Vorbzw. Nachsatzbl. als Spiegel auf dem VD bzw. HD aufgeklebt. Gegenbl. zu Bl. 145 herausgeschnitten (Textverlust, vgl. Reklamante). Am Ende der Lagen 1-4 sowie 17-18 schwarz-rot gerahmte Reklamanten mit einfachem Dekor, am Ende der Lagen 5-16 Kustoden in roten römischen Zahlen, bisweilen beschnitten. Zeitgenössische Foliierung in arabischen Ziffern 4-149. Am oberen Blattrand Foliierung 19. Jh. durch die ULB Tirol.

S: $\quad$ Bl. 1r-122v und 125r-144v: Schriftraum $115 \times 75$, von Tintenlinien gerahmt, zu 34 Zeilen auf Tintenlinierung. Zirkelstiche. Textualis von zwei Händen: 1) Bl. 1r-122v und 125r-126r in abwechselnder Größe; 2) Bl. 126v-144r.

Nachtrag B1. 123r-124v: Schriftraum $120 \times 75$, von Tintenlinien gerahmt, zu 25 bzw. 27 Zeilen. Zirkelstiche. Bastarda 15. Jh.

A : Rote Auszeichnungsstriche, Paragraphzeichen, Unterstreichungen, Rahmungen, Auctoritatesangaben und Überschriften. B1. 79v Randmarkierung in der Art eines Fleuronnée-Ausläufers. Zeigehände. Lagenreklamanten mit Zierrahmen (Bl. 132v mit Blüte, 140v). Am oberen Blattrand Bezeichnung der einzelnen Bücher in Rot. Ein- bis vierzeilige rote Lombarden.

E: Bibliothekseinband: helles Leder über Holz. Rignano sull’Arno (Prov. Firenze), 20. Jh.

Einband unter Verwendung von Resten des urspr. Ledereinbandes (15. Jh.) am Rücken sowie Bindung im Zuge der Restaurierung erneuert.

Am HD Signaturschild (s. bei G). Kanten gerade. Rücken: drei einfache Bünde, im ersten Feld Signaturschild (s. bei G). Kapitale mit natur- und ockerfarbenem Zwirn umstochen. Spiegel Pap. 20. Jh. Spiegel des VD leer, am Spiegel des HD Etikett der Restaurierwerkstätte (s. bei G).

G: Zeitpunkt und Art der Erwerbung durch Neustift unbekannt. 1809 anlässlich der vorübergehenden Aufhebung des Klosters Neustift der ULB Tirol übergeben. Am Rücken gelbes Signaturschild der ULB Tirol 532. Bl. 1r Stempel der ULB Tirol 19. Jh. 1921 aufgrund des Friedensvertrages von St. Germain an den italienischen Staat abgegeben und von diesem 1929 dem Kloster Neustift als Dauerleihgabe überlassen. Bl. 1r Stempel der Soprintendenza Tridentina 20. Jh. Am Spiegel des HD Etikett der Restaurierwerkstätte 20. Jh. (Laboratorio di restauro del libro S. Maria di Rosano), kein Restaurierprotokoll vorhanden. Am HD Signaturschild 20. Jh. 532. Bl. Ir Signatur 20. Jh. Ms 532 (Bleistift).

L: $\quad$ Kaeppeli Nr. 2346. - Bloomfield Nr. 5755. - Katalog ULB Tirol VI 102, 381.

(Ir-v) leer bis auf Signatur (s. bei G).

1 (1r-27r) TRACTATUS DE ABSENTIS PRAESENTIA.

(1r) Tit.: Incipit tractatus de gradibus virtutum.

(1r) Prolog. Inc.: Cum quadam vice animum meum infelicem vanis ac transitoriis occupacionibus assidue deditum ad meam recogitandam miseriam ... - Expl.. ... calor vincit teporem longum.

(1r) Text. Inc.: Hec ita cogitans menti occurrit illa vocatio trina apostolorum qui primo ad notitiam ... - Expl.: ... quidem docentem hominem scientiam. Dominum autem pro laboribus remunerantem invenire in cursus nostri termino meramur. Amen.

Parallelüberlieferung: Innsbruck, ULB Tirol, Cod. 390, Bl. 91r; München, BSB, Clm 5534, B1. 73; Augsburg, Staats- und Stadtbibl., $2^{\circ}$ Cod. 139, Bl. 258ra.

2 (27r-28v) 〈Ps.-Augustinus〉: De praedestinatione Dei (PL 45, 1677-1678. - CPL Nr. 383. CPPM II 180).

3 (28v-34v) 〈EADMerus CANTUARIEnsis〉: De beatitudine coelestis patriae (PL 159, 587B-643B).

$4 \quad(34 \mathrm{v}-122 \mathrm{v})\langle$ Ps.-Henricus de Frimaria $\rangle=\langle$ Ps.-Hugo de Sancto Caro : In libros I-IV Sententiarum sive Filia magistri (Stegmüller RS Nr. 373. Glorieux Nr. 2bh. Zumkeller Nr. 328d). 
Inc.: Quoniam velut IIII ${ }^{\text {or }}$ paradisi flumina ... Scriptura sacra de duobus agit ... Veteris ac nove legis continenciam considerantibus ... - Expl.: ... per gratiam evaserunt.

Schlussschrift mit Schreibervermerk: Finito libro sit laus et gloria Christo. Pitet got umb den der daz geschriben hat.

5 (123r-124r) 〈Richardus de Mediavilla〉: Commentarius in Petri Lombardi Sententiarum librum secundum, Prologus (Druck: u. a. GW M22506. - Stegmüller RS Nr. 722, II. Glorieux Nr. 324c). Tit.: [..., beschnitten] super secundum librum Sentenciarum etc. - Inc.: Omnia per ipsum facta sunt et sine ipso factum est nihil. Hec verba scripta Io. primo (3) sic possunt exponi. Omnia scilicet entia a Deo alia. Facta sunt per ipsum id est per verbum Dei. Unde Augustinus sermonem dirrigens ad Deum ... - Expl.: ... coniungantur cum eo. Quod nobis prestare dignetur ... per omnia secula seculorum. Amen.

$6 \quad(124 \mathrm{v})$ Notiz.

Inc.: Nota quod omnis disposicio ... - Expl.: ... quibus hoc forte meruerunt penitere et hiis similia.

7 (125r-144v) 〈Iohannes Friburgensis»: Confessionale (Druck: GW M13586. - Bloomfield Nr. 5755, mit Nennung der Hs. Kaeppeli Nr. 2346, mit Nennung der Hs.).

Tit.: Incipit tractatus de instruccione confessorum.

(125r) Prolog. Inc.: Simpliciores et minus expertos confessores de modo audiendi ... Anschließend Inhaltsübersicht.

(125v) Text. Inc.: Cum aliquid petit suam confessionem audiri quem antea ... - Expl.: ... et testamentum (!) celeriter expedient frequentibus admonicionibus impulsabis.

Schlussschrift: Explicit liber confessorum.

$(145 \mathrm{r}-\mathrm{v})$ leer.

$\left(\mathrm{I}^{*} \mathrm{r}-\mathrm{v}\right)$ leer.

C. S.

\section{Cod. 550}

\section{GUIDO DE MONTE ROCHERII. GUILELMUS DURANTIS}

Pap. I, 446, III* Bl. $295 \times 210$. T. I: Wiener Raum, 6. Jz. 15. Jh., T. II: Raum Brixen, u. a. Villanders, 7. Jz. 15. Jh. (u. a. 1465).

B: $\quad$ Zwei Teile: I (I, 1-92), II (93-447[446], III*). In der Mitte des oberen Blattrandes zeitgenössische Foliierung 1-87, anschließend Forts. im 19. Jh. durch die ULB Tirol; Fehler in der Zählung: 269 ausgelassen.

E: $\quad$ Schmuckloser Einband: dunkelrot gefärbtes Leder über Holz. Rignano sull’Arno (Prov. Firenze), um 1980 (?). Einband unter Verwendung der wohl urspr. Metallteile sowie Bindung im Zuge der Restaurierung erneuert. Zwei Leder-Metall-Schließen: Leder erneuert, Lager und Rasten verziert. Kanten gerade. Rücken: drei Doppelbünde. Im ersten Feld Spuren eines entfernten Signaturschildes, im vierten weißes Signaturschild (s. bei G). Kapitale mit rotem und hellgelbem Garn umstochen. Spiegel Pap. 20. Jh., leer bis auf Etikett der Restaurierwerkstätte am Spiegel des HD (s. bei G).

Originaldeckel gelöst und getrennt aufbewahrt (freundlicher Hinweis Simon Terzer, Neustift): rot gefärbtes Leder mit Blindlinien über Holz. Brixen, 15. Jh. (?). Leder abgegriffen, tw. nachgedunkelt und zerkratzt. VD durch zweifache Blindlinien gerahmt, Mittelfeld durch ebensolche Linien diagonal unterteilt. Reste von zwei am oberen Rücken und auf den VD überlappenden Papier(titel?)schildern. Spuren von fünf Beschlägen und zwei Schließen. HD heute Holz großteils freiliegend. Auf den Innenseiten der beiden Holzdeckel jeweils Abklatsch einer Urkunde, tw. unleserlich. Innenseite VD: Notariatsinstrument Brixen 1446, Juni 14 (Iohannes de Radmansdorff clericus Aquilegensis diocesis notarius publicus). Oben alte Signaturen der ULB Tirol: II [...] (Tinte, laut Alter Titelkopie an der ULB Tirol: II $\overline{3} A$ 9) und II $\overline{3} D 8$ (Bleistift). Innenseite HD: Notariatsinstrument Brixen (?) 1420, Juni 4 (Wolfangus Payr de Hederstorf clericus Pataviensis diocesis publicus imperiali auctoritate notarius). 
G: Zeitpunkt und Art der Erwerbung durch Neustift unbekannt. Bl. 1r Besitzvermerk 18. Jh. Collegii Neocell. 1809 anlässlich der vorübergehenden Aufhebung des Klosters Neustift der ULB Tirol übergeben. Bl. 1r Stempel der ULB Tirol 19. Jh. 1921 aufgrund des Friedensvertrages von St. Germain an den italienischen Staat abgegeben und von diesem 1929 dem Kloster Neustift als Dauerleihgabe überlassen. Bl. 1r Stempel der Soprintendenza Tridentina 20. Jh. Am Spiegel des HD Etikett der Restaurierwerkstätte 20. Jh. (Laboratorio di restauro del libro, S. Maria di Rosano), kein Restaurierbericht vorhanden. Bl. Ir Signatur (Bleistift) Ms. 550, am Rücken Signaturschild 20. Jh. 550.

L: $\quad$ Peintner, Stiftsbibliothek 121. - Katalog ULB Tirol VI 172, 381. - Stefani 110-111.

$$
\text { I (I, 1-92) }
$$

B: Pap. am Beginn sowie am Schluss etwas verschmutzt. Nachweise und Bilder der Wasserzeichen s. WZMA. Datierung nach Wasserzeichenbefund. Identische Wasserzeichen: u. a. Klosterneuburg, Stiftsarchiv, Rb 25/1 (dat. 1457); Wien, ÖNB, Cod. 4204 (dat. 1458). Lagen: (I-1) (Vorsatzbl., Pap. 20. Jh.) + 6.VI ${ }^{72}+2 . V^{92}$. Gegenbl. zum Vorsatzbl. als Spiegel auf dem VD aufgeklebt. Lagenreklamanten, tw. rubriziert.

S: $\quad$ Schriftraum 195/205×150 (Bl. 1r-24v) bzw. × 140 (ab Bl. 25r). Zwei Spalten, vereinzelt von Blindlinien gerahmt, zu 39-42 Zeilen. Bastarda. Am seitlichen Blattrand Hervorhebung und Wiederholung einzelner Wörter und kurzer Textpassagen sowie Korrekturen von späteren Händen, Bl. 4r-10r in Humanistischer Minuskel in Rot.

A: $\quad$ Rote Auszeichnungsstriche und -punkte, Paragraphzeichen, Unter- und Durchstreichungen sowie B1. 3ra-16ra Überschriften, tw. in schwarzer Tinte ergänzt. Bl. 87vb Schlussschrift in Blau. Zwei- bis vierzeilige, meist dreizeilige rote Lombarden, tw. mit Punktverdickungen, Aussparungen und einfach verzierten Ausläufern, Bl. 86va und 87va Binnenfelder mit einfachem Dekor in Blau gefüllt. Vereinzelt Buchstaben nach Initiale cadellenartig gedehnt und in Rot hervorgehoben (z. B. Bl. 25ra, 47va). Bl. 1ra und 25ra fünf- bzw. sechszeilige rote Lombarden mit fein gezeichnetem tintenbraunem Dekor (als Besatz kammartig abstehende, spitz zulaufende Fadengruppen; diese auch an Cadelle Bl. 25ra). Repräsentanten am unteren Blattrand, tw. beschnitten.

(Ir-v) leer bis auf Signatur (s. bei G).

1 (1r) Notiz zu T. II (18. Jh): Rationale Divinerum (!) Officiorum Guilelmi Episc. Minae. 1461. (1ra-88vb) Guido de Monte RocheriI: Manipulus curatorum (Druck: u. a. GW 11716. - Bloomfield Nr. 5019. Stegmüller RS Nr. 277).

Text bisweilen vom Druck leicht abweichend, vereinzelt Kürzungen bzw. Auslassungen, Erweiterungen bzw. Einschübe. Gliederung der Pars 2 vom Druck abweichend (hier Gliederung vom Druck übernommen). Überschriften zu den einzelnen Abschnitten nur vereinzelt vorhanden, tw. falsch zugeordnet. Überschriften im Register genannt, Reihenfolge jedoch nicht mit Gliederung der Traktate und Kapitel übereinstimmend, vom Druck bes. ab B1. 38 häufig abweichend. Tract. 3, cap. 6 und 7, sowie Tract. 4, Prolog und cap. 1 fehlen, obwohl laut Register vorgesehen. (1ra) Prolog. Inc.: Reverendo in Christo patri ac domino domino Raymundo divina providencia sancte sedis Valencie episcopo servorum devotorum minimus Gwido de Monte Rocheri cum devota... Quoniam secundum quod dicit propheta Malachias ymo dominus per Malachiam Labia ... - Expl.: ... ut videant ea que circa suum officium sunt agenda.

(2ra-44va) Pars 1. Inc.: Dividitur autem presens opusculum in tres partes in quarum prima agitur de sacramentis ... - Expl.: ... ecclesia in suo sensu habundat secundum quod habet in usu sequitur etc.

(2ra) Tract. 1. - (3vb) Tract. 2. Mit Einschub am Ende von cap. 2 (4vb-5ra): Inc.: Item si alicui presbytero presentaretur femella et ipse putaret masculum ... - Expl.: ... baptizatus baptismo flaminis. - (10ra) Tract. 3. - (11vb) Tract. 4. Mit Einschub am Ende von cap. 9 (24vb): Inc.: Notandum tamen etc. quod quidam sacerdos ... - Expl.: ... datur aliquantulum et pane et vino etc. - (31va) Tract. 5. - (34rb) Tract. 6. - (35rb) Tract. 7,1. - (37rb) Tract. 7,2.

(44vb-77ra) Pars 2. Inc.: Verus ac pius samaritanus dulcis Ihesus qui vinum et oleum fundit ...Expl.: ... animo sed benigne corrigat et emendet.

(44vb) Prolog. - (46va) Tract. 1. - (51va) Tract. 2. - (69rb) Tract. 3. 
(77ra-87vb) Pars 3. Inc.: Omnium magister et dominus Ihesus Christus de mundo ascensurus ad patrem ... - Expl.: ... faciat nos rex regum et dominus dominancium Ihesus Cristus. Amen. (87vb) Schlussschrift (blau): Laus Deo Amen.

(88ra) De fine huius operis. Ohne Tit. Inc.: Hec circa officium curatorum breviter a me scripta sunt ... - Expl.: ... et pro me peccatore preces ad dominum fundat.

(88ra-vb) Inhaltsverzeichnis, tw. mit Blattangabe (bis Bl. 12). - Schlussschrift: Finitur tabula huius libelli.

(89r-92v) leer.

Lit.: Schulte GQ II 430.

$$
\text { II (93-447[446], III*) }
$$

B: $\quad$ Bl. 96-97 und ab Bl. 352-445 Tintenfraß, tw. Textverlust. Bl. 94-97 und 352-II* im 20. Jh. restauriert (s. bei G). Nachweise und Bilder der Wasserzeichen s. WZMA. Datierung nach Wasserzeichenbefund. Identische Wasserzeichen: Neustift, Stiftsbibl., Cod. 155; Innsbruck, ULB Tirol, Cod. 566, T. I (dat. 1463). Lagen: $(\mathrm{I}+\mathrm{II})^{98}+29 . \mathrm{VI}^{447(446)}+\mathrm{I}^{\mathrm{II}^{*}}$ (Nachsatzbl., Pap. 15. Jh.) $+(\mathrm{I}-1)^{\mathrm{II} *}$ (Nachsatzbl., Pap. 20. Jh.). Bl. 94-97 eingehängter Binio. Gegenbl. zu Bl. III* als Spiegel auf dem HD aufgeklebt. Am oberen Blattrand ab Bl. 99r zeitgenössische Foliierung in Rot, zunächst in arabischen Ziffern (1-9), anschließend in römischen Zahlen $(X-L X X X X)$. Bl. 99, 150, 182, 195, 253, 262, 354 jeweils Spuren eines Signakels.

S: $\quad$ Schriftraum 210/230 × 145/150. Zwei Spalten, vereinzelt von feinen Tintenlinien gerahmt, zu 46-48 Zeilen. Schriftraum Register 210/215×140. Zwei Spalten, zu 42 Zeilen: Bastarda von drei Händen: 1) Bl. 96ra97vb, 180vb-382ra und 385ra-445ra, lokalisiert und dat. Villanders, 1465 (Bl. 97vb und 445ra [24.9.]). Schreiber: Laurencius Smyt (Bl. 445ra); 2) Bl. 99ra-180vb; 3) Bl. 382ra-384vb. Am Blattrand Ergänzungen und Korrekturen tw. von jeweiliger Schreiberhand, tw. von anderer Hand, bisweilen unterstrichen oder gerahmt. Bl. 180r am Blattrand neuzeitliche Bleistiftnotizen, radiert.

A: Rote Auszeichnungsstriche und -punkte, Paragraphzeichen, Durch- und Unterstreichungen, Rahmungen, Überschriften sowie Angaben des jeweiligen Buches am oberen Blattrand, tw. beschnitten und Bl. 201ra-va Hervorhebung der einzelnen Kapitel. Verweiszeichen. Ab Bl. 184r in der letzten Zeile Buchstaben bisweilen gedehnt und Ausläufer in Schleifen gelegt. Zwei- bis sechszeilige, meist vierzeilige (Bl. 262ra achtzeilig, nur durch Umrisslinien) rote Lombarden, meist mit Punktverdickungen, tw. mit Aussparungen, tw. mit Ausläufern (ab Bl. 256vb mehrfach mit Dreiblättern als Besatz), vereinzelt mit Dekor im Binnenfeld: Bl. 117rb Blatt, Bl. 123rb mit ausgespartem Knospenfleuronnée, B1. 183rb mit rotem Fleuronnée, Bl. 279vb mit eingeschriebenem Gesicht, Bl. 304rb die geometrischen Aussparungen tw. schwarz ausgemalt, Bl. 384vb mit Punktdekor. Bl. 99ra neunzeilige rote Initiale, Binnenfeld in Kompartimente unterteilt und mit Knospengarben gefüllt; Initialfeld, Perlenbesatz und Fadenausläufer (in dreiblättriger Blüte endend) sowie Profilkopf mit Zipfelmütze auf dem oberen Seitenrand recht flüchtig gezeichnet. Repräsentanten.

$(93 r-95 v)$ leer.

2 (96ra-445ra) 〈Guilelmus Durantis〉: Rationale divinorum officiorum (CCCM 140-140B). (96ra-97vb) Register.

(97vb) Schreibervermerk: Iste liber dicitur Racionale Wilhelmi Minacensis episcopi pro eo quod utitur racione et quia eorum qui funt in ecclesiasticis officiis continent (!) raciones.

Anno domini (gestrichen: mille) $M^{\circ} C C C C^{\circ}$ sexagesimo quinto finitus est presens liber in Willanders. $(98 \mathrm{r}-\mathrm{v})$ leer.

(99ra-445ra) Tit.: Incipit Racionale divinorum officiorum.

(99ra) Prolog. - (100va) Lib. 1. - (124va) Lib. 2. - (135va) Lib. 3. - (150rb) Lib. 4. - (232rb) Lib. 5. - (262ra) Lib. 6. - (396ra) Lib. 7. - (431va) Lib. 8.

(445ra) Schlussschrift mit Schreibernennung und Datierung: Explicit Racionale divinorum anno domini $M^{\circ}$ CCCC $^{\circ}$ LXV die $3^{\circ} 24$ mensis Septembris in Willanders per me Laurencium Smyt (24. September 1465).

(445rb-447v) leer.

(I*r-III*v) leer.

A.P./U.S. 


\section{Cod. 578}

\section{RAPHAEL VOLGOSIUS}

Pap. I, 10, I* Bl. 295×210. Brixen, 1480.

B: $\quad$ Erstes bzw. letztes Blatt verschmutzt. Am rechten Blattrand Wasserschaden. Bilder und Nachweise der Wasserzeichen s. WZMA. Wasserzeichnung mit Datierung übereinstimmend. Lage: $\mathrm{VI}^{\mathrm{I}, 10, \mathrm{I}^{*}}$. Am oberen Blattrand Foliierung der beschriebenen Blätter 19. Jh. durch die ULB Tirol.

S: $\quad$ Schriftraum mittig längs durch eine Blindlinie unterteilt: zwei Spalten mit wechselnder Zeilenzahl (40-51). Flüchtige Bastarda, lokalisiert und dat. Brixen, 1480 (Bl. 10vb).

E: $\quad$ Neuzeitlicher Bibliothekseinband: schwarz gesprenkeltes braunes Pap. Neustift, 2. H. 18. Jh. Am VD Signaturschild (s. bei G). Spiegel Pap. 18. Jh. Am Spiegel des VD Exlibris und Signaturen (s. bei G), Spiegel des HD leer.

G: $\quad$ Bl. Ir Kaufvermerk 15. Jh. Helene 1481 lib XXXVI crucif VIII. Am Spiegel des VD Exlibris der Stiftsbibl. Neustift 18. Jh. 1809 anlässlich der vorübergehenden Aufhebung des Klosters Neustift der ULB Tirol übergeben. Am Spiegel des VD alte Signaturen der ULB Tirol II [...] C [...] (radiert, Tinte), II 3 B 16 (Bleistift) und 578 (Tinte). Am VD gelbes Signaturschild der ULB Tirol 578. Bl. 1r Stempel der ULB Tirol 19. Jh. 1921 aufgrund des Friedensvertrages von St. Germain an den italienischen Staat abgegeben und von diesem 1929 dem Kloster Neustift als Dauerleihgabe überlassen. Bl. 1r Stempel der Soprintendenza Tridentina 20. Jh.

L: $\quad$ Wilhelm 109. - Wretschko-Sprung 22. - Dolezalek II o. S. - Peintner, Stiftsbibliothek 122. - Katalog ULB Tirol VI 296, 382. - Krämer, Scriptores, s. v. „Volgosius, Raphael“ (Schreiber nicht identisch mit Raphael Volgosius, gest. 1427 in Padua. Freundlicher Hinweis Leonardo Granata, Padua, vgl. C. Bukowska Gorgoni, „Raffaele Fulgosio“. Dizionario Biografico degli Italiani L. Roma 1998, https://www.treccani.it/enciclopedia/ raffaele-fulgosio_(Dizionario-Biografico)/.

(Ir) Tit.: Tituli omnium librorum legalium.

(Ir) Kaufvermerk (s. bei G).

(Iv) leer.

(1ra-10vb) Raphael Volgosius: Alphabetisches Titelverzeichnis zum Römischen Recht, in der Hs. geordnet nach Institutionum, Digesti veteris, Digesti novi, Inforciati, Codicis, Authenticorum, Trium librorum codices ffeudorum.

Institutionum. 1 Adoptionibus. Altiliano tutore. Auctoritate tutoris ... vasallo qui contra constitutionem/vocatis feudum.

(10vb) Schlussschrift mit Lokalisierung und Datierung: Expliciunt rubrice iuris civilis secundum ordinem alphabeti a Raphaele Volgosio compilate 1480 in Brixina.

$(\mathrm{I} * \mathrm{r})$ leer.

(I*v) SchuldVERMerk: Item Hanns doctor Grendner ist mir schuldig [...] gar IIII gulden minder IIII gulden.

C. S. 


\section{Cod. 579}

\section{PUBLIUS OVIDIUS NASO}

Pap. 14 Bl. $300 \times 210$. Wiener Raum oder Tirol (?), 1491 .

B: Pap. bes. am Beginn und am Ende stark verschmutzt, am oberen rechten Blattrand fleckig (Wasserschaden), B1. 12v-14r Tintenfleck, erstes und letztes Blatt an den Rändern eingerissen bzw. beschädigt, Bl. 2 Riss geklebt. Nachweise und Bilder der Wasserzeichen s. WZMA. Lage: VII ${ }^{14}$. Am oberen Blattrand Foliierung 19. Jh. durch die ULB Tirol. Am Spiegel des VD Reste eines orangen Papiersignakels der ULB Tirol.

S: Schriftraum $260 \times 100 / 105$, von jeweils zweifachen Blindlinien begrenzt, zu 30 Zeilen. Bastarda, dat. 3. November 1491 (B1. 14v). Interlinear- und Randglossen von zwei zeitgenössischen Händen in Bastarda. Bl. 14v Zusätze von späterer Hand.

A: Vereinzelt rote Auszeichnungsstriche, Paragraphzeichen, Unter- sowie Durchstreichungen, vereinzelt Randnotizen, Datierung (Bl. 14v) und Überschrift. Bl. 12v rote Zeigehand. Zweizeilige rote Lombarden.

E: $\quad$ Neuzeitlicher Bibliothekseinband: schwarz gesprenkeltes braunes Pap. Neustift, 2. H. 18. Jh. Rücken stark beschädigt, Bindung gelöst. Am Rücken bzw. VD Signaturschild (s. bei G). Schnitt rot gesprenkelt. Spiegel Pap. 18. Jh. Am Spiegel des VD Rahmung, Exlibris und Signaturen (s. bei G), Spiegel des HD leer.

G: $\quad$ Bl. 1r Besitzvermerk Anfang 16. Jh. Magistri Nicolaus Leopoldi [ex] Insprugga XXXIIII (?, beschnitten) (vgl. Cod. 167; 1511 Lehrer an der Pfarrschule von St. Jakob, Innsbruck [W. Steiner, Die Lateinschule der St. Jakobspfarrkirche in Innsbruck, in: K. Drexel, M. Fink (Hrsg.), Musikgeschichte Tirols I: Von den Anfängen bis zur Frühen Neuzeit (Schlern-Schriften 315). Innsbruck 2001, 404, 501], empfängt 1513 in Brixen die niederen Weihen und erhält 1515 Kanonikat, gest. 1535 [K. Wolfsgruber, Das Brixner Domkapitel in seiner persönlichen Zusammensetzung in der Neuzeit 1500-1803 (Schlern-Schriften 80). Innsbruck 1951, 42 und 170; W. Senn, Musik und Theater am Hof zu Innsbruck. Geschichte der Hofkapelle vom 15. Jahrhundert bis zu deren Aufhebung im Jahre 1748. Innsbruck 1954, 13 und 46]). Am Spiegel des VD Exlibris der Stiftsbibl. Neustift 18. Jh. 1809 anlässlich der vorübergehenden Aufhebung des Klosters Neustift der ULB Tirol übergeben. Am Spiegel des VD alte Signaturen der ULB Tirol II $\overline{1} D 3$ (Tinte, radiert), II $\overline{3}$ B 17 (Bleistift) und 579 (Tinte). Am Rücken gelbes Signaturschild der ULB Tirol 579. Bl. 1r Stempel der ULB Tirol 19. Jh. 1921 aufgrund des Friedensvertrages von St. Germain an den italienischen Staat abgegeben und von diesem 1929 dem Kloster Neustift als Dauerleihgabe überlassen. Bl. 1r Stempel der Soprintendenza Tridentina 20. Jh.

L: J. Lechner, De codice Aenipontano 579 quo continetur Ovidi Remedia amoris. Commentationes Aenipontanae 4 (1909) 17-104. - Kristeller I 439. - Neuhauser, Neustift 84. - Katalog ULB Tirol VI 296, 382. - Stefani 112.

(1r-14v) Publius Ovidius Naso: Remedia amoris (Ed. E. J. Kenney. Oxonii $\left.{ }^{2} 1995\right)$.

Tit.: Publii Ovidii Nasonis Sulmonensis remedium amoris etc.

Mit zahlreichen Interlinear- und Marginalglossen (Ed. Lechner 23-54).

(1r, am Rand) 〈ANTonius Volscus〉: Vita Ovidii (Druck: u. a. GW M28918). Inc.: Publii Ovidii Nasonis poete vetusta equestris ordinis familia fuit ... - Expl.: ... ut tradit Eusebius.

$(1 \mathrm{r}-7 \mathrm{v})$ V. 1-396. - (7v-14v) V. 397-814. Tit.: Publii Ovidii Nasonis liber secundus de remedio amoris. (14v) Schlussschrift mit Lokalisierung und Datierung: TEגos. (gestrichen: III Nonas Aprilis M CCCC $\left.9^{\circ} 1\right)$. (rot:) In Lipcks (Lipsiae?) III Nonas (gestrichen: Aprile) Novembres M CCCC $9^{\circ} 1$ (3. November 1491).

Darunter Notiz von anderer Hand: Roma vetus veteres cur (!) te rexere Quirites (Walther, Initia Nr. 16879).

(14v, am linken Blattrand, beschnitten sowie auf dem Kopf stehend) Federproben mit Briefanreden 16. Jh. von anderer Hand:

1) Freuntlicher lieber sorg auff ewr verschreyben so ir mir than habt fueg ich euch zw wissen das mir solichs.

2) Freuntlicher lieber vatter und schwager ich las euch ...

3) Freuntlicher lieber schwager auff ewr verschr[ 


\section{Cod. 597}

\section{SERMONES. AUGUSTINUS FAVARONI}

Pap. 58 Bl. $270 \times 210$. Wiener Raum, um 1464/65.

B: $\quad$ Pap. fleckig. Buchblock stark beschnitten. Bilder und Nachweise der Wasserzeichen s. WZMA. Datierung nach Wasserzeichenbefund. Verwandte Wasserzeichen: u. a. Klosterneuburg, Stiftsbibl., CCl 308, T. I, CCl 561 (dat. 1465), CCl 743B. Lagen: 4.VI ${ }^{48}+(\mathrm{VI}-2)^{58}$. Gegenbl. zu Bl. 49 und 50 herausgeschnitten (Textverlust). In den Lagenmitten Pergamentfälze, in der dritten Lage beschrieben (Ebermunt qui Penno. Eckehart et [?] frater Adili[...?] eundem / [...]). Am oberen Blattrand Foliierung 19. Jh. durch die ULB Tirol.

S: $\quad$ Schriftraum 225/230×150/155. Zwei Spalten, von feinen Tintenlinien begrenzt, zu 47-51 Zeilen. Bastarda von mehreren Händen: 1) Bl. 1ra-2vb, Z. 31, Bl. 3rb-vb; 2) Bl. 2vb, Z. 31-3ra; 3) Bl. 4ra-57vb; 4) Bl. 58ravb. Notizen am Rand (tw. stark beschnitten) von zeitgenössischer bzw. späterer Hand. Bl. 1r Vermerk 19. Jh. Alcorani doctrina.

A: $\quad$ Bl. 1r rote Auszeichnungsstriche, Paragraphzeichen, Unterstreichungen und Rahmung sowie zweizeilige einfache rote Lombarde. Ab B1. 1v keine Rubrizierung, Platz für zwei- und dreizeilige Initialen freigelassen, nicht ausgeführt. Repräsentanten.

E: $\quad$ Neuzeitlicher Bibliothekseinband: schwarz gesprenkeltes braunes Pap. Neustift, 2. H. 18. Jh.

Pap. am VD unten beschädigt, seitlich eingerissen, am HD löchrig. Rücken oben tw. freiliegend, Signaturschild (s. bei G). Schnitt rot gesprenkelt. Spiegel Pap. 18. Jh. Am Spiegel des VD Exlibris und Signaturen (s. bei G), Spiegel des HD leer.

G: Zeitpunkt und Art der Erwerbung durch Neustift unbekannt. Am Spiegel des VD Exlibris der Stiftsbibl. Neustift 18. Jh. 1809 anlässlich der vorübergehenden Aufhebung des Klosters Neustift der ULB Tirol übergeben. Am Spiegel des VD alte Signaturen der ULB Tirol II [...] (radiert, Tinte), II $\overline{3}$ C 18 (Bleistift) und 597 (Tinte). Am Rücken bzw. am VD gelbes Signaturschild der ULB Tirol 597. Bl. 1r Stempel der ULB Tirol 19. Jh. 1921 aufgrund des Friedensvertrages von St. Germain an den italienischen Staat abgegeben und von diesem 1929 dem Kloster Neustift als Dauerleihgabe überlassen. Bl. 1r Stempel der Soprintendenza Tridentina 20. Jh.

L: $\quad$ Zumkeller Nr. 162. - Katalog ULB Tirol VI 373, 382.

1 (1ra-43va) Quadragesimale 〈De schola Christi (48 Predigten) (vgl. J. B. Schneyer, Wegweiser zu lateinischen Predigtreihen des Mittelalters [Bayerische Akademie der Wissenschaften, Veröffentlichungen der Kommission für die Herausgabe ungedruckter Texte aus der mittelalterlichen Geisteswelt 1]. München 1965, 116 [ungedruckt]).

(1ra) Inc.: Cum ieiunatis nolite fieri sicut ypocrite tristes Mt. VI (16). Pro huius thematis introduccione invenio tres scolas. Prima igitur scola fuit Moisy in esse figurali ... - Expl.. ... ut Deus qui veritas est ut tibi in presenti ministret graciam et gloriam in futuris.

(2va) Inc.: [S]icut credidisti fiat tibi Mt. 8 (13). Pro huius thematis introduccione invenio tres scholas scilicet wlgarium wlgarium (!), naturalium, moralium. Prima mensuratur experiencia secunda racione $3^{a}$ (gestrichen: disar) discrecione ... - Expl.: ... et hereditatem eternam cum omnibus sanctis gloriose collocat et vitam eternam donat. Quam etc.

(4ra) Inc.: [D]iligite inimicos vestros Mt. $5^{\circ}$ (44). Pro huius thematis introduccione tres scolas reperio scilicet nature, scripture, gracie. Primo dico quod invenio scolam nature ... - Expl.: ... propter meritum quod expectas quod omnia pondera facit esse levia ad quod meritum nos perducat Amen.

(5rb) Inc.: [E]go sum nolite timere Mar. $6^{\circ}$ (50). Pro huius thematis introduccione tres scolas reperio scilicet Epicuriorum, Platonicorum, Ypotheticorum. Sed in omnibus istis scolis doctrina legitur que secundum aliquam partem merito nobis timorem ... - Expl.: ... adimpletur hic per graciam et in futuro per gloriam Amen.

(6rb) Inc.: [E]cce nunc tempus acceptabile ecce nunc dies salutis $2^{a}$ Cor $6^{\circ}$ (2). Pro huius thematis introduccione tres scolas reperio et fortune, nature, racionalis creature. Prima scola scilicet nature dicit quod omnia naturalia ... - Expl.. ... sanantur anime vulnera hic in presenti etc. 
(7ra) Inc.: [I]psi soli servies Mt. $4^{\circ}(10)$. Pro huius thematis introduccione invenio tres scolas scilicet Heremitarum, Predicatorum, Minorum. Prima scola est Heremitarum in Egidio qui videtur velle tenere quod si primus homo non peccasset... - Expl.: ... quod merito nostrum servicium ... cum nobis hic in presenti per graciam et in futuro per gloriam. Amen.

(8rb) Inc.: [C] um venerit filius hominis in maiestate sua etc. Mt. 26 (recte: 25,31). Pro huius thematis introductione invenio tres scolas scilicet Hebraicam Grecam et Latinam. Prima scola est Hebraica in qua considero Salomonem facientem iusticiam ... - Expl.: ... ibunt miseri in supplicium eternum, iusti autem in vitam eternam. Quam nobis concedat etc. Amen.

(9va) Inc.: [D]omus mea domus oracionis vocabitur Mt. 21 (13). Pro huius thematis introduccione invenio tres scolas scilicet Belzebub in Babilonia, Iani in Roma, Phariseorum in Ierusalem. Prima scola fuit in magna civitate Babilonie in qua tractabatur ... - Expl.: ... que non licent homini loqui et postea ait Cupio dissolvi et esse cum Christo in gloria quam nobis concedat etc. Amen.

(10vb) Inc.: [S]ignum non dabitur ei Mathei 12 (39). Pro huius thematis introduccione invenio tres scolas scilicet mechanicas, trepidas et incredulas. Primo invenio scolas mechanicas et iste sine dubio ut earum opera cognoscantur ... - Expl.: ... rem sacramenti. Ad quod nos perducat qui cum patre et spiritu sancto vivit etc. Amen.

(12ra) Inc.: [M]iserere mei fili David Mt. (gestrichen: $\left.X I^{\circ}\right) X V(22)$. Pro huius thematis introduccione tres scolas reperio scilicet illustrium magnificorum, $2^{a}$ eloquencium, $3^{a}$ decipiencium et proditorum. Prima scola fuit illustrium etc. ... - Expl.: ... si nos dabimus intercedente merito recipiemus gloriam. Ad quam ille nos perducat etc.

(13rb) Inc.: [S]anus fiebat a quacumque detinebatur infirmitate Ioh. $V^{\circ}$ (4). Pro huius thematis introduccione invenio tres scolas videlicet phisicam Avicenne, cyrusicam Galieni, ewangelicam Ihesu Christi. In prima scola fuit magnus medicus naturalis et in illa legebatur ... - Expl.: ... sanati sumus hic in presenti per graciam et in futuro per gloriam Amen.

(14rb) Inc.: [M]iserere nostri Deus omnium et respice nos Sapiencie 28 (recte: Sir 36,1). Pro huius thematis introduccione tres scolas reperio ethicam seu monasticam, yconomicam seu familiarem, politicam seu civilem. Prima scola est monastica in qua legitur ... - Expl.. ... misericordiam tuam nos redemisti et viam glorie nobis aperuisti hic per graciam et in futuro per gloriam. Ad quam nos etc.

(16ra) Inc.: [S]ic ambuletis ut habundetis magis prima ad Thessol. (!) $4^{\circ}$ (1). Pro huius thematis introduccione invenio tres scolas. Prima scola est agricultorum qui habundat in gracia temporali cum tales fructus terre et graciam Dei ... - Expl.: ... Quod apostolus considerans dicit in fine epistule Non enim vocavit nos Deus in immundiciam sed in sanctificacionem hic per graciam etc. Amen.

(17rb) Inc.: [T] ransfiguratus est ante eos Mt. XVII (2). Pro huius thematis introduccione invenio tres scolas scilicet alchimistarum, artistarum, poetarum. In omnibus autem hiis scolis legitur transfiguracio. Prima scola est alchimistarum ... - Expl.. ... eius cantu Ecce quanta est paradisi gloria. Ad quam nos perducat Amen.

(18vb) Inc.: [I]n peccato vestro moriemini Io. 8 (21). Pro huius thematis introduccione invenio 3 scolas scilicet celi, paradisi, mundi. Prima ergo scola fuit celi. Nam in principio creavit Deus celum et terram ... - Expl.: ... septem sunt peccata que impedire querunt animam ne valeat ad gloriam paradisi pervenire promissam in lege. Ad quam gloriam nos etc. Amen.

(20ra) Inc.: [Q]ui se exaltat humiliabiliter Mt. 23 (12). Pro huius thematis introduccione invenio tres scolas scilicet elegancie in naturalibus affluencie in temporalibus eminencie in dignitatibus ... - Expl.: ... paciens pauper factus est ut ad pacienciam superbum reduceret hic in presenti per graciam etc.

(21rb) Inc.: [N] escitis quid petatis Mathei $4^{\circ}$ (recte: 20,22). Pro huius thematis introduccione tres scolas reperio videlicet mundi, carnis, demonis. Prima scola est mundi in $1^{a}$ legitur apparencia 
sive existencia ... - Expl.: ... et induamur arma lucis sciencie et gracie. Quam nobis concedat qui sine fine vivit et regnat Amen.

(22va) Inc.: [M]ortuus est dives et sepultus est in inferno Luc. 16 (22). Pro huius thematis introduccione invenio tres scolas scilicet Sardanapelli in Asya, Catiline in Roma et Attile in Ungaria. Prima ergo scola est Sardanapelli ... - Expl.: ... contemptus Dei inhumanitas et oblivio mortis procedas sicut scis quia amplius de $1^{\circ}$ sermone non inveni in exemplari.

(24rb) Inc.: [H] eres est. Venite occidamus eum Mt. 21 (38). Pro huius thematis introduccione tres scolas invenio scilicet Polestinoris, Mesabellis, Pignaleonis. Prima scola fuit Polestinoris qui fuit rex cuiusdam insule ... - Expl.. ... et vineam suam locabit aliis agricolis quia ibi modo dicuntur esse Enoch et Helyas. Rogemus ergo etc.

(25va) Inc.: [D]issipavit bona sua vivendo luxuriose Luce III (recte: 15,13). Pro huius thematis introduccione tres invenio scolas scilicet Medee, Dyodonis, Ysiphile. Prima ergo scola fuit Medee nam Medea fuit filia Ochis (!) regis qui regnavit in insula Cholchos (!) ... - Expl.. ... sepe recommendemus nos virgini Marie qui impetrabit graciam pro nobis hic in presenti et in futuro gloriam. Ad quam etc.

(27ra) Inc.: [E]stote imitatores Dei sicut filii carissimi (Eph 5,1). Pro huius thematis introduccione invenio tres scolas scilicet dominorum, generatorum, magistrorum. Prima scola fuit dominorum et in ista et in aliis legitur quod omnes intendunt sibi assimilare ... - Expl.: ... nos ad bonum vocant sed pocius repellunt et Christus semper stat ad hostium et dicit Qui me invenerit inveniet vitam hic per graciam et in futuro per gloriam Amen.

(28ra) Inc.: [O]mne regnum in se divisum desolabitur Luce XI (17). Pro huius thematis introduccione invenio tres scolas scilicet Thebanam, Troyanam, Romanam. Prima scola fuit Thebana et in hac pro sui tempore lecta fuit divisio ... - Expl.. ... castri cum muris circumdata cum duobus custodibus cum portis cum populo etc. Procedas sicut scis quia ulterius non invenio.

(29ra) Inc.: [N]emo propheta acceptus est in patria sua Luce $4^{\circ}$ (24). Pro huius thematis introduccione tres scolas invenio scilicet filiorum, inimicorum, discipulorum. Prima scola est filiorum. In hac considero inter filios primi parentis ... - Expl.: ... invidia originetur. Quoniam exercitetur in quo figuretur, procedas sicut scis et vis etc.

(29rb) Inc.: [Q]uecumque solveris super terram erunt soluta et in celo Mt. 18 (18). Pro huius thematis introduccione tres scolas invenio scilicet nuptiarum, victoriarum et scienciarum. Prima ergo fuit nuptiarum et illam invenio in rege Aswero ... - Expl.: ... auctoritas originetur. Quoniam exercitetur in quo figuretur. Et procedas sicut placet etc.

(29vb) Inc.: [Q]ue procedunt de ore hec coinquinant hominem Mt. VI ${ }^{\circ}$ (recte: 15,18). Pro huius thematis introduccione invenio tres scolas invenio (!) Kathonis, Tulii et Senece. Prima scola est Cathonis et quamquam intra illam bona vita legatur tamen inter alia qui ibi leguntur ... - Expl.: ... verbum originetur. Quoniam exercitetur in quo figuretur dicas de verbo mentali et vocali et scripto etc.

(30rb) Inc.: [I]mperavit febri et dimisit illam Luc. $4^{\circ}$ (39). Pro huius thematis introduccione invenio tres scolas videlicet Origenis, Augustini, Ieronimi. Prima scola est Origenis cuius talis fuit opinio seu doctrina ... - Expl.: ... procedas qualiter originatur ex proporcione naturalium electorum seu 7 qualitatum etc.

(30va) Inc.: [H]ic est vere salvator mundi Io. 9 (recte: 4,42). Pro huius thematis introduccione invenio tres scolas scilicet lapidum, herbarum, verborum. Prima ergo scola est lapidum et in illa legitur magna virtus. Nam videmus quod carbunculus ... - Expl.: ... ut hoc facto possit haurire graciam hic in presenti et in futuro gloriam Amen.

(32ra) Inc.: [N]ec ego te contempnabo (!) Ioh. 8 (11). Pro huius thematis introduccione invenio tres scole (!) scilicet wlgaricam, canonicam, theologicam et in hiis legitur quod nullus possit iudicari ... - Expl.: ... unus sit iudex et quod iudex sine misericordia est severus. Procedas sicut tu scis. 
(32rb) Inc.: [N]on sumus filii ancille sed libere Gal. $6^{\circ}$ (recte: 4,31). Pro huius thematis introduccione tres scolas invenio scilicet potenciarum, naturarum, gramaticorum. Nam prima est potenciarum et quia habemus plures potencias ... - Expl.: ... unde filii originentur. Quoniam exercitentur in quo figurentur procedas sicut scis et vis et nota libri falsitatem.

(32vb) Inc.: [D]istribuit discumbentibus Io. $6^{\circ}$ (11). Pro huius thematis introduccione reperio tres scolas mirificam, munificam, magnificam. Prima scola est mirificum (!) et hec scola est Dei. Prope enim Deus qui fecit mirabilia ... - Expl.: ... utrum plus mereatur dando pauperibus quam divitibus procedas sicut placet.

(33rb) Inc.: [S]olvite templum hoc et in tribus diebus excitabo illud Io. $2^{\circ}$ (19). Pro huius thematis introduccione invenio 3 scolas scilicet extimam, intimam, extrinsecam. Prima scola dicitur extima et hec est excellencie dignitatis et in hac lego trinitatem ... - Expl.: ... unum solucio originetur. Quoniam exercitetur in quo figuretur procedas sicut scis et dic quod originatur a peccato etc.

(33va) Inc.: [Q]uomodo hic litteras scit cum non didicerit Io. $7^{\circ}$ (15). Pro huius thematis introduccione invenio tres scolas scilicet organicam, scientificam, ewangelicam. Prima scola dicitur organica et in hac legitur quod quis doctus esse non potest ... - Expl.: ... utrum infinite videat facialem visionem divinitatis. Nunc procedas sicut tibi placet.

(34ra) Inc.: [E]tatem habet ipse de se loquatur Io. 9 (21). Pro huius thematis introduccione tres scolas invenio scilicet examinacionis, confessionis, obligacionis. Prima scola est examinacionis et in ista scola legitur quod reus dato quod omnia sunt allegata et approbata ... - Expl.: ... non est opus valentibus medicus etc. sic peccator spiritualiter dum vivit etc.

(34va) Inc.: [T]ibi dico surge Luce $7^{\circ}$ (14). Pro huius thematis introduccione 3 scolas invenio scilicet equitatis, benignitatis, sanctitatis. Prima scola est equitatis et in hac legitur quod relevetur infirmus ... - Expl.: ... sicut mundari ad maculatum fuisse et qualiter causatur a libero arbitrio etc.

(34vb) Inc.: [D]omine si fuisses hic frater meus non fuisset mortuus (Io 11,21). Pro huius thematis introduccione reperio tres scolas scilicet elementalem, spiritualem, iudicialem. In hiis tribus scolis legitur mors. Prima ergo scola est elementalis quia composita originaliter ab hiis cum omne compositum resolvi ... - Expl.. ... in sphera et in cursu eiusdem etc.

(35rb) Inc.: [P] er proprium sanguinem introivit semel in sancta eterna redempcione inventa (Hbr 9,12). Pro huius thematis introduccione invenio tres scolas scilicet cordialem, pigmentalem, usualem. Prima est cordialis in qua legitur quod sanguis est summum elementum cordis ... Expl.: ... Ideo Dei filius sanguinem suum posuit homine ut dicunt verba proposita. In quibus queras $3^{a}$ etc.

(35vb) Inc.: [M] ortem non gustabit in eternum Io. 9 (recte: 8,52). Pro huius thematis introduccione invenio tres scolas scilicet planete, comete, monete. Prima est planete et in hac legitur vita secundum quod melior est constellacio vel planeta de tanto efficimur levioris vite ... - Expl.: ... In quibus tria quero scilicet unde nostra redempcio originetur, quoniam excitetur, in quo figuretur. Dicas sicut scis.

(36ra) Inc.: [Q]ueritis me et non invenietis Io. $7^{\text {mo }}$ (34). Pro huius thematis introduccione invenio tres scolas scilicet motorum, auditorum, bellatorum. Prima est motorum et in illa legitur lux gracie unde Gen. primo dixit Deus fiat lux et facta est lux ... - Expl.: ... et querat in scolis fidei quia eum querentibus dicitur verbum propositum. Queritis me etc. In quibus verbis quere $3^{a}$. Unum etc.

(36va) Inc.: [N]on enim volebat in Iudeam ambulare quia querebant eum Iudei interficere (Io 7,1). Pro huius thematis introduccione 3 scolas invenio scilicet Martis, partis, mortis. Prima est Martis. Nam Mars ut pluries dictum est planeta malivolus est et nati sub illo sunt pessimi ...Expl.: ... Non enim volebat etc. In quibus queras utrum velle interficere originetur et procedas ulterius sicut scis etc. 
(36vb) Inc.: [O]pera que ego facio in nomine patris mei ipsa testimonium perhibent de me Io. 20 (recte: 10,25). Pro huius thematis introduccione invenio tres scolas scilicet veneficas (darübergeschrieben: $b$ ), angelicas (darübergeschrieben: $a$ ), truffaticas. Prima scola est angelica et in hac legitur magna opera facta fuisse et primo legitur de archangelo Michaele ... - Expl.. ... et dicitur quod a virtutibus ut patet de pacientibus prosequerer sicut scis et sicut tibi placet. Sequitur. (37rb) Inc.: [L] acrimis rigavit pedes meos Luce $7^{\circ}$ (44). Pro huius thematis introduccione invenio tres scolas scilicet arborum et plantarum, vaporum et nebularum, dolencium animarum. Prima scola est plantarum et arborum in qua talis doctrina legitur quod quando arbores plorant ... Expl.: ... et sanguinem quo suscepto anima ad Deum evolavit et sic habuit graciam in presenti et in futuro gloriam Amen.

(38rb) Inc.: [C]ollegerunt pontifices et Pharisei concilium adversus Ihesum Io. primo (recte: 11,47). Pro huius thematis introduccione invenio tres scolas scilicet urbis fundatorum, in campo bellatorum, in campo clericorum. Prima scola est urbis fundatorum ... - Expl.: ... illi qui hic dat graciam et in futuro gloriam. Ad quam nos perducat idem dominus benedicans in secula Amen. (39va) Inc.: [P]ater clarifica nomen tuum Io. 12 (28). Pro huius thematis introduccione invenio tres scolas scilicet sapiencie, presencie, refulgencie. Prima scola est sapiencie in qua legitur quod sapiencium nomen clarificatur per famam in multis locis ... - Expl.. ... quero in quo nomine Dei figuretur. Respondeo quod figuratur in nomine generali procedas sicut vis.

(40va) Inc.: [N]on rapinam arbitratus est esse se equalem Deo ad Phil. $2^{\circ}$ (6). Pro huius thematis introduccione invenio 3 scole (!) angelice nature, humane creature, artificialis figure (gestrichen: Pro huius thematis introduccione) et in omnibus hiis legitur forma rapine. Prima scola est angelice nature in qua legitur rapina ... - Expl.: ... dico quod originatur ex inordinato appetitu et disproporcionato dicas sicut scis.

(40vb) Inc.: [C]eperunt ramos palmarum et processerunt obviam ei Luce 12 (recte: Io 12, 13). Pro huius thematis introduccione invenio tres scilicet olive in Minerba, lauri in Mercurio, palme in Marte. Prima scola est olive in Minerba. Nam ut possum capere ex dictis poetarum oliva consecrata est in nomine Minerbe ... - Expl.. ... et tunc dominus recipitur in Iherusalem id est in visionem pacis ad quam nos perducat Amen.

(42ra) Inc.: [M]artha ministrabat Io. 12 (2). Pro huius thematis introduccione invenio tres scolas scilicet internas, alternas, subalternas. Prima est interna et est voluntatis et in hac legitur quod ea que sunt in homine ipsi voluntati principaliori et digniori subalternas serviunt ... - Expl.: ... recipiat condimentum hoc per graciam et in futuro per gloriam Amen.

(43ra) Inc.: [V]enite mittamus lignum in panem eius Iere. 41 (recte: 11,19). Pro huius thematis introduccione invenio tres scolas scilicet mechanicas, piraticas, maleficas. Prima scola est mechanica et hec utitur ligno ... - Expl.: ... si crux que est lignum poneretur in membris corporis Christi Amen.

2 (43va-57vb) Augustinus Favaroni: Sermones bzw. Interrogationes seu introductiones quadragesimales (vgl. Schneyer II: Augustinus [Favaroni] de Roma, München, BSB, Clm 4706, B1. 1-36: Sermones 43 und 50-52 in Hs. nicht enthalten. Zumkeller Nr. 162. W. Eckermann, „Augustinus Favaroni“". Theologische Realenzyklopädie IV. Berlin 1979, 739-742).

Inc.: [R]edde illis mercedem Mt. 20 (8). Questio inter doctores scolasticos solet moveri utrum Deus posset non retribuere mercedem summe beatitudinis creature racionali diligenti eum fideliter ... - Expl.: ... et hoc in ligno sanctissime crucis de cuius morte et passione hodie ecclesia facit specialem mencionem etc.

Enthält 49 Sermones, Sermo 3 im Druck nicht enthalten: (44ra) Inc.: [V]obis datum est nosse misterium regni Dei Mt. XIII ${ }^{\circ}$ (11). Questio oritur inter doctores utrum in hac vita possit (gestrichen: aliquis) Deum videre facialiter ... - Expl.: ... doctores scolastici pro maiori parte tenent cum Augustino in hac questione etc. 
Schlussschrift: Expliciunt distinctiones reverendissimi magistri Augustini de Roma ordinis Heremitarum sancti Augustini.

(57ra-vb) Auflistung der Sermones, jeweils als Quaestio formuliert (ohne Nummerierung, ohne Blattangabe).

Inc.: [U]trum Deus posset non retribuere mercedem summe beatitudinis creature racionali diligenti eum fideliter et perseveranter ... - Expl.: ... Utrum aliqua pura creatura potuerit esse sufficiens ad redimendum genus humanum.

3 (57vb) Auctoritates-Zitate zu De Anima.

Tit.: Nota de anima. - Inc.: Cassiodorus in libro De anima. Magistri scolarium (!) litterarum aiunt animam esse substanciam simplicem speciem naturalem distantem a materia corporis sui organum membrorum ... - Expl.: ... sicut dicitur in libro de motu cordis. Item Seneca Anima est spiritus intellectualis ad beatitudinem in se et in corpore ordinatus.

4 (58ra-vb) SERMo, unvollständig.

Inc.: [V]os estis (darüber: autem) genus electum regale sacerdocium gens sancta etc. 1. Pe. 2 (9). Hec verba sunt beati Petri ad commendacionem et dignitatem sacerdotalem. In verbis premissis possumus notare triplicem gradum sive excellenciam cuiuslibet sacerdotis. Primo eius dignitatem ... - Expl. mut.: ... unico verbo liberare posset (gestrichen: ut) carcer aperiretur (gestrichen: et) vincula dirumperentur et liber a capti [

Tw. Sätze durchgestrichen, Ergänzungen und Zusätze am Blattrand (beschnitten).

U.S.

\section{Cod. 605}

\section{PETRUS HISPANUS. DE MODIS SIGNIFICANDI}

Perg. I, 8, I* Bl. $185 \times 135$. Entstehungsort unbestimmt, Ende 13./Anfang 14. Jh.

B: $\quad$ B1. 1 stark fleckig, B1. 5 Nahtspur, vereinzelt kleine Löcher. Lagen: $(\mathrm{I}-1)^{\mathrm{I}}$ (Vorsatzbl., Pap. 18. Jh.) + $\mathrm{I}^{2}+\mathrm{III}^{8}$ $+(\mathrm{I}-1)^{\mathrm{I}^{*}}$ (Nachsatzbl., Pap. 18. Jh.). Gegenbl. zum Vor- bzw. Nachsatzbl. als Spiegel auf dem VD bzw. HD aufgeklebt. Zw. Bl. 1 und 2 sowie nach Bl. 2 und 8 Textverlust: urspr. wohl Quaternionen. Am oberen Blattrand Foliierung 19. Jh. durch die ULB Tirol.

S: $\quad$ Schriftraum $140 / 145 \times 105$. Zwei Spalten, von nur mehr schwach erkennbaren Tintenlinien gerahmt, zu 35 Zeilen auf schwacher Tintenlinierung. Zirkelstiche. Textualis. Am Blattrand vereinzelt Nachträge von zeitgenössischer Hand.

A: Vereinzelt rote Auszeichnungsstriche, Paragraphzeichen, Zeilenfüllsel, Über- und Schlussschrift sowie Schreiberverse. Bl. 2rb Ergänzung am Blattrand in blauer Tinte. Zweizeilige rote Lombarden mit Punktverdickungen. Bl. 5va achtzeilige rote Initiale mit verzierten Ausläufern. Bl. 1ra sechszeilige abgeriebene Initiale, mit blauen und roten Umrisslinien nachgezeichnet, linker Buchstabenschaft abgetreppt. Bl. 5v und 6v spätere Bleistiftkritzeleien.

E: $\quad$ Neuzeitlicher Bibliothekseinband: schwarz gesprenkeltes braunes Pap. über Pappe. Neustift, 2. H. 18. Jh. Pap. tw. abgerieben und beschädigt. Am VD und HD Ecken mit braunem Leder verstärkt. Rücken: braunes Leder, drei Bünde, von jeweils dreifachen Streicheisenlinien gesäumt. Im zweiten Feld Signaturschild (s. bei G). Spiegel Pap. 18. Jh. Am Spiegel des VD Exlibris und Signaturen (s. bei G), Spiegel des HD leer.

G: Zeitpunkt und Art der Erwerbung durch Neustift unbekannt. Am Spiegel des VD Exlibris der Stiftsbibl. Neustift 18. Jh. 1809 anlässlich der vorübergehenden Aufhebung des Klosters Neustift der ULB Tirol übergeben. Am Spiegel des VD alte Signaturen der ULB Tirol II $\overline{6} D 13$ (? radiert, Tinte), II $\overline{3} C 5 \mathrm{~S} .2$ (Bleistift) und 605 (Tinte). Am Rücken bzw. VD gelbes Signaturschild der ULB Tirol 605. Bl. 1r Stempel der ULB Tirol 19. Jh. 1921 aufgrund des Friedensvertrages von St. Germain an den italienischen Staat abgegeben und von diesem 1929 dem Kloster Neustift als Dauerleihgabe überlassen. Bl. 1r Stempel der Soprintendenza Tridentina 20. Jh. 
L: $\quad$ Kristeller I 439. - Katalog ULB Tirol VII 43, 484.

(Ir) leer bis auf Bleistiftnotiz: Balos v. Menter (?).

(Iv) leer.

1 (1ra-5rb) 〈Petrus Hispanus〉: Tractatus sive Summulae logicales, unvollständig (Ed.: L. M. de Rijk, Tractatus called afterwards Summule logicales [Philosophical texts and studies 22]. Assen 1972). Gegenüber Ed. tw. erweitert, tw. leicht abweichend.

(1ra-vb) Tract. 1: De introductionibus, unvollständig.

Inc.: Dyaletica (!) est ars arcium sciencia scienciarum ad omnia methodorum principia habens viam. Sola enim dyalectica probabiliter disputat de principiis omnium artium ... - Expl. mut. (cap. 8): ... ut sortes currit [ (2ra-vb) Tract. 3: De praedicamentis, unvollständig, Tit. Bl. 2rb nachgetragen.

Inc. mut. (cap. 2): ] quedam forma substancialis ut anima est substancialis forma hominis alia autem et forma accidentalis ut album homini. Prima harum ... - Expl. mut. (cap. 12): ... et quibusdam aliis. Item substancia non sus[

(3ra-5rb) Tract. 5: De locis, unvollständig. Inc. von Ed. abweichend.

Inc. mut. (cap. 20): ]nens et materia transiens. Permanens est ut in cultello ferrum transiens est ut in pane farina et in vitro ... - Expl. (cap. 40, Schluss von Tract. 5): ... argumentum constructive et destructive.

(5rb) Schlussschrift: Explicit tractatus.

Darüber und darunter jeweils ein SchreIBERSPRUCH:

1) Lauda scriptorem donec videas meliorem (Colophons Nr. 22151. Vgl. Walther, Proverbia Nr. 13516a).

2) Detur pro penna scriptori pulchra puella (Colophons Nr. 20587. Walther, Proverbia Nr. 5527a). Lit.: M. Grabmann, Handschriftliche Forschungen und Funde zu den philosophischen Schriften des Petrus Hispanus, des späteren Papstes Johannes XXI. (SB der phil.-hist. Abt. der Bayerischen Akademie der Wissenschaften 9). München 1936, 1-85. Zur Verfasserfrage vgl. Rijk IX-XXIV.

2 (5va-8vb) De MODIS signifiCANDi (Grammatica speculativa), unvollständig. Anonymer Traktat nach (tw. übereinstimmend mit) Thomas de Erfordia: De modis significandi (vgl. Ed.: M. F. García, Lexicon scholasticum philosophico-theologicum. Hildesheim 1974 [hier Iohannes Duns Scotus zugeschrieben], Pars 1, cap. 46-53. Vgl. auch G. L. Bursill-Hall, Grammatica speculativa of Thomas of Erfurt. London 1972, 276-310).

Inc.: Ad cognoscendam naturam construccionis in se et in suis partibus sive speciebus sciendum quod construccio est quoddam incomplexum et quia incomplexum secundum Boecium cognoscitur dupliciter. Diffinicione que ordinatur ad cognoscendam rem in se ... - Expl. mut.: ... vel accusativus ut legitur librum vel ablati[

Lit.: S. Grotz, Thomas von Erfurt. Abhandlungen über die bedeutsamen Verhaltensweisen der Sprache (Tractatus de Modis significandi) (Bochumer Studien zur Philosophie 27). Amsterdam, Philadelphia 1988, VII-XLIV.

$\left(I^{*} \mathrm{r}-\mathrm{v}\right)$ leer.

A. P./U.S. 


\section{Cod. 606}

\section{TRACTATUS DE CONFESSIONE}

Perg. I, 6, I* Bl. $220 \times 155$. Entstehungsort unbestimmt, 14. Jh.

B: $\quad$ Dickes Perg. Lagen: (I-1) ${ }^{\mathrm{I}}$ (Vorsatzbl., Pap. 18. Jh.) $+\mathrm{III}^{6}+(\mathrm{I}-1)^{\mathrm{I}^{*}}$ (Nachsatzbl., Pap. 18. Jh.). Gegenbl. zum Vor- bzw. Nachsatzbl. als Spiegel auf dem VD bzw. HD aufgeklebt. Urspr. möglicherweise Quaternio (vor Bl. 1r und nach Bl. 6v Textverlust). Am oberen Blattrand Foliierung 19. Jh. durch die ULB Tirol.

S: $\quad$ Schriftraum $170 \times 110$. Zwei Spalten, von Tintenlinien gerahmt, zu 34 Zeilen auf Tintenlinierung. Zirkelstiche. Textualis. Am Rand vereinzelt Ergänzungen und Korrekturen tw. von zeitgenössischer, tw. von späterer Hand.

A: Rote Überschriften, Paragraphzeichen, Auszeichnungsstriche, Trennungsstriche und Unterstreichungen. Zweizeilige rote Lombarden, tw. mit Ausläufern. Bl. 1ra fünfzeilige rote Lombarde.

E: $\quad$ Neuzeitlicher Bibliothekseinband: schwarz gesprenkeltes braunes Pap. über Pappe. Neustift, 2. H. 18. Jh. Am VD und HD Ecken mit braunem Leder verstärkt. Rücken: braunes Leder, sechs dreifache Streicheisenlinien. Am Rücken bzw. VD Signaturschild (s. bei G). Spiegel Pap. 18. Jh. Am Spiegel des VD Exlibris und Signaturen (s. bei G), Spiegel des HD leer.

G: Zeitpunkt und Art der Erwerbung durch Neustift unbekannt. Am Spiegel des VD Exlibris der Stiftsbibl. Neustift 18. Jh. 1809 anlässlich der vorübergehenden Aufhebung des Klosters Neustift der ULB Tirol übergeben. Am Spiegel des VD alte Signaturen der ULB Tirol II $\overline{6}$ B 4 (radiert, Tinte), II $\overline{3}$ C 6 S. 2 (Bleistift) und 606 (Tinte). Am Rücken gelbes Signaturschild der ULB Tirol 606. Bl. 1r Stempel der ULB Tirol 19. Jh. 1921 aufgrund des Friedensvertrages von St. Germain an den italienischen Staat abgegeben und von diesem 1929 dem Kloster Neustift als Dauerleihgabe überlassen. Bl. 1r Stempel der Soprintendenza Tridentina 20. Jh.

L: $\quad$ Katalog ULB Tirol VII 43, 489.

$(\mathrm{Ir}-\mathrm{v})$ leer.

Tractatus DE CONFESsione, unvollständig (vgl. Bloomfield Nr. 1125 und Suppl. Nr. 1125. Hamesse Nr. 9778. Kaeppeli Nr. 3196).

(1ra) Prolog. Inc. mut.: ] nugis et ioco ac fabulis vacantes. Nota ad honorem individue trinitatis ... Expl.: ... duximus compilare in quo tractatu agere.

(1ra) Inhaltsübersicht. Tit.: Capitula. - Inc.: Quomodo confessor consideret condiciones confitentis ... - Expl.: ... De casibus pro quibus est ad superiorem recurrendum.

(1rb-6vb) Text. Tit.: Primum capitulum quomodo confessor debet considerare vitam et condiciones confitentis. - Inc.: Primum capitulum est quomodo confessor debet considerare condiciones confiteri volentis. Ubi notandum quod confessor sedens ad confessiones audiendas si confiteri volentem non cognoscit querat ab eo an sit suus parrochianus ... - Expl. mut. (cap. 16): ... potest confessor inquirere modum qui accidit sibi dormiendo an vigilando an aliquo tactu suo vel [

Vgl. Wilten, Stiftsbibl., Cod. 3203 07, Bl. 215ra.

Lit.: Schulte GQ II 530, Nr. 11; P. Michaud-Quantin, Sommes de casuistique et manuels de confession au moyen âge (XII-XVI siècles). Analecta Medievalia Namurcensia 13 (1962) 85, Index.

$\left(I^{*} \mathrm{r}-\mathrm{v}\right)$ leer. 


\section{Cod. 614}

\section{JURISTISCHE SAMMELHANDSCHRIFT}

Pap. I, 290, I* Bl. $210 \times 145$. Tirol, T. I: 7./8. Jz. 14. Jh, T. II: 1. Viertel 15. Jh. (u. a. 1419), T. III: 1. Jz. 15. Jh., T. IV: 4. Jz. 15. Jh.

B: $\quad$ Pap. im Zuge der Restaurierung 20. Jh. (s. bei G) am äußersten Blattrand tw. ergänzt, Bl. 173-182 verstärkt, Löcher geklebt. Vier Teile: T. I (I, 1-149), T. II (150-269), T. III (270-283), T. IV (284-290, I*). Am oberen Blattrand Foliierung 19. Jh. durch die ULB Tirol.

E: Bibliothekseinband: rot gefärbtes Leder über dicker Pappe. Rignano sull’Arno (Prov. Firenze), 20. Jh. Einband und Bindung im Zuge der Restaurierung erneuert. Kanten gerade. Kapitale mit gelblichem und grünem Garn umstochen. Rücken: drei einfache Bünde, im untersten Feld Signaturschild (s. bei G). Spiegel Pap. 20. Jh. Spiegel des VD leer, am Spiegel des HD Etikett der Restaurierwerkstätte (s. bei G).

G: Zeitpunkt und Art der Erwerbung durch Neustift unbekannt. 1809 anlässlich der vorübergehenden Aufhebung des Klosters Neustift der ULB Tirol übergeben. Bl. 1r alte Signaturen der ULB Tirol II [...] (radiert, Tinte), darüber 614 (Tinte) sowie Stempel der ULB Tirol 19. Jh. 1921 aufgrund des Friedensvertrages von St. Germain an den italienischen Staat abgegeben und von diesem 1929 dem Kloster Neustift als Dauerleihgabe überlassen. Bl. 1r Stempel der Soprintendenza Tridentina 20. Jh., dieser auch Bl. 2r. Am Spiegel des HD Etikett der Restaurierwerkstätte 20. Jh. (Laboratorio di restauro del libro S. Maria del Rosano), kein Restaurierbericht erhalten. Bl. Ir Signatur 20. Jh. Ms. 614 (Bleistift), am Rücken Signaturschild 20. Jh. 614.

L: $\quad$ Schulte GQ II 410. - Wilhelm I 136 und II 109. - Wretschko-Sprung 22. - Neuhauser, Neustift 88. - Stefani 113. - Katalog ULB Tirol VII 94, 484. - Krämer, Scriptores, s. v. „Weinkern, Albertus“.

$$
\text { I (I, 1-149) }
$$

B: $\quad$ Bl. 119 am oberen Blattrand beschnitten (ohne Textverlust). Bilder und Nachweise der Wasserzeichen s. WZMA. Datierung nach Wasserzeichenbefund. Lagen: (I-1) (Vorsatzbl. 20. Jh.) + VIII ${ }^{16}+2$. IV $^{32}+9 . \mathrm{VI}^{140}$ $+\left(\right.$ VI-3) ${ }^{149}$. Gegenbl. zum Vorsatzbl. als Spiegel auf dem VD aufgeklebt. Die letzten drei Blätter der letzten Lage herausgeschnitten (ohne Textverlust). Zwei Kustodenzählungen in zeitgenössischen schwarzen Ziffern: 1) am Lagenende beginnend bei 3, die zweite Lage hierbei übersprungen, folglich dritte Lage Forts. mit 4; 2) am Lagenanfang beginnend bei 1, Lage 1-5 in der Mitte oben, ab Lage 6 unten.

S: $\quad$ Schriftraum ca. 160/170 × 105/120, seitlich meist von Tintenlinien gerahmt, zu 35-47 Zeilen. Bastarda. Vereinzelt Ergänzungen und Korrekturen am Blattrand von derselben Hand. Oberlängen in der ersten Zeile vereinzelt gedehnt.

A: $\quad$ Bl. 1r-58r, 93r-97r, 105r-110r, 117r-125r, 129r-147v rote Auszeichnungsstriche, tintenfarbene und tw. rot übermalte Paragraphzeichen. Bl. 1r-17v, 23v-27v, 28v-45r, 57r-58r, 105r-110v, 117r-125r, 129r-147v am oberen Blattrand Titel der jeweiligen Kapitel in Rot angeführt. Durchgehend rote Überschriften sowie ein- bis fünfzeilige einfache Lombarden, vereinzelt mit Punktverdickungen, Ausläufern und Aussparungen; Lombarden bisweilen nicht ausgeführt. Bl. 1r vierzeilige rote Lombarde $Q$ mit Aussparungen und als Binnenfeld- und Caudafüllung Horizontalreihen aus winzigen Bögen (in Rot und hellem Tintenbraun). B1. 46v-56v, 59r-60r, 61r-64r, 65r-66v, 67v, 68v-69r, 71v, 72v, 76v, 78r, 79v-80r, 81r-v, 82v-83r, 84r, 85r, 86r-v, 87v, 88v-89r, 91r-v, 97v, 99r-100v, 101v, 102v, 103v-104v, 112r-116r, 125r, 126r und 128r keine Rubrizierung.

(Ir-v) leer bis auf Signatur (s. bei G).

1 (1r-147v) Raimundus de Pennaforte: Summa.

1.1 (1r-139r) Summa de paenitentia (= Summa, Lib. 1-3) (Ed.: X. Ochoa, A. Diez, S. Raimundus de Pennaforte, Summa de paenitentia [Universa Bibliotheca iuris I B]. Roma 1976. - Kaeppeli Nr. 3407. Bloomfield Nr. 4963, 5054)

(1r) Prooemium.

(1v) Lib. 1. - (40v) Lib. 2. - (68r) Lib. 3.

(73v) nur Rahmung sowie zweifacher Hinweis in den Ecken in Rot vacat. 
1.2 (139r-147v) Summa de matrimonio (= Summa, Lib. 4) (Ed.: X. Ochoa, A. Diez, S. Raimundus de Pennaforte [Universa Bibliotheca iuris I C]. Roma 1978. - Kaeppeli Nr. 3408. Bloomfield Nr. 4943).

(147v) Schlussschrift: Explicit summa casuum (darunter kleiner und in schwarzer Tinte wiederholt).

(148r-149r) leer.

Lit.: Schulte GQ II 410-413; Kuttner 443-445.

(149v) Federproben:

In nomine domini Amen. Anno nativitatis eiusdem. - Summa Raymundi. - Lex est defuncta ubi iudicis est manus uncta (darunter in kleinerer Schrift nochmals wiederholt) (Walther, Proverbia Nr. 13695).

$$
\text { II (150-269) }
$$

B: $\quad$ Bilder und Nachweise der Wasserzeichen s. WZMA. Datierung nach Wasserzeichenbefund. Lagen: 10.VI ${ }^{269}$. Am Lagenanfang und -ende Kustoden in zeitgenössischen roten arabischen Ziffern. Lagenreklamanten.

S: $\quad$ Schriftraum 140/145 $\times 90 / 95$, von Tintenlinien gerahmt, zu 18-24 Zeilen. Bastarda mit zunehmend breiter werdendem Duktus, dat. 12. Dezember 1419 (Bl. 261r). Schreiber: Albertus Weinkern (u. a. auch Brixen, Priesterseminarbibl., Cod. D.19, dat. 1421; München, BSB, Clm 8375, dat. 1418 in Innsbruck, vgl. Krämer, Scriptores; belegt auch als notarius publicus in Mairhofer 514 [Stift Wilten 1426]). Hervorhebungen am Rand von gleicher Hand, Korrekturen und Ergänzungen tw. von anderer Hand.

A: Rote Auszeichnungsstriche, Paragraphzeichen, Unterstreichungen und Rahmungen. Vereinzelt Zeigehände. Zwei- und dreizeilige rote Lombarden. B1. 151r neunzeiliger roter I-Versal mit ausgesparter Herzblattranke. Repräsentanten.

2 (150r-261r) Processus iudiciarius (dictus Schweidnitz).

(150r) Verworfener Text. Tit.: Incipit processus iudiciarius dictus Sweidnicz de causis delegatis et subdelegatis. - Inc.: In nomine domini Amen. Circa processum iudiciarium in causis delegatis et subdelegatis et ordinariis primo premittitur cum impetrator rescripti ... - Expl. mut.: ... inspecturi mandatis vestris [

(150v) nur Rahmung.

(151r-261r) Tit.: Incipit processus iudiciarius dictus Sweidnicz de causis delegatis et subdelegatis. - Inc.: In nomine domini Amen. Circa processum iudiciarium in causis delegatis ... - Expl.: ... Item oppone quod non est talis casus vel causa in quo vel in qua potuit appellare ut supra dictum est etc. Deo gracias gracias Deo Deo gracias etc.

Schlussschrift mit Schreibernennung und Datierung: Explicit processus iudiciarius dictus Sweidnicz de causis delegatis et subdelegatis. Qui scriptus est per Albertum Weinkernem notarium publicum ac clericum Frisingensis dioecesis anno etc. XIX' ${ }^{\circ}$ in vigilia sancte Lucie virginis etc. (12. Dezember 1419).

(261v-269v) nur Rahmung.

Parallelüberlieferung: u. a. Augsburg, Staats- und Stadtbibl., $2^{\circ}$ Cod. 260a, Bl. 1r und $2^{\circ}$ Cod. 312, Bl. 198ra.

In Augsburg, Staats- und Stadtbibl., $2^{\circ}$ Cod. 312 als Wiener Vorlesung des Magisters Nikolaus Schweidnitz überliefert. Zu Schweidnitz s. F. J. Worstbrock, „Schweidnitz, Nikolaus“. Verfasserlexikon² VIII 929-930; P. Uiblein, Acta facultatis artium universitatis Vindobonensis 1385-1418 (Publikationen des Instituts für Österreichische Geschichtsforschung VI, 2). Graz u. a. 1968, 25, 35, 553.

Vgl. auch Th. Muther, Zur Geschichte des Römisch-canonischen Prozesses in Deutschland während des vierzehnten und zu Anfang des fünfzehnten Jahrhunderts. Rostock 1872, 52-75. 
B: $\quad$ Bl. 283v stark verschmutzt. Bilder und Nachweise der Wasserzeichen s. WZMA. Datierung nach Wasserzeichenbefund. Identische Wasserzeichen: Innsbruck, ULB Tirol, Cod. 588, T. II, Cod. 590, T. V [Klausen/ Diözese Brixen]). Lage: VII'283.

S: $\quad$ Bl. 270r-282r: Schriftraum 145/160×95/105, von Bleistiftlinien gerahmt, zu 27-31 Zeilen. Bastarda. B1. 282v-283v: Schriftraum 180/185 × 100, von kaum sichtbaren Bleistift- bzw. Blindlinien seitlich begrenzt. Bastarda, Feder- und Tintenwechsel B1. 282v, Z. 34. Von gleicher Hand auch Zusatz auf B1. 282r.

A: Bl. 270r-274v: hellrote Trennungspunkte, Auszeichnungsstriche, Paragraphzeichen, Unterstreichungen, Rahmungen und Überschriften sowie zweizeilige Lombarden. B1. 270r dreizeilige rote Lombarde mit ungelenkem tintenfarbenem Knospenfleuronnée im Binnenfeld.

B1. 275r-282r: vereinzelt hellrote Auszeichnungsstriche und Unterstreichungen, zahlreiche Paragraphzeichen und Überschriften sowie meist einzeilige Lombarden, beim Buchstabenwechsel zwei- bis vierzeilige Lombarden, tw. mit Punktverdickungen und minimalem Dekor.

Bl. 282v-283v keine Rubrizierung.

3 (270r-273v) Iohannes DE Deo: Concordantiae Decretalium et Decretorum (G. Murano, Initia operum iuris canonici medii aevi. A shortlist of works, arranged by their incipit words [https:// home.uni-leipzig.de/jurarom/manuscr/murano/initican.htm]).

Tit.: Concordancie Decretalium et Decretorum. - Inc.: De constitucionibus d II. et III. per totum et d IIII c 1 ... - Expl.: ... Salomitane ubi Iohanne (!) plene notavit de hac materia. Lit.: Schulte GQ II 97-98.

4 (273v-274v) Erklärungen zur Gliederung des Decretum Gratiani, der Dekretalen und des CORPUS IURIS CIVILIS.

Inc.: Sciendum quod Decretum dividitur in tres partes principales, quarum prima vocatur Distincciones ... - Expl.. ... siquis dogmata conswevit de hoc notari d III § I secundum Hugonem et Io.

5 (275r-282r) REGULAE IURIS CIVILIS.

Alphabetisch geordnete Sammlung von Rechtssprichwörtern und -regeln (A-U/V).

Tit.: Regule iuris civilis huius littere A sunt hee. - Inc.: Alterius circumvencio alteri non prebet accionem. Actus legittimi ut supra. Aliud est vendere aliud vendicioni consentire ... - Expl.: ... furiosus absentis loco est et ita Pomponius L 1 epistolarum scripsit.

Inc. wie Bamberg, Staatsbibl., Msc. Can. 44, Bl. 109r.

(282r) Darunter: Ergänzungen von anderer Hand, nicht mehr alphabetisch geordnet.

Inc.: Omnis res per quascumque causas nascitur per easdem et dissolvitur (Decretum Gratiani, p. 2, C. 27, qu. 2, cap. 4). Ea facta que dubia sunt ut quo animo in meliorem partem interpretremur (!) ... - Expl.: ... quis homagium compellatur.

6 (282v-283v) 〈Bonifatius VIII.»: Regulae iuris sexti libri Decretalium (CIC, ed. Friedberg II 1122-1124).

Tit.: Regule iuris libri Sexti. - Inc.: Beneficium ecclesiasticum non potest licite sine institucione canonica obtineri ... - Expl.: ... qui verba legis complectens contra legis nititur voluntatem. Datum Rome apud sanctum Petrum quinto Nonas Marcii pontificatus nostri anno quarto.

$$
\text { IV (284-290, I*) }
$$

B: $\quad$ Bilder und Nachweise der Wasserzeichen s. WZMA. Datierung nach Wasserzeichenbefund. Lagen: $(\mathrm{V}-3)^{290}$ $+1^{\mathrm{I}^{*}}$ (Nachsatzbl. 20. Jh.). Gegenbl. zu Bl. 284-286 herausgeschnitten. Gegenfalz zum Nachsatzbl. vor Bl. 284.

S: $\quad$ Schriftraum 160/175 ×90/100, von Blindlinien gerahmt. Beschriftung vielfach über den gekennzeichneten Schriftraum hinausreichend. Bastarda (gleiche Hand wie Bl. 282v, Z. 34-Bl. 283v). 
7 (284r-289r) Summarium Quaestionum mercurialium Iohannis Andreae (vgl. Druck: u. a. GW 1735. G. Murano, Initia operum iuris canonici medii aevi. A shortlist of works, arranged by their incipit words [https://home.uni-leipzig.de/jurarom/manuscr/murano/initican.htm]).

Tit.: Secuntur Questiones mercuriales d. Io. An. disputate super regulas iu. li. VI. - Inc.: Artat statutum doctores legentes et ut questiones disputatas ... - Expl.: ... An magistri composiciones librorum vel scriptorum sua nomina debeant in illis inscribere.

8 (289v) Bartholomaeus Brixiensis: Quaestiones dominicales, De conditionibus appositis, qu. 1, unvollständig (Druck: Köln 1570, 89).

Tit.: Questiones dominicales Bartho. Brixiensis. - Inc.: Quidam habens uxorem condempnatus de crimine capitali ... - Expl. mut.: ... si reddendus sit an sit decapitandus [

Lit.: Schulte GQ II 86.

$\left(290 \mathrm{r}-\mathrm{I}^{*} \mathrm{v}\right)$ leer.

P. K./U.S.

\section{Cod. 617}

\section{SAMMELHANDSCHRIFT}

Pap. I, 282 Bl. $220 \times 145$. Tirol (u. a. Neustift), T. I, II, IV: 7. Jz. 15. Jh. (u. a. 1467), T. III: 6. Jz. 15. Jh. (u. a. 1455)

B: Vier Teile: I (I, 1-54), II (55-116), III (117-199[200]), IV (200[201]-281[282]). Am oberen Blattrand Foliierung 19. Jh. durch die ULB Tirol; Fehler in der Zählung: 187 doppelt angeführt. Neuzeitliche orange Papiersignakel der ULB Tirol.

E: $\quad$ Gotischer Einband: rot gefärbtes Schafsleder über Holz mit Blindlinien. Tirol, 2. H. 15. Jh.

VD und HD: von dreifachen Blindlinien gebildeter Rahmen, im Mittelfeld ein durch zweifache Linien gebildeter innerer Rahmen, am VD dieser durch zweifache Linien diagonal in mehrere Rautenfelder unterteilt. Spuren von je fünf kleinen Beschlägen. Leder-Metall-Schließe. Am VD Titelschild (Perg.) Donatus misticus de octo partibus oracionis cum pluribus [...] und Signatur (?) N 10. Kanten gerade. Rücken: Leder tw. beschädigt, zwei Fitzbünde und vier Doppelbünde, im ersten Feld Pergamentschild $M$ : S: de Oratione devota, im zweiten Pergamentschild $a$ (?) Sermones Festivales, im dritten Signaturschild (s. bei G). Am Spiegel des VD Pergamentmakulatur (s. bei Inhalt), Exlibris und Signaturen (s. bei G), am Spiegel des HD Reste urspr. aufgeklebter Pergament- und Papierblätter sowie Abklatsch.

G: $\quad$ Besitzvermerke 15. Jh.: Bl. Ir Iste liber est monasterii s. Marie virginis ad gracias alias ad Novacellam dicti; Bl. 281v Iste liber est monasterii s. Marie in Novacella, darunter in Textura Iste liber est monasterii s. Marie in No. Am Spiegel des VD Exlibris der Stiftsbibl. Neustift 18. Jh. 1809 anlässlich der vorübergehenden Aufhebung des Klosters Neustift der ULB Tirol übergeben. Am Spiegel des VD alte Signaturen der ULB Tirol II [...] (radiert, Tinte), II $\overline{3} D 3$ (Bleistift) sowie 617 (Tinte). Am Rücken gelbes Signaturschild der ULB Tirol 617. Bl. 1r Stempel der ULB Tirol 19. Jh. 1921 aufgrund des Friedensvertrages von St. Germain an den italienischen Staat abgegeben und von diesem 1929 dem Kloster Neustift als Dauerleihgabe überlassen. Bl. 1r Stempel der Soprintendenza Tridentina 20. Jh.

L: $\quad$ Wilhelm II 108. - Kristeller I 439. - Kaeppeli Nr. 146. - Hamesse Nr. 5333. - Stefani 114-115. - Katalog ULB Tirol VII 102, 484. - Krämer, Scriptores, s. v. „Fresell, Jacobus“.

$$
\text { I (I, 1-54) }
$$

B: Bilder und Nachweise der Wasserzeichen s. WZMA. Wasserzeichenbefund mit Datierung übereinstimmend. Identische Wasserzeichen in T. IV. Lagen: $1^{1}$ (Vorsatzbl.) + 4.VII $+(\mathrm{VI}-6)^{54}$. Gegenbl. zu Bl. 50-53 herausgeschnitten (ohne Textverlust). In den Lagenmitten Papierfälze. Gegenfalz zum Spiegel des VD sowie zu Bl. I zw. Lage 1 und 2. Lagensignaturen $(a 1, a 2, \ldots)$, tw. weggeschnitten. Lagenreklamanten. 
S: $\quad$ Schriftraum $140 \times 90$, von Blindlinien gerahmt, zu 30 Zeilen. Bastarda, dat. 1467 (Bl. 53r). Schreiber: Iacobus Fresell de Scocia, vgl. Krämer, Scriptores.

A: Rote Auszeichnungsstriche, Unterstreichungen und Überschriften sowie zweizeilige Lombarden. Repräsentanten.

1 (VDS) Fragment eines Psalteriums: Ps 105,7-21.

Schriftraum beschnitten, von Tintenlinien gerahmt, zu 23 Zeilen auf Zeilenlinierung. Textualis formata (Textura) Ende 13./Anfang 14. Jh. Rote Satzmajuskeln am Versbeginn. Mittig von Exlibris der Stiftsbibl. Neustift überklebt.

Inc. mut.: ] noster in universa terra iudicia eius ... - Expl. mut.: ... sue et principem omnis [

(Ir) Inhaltsverzeichnis und Besitzvermerk 15. Jh. (s. bei G).

(Iv) leer.

2 (1r-53r) Donatus Devotionis: De octo partibus orationis, Pars 1 (Druck: J. Rastell, Donatus devotionis de octo partibus orationis. London o. J. [um 1515]. - Bloomfield Nr. 8301 und 8731).

(1r) Tit.: Incipiunt octo partes oracionis devote secundum ordinem Donati grammatici.

(1r) Prolog. Inc.: Evangelica clamat hystoria. Sine intermissione orate hoc est semper quidem orat qui semper bene agit ... - Expl.: ... quod hec oracioni commendacio stet pro huius tractatus sequentis prologo et prohemio.

(2r) Inhaltsübersicht. Tit.: Capitula prime partis huius Donati oracionis.

(2v) Text. Inc.: Partes oracionis quot sunt? Octo. Que? Devocio lacrime dulcedo incendium ascensio meditacio contemplacio et languor. Devocio quid est ... - Expl.: ... et securitas eterne possessionis que ex eo et per eum habebuntur quam cognicionem eternaliter nobis concedat qui vivit et regnat in secula seculorum Amen.

(53r) Datierung und Schreibernennung: Explicit (korr. zu Expliciunt) octo partes oracionis devote scripte per Iacobum Fresell de Scocia primo die Iulii anno domini millesimo quadringentesimo sexagesimo septimo (1. Juli 1467).

Zur Überlieferung und zur Verfasserfrage s. A. I. Doyle, The European Circulation of Three Latin Spiritual Texts, in: A. J. Minnis (Hrsg.), Latin and Vernacular. Studies in Late-Medieval Texts and Manuscripts. Cambridge 1989, 129-146, hier v. a. 138-141. Vgl. auch Bibliothèque Nationale, Catalogue Général des manuscrits latins VI. Paris 1975, 319-320 zu Paris, BN, Ms. lat. 3593, B1. 1r; E. J. Devereux, Bibliography of John Rastell. Québec 1999, 95.

$(53 \mathrm{v}-54 \mathrm{v})$ leer.

$$
\text { II (55-116) }
$$

B: $\quad$ Bilder und Nachweise der Wasserzeichen s. WZMA. Datierung nach Wasserzeichenbefund. Lagen: 4.VI ${ }^{102}$ $+(\mathrm{VI}+2)^{116}$. Bl. 115 und 116 eingefügte Einzelbl. (mit Klebeband fixiert). Lagenreklamanten, tw. beschnitten. In den Lagenmitten beschriebene Pergamentfälze.

S: $\quad$ Schriftraum ca. $145 \times 100$, von Tintenlinien gerahmt, zu ca. 30 Zeilen. Bastarda.

A: Rote Auszeichnungsstriche, Unterstreichungen, Überschriften sowie drei- und vierzeilige Lombarden mit einfachem Dekor.

3 (55r-62v) Tractatus QuOMOdo Religiosus Proficere POSSIT IN RELIGIONE (Hamesse Nr. 5333).

(55r) Prolog. Inc.: Carissime frater. Vivatis in religione secundum doctrinam apostoli dicentis Sobrie et iuste et pie vivamus in hoc seculo expectantes beatam spem et adventum glorie magni Dei. In quibus verbis apostolus Paulus docet ... - Expl.: ... adventum glorie magni Dei non se habere credat per sentimenta et dulcedines sensibiles sed expectet.

(55r-62v) Text. Inc.: De primo est sciendum duplicem esse ebrietatem vitandam ... Secundo volens in religione proficere debet iuste cum fratribus vivere ... - Expl.: ... (Bl. 61r, mit Initiale letzter Abschnitt beginnend) Sobrie iuste et pie vivens ferventique zelo perseveranter et discrete 
ad perfeccionem tendens nec tamen credens se certe ipsam habere... huius caritatis affectus magnus inflammatur ut tandem homo ad perfeccionem quam tendit perveniat et vitam eternam obtineat Amen.

4 (63r-116v) «Nicolaus Kempf de Argentina»: Tractatus de proponentibus religionis ingressum et de anno probationis (Hauréau, Initia App. I 107).

(63r) Pars 1: 31 Kapitel.

Tit.: Capitulum primum. - Inc.: Convertimini ad me et salvi eritis. Ysaie (45) 22. Quamvis divina miseracio multis variisque modis in scripturis sanctis omnis vocare dignata est ... - Expl.. ... qui suum propositum roboravit spiritu sancto et trinitate unus Deus in seculum benedictus Amen. Explicit prima pars huius tractatuli.

(95v) Pars 2: 23 Kapitel.

Inc.: Novicius indutus quantocius potest in generali confessione se expediat in qua non sit nimis scrupulosus ... - Expl.: ... Numquid iterum post veteres declinaciones mores et conswetudines. Deo Gracias.

Zur reichen Parallelüberlieferung vgl. D. D. Martin, Kempf, „Nikolaus von Straßburg“. Verfasserlexikon² IV 1119.

$$
\text { III (117-199[200]) }
$$

B: $\quad$ Bl. 117 Riss. Bilder und Nachweise der Wasserzeichen s. WZMA. Wasserzeichenbefund mit Datierung übereinstimmend. Lagen: 7.VI ${ }^{199(200)}$. In den Lagenmitten beschriebene Pergamentfälze. Lagenreklamanten.

S: $\quad$ Schriftraum $165 \times 120$, von Tintenlinien gerahmt, zu 32 Zeilen. Bastarda, dat. 1455 (Bl. 134r und 191v [18. April]). Schreiber: Erasmus Lämpl (Bl. 134r und 191v), Chorherr in Neustift, vgl. Giner 10.

A: Rote Auszeichnungsstriche, Unterstreichungen, Überschriften und zweizeilige Lombarden. Repräsentanten.

5 (117r-134r) RABBI SAMUEL, ins Lat. übersetzt von Alfonsus Bonihominis: Epistola ad Rabbi Isaac (Kaeppeli Nr. 146 mit Angaben zur reichen Überlieferung, mit Nennung der Hs.). Abgeglichen mit GW M39838, gegenüber Druck tw. gekürzt, tw. leicht abweichend.

(117r) Tit.: Incipit disputacio Iudeorum cum ipsis Christicolis. 26 Kapitel.

(117r) Prolog. Inc.: Reverendissimo in Christo patri fratri Hugoni magistro ordinis fratrum Predicatorum dignissimo ac sacrosancte pagine professori. Eius subditus frater Alfonsus Bonihominis Yspanus promissam obedienciam ... - Expl.: ... per te Deo volente in veritate confirmari et in dubiis declarari.

(117v) Text. Cap. 1-26. Inc.: Desidero domine mi certificari per te ex testimoniis legis et prophetarum et aliarum scripturarum ... - Expl... ... contra dictum et eius scripturam docuit ut corruptus homo penitus et ignorans.

(134r) Schlussschrift mit Schreibernennung und Datierung: Explicit epistula magistri Samuelis missa ad Rabbi Ysaac magistrum sinagoge. Excerptus per Erasmum Lämpel in Ässnigk (Assling?) plebanum anno 1455.

6 (134v-193v) Sermones de SAnctis et de tempore, u.a. 〈Peregrinus Oppoliensis〉: Sermones de sanctis (Schneyer 4, 559-570 [Nummern - wenn nicht anders angegeben - im Folgenden darauf Bezug nehmend]).

Tit.: Sermones de sanctis.

(134v) De s. Andrea (Nr. 196). Expl.: ... et viginti milia hominum sua predicacione convertit. Ecce (?) quam viriliter etc. - (135r) De s. Nicolao (Nr. 198).

(136r) Tit.: De sancto Thoma. - Inc.: Affer manum tuam in latus meum. Ioh. 20 (27). Benigni homines habent modum dum vident aliquem carum amicum cecidisse in aliquam passionem solent eos instruere ... - Expl.: ... sine mortalibus existentibus. Rogemus. 
Parallelüberlieferung: Neustift, Stiftsbibl., Cod. 78, Bl. 8vb (Entstehungsort: Raum Brixen [Neustift?], 1. H. 15. Jh.); Innsbruck, ULB Tirol, Cod. 71, B1. 21rb (Vorbesitzer: Wilten, Entstehungsort: Tirol, 15. Jh.), Cod. 207, Bl. 5va (Vorbesitzer: Schnals, Entstehungsort: Österreich, dat. 1440, Schreiber: Christianus de Engelprecz).

(136r) Tit.: In nativitate domini. - Inc.: Parvulus natus est nobis. Ys. (9,5). Circa nativitatem domini tria notantur. Primo natus describitur secundo nativitatis tempus tercio nativitatis utilitas. De primo sciendum quod fuit natus admirabilis ineffabilis formidabilis venerabilis ... Expl.: ... faciat nos tanti gaudii participes quod nobis prestare dignetur.

(136v) De s. Stephano (Nr. 204). - (137r) De s. Iohanne ap. (Nr. 207). Expl. (geringfügig erweitert): ... perseveravit in fide Christi ut vicissitudinem amicicie Christi proposse daret. Rogemus ergo (Expl. wie Neustift, Stiftsbibl., Cod. 78, Bl. 15vb). - (137v) De s. Innocentibus (Nr. 208). Expl.: ... quia nomen patris eius scriptum est in frontibus eorum scilicet quod vocabuntur filii Dei in eternum.

(138v) Tit.: In circumcisione domini. - Inc.: Circumcisionis dies est solemnis quia octavus nativitatis Christi est. Voluit autem dominus die octava circumcidi unde Rabi Moyses philosophus et theologus licet Iudeus ... - Expl.: ... unde hec dies novus annus dicitur.

(139r) Tit.: In epiphania domini. - Inc.: Cum natus esset Ihesus in diebus Herodis regis etc. (Mt 2,1). Hodie triplex festivitas celebratur. Una est de adoracione magorum ... - Expl.. ... scilicet virtutum revertamur ad penitenciam celestem Amen.

(139v) In conversione s. Pauli (Nr. 216). Expl. (leicht abweichend): ... quod lac fluxit loco sanguinis de corpore suo. (Expl. wie Neustift, Stiftsbibl., Cod. 78, B1. 23va). - (140r) In purificatione BMV (Nr. 217). Expl. (leicht erweitert): ... ipsa stat pacem et veniam obtinendo petimus et graciam impetrando. Rogemus etc. - (141r) In cathedra s. Petri (Nr. 220). Expl.: ... et in Romana kathedra sedit annis XV. - (142r) De s. Matthia (Nr. 222). Expl.: ... et ei devotissime servivit.

(143r) Tit.: De commendacione ieiunii. - Inc.: Adest tibi venerabile tempus Quadragesime ... Expl.: ... Qui se in paupere esurire testatur. Rogemus etc.

(144r) De s. Gregorio (Nr. 126). Expl. (leicht abweichend): ... Ultima felicitas quam recepit est visio Dei quam ipse recepit que in celis finitur ad quam perducat nos etc. - (145r) In annuntiatione BMV (Nr. 228). Expl.: ... quis hominibus placeret. Respondit Si gesseris optima et locutus fueris pauca. Rogemus. (146v) Nr. 230. Inc. (geringfügig abweichend): Egredietur virga de radice Yesse. Ys. (11,1). Legitur de quinque virgis laudabilibus per quas beata virgo Maria merito figuratur ... (147r) Nr. 229. Inc. (leicht abweichend): Fons crevit in flumen magnum. Hester VI (recte: 10,6). Ibi dic historiam qualiter Mardocheus sompniavit duos dracones ...

(148r) 〈GRAECULUS〉: Sermo in annuntiatione BMV (Schneyer 2, 227, Nr. 267). Tit.: De eadem. (149r) Tit.: In die palmarum. - Inc.: Quadruplex agitur festum in hac septimana scilicet festum veneracionis festum recreacionis festum reconciliacionis ... - Expl.: ... Christus a morte resurgens discipulus ianuis clausis potuit apparere vel sicut virginis uterum ingrediens etc.

(150r) 〈Leo OCist.>: Speculum corporis Christi sive Dialogus increduli et ecclesiae de sacramento eucharistiae (Schneyer 4, 40, Nr. 369, hier ohne Prolog). Tit.: Incipiunt dicta Leutoldi sublectoris Bienne que intitulantur Speculum de corpore Christi.

(163v) Tit.: Sermo in die parasceves. - Inc.: Rex David cooperto capite etc. (?) R. (CAO Nr. 4650). Historia hec est de David quomodo planxit filium suum Absolon. Historia nota est scilicet quid significat ... - Expl.: ... audiamus illam dulcissimam vocem et vocacionem. Venite benedicti etc. quod ipse prestare dignetur.

(165r) De s. Georgio (Nr. 234). Expl. (geringfügig erweitert): ... a dracone cum XX $X^{t i}$ milibus qui conversi sunt ad dominum. - (166v) De s. Philippo et Iacobo (Nr. 238). - (167v) In inventione s. crucis (Nr. 239). Expl.: ... et quanta passus sit pro te et omnia erunt tibi dulcia.

$(168 v)$ Tit.: In diebus rogacionum. - Inc.: Omnis qui petit accipit etc. Ioh. (recte: Mt 7,8 oder Lc 11,10). In verbis istis notandum quod ad impetrandum salutaria $4^{\text {or }}$ oportet considerare 
videlicet a quo sit petendum quid sit petendum qualiter sit petendum quando sit petendum ... Expl.: ... Expelle eos quoniam irritaverunt te domine.

(169r) Tit.: De eodem. - Inc.: Petite et accipietis. Luc. IX (recte: 11,9). In hiis verbis notandum est quod sex sunt que invitant nos ad petendum ... - Expl.. ... Sextus gradus est quod solem suum facit oriri super bonos et malos.

(170r) Tit.: In domini ascensione. - Inc.: Quo abiit dilectus tuus o pulcherrima mulierum. Can. VI (1). In hiis verbis tria videnda sunt scilicet que sit dilecta quis sit dilectus quo et quomodo abiit. Circa primum sciendum quod dilecta est beata virgo ... - Expl.: ... Vado parare vobis locum ad hunc locum nos perducere dignetur.

(171r) Tit.: De eodem. - Inc.: Non est vir in domo sua abiit via longissima secum tulit sacculum pecunie in die plene lune reversurus Prover. VIII (recte: 7,19-20). Verba proposita possunt esse interioris hominis id est anime respondentis ad questionem sibi factam ... - Expl.: ... super malos maledicendo dicens Ite maledicti.

(172r) Tit.: De sancto spiritu. - Inc.: De excelso misit ignem in ossibus meis et erudivit me R. (Lam 1,13). Quantum ad presentem festivitatem possunt hec verba esse matris ecclesie ... Expl.: ... de iudicio quod non timuerunt ad quam iusticiam nos perducat.

(173r) Tit.: De corpore Christi. - Inc.: Accipite et manducate ex hoc omnes (vgl. Mt 26,26; 1 Cor 11,24). Bene fit illi homini qui hunc panem digne et recte manducat ... - Expl.. ... ad omnia opera bona insuper illo die cicius exauditur.

Vgl. Zwettl, Stiftsbibl., Cod. 115, Bl. 12r.

(173v) Tit.: De eodem. - Inc.: Rex Assuerus tercio anno imperii sui fecit grande convivium cunctis principibus et pueris suis et vocavit omnem populum qui inventus est in Susia Hester primo (3). Per hoc convivium Veteris Testamenti figuratum est nobis convivium a Christo hodie institutum sacri corporis et sanguinis sui ... - Expl.: ... digne et devote in hospicio cordis sui locaverit benediccionem eternam obtinebit.

(174r) De s. Iohanne Baptista (Nr. 245). Expl.: ... a puericia crevisse in heremo. Rogemus.

(175v) Tit.: De sancto Petro apostolo. - Inc.: Petre amas me. Tu scis domine quia amo te Mt. (recte: Ioh. 21,17). Dicit beatus Iohannes in suo ewangelio quod dominus interrogavit beatum Petrum de sua dileccione dicens ... - Expl.: ... Ecce quanta passus est beatus Petrus propter amicum suum Christum.

(176v) De s. Margareta (Nr. 252). - (177v) De s. Maria Magdalena (Nr. 254). - (178v) De s. Iacobo (Bibelzitat und Expl. wie Nr. 257). Inc.: Dic ut sedeant hii duo filii mei etc. Mt. 20 (21). Filius Dei volens loqui Iudeis dixit hec verba que eciam ego possum dicere. Mea doctrina non est mea sed eius ... - (180r) De s. Petro ad vincula (Nr. 149). Expl.: ... et regni eius non erit finis (Expl. wie Neustift, Stiftsbibl., Cod. 78, Bl. 72ra). - (181r) In assumptione BMV (Nr. 265). Expl.: ... honorificentia populi populi (!) mei scilicet generis humani.

$(182 v)$ Tit.: De eodem festo. - Inc.: Extendit Noe manum et comprehensam columbam in archam intulit. Gen. (8,9). Hic tria possunt notari scilicet Marie assumpcio cum dicitur Extendit Noe manum $2^{\circ}$ festivitas venerabilis Marie cum dicitur Apprehensam columbam $3^{\circ}$ assumpcionis securitas cum dicitur In archam ... - Expl.: ... et scio quia voluntas non abest cum sis mater misericordie obtine nobis graciam filii tui ut a te non separemur.

(183r) Tit.: Bartholomei apostoli. - Inc.: Percusserunt me et vulneraverunt me custodes murorum. Cant. V (7). In verbis propositis notatur triplex martirium quod suscipit beatus Bartholomeus fuit enim fustigatus deinde vivus excoriatus postremum decollatus ... - Expl.: ... non vult cognoscere celi gaudia et penas inferni.

Parallelüberlieferung: München, UB, fol. 64, Bl. 241rb.

(184v) De s. Augustino (Nr. 272). Expl.: ... sic ipse fugat tenebras infidelitatis. Rogemus etc. (186r) In nativitate BMV (Nr. 276). 
$\left(187^{\mathrm{I}} \mathrm{r}\right)$ Tit.: In exaltacione crucis. - Inc.: Ego dominus exaltavi lignum humile et humiliavi lignum sublime Ezech. $(17,24)$. In hiis verbis agitur de duobus lignis. Primo de ligno salvacionis in quo homo fuit vivificatus ... - Expl.: ... ergo ut congregemur. Rogemus dominum etc.

$\left(187^{\mathrm{I}} \mathrm{v}\right)$ Tit.: De sancto Matheo apostolo. - Inc.: Sequere me. Mt. 9 (9). In illo ewangelio duo notantur scilicet dignitas vocantis cum dicitur Sequere me ... - Expl.: ... quia omnes fideles Christus toto corde semper dilexit. Rogemus etc.

$(187 \mathrm{v})$ De s. Michaele et de s. angelis (Nr. 286). Expl.: ... a nobis sunt honorandi. Rogemus etc. (188v) Tit.: Simonis et Iude. - Inc.: Nimis honorati sunt amici tui Deus Ps. (138,17). Dicitur vulgariter Bonum ferrum trahit homini argentum de bursa ... - Expl.. ... dicit propheta Nimis honorati sunt amici etc.

(189r) Tit.: De omnibus sanctis. - Inc.: Gaudete et exultate omnes sancti quoniam merces vestra multa est in celo Mt. (recte: Lc 6,23). Verba proposita leguntur in ewangelio hodierno et per ea insinuatur nobis gloria premium omnium sanctorum quorum hodie festivitas celebratur ... Expl.: ... Ideo debemus hunc diem sermone honorare. Rogemus ergo dominum ut per intercessionem omnium sanctorum suorum perducat nos ad gaudia sine fine permansura.

Parallelüberlieferung: Innsbruck, ULB Tirol, Cod. 443, Bl. 131rb.

(190r) Tit.: De animabus. - Inc.: Animas pauperum tuorum ne obliviscaris in finem Ps. $(74,19)$. Notandum quod quintuplex est anima scilicet anima inmunda anima rapta anima sepulta anima salvata anima cruciata ... - Expl.: ... absolvunt animas quas purgans detinet ignis de hiis require in Peregrino de sanctis.

(190v) De s. Martino (Bibelzitat und Inc. wie Nr. 174). Expl.: ... et reliquam partem induit sequenti nocte vidit celum apertum et Christum etc. ibi dic legendam.

$(191 v)$ Tit.: De sancta Katherina. - Inc.: Inspice et fac secundum exemplar quod tibi in monte monstratum est (Ex 25,40). Nota quod Deus duo genera sanctorum habet in celo quosdam abscondit a nobis et quosdam nobis monstravit ... - Expl.: ... et cum sponso suo in eternum valemus conregnare Amen.

(191v) Schlussschrift mit Schreibernennung und Datierung: Explicit per Erasmum Lämpl canonicum Novecellensem et plebanum in Ässnigk in die Clavorum et Lancee anno $L^{\text {mo }}$ quinto (18. April 1455).

7 (194r-195r) 〈Iohannes Contractus»: Sermo de s. Andrea (Schneyer 3, 439, Nr. 88, zu München, BSB, Clm 3420). Expl.: ... deterremur et tamen vocantem sequi contempnimus.

Darunter Federproben:

1) Vermerk: Accipe o homo exemplum qui es in periculis huius mundi a sancto Andrea ... ad primam vocem omnibus relictis eum sequebatur.

2) Alphabet.

3) Notizen: Venerabilis domine $N$. Vos misistis ad me pro Amigdalis ego deberem nos providere cum Amigdalis ego locutus sum cum domino N. - Benedictum sit dulce nomen domini mei Ihesu Christi et gloriosissime virginis Marie matris eius in seculum et ultra nos cum prole pia benedicat virgo Maria. Benedictum.

(195v) nur Rahmung.

8 (196r) Exzerpt aus 〈Robertus Holcot〉: Commentarius in librum Sapientiae, cap. 3, lectio 31, art. 1 (Druck: u. a. GW 12884. - Stegmüller RB Nr. 7416. Kaeppeli Nr. 3497).

[A]brahe sinus dicitur requies sanctorum qui olim fuit limbus nunc est celum et sic orat ecclesia sinus te suscipiat.

(196v-199v) nur Rahmung. 
IV (200[201]-281[282])

B: $\quad$ Bilder und Nachweise der Wasserzeichen s. WZMA. Datierung nach Wasserzeichenbefund. Identische Wasserzeichen in T. I. Lagen: 3.VI ${ }^{235(236)}+\mathrm{V}^{245(246)}+3 . \mathrm{VI}^{281(282)}$. Lagenreklamanten. In den Lagenmitten beschriebene Pergamentfälze. Zw. vorletzter und letzter Lage Reste eines Papierfalzes, wohl zum urspr. als Spiegel auf dem HD aufgeklebten, herausgerissenen Blatt gehörig.

S: $\quad$ Schriftraum $160 \times 105$, von feinen, tw. kaum sichtbaren Tintenlinien umrahmt, zu 34 Zeilen. Bastarda.

A: $\quad$ Platz für zweizeilige Lombarden freigelassen. Lediglich Bl. 205v-207v, 218v-220r, 227v-229r, 250v-253r und 277v-280r rubriziert: Auszeichnungsstriche, Unterstreichungen, Notizen, Abschnittszählungen. Bl. 201v Zeigehand. Satzmajuskeln und einzelne Buchstaben der ersten Zeilen tw. gelängt.

9 (200r-280r) 〈Servasanctus de Faenza〉: Sermones (Schneyer 5, 388-391).

(200v) De apostolis (Nr. 193). Expl.: ... et que sunt infra nos mundum. Rogemus igitur omnipotentem. (202v) Nr. 194. (205v) Nr. 195. (207v) Nr. 196. - (210v) De evangelistis (Nr. 198). (212v) Nr. 199. - (214r) De uno martyre (Nr. 200). (217r) Nr. 201. (218v) Nr. 202. (220r) Nr. 203. (222r) Nr. 204. - (223v) De pluribus martyribus (Nr. 205). (226r) Nr. 206. (227v) Nr. 207. (229r) Nr. 208. (231r) Nr. 209. - (233v) De uno confessore (Nr. 210). (236v) Nr. 211. (239r) Nr. 212. (241r) Nr. 213. (243v) Nr. 214. - (246r) De pluribus confessoribus (Nr. 215). (248v) Nr. 216. (250v) De uno confessore (Nr. 217). (253r) Nr. 218. - (256v) De una virgine (Nr. 219). (258r) Nr. 220. (260r) Nr. 221. (261v) Nr. 222. (263v) Nr. 223. Expl.: ... quibus carui dum ista dictarem Valete fratres et orate pro me dominum nostrum Ihesum Christum. (267v) Nr. 188 bzw. Schneyer 7, 643, Nr. 9, zu Köln, Stadtarch. GB, fol. 146. Expl.: ... Sic paupertatem amare sic obedire etc. (= Expl. Schneyer 7, 643, Nr. 9). (269v) Nr. 191. (271v) Nr. 197. Expl.: ... confundit animam. (274v) De BMV (Nr. 224). (277v) Nr. 225. (279v) Nr. 226. Expl.: ... scias te esse vacuum et non plenum etc. Amen. Deo gracias.

(280v-281r) nur Rahmung.

(281v) Besitzvermerke (s. bei G).

U.S.

\section{Cod. 654}

LIBER HORARUM, Bd. 2 (zusammengehörend mit Cod. 353)

Perg. II, 207, I* Bl. $165 \times 120$. Raum Brixen, 1496.

B: $\quad$ Regelmäßiges Perg., sehr vereinzelt kleine Löcher und Nahtspuren. Lagen: (I-1) ${ }^{\mathrm{I}}$ (Vorsatzbl., Pap. 20. Jh.) $+(\mathrm{I}-1)^{\mathrm{II}}+\mathrm{VI}^{10 \mathrm{a(12})}+8 \cdot \mathrm{V}^{90(92)}+(\mathrm{V}-1)^{99(101)}+(\mathrm{V}-1+1)^{109(111)}+9 . \mathrm{V}^{197(201)}+(\mathrm{IV}-2)^{203(207)}+(\mathrm{I}-1)^{\mathrm{I}^{*}}$ (Nachsatzbl., Pap. 20. Jh.). Gegenbl. zum Vor- bzw. Nachsatzbl. als Spiegel auf dem VD bzw. HD aufgeklebt. Gegenbl. zu Bl. II, 91, 100, 199 und 200 herausgeschnitten (ohne Textverlust). Bl. 109 eingehängtes Einzelbl. Am oberen Blattrand zeitgenössische rote Foliierung in arabischen Ziffern von 1 bis 202, anschließend ein ungezähltes Bl. (ursprünglich wohl als Spiegel am HD aufgeklebt), Fehler in der Zählung: 7 und 119 doppelt angeführt, zw. Bl. 10 und 11 sowie zw. Bl. 191 und 192 jeweils ein ungezähltes Blatt.

S: $\quad$ Schriftraum $110 \times 70$, von zweifachen roten Tintenlinien gerahmt, zu 17-19, größtenteils einheitlich 19 Zeilen auf feiner Bleistift-, tw. Blindlinierung. Zirkelstiche. Kalligraphische Bastarda (auffällig gelängte Initialmajuskeln, Unterlängen und Kürzungsstriche, bisweilen i-Punkte in Kreisform), dat. 28. Juli 1496 (Bl. 202r). Schreiber: Georg Hölzl aus Mattighofen, vgl. Krämer, Scriptores.

A: Rote Auszeichnungsstriche, (Zwischen-)Überschriften, Interpunktionszeichen, Unterstreichungen, Zeilenfüllsel (Bl. 133r, 144v); wenige rote und blaue Paragraphzeichen. Bis Bl. 119r ein- bis sechszeilige Lombarden, abwechselnd hell-/dunkelrot und blau, mit Punktverdickungen bzw. gestielten Punkten; Bl. 16v Lombarde nicht ausgeführt. Repräsentanten.

Deckfarbenschmuck: 18 vier- bis siebenzeilige ornamentale Initialen mit Ranken; 26 ganzseitige (Schriftspiegelgröße) rankenlose Miniaturen, die ab Bl. 122r in drei gleiche, querrechteckige Felder untergliedert 
sind (Bl. 144r oberes und unteres Register zusätzlich in zwei quadratische Felder unterteilt), sodass sich, einschließlich des Kruzifixes B1. 93v, insgesamt 60 Bilder ergeben.

Die Ornamentalinitialen (Bl. 1r, 16r, 34r, 52r, 67r, 91r, 94r, 100r, 110r, 117r, 123r, 133r, 144v, 155r, 165v, $179 r, 188 v, 198 v)$ mit meist annähernd quadratischen, durch Konturlinien gerahmten Initialfeldern; Buchstabenkörper in der Regel mit großformigen Blattranken gefüllt; Bl. 117r etwas filigranere Initiale mit Ausläufer (Achterschlinge); folgende Binnenfeldgestaltungen in Deckfarbe: geometrische Muster, gegenständige Blattpaare, typisch das aus dem Federzeichnungsdekor der Zeit übernommene Motiv der aneinandergereihten Kopfstempel, die als Negativformen blattartige Gebilde entstehen lassen (z. B. Bl. 188v; vgl. auch Brixen, Priesterseminarbibl., Cod. C.8); B1. 165v Binnenfeldblätter mit „Erbsenschotenmotiv“ und B1. 91r, 100r, 110r, 155r Perlreihen, die von den Füllblättern des Buchstabenkörpers umschlossen werden. - Die Akanthusranken (mit variierenden Blattformen, u. a. mit tropfenförmig verdickten Adern) ohne Kontakt zur Initiale, meist um die untere rechte Blattecke gelegt, dabei in der Ecke eine goldgefüllte Schlinge ausbildend; als Dekor Goldpunkte, auch frei (mit meist rotem Federzeichnungsdekor), bisweilen Fadenranken; als Randschmuck auf einigen Folios naturalistische Zweige, die recht grob gemalt sind: Bl. 52r Distel, 91r Glockenblumen (?), 94r Akelei (?), 110r Erdbeeren, 117r Heckenrosen; Bl. 34r Akanthusranke mit naturalistischen Anschnitten. - Zur Gestaltung von Initialen (Buchstabenkörper und Binnenfelder) und Ranken s. auch Cod. 353.

Die Rahmen der Miniaturen in Gold oder Deckfarbe (einfarbig sowie verschiedenfarbige Abschnitte im Wechsel) mit Kontur- und Gehrungslinien; B1. 15v sowie Cod. 353, Bl. 93v, zusätzlich mittig an den Rahmenleisten Goldpunkte mit roter Federzeichnungszier (Fadenbündel mit Fibrillen); diese, in üppiger Ausformung, auch am Kruzifix Bl. 93v. In die ganzseitigen Miniaturen sind tw. Architekturrahmen eingeschrieben (Rundbogen, fallweise mit Zwickelblättern, Knospenkapitellen und -basen); in Cod. 654 werden auch durch die architektonischen Gegebenheiten (Bogen, Säulen, Durchgänge) Rahmungen geschaffen, die die Einzelfelder untergliedern. Hintergründe: nur selten Teppichgründe (rosafarben mit groben, karminroten Ranken; B1. 11v und 144r unten rechts) und Goldgrund (v. a. für die Marienfiguren, s. B1. 109v sowie Cod. 353, Bl. 130v; zu Punzierungen s. u. und Cod. 353); häufig nackte Mauerflächen (rosafarben oder grau); gerne auch Landschaftshintergründe (Fensterausblicke), diese simpel und mit wenigen Details angelegt, zu denen kleine Boote auf den Seen bzw. Flüssen gehören; etwas aufwändiger allerdings Bl. 15v, 177v (Mitte), 178r (oben) sowie Cod. 353, Bl. 54v, 70v; Wolken als ondulierende Bänder dargestellt; charakteristisch die Vogelformationen in helleren Himmelszonen; Vegetation der grünen Hügel nur durch horizontale Strichelung angedeutet, auch die meist breitblättrigen Pflanzen im Vordergrund eher grob, nur wenige Blumen differenzierter dargestellt (z. B. Bl. 177v oben und Cod. 353, Bl. 130v: Maiglöckchen). - Figuren mit uniformen Gesichtern (lange, zuweilen etwas klobige Nasen, kleine, rundliche Münder mit leicht nach unten gezogenen Mundwinkeln und rundbogige Augenbrauen), rosigem Inkarnat und einfachen, aber lebhaften Haarstrukturen (Marienfiguren mit langem, gewelltem Blondhaar); größere Heiligenscheine (v. a. von Gottvater und Christus) als Kreuznimben, das Kreuz in Rot eingetragen, tw. ergänzt durch Strahlenkranz (helleres Malmittel); Körper von Draperien verhüllt, deren Faltenwürfe durch lapidare Schattierungen, Schraffen und Höhungen herausgearbeitet sind, z. B. Schutzmantel-Madonna, Bl. 116v; Maria Magdalena stets mit zweifarbiger, turbanartiger Kopfbedeckung; ungelenke Anatomie des Gekreuzigten (Gliedmaßen im Verhältnis zum Rumpf zu kurz, tordierte Beine), der im Vergleich zum Kreuz meist zu klein angelegt ist, z. B. Bl. 93v; sein Lendentuch häufig abflatternd dargestellt. - Perspektivische Unsicherheiten, z. B. Bl. 144r (Mitte) die Fluchtlinien der Seitenwände; auch Einrichtungsgegenstände perspektivisch uneindeutig in das Raumgefüge eingezeichnet, z. B. die Pulte, auf denen jeweils ein aufgeschlagenes Buch liegt. Buntfarbiges Kolorit u. a. mit klarem (Kobalt-)Blau und charakteristischem Gelbgrün, u. a. für Holzflächen; gerade von Gesichtern Deckfarbenschicht immer wieder abgeplatzt, z.B. Jesus, Bl.153v (Mitte) oder auch Brust des rechten Schergen und Gesicht Jesu, Bl. 164v (oben); Blattgold nur wenig abgerieben, z. B. Binnenfeld der Ornamentalinitiale Bl. 67r, hier lachsroter Bolus sichtbar.

Bl. $11^{\mathrm{I}} \mathrm{v}$ Allerheiligen: Heiligenschar; in der vordersten Reihe (von links nach rechts): Katharina (Schwert und Bruchstück eines Rades), Andreas (X-Kreuz), Petrus (Tiara und Schlüssel), Sebastian (Pfeil) und Benedikt (Stab und Nuppenglas).

B1. 15v Auftraggeber-Bildnis: Junger, blondgelockter Mann in schwarzem, pelzbesetztem Mantel, wohl Kaspar Neuhauser, kniet mit gefalteten Händen und mit Gebetsschnur vor Christus an einem hohen Kreuz, das in einer Landschaft (von kleinen Städten übersäte Ebene und See oder Fluss vor einer Bergkette) aufgestellt ist; Gekreuzigter mit gelbgrünem Lendentuch. Am oberen Rand des Himmels Textabklatsch von Bl. 16r; über den Schwalben gelbe stilisierte Wolken (?).

Bl. 33v Armenseelenbild: Auf einem Friedhof kniet betend ein junger, blondgelockter Mann (mit schwarzem Umhang und roten Hosen) vor dem Beinhaus, während aus mehreren Gräbern mit Dreschflegel, Pfeil und Bogen, Schere etc. ausgestattete Skelette entsteigen, sich ihrer Leichentücher entledigen und bewaffnete Angreifer verjagen; neben dem Beinhaus, an dem außen ein Weihwasserkessel (mit Aspergil) angebracht ist, Kirche mit grünem Dach, Maßwerkfenstern und -rosette sowie Portal mit beschlagwerkartigen Verzierungen. - 
Dargestellt ist die Rettung eines von Feinden bedrohten Beters durch die Armenseelen, die ihm aus Dankbarkeit für sein Gebet zu Hilfe eilen (s. Wieser).

Bl. 51v In einem Kirchenraum mit blauem, von weißen Kreisen übersätem Rippengewölbe und Maßwerkfenstern sitzen drei Kleriker, vor denen (mit dem Rücken zu ihnen) ein Büßer, möglicherweise Kaspar Neuhauser, mit entblößtem Oberkörper auf dem nackten Steinfußboden kniet und eine brennende Kerze vor sich hält.

Bl. 66v (vgl. Bl. 33v) Auf einem Friedhof beten ein junger, blondgelockter Mann (in langem, schwarzem Gewand) und eine Frau (mit Rise und schwarzem Kleid), vermutlich Kaspar Neuhauser und seine Gemahlin, die eine Tochter von Michael Pacher war (s. C. Fischnaler, Die Erben Michael Pachers. Zeitschrift des Ferdinandeums für Tirol und Vorarlberg 37 [1893] 359-361). Der Mann kniet vor dem Beinhaus, die Frau im Vordergrund, tw. von der Kirchhofmauer verdeckt; zw. ihnen Gräber und Gebeine; beide Eheleute mit Gebetsschnüren; neben dem Beinhaus eine Kirche (ähnlich Bl. 33v, aber größer); sowohl an der Kirche als auch am Beinhaus Weihwassergefäß angebracht, auch neben der Frau ein Weihwasserkessel, jeweils mit Aspergil. B1. 93v Goldenes Kreuz mit den Evangelistensymbolen (jeweils mit Spruchband) in Medaillons (mit Dreipassbesatz) an den Kreuzenden (oben beginnend, im Uhrzeigersinn): Johannesadler, Markuslöwe, Lukasstier, Matthäusengel; große Goldpunkte in den Winkeln der Kreuzarme (zum Federzeichnungsdekor s. o.). Der Gekreuzigte mit weißem Lendentuch.

Bl. 109v Maria im Ährenkleid.

B1. 116v Schutzmantel-Madonna als Pestbild: Maria in goldenem Gewand versammelt unter ihrem blauen Mantel Frauen und Männer aller Stände (Papst und König deutlich erkennbar), die kniend beten. Im Himmel Gottvater mit Pfeil und Bogen als Symbole seines Zornes, der als Pest über die Menschen käme, wenn Maria sie nicht davor schützte.

Bl. 122r oben Zwei Engel mit blau-roten Flügeln verkünden Anna und Joachim die Geburt Mariens. - Mitte: Joachim umarmt Anna. - unten Geburt Mariens: Anna liegt mit Maria (als Wickelkind) im Bett und bekommt von einer Magd einen Teller mit Essen gereicht, das eine Köchin in der angrenzenden Küche zubereitet hat. B1. 122v oben der Tempelgang Mariens: Maria als Mädchen im Ährenkleid steigt betend eine Treppe empor, an deren Fuß ihre Eltern und oben ein Geistlicher (mit Bischofshut) stehen. - Mitte: Maria im Tempel (links sieht man sie diskutierend zw. zwei Jungfrauen, rechts lesend an einem Pult). - unten Vermählung Mariens: Bischof hält Josef und Maria, die ihn flankieren, jeweils an den Unterarmen; zwei Zeugen.

Bl. 132r oben Verkündigung (Engel, Schriftband AVE GRACIA PLENA um Säule geschlungen, Maria betend an einem Pult; über ihr die Taube, im Hintergrund grüner Vorhang). - Mitte Heimsuchung: Vor einem Haus mit rundbogigem Tor begrüßt Elisabeth Maria. - unten Geburt Christi: Im Stall, hinter dem Ochs und Esel hervorlugen, beten Maria und Josef (mit Kerze) kniend das auf dem Boden liegende, nackte Kind an. Bl. 132v oben Beschneidung Christi: Auf einem Holzthron ein greiser Priester; auf seinem Schoß das Jesuskind, das vom knienden Mohel kniend beschnitten wird; zwei Assistenzfiguren. - Mitte Anbetung der Heiligen Drei Könige: Vor dem Stall sitzt Maria mit dem nackten Kind auf dem Schoß; ihre Schattensilhouette zeichnet sich im Stallinneren ab; der dunkelhäutige König hebt seine Krone zum Gruß. - unten Darbringung Christi im Tempel: Neben dem Altar (mit gemustertem Tuch, darauf die Gesetzestafeln) links Frau und Priester mit dem Jesuskind, rechts Maria (mit gefalteten Händen) und Josef mit den Opfertauben.

B1. 143v oben links schläft Josef an einem Wangentisch; im Traum erscheint ihm ein Engel, der ihm befiehlt, mit seiner Familie zu fliehen; rechts stillt Maria das Kind. - Mitte: Flucht nach Ägypten. - unten Christus unter den Schriftgelehrten: links doziert Jesus von einem erhöhten Sitz herab, rechts steht er bei seinen Eltern.

Bl. 144r oben links Maria spinnend; rechts Josef als Zimmermann bei der Arbeit (Vermessen?), bei der ihm Jesus hilft (auf dem Boden Beil und Farbtopf?); deutliche Risse in der Mauer im Hintergrund. - Mitte: Josef, Jesus (als Jüngling) und Maria bei Tisch. - unten: links kniet Jesus betend vor einem Pult, rechts sitzt Maria lesend an einem Pult.

Bl. 153v oben Taufe Jesu im Jordan: am Ufer ein Engel mit den Gewändern Jesu. - Mitte Versuchung Jesu: flankiert von kahlen Bäumen Jesus und der Teufel (mit roten Vogelbeinen und hängenden Brüsten). - unten Berufung der Apostel Petrus und Andreas: links Petrus und Andreas als Fischer, die auf dem See von Galiläa ihre Netze ausbringen; rechts, am Seeufer, Jesus und die beiden Apostel im Boot.

Bl. 154r oben Hochzeit zu Kana: links Jesus, der das Wasser (in sechs hohen Krügen, dahinter Maria) in Wein verwandelt; rechts die Hochzeitsgesellschaft. - Mitte: Jesus predigt von einer Holzkanzel herab zu einer sitzenden Gruppe, dahinter stehen Maria und zwei Apostel. - unten: Heilung des Lahmen.

Bl. 154v oben Auferweckung des Lazarus: links Martha (rothaarig) und Maria (hält ihr Gewand vors Gesicht), die Schwestern des Lazarus; der Auferweckte steht, umhüllt von einem rosafarbenen Leichentuch, betend im Grab. - Mitte Einzug nach Jerusalem: Jesus reitet segnend auf der Eselin dem Stadttor zu, vor dem ein Mann einen roten Mantel ausbreitet. - unten Verrat des Judas: links ein Bischof auf einem verzierten Holzthron, der mit einem Mann mit roter Haube diskutiert; rechts ein Hohepriester und der gelbgewandete, rothaarige Judas mit rotem Geldbeutel. 
Bl. 163v oben Letztes Abendmahl an einem runden Tisch; Johannes kauert auf dem Schoß Jesu, Judas (wie Bl. 154v) deutlich erkennbar. - Mitte Ölberg: Jesus betet Blut schwitzend den Kelch im Felsen an, während die Jünger schlafen; Felsen als sandfarbene, kulissenartige Formationen mit gewellten Konturen gestaltet. unten Gefangennahme Jesu (Judaskuss).

Bl. 164r oben: Drei Apostel mit Maria Magdalena und Maria. - Mitte Verhöhnung: Pilatus als Bischof; Jesus mit Blutschweiß und verbundenen Augen. - unten Geißelung: auf dem Bein des rechten Schergen ein goldenes $M$ mit Krone darüber.

Bl. 164v oben Dornenkrönung; der grüne Rock des linken Schergen mit blattförmigen Schößen. - Mitte: links wäscht Pilatus seine Hände, rechts wird Jesus vorgeführt (einer der Soldaten mit geöffnetem Mund). unten Kreuztragung: links Maria und Johannes; Simon von Cyrene hilft Jesus beim Tragen.

Bl. 165r oben Kreuzigung: links Johannes stützt Maria; Gekreuzigter mit gelbgrünem Lendentuch. - Mitte Pietà, flankiert von Johannes und Maria Magdalena (mit Salbgefäß), im Hintergrund Querbalken des Kreuzes. - unten Grablegung Christi: Josef von Arimathäa bettet Jesus in Steinsarkophag, vor dem Johannes (als Rückenfigur), Maria (mit erhobenen, gefalteten Händen) und Nikodemus knien; stehend Maria Magdalena. Bl. 177v oben Höllenfahrt Christi: Jesus (mit Siegesfahne) befreit die Seelen der Gerechten, die ihm aus dem zerborstenen Höllentor entgegeneilen; aus Seitenfenster der Pforte blickt ein grüner Teufel. - Mitte Auferstehung Christi: Der Auferstandene in rotem Mantel (mit Wundmalen und Siegesfahne) steht vor dem geschlossenen Sarkophag; die schlafenden Soldaten verdeckt; Seelandschaft, darin u. a. Golgota, Baum mit Erhängtem, drei Figürchen, im Hintergrund Bergkette. - unten: Christus erscheint Maria, die betend an einem Pult sitzt.

Bl. 178r oben Noli me tangere: In einem von einem Flechthag (vgl. Bl. 163v) umzäunten Garten kniet Maria Magdalena (mit Salbgefäß) und betet Christus an, der segnend und mit Siegesfahne vor ihr steht; in der Hintergrundslandschaft u. a. Golgota sowie drei Soldaten vor einem Wirtshaus (?). - Mitte: Christus (segnend und mit Weltkugel) erscheint zw. vier Frauen (darunter Gottesmutter erkennbar) und drei Aposteln (zuvorderst Petrus, mit Schlüssel), denen er sich zuwendet. - unten Himmelfahrt Christi: Maria und Apostel flankieren den Auffahrtsberg (darauf Fußspuren Christi); aus dem Wolkenband ragen noch Füße und Gewandsaum Jesu sowie das untere Ende der Siegesfahne (?) heraus.

B1. 178v oben Pfingsten: Taube des hl. Geistes über Maria und Aposteln. - Mitte: Petrus predigt von einer verzierten Holzkanzel (dahinter weitere Apostel) zu einer sitzenden Gruppe herab, hinter der Maria und zwei Frauen stehen. - unten Letztes Gebet Mariens: Maria sitzt betend an einem Pult, links ihr Sterbebett (dahinter Vorhang), rechts (an der Tür) drei Apostel.

Bl. 187v oben: Engel (mit grünblättrigem Zweig) verkündet Maria, die an einem Pult sitzt, den Tod. - Mitte Marientod I: Die verstorbene Maria liegt mit geschlossenen Augen auf dem Bett; drei Apostel. - unten Marientod II: Umgeben von sechs Aposteln liegt die Verstorbene auf dem Bett, über ihr in einer Goldgloriole (mit Wolkenrand) Christus, der das Seelenfigürchen Mariens auf dem Arm hält.

Bl. 188r oben Himmelfahrt Mariens: Maria wird von sechs Engeln, zwei davon musizierend (Harfe und Laute), in den Himmel empor getragen. - Mitte: Maria, deren blaues Kleid von Goldglanz überzogen ist, flankiert von zwei weiblichen und vier männlichen Heiligen (davon zwei mit Schriftbändern: IMAR[...]O und HVEM). - unten Krönung Mariens: Maria kniet vor der Dreifaltigkeit; links Christus und rechts Gottvater, die ihr die Krone aufsetzen, hinter ihr der hl. Geist in Menschengestalt.

Punzierungen. Rautengitter aus winzigen Quadraten, im Binnenfeld Bl. 67r mit fünfblättrigen Blüten (aus kleinen Kreisen) gefüllt, Bl. 94r, auf kobaltblauem Deckfarbengrund, mit zwölfblättrigen Blüten und auf dem Miniaturenhintergrund Bl. 109v mit sechsblättrigen, abwechselnd rot und blau ausgemalten Blüten, Gitterschnittpunkte zudem mit vierblättrigen roten und blauen Blüten besetzt.

Deckfarbenschmuck von der Hand, die auch Cod. 353 illuminierte. Während Cod. 353 einige Detailfreude zeigt (ganzseitige Miniaturen, die mehr Gestaltungsfläche bieten), überwiegen in Cod. 654, bis auf Bl. 11v (Heiligenfiguren etwas individueller gestaltet), naiv-schematisierte Illuminationen; in beiden Bänden farbenfreudiges Kolorit und verhältnismäßig reicher Einsatz von Blattgold sowie Punzierungen. - Der Illuminator von Cod. 353 und 654 kannte sehr wahrscheinlich das wohl zu Beginn der 1480er Jahre in Neustift entstandene Epistolar (Cod. 196, Bl. 1r-20v) und Evangelistar (Esztergom, Kathedralbibl., Ms. II.2, und Cod. 196, Bl. 30r-35[26]v), s. die Blattgoldgründe mit gepunztem Rautengitter und sowohl punzierten als auch aufgemalten, bunten Blüten (vgl. Cod. 353, Bl. 1r, mit Cod. 196, Bl. 10v1), den um eine Folioecke geführten Randschmuck, der eine goldgefüllte Schlinge ausbildet (z. B. Ms. II.2, Bl. 3r und 11r; gerade im Evangelistar beginnt sich der Randschmuck vollständig von der Initiale zu lösen, wie das in Cod. 353 und 654 durchgängig der Fall ist; s.z. B. Ms. II.2, Bl. 34v, wo die Randzier die Initiale nur noch hauchfein berührt), die naturalistischen Zweige (vgl. z. B. Cod. 353, Bl. 94r mit Cod. 196, Bl. 34r: roter Klee) und generell den Akanthus mit seinen von Seite zu Seite variierenden Blattformen. - Als Vorlagen für die Miniaturen Cod. 654, Bl. 116v-188r, dürfte der Buchmaler die Holzschnitte aus dem Inkunabeldruck des Itinerarium seu peregrinatio BMV (s. bei Inhalt, Nr. 9) herangezogen haben, von denen er auch die dreiregistrige Unterteilung der Bildfelder übernahm. In Frage kommen sowohl die ca. 1487/88 von Johann Reger in Ulm 
gedruckte lat. Version dieses Werks (GW M15415) als auch die 1489 von Johann Schobser in Augsburg gedruckte dt. Fassung (GW M15419); die Holzschnittzyklen dieser beiden Drucke sind nicht völlig identisch, aber stark verwandt, und zeigen im Vergleich mit den Miniaturen in Cod. 654 mehr Übereinstimmungen als (geringfügige) Abweichungen.

Bei dem M mit Krone (Cod. 654, Bl. 164r unten) könnte es sich um eine Buchmaler-Signatur handeln, wobei sich die Frage stellt, warum gerade einer der geißelnden Schergen dieses Zeichen trägt. Cod. 353 ist unsigniert.

E: $\quad$ Renaissance-Einband: braunes Leder auf Holz mit Golddruck. Neustift, zw. 1569 und 1581 (identisch mit Cod. 353). Werkstatt: Narziß Schuechl.

Einband restauriert, Leder tw. ergänzt (deutlich sichtbar), Bindung erneuert. VD und HD gleich: ein von je zweifachen Streicheisenlinien in Gold begrenzter Rahmen: Rolle Enthauptung des Johannes, Eherne Schlange, Kreuzigung, Auferstehung (Nr. 1 = Neuhauser, Rolleneinbände, R 29). Im Mittelfeld des VD Plattenstempel mit Darstellung eines Erzengels (Michael?) mit Wappenschild von Propst Augustin Schabl (Propst 1569-1581) mit zwei steigenden geflügelten Löwen (Nr. 2 = Neuhauser, Rolleneinbände, P 3). Darüber Inschrift Augustinus praepositus Novcecelle. Im Mittelfeld des HD in den Ecken Einzelstempel mit floralem Dekor aus Vase wachsend (Nr. 3), in der Mitte Einzelstempel Kreuzigung Christi (Nr. 4). Zwei Leder-Metall-Schließen, beim Materialwechsel sich stark verjüngend, Leder erneuert. Kanten gerade und nach innen hin abgeschrägt und durch einfache Streicheisenlinie eingefasst. Rücken: vier Doppelbünde, von zweifachen goldenen Linien gesäumt, Linien am VD und HD fortgesetzt, spitz aufeinander zulaufend. In den Feldern zw. den Bünden jeweils florale Rolle (Nr. 5 = Neuhauser, Rolleneinbände, R 26). Kapitale mit naturfarbenem und rotem Zwirn umstochen (20. Jh.). Schnitt goldfarben und punziert. Spiegel Pap. 20. Jh. Am Spiegel des VD Signatur (s. bei G).

G: Hs. im Auftrag des Kaspar Neuhauser, bischöflicher Zöllner (1490/92) und Stadtrichter (1494-1501) in Klausen (vgl. Kustatscher I 300-302 und II 646; K. Brandstätter, Städtische Verwaltung und Bürgerschaft in Klausen im 15. Jh. Der Schlern 73 [1999] 442, 718), 1496 von Georg Hölzl geschrieben. Hs. spätestens seit der Zeit des Propstes Augustin Schabl (1569-1581) in Neustift. 1809 anlässlich der vorübergehenden Aufhebung des Klosters Neustift der ULB Tirol übergeben. Bl. IIr sowie 202v Stempel der ULB Tirol 19. Jh. 1921 aufgrund des Friedensvertrages von St. Germain an den italienischen Staat abgegeben und von diesem 1929 dem Kloster Neustift als Dauerleihgabe überlassen. Bl. IIr Stempel der Soprintendenza Tridentina 20. Jh. Am Spiegel des VD Signatur 20. Jh. Ms 654 (Bleistift).

L: $\quad$ Wilhelm II 108 und 109. - Hermann 209-211, Nr. 209. - H. Wieser, Die dankbaren Toten. Veröffentlichungen des Tiroler Landesmuseums Ferdinandeum 26/29 (1946/49) 491-501, Taf. XLVIII. - Laußermayer 6, 301308. - Colophons Nr. 5053. - Neuhauser, Neustift 85. - Peintner, Buchmalerei, 33-34, 65-83, 87, 91-92 (ohne Nennung der Sign.). - H. Rizzolli, Der Fachbogen der Hut- und Tuchmacher als spätmittelalterliches Heiligenattribut in Tirol. Der Schlern 60 (1986) 52, 56 (Abb. 4). - Stefani 116. - Peintner, Stiftsbibliothek 121. - Kustatscher I 302 (ohne Nennung der Sign.). - Katalog ULB Tirol VII 299, 485. - KustatscherKorenjak 157. - Krämer, Scriptores, s. v. „Höltzl (Hölzl), Georgius“.

Liber Horarum, Bd. 2.

(Ir-v) leer.

(IIr) Tit. von späterer Hand ergänzt (Abschrift von Cod. 353, Bl. Ir): Subscripti cursus sparsim hincinde in devocionum libellis inventi summa cum diligencia hic in unum sunt collecti ut quivis ad excitandam devocionem prout suus afficitur animus ad manum habeat quo se orando convertat: aut scilicet ad trinitatem beatissimam aut ad eternam sapienciam ad corpus Christi ad ipsius passionem vel eius animam ad spiritum sanctum vel beatissimam virginem Mariam ad beatos angelos vel omnes Dei sanctos aut pro misericordia inpetrandam (!) pro peccatis propriis vel fidelibus defunctis cum septem peniten$c$ [ialibus] psalmis cum mortuorum vigiliis et accessu altaris prout secundum ordinem huiusmodi cum numero foliorum hic sunt intitulati.

(IIv) Inhaltsangabe mit Blattangabe.

Cursus de omnibus sanctis 1/Cursus pro peccatis 16/Cursus de animabus 34/Septem psalmi 52/Vigilie mortuorum 67/Vespere mortuorum 87.

1 (1r-15r) CuRsus de OMNIBUS SANCTIS. Lektionen («Ps.-Augustinus`: Meditationes, cap. 24 [PL 40, 918-919. - CPL Nr. 386]). 
Die Beschriftung folgt nicht der Blattfolge, der Text auf Bl. 7r wird auf 8v fortgesetzt, anschließend folgt Bl. ${ }^{\mathrm{I}} \mathrm{r}$, dann 7v, 8r und schließlich $7^{\mathrm{I}} \mathrm{v}$, ehe der Text (ohne Textverlust) auf Bl. 9r weitergeht. Der Text von Bl. 10v wird auf 11r fortgesetzt, das Blatt dazwischen (11 ${ }^{\mathrm{I}}$ ) wurde erst später eingehängt.

Tit.: Cursus de omnibus sanctis. - Anrufung: Domine labia mea aperies. Et os. Deus in adiutorium meum.

(1r) Invitatorium mit Verweis auf Ps 95. - Matutin. Hymnus (AH 51, Nr. 129). - (1v) Ps 31,2025. - (2r) Antiphona. Te mirabilem in sanctis rex regum collaudamus tua opera Criste tua mirabilia ... - (2v) Benediccio. Per suffragia beate virginis Marie et omnium sanctorum tuorum ... - Leccio prima. Inc.: Felices sancti Dei omnes qui pertransistis pelagus mortalitatis et pervenire ... - Expl.: ... agitamur procellis. Tu autem. - (3r) Responsorium mit Versikel. - (3v) Leccio secunda. Inc.: Vos porte pulcerrime que in magnam surrexistis altitudinem ... - Expl.: ... salvi esse non possumus. - (4r) Responsorium mit Versikel. - Leccio tercia. Inc.: O vos electi sumus nanque (!) fragiles et nullius veritatis ... - Expl.: ... quietis continue pacis et nunquam sinende securitatis. - (4v) Responsorium mit Versikel. - (5r) Te Deum.

(5r) Laudes. Ps 150. - (5v) Antiphona. Omnes sancti Dei intercedere pro nobis ad dominum Ihesum Christum alleluia. - Capitulum. - Hymnus (AH 51, Nr. 130). - (6v) Canticum Zachariae. (7r) Antiphon (CAO Nr. 4689). - Oracio. Concede quesumus omnipotens Deus ut intercessio sancte Dei genitricis Marie sanctique Iohannis Baptiste ...

(8v) Prim. Hymnus (AH 51, Nr. 130). - (7' I r) Ps 117. - Antiphon (Cantus Nr. 203647). - Capitulum. - Responsorium mit Versikel. - $\left(7^{\mathrm{I}} \mathrm{v}\right)$ Oracio. Deus qui nos concedis omnium sanctorum tuorum merita venerari ...

(7lv) Terz. Hymnus (AH 51, Nr. 130). - (8r) Ps 33,1-6. - (8v) Antiphon (CAO Nr. 4583). - Capitulum. - Responsorium mit Versikel. - Oracio. Deus qui nos beate Marie semper virginis et beatorum spirituum patriarcharum ...

(9r) Sext. Hymnus (nur Verweis: AH 51, Nr. 130). - Ps 34,9-15. - (9v) Antiphon (CAO Nr. 3208). - Capitulum. - Responsorium mit Versikel. - (10r) Oracio. A cunctis iniquitatibus nostris exue nos domine et intercedente beata et gloriosa Dei genitrice virgine Maria ...

(10r) Non. Hymnus (nur Verweis: AH 51, Nr. 130). - Ps 34,16-23. - (10v) Antiphona. O quam digna et veneranda [

$\left(10^{\mathrm{I}} \mathrm{r}\right)$ Gebet: Corda nostra quesumus domine passionum carismatum et glorie racionalis ...

$\left(10^{\mathrm{I}} \mathrm{v}\right)$ ganzseitige Miniatur (s. bei A).

(11r) Forts. von Bl. 10v. Inc. mut.: ] est memoria omnium sanctorum Dei qui despecto pharaonis ... - Capitulum. - Responsorium mit Versikel. - (11v) Oracio. Infirmitatem paupertatem tribulacionem atque omnem angustiam nostram ...

(11v) Vesper. Ps 145,10-16. - (12r) Antiphon (CAO Nr. 4063). - Capitulum. - (12v) Responsorium mit Versikel. - Hymnus (AH 51, Nr. 129). (13r) Magnificat (nur Verweis). - Antiphon (CAO Nr. 3590). - (13v) Oracio. Concede quesumus omnipotens Deus ut intercessio sancte Dei genitricis Marie sanctique Iohannis Baptiste ...

(14r) Komplet. Ps 145,17-21. - Antiphon (CAO Nr. 2908). - Capitulum. - (14v) Hymnus (AH 51, Nr. 130). - Canticum Simeonis (nur Verweis). - Antiphon (CAO Nr. 3210). - (15r) Oracio etc. Ut tuam domine misericordiam consequamur fac nos per intercessionem ...

(15v) ganzseitige Miniatur (s. bei A).

2 (16r-33r) CURSUS PRO PECCATIS.

Tit.: Cursus pro peccatis multum devotus. Anrufung: Ave benigne Ihesu fili David miserere nobis. Domine labia mea aperies. Et os. Deus in adiutorium.

(16r) Invitatorium mit Verweis auf Ps 95. - Matutin. Hymnus (AH 51, Nr. 54, Str. 1-2). - Ps 5. (17r) Antiphon (CAO Nr. 1847). - (17v) Benediccio. Per magnam misericordiam domini nostri Ihesu Cristi et per multitudinem miseracionum suarum salvet et protegat ...-Leccio prima. Inc.: 
Deus meus confundar et erubesco levare faciem meam ... - Expl.: ... quoniam Deus miseracionum et clemens tu es. Tu autem (vgl. 2 Esr 9,31). - (18r) Responsorium mit Versikel. - (18v) Leccio secunda. Inc.: Iniquitates nostre contenderunt contra nos domine libera nos ... - Expl.: ... ne derelinquas nos domine Deus noster. - Responsorium mit Versikel. - (19r) Leccio tercia etc. (Ier 14,19-21). - (19v) Responsorium mit Versikel. - Te Deum (nur Verweis). .

(19v) Laudes. Ps 51,3-5. - (20r) Antiphon (vgl. CAO Nr. 4678). - Capitulum. - Hymnus (AH 51, Nr. 54, Str. 3-5). - (20v) Canticum Zachariae (nur Verweis). - Antiphon (CAO Nr. 2770). - Oracio. Omnipotens et sempiterne Deus cuius natura bonitas cum (!) voluntas potencia cuius opus ... (21r) Prim. Hymnus (AH 51, Nr. 55). - (21v) Ps 6. - (22v) Antiphona. Miserere mei domine quoniam infirmus sum sana me domine quoniam conturbata sunt ossa mea. - Capitulum. - Responsorium mit Versikel. - (23r) Oracio. Omnipotens sempiterne Deus confitentibus tibi famulis tuis pro tua pietate relaxa peccata ...

(23v) Terz. Hymnus (AH 51, Nr. 55). - (24r) Ps 32. - (24v) Antiphona. Delictum meum cognitum tibi feci et iniusticiam meam a te non abscondi. - Capitulum. - (25r) Responsorium mit Versikel. - Oracio. Exaudi quesumus domine preces supplicum et confitencium tibi ...

(25r) Sext. - (25v) Hymnus (nur Verweis: AH 51, Nr. 55). - Ps 38. - (27r) Antiphon (vgl. Cantus Nr. 204374). - Capitulum. - Responsorium mit Versikel. - Oracio. Deus infinite misericordie veritatisque immense propiciare iniquitatibus nostris et animarum nostrarum ...

(27v) Non. Hymnus (nur Verweis: AH 51, Nr. 55). - Ps 130. - (28r) Antiphon (CAO Nr. 1466). Capitulum. - Responsorium mit Versikel. - (28v) Oracio. Adesto domine supplicacionibus nostris ne sit a nobis famulis tuis longinqua tua miseracio ...

(28v) Vesper. - (29r) Ps 102,2-19. - (30r) Antiphon (CAO Nr. 7820). - Capitulum. - Hymnus (AH 51, Nr. 89). - (30v) Magnificat (nur Verweis). - Antiphon (CAO Nr. 5013). - Oracio. Deus sub cuius oculis omne cor trepidat omnesque conscientis (!) contremiscunt ...

(31r) Komplet. Ps 102 (nur Verweis). - Antiphona. Non avertas faciem tuam a me et similis ero descendentibus in lacum. - Hymnus (AH 51, Nr. 22). - (32r) Capitulum. - Versikel. - Canticum Simeonis (nur Verweis). - Antiphon (CAO Nr. 4461). - (32v) Oracio. Fideles tuos quesumus domine ab ira tua confugientes ad te paterna recipe pietate ... - (33r) Alia oracio. Omnipotens sempiterne Deus ne nos miseros peccatores permittas propter peccata nostra perire ...

(33v) ganzseitige Miniatur (s. bei A).

3 (34r-51r) CuRsus PRO DEFunctis. Hymnen (AH 30, Nr. 81 Vesper und Completorium vertauscht). Tit.: Cursus pro defunctis fidelibus animabus.

(34r) Invitatorium mit Verweis auf Ps 95. - Matutin. Hymnus. - (34v) Ps 3. - (35r) Antiphon (vgl. CAO Nr. 1512). - Benediccio. Exaudi domine preces servorum tuorum ut anime fidelium defunctorum a penis liberentur infernorum ... - (35v) Leccio prima. Inc.: Deus cui omnia moriencia vivunt et cui non pererint (!) moriendo corpora nostra sed mutantur in melius ... - Expl.: ... iudicare vivos et mortuos et seculum per ignem. Tu autem domine. - (36r) Responsorium mit Versikel. - Leccio secunda. Inc.: Deus vite dator humanorum corporum reparator qui a peccatoribus exorari voluisti exaudi quesumus preces nostras ... - Expl.: ... per resurgentem a mortuis dominum Ihesum Christum. Tu autem. - (36v) Responsorium mit Versikel. - Leccio tercia. Inc.: Te domine sancte pater omnipotens eterne Deus supplices deprecamur pro animabus omnium fidelium defunctorum quas ab origine mundi accersiri voluisti ... - Expl.: ... per resurgentem a mortuis dominum nostrum Ihesum. Tu autem. - (37r) Responsorium mit Versikel.

Parallelüberlieferung der Lectiones: Innsbruck, ULB Tirol, Cod. 398, Bl. 91v-93r.

(37v) Laudes. Ps 51,3-21. - (38v) Antiphon (CAO Nr. 1912). - (39r) Capitulum. - Hymnus. (39v) Ps 72,18 (nur Verweis). - Antiphon (Cantus Nr. 200808). - (40r) Oracio. Respice quesumus omnipotens et misericors Deus super animas omnium fidelium defunctorum ...

(40r) Prim. Hymnus. (40v) Ps 67. - (41r) Antiphon (CAO Nr. 2444). - Capitulum. - Responsorium mit Versikel. - (41v) Oracio. Da quesumus omnipotens et misericors Deus ut anime omnium 
fidelium defunctorum hic et ubique in Christo quiescencium ...

(41v) Terz. Hymnus. - (42r) Ps 56. - (43r) Antiphon (CAO Nr. 1211). - Capitulum. - Responsorium mit Versikel. - (43v) Oracio. Sacratissimam domine dilectissimi filii tui passionis memoriam devote recolentes pro liberacione animarum ...

(44r) Sext. Hymnus. - Ps 57. - (45r) Antiphon (vgl. Cantus Nr. g02393). - Capitulum. - Responsorium mit Versikel. - (45v) Oracio. Deus qui unicum filium tuum ut servum redimeres sponte in mortem crucis tradidisti ...

(45v) Non. - (46r) Hymnus. - Ps 130. - (46v) Antiphona. Domine Ihesu Christe pastor bone qui ovem perditam reportasti ad ovile veniant omnes sancti in adiutorium animabus omnium fidelium qui pius et misericors es salvator noster. - Capitulum. - Responsorium mit Versikel. - (47r) Oracio. Domine Ihesu Criste fili Dei vivi qui precioso sanguine tuo mundum redemisti ...

(47v) Vesper. Ps 116,1-9. - (48r) Antiphon (vgl. CAO Nr. 1783,1). - Capitulum. - Responsorium mit Versikel. - (48v) Hymnus. - (49r) Versikel. - Magnificat (nur Verweis). - Antiphon (CAO Nr. 4689). - Magnificat (nur Verweis). - Oracio. Domine Ihesu Criste iudex vivorum et mortuorum qui ob hoc irasceris ut subvenias ad hoc minaris ...

(49v) Komplet. Ps. (recte: Ies. 38,10). - (50r) Antiphon (Cantus Nr. g01573). - Hymnus. - (50v) Capitulum. - Versikel. - Canticum Simeonis (nur Verweis). - Antiphon (CAO Nr. 3732). - Oracio. Deus qui unigeniti filii tui domini nostri Ihesu Christi precioso sangwine humanum genus redimere dignatus es...

(51v) ganzseitige Miniatur (s. bei A).

4 (52r-66r) Septem psalmi Paenitentiales mit Allerheiligenlitanei.

(52r-59v) Tit.: Septem psalmi penitenciales sequuntur ut infra (Ps 6, 32, 38, 51, 102, 130, 143). Nach jedem Psalm jeweils Gloria. Anschließend Antiphon (CAO Nr. 3861).

(59v-64r) LITANIA OMNIUM SANCTORUM.

(64r-66r) Orationes.

(64r) Inc.: Et veniat super nos misericordia tua domine ... - (64v) Alia oracio. Omnipotens sempiterne Deus dirige actus nostros in beneplacito tuo ... - Oracio. Fac nos quesumus domine sancte Marie semper virginis subsidiis attolli ... - (65r) Oracio. Ecclesie tue quesumus domine preces placatus admitte ... - Oracio. Pretende quesumus domine famulis et famulabus tuis ...(65v) Oracio. Suppliciter te Deus pater omnipotens qui es creator omnium rerum ... - Oracio. Ure igni sancti spiritus renes nostros et corda nostra domine ... - (66r) Oracio. Animabus quesumus domine omnium fidelium defunctorum oracio proficiat ...

(66v) ganzseitige Miniatur (s. bei A).

5 (67r-90v) VigILIAE MORTUORUM.

Tit.: Vigilie mortuorum sequuntur. - Anrufung: Oremus pro fidelibus defunctis. Requiem eternam dona eis domine.

(67r) Invitatorium mit Ps 95. - (68r) Ps 5. - (69r) Antiphon (CAO Nr. 2244). - Ps 6. - (70r) Antiphon (CAO Nr. 1921). - Ps 7. - (71v) Antiphon (CAO Nr. 3875). - Versikel. - Leccio prima (Iob 7, 16-21). - (72r) Responsorium mit Versikel. - Leccio secunda (Iob 10,1-7). - (72v) Responsorium mit Versikel. - Leccio tercio (!) (Iob 10, 8-12). - (73r) Responsorium mit Versikel. (73v) Tit.: In secundo nocturno. Ps 23. - (74r) Antiphon (CAO Nr. 3250). - Ps 25. - (75v) Antiphon (CAO Nr. 2146). - Ps 27. - (76v) Antiphon (CAO Nr. 1948). - Leccio quarta: Iob 13, 23-28. - (77r) Responsorium mit Versikel. - (77v) Leccio quinta (Iob 14,1-6). - (78r) Responsorium mit Versikel. - Leccio sexta (Iob 14, 13-16). - (78v) Responsorium mit Versikel. - Ps 6 (nur Verweis). - Antiphona. Non derelinquas me domine Deus meus ne discesseris a me. - Ps 41. - (80r) Antiphon (CAO Nr. 4696). - Ps 42. - (81r) Antiphona. Sitivit anima mea ad Deum fontem vivum quando veniam et apparebo ante faciem domini. - Versikel. - Leccio septima (Iob 17). - (81v) Responsorium mit Versikel. - (82r) Psalmus (recte: Lectio Iob 19,20-27). - (82v) Responsorium mit Versikel. - (83r) Leccio VIII ${ }^{\circ}$ (Iob 10,18-22). - (83v) Responsorium mit Ver- 
sikel. - Ps 51 (nur Verweis). - Antiphon (CAO Nr. 2810). - Ps 65. - (84bv) Antiphon (CAO Nr. 2767). - (85r) Antiphon (CAO Nr. 3725). - Psalmus (recte: Lectio: Is 38,10-20). - (86r) Antiphon (CAO Nr. 2674). - Ps 148 (nur Verweis). Antiphon (CAO Nr. 4154). - Canticum Zachariae (nur Verweis). - Antiphon (CAO Nr. 2601). - (86v) Oracio. Inclina domine aurem tuam ad preces nostras quibus misericordiam tuam suppliciter deprecamur ut animam famuli tui ...(87r) Alia oracio. Quesumus domine pro tua pietate miserere anime famuli tui a contagiis mortalitatis ... - Oracio. Deus qui nos patrem et matrem honorare precepisti miserere queso clementer animabus patris mei et matris mee omniumque parentum ... - Oracio. Deus venie largitor et humane salutis amator quesumus clementiam tuam ... - (87v) Oracio. Fidelium Deus omnium conditor et redemptor animabus famulorum famularumque omnium fidelium ...-(88r) Antiphon (CAO Nr. 3732).

(88r) Tit.: Vespere mortuorum. Ps 116, 1-9. - (88v) Antiphon (CAO Nr. 4293). - Ps 120 (nur Verweis). - Antiphon (CAO Nr. 3038). - Ps 121. - (89r) Antiphon (CAO Nr. 2402). - Ps 130 (nur Verweis). - (89v) Antiphon (CAO Nr. 4899). - Ps 138. - (90r) Antiphon (CAO Nr. 4159). - Magnificat (nur Verweis). - Antiphon (CAO Nr. 1211). - Antiphon (CAO Nr. 4115).

(90v-93r) Oratio pro animabus (Ablassgebet Papst Johannes’ XXII.).

(90v) Ablassvermerk (rot): Oracio pro animabus. Papa Iohannes vicesimus secundus concessit cuilibet dicenti subscriptam oracionem cum devocione in cimiterio cum uno Pater noster Ave Maria et Credo tot annos indulgenciarum quot corpora requiescunt et Innocencius papa tercius concessit cuilibet dicenti pro quolibet vice trecentos annos indulgenciarum.

(91r) Avete omnes fideles anime in sancta pace quiescite qui vos redemit suo precioso sanguine vobis dignetur misereri penasque vestras ... - (91v) Ps 130 (nur Verweis). - Oremus. Miserere domine per sanctam anuncciacionem adventum nativitatem ieiunium ... - (92v) Oracio. Fidelium Deus omnium conditor et redemptor animabus famulorum famularumque tuarum omnium fidelium ...

Darunter Ablassvermerk (rot): Ista metra subscripta sunt dicenda in cimiterio et qui ea devote dixerit ab aliquibus summis pontificibus maximas consequitur indulgencias ut sequuntur. (schwarz:) Sex milia sexcenta sexaginta sex tot fertur Ihesus pro nobis vulnera passus. Da requiem cunctis Deus hic et ubique sepultis. Ut sint in requie propter vulnera quinque.

(93v) ganzseitige Miniatur (s. bei A).

6 (94r-98v) ANFÄNGE DER VIER EVANGELIEN.

(94r) Tit.: Quatuor inicia ewangeliorum. - (94r) Tit.: Secundum Matheum. Matth 1,1-16. Anschließend: Deo gracias per istos sermones et per verba et virtutem sancti ewangelii dignetur dominus noster Ihesus Christus nos et fructus terre nostre custodire ... - (95v) Oracio. A domo tua quesumus domine spiritales nequicie repellantur et aeriarum discedat maligni ... - Tit.: Secundum Marcum. Marc 1,2-8. - (96v) Tit.: Secundum Lucam. Luc 1,5-17. - (97v) Tit.: Secundum Iohannem. Ioh 1,1-14. Anschließend: Deo gracias per istos sermones et per verba et per virtutem sancti ewangelii dignetur dominus noster Ihesus Christus ... - (98v) Verweis: Oracio ut supra.

(99r-v) nur Rahmung und Linierung.

7 (100r-108v) 〈Ps.-〉BIrgitta Suedensis: Orationes XV de passione dni (Druck: GW 4362-4383). Tit.: Incipiunt quindecim oraciones sancte Brigite. - Inc.: O domine Ihesu Criste eterna dulcedo te amancium iubilus excedens omne gaudium et omne desiderium ... - Expl.. ... ut post vite mee terminum te laudare merear cum omnibus sanctis tuis in eternum Amen. Ave dulcissime Ihesu Christe.

(109r) leer.

(109v) ganzseitige Miniatur (s. bei A). 
8 (110r-115v) Oratio Pro BMV (Ablassgebet Papst Innozenz’ IV.).

(110r) Ablassvermerk (rot): Hanc oracionem suprascriptam composuit s. Bonaventura quam postea Innocencius papa quartus confirmavit et dedit omnibus eam devote dicentibus de quolibet vice trecentos dies indulgenciarum.

(110r) Domina mea sancta Maria perpetua virgo virginum mater summe benignitatis et misericordie deprecor te...

Parallelüberlieferung: Innsbruck, ULB Tirol, Cod. 402, Bl. 159r.

(116r) nur Rahmung und Linierung.

(116v) ganzseitige Miniatur (s. bei A).

9 (117r-202r) Itinerarium SEU PEREGRINATIO BMV (Druck: GW M15411 und M15415).

Tit.: Prefacio in itinerarium seu peregrinacionem: beate virginis et Dei genitricis Marie. - Inc.: Subsequens oratio de beata virgine et Dei genitrice Maria continens principaliora ipsius et filii eius gesta ... - Expl.: ... ac te sibi congregare constituit et previdit in eternum. Amen. (rot:) Finis itinerarii seu peregrinacionis beate Marie virginis.

$(122 \mathrm{r}-\mathrm{v}, 132 \mathrm{r}-\mathrm{v}, 143 \mathrm{v}-144 \mathrm{r}, 153 \mathrm{v}-154 \mathrm{v}, 163 \mathrm{v}-165 \mathrm{r}, 177 \mathrm{v}-178 \mathrm{v}, 187 \mathrm{v}-188 \mathrm{r})$ ganzseitige Miniaturen (s. bei A).

(202r) Schlussschrift mit Schreibernennung und Datierung: Hec oraciones scripte sunt per me Georgium Höltzl de oppido Matikofen in expensis domini Caspar Newhauser tunc temporis iudex in Clusna in anno domini millesimo quadragentesimo nonagesimo sexto vigesimo octavo die mensis Iulii etc. Laus Deo (28. Juli 1496) (Colophons Nr. 5053).

(202v) nur Rahmung und Linierung sowie Stempel (s. bei G).

(203r) nur Rahmung und Linierung.

(203v und $\left.\mathrm{I}^{*} \mathrm{r}-\mathrm{v}\right)$ leer.

U.S.

\section{Cod. 691}

\section{ARGUMENTA LIBRORUM DICTYS CRETENSIS}

Pap. 5 Bl. $210 \times 145$. Neustift (?), Anfang 16. Jh.

B: Pap. am unteren Blattrand fleckig (Wasserschaden). Wasserzeichen nur fragmentarisch erhalten, kein Nachweis möglich. Lage: $(1+\mathrm{II})^{5}$. Bl. 1 eingehängtes Einzelbl., am Spiegel des VD angeklebt. Am oberen Blattrand Foliierung 19. Jh. durch die ULB Tirol.

S: Schriftraum 165/170 × 95, seitlich von Blindlinien begrenzt, zu 30-32 Zeilen. Humanistische Kursive von zwei Händen: 1) Bl. 1r-4r; 2) Bl. 4v.

E: $\quad$ Neuzeitlicher Bibliothekseinband: schwarz gesprenkeltes braunes Pap. Neustift, 2. H. 18. Jh.

Am VD Signaturschild (s. bei G). Spiegel Pap. Am Spiegel des VD Exlibris, Signaturen und Stempel (s. bei G), Spiegel des HD leer.

G: $\quad$ Am Spiegel des VD Exlibris der Stiftsbibl. Neustift 18. Jh. 1809 anlässlich der vorübergehenden Aufhebung des Klosters Neustift der ULB Tirol übergeben. Am Spiegel des VD alte Signaturen der ULB Tirol II $\overline{1} D 5$ (Tinte), II $\overline{3}$ E 27 S. 2 (Bleistift) und 691 (Tinte). Am VD gelbes Signaturschild der ULB Tirol 691. Bl. 1r Stempel der ULB Tirol 19. Jh. 1921 aufgrund des Friedensvertrages von St. Germain an den italienischen Staat abgegeben und von diesem 1929 dem Kloster Neustift als Dauerleihgabe überlassen. Am Spiegel des VD Stempel der Soprintendenza Tridentina 20. Jh.

L: W. Speyer, Die unbekannte Epitome des Dictys Cretensis im Codex Brixinensis 691. Rheinisches Museum für Philologie, N. F. 107/1 (1964) 76-92. - Kristeller I 439. - Katalog ULB Tirol VII 470, 485.

Argumenta librorum Dictys Cretensis: De Troiani regni excidio cum appendiculis (Ed. Speyer 84-91 [basierend auf Neustift, Stiftsbibl., Cod. 691]). 
Inc.: Minos Iovis et Europe filius Androgeum Ariadnam Phedram Daucalionem (!) et Molum progenuit. Ex Deucalione Idomeneus ex Molo Meriones seu Mirion et Idomeneus alter nascitur. Item Tantalus Iovis filius genuit Pelopem ... - Expl.: ... ex quo Anchises editus est Aeneam filium procreavit. Der Text umfasst Inhaltsangaben der sechs Bücher des Dictys Cretensis, die von zwei Appendices gerahmt werden:

(1r) Appendix prima. Ohne Tit. - (1v) Tit.: Argumentum primi libri. - (2v) Tit.: Argumentum secundi libri. - (3r) Tit.: Argumentum tercii libri. - (3r) Tit.: Argumentum quarti libri. - (3v) Tit.: Argumentum quinti libri. - (4r) Tit.: Argumentum sexti et ultimi libri Dictis Cretensis. - (4v) Tit.: De origine Troianorum (= Appendix secunda).

Zur Überlieferungsgeschichte sowie zum Aufbau des Textes vgl. Speyer 76-83.

$(5 \mathrm{r}-\mathrm{v})$ leer.

A. P./U.S.

\section{Cod. 694}

\section{PAULUS URSINUS}

Pap. 27 Bl. $205 \times 150$. Tirol, 1523.

B: $\quad$ Bilder der Wasserzeichen s. WZMA. Lagen: 2.VI ${ }^{24}+(\mathrm{II}-1)^{27}$. Gegenbl. zu Bl. 25 als Spiegel auf dem HD aufgeklebt. Am oberen Blattrand Foliierung 19. Jh. durch die ULB Tirol.

S: $\quad$ Schriftraum 140/145 $\times 70 / 75$, seitlich von Blindlinien begrenzt, zu 23-26 Zeilen. Humanistische Kursive, dat. (erschlossen) 1523. Vermutlich Autograph (Widmungsexemplar).

A: $\quad$ Weinrote Marginalien, Personenangaben im Text, Überschriften und Schlussschrift.

E: $\quad$ Neuzeitlicher Bibliothekseinband: schwarz gesprenkeltes braunes Pap. Neustift, 2. H. 18. Jh. Pap. leicht beschädigt, Bindung gelockert (Lage 1 oben gelöst). Am Rücken bzw. VD Signaturschild (s. bei G). Schnitt rot gesprenkelt. Spiegel des VD und HD Pap. 18. Jh. Am Spiegel des VD Exlibris und Signaturen (s. bei G), Spiegel des HD leer.

G: $\quad$ Am Spiegel des VD Exlibris der Stiftsbibl. Neustift 18. Jh. 1809 anlässlich der vorübergehenden Aufhebung des Klosters Neustift der ULB Tirol übergeben. Am Spiegel des VD alte Signaturen der ULB Tirol II [ ...] E [...] (Tinte, radiert), II $\overline{3}$ E 30 S. 2 (Bleistift) und 694 (Tinte). Am Rücken bzw. VD gelbes Signaturschild der ULB Tirol 694. Bl. 1r Stempel der ULB Tirol 19. Jh. 1921 aufgrund des Friedensvertrages von St. Germain an den italienischen Staat abgegeben und von diesem 1929 dem Kloster Neustift als Dauerleihgabe überlassen. Bl. 1r Stempel der Soprintendenza Tridentina 20. Jh.

L: $\quad$ Wilhelm I 137. - Kristeller I 439. - Katalog ULB Tirol VII 473, 485.

Paulus Ursinus: Dialogus de formidine diluvii instantis anni vigesimi quarti abigenda.

(1r) Tit.: Dialogus de formidine diluvii instantis anni vigesimi quarti abigenda.

(1v) Widmungsbrief. Tit.: Epistola. - Inc.: Reverendissimo in Christo patri ac domino domino Sebastiano Dei gracia episcopo Brixinensi necnon egregiis eximia doctrina et sapiencia eiusdem ecclesie prelatis ac canonicis Paulus Ursinus philosophus et medicus s. d. Que vicio nostro non proveniunt, queque in nostra minime sita sunt ... - Expl.: ... complurium interventu beneficiorum me frui cercior sum.

(3r) Text. Tit.: Dialogus non minus festivus quam facetus de formidine diluvii anni $24^{t i}$ ultra sesquemillesimum abigenda. Interlocutores: Philagrus Mercurius Genius. - Inc.: Phil[agrus]. Ut quid Mercuri hic ades galero redimitus et citharam gestans ... - Expl.: ... si non suprema de omnibus iudicet dies. Finis.

$(27 \mathrm{v})$ leer.

Paulus Ursinus ex Nisia (Neiße) wurde nach dem Studium in Bologna und Ferrara 1512 zum Doktor der Medizin promoviert (vgl. C. Zonta, Schlesische Studenten an italienischen Universitäten. Stuttgart 
2004, 168). Seine dem Brixner Fürstbischof Sebastian Sprenz (1521-1525) gewidmete Schrift steht im Kontext der Sintflutdebatte, die durch astrologische Vorhersagen für das Jahr 1524 ausgelöst wurde. Zur Debatte s. H. Talkenberg, Sintflut. Prophetie und Zeitgeschehen in Texten und Holzschnitten astrologischer Flugschriften 1488-1528. Tübingen 1990.

L. $\check{\text { S. }}$

\section{Cod. 726}

\section{RITUALE NEOCELLENSE}

Pap. III, 78, I* Bl. $120 \times 100$. Neustift, 1523 (mit Zusätzen 16. und 17. Jh.).

B: $\quad$ Bilder der Wasserzeichen s. WZMA. Lagen: $(\mathrm{II}-2)^{\mathrm{II}}+10 . \mathrm{IV}^{\mathrm{III}, 77(78)}+(\mathrm{I}-1)^{\mathrm{I}^{*}}$. Gegenbl. zu Bl. I herausgeschnitten, Gegenbl. zu Bl. II als Spiegel auf dem VD, Gegenbl. zu Bl. I* als Spiegel auf dem HD aufgeklebt. Am oberen Blattrand Foliierung 19. Jh. durch die ULB Tirol; Fehler in der Zählung: 24 und 37 doppelt angeführt, Bl. 77 nicht foliiert.

S: $\quad$ Bl. 1r-70v: Schriftraum 95×70, zu 21 Zeilen, seitlich und tw. oben von Tintenlinien gerahmt. Textualis mit kursivem Einschlag, dat. 1523 (Bl. 24v, 40v, 65r, 70r und 70v [11.6.]). Schreiber: Franciscus Prensteiner (Bl. 70v), Dekan von Neustift, vgl. Giner 12.

Bl. 71r-73v: Schriftraum $105 \times 70$, zu ca. 18 Zeilen, seitlich von Tintenlinien gerahmt. Humanistische Halbkursive in schwarzer und roter Tinte 16. Jh.

Bl. 74r: Schriftraum $100 \times 70$, zu 10 Zeilen, seitlich von Tintenlinien gerahmt. Antiquakursive 17. Jh. (1684?).

Bl. 76r: Schriftraum $105 \times 70$, zu 14 Zeilen, seitlich von Tintenlinien gerahmt. Antiquakursive 16. Jh. (1581?).

A: $\quad$ Bl. 1r-70v: Rote Auszeichnungsstriche, Überschriften, Benediktionskreuze (tw. gerahmt), Satzmajuskeln und zweizeilige Lombarden mit Punktverdickungen. Repräsentanten.

Bl. 71r-73v: Weinrote Überschriften und Satzmajuskeln.

E: $\quad$ Renaissance-Einband: hellbraunes Leder mit Blinddruck über Holz. Brixen oder Neustift, 2. H. 16. Jh VD und HD gleich: zwei aus je dreifachen Streicheisenlinien begrenzte Rahmen: Rahmen 1: Rolle Köpfe in Medaillon, dazwischen Rankenmuster und Inschrift SOLI bzw. CARO bzw. OCDA (Nr. 1 = Neuhauser, Rolleneinbände, R 56 [Gruppe 7]); Rahmen 2: Rolle S-förmiges (Schrift-?)Band, ineinander verhakt (Nr. 2). Im Mittelfeld Einzelstempel Maria mit Kind (Nr. 3), von mehrfachen Streicheisenlinien begrenzt. Reste einer Leder-Metall-Schließe. Kanten gerade. Rücken: blau gefärbt (wie öfters in Neustift), drei Doppelbünde. Im ersten und zweiten Feld Papiertitelschild MS Manuale Benedictionum ac Rituum Neocellensium, im dritten Signaturschild (s. bei G). Kapitale mit rötlich-weißem Zwirn umstochen. Spiegel Pap. 16. Jh. Am Spiegel des VD Exlibris und Signaturen (s. bei G), Spiegel des HD leer.

G: $\quad$ Am Spiegel des VD Exlibris der Stiftsbibl. Neustift 18. Jh. 1809 anlässlich der vorübergehenden Aufhebung des Klosters Neustift der ULB Tirol übergeben. Am Spiegel des VD alte Signatur der ULB Tirol II $\overline{3} F 12$ S. 2 (Bleistift) und 726 (Tinte). Bl. Iv Abklatsch des Stempels der ULB Tirol 19. Jh. (urspr. möglicherweise auf Recto des herausgerissenen Gegenbl. zu Bl. I). Am Rücken gelbes Signaturschild der ULB Tirol 726. 1921 aufgrund des Friedensvertrages von St. Germain an den italienischen Staat abgegeben und von diesem 1929 dem Kloster Neustift als Dauerleihgabe überlassen. Bl. IIIv Stempel der Soprintendenza Tridentina 20. Jh.

L: $\quad$ Gschwend 86-88 (ohne Nennung der Sign.). - Lipphardt III 1086; VI 352, Nr. 629 (Sigle Neust ${ }^{4}$ ). - Stefani 117. - Peintner, Stiftsbibliothek 126. - Gozzi 548, Nr. 80. - Katalog ULB Tirol VIII 127, 529.

(Ir-IIIv) leer bis auf Stempel (s. bei G).

1 (1r-70v) Rituale Neocellense. Vgl. Cod. 194 und Sign. 14820.

(1r-7r) In PURIFICATIONE BMV.

(1r) Benedictio candelarum. Tit.: Purificacionis Marie cereorum benedictio post $3^{\text {as }}$. - Inc.: Oremus. Erudi quesumus domine plebem tuam ... - (5v) Processio candelarum. - (6r) Canticum Zachariae. 
(7r-9r) Fer. 4 CINERUM (nicht in Cod. 194 und Sign. 14820).

(7r) Benedictio cinerum. Tit.: Feria IIII ${ }^{a}$. In capite ieiunii. Benedictio cineris. - (8v) Impositio cinerum. Rubrik: Tunc ponendi sunt cineres super capita singulorum dicens.

(9r-21v) DNCA IN PALMis.

(9r) In die palmarum ad processionem. - (12v) Exorcismus florum et frondium. - (12v) Benedictio palmarum. - (16v) Praefatio. - (17v) Aspersio et thurificatio palmarum. - (18r) Distributio palmarum. - (18v) In reditu. - (19v) Adoratio crucis. - (21r) Canticum puerorum. - (21v) In reditu ante altare oratio.

$(21 \mathrm{v}-24 \mathrm{v})$ FER. 5. IN COENA DNI.

(21v) In cena domini benedictio ignis. - (23r) Ad mandatum.

(24v) Datierung (in Rot) 1523.

(25r-35r) FER. 6. IN PARASCEVE.

(25r) Adoratio crucis. - (29r) Depositio crucis (Gschwend 86). - (29v) Vesper.

(35r-44r) In VIGILIA PASCHATIS.

(35r) Benedictio ignis. - (36v) In reditu canitur himnus Prudencii (AH 50, Nr. 31). - (37r) Exsultet. - (39v) Benedictio aquae. - (43v) Litaniae sanctorum.

(40v) Datierung 1523.

(44r-46v) DNCA RESURRECTIONIS DNI (Gschwend 86-88).

(46v-47r) Benedictio aQuae in vigilia Pentecostes (Verweis).

(47r) In ASSUMPTIONE BMV.

(47r-55v) ORdo PAENITENTIAE.

(55v-58r) EINKLEIDUNG DER Novizen.

Tit.: De induitione noviciorum.

(58r-65r) PROFESS.

Tit.: De professione noviciorum. - (65r) Datierung 1523.

(65r-67r) Ordo FÜR die Aufnahme von LaIen.

Tit.: De fraternitate laicali.

(67r-70v) Totenliturgie FÜR Die KonVEntualen.

Tit.: De obitu fratrum professorum nostri ordinis. Mit Datierung Bl. 70r 1523.

(70v) Schlussschrift mit Datierung und Schreibernennung: 1523 f.p. (= Franciscus Prensteiner). Anno domini $M^{\circ} C C C C C X X I I I$ tercio Idus Iunii is finitus est codiculus seu Obsequiale. Scriptus ad honorem et gloriam unigeniti ante secula summi patris filii domini nostri Hiesu (!) Christi eiusdemque matris gloriose virgini (!) Marie Novecelle patrone graciosissime per fratrem Franciscum Prenstainer tunc temporis in Novacella decanum (11. Juni 1523).

2 (71r-73v) Ordo BAptisteri (vgl. J. Baur, Die Spendung der Taufe in der Brixner Diözese in der Zeit vor dem Tridentinum [Schlern-Schriften 42]. Innsbruck 1938, 35-36).

Tit.: Exorcismus salis minor ad baptizandum si alias non esset in promptu. - Inc.: Exorciso te creatura salis in nomine patris omnipotentis et in charitate domini nostri Ihesu Christi et in virtute spiritus sancti ... - Expl.: ... sit tibi Deus in vitam eternam. Pax tecum.

3 (74r) Verfügung des Propstes Fortunat Troyer (Propst 1678-1707), betreffend die Offizien beim Begräbnis eines Klerikers, dat. 4. August 1687. 
Tit.: Declaratio Reverendissimi et Domini Domini Prcelati Fortunati circa Sepulturam Clerici. $(74 \mathrm{v}-75 \mathrm{v})$ leer.

4 (76r) Vermerke über den 1581 verstorbenen Neustifter Propst Augustinus Schbäl (recte: Schabl) und den 1581 zum Propst gewählten Adamus Lang.

$(76 \mathrm{v}-77 \mathrm{v})$ leer.

$\left(I^{*} \mathrm{r}-\mathrm{v}\right)$ leer.

W. N./U. S.

\section{Cod. 748}

\section{MEDIZINISCHE SAMMELHANDSCHRIFT}

Pap. III, 220 B1. $290 \times 215$. T. I-III: Wiener Raum (?), um 1440, T. IV: Schwäbisch-Schweizer Raum, um 1430.

B: $\quad$ Vier Teile: I (III, 1-40), II (41-52), III (53-137), IV (138-219[220]). Wohl im Zuge der Bindung am oberen rechten Blattrand zeitgenössische Lagenzählung jeweils am Lagenbeginn, tw. ausgeschrieben primo, tw. in arabischen Ziffern 2-9 und 12-19, tw. in römischen Zahlen X-XI ergänzt. Am oberen Blattrand Foliierung 19. Jh. durch die ULB Tirol; Fehler in der Zählung: 211 doppelt angeführt.

E: $\quad$ Schmuckloser gotischer Einband: Leder über Holz. Tirol (?), Mitte 15. Jh.

Der urspr. Bezug aus rotgefärbtem Leder auf den Deckeln nur in Spuren vorhanden, tw. noch als Einschläge auf der Innenseite der Deckel sichtbar. Die urspr. unter dem Bezug aufgeklebten Pergamentstreifen auf der äußeren und inneren Seite der Deckel freiliegend. Am Holz tw. Einritzungen (Rautenmuster) zur besseren Haftung sichtbar. Am VD und HD Spuren von je fünf Beschlägen. Spuren von zwei Langriemen-LederMetall-Schließen. Kanten abgeschrägt und gerade. Rücken: nach der Entfernung des Lederbezuges und der Beschläge mit braunem Leder neu bezogen, drei Doppelbünde. Kapitale mit Zwirn umstochen (oben urspr. dunkel gefärbt, unten naturfarben), gebrochen. An der Innenseite der Deckel Holz freiliegend. An der Innenseite des VD Exlibris und Signatur (s. bei G), an der Innenseite des HD Spuren des entfernten beschriebenen urspr. Spiegels.

G: Geschenk des Neustifter Präbendars und Klosterarztes Bertoldus de Saxonia ans Stift (gemeinsam mit Cod. 123 und vermutlich auch dem tw. von denselben Händen geschriebenen Cod. 453): Bl. IIIv Schenkungsvermerk (s. Nr. 2) mit Neustifter Wappen, Bl. 137v Besitzereintragung Bertoldus medicus Saxo. Zu Bertoldus vgl. Liber anniversariorum Novae Cellae Brixinensis (MGH Necrologia Germaniae III 46): „Item magister Bertoldus de Saxonia, medicine doctor, prebendarius et phisicus huius monasterii, in vita sua multa fecit bona et libere omnia sua dedit monasterio, prout continetur in litera prebendali, quam monasterio dedit"“. Bl. 137v Besitzvermerk 15. Jh. Liber iste est monasterii sancte Marie virginis in Novacella Brixinensis dyocesis mit Neustifter Wappen, Bl. 219r Besitzvermerk 15. Jh. (von gleicher Hand) Iste liber est monasterii sancte Marie virginis in Novacella. Bl. 1r Inhaltsangabe und Besitzvermerk 18. Jh. Summarium de febribus per Antonium Gaynerium. In fine Ysac de urinis. Ad Bibliothecam Neocell. An der Innenseite des VD Exlibris der Stiftsbibl. Neustift 18. Jh. 1809 anlässlich der vorübergehenden Aufhebung des Klosters Neustift der ULB Tirol übergeben. Bl. Ir alte Signaturen der ULB Tirol II $\overline{3}$ B 14 (Tinte, radiert), II $\overline{4}$ C 11 (Bleistift) und 748 (Tinte). Letztere beiden auch auf Bl. IIIv (Bleistift), 748 auch an der Innenseite des VD. Am Rücken gelbes Signaturschild der ULB Tirol 748. Bl. 1r Stempel der ULB Tirol 19. Jh. 1921 aufgrund des Friedensvertrages von St. Germain an den italienischen Staat abgegeben und von diesem 1929 dem Kloster Neustift als Dauerleihgabe überlassen. Bl. 1r Stempel der Soprintendenza Tridentina 20. Jh.

L: $\quad$ Kristeller I 439. - Neuhauser, Neustift 89. - Katalog ULB Tirol VIII 247, 530.

$$
\text { I (III, 1-40) }
$$

B: $\quad$ Pap. tw. stark verschmutzt (u. a. Wasserschaden), an den Rändern leicht eingerissen, Bl. 7 Loch. Bilder und Nachweise der Wasserzeichen s. WZMA. Datierung nach Wasserzeichenbefund. Identische Wasserzeichen: Neustift, Stiftsbibl., Cod. 748, T. III. Lagen: $3^{\mathrm{III}}$ (Vorsatzbl. $)+(\mathrm{VI}+1)^{13}+\mathrm{VII}^{25}+(\mathrm{VII}+1)^{40}$. Bl. 1 und 39 ein- 
geklebte Einzelbl. Lagen außen und in der Mitte durch Pergamentfälze verstärkt. Am oberen Blattrand mittig Kustoden in arabischen Ziffern 1-3.

S: $\quad$ Bl. Ir-IIIv (Vorsatzbl.) horizontale Tintenlinienrahmung, Bl. Iv-IIr zusätzlich seitlich von zwei Tintenlinien begrenzt. Schriftraum 210/225×130/140, seitlich von Tintenlinien begrenzt, zu 45-49 Zeilen. Bastarda (= Schreiber von T. II und III, von Neustift, Stiftsbibl., Cod. 453, T. II-IV und von Neustift, Stiftsbibl., Cod. 123, Schreiber 2, möglicherweise zu identifizieren mit Bertoldus de Saxonia, s. bei G). Bl. Ir-v, 1r, 40v vermutlich deutlich spätere Nachträge vom selben Schreiber.

A: $\quad$ Rote Auszeichnungsstriche, Paragraphzeichen, Unterstreichungen, $\mathrm{Bl}$. 29v und 31v jeweils rote Überschrift am Blattrand. Platz für Lombarden freigelassen, nicht ausgeführt. Tw. rote, tw. schwarze Repräsentanten. Bl. IIIv Neustifter Wappen in schwarzer Tinte.

1 (Ir-v) RezePte und Notizen.

(Ir) 1) Inc. mut.: ] aqua de floribus fabarum aut aqua furfuris aut aqua ... - Expl.: ... cum istis tribus aquis maxime albatur facies.

2) Tit.: Contra fluxum sanguinis narium. - Inc.: Sanguinaria id est bursa pastoris sive succus ...Expl.: ... in albumen ovi involvatur et immittatur.

(Iv) 3) Inc.: Signa generalia putridarum eis propria sunt duo ut dicit Averroes ... - Expl.. ... Si non tunc est effimera et hoc supposito quod febret.

4) Tit.: De tertiana continua. - Inc.: Nota. Galieus (!) $2^{\circ}$ de crisi dicit quod si videris urinam egri tendentem ... - Expl.: ... pervenerint VII periodi deinde consumetur.

5) Inc.: Ab infirmitate surgentibus cibaria nociva petentibus non est denegandum ... - Expl.. ... potius natura viget dum vota replentur.

6) Inc.: Vehemenciores fiunt motus egrium (!) et acta eorum in nocte ... - Expl.. ... quando sompnum auferunt ut in nocte.

(IIr-IIIr) tw. Rahmung.

2 (IIIv) SchenkUngsvermerk mit Inhaltsangabe: Liber iste donatus est monasterio sancte Marie virginis ad Novamcellam Brixinensis dyocesis a dive memorie magistro Bertoldo de Saxonia doctore medicine eximio cum aliis libris et rebus pro prebenda et remedio anime sue. Obiit 1476. Continet vero liber presens summarium de febribus editum per Antonium de Gaynerys. Librum Ysaac de urinis. Item librum Ysaac de febribus. Synonima Rasis.

3 (1r) Verse und Notizen.

1) Am oberen Blattrand sechs Verse aus Regimen Sanitatis Salernitanum (vgl. S. Renzi, Collectio Salernitana V. Naples 1859, V. 1931-1937). Inc.: Triplex causa febrem generat custodit et auget ... - Expl.: ... quare generatur putrida febris.

2) Inc.: Nota. Decrementa et incrementa paroxismorum ad invicem aut sunt secundum quantitatem aut secundum tempora aut secundum qualitatem. Si secundum quantitatem aut longior ... - Expl.: ... aut non precesserunt et sic est principium.

3) Inc.: Nota. Anticipacio paroxismi augmentum non significat nisi cum hoc longitudo temporis aut fortitudo febris augeatur ... - Expl.: ... completur digestio.

4 (1v-40v) Antonius Guainerius: Summarium de febribus (Druck: u. a. GW 11586. - ThorndikeKibre 318).

Tit.: Incipit summarium de febribus editum per me Anthonium de Gayneriis ad insignem arcium et medicine doctorem magistrum Antonium Maglianum de Cherio illustrissimi domini domini ducis Subaudie phisicum ad laudem Dei patris et filii et spiritus sancti feliciter incipit.

(1v) Prolog mit anschließender Kapitelübersicht. Inc.: [T]ui amoris gratia my Antoni Magliane ad hunc deveni locum ... - Expl.: ... me venire permittat qui est de virgine natus.

(2r) Text. Inc.: [C]um mee sit intencionis hoc in summario febrium ... - Expl.: ... sic breviter dicta sufficiant que huic summario finem imponit pro quo Ihesu crucifixo sint infinite laudes Amen. 
Schlussschrift: Et sic est finis tractatus de febribus ad insignem arcium et medicine doctorem magistrum Anthonium Maglianum de Chero (!) altissimi domini domini ducis Subaudie phisicum editus per Anthonium de Gayneriis de Papia in villa Crambraraci commorantem.

5 (40v) Notizen.

1) Inc.: Confortatio fit multipliciter. Primo per restauracionem bonam sicud spiritus ex vino aromatico dicuntur confortari ... - Expl.: ... vite ut faciunt bezaartica omnia.

2) Accidens morbi est triplex scilicet preventivus ut rigor concomitans ut dolor capitis et subsequens ut prostratio appetitus.

3) Nota. Triplex est rigor scilicet precedens et est in interpolates coincidens ex multitudine materie et subsequens a fortitudine expulsive. Et isti duo rigores sunt aliquando in compositis febribus.

$$
\text { II (41-52) }
$$

B: $\quad$ Pap. insbes. am Blattrand verschmutzt und eingerissen. Bilder und Nachweise der Wasserzeichen s. WZMA. Datierung nach Wasserzeichenbefund. Identische Wasserzeichen: Neustift, Stiftsbibl., Cod. 453, T. III. Lage: VI ${ }^{52}$. Lage außen und in der Mitte durch Pergamentfälze verstärkt.

S: Schriftraum $225 / 240 \times 135 / 140$, seitlich von Tintenlinen begrenzt, zu 51 Zeilen. Links neben dem Schriftraum eine Zählspalte, seitlich von Tintenlinien begrenzt. Bastarda (= Schreiber von T. I und III, von Neustift, Stiftsbibl., Cod. 453, T. II-IV und von Neustift, Stiftsbibl., Cod. 123, Schreiber 2, möglicherweise zu identifizieren mit Bertoldus de Saxonia, s. bei G).

A: $\quad$ Rote Auszeichnungsstriche, Paragraphzeichen, Unterstreichungen und Überschriften. Platz für Lombarden freigelassen, nicht ausgeführt. Repräsentanten.

6 (41r-51v) Christophorus BARsisius: De febrium cognitione et cura (Druck: Clementii Clementini lucubrationes. Basileae 1535, 251-283. - Thorndike-Kibre 765, vgl. auch 667).

Inc.: [I]ntenciones habende in febribus excerpte ex mente Avicenne ex locis universalibus et particularibus. In colerica interpollata pura sunt intenciones (am Blattrand ergänzt: Prima intencio) Est administracio regiminis debiti sex rerum ... - Expl.: ... Duodecima est respectus et cura accidencium que intelligenti sunt nota.

Schlussschrift: Expliciunt declaraciones intencionum in febribus humidarum et earum ordinacionem ad introduccionem iuvenum ad curacionem febrium et contra quosdam detrahentes Avicenne quod in curis egritudinum insufficienter procedat per magistrum Cristoforum de Pergamo arcium et medicine doctorem collectarum.

7 (52r-v) Tit.: Intenciones morborum materialium. - Inc.: Nota. In morbo materiali sunt habende iste intenciones. Prima amministracio regiminis debiti ... - Expl.: ... confortatio et remocio male qualitatis morbi etc.

8 (52v) Notizen.

1) Nota. Flebotomia electiva debet fieri parum post ortum solis et post primam et secundam digestionem et superfluitum expulsionem et post modicum exercicii. Sed coacta potest fieri omni hora secundum necessitatem cogentem.

2) Inter medicinas et corpora currunt proporciones que non comprehenduntur nisi cum experimento. Cum ergo experieris consequeris quid magis iuvativum sit, ut patet $X 3^{i i}$ capitulo de cura asumatis.

$$
\text { III (53-137) }
$$

B: Pap. leicht verschmutzt, am Blattrand tw. eingerissen. Bilder und Nachweise der Wasserzeichen s. WZMA. Datierung um 1435/40 nach Wasserzeichenbefund. Identische Wasserzeichen: Neustift, Stiftsbibl., Cod. 453, T. III und IV, Cod. 748, T. I. Lagen: $(\mathrm{V}+1)^{63}+\mathrm{V}^{73}+2 \cdot \mathrm{VI}^{97}+4 \cdot \mathrm{V}^{137}$. Bl. 58 eingeklebtes Einzelbl. Lagen 
außen und in der Mitte durch Pergamentfälze verstärkt. Lage 2-5 am oberen Blattrand mittig Kustoden in arabischen Ziffern. Bl. 137 neuzeitliches oranges Papiersignakel der ULB Tirol.

S: $\quad$ Bl. 52r-63v: Schriftraum 205/215×145/150. Zwei Spalten, von Bleistiftlinien begrenzt (Bl. 54v-59r und 63v über die zweispaltige Rahmung einspaltig beschrieben), zu 45-51 Zeilen. Bastarda (= Schreiber von T. I und II, von Neustift, Stiftsbibl., Cod. 453, T. II-IV und von Neustift, Stiftsbibl., Cod. 123, Schreiber 2, möglicherweise zu identifizieren mit Bertoldus de Saxonia, s. bei G). Bl. 91r-137r Überschriften in Textualis formata. Bl. 69v-73v, 90r und 117v vermutlich deutlich spätere Nachträge vom selben Schreiber. Bl. 91r137r Überschriften in Textualis formata.

A: Rote Auszeichnungsstriche, Paragraphzeichen, Unter- und Durchstreichungen, Marginalien, Besitzvermerk und Titel. Bl. 132v dreizeilige rote Lombarde. Platz für Lombarden freigelassen, nicht ausgeführt. Repräsentanten. Rubrikator vermutlich Bertoldus de Saxonia (s. bei G). Bl. 137v Neustifter Wappen in schwarzer Tinte.

9 (53ra-54ra) De AQUA VITAE (Thorndike-Kibre 779).

Tit.: De aqua vite. - Inc.: [H]ec sunt virtutes aque ardentis vel vite. Est enim clarior quam aqua rosacea et quia plus est secure ... - Expl.: ... distilla cum lento igne. Ista aqua ponitur loco balsami.

Parallelüberlieferung: Erfurt, UB, Dep. Erf. CA. 4 223, Bl. 157v.

10 (54ra-b) Notizen und REZEPTE.

1) Inc.: Nota verum secretum in provocacione urine. Recipe corticis interioris ... - Expl.: ... da cum aqua apericiam.

2) Inc.: Nota oleum factum per decoccionem medicinarum ... - Expl.: ... per inspissacionem a radiis solaribus facto.

3) Recipe lixinii partis (!) III olei nucum partis (!) I et valet contra cancrum et lupum et ignem persicum in principio certissimum est.

4) (von anderer Hand) Inc.: Antrax et carbunculus quia fiunt ex materia grossa ... - Expl.: ... fermentum est basis et materia emplastrorum.

5) Inc.: Nota. Quicumque esset lesus vel percussus a malicia Mercurii ... - Expl.: ... et unge locum et sanabitur.

11 (54v-64v) 〈Raimundus Chalmelli De Vinario»: De pestilentia libri tres, unvollständig (Druck: De peste libri tres opera Iacobi Dalechampii. Lugduni 1553. Ed. [Buch 1]: R. Hoeniger, Der schwarze Tod in Deutschland. Berlin 1882, 160-161, 163-169, 170-176).

Tit.: Ista sunt extracta ex quodam libro pestilenciali (rot:) optimo (schwarz:) de pestilencia primo tempore facta. - Inc.: Pestilencie causa dicitur esse triplex. Nam vel est causa radix superior tantum et hec est superior et celestis ... - Expl.: ... preparatio et earum evacuacio cum laxativis apropriatis dictis vel aliis.

Der Text auf Bl. 54v-58r entspricht Ed. Hoeniger 160-161, 163-169, 170-176, der Rest des Textes weicht von der freien Bearbeitung des Dalechampius erheblich ab (vgl. dazu Hoeniger 157-159).

Parallelüberlieferung: u. a. Heiligenkreuz, Stiftsbibl., Ms. 485, Bl. 142r; Padova, Biblioteca del Seminario vescovile, Cod. 16, Bl. 1ra.

12 (64v) REZEPT.

Inc.: Nota. Frequenter fit aurum potabile sic et confert pestilenciatis. Recipe auri optimi ... Expl.: ... secundum quos datur credo paucum conferre quia minime digeritur.

13 (64v-66r) Tit.: Dubia quedam optima. - Inc.: Primum dubium quare confert tyriaca et metridatum cum sint excellentis calefactionis et notum est quod que augmentant caliditatem in corpore nostro ... - Expl.: ... sub arbore nucis in ortis caulium et sub umbra oleandri. Et sic est finis. 
14 (66r) Notiz.

Inc.: Nota rupto apostemate et extracta materia ... - Expl.: ... antracis foliis basiliconis cito implebitur carne.

15 (66v, am oberen Blattrand) Zitat aus «Gentilis de Fulgineo»: Consilium de peste, Textbeginn (Druck: u. a. GW 10620).

Quoniam gloriosus et excelsus Deus de largitate sua medicinam produxit et medicum velud nature refugium creavit decet eum nichil negligencie habere in ostendendo sanitatis ingenium ut primo de [ingenio] sanitatis.

16 (66v-69v) Practica contra Pestem (Ed.: G. Sticker, Tractatus de epidemia anni 1424. Janus 27 [1923] 15-27. - Thorndike-Kibre 1288).

Tit.: Contra pestem alia practica. Schlussschrift: Deo laus eiusque matri virgini Marie, beate Barbare et omnibus sanctis Amen.

17 (69v) Notizen.

1) Nota quod succus peonie vulneribus noviter fissis applicatus nondum ad sanacionem provenientibus curat. Expertum est.

2) Nota. Elleborus niger decoctus in pomo sub prunis datus in scrupulis II optime purgat tempore pestilencie.

$18(69 \mathrm{v}-70 \mathrm{v})$ IOHANNES DE TORNAmiRa: Preservatio et cura apostematum antrosorum pestilentialium (Ed.: K. Sudhoff, Pestschriften aus den ersten 150 Jahren nach der Epidemie des ,schwarzen Todes“ 1348 III. Sudhoffs Archiv 5 [1912] 48-53. - Thorndike-Kibre 313).

Tit.: Preservacio et cura apostematum antrosorum pestilencialium secundum intencionem Iohannis de Tornamira.

19 (70v) REZEPTE.

Tit. (am Blattrand): Receptum preservacionis aliud. - Inc.: Contra aeris infeccionem. Eius enim attraccione membra principalia ... - Expl.: ... sumendum est ad modum unius nucis mus sine potu.

20 (70v) REZEPT.

Tit. (am Blattrand): Nota contra antracem. - Inc.: Nota. Tempore pestilenciali si vis ut apostema ex materia venenosa ... - Expl.: ... postea ligetur et superponatur pannus.

21 (71r) Kurzes Pestregimen.

Tit.: Remedia et regimen contra pestilenciam. - Inc.: Oportet ut extrahantur (gestrichen: primo) superfluentes humide primo per flebotomiam ... - Expl.: ... vitetur ira et tristicia et fiat conversacio socialis cum dilectis.

22 (71r-72r) Iohannes de SAncta Sophia: Consilium de pestilentia.

Tit.: Consilium aliud de pestilencia magistri Iohannis de sancta Sophia. - Inc: Quamvis venerandi domini hec pestis tam admirabilis et horrenda a causis superioribus procedat regulantibus et gubernantibus corpora nostra ... - Expl.: ... et quia ut cognovi bonum animum geritis erga me. Deus vos conservet ab hac peste Amen.

23 (72r) REZEPT.

Tit.: Tragea contra pestem. - Recipe tormentille drachmas 15 terre sigilate ... fiat tragea.

24 (72r-73v) Tit. (am Blattrand): Contra pestilenciam. - Inc.: Pestilencia est mutacio quedam in aere facta propter admixtionem vaporum corruptorum vel sic est morbus quidam contagiosus ... - Expl.: ... hoc idem potest fieri si infirmus iaceat continue dormiendo.

25 (74r-90r) Mundinus de LeuciIs: Anatomia (Druck: u.a. GW M25667. Weitere Drucke s. A. 
C. Klebs, Incunabula scientifica et medica. Bruges 1938, ND Hildesheim 1963, 230-231. Thorndike-Kibre 1306).

Tit.: Anathomia Mundini. - Inc.: [Q]uoniam ut ayt Galienus septimo terapentice (!) methodi auctoritate Platonis opus in aliqua sciencia vel arte ... - Expl.: ... debet esse excarvata ne aggravet pedem.

Schlussschrift: Et ex hoc est huius doctrine dictum completum que est de corporis humani anothomia (!) a magistro Mundino artis medicine professore dignissimo ad utilitatem studencium Bononie compilata. Deo gracias.

26 (90r) Tractatus de anthrace.

Tit. (am Blattrand): De antrace. - Inc.: Antrax est apostema quod partim fit de colera partim de sanguine partim de melancholia. De sanguine habet putredinem ... - Expl.: ... cum bombace ex aliquo ungento calido vel oleo ungatur.

27 (90v-137v)<ANTONIUS GuAINERIUS»: Tractatus de peste et venenis (Druck: GW 11591).

Tit.: Incipit tractatus de peste ad illustrissimum dominum dominum Philippum Mariam Vicecomitem ducem Mediolanensem Papie Anglarieque comitem et Ianue dominum.

(90v) Prolog (Thorndike-Kibre 1036). Inc.: [P]ersepe animadvertens hoc mortale hominum genus iniuriis casibus additum et infinita mortis ... - Expl.. ... prefati illustrissimi et clementissimi domini domini mei precipuam utilitatem Amen.

(91r) Inhaltsübersicht zu Pars 1.

(91r) Pars 1 (Thorndike-Kibre 280). Inc.: [C] um aliquem pestis rapit eum taliter alterat et devorat ut velud incendium totum in brevi ... - Expl.. ... eius genitricis alme tociusque celestis curie triumphantis Amen.

(122r) Inhaltsübersicht zu Pars 2.

(122r) Pars 2 de venenis (Thorndike-Kibre 529). Inc.: [E]t si venenum multipliciter accipi possit hic per venenum id solum intellego quod qualitercumque humano corpori ... - Expl.: ... dissonum quod me advertere nichil est meeque compaciendum est ignorancie et non arrogancie imputandum.

Schlussschrift: Explicit et est finis. Besitzereintrag und Besitzvermerk (s. bei G).

$$
\text { IV (138-219[220]) }
$$

B: $\quad$ Pap. verschmutzt, am oberen Blattrand tw. Wasserflecken. B1. 138-147 schmaler $(290 \times 210)$. Bilder und Nachweise der Wasserzeichen s. WZMA. Datierung nach Wasserzeichenbefund. Lagen: $\mathrm{V}^{147}+6 \cdot \mathrm{VI}^{218(219)}+$ $1^{219(220)}$. Lagen außen und in der Mitte durch Pergamentfälze verstärkt. Am Lagenbeginn Kustoden am oberen Blattrand in arabischen Ziffern (1 und 3-7) und am unteren Rand tw. ausgeschrieben, tw. in arabischen Ziffern (primus sexternus, $3^{\text {us }}$ sexternus, $4^{\text {us }}, 5^{\text {us }}, 6^{\text {tus }}$ ). Bl. 159v und 207v Lagenreklamanten erhalten. Bl. 138 neuzeitliches gelbes Papiersignakel der ULB Tirol.

S: $\quad$ Bl. 138r-212v: Schriftraum 190/195×130/135. Zwei Spalten, von Tintenlinien gerahmt, zu 38-43 Zeilen. Zirkelstiche. Bl. 213r-219v: Schriftraum 230/235×160/170. Drei Spalten, von Tintenlinien gerahmt, zu 47-53 Zeilen. Bastarda von einer Hand. Ergänzungen und Notizen (Bl. 203r und 209r ausführlich) von demselben Schreiber wie T. I, II und III (= Schreiber von Neustift, Stiftsbibl., Cod. 453, T. II-IV und Neustift, Stiftsbibl., Cod. 123, Schreiber 2, möglicherweise zu identifizieren mit Bertoldus de Saxonia, s. bei G), Duktus der späteren Nachträge.

A: Rote Auszeichnungsstriche, Paragraphzeichen, Unter- und Durchstreichungen, Überschriften. Platz für Lombarden freigelassen, nicht ausgeführt. Repräsentanten.

28 (138ra-161rb) Isaac Iudaeus, ins Lat. übersetzt von «Constantinus Africanus»: Liber de urinis (Druck: Opera omnia. Lugduni 1515. J. Peine, Die Harnschrift des Isaac Judaeus, Diss. Leipzig 1919, 10-74). Tit.: Isaac de urinis. 
(138ra) 〈Constantinus Africanus〉: Praefatio (Thorndike-Kibre 688). Inc.: [I]n Latinis quidem libris nullum auctorem invenire potui qui de urina certam et auctenticam cognicionem dederit ... - Expl.: ... de unaquaque urina et ypostasi quid significet etc.

(138ra) Text (Thorndike-Kibre 1608). Inc.: [U]rina est colamentum sanguinis et aliorum similiter humorum de nature quidem actionibus natum ... - Expl.: ... Urina spumosa in superficie sicut uva (!) dolorem renum significat etc.

Schlussschrift: Expliciunt urine Ysac etc.

(161v) nur Rahmung.

29 (162ra-212vb) IsaAc Iudaeus, ins Lat. übersetzt von «Constantinus Africanus»: Liber de febribus (Druck: Opera omnia. Lyon 1515). Tit.: Incipit Ysaac de febribus.

(162ra) 〈Constantinus Africanus»: Praefatio (Thorndike-Kibre 1304). Inc.: [Q]uoniam te karissime filii Iohannes lacrimas mesto cordis dolore perpetim effundere perspexi ... - Expl.: ... Quibus itaque cognitis curas earum levissime impendere sciet.

(162ra) Text (Thorndike-Kibre 820). Inc.: [L]iber ergo iste in V partes dividitur. Prima est de essencia febris eiusque diffinicione febris naturam et causas ... - Expl... ... sanguinem qui est eius materia et propter vicinitatem cordis etc.

Schlussschrift: Et sic est finis huius operis. Deo gracias.

Zur Überlieferung s. R. Veit, Das Buch der Fieber des Isaac Israeli und seine Bedeutung im lateinischen Westen. Wiesbaden 2004.

30 (176ra, 212vb) Verse aus Regimen Sanitatis Salernitanum (Ed.: S. Renzi, Collectio Salernitana V. Naples 1859).

30.1 (176ra) am unteren Blattrand vier Verse aus Regimen Sanitatis Salernitanum (Ed. [V. 1 und 2] Renzi V. 2924-2925).

Tit.: Metra. - Inc.: Est triplex tipus rigor oripilacio frigus /... - Expl.: ... A causa nigra sit orippilacio vera / Est quartus tremor quod febres circuit has tres.

Die letzten zwei Verse nicht bei Renzi.

30.2 (212vb) Sechs Verse aus Regimen Sanitatis Salernitanum (Ed. Renzi V. 1588-1589, 1604-1605, 1590-1591).

Inc.: Grana quater quinque scrupuli pro pondere summe/... - Expl.: .../Exagium solido difert in nomine solo.

31 (212v) am unteren Blattrand Notiz.

Inc.: Item nota quod febricitantibus acutatarum (!) febrium et etiam aliis qui paciuntur ... Expl.: ... in lecto ut bene possit resistere et hoc per unam horam.

32 (213ra-218vb) Synonyma Rasis (Thorndike-Kibre 73, 81). Auch Serapion und Mesue zugeschrieben.

Inc.: [Allia]seph puncti rubei qui sunt ut pulicis morsus et fiunt in omnibus membris ... - Expl.: ... [V]egi id est vitreolum. [V]erusca id est pondera etc.

Schlussschrift: Expliciunt Synonima Rasis.

33 (218vc) Notizen.

Tit.: Questio utrum spiritus sit subiectum sanitatis. - Inc.: Spiritus est vapor temperatus genitus ex parte subtiliori sanguinis ... - Expl.: ... dicitur de turbulencia oculi.

Darunter: Venetus color id est celescis (!).

(219r) Besitzvermerk (s. bei G).

(219v) nur Rahmung. 
Cod. 754

\section{THEOLOGISCHE SAMMELHANDSCHRIFT, u. a. IOHANNES GERSON}

Pap. 26 Bl. $280 \times 195$. Tirol, 3. Viertel 15. Jh.

B: Bilder und Nachweise der Wasserzeichen s. WZMA. Datierung nach Wasserzeichenbefund. Identische Wasserzeichen: u. a. Innsbruck, ULB Tirol, Cod. 8 (dat. 1459), Cod. 101 (dat. 1464). Lagen: VI ${ }^{12}+\mathrm{V}^{22}+4^{26}$. Bl. 27 als Spiegel auf dem HD aufgeklebt. In der Mitte der Lage 2 in Textura beidseitig beschriebener Pergamentfalz (zwei Spalten, Rubrizierung, u. a. Ps 26,14). Am Ende der Lage 1 Reklamante. Bis Bl. 6 am unteren Blattrand mittig zeitgenössische Foliierung. Am oberen Blattrand Foliierung 19. Jh. durch die ULB Tirol.

S. Schriftraum $220 \times 125 / 135$, von Tintenlinien gerahmt, zu 36-40 Zeilen. Textualis cursiva mit variierender Schriftgröße von zwei Händen: 1) Bl. 1r-12v; 2) Bl. 13r-26v.

A: B1. 1r-12v schwarze Unterstreichungen, Paragraphzeichen. Aussparungen für zwei- und dreizeilige Lombarden. Vereinzelt rote Auszeichnungsstriche. Bl. 13r und 18r-26v Überschriften sowie zwei- und dreizeilige Lombarden, tw. mit Punktverdickungen und Ausläufern. Repräsentanten. Bl. 16v Nota-Hinweis mit Segenshand $O$ vere nota. Ab Bl. 14r Oberlängen in der ersten bzw. Unterlängen in der letzten Zeile bisweilen cadellenartig gedehnt.

E: $\quad$ Neuzeitlicher Bibliothekseinband: schwarz gesprenkeltes braunes Pap. Neustift, 18. Jh.

Buchblock tw. nur mehr schwach mit dem Einband verbunden, Rücken tw. freiliegend. Signaturschild (s. bei G). Schnitt rot gesprenkelt. Spiegel Pap. 18. Jh. Am Spiegel des VD Rahmung, Exlibris und Signaturen (s. bei G), am HD nur Rahmung.

G: Zeitpunkt und Art der Erwerbung durch Neustift unbekannt. Am Spiegel des VD Exlibris der Stiftsbibl. Neustift 18. Jh. 1809 anlässlich der vorübergehenden Aufhebung des Klosters Neustift der ULB Tirol übergeben. Am Spiegel des VD alte Signaturen der ULB Tirol II $\overline{6} D$ [...] (?, Tinte, radiert), II $\overline{4} C 17$ (Bleistift), 754 (Tinte). Am Rücken bzw. VD gelbes Signaturschild der ULB Tirol 754. Bl. 1r Stempel der ULB Tirol 19. Jh. 1921 aufgrund des Friedensvertrages von St. Germain an den italienischen Staat abgegeben und von diesem 1929 dem Kloster Neustift als Dauerleihgabe überlassen. Bl. 1r Stempel der Soprintendenza Tridentina 20. Jh.

L: $\quad$ Wilhelm I 137. - Peintner, Stiftsbibliothek 121. - J. Mangei, Kartäuserorden und Visionsliteratur im Mittelalter und in der Frühen Neuzeit, in: S. Lorenz (Hrsg. in Zusammenarbeit mit dem Institut für Geschichtliche Landeskunde und Historische Hilfswissenschaften der Eberhard-Karls-Universität Tübingen und dem Instytut Informacji Naukowej i Studiów Bibliogicznych der Universität Warschau), Bücher, Bibliotheken und Schriftkultur der Kartäuser. Festgabe zum 65. Geburtstag von Edward Potkowski (Contubernium 59). Stuttgart 2002, 289-316, hier 301 und Anm. 76. - D. D. Martin, Carthusians as Advocates of Women Visionary Reformers, in: J. M. Luxford, Studies in Carthusian Monasticism in the Late Middle Ages. Turnhout 2009, 127-153, hier 139. - Katalog ULB Tirol VIII 269, 530.

1 (1r-11v) Iohannes Gerson: De oratione et suo valore (Ed.: Glorieux, Oeuvres II 169-191).

2 (11v-13r) 〈Dionysius Carthusianus : Revelatio cuiusdam Carthusiensis in missa, dat. 1454 (vgl. Dionysius Carthusianus, Opera Omnia, Bd. 1, XLI-XLVIII).

Bl. 11v Vermerk am Rand [V]isio cuiusdam Karthusiensis [...]c persecucione seu statu sancte matris ecclesie anno domini 1454. Rubrica.

Inc.: [Q]uidam religiosus ordinis Cartusiensis monasterii in Ruremunda in solempnitate purificacionis gloriosissime virginis Marie in summa missa toto conventu presente et inspiciente ab exterioribus sensibus ... - Expl.: ... Accidit autem hec visio currente videlicet anno domini milesimo quadringentesimo quinquagesimo quarto duravitque revelacio ista per integram circiter horam quia usque ad finem misse sedit in ea frater quasi immobilis et abstractus sicut nunc cecitatum est ad laudem et gloriam omnipotentis Dei qui est super omnia Deus gloriosus et adorandus in secula seculorum benedictus Amen.

Zur handschriftlichen Überlieferung und zum Verhältnis der Textredaktionen bzw. -fassungen vgl. Mangei 289-316. 
3 (13r-18r) EpISTOLA DE VISIONE CUIUSDAM FRATRIS ORDINIS CARTHUSIENSIS IN RUREMUNDA.

Tit.: Sentimentum cuiusdam Cartusiensis super infestacione Thorcorum. - Inc.: Venerande ac predilecte pater ad satisfaciendum obediencie michi per paternitatem vestram nuper iniuncte sub actu visitacionis videlicet ut scribere vobis deberem quid senciam ... - Expl.. ... propter peccata nostra ut animabus saltem nostris provideat de salute eterna. Quod nobis prestare dignetur pater et filius et spiritus sanctus.

Inc. u. a. Melk, Stiftsbibl., Cod. 1799, Bl. 78r.

Lit.: Martin 127-153, bes. 139-142.

4 (18r-26v) 〈Ps.-Nicolaus De DinKelSBÜHL〉: Speculum artis bene moriendi (Druck: u. a. GW 2571. R. Rudolf, Ars moriendi. Von der Kunst des heilsamen Lebens und Sterbens [Forschungen zur Volkskunde 39]. Köln, Graz 1957, 75. Madre 292. Bloomfield Nr. 1076). Gegenüber Druck gekürzt.

Tit.: Tractatus de arte moriendi magistri Iohannis Gerson. - Inc.: Cum de presentis exilii [miseria] mortis transitus propter moriendi impericiam ... - Expl.. ... ut prius antequam mors ipsum arripiat id ipsum scire mori discat. Quod nobis prestare dignetur pater et filius et spiritus sanctus Amen.

Zur handschriftlichen Überlieferung, zum Werk und zur Verfasserfrage (in den Hs. u. a. auch Albertus Magnus, Dominicus de Capranica, Henricus de Langenstein, Iohannes Nider, Matthaeus de Cracovia, Thomas Peuntner zugeschrieben) s. Madre 292-295 und Rudolf 75-82. Bei Madre 292-295 unter den Opera dubia des Nicolaus de Dinkelsbühl angeführt, von Rudolf zu den echten Werken gezählt. Vgl. K. Schneider, „Speculum artis bene moriendi“. Verfasserlexikon² IX 40-49.

5 (26v) Votivmessen und Gebete für Verstorbene (nicht im Druck für De arte moriendi nachweisbar).

Inc.: Quidam egregius doctor in sermone publice predicavit quod quicumque devota intencione infrascriptas missas legeret seu legi disponeret pro anima ... - Expl.. ... quibus completis anima eidem apparuit leta et liberata magnas grates referens.

Fünf Messen. Inc.: Prima missa est de exaltacione sancte crucis ... In secunda missa sic domine Ihesu Christe qui iudicium innocentis sustinuisti... In tercia sic domine Ihesu Christe qui innocenter et indigne in cruce es conclamatus ... In quarta missa sic domine Ihesu Christe per vulnera piissimi corporis et cordis tui ... In quinta sic domine Ihesu Christe rex celorum per sepulturam tuam dignare animam ... - Expl.. ... ut ipsa a te numquam separetur in perpetuum. Parallelüberlieferung: Weimar, Herzogin-Anna-Amalia Bibl., Cod. Q 108, Bl. 316r.

Schlussschrift: Amen dicat hec fidelis / qui regnare vult in celis. 


\section{Cod. 755}

\section{THEOLOGISCHE SAMMELHANDSCHRIFT}

Pap. 12 Bl. $270 \times$ 200. Neustift oder Wiener Raum (?), 6. Jz. 15. Jh., 1481 (?) und 16. Jh.

B: $\quad$ Bilder und Nachweise der Wasserzeichen s. WZMA. Datierung nach Wasserzeichenbefund. Lage: VI ${ }^{12}$. Bl. 1r-9v am oberen Blattrand mittig in Rot Werktitel des jeweiligen Textabschnittes, auf Recto und Verso aufgeteilt, stark beschnitten. Am oberen Blattrand Foliierung 19. Jh. durch die ULB Tirol. Bl. 4 neuzeitliches gelbes Papiersignakel der ULB Tirol.

S: $\quad$ Schriftraum $200 \times 140$. Zwei Spalten, von Tintenlinien gerahmt, Bl. 1ra-9vb zu 42-46, Bl. 10ra-12vb zu 27-37 Zeilen. Zwei Hände: 1) Bl. 1ra-9vb Bastarda, möglicherweise dat. [14]81 (Bl. 3vb); 2) Bl. 10ra-12vb Humanistische Kursive 16. Jh. Nach Goy 424 möglicherweise in Neustift entstanden.

A: $\quad$ Bl. 1ra-9vb rote Auszeichnungsstriche, Unterstreichungen und Überschriften. Bl. 1ra dreizeilige, sonst zweizeilige rote Lombarden. Am oberen Blattrand Buchtitel in Rot, beschnitten, tw. zur Gänze weggeschnitten. Bl. 10r-12v keine Rubrizierung.

E: $\quad$ Neuzeitlicher Bibliothekseinband: schwarz gesprenkeltes braunes Pap. Neustift, 2. H. 18. Jh. Am Rücken bzw. VD Signaturschild der ULB Tirol. Schnitt rot gesprenkelt, kaum sichtbar. Spiegel Pap. 18. Jh., am Spiegel des VD Exlibris und Signaturen (s. bei G), Spiegel des HD leer.

G: $\quad$ Hs. möglicherweise in Neustift entstanden; andernfalls Zeitpunkt und Art der Erwerbung unbekannt. Am Spiegel des VD Exlibris der Stiftsbibl. Neustift 18. Jh. 1809 anlässlich der vorübergehenden Aufhebung des Klosters Neustift der ULB Tirol übergeben. Am Spiegel des VD alte Signaturen der ULB Tirol II $\overline{6} D[\ldots]$ (? Tinte, radiert), II $\overline{4} C 18$ (Bleistift) und 755 (Tinte). Am Rücken bzw. VD gelbes Signaturschild der ULB Tirol 755. Bl. 1r Stempel der ULB Tirol 19. Jh. 1921 aufgrund des Friedensvertrages von St. Germain an den italienischen Staat abgegeben und von diesem 1929 dem Kloster Neustift als Dauerleihgabe überlassen. Bl. 1r Stempel der Soprintendenza Tridentina 20. Jh.

L: $\quad$ Goy 424, Nr. 135. - Peintner, Stiftsbibliothek 122. - Katalog ULB Tirol VIII 269, 530.

1 (1ra-3vb) Iohannes Gerson: De probatione spirituum (Ed.: Glorieux, Oeuvres IX 177-185. Bloomfield Nr. 4280).

Tit.: Sequitur alius tractatulus specialis de probacione spirituum editus per supra nominatum arcium et sacre theologie professorem m. Io. Gerson [in] concilio Constanciensi. (3vb) unmittelbar an das Explicit anschließend Datierung (?) in Rot: LXXXI.

2 (4ra-8ra) Hugo de Sancto Victore: De orando Deum (PL 176, 977-988. - Goy 424, Nr. 135. Bloomfield Nr. 4865). Gegenüber PL tw. leicht abweichend. Ohne Prolog, Beginn der einzelnen Kapitel in der Hs. nicht hervorgehoben.

Tit.: Hugo de Sancto Victore de orando Deum etc. - Inc.: Quo studio et quo affectu a nobis orandus sit Deus ... - Expl.: ... et gratissimum Deo sacrificium in ara crucis adoletur ibi Amen etc. Bl. 6v nur Rahmung, Forts. des Textes von Bl. 6vb auf Bl. 7ra ohne Textverlust.

3 (8rb-vb) Iohannes Gerson: De modo confessionis et absolutionis sacramentalis (Ed.: Glorieux, Oeuvres IX 646-648).

4 (8vb-9va) Iohannes Gerson: De modo excommunicationum (Ed.: Glorieux, Oeuvres IX 92-94).

5 (9va-b) Direkt anschließend ohne Hervorhebung: 〈Iohannes Gerson (?)〉: De iniunctione paenitentiae (Ed.: Glorieux, Oeuvres I 48. - Bloomfield Nr. 5390).

6 (10ra-12vb) Auszüge aus verschiedenen LAt. Autoren.

(10ra-11rb) Publius Terentius Afer, mit vereinzelten Auszügen aus dem Kommentar des Iohannes Calphurnius und des Aelius Donatus (Druck: Lipsiae 1830. Ed.: R. Kauer, W. M. Lindsay. Oxonii 1958. Kommentar nur im Druck enthalten). Vereinzelt Einschübe aus Werken anderer Autoren. 
(10ra) Tit.: Andria: Prolog, 22-23. - 1,1,60-61. - 1,1,68. - 1,1,77-79. - 1,2,191. - 1,3,218. 1,5,266. - 2,1,305-306. - 2,1,309. - 2,1,330-331. - 2,5,425-427. - 3,3,555. - 5,3,903. 5,4,940. - 5,5,959-961.

(10ra-b) Tit.: Eunuchus: Prolog, 41. - 1,2,178. - 2,1,225-226. - 2,2,248-249. - 2,2,251-253. 2,2,265. - 2,2,276. - Kommentar zu 2,3,379. - 2,3,381. - 3,1,408-409. - 3,1,426. - 3,1,445. 3,2,476. - 3,2,490-491. - 3,2,494-495. - 4,2,640-641. - 4,4,722. - 4,4,732. - 4,6,761-762. 4,7,788-789. - Plautus: Miles gloriosus 1,1,68. - Forts. Terenz 5,1,832.

(10rb-vb) Tit.: Heautontimorumenon. Cicero: De officiis 1,22 - 1,2,177. - 1,2,202. - 2,2,239240. - 2,3,256. - 2,3,314. - 2,3,364. - Kommentar zu 2,4,382. - 3,3,419. - Cicero: Cato maior de senectute 3,7. - Forts. Terenz 1,1,77. - 1,2,209-210 - 3,3,481-483. - 3,3,503-506. - 3,3,573. 3,3,566-567 - 3,3,578. - 3,3,611. - 4,1,646. - 4,1,648. - 4,1,666. - 6,2,675. - Kommentar zu 4,3,687. - Kommentar zu 4,3,693. - 4,3,706. - Kommentar zu 4,4,732. - Kommentar zu 4,5,753. - 4,5,796. - 4,6,805. - 4,7,839. - 5,1,887. - 5,1,922-923. - 5,2,962-963. - 5,3,991-993. (10vb-11ra) Tit.: Adelphis: 1,1,74-75. - 1,2,98-99. - 1,2,105 - 2,2,216. - 2,3,254 - 3,3,386388. - 3,3,414-416. - 3,3,399. - Pii esse debemus in parentes in saguine (!) nobis iniunctos ad neccesitatem precipue autem post debemus esse in Deo. - 3,4,508-509. - 4,1,537. - 4,7,734. 4,7,739-741. - 5,3,833-834. - 5,4,855-856. - 5,4,861.

(11ra-b) Tit.: Phormio: 1,1,41-42. - 1,1,55-56. - 1,2,77-78. - 1,2,138. - 1,3,172. - 1,4,203. 2,1,264-265. - 2,1,275-277. - 2,2,330-331. - 2,4,454-456. - 3,2,487. - 4,1,587. - 4,5,726. 5,1,756-758. - 5,2,766-767. - 5,8,903-904. - 5,8,948-950.

(11rb) Tit.: Echira (recte: Hecyra): 2,1,199-200. - 2,1,202-204. -4,4,660-661. - Kommentar zu 4,4,687.

(11va-b) Quintus Horatius Flaccus: Carmina (Ed.: D. R. Shackleton Bailey, Q. Horati Flacci Opera. Berolini et Novi Eboraci 2008). Tit. stark beschnitten: Horacii par[...]. Ode in libro primo.

(11va) 1,3,37-40. - 1,4,13-20. - 1,10,7-9. - 1,35,26-28.

(11va) Decimus Iunius Iuvenalis: Saturae (Ed. J. A. Willis. Stutgardiae 1997) 9,128-129.

(11va-b) Quintus Horatius Flaccus: Carmina (Ed. wie oben) 2,2,9-12. - 2,3,21-28. - 2,10,912. - 2,10,19-20. - 2,11,16-18.

(11vb) Publius Ovidius Naso: Ars amatoria (Ed. E. J. Kenney. Oxonii $\left.{ }^{2} 1995\right)$ 2,279-280.

(11vb) Gaius Sallustius Crispus: De coniuratione Catilinae (Ed. L. D. Reynolds. Oxonii 1991) 52,29 .

(11vb) Quintus Horatius Flaccus: Carmina (Ed. wie oben) 2,13,13-14.

(11vb-12ra) Quintus Horatius Flaccus: Carmina (Ed. wie oben) 2,14,1-4. - 2,16,13-16. 2,16,25-28. - 2,18,15-16. - 3,1,13-15. - 3,1,16-20. - 3,2,13. - 3,2,29-32. - 3,2,21-22. - 3,3,910. $-3,29,29-32$.

(12ra) Decimus Iunius Iuvenalis: Saturae (Ed. wie oben) 2,3. - 13,209-210.

(12ra) Quintus Horatius Flaccus: Sermones (Ed. wie oben) 2,8,61-63.

(12ra) IuvenaLIs: Saturae (Ed. wie oben) 6,53-54.

(12ra) Quintus Horatius Flaccus: Carmina (Ed. wie oben) 4,7,7-8. - 4,7,14-18.

(12rb) Quintus Horatius Flaccus: Ars poetica (Ed. wie oben) 158-174. - 25-26. - 139. - 359. 337. - 343. - 350. - 356. - 390. - 385. - 365. - 476.

(12va) Quintus Horatius Flaccus: Sermones (Ed. wie oben) 1,1,106-107. - 1,2,86-91. - 1,3,6869. - 2,3,325-326. - 2,3,94-99. - 2,5,7. - 2,6,94-97.

(12va-b) Quintus Horatius Flaccus: Epistolae (Ed. wie oben) 1,1,45-46. - 1,2,14. - 1,2,27-31. 1,2,57-59. - 1,2,69-70. - 1,4,14. - 1,5,12. - 1,5,16-20. - 1,6,27-28. - 1,6,36-38. - 1,7,98. 1,8,11. - 1,12,4. - 1,10,47-48. - 1,16,48. - 1,16,52-53. - 1,16,78-79. 


\section{Cod. 756}

\section{MATTHIAS ENGELSCHALK}

Pap. 53 Bl. $275 \times 200$. Süddeutscher Raum, 1479 .

B: $\quad$ Bilder und Nachweise der Wasserzeichen s. WZMA. Wasserzeichenbefund mit Datierung übereinstimmend. Lagen: 4. VI ${ }^{48}+5^{53}$. Bl. 49-53 eingehängte Einzelbl. In den Lagenmitten beidseitig beschriebene Pergamentfälze, tw. rubriziert (Makulatur aus liturgischen Hs.). Am oberen Blattrand Foliierung 19. Jh. durch die ULB Tirol.

S: $\quad$ Schriftraum $255 \times 165$. Zwei Spalten, von Tintenlinien gerahmt, zu vorwiegend 43 bzw. 46 Zeilen. Bastarda, dat. 1479 (Bl. 53ra).

A: Rote Auszeichnungsstriche, Unterstreichungen, zweizeilige (Bl. 1ra vierzeilige) rote Lombarden mit Punktverdickungen.

E: $\quad$ Neuzeitlicher Bibliothekseinband: schwarz gesprenkeltes braunes Pap. Neustift, 2. H. 18. Jh. Rücken: Pap. oben eingerissen und geklebt, drei einfache Bünde. Im zweiten Feld Signaturschild (s. bei G). Spiegel Pap. 18. Jh. Am Spiegel des VD Exlibris, Signaturen und Stempel (s. bei G), Spiegel des HD leer.

G: Zeitpunkt und Art der Erwerbung durch Neustift unbekannt. Am Spiegel des VD Exlibris der Stiftsbibl. Neustift 18. Jh. 1809 anlässlich der vorübergehenden Aufhebung des Klosters Neustift der ULB Tirol übergeben. Am Spiegel des VD alte Signaturen der ULB Tirol II [...] (radiert, Tinte), II $\overline{4}$ C 19 (Bleistift) und 756 (Tinte). Am Rücken gelbes Signaturschild der ULB Tirol 756. Bl. 1r Stempel der ULB Tirol. 1921 aufgrund des Friedensvertrages von St. Germain an den italienischen Staat abgegeben und von diesem 1929 dem Kloster Neustift als Dauerleihgabe überlassen. Am Spiegel des VD Stempel der Soprintendenza Tridentina 20. Jh.

L: $\quad$ Stegmüller RB Nr. 5550 Suppl. - Stefani 118. - Peintner, Stiftsbibliothek 121. - Katalog ULB Tirol VIII 269, 530 .

«Matthias Engelschalk»: De passione Christi secundum quattuor evangelistas (Stegmüller RB Nr. 5550 Suppl., mit Nennung der Hs.)

Tit.: Passio domini nostri Ihesu Christi secundum Matheum Marcum Lucam et Iohannem. - Inc.: In illo tempore dixit Ihesus discipulis suis. Scitis quia post biduum pascha fiet et filius hominis tradetur ut crucifigatur... (Mt 26,2-25). Quia nullus ewangelistarum materiam dominice passionis plene ac complete conscripsit ... - Expl.: ... vindicta inflicta Iudeis propter innocentem Christi mortem.

(53ra) Datierung (in Rot): Anno $M^{\circ} C C C C^{\circ}$ et LXX9. Darunter: Et sic est finis. Darunter von späterer Hand (in Rot) Carnem.

(53rb) Nachtrag: 17. Jh. (kursiv): Commonefacio vos enim fratres mei collegaeque devoti, futuri festi nativitatis Christi, ad sacras ordines nempe ipsasque assumere promoveritis vosque ideo summa doctrinae providentia provideatis ut digne eas percipere possitis.

Darunter wiederholt (leicht abgeändert) in Rot.

(53v) leer. 


\title{
Cod. 776
}

\section{MUSIKALISCH-ASTRONOMISCHE SAMMELHANDSCHRIFT}

\author{
Pap. I, 71, I* Bl. $210 \times 155$. Neustift (?), Anfang 16. Jh. (u. a. 1502).
}

B: Drei Teile: I (I, 1-22), II (23-46), III (47-71, I*). Buchblock nachträglich leicht beschnitten (vgl. Randnotizen). Am oberen Blattrand Foliierung 19. Jh. durch die ULB Tirol. Bl. 22 und 47 neuzeitliche gelbe Papiersignakel der ULB Tirol.

E: $\quad$ Bibliothekseinband: Perg. über Pappe. Italien, 20. Jh.

Neubindung im Zuge der Restaurierung (kein Restaurierbericht vorhanden). Kapitale mit weißem und grünem Zwirn umstochen. Schnitt rot gesprenkelt. Spiegel Pap. 20. Jh., leer.

G: Hs. möglicherweise in Neustift entstanden und urspr. mit Innsbruck, ULB Tirol, Cod. 1015 in einer Hs. vereinigt (vgl. die übereinstimmenden Wasserzeichen sowie die Größe der Hs.). Gegebenenfalls wohl im Zuge der Neuaufstellung der Neustifter Bibliothek in der 2. H. 18. Jh. (wie dies auch bei anderen Hs. und Inkunabeln gemacht wurde) in Einzelhandschriften aufgelöst. Vor Bl. 1 Exlibris der Stiftsbibl. Neustift 18. Jh. eingebunden, urspr. wohl am Spiegel des VD (nicht mehr vorhanden) aufgeklebt. 1809 anlässlich der vorübergehenden Aufhebung des Klosters Neustift der ULB Tirol übergeben. Bl. 1r alte Signatur der ULB Tirol 776 und Stempel der ULB Tirol 19. Jh. 1921 aufgrund des Friedensvertrages von St. Germain an den italienischen Staat abgegeben und von diesem 1929 dem Kloster Neustift als Dauerleihgabe überlassen. Bl. 1r Stempel der Soprintendenza Tridentina 20. Jh. und der Stiftsbibl. Neustift 20. Jh. Vor Exlibris zusätzlicher schmaler Papierstreifen eingebunden ms. 776. Biblioteca dell'abbazia di Novacella - Varna-Bressanone (Bolzano).

L: $\quad$ Wilhelm I 137. - Kristeller I 439. - P. Fischer, The Theory of Music from the Carolingian Era up to 1400 II: Italy. München, Duisburg 1968, 73. - Neuhauser, Neustift 87. - Peintner, Stiftsbibliothek 126. - M. H. Peintner, Psallite Deo! Zur Musikgeschichte des Stiftes Neustift, in: 850 Jahre Augustiner Chorherrenstift Neustift 134-153, hier 137 (ohne Nennung der Sign.). - M. Peintner, Musikgeschichte des Stiftes, in: 850 Jahre Neustift. Katalog 94-100, hier 97 (ohne Nennung der Sign.). - Stefani 119. - Neuhauser, Musikgeschichtliche Quellen 194. - M. Bernhard, Zur Rezeption der musiktheoretischen Werke des Hermannus Contractus, in: W. Pass, A. Rausch (Hrsg.), Beiträge zur Musik, Musiktheorie und Liturgie der Abtei Reichenau (Musica mediaevalis Europae occidentalis 8). Tutzing 2001, 99-126, hier 115-116, 120. - Katalog ULB Tirol VIII 426, 530.

$$
\text { I (I, 1-22) }
$$

B: $\quad$ B. 1r leicht, Bl. 22v stark verschmutzt und fleckig. Bilder und Nachweise der Wasserzeichen s. WZMA Wasserzeichenbefund mit Datierung übereinstimmend. Lagen: $(\mathrm{I}-1)^{\mathrm{I}}$ (Vorsatzbl. 20. Jh.) $+\mathrm{VI}^{12}+\mathrm{V}^{22}$. Gegenbl. zum Vorsatzbl. als Spiegel auf dem VD aufgeklebt.

S: $\quad$ Schriftraum stark wechselnd, seitlich von Blindlinien begrenzt, Zeilenzahl wechselnd. Flüchtige Humanistische Kursive, dat. 2. Jänner 1502 (Bl. 12v). Überschriften bzw. Textanfänge sowie einzelne Wörter im Text in Auszeichnungsschrift. Zahlreiche Notenbeispiele tw. in gotischer Choralnotation mit c- und f-Schlüssel auf Vier- bzw. Fünfliniensystemen, tw. in Quadratnotation auf Drei- bis Fünfliniensystemen. Zahlreiche geschwungene Klammern als strukturierende Gliederungshilfen.

A: $\quad$ Rote Unterstreichungen. Bl. 1v und 13r drei- bzw. zweizeilige blassrote Lombarden mit Punktverdickungen. Bl. 8v und 9r Schemata zu Tonschlüssen (Primus et secundus toni finiuntur in D sol re ... septimus et octavus finiuntur in $G$ sol re ut [gravi naturaliter sive regulariter]).

1 (1r-12v) Musicae MOdulationis COMMENDATIO.

(1r) Signatur und Stempel (s. bei G). Tit.: Musica gregoriana.

(1v) Tit.: Musice modulacionis commendacio. - Inc.: Sicut apotheca est salubris ita musica delectabilis quia dulcedine sua ... - Expl.. ... Artem discamus usum vero teneamus. (8v-9r) Schemata zu Tonschlüssen.

(12v) Schlussschrift mit Datierung: Finis adest fauste anno 1502 die II ${ }^{a}$ Ianuarii (2. Jänner 1502). 
2 (13r-20v) Musiktraktat.

Inc.: Musica humane vite necessaria nedum apud Grecos aut Romanos verum etc. apud barbaros semper magna laude prosecuta est ... - Expl.: ... Excedes duplum - Non caudata - Non quadrataAscendit tunc quelibet videlicet brevem/Descendit tunc prima videlicet longam et quevis sequens brevem.

Enthält zwölf Kapitel.

(21r-22v) leer.

$$
\text { II (23-46) }
$$

B: $\quad$ Pap. tw. fleckig, Bl. 23r-24r stark verschmutzt. Bilder und Nachweise der Wasserzeichen s. WZMA. Identische Wasserzeichen: u. a. Innsbruck, ULB Tirol, Cod. 1015 (dat. 1509). Lagen: 2.VI ${ }^{46}$.

S: $\quad$ Schriftraum stark wechselnd, seitlich von Blindlinien begrenzt, stark wechselnde Zeilenzahl. Zwei Hände: 1) Bl. 23r-29v flüchtige Humanistische Kursive, wohl von derselben Hand wie T. I (dat. 1502); 2) Bl. 31r46v regelmäßige Bastarda, Überschriften bzw. Textanfänge und einzelne Wörter im Text jeweils in Auszeichnungsschrift. Zahlreiche Notenbeispiele in gotischer Choralnotation mit c- und f-Schlüssel auf Vierund Fünfliniensystemen. Geschwungene Klammern als strukturierende Gliederungshilfen.

3 (23r-46v) TRACTATUS DE Divisionibus In MUSiCA.

Tit.: [M] usica Isidoro diffiniente est recte canendi sciencia ad laudem Dei finaliter adinventa. Inc.: Et dedumur (!) a Musis que per Bocacium XI libro De genologia (!) Deorum gentilium ... Expl.: ... Examen clavium. Hec habui amantissimi scholares que vobis et condiscendam musicam practicam et planam digna ducerim colligenda que et si meo ingenio minime invenerim sed maiorum nostrorum tradicionibus et informacione perfecto magistri mei in his rebus Udalrici Flordigalis per benigna dedicerim (!). Isto tamen ordine quem vobis omnibus (gestrichen: meis) magis conveniente existimavissem in unum opusculum collegi quare vos omnes oro obtestor laborem hunc meum non aspernemini unde vobis non modicum utilitatis ubi non vos ipsos in hiis meis sudoribus exercitare non pugnerit (?) sit accessurum.

Lit.: Bernhard 115-116, bezogen auf Bl. 27v Ter terni sunt modi ...

$$
\text { III }\left(47-71, I^{*}\right)
$$

B: $\quad$ Pap. bes. Bl. 47r, 61r und 71v fleckig, B1. 47v-50r Tinte stark verwischt (Tintenfraß?). Bilder der Wasserzeichen s. WZMA. Lagen: VII ${ }^{60}+(\mathrm{VI}-1)^{71}+(\mathrm{I}-1)^{I^{*}}$ (Nachsatzbl., 20. Jh.). Gegenbl. zum Nachsatzbl. als Spiegel auf dem HD aufgeklebt. Gegenbl. zu Bl. 61 herausgeschnitten (ohne Textverlust), Gegenfalz auf Bl. 71 aufgeklebt.

S: $\quad$ Schriftraum 150/160 $\times 95 / 100$. Seitlich von Blind-, Bl. 55r-60r von Tintenlinien begrenzt, zu 29-33 Zeilen. Bastarda mit wechselnder Tinte. Oberlängen in der ersten Zeile bisweilen gedehnt. Überschriften bzw. Textanfänge in Auszeichnungsschrift. Ergänzungen am Blattrand wohl von derselben Hand.

A: Bl. 68v rote Auszeichnungsstriche. Zeigehände. Bl. 61r Platz für siebenzeilige Initiale freigelassen, nicht ausgeführt. Bl. 68r Fixsterntabelle mit Spalten- und Zeilenbezeichnungen in Rot. Bl. 71v Skizze einer Alhidade (Vorrichtung zur Winkelanzeige oder Winkeleinstellung am Astrolabium).

$4 \quad(47 \mathrm{r}-71 \mathrm{v})$ Astronomische Texte.

4.1 (47r-60v) 〈Robertus Anglicus (?)〉: De astrolabio (Druck: GW M38333. - Thorndike-Kibre 331,4 und 1228,5).

Inc.: Quia plurimi obnimiam quandoque accurationem et magnam scriptorum sentenciam canones utilis astrolabii declarantes intelligere ... - Expl.: ... pars altitudinis rei tui adde.

Enthält 53 Canones.

Parallelüberlieferung: u. a. Melk, Stiftsbibl., Cod. 601, Bl. 18ra.

Lit.: F. J. Carmody, Arabic astronomical and astrological sciences in latin translation. A critical bibliography. Berkeley, Los Angeles 1956, 19 Nr. 14; G. Rosinska, Instrumenty astronomiczne 
na Uniwersytecie Krakowskim w 15 wieku (Studia Copernicana 11). Wroclaw u. a. 1974, 105106, Nr. 12; Dies., Scientific writings and astronomical tables in Cracow I: Initien (Studia Copernicana 22). Wroclaw u. a. 1984, Nr. 1779.

4.2 (61r-71v) 〈Prosdocimus de Beldemandis〉: Compositio astrolabii (Druck: GW M38333. - Thorndike-Kibre 1164,1).

Inc.: [Q]uamvis de astrolabii composicione tam modernorum quam veterum dicta habeantur ...Expl.: ... restringens in foramine illud inmitte ut teneat. Et habebis astrolabium perfectum.

Parallelüberlieferung: Rostock, UB, Mss. math.-phys. 1, Bl. 173v; Melk, Stiftsbibl., Cod. 794*, Bl. 369r.

Lit.: P. Spunar, Repertorium auctorum Bohemorum provectum idearum post universitatem Pragensem conditam illustrans I (Studia Copernicana 25). Wratislaviae u. a. 1985, 126, Nr. 334 (unter den Werken des Cristannus de Prachaticz = de Praga); N. Severino, Il libro degli astrolabi. La storia dell'Astrolabio da Tolomeo a Regiomontano. Roccasecca 1994, 39; G. Rosinska, Instrumenty astronomiczne (s. o.) Nr. 11; Dies., Scientific writings (s. o.) Nr. 1715; A. Hadravová, P. Hadrava, Křršt’an z Prachatic. Stavba a užití astrolábu. Praha 2001.

4.3 (71v) Notiz zur Verwendung der Alhidade mit Skizze (vgl. R. B. Thomson, Pseudo-Mash'allah. On the Astrolabe part II. Toronto 2012, 68).

Inc.: Si per allidadam horariam vis horam diei invenire naturalem poni aldidam (!) super altitudinem medie diei illius in dorso astrolabii suspensi ... - Expl.: ... in divisionibus erit hora quesit[a].

$(\mathrm{I} * \mathrm{r}-\mathrm{v})$ leer.

A. P./U. S.

\section{Cod. 780}

\section{GAIUS SALLUSTIUS CRISPUS}

Pap. 86 Bl. $210 \times 145$. Oberitalien (?), Ende 15. Jh.

B: Bl. 10-15 und 46-49 beinahe, Bl. 72/73 vollständig lose. Buchblock nachträglich beschnitten (vgl. Randbemerkungen mit Textverlust). Bilder und Nachweise der Wasserzeichen s. WZMA. Datierung nach Wasserzeichenbefund. Lagen: XII ${ }^{24}+\mathrm{VI}^{36}+\mathrm{XII}^{59(60)}+\mathrm{XIII}^{85(86)}$. Am oberen Blattrand Foliierung 19. Jh. durch die ULB Tirol; Fehler in der Zählung: 41 doppelt angeführt. Reste von zwei neuzeitlichen gelben Papiersignakeln der ULB Tirol.

S: $\quad$ Schriftraum Bl. 1r-v: 160/175× 90/105, Bl. 2r-35v: 170×70/75, Bl. 37r-85v: 165/180×80/85, seitlich von Blindlinien begrenzt, Bl. 1r-v zu 35 Zeilen, Bl. 2r-35v zu 27-28 Zeilen, Bl. 37r-85v zu 28-35 Zeilen. Humanistische Kursive, wohl von einer Hand mit unterschiedlichem Duktus. Notizen von zeitgenössischer Hand.

A: $\quad$ Randmarkierungen in Form von vereinfachtem Perlenbesatz. Bl. 40r Zeigehand. Bl. 2r-28r zweizeilige tintenfarbene Lombarden mit Punktverdickungen, anschließend Platz für Lombarden freigelassen, nicht ausgeführt.

E: $\quad$ Neuzeitlicher Bibliothekseinband: schwarz gesprenkeltes braunes Pap. Neustift, 2. H. 18. Jh. Pap. insbes. am HD und am Rücken beschädigt. Am Rücken Signaturschild der ULB Tirol. Spiegel Pap. 18. Jh. Am Spiegel des VD Exlibris und Signaturen (s. bei G) sowie Bleistiftnotiz (s. bei Inhalt), Spiegel des HD leer.

G: Zeitpunkt und Art der Erwerbung durch Neustift unbekannt. Am Spiegel des VD Exlibris der Stiftsbibl. Neustift 18. Jh. 1809 anlässlich der vorübergehenden Aufhebung des Klosters Neustift der ULB Tirol übergeben. Am Spiegel des VD alte Signaturen der ULB Tirol II [...] B 11 (Tinte, radiert), II $\overline{4}$ D 9. S. 2 (Bleistift) und 780/(I) (Tinte, Bleistift). Am Rücken gelbes Signaturschild der ULB Tirol 780. Bl. 1r Stempel der ULB Tirol 
19. Jh. 1921 aufgrund des Friedensvertrages von St. Germain an den italienischen Staat abgegeben und von diesem 1929 dem Kloster Neustift als Dauerleihgabe überlassen. Bl. 1r Stempel der Soprintendenza Tridentina 20. Jh.

L: $\quad$ Peintner, Stiftsbibliothek 126 (hier fälschlich als Cod. 789 bezeichnet). - Neuhauser, Neustift 84. - Katalog ULB Tirol VIII 434, 530.

(VDS) Bleistiftnotiz 19. Jh.: NB. Continet etiam librum de bello Iugurthino; hoc est in catalogo notandum.

1 (1r-v) Iulius Pomponius Laetus: Begleitbrief an Augustinus Maphaeus, der Sallustedition vorangestellt (GW M39655).

Tit.: Augustino Maffeo rerum Ro. thesauro Pomponius Letus. - Inc.: M. Valerius Probus unice vetustatis amator ... - Expl.: ... ab omni offensiuncula vindicabis. Vale foelicissime.

2 (2r-36v) Gaius Sallustius Crispus: De coniuratione Catilinae (Ed. L. D. Reynolds. Oxonii 1991, 5-53). Mit zahlreichen Rand- und Interlinearglossen, u. a. Zitate aus Ovid (z. B. Bl. 2r Metamorphoses, Lib. 1, V. 84-86), Vergil (z. B. Bl. 2v Georgica, Lib. 2, V. 532-540), Iuvenal (z. B. Bl. 2v Saturae XV, V. 168).

Tit.: C. Crispii Sallustii liber de coniuratione L. Sergii Catilinę.

(36r-v) nur Rahmung.

3 (37r-85v) Gaius Sallustius Crispus: De bello Iugurthino (Ed. L. D. Reynolds. Oxonii 1991, 54-149). Mit zahlreichen Rand- und Interlinearglossen.

Tit.: C. Crispi Sallusti liber de bello Iugurthino. 


\section{Sign. 14820}

\section{RITUALE NEOCELLENSE}

Perg. X, 85, II* Bl. $300 \times 230$. Neustift, Anfang 16. Jh. (mit Zusätzen, u. a. 1578).

B: $\quad$ Dickes Perg. Lagen: $2^{\mathrm{II}}$ (Pap.) $+(\mathrm{IV}-2)^{\mathrm{VIII}}($ Perg. $)+2^{\mathrm{X}}($ Pap. $)+(\mathrm{II}+1)^{5}+9 . \mathrm{III}^{59}+2$ 2.(III-1 $)^{69}+2 . \mathrm{IV}^{86(85)}+\mathrm{I}^{\mathrm{II}}$ (Pap.). Gegenbl. zu Bl. III und IV herausgeschnitten (ohne Textverlust), Bl. IX und X (ein Doppelbl.) auf Fälze aufgeklebt. Bl. IX und X urspr. kleineren Formates $(300 \times 210)$, Bl. IX am Blattrand durch zusätzlichen aufgeklebten Rahmen auf Größe des Buchblocks ergänzt, Bl. X auf anderes Papierblatt aufgeklebt. Bl. 5 eingehängtes Einzelbl. Gegenbl. zu Bl. 62 und 67 herausgeschnitten (ohne Textverlust). Am oberen Blattrand mittig zeitgenössische Foliierung in roten römischen Zahlen von $I-L X X X V$; Fehler in der Zählung: LXXII ausgelassen. Bl. 56v, 57rv, 58r, 62v, 63rv, 77rv Reste von braunen Ledersignakeln.

S: Bl. 1r-85v: Schriftraum $225 \times 155$, von feinen Tinten- bzw. Blindlinien gerahmt, zu einheitlich 24 Zeilen auf feiner Tinten- bzw. Blindlinierung (mit Hilfslinien für Minuskeln). Zirkelstiche. Textualis formata (Textura mit Rotundaeinflüssen, verzierte Doppelschrägstriche als Skriptoriumseigenart?). Schreiber (?): F. H. (Bl. 85v). Bl. 64v und 67r kurze deutschsprachige Einschübe, Buchstaben nach rechts geneigt. Am Blattrand sehr vereinzelt Ergänzungen von späterer Hand. Bl. 85v Zusätze von zwei späteren Händen. Datierung 1578 (Bl. 72v) wohl nicht auf Haupthand bezogen, sondern auf spätere Nachträge, möglicherweise auf die Bl. 67v-71v nachgetragenen Seitenverweise (vgl. Register).

Spätere Zusätze von verschiedenen Händen: Bl. IIIv: Schriftraum $240 \times 150$. Zwei Textspalten sowie zwei zusätzliche Spalten für die Blattangabe, seitlich jeweils von Blindlinien begrenzt, zu 34 Zeilen. Textualis formata (Textura) 16. Jh. Bl. IVr-VIIIr: Schriftraum 225/230×150/155. Von Blindlinien gerahmt, zu 23 Zeilen auf Blindlinierung. Antiquakursive wohl 17. Jh. Bl. IXr-Xr: Schriftraum $250 \times 160$. Zwei Spalten, von jeweils doppelten Tintenlinien gerahmt, zu ca. 30 Zeilen auf Blindlinierung. Antiqua 17./18. Jh. Bl. 86r: Schriftraum $235 \times 165$. Von Bleistiftlinien gerahmt, 21 Zeilen auf Bleistiftlinierung, diese jedoch nicht immer berücksichtigend. Vier verschiedene Hände. Antiqua bzw. Textura 17./18. Jh.

N: Bl. 7v-9v, 19r-20v, 38v-42v, 65r: Gotische Choralnotation mit f- bzw. c-Schlüssel auf vier roten Linien. Kustoden. Reperkussionston mit einem ornamentalen Haarstrich. Rote Gliederungsstriche.

A: Rote Auszeichnungsstriche, Überschriften, Verweiszeichen, Durchstreichungen und Zeilenfüllsel; wenige große Paragraphzeichen in (Dunkel-)Rot und auch Grün; (dunkel-)rote Benediktionskreuze (zumeist in Tatzenkreuzform, Bl. 17r-18r in den untersten Zeilen auch als lat. Kreuze mit Dekor). Zur Wasserweihe drei Zeichen (jeweils ca. eine Notenzeile hoch), die die schriftlichen Handlungsanweisungen visuell unterstützen (vgl. Cod. 194): Bl. 40v Kreuz (dunkelrot, mit verzierten Enden) zu hic insuffla per modum crucis sancte, Bl. 41v Stern (blau, mit vier spindelförmigen Strahlen) zu hic proiciatur aqua in quatuor partes und $\mathrm{Bl}$. 43r Lilie (dreiblättrig mit Herzblatt als Gegenmotiv, blau mit roten Konturlinien) zu suffla ter in fontem in hunc modum. Vereinzelt aufwändigere (schwarz-)rote Cadellen in den obersten Zeilen (z. B. Bl. 73r); einige (cadellenartig) auf den unteren Seitenrand verlängerte Textualis-Buchstaben. In den Binnenfeldern der Textualis-Majuskeln bisweilen feine Doppelschrägstriche, tw. mit kleinen angesetzten Bögen (z. B. Bl. 51v, 10. Z. von unten). Im Register ein- und zweizeilige rote Initialbuchstaben, Bl. VIIv mit einfachem Dekor. Vielzahl von ein- bis zehnzeiligen Lombarden in Blau, in charakteristischem zu Türkis tendierendem (Hell-) Grün sowie in mehreren Rot- und Violetttönen, davon ca. 250 mit Fleuronnée verziert. Lombarden aller Farben können mit (wein-)rotem Fleuronnée kombiniert werden, blaue und rottonige Lombarden mit (oliv-) grünem Fleuronnée, hellrote und -grüne Lombarden mit (blass-)braunem und nur hellrote Lombarden mit (blass-)blauem Fleuronnée; häufig Punktverdickungen; v.a. in den untersten Zeilen einige aufwändigere Lombarden, deren Ausläufer in Achterschlaufen gelegt sind, z.B. Bl. 82v6 (sehr ähnlich in Cod. 100, vgl. z.B. Bl. 5va; aber wohl nicht von einer Hand); größere Lombarden (fünfzeilig und höher) fallweise kopfstempelartig sowie in diversen geometrischen Formen rot-blau oder rot-grün gespalten und mit zweifarbigem Fleuronnée geschmückt (zu Bl. 49r, mit ausgesparten Blättchenranken, s. u.).

In den Binnenfeldern vielfältige Formationen aus aneinandergereihten, länglichen, (leicht) blasigen Knospen (in verschiedenen Größen); gerne auch ondulierende, fallweise aus vollfarbigem Grund ausgesparte Ranken mit dreizackigen Blättern, deren Mitteladern tropfenförmig verdickt und mit kleinen Punkten oder Kreisen gefüllt sein können („Erbsenschotenmotiv“), z. B. Bl. 47r3, 76r3; selten geometrisch strukturierte Binnenfelder, z. B. Bl. 63r Rautengitter mit eingeschriebenen Blüten. Konturlinie(n); als Besatz sehr oft Zweieroder Dreierkombinationen von Knospen bis hin zu Knospenreihen (jeweils im Wechsel mit Dornen), deren Endperlen in mehr oder weniger geschwungene Fäden auslaufen können; häufig kammartig abstehende, spitz zulaufende, tw. gebündelte Fadenausläufer (mit hakenartig geschwungenen Enden), die meist orthogonal oder radial abstehen, aber auch - dies ist eher ungewöhnlich - an einer Initiale alle senkrecht nach oben ausgerichtet sein können (s. B1. 75v1); seltener Fleuronnée-Leisten: aus mehreren Konturlinien und 
Knospenreihen aufgebaut, am Schriftspiegel entlang geführt, mit bes. stark geschwungen bzw. spiralig eingedrehten Fadenausläuferenden (z. B. Bl. 24v: Leiste verknüpft die beiden Initialen). Bei größeren Fleuronnée-Initialen Ausbildung von mehrlinig gerahmten Initialfeldern (z. B. Bl. 3r1) und Vollfarbigkeit möglich, s. türkisgrün ausgemaltes Binnenfeld B1. 48r2 (s. auch bei figürlichem Schmuck) sowie die Initialen B1. 12r2, 50v1, 52r4, 53r2, 73r2, bei denen die Buchstabenkörper (in Rot, Grün und nachgedunkeltem, jetzt ockerfarbenem bis bräunlichem Gelb) tw. mit Blattranken (s. o. Binnenfeldranken) verziert, mit ausgemalten Profilrahmen umgeben und von einem mit (Blatt-)Ranken überzogenen, vollfarbigen Initialfeld hinterlegt sind, wobei die verwendeten Farben (z. B. Bl. 52r4 Violett für das Initialfeld) dünn aufgetragen wurden; Bl. 52r4 und 53r2 ohne Besatzfleuronnée.

Figürlicher Dekor in (zumeist weinroter) Federzeichnung. Besatz: kleinere Blattmasken und Gesichter (B1. 1v2, 4r1); diverse Profilköpfe mit langen Nasen (charakteristisch der gewellte Nasenrücken, z.B. B1. 24r); B1. 74r größere Profilbüste mit herausgestreckter Zunge. Binnenfeld: B1. 29v Gesicht, B1. 48r2 (Fronleichnam) goldener Kelch mit Hostie darüber (vollfarbig), Bl. 60v Mönchsbüste. Bl. 4v (die untere Seitenhälfte ausfüllend): Neustifter Wappen mit kartuschenartigem Schild, Geviert, Feld 1 und 4: auf rotem Grund je vier silberne Spitzen, Feld 2: Tau-Kreuz, Feld 3: Patriarchenkreuz auf Dreiberg; als Zimier Engel (in Wams mit weiten Ärmeln, auf dem Kopf florales Gebinde), dem zwei große spiegelsymmetrisch angelegte Heckenrosenvoluten (mit distelartigen Knospen) entwachsen, nach denen er die Arme ausbreitet.

Der allergrößte Teil des verschwenderisch eingesetzten, variationsreichen Fleuronnée, das das Gesamterscheinungsbild der Handschrift entscheidend prägt, stammt von der am Anfang des 16. Jh. nachweisbaren Hand, die auch in Cod. 405 (dat. 1501), Cod. 194 (dat. 1507; zu dieser Hs. zudem Textbezüge) und Cod. 142, T. I (dat. 1521) tätig war, und in beiden Bänden des Zollner-Graduales einige Initialen mit Fleuronnée geschmückt hat (s. jeweils Ergänzungshand 2, speziell die große Ähnlichkeit der zweifarbig gespaltenen Initialen mit ausgesparten Blättchenranken in Sign. 14820, Bl. 49r, und im ersten Gradualband, Bl. 187 ${ }^{\mathrm{bis}} \mathrm{v}$ ). Die Formenvielfalt kann die Entscheidung erschweren, ob eine Variante vorliegt oder ob weitere Hände am Werk waren, so Bl. 65r (Notation) zwei Cadellen mit Profilköpfen, B1. 85v (Nachtrag) Initiale mit Profilkopf, der von anderer Hand gezeichnet sein könnte (Besatz dem Hauptfleuronnée allerdings sehr ähnlich); Bl. 7r1, 18r, 21v1, 38r2 jeweils das $O$ von Omnipotens sempiterne Deus mit ansonsten nicht verwendeten Überschneidungen bzw. Doppelungen im Buchstabenkörper und im Liniennetzdekor sowie plastisch wirkenden Fibrillen, wohl von anderer Hand, die wahrscheinlich auch Bl. 77v1 das d (mit Fleuronnée im Binnenfeld) über ein hellrotes I gesetzt hat (vgl. weinrote Tinte).

Der Aufbau der Binnenfeld-Blattranken erinnert an Deckfarbenranken, was vermuten lässt, dass der Florator auch als Deckfarbenmaler tätig war (oder zumindest Vorzeichnungen für ornamentalen Deckfarbenschmuck lieferte), vgl. Bl. 76r3 bzw. Bl. 5v mit Cod. 194, Bl. 27r (Ranken hier verkürzt zu zwei gegenständigen Blättern mit tropfenförmig verdickten Mitteladern); des Weiteren zeigt auch die Fleuronnée-Initiale Cod. 405, Bl. 124r, die von der in Sign. 14820 tätigen Hand stammt, starke Ähnlichkeiten zur Buchstabenkörperfüllung der Ornamentalinitiale Cod. 405, Bl. 41v, sowie zum Binnenfeld Cod. 194, Bl. 27r. Ein weiterer Bezug zu Cod. 194 und zugleich Beleg für die Verbindung zw. Fleuronnée- und Deckfarbenhand ist die vierzeilige Fleuronnée-Initiale Sign. 14820, B1. 47v3, die in der Art einer Ornamentalinitiale gestaltet wurde, wofür eine Deckfarbeninitiale wie Cod. 194, Bl. 45v (oder auch Cod. 405, Bl. 31v) als Vorlage gedient haben könnte (vgl. Rankenschlinge und Sitz des Goldpunktes). Der Versuch, eine Fleuronnée-Handschrift an die Farbigkeit eines mit Deckfarben ausgemalten Codex heranzuführen (durch Nuancierung: alle Farben auch in helleren bzw. blasseren Tönen eingesetzt), ist evtl. ein zusätzlicher Beleg dafür, dass der Florator auch Deckfarbendekor ausführte.

E: $\quad$ Roter Samteinband über Holz. Neustift, 17. Jh. (?)

Samt insbes. an den Ecken und Kanten etwas abgerieben, Holz vereinzelt freiliegend. Kanten gerade, nach innen abgeschrägt. Schnitt golden gefärbt. Am Spiegel des VD und HD sowie am Recto des Vor- und am Verso des Nachsatzbl. weiße Papiertapete mit Rankendekor aufgeklebt, am Übergang von Spiegel zu Vorbzw. Nachsatzbl. jeweils ein ca. $30 \mathrm{~mm}$ breiter Streifen schwarz gefärbt. Am Spiegel des VD Signaturschild (s. bei G).

G: Das Neustifter Wappen Bl. 4v lässt darauf schließen, dass die Hs. in Neustift hergestellt wurde. Hs. bei vorübergehender Aufhebung des Klosters 1807 nicht an die Universitätsbibliothek Innsbruck gelangt. Am Spiegel des VD Neustifter Signaturschild 14.820 (= wohl Numerus currens der Neustifter Stiftsbibl.).

L: $\quad$ Gschwend 86-88 (ohne Nennung der Sign.). - Lipphardt III 1086; VI 353, Nr.629a (Sigle Neust ${ }^{5}$ ). Gozzi 548, Nr. 82. - R. Kay, Pontificalia. A Repertory of Latin Manuscript Pontificals and Benedictionals. Lawrence 2007, 108, Nr. 559. - Baroffio 324, Nr. 16721. 
(Ir-IIIr) leer.

(IIIv) Inhaltsverzeichnis.

1 (IVr-VIIIr) Vier EvangeliEn bei der Fronleichnamsprozession (von späterer Hand, s. bei S). (VIIIv) leer.

2 (IXr-Xr) Gebete des Bischofs beim Anziehen der Bischöflichen Gewänder (vgl. Bl. 76r-77v) (von späterer Hand, s. bei S). Gebet Ad caligas nur Titel, Text des Gebetes Ad calceos. (Xv) leer.

3 (1r-85v) Rituale Neocellense mit Breviertexten. Vgl. Cod. 194 und Cod. 726. (1r-2r) In NATivitaTE DNi (zusätzlich Ad laudes).

(2r-3r) In CIRCUMCISIONE DNI.

(3r-4r) IN EPIPHANIA DNI.

(4r-12r) IN PURIFICATIONE BMV.

(5r) Benedictio candelarum. Tit.: In die sancto post tertias sequitur Benedictio Cereorum. - (10r) Processio candelarum. - (11r) Canticum Zachariae.

(12r-13r) In ANNUNTIATIONE BMV.

(13r-24r) DNCA IN PALMIS.

(13r) In die palmarum ad processionem. - (15r) Exorcismus florum et frondium. - (15v) Benedictio palmarum. - (18v) Praefatio. - (21r) Aspersio et thurificatio palmarum. - Distributio palmarum. (21v) In reditu. - (22v) Adoratio crucis. - (23v) Canticum puerorum. - (24r) In reditu ante altare oratio.

(24v-27r) FER. 5. IN COENA DNI.

(24v) In cena domini benedictio ignis. - (25r) Ad mandatum.

(27v-35r) Fer. 6. IN PARASCEVE.

(27v) Adoratio crucis. - (30r) Depositio crucis (Gschwend 86). - (30v) Vesper.

(35r-43v) IN VIGILIA PASCHATIS

(35r) Benedictio ignis. - (37r) In reditu canitur himnus Prudencii (AH 50, Nr. 31). - (37r) Exsultet (nur Verweis). - (37r) Benedictio aquae. Mit Verweis auf Allerheiligenlitanei.

(43v-46r) Dnca ResurRectionis Dni. (Gschwend 86-88).

(46r-47r) IN VIGILIA ASCENSIONIS DNI.

(47r-48r) Benedictio aquae in vigilia Pentecostes.

(48r-49r) In FESTO SS. CORPORIS CHRISTI.

(49r-50r) IN ASSUMPTIONE BMV.

(50v-51r) Augustinus.

(51r-52r) In nativitate BMV. Eingeschoben: (51v) Adrianus (Ad Matutinas) und (51v) Corbinianus (Ad Matutinas).

(52r-53r) In DEDICATIONE ECCLESIAE.

(53r-v) De omnibus sanctis. Eingeschoben: (53v) Caesarius (Ad Matutinas). 
(54r-v) In COMmemoratione omnium fidelium Defunctorum. Mehrere Gebete, davon eines Ad Completorium. Eingeschoben: (54r) In depositione beati Hartmanni.

(55r-61r) Ordo PAENITENTIAE.

(61v-63r) EinKleidung der Novizen.

Tit.: De indutione novitiorum.

(63v-69r) Profess.

(69r-70v) Ordo Für die AufNahme von LaIEn.

Tit.: De fraternitate laicali.

(70v-72v) Totenliturgie Für die Konventualen.

(72v) Datierung 1578.

(73r-76r) ACCESsus ALTARIs (vgl. Jungmann I 354-355).

(76r-77v) Gebete des Bischofs beim AnZiehen der Bischöflichen Gewänder (vgl. Bl. IXr-Xr; Jungmann I 358ff.).

(77v-78r) BischöFliche SEgENSFORMEl (Jungmann II 551).

Tit.: Sequitur benedictio post missam.

(78r-79r) Gebete nach der Messe (Jungmann II 571).

(79v-83r) Collectae de tempore.

Tit.: Sequuntur collecte seu orationes de tempore. Für Dnca 3., 4., 5. post epiph., Septuages., Sexages., Quinquages., Dnca 1., 2. in Quadrages., Dnca 3. mit Collectae feriales, Dnca 4. mit Collectae feriales, Dnca passionis mit Collectae feriales, Dnca 8.-16., 19.-22. post pent.

(83r-85r) COLLECTAE de SANCTIS.

Tit.: Sequuntur Collecte de sanctis. Für Philippus et Iacobus, Monica, Iohannes ante Portam Latinam, Gordianus et Epimachus, Nicomedes, Marcellinus, Erasmus, Bonifatius, Primus et Felicianus, Barnabas, Basilides et Cyrinus et Nabor, Vitus et Modestus, Marcus et Marcellinus, Eusebius, Hermes, Undecim milia virginum, Severinus, Amandus, Simon et Iudas (mit Oratio in secundis vesperis), Narcissus.

Vgl. Cod. 100, Bl. 97va-104ra mit ähnlicher Auswahl und Anordnung.

(85r-v) Versikel.

Tit.: Sequuntur nunc versiculi communes per annum. Enthält: Sabbatinus diebus ad vesperas, in secundis vesperis. De apostolis ad vesperas, ad matutinas. De martiribus ad vesperas, ad matutinas. De uno martire sive confessore ad vesperas, ad matutinas. De virginibus ad vesperas, ad matutinas.

(85v) Schlussschrift: Laus Deo. Darunter Schreibernennung (?): F. H.

4 (85v-86r) NACHTRÄGE (von mehreren Händen, s. bei S).

(85v) Drei Gebete:

De s. Pangracio. Presta quesumus omnipotens Deus ut qui beati Pangratii martiris tui natalicia colimus ... (vgl. Corpus orationum Nr. 4520a, für Valentin).

Nereus et Achilleus. Semper nos domine martirum tuorum Nerei et Achillei foveat ... (Corpus orationum Nr. 5465).

De s. Wolffgango episcopo. Exaudi domine preces nostras quas in sancti Wolffgangi confessoris tui atque pontificis solemnitate deferimus ... (vgl. Corpus orationum Nr. 2479, für Marcellus). (85v) Totengebet. Quesumus domine ut anime famuli tui cuius obitus sive diem commemoramus sanctorum tuorum largiri digneris consortium et rorem misericordie tue perennis infundere. Per. 
(86r) Gebet. Deus cuius misericordie non est numerus suscipe propicius preces humilitatis nostre et animabus que nobis in oracionem commendate sunt et qua utimur vel usi suus elemosinis quibus tui nominis dedisti confessionem remissionem cunctorum tribue peccatorum. Per (Corpus orationum Nr. 1178).

(86r) Oratio de s. Floriano. Deus qui nos annua beati Floriani martiris tui sociorumque eius gloriosa passionis solemnitate letificas ... (vgl. Corpus orationum Nr. 1843, für Cyriacus).

(86r) Totengebet in anniversario. Deus indulgentiarum domine da anime famuli (daneben: $e$ ) tui (daneben: $e$ ) cuius anniversarium depositionis diem et memoriam agimus refrigerii sedem quietis beatitudinem luminis claritatem.

(86r) Versikel. Christus factus est pro nobis obediens usque ad mortem.

(86r) Gebet. Domine Iesu Christe fili Dei vivi pone amaram mortem et passionem tuam inter animas nostras et misericordiam et districtum iudicium qui cum Deo patre et spiritu sancto vivis et (Corpus orationum Nr. 1251).

$(86 v)$ leer.

$\left(\mathrm{I}^{*} \mathrm{r}-\mathrm{II} * \mathrm{v}\right)$ leer.

W. N./U.S.

\section{Sign. 15063}

\section{ANTIPHONARIUM}

Perg. 197 Bl. $355 \times 255$. Wohl Neustift, 2. H. 15. Jh. (mit späteren Zusätzen).

B: Perg. stark abgegriffen, vereinzelt kleine Löcher und Nahtspuren. Am unteren Blattrand bisweilen Fehlstellen. Bl. 58, 76, 77, 138 und 193 am Blattrand beschnitten. Lagen: $(\mathrm{IV}-1)^{7}+(\mathrm{IV}-1)^{14}+(\mathrm{IV}-1)^{21}+5 . \mathrm{IV}^{61}$ $+(\mathrm{IV}-1)^{68}+\mathrm{IV}^{76}+(\mathrm{IV}-1)^{83}+(\mathrm{II}-2)^{85}+\mathrm{III}^{91}+(\mathrm{III}-1)^{96}+(\mathrm{IV}-1)^{103}+\mathrm{IV}^{111}+(\mathrm{IV}-1)^{117(118)}+\mathrm{IV}^{124(126)}+\mathrm{III}^{130(132)}$ $+5 . \mathrm{IV}^{169(172)}+(\mathrm{IV}-2)^{175(178)}+(\mathrm{I}+3)^{180(181)}+(\mathrm{IV}-1)^{187(190)}+(\mathrm{IV}-3)^{192(195)}+\mathrm{I}^{194(197)}$. Gegenbl. zu Bl. 7 als Spiegel auf dem VD aufgeklebt, Gegenbl. zu Bl. 8, 16, 65, 77, 84, 85, 95, 103, 114, 170, 171, 184, 188, 189, 190 herausgeschnitten (tw. Textverlust, s. bei Inhalt). Bl. 178-180 Einzelbl. Um die 14. und 19. Lage (Bl. 92 und 96, 125 und 130) Falz geschlagen, urspr. wohl Quaternionen. Am Lagenende bisweilen (Lagen 4-10, 17, 19, 21-23) Reklamanten. Am oberen Blattrand Foliierung 19. Jh.; Fehler in der Zählung: 116, 121 und 169 doppelt angeführt. Bl. 21 Spuren, Bl. 92 und 110 Reste von Ledersignakeln.

S: $\quad$ Schriftraum $245 / 250 \times 170 / 175$, von zweifachen feinen Tinten- bzw. Blindlinien seitlich begrenzt: Spalte links jeweils für Notenschlüssel, Spalte rechts für Kustos verwendet. Zirkelstiche. Zehn rote Vierliniensysteme mit ebenso vielen Textzeilen auf feiner Tinten- bzw. Blindlinierung. Textualis formata (Textura). Zahlreiche Ergänzungen und Korrekturen von verschiedenen Händen in Tinte und Bleistift (bis ins 19. Jh.), zahlreiche Rasuren (s. bei Inhalt).

N: Gotische Choralnotation (mit Virga) auf vier roten Linien, c- bzw. f-Schlüssel, Kustoden. Reperkussionston mit einem ornamentalen Haarstrich. Vereinzelt schwarze Gliederungsstriche, insbes. am Schluss der einzelnen Gesänge.

A: Rote Durchstreichungen und Überschriften. Rote und blaue Lombarden, selten mit Punktverdickungen, meist in der Höhe einer Notenzeile. Bl. 1r rote Lombarde mit einfacher Aussparung, zwei Notenzeilen hoch. Bl. 5r-v (Ergänzung) schwarze Initialbuchstaben. Schwarze Cadellen, eine Notenzeile hoch, mit rotem Füllstrich (Bl. 1r und 2r Cadelle nachträglich weinrot konturiert) und schwarzem Fleuronnée von einer Hand, fallweise flüchtig ausgeführt: In den Binnenfeldern in der Regel Knospenformationen, bisweilen ausgesparte vereinfachte Blattformen oder Liniendekor; Konturlinien; als Besatz zumeist vereinfachter Perlenbesatz sowie häufig Profilköpfe, die an die Besatzköpfe des Hauptflorators der Neustifter Gradualien erinnern (Stirnwulst), Bl. 10v bärtiger Profilkopf, Bl. 53r weibliche Dreiviertelfigur.

Auch bei den (späteren) Ergänzungen einfacher Dekor von mehreren Händen: 1) Bl. 81v-83v, 84v-95v und z.B. auch über Rasur Bl. 97r: abwechselnd rote und blaue (Blau pastos aufgetragen) Lombarden (I-Lombarde mit kopfstempelförmigem Besatzelement, z. B. B1. 87v) mit Punktverdickungen; 2) B1. 96v schwarzes Fleuronnée, ebenfalls den Hauptflorator der Neustifter Gradualien imitierend; diese Hand ergänzte 
möglicherweise auch Fadenausläufer (z. B. Bl. 12r Bas-de-page); 3) Bl. 97r2 blaue Lombarde (zwei Notenzeilen hoch) mit rotem Knospenfleuronnée, als Besatz Perlenpyramiden mit Fibrillen; 4) Bl. 193v rote Lombarde mit Punktverdickungen und Ausläufern, Cadellen mit rotem Füllstrich und etwas Dekor, jeweils eine Notenzeile hoch; 5) Bl. 194v schwarze Initialbuchstaben mit kritzeligem schwarzem Dekor (stilisierte Blätter).

E: Renaissance-Einband: dunkelbraun gefärbtes Leder über Holz mit Blinddruck. Neustift, 2. H. 16. Jh., Werkstatt: Narziß Schuechl.

VD und HD gleich: sechs durch je zweifache Streicheisenlinien gebildete Rahmen (von außen nach innen): Rahmen 1 gefüllt mit Rolle Profilköpfe in Handspiegeln mit Quastenbehang (Nr. 1 = Neuhauser, Rolleneinbände, R 22), Rahmen 2 gefüllt mit Rolle Eherne Schlange, Kreuzigung, Auferstehung (Nr. 2 = Neuhauser, Rolleneinbände, R 20), Rahmen 3 gefüllt mit Rolle Menschenpaare unter Baldachin mit floralem Dekor; am Ende der Rolle jeweils Umschrift DVRKO (Nr. 3 = Neuhauser, Rolleneinbände, R 45), Rahmen 4 gefüllt mit Einzelstempel Herzblatt (Nr. 4 = Neuhauser, Rolleneinbände, S 18 [?]) und Doppellilie mit rhombischem Mittelblatt (Nr. 5 = Neuhauser, Rolleneinbände, S 40), Rahmen 5 gefüllt mit Rolle florales Dekor (Nr. $6=$ Neuhauser, Rolleneinbände, R 25), Rahmen 6 gefüllt mit Ranke mit eingeschlossener Fünfpunktblüte (Nr. 7 = Neuhauser, Rolleneinbände, R 23). Mittelfeld gefüllt mit Rolle Eherne Schlange, Kreuzigung, Auferstehung (Nr. 2). Jeweils fünf Beschläge, am VD und HD unterschiedlich: Am VD mittig rautenförmig mit geradem Abschluss und mit mittig größerem und außen mehreren kleineren Buckeln. Eckbeschläge jeweils mit Spruchband ([...] mater [...]), Mittelbeschlag und Blattwerkabschluss mit sechs kleineren Buckeln. Am HD mittig rautenförmiger Beschlag mit Blattornament, in den Ecken spitz zulaufende Beschläge mit floralem Dekor. Reste (oben) bzw. Spuren (unten) von zwei Leder-Metall-Schließen. Kanten gerade, nach innen hin abgeschrägt. Rücken: Häubchen oben und unten beschädigt; vier Doppelbünde, jeweils von zweifachen Streicheisenlinien gesäumt. Im untersten Feld Signaturschild 19. Jh. Kapitale, unten tw. beschädigt, mit naturfarbenem und rötlichem Zwirn umstochen. Spiegel des VD Pergamentblatt, beschrieben, unten tw. gelöst, Abklatsch auf Holz sichtbar, Spiegel des HD Pergamentblatt mit Federproben.

G: Hs. bei vorübergehender Aufhebung des Klosters 1807 nicht an die Universitätsbibliothek Innsbruck gelangt. Am Rücken Neustifter Signaturschild 15.063 (= wohl Numerus currens der Neustifter Stiftsbibl.).

L: $\quad$ G. Gabrielli, Tropes in cantus planus sources from South Tyrol, in: J. Border u. a., Cantus Planus. Venice meeting 2014. Venezia (in Druck). - MeSch VI (in Vorbereitung), bei Wien, ÖNB, Cod. 2777 (Oswald von Wolkenstein, Liederhandschrift A) Sign. 15063 erwähnt (K. G. Pfändtner).

ANTIPHONARIUM.

1 (VDS) Hymnus In adventu dni (AH 51, Nr. 47) mit Notation von späterer Hand.

Darunter Ergänzung in Bleistift 19. Jh.: Versikel. Rorate Coeli desuper \& nubes pluant iustum. Responsorium. Aperiatur terra et germinet salvatorem (Ies. 45,8).

2 (1r-58r) Temporale (Dnca 1. adventus bis In vigilia paschatis).

(1r) Dnca 1. adventus. - (1v) Dnca 2. adv. - (2r) Dnca 3. adv. - (2v) O-Antiphonen (ab B1. 3v, Z. 7 radiert). - (5r) In nativitate dni (z. T. von späterer Hand auf Rasur). Responsorium Descendit de celis mit Prosula (Hofmann-Brandt Nr. 416, CAO Nr. 6411); Responsorium Verbum caro mit Prosula (AH 34, Nr. 1, Hofmann-Brandt Nr. 537). - (13r) Stephanus. - Suff. (In nativitate BMV). - Zweistimmiger Tropus (B. Stäblein, Hymnen I: Die mittelalterlichen Melodien des Abendlandes [Monumenta Monodica Medii Aevi 1]. Kassel, Basel 1956, 396 [mit Transkription der Melodien]). - (14v) Expl. mut. (Antiphon BMV): ... eius gloriam quasi uni[geniti (1 Bl. fehlt, s. bei B)

(15r) Iohannes ap. Inc. mut. (Antiphon): ] michi ianuam vite et ... - (15r) Innocentes. - (15v) Dnca infra octavam (tw. radiert). - (16v) In circumcisione dni. (Bl. 16v, 17v: tw. radiert und von späteren Händen neu geschrieben, Bl. 18r-19v mittig radiert). - (19v) In epiphania dni. - (20r) Dnca infra octavam epiph. - Per hebdomadam. - (21r) In octava epiph. - (21v) Dnca 1. post octavam epiph. - (22v) Fer. 2. - Fer. 3. - (23r) Fer. 4. - Fer. 5. - (23v) Fer. 6. - (24r) Dnca 2. post octavam epiph. - Dnca 3. post octavam epiph. - Dnca in Septuages. - (25v) Dnca in Sexages. $(26 v)$ Dnca in Quinquages. - (27v) Dnca in Quadrages. - (29r) Fer. 2. (Notation nicht ausgeführt). - Fer. 3. (Notation nicht ausgeführt). - Fer. 4. (Notation nicht ausgeführt). - (29v) 
Fer. 5. - Fer. 6. - Dnca 2. in Quadrages. - (30v) Fer. 2. - (31r) Fer. 3. - Fer. 4. - Fer. 5. - Fer. 6. Dnca 3. in Quadrages. - (31v-32r) am unteren Blattrand Ergänzung von drei Versen (Cantus Nr. 203225, CAO Nr. 3732zc und CAO Nr. 3732zb) mit Notation von späterer Hand zur Antiphon Media vita. - (32v) Fer. 2. - Fer. 3. - Fer. 4. - Fer. 5. - (33r) Fer. 6. - Dnca 4. in Quadrages. (34r) Fer. 2. - Fer. 3. - Fer. 4. - (34v) Fer. 5. - Dnca in passione dni. - (35v) Fer. 2. - (36r) Fer. 3. - Fer. 4. - Fer. 5. - Fer. 6. - (36v) Dnca in palmis. - (37v) Fer. 2. - Fer. 3. - Fer. 4. - In coena dni (tw. radiert). Mit Nokturnen und Kyrie Qui passurus advenisti propter nos (CAO Nr. 8446,1). - (45v) Fer. 6. in parasceve. Mit Nokturnen. - (52r) Sabbato. - (58r) Ergänzung von späterer Hand: Antiphona de b. virgine (Salve sanctissima virgo Maria mater, nur Beginn mit metrischer Notation mit Zeichen der Mensuralnotation).

(58v) nur Linierung.

3 (59r-84v) SANCtoRALE.

(59r) Andrea. - (60r) Barbara: Reimoffizium (AH 25, Nr. 42). - (62r) Nicolaus. - (64r) Lucia. $(64 v)$ Thomas Cant. (tw. radiert). Expl. mut. (Antiphon): ... pravorum framea ce[(lum) (1 Bl. fehlt, s. bei B)

(65r) [Fabianus et Sebastianus]. Inc. mut. (Antiphon): ] virum de plebe et claritatem ... (tw. radiert). - (65v) Agnes (tw. radiert). - (66r) In conversione s. Pauli. - (67v) In purificatione BMV: Reimoffizium Videtur miraculum mater domini concepit (in AH nicht angeführt). Responsorium Videte miraculum mit zwei Tropen (Hoffmann-Brandt Nr. 281, CAO Nr. 7869 und Hoffmann-Brandt Nr. 262, CAO Nr. 7869zd). Mit Nokturnen (Bl. 71v, Z. 2-8 ohne Notation). - (72r) Agatha (fälschlich Agnetis v.). - (73v) Dorothea: Reimoffizium (AH 5, Nr. 56 [mit leichten Abweichungen]). - (76r) Ingenuinus et Albuinus (vgl. Breviarium Brixinense 1489, Bl. 271aß).(78r) Gregorius: Reimoffizium (AH 5, Nr. 64). - (79v) In annuntiatione BMV.

(81v-84r, Z.1) Ergänzung von späterer Hand: (81v) In festo s. Michaelis archangeli. - (82v) In festo omnium sanctorum.

(84r) Rudpertus. Inc. mut. (Antiphon): ] in populo Dei ... - Expl. mut.: ...viri sancti quod mole [

4 (84v-95v) Ergänzung von späterer Hand: Commune SANCTORUM.

(84v) De apostolis. - (85v) Temp. pasch. de apost. et martyr. - (87r) De uno martyre. - (88r) De martyribus. - (90r) De episcopo et confessore. - (91r) Pro doctore. - (91v) Pro solis sanctis pontificibus. - De communi confessore non pontifice. - (92v) De virginibus. - (94v) In dedicatione ecclesiae.

(96r) Inc. mut. (Antiphon „Regina caeli“ mit Tropus Cantus Nr. 850222): si]cut dixit alleluia ...Marianische Antiphon. - (96v) Ergänzung von anderer Hand: De s. spiritu. Expl. mut. (Responsorium): ... et spiritui sancto [ (1 Bl. fehlt, s. bei B)

5 (97r-120v) Forts. des Temporale (Dnca resurrectionis dni bis In festo ss. corporis Christi). (97r) Dnca resurrectionis dni (tw. von späterer Hand auf Rasur). Mit Nokturnen. - (100r) Visitatio sepulchri (bei Lipphardt nicht angeführt; tw. von späterer Hand auf Rasur). - (102v) Fer. 2. (103r) Fer. 3. - Fer. 4. - (103v) Fer. 5. (fälschlich Feria IIII). - Fer. 6. - Dnca 1. post pascha. (104v) Dnca 2. post pascha. - (105r) Dnca 3. post pascha. - (106r) Dnca 4. post pascha (Dominica ultima). - (106v) In ascensione dni (tw. von späterer Hand auf Rasur). - (108v-109v, Z. 4) Rasur. - (109v) Dnca pentecostes et de spiritu sancto: nur Antiphon zum Magnificat der zweiten Vesper. - (110r) Fer. 2. - Fer. 3. - Fer. 4. - (110v) In festo ss. trinitatis (tw. von späterer Hand auf Rasur): Reimoffizium Gloria tibi trinitas equalis una Deitas (in AH nicht angeführt, Beginn mit Chev. Nr. 7287 übereinstimmend). - (112v) In festo ss. corporis Christi. Responsorium Homo quidam fecit cenam mit Prosula (Hofmann-Brandt Nr. 448, Cantus Nr. 601068Pa). Mit Nokturnen. 
(120v-128r) Historiae aestivales.

(120v) Liber Regum (tw. von späterer Hand auf Rasur). - (121v) Liber Sapientiae. - (123r) Historia Iob, unvollständig. (124v) Expl. mut. (Antiphon): ... et peccata responde michi cur [ (1 Bl. fehlt, s. bei B)

(125r) Liber Iudith, unvollständig. Inc. mut. (Responsorium): ]date cum omnes populi ... - Liber Esther. - (125v) Liber Maccabaeorum. - (126v) Liber Ezechielis.

7 (128r-132r) Forts. des Temporale (Dncae post festum ss. trinitatis).

(128r) Dnca 1. post trinitatem. - (128v) Dnca 2. - (129r) Dnca 3. - Dnca 4. - Dnca 5. - (129v) Dnca 6. - Dnca 7. - Dnca 8. - (130r) Dnca 9. - Dnca 10. - (130v) Dnca 11. - Dnca 12, unvollständig. Expl. mut. (Antiphon): ... Dum transiret dominus [ (1 Bl. fehlt, s. bei B)

(131r) Dnca 17. Inc. mut. (Antiphon): prin]cipis phariseorum sabbato manducare ... - Dnca 18. - Dnca 19. - Dnca 20. - (131v) Dnca 21. - Dnca 22. - Dnca 23. - (132r) Dnca 24. - Dnca 25 (tw. radiert und gelöscht).

8 (132r-175v) Forts. des SAnctorale.

(132r) Incipiunt hystorie de sanctis primo tempore paschali. Antiphonen und Responsorien aus dem Commune Sanctorum (tw. von späterer Hand auf Rasur). - (135r) Philippus et Iacobus. (136r) In inventione s. crucis. - (137v) De lancea dni. Mit Hymnus (AH 52, Nr. 6) und Reimoffizium (AH 5, Nr. 7). - (140r) Suffragia s. Alexandris. - Iohannes Baptista. - (141v) Iohannes et Paulus. - (142v) Petrus. - (144v) In octava Iohannis Baptistae. - (145r) In visitatione BMV. Mit zwei Tropen: 1) Responsorium Hec est ista (in Cantus nicht angeführt) mit Tropus Currens vini fluminis (in Hofmann-Brandt nicht angeführt); 2) Responsorium O preclara stella maris mit Prosula (AH 48, Nr. 399, Hofmann-Brandt Nr. 403). - (148v) Margaretha: Reimoffizium (AH 28, Nr. 3). Responsorium Quadam die Olibrius mit Prosula (Hofmann-Brandt Nr. 445). - (150v) Maria Magdalena. - (153r) Iacobus. - (153v) Petrus ad vincula. - (154v) Laurentius. - (155r) In assumptione BMV: Responsorium Que est ista que ascendit mit Prosula (Hofmann-Brandt Nr. 694). - (158v) Augustinus. - (162r) Suffragia Iohannis. - (162v) In nativitate BMV. - (164v) In exaltatione s. crucis. - (165r) In octava nativitatis BMV. - Matthaeus. - (166r) Suffragia Mauritii. - (166v) Suffragia Cosmi. - (167r) Michael (tw. radiert). - (168v) In translatione s. Augustini: Reimoffizium O rex altissime Deus mirabilis (bestehend aus zwei rhythmisierten Antiphonen, die eine ähnlich wie AH 25, Nr. 85 [Dominicus], die andere ähnlich wie Cantus Nr. 206563 [Monica]). - (169r) Gallus. - (169v) Ursula et undecim milia virginum. - (169 $\left.{ }^{\text {bis }} v\right)$ Omnes sancti. - (170v) Martinus. - (172v) Suffragia Othmari. - Elisabeth: Reimoffizium (AH 25, Nr. 90). - (175r) Caecilia. - Clemens. - Catharina: Reimoffizium (AH 18, Nr. 37 und AH 26, Nr. 69). (175v) Expl. mut. (Antiphon): ... et spiritui sanc[to (1 Bl. fehlt, s. bei B)

9 (176r-184r) COMMUNE SANCTORUM.

(176v) De apostolis. - (177v) De evangelistis. - (178v) De martyribus. - (180r) De uno martyre (tw. ohne Notation). - (183r) De virginibus (tw. ohne Notation).

10 (184r-185v) De conceptione BMV: Reimoffizium (AH 5, Nr. 13; Cantus Nr. 200447).

11 (185v-192v) Officium defunctorum. Mit Nokturnen (zweite Vesper ohne Notation, Responsorienreihe der Nokturnen nicht in K. Ottosen, The responsories and versicles of the Latin Office of the Dead. Aarhus 1993 angeführt).

12 (193r-194r) Marianische GeSÄNGe (von verschiedenen späteren Händen). Mit Sequenz (AH 54, Nr. 201).

13 (194v) Ergänzung von späterer Hand: Antiphonae SAbBato Per annum (nur Inc.).

(HDS) Federproben, u. a. Specie tua et pulchritudine tua und Sancti tui domine florebunt.

G. G./U. S. 
Nr. 139 (olim Sign. 14819)

\section{GRADUALE. ANTIPHONARIUM}

Pap. 231 Bl. $315 \times 215$. Umfeld Neustift, Ende 15. Jh. (T. I: 1495/96).

B: $\quad$ Zwei Teile: I (1-153), II (154-231). T. I 1495/96 dat. (s. bei S), T. II nach Wasserzeichenbefund zeitnah entstanden. Wasserzeichen beider Teile z. T. übereinstimmend. Verwandte Wasserzeichen: u. a. in Neustift, Stiftsbibl., Nr. 940. Am unteren Blattrand Foliierung 20. Jh. (Bleistift, hier berücksichtigt).

E: $\quad$ Gotischer Einband: helles Schweinsleder über Holz mit Blinddruck. Brixen oder Neustift, Ende 15. Jh. Leder abgerieben und insbes. am VD etwas fleckig. Am VD ein durch zwei- (oben) bzw. dreifache Streicheisenlinien gebildeter Rahmen, gefüllt mit Einzelstempel vierblättrige Blüte frei (Nr. 1) im Wechsel mit Adler in Rhombus (Nr. 2). Mittelfeld mit dreifachen Streicheisenlinien gerautet. In den vier Mittelfeldern Einzelstempel (stark abgerieben, nicht mehr erkennbar) in Kreis (Nr. 3), in den Außenfeldern vierblättrige Blüte (Nr. 4). An den Schnittpunkten Einzelstempel Lilie in konkavem Karo (Nr. 5). Aufschrift in Tinte 1496. Am HD ein durch dreifache Streicheisenlinien gebildeter Rahmen, gefüllt mit Einzelstempel sechsblättrige Blüte in Kreis (Nr. 6), seitlich rechts im Wechsel mit Lilie frei (Nr. 7). Mittelfeld mit dreifachen Streicheisenlinien gerautet. In den Feldern Einzelstempel fünfblättrige Blüte frei (Nr. 8). Auf den Schnittpunkten mittig Einzelstempel fünfblättrige Blüte frei (Nr. 8), ansonsten Dreiblatt frei (Nr. 9). Zwei LederMetall-Schließen, untere nur noch als Rest erhalten. Kanten gerade, unten und oben Einkerbungen im Holz. Rücken: blau gefärbt (wie öfters in Neustift), vier Doppelbünde. Unten aufgeklebtes Papiertitelschild, darunter ältere Signatur sichtbar (s. bei G). Kapitale mit Leder umschlagen, oben etwas beschädigt. Spiegel des VD und HD jeweils ein Pergamentblatt, am VD mit Besitzvermerk und Exlibris (s. bei G).

G: $\quad$ Die Hs. stimmt in Inhalt und Aufbau weitestgehend mit Neustift, Stiftsbibl., Nr. 940 überein (vgl. auch verwandte Wasserzeichen); möglicherweise stellt Nr. 139 eine Abschrift von Nr. 940 für die Verwendung in der Pfarre Kiens dar, geschrieben wohl vom selben Schreiber Heinrich Edlinger (vgl. Nr. 940).

Am Spiegel des VD Besitzvermerk Ad ecclesiam [...] V. M. [...] parochiae Kiens, darüber Exlibris der Stiftsbibl. Neustift 18. Jh. Wann die Hs. aus der von Neustift betreuten Pfarre in die Stiftsbibl. gelangte, ist nicht bekannt. Hs. bei vorübergehender Aufhebung des Klosters 1807 nicht an die Universitätsbibliothek Innsbruck gelangt. Am Rücken Neustifter Signaturschild 14819 (= wohl Numerus currens der Neustifter Stiftsbibl.) und Signaturschild 20. Jh. 139.

L: $\quad$ M. Peintner, Musikgeschichte des Stiftes, in: 850 Jahre Neustift. Katalog 94-100, hier 94 (ohne Nennung der Sign.). - Stefani 98. - Engels 309-310 (mit Abb. und Notenbeispielen). - G. Gabrielli, Tropes in cantus planus sources from South Tyrol, in: J. Border u. a. (Hrsg.), Cantus Planus. Venice meeting 2014. Venezia (in Druck).

$$
\text { I (1-153) }
$$

B: $\quad$ Pap. tw. stark verschmutzt, bes. an den Lagenanfängen und -enden, Bl. 56r am oberen Blattrand kreisförmiger Fleck, elfte Lage stark vergilbtes Pap., Bl. 1 Wurmfraß, Bl. 1, 64, 109, 113 eingerissen. Bl. 3 und 6, 50-51 etwas kleiner $(295 / 305 \times 215)$. Lagen: $(\mathrm{V}-1)^{9}+3 \cdot \mathrm{VI}^{45}+(\mathrm{VI}-2)^{55}+(\mathrm{V}-1)^{64}+(\mathrm{VI}-1)^{75}+(\mathrm{V}-1)^{84}+$ 2. $\mathrm{VI}^{108}+2 . \mathrm{V}^{128}+(\mathrm{VI}+1)^{141}+\mathrm{VI}^{153}$. Erste Lage mit Papierfalz umschlagen, in der Mitte der ersten Lage Pergamentfalz mit Resten einer Beschriftung. Gegenfalz zu Bl. 7 auf Bl. 3r aufgeklebt. Gegenbl. zu Bl. 48, 52, 68 herausgeschnitten (ohne Textverlust), an den Gegenfälzen Rahmung erhalten. Gegenfalz zu Bl. 56 auf Bl. 64v, zu Bl. 84 auf 76r aufgeklebt. Bl. 129 eingehängtes Einzelbl., Gegenfalz auf Bl. 141v aufgeklebt. Am Lagenende Reklamanten, meist stark beschnitten. Zw. Bl. 20 und 21 nachträglich eingehängtes kleines Einzelbl. $(120 \times 210)$, in Zählung (und Lagenformel) nicht berücksichtigt. Am unteren Blattrand alte Foliierung (?) in arabischen Ziffern in Tinte nur mehr tw. sichtbar. Am rechten unteren Blattrand Oberlängen einer ehem. Beschriftung stark beschnitten. Am oberen Blattrand Foliierung wohl von der Hand des Schreibers in roten römischen Zahlen von IIII-CIIC (= Bl. 3-153); Fehler in der Zählung: XVI, XIX, XXIV, XLIV, XLVI, XLIX, LII, LIII, LVII, LIX, LXII, LXVI, LXXII, LXXIV, LXXXII, LXXXIII, LXXXV, LXXXVI, LXXXVIII, XCI, XCIII, XCVIII, CVI, CVIII, CXI, CXIV, CXV, CXXII, CXXIII, CXXIV, CXXIX, CXXXII, CL, CLIII, CLVIII, CLXV, CLXVIII, CLXXXIV, CXCIII, CXCIV ausgelassen; C und CLXXI zwar ausgelassen, Blatt in der fortlaufenden Zählung jedoch berücksichtigt (heute Bl. 73 bzw. 129); LXXI doppelt angeführt. Bl. LXV falsch eingebunden, zw. Bl. LXXXIV und LXXXVII, heute als Bl. 63 gezählt.

S: Schriftraum $185 / 200 \times 125 / 140$. Von zweifachen roten Tintenlinien gerahmt, zu sieben bis acht Vierliniensystemen sowie Textzeilen. In seitlicher Rahmung jeweils Notenschlüssel bzw. Kustos eingetragen. Textualis mit kursivem Einschlag, dat. 1495 (Bl. 1r) und 17. Juli 1496 (Bl. 54v). Schreiber: Heinricus Edlinger (vgl. 
Nr. 940, Bl. 1r) (vgl. Krämer, Scriptores: wohl identisch mit Henricus Edling: München, BSB, Clm 6195, dat. 1482, Prov. Frauenzell). Bl. 123v Text in Bastarda (wohl von gleicher Hand). Vereinzelt Abschriften einzelner Wörter in Bleistift 19./20. Jh.

Inhaltsverzeichnis (Bl. 1v-2v): Schriftraum 190/240×145/160. Vier Spalten, mit horizontaler Unterteilung für die Überschrift, jeweils von zweifachen roten Tintenlinien gerahmt, Textualis cursiva. Blätter zusätzlich von je zweifachen roten Tintenlinien am äußersten Blattrand gerahmt, urspr. wohl gesamte Hs. (vgl. Reste Bl. 3r unten, $4 \mathrm{r}$ oben), heute beschnitten.

Bl. 1r Rahmung durch zweifache rote Tintenlinien mit Abgrenzung eines Binnenfeldes $(175 \times 95)$ und zusätzlicher horizontaler Unterteilung.

N: Gotische Choralnotation auf vier roten Linien, c- bzw. f-Schlüssel, Kustoden, rote vertikale Trennstriche (lange Striche, d. h. über alle vier Notenlinien als Abschluss bei jedem Gesang; kurze Striche zw. den einzelnen Wörtern).

Metrische Notation mit Zeichen der Mensuralnotation: Bl. 59v-60v Gloria Spiritus et alme unter Verwendung von Semibreves, Breves (gebildet aus zwei aneinandergefügten Semibreves) und Minimae (mit rotem Notenhals). Beim Tropus Rubriken chorus und pueri; Bl. 118v-121v, 123v: vier Credos und eine Sacra Cantio unter zusätzlicher Verwendung von Semiminimae.

A: Rote Paragraphzeichen, Auszeichnungsstriche, Verbindungsstriche (vereinzelt auch in Mintgrün), Trennstriche (bei Notation), Unterstreichungen, Überschriften. Oberlängen und Unterlängen vereinzelt cadellenartig verziert. Rote und tintenfarbene, vereinzelt auch mintgrüne Initialen mit Aussparungen (vereinzelt kopfstempelförmig), Punktverdickungen und einfachen Ausläufern, bisweilen mit einzelnen Punkten, einander gegenüberstehenden Punkten oder auch Dreipunktmotiv am Buchstabenschaft und vereinzelt auch im Binnenfeld, bisweilen mit Ausläufern in Achterform gelegt, tw. gestrichelt (Bl. 118v, 135r), tw. mit Punkten versehen (Bl. 129r). Bl. 69v Ausläufer als Band gestaltet. Tintenfarbene Initialen mit roter Tinte umrahmt oder verziert, meist cadellenartig gestaltet. Bl. 109r rote Initialen mit mintgrüner Farbe nachgefahren. Bl. 126v am unteren Blattrand rote Tinte verschmiert/verwischt.

Graduale.

(1r) Datierung in Rot: Anno Cristi filii Dei millesimo quadringentesimo novagesimo quinto die commemoracionis s. Pauli. Darunter später in Schwarz: anno 1496, darunter korr. 1495.

Todesnotiz in Rot: Heinricus Edlinger devixit anno Christi 1496 in die s. Steffani (26. Dezember 1496). Darunter in Schwarz abgeschrieben 19. Jh. Henricus Edlmor (!) devixit anno Christi 1496 in die s. Stephani.

(1v) nur Rahmung.

(2ra-va) Inhaltsübersicht mit Blattangabe.

$1 \quad(3 r-54 v)$ Temporale.

(3r) Dnca 1. adventus. - (4r) Dnca 2. adv. - (5r) Dnca 3. adv. - (6v) Dnca 4. adv. - (7v) In galli cantu. Mit Sequenz (AH 53, Nr. 16). - (8v) In aurora. Mit Sequenz (AH 53, Nr. 15 mit propter beatam virginem divisio). - (11v) In nativitate dni (publica missa). Mit Sequenz (AH 53, Nr. 16). - (14v) Stephanus. Mit Sequenz (AH 53, Nr. 215). - (18r) Iohannes ev. Mit Sequenz (AH 53, Nr. 168). - (20v) Innocentes. Mit Sequenz (AH 53, Nr. 157). Mit eingehängtem kleinen Einzelbl. 20I. - (22v) In circumcisione dni. Mit Sequenz (AH 53, Nr. 16). - (24v) In epiphania dni. Mit Sequenz (AH 53, Nr. 29). - (27v) In coena dni. - (29r) Dnca resurrectionis dni. Mit drei Sequenzen (AH 53, Nr. 50; AH 54, Nr. 148; AH 54, Nr. 7). - (34r) In rogacionibus. - (35v) In ascensione dni. Mit Sequenz (AH 53, Nr. 67). - (38r) Dnca pentecostes et de spiritu sancto. Mit Sequenz (AH 53, Nr. 70). - (42r) In festo ss. trinitatis. Mit Sequenz (AH 53, Nr. 81). - (44v) In festo ss. corporis Christi. Mit Sequenz (AH 50, Nr. 385 mit divisio), Offertorium Sacerdotes mit Prosula Ad panem vite nunc accedite und zusätzlich zum Schluss Alia prosa (anderer Text für dieselbe Melodie: AH 49, Nr. 643). - (49v) In dedicatione ecclesiae. Mit Sequenz (AH 53, Nr. 247). - (52r) Pro defunctis. Mit drei Communiones (CAO Nr. 1211, CAO Nr. 1420 und Cantus Nr. 204995). Darunter (Bl. 54v): Anno 1496 in beati Allexii profesto (= 17. Juli). (55r-v) nur Rahmung und Linierung. 
2 (56r-80v) MisSAE BMV.

(56r) Ohne Tit. Mit Sequenz (AH 54, Nr. 218), Offertorium Recordare mit Prosula (AH 49, Nr. 624). - (59r) In summo festo b. Marie. Kyrie, Gloria rhythmisiert mit Tropus Spiritus et alme orphanorum paraclite (Bosse Nr. 49). Anschließend Aliud et mediocre: Kyrie, Gloria mit Tropus Spiritus et alme (Bosse Nr. 23). - (63r) Aliud de virginibus. Kyrie. - Aliud ad idem. Kyrie. (63v) Alleluia Ave benedicta Maria mit Tropus (Cantus Nr. 507047), Sequenz (AH 54, Nr. 218). (64v) Tit.: Sequitur de s. Maria in adventu domini. Mit Sequenz (AH 54, Nr. 191). - (67v) Infra nativitatem et purificationem. Mit zwei Sequenzen (nur Verweis auf Gaude Dei genitrix, Divisio von AH 53, Nr. 15 und AH 54, Nr. 2). - (69r) In purificatione BMV: Ante processionem antiphona (Cantus Nr. 200456). - (69v) Ad missam. Mit Sequenz (AH 53, Nr. 99). - (73r) In annuntiatione BMV. - (73r) Circa festa pascalia. Mit Sequenz (AH 54, Nr. 18). - (74v) In assumptione BMV. Mit Sequenz (AH 53, Nr. 104). - (76v) In nativitate BMV. Mit Sequenz (AH 53, Nr. 95). - (78r) In visitatione BMV. Mit zwei Sequenzen (AH 54, Nr. 193; AH 54, Nr. 219 mit Rubrik: Generalis).

3 (80v-108v) SANCtorale.

Tit.: Sequitur modo de sanctis per circulum anni.

(80v) Iohannes Baptista. Mit Sequenz (AH 53, Nr. 163). - (83r) Petrus et Paulus. Mit Sequenz (AH 53, Nr. 210). - (85r) Paulus. - (85v) Maria Magdalena. Mit Sequenz (AH 50, Nr. 268). (88v) Laurentius. Mit Sequenz (AH 53, Nr. 173). - (90v) Michael. Mit Sequenz (AH 53, Nr. 192). - (93v) Omnes sancti. Mit Sequenz (AH 53, Nr. 112). - (94v) Martinus. Mit Sequenz (AH 53, Nr. 181 mit Divisio propter simplices conf.). - (97r) Elisabeth. Mit Sequenz (AH 55, Nr. 120). - (98v) Catharina. Mit Sequenz (AH 54, Nr. 52). - (100v) Andreas. Mit Sequenz (AH 53, Nr. 122). - (102r) Nicolaus. Mit Sequenz (AH 55, Nr. 265). - (105r) In cathedra s. Petri. - (105v) De quodlibet sancto post septuagesimam. - (106r) De uno beato post pasca videlicet Georgio vel alio. Mit Verweis auf Sequenz (AH 54, Nr. 7). - (107r) Philippus et Iacobus. Mit Verweis auf Sequenz (AH 54, Nr. 7). - (108r) In inventione s. crucis. Mit Verweis auf Sequenz (AH 54, Nr. 7).

4 (109r-123v) Kyriale.

4.1 (109r-118v) KYrIE. GloRIA.

(109r) In summis festis. Kyrie mit Tropus (AH 47, Nr. 99, Str. 1a, 2a und 3a). - (109r) Aliud in festo summo. Kyrie mit Tropus (AH 47, Nr. 5, Str. 1a, 2a und 3c). - (109v) Angelicum sive solemne. Kyrie, Gloria. - (111v) Pascale. - (112v) De apostolis. Nur Kyrie. - (113r) De confessoribus. - (114v) De martiribus. - (116r) De virginibus. - (117r) Dominicale.

4.2 (118v-121v) CREDO.

(118v) Tit.: Symbolum concilii Nyceni. - Patrem omnipotentem ... et sepultus est (Miazga Nr. 450, in C statt in F; in C auch in Innsbruck, ULB Tirol, Cod. 457, Bl. 90r). - (119v) Patrem omnipotentem ... et homo factus est (bei Miazga nicht angeführt). - (120r) Aliud. - Patrem omnipotentem ... et homo factus est (Miazga Nr. 84). - (120v) Aliud. - Patrem omnipotentem ... et sepultus est (Miazga Nr. 123).

$4.3(121 v-123 v)$ Sanctus. Agnus Dei.

(121v) Angelicum. Nur Sanctus. - (122r) Solenne. Sanctus mit Tropus (AH 47, Nr. 382, Str. 1a).(122v) Ohne Tit. Nur Sanctus. - (123r) Paschale.

5 (123v) SACRa CANTIO.

Rubrik: Infra elevacionem canendum est hoc. - Iesus Christus nostra salus (rhythmisiert) (AH 45, Nr. 125). 
7 (125v-129r) Forts. des Kyriale: Sanctus. Agnus Dei.

(125v) De beata virgine Maria. Nur Sanctus. - (126r) Aliud de eadem. Nur Sanctus. - (126v) De virginibus. - (127r) De martiribus. - (127v) De confessoribus. - (128v) In adventu dni. - (129r) In festis generale. Nur Sanctus (unvollständig).

(129v) nur Rahmung und Linierung.

8 (130r-153r) COMMUNE SANCTORUM.

Jeweils mehrere Introitus, Gradualia, Alleluia, Offertoria und Communiones angeführt.

(130r) De apostolis. Mit Sequenz (AH 53, Nr. 228). - (133r) De martyribus. Mit zwei Sequenzen (AH 55, Nr. 14; AH 53, Nr. 229). - (138r) De uno martyre. Mit Sequenz (AH 55, Nr. 9) und zwei Communiones (die zweite Communio mit zwei unterschiedlichen Melodien). - (142v) De confessore et pontifice. - (143r) De simplici confessore. Mit zwei Sequenzen (AH 54, Nr. 88; AH 53, Nr. 243). - (147v) De virginibus. Introitus mit Angabe von zwei zusätzlichen Versen: 1) De omnibus sanctis; 2) In assumptione BMV. - (148r) De virginibus (!). Mit Sequenz (AH 50, Nr. 271) und zwei Offertoria mit unterschiedlicher Melodie (maius, minus).

(153v) nur Rahmung und Linierung.

$$
\text { II (154-231) }
$$

B: $\quad$ Bl. 154r stark verschmutzt, Bl. 170v-171r Tintenklecks, Bl. 171v Tintenspritzer. Bl. 206 und 207 etwas kleiner $(295 \times 215)$. Lagen: $(\mathrm{VI}-1)^{164}+5 \cdot \mathrm{VI}^{224}+(\mathrm{IV}-1)^{231}$. In der Mitte der letzten Lage Pergamentfalz. Am unteren Blattrand alte Foliierung (?) in arabischen Ziffern in Tinte tw. beschnitten, tw. sichtbar. Am unteren Blattrand Reste einer ehem. Beschriftung stark beschnitten, tw. sichtbar. Am oberen Blattrand zeitgenössische Foliierung in roten römischen Zahlen von I-XCII (= Bl. 154-224); Fehler in der Zählung: X, XXVI, XXVII, XXIX-XXXIX, XLV, XLVI, LIII, LVII, LXIV, XCI ausgelassen; LXXXVII zwar ausgelassen, Blatt in der fortlaufenden Zählung jedoch berücksichtigt (heute Bl. 221).

S: $\quad$ Schriftraum 190/205×130/140. Von zweifachen roten Tintenlinien gerahmt, zu jeweils 7-8, Bl. 223v 9 Vierliniensystemen samt Textzeilen. Textualis mit kursivem Einschlag, von gleicher Hand wie T 1. Bl. 220v und 221r-v. Am äußersten seitlichen Blattrand Notizen in Bastarda, beschnitten. Bl. 220v-223v am seitlichen Blattrand Bleistiftnotiz 19./20. Jh.

Inhaltsverzeichnis (Bl.154r-v) Schriftraum 185/200×150. Vier Spalten, mit horizontaler Unterteilung für die Überschrift, jeweils von zweifachen roten Tintenlinien gerahmt, Textualis cursiva (wohl gleiche Hand wie Schreiber). Blätter zusätzlich von je zweifachen roten Tintenlinien am äußersten Blattrand gerahmt. Auch Bl. 155r zusätzlicher äußerer Rahmen erhalten.

N: Gotische Choralnotation auf vier roten Linien, c- bzw. f-Schlüssel, Kustoden, rote vertikale Trennstriche (lange Striche, d. h. über alle vier Notenlinien als Abschluss bei jedem Gesang; kurze Striche zw. den einzelnen Wörtern).

A: Rote Paragraphzeichen, Auszeichnungsstriche, Verbindungsstriche (vereinzelt auch in Mintgrün), Trennstriche (bei Notation), Unterstreichungen, Überschriften. Rote, tintenfarbene und mintgrüne Initialen mit Aussparungen (vereinzelt kopfstempelförmig), Punktverdickungen und einfachen Ausläufern, bisweilen mit einzelnen Punkten, einander gegenüberstehenden Punkten oder auch Dreipunktmotiv am Buchstabenschaft und vereinzelt auch im Binnenfeld, bisweilen mit Ausläufern in Achterform gelegt, an den Schnittstellen tw. gestrichelt (B1. 159v, 166v, 174r in der Gegenfarbe), tw. mit Punkten versehen. B1. 164v Initiale D Buchstabenkörper mit Punkten versehen, am Schaft zwei einander gegenüberstehende Punkte, Fadenausläufer nach unten und oben, nach links Ausläufer in Form eines zehnlinigen Notensystems, mit einzelnen Noten (Punkten) versehen.

ANTIPHONARIUM.

(154r-v) REGISTER.

(154r) Tit.: Registrum Antiphonarii. Am unteren Blattrand Federprobe Notation.

(154v) Inhaltsübersicht mit Blattangabe. 
1 (155r-191v) Temporale und Sanctorale, gemischt.

(155r) Dnca 1. adventus. - (155v) Dnca 2. adv. - (156r) Dnca 3. adv. - (157r) Dnca 4. adv. (157v) In die Lucie an. O (O-Antiphon). - (158r) Dnca 2. (O-Antiphon). - Dnca 3. (O-Antiphon). Ohne Tit. (O-Antiphon). - (158v) In sancta nocte nativitatis dni. Responsorium Descendit de caelo, Vers Tamquam sponsus mit Prosula (Hofmann-Brandt Nr. 416, CAO Nr. 6411). - (167r) De BMV. - (168v) Stephanus. - (168v) Maria. - (169r) Iohannes. - (169r) Innocentes. - (169v) Dominica infra [octavam]. - In circumcisione dni. - (170r) In epiphania dni. Responsorium Illuminare illuminare Ierusalem mit Prosula (Hofmann-Brandt Nr. 673). - (172r) Paulus. - (172v) In purificatione BMV. - (173v) In annuntiatione angelica. - (174v) In nocte sancti pascatis. - (179r) Ad visitationem sepulchri (Engels 310 [mit Transkription]). - (179v) Ad laudes antiphona. Angelus autem domini descendit de celo et accedens ... - (180r) Ad Benedictus antiphona. - Et valde mane una sabbatorum ... - (180v) In secundis vesperis. - Et dicebant ad inficem (!) quis revolvet nobis lapidem ...- $(181 \mathrm{v})$ Alia antiphona. - Isti sunt sermones quos dicebam vobis ...(182r) In ewangelio. - Cum esset sero die illa una sabbatorum ... - (183r) In vigilia ascensionis dni. - (183v) In ascensione dni. - (184v) De sanctis infra pascha et pentecostes. - (185v) In inventione s. crucis. - (187r) Iohannes ante Portam Latinam. - In nocte sancta pentecostes. (188r) In festo ss. trinitatis: Reimoffizium (LMLO XT31). - (189r) In festo ss. corporis Christi. Responsorium Homo quidam fecit cenam mit Prosula (Hofmann-Brandt Nr. 448).

2 (191v-194r) Historiae aestivales.

(191v) Tit.: Incipiunt hystorie estivales.

(191v) Et primo de libris Regum. - (192r) Hystorie Sapiencie. - (192v) Hystoria Iob. - (193r) Hystoria Thobie. - (193r) Iudith et Hester. - (193v) Hystoria Machabeorum. - (194r) Hystoria Ezechielis.

$3 \quad(194 v-210 v)$ Forts. des SANCtorale.

(194v) Iohannes Baptista. - (195r) Petrus et Paulus. - (196r) Margaretha: Reimoffizium (AH 28, Nr. 3). Responsorium Quadam die Olibrius mit Prosula (Hofmann-Brandt Nr. 445). - (197v) Maria Magdalena. Responsorium Accessit ad pedes mit Prosula (Hofmann-Brandt Nr. 696). (199r) Laurentius. - (199v) In assumptione BMV. - (201v) In nativitate BMV. - (203v) Michael. (204v) Omnes sancti. - (205v) Martinus. - (207r) Catharina. Antiphon zum Magnificat (AH 18, Nr. 37 und AH 26, Nr. 69). Responsorium Surge virgo mit Prosula (Hofmann-Brandt Nr. 483). (208r) Andreas. - (209r) Nicolaus. - (210r) Thomas.

(211r-212v) nur Linierung.

4 (213r-220v) Commune SANCTORum.

(213r) Commune apostolorum. - (213v) De evangelistis. - (214v) De pluribus martyribus. $(215 \mathrm{v})$ De uno martyre. - (216v) De confessore et pontifice. - (217r) De simplici confessore. (218r) De una virgine vel electa. - (219r) In dedicatione ecclesiae.

5 (220v-221v) Differentiae et Toni PSALMorum.

(220v) Tit. (am Blattrand von späterer Hand ergänzt): Versus memoriales pro octo tonis. Übersicht (Summula tractatus metricus de musica glossis commentarioque instructus, ed. E. Vetter [Divitiae musicae artis, A/VIIIa]. Buren 1988, 89). - (220v) Primus tonus. - (221r) Secundus tonus. Tercius. Quartus. Quintus. - (221v) Sextus. Septimus. Octavus.

6 (221v-223r) Melodien für Benedicamus Domino.

(221v) Solenniter. Pascaliter. - (222r) Medium. Simplex cum tribus. De corpore Christi. Mit Tropus Benedicamus in laude panis ... - (222v) Minus. De beata virgine Maria. Mit Tropus (Cantus Nr. a00821). - De apostolis. De martiribus. De confessoribus. De virginibus. Mit Tropus Benedicamus ad honorem virginis pie Katherine ... - (223r) De apostolis. Mit Tropus Apostolorum solennia sacrata ... Laudetur sancta trinitas ... 
7 (223r-224r) MELOdIEN FÜR ITE MISSA EST.

(223r) Solenniter. Mit Tropus (AH 47, Nr. 481). - (223v) De BMV. Mit Tropus (AH 47, Nr. 487). - De s. Maria. Mit Tropus (MMMA XIX Nr. 221). - De apostolis. Mit Tropus (AH 47, Nr. 475).

8 (223v-224v) Zwei Antiphonen: De BMV, De omnibus sanctis.

(225r-228r) nur Rahmung und Linierung.

(228v-231r) nur Rahmung.

(231v) nur Rahmung und Linierung.

G. G./U. S.

\section{Nr. 940}

\section{GRADUALE. ANTIPHONARIUM}

Pap. I, 229, I* Bl. $310 \times 220$. Umfeld Neustift, 1490/93.

B: $\quad$ Zwei Teile: I (I, 1-151), II (152-229, I*). T. I dat. 1490/93 (s. bei S), T. II nach Wasserzeichenbefund zeitnah entstanden. Wasserzeichen beider Teile z. T. übereinstimmend. Verwandte Wasserzeichen: u. a. in Neustift, Stiftsbibl., Nr. 139 (olim Sign. 14819). Am unteren Blattrand Bleistiftzählung 21. Jh. (hier berücksichtigt).

E: $\quad$ Gotischer Einband: braunes Leder über Holz mit Blinddruck. Brixen oder Neustift, Ende 15. Jh. Leder insbes. am HD tw. abgerieben und beschädigt, am Rücken oben eingerissen. Am VD ein durch zwei- (unten) bzw. dreifache Streicheisenlinien begrenzter Rahmen, gefüllt mit drei einander abwechselnden Einzelstempeln vierblättrige Blüte frei (Nr. 1), gebogener Ast (Nr. 2) und punktiertes Herz frei (Nr. 3). Mittelfeld von zwei- bzw. dreifachen Streicheisenlinien gerautet. In den vier Mittelfeldern am VD Einzelstempel sechsblättrige Blüte in Kreis (Nr. 4), in den Außenfeldern rautenförmige Lilie frei (Nr. 5). Auf den Schnittpunkten Einzelstempel Punktdekor in Karo (Nr. 6). Am HD ein durch dreifache Streicheisenlinien begrenzter Rahmen, gefüllt mit Einzelstempel Astdekor in Rechteck (Nr. 7). Mittelfeld mit dreifachen Streicheisenlinien gerautet. In den vier Mittelfeldern Einzelstempel Osterlamm mit Fahne in Kreis (Nr. 8), in den Außenfeldern Nr. 5. Auf den Schnittpunkten Einzelstempel Vierblatt in konkavem Karo (Nr. 9). Jeweils drei der urspr. vier spitz zulaufenden Eckbeschläge mit kleinem halbrundem Buckel erhalten, von einstigem rautenförmigen Mittelbeschlag nur Nägel tw. erhalten. Zwei Leder-Metall-Schließen, obere nur mehr tw. erhalten, unten Leder beschädigt, Lager und Raster mit Aufschrift Maria. Kanten gerade, unten, seitlich und oben jeweils leichte Einkerbungen im Holz. Rücken: vier Doppelbünde, durch Streicheisenlinien betont. Felder zw. den Bünden jeweils mit zweifachen Streicheisenlinien mittig unterteilt. Im vierten Feld aufgeklebtes Signaturschild (s. bei G). Kapitale mit naturfarbenem, grünem und rötlichem Garn umstochen, oberes Kapital leicht beschädigt. Spiegel des VD und HD jeweils ein Papierblatt, am VD leer, am HD mit Notiz (s. bei Inhalt).

G: Hs. von dem aus Passau stammenden Heinrich Edlinger für die Verwendung in der Diözese geschrieben (vgl. Bl. 1r). Die Hervorhebung des hl. Ulrich sowie die später ergänzten Gebete am Spiegel des HD lassen auf eine Verwendung in der Kirche St. Ulrich in Ilstern (Pfarrei St. Sigmund/Kiens) schließen; Entstehung möglicherweise in Zusammenhang mit Neuerrichtung der Kirche 1491. Wann die Hs. aus der von Neustift betreuten Pfarre in die Stiftsbibl. gelangte, ist nicht bekannt. Hs. bei vorübergehender Aufhebung des Klosters 1807 nicht an die Universitätsbibliothek Innsbruck gelangt. Am Rücken Neustifter Signaturschild 20. Jh. 940.

Die Hs. stimmt in Inhalt und Aufbau weitestgehend mit Neustift, Stiftsbibl., Nr. 139 (olim Sign. 14819) überein (vgl. auch verwandte Wasserzeichen); möglicherweise stellt Nr. 139 eine Abschrift von Nr. 940 für die Verwendung in der Pfarre Kiens dar.

$$
\text { I (I, 1-151) }
$$

B: Pap. tw. verschmutzt, B1. 11, 20 sowie B1. 103-123 an der rechten unteren Ecke große Tintenflecke, Pap. dadurch auch tw. beschädigt und eingerissen, Bl. 105 Pap. seitlich eingerissen. Lagen: $1^{1}$ (Vorsatzbl., Perg.) $+2 \cdot V^{20}+\mathrm{VI}^{32}+5 \cdot \mathrm{V}^{82}+\mathrm{VI}^{94}+\mathrm{IV}^{102}+\mathrm{V}^{112}+(\mathrm{VI}-1)^{123}+2 \cdot \mathrm{V}^{143}+\mathrm{IV}^{151}$. Vorsatzbl. eingehängtes Einzelbl. In 
der Mitte der ersten Lage Pergamentfalz. Gegenbl. zu Bl. 123 herausgeschnitten (ohne Textverlust). Lagenreklamanten mittig, tw. stark beschnitten, vereinzelt auch Seitenreklamanten am Blattrand (vgl. z. B. Bl. 54r, 57r, 61r, 68r). Am Lagenanfang Kustoden (Ordinalzahlen), stark beschnitten. Am oberen Blattrand Foliierung wohl von der Hand des Schreibers in roten römischen Zahlen von $I-C L X X V$; Fehler in der Zählung: XI, XII, XIII, XV, XVIII, XXVIII, XXXVII, XLV, L, LII, LVII, LXII, LXVIII, LXXIX, LXXXII, LXXXVI, XCV, XCVI, CVIII, CIX, CXVIII, CXIX, CXXXI, CXXXIII, CXLV und CLXVII ausgelassen; XVI und LXXX doppelt angeführt; VIII und XXII zwar nicht angeführt, Blätter in der fortlaufenden Zählung jedoch berücksichtigt.

S: Schriftraum 180/205 $\times 120 / 140$. Von zweifachen roten Tintenlinien gerahmt, zu sieben Vierliniensystemen sowie Textzeilen. In seitlicher Rahmung jeweils Notenschlüssel bzw. Kustos eingetragen. Textualis mit kursivem Einschlag. Schreiber: Heinricus Edlinger, gest. 26. Jänner 1496 (vgl. Nr. 139 [olim Sign. 14819], Bl. 1r) (Bl. 1r), dat. 1490 (Bl. 1r) bzw. 1493 (Bl. 2r) (vgl. Krämer, Scriptores: wohl identisch mit Henricus Edling: München, BSB, Clm 6195, dat. 1482, Prov. Frauenzell).

Inhaltsverzeichnis (B1. 1v-2v): Schriftraum ca. $250 \times 150$. Vier Spalten, jeweils von zweifachen roten Tintenlinien gerahmt, mit zusätzlicher horizontaler Unterteilung für die Überschrift. Textualis cursiva (ebenso von Henricus Edlinger). Blätter zusätzlich von je zweifachen roten Tintenlinien am äußersten Blattrand gerahmt, tw. beschnitten, urspr. wohl gesamte Hs. (vgl. auch Bl. 3r).

Bl. 1r Rahmung durch zweifache rote Tintenlinien mit Abgrenzung eines Binnenfeldes $(170 \times 95)$ und zusätzlicher horizontaler Unterteilung.

N: Gotische Choralnotation auf vier roten Linien, c- bzw. f-Schlüssel, Kustoden, rote vertikale Trennstriche (lange Striche, d. h. über alle vier Notenlinien als Abschluss bei jedem Gesang; kurze Striche zw. den einzelnen Wörtern).

Metrische Notation mit Zeichen der Mensuralnotation: Bl. 23r-v Prosula Triumphat Dei filius unter Verwendung von Semibreves, Breves (gebildet aus zwei aneinandergefügten Semibreves) und Minimae (mit rotem Notenhals).

A: Rote Paragraphzeichen, Auszeichnungsstriche, Verbindungsstriche (B1. 112v auch in Mintgrün), Trennstriche (bei Notation), Unterstreichungen, Überschriften. Oberlängen und Unterlängen vereinzelt cadellenartig verziert. Rote und tintenfarbene (Bl. $112 \mathrm{v}$ auch mintgrüne) Initialen mit Aussparungen (vereinzelt kopfstempelförmig), Punktverdickungen und einfachen Ausläufern, bisweilen mit einzelnen Punkten, einander gegenüberstehenden Punkten oder auch Dreipunktmotiv am Buchstabenschaft und vereinzelt auch im Binnenfeld, bisweilen mit Ausläufern in Achterform gelegt, vereinzelt gestrichelt (B1. 83r, 113v), vereinzelt mit Punkten versehen (Bl. 112v). Tintenfarbene Initialen mit roter Tinte umrahmt oder verziert, meist cadellenartig gestaltet.

Graduale.

(Ir) Tit. (rot): Graduale sancti Udalrici.

(Iv) leer.

(1r) Datierung und Schreibernennung: (rot:) Anno Cristi celitus missi (schwarz:) millesimo quadringentesimo nonagesimo conscriptus est presens libellus cantualis ad divinum cultum augmentandum (gestrichen: conscriptus) per Heinricum Edlinger presbiterum Pataviensis diocesis. Cuius inicium dies prima Aprilis habuit feliciter secundum chorum Brixinensis ecclesie. Ut videri habet registrum et rubrica subsequentes in speciali de maioribus festis et ceteris minoribus agentes. Primo Graduale deinde Antiphonarium exequentes.

(1va-2ra) InhaltsüBersicht mit Blattangabe. Tit.: Registrum Gradualis in presenti libello contenti iuxta numerum foliis assignatum.

Darunter Datierung (rot): 1493.

(2va-b) nur Rahmung.

1 (3r-55r) Temporale.

(3r) In galli cantu. Mit Sequenz (AH 53, Nr. 16). - (4r) In nativitate dni (Ad missam publicam). Mit Sequenz (AH 53, Nr. 16). - (7r) Stephanus. Mit Sequenz (AH 53, Nr. 215). - (10r) Iohannes ev. Mit Sequenz (AH 53, Nr. 168). - (12v) Innocentes. Mit Sequenz (AH 53, Nr. 157). - (15r) In circumcisione dni. Tit.: In circumcisione domini aut de sancta Maria infra nativitatem Christi et purificacionem eiusdem Marie. Ad missam. Mit Verweis auf Sequenz Gaude Dei genitrix 
(Divisio von AH 53, Nr. 15) und Sequenz (AH 53, Nr. 15, mit Divisio). - (18r) In epiphania dni. Mit Sequenz (AH 53, Nr. 29). - (21v) Rubrik: De accionibus fiendis modo vide alibi. - (21v) In die pasce ante processionem. - (22r) Ad processionem. Antiphon Cum rex glorie (Cantus Nr. 201042) mit Prosula (Cantus textualis) Triumphat Dei filius in metrischer Notation (Lipphardt II 526-527, Nr. 385a, Z. 37-39 und 43-46). - (23v) Cantus puerorum (Salve festa dies ..., AH 50, S. 79 [o. Nr.]). Mit Angabe der Variationen für Christi Himmelfahrt und Pfingsten. (24r) Ad chorum (Prozessionsantiphon). - (24v) Dnca resurrectionis dni. Mit drei Sequenzen (AH 54, Nr. 7; AH 53, Nr. 50; AH 54, Nr. 148).

(30v) De uno martire post pasca. Mit Verweis auf Sequenz (AH 54, Nr. 7). - (31v) Philippus et Iacobus. - (32v) De s. cruce. Mit Verweis auf Sequenz (AH 54, Nr. 7). - (34r) In rogacionibus ad processionem. - (35v) In ascensione dni. Mit Sequenz (AH 53, Nr. 67). - (38v) Dnca pentecostes et de spiritu sancto. Mit Sequenz (AH 53, Nr. 70). - (42r) In festo ss. trinitatis. Mit Sequenz (AH 53, Nr. 81). - (45r) In festo ss. corporis Christi. Mit Sequenz (AH 50, Nr. 385, mit Divisio), Offertorium Sacerdotes mit Prosula (Rubrik: Salutatio, AH 49, Nr. 643). - (50r) In dedicatione ecclesiae. Mit Sequenz (AH 53, Nr. 247). - (52v) Pro defunctis. Mit drei Communiones (zusätzlich zu Absolve Domine auch CAO Nr. 1420 und Cantus Nr. 204995).

2 (55r-77v) MisSAe BMV.

(55r) De veneracione s. Marie per annum. Mit Kyrie, Gloria mit Tropus Spiritus et alme, Alleluia Ave benedicta Maria mit Tropus (Cantus Nr. 507047), Sequenz (AH 54, Nr. 218), Offertorium Recordare mit Prosula (AH 49, Nr. 624), Communio mit Einschub für De visitatione BMV. (60v) In adventu domini de s. Maria aut in annunciacione angelica. Mit Sequenz (AH 54, Nr. 191). - (63r) Infra nativitatem et purificationem. Mit Sequenz (AH 54, Nr. 2). - (65r) In purificatione BMV: Ante officium canitur hec antiphona (Cantus Nr. 200456). - (65v) Ad missam. Mit Sequenz (AH 53, Nr. 99). - (69v) In annuntiatione BMV. - (69v) Post pasca de s. Maria officium. Mit Sequenz (AH 54, Nr. 18). Mit Hinweis am Schluss: Crist ist erstanden (rot:) Singt das volckh. - (71r) In assumptione BMV. Mit Sequenz (AH 53, Nr. 104). - (73r) In nativitate BMV. Mit Sequenz (AH 53, Nr. 95). - (74v) In visitatione BMV. Mit Sequenz (AH 54, Nr. 193) (76r) Sequencia de s. Maria per annum communis (AH 54, Nr. 219). Daran anschließend zusätzliche Sequenz (AH 54, Nr. 245).

3 (77v-101v) SANCTORALE.

(77v) Iohannes Baptista. Mit Sequenz (AH 53, Nr. 163). - (80r) Petrus et Paulus. Mit Sequenz (AH 53, Nr. 210). - (82r) Paulus. Mit Verweis auf Sequenz (AH 53, Nr. 228). - (83r) Maria Magdalena. Mit Sequenz (AH 50, Nr. 268). - (86r) Laurentius. Mit Sequenz (AH 53, Nr. 173). (88v) Michael. Mit Sequenz (AH 53, Nr. 192). - (91v) Omnes sancti. Mit Sequenz (AH 53, Nr. 112). - (93r) Martinus. Mit Sequenz (AH 53, Nr. 181 mit Divisio huius propter simplices conf.). - (95v) Catharina. Mit Sequenz (AH 55, Nr. 203). - (97r) Andreas. Mit Sequenz (AH 53, Nr. 122). - (98v) Nicolaus. Mit Sequenz (AH 55, Nr. 265, die letzten zwei Zeilen ohne Notation). - (101v) Beginn der Sequenz zu Elisabeth (AH 55, Nr. 120, ohne Notation): Gaude Syon quod egressus a te decor et depressus [ (102r-v) nur Rahmung und Linierung.

4 (103r-118r) KYRIALE.

4.1 (103r-112r) KYrIE. GLORIA.

(103r) Summum. Kyrie mit Tropus (AH 47, Nr. 99, 1a, 2a und 3a). - (103r) Aliud summum. Kyrie mit Tropus (AH 47, Nr. 5, 1a, 2a und 3c). - (103v) Angelicum. - (105r) Pascale. - (106v) De apostolis. - (108v) De martiribus. - (109v) De virginibus vel de s. Maria. - (111r) Dominicale.

4.2 (112r-118r) Sanctus. Agnus Dei.

(112r) Tit.: Sequitur cantus omnium sanctorum continuus. - (112v) Angelicum. Nur Sanctus. (112v) Aliud summum. Sanctus mit Tropus (AH 47, Nr. 382). - (113v) Summum. Sanctus. - 
(114r) Pascale. - (114v) De dominica nec s. Maria. Sanctus mit Tropus Benedictus Marie filius qui venit ... - (115r) De sancta Maria. Sanctus mit Tropus Benedictus Marie filius qui venit ... (115v) Aliud. Sanctus. - (116r) De apostolis. - (116v) De martiribus. - (117r) De confessoribus. - (117v) Dominicaliter.

5 (118r-142r) COMMUNE SANCTORUM.

Jeweils mehrere Introitus, Gradualia, Alleluia, Offertoria und Communiones angeführt.

(118r) Tit.: Sequitur commune sanctorum apostolorum. - (118v) [De apostolis]. Mit Sequenz (AH 53, Nr. 228). - (122r) De pluribus martyribus. Mit Sequenz (AH 55, Nr. 14). - (127r) De uno martyre. Mit Sequenz (AH 55, Nr. 9). - (132r) De confessore et pontifice. Mit Sequenz (AH 54, Nr. 88). - (136r) De simplici confessore aut evangelista. Mit Hinweis auf Sequenz (Divisio von AH 53, Nr. 181, Str. 15). - (136r) De virginibus. Introitus mit Angabe von zwei zusätzlichen Versen: 1) De assumpcione beate virginis; 2) Omnium sanctorum. Mit Sequenz (AH 50, Nr. 271) und zwei Offertoria mit unterschiedlicher Melodie (offertorium maius, offertorium minus).

$6 \quad(142 \mathrm{r}-148 \mathrm{v})$ Forts. des Temporale.

(142r) Rubrik: Tractus in LXX continentur folio CLXXII. - (142r) Dnca 1. adventus. - (143v) Dnca 2. adv. - (144v) Dnca 3. adv. - (146r) Dnca 4. adv. - (147r) In cathedra s. Petri. Nur Tractus. - (148r) In quadragesima de uno martire aut confessore. Nur Tractus.

(149r-151r) nur Rahmung und Linierung.

$$
\text { II }\left(152-229, I^{*}\right)
$$

B: Pap. vereinzelt leicht verschmutzt, selten kleine Tintenflecken und Tintenspritzer. Bl. 175 unten leicht eingerissen. Lagen: (VI-3) ${ }^{160}+2 . \mathrm{V}^{180}+\mathrm{VI}^{192}+2 . \mathrm{V}^{212}+(\mathrm{II}+1)^{217}+\mathrm{VI}^{229}+1^{\mathrm{I}^{*}}$ (Nachsatzbl., Perg.). Gegenbl. zu Bl. 152, 156 und 160 herausgeschnitten (jeweils ohne Textverlust, trotz Reste urspr. Buchstabenausläufer in Rot auf Gegenfalz zu Bl. 160). Bl. 217 eingehängtes Einzelbl., Falz auf Gegenfalz zum Nachsatzbl. mit Papierstreifen aufgeklebt. In der Mitte der letzten Lage Pergamentfalz. Lagenreklamanten, nur vereinzelt erhalten, vereinzelt auch Seitenreklamanten am Blattrand (vgl. z. B. Bl. 174r, 175r, 193r, 196r). Bl. 171r und 193r am Lagenanfang Kustode XVIII bzw. XX. Am oberen Blattrand zeitgenössische Foliierung in roten römischen Zahlen von I-CXC; Fehler in der Zählung: IX, XI, XII, XXIII, XXXVII, XLVII, LVI, LIX, LXI, LXVIII, LXXI, LXXIII-LXXVIII, LXXX, LXXXIV, CLXXXIV, CLXXXVI und CLXXXVIII ausgelassen; statt LXVII fälschlich $L X X V I I$; auf $L X X X V$ folgt $C L X X V I$; LXX zwar nicht angeführt, Blatt in der fortlaufenden Zählung jedoch berücksichtigt (heute Bl. 211).

S: $\quad$ Schriftraum $185 / 205 \times 120 / 135$. Von zweifachen roten Tintenlinien gerahmt, zu jeweils sieben Vierliniensystemen samt Textzeile, B1. 228r-229r ca. 28 Zeilen. Textualis mit kursivem Einschlag, von gleicher Hand wie T. I.

N: Gotische Choralnotation auf vier roten Linien, c- bzw. f-Schlüssel, Kustoden, rote vertikale Trennstriche (lange Striche, d. h. über alle vier Notenlinien als Abschluss bei jedem Gesang; kurze Striche zw. den einzelnen Wörtern).

A: Rote Paragraphzeichen, Auszeichnungsstriche, Verbindungsstriche (vereinzelt auch in Mintgrün), Trennstriche (bei Notation), Unterstreichungen, Überschriften. Oberlängen und Unterlängen vereinzelt cadellenartig verziert. Rote und tintenfarbene Initialen mit Aussparungen (vereinzelt kopfstempelförmig), Punktverdickungen und einfachen Ausläufern, bisweilen mit einzelnen Punkten, einander gegenüberstehenden Punkten oder auch Dreipunktmotiv am Buchstabenschaft und vereinzelt auch im Binnenfeld, bisweilen mit Ausläufern in Achterform gelegt. Tintenfarbene Initialen mit roter Tinte umrahmt oder verziert, meist cadellenartig gestaltet.

ANTIPHONARIUM.

1 (152r-182v) Temporale und Sanctorale, gemischt.

(152r) Dnca 1. adventus. - (152v) Dnca 2. adv. - (153r) Dnca 3. adv. - (154r) De s. Maria antiphona. - Dnca 4. adv. - (154v) Rubrik: Hic canuntur O ad singulas dominicas a festo s. Lucie (vier O-Antiphonen). - (155v) In sancta nocte nativitatis dni. Responsorium Iudea et Ierusalem mit Prosula (Hofmann-Brandt Nr. 176). Responsorium Descendit de caelo, Vers Tamquam 
sponsus mit Prosula (Hofmann-Brandt Nr. 416, CAO Nr. 6411). - (164r) De BMV (gleich wie in Nr. 139 [olim Sign. 14819], hier aber ohne Titel). - (165v) Stephanus. - (166r) BMV. - Iohannes. (166v) Innocentes. - Dominica infra [octavam]. - In circumcisione dni. - (167r) In epiphania dni. Responsorium Illuminare illuminare Ierusalem mit Prosula (Hofmann-Brandt Nr. 673). (169r) In conversione s. Pauli. - In purificatione BMV. - (170r) In annuntiatione BMV. - (171r) Alia quere. - In die pasce in matutinas invitatorium (gleich wie in Nr. 139). - (175v) Ad visitationem sepulchri (vgl. Engels 310 [mit Transkription], bezogen auf Nr. 139, Bl. 179r). (176r) Ad laudes antiphona. Angelus autem domini descendit de celo et accedens ... Vorangestellt: (rot:) Wlgus (schwarz:) Crist ist erstanden von der marter allen. - Ad Benedictus. Et valde mane una sabbatorum ... - (176v) In vigilia ascensionis. - (177r) In vigilia pentecostes. - (178r) In festo ss. trinitatis: Reimoffizium (LMLO XT31). - (179v) De corpore Christi. Responsorium Homo quidam fecit cenam mit Prosula (Hofmann-Brandt Nr. 448).

2 (182v-185v) Historiae aestivales.

(182v) Tit.: Sequuntur historiae estivales.

(182v) Et prima Regum. - (183r) Historia Sapiencie. - (183v) Historia Iob. - (184r) Historia Thobie. - (184v) Historia Iudith. - Historia Machabeorum. - (185r) Historia Ezechielis.

3 (185v-193r) COMMUNE SANCTORUM.

(185v) In dedicatione ecclesiae. - (187r) Commune Apostolorum. - (188r) De pluribus martyribus. $-(189 \mathrm{v})$ De uno martyre. $-(190 \mathrm{v})$ De confessore et pontifice. - (191v) De simplici confessore. - (192r) De una virgine.

4 (193r-211r) Forts. des SAnctorale.

(193r) Tit.: Sequuntur de sanctis per estatem. - Iohannes Baptista. - (194r) Petrus et Paulus. (195r) Margaretha: Reimoffizium (AH 28, Nr. 3). Responsorium Quadam die Olibrius mit Prosula (Hofmann-Brandt Nr. 445). - (196v) Maria Magdalena. Responsorium Accesit ad pedes mit Prosula (Hofmann-Brandt Nr. 696). - (198v) Laurentius. - (199v) In assumptione BMV. - (201v) In nativitate BMV. - (203r) Michael. - (204r) Omnes sancti. - (205v) Martinus. - (207r) Catharina. Antiphon zum Magnificat (AH 18, Nr. 37 und AH 26, Nr. 69). Responsorium Surge virgo mit Prosula (Hofmann-Brandt Nr. 483). - (208v) Andreas. - (209v) Nicolaus. - (210v) Thomas.

5 (211r-212v) Differentiae Et TONi PSALMorum, unvollständig.

(211r) Tit.: Inductio puerorum ad tonos flectendos in psalmodia. Übersicht (Ed.: E. Vetter, Summula tractatus metricus de musica glossis commentarioque instructus [Divitiae musicae artis, A/ VIIIa]. Buren 1988, 89). - (211v) Primus tonus. Secundus tonus. Tertius tonus. - (212r) Quartus tonus. - (212v) Quintus tonus. Sextus tonus. Expl. mut.: ... fratres in unum. Magnificat [ (Kustos vorhanden)

(213r-227r) nur Rahmung und Linierung.

6 (227v-229r) Dedicatio Ecclesiae (Udalricus?).

(227v) Hymnus (AH 51, Nr. 102, mit Divisio). - (228r) Psalmi ad vesperas in solemnitatibus. (229r) Hinweis in Rot: Capitula et collecte habentur in missalibus.

(229v) Hymnus de confessore et pontifice (AH 51, Nr. 118).

$\left(\mathrm{I}^{*} \mathrm{r}-\mathrm{v}\right)$ leer.

7 (HDS) von späterer Hand ergänzt: GeBETE, dt.

1) Pit umb des Nikclas Geczenperger vater sel und umb seiner muter vatter und mutter sel und umb seiner hawsfrau vatter sel et omnium etc.

2) Pitt umb Michel auff Ellen sel und umb seins vater und miter sel und umb seiner ersten hausfrau vater und muter sel und umb der iczingen vater und muter sel et omnium etc. 
3) Pitt umb Michel (gestrichen: auff) Pranttner sel auff dem Kunperch und umb seiner vater und mutter sel und umb seines Iacob veter sel und umb der Pranttnerin vater und muter sel und antecessores et omnium fidelium.

\section{G. G./U.S.}

\section{ohne Sign.}

\section{NEUSTIFTER WAPPENBUCH}

Perg. I, 88, I* Bl. $245 \times 180$. Sterzing (?), 1548-1552.

B: $\quad$ Lagen: (I-1) $($ Vorsatzbl., Pap. 18. Jh. $)+16 . \mathrm{II}^{124(62)}+(\mathrm{II}-1)^{130(65)}+2 . \mathrm{II}^{146(73)}+\mathrm{I}^{150(75)}+(\mathrm{II}-1)^{156(78)}+2 . \mathrm{II}^{172(86)}+$ $(\mathrm{II}-2)^{176(88)}+(\mathrm{I}-1)^{\mathrm{I*}}$ (Nachsatzbl., Pap. 18. Jh.). Gegenbl. zum Vor- bzw. Nachsatzbl. als Spiegel auf dem VD bzw. HD aufgeklebt. Gegenbl. zu Bl. 65 (S. 129/130) und 72 (S. 153/154) herausgeschnitten (Textverlust?). Am oberen Blattrand Paginierung, beginnend mit der Zahl 2, Anfang 20. Jh. radiert und ersetzt, beginnend mit der Zahl 1 (wohl durch Marie Fischnaler, s. Arch 11). Eingelegtes Bl. (gefaltet) mit zwei schwarzweiß ausgeführten und einem kolorierten Wappen. S. 53-77 kleine Papiermarken mit Buchstaben „M“ (S. 55, zweite Zeile Mitte „55 M“) in Tinte über den Wappen aufgeklebt, nachträglich. Bisweilen über den Wappen Klebespuren derartiger Papiermarken sowie Reste von rotem, vereinzelt auch grünem Wachs (?), das als Klebstoff verwendet wurde.

S: Zuweisungen über dem jeweiligen Wappen von unterschiedlichen Händen, Haupthand bastardaähnliche Buchschrift, wohl Vigil Raber.

A: Da das Wappenbuch durch die Edition von H. W. Arch umfassend und rezent erschlossen ist, an dieser Stelle nur grundlegende Angaben zur Wappenanzahl, Technik, Händescheidung und Datierung.

Insgesamt 1562 Wappen (koloriert und unkoloriert, mit und ohne Namen der Wappenträger; ohne Leerwappen [13] und Hauszeichen [2]); Zahlenangabe 1558 (S. 176) evtl. keine Jahreszahl, was aber nicht völlig verworfen werden sollte, sondern Wappenzählung (s. Arch 16): 1562 minus vier übermalte, unfertige oder verschmierte Wappen; in der Regel drei mal drei Wappen pro Seite, S. 176 nur zwei Wappen.

Rundbogige Schilde (54×47, mit Schablone angelegt). S. 104-105 Umrisszeichnung mit schwarzer Tinte, 104,7 zusätzlich Vorzeichnung erkennbar (nur 105,8 koloriert); ansonsten Ausmalung mit Deckfarben (ohne Verwendung von Blattgold), fallweise dünnerer Farbauftrag; Originalkolorit etwas kräftiger als in Ed. Seitenverkehrte Darstellung unsymmetrischer Wappen (möglicherweise für geplanten Druck, s. Arch 14-15). Plastizität von Holz- bzw. Steinschilden (mit Graten) wird durch verschattete Kanten und horizontal gestrichelte (mit Pinsel ausgeführte) Schattenpartien in Grau bzw. in dunklerer Lokalfarbe erzeugt; auch Wappenbilder durch Schattenwürfe immer wieder räumlich hervorgehoben (z. B. 7,4).

Es fällt auf, dass ab S. 106, also nach dem Abschnitt mit den unkolorierten Zeichnungen, bis einschließlich S. 116 Binnenzeichnungen minutiöser ausgeführt sind, vgl. z. B. die einfache Fellstrukturierung des Löwen 85,2 mit den bewegten Binnenmodellierungen S. 107; zudem verstärkte, die Plastizität von Schilden und Motiven erhöhende Flächenschattierung: hier wohl andere Hand tätig; ab S. 117 bis S. 123 möglicherweise wieder die urspr. Hand tätig; danach vergröbert sich die Ausführung bis zum Ende der Hs. Die beiden Wappen S. 176, v. a. 176,2, könnten Ergänzungen im Stile der voranstehenden Wappen sein. Inwieweit daraus (in Zusammensicht mit Handwechseln in der Schrift) de facto auf Handwechsel in der malerischen Ausgestaltung geschlossen werden kann, die in der Hauptsache sicherlich Raber zugeschrieben werden muss, bleibt noch zu untersuchen.

Arch gibt das Wappenbuch in die letzten Lebensjahren Rabers (vor 1552, s. auch bei G). Sollte es sich bei den Wappen S. 176 tatsächlich um Ergänzungen handeln, dann könnte 1558 doch eine Jahreszahl sein, die auf die Ergänzungen Bezug nimmt.

E: $\quad$ Neuzeitlicher Bibliothekseinband: schwarz gesprenkeltes braunes Pap. über Pappe. Neustift (?), 2. H. 18. Jh. Pap. tw. stark abgerieben. Am VD und HD Ecken mit braunem Leder verstärkt. Rücken: braunes Leder, fünf einfache Bünde, von Goldbordüren gesäumt. In den Feldern 1 sowie 3-6 in Goldprägung Einzelstempel kleine Blumensträußchen (Vignetten) frei (Nr. 1). Zw. erstem und zweitem Bund rotes Titelschild mit Golddruck WAPPEN[BU]CH. Schnitt rot gefärbt. Spiegel Pap. 18. Jh. Am Spiegel des VD Exlibris, Besitzvermerke und Signaturen (s. bei G), Spiegel des HD leer. 
G: Entstanden zw. Vigil Rabers Arlberg-Aufenthalt 1548 und dessen Tod 1552. Am Spiegel des VD alte Signaturen, wohl nicht der Stiftsbibl. Neustift: 2602 (Tinte), Z. I. e. C. (Tinte, gestrichen) und Z. III. l (Bleistift). Besitzvermerk Stiftsbibl. Neustift 18. Jh. Bibliotheca Neocell., mit Exlibris der Stiftsbibl. Neustift 18. Jh. überklebt. Darunter in Bleistift (fälschlich) 1.576 Wappen. S. 176r 1558 (Tinte), am Spiegel des VD 155(9) (Bleistift, schlecht lesbar), wohl nicht Jahreszahl, sondern Wappenzählung (nicht korrekt). Bei der vorübergehenden Klosteraufhebung 1807 nicht an die Universitätsbibliothek Innsbruck gelangt.

L: $\quad$ C. Fischnaler, Vigil Rabers Wappenbuch der Arlberg-Bruderschaft in Weimar. Der deutsche Herold. Zeitschrift für Wappen-, Siegel- u. Familienkunde 14 (1909), Nr. 8, 153-176, hier 162-162. - G. Gerola, Il codice araldico di Novacella in Alto Adige. Bollettino ufficiale della consulta araldica del Regno 9, 43 (1937) 127-164. - Rasmo 63 (Nr. 235) und Abb. 189. - H. W. Arch, Vigil Rabers Neustifter Wappenbuch. Aus der Bibliothek des Augustiner Chorherren-Stiftes Neustift. Brixen 2001.

$(\mathrm{Ir}-\mathrm{v})$ leer.

VigIL RABER: Neustifter Wappenbuch (Ed. und Faksimile mit Blasonierungen sowie ausführlicher Einleitung: H. W. Arch, Vigil Rabers Neustifter Wappenbuch. Aus der Bibliothek des Augustiner Chorherren-Stiftes Neustift. Brixen 2001).

Insgesamt 1577 Wappendarstellungen, darunter zwei Hauszeichen und 13 leere Wappenschablonen. 352 ohne Namenszuweisungen.

Wahrscheinlich diente das Wappenbuch des Jörg Rugen(n), Innsbruck, ULB Tirol, Cod. 545 im Original oder in einer Kopie als Vorlage, vgl. bes. Bl. 249r-260r „Vnder dem keissertom Constantinoppel“ (Phantasiewappen).

Vgl. Weimar, Herzogin-Anna-Amalia-Bibl., Fol. 220: Vigil Raber, Wappenbuch 1548 (Konrad Fischnaler, Vigil Rabers Wappenbuch der Arlberg-Bruderschaft in Weimar. Der Deutsche Herold 8 [1909] 1-24).

Eingelegter Zettel mit drei Wappendarstellungen (jeweils mit Helmzier).

$\left(I^{*} \mathrm{r}-\mathrm{v}\right)$ leer.

C.S.

ohne Sign.

\section{GRADUALE NEOCELLENSE I}

Perg. II, 289, I* Bl. $725 \times 505$. Neustift, 1442.

B: $\quad$ Hs. um 1980 restauriert (s. bei G). Perg. am rechten unteren Blattrand tw. stark abgegriffen, daher Ecken häufig im Zuge der Restaurierung ergänzt bzw. ersetzt. Perg. tw. dünn und Tinte durchscheinend. Einzelne Blätter oder Teile von Blättern stark vergilbt (insbes. Bl. 31r-v unten, 74v, 76v, 156v, 209r-v, 274r-v, 277rv). Am Blattrand vereinzelt kleine Löcher und Risse, Nahtspuren. Risse und Fehlstellen tw. mit Pergament geklebt. Zahlreiche Bl. verloren gegangen (Textverlust, s. bei Inhalt), Gegenfälze der Einzelbl. meist im Zuge der Restaurierung verstärkt bzw. erneuert. Bisweilen Korrektur durch Aufkleben von zusätzlichen Pergamentstreifen und -stücken (z. B. B1. 199v, 213r, 214r, 215v, 245r). Zahlreiche Melismen zur Vereinfachung und Modifizierung der Melodien mit Papierstreifen mit rotem Vierliniensystem (meist leer, vereinzelt Kustode neu aufgetragen) im 16./17. Jh. überklebt (Bl. 1v, 2r, 3v, 4r, 4v, 6v, 8v, 17r, 17v, 19r, 48v, 49r, 51r, 51v, 52r, 54r, 57v, 59r, 62v, 63r, 70r, 76r, 76v, 88r, 88v, 89r, 116v, 117r, 118r, 130v, 131r, 132r, 136v, 139v, 141r, 142r, 282v, 283r), heute jeweils nur mehr am linken Rand festgeklebt, darunter Klebespuren und Durchstreichungen sowie Bleistifthinweise und tw. Abgrenzungen in Rot deutlich sichtbar. Papierstreifen vereinzelt verloren gegangen (vgl. Klebespuren bzw. Verfärbungen).

Lagen: (I-1) $)^{\mathrm{I}}\left(\right.$ Vorsatzbl. 20. Jh.) $+1^{\mathrm{II}}+(\mathrm{IV}-1)^{7}+3 \cdot \mathrm{IV}^{31}+(\mathrm{IV}-1)^{38}+(\mathrm{IV}-2)^{47(44)}+(\mathrm{IV}-1)^{55(51)}+3 . \mathrm{IV}^{79(75)}+$ $(\mathrm{IV}-6)^{87(77)}+\mathrm{IV}^{95(85)}+(\mathrm{IV}-1)^{103(92)}+3 . \mathrm{IV}^{127(116)}+(\mathrm{IV}-2)^{135(122)}+\mathrm{IV}^{143(130)}+(\mathrm{IV}-8)^{151(130)}+(\mathrm{IV}-1)^{158(137)}+$ $(\mathrm{IV}-3)^{167(142)}+2 . \mathrm{IV}^{183(158)}+(\mathrm{IV}+1)^{191(167)}+\mathrm{IV}^{199(175)}+(\mathrm{IV}-6)^{207(177)}+\mathrm{IV}^{215(185)}+(\mathrm{IV}-2)^{223(191)}+3 . \mathrm{IV}^{248(215)}+$ $(\mathrm{IV}-1)^{255(222)}+\mathrm{IV}^{263(230)}+(\mathrm{IV}-3)^{27(235)}+\mathrm{IV}^{279(243)}+(\mathrm{IV}+1)^{287(252)}+\mathrm{IV}^{295(260)}+(\mathrm{IV}+1)^{303(269)}+\mathrm{IV}^{311(277)}+$ $(\mathrm{IV}+4)^{325(289)}+(\mathrm{I}-1)^{\mathrm{I}^{*}}$ (Nachsatzbl. 20. Jh.). Urspr. Bindung bzw. Lagenordnung bei Restaurierung tw. nicht berücksichtigt (z.B. Bl. 218 und 220 [urspr. Gegenbl. zu Bl. 219 und 221] herausgeschnitten, Gegenfälze heute zw. Bl. 217 und 219 und somit Bl. 219 fälschlich der zweiten Lagenhälfte zugeordnet). 
Bl. II eingehängtes Einzelbl., anderes Perg. kleineren Formats $(690 / 705 \times 450 / 460)$, urspr. wohl als Spiegel auf dem VD aufgeklebt (Holzfaserung auf Recto sichtbar), heute gelöst und auf neuen Pergamentfalz aufgeklebt (zw. Bl. 6 und 7). Bl. 7 eingehängtes Einzelbl., möglicherweise urspr. Gegenbl. zu heutigem Bl. II., Gegenfalz nach Lage 2 (zw. Bl. 15 und 16). Gegenbl. zu Bl. 32, 45, 46, 50, 102, 134, 135, 152, 165, 166, 167, 219, 221, 255, 270 (Textverlust), Gegenbl. zu Bl. 218 und 219 (ohne Textverlust) herausgeschnitten. Zusätzlich Bl. 81-86, 144-151 (= Lage 19), 201-206, 266/269, 322 und 323 (Textverlust) herausgeschnitten. B1. 318-321 eingehängte Einzelbl. Zw. Bl. 187 und 188, 282 und 283, 301 und 302 jeweils ein später eingehängtes Einzelbl., Perg., in zeitgenössischer Foliierung nicht beachtet, mit Bleistift als „187 bis“، „282 bis“ bzw. „301 bis“ foliiert. Am Lagenende jeweils Kustoden in römischen Zahlen. Lagenreklamanten. Am oberen Blattrand zeitgenössische Foliierung in roten römischen Zahlen I-CCCXXIIII; Fehler in der Zählung: 244 ausgelassen. Bl. 28, 36, 157, 199 und 227 Spuren von Signakeln.

S: $\quad$ Schriftraum 535/540 $\times 350 / 360$, seitlich von zweifachen roten Tintenlinien begrenzt (linke Spalte Notenschlüssel, rechte Spalte Kustos), jeweils sieben rote Vierliniensysteme (39 mm) mit Textzeilen. B1. 325r-v: zwölf bzw. acht Zeilen auf roter Tintenlinierung. Zirkelstiche. Textualis formata (Textura), dat. 7. September 1442 (Bl. 325v). Schreiber: Friedrich Zollner, Chorherr aus Langenzenn (Bl. 325r; zu Friedrich Zollner s. Giner 10: gest. 1449; laut Eintrag auf Bl. 325v gest. 1446). Nur vereinzelt Radierungen und Korrekturen (sowohl bei Noten als auch bei Text).

Zahlreiche Radierungen, Durchstreichungen, Ergänzungen und Korrekturen von späteren Händen (Bl. 324r: dat. 1512), meist ebenfalls in Textualis formata (Textura), tw. auch in Rotunda (z. B. 271r, Z. 2-7). Blattgestaltung (Höhe der Vierliniensysteme sowie Schriftgröße) meist nachgeahmt, vereinzelt Abweichungen (z.B. Bl. 287 ${ }^{\text {bis }}$ nur sechs Notensysteme). Zusätze in schwarzer und roter Tinte sowie Bleistift bis ins 18. Jh., z.B. Vacat, Gliederungsstriche von unterschiedlicher Breite, Rubriken, Buchstaben für die Aufführungspraxis (mit Orgel? bzw. Bl. 223r-v, 225r in tw. pastosem Rot Chorus - Rectores), Blattverweise. Mehrere Feste zur Gänze von späterer Hand gestrichen.

N: Gotische Choralnotation (mit Virga) auf vier roten Linien, c- bzw. f-Schlüssel, Kustoden. Kustoden in Rot weisen auf einen Wechsel des Schlüssels innerhalb eines Gesangs hin. Reperkussionston mit einem ornamentalen Haarstrich. Bl. 297v und 306v (Tropus zum Sanctus bzw. Agnus Dei) metrische Notation mit Zeichen der Mensuralnotation. Bl. 301 $1^{\text {bis }} \mathrm{r}-\mathrm{v}$ von anderer Hand 15. Jh.: sog. „umgekehrte Hufnagelnotation“ (vgl. hierzu auch Graduale II). Im 16./17. Jh. zahlreiche Melismen gestrichen und durch Pergamentstreifen überklebt, Notation bisweilen ergänzt bzw. verändert. Hinzufügung von zahlreichen, tw. sehr dicken schwarzen vertikalen Gliederungsstrichen am Beginn und am Schluss der zu streichenden Melismen (z.B. Bl. 4v). Im 18. Jh. Ergänzung von langen Gliederungsstrichen in Rot (oben lilienförmig bzw. Rhombusform), die über das Vierliniensystem hinausreichen (z.B. Bl. 1r), möglicherweise Hinweis auf AlternatimAufführungsform, vielfach in Verbindung mit den Rubriken Rectores und Chorus (z. B. Bl. 110r). Bl. 271v310v (Kyriale) am Blattrand entsprechend den verschiedenen Abschnitten Ergänzung der Buchstaben $A, B$, $C, D$ : Bedeutung nicht eindeutig geklärt, möglicherweise jedoch Hinweis auf Aufführungspraxis. Von noch späterer Hand zahlreiche Vorzeichen (\# und b) in Schwarz und Rot ergänzt.

A: $\quad$ Rubriken und Foliierung in Rot; spätere Zeigehand Bl. 4r.

Fleuronnée: gut 800 Fleuronnée-Initialen (abwechselnd rote und blaue, in der Regel eine Notenzeile hohe Buchstaben mit Punktverdickungen und wenigen herzblattförmigen Verzierungen, z.B. Bl. 150v; in der Regel keine Aussparungen, die Palmettenaussparungen Bl. 136r wohl von anderer Hand; Einleitungsinitiale des Sanctus-Teils Bl. 291r in der Höhe von zwei Notenzeilen mit rot-blauem, durch schraffierte Blattaussparungen verziertem Buchstabenkörper; Bl. 319v und 321r zwei rot-blau kopfstempel- bzw. bogenförmig gespaltene Initialen von späterer Hand) und ca. 400 fleuronnierte Cadellen, zumeist in der Höhe einer Notenzeile; von diesen etwa 1200 erhaltenen fleuronnierten Buchstaben die allermeisten vom Hauptflorator; nur wenige Fleuronnée-Nachträge (von mindestens acht Händen, s. u.). Das Fleuronnée der Haupthand ungeachtet der großen Anzahl der zu dekorierenden Buchstaben sehr gleichmäßig und akkurat ausgeführt; wenige Motive, die trotz unterschiedlichster Kombinationen einen relativ gleichförmigen Gesamteindruck erzeugen. Außer bei Cadellen in den obersten Notenzeilen, die aufwändiger geschmückt sein können (z. B. B1. 23v, 91r, 118v, 305v), das Formenvokabular des Cadellen-Fleuronnée sehr ähnlich, aber noch etwas reduzierter (z.B. weniger Besatz); Cadellen-Fleuronnée in Schwarz, mit wenig rotem Dekor, vorwiegend Konturlinien und Punkte. Die blauen Initialen mit Fleuronnée in tw. changierenden Rot- und Violetttönen (Hell- und Dunkelrot, Orangerot bis Bräunlich, oft sehr blasses Violett, Rosa), seltener in Grün; rote Initialen vorwiegend mit grünem, seltener mit rotem oder violettem Fleuronnée; fallweise Farbkombinationen im Fleuronnée, z. B. Bl. 195r (grün-violett) und 291r (grün-rot), ab und an Profilköpfe (s. u.) in Rot zusammen mit andersfarbigem Ornament, z. B. B1. 112v (grün), 215v2 (violett), 270v (grün-violett); wenige Fälle von andersfarbigen, evtl. nachgetragenen Punkten und/oder Kernen (z. B. Bl. 25r4). 
Drei Knospenformen: (1) spitz, auch zu Paaren bzw. Ähren zusammengefasst (z. B. B1. 249r1) oder als Knospenwiegen (häufig als Binnenfeldgliederung, s. u.); (2) rund, zumeist stark eingerollt, auch als Ähren (z. B. Bl. 7v1, oberes Binnenfeld) oder Knospenwiegen (z. B. beim „bedachenden“ Besatzmotiv, s. u.); (3) rund und durch Doppelstriche mit den Stielen der Knospenwiegen verbunden (z. B. als Besatz der Initiale Bl. 55v); (2) und (3) auch im Wechsel mit Dornen. Gestrichelte Halbpalmetten, die den spitzen Knospen ähneln, aber größer sind als diese und sich eng an ihre Stiele zurückklappen (z. B. Bl. 212r). Binnenfelder immer wieder in Kompartimente, oftmals Streifen (v. a. friesartig übereinander gesetzte Knospenwiegen, z. B. bei der Initiale Bl. 102r) unterteilt, bisweilen Kachelungen (so ergeben aneinander gesetzte Dreiecksformen, gefüllt mit Knospenpaaren, wie (1), Herzformen, z. B. Bl. 105v1 und im gesamten großflächigen, teppichartigen Initialfeld Bl. 291r; Bl. 208v2 quadratische Kachelung, mit Kreuzverbindungen), Medaillons bzw. S-förmige Doppelspiralen (z. B. Bl. 107v); aus vollfarbigem Binnenfeldgrund ausgespart werden u. a. die gekachelten Knospenpaare und die zu Ähren zusammengefassten Halbpalmetten (z. B. Bl. 212r) oder Doppelknospen, die runde Knospen und Halbpalmetten kombinieren können (z. B. in den Binnenfeldern der Initiale Bl. 78v); speziell in den Binnenfeldern von Cadellen aus schwarzem Grund ausgesparte ondulierende Halbpalmettenranken (z.B. Bl. 17r) und Halbblätter mit sanft eingebuchteten und in regelmäßigen Abständen tief eingeschnittenen Rändern, am Ende des Einschnitts jeweils ein kleines „Loch“ (z. B. bei der oberen Cadelle Bl. 163v; zur Herleitung dieses Motivs als Negativform von Kopfstempeln s. S. Rischpler, Der Illuminator Michael. Purkersdorf 2009 [Codices Manuscripti. Suppl. 1], 49). Konturlinien. Als Besatz immer wieder runde Knospen, u. a. weit auseinander stehend (z. B. Bl. 208v2), auch als gegeneinander gekehrte Paare (z. B. unten an der Initiale Bl. 114v) oder seltener als Ähren (z. B. B1. 126r); ab und an Laufender Hund (z. B. Bl. 246v) sowie ein dreieckiges Motiv, das häufig bedachend eingesetzt wird: auf einer Knospenwiege, hier mit runden Knospen, sitzt eine gefüllte Dreiecksform, deren Schrägen von Fadenausläufern begleitet werden, die von den Knospen ausgehen und mit den Schrägen durch Doppellinien verspannt sind (z.B. Bl. 12r); sehr oft Halbpalmetten, die durch Zackenlinien verbunden sind, wodurch sich charakteristische Ketten aus rautenartigen Gliedern ergeben, welche zusätzlich mit Doppelstrichen verziert sind (z. B. Bl. 7v1); nur bei der aufwändigsten Initiale dieses Gradualbandes, Bl. 291r, Besatzmotiv aus gereihten, mit den Spitzen zueinander zeigenden Halbpalmettenpaaren, zw. denen jeweils eine eng an ihren Stiel geklappte Halbpalmette aufragt; über den Palmettenpaaren zwei einander zugewandte Elemente des Laufenden Hunds mit einem hochstehenden Herzblatt in der Mitte. Charakteristisches Besatzmotiv: Profilköpfe (maximal fünf Köpfe an einer Initiale, Bl. 270v; Bl. 177r in der untersten Zeile zum urspr. I mit Besatzkopf weiteres I spiegelsymmetrisch ergänzt, um den Kopf in ein Binnenfeld zu integrieren), die gegenständig (z. B. Bl. 52v1), spiegelsymmetrisch über- (z. B. Bl. 246v) oder wie Janusköpfe nebeneinander angeordnet sein können (z.B. an beiden Cadellen auf Bl. 143r); die zumeist langgezogenen Köpfe eher stereotyp gestaltet: markanter Wulst über der Nase, der die niedrige Stirnpartie stark gerunzelt wirken lässt und in Kombination mit dem schmal geschnittenen, oft etwas schräg gestellten Auge (stets mit geschwungenem Brauen- und betonendem Unterstrich) und der dünnen, meist deutlich nach unten gezogenen Mundlinie einen ernsten, fallweise mürrischen Eindruck erzeugt; bei Cadellen zuweilen rote Zunge ergänzt (z. B. Bl. 305v1) oder Bl. 2v1 ein Blättchen. Variationen eigentlich nur bei den Nasenformen (z. B. Bl. 31v1 sehr ausgeprägte Nase) und in der Gestaltung von Haar und Kopfbedeckung: bei Profilköpfen der FleuronnéeInitialen höhere „Stoppelfrisuren“ oder dünnere Haarkränze (Tonsuren?, s. z. B. Bl. 178r) aus feinen Parallelstrichen (der Bart B1. 78v dürfte ergänzt sein); Cadellen-Köpfe tragen häufig mehr oder weniger hohe kegelförmige Mützen mit breiten Krempen. Konturlinien. Nicht allzu lange, oft doppelgestrichelte und Achterschlaufen bildende Fadenausläufer, tw. auch um Ausläufer der Initialen gewickelt, selten gebündelt (z. B. Bl. 163r: rote Bündelstriche, Fäden doppelgestrichelt, symmetrisch angeordnet und mit zurückschwingenden Häkchenenden); Fibrillen; nur wenige Fleuronnée-Leisten, jeweils mit Fadenausläuferbündeln an den Enden: B1. 271v u. a. aus spiegelsymmetrisch zueinander gebogten Knospenähren; B1. 291r Leisten, bei denen der charakteristische, mit Herzblättern garnierte Besatz (s. o.) spiegelsymmetrisch gedoppelt wurde. Bl. 33r und 36v nehmen die in Deckfarbe ausgeführten Randdrolerien (s. u.) eindeutig Bezug auf die Fleuronnée-Initialen bzw. orientieren sich auf diese hin, woraus für den Arbeitsablauf geschlossen werden kann, dass die Fleuronnée-Initialen zusammen mit Notation und Texten vor der Deckfarbenausstattung fertiggestellt waren.

Der Hauptflorator ist darüber hinaus auf dem Einband von Cod. 540 (Cadelle mit Profilköpfen) sowie in den Handschriften Cod. 76 und Brixen, Priesterseminarbibl., Cod. C.2 (jeweils eine Fleuronnée-Initiale) nachweisbar - allesamt Zeugnisse ohne Deckfarbenschmuck, die im 5. Jz. des 15. Jh. in Neustift oder Brixen entstanden sind. Er ist aber auch in drei älteren Hs. (ebenfalls ohne Deckfarbenschmuck) belegt, die im Augustiner Chorherrenstift Neunkirchen am Brand bei Nürnberg geschaffen wurden (Bamberg, Staatsbibl., Msc. Patr. 40 [1415], Msc. Patr. 164 [um 1415] und Msc. Patr. 147 [1420]; s. Die Handschriften und Drucke des 15. und frühen 16. Jahrhunderts der Staatsbibliothek Bamberg. Katalog der illuminierten Handschriften der Staatsbibliothek Bamberg, Bd. 4, in Vorbereitung). Dieser Buchmaler, von dem aus der geraumen Spanne zwischen seiner Tätigkeit in Franken und seinem Wirken in Südtirol (bislang) keine weiteren Zeugnisse 
bekannt sind, könnte gemeinsam mit dem aus Langenzenn, dem Tochterstift von Neunkirchen am Brand, stammenden Schreiber Friedrich Zollner oder auf dessen Anregung nach Neustift gekommen sein, wohin er (ost-)mitteleuropäisches Formenvokabular mitbrachte. So sind seine Profilköpfe in der mitteleuropäischen Buchmalerei des 14./15. Jh. weit verbreitet und begegnen beispielsweise in der großen Neunkirchener Bibel von 1389/90 (Bamberg, Staatsbibl., Msc. Bibl. 9/1-3, hier im Motivschatz der 2. Hand, z. B. Msc. Bibl. 9/1, Bl. 1v; s. K.-G. Pfändtner, S. Westphal, Die Handschriften des 14. und 15. Jahrhunderts der Staatsbibliothek Bamberg. Katalog der illuminierten Handschriften der Staatsbibliothek Bamberg, Bd. 3. Wiesbaden 2015, 74-79, Kat.-Nr. 42, Abb. 154; mit der zweiten Hand der Neunkirchener Bibel arbeitete der Hauptflorator in Msc. Patr. 164 [jeder eine Fleuronnée-Initiale] und Msc. Patr.147 [an einer Fleuronnée-Initiale] zusammen). Aus der ostmitteleuropäischen Buchmalerei entlehnte der Hauptflorator z. B. die Buchstabenkörper mit ausgesparten Blattformationen oder die sich eng an ihre Stiele zurückklappenden Halbpalmetten, vgl. z.B. Stuttgart, Württembergische LB, Cod. poet. et phil. 2 34, Bl. 1r, 79r (Böhmen/Schlesien, 2. Viertel 14. Jh., s. P. Burkhart, Die gotischen Handschriften der Württembergischen Landesbibliothek Stuttgart, Bd. 2: Vom späten 13. bis zum frühen 15. Jahrhundert. Wiesbaden 2005, 109-110, Kat.-Nr. 69, Abb. 250, 253; Volldigitalisat der Hs. unter digital.wlb-stuttgart.de/purl/bsz408922788). Für die großformatigen Gradualbände mit ihren annähernd 3000 Initialen und Cadellen musste der Hauptflorator seine Gestaltungskonzepte adaptieren, wobei auch italienischer Einfluss vorbildgebend gewesen sein könnte, vgl. die opulenten Initialen Bd. 1, Bl. 291r und Bd. 2, Bl. 254r, 278r, deren Binnenfeldgründe farbig ausgemalt sind, mit Vorbildern aus der Toskana, wo im 14. Jh. Chorbücher mit großformatigen Fleuronnée-Initialen geschaffen wurden, die man ab Ende des 14. Jh. mit üppigen, seitenumrahmenden Ausläufern versah (s. RDK, Fleuronné, Sp. 1180) - als Beispiel hierzu ein Hymnar aus dem frühen 15. Jh.: London, British Library, Add. 30014, Bl. 16r; s. G. Vailati Schoenburg Waldenburg, Un innario senese del 1415, in: E. Sesti (Hrsg.), La miniatura italiana tra Gotico e Rinascimento. Firenze 1985, Bd. 2, 545-562, Fig. 6.

Auch die erste Deckfarbenhand führte etwas Fleuronnée aus (zu diesem Miniator s. beim zweiten Gradualband unter „Deckfarbenschmuck“ sowie Rischpler): z. B. B1. 36v Ähren aus spitzen, gepunkteten Knospen auf die blattvergoldeten Außengrundzwickel der Deckfarbeninitiale mit weißlichem Malmittel aufgetragen, vgl. goldenes Binnenfeld-Fleuronnée auf B1. 175r des zweiten Gradualbandes, s. des Weiteren Cod. F.8 der Brixner Priesterseminarbibl., dessen Deckfarben- und Fleuronnée-Schmuck (Goldfleuronnée in Binnenfeldern von Deckfarbeninitialen sowie rotes und blaues Lombarden-Fleuronnée) fast zur Gänze von dieser Hand stammt, oder die Gutenberg-Bibel München, BSB, 2 Inc. s.a. 197 (gedruckt Mainz, 1454/55, nicht nach 24.8. bzw. 15.8.1456), s. beispielsweise Fleuronnée-Initiale im ersten Bibelband, Bl. 1r (http://daten. digitale-sammlungen.de/bsb00004647/image_5).

Zudem mindestens acht (jüngere) Fleuronnée-Hände, großteils unter Einfluss des Hauptflorators: (1) Bl. 316v-319v: an 23 Initialen und Cadellen variationsreiches, sauber gezeichnetes Fleuronnée, das wie (2) plastisch herausmodellierte Blattranken als Binnenfeldfüllungen zeigt (z. B. Bl. 317v3); diese Hand auch im zweiten Gradualband tätig (Ergänzungshand 1). (2) Bl. 187 ${ }^{\mathrm{bis}} \mathrm{r}-\mathrm{v}$ und 321r: Fleuronnée von der geübten, wohl in das 1. Fünftel 16. Jh. zu datierenden Hand, die in Cod. 405 (dat. 1501, hier das Fleuronnée flüchtiger), Cod. 194 (dat. 1507), Cod. 142 (Teil mit in Rede stehendem Fleuronnée, dat. 1521) zu finden ist, eine Reihe von Initialen im zweiten Band des Zollner-Graduales gezeichnet und Sign. 14820 zur Gänze ausgestattet hat (ausführlich zu dieser Hand bei Sign. 14820); bei den vier Initialen Bl. 187 ${ }^{\mathrm{bis}} \mathrm{V}$ orientierte sie sich stark an der größten Fleuronnée-Initiale, die der Hauptflorator im ersten Gradualband geschaffen hat (Bl. 291r), vgl. z. B. den charakteristischen, mit Herzblättern garnierten Besatz; es ist eher unwahrscheinlich, dass diese Hand auch die aufwändige Cadelle Bl. $187^{\mathrm{bis}}$ r (u. a. zwei kleine Drachen mit verschlungenen Hälsen als Besatz) gestaltet hat. (3) Bl. 273v4, 278v5, 314v: unsicher fleuronnierte Initialen, Bl. 278v5 mit „Janusköpfen“. (4) Bl. 91v, 245r (hier auf eingeklebtem Streifen mit schwungvollem Profilkopf): flüchtig dekorierte Cadellen. (5) Bl. 14r: fleuronnierte Cadelle (zusammen mit ergänzter Notenzeile). (6) Bl. 99r: an einer Initiale Besatzkopf radiert, schwarzes Fleuronnée des Hauptflorators belassen und rotes, ungelenkes Fleuronnée ergänzt. (7) Bl. 324r (mit Datierung 1519): größere Fleuronnée-Cadelle von einer Hand, die wiederum (2) nachahmt. (8) Bl. 325r (Kolophon): schwarzer Fleuronnée-Dekor (mit betonender Funktion) in den Binnenfeldern des $N$ von Nicolaus und des $Q$ von Qui incepit, von der Hand, die den auf Propst Nikolaus Scheiber bezogenen Sterbevermerk geschrieben hat.

Frontispiz. Bl. IIv (eingehängtes Pergamentblatt, s. bei B): Thronende Madonna in lavierter und partiell kolorierter Federzeichnung (in Hell- und Dunkelbraun). Kopie nach dem wohl urspr. Frontispiz des Gradualbandes, das 1925 aus einer unbekannten Berliner Sammlung vom Städel (Frankfurt a. M.) erworben wurde, wo es sich noch heute befindet (Inv.-Nr. SG 355). Bis auf die Maße (Original 710 × 485, leicht unregelmäßig; Kopie 690/704×450/460) äußerst getreue Kopie, die beispielsweise den beschnittenen oberen Rand der Zeichnung sowie deren delikate Farbgebung minutiös berücksichtigt, aber den Abklatsch der Rubrik auf Bl. 1r des ersten Gradualbandes ignoriert, der auf dem Original sicht- und entzifferbar ist; zudem differieren die Physiognomien der Madonnenfiguren minimal (während die kopierte Muttergottes ernst blickt, scheint sie auf dem Original zu lächeln). Gerade die Beschneidung des Blattes lässt daran zweifeln, ob die Frankfurter 
Zeichnung explizit für das Graduale geschaffen wurde (vgl. Roland, Gotik 287-288 [Kat. 184], hier 287; mit Abb., die allerdings die Kopie, ohne Schriftabklatsch, zeigt); eine sekundäre Verwendung ist wahrscheinlicher, so schlagen Brinkmann-Kemperdick (s. u.) vor, dass das originale Frontispiz als Vorzeichnung für eine Wandmalerei angelegt worden sei. - In imposanter und mittels Fialen, Maßwerk, bewegten Kreuzblumen, Akanthusblatt- und Krabbenbesatz detailreich gestalteter Thronarchitektur mit Podest, apsisartig gerundeter Sitznische und einem an ein Altargesprenge erinnernden Aufbau wird die auf einer Bank sitzende und ihr Kind zärtlich umfassende Gottesmutter von zwei Kerzen tragenden Engeln mit heraldisch anmutenden Flügeln flankiert; Mantel der Gottesmutter reich gefältelt, auffällig ihre große, üppig mit Perlen und Edelsteinen geschmückte Krone, die abgeflacht wirkt; im Giebel über Thronnische, von einem Strahlenkranz umgeben, Kopf Gottvaters, der seine Rechte zum Segen erhebt und mit der Linken die Taube des Heiligen Geistes präsentiert; darunter zwei Posaunenengel, von deren Instrumenten weiße Fahnen mit roten Tatzenkreuzen abflattern; zwei Seitengiebel: links Verkündigungsengel, rechts Maria. S. auch ausführliche Beschreibung mit Abb. bei B. Brinkmann, St. Kemperdick, Deutsche Gemälde im Städel 1300-1500. Mainz 2002, 155-161 sowie https://sammlung.staedelmuseum.de/de/werk/thronende-madonna-mit-engeln (mit Abb.); detaillierte Beschreibung ebenso bei Hermann 221-222. - Es ist anzunehmen, dass das originale, jetzt in Frankfurt aufbewahrte Blatt nicht allzu lang vor der Fertigstellung des ersten Gradualbandes 1442 geschaffen wurde, wahrscheinlich von einem (Süd-)Tiroler Zeichner, der definitiv unter (ober-)italienischem Einfluss stand (s. Hermann 221-222; Brinkmann-Kemperdick; Roland, Gotik 288); die Kopie dürfte anlässlich der Veräußerung des Originalfrontispizes Anfang 20. Jh. entstanden sein.

Deckfarbenschmuck: ein Wappen; acht (erhaltene) figürliche Initialen mit bevölkerten Ranken (B1. 1r, 27v, 33r, 36v, 156v, 200r, 227v, 261r; bis auf das fünfzeilige, fast $400 \mathrm{~mm}$ hohe P auf Bl. 27v Initialen in der Höhe von zwei bis drei Notenzeilen) von zwei Händen: Bl. 1r von der ersten, der Rest von der zweiten Hand. Darüber hinaus mindestens zwei Folios mit figürlichem Deckfarbenschmuck herausgetrennt; diese Seiten (B1. 129 und 218: Dnca in palmis und In festo ss. trinitatis), die bei Laußermayer nicht mehr aufgeführt sind, von Hermann noch beschrieben, was bedeutet, dass sie zw. 1905 und 1965 entfernt worden sein müssen. $\mathrm{Zu}$ Einordnung und Charakteristika der ersten Hand s. beim zweiten Gradualband unter „Deckfarbenschmuck", der zur Gänze von diesem Illuminator stammt, sowie Rischpler; nachfolgend Einordnung der zweiten Hand und ihr Verhältnis zur ersten sowie die Charakteristika, die die zweite Hand im vorliegenden Band zeigt:

Die zweite Hand, von Roland (288) als „Gradualmaler B“ bezeichnet, auch in den Handschriften Brixen, Priesterseminarbibl., Cod. F. 4 als „Hand 1“ und Cod. E. 21 für gesamte Deckfarbenausstattung nachweisbar; Gestaltung der Binnenfelder im zweiten Gradualband jedoch wesentlich elaborierter; bei seinem Randschmuck zeigt dieser Illuminator sowohl eine üppig-flächendeckende Variante (s. insbes. Cod. E.21, B1. 14r) als auch eine italianisierende Version mit Rankenstäben, die mit diversen Manschetten und häufig symmetrisch angeordneten Motiven geschmückt sind (s. u.). Da diese Art des Marginaldekors beispielsweise auch den niederösterreichischen Randleistenstil (ca. letztes Viertel 14. Jh., s. Roland, einschlägige Einleitung in MeSch II 129-131) prägt, muss man nicht unbedingt von einer Beeinflussung des Illuminators vor Ort in Italien ausgehen, sondern kann auch eine indirekte Beeinflussung im süddeutsch-österreichischen Raum bzw. - und dies ist wahrscheinlicher - in Südtirol annehmen. Roland (ebda) geht davon aus, dass der „Gradualmaler B“ der ersten Hand untergeordnet war. Am Anfang bzw. während der Arbeiten an der Deckfarbenausstattung des vorliegenden Gradualbandes dürfte dies jedoch umgekehrt gewesen sein. Möglicherweise haben beide Buchmaler zunächst eine „Probearbeit“ abgeliefert: die erste Hand die Einleitungsseite und die zweite Hand Bl. 27v, woraufhin man - auch wenn sich die erste Hand durch akkuratere Arbeitsweise, reinere Farbgebung und delikatere Figurengestaltung auszeichnet - die lebendigere zweite Hand, die bei der Ausführung der Binnenfelder über die Hintergrundfolien der ersten Hand hinausgeht und versucht, mit ihren Architekturen und Landschaften räumliche Tiefe zu erzeugen, mit der Ausstattung und dem damit verbundenen, relativ komplexen Bildprogramm des 1442 fertiggestellten Bandes betraute. Während die erste Hand auch Ornamentalinitialen gestaltete und die Akanthusranken überwiegend mit Tierdrolerien belebte, führte die zweite Hand ausschließlich figürliche Initialen aus, die in der Buchschmuck-Hierarchie über den ornamentalen Initialen stehen, und fügte darüber hinaus bei den Initialen der Feste Weihnachten, Epiphanie, Ostern und Kirchenweihe (Bl. 27v, 36v, 156v, 261r) in die Buchstabenkörper und in den Marginaldekor eine beachtliche Anzahl alt- und neutestamentarischer Verweise und Zusatzszenen ein (abweichend: Medaillon mit der Schweineschlachtung, Bl. 156v, das an Monatsbilder erinnert, dort allerdings zumeist dem Dezember zugeordnet). Sind Weihnachts-, Oster- und Kirchweih-Initiale (jeweils drei Notenzeilen hoch) durch Binnenfelder herausgestellt, die an Bildteppiche mit übereinander geschichteten bzw. ineinandergreifenden Szenen erinnern, so werden bei der Epiphanie-Initiale (Bl. 36v), die lediglich zwei Notenzeilen hoch ist und keine figurative Buchstabenkörperfüllung aufweist, die typologischen Verweise in das Binnenfeld integriert. Zudem findet sich auf dem Blattgold-Außengrund dieser Initiale Fleuronnée-Dekor, der von der ersten Hand stammt (s. unter „Fleuronnée“); demnach assistierte in dieser Ausstattungsphase die erste Hand der zweiten. Im Folgenden die Charakteristika der zweiten Hand: 
Schlichte Initialrahmen, B1. 33r lediglich violette Linie. Außengründe bzw. -zwickel mit Blattgold belegt (tw. abgeblättert) und mit weißlichem Malmittel verziert; dabei wohl nicht nur der Fleuronnée-Dekor B1. 36v von der ersten Deckfarbenhand, sondern auch die zarten Ranken wie bei der Initiale Bl. 261r. Stämmige Buchstabenkörper mit feinen Konturstegen (nur Bl. 27v Buchstabenkörper von breiterem, mit gelben Zierkreisen dekoriertem Rahmen eingefasst) sowie fallweise mit kleinen Blattausläufern und Manschetten in Form von (andersfarbigen) stilisierten Blüten (z. B. Bl. 261r); Bl. 27v steht der grüne Buchstabenschaft, an dem inwendig eine violette Zierleiste mit Golddekor anliegt, auf einem kleinen, stilisierten Drachen in Orangerot, der in den Letternschaft beißt. Bl. 27v, 33r und 156v Buchstabenkörper mit diversen Ton in Ton gemalten figurativen Szenen (Beschreibung s. u. in Auflistung), ansonsten mit tendenziell symmetrisch angelegtem Blattwerk gefüllt, dessen Einzelbl. sich stark eindrehen können; Bl. 36v die vegetabile Füllung des violetten Buchstabenkörpers unfertig, Vorzeichnung (?) sichtbar; bei dieser E-Initiale Querstrich mit andersfarbigen und -formigen Blättern geschmückt; Bl. 227r mittig im linken Buchstabenschaft kleines Köpfchen, dem Füllranken entwachsen. In Binnenfeldern charakteristische blau oder violett „marmorierte“ Hintergründe (tw. mit Farbverläufen), die Himmel oder Ausblicke bezeichnen (besonders aufwändig Bl. 36v und 200r); B1. 227r als Hintergrund blaugrundiges Kachel- bzw. Teppichmuster.

Die eher dünnen, (fast) zweiseitig bis (annähernd) vierseitig angelegten Äste der Marginalranken - sowohl lichte, in den Blattecken rechtwinklig geführte Rankenstäbe mit symmetrischen Blattpaaren und Fantasieblüten (z. B. Bl. 227v) als auch dichtere Voluten - gehen zumeist von den Serifen aus, Bl. 36v von der Manschettenblüte; diverse Blatttypen, häufig Paare von kleinen, spitzen Blättern sowie mehrbahnige Blätter, bei denen sich eine Bahn stark einrollt (vgl. Buchstabenkörperfüllungen); im Umfeld von Drolerien üppigere, tw. an drapierte Stoffbahnen erinnernde Blätter; Verzierung der Rankenäste durch Manschetten in diversen Ausformungen, Goldpunkte und -tropfen (in Astgabelungen). Auf allen Deckfarbenseiten Drolerien, zumeist anthropomorph (nur B1. 227r ausschließlich Tierdrolerien wie bei der ersten Hand, s. Bl. 1r) und häufig in Rankenvoluten eingefügt; Marginaldekor Bl. 1r und 261r in der rechten unteren und Bl. 156v in der linken unteren Ecke abgegriffen und daher schlecht erkennbar.

Eher ungelenke Figuren mit diversen anatomischen Unsicherheiten, beispielsweise Knieposition der Gottesmutter (Bl. 27v) oder des Königs, der dem Jesuskind seine Gabe überreicht (Bl. 36v), des Weiteren gummiartige, nackte Gliedmaßen (z.B. Bl. 33r rechtes Bein des Rankenkletterers sowie Arme und Beine des horizontal am Rankenast hängenden Putto, Bl. 200r, Bas-de-page) oder auch der flächige Brustkorb des Auferstandenen B1. 156v; besonders unsicher die Darstellung von Rückenfiguren, z. B. die beiden Engel mit Notenblättern im Vertikalschaft der Initiale Bl. 156v; bei Frauenfiguren kleine, kugelige Brüste (z. B. Maria B1. 27v oder Königstochter B1. 27v, unterer Seitenrand). Gesichter von Älteren mit akzentuierenden Faltenlinien und charakteristischer Kerbe über der Nase (z. B. Bl. 33r: Priester und Rankenkletterer); Antlitz der Gottesmutter B1. 27v folgt zwar dem üblichen Gesichtsschema (konturierte Nase, relativ kleiner Mund, rundes Kinn), wirkt aber durch die zurückgenommene Augenlinierung und die hohe, gewölbte Stirn besonders lieblich; geöffnete Münder müssen nicht, wie sonst oft der Fall, für Verkommenheit stehen, sondern drücken vielmehr mündliche Rede aus (z.B. Prophetenreihe, Bl. 156v, oberer Foliorand) oder Gesang (z.B. ebda, linke untere Ecke, hier Zahnandeutungen, vgl. Propheten, abgerieben); Haare in der Regel einfach gesträhnt, mit relativ dicken Flechten. Unaufgeregte Draperien mit Röhren- und Knickfalten, lediglich Umhang des Auferstandenen Bl. 156v etwas aufwändiger gefältelt; sich abzeichnende Gliedmaßen mit Weißhöhungen herausgearbeitet, z.B. Beine und Knie Mariens, Bl. 27v. Bei Stoffen und Preziosen wenig Detailfreude (s.z. B. Bas-de-page Bl. 27v die lediglich mit schwarzen Kontur- und Binnenlinien gestaltete Goldrüstung des Drachenkämpfers oder den Bischofsstab, Bl. 261r), einfache Holzsichtigkeit (z. B. Holzmaserung des Beschneidungstisches Bl. 33r); lediglich die für diesen Buchmaler typischen „marmorierten“ Flächen, die Himmel bzw. Weite, aber auch kostbaren Stein bezeichnen (z. B. grüne Säulen Bl. 36v), von einiger Delikatesse; recht fein sind auch Notenblätter dargestellt, s. v. a. im Buchstabenkörper Bl. 156v.

Vorliebe für Architekturen, die sehr detailreich (gerne mit Rundbogen) gestaltet sein können; dabei perspektivische Unsicherheiten, so setzt bei der Kirche Bl. 261r die Giebelfront des Seitenschiffs direkt am Hauptportal an, oder bei dem Mauervorbau Bl. 33r (am unteren Binnenfeldrand) scheint das linke Mauerstück zu kippen; charakteristische Baumdarstellungen mit Kronen aus konzentrisch angeordneten Blättern, in deren Mittelpunkt jeweils ein roter Apfel (?) sitzt; Felsen (und Erde?) durch dunkelgraue Schollen wiedergegeben; der Fluss Bl. 261r kompakt wie ein Garnstrang.

Insgesamt gedecktere (etwas nachgedunkelte?) Farbigkeit, speziell bei Marginalranken, mit gebrochenen Blau-, Grün- und Violetttönen; allerdings häufig auch Orange verwendet, das recht leuchtend sein kann; Vorliebe für Violett (Rosa), u. a. für (einfachen) Baustein; auffällig die violetten Himmel Bl. 156v, 200r und 261v; Bl. 156v die ockerfarbene Initiale in Pinselgold ausgeführt; wenn Blattgold (v. a. Außengründe der Initialen) abgerieben, rosafarbener Bolus gut erkennbar.

Bl. 1r König David, der seine Seele zu Gott erhebt: David kniet (?) betend im unteren Binnenfeld; Haltung der zum Gebet gefalteten Hände unklar wiedergegeben; aus seiner Brust entweicht relativ großes Seelenfigürchen (ebenfalls mit gefalteten Händen), zu dem David aufblickt; im oberen Binnenfeld segnender 
Gottvater (als Dreiviertelfigur) mit Weltkugel in der Linken. Drolerien konzentrieren sich auf Bas-de-page; erkennbar sind (von links nach rechts): dunkelblau-gelber (?) Vogel, „lächelnder“ Hase, Storch mit Schlange (?) im Schnabel, grüner Papagei, mittig Neustifter Wappen: goldenes, bedorntes Tau-Kreuz auf rotem Schild; darüber Blattranke mit Profilgesicht, rechts daneben kugelige Maus (?), des Weiteren stehender Bär mit Dudelsack und rotes Eichhörnchen.

Bl. 27v Im Binnenfeld Geburt Christi und Verkündigung an die Hirten; über dezent bewachsenen Erdschollen, die nach unten bzw. vorne von einem durch wenige Bäume bezeichneten Garten und einen Flechthag abgegrenzt werden, über den drei Hasen springen, erhebt sich rosafarbene Stadt mit bewehrter Mauer, Türmen, Treppengiebeln, hohem rundbogigen Tor und größerer Kirche (mit aufwändigem Portal), deren Chorturm (?) und Glockentürmchen Kuppelhauben tragen; diese repräsentieren in der Regel orientalisch-fremdländische Architekturen und sind an dieser, in ihrem restlichen Aufbau durchweg abendländischen Kirche wohl als Reminiszenz an Bethlehem zu verstehen; darüber Maria (groß angelegt und die Komposition beherrschend), die das in einer mit Heu gefüllten Krippe liegende Jesuskind kniend anbetet; Kind hält roten Apfel in der Linken und hat die Rechte zu seiner Mutter erhoben; hinter der Krippe roter Engel (mit Spruchband In dulcis [!] iubilo, singet und seyt fro, $m$ [eines?] $h$ [erzens] $w$ [onne] $l[$ eit] $i[\mathrm{n}] p$ [raesepio]), daneben Ochse und Esel, die von dem Heu fressen; hinter der Gottesmutter Stall (mit verwinkeltem Strohdach), in dem hinter einem violetten Vorhang Josef schläft; darüber baumbestandene Felslandschaft mit Schafen, in der ein weiterer roter Engel (als Büste auf stilisiertem Wolkenband, vom dem kompakte Strahlen ausgehen, mit Spruchband Ecce ewangeliso vobis gaudium $m$ [agnum], Lc 2,10) drei Hirten (mit zwei Hunden, Hirtenstab, Fässchen und Spruchband Transeamus usque Bethle[hem], Lc 2,15) die Geburt Christi verkündet; die vertikale Mittelachse des Bildfeldes betonend reckt sich ein Widder (?), der seine Vorderhufe an einem Baum abstützt, zu dessen Blätterkrone hinauf; im Himmel (auf einem Wolkenband) fünf rote Engel, die sich um ein Notenblatt scharen (darauf Gloria in excelsis Deo et in terra erkennbar). - Im Schaft des Buchstabenkörpers drei Figuren: oben und unten eine mit erhobenen Händen betende Frau, jeweils von hinten gegeben, in der Mitte ein von vorne zu sehender Engel (Flügel nicht eindeutig erkennbar, es könnte sich auch um Blattpaar handeln, vgl. die anderen Blätter der Schaftfüllung) mit einem Spruchband in der Linken und erhobener Rechter mit ausgestrecktem Zeigefinger; im P-Bogen frontal thronender König David (?) mit Zepter in der Linken und Spruchband in der Rechten, zu seinen Füßen ruhender Löwe, darunter Teufel mit Eselsohren. - Marginalschmuck: auf Initialhöhe zwei Männchen (blau und violett), die übereinander in der Ranke sitzen und aufeinander deuten, wobei sich die obere Figur mit der Linken an draperieartigem Blattausläufer festhält; gänzlich in die Ranke integriert, die hier eine starke, mit kleinen Kreisen verzierte Mittelrippe aufweist, ein kopfloser grüner Drache mit violettem Flügel; direkt darunter ein kleinerer orangefarbener Drache; auf der Höhe des P-Schafts in Rankenvolute hockend der greise Prophet Jesaja mit violetter Kappe und Spruchband (Ecce virgo concipiet et par[iet] fi[lium], Is 7,14); auf dem unteren Seitenrand Drachenkampf: Ritter in Goldrüstung auf Schimmel (hl. Georg?) stößt einem grünen Drachen mit orangefarbenen Fledermausflügeln seine zersplitternde Lanze ins Maul, dem nicht nur Feuerzungen, sondern auch die Bas-de-page-Ranken entwachsen; in Rankenmedaillon zwischen den Kontrahenten eine kniend (?) betende Frau mit Krone (Königstochter, die von Georg befreit wurde?).

Bl. 33r Im Binnenfeld drastisch dargestellte Beschneidung: In farbfreudigem Architekturrahmen (mit Säulen, unterschiedlich ausgeformten Bögen und kassettierten Decken), der Himmelsausblicke freigibt, beschneidet jüdischer Priester (Mochel) mit einer Schere das auf einem breiten Holztisch liegende, relativ große Jesuskind, das von vier weiteren Priestern (einer davon mit Krücke) und einem Mann mit Judenhut festgehalten wird; zu dieser Szenerie führt eine Treppe hinauf, welche zu einer Art Stadtmauer gehört; auf einem Vorsprung dieser Mauer zwei Frauen, die nach oben zum Beschneidungstisch blicken. - Im Buchstabenkörper links Geburt und Waschung Christi: Ein Engel hebt den Vorhang über dem Bett, auf dem Maria liegt und auf Josef und ihr Kind blickt; Josef mit Stock und Fässchen (?); das Kind in einem von Engeln umgebenen Weidenbottich sitzend; darunter weiterer Engel und eine weibliche Figur (Engel?) von hinten; rechts im Buchstabenkörper zwei weitere Engel, jeweils mit Spruchband; in der Serife vier Engelsfiguren bzw. -köpfe. - Marginalschmuck: auf Rankenspitze Männchen mit Krone, der zwei Blattzipfel entwachsen; diese Figur hält sich, auf den Schultern eines weiteren Männchens hockend, mit seiner Linken an der nächstliegenden Fleuronnée-Initiale fest und deutet mit der Rechten auf den geöffneten Mund seines Trägers, dessen Beine bzw. Füße in den Rankenstab übergehen; auf der Höhe der Deckfarbeninitiale weiterer Rankenkletterer mit ebenfalls geöffnetem Mund und roter Haube, nach dessen Stiefel von unten her ein nacktes Männchen mit Lendentuch und grünem Umhang greift; links auf Bas-de-page in einem Blattpaar blaue Büste, die mit einem Stock eine orangefarbene Figur attackiert, welche mit einem Ausfallschritt und sich an einem Ast festhaltend die Verbindung zw. zwei Rankenabschnitten herstellt.

B1. 36v Im Binnenfeld Epiphanie mit typologischem Charakter: Im oberen Binnenfeld links, in Felslandschaft mit drei burgartigen Städtchen, die Heiligen Drei Könige, die auf das Kind im Strahlenkranz (auf Felsspitze, rotes Äpfelchen in der Linken) und damit auf die Worte des Bileam (Nm 24,17) weisen, die das Kind als Spruchband in der Rechten hält Orietur stella ex [Iacob ...] (Hermann liest zudem: in Iudeam et 
invenietis); tw. verdeckt von der Felsnadel, auf der das Kind sitzt, haben sich die Könige auf ihren Pferden nach rechts gewandt, in Richtung eines kleinen rundbogigen Tores. Im unteren Binnenfeld auf reich verziertem Holzthron Maria mit dem Kind, das die Hände nach den Gaben der Heiligen Drei Könige ausstreckt; links neben dem Thron schläft Josef auf seinen Stock gestützt, hinter ihm das rundbogige, hier größer angelegte Tor, das die obere mit der unteren Bildebene und somit die alttestamentarische Prophezeiung des Jakobssterns mit dem neutestamentarischen Stern der Heiligen Drei Könige verbindet. Diese Verknüpfung wird noch durch den mittleren König unterstrichen, der auf das Tor hinter Josef bzw. nach oben weist. - Marginalschmuck: Büste eines greisen Königs (David), der auf die Deckfarbeninitiale deutet und Spruchband mit dem Psalm Reges Tarsis (Ps 71,10) hält, welcher ebenfalls auf die Anbetung der Heiligen Drei Könige verweist. Auf der Höhe der Fleuronnée-Initiale hockende Figur in Blaugrau, die in Richtung Initiale weist; grüner Drache mit verschlungenem Hals, der dem oberen Profilkopf des Fleuronnée-Dekors in die Nase beißt; gräulicher Bär mit Dudelsack (?); grauer Kopf, der aus eingerolltem Blatt wie aus einem Mantelkragen herausblickt; auf Bas-de-page vier figurierte Voluten (von links nach rechts): Prophet Ezechiel (Halbfigur) mit Spruchband Et effundam super eos aquam mundam (Ez 36,25); Taufe Christi; Prophet Baruch (knappe Dreiviertelfigur) mit Spruchband Post hec in terris visus est (Bar 3,38); Hochzeit zu Kana: Maria mit Spruchband Vinum non habent (Io 2,3) und Jesus, der mit der Rechten auf sechs blaue Weinkrüge deutet und mit der Linken Segensgestus ausführt.

[Bl. 129r Einzug in Jerusalem, Ranke mit Brustbildern]

Bl. 156v Im Binnenfeld Auferstehung Christi: In einem von einem Flechtzaun umschlossenen Garten steht der Auferstandene, dessen Wundmale deutlich zu sehen sind, frontal auf dem geschlossenen Sarkophag (mit Halteringen auf dem Deckel und versiegelt?), die Rechte segnend erhoben, in der Linken die Siegesfahne; zu seinen Füßen die schlafenden Soldaten; das felsige Terrain von einigen Bäumen bestanden (an einem nagt, rechts unten neben Christus, ein kleiner Hase), links wölben sich die grauen Felsen grottenartig über den Sarkophag; zwei kleinere Stadtveduten mit Türmchen. - Im Buchstabenkörper links drei Engel, die drei Notenblätter mit österlichen Gesängen präsentieren (von oben nach unten): Salve festa dies toto venerabilis evo, Regina celi letare und Alle[luia] Dei filius ab hoste superbissimo resurgens; rechts oben Noli me tangere: in einem Garten kniet Maria Magdalena (mit Salbgefäß) vor Christus und weist mit der Rechten auf die Wundmale seiner Füße; rechts unten Drei Frauen am Grabe: in einem Garten zeigt ein Engel den drei Marien den offenen und leeren Sarkophag. - Marginalschmuck, jeweils in Rankenvoluten: auf dem oberen Seitenrand siebenmal der Prophet Hosea, jeweils mit Spruchband (Verse Os 6,1-3 lassen sich auf Auferstehung beziehen): Venite et revertamur ad dominum (Os 6,1), Quia ipse cepit et sanabit nos (Os 6,2), Percutiet et curabit nos (Os 6,2), Vivificabit nos post duos di[es] (Os 6,3), In die tertia suscitabit nos (Os 6, 3), Et vivemus in conspectu eius (Os 6,3), Sciemus sequemurque ut cognoscamus dominum (Os 6,3); auf dem linken Seitenrand (oben) vier stehende Engel, jeweils mit Spruchband (Verse eines deutschen Ostergesanges, von oben nach unten): Maria du zarte, Du bis ayn rosengarten, Den got selwer geczyrt hat, Wen her von dyr geporen wart; darunter fünfmal der Prophet Jesaja (sitzend, mit langem grauem Haar und Bart), jeweils mit Spruchband (von oben nach unten): Quis est iste qui venit de Edom (Is 63, 1), Iste formosus in stola gradiens (Is 63, 1), Torcular calcavi solus de gen[tibus] (Is 63, 3), Dies enim ulcionis in corde meo (Is 63, 4), Annus retribucionis mee venit (Is 63, 4); auf Bas-de-page (von links nach rechts; abgerieben): zwei sitzende, singende Männer mit Notenblatt (Vespere autem schabati [que] lu[cescit], Mt 28,1), zwei Männer, die Schwein schlachten, je ein Prophet mit Spruchband (Beschriftung des ersten nicht mehr lesbar, auf dem zweiten nur noch gentes et zu erkennen), Lamm mit Siegesfahne (dieses Motiv mit erhaltenem Kolorit in Cod. E.21, Bl. 29v, vgl. die identische Haltung der ungelenk verschränkten Vorderbeine).

Bl. 200r Im Binnenfeld Himmelfahrt Christi: Hinter einem Flechthag ragt der an seinem Fuß und auf dem Gipfel baumbestandene Auffahrtsfelsen empor, um den sich Maria und Apostel betend geschart haben; violetter Himmelsgrund, in dem Engelspaar auf Wolkenbändern schwebt, jeweils mit Spruchband (Viri Galilei quid admiramini/[Asp]icie[nte]s in celum, Apc 1,11); darüber stilisiertes Wolkenband mit Ton in Ton gemalten orangefarbenen Engeln, die den Auffahrenden umgeben, von dem noch Füße (mit Wundmalen) und Gewandsaum zu sehen sind; auf dem Felsen sind Fußspuren erkennbar. - Drolerien: auf dem rechten Seitenrand heraldisch aufsteigendes gelbes Einhorn (vgl. sehr ähnliche Ausführung dieses Fabeltiers in Cod. E.21, B1. 14r, links auf Bas-de-page), mittig auf Bas-de-page Drachenpaar (orange und grün) mit verschlungenen Köpfen, flankiert von Putti, die in Ranken bzw. auf Rankenstäben sitzen oder an ihnen hängen und sich gegenseitig mit Stöcken attackieren (Turnierpersiflage).

[Bl. 218r In festo ss. trinitatis (zweimal)]

Bl. 227v Binnenfeld von Vorhang horizontal in zwei Bereiche aufgeteilt: Vorne kniet auf Rasenstück ein Augustiner Chorherrenpropst im hellen Chorherren-Mantel mit grauem Kapuzenkragen (mit Schweifen besetztes Feh-Almutium), mit violetter Kappe und Spruchband (Domine in tua misericordia speravi exultavit cor meum) und betet Schmerzensmann an; dieser als Dreiviertelfigur in Sarkophag (zw. Vorhang und teppichartigem Hintergrund), Hände vor der Brust überkreuzt, mit Dornenkrone, Rutenbündel und Geißel. Drolerien: auf dem linken Seitenrand Fabelwesen mit Drachenkörper und Vogelkopf, dessen Hals sich um 
den Rankenstab windet, in den er zusätzlich mit seinem langen Schnabel beißt; auf Bas-de-page zwei graue Häschen.

B1. 261r Im Binnenfeld Kirchweihe: Im unteren Feldbereich hölzerner Steg, der flankiert von geradstämmigen Bäumen über einen Fluss führt; dahinter Mauer, über der sich Kirche mit Seitenschiff (goldene Krabben auf Giebeln) und Turm erhebt, von dessen Satteldach die prächtige Kirchweihfahne (Kreuzfahne) weht; vor der Kirche (neben einem Baum) Bischof im Ornat mit großem, goldenem Krummstab; hinter der Mauer bzw. über dem Kirchenareal dicht stehende Bäume, vor denen (auf stilisiertem Wolkenband) segnender Christus mit Spruchband (Ista tenella florens ut rosa Nova Cella) schwebt; hinter ihm schmaler violetter Himmelsstreifen. - Marginalschmuck: auf Bas-de-page, jeweils in zarte Rankenmedaillons eingeschrieben, Strahlenkranzmadonna (Mutter und Kind mit roten Heiligenscheinen, Kind hält Äpfelchen? in der Rechten), flankiert von zwei adorierenden Klerikergruppen; links fünf Augustiner Chorherren, zuvorderst ein Chorherrenpropst mit Schweifen am Feh-Almutium, roter Kappe und Spruchband (Nos cum prole pia benedic[at] vi[rgo] M[aria]), etwas abgesetzt von der Gruppe Mönch in dunkler Kutte (Franziskaner?) mit Spruchband (Suppliciter te petimus); rechts von Strahlenkranzmadonna weitere fünf Chorherren, der nächste zur Gottesmutter mit Spruchband (Ora pro nobis mater mi[sericordi]e); auf dem rechten Seitenrand (von unten nach oben): Christus und Zachäus, auf zwei Medaillons aufgeteilt; unten Christus mit Gefolgschaft (drei Jünger, zwei Juden, zwei Frauen); Spruchband Jesu (Zachee festinans descende, Lc 19,5) schlägt Brücke zum oberen Medaillon, in dem der Zöllner Zachäus in den Bäumen steht; in Rankenvolute darüber schläft Jakob mit dem Kopf auf einer Bodenandeutung (ansonsten keine Auflagefläche angegeben, sodass Jakob zu schweben scheint), über ihm gelbe Leiter (am Fuß flankiert von zwei Spruchbändern: Vidit Jacob scalam und Et summitas eius tangebat celum, Gn 28,12), auf der fünf Engel (die beiden unteren von vorne, die drei oberen von hinten zu sehen) hinauf zu Christus klettern, der als Büste auf stilisiertem Wolkenband die Rechte segnend erhebt und in der Linken ein Spruchband (Benedicens benedicam tibi terram in qua dormis dabo et ..., Gn 28,13) hält. Zur Interpretation dieser Seite s. zweiter Gradualband unter „Bildnisse“.

Bildnisse. Die angeführten Darstellungen sind nicht als Porträts im Sinne getreuer Abbilder mit individuellen Zügen zu verstehen, sondern als bildliche Repräsentanten der betreffenden Persönlichkeiten. Der anbetende Augustiner Chorherr Bl. 227v, den der Fehschweifbesatz seines Almutiums und die violette Kappe als Propst auszeichnen, dürfte - wie schon Hermann (223) annahm - den Auftraggeber, Propst Nikolaus Scheiber darstellen; ebenso der Chorherr, der auf dem Bas-de-page Bl. 261r die adorierende Gruppe zur linken Hand der Strahlenkranzmadonna anführt (s. Giner 10; vgl. zudem Darstellung im zweiten Band B1. 210v). Wen der Mönch (Franziskaner?) darstellen soll, der sich Bl. 261r (Bas-de-page) zu den anbetenden Chorherren gesellt, ist bislang ungeklärt; es dürfte sich jedoch nicht, wie von Hermann (224) angenommen, um den Schreiber Friedrich Zollner handeln, da dieser Augustiner Chorherr war.

E: Renaissance-Einband: dunkelbraun gefärbtes Leder über Holz mit Blinddruck. Neustift, 2. H. 16. Jh Einband restauriert, Leder tw. ergänzt (bes. deutlich sichtbar am VD und HD zum Rücken hin sowie am Rücken), Bindung erneuert. VD und HD ähnlich, Gliederung jeweils durch dreifache Streicheisenlinien. Am VD fünf Rahmen (von außen nach innen): Rahmen 1 gefüllt mit Rolle einseitwändig verschränkte Bögen mit Lilienbekrönung, darüber Leiste aus fünfblättrigen Blumen, seitlich je eine Rolle, oben und unten zwei Rollen spiegelsymmetrisch angeordnet (Nr. 1); Rahmen 2 gefüllt mit Rolle Profilköpfe in Kreis im Wechsel mit Schriftband und begleitendem floralem Dekor (Nr. 2 = Neuhauser, Rolleneinbände, R 48); Rahmen 3 gefüllt mit Rolle Wappen von Neustift (Tau-Kreuz), Säben und Patriarchenkreuz einander abwechselnd, verbunden mit Rankendekor in gegenständigen Dreipassformen (Nr. 3 = Neuhauser, Rolleneinbände, R 58); Rahmen 4 gefüllt mit Rolle Profilköpfe in Handspiegeln mit Quastenbehang (Nr. $4=$ Neuhauser, Rolleneinbände, R 22); Rahmen 5 gefüllt mit eng aneinander gereihten Einzelstempeln Schriftband „Maria“, dazwischen Fischblasenmotiv und in den Zwickeln Trifolien (Nr. 5). Mittelfeld in vier Einzelfelder unterteilt, die jeweils wieder zwei von je dreifachen Streicheisenlinien begrenzte Rahmen aufweisen (von außen nach innen): Rahmen 6 gefüllt mit Einzelstempel Maske frei (Nr. 6 = Neuhauser, Rolleneinbände, S 41) im Wechsel mit Lilie frei (Nr. 7); Rahmen 7 gefüllt mit Rolle (Nr. 3, s. Rahmen 3). Ecken des äußeren und inneren Rahmens jeweils mit Blindlinien verbunden, sodass in der Mitte des VD ein Andreaskreuz gebildet ist. Mittig Einzelstempel Stempelblüte mit Rautenranke (Nr. 8 = Neuhauser, Rolleneinbände, S 39) mit eingeschlossener Lilie frei (Nr. 7). Spuren eines großen Mittelbeschlags mit sechs (?) Nagellöchern, Spuren von Eckbeschlägen mit je drei (?) Nagellöchern.

Am HD fünf Rahmen (von außen nach innen): Rahmen 1 gefüllt mit Rolle ineinander greifende, aus drei Linien aufgebaute Bögen mit Lilienbekrönung und zwei eingeschlossenen vierblättrigen Blüten (Nr. 9); Rahmen 2 gefüllt mit Rolle (Nr. 1); Rahmen 3 gefüllt mit Rolle (Nr. 3); Rahmen 4 gefüllt mit Rolle (Nr. 2); Rahmen 5 gefüllt mit Rolle (Nr. 4). Mittelfeld gerahmt, Längsfelder frei, unten und oben jeweils drei Einzelstempel Lilie in Raute (Nr. 10), mittig gerahmte Raute eingeschrieben: Rahmen gefüllt mit Rolle (Nr. 4); im 
Rautenmittelfeld Brokatmotiv (mittig zum Vierblatt angeordnet, oben und unten jeweils ein Brokatmotiv geschlossen) (Nr. 11), oben mit eingeschlossenem Schriftband (?), unten mit eingeschlossenem Einzelstempel florales Dekor, rautenförmig (Nr. 12). In der unteren Rautenhälfte zudem zwei seitlich angeordnete Einzelstempel florales Dekor mit geschlossener Knospe in Rautenform (Nr. 13). In den Außenfeldern der Raute oben und unten jeweils zwei am Rahmen angesetzte Brokatmotive offen (Nr. 14) sowie in der unteren Hälfte Einzelstempel (Nr. 13, Nr. 5 und Nr. 10), in der oberen Hälfte Einzelstempel (Nr. 5 und Nr. 10). Am HD vier Eckbeschläge in Form von steigenden gekrönten Löwen mit eckigen Buckeln.

Holz am oberen, unteren und seitlichen Rand eingekerbt, durch jeweils sechsfache Streicheisenlinien betont. Zwei Langriemen-Leder-Metallschließen mit Tierkopfabschluss (wohl nicht original), Leder erneuert, am VD Haltedorn auf runden Platten. Am VD und HD jeweils zwei Stehkanten. Kanten gerade. Rücken: sieben Doppelbünde. Kapitale mit naturfarbenem und rotem Zwirn umstochen. Spiegel sowie Vor- und Nachsatzbl. Perg. 20. Jh., leer bis auf Etikett der Restaurierwerkstätte (s. bei G) am Spiegel des HD.

G: Hs. im Auftrag des Propstes Nikolaus Scheiber (Propst 1439-1449) in Neustift angefertigt. Die zahlreichen Streichungen, Ergänzungen und Hinweise belegen eine Verwendung der Hs. bis ins 19. Jh. Hs. bei vorübergehender Aufhebung des Klosters 1807 nicht an die Universitätsbibliothek Innsbruck gelangt. Zahlreiche Bl. (s. auch bei B, A und Inhalt) verloren, tw. erst zw. 1905 und 1965 (vgl. Beschreibung bei Hermann bzw. Laußermayer). Am Spiegel des HD Etikett der Restaurierwerkstätte 20. Jh. (Laboratorio di restauro del libro, S. Maria di Rosano [Firenze]), kein Restaurierbericht erhalten.

L: $\quad$ Hermann 221-224, Nr. 222. - B. Rutz, Illuminierte Choralhandschriften zu Neustift. Kirchenmusikalische Jahrbuch 22 (1909) 88-95, hier 90-94. - Laußermayer 246-248, 257-267. - H. Lehmann-Haupt, Gutenberg and the Master of the Playing Cards. New Haven-London 1966, 35-36, 43. - G. Schmidt, Gotik in Österreich. Ausstellung 19. Mai bis 15. Oktober 1967, Minoritenkirche Krems-Stein. Krems an der Donau ${ }^{3} 1967$, 136 (auch in: M. Roland [Hrsg.], Gerhard Schmidt, Malerei der Gotik. Fixpunkte und Ausblicke I: Malerei der Gotik in Mitteleuropa. Graz 2005, 46). - W. A. Schulze, Alte Dreikönigsbilder in Südtirol. Der Schlern 53 (1979) 5-17. - W. Salmen, Katalog der Bilder zur Musikgeschichte in Österreich 1 (Innsbrucker Beiträge zur Musikwissenschaft IV). Innsbruck 1980, Nr. 269. - Peintner, Buchmalerei 14, 21, 43, 45, 49-57, 6364. - M. Peintner, Kloster Neustift. Augustiner Chorherren in Südtirol. Bozen 1985, 19. - N. Rasmo, Kunstschätze Südtirols, Rosenheim 1985, 132-133. - M. H. Peintner, Psallite Deo! Zur Musikgeschichte des Stiftes Neustift, in: 850 Jahre Augustiner Chorherrenstift Neustift. 134-153, hier 138-139. - Ch. Giner, Leben im Kloster, in: 850 Jahre Chorherrenstift Neustift. Katalog 85-90, hier 89. - M. Peintner, Das Skriptorium von Neustift, in: 850 Jahre Neustift. Katalog 91-93, hier 93. - M. Peintner, Musikgeschichte des Stiftes, in: 850 Jahre Neustift. Katalog 94-100, hier 94. - Th. (H.) Innerhofer, Wappen und Siegel des Konvents und der Pröpste von Neustift, in: 850 Jahre Neustift. Katalog 199-214, hier 199. - P. Caneppele, Ista tenella florens ut rosa Nova Cella. Una raffigurazione ideale della chiesa abbaziale di Novacella? Archivio per l'Alto Adige 88/89 (1994/95) 356-366. - Gozzi 546, Nr. 45. - Stefani 120-121. - O. Lässer, Bilder zur Musikgeschichte in Tirol. Von den Anfängen bis 1600, in: K. Drexel, M. Fink (Hrsg.), Musikgeschichte Tirols I: Von den Anfängen bis zur Frühen Neuzeit (Schlern-Schriften 315). Innsbruck 2001, 705-769, hier 730, Nr. 70. - Neuhauser, Musikgeschichtliche Quellen 151, 161, 164, 194. - Engels 310. - J. G. Alexander, J. H. Marrow, L. Freeman Sandler, The Splendor of the Word. Medieval and Renaissance Illuminated Manuscripts at The New York Public Library. London 2005, hier 181. - M. Studničková, Vážka jako obraz duše hledající spásu. Výzdoba Bratislavského misálu IV (AMB EL 13a) a skupina iluminovaných rukopisů brixenského, vídeňského a jihoněmckého původu z poloviny 15. století/Libelle als Sinnbild der heilsuchenden Seele. Die Ausstattung des Pressburger Missale IV und eine Gruppe illuminierter Handschriften aus Brixen, Wien und Süddeutschland aus der Mitte des 15. Jahrhunderts, in: D. Buran (Hrsg.), Galéria. Ročenka Slovenskej národnej galérie / Jahrbuch der Slowakischen Nationalgalerie in Bratislava 2004/2005. Príspevky Medzinárodného kolokvia Gotika na Slovensku a jej stredoeurópsky kontext/Beiträge des Internationalen Kolloquiums Gotik in der Slowakei und ihr mitteleuropäischer Kontext. Bratislava 2006, 149-159, insbes. 158. - Roland, Gotik 274, 288-289 (Kat. 185). - Beier I 15-21, insbes. 16. - Baroffio 325, Nr. 16756. - G. Gabrielli, Tropes in cantus planus sources from South Tyrol, in: J. Border u. a. (Hrsg.), Cantus Planus. Venice meeting 2014. Venezia (in Druck). - Rischpler.

Graduale Neocellense.

(Ir-v) leer.

(IIr) Frontispiz (s. bei A).

(IIv) leer. 
(1r-260v) Temporale (pars hiemalis und pars aestivalis).

(1r) Dnca 1. adventus. - (3r) Dnca 2. adv. - (5r) Dnca 3. adv. - (7r) Fer. 4. quattuor temporum. (9v) Fer. sexta. - (11r) Sabbato quattuor temporum. - (13v) Canticum trium puerorum (Dn 3,5788). - (16v) Dnca 4. in adv. - (18r) In vigilia nativitatis dni. - (19v) In galli cantu. Mit Sequenz (AH 53, Nr. 10). - (22v) In aurora. Mit Sequenz (AH 53, Nr. 16). - (26v) Ad tertiam missam. Mit Tropus (AH 49, Nr. 1) und Sequenz (AH 53, Nr. 15). - (31v) Dnca 1. post nativitatem dni. Mit Verweis auf Sequenz (AH 53, Nr. 10). - (33r) In circumcisione dni. Mit Verweis auf Sequenz (AH 53, Nr. 16). - (35v) In vigilia epiphaniae dni. Nur Verweis auf Introitus: Dum medium silencium (rot:) per totum. - In epiphania dni. Rubrik: In epiphania domini tropus (von anderer Hand hinzugefügt) non canitur. Introitus mit Tropus (AH 49, Nr. 77, 1, 3a, 2b und Nr. 11) und Sequenz (AH 53, Nr. 29, unvollständig). - (Bl. 38v) Expl. mut.: ... O Christe quantum patri exercitum. Iuvenis doc [tus (1 Bl. fehlt)

(40r) Inc. mut. (Forts. der Sequenz): ausculta]te populi preceptori ... - (40v) Dnca 1. post epiph. dni. Expl. mut. (Introitus): ... angelorum psallentes in unum ecce cuius [ (2 Bl. fehlen, Textverlust)

(43r) Inc. mut. (Communio): ] tuus dolentes querebamus te et quid est quod me querebatis ... Dnca 2. post epiph. dni. - (45v) Dnca 3. post epiph. dni. - (47v) Dnca in Septuages. - (50r) Dnca in Sexages. - (52v) Dnca in Quinquages. Expl. mut. (Introitus): ... Esto mihi in Deum am [ (1 Bl. fehlt)

(54r) Inc. mut. (Graduale): ]um filios Israhel et Ioseph ... - (55v) In capite ieiunii: Ad processionem. Mit Antiphonen Exaudi nos domine (CAO Nr. 2770), Immutemur habitu (CAO Nr. 3193), Iuxta vestibulum (CAO Nr. 3554). - (56v) Ad missam. - (59v) Fer. 5. post Quinquages. - (60v) Fer. 6. post Quinquages. - (62r) Verweis Sabbato ad missam Esto mihi (rot:) per totum. - (62r) Dnca 1. in Quadrages. - (66v) Fer. 2. - (68r) Fer. 3. - (69v) Fer. 4 quattuor temporum. - (72r) Fer. 5. - (74r) Fer. 6. - (75v) Sabb. - (77r) Dnca 2. in Quadrages. - (77v) Fer. 2. - (79r) Fer. 3. (80r) Fer. 4. - (80v) Expl. mut. (Graduale): ... Salvum fac populum tuum domine [ (6 Bl. fehlen) (87r) Sabbato post dncam 2. in Quadrages. Inc. mut. (Offertorium): ob]dormiam in morte ne quando dicat inimicus meus ... - Dnca 3. in Quadrages. - (90v) Fer. 2. - (92v) Fer. 3. - (94r) Fer. 4. - (95v) Fer. 5. - (96v) Expl. mut. (Versus von Graduale): ... Aperis tu manum tuam et imples [ (1 Bl. fehlt)

(98r) Fer. 6. - (99v) Sabb. - (101r) Dnca 4. in Quadrages. - (104r) Fer. 2. - (105r) Fer. 3. - (107v) Fer. 4. - (110r) Fer. 5. - (112r) Fer. 6. - (114r) Sabb. - (116r) In passione dni. - (119v) Fer. 2. (121v) Fer. 3. - (123r) Fer. 4. - (125v) Fer. 5. - (127v) Expl. mut. (Communio): ... michi spem dedisti hec me consolata est in humilitate me $a$ [ (2 Bl. fehlen: Es fehlen die Prozessionsgesänge des Palmsonntags, s. auch bei B und A.)

(130r) Dnca in palmis. Inc. mut. (Introitus): ] facias auxilium tuum a me ad defensionem meam ... - (136r) Fer. 2. Am Rand von späterer Hand (18. Jh.) ein Kyrie-Ruf ergänzt. - (137v) Fer. 3. - (140r) Fer. 4. - (143v) Expl. mut. (Offertorium): ... Domine exaudi orationem meam et clamor meus ad [ (8 Bl. fehlen: Es fehlt beinahe das gesamte Triduum.)

(152r) Sabbatum sanctum. Inc. mut. (Tractus): ] Hic Deus meus et honorabo eum Deus patris mei ... - (155v) Ad vesperas. - (156r) Ad processionem: Mit Antiphon (CAO Nr. 3222). - (156v) Dnca resurrectionis dni. Mit Sequenz (AH 53, Nr. 36, unvollständig). - (158v) Expl. mut. (Str. 3): ... Qui se ipsum exinanivit ut nos [ (4 Bl. fehlen)

(163r) Dnca resurrectionis dni. Inc. mut. (Communio): epule]mur in azimis sinceritatis et veritatis. - (163r) Fer. 2. Mit Sequenz (AH 53, Nr. 46). - (167v) Fer. 3. Mit Sequenz (AH 53, Nr. 50). - (171r) Fer. 4. Mit Sequenz (AH 53, Nr. 52). - (174v) Fer. 5. Mit Sequenz (AH 53, Nr. 53). - (178v) Fer. 6. Mit Sequenz (AH 53, Nr. 54). - (182r) Sabbato. Mit Sequenz (AH 53, Nr. 56). - (185r) Dnca in albis = Dnca 1. post pascha. Mit Sequenz (AH 54, Nr. 7). - (187v) Fer. 2. - Fer. 3. - (187 ${ }^{\text {bis }}$ r) Fer. 4. - $\left(187^{\text {bis }} v\right)$ Kyrie-Ruf. Pascale minus. - (188r) Fer. 4. - Fer. 6. (188v) De lancea dni. Mit Sequenz (AH 54, Nr. 140). - (191v) Dnca 2. post pascha. Mit Verweis 
auf Sequenz (AH 54, Nr. 7). - (193r) Dnca 3. post pascha. Mit Rubrik von späterer Hand: Verweis auf drei Sequenzen (AH 54, Nr. 7; AH 54, Nr. 148; AH 50, Nr. 240). - (195r) Dnca 4. post pascha. Mit Verweis auf Sequenz (AH 54, Nr. 148). - (195v) Dnca 5. post pascha. Mit Verweis auf Sequenz (AH 50, Nr. 240). - (196v) Rogacionum. - (198v) In vigilia ascensionis dni. - (199v) In die sancto. - (200v) Expl. mut.: ... (Versus) Ascendit Deus in iubilacione et dominus in voce tube. Alleluia. (rot:) V. [ (6 Bl. fehlen: Es fehlen beinahe die gesamten Gesänge des Pfingstfestes sowie die entsprechenden Prozessionsgesänge „Rex sanctorum angelorum“, „Salve festa dies“.) (207r) Dnca pentecostes et de spiritu sancto. Inc. mut. (Alleluia. Versus): ] faciem terre. Alleluia. Mit zwei Sequenzen (AH 53, Nr. 70; AH 54, Nr. 153). - (212r) Fer. 2. Mit Verweis auf Sequenz (AH 53, Nr. 70). - (213r) Fer. 3. Mit Verweis auf Sequenz (AH 53, Nr. 70). - (214v) Fer. 4. Mit Verweis auf Sequenz (AH 54, Nr. 153). - (215v) Fer. 5. Mit Verweis auf Sequenz (AH 54, Nr. 153). - (217r) Sabbato quattuor temporum. - (217v) In festo ss. trinitatis. Expl. mut.: ... Alleluia. (rot:) De sancta trinitate Introitus [ (1 Bl. fehlt)

(219r) Inc. mut. (Alleluia. Versus): ]ia. Benedictus es domine Deus patrum nostrorum ... Mit Sequenz (AH 53, Nr. 81, unvollständig). - (219v) Expl. mut. (Sequenz, Str. 7): ... Proprietas in personis unitas est et in essencia. Maiestas par et po[testas (1 Bl. fehlt)

(221r) Inc. mut. (Sequenz, Str. 17): aeter]nitas. Per te sumus redempti summa tu caritas ... (222r) In festo ss. corporis Christi. Mit Sequenz (AH 50, Nr. 385) und Offertorium mit Prosula (AH 43, Nr. 643). - (227r) Dnca 1. post trinitatis. - (229r) Dnca 2. - (230r) Dnca 3. - (231r) Dnca 4. - (232v) Dnca 5. - (234r) Dnca 6. - (235v) Dnca 7. - (237r) Dnca 8. - (238v) Dnca 9. (240r) Dnca 10. - Dnca 11. - (241v) Dnca 12. - (243r) Dnca 13. - Dnca 14. - (246v) Dnca 15. (247v) Dnca 16. - (248v) Dnca 17. Expl. mut. (Introitus): ... secundum misericordiam tuam. Beat [i (1 Bl. fehlt, Foliierung durchgehend, s. bei B)

(249r) Communio. - (249r) Fer. 4 quattuor temporum. - (250v) Fer. 6. - (251r) Sabbato. - (251v) Dnca 18. - (253r) Dnca 19. - (253v) Dnca 20. - (254r) Dnca 21. - (256v) Dnca 22. - (258v) Dominica ultima = Dnca 23. - (260v) In dedicatione ecclesiae. Mit Sequenz (AH 53, Nr. 247). (264v) In dedicatione unius altaris. Expl. mut. (Introitus): ... munera tua accepta erunt super altare meum. Miseri[ (2 Bl. fehlen)

(267r) Inc. mut. (Ende der Sequenz AH 53, Nr. 112): gau]diorum vestrorum.

(267r) Pro Defunctis. - (268v) Expl. mut. (Offertorium): ... libera animas omnium fidelium defunctorum de manu inferni et de profundo lacu libera eas de ore leo[nis (1 Bl. fehlt)

(270r) Inc. mut. (Offertorium): ] eas in sinum Abrahe in lucem sempiternam. (rot:) Communione. (schwarz:) Absolve domine animas ... - (270v) Pro pontificibus et praelatis defunctis. - (271r) später hinzugefügt: Dom. 2. Quad.

2 (271v-310v) KYRIALE.

$2.1(271 v-290 v)$ Kyrie. Gloria.

(271v) Ohne Tit. Nur Kyrie. - Aliud, am Blattrand von späterer Hand ergänzt: De Apostolis 1. (273v) Ohne Tit. Nur Kyrie. - Aliud, am Blattrand von späterer Hand ergänzt: De Confessoribus 2. Nur Kyrie. - (274r) Aliud Kyrie, am Blattrand von späterer Hand ergänzt: Angelicum 3. Aliud, am Blattrand von späterer Hand ergänzt: De Martyribus 4. Nur Kyrie. - (274v) Aliud. (276r) Ohne Tit., am Blattrand von späterer Hand ergänzt: Ascendens 5. Nur Kyrie. - (276v) Aliud, am Blattrand von späterer Hand ergänzt: De Virginibus 6. - (278r) Ohne Tit., am Blattrand von späterer Hand ergänzt: Descendens 7. Nur Kyrie. - (279v) Aliud, am Blattrand von späterer Hand ergänzt: De Beata Virgine minus 8. - (280r) Ohne Tit., am Blattrand von späterer Hand ergänzt: Ad proprias laudes 9. - (281v) Ohne Tit., am Blattrand von späterer Hand ergänzt: De B. M. Virgine maius 10. Gloria mit Tropus Spiritus et alme (Bosse Nr. 23, mit Abweichungen in der Melodie). Tropus mit Papierstreifen überklebt, Gloria auf später eingefügtem $\mathrm{Bl}$. $282^{\text {bis }} \mathrm{r}-\mathrm{V}$ ohne Tropus wiederholt, urspr. Forts. auf Bl. 283r. - (284r) Pascale, am Blattrand von späterer 
Hand ergänzt: Pascale 11. - (285v) De martiribus. Nur Kyrie. - De uno martire sive confessore. (287r) De virginibus. - (289r) Dominicale. Nur Kyrie. - Ad priorem.

2.2 (291r-311r) Sanctus. Agnus Dei.

(291r) Ohne Tit. - (292r) Ohne Tit., am Blattrand von späterer Hand ergänzt: De apostolis 1. (293r) Ohne Tit., am Blattrand von späterer Hand ergänzt: De virginibus 2. - (294r) Ohne Tit., am Blattrand von späterer Hand ergänzt: De martyribus 3. - (295r) Ohne Tit. Sanctus mit Tropus Benedictus Marie natus qui venit ... - (296r) Ohne Tit., am Blattrand von späterer Hand ergänzt: Descendens 4. Sanctus mit Tropus Benedictus Marie filius (?) qui venit ... (radiert). - (297r) Ohne Tit. Sanctus mit Tropus Benedictus Marie natus qui venit ..., Agnus Dei mit Tropus Summi celi qui tollis ... - (298v) Ohne Tit., am Blattrand von späterer Hand ergänzt: Maius de b. virgine 5. Sanctus mit Tropus Benedictus Marie filius qui venit ... - (299r) Ohne Tit. - (300r) Ohne Tit. (301r) Ohne Tit. Sanctus mit Tropus Benedictus Marie filius qui venit ... - (301 $\left.{ }^{\mathrm{bis}} \mathrm{r}\right)$ Ohne Tit., am Blattrand von späterer Hand ergänzt: De confessoribus 6. - (302r) Ohne Tit., am Blattrand von späterer Hand ergänzt: De b. virgine minus 7. - (302v) Ohne Tit., am Blattrand von späterer Hand ergänzt: Ad propr. laudes 8. - (303v) Ohne Tit., am Blattrand von späterer Hand ergänzt: Paschale 9. - (304r) Ohne Tit., am Blattrand von späterer Hand ergänzt: Dominicale 10. - (305r) Ohne Tit. - (306v) Ohne Tit. Agnus Dei mit Tropus O dulcis Ihesu Christe ab arce patris misse tu redemisti omnia nostra delesti crimina dona nobis pacem ... (Melodie mit M. Schildbach, Das einstimmige Agnus Dei und seine handschriftliche Überlieferung vom 10. bis zum 16. Jahrhundert, Diss. Erlangen, Nürnberg 1967, 122, Nr. 149 übereinstimmend, jedoch kein Verweis auf Tropen). - (306v) Ohne Tit., am Blattrand von späterer Hand ergänzt: Angelicum 11. - (307v) Ohne Tit., am Blattrand von späterer Hand ergänzt: Ascendens 12. - (308v) Ohne Tit. - (309v) Ohne Tit. - (310r) Ohne Tit. - (310v) Ohne Tit., am Blattrand von späterer Hand ergänzt: Simplex 13.

3 (311r-314r) Missa CONTRA PESTILENTIAM.

4 (314v) Antiphonen. - (315v) Karfreitagsliturgie. Trisagion mit Antiphon Crux fidelis omnes ... (316r) Ecce lignum. Beati immaculati.

5 (316v-317r) Alleluia-Verse.

(316v) Dnca 5. post pascha. - (317r) In ascensione dni (Dominica $1^{a}$ ascensionis).

6 (317r-324r) Ergänzung von späterer Hand (Terminus post quem 1457 [Einführung des Festes In transfiguratione dni]) zum Temporale.

(317r) In transfiguratione dni. Mit Sequenz (AH 50, Nr. 274). - (319v) De resurrectione. Zwei Sequenzen (AH 54, Nr. 148; AH 50, Nr. 240, unvollständig). - (321v) Expl. mut. (Sequenz, Str. 3a): ... superis dies duplicis baptismi legis evan[gelii (2 Bl. fehlen)

(324r) Inc. mut. (Sequenz, Str. 6b): ] parenti veteri tu membris forcioribus ... - Rubrik: Versus sequens obmissus est supra dominica $8^{a}$ post penthe. in alleluia. (Text) Replebimur in bonis domus tue sanctum est templum tuum mirabile in equitate.

7 (324v) Sanctus mit Verweis auf vorangehendes Kyriale.

8 (325r) Schlussschrift (rot): Hunc librum comparavit venerabilis pater dominus Nycolaus permissione divina prepositus Novecellum (!) pro suo monasterio ob reverenciam virginis gloriose.

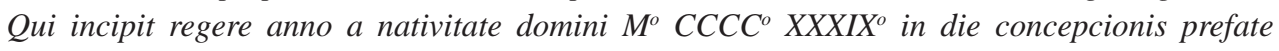
virginis gloriose. Scriptus et finitus est per fratrem Fridericum Zolner sacerdotem professum eiusdem monasterii. Anno domini millesimo quadringentesimo quadragesimo secundo in vigilia nativitatis eiusdem virginis gloriose. Cui est honor laus et gloria per infinita seculorum secula. Amen (7. September 1442). 
Daneben von späterer Hand in Rot, Textualis formata (Textura) ergänzt: dominus Fridericus qui scripsit hunc librum obiit 1446 (!).

(325r) Notiz von späterer Hand am rechten Rand der vierten Textzeile in Bastarda: obiit 1449 feria 3 a post assumpcionem s. Marie.

$\left(\mathrm{I} *_{\mathrm{r}-\mathrm{v})}\right.$ leer.

G. G./U. S.

\section{ohne Sign.}

\section{GRADUALE NEOCELLENSE II}

Perg. I, 317, I* Bl. $700 \times 500$. Neustift, Mitte 15. Jh. (zw. 1442 und 1446).

B: $\quad$ Hs. um 1980 restauriert (s. bei G). Perg. am rechten unteren Blattrand tw. stark abgegriffen, daher Ecken vielfach im Zuge der Restaurierung ergänzt bzw. ersetzt. Am Blattrand vereinzelt kleine Löcher (selten auch im Schriftfeld) und Risse, selten Nahtspuren, bisweilen Naht erhalten (Bl. 20, 38, 52, 55, 261). Risse und Fehlstellen mit Perg. überklebt und ergänzt, Bl. 49 fehlende Textstellen nachgetragen. Korrekturen durch Aufkleben von zusätzlichen Pergamentstücken und -streifen (z. B. Bl. 133r, 165r, 187v, 197v, 198v, 199r, 203v, 253r-v, 288r).

Lagen: (I-1) $($ Vorsatzbl. 20. Jh. $)+(\mathrm{IV}-1)^{7}+6 . \mathrm{IV}^{55}+(\mathrm{IV}+1)^{63(64)}+10 . \mathrm{IV}^{143(144)}+(\mathrm{IV}+1)^{151(153)}+14 . \mathrm{IV}^{263(265)}$ $+(\mathrm{IV}+1)^{271(274)}+\mathrm{V}^{279(284)}+\mathrm{IV}^{287(292)}+(\mathrm{IV}-1+1)^{295(300)}+\mathrm{IV}^{303(308)}+(\mathrm{IV}+1)^{312(317)}+(\mathrm{I}-1)^{\mathrm{I}^{* *}}($ Nachsatzbl. 20. Jh. $)$. Gegenbl. zum Vor- bzw. Nachsatzbl. als Spiegel auf dem VD bzw. HD aufgeklebt. Gegenbl. zu Bl. 7 herausgeschnitten (ohne Textverlust). Bl. 56 $6^{\text {bis }}$ eingehängtes Einzelbl. Gegenbl. zu Bl. 57 und 58 (urspr. Bl. 62 und 63) herausgeschnitten (Textverlust, Reste der Ausstattung im Falz sichtbar), im Zuge der Restaurierung durch leere Bl. ersetzt. Urspr. Gegenbl. zu Bl. 102 und 103 herausgeschnitten, später durch zwei Einzelbl. ergänzt (auf Falz aufgeklebt, in Foliierung berücksichtigt). Bl. 144 ${ }^{\mathrm{I}}$ eingehängtes Einzelbl. mit (im Kontext) ergänztem Text von späterer Hand (Vierliniensystem etwas enger), in Foliierung nicht berücksichtigt. Bl. 264 ${ }^{\text {bis }}$ eingehängtes Einzelbl. (Pap., Schrift- und Notenspiegel an die restliche Hs. angepasst) mit Forts. des Gloria von Bl. 264v ohne Tropus (s. bei Inhalt), in Foliierung nicht berücksichtigt. Bl. 295 relativ zeitnah mit fortlaufendem Text ersetzt (ohne rote Foliierung, in Bleistift später ergänzt). Bl. 312 eingehängtes Einzelbl., auf Bl. 311 aufgeklebt.

Bis Bl. 287 (= Ende der Lage 36) am Lagenende Kustoden in römischen Zahlen sowie Reklamanten. Am oberen Blattrand zeitgenössische Foliierung in roten römischen Zahlen I-CCCXII; Fehler in der Zählung: 96 ausgelassen (stattdessen XCVII doppelt angeführt), nach Bl. 274 zwei Blätter ungezählt (heute $274^{\text {bis }}$ und $\left.274^{\text {ter }}\right)$.

S: $\quad$ Schriftraum $535 / 540 \times 350 / 360$, seitlich von zweifachen roten Tintenlinien begrenzt (linke Spalte Notenschlüssel, rechte Spalte Kustos), jeweils sieben rote Vierliniensysteme (39 mm) mit Textzeilen. Zirkelstiche. Textualis formata (Textura), 1442-1446. Hauptschreiber: Friedrich Zollner (vgl. Graduale I, Bl. 325r). Einschübe von mehreren anderen zeitgenössischen Händen (z. B. Bl. 160r-164v; Bl. 179r, Z. 4, Ergänzung auf Bl. 187v; Bl. 199r, Bl. 203v; Bl. 246v, Z. 1; Bl. 252v, Z. 3-253v, Z. 1; Bl. 272r, Z. 4-276v, Bl. 298r-v, Bl. 304v, Z. 4-312r). Nur vereinzelt Radierungen und Korrekturen (sowohl bei Noten als auch bei Text). Zahlreiche Radierungen, Durchstreichungen, Ergänzungen und Korrekturen von späteren Händen, meist ebenfalls in Textualis formata (Textura), tw. auch in Rotunda (z. B. Bl. 63r, 95r-96v, 253v, 312v). Blattgestaltung (Höhe der Vierliniensysteme sowie Schriftgröße) meist nachgeahmt. Zusätze in schwarzer und roter Tinte sowie Bleistift bis ins 18. Jh., z. B. Vacat, Gliederungsstriche von unterschiedlicher Breite, Rubriken, Buchstaben für die Aufführungspraxis (mit Orgel? bzw. Bl. 223r-v, 225r in Rot Chorus - Rectores), Blattverweise.

Mehrere Feste zur Gänze von späterer Hand gestrichen.

N: Gotische Choralnotation (mit Virga) auf vier roten Linien, c- bzw. f-Schlüssel, Kustoden. Beginn neuer Abschnitte (z. B. am Beginn des zweiten Teils des Kyriale auf B1. 275r) vielfach von anderer Hand 15. Jh.: sog. ,umgekehrte Hufnagelnotation“. Wie im Graduale I Verwendung von Kustoden in Rot als Hinweis auf einen Schlüsselwechsel innerhalb eines Gesangs. Reperkussionston mit einem ornamentalen Haarstrich. Im 16./17. Jh. zahlreiche Melismen gestrichen und durch Pergamentstreifen überklebt, Notation bisweilen ergänzt bzw. verändert. Wie im Graduale I Ergänzung (18. Jh.) von langen Gliederungsstrichen in Rot (oben lilienförmig bzw. Rhombusform), die über das Vierliniensystem hinausreichen, möglicherweise Hinweis auf 
Alternatim-Aufführungsform. Am Blattrand im Kyriale bisweilen Ergänzung von Buchstaben (18. Jh.) als Hinweis zur Aufführungspraxis.

A: Rubriken und Foliierung in Rot; in Textpassagen (z. B. Bl. 131v-132v) abwechselnd große Paragraphzeichen in Rot und Blau, tw. mit (interlinearen) Ausläufern und Fibrillen, sowie rote Durchstreichungen; Bl. 281v ein Teil der Notenzeile mit rotem Rautengitter ausgestrichen. Bl. 312v die beiden Anfangsbuchstaben mit etwas (Besatz-)Dekor.

Fleuronnée: fast 1400 Fleuronnée-Initialen (abwechselnd rote und blaue, in der Regel eine Notenzeile hohe Buchstaben mit Punktverdickungen, selten Ausläufer mit Achterschlaufen und Fibrillen; Einleitungsinitialen des Kyriale und der Forts. desselben, B1. 254r und 275r, in der Höhe von zwei Notenzeilen und, wie die meisten Initialen an den Abschnittsanfängen in diesen Graduale-Teilen und einige Initialen im Commune Sanctorum und im Sanctorale, als aufwändigere rot-blau gespaltene Initialen mit verzierten Blattaussparungen gestaltet; Bl. 56r, 252v, 272r, 296v, 300v, 304r, 306v, 308r, 309v rot-blau gespaltene Initialen von anderen Initialmalern) und ca. 260 fleuronnierte Cadellen, zumeist in der Höhe einer Notenzeile; von diesen etwa 1460 erhaltenen fleuronnierten Buchstaben das Gros von der Hand des Hauptflorators; FleuronnéeNachträge von mindestens drei weiteren Händen (s. u.). Aufwändigere Fleuronnée-Initialen des Hauptflorators im Commune Sanctorum: Bl. 13v, 14r, 14v, 15r, 15v, 16r (2), 17r (2), 37r, 37v (2), 38r, 38v, 39r, 50r, 50v, 51r, 51v, [63r], 64r; Sanctorale: Bl. 85v2, 89v, 92v2, 98v, 124r, 125r, 132r, 133v, 135r, 138r, 139r, 148r3, 169r1, 174v, 178r2, 193r, 206r; Kyriale (ohne Einleitungsinitiale): B1. 254r4, 254v3, 256r1, 256r3, 256v1, 256v4, 257r2, 257r5, 258v1, 258v4, 260r, 260v4, 261r, 262r1, 262v, 263v1, 264r5, 266r1, 266r5, 267v1, 267v5, 267v9, 269r1, 269r8, 270v1, 270v5, 271r; Forts. des Kyriale (ohne Einleitungsinitiale): Bl. 275v2, 276v2, 277v, 278v, 279v, 280r2, 281r, 282r, 283r1, 283v, 284v, 285r, 286r1, 286v, 287r1, 288r, 289r, 290r, 290v2, 291v, 292v2.

Fleuronnée der Haupthand wie im ersten Gradualband sehr gleichmäßig und akkurat ausgeführt; wenige Motive, die trotz unterschiedlichster Kombinationen einen relativ gleichförmigen Gesamteindruck erzeugen. Formenvokabular des Cadellen-Fleuronnée sehr ähnlich, aber noch etwas reduzierter (z. B. weniger Besatz), außer bei Cadellen in den obersten Notenzeilen, die etwas aufwändiger geschmückt sein können (z. B. Bl. 70r, 86v, 144v, 172r, 206v); Cadellen-Fleuronnée in Schwarz, mit wenig rotem Dekor, vorwiegend Konturlinien und Punkte. Blaue Initialen mit Fleuronnée in Rot, (manchmal verblasstem) Violett, seltener in Grün; rote Initialen vorwiegend mit grünem, seltener mit rotem oder violettem Fleuronnée; bei aufwändigeren Initialen Farbkombinationen im Fleuronnée, v. a. grün-violett und grün-rot, bei Einleitungsinitialen grün-violett-rot; wenige Fälle von andersfarbigen, evtl. nachgetragenen Punkten (z. B. Bl. 140v3).

Fleuronnée-Motive sehr ähnlich wie im ersten Gradualband mit folgenden Unterschieden: Häufiger gestrichelte Halbpalmetten mit deutlicherer Längungstendenz, insbes. in Binnenfeldern als S-förmig ineinander geschmiegte Paare (z.B. Bl. 8r1), auch in Kombination mit runden Knospen (z. B. Bl. 12v2), diese Knospen zuweilen gepunktet oder statt der Knospen kleine, rundblättrige Blüten (z. B. bei Cadelle Bl. 66r). Als Besatz auch große Halbpalmetten mit gebogten Rändern und plastisch herausschraffiertem Rückengrat (z. B. obere Cadelle B1. 86v), die den aus den Buchstabenkörpern der aufwändigeren Fleuronnée-Initialen ausgesparten Halbpalmetten stark ähneln. Bei den quadratischen Binnenfeld-Kachelungen werden Kreuzverbindungen zu Stielen, Unterquadrate zu Blättchen (z. B. Bl. 106v1); zudem radial unterteilte Binnenfelder (z. B. Bl. 289r: Kompartimente jeweils mit Knospen gefüllt). Im Cadellen-Fleuronnée häufiger die aus schwarzem Binnenfeldgrund ausgesparten ondulierenden Halbpalmettenranken. Bei den typischen Profilköpfen die mürrisch nach unten gezogenen Münder tw. (wie zum Sprechen) seitlich leicht geöffnet (z. B. Bl. 29v, zweite Cadelle) und häufiger "fließende“, an den Verlauf des Buchstabenkörpers angepasste Kinnpartien (z.B. Initiale B1. 110v; noch ausgeprägter B1. 74v1, hier auch Fadenausläufer, der direkt dem Mund des Profilkopfs entwächst). Weitaus mehr aufwändig gestaltete Initialen (ca. 70) mit rot-blau gespaltenen Buchstabenkörpern, die mit binnendekorierten vegetabilen Aussparungen in symmetrischer Anordnung verziert sind (zu Halbpalmetten s. o., zudem ondulierende Ranken mit Herz- und Rundblättern, die in Rankenvoluten eingeschriebene Blüten ausbilden können, z. B. bei Sanctus-Initiale B1. 275r; hier Blüten auch im Binnenfeld, in eng ondulierender Ranke; Rankenvoluten rot-, Binnenfeld grüngrundig; Bl. 14v Aussparungen bräunlich-grün ausgemalt); aufwändigere Initialen darüber hinaus mit längeren Fadenausläuferbündeln (rote Bündelstriche, Fäden doppelgestrichelt, symmetrisch angeordnet und mit zurückschwingenden Häkchenenden), die orthogonal und/oder diagonal abstehen können (z. B. B1. 281r), sowie mit üppigen Fleuronnée-Leisten, die der Hauptflorator aus den gängigen Motiven aufbaut (z. B. Bl. 267v: hier verbindet die Leiste die drei aufwändigen Initialen dieser Seite; etwas ausgefallener Bl. 37v: aneinander gereihte Elemente des Laufenden Hunds, denen hängende Herzblätter fibrillenartig entwachsen) und fallweise in Fadenausläuferbündeln enden lässt. Auch die im vorliegenden Gradualband tätige Deckfarbenhand (zu diesem Miniator s. unter „Deckfarbenschmuck“" sowie Rischpler) führte etwas Fleuronnée aus: z. B. goldenes Binnenfeld-Fleuronnée der Ornamentalinitiale B1. 175r (zu weiteren Beispielen dieses Fleuronnée s. erster Gradualband unter „Fleuronnée). 
Darüber hinaus mindestens drei (jüngere) Fleuronnée-Hände, vielfach unter Einfluss des Hauptflorators: (1) Bl. 56r-v, 113r (oben), 160r-164v, 272r-274ter $\mathrm{r}, 303 \mathrm{r}-304 \mathrm{v}$ : über 80 Initialen und Cadellen mit variationsreichem, sauber gezeichnetem Fleuronnée (Bl. 56r1 aufwändiger); diese Hand auch im ersten Gradualband tätig (Ergänzungshand 1). (2) Bl. 144 ${ }^{\mathrm{bis}} \mathrm{r}-\mathrm{v}, 304 \mathrm{r} 2$ (?), 305r-310v ca. 40 Fleuronnée-Nachträge (B1. 306v2, 308r2 und 309v aufwändiger: u. a. mehrfarbiges Fleuronnée und längere Ausläufer; unklar ist die Zugehörigkeit der beiden Fleuronnée-Initialen Bl. 310r-v) von der geübten, wohl in das 1. Fünftel 16. Jh. zu datierenden Hand, die in Cod. 405 (dat. 1501, hier das Fleuronnée flüchtiger), Cod. 194 (dat. 1507), Cod. 142 (Teil mit in Rede stehendem Fleuronnée, dat. 1521) zu finden ist, einige Initialen im ersten Band des ZollnerGraduales gezeichnet und Sign. 14820 zur Gänze ausgestattet hat (ausführlich zu dieser Hand bei Sign. 14820). (3) Bl. 203v, 301v: flüchtig dekorierte Cadellen. Unklar ist auch die Zuordnung der Cadelle B1. $288 \mathrm{v}$ (mit spitznasigem Profilkopf).

Deckfarbenschmuck. Ein Wappen; acht (erhaltene) figürliche Initialen in der Höhe von zwei bis drei Notenzeilen (Bl. 1r, 3r, 13r, 49v, 76r, 102v, 112r, 210v) und fünf ornamentale Initialen, jeweils zwei Notenzeilen hoch (Bl. 36v, 142r, 171v, 175r, 186r), jeweils mit fallweise belebten Ranken; ein herausgeschnittenes Folio (B1. 62) mit figürlichem Deckfarbenschmuck, der von Hermann noch beschrieben wurde, woraus folgt, dass diese Seite nach 1905 entfernt worden sein muss. - Gestaltung der Bestandteile sowohl der figürlichen als auch der ornamentalen Initialen (Rahmen, Außengründe, Buchstabenkörper etc.) unterliegt keiner strikten hierarchischen Gewichtung, d. h. figürliche Initialen wurden nicht wesentlich üppiger angelegt als ornamentale (Ausnahme: Rankendrolerien, s. u.). Dieser Gradualband war den Neustifter Augustiner Chorherren demnach so kostbar, dass jede Deckfarbenseite annähernd den gleichen Illuminationsaufwand rechtfertigte. Deckfarbenschmuck von einer Hand ausgeführt, die auch Einleitungsseite des ersten Gradualbandes gestaltete; nachfolgend die Charakteristika dieses Illuminators:

Initialrahmen eher einfach gehalten, aber zumeist mit andersfarbigem Binnenrähmchen versehen; nur Rahmen Bl. 1r (mit Stufenband), 76r (mit feinen Goldranken überzogen) und 36v, 112r, 210v (jeweils mit plastisch herausgearbeiteten Zierrauten, so auch im ersten Gradualband, Bl. 1r) etwas aufwändiger. Außengründe bzw. -zwickel in der Regel mit Blattgold belegt, tw. mit rahmenden Linien aus Punktpunzen umgeben und zumeist von feinem, in weißlichem Malmittel ausgeführten Rankenwerk überzogen, seltener mit radial vom Buchstabenkörper ausgehenden Strahlen (Strahlendekor in dieser Technik oft auch auf den vergoldeten Heiligenscheinen); Bl. 112r Außengrund zartgrün mit goldenen, in Voluten gelegten Blättchenranken. Elegante Buchstabenkörper (mit feinen, plastisch herausgearbeiteten Konturierungen), die in dünne Rankenäste übergehen und seltener mit Stufenbändern, meist mit Blattwerk gefüllt sind: einerseits ondulierend, mit Adern, die mit Reihen von Perlen gefüllt sind, welche sich zur Blattmitte hin vergrößern („Erbsenschotenmotiv“), sowie mit den charakteristischen zweifachen Querstrichen (beide Motive z.B. Bl. 210v), andererseits lang und flach aufliegend, mit mehr oder weniger gebogten Blatträndern (z. B. B1. 49v). Binnenfelder einfarbig (gerne in Blau) grundiert, oft von feinem goldenem Gitter überzogen, in dessen Quadrate stilisierte vierblättrige Blüten eingeschrieben wurden (fallweise integrieren sich die mit zarten Maßwerkbögen verzierten Heiligenscheine der Figuren in dieses Gitternetz, z. B. Bl. 3r), oder von goldenen Blättchenranken, die sich zu Voluten eindrehen und dabei Blüten umschließen können (z. B. Bl. 142r); Bl. 112r blauer, mit Goldsternen übersäter Grund; nur Bl. 175r spitzknospiges, gepunktetes Fleuronnée (in Gold) im orangeroten Binnenfeld; Bl. 1r zusätzlich schlichter gelber Rahmen um das Binnenfeld geführt.

Akanthusranken zweiseitig bis (annähernd) umlaufend und auf Rectos von der römischen Foliierung unterbrochen, häufig in dichte Voluten gelegt, mit herausgearbeiteten Rippen (immer wieder verlängerte und als Fibrille auslaufende Mittelrippe) und mit sich tw. zurückbiegenden, spitz zulaufenden Einzelbl.; Bl. 142r auf dem linken Blattrand (fast im Falz verschwindend) italianisierender, sich um Vertikalachse windender Rankentyp; seltener Rankenstäbe (B1. 3r fußt Initiale auf dünnem Stab, von dem aus sich Akanthusäste auf dem Seitenrand verzweigen); Bl. 1r des ersten Gradualbands wächst ein Rankenast zw. Buchstabenkörper und Binnenrahmen hindurch und legt sich hinter den Nimbus Gottvaters; singulär das naturalistische Rosenrankenstück Bl. 210v (rechte untere Ecke); Verzierung durch (Fantasie-)Blüten (zu den Akeleien [Spielkarten-Motive] Bl. 1r s. van Buren, Edmunds, 27 [D.8]), Manschetten, Goldtropfen (in Astgabelungen, tw. einfach punziert und mit Gitterbemalung in hellem Malmittel) mit langen schwarzen Strahlen, Goldpunkte mit kürzeren und längeren, orthogonal abstehenden, schwarzen Fibrillen und seltener Goldfelder, die die Flächen in Rankenvoluten oder zw. sich überschneidenden Ästen ausfüllen; wenig (jetzt nachgedunkelter) Silberdekor, z. B. Rankenfeld neben Initiale B1. 210v oder Tropfen auf Bas-de-page Bl. 175r. V. a. auf Folios mit historisierten Initialen Ranken mit Tierdrolerien und figürlichen Medaillons geschmückt, s. auch Einleitungsseite des ersten Gradualbandes; lediglich bei Ornamentalinitiale Bl. 36v Drolerien im Akanthus (s. u. in Auflistung); durch Abreibungen und Beschädigungen des Marginaldekors im Bas-de-page-Bereich und an den unteren Seitenecken evtl. einige Drolerien nicht mehr erkennbar.

Figuren fallweise mit anatomischen Unsicherheiten, beispielsweise Bl. 13r ungelenke Knieposition des linken Märtyrers (ebenso bei König David, Bl. 1r im ersten Band, kniende Körperhaltung etwas diffus, da Unterschenkel und Füße unter Gewandausläufern nicht deutlich erkennbar sind), Bl. 76r verdrehter Körperbau 
des aus dem Boot steigenden Petrus (rechtes, über den Bootsrand gestrecktes Bein sitzt an der Stelle des linken) und Bl. 102v: nacktes Jesuskind ähnelt Gliederpuppe, Positionierung seines linken Ärmchens ist unklar, ebenso die Darstellung der Arme des Priesters (sollten sie sich unter dem Schal befinden, dann hätten sie nur Stumpflänge), zudem ungeschickter Armansatz bei der Marienfigur. Gesichter in der Farbigkeit des Inkarnats, bei Mund- bzw. Lippenformen, Augenschnitten (durchgängig lediglich die deutlich gesetzten, dunklen Pupillen) und Gestaltung des Haupthaars so variationsfreudig, dass sich die Frage stellt, ob diese Komponenten alle von einer Hand stammen oder ob hier nicht Arbeitsteilung anzunehmen ist. Charakteristisch die betonte Längung von Händen, die zum Gebet gefaltet sind (z. B. bei Märtyrern Bl. 13r). Unbeholfenheiten in der Darstellung der körperlichen Gestalt werden durch geschickte Anlage der Gewanddraperien und v. a. durch gekonnte Behandlung von Stofflichkeiten aufgewogen: So wirkt z. B. die Bischofskasel (Bl. 49v) mittels breiter grauer Schattenstreifen im Brustbereich schwer und ruhig, der zweifarbige Mantel des hl. Bartholomäus (Bl. 1r) durch den kaskadenartigen Faltenwurf sehr bewegt und das weiße Mariengewand (Bl. 112r) nicht nur durch die reiche Fältelung, sondern auch durch die zartgelben Schattierungen duftig-leicht. Einige Detailfreude bei Stoffmustern (s.z.B. priesterliches Schultertuch Bl. 102v oder den Mantel Davids im ersten Gradualband Bl. 1r), v. a. aber bei der Ausarbeitung von Edelstein- und Perlendekor (s. Mitra Bl. 49v, Marienkrone Bl. 210v und Davidskrone, erster Band Bl. 1r) und auch bei der Zeichnung der Holzmaserung (s. z. B. Thron Bl. 210v).

Keine Raumdarstellungen oder Architekturen, Figuren agieren vor teppichartigen Ornamentalgründen; Altar Bl. 102v und Betpult Bl. 112r in etwas unsicherer Parallelperspektive, Thron Bl. 210v zentralperspektivisch gegeben (unklare Gestaltung von Sitzfläche und Lehne, die dreieckig wirkt).

Klares und leuchtendes Kolorit; charakteristisch das zarte Gelb, das im Zusammenspiel mit Rosa und Weiß einen irisierenden Eindruck erzeugt (z. B. Bl. 112r auf den Spitzen der Füllblätter im rosafarbenen Buchstabenkörper oder als Schattierung des weißen Mariengewands, s. o.) und im Gesichtsinkarnat die Niedertracht der bezeichneten Figur betont (s. Schergen B1. 13r); das Seelenfigürchen (erster Band B1. 1r) wird durch wenige Gelbhöhungen auf seinem hellen Gewand zu einer Lichtgestalt; üppiger Einsatz von Blattgold; wenn Goldbelag abgerieben bzw. abgegriffen, rosafarbener Bolus gut erkennbar (s.v.a. Bas-de-page-Zonen); simple Punzierungen (Punkte, kleine Kreise).

B1. 1r Apostel Bartholomäus mit Winzermesser und geschlossenem Buch, vor dem E-Querstrich auf Wiesengrund stehend; in Bas-de-page-Ranken Neustifter Wappen: in blaugrundigem, von feinen, weißen Ranken überzogenem Vierpass roter Schild mit goldenem Tau-Kreuz; Drolerien: Libelle, zwei Fliegen, Falter, Eichhörnchen (?), hockender Bär mit Dudelsack; grauer, auf einem Bein stehender Vogel mit zurückgebogenem Kopf und aufgestellten Schwanzfedern, dessen langem Schnabel sich kleinerer grüner Vogel nähert; grauer Vogel: Kopie nach Kupferstichmotiv des Spielkartenmeisters: Vogel-Drei, Reiher unten links (s. Lehrs I 110, 61; von Lehrs I 143, explizit im Neustifter Graduale identifiziert).

Bl. 3r Apostel Petrus (mit Schlüssel und Buch) und Paulus (mit Schwert und Buch) auf grauem Grund stehend; auf dem linken Seitenrand zwei Rankenmedaillons mit je einem Kopf, der obere blond, der untere schwarzhaarig, im Bas-de-page-Akanthus weiteres Medaillon mit der Büste eines Augustiner Chorherrn im Dreiviertelprofil mit hoher, gewölbter Stirn, markanter Nase, mürrisch nach unten gezogenem Mund, ausgeprägtem Kinn mit grauem Bart (?), kapuzenartig hochstehendem Kragen und schwarzer Kappe; Laußermayer (248) sieht eine Tonsur, was den Schluss nahelegt, dass die Kopfbedeckung nach 1965 nachgetragen wurde (jedoch fraglich).

Bl. 13r Enthauptung von Märtyrern: Der Scherge, der gerade einem Märtyrer den Kopf abgeschlagen hat (dieser liegt auf dem Boden), wischt sein Schwert ab; auf grauem Grund kniet ein weiterer Märtyrer und betet; in den Ranken auf dem oberen Seitenrand: Eichhörnchen, auf dem Bas-de-page in zwei Medaillons: Kopf eines vornehmen Mannes mit roter Kappe mit Hermelinrand und Kopf einer Frau, die Krone mit drei Blattzacken trägt (Medaillon stark berieben).

B1. 36v ornamentale Initiale; in den Ranken folgende Drolerien: blaugrüner sowie gelblich-brauner Vogel, an Rankenast angeleinter dunkelgrauer Bär, dunkelgraues Eichhörnchen, zwei grüne Papageien, großer Hase auf separatem Wiesenstück.

Bl. 49v Bischof mit prächtiger Mitra, schwarzem geschlossenem Buch und Stab (mit Sudarium) steht auf Wiesengrund.

[Bl. 62r Hl. Agathe]

B1. 76r Berufung der ersten Jünger: In einem Boot, das in fischreichem Wasser schwimmt, drei nimbierte Männer, von denen einer schlafend (?) am Ruder sitzt, der zweite (Andreas) ein Netz mit Fischen an Bord zieht und der dritte (Petrus) sich Jesus (mit unbeschriftetem Spruchband) zuwendend aus dem Boot steigt. Bl. 102v Darbringung Christi im Tempel: Maria reicht das Kind über Altar hinweg dem Priester, hinter Maria Frau mit zwei Opfertauben auf der verhüllten Rechten.

Bl. 112r Verkündigung: Maria kniet mit vor der Brust verschränkten Armen an hölzernem Betpult, auf dem ein aufgeschlagenes Buch liegt, zu ihren Füßen schlafendes Hündchen, ihr gegenüber der Engel (mit Pfauenflügeln), der mit der Linken einen Lilienzweig hält und mit der Rechten Maria segnet; über ihm zwei mit 
Goldbuchstaben beschriftete und mit Zierpunkten geschmückte Spruchbänder (erstes Band: Spiritus sanctus super[ve]niet und Ave gratia plena dominus tecum; zweites Band: Ecce ancilla domini fiat); im oberen Teil des Binnenfelds Büste des segnenden Gottvaters (mit Weltkugel in der Linken) auf stilisiertem Wolkenband, von dem goldene Strahlen ausgehen, auf welchen das nimbierte Jesuskind (mit gelbem Kreuz in Händen) und die Taube des Heiligen Geistes zu Maria hinabgleiten.

Bl. 210v Thronende Muttergottes mit Kind wird von Augustiner Chorherrenpropst angebetet; Maria im blauen Sternenmantel mit reich verzierter Krone sitzt auf schlichtem Holzthron, das Kind (ebenfalls in besterntem Gewand) steht auf ihrem rechten Oberschenkel, hat den linken Arm um ihre Schultern gelegt und greift mit der Rechten nach dem Spruchband (in Goldlettern mit Zierpunkten: $O$ fili dei miserere mei), das sich über dem vor dem Thron knienden, bartlosen Kleriker wölbt; dieser im hellen Chorherren-Mantel mit grauem Kapuzenkragen (mit Schweifen besetztes Feh-Almutium) und dunkler Kappe; Akanthusranken durch verhältnismäßig viele Drolerien belebt: sitzender Bär mit Dudelsack, vier Fliegen, zwei Schnecken, blau-gelber (?) Vogel, Eichhörnchen, grüner Papagei, grüne Eidechse, angeleintes (?) Äffchen mit Rundspiegel, roter Falter und dunkelgrauer Vogel; dieser sitzt auf Rosenzweigvolute, die zartrosa Heckenrose umschließt; daneben in Akanthusvolute Büste eines im Dreiviertelprofil gegebenen braunhaarigen, bärtigen Mannes, der mit blauem Mantel und Chaperon über einem weißen Gewand bekleidet ist (Sendelbinde auf linke Schulter gelegt); unter seinem Kinn weiße Halsbinde sichtbar; mit gefalteten Händen, an denen er helle Handschuhe trägt, hält er Spruchband Der liben Maria nam, vertikal über ihm weiteres Band Servacius Lichtensteyn de Prussia (beide Beschriftungen in Goldbuchstaben).

Bildnisse: Die in Rede stehenden Darstellungen sind nicht als (Selbst-)Porträts im Sinne getreuer Abbilder mit individuellen Zügen zu verstehen, sondern als bildliche Repräsentanten der betreffenden Persönlichkeiten. - 1.) Laußermayer (247) vermutet in der Büste des Augustiner Chorherrn auf dem Bas-de-page Bl. $3 r$ ein ,verborgenes Porträt des Miniators“; Hermann (226) sieht darin ein Schreiber- oder Miniatorenbildnis. Friedrich Zollner, der Schreiber der Gradualien, ist als Augustiner Chorherr belegt (s. Giner 10); es ist also durchaus denkbar, dass das Medaillon auf $\mathrm{Bl}$. $3 \mathrm{r}$ an Zollner erinnern soll, der sich auch im stattlichen Kolophon (erster Gradualband, Bl. 325r-v) zusammen mit dem Auftraggeber, Propst Nikolaus Scheiber, nennt. Laußermayer sieht - in der Tat nachvollziehbare - physiognomische Ähnlichkeiten (niedrige Stirn, lange Nase mit Wulst über der Wurzel) zw. dem Chorherren-Bildnis B1. 3r und den Profilköpfen im Fleuronnée (vgl. z. B. im ersten Band, Bl. 31v1; detaillierte Beschreibung der Köpfe s. erster Band unter „Fleuronnée“), was allerdings nicht zu bildnisbezogener Interpretation verleiten sollte. - 2.) Bl. 210v wird der Augustiner Chorherr, der die Madonna anbetet, durch den Fehschweifbesatz seines Almutiums als Propst ausgewiesen. Wie schon Hermann (227) und Laußermayer (248) vermuteten, dürfte er den Auftraggeber, Propst Nikolaus Scheiber, verbildlichen (s. Giner 10 und vgl. Darstellungen im ersten Band, Bl. 227v und Bl. 261r, Bas-depage). - 3.) Zur Darstellung und Person des Servacius Lichtensteyn de Prussia auf Bl. 210v s. Rischpler.

S. R.

E: $\quad$ Bibliothekseinband: helles Leder über Holz. S. Maria di Rosano (Firenze), Ende 20. Jh.

Einband sowie Bindung im Zuge der Restaurierung unter Verwendung von Beschlägen und Schließen unbekannter Herkunft erneuert. Am VD keine Beschläge erhalten, am HD Eckbeschläge in Form von steigenden gekrönten Löwen mit eckigen Buckeln, in der Mitte runder ornamentaler Beschlag (romanisch?) mit Buckel. Am unteren Rand filigrane Kette, untere und obere Stehkanten (jeweils zwei ca. $5 \mathrm{~cm}$ lange Eisenkanten) integriert. Zwei Langriemen-Leder-Metallschließen, obere Schließe schmucklos (möglicherweise original), untere Schließe Renaissance-Löwenkopf mit Datierung 1548 (wohl kein Bezug zur Hs.); am HD aufgenageltes Deckblech (original), hier funktionslos. Kanten gerade. Rücken: sieben Doppelbünde. Kapitale mit naturfarbenem Garn umschlagen. Spiegel sowie Vor- und Nachsatzbl. Perg. 20. Jh., leer bis auf Etikett der Restaurierwerkstätte (s. bei G) am Spiegel des HD.

G: $\quad$ Hs. im Auftrag des Propstes Nikolaus Scheiber (Propst 1439-1449) in Kloster Neustift angefertigt. Die zahlreichen Streichungen, Ergänzungen und Hinweise belegen eine Verwendung der Hs. bis ins 19. Jh. Hs. bei vorübergehender Aufhebung des Klosters 1807 nicht an die Universitätsbibliothek Innsbruck gelangt. Am Spiegel des HD Etikett der Restaurierwerkstätte 20. Jh. (Laboratorio di restauro del libro, S. Maria di Rosano [Firenze]), kein Restaurierbericht erhalten.

L: $\quad$ Chev. Nr. 28513. - AH 9, Nr. 65. - Hermann 225-227, Nr. 223. - M. Lehrs, Geschichte und kritischer Katalog des deutschen, niederländischen und französischen Kupferstichs im XV. Jahrhundert. 9 Text-, 9 Tafelbände. Wien 1908-1934, hier I, 110 und 143. - B. Rutz, Illuminierte Choralhandschriften zu Neustift. Kirchenmusikalische Jahrbuch 22 (1909) 88-95, hier 90-94. - Laußermayer 246-248, 257-267. - G. Schmidt, Gotik in Österreich. Ausstellung 19. Mai bis 15. Oktober 1967, Minoritenkirche Krems-Stein. Krems an der Donau ${ }^{3}$ 1967, 136 (auch in: M. Roland [Hrsg.], Gerhard Schmidt, Malerei der Gotik. Fixpunkte und Ausblicke I: Malerei der Gotik in Mitteleuropa. Graz 2005, 46). - A. H. v. Buren, S. Edmunds, Playing Cards 
and Manuscripts: Some Widely Disseminated Fifteenth-Century Model Sheets. The Art Bulletin 56 (1974) 12-30, hier 27. - H. Lehmann-Haupt, Gutenberg and the Master of the Playing Cards. New Haven, London 1966, 35-36, 43. - W. A. Schulze, Alte Dreikönigsbilder in Südtirol. Der Schlern 53 (1979) 5-17, hier 11. - Peintner, Buchmalerei 14, 44, 46-48, 58-62. - M. Peintner, Kloster Neustift. Augustiner Chorherren in Südtirol. Bozen 1985, 19. - N. Rasmo, Kunstschätze Südtirols, Rosenheim 1985, 134-135. - M. H. Peintner, Psallite Deo! Zur Musikgeschichte des Stiftes Neustift, in: 850 Jahre Augustiner Chorherrenstift Neustift 134-153, hier 138. - M. Peintner, Das Skriptorium von Neustift, in: 850 Jahre Neustift. Katalog 91-93, hier 93. - M. Peintner, Musikgeschichte des Stiftes, in: 850 Jahre Neustift. Katalog 94-100, hier 94. - Gozzi 546, Nr. 46. - Neuhauser, Musikgeschichtliche Quellen 151, 161, 164, 194. - Engels 310. - J. G. Alexander, J. H. Marrow, L. Freeman Sandler, The Splendor of the Word. Medieval and Renaissance Illuminated Manuscripts at The New York Public Library. London 2005, hier 181. - M. Studničková, Vážka jako obraz duše hledající spásu. Výzdoba Bratislavského misálu IV (AMB EL 13a) a skupina iluminovaných rukopisů brixenského, vídeňského a jihoněmckého původu z poloviny 15. století/Libelle als Sinnbild der heilsuchenden Seele. Die Ausstattung des Pressburger Missale IV und eine Gruppe illuminierter Handschriften aus Brixen, Wien und Süddeutschland aus der Mitte des 15. Jahrhunderts, in: D. Buran (Hrsg.), Galéria. Ročenka Slovenskej národnej galérie/ Jahrbuch der Slowakischen Nationalgalerie in Bratislava 2004/2005. Príspevky Medzinárodného kolokvia Gotika na Slovensku a jej stredoeurópsky kontext/Beiträge des Internationalen Kolloquiums Gotik in der Slowakei und ihr mitteleuropäischer Kontext. Bratislava 2006, 149159, insbes. 158. - Roland, Gotik 274, 288-289 (Kat. 185). - Beier I 15-21, insbes. 16. - Baroffio 325, Nr. 16755. - G. Gabrielli, Tropes in cantus planus sources from South Tyrol, in: J. Border u. a. (Hrsg.), Cantus Planus. Venice meeting 2014. Venezia (in Druck). - Rischpler.

Graduale Neocellense.

(Ir-v) leer.

1 (1r-76r) Commune Sanctorum.

(1r) In vigilia unius apostoli. - (3r) In die sancto. Mit zwei Sequenzen (AH 53, Nr. 228; AH 55, Nr. 6). - (13r) De pluribus martyribus. Mit zwei Sequenzen (AH 53, Nr. 229; AH 55, Nr. 14). (36r) De uno martyre. Mit Sequenz (AH 55, Nr. 9). - (49v) De uno confessore. Mit drei Sequenzen (AH 54, Nr. 90 auf später eingefügtem Einzelbl. Bl. 56 $6^{\text {bis; }}$ AH 54, Nr. 88; AH 9, Nr. 388). (62v) De virginibus. Nur Tit. Introitus. (2 Bl. fehlen, Textverlust)

(64r) Inc. mut. (Introitus): man]datis tuis que dilexi ... Mit Sequenz (AH 50, Nr. 271).

2 (76r-210r) Sanctorale.

(76r) In vigilia s. Andreae. - (77r) In die sancto. Mit Sequenz (AH 53, Nr. 122). - (79r) Candidus martyr et pontifex (Rubrik von späterer Hand in Rot durchgestrichen). - Barbara virgo et martyr. Mit Verweis auf Sequenz (AH 50, Nr. 271). Mit Sequenz Gratuletur gloriose unitas nunc fidelium ... (nicht in AH, Chev., Mone und Dreves angeführt). Mit Hinweis vacat. - (81r) Nicolaus episcopus et confessor (mit späterer Ergänzung: In eius transactione). Mit Sequenz (AH 55, Nr. 265). - (85r) In octava s. Andreae. - In conceptione BMV (mit Verweis von späterer Hand auf Rasur: Sed Alleluia cum sequencia propria quere in fine libri post Sanctus folio CCCII CCCIII). Damasius papa (Rubrik von späterer Hand in Rot durchgestrichen). - Lucia virgo et martyr. Ottilia virgo (Rubrik von späterer Hand in Rot durchgestrichen). - In vigilia s. Thomae. - In die sancto. Mit Verweis auf Sequenz (AH 53, Nr. 228). - (85v) Stephanus. Mit Sequenz (AH 53, Nr. 215). - (89v) Iohannes ev. Mit Sequenz (AH 53, Nr. 168). - (92v) Innocentes. Mit Sequenz (AH 53, Nr. 157). - (95r) Thomas martyr et pontifex. Mit Verweis auf Sequenz (AH 55, Nr. 9). Silvester papa. Mit Verweis auf Sequenz (AH 54, Nr. 88). - In octava s. Stephani. - In octava s. Iohannis ev. - (95v) In octava Innocentium. - Erhardus episcopus (Rubrik von späterer Hand in Rot durchgestrichen). - Felix presbyter. - Marcellus papa et martyr. - Antonius abbas. - Prisca virgo et martyr. - Fabianus et Sebastianus. - Agnes virgo et martyr. Mit Expl. mut.: ... Alleluia. Vers: Felix [ (2 Bl. fehlen, später ersetzt durch zwei eingehängte Einzelbl.)

(96r-97v) spätere Ergänzung: (96r) Ignatius. - (97r) In transfiguratione dni. 
(98r) Forts. Agnes virgo et martyr. Inc. mut. (Sequenz AH 55, Nr. 51, Str. 12): en]sis cedit mortique vita succedit ecce vidit ... - (98r) Vincentius martyr. - (98v) Timotheus ap. - In conversione s. Pauli. Mit Sequenz (AH 50, Nr. 269). - (102v) Policarpus episcopus et martyr. - In octava Agnetis. - Brigida virgo (Rubrik von späterer Hand in Rot durchgestrichen). - Anschließende Rubrik radiert, möglicherweise Ignatius. - (102v) In purificatione BMV. Mit Sequenz (AH 53, Nr. 99). - (106v) Blasius martyr et pontifex. - Agatha virgo et martyr. - (107r) Ingenuinus et Albuinus episcopi. Mit Sequenz (AH 9, Nr. 236). - (110r) Dorothea virgo et martyr. Mit Verweis auf Sequenz (AH 50, Nr. 271). - Amandus episcopus et confessor. - (110v) Scholastica virgo. Euphrasia virgo (Rubrik von späterer Hand in Rot durchgestrichen). - Euphrosina virgo (Rubrik von späterer Hand in Rot durchgestrichen). - Valentinus martyr. - Faustinus et Iovita (Rubrik von späterer Hand in Rot durchgestrichen). - Iuliana virgo et martyr. - In cathedra s. Petri. (111v) In vigilia s. Matthiae. - In die sancto. - (am unteren Blattrand von späterer Hand ergänzt:) Iosephus. - (112r) Walpurgis virgo (Rubrik von späterer Hand in Rot durchgestrichen). - Cunegundis virgo. - Gregorius papa. - Gerdrudis virgo (Rubrik von späterer Hand in Rot durchgestrichen). - Benedictus abbas. - In annuntiatione BMV. - (115r) Rupertus episcopus - (am Blattrand von späterer Hand ergänzt:) Conversio Mariae Magdalenae. - Ambrosius episcopus. Mit drei Sequenzen (AH 53, Nr. 36; AH 53, Nr. 50; AH 53, Nr. 67). - (123v) Tiburtius et Valerianus martyres. - Georgius martyr. Mit Verweis auf Sequenz (AH 53, Nr. 50). - Marcus ev. Mit Verweis auf Sequenz (radiert, nicht mehr leserlich). - (124r) Trudbertus martyr. - Vitalis martyr. - Philippus et Iacobus ap. Mit Verweis auf Sequenz (AH 53, Nr. 36). - (125r) (am Blattrand von späterer Hand ergänzt:) Sigismundus. - Inventio s. crucis. Mit Verweis auf Sequenz (AH 54, Nr. 120) und Sequenz (AH 53, Nr. 56). - (128v) Florianus martyr et socii. - Iohannes ante Portam Latinam. Mit Sequenz (AH 55, Nr. 188). - (von späterer Hand ergänzt:) Monica. Mit Verweis auf Sequenz (AH 53, Nr. 50). - (132r) Gordianus et Epimachus. - Pancratius et socii eius. Mit Verweis auf Sequenz (AH 53, Nr. 50). - (132v) In translatione s. Albuini (Rubrik von späterer Hand in Rot durchgestrichen). Mit Verweis auf zwei Sequenzen (AH 53, Nr. 50 und AH 53, Nr. 67). - Victor martyr (Rubrik von späterer Hand in Rot durchgestrichen). Mit Verweis auf Sequenz (AH 53, Nr. 50). - Urbanus papa et martyr. - (133r) Petronella virgo (Rubrik von späterer Hand in Rot durchgestrichen). - Nicomedes martyr (Rubrik von späterer Hand in Rot durchgestrichen). Marcellinus et Petrus martyres. - Erasmus martyr et pontifex. - Bonifatius et socii eius (Rubrik von späterer Hand in Rot durchgestrichen). - Primus et Felicianus martyres. - Barnabas ap. Mit Verweis auf Sequenz (AH 53, Nr. 228). - Basilides, Cyrinus, Nabor et Nazarius martyres. - Vitus, Modestus et Crescentia martyres. Mit Verweis auf Sequenz (AH 53, Nr. 229). - Quirinus (Rubrik von späterer Hand in Rot durchgestrichen). - (133v) Marcus et Marcellianus martyres. Gervasius et Prothasius martyres. - Albanus martyr (Rubrik von späterer Hand in Rot durchgestrichen). - Achatius et socii martyres. Mit Verweis auf Sequenz (AH 53, Nr. 229). - In vigilia s. Iohannis Baptistae. - (135r) In die sancto. Mit Sequenz (AH 53, Nr. 163). - (138r) Iohannes et Paulus martyres. - Septem dormientes (Rubrik von späterer Hand in Rot durchgestrichen). - Leo papa (Rubrik von späterer Hand in Rot durchgestrichen). - In vigilia s. Petri et Pauli ap. - (139r) In die sancto. Mit Sequenz (AH 53, Nr. 210). - (141v) In commemoratione s. Pauli. Mit Verweis auf Sequenz (AH 53, Nr. 228). - In octava s. Iohannis Baptistae. - Erentrudis virgo. - In visitatione BMV. Mit Sequenz (AH 54, Nr. 193). - (144r) Prosula zum Offertorium Filiae regum Mater Christi veneranda (AH 48, Nr. 399; Hofmann-Brandt Nr. 403). Mit Expl. mut.: ... De tua letemur prole virgo pre[ (Forts. Bl. 145r)

$\left(144^{\mathrm{I}} \mathrm{r}-\mathrm{v}\right)$ spätere Ergänzung von anderer Hand: Forts. bzw. Abschluss der Prosula. Anschließend Alleluia: Hoc alleluia per octavam canitur.

(145r) Forts. von Bl. 144v. Inc. mut. (Prosula zum Offertorium): prae]clarissima Amen. - In translatione s. Martini. - Processus et Martinianus martyres. - Udalricus episcopus. - In octava apostolorum s. Petri et Pauli. Mit Verweis auf Sequenz (AH 53, Nr. 228). - Willibaldus epis- 
copus. - Kilianus et socii eius. - In octava visitationis BMV. - In translatione s. Nicolai. Mit Sequenz (AH 54, Nr. 66). - (148r) Septem fratres. - (148v) In translatione s. Benedicti abbatis. Margaretha virgo et martyr. Mit Sequenz (AH 54, Nr. 64). - (151v) Hainricus confessor (Rubrik von späterer Hand in Rot durchgestrichen). - In divisione apostolorum. Mit Sequenz (AH 50, Nr. 267). - (155v) Alexius confessor. - Praxedis virgo. - Maria Magdalena. Mit Sequenz (AH 50, Nr. 268). - (159r) Apollinaris martyr et pontifex. - (159v) Christina virgo (Rubrik von späterer Hand in Rot durchgestrichen). - In vigilia s. Iacobi. - In die sancto. Mit Verweis auf Sequenz (AH 53, Nr. 228). - Christophorus martyr (Rubrik von späterer Hand in Rot durchgestrichen). Anna. Mit Sequenz (AH 55, Nr. 62). - (161v) Martha. Mit Sequenz (AH 55, Nr. 244). - (164v) De virginibus. - (165r) Panthaleon martyr. - Felix papa. - Abdon et Sennen martyres. - Tertullinus martyr. Si sollempnizatur die dedicacionis Brixinensis cantetur sequentia Spe mercedis (Rubrik von späterer Hand in Rot durchgestrichen). - Petrus ad vincula. Mit Verweis auf Sequenz (AH 53, Nr. 228). - Stephanus papa et martyr. - In inventione s. Stephani. - Oswaldus rex et martyr. - (165v) Sixtus et socii eius. - (am Blattrand von späterer Hand ergänzt:) De transfiguracione domini quere de tempore in fine libri. - Donatus martyr et pontifex. - Afra et sodales eius. Mit Sequenz (AH 53, Nr. 119). - (168r) Cyriacus et socii eius. - (168v) Romanus martyr (Rubrik von späterer Hand in Rot durchgestrichen). - In vigilia s. Laurentii. - (169r) In die sancto. Mit Sequenz (AH 53, Nr. 173). - (171v) Tiburtius martyr. Mit Verweis auf Sequenz (AH 53, Nr. 229). - Hyppolitus et socii eius. - Cassianus martyr et pontifex. Mit Verweis auf Sequenz (AH 54, Nr. 89). - Eusebius confessor. - In vigilia assumptionis BMV. - In die sancto. Introitus Gaudeamus mit Verweis auf Tropus Quia virgo, von späterer Hand Incipit gestrichen und non canitur nach Rasur ergänzt. Mit Sequenz (AH 53, Nr. 104). - (174v) In octava s. Laurentii. Agapitus martyr. - (175r) Magnus martyr (Rubrik von späterer Hand in Rot durchgestrichen). Bernardus abbas (Rubrik von späterer Hand in Rot durchgestrichen). - In octava assumptionis BMV. - Timotheus et Symphorianus martyres. - In vigilia s. Bartholomaei. - In die sancto. Mit Verweis auf Sequenz (AH 53, Nr. 228). - Genesius martyr (Rubrik von späterer Hand in Rot durchgestrichen). - Ruffus et Abundus martyres (Rubrik von späterer Hand in Rot durchgestrichen). - Hermes. Mit Verweis auf Sequenz (AH 53, Nr. 229). - Augustinus. Introitus Statuit ei mit Verweis auf Tropus Augustino, von späterer Hand Incipit gestrichen und non dicitur nach Rasur ergänzt. Mit Sequenz (AH 53, Nr. 126). - (178r) In decollatione s. Iohannis Baptistae. (179r) Iohannes Baptista. Mit Sequenz (AH 50, Nr. 270). - (182r) Felix et Adauctus martyres. Aegidius abbas. - (183r) In octava s. Augustini. Mit Verweis auf Sequenz (AH 54, Nr. 88) und Sequenz (AH 54, Nr. 32). - (von späterer Hand ergänzt:) In translatione s. Erndrudis. - (186r) Magnus abbas (Rubrik von späterer Hand in Rot durchgestrichen). - Ioachim et Anna (Rubrik von späterer Hand in Rot durchgestrichen). - Regina virgo et martyr. - Adrianus martyr. - In nativitate BMV. Introitus Gaudeamus mit Verweis auf Tropus Nata summa, von späterer Hand Incipit gestrichen und non canitur nach Rasur ergänzt. Mit Sequenz (AH 53, Nr. 95). - (187v) In translatione s. Cunegundis. Mit Verweis auf Sequenz (AH 50, Nr. 271). - Gorgonius martyr. (von späterer Hand ergänzt:) Infra octavas nativitatis beate Marie. - (188r) Prothus et Iacinthus. In exaltatione s. crucis. Mit Sequenz (AH 54, Nr. 120). - (192v) In octava BMV. - Nicomedes martyr. - Euphemia virgo. - Lucius et Geminianus (Rubrik von späterer Hand in Rot durchgestrichen). - Lampertus martyr et pontifex. - In vigilia s. Matthaei ap. et ev. - In die sancto. Mit Verweis auf Sequenz (AH 55, Nr. 6). - (193r) Mauritius et socii eius. - In translatione s. Ruperti. Mit Verweis auf Sequenz (AH 54, Nr. 89). - In translatione s. Virgilii. - Cosmas et Damianus. Wenzelaus dux et martyr (Rubrik von späterer Hand in Rot durchgestrichen). - Michael. Mit Sequenz (AH 53, Nr. 192). - (197v) Hieronymus presbyter. Mit Verweis auf Sequenz (AH 54, Nr. 90). - Remigius, Germanus et Vedastus episcopi (Rubrik von späterer Hand in Rot durchgestrichen). - Leodegarius martyr. - Franciscus confessor. - Sergius et Bacchus (Rubrik von späterer Hand in Rot durchgestrichen). - Marcus papa. - In translatione s. Wolfgangi (Rubrik von späterer Hand in Rot durchgestrichen). - In translatione s. Erhardi (Rubrik von späterer Hand in 
Rot durchgestrichen). - Dionysius et socii eius. Mit Verweis auf Sequenz (gestrichen). - Gereon et socii eius. - In translatione s. Augustini. Mit Verweis auf Sequenz (AH 54, Nr. 32). - (198r) Maximilianus episcopus. - Colomannus martyr. - Calixtus papa et martyr. - Gallus abbas. - In translatione s. Marthae. - Lucas ev. Mit Verweis auf Sequenz (AH 55, Nr. 6). - (198v) Ianuarius et socii eius. - Ursula et undecim milia virginum. Mit Verweis auf Sequenz (AH 55, Nr. 333). Severus episcopus (Rubrik von späterer Hand in Rot durchgestrichen). - Severinus episcopus. Crispinus et Crispinianus martyres. - Amandus episcopus. - In vigilia s. Simonis et Iudae. - In die sancto. Mit Verweis auf Sequenz (AH 53, Nr. 228). - (199r) Narcissus martyr et episcopus. - (am Blattrand von späterer Hand ergänzt:) Wolfgangus episcopus. - In vigilia omnium sanctorum. In die sancto. Mit Sequenz (AH 53, Nr. 112). - (200v) Eustachius et socii eius. - Leonhardus confessor. - Willibrordus episcopus. - In octava omnium sanctorum. - Quattuor coronati. Theodorus martyr. - Martinus episcopus. Mit Sequenz (AH 53, Nr. 181). - (203r) Brictius episcopus. - (203v) am Blattrand später ergänzt: Leopoldus. Mit Verweis auf Sequenz (AH 54, Nr. 90). - Othmar abbas. - In octava s. Martini. Mit Verweis auf Sequenz (AH 9, Nr. 388). Elisabeth. Mit Sequenz (AH 55, Nr. 120). Alleluia auf Rasur. - (206r) Caecilia virgo et martyr. Clemens papa et martyr. - (206v) Chrysogonus martyr. - Catharina virgo et martyr. Mit Sequenz (AH 54, Nr. 56). - (210r) Virgilius episcopus. Mit Verweis auf Sequenz (AH 54, Nr. 88).

3 (210r-253r) De COMMEMORATIONE BMV.

(210r-243v) Propriumsgesänge mit 13 Sequenzen: (212r) AH 54, Nr. 219. - (214r) AH 50, Nr. 241. - (217v) AH 54, Nr. 227. - (219v) AH 54, Nr. 248. - (222r) AH 54, Nr. 225. - (223v) AH 54, Nr. 237. - (225r) AH 54, Nr. 218. - (227r) AH 42, Nr. 74 (Str. 6 zw. Str. 1 und 2). (229v) AH 54, Nr. 238. - (232v) AH 54, Nr. 232. - (234v) AH 54, Nr. 245. - (238v) AH 54, Nr. 221. - (240v) AH 54, Nr. 279. - (242r) Offertorium Recordare mit Prosula (AH 49, Nr. 634). - (243v) In adventu dni de BMV. Mit Sequenz (AH 54, Nr. 191). - (246r) Infra nativitatem usque ad purificationem. Mit Verweis auf zwei Sequenzen (AH 54, Nr. 2 und AH 53, Nr. 15, Str. 9-12) und Sequenz mit Hinweis vacat (AH 53, Nr. 15, bei Beginn der Str. 9 am Blattrand Verweis von späterer Hand Hic de beata v.). - (248r) De BMV post festum purificationis usque ad Quadrages. - De BMV in Quadrages. diebus sabbatis post primas feriales. - (248v) Tempore paschali de BMV. Mit drei Sequenzen (AH 9, Nr. 65, mit Nennung der Hs. bzw. Chev. Nr. 28513, mit Nennung der Hs.; AH 54, Nr. 18 und AH 54, Nr. 21). - (252v) von anderer Hand: Post ascensionem. Mit Sequenz (AH 54, Nr. 226).

(253v) Offertorium von späterer Hand 17./18. Jh.

4 (254r-293r) KYRIALE.

4.1 (254r-272r) KYrIE. GLORIA.

(254r) Ohne Tit. Nur Kyrie. - Aliud, am Blattrand von späterer Hand ergänzt: De Apostolis 1. - (256r) Ohne Tit., am Blattrand von späterer Hand ergänzt: De Confessoribus 2. Nur Kyrie. (256v) Aliud Kyrie, am Blattrand von späterer Hand ergänzt: Angelicum 3. - Aliud, am Blattrand von späterer Hand ergänzt: De martiribus 4. Nur Kyrie. - (257r) Aliud. - (258v) Ohne Tit., am Blattrand von späterer Hand ergänzt: Ascendens 5. Nur Kyrie. - Aliud, am Blattrand von späterer Hand ergänzt: De virginibus 6. - (260r) Ohne Tit., am Blattrand von späterer Hand ergänzt: Descendens 7. Nur Kyrie. - (260v) Aliud, am Blattrand von späterer Hand ergänzt: Minus de B. V. Maria 8. - (262r) Ohne Tit., am Blattrand von späterer Hand ergänzt: Ad proprias laudes 9. - (263v) Ohne Tit., am Blattrand von späterer Hand ergänzt: Maius de B. Virgine 10. Mit späterer Abänderung: Bl. 264 ${ }^{\text {bis }} \mathrm{r}-\mathrm{v}$ (Pap.) später eingefügt, urspr. Version auf Bl. 265r fortgesetzt mit Tropus Spiritus et alme (Bosse Nr. 23, mit Abweichungen in der Melodie). - (266r) Pascale, am Blattrand von späterer Hand ergänzt: Paschale 11. - (267v) De martiribus, am Blattrand von späterer Hand ergänzt: 12. Nur Kyrie. - De uno martire sive confessore, am Blattrand von späterer Hand ergänzt: 13. - (269r) De simplicibus virginibus, am Blattrand von späterer Hand 
ergänzt: 14. - (270v) Dominicis diebus, am Blattrand von späterer Hand ergänzt: 15. Nur Kyrie. - Ad priorem, am Blattrand von späterer Hand ergänzt: 16.

5 (272r-274v) Alleluia-Rufe mit Sequenz.

(272r) De s. confessore [In die translationis] mit Zuweisung an Rudbertus, von späterer Hand an Virgilius). Sequenz (AH 54, Nr. 89). - (274v) De s. Cassiano. Sequenz (AH 54, Nr. 89 [Text leicht abweichend]).

$4.2\left(274^{\text {ter }} \mathrm{r}-\mathrm{v}\right)$ Zusatz zum KYRIALE.

$\left(274^{\text {ter }}\right.$ r) In inventione crucis. Offertorium. - (274 $\left.{ }^{\text {ter }} v\right)$ Kyrie. Später ergänzt: 20.

4.3 (275r-293r) Forts. des Kyriale: Sanctus. Agnus DeI.

(275r) Ohne Tit. - (275v) Ohne Tit., am Blattrand von späterer Hand ergänzt: De Apostolis 1. (276v) Ergänzung am Blattrand fast zur Gänze weggeschnitten: ]ini 2. - (277v) Ohne Tit., am Blattrand von späterer Hand ergänzt: De martyribus 3. - (278v) Ohne Tit., am Blattrand von späterer Hand ergänzt: 13. Sanctus mit Tropus Benedictus Marie natus qui venit ... - (279v) Ohne Tit., am Blattrand von späterer Hand ergänzt: Descendens 4. Sanctus mit Tropus Benedictus Marie filius qui venit ... - (280r) Ohne Tit. Sanctus mit Tropus Benedictus Marie natus qui venit. .., Agnus Dei mit Tropus Summi celi qui tollis ... - (281r) Ohne Tit., am Blattrand von späterer Hand ergänzt: Maius de Beata Virgine. Sanctus mit Tropus Benedictus Marie filius qui venit ... (in Rot durchgestrichen). - (282r) Ohne Tit. - (283r) Ohne Tit. - (283v) Ohne Tit. Sanctus mit Tropus Benedictus Marie filius qui venit ... - (284v) Ohne Tit., am Blattrand von späterer Hand ergänzt: Minus de Bea. Virgine 6. - (285r) Ohne Tit., am Blattrand von späterer Hand ergänzt: Ad proprias laudes 7. - (286r) Ohne Tit., am Blattrand von späterer Hand ergänzt: Paschale 8. - (286v) Ohne Tit., am Blattrand von späterer Hand ergänzt: Dominicale 9. - (287v) Ohne Tit. - (288r) Ohne Tit., am Blattrand von späterer Hand ergänzt: De Confessoribus 10. Agnus Dei mit Tropus O dulcis Iesu Christe, radiert und nur Forts. auf Bl. 289r lesbar: ]misse tu redemisti ... - (289r) Ohne Tit., am Blattrand von späterer Hand ergänzt: Angelicum 11. - (290r) Ohne Tit., am Blattrand von späterer Hand ergänzt: Ascendens 12. - (290v) Ohne Tit. - (291v) Ohne Tit. - (292r) Ohne Tit. - (292v) Ohne Tit., am Blattrand von späterer Hand ergänzt: Simplex 13.

5 (293v-304r) Forts. der Alleluia-Rufe mit Sequenz (BMV).

(293v) Die ersten zwei Notenlinien leer, dann Alleluia und Sequenz (AH 54, Nr. 201). - (296v) AH 54, Nr. 278. - (300r) AH 54, Nr. 250. - (302r) AH 54, Nr. 188.

6 (304r-312r) SequenZen FÜr HeILIGE und BMV.

(304r) Henricus (AH 55, Nr. 159). - (306v) Achatius et socii (AH 55, Nr. 38). - (308r) Sequencia de beata virgine post nativitatem domini (AH 54, Nr. 2). - (309v) Ursula et undecim milia virginum (AH 55, Nr. 333).

7 (312v) Ergänzung von späterer Hand 18. Jh.: Introitus. Minuisti eum paulo minus ab Angelis gloria et honore corona ...

$\left(\mathrm{I}{ }^{*} \mathrm{r}-\mathrm{v}\right)$ leer.

G. G./U. S. 

ANHANG 



\section{Verzeichnis der heute noch an der ULB Tirol befindlichen, zu Beginn des 19. Jahrhunderts aus Neustift dorthin gebrachten Handschriften}

Die 1921 nicht an Italien abgetretenen Handschriften sind in den Katalogbänden zu den Handschriften der Universitäts- und Landesbibliothek Tirol in Innsbruck mit genauen Beschreibungen berücksichtigt. Hier erfolgt lediglich ein Überblick (Stand 2021).

\section{Cod. 59}

THEOLOGISCHE SAMMELHANDSCHRIFT

Pap. I, 380 Bl. $318 \times 215$. Erfurt, um 1455 .

\section{Cod. 82}

HENRICUS DE LANGENSTEIN

Pap. I, 37, I* B1. $285 \times 207$. Wien (?), 15. Jh.

\section{Cod. 157}

ARISTOTELES, LAT.

Pap. I, 55, I* B1. $285 \times 223$. Wien, 1366 .

Cod. 159

ALBERTUS DE SAXONIA

Pap. I, 73, I* B1. $285 \times 224$. Wien, 1365 .

\section{Cod. 164}

ANSHELMUS HAVELBURGENSIS

Pap. I, 37, I* Bl. $287 \times 213$. Tirol (?), Ende 14./Anfang 15. Jh.

\section{Cod. 169}

SCHWABENSPIEGEL

Pap. I, 130, I* B1. $285 \times 207$. Neustift (?), um 1410-1420.

Cod. 170

ALANUS AB INSULIS

Pap. I, 131, I* B1. $275 \times 203$. Neustift (?), ca. 1460 .

Cod. 172

IOHANNES DE SOMMERFELD

Pap. I, 142, I* B1. $277 \times 199$. Neustift (?), um 1425.

Cod. 175

SERMONES CONCILII BASILIENSIS

Pap. IV, 235 Bl. $283 \times 203 / 206$. Rheinland (?), um 1440 . 


\section{Cod. 176}

PROTOKOLL DES REICHSKAMMERGERICHTES SPEYER, 1522-1533, LAT./DT.

Pap. I, 329, I* B1. 285/290×205. Speyer, 1522-1533.

\section{Cod. 421}

THOMAS EBENDORFER

Pap. I, 428, I* B1. $310 \times 210$. Süddeutschland (?), 3. Viertel 15. Jh.

Cod. 553

NEUSTIFTER RITUALE (FRAGMENT)

Pap. I, 25, I* Bl. $335 \times 220$. Neustift, Anfang 17. Jh.

\section{Cod. 593}

RECHENBEHELFE UND MESSGERÄT

Pap. I, 24, I* B1. $265 \times 185$. Entstehungsort unbestimmt, 1443.

Cod. 596

(KIRCHEN-)HISTORISCHE SAMMELHANDSCHRIFT

Pap. 38 B1. $280 \times 205 / 210$. Entstehungsort unbestimmt, 15. Jh. (T. II: Ende 15. Jh.).

Cod. 598

THEOLOGISCHE SAMMELHANDSCHRIFT, U. A. IOHANNES CAPISTRANUS Pap. 22 B1. $265 \times 205$. Sachsen oder Brixen (?), 2. H. 15. Jh.

\section{Cod. 642}

FORMELSAMMLUNG FÜR RECHTSGESCHÄFTE

Pap. I, 53, I* B1. $220 \times 160$. Brixen, 1. H. 16. Jh.

Cod. 681

RHETORISCHE SAMMELHANDSCHRIFT (U. A. JOHANNES WILDENAUER)

Pap. I, 115 Bl. $205 \times 150$. Südtirol (?), 1. H. 16. Jh.

Cod. 692

AENEAS SILVIUS PICCOLOMINI (PIUS II). (PS.?-)FRANCISCUS DE ASSISI

Pap. 4 Bl. $225 \times 155$. Entstehungsort unbestimmt, Ende 15. Jh. (nach 1480).

\section{Cod. 693}

IACOBUS FISCHER

Pap. 14 B1. $210 \times 150 / 155$. Neustift, 1588 .

Cod. 717

MECHTHILD DE HACKEBORN. PS.-BONAVENTURA

Pap. 20 B1. $160 \times 105$. Entstehungsort unbestimmt, 2. H. 15. Jh.

Cod. 718

SERMO DE FLAGELLIS DEI

Pap. 12 Bl. $160 \times 105$. Neustift, 16. Jh.

Cod. 723

MELCHIAS UKEN

Pap. I, 39, I* B1. $155 \times 100$. Entstehungsort unbestimmt, nach 1773 .

Cod. 762

BREVIARIUM BRIXINENSE

Pap. IV, 201 Bl. $215 \times 140$. Brixen (?), 9. Jz. 15. Jh. 
Cod. 763

THEOLOGISCHE SAMMELHANDSCHRIFT

Pap. 313 Bl. $213 \times 140 / 145$. Neustift (?), 15. Jh.

Cod. 764

SERMONES DE TEMPORE. LEGENDEN

Pap. I, 371 Bl. $215 \times 145$. Kärnten (?), 15. Jh.

Cod. 765

EVANGELISTAR, DT.

Pap. 196 Bl. $220 \times 159$. Tirol, 1472 .

Cod. 788

GELDSCHULD ZU NATZ (URBAR), DT.

Pap. VII, 132, I* Bl. 210×155. Südtirol, 1. H. 16. Jh. (u. a. 1510).

Cod. 799

COMPUTUS. ARS PUNCTANDI. COLUTIUS SALUTATUS

Pap. 18 Bl. $205 \times 150$. Südtirol (?), um 1530 .

Cod. 800

SENSATUS

Pap. 24 Bl. $280 \times 195$. Entstehungsort unbestimmt, Mitte 15. Jh.

Cod. 842

SCHWABENSPIEGEL. AUSZUG AUS DEM LANDRECHT, DT.

Perg. I, 33, I* Bl. $205 \times 145$. Entstehungsort unbestimmt, 2. H. 14. Jh.

Cod. 922

SPIEGEL DEUTSCHER LEUTE (DEUTSCHENSPIEGEL), DT.

Perg. II, 80, I* B1. $220 \times 170$. Süddeutschland (Neustift?), 14. Jh.

Cod. 960

NEUSTIFTER-INNSBRUCKER SPIELHANDSCHRIFT, DT.

Pap. I, 60, I* Bl. 275/280× 105/110. Schmalkalden oder Neustift, 1391.

Cod. 961

HANS VINTLER

Pap. 3 Hefte (40, 21 und 28 Bl.) $305 \times 110$. Tirol, um 1415 .

Cod. 988

AUGUSTINER CHORHERRENSTIFT GRIES (BOZEN): STIFTUNGEN UND ÄBTELISTE

Pap. III, 15 Bl. $160 \times 105$. Gries (Bozen), 1651 .

Cod. 992

DECIMUS IUNIUS IUVENALIS

Pap. I, 49, I* B1. $305 \times 210$. Entstehungsort unbestimmt, 4. Viertel 15. Jh.

Cod. 1013

AUCTARIUM GRAMMATICAE

Pap. 14 Bl. $195 \times 145$. Neustift (?), 1. H. 16. Jh.

Cod. 1014

AENEAS SILVIUS PICCOLOMINI (PIUS II.)

Pap. 4 Bl. $215 \times 150$. Neustift, 15 . Jh. 


\section{Cod. 1015}

KOSMOGRAPHIE

Pap. 32 Bl. $205 \times 155$. Neustift, 1509 .

Cod. 1031

HIERONYMUS I. PIESENDORFER

Pap. I, 43 Bl. $160 \times 110$. Neustift, 1535-1536.

Cod. 1190

KANONIKERLISTE DES CHORHERRENSTIFTS NEUSTIFT

Pap. 2 Bl. $245 \times 200$. Neustift, 1815 .

\section{Urspr. Besitzer bzw. Zwischenbesitzer (nicht Letztbesitzer) Neustift}

Diese Handschriften befanden sich einst in Neustifter Besitz, sie sind jedoch nicht direkt aus Neustift an die ULB Tirol gelangt.

\section{Cod. 457}

SERMONES. CANTIONARIUM.

Perg. 107 B1. $240 \times 170$. Tirol (?), 14. Jh. bzw. Neustift (?), Ende 14./Anfang 15. Jh.

(Letztbesitzer: Schnals)

Ink. 156 F 20

BREVIARIUM SALISBURGENSE (INK.) MIT HANDSCHRIFTLICHEM ANHANG FÜR NEUSTIFT

Perg. 12 Bl. $165 \times 115$. Neustift, 1487 und 1501 .

(Letztbesitzer: Innsbruck, Wappenturm-Bibl.)

\section{Fraglich, ob aus Neustift an die ULB Tirol gelangt}

\section{Cod. 15}

MISSALE BRIXINENSE

Perg. 232 Bl. $395 \times 295$. Augsburg oder Tirol, um 1490 .

\section{Cod. 21}

ANTIPHONALE

Perg./Pap. 224 B1. $369 \times 255$. Halltal, 1492 .

\section{Cod. 47}

FRONLEICHNAMSPREDIGT, DT.

Pap. 7 B1. $160 \times 109$. Tirol, 16. Jh.

Cod. 96

ABBILDUNGEN VON PFLANZEN UND TIEREN

Perg./Pap. I, 31, I* Bl. $437 \times 350$. Italien, 18. Jh.

\section{Cod. 111}

PIRRO ANTONIO FERRARO. GIOVANNI BATTISTA FERRARO

Pap. 2 Bde. ca. $335 \times 220$. Italien, 17. Jh. 


\section{Cod. 189}

BARTHOLOMAEUS A SANCTO CONCORDIO

Pap. I, 203, I* B1. $316 \times 225$. Oberitalien, 1433 .

Cod. 233

IOHANNES HEROLT („DISCIPULUS“)

Pap. I, 241 Bl. $285 \times 215$. Tirol (?), 1439 .

Cod. 321

PONTIFICALE BZW. RITUALE (BENEDICTIONALE)

Perg. II, 36 Bl. $195 \times 140$. Tirol, 1497.

Cod. 351

BREVIARIUM

Perg. V, 322 Bl. $180 \times 125$. Schlesien (Diözese Breslau), 14. Jh.

Cod. 370

BENEDICTIONALE UND RITUALE

Perg. 47 Bl. $163 \times 115$. Süddeutschland (Bamberg oder Salzburg?) und Halltal, 15. Jh. (wohl nach 1481).

Cod. 387

RAIMUNDUS DE PENNAFORTE

Perg. IV, 348, IV* B1. 135/140×95. Frankreich, 14. Jh.

Cod. 394

BREVIARIUM

Pap. 330 Bl. $145 \times 105$. Hauptteil Schlesien, Zusätze Österreich, wohl Tirol, vor 1512 (um 1465/1468).

\section{Cod. 442}

COLLECTIO CONCLUSIONUM ET RESOLUTIONUM SACRAE CONGREGATIONIS CARDINALIUM S. CONCILII TRIDENTINI

Pap. II, 254 Bl. $260 \times 190$. Rom (?), Anfang 17. Jh.

Cod. 511

BERICHTE DER JESUITENMISSION IN SÜDDEUTSCHLAND UND TIROL

Pap. II, 92 B1. $198 \times 159$. Tirol, nach 1719 .

Cod. 563

MISSALE BRIXINENSE („TEYSER-MISSALE“)

Perg. VIII, 210 Bl. $295 \times 215$. Neustift oder Pustertal (Bruneck oder Kiens?), 1414 .

Cod. 607

IOHANNES DE AUERBACH

Pap. 9 Bl. $215 \times 145$. Diözese Passau, Ende 15. Jh.

Cod. 610

BREVIARIUM BRIXINENSE

Pap. I, 380, I* B1. $215 \times 150$. Neustift oder Brixen, 2. H. 15. Jh.

Cod. 616

THEOLOGISCHE SAMMELHANDSCHRIFT

Pap. 240 Bl. $215 \times 155$. Tirol, 1457-1458.

Cod. 628

BREVIARIUM PATAVIENSE, PARS AESTIVALIS

Pap. 417 B1. $225 \times 135$. Diözese Passau, 1486 . 


\section{Cod. 632}

BREVIARIUM PATAVIENSE (TEILBREVIER)

Pap. 202 B1. $213 \times 145$. Diözese Passau, Ende 15. Jh.

\section{Cod. 640}

ANTONIUS AZARO DE PARMA

Pap. 348 Bl. $215 \times 145$. Entstehungsort unbestimmt (Wien?), 1. H. 15. Jh.

Cod. 645

ARZNEIBUCH, DT.

Perg. $175 \times 124$, 65 Bl. (130 S.) $175 \times 124$. Tirol, 16. Jh.

Cod. 657

BIBLIA LATINA

Perg. II, 402, III* B1. $185 \times 125$. Raum Paris, Ende 13./Anfang 14. Jh.

Cod. 688

LECTURA INSTITUTIONUM IUSTINIANI

Pap. 75 B1. $200 \times 150$. Neustift (?), 16. Jh.

Cod. 716

BELLUM BOICO-SUEVICUM

Pap. I, 25 Bl. $175 \times 120$. Entstehungsort unbestimmt, 1. H. 18. Jh.

\section{Cod. 719}

ADAM WALASSER

Pap. 123 B1. $149 \times 90$. Entstehungsort unbestimmt, 1638 .

Cod. 727

DE LA GEOMETRIE, FRZ.

Pap. I, 147, I* B1. $104 \times 70$. Entstehungsort unbestimmt, nach 1624.

Cod. 731

STUNDENBUCH, LAT.

Pap. 142 Bl. $142 \times 105$. Entstehungsort unbestimmt, 5. Jz. 15. Jh.

Cod. 732

ANDREAS ORNITHOPARCHUS. IOHANNES COCHLAEUS

Pap. 171 Bl. $154 \times 110$. Entstehungsort unbestimmt, 1523 .

Cod. 783

SAMMELHANDSCHRIFT VON BREVIERTEXTEN (ORDO BREVIARII, OFFICIA, LEGENDEN) MIT AUTOGRAPHEN IOHANNES HINDERBACHS

Pap. III, 116 Bl. $215 \times 145$. U. a. Trient, 2. H. 15. Jh.

Cod. 794

NATURWISSENSCHAFTLICHE SAMMELHANDSCHRIFT

Pap. I, 53, I* B1. $200 \times 145$. Entstehungsort unbestimmt, Anfang 16. Jh.

Cod. 818

STATUS CAMERALIS, CIVILIS ET PROVINCIALIS DER GEFÜRSTETEN GRAFFSCHAFFT TYROL, DT.

Pap. I, 54, I* B1. $340 \times 235$. Tirol, 18. Jh.

\section{Cod. 829}

LANDRECHT FÜR DIE GERICHTE MÖLTEN, SARNTAL, RITTEN UND VILLANDERS, DT. Pap. I, 61 Bl. $330 \times 205$. Tirol, 18. Jh. 


\section{Cod. 835}

ROGER SCHRANZHOFER, DT.

Pap. II, 48, I* Bl. $265 \times 210$. Mais (Meran) bzw. Lana, 1796 bzw. 1797).

\section{Cod. 850}

ANTON ROSCHMANN

Pap. 31 Bl. $325 \times 215$. Innsbruck, 1742 .

Cod. 958

PETRUS CANTOR

Perg. I, 24, I* B1. $285 \times 195$. Entstehungsort unbestimmt, 14. Jh.

\section{Cod. 962}

SAMMELHANDSCHRIFT

Pap. 174 Bl. $210 \times 145$. Paris (?), Mitte 15. Jh. (u. a. Paris 1457, 1460, 1462, 1466). 


\section{Konkordanz der Signaturen der Stiftsbibliothek Neustift mit den Projektnummern der Hill Monastic Manuscript Library}

\begin{tabular}{|c|c|}
\hline Cod. 7 & 29.646 \\
\hline Cod. 19 & 29.647 \\
\hline Cod. 20 & 29.695 \\
\hline Cod. 31 & 29.648 \\
\hline Cod. 38 & 29.649 \\
\hline Cod. 52 & 29.650 \\
\hline Cod. 53 & 29.651 \\
\hline Cod. 54* & 29.668 \\
\hline Cod. 56* & 29.663 \\
\hline Cod. 77 & 29.652 \\
\hline Cod. 78 & 29.664 \\
\hline Cod. 83 & 29.665 \\
\hline Cod. 85 & 29.666 \\
\hline Cod. 86 & 29.667 \\
\hline Cod. 99 & 29.645 \\
\hline Cod. 100 & 29.632 \\
\hline Cod. 106 & 29.667 \\
\hline Cod. 107 & 29.668 \\
\hline Cod. 123 & 29.653 \\
\hline Cod. 125 & 29.669 \\
\hline Cod. 142 & 29.638 \\
\hline Cod. 145 & 29.662 \\
\hline Cod. 146 & 29.670 \\
\hline Cod. 153 & 29.671 \\
\hline Cod. 155 & 29.672 \\
\hline Cod. 156 & 29.673 \\
\hline Cod. 158 & 29.673 \\
\hline Cod. 160 & 29.654 \\
\hline Cod. 161 & 29.654 \\
\hline Cod. 162 & 29.654 \\
\hline
\end{tabular}

\begin{tabular}{|c|c|}
\hline Cod. 163 & 29.654 \\
\hline Cod. 165 & 29.655 \\
\hline Cod. 166 & 29.633 \\
\hline Cod. 167 & 29.688 \\
\hline Cod. 168 & 29.688 \\
\hline Cod. 171 & 29.656 \\
\hline Cod. 173 & 29.688 \\
\hline Cod. 174 & 29.675 \\
\hline Cod. 177 & 29.657 \\
\hline Cod. 181 & 29.658 \\
\hline Cod. 182 & 29.658 \\
\hline Cod. 183 & 29.658 \\
\hline Cod. 190 & 29.659 \\
\hline Cod. 194 & 29.637 \\
\hline Cod. 196 & 29.633 \\
\hline Cod. 200 & 29.660 \\
\hline Cod. 204 & 29.661 \\
\hline Cod. 217 & 29.677 \\
\hline Cod. 252 & 29.637 \\
\hline Cod. 253 & 29.677 \\
\hline Cod. 282 & 29.678 \\
\hline Cod. 293 & 29.678 \\
\hline Cod. 308 & 29.679 \\
\hline Cod. 315 & 29.678 \\
\hline Cod. 327 & 29.681 \\
\hline Cod. 353 & 29.635 \\
\hline Cod. 360 & 29.681 \\
\hline Cod. 397 & 29.681 \\
\hline Cod. 405 & 29.636 \\
\hline Cod. 440 & 29.676 \\
\hline
\end{tabular}




\begin{tabular}{l|r} 
Cod. 447 & 29.680 \\
\hline Cod. 453 & 29.685 \\
\hline Cod. 483 & 29.690 \\
\hline Cod. 485 & 29.690 \\
\hline Cod. 495 & 29.689 \\
\hline Cod. $501^{*}$ & 29.642 \\
\hline Cod. $503^{*}$ & --- \\
\hline Cod. 532 & 29.697 \\
\hline Cod. 550 & 29.682 \\
\hline Cod. 578 & --- \\
\hline Cod. 579 & --- \\
\hline Cod. 597 & 29.674 \\
\hline Cod. 605 & --- \\
\hline Cod. 606 & --- \\
\hline Cod. 614 & 29.691 \\
\hline Cod. 617 & 29.687 \\
\hline Cod. 654 & 29.634 \\
\hline Cod. 691 & -- \\
\hline Cod. 694 & --- \\
\hline
\end{tabular}

\begin{tabular}{l|r} 
Cod. 726 & --- \\
\hline Cod. 780 & --- \\
\hline Cod. 836a* & 29.692 \\
\hline Cod. 836b* & 29.642 \\
\hline Cod. 839* & 29.696 \\
\hline Cod. 924* & --- \\
\hline Cod. 927* & --- \\
\hline Cod. 930* & --- \\
\hline Cod. 931* & 29.694 \\
\hline Cod. 1012 & --- \\
\hline Sign. 14820 & \\
\hline Sign. 15063 & 29.639 \\
\hline Nr. 139 (olim Sign. 14819) & -- \\
\hline Nr. 940 & \\
\hline Neustifter Wappenbuch & -- \\
\hline Graduale Neocellense I und II & -- \\
\end{tabular}

Mit * gekennzeichnete Signaturen bezeichnen Archivhandschriften, die im vorliegenden Katalog nicht berücksichtigt wurden. 


\section{Verzeichnis der Heiligenfeste in den Missalien, Gradualien, Antiphonarien und Brevieren}

Die Anordnung der Heiligenfeste folgt jener im zweiten Band des Graduale Neocellense, der das umfassendste Sanctorale der beschriebenen Handschriften aufweist.

\begin{tabular}{|c|c|c|c|c|c|c|c|c|c|}
\hline \multirow{2}{*}{$\begin{array}{c}\text { Heiligenfest } \\
* \text { mit Vigil, } \\
* * * * \text { mit Oktav, } \\
\end{array}$} & \multicolumn{5}{|c|}{ Missalien, Gradualien } & \multicolumn{4}{|c|}{ Breviere, Antiphonarien } \\
\hline & Cod. 100 & Cod. 154 & Nr. 139 & Nr. 940 & GN II & Cod. 405 & Sign. 15063 & Nr. 139 & Nr. 940 \\
\hline Andreas & & & - & - & $\bullet *, * *$ & - & $\bullet$ & - & $\bullet$ \\
\hline Candidus pontifex & & & & & $\bullet$ & & & & \\
\hline Barbara & & & & & $\bullet$ & & $\bullet$ & & \\
\hline Nicolaus & & & $\bullet$ & $\bullet$ & $\bullet$ & $\bullet$ & $\bullet$ & $\bullet$ & $\bullet$ \\
\hline In conceptione BMV & - & & & & - & & & & \\
\hline Damasus papa & & & & & $\bullet$ & & & & \\
\hline Lucia & & & & & $\bullet$ & & $\bullet$ & $\bullet$ & $\bullet$ \\
\hline Ottilia & & & & & - & & & & \\
\hline Thomas & & & & & $\bullet *$ & & - & - & $\bullet$ \\
\hline Stephanus & & & & $\bullet$ & $\bullet * *$ & & & $\bullet$ & $\bullet$ \\
\hline Iohannes ev. & & & & - & $\bullet * *$ & & & - & - \\
\hline Innocentes & & & & & $\bullet * *$ & & & $\bullet$ & $\bullet$ \\
\hline Thomas pontifex & & & & & $\bullet$ & & & & \\
\hline Silvester papa & & & & & $\bullet$ & & & & \\
\hline Erhardus episcopus & & & & & $\bullet$ & & & & \\
\hline Felix presbyter & & & & & - & & & & \\
\hline Marcellus papa & & & & & - & & & & \\
\hline Antonius abbas & & & & & $\bullet$ & & & & \\
\hline Prisca & & & & & $\bullet$ & & & & \\
\hline Fabianus et Sebastianus & & & & & - & & - & & \\
\hline Agnes & - & - & & & $\bullet * *$ & & - & & \\
\hline Vincentius & & $\bullet$ & & & - & & & & \\
\hline Thimotheus & & & & & - & & & & \\
\hline In conversione s. Pauli & & & & & $\bullet$ & & $\bullet$ & $\bullet$ & $\bullet$ \\
\hline Policarpus & & & & & $\bullet$ & & & & \\
\hline Brigida & & & & & $\bullet$ & & & & \\
\hline
\end{tabular}




\begin{tabular}{|c|c|c|c|c|c|c|c|c|c|}
\hline Heiligenfest & & Miss & ien, Gra & lien & & & Breviere, An & iphonarie & \\
\hline${ }^{*}$ mit Vigil, $* *$ mit Oktav, & Cod. 100 & Cod. 154 & Nr. 139 & Nr. 940 & GN II & Cod. 405 & Sign. 15063 & Nr. 139 & Nr. 940 \\
\hline Ignatius & & & & & - & & & & \\
\hline In purificatione BMV & & & & & • & - & $\bullet$ & - & $\bullet$ \\
\hline Blasius pontifex & & & & & $\bullet$ & & & & \\
\hline Agatha & & & & & - & & - & & \\
\hline $\begin{array}{l}\text { Ingenuinus et Albuinus } \\
\text { episcopi }\end{array}$ & & & & & $\bullet$ & $\bullet$ & $\bullet$ & & \\
\hline Dorothea & & & & & $\bullet$ & & $\bullet$ & & \\
\hline Amandus episcopus & & & & & $\bullet$ & & & & \\
\hline Scholastica & & & & & $\bullet$ & & & & \\
\hline Euphrasia & & & & & $\bullet$ & & & & \\
\hline Euphrosina & & & & & $\bullet$ & & & & \\
\hline Valentinus & & & & & $\bullet$ & & & & \\
\hline Faustinus et Iovita & & & & & $\bullet$ & & & & \\
\hline Iuliana & & & & & - & & & & \\
\hline In cathedra s. Petri & & & $\bullet$ & & $\bullet$ & & & & \\
\hline Matthias & & $\bullet$ & & & $\bullet *$ & & & & \\
\hline Iosephus & & & & & $\bullet$ & & & & \\
\hline Walpurgis & & & & & - & & & & \\
\hline Cunegundis & & & & & $\bullet$ & & & & \\
\hline Gregorius & & & & & $\bullet$ & & $\bullet$ & & \\
\hline Gertrudis & & & & & $\bullet$ & & & & \\
\hline Benedictus abbas & & & & & $\bullet$ & & & & \\
\hline In annuntiatione BMV & $\bullet$ & $\bullet$ & & & $\bullet$ & $\bullet$ & $\bullet$ & $\bullet$ & $\bullet$ \\
\hline Rupertus episcopus & & & & & $\bullet$ & $\bullet$ & $\bullet$ & & \\
\hline $\begin{array}{l}\text { Conversio Mariae } \\
\text { Magdalenae }\end{array}$ & & & & & • & & & & \\
\hline Ambrosius & & & & & $\bullet$ & & & & \\
\hline Tiburtius et Valerianus & & & & & $\bullet$ & & & & \\
\hline Georgius & & & & & $\bullet$ & & & & \\
\hline Marcus ev. & & & & & - & & & & \\
\hline Trudbertus & & & & & $\bullet$ & & & & \\
\hline Vitalis & & & & & $\bullet$ & & & & \\
\hline Philippus et Iacobus ap. & $\bullet$ & & $\bullet$ & $\bullet$ & $\bullet$ & & $\bullet$ & & \\
\hline Sigismundus & $\bullet$ & & & & $\bullet$ & & & & \\
\hline Inventio s. crucis & $\bullet$ & & $\bullet$ & & $\bullet$ & $\bullet$ & $\bullet$ & $\bullet$ & \\
\hline De lancea dni & & & & & & & $\bullet$ & & \\
\hline Florianus et socii & & & & & $\bullet$ & & & & \\
\hline Alexander et Eventius & $\bullet$ & & & & & & & & \\
\hline $\begin{array}{l}\text { Iohannes ante Portam } \\
\text { Latinam }\end{array}$ & $\bullet$ & & & & $\bullet$ & & & • & \\
\hline
\end{tabular}




\begin{tabular}{|c|c|c|c|c|c|c|c|c|c|}
\hline Heiligenfest & & Miss & ien, Grad & lien & & & Breviere, Ant & iphonarie & \\
\hline${ }^{*}$ mit Vigil, $* *$ mit Oktav, & Cod. 100 & Cod. 154 & Nr. 139 & Nr. 940 & GN II & Cod. 405 & Sign. 15063 & Nr. 139 & Nr. 940 \\
\hline Monica & - & & & & - & - & & & \\
\hline Gordianus et Epimachus & $\bullet$ & & & & $\bullet$ & & & & \\
\hline Pancratius et socii & $\bullet$ & & & & $\bullet$ & & & & \\
\hline Maria ad martyres & - & & & & & & & & \\
\hline Translatio s. Albuini & $\bullet$ & & & & $\bullet$ & & & & \\
\hline Victor & $\bullet$ & & & & $\bullet$ & & & & \\
\hline Urbanus papa & $\bullet$ & & & & $\bullet$ & & & & \\
\hline Petronella & & & & & $\bullet$ & & & & \\
\hline Nicomedes & $\bullet$ & & & & $\bullet$ & & & & \\
\hline Marcellinus et Petrus & $\bullet$ & & & & $\bullet$ & & & & \\
\hline Erasmus martyr et pontifex & $\bullet$ & & & & $\bullet$ & & & & \\
\hline Bonifatius et socii & $\bullet$ & & & & $\bullet$ & & & & \\
\hline Primus et Felicianus & $\bullet$ & & & & $\bullet$ & & & & \\
\hline Barnabas ap. & $\bullet$ & & & & $\bullet$ & & & & \\
\hline $\begin{array}{l}\text { Basilides, Cyrinus, Nabor } \\
\text { et Nazarius }\end{array}$ & $\bullet$ & & & & $\bullet$ & & & & \\
\hline $\begin{array}{l}\text { Vitus, Modestus et } \\
\text { Crescentia }\end{array}$ & $\bullet$ & & & & $\bullet$ & & & & \\
\hline Quirinus & & & & & $\bullet$ & & & & \\
\hline Marcus et Marcellianus & $\bullet$ & & & & $\bullet$ & & & & \\
\hline Gervasius et Prothasius & $\bullet$ & & & & $\bullet$ & & & & \\
\hline Albanus & & & & & $\bullet$ & & & & \\
\hline Achatius et socii & $\bullet$ & & & & $\bullet$ & & & & \\
\hline Iohannes Baptista & & & $\bullet$ & $\bullet$ & $\bullet *, * *$ & $\bullet$ & $\bullet * *$ & $\bullet$ & $\bullet$ \\
\hline Iohannes et Paulus & & & & & $\bullet$ & & $\bullet * *$ & & \\
\hline Septem dormientes & & & & & $\bullet$ & & & & \\
\hline Leo papa & & & & & $\bullet$ & & & & \\
\hline Petrus et Paulus ap. & & & - & - & $\bullet *, * *$ & - & - & - & - \\
\hline $\begin{array}{l}\text { In commemoratione } \\
\text { s. Pauli }\end{array}$ & & & $\bullet$ & $\bullet$ & • & & & & \\
\hline Erentrudis & & & & & $\bullet$ & & & & \\
\hline In visitatione BMV & - & & & & $\bullet$ & - & - & & \\
\hline Processus et Martinianus & & & & & $\bullet$ & & & & \\
\hline Translatio s. Martini & & & & & $\bullet$ & & & & \\
\hline Udalricus & & & & & $\bullet$ & & & & \\
\hline Willibaldus episcopus & & & & & $\bullet$ & & & & \\
\hline Kilianus et socii & & & & & $\bullet$ & & & & \\
\hline Translatio s. Nicolai & & & & & $\bullet$ & & & & \\
\hline $\begin{array}{l}\text { Translatio s. Benedicti } \\
\text { abbatis }\end{array}$ & & & & & • & & & & \\
\hline Septem fratres & & & & & $\bullet$ & & & & \\
\hline
\end{tabular}




\begin{tabular}{|c|c|c|c|c|c|c|c|c|c|}
\hline \multirow{2}{*}{$\begin{array}{c}\text { Heiligenfest } \\
* \text { mit Vigil, } * * \text { mit Oktav, } \\
* * * \text { nur Suffragien }\end{array}$} & \multicolumn{5}{|c|}{ Missalien, Gradualien } & \multicolumn{4}{|c|}{ Breviere, Antiphonarien } \\
\hline & Cod. 100 & Cod. 154 & Nr. 139 & Nr. 940 & GN II & Cod. 405 & Sign. 15063 & Nr. 139 & Nr. 940 \\
\hline Margaretha & & $\bullet$ & & & $\bullet$ & & $\bullet$ & $\bullet$ & $\bullet$ \\
\hline Hainricus confessor & & & & & $\bullet$ & & & & \\
\hline In divisione apostolorum & & & & & $\bullet$ & & & & \\
\hline Alexius & & & & & $\bullet$ & & & & \\
\hline Praxedis & & & & & - & & & & \\
\hline Maria Magdalena & & & $\bullet$ & - & $\bullet$ & $\bullet$ & $\bullet$ & $\bullet$ & $\bullet$ \\
\hline Apollinaris & & & & & $\bullet$ & & & & \\
\hline Christina & & & & & $\bullet$ & & & & \\
\hline Iacobus & & & & & $\bullet *$ & & $\bullet$ & & \\
\hline Christophorus & & & & & $\bullet$ & & & & \\
\hline Anna & & & & & $\bullet$ & $\bullet$ & & & \\
\hline Martha & & & & & $\bullet$ & $\bullet$ & & & \\
\hline De virginibus & & & & & $\bullet$ & & & & \\
\hline Panthaleon & & & & & $\bullet$ & & & & \\
\hline Felix papa & & & & & $\bullet$ & & & & \\
\hline Abdon et Sennen & & & & & $\bullet$ & & & & \\
\hline Tertullinus & & & & & $\bullet$ & & & & \\
\hline Petrus ad vincula & & & & & $\bullet$ & $\bullet$ & $\bullet$ & & \\
\hline Stephanus papa & & & & & $\bullet$ & & & & \\
\hline In inventione s. Stephani & & & & & $\bullet$ & & & & \\
\hline Oswaldus rex & & & & & $\bullet$ & & & & \\
\hline In transfiguratione dni & & & & & & $\bullet$ & & & \\
\hline Sixtus et socii & & & & & $\bullet$ & & & & \\
\hline Donatus & & & & & $\bullet$ & & & & \\
\hline Afra et sodales & & & & & $\bullet$ & $\bullet *$ & & & \\
\hline Cyriacus et socii & & & & & $\bullet$ & & & & \\
\hline Romanus & & & & & $\bullet$ & & & & \\
\hline Laurentius & & & $\bullet$ & $\bullet$ & $\bullet *, * *$ & $\bullet$ & - & $\bullet$ & $\bullet$ \\
\hline Tiburtius & & & & & $\bullet$ & & & & \\
\hline Hyppolitus et socii & & & & & $\bullet$ & & & & \\
\hline $\begin{array}{l}\text { Cassianus martyr et } \\
\text { pontifex }\end{array}$ & & & & & $\bullet$ & & & & \\
\hline Eusebius & & & & & $\bullet$ & & & & \\
\hline In assumptione BMV & $\bullet$ & & & & $\bullet *$ & $\bullet$ & $\bullet$ & $\bullet$ & - \\
\hline Agapitus & & & & & $\bullet$ & & & & \\
\hline Magnus & & & & & $\bullet$ & & & & \\
\hline Bernardus abbas & & & & & $\bullet$ & & & & \\
\hline $\begin{array}{l}\text { Timotheus et } \\
\text { Symphorianus }\end{array}$ & & & & & $\bullet$ & & & & \\
\hline Bartholomaeus & & & & & $\bullet *$ & & & & \\
\hline
\end{tabular}




\begin{tabular}{|c|c|c|c|c|c|c|c|c|c|}
\hline Heiligenfest & & Miss & ien, Gra & lien & & & Breviere, Ant & iphonarie & \\
\hline$* \underset{* * * \text { nur Suffragien }}{*}$ mit Vigil, $* *$ mit Oktav, & Cod. 100 & Cod. 154 & Nr. 139 & Nr. 940 & GN II & Cod. 405 & Sign. 15063 & Nr. 139 & Nr. 940 \\
\hline Genesius & & & & & - & & & & \\
\hline Rufus et Abundus & & & & & $\bullet$ & & & & \\
\hline Hermes & $\bullet$ & & & & $\bullet$ & & & & \\
\hline Augustinus & $\bullet$ & & & & $\bullet * *$ & - & - & & \\
\hline $\begin{array}{l}\text { In decollatione s. Iohannis } \\
\text { Baptistae }\end{array}$ & & & & & $\bullet$ & & & & \\
\hline Iohannes Baptista & & & & & $\bullet$ & & $\bullet * * *$ & & \\
\hline Felix et Adauctus & & & & & $\bullet$ & & & & \\
\hline Aegidius abbas & & & & & $\bullet$ & & & & \\
\hline Translatio s. Erentrudis & & & & & - & & & & \\
\hline Magnus abbas & & & & & $\bullet$ & & & & \\
\hline Ioachim et Anna & & & & & $\bullet$ & & & & \\
\hline Regina & & & & & $\bullet$ & & & & \\
\hline Adrianus & $\bullet$ & & & & $\bullet$ & & & & \\
\hline In nativitate BMV & $\bullet$ & & & & $\bullet$ & $\bullet$ & $\bullet * *$ & $\bullet$ & $\bullet$ \\
\hline Corbinianus & • & & & & & & & & \\
\hline Translatio s. Cunegundis & & & & & $\bullet$ & & & & \\
\hline Gorgonius & & & & & $\bullet$ & & & & \\
\hline Prothus et Iacinthus & & & & & $\bullet$ & & & & \\
\hline In exaltatione s. crucis & & & & & $\bullet$ & & $\bullet$ & & \\
\hline Nicomedes martyr & & & & & $\bullet$ & & & & \\
\hline Euphemia & & & & & - & & & & \\
\hline Lucius et Geminianus & & & & & $\bullet$ & & & & \\
\hline Lampertus & & & & & $\bullet$ & & & & \\
\hline Matthaeus & & - & & & $\bullet *$ & & $\bullet$ & & \\
\hline Mauritius et socii & & & & & $\bullet$ & & $\bullet * * *$ & & \\
\hline Translatio s. Ruperti & & & & & $\bullet$ & & & & \\
\hline Translatio s. Virgilii & & & & & - & & & & \\
\hline Cosmas et Damianus & & & & & $\bullet$ & & $\bullet * * *$ & & \\
\hline Wenzeslaus & & & & & $\bullet$ & & & & \\
\hline Michael archangelus & & & - & - & - & - & - & - & - \\
\hline Hieronymus presbyter & & & & & $\bullet$ & & & & \\
\hline $\begin{array}{l}\text { Remigius, Germanus et } \\
\text { Vedastus episcopi }\end{array}$ & & & & & $\bullet$ & & & & \\
\hline Leodegarius & & & & & $\bullet$ & & & & \\
\hline Franciscus & & & & & $\bullet$ & & & & \\
\hline Sergius et Bachus & & & & & $\bullet$ & & & & \\
\hline Marcus papa & & & & & $\bullet$ & & & & \\
\hline Translatio s. Wolfgangi & & & & & $\bullet$ & & & & \\
\hline Translatio s. Erhardi & & & & & $\bullet$ & & & & \\
\hline
\end{tabular}




\begin{tabular}{|c|c|c|c|c|c|c|c|c|c|}
\hline \multirow{2}{*}{$\begin{array}{c}\text { Heiligenfest } \\
* \text { mit Vigil, } * * \text { mit Oktav, } \\
* * * \text { nur Suffragien }\end{array}$} & \multicolumn{5}{|c|}{ Missalien, Gradualien } & \multicolumn{4}{|c|}{ Breviere, Antiphonarien } \\
\hline & Cod. 100 & Cod. 154 & Nr. 139 & Nr. 940 & GN II & Cod. 405 & Sign. 15063 & Nr. 139 & Nr. 940 \\
\hline Dionysius et socii & & & & & $\bullet$ & & & & \\
\hline Gereon et socii & & & & & $\bullet$ & & & & \\
\hline Translatio s. Augustini & & & & & $\bullet$ & & $\bullet$ & & \\
\hline Maximilianus episcopus & & & & & $\bullet$ & & & & \\
\hline Colomannus & & & & & $\bullet$ & & & & \\
\hline Calixtus papa & & & & & $\bullet$ & & & & \\
\hline Gallus abbas & & & & & $\bullet$ & & $\bullet$ & & \\
\hline Translatio s. Marthae & & & & & $\bullet$ & & & & \\
\hline Lucas ev. & & & & & $\bullet$ & & & & \\
\hline Ianuarius et socii & & & & & $\bullet$ & & & & \\
\hline $\begin{array}{l}\text { Ursula et undecim milia } \\
\text { virginum }\end{array}$ & $\bullet$ & & & & $\bullet$ & & $\bullet$ & & \\
\hline Severus episcopus & & & & & - & & & & \\
\hline Severinus episcopus & $\bullet$ & & & & $\bullet$ & & & & \\
\hline Crispinus et Crispinianus & $\bullet$ & & & & $\bullet$ & & & & \\
\hline Translatio s. Amandi & $\bullet$ & & & & & & & & \\
\hline Amandus & & & & & $\bullet$ & & & & \\
\hline Simon et Iuda & & & & & $\bullet *$ & & & & \\
\hline Narcissus episcopus & & & & & $\bullet$ & & & & \\
\hline Wolfgangus episcopus & & & & & $\bullet$ & & & & \\
\hline Dedicatio ecclesiae & $\bullet$ & $\bullet$ & & $\bullet$ & & & & & \\
\hline Omnes sancti & $\bullet$ & & $\bullet$ & $\bullet$ & $\bullet *, * *$ & $\bullet$ & $\bullet$ & - & $\bullet$ \\
\hline Caesarius & $\bullet$ & & & & & & & & \\
\hline Eustachius et socii & & & & & $\bullet$ & & & & \\
\hline Leonhardus & & & & & $\bullet$ & & & & \\
\hline Willibrordus episcopus & & & & & $\bullet$ & & & & \\
\hline Quattuor coronati & & & & & $\bullet$ & & & & \\
\hline Theodorus & & & & & $\bullet$ & & & & \\
\hline Martinus episcopus & & & $\bullet$ & $\bullet$ & $\bullet$ & $\bullet$ & $\bullet$ & $\bullet$ & $\bullet$ \\
\hline Brictius episcopus & & & & & $\bullet$ & & & & \\
\hline Leopoldus & & & & & $\bullet$ & & & & \\
\hline Othmar abbas & & & & & $\bullet$ & & $\bullet * * *$ & & \\
\hline Elisabeth & & & $\bullet$ & $\bullet$ & $\bullet$ & $\bullet$ & $\bullet$ & & \\
\hline Caecilia & & & & & $\bullet$ & & $\bullet$ & & \\
\hline Clemens papa & & & & & $\bullet$ & & $\bullet$ & & \\
\hline Chrysogonus & & & & & $\bullet$ & & & & \\
\hline Catharina & & & - & - & $\bullet$ & - & - & - & - \\
\hline Virgilius episcopus & & & & & $\bullet$ & & & & \\
\hline
\end{tabular}




\section{Verzeichnis der Hymnen}

\section{Temporale}

\begin{tabular}{|c|c|c|c|c|}
\hline Incipit & Nachweis & Anlass & Cod. 405 & Sign. 15063 \\
\hline A patre unigenitus ad nos venit ... & AH 2, Nr. 107 & $\begin{array}{l}\text { Per octavam [epiphaniae dni] ad } \\
\text { nocturnum }\end{array}$ & $140 \mathrm{r}$ & \\
\hline A solis ortus cardine ... & $\begin{array}{l}\text { AH 2, Nr. 23, mit Einschub zw. } \\
\text { Str. } 3 \text { und 4: AH 27, Nr. 82, Str. } 4\end{array}$ & In secundis vesperis & $137 v$ & \\
\hline Ad coenam agni providi ... & AH 51, Nr. 83 & Ad completorium & $143 r$ & \\
\hline Aeterna Christi munera ... & AH 52, Nr. 7 & Ad completorium & $144 \mathrm{r}$ & \\
\hline Agnoscat omne saeculum ... & AH 50, Nr. 71 & In nativitate dni. Ad nocturnum & $137 \mathrm{r}$ & \\
\hline Audi benigne conditor ... & AH 51, Nr. 54 & Ad nocturnum & $141 \mathrm{r}$ & \\
\hline Beata nobis gaudia ... & AH 2, Nr. 51 & Ad nocturnum & $146 \mathrm{v}$ & \\
\hline Chorus nove Ierusalem novam ... & AH 50, Nr. 215 & Ad laudes & $143 \mathrm{v}$ & \\
\hline Christe qui lux es et dies ... & AH 51, Nr. 22 & Ad completorium & $141 \mathrm{r}$ & \\
\hline Christe redemptor omnium ... & AH 2, Nr. 22 & Ad laudes & $137 v$ & \\
\hline $\begin{array}{l}\text { Christus ascendens choros } \\
\text { angelorum ... }\end{array}$ & AH 52, Nr. 11 & In secundis vesperis & $145 r$ & \\
\hline Clarum decus ieiunii monstratur ... & AH 51, Nr. 57 & Ad laudes & $141 \mathrm{v}$ & \\
\hline Conditor alme siderum ... & AH 51, Nr. 47 & In adventu dni (Ad vesperas) & $135 v$ & \\
\hline Corde natus ex parentibus ... & AH 50, Nr. 26 & Ad completorium & $138 \mathrm{r}$ & \\
\hline Dies absoluti praetereunt dies ... & AH 52, Nr. 2 & Dnca in Septuages. & $140 \mathrm{r}$ & \\
\hline Ex more docti mistico ... & AH 51, Nr. 55 & Dnca 1. in Quadrages. & $140 \mathrm{v}$ & \\
\hline Festum nunc celebre ... & AH 50, Nr. 143 & In ascensione dni & $145 v$ & \\
\hline Gratuletur omnis caro nato ... & AH 50, Nr. 145, Str. $1-4$ und 14 & Ad laudes & $139 v$ & \\
\hline Hostis Herodes impie Christum ... & AH 50, Nr. 53, Str. 8-9, 11 und 13 & In epiphania dni & $139 v$ & \\
\hline Iam lucis orto sidere ... & AH 52, Nr. 10 & Ad primam & $145 r$ & \\
\hline Iesu quadragenarie dicatur ... & AH 51, Nr. 58 & Dnca 3. in Quadrages. Ad vesperas & $141 \mathrm{v}$ & \\
\hline $\begin{array}{l}\text { Iesum nostra redempto amor et } \\
\text { desiderium ... }\end{array}$ & AH 51, Nr. 89 & Ad completorium et laudes & $146 r$ & \\
\hline O salutaris hostia ... & AH 50, Nr. 388, Str. 5 und 6 & Ad completorium & $148 \mathrm{r}$ & \\
\hline Pange lingua gloriosae lanceae ... & AH 52, Nr. 6 & De lancea domini ad vesperas & $143 \mathrm{v}$ & $138 \mathrm{v}$ \\
\hline Pange lingua gloriosi ... & AH 50, Nr. 386 & In festo corporis Christi ad vesperas & $146 \mathrm{v}$ & \\
\hline Paschali iubilo iunctra sint ... & AH 52, Nr. 8 & Ad nocturnum & $144 \mathrm{r}$ & \\
\hline Praesepe iam fulget ... & AH 50, Nr. 8, Str. 8 & In die natalis (!) domini. Ad vesperas & $136 v$ & \\
\hline
\end{tabular}




\begin{tabular}{|c|c|c|c|c|}
\hline Incipit & Nachweis & Anlass & Cod. 405 & Sign. 15063 \\
\hline $\begin{array}{l}\text { Rex Christe factor omnium } \\
\text { redemptor ... }\end{array}$ & AH 51, Nr. 72 & Ad laudes & $142 \mathrm{v}$ & \\
\hline Sacris solennis iuncta ... & AH 50, Nr. 387 & Ad nocturnum & $147 \mathrm{r}$ & \\
\hline Summo parenti gloria natoque ... & AH 12, Nr. 184, Str. 6 & In epiphania dni & $139 v$ & \\
\hline Texilla regis prodeunt ... & AH 2, Nr. 42, o. Str. 2 & In passione dni & $142 \mathrm{r}$ & \\
\hline Veni creator spiritus mentes ... & $\begin{array}{l}\text { AH 50, Nr. } 144 \text { mit Einschub zw. } \\
\text { Str. 5. und 6: Da gaudiorum premia } \\
\text { da graciarum munera, dissolve litis } \\
\text { vincula astringe pacis federa }\end{array}$ & In festo penthecostes & $146 r$ & \\
\hline Veni redemptor gentium ... & AH 50, Nr. 8, Str. 2-7 & Ad completorium & $136 r$ & \\
\hline Verbum supernum prodiens ... & AH 51, Nr. 48 & Ad nocturnum & $136 \mathrm{v}$ & \\
\hline Verbum supernum prodiens ... & AH 52, Nr. 9 & Ad laudes & $144 \mathrm{v}$ & \\
\hline Verbum supernum prodiens ... & AH 50, Nr. 388, Str. 1-4 & Ad laudes & $147 \mathrm{v}$ & \\
\hline Vita sanctorum decus angelorum ... & AH 51, Nr. 85 & Tempore paschali & $142 \mathrm{v}$ & \\
\hline Vox clara ecce intonat ... & AH 51, Nr. 49 & Ad laudes & $136 \mathrm{v}$ & \\
\hline
\end{tabular}

\section{Sanctorale}

\begin{tabular}{|c|c|c|c|c|}
\hline Incipit & Nachweis & Anlass & Cod. 405 & Nr. 940 \\
\hline \multicolumn{5}{|c|}{ * nur Verweis } \\
\hline Alma mater generosa doctoris ... & AH 4, Nr. 397 & De sancta Monica matre Augustini & $151 \mathrm{v}$ & \\
\hline Anni reduxit circulus festum ... & AH 4, Nr. 13 & Ad nocturnum & $157 \mathrm{r}$ & \\
\hline Assunt Annae solennia huius dent ... & AH 52, Nr. 105 & Anna & $155 r$ & \\
\hline $\begin{array}{l}\text { Assunt festa iubilea in Mariae nunc } \\
\text { gaudia ... }\end{array}$ & AH 48, Nr. 402 & In visitatione $\mathrm{BMV}$ & $153 v$ & \\
\hline Aurea luce et decore ... & AH 51, Nr. 188 & Petrus et Paulus & $153 \mathrm{r}$ & \\
\hline Ave Catherina martyr et regina ... & AH 52, Nr. 248 & Catharina & $161 v$ & \\
\hline Ave maris stella Dei mater alma ... & AH 51, Nr. 123 & In annuntiatione BMV & 150r & \\
\hline Ave vitae vitis avia Christi ... & AH 4, Nr. 141 & Ad secundas vesperas & $155 \mathrm{v}$ & \\
\hline $\begin{array}{l}\text { Caelestes gemmae confessione nitide } \\
\text { cernite ... }\end{array}$ & AH 51, Nr. 107 & Ad laudes & $150 \mathrm{r}$ & \\
\hline Caeli cives applaudite ... & Chev. I Nr. 3471 & Ad nocturnum & $158 \mathrm{v}$ & \\
\hline Caelum digne tripudiat terra ... & AH 23, Nr. 139 & Ingenuinus et Albuinus & $149 \mathrm{v}$ & \\
\hline Christe caelorum habitator ... & AH 51, Nr. 104 & Ad nocturnam & $162 \mathrm{v}$ & \\
\hline Christe cunctorum dominator ... & AH 51, Nr. 103, Str. 1-6 & Ad laudes et secundas vesperas & $163 r$ & \\
\hline $\begin{array}{l}\text { Christe redemptor omnium } \\
\text { conserva ... }\end{array}$ & AH 2, Nr. 81 & Ad laudes & $160 v$ & \\
\hline $\begin{array}{l}\text { Christe sanctorum decus } \\
\text { angelorum ... }\end{array}$ & AH 50, Nr. 146 & Michael & $159 v$ & \\
\hline Concentu parali hic te Maria ... & AH 53, Nr. 99 & $\begin{array}{l}\text { In purificatione BMV. Si fuerit infra } \\
\text { Septuagesimam in secundis vesperis } \\
\text { pro ymno dicitur sequens }\end{array}$ & $149 \mathrm{r}$ & \\
\hline Conscendant usque sidera ... & AH 50, Nr. 227 & Laurentius & $157 \mathrm{v}$ & \\
\hline De patre verbum prodiens ... & AH 51, Nr. 161 & Iohannes ev. & $138 v$ & \\
\hline
\end{tabular}




\begin{tabular}{|c|c|c|c|c|}
\hline Incipit & Nachweis & Anlass & Cod. 405 & Nr. 940 \\
\hline \multicolumn{5}{|c|}{ * nur Verweis } \\
\hline De sacro tabernaculo ... & AH 50, Nr. 44 & Ad nocturnum & $154 \mathrm{r}$ & \\
\hline En miranda prodigia concepit ... & AH 48, Nr. 404 & Ad laudes & $154 v$ & \\
\hline Exorta a Bethsaida duo ... & AH 52, Nr. 99 & Andreas & $148 \mathrm{r}$ & \\
\hline Eya fratres extollamus ... & AH 52, Nr. 335 & In deposicione s. Ruperti & $150 \mathrm{v}$ & \\
\hline $\begin{array}{l}\text { Fit porta Christi pernia referta } \\
\text { plena ... }\end{array}$ & AH 27, Nr. 1081, Str. 4-6 & Ad completorium et laudes & $150 v$ & \\
\hline Gaude visceribus mater ... & AH 51, Nr. 125 & In nativitate BMV & $158 v$ & \\
\hline Haec sacras Iesu lacrimis plantas ... & AH 51, Nr. 175, Str. 3 und 4 & Ad laudes & $155 r$ & \\
\hline Hymnizet nunc plebs ... & AH 4, Nr. 380 & Martha & $156 r$ & \\
\hline Hymnum Deo vox iocunda ... & AH 52, Nr. 181, Str. $1-4$ und 10 & Ad nocturnum & $161 \mathrm{r}$ & \\
\hline Iesu Christe auctor vitae * & AH 51, Nr. 174 & Afra & $155 r$ & \\
\hline Iesu Christi auctor vitae * & AH 51, Nr. 174 & De sancta Affra & $157 \mathrm{v}$ & \\
\hline Iesu Christi auctor vitae ... & AH 51, Nr. 174 & Maria Magdalena & $154 v$ & \\
\hline Iesu salvator saeculi redemptis ... & AH 51, Nr. 130 & Ad nocturnum & $160 \mathrm{r}$ & \\
\hline Laetetur plebs fidelium ... & AH 19, Nr. 391 & Ad laudes & $152 \mathrm{r}$ & \\
\hline Magnae laetitiae fulget lux hodie ... & AH 4, Nr. 381 & In secundis vesperis & $156 r$ & \\
\hline Magne pater Augustine preces ... & AH 52, Nr. 117 & Augustinus & $158 \mathrm{r}$ & \\
\hline Martine confessor Dei valens ... & AH 27, Nr. 154 & Martinus & $160 v$ & \\
\hline Novum sidus emicuit ... & AH 52, Nr. 182 & Elisabeth & $161 \mathrm{r}$ & \\
\hline O laudat laetitia lux hodierna ... & AH 51, Nr. 183 & Nicolaus & $148 \mathrm{v}$ & \\
\hline O mater Christi fulgida ... & AH 48, Nr. 403 & Ad completorium & $154 \mathrm{r}$ & \\
\hline O nata lux de lumine ... & AH 51, Nr. 99, Str. 1-4, 6-7 & In transfiguratione dni & $157 \mathrm{r}$ & \\
\hline O sancta mundi domina ... & AH 51, Nr. 122 & In nativitate BMV & $159 r$ & \\
\hline O stella maris fulgida absolve ... & AH 52, Nr. 74 & Ad nocturnum & $155 v$ & \\
\hline Omnes superni ordines ... & AH 50, Nr. 228 & Omnes sancti & $160 \mathrm{r}$ & \\
\hline $\begin{array}{l}\text { Patris nostri Augustini mater sancta } \\
\text { Monica ... }\end{array}$ & AH 4, Nr. 398 & Ad nocturnum & $151 v$ & \\
\hline Petre pontifex inclite Christi ... & AH 51, Nr. 190 & Petrus ad vincula & $156 \mathrm{v}$ & \\
\hline Quem terra pontus aethera ... & AH 50, Nr. 72, Str. $1-2,4-8$ & In assumptione BMV & $157 \mathrm{v}$ & \\
\hline Quod chorus vatum venerandus ... & AH 2, Nr. 28 & In purificatione BMV & $148 \mathrm{v}$ & \\
\hline $\begin{array}{l}\text { Salve crux sancta salve mundi } \\
\text { gloria ... }\end{array}$ & AH 50, Nr. 223 & In inventione s. crucis & $\begin{array}{l}\text { 151r (mit } \\
\text { Divisio) }\end{array}$ & \\
\hline $\begin{array}{l}\text { Sancte Dei preciose protomartyr } \\
\text { Stephane ... }\end{array}$ & AH 48, Nr. 79 & Stephanus & $138 v$ & \\
\hline Solennis dies advenit qua virgo ... & AH 51, Nr. 160 & Ad nocturnum & $139 r$ & \\
\hline Tandem viro destituta ... & AH 52, Nr. 181, Str. 7-9 & Ad laudes & $161 \mathrm{v}$ & \\
\hline Tibi Christe splendor ... & AH 50, Nr. 156 & Ad laudes et secundas vesperas & $159 v$ & \\
\hline Urbs beata Ierusalem ... & AH 51, Nr. 102 & In dedicatione ecclesiae & $162 \mathrm{r}$ & $\begin{array}{l}227 \mathrm{v} \text { (mit } \\
\text { Divisio) }\end{array}$ \\
\hline Ut queant laxis resonare ... & AH 50, Nr. 96 & Iohannes Baptista & $152 \mathrm{v}$ & \\
\hline $\begin{array}{l}\text { Votiva cunctis orbita lucis } \\
\text { triumphat ... }\end{array}$ & AH 51, Nr. 175, Str. 1,2 und 5 & Ad nocturnum & $155 r$ & \\
\hline
\end{tabular}




\section{Commune Sanctorum}

\begin{tabular}{|c|c|c|c|c|}
\hline Incipit & Nachweis & Anlass & Cod. 405 & Nr. 940 \\
\hline Aeterna Christi munera ... & AH 50, Nr. 17, Str. 1, 3-5 und 8 & Ad matutinas & $170 v$ & \\
\hline Deus tuorum militum sors ... & AH 51, Nr. 114a & In festo unius martiris & $169^{\mathrm{I}} \mathrm{v}$ & \\
\hline Exsultet caelum laudibus ... & AH 51, Nr. 108 & In festis apostolorum & $163 v$ & \\
\hline Hic est verus Christi ... & AH 52, Nr. 70 & $\begin{array}{l}\text { De simplici confessore (= De uno } \\
\text { confessore non pontifice). Ad laudes }\end{array}$ & $188 \mathrm{r}$ & \\
\hline Iesu corona virginum ... & AH 50, Nr. 21 & De virgine et martyre & $191 \mathrm{r}$ & \\
\hline Iesu redemptor omnium ... & AH 51, Nr. 117 & Ad laudes & $179 v$ & \\
\hline Iste confessor domini sacratus ... & AH 51, Nr. 118 & De confessore et pontifice & $176^{\mathrm{I}} \mathrm{v}$ & $229 v$ \\
\hline Martyr Dei qui unicum patris ... & AH 51, Nr. 113 & Ad laudes & $172^{\mathrm{I}} \mathrm{r}$ & \\
\hline Ortu phebi iam primo ... & AH 51, Nr. 109 & De apostolis ad laudes & $167 \mathrm{r}$ & \\
\hline Rex gloriose martyrum corona ... & AH 51, Nr. 112 & Ad laudes & $173 \mathrm{r}$ & \\
\hline Sanctorum meritis inclita ... & AH 50, Nr. 153 & De pluribus martyribus & $169 v$ & \\
\hline Virginis proles opiferque ... & AH 51, Nr. 121 & Ad laudes & $194 \mathrm{r}$ & \\
\hline
\end{tabular}

\section{Cursus BMV}

\begin{tabular}{|c|c|c|c|c|c|}
\hline Incipit & Nachweis & Anlass & Cod. 353 & Cod. 405 & Cod. 654 \\
\hline $\begin{array}{l}\text { Adesto sancta trinitas par splendor } \\
\text { una Deitas ... }\end{array}$ & Chev. Nr. 487. AH 51, Nr. 96 & $\begin{array}{l}\text { De sancta trinitate (Matutin, } \\
\text { Vesper) }\end{array}$ & $\begin{array}{l}116 r \\
127 \mathrm{v}\end{array}$ & & \\
\hline $\begin{array}{l}\text { Audi benigne conditor nostras } \\
\text { preces ... }\end{array}$ & AH 51, Nr. 54 & Pro peccatis (Matutin, Laudes) & & & $\begin{array}{l}16 r \\
20 r\end{array}$ \\
\hline $\begin{array}{l}\text { Ave manna caelicum verius } \\
\text { legabi ... }\end{array}$ & Chev. Nr. 23597 & De corpore Christi (Prim) & $61 \mathrm{r}$ & & \\
\hline Ave maris stella Dei mater alma ... & AH 2, Nr. 29 & $\begin{array}{l}\text { Cursus communis de BMV } \\
\text { (Vesper) }\end{array}$ & $157 \mathrm{r}$ & & \\
\hline Ave maris* & AH 51, Nr. 123 & BMV (Vesper) & & $214 v$ & \\
\hline $\begin{array}{l}\text { Ave plenum gaudium vita beatorum } \\
\text { pauperum ... }\end{array}$ & Chev. Nr. 23749 & De corpore Christi (Terz) & $62 v$ & & \\
\hline Ave vivens hostia veritas et vita ... & AH 50, Nr. 395 & De corpore Christi (Laudes) & $60 \mathrm{r}$ & & \\
\hline $\begin{array}{l}\text { Beate nobis gaudia anni reduxit } \\
\text { orbita ... }\end{array}$ & Chev. Nr. 2340 & De sancto spiritu (Laudes) & $28 \mathrm{r}$ & & \\
\hline $\begin{array}{l}\text { Castae parentis viscera poena } \\
\text { torquentur ... }\end{array}$ & Mone II 142, Nr. 439 & $\begin{array}{l}\text { De compassione BMV } \\
\text { (Vesper) }\end{array}$ & $110 \mathrm{v}$ & & \\
\hline $\begin{array}{l}\text { Christe qui lux es et dies noctis } \\
\text { tenebras detegis ... }\end{array}$ & AH 51, Nr. 22 & Pro peccatis (Komplet) & & & $31 \mathrm{r}$ \\
\hline $\begin{array}{l}\text { Christe redemptor omnium conserva } \\
\text { tuos famulos ... }\end{array}$ & AH 51, Nr. 129 & $\begin{array}{l}\text { De omnibus sanctis (Matutin, } \\
\text { Vesper) }\end{array}$ & & & $\begin{array}{c}1 \mathrm{r} \\
12 \mathrm{v}\end{array}$ \\
\hline $\begin{array}{l}\text { Christe sanctorum decus } \\
\text { angelorum rector humani generis } \\
\text { et auctor ... }\end{array}$ & AH 50, Nr. 146 & $\begin{array}{l}\text { De proprio angelo (alle } \\
\text { Tagzeiten) }\end{array}$ & $\begin{array}{c}2 \mathrm{r} \\
4 \mathrm{v} \\
5 \mathrm{v} \\
7 \mathrm{r} \\
8 \mathrm{r} \\
9 \mathrm{r} \\
10 \mathrm{v} \\
11 \mathrm{v}\end{array}$ & & \\
\hline
\end{tabular}




\begin{tabular}{|c|c|c|c|c|c|}
\hline Incipit & Nachweis & Anlass & Cod. 353 & Cod. 405 & Cod. 654 \\
\hline $\begin{array}{l}\text { Christi felix anima sacrari tuo } \\
\text { vultui ... }\end{array}$ & AH 30, Nr. 8 & $\begin{array}{l}\text { De anima Christi } \\
\text { (alle Tagzeiten) }\end{array}$ & $\begin{array}{l}184 \mathrm{r} \\
186 \mathrm{v} \\
187 \mathrm{v} \\
188 \mathrm{v} \\
190 \mathrm{r} \\
191 \mathrm{r} \\
193 \mathrm{r} \\
195 \mathrm{r}\end{array}$ & & \\
\hline $\begin{array}{l}\text { Deus aeterne gloriae pater } \\
\text { misericordiae ... }\end{array}$ & AH 30, Nr. 81 & Pro defunctis & & & $\begin{array}{l}34 \mathrm{r} \\
39 \mathrm{r} \\
40 \mathrm{r} \\
41 \mathrm{v} \\
44 \mathrm{r} \\
46 \mathrm{r} \\
48 \mathrm{v} \\
50 \mathrm{r}\end{array}$ \\
\hline $\begin{array}{l}\text { Dicamus omnes cernui clamemus } \\
\text { atque singuli ploremus ... }\end{array}$ & AH 51, Nr. 55 & $\begin{array}{l}\text { Pro peccatis } \\
\text { (Prim, Terz, Sext, Non) }\end{array}$ & & & $\begin{array}{l}21 \mathrm{r} \\
23 \mathrm{v} \\
25 \mathrm{v} \\
27 \mathrm{v}\end{array}$ \\
\hline $\begin{array}{l}\text { Fit porta Christi pervia referta plena } \\
\text { gratia ... }\end{array}$ & Chev. Nr. 6346 & $\begin{array}{l}\text { Cursus communis de BMV } \\
\text { (Komplet) }\end{array}$ & $160 v$ & & \\
\hline $\begin{array}{l}\text { Hic Iesu veraciter duplex est } \\
\text { natura ... }\end{array}$ & Chev. Nr. 7807 & De corpore Christi (Sext) & $64 \mathrm{r}$ & & \\
\hline $\begin{array}{l}\text { Hoc ardoris calculo veni nos } \\
\text { ignire ... }\end{array}$ & Chev. Nr. 27686 & De corpore Christi (Vesper) & $67 r$ & & \\
\hline $\begin{array}{l}\text { Iesu nate de virgine ex mistico } \\
\text { spiramine ... }\end{array}$ & Chev. Nr. 9578 & De compassione BMV (Prim) & $102 v$ & & \\
\hline $\begin{array}{l}\text { Iesu nostra redemptio amor et } \\
\text { desiderium Deus creator ... }\end{array}$ & AH 51, Nr. 89 & Pro peccatis (Vesper) & & & $30 \mathrm{r}$ \\
\hline $\begin{array}{l}\text { Iesu salvator saeculi redemptis ope } \\
\text { subveni ... }\end{array}$ & AH 51, Nr. 130 & $\begin{array}{l}\text { De omnibus sanctis } \\
\text { (Laudes, Prim, Terz, Sext, Non, } \\
\text { Komplet) }\end{array}$ & & & $\begin{array}{c}5 \mathrm{v} \\
8 \mathrm{v} \\
7 \mathrm{v} \\
9 \mathrm{r} \\
10 \mathrm{r} \\
14 \mathrm{v}\end{array}$ \\
\hline Iesum dulcissime cibus salutaris ... & Chev. Nr. 28563 & De corpore Christi (Komplet) & $69 r$ & & \\
\hline $\begin{array}{l}\text { Iesus dulcis memoria dans vera } \\
\text { cordis gaudia ... }\end{array}$ & Mone I 329 Nr. 258 & $\begin{array}{l}\text { De aeterna sapientia } \\
\text { (alle Tagzeiten) }\end{array}$ & $\begin{array}{l}13 \mathrm{r} \\
16 \mathrm{v} \\
18 \mathrm{r} \\
19 \mathrm{r} \\
20 \mathrm{v} \\
21 \mathrm{v} \\
23 \mathrm{r} \\
24 \mathrm{v}\end{array}$ & & \\
\hline $\begin{array}{l}\text { Imperatrix clementiae rorem infunde } \\
\text { gratiae ... }\end{array}$ & Chev. Nr. 8483 & $\begin{array}{l}\text { De compassione BMV } \\
\text { (Matutin) }\end{array}$ & $94 \mathrm{v}$ & & \\
\hline $\begin{array}{l}\text { Novum salutis gaudium caelesti } \\
\text { sponsae mittitur ... }\end{array}$ & AH 30, Nr. 52 & $\begin{array}{l}\text { De septem gaudiis Mariae } \\
\text { virginis (alle Tagzeiten) }\end{array}$ & $\begin{array}{l}165 \mathrm{r} \\
170 \mathrm{v} \\
172 \mathrm{v} \\
174 \mathrm{v} \\
176 \mathrm{r} \\
177 \mathrm{v} \\
179 \mathrm{v} \\
181 \mathrm{v}\end{array}$ & & \\
\hline $\begin{array}{l}\text { Nunc rex creator omnium crucem } \\
\text { fers ... }\end{array}$ & Chev. Nr. 12570 & De compassione BMV (Terz) & $104 \mathrm{v}$ & & \\
\hline
\end{tabular}




\begin{tabular}{|c|c|c|c|c|c|}
\hline Incipit & Nachweis & Anlass & Cod. 353 & Cod. 405 & Cod. 654 \\
\hline $\begin{array}{l}\text { O gloriosa domina quae tua } \\
\text { cruciamina ... }\end{array}$ & AH 4, Nr. 87 & $\begin{array}{l}\text { De compassione BMV } \\
\text { (Laudes) }\end{array}$ & $100 \mathrm{r}$ & & \\
\hline $\begin{array}{l}\text { O gloriosa femina excelsa super } \\
\text { sidera ... }\end{array}$ & AH 2, Nr. 27, Str. 5-7 & BMV (Laudes) & & $210 \mathrm{r}$ & \\
\hline $\begin{array}{l}\text { O lux beata trinitas et principalis } \\
\text { unitas ... }\end{array}$ & $\begin{array}{l}\text { Chev. Nr. } 13150 . \\
\text { AH 51, Nr. } 40 \text { und 2, Nr. } 17\end{array}$ & $\begin{array}{l}\text { De sancta trinitate } \\
\text { (Prim, Terz, Sext, Non) }\end{array}$ & $\begin{array}{l}121 \mathrm{r} \\
123 \mathrm{r} \\
124 \mathrm{r} \\
125 \mathrm{r}\end{array}$ & & \\
\hline $\begin{array}{l}\text { O lux misericordiae tu primo mortis } \\
\text { tempore ... }\end{array}$ & $\begin{array}{l}\text { Chev. Nr. } 30585 . \\
\text { AH 30, Nr. } 12\end{array}$ & $\begin{array}{l}\text { De misericordia dni } \\
\text { (alle Tagzeiten) }\end{array}$ & $\begin{array}{l}40 \mathrm{r} \\
44 \mathrm{v} \\
46 \mathrm{r} \\
47 \mathrm{r} \\
48 \mathrm{v} \\
49 \mathrm{v} \\
51 \mathrm{v} \\
52 \mathrm{v}\end{array}$ & & \\
\hline $\begin{array}{l}\text { O paterne gloriae splendor per } \\
\text { respectum tuum ... }\end{array}$ & Chev. Nr. 13381. AH 31, Nr. 5 & De sancta trinitate (Laudes) & $119 v$ & & \\
\hline Patris sapientia veritas divina ... & AH 30, Nr. 13 & $\begin{array}{l}\text { De passione Christi } \\
\text { (alle Tagzeiten) }\end{array}$ & & $\begin{array}{l}211 r \\
212 r \\
213 r \\
213 v \\
214 r \\
215 r \\
215 v\end{array}$ & \\
\hline Quem terra pontus aethera colunt ... & $\begin{array}{l}\text { Chev. Nr. } 16347 . \\
\text { AH 50, Nr. } 72 \\
\end{array}$ & $\begin{array}{l}\text { Cursus communis de BMV } \\
\text { (Matutin, Laudes) }\end{array}$ & $\begin{array}{l}131 \mathrm{r} \\
141 \mathrm{v}\end{array}$ & & \\
\hline $\begin{array}{l}\text { Qui pressura mortis dura soluisti } \\
\text { nexus ... }\end{array}$ & AH 50, Nr. 382 & $\begin{array}{l}\text { De passione Christi } \\
\text { (alle Tagzeiten) }\end{array}$ & $\begin{array}{l}71 \mathrm{v} \\
76 \mathrm{r} \\
78 \mathrm{r} \\
80 \mathrm{r} \\
82 \mathrm{v} \\
84 \mathrm{v} \\
88 \mathrm{v} \\
91 \mathrm{v}\end{array}$ & & \\
\hline $\begin{array}{l}\text { Rector nunc piissimus ut reus } \\
\text { crucifigitur ... }\end{array}$ & Chev. Nr. 17058 & De compassione BMV (Sext) & $106 r$ & & \\
\hline $\begin{array}{l}\text { Regi regum soli vita decus et } \\
\text { imperium trinitati ... }\end{array}$ & $\begin{array}{l}\text { Chev. Nr. } 10968 . \\
\text { AH 52, Nr. 117, } 5\end{array}$ & De sancta trinitate (Komplet) & $129 r$ & & \\
\hline $\begin{array}{l}\text { Rerum Deus tenax vigor Christus in } \\
\text { cruce moritur sed poena fit acerbior } \\
\text { cum reus non compatitur }\end{array}$ & & De compassione BMV (Non) & $107 v$ & & \\
\hline $\begin{array}{l}\text { Rex Christe clementissime tu corda } \\
\text { nostra posside ... }\end{array}$ & AH 32, Nr. 130 & $\begin{array}{l}\text { Cursus communis de BMV } \\
\text { (Prim, Terz, Sext, Non) }\end{array}$ & $\begin{array}{l}143 \mathrm{v} \\
147 \mathrm{r} \\
149 \mathrm{v} \\
152 \mathrm{r}\end{array}$ & & \\
\hline $\begin{array}{l}\text { Rex Christe clementissime tu corda } \\
\text { nostra posside ... }\end{array}$ & AH 32, Nr. 130 & $\begin{array}{l}\text { BMV (Prim, Terz, Sext, Non, } \\
\text { Komplet) }\end{array}$ & & $\begin{array}{l}211 v \\
213 r \\
214 r\end{array}$ & \\
\hline $\begin{array}{l}\begin{array}{l}\text { Sumptum non consumitur corpus } \\
\text { salvatoris ... }\end{array} \\
\end{array}$ & Chev. Nr. 33769 & De corpore Christi (Non) & $65 r$ & & \\
\hline $\begin{array}{l}\text { Tu lucis ante terminum Christe } \\
\text { sepulcro clauderis te plorat virgo } \\
\text { virginum Deus humani generis ... }\end{array}$ & & $\begin{array}{l}\text { De compassione BMV } \\
\text { (Komplet) }\end{array}$ & $113 r$ & & \\
\hline
\end{tabular}




\begin{tabular}{|c|c|c|c|c|c|}
\hline Incipit & Nachweis & Anlass & Cod. 353 & Cod. 405 & Cod. 654 \\
\hline $\begin{array}{l}\text { Veni creator spiritus mentes tuorum } \\
\text { visita ... }\end{array}$ & AH 50, Nr. 144 & $\begin{array}{l}\text { De sancto spiritu (Prim, Terz, } \\
\text { Sext, Non, Vesper, Komplet) }\end{array}$ & $\begin{array}{l}31 \mathrm{v} \\
33 \mathrm{r} \\
34 \mathrm{v} \\
35 \mathrm{v} \\
37 \mathrm{r} \\
38 \mathrm{v}\end{array}$ & & \\
\hline $\begin{array}{l}\text { Veni sancte spiritus et emitte caelitus } \\
\text { lucis tuae radium ... }\end{array}$ & AH 54, Nr. 153 & De sancto spiritu (Matutin) & $26 r$ & & \\
\hline $\begin{array}{l}\text { Verbum supernum prodiens nec } \\
\text { patris linquens ... }\end{array}$ & AH 50, Nr. 388 & De corpore Christi (Matutin) & $55 r$ & & \\
\hline
\end{tabular}




\section{Verzeichnis der Reimoffizien}

\begin{tabular}{|c|c|c|c|c|c|}
\hline Incipit & Nachweis & Anlass & Sign. 15063 & Nr. 139 & Nr. 940 \\
\hline $\begin{array}{l}\text { Ave gemma virtuosa } \\
\text { Dorothea ... }\end{array}$ & AH 5, Nr. 56 & Dorothea & $73 v$ & & \\
\hline $\begin{array}{l}\text { Deus ante luciferum in sinu sui } \\
\text { patris ... }\end{array}$ & AH 5, Nr. 13. Cantus Nr. 200447 & De conceptione BMV & $184 \mathrm{r}$ & & \\
\hline Gaude pia plebs iustorum ... & AH 5, Nr. 7 & De lancea dni & $138 v$ & & \\
\hline $\begin{array}{l}\text { Gloria tibi trinitas aequalis una } \\
\text { Deitas ... }\end{array}$ & $\begin{array}{l}\text { in AH nicht angeführt, } \\
\text { Beginn mit Chev. Nr. } 7287 \\
\text { übereinstimmend }\end{array}$ & In festo ss. trinitatis & $110 v$ & & \\
\hline $\begin{array}{l}\text { Gratulemur regi digna } \\
\text { psallentes ... } \\
\end{array}$ & AH 25, Nr. 42 & Barbara & $60 \mathrm{r}$ & & \\
\hline $\begin{array}{l}\text { Gregorius ut creditur divinitus } \\
\text { sic dicitur ... }\end{array}$ & AH 5, Nr. 64 & Gregorius & $78 \mathrm{r}$ & & \\
\hline Inclita sanctae virginis ... & $\begin{array}{l}\text { AH 18, Nr. } 37 \text { und AH 26, } \\
\text { Nr. } 69\end{array}$ & Catharina & $175 v$ & & \\
\hline $\begin{array}{l}\text { Laetare Germania claro felix } \\
\text { germine ... }\end{array}$ & AH 25, Nr. 90 & Elisabeth & $172 v$ & & \\
\hline $\begin{array}{l}\begin{array}{l}\text { O Margareta caelorum virgo } \\
\text { secreta ... }\end{array} \\
\end{array}$ & AH 28, Nr. 3 & Margaretha & $148 v$ & $196 r$ & $195 r$ \\
\hline $\begin{array}{l}\text { O rex altissime Deus } \\
\text { mirabilis ... }\end{array}$ & $\begin{array}{l}\text { zwei rhythmisierte Antiphone: } \\
\text { 1. ähnlich wie AH 25, Nr. } 85 \\
\text { (Dominicus), 2. ähnlich wie } \\
\text { Cantus Nr. 206563 (Monica) }\end{array}$ & In translatione s. Augustini & $168 v$ & & \\
\hline $\begin{array}{l}\text { Summae trinitati simplici Deo } \\
\text { una divinitas ... }\end{array}$ & LMLO XT31 & In festo ss. trinitatis & & $188 \mathrm{r}$ & $178 \mathrm{r}$ \\
\hline $\begin{array}{l}\text { Videtur miraculum mater domini } \\
\text { concepit ... }\end{array}$ & in AH nicht angeführt & In purificatione BMV & $67 \mathrm{v}$ & & \\
\hline
\end{tabular}




\section{Verzeichnis der Sequenzen}

\section{Temporale}

\begin{tabular}{|c|c|c|c|c|c|c|c|}
\hline Incipit & Nachweis & Anlass & Cod. 100 & Cod. 154 & Nr. 139 & Nr. 940 & GN I \\
\hline \multicolumn{8}{|c|}{ * nur Verweis, ** unvollständig (Inc. oder Expl. mut. bzw. Fehlstelle) } \\
\hline Agni paschalis esu ... & AH 53, Nr. 50 & Dnca resurrectionis dni & & & $30 \mathrm{v}$ & $27 \mathrm{v}$ & \\
\hline Agni paschalis esu ... & AH 53, Nr. 50 & Fer. 3 & & & & & $169 \mathrm{r}$ \\
\hline $\begin{array}{l}\text { Benedicta semper sancta } \\
\text { sit trinitas ... }\end{array}$ & AH 53, Nr. 81 & In festo ss. trinitatis & $70 \mathrm{vb}$ & & $2 \mathrm{r}$ & & \\
\hline Carmen suo dilecto ... & AH 53, Nr. 54 & Fer. 6 & & & & & $179 \mathrm{v}$ \\
\hline Concentu parili ... & AH 53, Nr. 99 & In purificatione BMV & 10va & & & & \\
\hline $\begin{array}{l}\text { Eia recolamus } \\
\text { laudibus ... }\end{array}$ & AH 53, Nr. 16 & In aurora & & & & & $24 \mathrm{r}$ \\
\hline $\begin{array}{l}\text { Eia recolamus } \\
\text { laudibus ... }\end{array}$ & AH 53, Nr. 16 & In nativitate dni & & & $12 \mathrm{v}$ & $4 \mathrm{v}$ & \\
\hline $\begin{array}{l}\text { Eia recolamus } \\
\text { laudibus ... }\end{array}$ & AH 53, Nr. 16 & In circumcisione dni & $7 \mathrm{va}$ & & $22 \mathrm{v}$ & & $34 v$ \\
\hline Festa Christi ... & AH 53, Nr. 29 & In epiphania dni & $8 \mathrm{vb}$ & & $25 r$ & $19 r$ & $37 \mathrm{v}^{* *}$ \\
\hline Gaude Dei genitrix * & AH 53, Nr. 15, Str. 9 & In circumcisione dni & & & & $15 \mathrm{v}$ & \\
\hline Grates nunc omnes ... & AH 53, Nr. 10 & In galli cantu & 3va & & $8 \mathrm{r}$ & $3 r$ & $21 \mathrm{r}$ \\
\hline $\begin{array}{l}\text { Grates nunc omnes } \\
\text { reddamus * }\end{array}$ & AH 53, Nr. 10 & $\begin{array}{l}\text { Dnca 1. post nativitatem } \\
\text { dni }\end{array}$ & & & & & $33 r$ \\
\hline Grates salvatori ... & AH 53, Nr. 52 & Fer. 4 & & & & & $172 v$ \\
\hline $\begin{array}{l}\text { Haec est sancta } \\
\text { sollemnitas ... }\end{array}$ & AH 53, Nr. 56 & Sabbato & & & & & $183 v$ \\
\hline $\begin{array}{l}\text { Hodiernae festum } \\
\text { lucis ... }\end{array}$ & AH 54, Nr. 140 & De lancea dni & & & & & $189 v$ \\
\hline $\begin{array}{l}\text { Lauda Sion salvatorem } \\
\text { lauda ducem et } \\
\text { pastorem ... }\end{array}$ & AH 50, Nr. 385 & $\begin{array}{l}\text { In festo ss. corporis } \\
\text { Christi }\end{array}$ & 72ra & & & & \\
\hline Laudes Deo concinat ... & AH 53, Nr. 53 & Fer. 5 & & & & & $176 r$ \\
\hline $\begin{array}{l}\text { Laudes salvatori } \\
\text { voce ... }\end{array}$ & AH 53, Nr. 36 & Dnca resurrectionis dni & $62 \mathrm{rb}$ & $1 \mathrm{r}^{* *}$ & & & $158 \mathrm{v}^{* *}$ \\
\hline Mundi renovatio * & AH 54, Nr. 148 & Dnca 3. post pascha & & & & & $194 \mathrm{r}$ \\
\hline Mundi renovatio * & AH 54, Nr. 148 & Dnca 4. post pascha & & & & & $195 v$ \\
\hline $\begin{array}{l}\text { Mundi renovatio } \\
\text { nova ... }\end{array}$ & AH 54, Nr. 148 & Dnca resurrectionis dni & & & $31 v$ & $28 v$ & \\
\hline
\end{tabular}




\begin{tabular}{|c|c|c|c|c|c|c|c|}
\hline Incipit & Nachweis & Anlass & Cod. 100 & Cod. 154 & Nr. 139 & Nr. 940 & GN I \\
\hline \multicolumn{8}{|c|}{ * nur Verweis, ${ }^{* *}$ unvollständig (Inc. oder Expl. mut. bzw. Fehlstelle) } \\
\hline Natus ante saecula ... & AH 53, Nr. 15 & In aurora & & & $\begin{array}{l}9 \mathrm{v} \text { (mit } \\
\text { Divisio) }\end{array}$ & & \\
\hline Natus ante saecula ... & AH 53, Nr. 15 & $\begin{array}{l}\text { In nativitate dni } \\
\text { (Ad summam missam) }\end{array}$ & $6 r a$ & & & & $29 r$ \\
\hline Natus ante saecula ... & AH 53, Nr. 15 & In circumcisione dni & & & & $\begin{array}{l}\text { 16r (mit } \\
\text { Divisio) }\end{array}$ & \\
\hline Pangamus creatori ... & AH 53, Nr. 46 & Fer. 2 & & & & & $164 \mathrm{v}$ \\
\hline Rex regum * & AH 50, Nr. 240 & Dnca 3. post pascha & & & & & $194 \mathrm{r}$ \\
\hline Rex regum * & AH 50, Nr. 240 & Dnca 5. post pascha & & & & & $196 \mathrm{v}$ \\
\hline Sancti spiritus adsit * & AH 53, Nr. 70 & Fer. 2 & & & & & $213 r$ \\
\hline Sancti spiritus adsit * & AH 53, Nr. 70 & Fer. 3 & & & & & $214 \mathrm{r}$ \\
\hline Sancti spiritus adsit ... & AH 53, Nr. 70 & \begin{tabular}{|l|}
$\begin{array}{l}\text { Dnca pentecostes et de } \\
\text { spiritu sancto }\end{array}$ \\
\end{tabular} & $69 \mathrm{rb}$ & $1 \mathrm{v}$ & $39 r$ & $39 v$ & $207 r$ \\
\hline $\begin{array}{l}\text { Summi triumphum } \\
\text { regis ... }\end{array}$ & AH 53, Nr. 67 & In ascensione dni & $64 \mathrm{rb}$ & $1 \mathrm{v}$ & $36 r$ & $36 v$ & \\
\hline Veni sancte spiritus ... & AH 54, Nr. 153 & $\begin{array}{l}\begin{array}{l}\text { Dnca pentecostes et de } \\
\text { spiritu sancto }\end{array} \\
\end{array}$ & & & & & $210 \mathrm{r}$ \\
\hline $\begin{array}{l}\text { Victimae paschali } \\
\text { laudes * }\end{array}$ & AH 54, Nr. 7 & Dnca 2. post pascha & & & & & $192 \mathrm{v}$ \\
\hline $\begin{array}{l}\text { Victimae paschali } \\
\text { laudes * }\end{array}$ & AH 54, Nr. 7 & Dnca 3. post pascha & & & & & $194 \mathrm{r}$ \\
\hline $\begin{array}{l}\text { Victimae paschali } \\
\text { laudes ... }\end{array}$ & AH 54, Nr. 7 & Dnca resurrectionis dni & & & $32 \mathrm{v}$ & $25 v$ & \\
\hline $\begin{array}{l}\text { Victimae paschali } \\
\text { laudes ... }\end{array}$ & AH 54, Nr. 7 & $\begin{array}{l}\text { Dnca in albis = Dnca } 1 . \\
\text { post pascha }\end{array}$ & & & & & $186 \mathrm{r}$ \\
\hline
\end{tabular}

\section{Sanctorale}

\begin{tabular}{|c|c|c|c|c|c|c|}
\hline Incipit & Nachweis & Anlass & Cod. 100 & GN II & Nr. 139 & Nr. 940 \\
\hline \multicolumn{7}{|c|}{ * nur Verweis, ** Inc. mut. } \\
\hline Ad laudes salvatoris * & AH54, Nr. 88 & Silvester papa & & $95 r$ & & \\
\hline Agni * & AH 53, Nr. 50 & Georgius & & $123 v$ & & \\
\hline Agni * & AH 53, Nr. 50 & Monica & & $128 \mathrm{v}$ & & \\
\hline Agni paschali esu ... & AH 53, Nr. 50 & Ambrosius & & $120 \mathrm{r}$ & & \\
\hline Agni paschalis * & AH 53, Nr. 50 & Pancratius et socii & & $132 \mathrm{v}$ & & \\
\hline Agni paschalis * & AH 53, Nr. 50 & In translatione s. Albuini & & $132 \mathrm{v}$ & & \\
\hline Agni paschalis * & AH 53, Nr. 50 & Victor & & $132 \mathrm{v}$ & & \\
\hline Agone * & AH 53, Nr. 229 & Achatius et socii & & $133 v$ & & \\
\hline Agone triumphali * & AH 53, Nr. 229 & \begin{tabular}{|l|} 
Vitus, Modestus et \\
Crescentia
\end{tabular} & & $133 r$ & & \\
\hline Agone triumphali * & AH 53, Nr. 229 & Tiburtius & & $171 v$ & & \\
\hline $\begin{array}{l}\text { Caeli enarrant gloriam } \\
\text { Dei ... }\end{array}$ & AH 50, Nr. 267 & In divisione apostolorum & & $151 v$ & & \\
\hline Caeli regem attollamus ... & AH 55, Nr. 62 & Anna & & $160 \mathrm{r}$ & & \\
\hline
\end{tabular}




\begin{tabular}{|c|c|c|c|c|c|c|}
\hline Incipit & Nachweis & Anlass & Cod. 100 & GN II & Nr. 139 & Nr. 940 \\
\hline \multicolumn{7}{|c|}{ * nur Verweis, ** Inc. mut. } \\
\hline Clare sanctorum * & AH 53, Nr. 228 & Thomas ap. & & $85 r$ & & \\
\hline Clare sanctorum * & AH 53, Nr. 228 & Barnabas ap. & & $133 r$ & & \\
\hline Clare sanctorum * & AH 53, Nr. 228 & In commemoratione s. Pauli & & $141 \mathrm{v}$ & & $82 v$ \\
\hline Clare sanctorum * & AH 53, Nr. 228 & In octava ap. s. Petri et Pauli & & $145 \mathrm{r}$ & & \\
\hline Clare sanctorum * & AH 53, Nr. 228 & Iacobus & & $159 v$ & & \\
\hline Clare sanctorum * & AH 53, Nr. 228 & Petrus ad vincula & & $165 r$ & & \\
\hline Concentu parili ... & AH 53, Nr. 99 & In purificatione BMV & & $104 \mathrm{r}$ & & \\
\hline $\begin{array}{l}\text { Congaudentes exultemus } \\
\text { vocali ... }\end{array}$ & AH 54, Nr. 66 & In translatione s. Nicolai & & $145 \mathrm{r}$ & & \\
\hline Deus in tua virtute ... & AH 53, Nr. 122 & Andreas & & $77 \mathrm{v}$ & $100 \mathrm{v}$ & $97 r$ \\
\hline Dixit dominus ex Basan ... & AH 50, Nr. 269 & In conversione s. Pauli & & $100 \mathrm{r}$ & & \\
\hline Exultent filiae Sion * & AH 50, Nr. 271 & Barbara & & $79 r$ & & \\
\hline Exultent filiae Sion * & AH 50, Nr. 271 & Dorothea & & $110 \mathrm{r}$ & & \\
\hline Grates Deo et honor ... & AH 53, Nr. 119 & Afra et sodales & & $165 \mathrm{v}$ & & \\
\hline Gratuletur gloriose unitas ... & & Barbara & & $79 v$ & & \\
\hline $\begin{array}{l}\begin{array}{l}\text { Haec est sancta } \\
\text { sollemnitas ... }\end{array} \\
\end{array}$ & AH 53, Nr. 56 & Inventio s. crucis & & $126 \mathrm{v}$ & & \\
\hline Hanc concordi famulatu ... & AH 53, Nr. 215 & Stephanus & & $87 \mathrm{r}$ & $15 \mathrm{v}$ & $7 \mathrm{v}$ \\
\hline Innoventur hac in die ... & AH 9, Nr. 236 & $\begin{array}{l}\text { Ingenuinus et Albuinus } \\
\text { episcopi }\end{array}$ & & $107 v$ & & \\
\hline Iohannes Iesu Christo ... & AH 53, Nr. 168 & Iohannes ev. & & $90 v$ & $18 \mathrm{v}$ & $10 \mathrm{v}$ \\
\hline Laude Christo debita ... & AH 55, Nr. 265 & Nicolaus & & $81 \mathrm{r}$ & $102 \mathrm{r}$ & $98 \mathrm{v}$ \\
\hline Laudes crucis * & AH 54, Nr. 120 & Inventio s. crucis & & $126 \mathrm{v}$ & & \\
\hline Laudes salvatori * & AH 53, Nr. 36 & Philippus et Iacobus ap. & & $124 \mathrm{v}$ & & \\
\hline Laudes salvatori voce ... & AH 53, Nr. 36 & Ambrosius & & $117 r$ & & \\
\hline Laurenti David ... & AH 53, Nr. 173 & Laurentius & & $169 v$ & $89 r$ & $86 v$ \\
\hline Laus sit regi gloriae ... & AH 55, Nr. 51 & Agnes & $74 \mathrm{vb}$ & $98 r^{* *}$ & & \\
\hline Laus tibi Christe patris ... & AH 53, Nr. 157 & Innocentes & & $93 \mathrm{v}$ & $21 \mathrm{r}$ & $13 r$ \\
\hline Laus tibi Christe qui es ... & AH 50, Nr. 268 & Maria Magdalena & & $156 r$ & $86 r$ & $83 v$ \\
\hline $\begin{array}{l}\text { Mundi decor mundi } \\
\text { forma ... }\end{array}$ & AH 55, Nr. 244 & Martha & & $162 \mathrm{r}$ & & \\
\hline $\begin{array}{l}\text { Omnes sancti Seraphin } \\
\text { Cherubin throni ... }\end{array}$ & AH 53, Nr. 112 & Omnes santi & $87 r b$ & & & \\
\hline Petre summe Christi ... & AH 53, Nr. 210 & Petrus et Paulus ap. & & $140 \mathrm{r}$ & $83 v$ & $80 \mathrm{v}$ \\
\hline $\begin{array}{l}\text { Regi psalmistae } \\
\text { citharistae ... }\end{array}$ & AH 54, Nr. 64 & Margaretha & & $148 v$ & & \\
\hline Sancti Baptistae Christi ... & AH 53, Nr. 163 & Iohannes Baptista & & $136 r$ & $81 \mathrm{r}$ & $78 \mathrm{r}$ \\
\hline Spe mercedis * & AH 55, Nr. 9 & Thomas mart. & & $95 r$ & & \\
\hline Summi triumphum* & AH 53, Nr. 67 & In translatione s. Albuini & & $132 \mathrm{v}$ & & \\
\hline Summi triumphum * & AH 53, Nr. 67 & Victor & & $132 \mathrm{v}$ & & \\
\hline $\begin{array}{l}\text { Summi triumphum regis ... } \\
\text { (Ascensio) }\end{array}$ & AH 53, Nr. 67 & Ambrosius & & $121 \mathrm{v}$ & & \\
\hline
\end{tabular}




\begin{tabular}{|c|c|c|c|c|c|c|}
\hline Incipit & Nachweis & Anlass & Cod. 100 & GN II & Nr. 139 & Nr. 940 \\
\hline \multicolumn{7}{|c|}{ * nur Verweis, ${ }^{* *}$ Inc. mut. } \\
\hline Veni praecelsa domina ... & AH 54, Nr. 193 & In visitatione BMV & 78ra & $142 \mathrm{r}$ & & \\
\hline Verbum Dei Deo natum ... & AH 55, Nr. 188 & $\begin{array}{l}\text { Iohannes ante Portam } \\
\text { Latinam }\end{array}$ & & $128 \mathrm{v}$ & & \\
\hline Victime paschali * & AH 54, Nr. 7 & Philippus et Iacobus ap. & & & $107 \mathrm{r}$ & \\
\hline Victime paschali * & AH 54, Nr. 7 & Inventio s. crucis & & & $108 \mathrm{r}$ & $33 r$ \\
\hline radiert, nicht mehr leserlich & & Marcus ev. & & $123 \mathrm{v}$ & & \\
\hline
\end{tabular}

\section{Commune Sanctorum}

\begin{tabular}{|c|c|c|c|c|c|c|c|c|}
\hline Incipit & Nachweis & Anlass & Cod. 100 & Cod. 154 & Nr. 139 & Nr. 940 & GN I & GN II \\
\hline \multicolumn{9}{|c|}{ * nur Verweis, ** Inc. mut. } \\
\hline $\begin{array}{l}\text { Ad laudes } \\
\text { salvatoris ... }\end{array}$ & AH 54, Nr. 88 & \begin{tabular}{|l} 
De simplici \\
confessore/De \\
confessore et \\
pontifice/De uno \\
confessore
\end{tabular} & & & $143 v$ & $133 r$ & & $57 \mathrm{r}$ \\
\hline $\begin{array}{l}\begin{array}{l}\text { Agone } \\
\text { triumphali ... }\end{array} \\
\end{array}$ & AH 53, Nr. 229 & \begin{tabular}{|l|}
$\begin{array}{l}\text { De (pluribus) } \\
\text { martyribus }\end{array}$ \\
\end{tabular} & & & $136 \mathrm{v}$ & & & $27 v$ \\
\hline $\begin{array}{l}\begin{array}{l}\text { Clare sanctorum } \\
\text { senatus ... }\end{array} \\
\end{array}$ & AH 53, Nr. 228 & De apostolis & & & $131 \mathrm{r}$ & $120 \mathrm{r}$ & & \\
\hline $\begin{array}{l}\text { Clare sanctorum } \\
\text { senatus ... }\end{array}$ & AH 53, Nr. 228 & De uno apostolo & & & & & & $7 \mathrm{r}$ \\
\hline $\begin{array}{l}\text { Dilectus Deo et } \\
\text { hominibus ... }\end{array}$ & AH 54, Nr. 90 & De uno confessore & & & & & & $56^{\text {bis }} \mathrm{V}$ \\
\hline \begin{tabular}{|l|} 
Exultent filiae \\
Sion ... \\
\end{tabular} & AH 50, Nr. 271 & De virginibus & & $2 \mathrm{v}$ & $149 v$ & $138 v$ & & $71 \mathrm{r}$ \\
\hline $\begin{array}{l}\text { Hic oculis ac } \\
\text { manibus ... }\end{array}$ & AH 9, Nr. 388 & De uno confessore & & & & & & $59 v$ \\
\hline $\begin{array}{l}\text { Hic oculis ac } \\
\text { manibus* }\end{array}$ & $\begin{array}{l}\text { AH 53, Nr. 181, } \\
\text { Str. 15 (Divisio) }\end{array}$ & $\begin{array}{l}\text { De simplici } \\
\text { confessore aut } \\
\text { evangelista }\end{array}$ & & & & $136 r$ & & \\
\hline $\begin{array}{l}\text { O beata } \\
\text { beatorum ... }\end{array}$ & AH 55, Nr. 14 & \begin{tabular}{|l|}
$\begin{array}{l}\text { De (pluribus) } \\
\text { martyribus }\end{array}$ \\
\end{tabular} & & & $135 r$ & $124 \mathrm{v}$ & & $29 r$ \\
\hline $\begin{array}{l}\begin{array}{l}\text { Omnes sancti } \\
\text { seraphin } \\
\text { cherubin ... }\end{array} \\
\end{array}$ & AH 53, Nr. 112 & $\begin{array}{l}\text { In dedicatione unius } \\
\text { altaris }\end{array}$ & & & & & $267 r^{* *}$ & \\
\hline \begin{tabular}{|l|} 
Plausu chorus \\
laetabundo ...
\end{tabular} & AH 55, Nr. 6 & De uno apostolo & & & & & & $8 r$ \\
\hline $\begin{array}{l}\text { Psallat ecclesia } \\
\text { mater illibata ... }\end{array}$ & AH 53, Nr. 247 & \begin{tabular}{|l}
$\begin{array}{l}\text { In dedicatione } \\
\text { ecclesiae }\end{array}$ \\
\end{tabular} & $85 \mathrm{va}$ & $3 r$ & $50 \mathrm{v}$ & $50 v$ & $262 v$ & \\
\hline \begin{tabular}{|l|} 
Rex regum Deus \\
noster ... \\
\end{tabular} & AH 53, Nr. 243 & $\begin{array}{l}\text { De simplici } \\
\text { confessore }\end{array}$ & & & $145 \mathrm{v}$ & & & \\
\hline $\begin{array}{l}\text { Spe mercedis et } \\
\text { coronae ... }\end{array}$ & AH 55, Nr. 9 & De uno martyre & & & $140 \mathrm{r}$ & $129 v$ & & $46 v$ \\
\hline Victime paschali * & AH 54, Nr. 7 & $\begin{array}{l}\text { De uno beato } \\
\text { in tempore } \\
\text { paschali/De uno } \\
\text { martyre in tempore } \\
\text { paschali }\end{array}$ & & & $106 v$ & $31 \mathrm{r}$ & & \\
\hline
\end{tabular}




\section{De BMV}

\begin{tabular}{|c|c|c|c|c|c|c|c|c|}
\hline Incipit & Nachweis & Anlass & Cod. 100 & Cod. 154 & Sign. 15063 & Nr. 139 & Nr. 940 & GN II \\
\hline \multicolumn{9}{|c|}{ * nur Verweis } \\
\hline $\begin{array}{l}\text { Ave Maria gratia } \\
\text { plena dominus } \\
\text { tecum ... }\end{array}$ & AH 40, Nr. 119 & De BMV & & $3 v$ & & & & \\
\hline Concentu parili ... & AH 53, Nr. 99 & $\begin{array}{l}\text { In purificatione } \\
\text { BMV }\end{array}$ & $10 \mathrm{va}$ & & & $70 \mathrm{r}$ & $66 \mathrm{v}$ & $104 \mathrm{r}$ \\
\hline $\begin{array}{l}\text { Conceptio Mariae } \\
\text { virginis ... }\end{array}$ & AH 54, Nr. 188 & $\begin{array}{l}\text { In conceptione } \\
\text { BMV }\end{array}$ & 73va & & & & & \\
\hline $\begin{array}{l}\text { Congaudent } \\
\text { angelorum chori ... }\end{array}$ & AH 53, Nr. 104 & $\begin{array}{l}\text { In assumptione } \\
\text { BMV }\end{array}$ & $79 v b$ & & & $75 r$ & $71 \mathrm{r}$ & $172 \mathrm{r}$ \\
\hline Gaude Dei genitrix * & \begin{tabular}{|l|} 
Divisio von AH 53, \\
Nr. 15
\end{tabular} & \begin{tabular}{|l|}
$\begin{array}{l}\text { Infra nativitatem et } \\
\text { purificationem }\end{array}$ \\
\end{tabular} & & & & $67 v$ & & \\
\hline $\begin{array}{l}\text { Hodiernae lux } \\
\text { diei ... }\end{array}$ & AH 54, Nr. 219 & In visitatione BMV & & & & $79 v$ & & \\
\hline $\begin{array}{l}\text { Hodiernae lux diei } \\
\text { celebris ... }\end{array}$ & AH 54, Nr. 219 & De BMV & & $3 v$ & & & $76 r$ & \\
\hline $\begin{array}{l}\text { Laetabundus exultet } \\
\text { fidelis ... }\end{array}$ & AH 54, Nr. 2 & $\begin{array}{l}\text { Infra nativitatem et } \\
\text { purificationem. }\end{array}$ & & & & $68 r$ & $63 \mathrm{v}$ & \\
\hline $\begin{array}{l}\text { Mittit ad } \\
\text { virginem ... }\end{array}$ & AH 54, Nr. 191 & $\begin{array}{l}\text { In adventu domini } \\
\text { aut in annuntiatione } \\
\text { angelica }\end{array}$ & & & & $65 v$ & $61 \mathrm{r}$ & \\
\hline $\begin{array}{l}\text { Salve mater } \\
\text { salvatoris * }\end{array}$ & AH 54, Nr. 245 & De BMV & & & & & $77 v$ & \\
\hline $\begin{array}{l}\text { Stabat mater } \\
\text { dolorosa } \\
\text { iuxta crucem } \\
\text { lacrimosa ... }\end{array}$ & AH 54, Nr. 201 & $\begin{array}{l}\text { De compassione } \\
\text { BMV }\end{array}$ & & & $193 v$ & & & \\
\hline $\begin{array}{l}\text { Stirpe Maria } \\
\text { regia ... }\end{array}$ & AH 53, Nr. 95 & In nativitate BMV & 83ra & & & $77 \mathrm{r}$ & $73 v$ & $186 \mathrm{v}$ \\
\hline $\begin{array}{l}\text { Veni praecelsa } \\
\text { domina ... }\end{array}$ & AH 54, Nr. 193 & In visitatione BMV & 78ra & & & $78 \mathrm{r}$ & $75 r$ & $142 \mathrm{r}$ \\
\hline $\begin{array}{l}\text { Verbum bonum et } \\
\text { suave ... }\end{array}$ & AH 54, Nr. 218 & $\begin{array}{l}\text { De veneracione s. } \\
\text { Marie per annum }\end{array}$ & & & & $\begin{array}{l}57 \mathrm{r} \\
64 \mathrm{v} \\
\end{array}$ & $58 v$ & \\
\hline $\begin{array}{l}\text { Virgini Mariae } \\
\text { laudes ... }\end{array}$ & AH 54, Nr. 18 & $\begin{array}{l}\text { In annuntiatione } \\
\text { BMV circa festa } \\
\text { pascalia }\end{array}$ & & & & $73 v$ & & \\
\hline $\begin{array}{l}\text { Virgini Mariae } \\
\text { laudes ... }\end{array}$ & AH 54, Nr. 18 & $\begin{array}{l}\text { Post pasca de s. } \\
\text { Maria officium }\end{array}$ & & & & & $70 \mathrm{r}$ & \\
\hline
\end{tabular}




\section{Verzeichnis und Abbildungen der Abreibungen}

Vorbemerkung: Alle Abbildungen einzelner Stempel und Rollen in Originalgröße, Ausnahme bildet eine Stempelanordnung im Mittelfeld des Hinterdeckels vom ersten Band des Graduale Neocellense I (Tafel VII). Aufgrund der Größe musste die Abreibung auf 75\% verkleinert werden. Wiedergegeben werden alle Stempel, Rollen und Platten der verzierten Einbände. Fotos der Einbände sind im Handschriftenportal www.manuscripta.at veröffentlicht. Die Anordnung erfolgt (mit wenigen Ausnahmen) nach den Signaturen der Handschriften und nicht nach Werkstätten oder Motiven; die angeführten Nummern beziehen sich auf die Beschreibungen im Katalog.

Taf. I, Abb. 1: $\quad$ Cod. 123: Nr. 1: kreisförmiger Stempel

Taf. I, Abb. 2: $\quad$ Cod. 142: Nr. 1: Rolle Ranke mit eingeschlossenen Blüten und Granatapfel; Nr. 2: Rolle Ranke mit eingeschlossenen Blüten und Granatapfel; Nr. 3: Rolle Rundbogen auf Stab; Nr. 4: zwölfblättrige Rosette mit zwölfblättriger Mittelblüte frei; Nr. 5: florales Dekor frei

Taf. I, Abb. 3: Cod. 194: Nr. 1: Rolle verschränkte Bögen mit floralem Dekor; Nr. 2: Rolle Sichel mit eingeschriebenem Blattmotiv abwechselnd mit floralem Dekor; Nr. 3: Rolle mit Kornblumenmotiv

Taf. I, Abb. 4: $\quad$ Cod. 204: Nr. 1: Drache (Vogel?) in Raute; Nr. 2: fünfblättrige Blüte frei; Nr. 3: Schriftband „Maria“; Nr. 4: Einhorn in Raute; Nr. 5: doppelköpfiger Adler in Raute

Taf. II, Abb. 5: Cod. 353 und 654: Nr. 1: Rolle Enthauptung des Johannes, Eherne Schlange, Kreuzigung, Auferstehung; Nr. 2: Platte Erzengel (Michael?) mit Wappenschild von Propst Augustin Schabl (Propst 1569-1581) mit zwei steigenden geflügelten Löwen, darüber Inschrift Augustinus praepositus Novcecelle; Nr. 3: florales Dekor aus Vase wachsend; Nr. 4: Kreuzigung Christi; Nr. 5: florale Rolle

Taf. II, Abb. 6: Cod. 405: Nr. 1: Rolle mit in stilisierten Blättern auslaufender Volute; Nr. 2: rautenförmiger floraler Einzelstempel; Nr. 3: gebündeltes Dreiblatt in Quadratform; Nr. 4: fünfblättrige Blüte frei; Nr. 5: florales Dekor in Rhombusform; Nr. 6: achtblättrige Blüte frei

Taf. II, Abb. 7: Cod. 440: Nr. 1: kleine Siebenpunktblüte; Nr. 2: Schriftband „Maria“; Nr. 3: Doppeladler mit Krone in Tropfenform; Nr. 4: Rosette mit zweifachem Blütenkranz frei; Nr. 5: Kielbogen mit Blüte frei; Nr. 6: nach links blickender Steinbock in Rhombus

Taf. III, Abb. 8: $\quad$ Cod. 397: ganzer Einband (Vorderdeckel und Hinterdeckel) 
Taf. IV, Abb. 9: $\quad$ Cod. 726: ganzer Einband (Vorderdeckel = Hinterdeckel)

Taf. IV, Abb. 10: $\quad$ Sign. 15063: Nr. 1: Rolle Profilköpfe in Handspiegeln mit Quastenbehang; Nr. 2: Rolle Eherne Schlange, Kreuzigung, Auferstehung; Nr. 3: Rolle Menschenpaare unter Baldachin mit floralem Dekor; am Ende der Rolle jeweils Umschrift DVRKO; Nr. 4: Herzblatt; Nr. 5: Doppellilie mit rhombischem Mittelblatt; Nr. 6: Rolle florales Dekor; Nr. 7: Rolle Ranke mit eingeschlossener Fünfpunktblüte

Taf. V, Abb. 11: Nr. 139 (olim Sign. 14819): Nr. 1: vierblättrige Blüte frei; Nr. 2: Adler in Rhombus; Nr. 3: Einzelstempel (stark abgerieben, nicht mehr erkennbar) in Kreis; Nr. 4: vierblättrige Blüte; Nr. 5: Lilie in konkavem Karo; Nr. 6: sechsblättrige Blüte in Kreis; Nr. 7: Lilie frei; Nr. 8: fünfblättrige Blüte frei; Nr. 9: Dreiblatt frei

Taf. V, Abb. 12: Nr. 940: Nr. 1: vierblättrige Blüte frei; Nr. 2: gebogener Ast; Nr. 3: punktiertes Herz frei; Nr. 4: sechsblättrige Blüte in Kreis; Nr. 5: rautenförmige Lilie frei; Nr. 6: Punktdekor in Karo; Nr. 7: Astdekor in Rechteck; Nr. 8: Osterlamm mit Fahne in Kreis; Nr. 9: Vierblatt in konkavem Karo

Taf. V-VII, Graduale Neocellense I: Nr. 1: Rolle einseitwändig verschränkte Bögen mit Abb. 13: Lilienbekrönung, darüber Leiste aus fünfblättrigen Blumen; Nr. 2: Rolle Profilköpfe in Kreis im Wechsel mit Schriftband und begleitendem floralem Dekor; Nr. 3: Rolle Wappen von Neustift (Tau-Kreuz), Säben und Patriarchenkreuz einander abwechselnd, verbunden mit Rankendekor in gegenständigen Dreipassformen; Nr. 4: Rolle Profilköpfe in Handspiegeln mit Quastenbehang; Nr. 5: eng aneinander gereihte Einzelstempel Schriftband „Maria“, dazwischen Fischblasenmotiv und in den Zwickeln Trifolien; Nr. 6: Maske frei; Nr. 7: Lilie frei; Nr. 8: Stempelblüte mit Rautenranke; Nr. 9: Rolle ineinander greifende, aus drei Linien aufgebaute Bögen mit Lilienbekrönung und zwei eingeschlossenen vierblättrigen Blüten; Nr. 10: Lilie in Raute; Nr. 11: Brokatmotiv (mittig zum Vierblatt angeordnet, oben und unten jeweils ein Brokatmotiv geschlossen); Nr. 12: florales Dekor, rautenförmig; Nr. 13: florales Dekor mit geschlossener Knospe in Rautenform; Nr. 14: Brokatmotive offen 


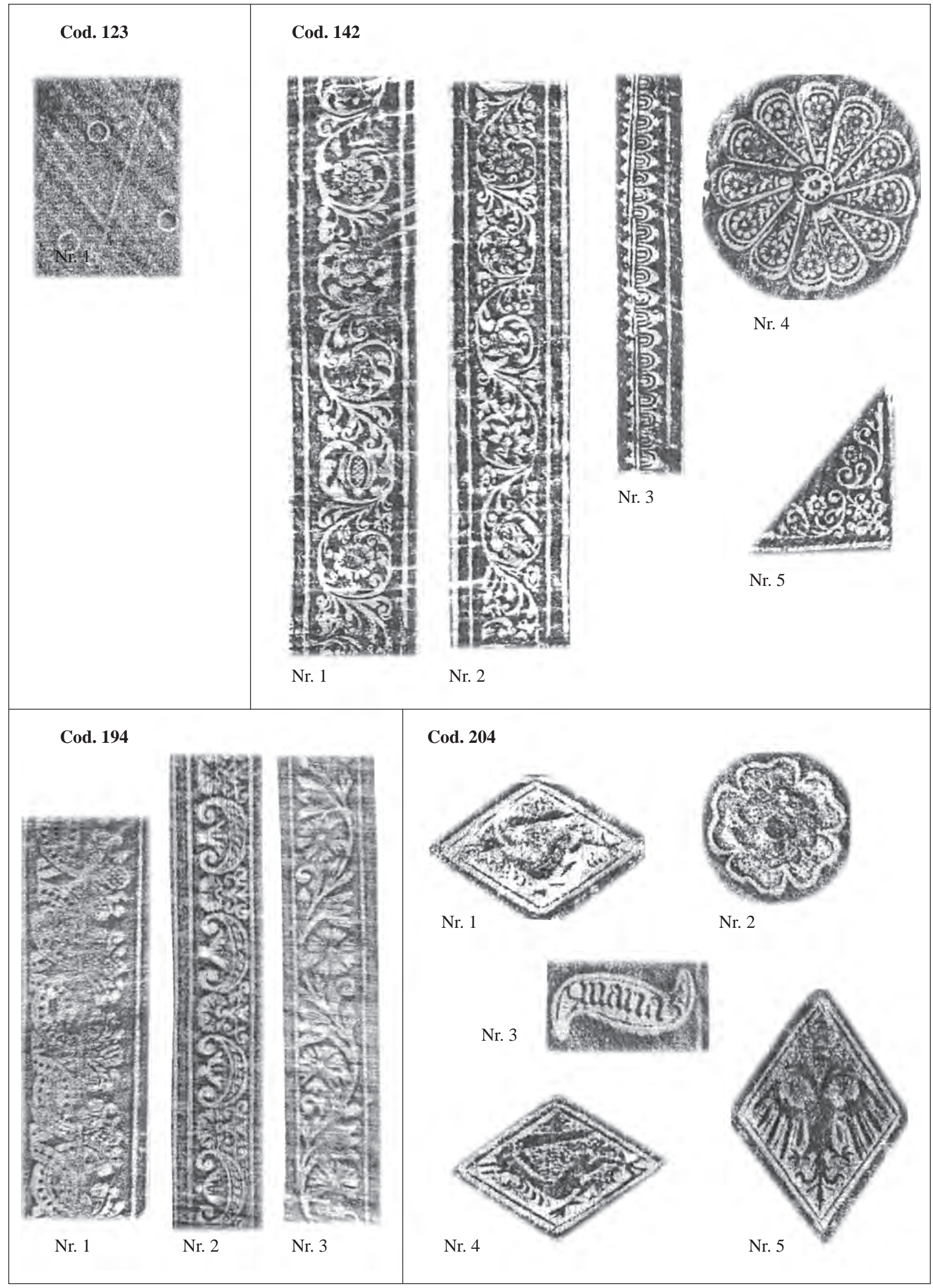




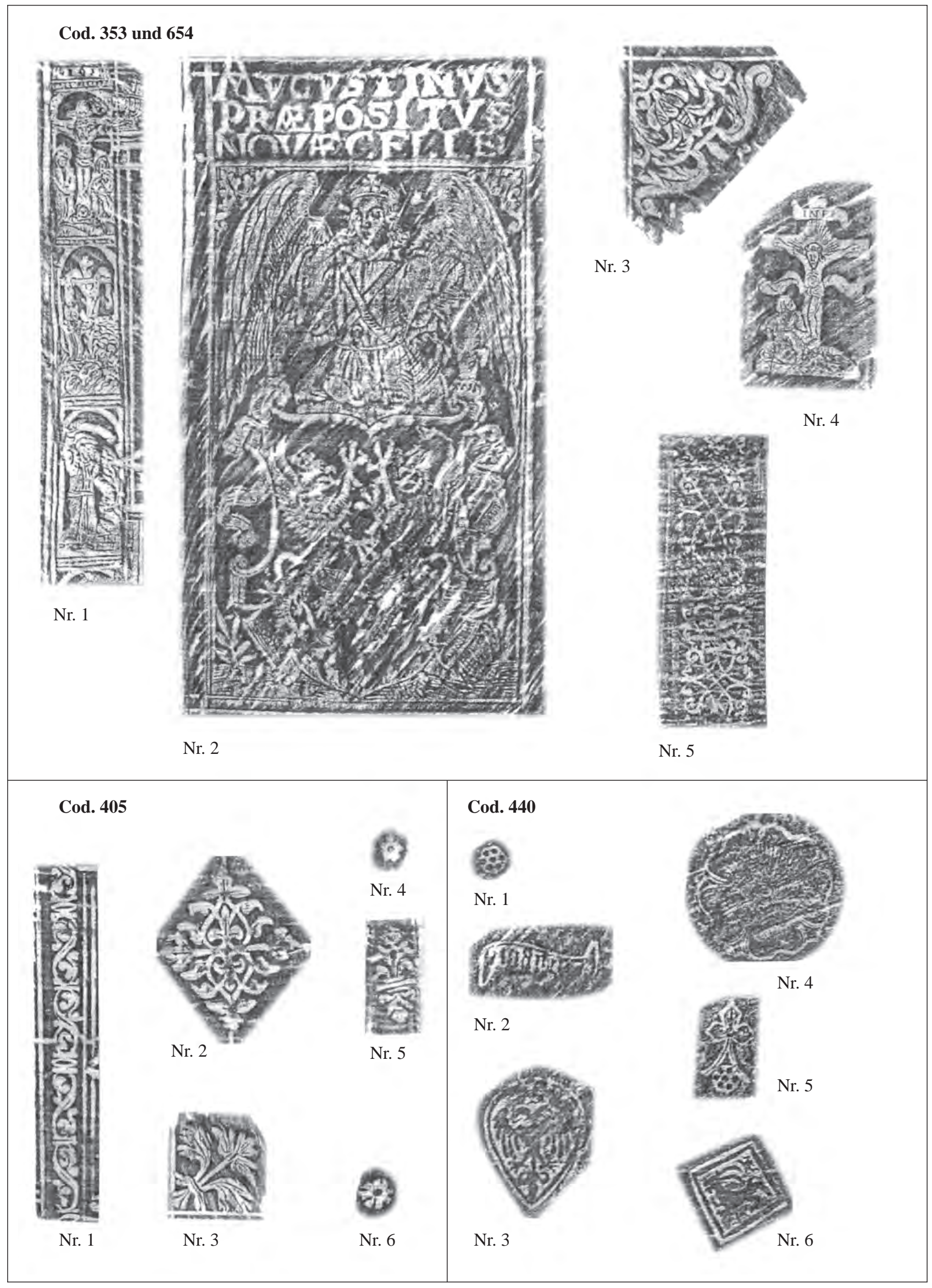




\section{Cod. 397}

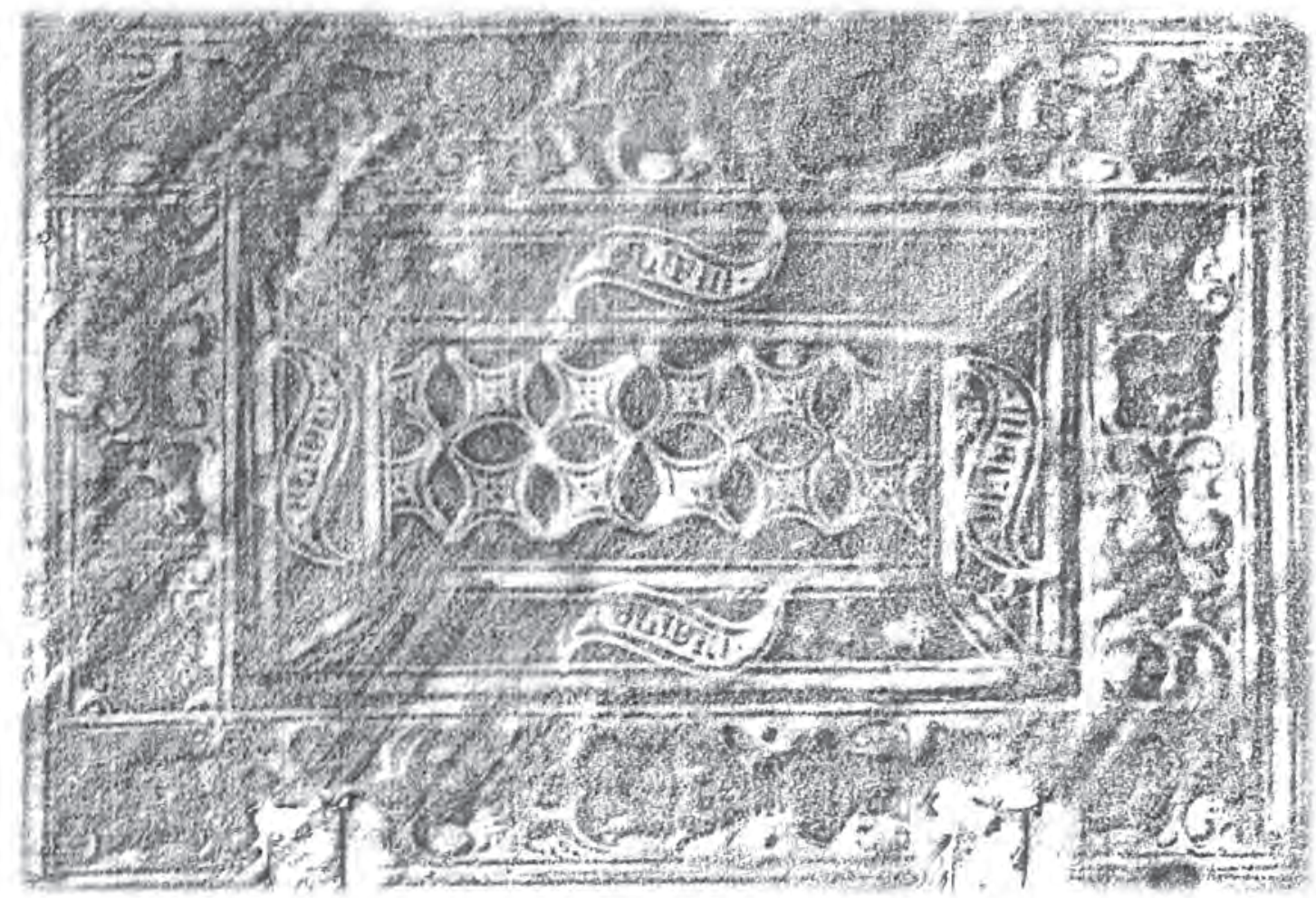

Vorderdeckel

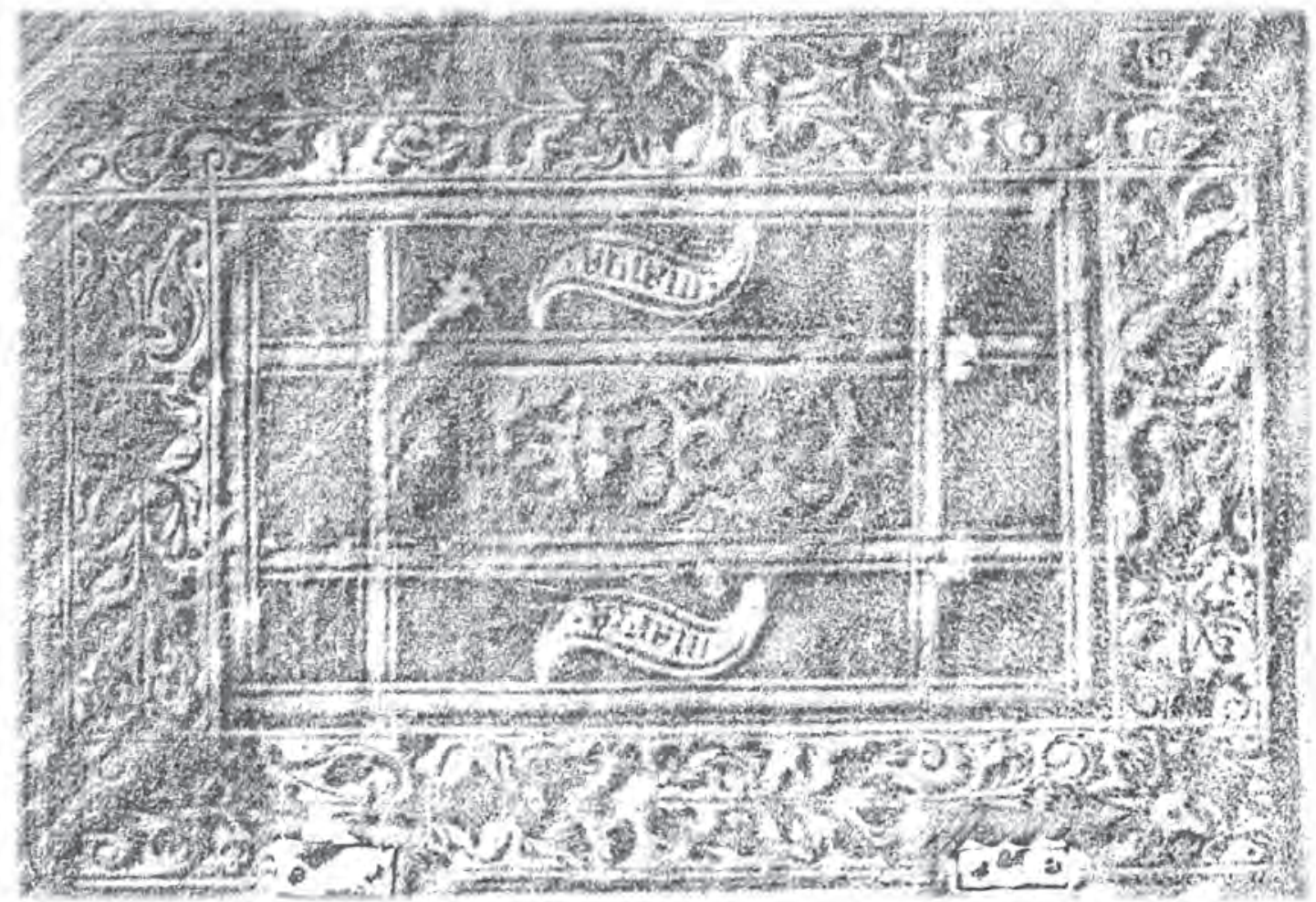

Hinterdeckel 


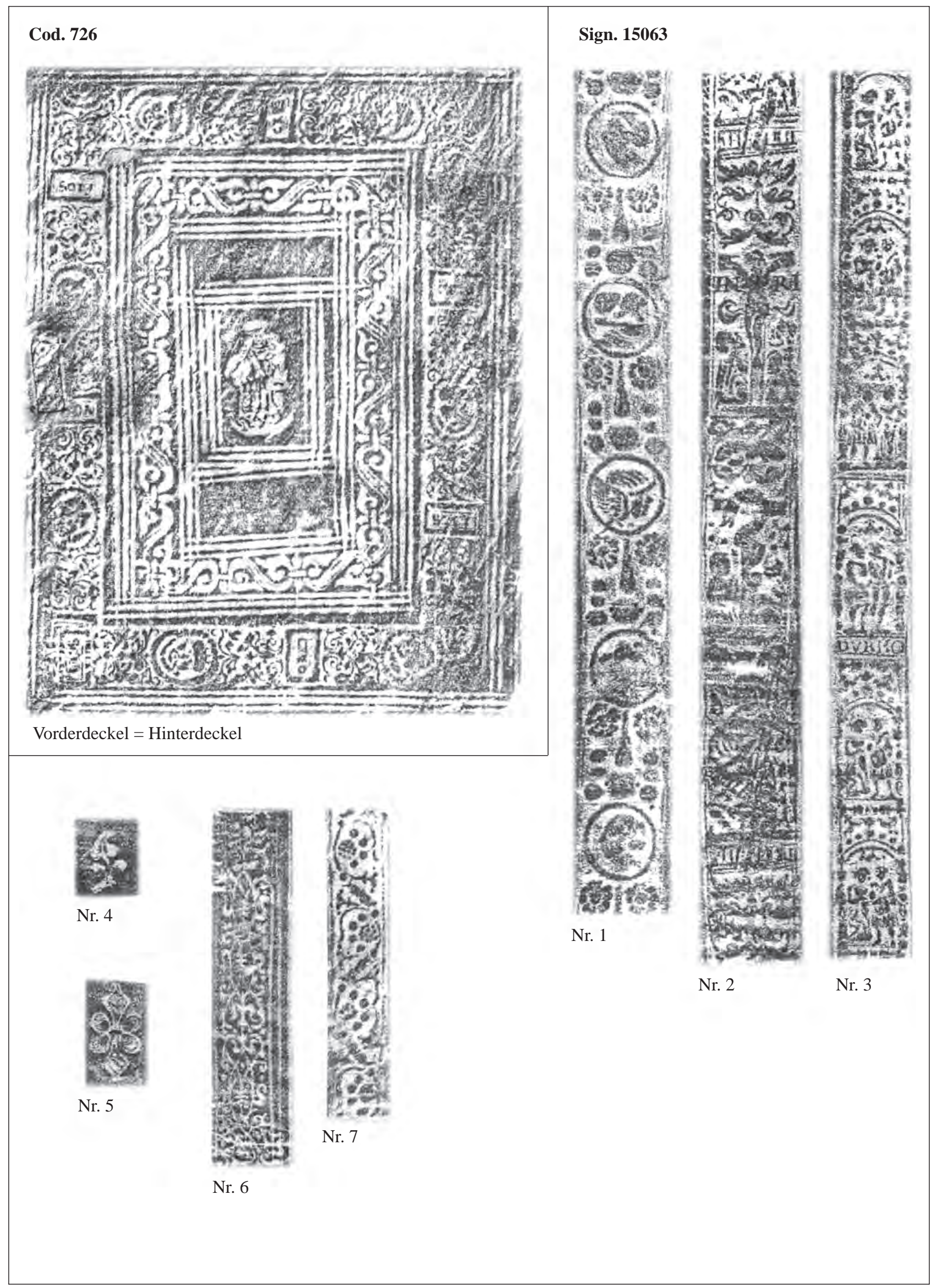




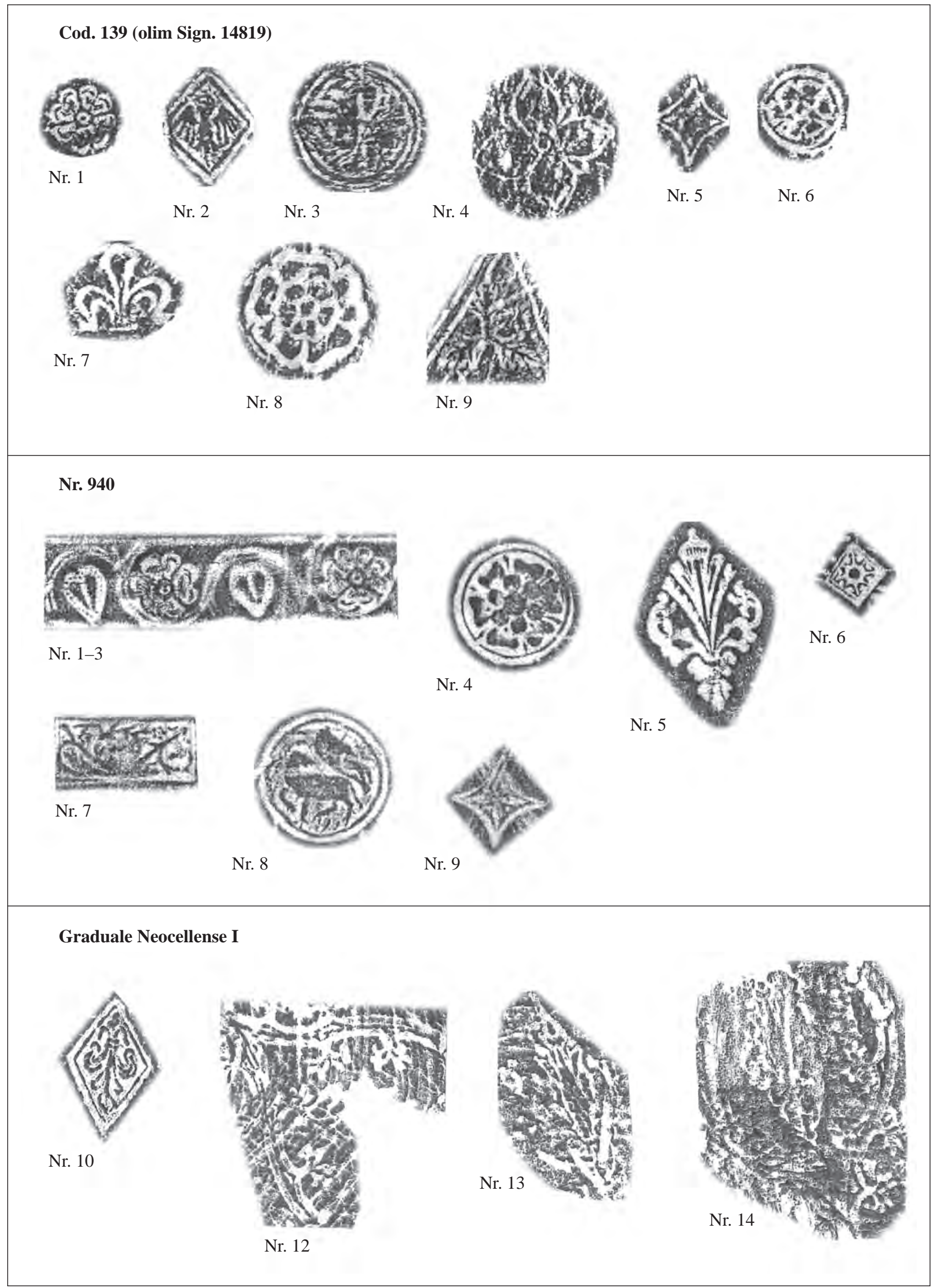




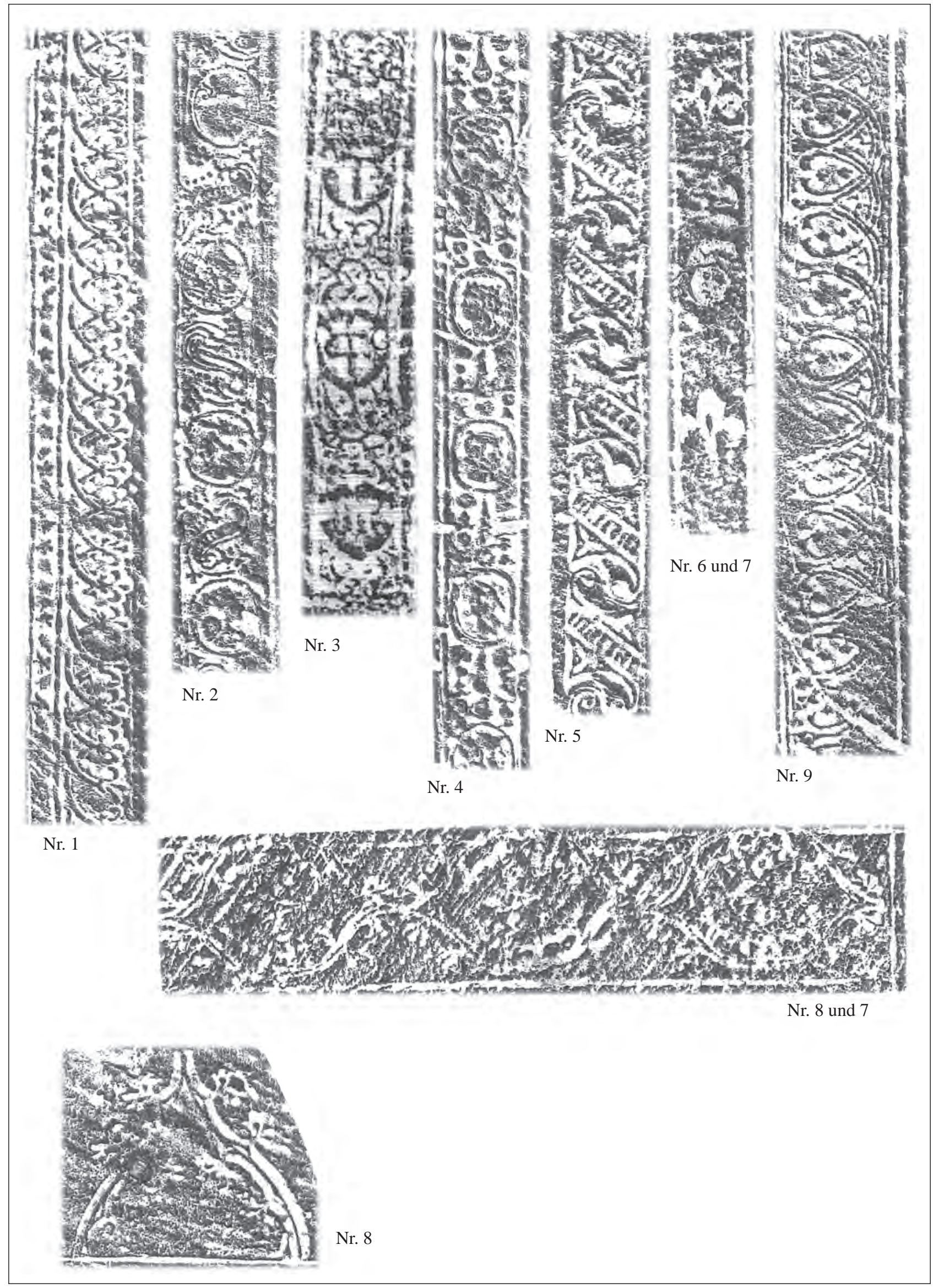




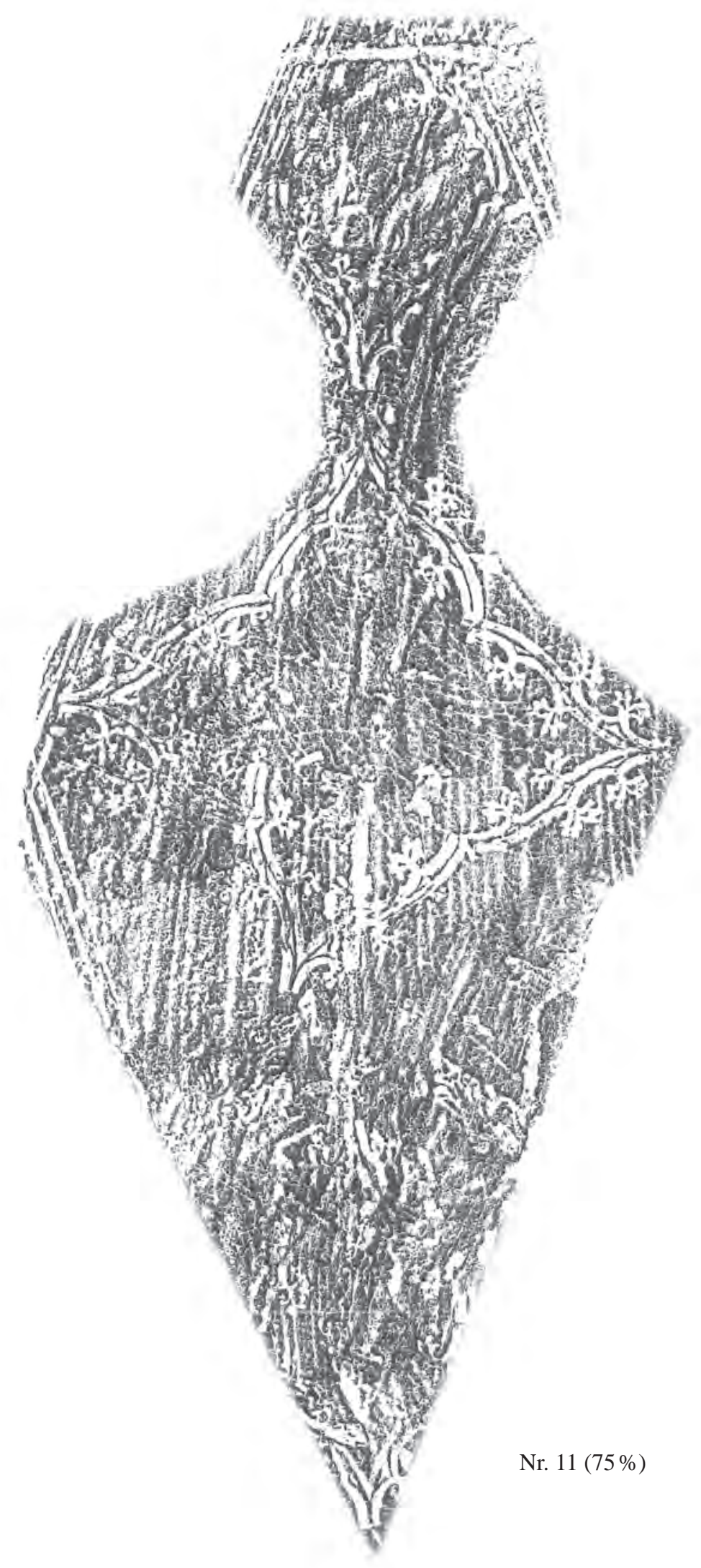





\section{REGISTER}





\section{TEXTANFÄNGE (INCIPIT)}

A cunctis iniquitatibus nostris exue nos domine et intercedente beata et gloriosa Dei genitrice virgine Maria 654, $10 \mathrm{r}$

A cunctis nos quaesumus domine mentis et corporis defende periculis et intercedente gloriosa virgine Dei genitrice 405, 220r

A domo tua quaesumus domine spiritales nequitiae repellantur et aeriarum discedat maligni $654,95 \mathrm{v}$

A haec dictio. A Interdum includit ut $\mathrm{C}$ de $\mathbf{4}$, 1va

$\mathrm{Ab}$ infirmitate surgentibus cibaria nociva petentibus non est denegandum 748, Iv

Abicit mundus pauperes et honorat divites. Nota Augustinus dicit super quod corvus est illius naturae quod pullos suos 52, 202ra

Abigeus dicitur ille qui pecora alicuius a pascuis et armentis subducit ... Abolitio est ab accusando cessatio 155, 18ra

Abiit Iesus trans mare Galilaeae quod est Tiberiadis et sequebatur eum multitudo magna etc. (Io 6,1). In hoc evangelio considerantur triplices personae scilicet Christus discipuli et turbae 53, 242vb

- Licet secundum Augustinum in quodam sermone ad fratres Non debeamus loqui sublimia 53, 242rb

Abrahae sinus dicitur requies sanctorum qui olim fuit limbus nunc est caelum et sic orat ecclesia sinus te suscipiat 617, $196 r$

Absolve quaesumus domine animam fratrum et sororum parentum et benefactorum nostrorum et omnium fidelium defunctorum $405,128 \mathrm{v}$

Absolve domine quaesumus animas famulorum famularumque tuarum ab omni vinculo delictorum 405, 206v

Absque synagogis facient vos (Io 16,2). Sciendum quod sicut Iudaei olim tenuerunt se ad discipulos Christi scilicet separando eos a participatione et communione ipsorum 153,131vb

Absterget Deus omnem lacrimam etc. (Apc 7,17 und 21,4). Ad imitationem sanctorum flere debemus et nos quinque de causis 78, 97vb

Abstinentia est meriti augmentativa. Sapientiae acquisitiva 125, 9ra

Accepta sit quaesumus domine in conspectu tuo nostra devotio ut passionum charismatum et gloriae rationalis ac beatissimae animae 353, 192r

Accidens morbi est triplex scilicet praeventivus ut rigor concomitans ut dolor capitis $\mathbf{7 4 8 , 4 0 v}$

Accipe itaque quascumque exiles quascumque meritis tuis impares gratiarum actiones $405,209 \mathrm{v}$

Accipe o homo exemplum qui es in periculis huius mundi a sancto Andrea 617, 195r

Accipite et manducate ex hoc omnes (1 Cor 11,24). Bene fit illi homini qui hunc panem digne et recte manducat 617, $173 \mathrm{r}$

- Nota quando tritulator est debilis et habet grave flagellum in manu 174, 187rb

Accipite spiritum sanctum quorum remiseritis peccata Ioh. 20 (22). Salvator noster Christus dominus sicut omnia in sua passione ostendit ut declararet suam humanitatem 53, 318rb

Actiones nostras quaesumus domine aspirando praeveni et adiuvando prosequere 252, 24r; 405, 128r, 225r

Ad XVI numerum quintum dato primum $360,26 \mathrm{v}$

Ad cognoscendam naturam constructionis in se et in suis partibus sive speciebus. Sciendum quod constructio est quoddam incomplexum et quia incomplexum secundum Boetium cognoscitur dupliciter. Definitione quae ordinatur ad cognoscendam rem in se $\mathbf{6 0 5}, 5 \mathrm{va}$

Ad eum veniemus et mansionem apud eum faciemus (Io 14,23). Sciendum quod hodierna festivitas inter alia festa dignitatem singularem obtinet 153, 134va

Ad gaudia supernorum perducat nos regina caelorum 405, 210r

Ad imitationem sanctorum flere debemus et nos quinque de causis $\mathbf{7 8}, 97 \mathrm{vb}$

Ad mensam magnam sedisti (Sir 31,12). Scito quod talia oportet te praeparare qualia sunt in hostia. Quanto maior est festivitas tanto se melius homines praeparare debent 177, 75rb

Adest tibi venerabile tempus Quadragesimae 617, 143r 
Adesto Deus unus omnipotens pater et filius et spiritus sanctus te unum in substantia trinum $353,117 \mathrm{v}$

Adesto domine supplicationibus nostris ne sit a nobis famulis tuis longinqua tua miseratio 654, 28v

Adesto nobis domine Deus noster et quos sanctae crucis laetari fecisti 405, 221v

Adesto supplicationibus nostris omnipotens Deus et quibus fiduciam sperandae pietatis 353, 49v

Adesto supplicationibus nostris quaesumus omnipotens Deus et quibus fiduciam sperandae pietatis indulges $\mathbf{4 0 5}$, $217 \mathrm{v}, 218 \mathrm{v}$

Adiutorium nostrum in nomine domini 405, 129r

Adiuvent nos quaesumus domine et haec mysteria 154, $4 \mathrm{r}$

Adiuvet nos quaesumus domine beatae Mariae semper virginis intercessio veneranda 405, 211r

Aetatem habet ipse de se loquatur (Io 9,21). Pro huius thematis introductione tres scholas invenio scilicet examinationis, confessionis, obligationis. Prima schola est examinationis et in ista schola legitur quod reus dato quod omnia sunt allegata et approbata 597, 34ra

Affer manum tuam et mitte in latus meum (Io 20,27). Benigni homines habent modum dum vident aliquem carum amicum cecidisse in aliquam passionem solent eos instruere 617, 136r

- Benigni homines habent modum dum vident aliquem ex caris amicis suis cecidisse in aliquam passionem solent eos instruere $\mathbf{7 8}, 8 \mathrm{vb}$

Ait vere dominus est in loco isto et ego nesciebam (Gn 28,16). His verbis possumus quattuor notare. Primo quis sit Iacob secundo quod dormivit tertio quae sit scala quarto quod angelos vidit 162, 3va

Aliquis cognovit matrem et filiam vel duas sorores vel duas consanguineas mulieres 155, 8va

Aliquis confitetur aliquod crimen sacerdoti et episcopus excommunicat omnes huius criminis consocios 155, 9rb

Aliquis confitetur peccata sua sacerdoti et dicit quod non potest cessare 155, 9rb

Aliquis contraxit sponsalia cum aliqua muliere et contracto matrimonio cognovit carnaliter mulierem sponsae ante sponsam 155, 8vb

Aliquis dicit confessori suo quod mulierem quam nunc habet duxit in uxorem in facie ecclesiae 155, 8vb

Aliquis est surdus et mutus vel ita aeger quod non potest peccata sua confiteri sacerdoti 155, 9rb

Aliquis fuit testis in causa matrimoniali qui falsum protulit testimonium vel aliqua dixit de causa matrimoniali se scire quae in veritate ignoravit 155, 8rb

Aliquis furiosus interfecit hominem postea factus sanae mentis se hominem interfecisse confitetur 155, 9ra

Aliquis habens uxorem postmodum commisit cum filia uxoris suae adulterium 155, 8va

Aliquis habetur pro praelato et in veritate non est praelatus audit confessiones parrochianorum illius parrochiae 155, 9va

Aliquis in infirmitate petit sacerdotem et antequam ad eum venerit sacerdos 155, 9va

Aliquis peregrinus vel viator seu negotiator vel mercator venit ad extraneum sacerdotem 155, 9rb

Aliquis segetem meam sevit tempore opportuno animo surripiendi sed nihil de ea asportavit 155, 9ra

Aliquis venit ad confessorem et dicit ei peccata sua et dicit se non posse abstinere a luxuria 155, 9ra

Aliquis vovebat perpetuam continentiam postmodum non obstante voto 155 , 8va

Alliaseph puncti rubei qui sunt ut pulicis morsus et fiunt in omnibus membris 748, 213ra

Alterius circumventio alteri non praebet actionem. Actus legitimi ut supra. Aliud est vendere aliud venditioni consentire 614, 275r

Ambrosius cum incunabulis in atrio praetorii esset positus et dormiret 308, 22vb

Amen Amen dico vobis. Si quid petieritis patrem in nomine meo dabit vobis (Io 16,23). Quamvis multis modis homo serviat Deo et pro peccatis suis satisfaciat 53, 338rb

An maritus uxori adulterae subtrahere possit debitum cohabitationum et dotem sine iudicio ecclesiae. Tua fraternitas hic tractantur iura an vir uxori adulterae 155, 6vb

An reddituarii teneantur propriis sumptibus deferre dominis redditus et praesertim ecclesiarum. Et videtur quod sic quia redditus ecclesiae videntur esse dos ipsius 155, 7va

Animabus quaesumus domine omnium fidelium defunctorum oratio proficiat $654,66 \mathrm{r}$

Animam meam pono pro ovibus meis (Io 10,15). Hic dicendum est de caritate Dei quam habet ad nos et etiam de caritate quam nos ad ipsum habere debemus 153, 109vb

Animas pauperum tuorum ne obliviscaris in finem (Ps 74,19). Notandum quod quintuplex est anima scilicet anima immunda anima rapta anima sepulta anima salvata anima cruciata 617, 190r

Anno salutis MDCLIII septimo Kalendis Septembris ad maiorem Dei gloriam S. P. N. Augustini honorem 76, 74r

Annuntio vobis gaudium magnum ... (Lc 2,10). Scire debetis in Christo dilectissimi quod dies hodierna ex salvatoris nostri nativitate nobis redditur gaudiosa 153, 4va

Ante diem festum paschae sciens Iesus quia venit hora eius etc. (Io 13,1). Chrysostomus super Iohannem tractans illud Ioh. 10. Facta sunt encaenia 53, 265ra

- Sicut auris non potest satiari auditu nec oculus 53, 265va

Anthrax est apostema quod partim fit de cholera partim de sanguine partim de melancholia. De sanguine habet putredinem 748, 90r

Anthrax et carbunculus quia fiunt ex materia grossa $748,54 \mathrm{rb}$ 
Anticipatio paroxysmi augmentum non significat nisi cum hoc longitudo temporis aut fortitudo febris augeatur 748, $1 \mathrm{r}$

Apostolicis nos quaesumus domine beatorum apostolorum Petri et Pauli et aliorum apostolorum attolle praesidiis 405, $217 \mathrm{r}$

Arescentibus hominibus prae timore et exspectatione quae supervenient universo orbi (Lc 21,26). In praecedenti sermone dixi de signis adventus diei iudicii 53, 13ra

Arguet mundum de iustitia (Io 16,8). Glossa semper quam non habet. Unde hic est dicendum quomodo homo debet iustus inveniri si vult salvari 153, 119vb

Arguet mundum de peccato quia non credunt in me (Io 16,8). Glossa semper quod habet. Unde hic est dicendum quomodo quis committit septem peccata mortalia 153, 119vb

- Sciendum quod plura genera hominum sunt qui dicunt verbis se credere in Deum 153, 115va

- Sciendum quod sicut Deus arguet peccatores de suis excessibus in futuro 153, 117vb

Aristoteles $2^{\circ}$ De anima Simile a simili nutritur sicut patet in cibo digesto a quo corpus nutritur $153,81 \mathrm{rb}$

Aristoteles $1^{\circ}$ Ethicorum finis per quem omnia desiderantur et sperantur optimus est 153, $7 \mathrm{rb}$

Aristoteles $8^{\circ}$ Ethicorum dicit Vera amicitia habet reamationem. Et quia Christus vere nos dilexit 153, 77ra

Aristoteles $9^{\circ}$ Metaphysicae Contraria non fiunt in eodem. Cum ergo spiritus sanctus intrat in cor hominis tunc mala et peccata depellit 153, 137ra

Aristoteles $5^{\circ}$ Physicorum Omnis motus tendit ad aliquem terminum per debita media 153, 74va

Aristoteles $8^{\circ}$ Physicorum Illud est prius quo non existente non sunt alia sed sine fide 153, 67va

Aristoteles In sempiternis nihil violentum. Qui ergo alte in caelo vult 153, 46vb

Ars praedicandi est scientia docens de aliquovis termino vel ente aliquid dicere 155, 139r

Artat statutum doctores legentes et ut quaestiones disputatas 614, 284r

Ascendente Iesu in naviculam etc. (Mt 8,23). Christus dominus tempore quo suam praedicationem incepit semper operatus est $\mathbf{5 3}, \mathbf{1 1 5} \mathrm{ra}$

- Licet mundus iste primo appareat valde amicus tranquillus et pacificus hominibus 53, 114va

Asma ut dicit Avicenna est aegritudo pulmonis cum qua patiens non invenit excusationem ab anhelitu ... Et Rasis addit tussim et quod laeditur ex iacendo 123, 212r

Assumpsit Iesus duodecim discipulos suos et ait illis Ecce ascendimus Hierosolymam et consummabuntur omnia etc. (Lc 18,31). Caelestis medicus quamvis vocatus ab infirmo homine propter originale peccatum 53, 145vb

- Hoc evangelium facit memoriam de Christi passione et secundum Wilhelmum Duranti 53, 152ra

- In praesenti evangelio ponuntur duo principalia. Primum de Christi passione 53, 146rb

- Secundum scripturas sanctorum homo per peccatum fit instabilis et mutabilis et despectus 53, 151va

Audi Israel Deus tuus unus est (Dt 6,4). Sunt autem septem genera hominum qui Deum non colunt sed idola adorant. Primus genus est de quibus 308, 210ra

Audite haec omnes gentes auribus percipite omnes qui habitatis orbem 19, 1ra

Audite haec quae dicturus sum. Hic attentos facit omnes Gregorius id est omnes iniqui, haec iam hodie 19, 1ra

Auge in nobis domine fidem rectam spem firmam caritatemque perfectam 405, 224r

Augustinus dicit in De consensu evangelistarum et magistri historiarum quod Herode mortuo 53, 76va

Augustinus in quodam sermone de Christi nativitate qui incipit Adiuvet nos humillimos 53, 57va

Augustinus Non solum Christi verba sunt nobis in documentum sed etiam Christi facta sunt nobis in exemplum 153, 30va

Aures tuae pietatis mitissime Deus inclina precibus meis 154, 6r; 405, 223v

Aut fratres sunt ex utroque coniuncti aut non. Si ex utroque coniuncti et tunc aut soli fratres exstant 155, 106r

Ave gloriosa Maria mater Christi virgo pia pone misericordiam et compassionem 353, 161v

Ave gratia plena dominus tecum (Lc 1,28) benedicta tu in mulieribus (Lc 1,42). Dixit angelus ad virginem de caelo missus. Et benedictus fructus ventris tui. Adicit Elisabeth spiritu prophetico inspirata 31, 49ra

Ave gratia plena dominus tecum (Lc 1,28). Ista dies praecipue maior est omnibus festivitatibus 174, 155ra

- Si quis princeps vel rex vel magnus dominus vult destinare nuntium vel legatum ad summum principem vel regem vel dominum magnum pro magna et ardua causa 31, 67rb

Avete omnes fideles animae in sancta pace quiescite qui vos redemit suo pretioso sanguine vobis dignetur misereri poenasque vestras 654 , $91 \mathrm{r}$

Avete omnium fidelium animae in pace Christi requiescite quos redemit suo pretioso sanguine 405, 220r

Beata virgo comparatur caelo. Caelum enim dicitur quasi gaza heliorum id est solis domus, quia quasi in domo propria 171, 62ra

Beatae et gloriosae semperque virginis Dei genitricis Mariae quaesumus omnipotens Deus intercessio gloriosa nos protegat 405, 216v

Beati Petri apostoli tui quaesumus domine intercessione nos protege et animas famulorum tuorum sacerdotum sanctorum tuorum iunge $\mathbf{4 0 5}, 128 \mathrm{v}, 129 \mathrm{r}$ 
Beati qui habitant in domo tua domine (Ps 84,5). David dicit haec verba. Notandum est quod domus domini est quadruplex scilicet domus materialis 162, 2rb

Beatus Bernardus in sermone De quadragesima dicit quod septem sunt impedimenta 53, 134ra

Beatus Thomas sanctitatem suam ita subtiliter occultabat ut salvo semper honestatis rigore $\mathbf{3 0 8}, 1 \mathrm{vb}$

Beatus vir qui non abiit/Pestilentiae (darüber:) Der Suechte 308, 203ra

Beatus vir. Pestilentiae contagie (!) quod dum unum apprehendit celeriter transit ad plures quia velut incendium 155, $141 \mathrm{r}$

Bene fit illi homini qui hunc panem digne et recte manducat 617, 173r

Benedicta tu in mulieribus (Lc 1,42). Dixit angelus ad virginem de caelo missus. Et benedictus fructus ventris tui. Adicit Elisabeth spiritu prophetico inspirata 31, 49ra

- Illud digne commendatur quod in se consideratum bonum apparet et aliis comparatum excellit 31, 84va

- Si volumus amplius scire quod multipliciter est sanctissima virgo domina Maria benedicta inspiciamus 31, 89rb

Benedictionem omnium gentium dedit illi (Sir 44,25). In verbis istis ostendit nobis spiritus sanctus quaedam signa in beato Nicolao propter quae signa obtinuit benedictionem omnium gentium $\mathbf{7 8}$, 4rb

Benedictum sit dulce nomen domini mei Iesu Christi et gloriosissimae virginis Mariae matris eius in saeculum 617, $195 \mathrm{r}$

Benedictus qui venit in nomine domini (Mt 21,9; Mc 11,9; Lc 13,35; Io 12,13). Hodie sancta mater ecclesia duas processiones recolit $153,79 \mathrm{rb}$

Beneficium ecclesiasticum non potest licite sine institutione canonica obtineri $614,282 \mathrm{v}$

Benigni homines habent modum dum vident aliquem carum amicum cecidisse in aliquam passionem solent eos instruere 617, 136r

Benigni homines habent modum dum vident aliquem ex caris amicis suis cecidisse in aliquam passionem solent eos instruere 78, 8vb

Benignitas salvatoris Dei nostri maior est in exaudiendo petitiones filiorum suorum 153, 119vb

Bonorum honorabilium notitiam opinantes magis autem alteram altera aut secundum certitudinem aut ex eo $\mathbf{1 6 3}$, $32 \mathrm{r}$

Caelesti quaesumus domine lumine semper et ubique nos praeveni rationalis 353, 187r

Caelestis medicus quamvis vocatus ab infirmo homine propter originale peccatum $53,145 \mathrm{vb}$

Carissime frater. Vivatis in religione secundum doctrinam apostoli dicentis Sobrie et iuste et pie vivamus in hoc saeculo exspectans beatam spem et adventum gloriae magni Dei. In quibus verbis apostolus Paulus docet 617, $55 \mathrm{r}$

Caro mea vere est cibus ... (Io 6,55). Sic legimus quod unigenitus Dei filius volens [ 153, 156vb

- Sicut dicit Aristoteles $4^{\circ}$ Ethicorum Terribilissimum omnium terribilium videtur esse mors 153, 154ra

Cassiodorus in libro De anima. Magistri scholarum litterarum aiunt animam esse substantiam simplicem speciem naturalem distantem a materia corporis sui organum membrorum $597,57 \mathrm{vb}$

Casus talis est. Quaedam domus religiosae quarum fratres non manducant emerunt pensiones annuas perpetuas ipsis opportunas 447 , 208ra

Ceperunt ramos palmarum et processerunt obviam ei (Io 12,13). Pro huius thematis introductione invenio tres scilicet olivae in Minerva, lauri in Mercurio, palmae in Marte. Prima schola est olivae in Minerva. Nam ut possum capere ex dictis poetarum oliva consecrata est in nomine Minervae 597, 40vb

Christe rex clementissime fili Mariae qui inter plurima opprobria sanctissimum spiritum emittendo patri tuo 353 , $114 \mathrm{r}$

Christi nomen invocans ad honorem ipsius et reverentissimi patris domini Bononiensis archidiaconi qui divinam potentiam imitatus de me nihil fecit aliquid 99, 32va

Christus dominus frequenter in suis sermonibus arguit Iudaeis super peccatis suis 53, 246va

Christus dominus ne dum aetate virili sed etiam in pueritia sua se nobis ita exhibet ut ostendat quanta caritate nos diligat 53, 76ra

Christus dominus per scripturas nobis valde incutit timorem de extremo iudicio 53, 6va

Christus dominus tempore quo suam praedicationem incepit semper operatus est 53, 115ra

Christus dominus volens omnem dubitationem de sua divinitate a nobis excludere 53, 96va

Christus ieiunavit nobis in doctrinam et exemplum quia secundum Gregorium Omnis Christi actio nostra est instructio 153, 62va

Christus nobis tribuit normam (!) hic vivendi/Et exemplo docuit viam gradiendi/Ut mundana vanitas possit vilipendi 165, 143va

Chrysostomus et Theophilus dicunt et habetur Matthaei 12 Ille daemoniacus erat mutus 53, 240va

Chrysostomus homilia 16 super Matthaeum dicit Omnium malorum tria et fortiora sunt tria mala 53, 185va

Chrysostomus super Iohannem tractans illud Ioh. 10. Facta sunt encaenia 53, 265ra 
Chrysostomus super Matthaeum homilia 28 Homo Christus paterfamilias cui caeli et pater (recte: terra) una est domus familia 53, 124va

Circa distinctionem sacramenti (!) quaeritur utrum haec distinctio sit bona. Sacramentum est invisibilis gratiae visibilis forma ut imaginem gerat et causa existat. Respondeo quod sic quia completissime rationem sacramenti designat 77, 1ra

Circa initium huius libri sicut aliorum sunt aliqua generalia autem textus in titulationem praenotanda. Primo in quali scientia 163, 32r

Circa nativitatem domini tria notantur. Primo natus describitur secundo nativitatis tempus tertio nativitatis utilitas. De primo sciendum quod fuit natus admirabilis ineffabilis formidabilis venerabilis $\mathbf{6 1 7}, \mathbf{1 3 6 r}$

Circa quartum librum Sententiarum primo quaeritur quid sit sacramentum. Dicendum quod sacramentum quattuor modis solet describi vel definiri. Primo sic sacramentum est sacrae rei signum 52, 112r

Circa quartum Meteorum. Utrum tamen quattuor sunt qualitates primae scilicet caliditas frigiditas siccitas et humiditas. Et arguitur primo quod non quia 440, 411va

Circa quem textum est dicendum an sancti in aeterna beatitudine quam habebunt post resurrectionem sedebunt vel stabunt 53, 346vb

Circa quod sciendum quod sunt sex quae debent hominem retrahere ab omni peccato mortali 153, 96ra

Circa textum notandum quod philosophus in textu dicit quod erit determinandum 163, 47r

Circumcisionis dies est sollemnis quia octavus nativitatis Christi est. Voluit autem dominus die octava circumcidi unde Rabbi Moyses philosophus et theologus licet Iudaeus 617, 138v

Coitus maxime exsiccat quia per ipsum recedit magna humiditas 155, 138r

Collegerunt pontifices et Pharisaei concilium adversus Iesum (Io 11,47). Pro huius thematis introductione invenio tres scholas scilicet urbis fundatorum, in campo bellatorum, in campo clericorum. Prima schola est urbis fundatorum 597, 38rb

Commendo domine in misericordiam tuae divinitatis maiestatis ac magnificentiae $\mathbf{4 4 0}$, urspr. VDS (heute abgelöst)

Commonefacio vos enim fratres mei collegaeque devoti futuri festi nativitatis Christi ad sacras ordines 756, 53rb

Concede misericors Deus fragilitati nostrae praesidium ut qui sanctae Dei genitricis Mariae 353, 149r; 405, 215v

Concede nos famulos tuos quaesumus domine Deus noster perpetua mentis et corporis sanitate gaudere 353, 143r; 405, 212v, 218r

Concede quaesumus omnipotens Deus sanctum nos spiritum vocis promereri 353, 29v

Concede quaesumus omnipotens Deus ut intercessio sanctae Dei genitricis Mariae sanctique Iohannis Baptistae 654, 7r, 13v

Concede quaesumus omnipotens Deus ut quod beati Iohannis Baptistae sollemnia colimus 405, 218v

Concede quaesumus omnipotens Deus ut sicut in nomine patris et filii divini generis intellegimus 353, 126r

Confiteor tibi pater domine caeli et terrae siehe In illo tempore respondens Iesus dixit Confiteor tibi pater domine caeli et terrae quia abscondisti haec a sapientibus et prudentibus etc. (Mt 11,25).

Confortatio fit multipliciter. Primo per restaurationem bonam sicut spiritus ex vino aromatico dicuntur confortari $748,40 \mathrm{v}$

Consecrata est Seccoviensis ecclesia a venerabili in Christo patre et domino Hartmanno Brixinensi episcopo circa anno domini $\mathrm{M}^{\circ} \mathrm{C}^{\circ} \mathrm{XL}^{\circ} 293$, 22r

Constat in altari carnem de pane creari/illa caro Deus est qui dubitat reus est 167, 71vb

Constitutio est ius relatum in scriptis redactum. Vel aliter est ius ubi non sequitur poena. Sed sanctio est ius ubi sequitur poena. Consultatio est in qua 155, 45va

Consuetudo est regum terrae ut quando volunt aliqua seriosa bellica exercere 53, 249ra

Consuetudo in mundo est quando aliquis usque in mortem in carcere cruciatur mittit ad amicos suos de quibus maxime confidit 78, 112 ra

Continuo oportet in medicina libros aphoristica brevitate collationes componere 453, 39r

Contra aeris infectionem. Eius enim attractione membra principalia $\mathbf{7 4 8 , 7 0 v}$

Contra debilitatem capitis naturalem 160, $1 \mathrm{r}$

Contra debilitatem oculorum equorum et macularum 160, $1 \mathrm{r}$

Contra inflationem colli equorum 160, $1 \mathrm{r}$

Contra scabiem equorum 160, $1 \mathrm{r}$

Contra vermes in intestivis equorum 160, $1 \mathrm{r}$

Contraria non fiunt in eodem. Cum ergo spiritus sanctus intrat in cor hominis tunc mala et peccata depellit 153, 137ra

Conversus quidam in quodam coenobio cum monachis loquendo 308, 197rb

Convertimini ad me ... (Ioel 2,12). Unde Iohannes de Sancto Geminiano Videmus enim quod cum animal brutum sentit se vulneratum sollicite quaerit et procurat sanationis remedium 153, 60va

Convertimini ad me et salvi eritis (Is 45,22). Quamvis divina miseratio multis variisque modis in scripturis sanctis omnis vocare dignata est $\mathbf{6 1 7}, 63 \mathrm{r}$

Corda nostra quaesumus domine aeternae sapientiae splendor illustret 353, 19r 
Corda nostra quaesumus domine passionum charismatum et gloriae rationalis $654,11^{\mathrm{I}} \mathrm{r}$

Cordibus nostris quaesumus domine spiritum sanctum 353, 33r

Corporis et sanguinis domini nostri Iesu Christi sacramentum sit 353, 56v

Creaturarum consideratio pertinet ad theologos et philosophos 86, 1ra

Credimus te Deum patrem a temetipso non ab alio nec factum nec creatum nec genitum te filium $353,118 \mathrm{v}$

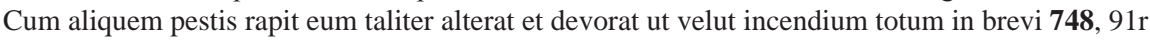

Cum aliquid petit suam confessionem audiri quem antea $532,125 \mathrm{v}$

Cum appropinquasset Iesus Hierosolymis et venisset Bethfage ad montem Oliveti tunc misit duos discipulos etc. (Mt 21,1). Consuetudo est regum terrae ut quando volunt aliqua seriosa bellica exercere 53, 249ra

- Hodie sancta mater ecclesia incipit celebrare adventum domini et hanc observantiam recepit a sanctis patribus 53, 1ra

- Pro intellectu litterae notandum quod Iohannis 12 dicitur Quando Iudaei iam ex consilio Caiphae 53, 249va

Cum audisset Iohannes in vinculis opera Christi mittens duos de discipulis suis ait illi etc. (Mt 11,2). Ex quo inter cetera multum provocat ad virtutes et virtuosorum hominum laudabilis conversatio 53, 25vb

- Pro intellectu notandum quod secundum magistrum historiarum Iohannes arguebat Herodem propter Herodiadem quam a fratre suo receperat 53, 26ra

Cum autem descendisset Iesus de monte secutae sunt turbae multae. Et ecce leprosus etc. (Mt 8,1). Christus dominus volens omnem dubitationem de sua divinitate a nobis excludere 53, 96va

- Ecclesia instituit quod per totum annum cantantur et praedicantur Christi miracula 53, 110va

- Quia postillatio verborum evangelii satis patet ex alio sermone facto de eodem. Ideo solummodo dicendum erit 53, 110vb

- Sciendum quod dicit Haimo Mons in quo Deus sedet caelum intellegitur 153, 37va

- Secundum Chrysostomum homilia 24 super Matthaeum Ne forte diceret populus apud se 53, 97ra

Cum beatus Augustinus febribus laboraret et lecto decumberet 308, 14va

Cum de febribus phlegmaticis iam tractandum est. Primo videndum est 123, 203r

Cum de praesentis exilii [miseria] mortis transitus propter moriendi imperitiam 754, 18r

Cum ergo sero factum esset die illa una sabbatorum etc. (Io 20,19). Hodie divina dies resurrectionis colitur in quo (!) perfecta requies designatur 53, 322rb

Cum ex primo et principali nostrae regulae praecepto teneamur habere cor unum et animam unam 76, $17 \mathrm{r}$

Cum factus esset Iesus annorum duodecim ascendentibus illis in Ierusalem secundum consuetudinem etc. (Lc 2,42). Augustinus dicit in De consensu evangelistarum et magistri historiarum quod Herode mortuo 53, 76va

- Christus dominus ne dum aetate virili sed etiam in pueritia sua se nobis ita exhibet ut ostendat quanta caritate nos diligat 53, 76ra

- In praesenti enim evangelio instruit Maria parentes qualiter se debeant habere ad filios 153, 27va

Cum ieiunasset quadraginta diebus ... (Mt 4,2; vgl. Mc 1,13; vgl. Lc 4,1). Christus ieiunavit nobis in doctrinam et exemplum quia secundum Gregorium Omnis Christi actio nostra est instructio 153, 62va

Cum ieiunatis nolite fieri sicut hypocritae tristes $(\mathrm{Mt} \mathrm{6,16).} \mathrm{Pro} \mathrm{huius} \mathrm{thematis} \mathrm{introductione} \mathrm{invenio} \mathrm{tres} \mathrm{scholas.}$ Prima igitur schola fuit Moysii inesse figurali 597, 1ra

Cum Martinus pergeret ad Candacensem dioecesim causa sedandae discordiae vidit mergos in flumine piscibus insidiantes 308, 28va

Cum meae sit intentionis hoc in summario febrium $\mathbf{7 4 8}, 2 \mathrm{r}$

Cum natus esset Iesus (Mt 2,1). Hodie triplex festivitas celebratur. Una est de adoratione magorum 617, 139r

- Omnipotens Deus ex supereffluenti non ex operibus iustitiae quae fecimus 53,66rb

- Pro intellectu litterae notandum ut narrat Iosephus 13 libro Antiquitatum capitulo 14 regnum Iudaeorum fuit interceptum 481 annis et duos menses a captivitate 53, 71ra

- Sicut Deus disposuit omnia sapienter sic fidei incrementum et suam humanitatem 53, 70va

Cum non paucorum erga beneficia indulgentiarum mens errabunde vagetur 161, 1ra

Cum quadam vice animum meum infelicem vanis ac transitoriis occupationibus assidue deditum ad meam recogitandam miseriam $532,1 \mathrm{r}$

Cum sancto Lupo Senonensi archiepiscopo omnes qui de curia 308, 41rb

Cum turba plurima conveniret et de civitatibus properarent ad Iesum dixit per similitudinem Exiit qui seminat seminare semen suum etc. (Lc 8,4). Beatus Bernardus in sermone De quadragesima dicit quod septem sunt impedimenta 53, 134ra

- In praesenti evangelio dominus ostendit multorum auditorum Christi devotionem 53, 139ra

- Praesens evangelium mea non indiget expositione quia summa veritas 53, 134va

- Salvator noster Christus dominus saepius verbis suis nos admonet non solum mala fugere 53, 142rb

- Secundum Bedam Satorem istum nullum melius quam Dei filium intellegere possumus 53, 142vb

- Vera patientia quanta bona et quantas utilitates afferat homini possumus ex diversis scripturis sacris colligere 53, 138va 
Cum venerit filius hominis in maiestate sua etc. (Mt 25,31). Pro huius thematis introductione invenio tres scholas scilicet Hebraicam, Graecam et Latinam. Prima schola est Hebraica in qua considero Salomonem facientem iustitiam 597, 8rb

Cum venerit paraclitus quem ego mittam vobis a patre etc. (Io 15,26). Misericors pater qui est prope est omnibus invocantibus eum in veritate quia nos orphanos non relinquit 53, 344rb

- Sicut in dominica proxima futura recolitur spiritus sancti missio 153, 129va

Curatio. Aut enim intendimus sudorem provocare aut auferre 123, 11av

Currite gentes undique et miramini erga vos caritatem Dei 125, 161ra; 165, 132v

Da nobis domine continua omnium sanctorum tuorum veneratione laetari $405,217 \mathrm{v}$

Da nobis quaesumus domine continua omnium sanctorum tuorum veneratione laetari 405, 218v

Da nobis quaesumus domine vitiorum nostrorum flammas extinguere $405,225 \mathrm{v}$

Da nobis quaesumus omnipotens Deus vitiorum nostrorum flammas extinguere 405, 219v

Da quaesumus omnipotens et misericors Deus ut animae omnium fidelium defunctorum hic et ubique in Christo quiescentium 654, $41 \mathrm{v}$

Daemones enim frequenter plus solito ante et circa Christi adventum obsidebant homines 53, 239ra

David dicit haec verba. Notandum est quod domus domini est quadruplex scilicet domus materialis 162, 2rb

De cruce quando dominus ad cumulum portatur confestim ei genitrix portantes $353,96 \mathrm{v}$

De constitutionibus d II et III per totum et d IV c 1 614, 270r

De duabus ecclesiis noviter 125, 199va

De dulcissimo nomine ipsius Mariae adhuc amplius videamus. Est notandum quod nomen huius dulcissimae virginis est a Deo revelatum 31, 58rb

De duobus filiis summae deitatis (recte: veritatis)/Quos dedit ecclesiae pater pietatis/Quos eorum habeat plus auctoritatis 52, VDS

De excelso misit ignem in ossibus meis et erudivit me R. (Lam 1,13). Quantum ad praesentem festivitatem possunt haec verba esse matris ecclesiae $617,172 \mathrm{r}$

De nomine huius ineffabilis virginis adhuc est plus dicendum. Et est notandum quod haec virgo postquam Christum concepit reperitur in scriptura 31, 60va

De parte autem animae. Iste est tertius liber partialis in quo dicitur de aliis animae potentiis 162, 71v

De praesenti sollemnitate locuturus auribus vestrae caritatis dilectissimi amor venit ad memoriam 161, 6ra

De prima parte evangelii dicendum est sed referendo ad nuptias corporales de quibus loquitur specialiter evangelium 53, 89vb

De primo est sciendum duplicem esse ebrietatem vitandam ... Secundo volens in religione proficere debet iuste cum fratribus vivere $617,55 \mathrm{r}$

De quadam muliere dicebatur una vice casus supradictus fuisse $155,7 \mathrm{rb}$

De tribus nuptiis legitur in evangelio 483, $67 \mathrm{r}$

Decrementa et incrementa paroxysmorum ad invicem aut sunt secundum quantitatem aut secundum tempora aut secundum qualitatem. Si secundum quantitatem aut longior $\mathbf{7 4 8 ,} 1 \mathrm{r}$

Defende quaesumus domine Deus beata Maria semper virgine 405, 133v

Descendit cum eis ... (Lc 2,51). Augustinus Non solum Christi verba sunt nobis in documentum sed etiam Christi facta sunt nobis in exemplum 153, 30va

Deserta cui inest miraculum 125, 199va

Desidero domine mi certificari per te ex testimoniis legis et prophetarum et aliarum scripturarum $617,117 \mathrm{v}$

Detur quid tunc si superest filius fratris ex uno parente coniuncti 155, 106v

Deus a quo sancta desideria recta consilia et iusta sunt opera 405 , 220r

Deus amator omnium bonorum qui sanctissimum Augustinum confessorem 405, 218r

Deus cui omne cor patet et omnis voluntas loquitur et quem nullum latet secretum 353, 35r; 405, 134v, 223v

Deus cui omnia morientia vivunt et cui non pereunt moriendo corpora nostra sed mutantur in melius 654, 35v

Deus cui proprium est misereri semper et parcere suscipe deprecationem 405, 207r

Deus cuius misericordiae non est numerus suscipe propitius preces humilitatis nostrae 405, 129r; 14820, 86r

Deus cuius unigenitus tuus pro nobis usque ad mortem oboediens 353, 70r

Deus gratias tibi vera una trinitas: una et trina unitas te sanctam trinitatem $353,118 \mathrm{r}$

Deus indulgentiarum domine da animae famuli tui (famulae tuae) cuius anniversarium depositionis diem et memoriam agimus refrigerii sedem quietis beatitudinem luminis claritatem 14820, 86r

Deus indulgentiarum domine da fidelibus tuis quorum anniversarium depositionis diem et memoriam agimus $\mathbf{4 0 5}$, $129 \mathrm{r}$

Deus infinitae misericordiae veritatisque immensae propitiare iniquitatibus nostris et animarum nostrarum $654,27 \mathrm{r}$

Deus largitor pacis et amator caritatis da famulis tuis $405,133 \mathrm{v}$

Deus meus confundar et erubesco levare faciem meam $654,17 \mathrm{v}$

Deus pacis caritatisque amator et custos da omnibus 405, 134r 
Deus qui apostolo Petro collatis clavibus 405, 218r

Deus qui beatam Mariam Magdalenam dominicae resurrectionis gaudium sanctis apostolis innotescere voluisti 405, $218 \mathrm{v}$

Deus qui beatam virginem Margaretam ad caelos per martyrii palmam pervenire fecisti 405, 219r

Deus qui beatissimam semper virginem Mariam in conceptu et partu virginitate servata triplici gaudio 353, 182v

Deus qui beatum Nicolaum pontificem tuum innumeris decorasti miraculis 405, 219r

Deus qui benedictae et gloriosae semper virginis genitricis filii tui Mariae corpus et animam sancti spiritus illustrationem perfecisti $353,180 \mathrm{v}$

Deus qui caritatis dona per gratiam sancti spiritus cordibus fidelium infundis $405,134 \mathrm{v}$

Deus qui corda fidelium sancti spiritus illustratione docuisti 353, 38r; 405, 219r, 224r

Deus qui crucem sanctam ascendisti et mundi tenebras illuminasti $405,216 \mathrm{v}$

Deus qui de beatae Mariae virginis utero verbum tuum angelo annuntiante carnem suscipere voluisti 405, 211r

Deus qui dedisti legem Moysi in summitate montis Sinai et in eodem loco per sanctos angelos 405, 219r

Deus qui diem discernis a nocte $\mathbf{4 0 5}, 129 \mathrm{v}$

Deus qui diligentibus te misericordiam tuam semper impendis et a servientibus tibi in nulla $\mathbf{4 0 5}, 134 \mathrm{r}$

Deus qui ecclesiam tuam pretiosi corporis et sanguinis domini nostri Iesu Christi mysterio 353, 63v

Deus qui fidelium tuorum deprecationem semper exaudis praesta mihi indigno peccatori 353, $12 \mathrm{v}$

Deus qui miro ordine angelorum ministeria hominumque dispensas concede propitius $405,217 \mathrm{r}$

Deus qui nobis sub sacramento mirabili passionis tuae memoriam reliquisti tribue 353, 60v; 405, 219v

Deus qui nos annua beati Floriani martyris tui sociorumque eius gloriosa passionis sollemnitate laetificas 14820, $86 r$

Deus qui nos beatae Mariae semper virginis et beatorum spirituum patriarcharum 654, 7Iv

Deus qui nos concedis omnium sanctorum memoriam agere 353, 149r

Deus qui nos concedis omnium sanctorum tuorum merita venerari $654,7 \mathrm{v}$

Deus qui nos hodie beatae virginis tuae annua sollemnitate laetificas $154,4 \mathrm{r}$

Deus qui nos miseros peccatores perire non sinis praesta quaesumus ut angelum mihi deputatum 353, 9r

Deus qui nos patrem et matrem honorare praecepisti miserere quaeso clementer animabus patris mei et matris meae omniumque parentum $654,87 \mathrm{r}$

Deus qui novo stellae signo novum filium regibus ostendisti praesta quaesumus ut intercedente benedicta et gloriosa semper virgine $353,176 \mathrm{r}$

Deus qui omnipotentiam tuam parcendo maxime et miserando manifestas multiplica super nos misericordiam tuam $353,45 \mathrm{v}$

Deus qui per coaeternam sapientiam hominem cum non esset condidisti 353, 18r, 20r, 23v

Deus qui populo tuo beatum Augustinum aeternae salutis ministrum constituisti 405, 222r

Deus qui post baptismi sacramentum secundam abolitionem peccatorum eleemosynis 405, 134r

Deus qui salutis aeternae beatae Mariae virginitate fecunda humano generi praemia praestitisti 353, 146r; 405, 211v

Deus qui summa providentia humano generi supernorum spirituum praesidia subministras $353,5 \mathrm{v}$

Deus qui tribus pueris mitigasti flammas ignium concede propitius 154, 8r; 252, 24r; 405, 225r

Deus qui unicum filium tuum ut servum redimeres sponte in mortem crucis tradidisti $654,45 \mathrm{v}$

Deus qui unigeniti filii tui domini nostri Iesu Christi pretioso sanguine humanum genus redimere dignatus es 654, $50 \mathrm{v}$

Deus qui unigeniti filii tui pretioso sanguine vivificae crucis vexillum sanctificare voluisti $405,221 \mathrm{r}$

Deus qui virginalem aulam beatae Mariae virginis in qua habitares eligere dignatus es 353, 30v

Deus sub cuius oculis omne cor trepidat omnesque conscientiae contremiscunt 654, 30v

Deus veniae largitor et humanae salutis amator quaesumus clementiam tuam 405, 128v, 129r; 654, 87r

Deus vitae dator humanorum corporum reparator qui a peccatoribus exorari voluisti exaudi quaesumus preces nostras 654, 36r

Devotus sit in choro discretus in capitulo sobrius in refectorio disciplinatus in omni loco 145, 314va

Dialectica est ars artium scientia scientiarum ad omnia methodorum principia habens viam. Sola enim dialectica probabiliter disputat de principiis omnium artium 605, 1ra

Dic ut sedeant hi duo filii mei etc. (Mt 20,21). Filius Dei volens loqui Iudaeis dixit haec verba quae etiam ego possum dicere. Mea doctrina non est mea sed eius $617,178 \mathrm{v}$

Dicit beatus Augustinus quod duplex est civitas 162, 8vb

Dicit beatus Iohannes in suo evangelio quod dominus interrogavit beatum Petrum de sua dilectione dicens 617, $175 \mathrm{v}$

Dicit Ecclesiasticus $(39,3)$ occulta Proverbiorum exquirit sapiens et in absconditis parabolarum 156, 1r 
Dicite filiae Sion Ecce rex tuus venit tibi mansuetus etc. ubi supra (Mt 21,5) et originaliter Zachariae 9 capitulo (9). Secundum doctores adventus domini agitur per quattuor hebdomadas ad denotandum quod est quadruplex adventus filii Dei 53, 1va

Dicitur vulgariter Bonum ferrum trahit homini argentum de bursa 617, 188v

Dicto de restitutione fienda damnificatis in rebus exterioribus nunc restat dicere de restitutione fienda in bonis animae et corporis $\mathbf{5 3}, 227 \mathrm{ra}$

Dictum est prius quomodo dulcissima virgo Maria est gloriose salutata in hoc verbo Ave. Nunc dicendum est quomodo gratiose est adornata 31, 69ra

Digitos in aures surde (!) et tandem rogaverunt tam ut imponeret sibi manum 177, 134rb

Dilecto sibi in Christo socio et amico N. clerico de tali loco verae sapientiae et augmentum continuum vitae praesentis. Iste liber cuius subiectum est ens mobile contractum ad naturam secretorum mulierum 155, 123r

Diligite inimicos vestros (Mt 5,44). Pro huius thematis introductione tres scholas reperio scilicet naturae, scripturae, gratiae. Primo dico quod invenio scholam naturae 597, 4ra

Diligite iustitiam qui iudicatis terram. Circa istum librum qui liber Sapientiae nuncupatur sunt in principio tria notanda 200, 2va

Dirigere sanctificare et regere digneris domine sancte pater omnipotens aeterne Deus 405, 128r

Discite a me quia mitis sum ... (Mt 11,29). Aristoteles In sempiternis nihil violentum. Qui ergo alte in caelo vult 153, $46 \mathrm{vb}$

Dissipavit bona sua vivendo luxuriose (Lc 15,13). Pro huius thematis introductione tres invenio scholas scilicet Medeae, Dyodonis, Ysiphilae. Prima ergo schola fuit Medeae nam Medea fuit filia Ochis (!) regis qui regnavit in insula Colchide 597, 25va

Distinctio prima Christus est nobis prope quattuor modis $174,4 \mathrm{v}$

Distribuit discumbentibus (Io 6,11). Pro huius thematis introductione reperio tres scholas mirificam, munificam, magnificam. Prima schola est mirificum (!) et haec schola est Dei. Prope enim Deus qui fecit mirabilia 597, $32 \mathrm{vb}$

Dividitur autem praesens opusculum in tres partes in quarum prima agitur de sacramentis 550, 2ra

Divina dispositione et providentia ab aeterno Deus piissimus disposuit postquam Iudaicus populus 53, 333rb

Divina scriptura istam habet proprietatem quod in una sui parte fideles admonet lacrimari 53, 304vb

Dixit angelus ad virginem de caelo missus. Et benedictus fructus ventris tui. Adicit Elisabeth spiritu prophetico inspirata 31, 49ra

Dixit Iesus turbis Iudaeorum et principibus sacerdotum Quis ex vobis arguet me de peccato si veritatem dico quare non creditis mihi etc. (Io 8,46). Quod quilibet homo et maxime Christianus debeat fugere lites et contentiones 53, 246ra

Doctrinarum autem animae. Capitulum tertium in quo determinatur de potentiis animae 163, 50v

Domina mea sancta Maria perpetua virgo virginum mater summae benignitatis et misericordiae deprecor te $\mathbf{6 5 4}$, $110 \mathrm{r}$

Domine Deus pater omnipotens qui nos ad principium huius diei pervenire fecisti 405, 127v

Domine Deus pater omnipotens qui consubstantialem et coaeternum tibi ante omnia saecula ineffabiliter $405,207 \mathrm{v}$

Domine Deus virtutum qui collapsa restauras et restaurata conservas 353, 193v

Domine Iesu Christe absolve me per sanctam captivitatem tuam ob omnibus vitiis 405, 211r

Domine Iesu Christe clementissime qui pro nobis peccatoribus mortem subiens temporalem nec materno dolori $353,101 \mathrm{v}$

Domine Iesu Christe fili Dei vivi mundi creator et redemptor qui dixisti 405, 220v

Domine Iesu Christe fili Dei vivi pone amaram mortem et passionem tuam inter animas nostras et misericordiam et districtum iudicium 14820, 86r

Domine Iesu Christe fili Dei vivi qui dixisti nolo mortem peccatoris sed ut magis convertatur et vivat quaeso pone amaram mortem 353, 143v, 146v, 149v, 152r, 153랄, 158r

Domine Iesu Christe fili Dei vivi qui es verus et omnipotens Deus splendor et imago patris vita aeterna 405, 207v

Domine Iesu Christe fili Dei vivi qui hora completorii sepultus es et a mulieribus planctus es et lamentatus 353, 92r

Domine Iesu Christe fili Dei vivi qui hora diei nona pendens in cruce et clamans voce magna te derelictum dixisti $353,85 \mathrm{v}$

Domine Iesu Christe fili Dei vivi qui hora diei prima permisisti te duci in consilio Iudaeorum 353, 79r

Domine Iesu Christe fili Dei vivi qui hora diei tertia fuisti ab Herode illusus 353, 81v

Domine Iesu Christe fili Dei vivi qui hora matutina stans ligatus 353, 77r

Domine Iesu Christe fili Dei vivi qui hora vesperarum cenasti cum discipulis tuis turbatus spiritu unum ex eis te traditurum 353, 89r

Domine Iesu Christe fili Dei vivi qui pretioso sanguine tuo mundum redemisti 654, 47r

Domine Iesu Christe fili Dei vivi qui pro nobis in cruce moriens dulcissimi lateris 353, 66r

Domine Iesu Christe fili virginis et matris Mariae qui hora matutinali pro salute humani generis ex Maria 353, 101v 
Domine Iesu Christe fili virginis Mariae salus mundi qui hora diei nona crucifixus manibus et pedibus verberibus et flagellis $353,108 \mathrm{v}$

Domine Iesu Christe fili virginis Mariae salus mundi qui hora diei prima Pilato praesidi fuisti praesentatus 353, 104r

Domine Iesu Christe fili virginis Mariae salus mundi qui hora diei sexta in cruce alta clavis durissimis affixus fuisti $353,107 \mathrm{r}$

Domine Iesu Christe fili virginis Mariae salus mundi qui hora diei tertia coram Pilato praeside purpura indutus fuisti 353, 105v

Domine Iesu Christe fili virginis Mariae salus mundi qui hora diei vespertina pressuris innumeris nimis fatigatus $353,111 \mathrm{v}$

Domine Iesu Christe iudex vivorum et mortuorum qui ob hoc irasceris ut subvenias ad hoc minaris 654, 49r

Domine Iesu Christe qui ante iudices legatis manibus stare voluisti 405, 212r

Domine Iesu Christe qui dum hora sexta pro redemptione mundi crucis ascendisses lignum 353, 190v

Domine Iesu Christe qui hora diei sexta ante crucem fuisti denudatus 353, 83v

Domine Iesu Christe qui in cruce suspensus es pro nostra redemptione tuum dulcissimum spiritum in manus Dei patris $405,224 \mathrm{v}$

Domine Iesu Christe qui in ultima cena tradidisti discipulis tuis $353,68 \mathrm{r}$

Domine Iesu Christe qui pro nobis peccatoribus in cruce agonizans 353, 103v, 105v

Domine Iesu Christe qui proprio sanguine tuo mundum redemisti redime me ab omnibus peccatis et neglegentiis 405, $215 r$

Domine Iesu Christe qui propter me mortem pati voluisti 405, 214r

Domine Iesu Christe rogo te per amaram extensionem omnium membrorum et nervorum tuorum 405, 213v

Domine Iesu Christe sanctifica me per spineam coronam et per sacra vulnera 405, 213r

Domine Iesu Christe virginis fili dulcissime qui cum proditore cenasti 353, 111r

Domine nonne bonum semen seminasti etc. (Mt 13,27). Plures sunt agri in quibus seminat 177, 44vb

Domine sancte pater omnipotens sempiterne Deus famulos tuos maiestati tuae subiectos per unicum filium tuum $353,125 r$

Domine sancte spiritus qui coaeternus coaequalis et consubstantialis patri filioque exsistens ab eis inenarrabiliter 405, 208r

Domine si fuisses hic frater meus non fuisset mortuus (Io 11,21). Pro huius thematis introductione reperio tres scholas scilicet elementalem, spiritualem, iudicialem. In his tribus scholis legitur mors. Prima ergo schola est elementalis quia composita originaliter ab his cum omne compositum resolvi 597, 34vb

Domini Iesu felix anima divinitati personaliter unita humanae infirmitatis defectus habuit mihi tristis fuit 353, 185r

Dominus Deus creavit hominem immo et totum mundum propter suam bonitatem 53, 124ra

Dominus Deus non invitat solum cottidie per suos nuntios praedicatores sed etiam per se ipsum 53, 119va

Dominus dicit in evangelio Paenitentiam agite appropinquabit enim regnum caelorum (Mt 3,2). Petrus apostolus dicit Paenitentiam agite et baptizetur 181, 41rb

Dominus Iesus Christus et magister noster pretiosum nostrae redemptionis pretium 53, 272rb

Dominus tecum (Lc. 1,28). O Maria dominus tecum te associans tecum te custodiens tecum te glorificans 31, 82ra

- Secundum ordinem naturalem in mundo corpora magis conformia in natura sint magis propinqua in situ 31, $79 \mathrm{vb}$

Domus mea domus orationis vocabitur (Mt 21,13). Pro huius thematis introductione invenio tres scholas scilicet Belzebub in Babylonia, Iani in Roma, Pharisaeorum in Ierusalem. Prima schola fuit in magna civitate Babyloniae in qua tractabatur 597, 9va

Dona ferunt proceres colitur quibus inclitus heres $\mathbf{3 0 8}, 228 \mathrm{va}$

Dubitatur numquid aliquid peccatum sit tam grande 165, 114r

Dubitatur utrum scientia naturalis est scientia de omnibus rebus $168,1 \mathrm{r}$

Ductus est Iesus in desertum a spiritu ut temptaretur a diabolo etc. (Mt 4,1). Ex quo omnia tempora tempus suum habent ut dicit sapiens Ecclesiastes 3 Est tempus flendi 53, 159ra

- Ex quo sequitur assumpsit eum diabolus etc. Dubitatur a quo spiritu ductus sit in desertum 53, 159vb

- Glossa dicit Christus non permisit se temptari nisi post baptismum 53, 164va

- Pro intellectu dubitatur quale fuit illud desertum ad litteram 53, 174va

- Sicut dicit Gregorius homilia 2 super evangelia Miracula domini et salvatoris nostri sic accipienda sunt 53, 174ra

- Sicut in bello corporali securius pugnatur et citius obtinetur triumphus contra hostes 53, 169rb

- Tota summa huius evangelii est quod Christus voluntarie ivit ad desertum locum 53, 170ra

- Totam vitam nostram plenam fecit Deus temptationibus et etiam rationabiliter Deus permittit electos suos temptari 53, 164ra

Dum mors grassatur puero fuga tuta paratur 308, 228va

Dum temptationes diaboli ipsum nimio molestarent 308, 47va 
Duo enim manifestantur in evangelio praesenti scilicet passio Christi et illuminatio cuiusdam caeci 153, 55rb

Duodecim sunt signa scilicet aries taurus ... Notandum quod in his duodecim signis sol perficit cursum suum 162, 4va

Ea facta quae dubia sunt ut quo animo in meliorem partem interpretemur 614, 282r

Ecce ascendimus Hierosolymam ... (Lc 18,31; Mt 20,18; Mc 10,33). Duo enim manifestantur in evangelio praesenti scilicet passio Christi et illuminatio cuiusdam caeci 153, 55rb

Ecce ego mitto angelum meum qui praeparabit viam ante faciem tuam (Mal 3,1). In verbis istis quattuor notantur. Primum est quod dominus dicit Ecce ego mitto angelum meum etc. Secundum est quod dicit 78, 29rb

Ecce evangelizo vobis ... (Lc 2,10). Nota quod inter omnia festa laetabunda totius anni hoc festum nativitatis est tanto laetius 153, 1va

Ecce filiae Ierusalem quas delicias vobis praeparavi 483, 76v

Ecce magi veniunt ... (Mt 2,1). Hodiernae diei festivitas magna est. Unde merito dicitur apparitio 153, 23ra

Ecce nunc tempus acceptabile ecce nunc dies salutis (2 Cor 6,2). Pro huius thematis introductione tres scholas reperio et fortunae, naturae, rationalis creaturae. Prima schola scilicet naturae dicit quod omnia naturalia 597, $6 \mathrm{rb}$

Ecce video caelos apertos (Act 7,56). Prosequendo sermonem iam inceptum tunc sciendum quod quanto caelum aperitur per intensam contritionem 153, 9rb

Ecclesia instituit quod per totum annum cantantur et praedicantur Christi miracula 53, 110va

Ecclesiae tuae quesumus domine preces placatus admitte 654, 65r

Ecclesiam tuam quaesumus domine benignus illustra ut beati Iohannis apostoli tui et evangelistae illuminata doctrinis $405,217 \mathrm{v}, 218 \mathrm{v}$

Ego dixi miserere mei domine. Sana animam meam quia peccavi tibi. Convertere domine 353, 53v; 405, 223v

Ego dominus exaltavi lignum humile et humiliavi lignum sublime (Ez 17,24). In his verbis agitur de duobus lignis. Primo de ligno salvationis in quo homo fuit vivificatus 617, $187^{\mathrm{I}} \mathrm{r}$

Ego sum nolite timere (Mc 6,50). Pro huius thematis introductione tres scholas reperio scilicet Epicureorum, Platonicorum, Hypotheticorum. Sed in omnibus istis scholis doctrina legitur quae secundum aliquam partem merito nobis timorem $\mathbf{5 9 7}$, 5rb

Ego sum pastor bonus. Bonus pastor animam suam dat pro ovibus suis (Io 10,11). Licet multae sunt causae in particulari quare lites et turbationes surgunt inter homines in mundo 53, 325ra

- Hic Christus seipsum commendat. Unde hic est dicendum quando quis potest se licite commendare et quando est veniale et quando est mortale 153, 109vb

- Sciendum quod per pastorem in praesenti evangelio intelleguntur praelati et per oves intelleguntur subditi $153,107 \mathrm{vb}$

Ego veniam et curabo eum (Mt 8,7). In his verbis notatur magna humilitas Christi qui servum centurionis dignatus est visitare 153, 39rb

Egredietur virga de radice Yesse (Is 11,1). Legitur de quinque virgis laudabilibus per quas beata virgo Maria merito figuratur $617,146 \mathrm{v}$

Egregius praedicator et apostolus invitans nos ad opera virtutum. In istis verbis tria facit. Primo allegat temporis opportunitatem 174, 168ra

Egressus Iesus cum discipulis suis trans torrentem Cedron ubi erat ortus etc. (Io 18,1). Quando enim occurrat festum alicuius sancti tunc consuevimus eius legendam et passionem ut Laurentii Petri etc. Sic enim hodie est flendum 174, 156ra

- Sapiens Ecclesiastes 3 (1 und 4) dicit quod omnia tempora tempus habent. Est tempus flendi et tempus ridendi 53, 280rb

- Sicut enim tunc vos scitis, quod mos praedicatorum est in principio sermonum praedicatorum ad beatam virginem recurrere $\mathbf{1 7 4}, 156$ ra

Egressus Iesus perambulabat Iericho (Lc 19,1). Zacchaeus interpretatur iustus sed quia ille iustus non erat ideo dominum videre non poterat. Sunt autem tres causae quare dominum videre non poterat. Primo propter divitias 162, 4ra

Egressus Iesus secessit in partes Tyri et Sidonis etc. (Mt 15,21). Inter cetera quae reconciliant peccatorem Deo postquam in peccatum mortale corruit est recognitio $53,236 \mathrm{vb}$

- Pro intellectu notandum sicut habetur Mt 14 Postquam Christus transfretavit per mare Tiberiadis venit Capharnaum 53, 237rb

Emitte quaesumus domine lucem tuam in corda nostra ut mandatorem 405, 41r

Eo tempore in Lamon sanctissimus monachus 308, 42ra

Eorum quae. Iste est liber secundus Physicorum in quo Aristoteles determinat de principiis doctrinae 168, 9r

Equus calidae naturae iudicatur sed temperatae calor ostenditur per levitatem 160, 4rb 
Erant duo socii simul coniuncti unus quaesivit alterum quis eorum remotius ambulasset. Dixit primus Fui in provincia 125, 311v

Erat Iesus eiciens daemonium et illud erat mutum etc. (Lc 11,14). Chrysostomus et Theophilus dicunt et habetur Matthaei 12 Ille daemoniacus erat mutus 53, 240va

- Daemones enim frequenter plus solito ante et circa Christi adventum obsidebant homines 53, 239ra

- Iohannes de Sancto Geminiano Videmus naturaliter quod lux habet expellere tenebras. Christus autem est lux 153, 69ra

- Quam detestabile sit vitium invidiae et fugiendum patet propter multa mala 53, 240ra

- Secundum quod dicit Beda in homilia de Christi transfiguratione ut patet Matthaei 17 Salvator humani generis Christus dominus 53, 238va

Erat Ioseph et Maria mater Iesu mirantes super his quae dicebantur de illo etc. (Lc 2,33). Augustinus in quodam sermone de Christi nativitate qui incipit Adiuvet nos humillimos 53, 57va

- Evangelium praesens tangit primo de parentibus salvatoris id est patre et matre 53, 58rb

Erudi quaesumus domine plebem tuam 194, 1r; 726, 1r

Erunt signa in sole luna et stellis etc. (Lc 21,25). Quod multum terribile sit extremum iudicium videtur posse trahi ex his quae in proximo sermone dixi 53, 11rb

- Christus dominus per scripturas nobis valde incutit timorem de extremo iudicio 53, 6va

- In praesenti evangelio monet nos dominus quatenus praeparemus nos ad istam ultimam rationem quam oportet nos facere in extremo iudicio 53, 7ra

Est amor ordinatus videlicet ut amet 165, 42ra

Est discretio testantisque suprema voluntas actio 155, 122ra

Est dubitatio de monialibus occulte corruptis quia in quibusdam monasteriis consuetudo est quod solae virgines 155, 10ra

Est enim semen verbum Dei quod Christus de caelo attulit in terra seminavit 153, 54ra

Est puer unus hic qui habet quinque panes ... (Io 6,9; vgl. Mt 14,17). Iohannes de Sancto Geminiano dicit quod totum officium praesentis diei dominicae continet quasi quaedam nova et laeta $153,71 \mathrm{vb}$

Est triplex typus rigor oripilatio frigus 748, 176ra

Estote imitatores Dei sicut filii carissimi (Eph 5,1). Pro huius thematis introductione invenio tres scholas scilicet dominorum, generatorum, magistrorum. Prima schola fuit dominorum et in ista et in aliis legitur quod omnes intendunt sibi assimilare 597, 27ra

Estote misericordes sicut et pater vester misericors est (Lc 6,36). Nota in praecedenti evangelio dominicali dicitur quod publicani et peccatores 174, 205va

Et accedens temptator dixit ei Si filius Dei es ... (Mt 4,3). Sciendum quod Christus voluit temptari ut ostenderetur quod nos spiritualiter pugnare oporteret $153,65 \mathrm{rb}$

Et cum ieiunasset 40 diebus et 40 noctibus postea esuriit (Mt 4,2). Sancti patres primitivi Christianae ecclesiae instituerunt ieiunium fidelibus observandum $53,176 \mathrm{vb}$

Et dedimur a Musis quae per Bocacium XI libro De genealogia Deorum gentilium 776, 23r

Et in evangelio hodierno sicut scriptura sacra Veteris et Novi Testamenti persuadet fideles ut diligant et amplexentur humilitatem 53, 30ra

Et quaerebat videre Iesum quis esset (Lc 19,3). Haec verba scribit Lucas de quodam Iudaeo qui vocabatur Zachaeus qui desiderabat videre filium Dei 162, 7va

Et si venenum multipliciter accipi possit hic per venenum id solum intellego quod qualitercumque humano corpori 748, $122 \mathrm{r}$

Et tunc videbunt filium hominis venientem in nube cum potestate magna et maiestate (Lc 21,27). Sicut valde consultum est servo procuratori alicuius potentis domini qui numquam rationem fecit $\mathbf{5 3}$, 19rb

- In istis verbis describit salvator adventum suum ad iudicium extremum 53, 20ra

Et ut tanti beneficii iugis in nobis maneret memoria corpus suum in cibum $353,57 \mathrm{v}$

Et veniat super nos misericordia tua domine 654, 64r

Evangelica clamat historia. Sine intermissione orate hoc est semper quidem orat qui semper bene agit $\mathbf{6 1 7}, 1 \mathrm{r}$

Evangelium praesens tangit primo de parentibus salvatoris id est patre et matre 53, 58rb

Ex praemissis patet quod quam cito homo moritur qui adhuc stat in innocentia baptismali 153, 152va

Ex quo dominus noster Iesus Christus in verbis praemissis invitat nos ad orandum tunc hic quaeritur 153, 123rb

Ex quo evangelium hodiernum mentionem facit de matrimonio et de nuptiis in quibus Christus Deus et homo cum benedicta matre 153, 35va

Ex quo hodie est ultima dies celebris praesentis festivitatis paschae et modo homines redire debent ad pristinos labores suos 153, 101ra

Ex quo hodie peragitur festum illorum puerorum innocentium qui ab iniquo Herode interfecti sunt 153, 14ra

Ex quo iam illis sacris diebus peragitur missio spiritus sancti tunc aliquid de donis spiritus sancti pro praesenti sermone dicendum est 153, 141rb

Ex quo in praesenti evangelio fit mentio de patrefamilias qui conduxit operarios 153, 50ra 
Ex quo in praesenti evangelio fit mentio de puero nobis recenter nato. Tunc pro praesenti sermone tria sunt dicenda. Primo quare Christus parvulus factus est 153, 15vb

Ex quo in verbis praemissis fit mentio de partu mulierum. Tunc in praesenti sermone tria sunt dicenda 153, 112vb

Ex quo inter cetera multum provocat ad virtutes et virtuosorum hominum laudabilis conversatio 53, 25vb

Ex quo omnia tempora tempus suum habent ut dicit sapiens Ecclesiastes 3 Est tempus flendi 53, 159ra

Ex quo sequitur assumpsit eum diabolus etc. Dubitatur a quo spiritu ductus sit in desertum 53, 159vb

Ex quo spiritus sanctus est fons totius dulcedinis tunc quaeritur quare Deus quandoque dilectis suis subtrahit in praesenti consuetam gratiam 153, 139ra

Ex quo tota Christi vita et conversatio nostra est instructio 53, 63ra

Ex testimoniis quattuor evangeliorum et exemplo Hieronymi contra Helvidium Sancta Maria mater domini et Maria mater Iacobi Alphaei et Ioseph et mater filiorum Zebedaei scilicet maioris Iacobi et Iohannis evangelistae tres sorores fuerunt $\mathbf{2 9 3}, 23 \mathrm{r}$

Exaudi domine Iesu Christe preces servorum tuorum qui cum Deo patre et spiritu sancto 405, $7 \mathrm{v}$

Exaudi domine preces nostras quas in sancti Wolfgangi confessoris tui atque pontificis sollemnitate deferimus $14820,85 \mathrm{v}$

Exaudi domine preces servi tui ad te clamantis qui in trinitate perfecta vivis et regnas Deus 353, 185r

Exaudi domine preces servorum tuorum ut animae fidelium defunctorum a poenis liberentur infernorum 654 , 35r

Exaudi nos Deus salutaris noster 405, 167r

Exaudi nos domine sancte pater omnipotens aeterne Deus invocationem omnipotentis filii tui 353, 130r

Exaudi nos misericors Deus et mentibus nostris sapientiae tuae lumen ostende 353, 21v

Exaudi quaesumus domine preces supplicum et confitentium tibi $\mathbf{6 5 4}, 25 \mathrm{r}$

Excita quaesumus domine in ecclesia tua spiritum cui beatus Augustinus confessor tuus et pontifex servivit 405, $221 \mathrm{v}$

Exemplum de quodam rege qui habuit duos camerarios valde invidos 308, 219ra

Exemplum legitur quod quidam pauper manibus laborabat 308, 201vb

Exiit edictum a Caesare Augusto (Lc 2,1). Secundum historiam post mortem Iulii Caesaris qui a poetis commendatur $53,47 \mathrm{vb}$

- Nota Octavianus imperator dictus est Augustus primus quia regnum Romanorum notabiliter auxit 53, 43va

- Sicut dicit Bernardus in sermone de epiphania Priusquam appareret Dei humanitas latebat 53, 47va

- Sicut omnipotens Deus verax est in praemissis Ita et misericors 53, 43rb

Exiit qui seminat ... (Lc 8,5). Ubi sciendum quod seminator est Deus omnipotens qui exiit seminare semen suum id est genus humanum creando 153, 51vb

Exorcizo te creatura salis in nomine patris omnipotentis et in caritate domini nostri Iesu Christi et in virtute spiritus sancti 726, 71r

Expurgate vetus fermentum etc. (1 Cor 5,7). Hodiernam paschalem videlicet festivitatem inter ceteras festivitates Christi praecipuam 53, 313vb

Extendit Noe manum et comprehensam columbam in arcam intulit (Gn 8,9). Hic tria possunt notari scilicet Mariae assumptio cum dicitur Extendit Noe manum secundo festivitas venerabilis Mariae cum dicitur Apprehensam columbam tertio assumptionis securitas cum dicitur In arcam 617, 182v

Fac nos quaesumus domine sanctae Mariae semper virginis subsidiis attolli $654,64 \mathrm{v}$

Facite dignos fructus paenitentiae (Mt 3,8; Lc 3,8). Ita hortatur nos praedicator paenitentiae beatus Iohannes Baptista in deserto praedicans baptismum paenitentiae Matthiae 3 et Lucae 3 quod specialiter nobis dicitur hoc sacratissimo ieiuniorum tempore legimus 53, 227vb

Famulorum tuorum quaesumus domine delictis ignosce ut qui tibi placere 353, 151v; 405, 214v, 221v

Febris secundum Avicennam quarto canonis in principio est calor extraneus accensus in corde et ab eo procedens mediantibus spiritu et sanguine ... Et talis calor extraneus quandoque est in spiritibus, quandoque in umoribus 123, $195 \mathrm{r}$

Fecit Moyses labrum aeneum de speculis mulierum quem plenum aqua posuit 293, 1r

Felices sancti Dei omnes qui pertransistis pelagus mortalitatis et pervenire 654, $2 \mathrm{v}$

Fert paranymphus ave quo mundus solvitur ave 308, 228rb

Fertur quoque quod dum vir quidam sancto Augustino valde devotus in spiritu raptus 308, 16va

Festina quaesumus domine Iesu festina ne tardaveris et auxilium nobis supernae virtutis impende 353, 178v

Fideles tuos quaesumus domine ab ira tua confugientes ad te paterna recipe pietate $654,32 \mathrm{v}$

Fidelium Deus omnium conditor et redemptor animabus famulorum famularumque tuarum omnium fidelium $\mathbf{4 0 5}$, 129r; 654, 87v, 92v

Filium tuum omnipotens pater ante saecula gemitum invocantes exoramus 353, 128r

Filius carnalis dicit confessori suo se duxisse in uxorem illam quam pater suus baptizaverit 155, 9vb

Filius Dei volens loqui Iudaeis dixit haec verba quae etiam ego possum dicere. Mea doctrina non est mea sed eius 617, $178 \mathrm{v}$ 
Fons crevit in flumen magnum (Est 10,6). Ibi dic historiam qualiter Mardochaeus somniavit duos dracones 617, $147 \mathrm{r}$

Fons vitae lassus solus sitit essibus assus 308, 228vb

Formavit Deus hominem ad imaginem et similitudinem suam 7, 66ra

Fragilitatem nostram quaesumus domine benignus respice et saporem nobis aeternae sapientiae 353 , 25v

Frater Ruodbertus eius monachus et secundum carnem 308, 62ra

Frequenter fit aurum potabile sic et confert pestilentiatis. Recipe auri optimi 748, 64v

Fuit quidam rusticus qui cum iret 308, 200vb

Fuit quidam vir lascivus valde contigit eum 308, 198rb

Galienus secundo de crisi dicit quod si videris urinam aegri tendentem $\mathbf{7 4 8}$, Iv

Gaude felix mater cum tibi per angelum Dei filius nuntiatur cum pudicus alvus tuus spiritu sancto fecundatur 353, $166 \mathrm{v}$

Gaude virgo quae de caelis iuxta vocem Gabrielis concepisti filium. Gaude mater Iesu Christi quia virgo peperisti creatorem omnium 353, 182v

Gaudete et exsultate omnes sancti quoniam merces vestra multa est in caelo (Lc 6,23). Verba proposita leguntur in evangelio hodierno et per ea insinuatur nobis gloria praemium omnium sanctorum quorum hodie festivitas celebratur $\mathbf{6 1 7}, 189 \mathrm{r}$

Gloriosa passio Christi perducat nos ad gaudia paradisi 353, 71r

Glossa dicit Christus non permisit se temptari nisi post baptismum 53, 164va

Glossa non fuit satis evangelistae dicere gavisi sunt sed addit valde magno gaudio 153, 25vb

Glossa semper quam non habet. Unde hic est dicendum quomodo homo debet iustus inveniri si vult salvari 153, $119 \mathrm{vb}$

Glossa semper quod habet. Unde hic est dicendum quomodo quis committit septem peccata mortalia 153, 119vb

Glossarum diversitas intelligentiam textus nec numquam obtenebrat 253, 1ra

Graecorum studia nimiumque diuque secutus 327, 20ra

Grana quater quinque scrupuli pro pondere summae $\mathbf{7 4 8}, 212 \mathrm{vb}$

Grata tibi sit domine haec oblatio plebis tuae quam tibi offerimus in honore sanctae $\mathrm{N}$ virginis tuae ut cunctis proficiat ad salutem $154,4 \mathrm{r}$

Gratia plena (Lc 1,28). Dictum est prius quomodo dulcissima virgo Maria est gloriose salutata in hoc verbo Ave. Nunc dicendum est quomodo gratiose est adornata 31, 69ra

- Notandum quod sicut sunt septem utilitates sive efficaciae quas gratia confert animae de quibus dictum est in sermone praecedenti dicendum est 31, 71va

- Prius dictum est quod gratia habet septem efficacias quas in anima facit et quod sunt septem praeparationes quibus homo ad gratiam se disponit 31, 73rb

- Prius dictum est quomodo Maria fuit gratiose salutata quod notabatur in hoc verbo Ave 31, 75vb

Gratias tibi agimus domine sancte pater omnipotens aeterne Deus qui nos de transacto noctis spatio ad matutinas horas perducere dignatus es $\mathbf{4 0 5}, 51 \mathrm{r}, 65 \mathrm{v}$

Gratias tibi ago omnipotens Deus qui me dignatus es custodire in hac nocte 405, 208r

Grex cum pastore pacis laetatur amore 308, 228va

Hae duae fuerunt ultimae sorores ex parte matris cum virgine gloriosa 53, 299vb

Haec circa officium curatorum breviter a me scripta sunt 550, 88ra

Haec est dies quam fecit dominus ... (Ps 117,24). Sciendum quod praesens festivitas praecellit alias festivitates in sollemnitate et iucunditate 153, 89va

Haec est vita virginis Mariae gloriosae/Summi Dei filii matris generosae ... Maria sibi regulam statuit vivendi/et sub quodam ordine Deo serviendi 166, 51va

Haec ita cogitans menti occurrit illa vocatio trina apostolorum qui primo ad notitiam 532, 1r

Haec sunt virtutes aquae ardentis vel vitae. Est enim clarior quam aqua rosacea et quia plus est secure 748, 53ra

Haec verba canit ecclesia per illud sacrum tempus paschale usque ad ascensionem 153, 91vb

Haec verba licet ad litteram sint dicta de agno paschali cuius immolatione 53, 251va

Haec verba locutus est dominus Deus et ante passionem suam post cenam 153, 109vb

Haec verba possunt exponi de beata Maria Magdalena quae intellegitur per arcum caelestem propter tria. Primo ratione materiae $\mathbf{7 8}, 69 \mathrm{vb}$

Haec verba scribit Lucas de quodam Iudaeo qui vocabatur Zachaeus qui desiderabat videre filium Dei 162, 7va

Haec verba sunt beati Petri ad commendationem et dignitatem sacerdotalem. In verbis praemissis possumus notare triplicem gradum sine excellentiam cuiuslibet sacerdotis. Primo eius dignitatem 597, 58ra

Haereticus quidam illud gloriosum corpus dicens publice 125, 200ra

Has horas canonicas Maria mater pia tuae laudi refero cordis symphonia 353, 161v 
Helleborus niger decoctus in pomo sub prunis datus in scrupulis II optime purgat tempore pestilentiae 748, 69v Heres est. Venite occidamus eum (Mt 21,38). Pro huius thematis introductione tres scholas invenio scilicet Polestinoris, Mesabellis, Pignaleonis. Prima schola fuit Polestinoris qui fuit rex cuiusdam insulae 597, 24rb

Hic dicendum est de caritate Dei quam habet ad nos et etiam de caritate quam nos ad ipsum habere debemus 153, $109 \mathrm{vb}$

Hic est dicendum quare Deus permittit aliquos bonos homines ita acerbissime tribulari in praesenti 153, 115rb

Hic est dicendum quare gaudium mundi est fugiendum et quando est mortale 153, 115va

Hic est vere salvator mundi (Io 4,42). Pro huius thematis introductione invenio tres scholas scilicet lapidum, herbarum, verborum. Prima ergo schola est lapidum et in illa legitur magna virtus. Nam videmus quod carbunculus 597, 30va

Hic Christus seipsum commendat. Unde hic est dicendum quando quis potest se licite commendare et quando est veniale et quando est mortale 153, 109vb

Hic contra morem vini gerit unda saporem 308, 228va

Hic iam est pars executiva in qua prosequitur intentum volens depellere ignorantiam depositionis circa quid sciendum quod duplex est ignorantia scilicet ignorantia abnegationis et ignorantia depositionis 167, 1rb

Hic possit quaeri de tempore et loco et sic de aliis. Ad illud respondet evangelista Iohannes 2 53, 85rb

Hic post postillationem evangelii alias habitam dicam solum de illa parte Venite ad me 53, 119vb

Hic s. Hieronymus sacerdos fuit ordine peregrinationis ... Frater Iacobus de varietatibus legendarum 165, 73va

Hic sumat peccatrix anima confidentiam tripliciter. Quia Christus venit quaesivit et salvum fecit venit nascendo quaesivit praedicando salvum fecit moriendo 162, 7rb

Hic tria possunt notari scilicet Mariae assumptio cum dicitur Extendit Noe manum secundo festivitas venerabilis Mariae cum dicitur Apprehensam columbam tertio assumptionis securitas cum dicitur In arcam 617, 182v

His verbis possumus quattuor notare. Primo quis sit Iacob secundo quod dormivit tertio quae sit scala quarto quod angelos vidit 162, 3va

Historia haec est de David quomodo planxit filium suum Absolon. Historia nota est scilicet quid significat 617, $163 \mathrm{v}$

Historia passionis Christi fuit per istum modum sicut tunc dicit beatus Iohannes evangelista qui tunc passionem filii Dei scripsit 174, 156'ra

Hoc evangelium facit memoriam de Christi passione et secundum Wilhelmum Duranti 53, 152ra

Hoc facite in meam commemorationem (1 Cor 11,24). In hodierna epistola dominus noster Iesus Christus de hoc mundo per passionem suam acerbissimam 53, 257vb

- Sacramentum mei corporis sumite quo ad fideles et conficite quo ad presbyteros 53, 258rb

Hoc opusculum dividitur in tres partes scilicet in exordium in quo benevolentia captatur tractatum 161, 9ra

Hodie agimus festum omnium angelorum et hoc propter plures causas. Primo quia singulariter omnes honorare non possumus. Isto die omnes honoremus $\mathbf{7 8 , 1 0 0 v a}$

Hodie carissimi dies celebratur insignis et festiva in tanto maioris devotionis affectu a singulis Christi fidelibus est celebranda 174, 163ra

Hodie divina dies resurrectionis colitur in quo (!) perfecta requies designatur 53, 322rb

Hodie in ecclesia agitur de duabus personis scilicet de Iuda qui est de honore suo detrusus $\mathbf{7 8}$, 35ra

Hodie sancta mater ecclesia duas processiones recolit 153, 79rb; 174, 162va

Hodie sancta mater ecclesia incipit celebrare adventum domini et hanc observantiam recepit a sanctis patribus $\mathbf{5 3}$, $1 \mathrm{ra}$

Hodie triplex festivitas celebratur. Una est de adoratione magorum 617, $139 \mathrm{r}$

Hodiernae diei festivitas magna est. Unde merito dicitur apparitio 153, 23ra

Hodiernae diei gaudiosa festivitas nos admonet et accendit aliquid de temporali Christi 53, 52rb

Hodiernam paschalem videlicet festivitatem inter ceteras festivitates Christi praecipuam 53, 313vb

Homo est optimum eorum quae sunt in mundo quattuor Ethicorum et mundus 155, 123r

Hora est iam nos de somno surgere (Rm 13,11). Egregius praedicator et apostolus invitans nos ad opera virtutum. In istis verbis tria facit. Primo allegat temporis opportunitatem 174, 168ra

Hos vocat in primis Pelagi salvator 308, 228va

Iam de mari composita fuerunt multa super primum librum. Sed adhuc super secundum quaeritur de perpetuitate vel generatione maris scilicet utrum fuerit perpetuum 440, 319ra

Ibi dic historiam qualiter Mardochaeus somniavit duos dracones 617, 147r

Iericho interpretatur luna et signat mundum propter suum defectum 162, 2va

Iesu mi dulcissime felicissima sapientia verbum patris principium et finis alpha et o omnium entium $353,14 \mathrm{v}$

Igitur locuturus hodie nunc amplius de dira Christi morte et innocenti passione 53, 281ra

Illo nos igne spiritus sanctus inflammet quem dominus noster Iesus Christus 353, 36r

Illud digne commendatur quod in se consideratum bonum apparet et aliis comparatum excellit 31, 84va

Illud est prius quo non existente non sunt alia sed sine fide 153, 67va 
Illumina quaesumus domine populum tuum et splendore passionum charismatum et gloriae rationalis ac beatissimae animae unigeniti filii tui domini nostri Iesu Christi 353, 188v

Immensa divinae largitatis beneficia exhibita populo Christiano inaestimabilem ei conferunt dignitatem $353,56 \mathrm{v}$ Imminente hora qua Christus dominus voluit pro nobis crucis passionem et mortem pati 53, 328va

Imperatoris susceptio est triumphi imitatio. Triumphus namque regis exhibebatur $483,72 \mathrm{v}$

Imperavit febri et dimisit illam (Lc 4,39). Pro huius thematis introductione invenio tres scholas videlicet Origenis, Augustini, Hieronymi. Prima schola est Origenis cuius talis fuit opinio seu doctrina 597, 30rb

In annuntiatione dominica Deus homo factus est et die eodem passus, Ioseph venditus, Isaac immolatus, Adam formatus 52, VDS

In conclusione prima dicitur quod de virtutibus potest esse scientia arguitur virtus non est scientialis 440 , 91rb

In exordio praesentis negotii Deo scientiarum domino humiliter invocato protestamur quod circa puncta nuper in forma publicae scripturae de oppido Ulmensi Constantiensis dioecesis transmissa 165, 129r

In fontibus ecclesiarum non in privatis domibus debet baptisma concedi 52, 39ra

In his verbis agitur de duobus lignis. Primo de ligno salvationis in quo homo fuit vivificatus 617, $187^{1} \mathrm{r}$

In his verbis notandum est quod sex sunt quae invitant nos ad petendum $\mathbf{6 1 7}, \mathbf{1 6 9 \mathrm { r }}$

In his verbis notatur magna humilitas Christi qui servum centurionis dignatus est visitare 153, 39rb

In his verbis tria videnda sunt scilicet quae sit dilecta quis sit dilectus quo et quomodo abiit. Circa primum sciendum quod dilecta est beata virgo $617,170 \mathrm{r}$

In historia ecclesiastica habetur de institutione vitae sanctorum patrum in Aegypto 165, 111rb

In hoc differunt Graeci a Latinis quia Graeci similiter omnes dicunt 52, 1ra

In hoc evangelio considerantur triplices personae scilicet Christus discipuli et turbae 53, 242vb

In hoc verbo Gabriel angelus sacramenti regalis conscius ac Dei fore virginis paranymphus describitur 31, 49vb

In hodierna epistola dominus noster Iesus Christus de hoc mundo per passionem suam acerbissimam 53, 257vb

In illo die quo videtur corpus Christi victus necessarius retribuitur lenia colloquia dimittantur 167, 71va

In illo evangelio duo notantur scilicet dignitas vocantis cum dicitur Sequere me 617, 187Iv

In illo tempore dixit Iesus discipulis suis. Scitis quia post biduum pascha fiet et filius hominis traditur ut crucifigatur... (Mt 26,2). Quia nullus evangelistarum materiam dominicae passionis plene ac complete conscripsit 756, 1ra

In illo tempore respondens Iesus dixit Confiteor tibi pater domine caeli et terrae quia abscondisti haec a sapientibus et prudentibus etc. (Mt 11,25). Dominus Deus non invitat solum cottidie per suos nuntios praedicatores sed etiam per se ipsum 53, 119va

- Hic post postillationem evangelii alias habitam dicam solum de illa parte Venite ad me 53, 119vb

- Sicut inter virtutes morales quae pertinentes sunt ad mores exteriores praecipue praecipua est gratitudo 53, $156 \mathrm{rb}$

- Quia Christus multa signa fecit in civitatibus Iudaeorum ipsi nihilominus in sua pertinacia permanserunt 53, $156 \mathrm{vb}$

In illo tempore stabat Maria ad monumentum foris plorans et reliqua (Io 20,11). Homilia Origenis. De praesenti sollemnitate locuturus auribus vestrae caritatis dilectissimi amor venit ad memoriam 161, 6ra

In istis verbis describit salvator adventum suum ad iudicium extremum 53, 20ra

In latinis quidem libris nullum auctorem invenire potui qui de urina certam et authenticam cognitionem dederit 748, 138 ra

In matutinis domine precibus pater sancte famulos tuos exaudi 405 , 77r

In mentibus nostris quaesumus domine tuae gratiae lumen infunde ut qui conceptum et natum de virgine Deum verum et hominem confitemur 353, 174r

In morbo materiali sunt habendae istae intentiones. Prima administratio regiminis debiti 748, 52r

In nomine domini Amen. Circa processum iudiciarium in causis delegatis et subdelegatis et ordinariis primo praemittitur cum impetrator rescripti $\mathbf{6 1 4}, 150 \mathrm{r}, 151 \mathrm{r}$

- Quia in libris sacrorum Canonum et in legibus imperialibus plerumque restat difficultas vocabulorum 155, 18ra

- Splendor paternae gloriae 76, 66r

In nomine sanctae et individuae trinitatis et in honore sanctae Mariae perpetuae virginis et sanctae Margarethae virginis et martyris omniumque caelestium virtutum consecrata est haec ecclesia anno dominicae incarnationis millesimo centesimo quinquagesimo sexto 293 , 22r

In odium quoque Christianorum Iulianus templum 308, 149vb

In omnibus doctrinis quae secundum ordinem currunt incessus sunt secundum rerum ordines. Una earum est quae fit secundum $453,1 \mathrm{v}$

In peccato vestro moriemini (Io 8,21). Pro huius thematis introductione invenio tres scholas scilicet caeli, paradisi, mundi. Prima ergo schola fuit caeli. Nam in principio creavit Deus caelum et terram 597, 18vb

In praecedenti sermone dixi de signis adventus diei iudicii 53, 13ra

In praesenti enim evangelio instruit Maria parentes qualiter se debeant habere ad filios 153, 27va 
In praesenti evangelio dominus ostendit multorum auditorum Christi devotionem 53, 139ra

In praesenti evangelio monet nos dominus quatenus praeparemus nos ad istam ultimam rationem quam oportet nos facere in extremo iudicio 53 , 7ra

In praesenti evangelio ponuntur duo principalia. Primum de Christi passione 53, 146rb

In quadam legenda transmissa de Roma 125, 199vb

In quibus verbis monemur ne a bono iam incepto desistamus 153, 94va

In sempiternis nihil violentum. Qui ergo alte in caelo vult 153, 46vb

In summis festis ad missam dicitur una. Tantum collecta nisi sit coniuncta diei. In defunctorum collectam dicere missa de sanctis poteris sed illa paenultima fiat $167,1 \mathrm{rb}$

In verbis istis apostolus duo facit, ostendit enim fidelis animae sanctitatem et exsecratur sanctitatis violatorem 162, 8ra

In verbis istis notandum quod ad impetrandum salutaria quattuor oportet considerare videlicet a quo sit petendum quid sit petendum qualiter sit petendum quando sit petendum $617,168 \mathrm{v}$

In verbis istis ostendit nobis spiritus sanctus quaedam signa in beato Nicolao propter quae signa obtinuit benedictionem omnium gentium $\mathbf{7 8}, 4 \mathrm{rb}$

In verbis istis quattuor notantur. Primum est quod dominus dicit Ecce ego mitto angelum meum etc. Secundum est quod dicit 78, 29rb

In verbis istis tria notantur de sancto Bernhardo. Primo sanctitas vitae cum dicitur Vidi alterum angelum descendentem de caelo amictum nube. Primus enim angelus fuit beatus Benedictus 78, 80ra

In verbis propositis notatur triplex martyrium quod suscipit beatus Bartholomaeus fuit enim fustigatus deinde vivus excoriatus postremum decollatus $617,183 \mathrm{r}$

Incipit tractatus venerabilis doctoris Iohannis Gerson olim cancellarii Parisiensis de oratione et suo valore 754, 1r

Inclina domine aurem tuam ad preces nostras quibus misericordiam tuam suppliciter deprecamur ut animam famuli tui $654,86 \mathrm{v}$

Inclinato capite emisit spiritum ... (Io 19,30). Iohannes de Sancto Geminiano dicit Mors salvatoris carissimi quam hodie recolimus fuit ultima consummatio dominicae passionis 153, 86ra

Infer digitum tuum huc (Io 20,27). Sciendum primo quod Christus servavit cicatrices vulnerum in suo corpore glorificato 153, 104va

Infirmitatem paupertatem tribulationem atque omnem angustiam nostram $654,11 \mathrm{v}$

Infunde quaesumus domine Deus tuae cordibus lumen sapientiae $353,22 \mathrm{v}$

Ingressus Iesus ambulabat Iericho (Lc 19,1). Iericho interpretatur luna et signat mundum propter suum defectum 162 , 2va

Iniquitates nostrae contenderunt contra nos domine libera nos $654,18 \mathrm{v}$

Inspice et fac secundum exemplar quod tibi in monte monstratum est (Ex 25,40). Nota quod Deus duo genera sanctorum habet in caelo quosdam abscondit a nobis et quosdam nobis monstravit $\mathbf{6 1 7}, \mathbf{1 9 1 \mathrm { v }}$

Intentiones habendae in febribus excerptae ex mente Avicennae ex locis universalibus et particularibus. In cholerica interpolata pura sunt intentiones. Est administratio regiminis debiti sex rerum $\mathbf{7 4 8 , 4 1 r}$

Intentionis discussio - ne propter vanam gloriam 167, 72r

Inter cetera quae reconciliant peccatorem Deo postquam in peccatum mortale corruit est recognitio 53, 236vb

Inter doctores populi sedet et seniores 308, 228va

Inter medicinas et corpora currunt proportiones quae non comprehenduntur nisi cum experimento $748,52 \mathrm{v}$

Interrogatus Socrates a quodam quomodo posset optime respondere seu dicere. Respondit Si nihil 123, 1r

Interveniat pro nobis domine Iesu Christe nunc et in hora nostrae mortis apud tuam clementiam gloriosa Dei genitrix virgo Maria 353, 163r

Interveniat pro nobis quaesumus Deus sanctus tuus Lucas evangelista qui crucis mortificationem 405, 219v

Interveniat quaesumus domine Iesu Christe pro nobis apud tuam ineffabilem clementiam nunc et in hora mortis nostrae 353, 114r

Iohannes abbas cum quendam qui per quadraginta annos in eremo habitaverat interrogasset $\mathbf{3 0 8}, 48 \mathrm{vb}$

Iohannes de Sancto Geminiano dicit Mors salvatoris carissimi quam hodie recolimus fuit ultima consummatio dominicae passionis 153, 86ra

Iohannes de Sancto Geminiano dicit quod totum officium praesentis diei dominicae continet quasi quaedam nova et laeta $153,71 \mathrm{vb}$

Iohannes de Sancto Geminiano Videmus naturaliter quod lux habet expellere tenebras. Christus autem est lux 153, 69ra

Iohannes episcopus servus servorum Dei. Ad perpetuam rei memoriam valitura canonum. Non est dubium pertinere cum statuta a se vel praedecessoribus suis edita obesse percipit potius quam prodesse ne ulterius adesse valeant providere. Dudum si quidem felicis recordationis Nicolaus papa IIIus praedecessor noster attente prospiciens 99, 33vb

Iohannes qui non est pater meus nec consanguineus duxit matrem meam in uxorem suam. Ipsa moritur postmodum 155, 10ra 
Iordanis sacri subit hic baptisma lavatri 308, 228va

Ipsi soli servies (Mt 4,10). Pro huius thematis introductione invenio tres scholas scilicet Eremitarum, Praedicatorum, Minorum. Prima schola est Eremitarum in Aegidio qui videtur velle tenere quod si primus homo non peccasset 597, 7ra

Ista dies praecipue maior est omnibus festivitatibus 174, 155ra

Ista scribit beatus Lucas et sunt verba nostri salvatoris suam dilectionem quam ad quendam humanum habuit 162, 1ra

Iste est liber sextus Physicorum, in quo philosophus determinat de divisione motus et quietis in suas partes 163, 1r Iste liber Physiologus intitulatur et dicitur a physis id est natura 155, 151r

Isti sunt filii [...] Iohannes bonus et Lafrancus filius Ambrosii est Albertus Zicerius 360, 26r

Ita hortatur nos praedicator paenitentiae beatus Iohannes Baptista in deserto praedicans baptismum paenitentiae Matthiae 3 et Lucae 3 quod specialiter nobis dicitur hoc sacratissimo ieiuniorum tempore legimus 53, 227v Item cum quidam frater in subscripta manens 125, 199rb

Item dum exercitus domini regis Roberti 125, 199ra

Item Favinus de Slappis 125, 199rb

Item Iohannes infans cum sorore maiore 125, 199va

Item magister barbatus sancti Georgii 125, 199ra

Item maiora de terra 125, 199va

Item miles quidam Gallicus familiaris 125, 199rb

Item mundus assimilatur duobus viris scilicet patri et filio quorum unus scilicet pater equitabat super asinum et filius pedester ambulabat 153, 161ra

Item nota quod febricitantibus acutarum febrium et etiam aliis qui patiuntur $\mathbf{7 4 8}, 212 \mathrm{v}$

Item nota quod per quidditatem animae intellegitur summa et essentia ipsius animae 163, 79v

Item Petrus frater domini Matthaei de Salerno 125, 199rb

Item pro secundo sermone in hac die tria sunt dicenda. Primo quomodo quattuor genera hominum 153, 84ra

Item quaedam mulier in Arriano peperit 125, 199rb

Item quidam nobilis falconem unum perdiderat 125, 199rb

Item si alicui presbytero praesentaretur femella et ipse putaret masculum $\mathbf{5 5 0}, 4 \mathrm{vb}$

Item si est haereticus. Item si publicus peccator poena usurarius concubinarius etc. 145, 314va

Item ubi quis in testamento disposuit 145, 314vb

Iuste iudicate filii hominum et nolite iudicare secundum faciem sed secundum iustum iudicium iudicate ut ostendatis vero diligere iustitiam qui iudicatis $\mathbf{1 0 7}$, 1ra

Lacrimis rigavit pedes meos (Lc 7,44). Pro huius thematis introductione invenio tres scholas scilicet arborum et plantarum, vaporum et nebularum, dolentium animarum. Prima schola est plantarum et arborum in qua talis doctrina legitur quod quando arbores plorant 597, 37rb

Laetifica et adiuva qui sumus omnipotens et misericors Deus dominicae annuntiationis et conceptionis gaudia recolentes $353,172 \mathrm{r}$

Legitur de quinque virgis laudabilibus per quas beata virgo Maria merito figuratur 617, 146v

Legitur de sancto Severino quod vivens mortuos suscitavit imo omnem infirmitatem 308, 197vb

Legitur de sancto Udalrico cum vellet causa devotionis 308, 200va

Legitur quod in dioecesi Tridentina quidam latro fuerat famosus 308, 193ra

Liber Aviani poetae in quo primo introducit fabulam de villana et lupo ostendens in eo quod fraudulenti mulieri non est fides $155,155 \mathrm{v}$

Liber ergo iste in quinque partes dividitur. Prima est de essentia febris eiusque definitione febris naturam et causas 748, 162ra

Licet laico plus in die 483 , 28r

Licet multae sunt causae in particulari quare lites et turbationes surgunt inter homines in mundo 53, 325ra

Licet mundus iste primo appareat valde amicus tranquillus et pacificus hominibus $\mathbf{5 3}, 114 \mathrm{va}$

Licet secundum Augustinum in quodam sermone ad fratres Non debeamus loqui sublimia 53, 242rb

Loquendo de manducatione huius venerabilis sacramenti sciendum quod hoc sacramentum tripliciter sumitur $\mathbf{1 5 3}$, $158 \mathrm{va}$

Magister Iacobus scutellarius commendabilis vitae 125, 198vb

Magistri scholarum litterarum aiunt animam esse substantiam simplicem speciem naturalem distantem a materia corporis sui organum membrorum $597,57 \mathrm{vb}$

Magnam hodie et praecipuam carissimi omnique devotione recolendam agimus sollemnitatem ad cuius celebrationem venerandam venerabilis Hugo de Sancto Victore in quodam sermone ipsius sollemnitatis nos devote invitat 174, 166va 
Maiestatem tuam domine supplices exoramus ut sicut iugiter sanctorum tuorum 405, 221v

Maiestatem tuam domine suppliciter exoramus ut sicut ecclesiae tuae beatus Andreas 405, 219v

Mane nobiscum domine (Lc 24,29). Circa quod sciendum quod sunt sex quae debent hominem retrahere ab omni peccato mortali 153, 96ra

- Haec verba canit ecclesia per illud sacrum tempus paschale usque ad ascensionem 153, 91vb

- In quibus verbis monemur ne a bono iam incepto desistamus 153, 94va

Manus Zorobabel fundaverunt eam $(\mathrm{Za} 4,9)$ scilicet animam per istum Zorobabel eam 165, 144rb

Marcus Valerius Probus unicae vetustatis amator 780, 1r

Maria du hochgelobter Namen ein Khönigin des Himels 397, I*v

Maria Magdalena et Maria Iacobi et Salome emerunt aromata ut venientes ungerent Iesum (Mc 16,1). Divina scriptura istam habet proprietatem quod in una sui parte fideles admonet lacrimari 53, 304vb

- Hae duae fuerunt ultimae sorores ex parte matris cum virgine gloriosa 53, 299vb

- Praesens Novi Testamenti praecipua festivitas inter ceteras venerabilis toto orbe terrarum 53, 299ra

Maria mater gratiae mater misericordiae tu nos ab hoste protege in hora mortis suscipe 405, 208v

Martha ministrabat (Io 12,2). Pro huius thematis introductione invenio tres scholas scilicet internas, alternas, subalternas. Prima est interna et est voluntatis et in hac legitur quod ea quae sunt in homine ipsi voluntati praesenti principaliori et digniori subalternas serviunt $5 \mathbf{9 7}, 42 \mathrm{ra}$

Matutina supplicium vota quaesumus domine propitius intuere 405, 31r

Medicina est scientia sanorum aegrorum et neutrorum 453, $1 \mathrm{v}$

Memento ut sanctifices diem sabbati. Per sabbatum intellegimus sollemnitates sanctorum in quibus quam plurimum homines vacant commessationibus et ebrietatibus 308, 225va

Memoriam esse thesaurum inventorum eleganter ait Cicero in Rhetoricis ad Herennium libro tertio 4, 1ra

Mentes nostras quaesumus domine spiritus sanctus reparet 353, 34r

Miles quidam apud Fridericum imperatorem in multis est accusatus 308, 191rb

Miles quidam beatum Thomam apostolum ardenter diligebat 308, 196rb

Miles quidam in dandis decimis suis tantae erat iustitiae ut ei summum esset studium 308, 197ra

Minos Iovis et Europae filius Androgeum Ariadnam Phaedram Deucalionem et Molum progenuit. Ex Deucalione Idomeneus ex Molo Meriones seu Mirion et Idomeneus alter nascitur. Item Tantalus Iovis filius genuit Pelopem 691, $1 \mathrm{r}$

Miseremini mei etc. (Iob 19,21). Notandum monere paenitentiae portando debemus fratres nostros exemplo Christi qui poenam peccatorum portavit $\mathbf{7 8}, 113 \mathrm{rb}$

Miserere domine per sanctam annuntiationem adventum nativitatem ieiunium 654, 91v

Miserere mei fili David (Mt 15,22). Pro huius thematis introductione tres scholas reperio scilicet illustrium magnificorum secunda eloquentium tertia decipientium et proditorum. Prima schola fuit illustrium etc. 597, $12 \mathrm{ra}$

Miserere nostri Deus omnium et respice nos (Sir 36,1). Pro huius thematis introductione tres scholas reperio ethicam seu monasticam, oeconomicam seu familiarem, politicam seu civilem. Prima schola est monastica in qua legitur 597, $14 \mathrm{rb}$

Misericors pater qui est prope est omnibus invocantibus eum in veritate quia nos orphanos non relinquit 53, 344rb

Miserunt Iudaei a Hierosolymis sacerdotes et levitas ad Iohannem ut interrogarent eum Tu quis es Iohannis 1 capitulo (19). Et in evangelio hodierno sicut scriptura sacra Veteris et Novi Testamenti persuadet fideles ut diligant et amplexentur humilitatem 53, 30ra

- Secundum Originem Iudaei videntes prope esse tempus adventus Messiae 53, 30va

Misit digitos suos ... (Mc 7,33). Digitos in aures surde (!) et tandem rogaverunt tam ut imponeret sibi manum 177, $134 \mathrm{rb}$

Missae sunt celebrandae in locis Deo consecratis vel in locis in quibus episcopus permiserit celebrare quia melius est missam non celebrare aut non audire 155, 14rb

Missus est Gabriel angelus a Deo (Lc 1,26). In hoc verbo Gabriel angelus sacramenti regalis conscius ac Dei fore virginis paranymphus describitur 31, 49vb

- Vehementia desiderii, fervore devotionis, puritate orationis fontem attingit pietatis 171, 88rb

Mittens Herodes occidit omnes pueros ... (Mt 2,16). Ex quo hodie peragitur festum illorum puerorum innocentium qui ab iniquo Herode interfecti sunt 153, 14ra

Mittite partes eis qui non praeparaverunt sibi $(2$ Esr 8,10). Consuetudo in mundo est quando aliquis usque in mortem in carcere cruciatur mittit ad amicos suos de quibus maxime confidit 78, 112ra

Modicum et iam non videbitis me (Io 16,16). Haec verba locutus est dominus Deus et ante passionem suam post cenam 153, 109vb

- Imminente hora qua Christus dominus voluit pro nobis crucis passionem et mortem pati 53, 328va

Modus est nobilium et aliorum honestorum virorum quod ad filiorum suorum custodiam et instructionem ponunt suos servos 78, 98va

Monachus quidam vitae laudabilis sed corpore debilis fuit 308, 192vb 
Mortem non gustabit in aeternum (Io 8,52). Pro huius thematis introductione invenio tres scholas scilicet planetae, cometae, monetae. Prima est planetae et in hac legitur vita secundum quod melior est constellatio vel planeta de tanto efficimur levioris vitae $597,35 \mathrm{vb}$

Mortuus est dives et sepultus est in inferno (Lc 16,22). Pro huius thematis introductione invenio tres scholas scilicet Sardanapalli in Asia, Catilinae in Roma et Attilae in Hungaria. Prima ergo schola est Sardanapalli 597, 22va

Mos paganorum versus est in religionem Christianorum 483, 76r

Motus magnus factus est ... (Mt 8,24; Mc 4,37; Lc 8,23). Ubi sciendum est quod per mare intellegitur praesens mundus et per motum magnum 153, 41va

Mulier dum parit tristitiam habet (Io 16,21). Ex quo in verbis praemissis fit mentio de partu mulierum. Tunc in praesenti sermone tria sunt dicenda $153,112 \mathrm{vb}$

Mulier magna est fides tua ... (Mt 15,28; Mc 7,25) etc. Aristoteles $8^{\circ}$ Physicorum Illud est prius quo non existente non sunt alia sed sine fide 153, 67va

Mulier uxor alicuius confitetur sacerdoti se tenuisse filium proprium coram episcopo 155, 9vb

Multae fuit potestatis erga daemones pellendos non solum ex hominibus 308, 28rb

Multae subtilitatis fuit erga daemones cognoscendos. Quadam vice diabolus in forma regis purpura 308, 28rb

Mundat leprosum tangens sub lege perosum 308, 228va

Mundus autem gaudebit (Io 16,20). Hic est dicendum quare gaudium mundi est fugiendum et quando est mortale 153, 115va

Musica humanae vitae necessaria nedum apud Graecos aut Romanos verum etc. apud barbaros semper magna laude prosecuta est 776, $13 r$

Nabuchodonosor quippe rex Babylonis bellica manu Ierusalem destruxit 483, 38v

Nec ego te condemnabo (Io 8,11). Pro huius thematis introductione invenio tres scholas scilicet vulgaricam, canonicam, theologicam et in his legitur quod nullus possit iudicari 597, 32ra

Nemo potest conficere corpus Christi nisi sacerdos qui rite fuerit ordinatus secundum claves ecclesiae 155, 10rb

Nemo potest venire ad me nisi pater meus traxerit eum (Io 6,44). Sciendum quod circa praedicta verba tria sunt dicenda. Primo quomodo Deus trahit et vocat hominem 153, 144rb

Nemo propheta acceptus est in patria sua (Lc 4,24). Pro huius thematis introductione tres scholas invenio scilicet filiorum, inimicorum, discipulorum. Prima schola est filiorum. In hac considero inter filios primi parentis 597, 29ra

Nescitis quid petatis (Mt 20,22). Pro huius thematis introductione tres scholas reperio videlicet mundi, carnis, daemonis. Prima schola est mundi in prima legitur apparentia sive existentia 597, 21rb

Nicolaus Iohannis marescalci 125, 199va

Nimis honorati sunt amici tui Deus (Ps 138,17). Dicitur vulgariter Bonum ferrum trahit homini argentum de bursa 617, $188 \mathrm{v}$

Nisi quis renatus fuerit ex aqua ... (Io 3,5). Sciendum quod triplex est nativitas naturalis spiritualis et caelestis $\mathbf{1 5 3}$, $150 \mathrm{va}$

- Ex praemissis patet quod quam cito homo moritur qui adhuc stat in innocentia baptismali 153, 152va

Noctis sub silentio tempore brumali deditus $\mathbf{3 0 8}$, 189ra

Nomen virginis Maria (Lc 1,27). De dulcissimo nomine ipsius Mariae adhuc amplius videamus. Est notandum quod nomen huius dulcissimae virginis est a Deo revelatum 31, 58rb

- De nomine huius ineffabilis virginis adhuc est plus dicendum. Et est notandum quod haec virgo postquam Christum concepit reperitur in scriptura 31, 60va

- Nulla res potest amari nec laudari nisi prius cognoscetur dicente Augustinus (!) de trinitate 31, 55va

- Prius dictum est de nomine. Nunc dicendum est de hoc vocabulo Maria. Et est notandum quod quattuor genera volatilium solent nidos suos ornare $31,65 \mathrm{va}$

Non enim volebat in Iudaeam ambulare quia quaerebant eum Iudaei interficere (Io 7,1). Pro huius thematis introductione tres scholas invenio scilicet Martis, partis, mortis. Prima est Martis. Nam Mars ut pluries dictum est planeta malevolus est et nati sub illo sunt pessimi 597, 36va

Non est vir in domo sua abiit via longissima secum tulit sacculum pecuniae in die plenae lunae reversurus (Prv 7,19). Verba proposita possunt esse interioris hominis id est animae respondentis ad quaestionem sibi factam $\mathbf{6 1 7}$, $171 \mathrm{r}$

Non rapinam arbitratus est esse se aequalem Deo (Phil 2,6). Pro huius thematis introductione invenio tres scholas angelicae naturae, humanae creaturae, artificialis figurae et in omnibus his legitur forma rapinae. Prima schola est angelicae naturae in qua legitur rapina 597, 40va

Non solum Christi verba sunt nobis in documentum sed etiam Christi facta sunt nobis in exemplum 153, 30va

Non sumas nomen Dei tui invanum. Augustinus: Nomen Dei sumit invanum qui semper turpia verba profert ex corde. Unde legitur in dialogo Gregorii 308, 211rb 
Non sumus filii ancillae sed liberae (Gal 4,31). Pro huius thematis introductione tres scholas invenio scilicet potentiarum, naturarum, grammaticorum. Nam prima est potentiarum et quia habemus plures potentias 597, 32rb

Nonae Aprilis norunt quinos 360, 26r

Nos cum prole pia benedicat virgo Maria 405, 209v

Nos enim videmus ad sensum quod quando aliqui evaserunt mortem qui fuerunt in bello fortissimo ubi multi mortui fuerunt ad suos dilectos veniunt et dicunt 174, 90vb

Nota in praecedenti evangelio dominicali dicitur quod publicani et peccatores 174, 205va

Nota Octavianus imperator dictus est Augustus primus quia regnum Romanorum notabiliter auxit 53, 43va

Nota oleum factum per decoctionem medicinarum 748, 54ra

Nota praedicatores dicuntur pastores quibus dicuntur Iohannes XXI ${ }^{\circ}$ Afferte mihi de piscibus 174, 222ra

Nota quando tritulator est debilis et habet grave flagellum in manu 174, 187rb

Nota quod Deus duo genera sanctorum habet in caelo quosdam abscondit a nobis et quosdam nobis monstravit 617, $191 \mathrm{v}$

Nota quod est triplex via. Prima in mundum, secunda per mundum, tertia extra mundum. Prima via in mundo (!) est lamentabilis 78, 64vb

Nota quod inter omnia festa laetabunda totius anni hoc festum nativitas est tanto laetius 153, 1va

Nota quod omnis dispositio 532, 124v

Nota quod post symbolum apostolorum quod dicitur Credo in Deum concilia praedicta fuerunt olim a sanctis patribus de summa trinitate et fide catholica contra quosdam haereticos de quibus quattuor conciliis legitur 155, 106ara

Nota quod quidam Deum recipiunt in domum suam et non in animam quidam in animam et non in domum quidam in animam et in domum quidam nec in animam nec in domum 162, 1va

Nota quod sponsa Christo debet se praeparare ad eius adventum quinque modis. Primo se lavando 162, 6va

Nota quod succus paeoniae vulneribus noviter fissis applicatus nondum ad sanationem provenientibus curat $\mathbf{7 4 8}$, $69 \mathrm{v}$

Nota rupto apostemate et extracta materia $\mathbf{7 4 8 , 6 6 r}$

Nota secundum Averroim quod medicina est de subiecto cuius subiecti ratio in medicina salvatur 453, $1 \mathrm{v}$

Nota verum secretum in provocatione urinae. Recipe corticis interioris 748, 54ra

Notandum circa textum nonnulli priorum opinati sunt quod quando anima ingrediebatur corpus 163, 35r

Notandum monere paenitentiae portando debemus fratres nostros exemplo Christi qui poenam peccatorum portavit 78, 113rb

Notandum quod beatus Thomas Christum discipulis apparentibus non vidit quia non fuit cum eis sed post octo dies eum vidit 153, 103va

Notandum quod Octavianus imperator 42 anno imperii sui quia 57 annis regnavit et versus finem valde pacifice $53,52 \mathrm{vb}$

Notandum quod quintuplex est anima scilicet anima immunda anima rapta anima sepulta anima salvata anima cruciata 617, $190 \mathrm{r}$

Notandum quod sicut sunt septem utilitates sive efficaciae quas gratia confert animae de quibus dictum est in sermone praecedenti dicendum est $\mathbf{3 1}, 71 \mathrm{va}$

Notandum tamen etc. quod quidam sacerdos $550,24 \mathrm{vb}$

Nova lux oriri visa est honor et tripudium apud omnes populos urbes et provincias (Est 8,16). Quia nativitatem beatae Mariae agimus ideo gaudere debemus quia ipsa est stella 78, 91rb

Nova veniens e caelo nuptiali thalamo (vgl. AH 51, Nr. 102, Str. 2). Nota quod sponsa Christo debet se praeparare ad eius adventum quinque modis. Primo se lavando 162, 6va

Novicius indutus quantocius potest in generali confessione se expediat in qua non sit nimis scrupulosus $617,95 \mathrm{v}$

Novissime audistis quomodo in hoc sacratissimo tempore matamur (!) ad paenitentiam 53, 232va

Nulla obstetrix nulla muliercularum sedulitas intercessit ipsa pannis involvit infantem 52, 38vb

Nulla res potest amari nec laudari nisi prius cognoscetur dicente Augustinus (!) de trinitate 31, 55va

Nullum etiam sacramentum est isto salubrius quo purgantur peccata $353,58 \mathrm{v}$

Numquid Iudaeus litigans cum Christiano iurabit de calumnia super evangelio videtur 155, 6va

Nunc ergo de confessione videndum est ad quam homo obligatur qui peccavit mortaliter ex Dei institutione et praecepto (Io 20,22) ubi confessionem instituit quando dixit apostolis Accipite spiritum sanctum 53, 205ra

Nunc igitur de gula videndum est isto tempore sacro quia secundum Gregorium 53, 191ra

Nunc igitur iuxta praemissa sicut dixi ad contemplationem 53, 252ra

Nuptiae factae sunt in Chana Galilaeae (Io 2,1). De prima parte evangelii dicendum est sed referendo ad nuptias corporales de quibus loquitur specialiter evangelium 53, 89vb

- Ex quo evangelium hodiernum mentionem facit de matrimonio et de nuptiis in quibus Christus Deus et homo cum benedicta matre 153, 35va

- Hic possit quaeri de tempore et loco et sic de aliis. Ad illud respondet evangelista Iohannes 53, 85rb 
- Prima pars praesentis evangelii congruit multum praesenti tempore in quo celebrantur nuptiae et matrimonia $53,92 \mathrm{vb}$

- Propter multiplicationem humani generis Deus specialiter instituit matrimonium 53, 84vb

- Quamvis haeretici miseri mentiantur carnale martyrium esse illicitum eorum tamen falsitas manifeste apparet 153, 32va

- Quamvis in nuptiis homines soleant convivia tenere haec autem caute tenenda sunt in Dei timore 53, 92rb

O admiranda et laudanda tuae dispensationis gratia omnipotentissime domine Deus. Quia enim in natura tua ab homine videri non poteras ut hominem notitiae tuae participem faceres opus fecisti 397, $1 \mathrm{r}$

O altitudo divitiarum sapientiae et scientiae Dei ... ( $\mathrm{Rm} 11,33$ und 36). Sciendum quod hodie festum trinitatis institutum est ut omnes fideles agnoscant unam simplicem deitatem et trinitatem 153, 147va

O beata et gloriosa virgo Maria quis digne tibi valeat iura gratiarum 405, 209v

$\mathrm{O}$ dies aeterne numquam deficiens et sol numquam occidens qui circa solis occasum sepultus suscepisti $405,215 \mathrm{v}$

O domine Iesu Christe fili Dei vivi benedicti qui pro nobis peccatoribus agonizans in cruce praedilectam matrem $353,177 \mathrm{r}$

O domine Iesu Christe aeterna dulcedo te amantium iubilus excedens omne gaudium et omne desiderium 654, 100r

O Maria dominus tecum te associans tecum te custodiens tecum te glorificans 31, 82ra

O quam magnum donum et mirificum bonum de Dei misericordia quia tanta est dignitas 167, 71va

$\mathrm{O}$ refugium meum o liberator meus per immensum amorem qui te in patibulo crucis amarissimam mortem pro me subire coegit $353,15 \mathrm{v}$

O regina virginum fac tecum gratulari / Quos hic in exilio vides tribulari 166, 52ra

$\mathrm{O}$ stulti et tardi corde ad credendum (Lc 24,25). Sciendum quod secundum dictum Salomonis stultorum infinitus est numerus 153, 99rb

$\mathrm{O}$ virgo virginum beatissima virgo Maria propter angustias et cruciam inaque cor tuum sustinuit $353,81 \mathrm{v}$

O virgo virginum castissima Dei genitrix Maria propter planctum acerbi eiulatus 353, 89v

O virgo virginum clementissima mater Maria propter doloris gladium qui pertransivit animam tuam 353, 84r

$\mathrm{O}$ virgo virginum gloriosissima mater Maria propter gemitus et suspiria indicibiliaque lamenta quibus afficiebaris $353,92 \mathrm{v}$

O virgo virginum praedulcissima mater Maria quando vidisti filium tuum $353,79 \mathrm{v}$

O virgo virginum sanctissima Dei genitrix Maria propter gravamen et tormentum quo torquebatur $353,77 \mathrm{v}$

$\mathrm{O}$ virgo virginum sanctissima regina propter gravamen et tormentum quo torquebatur spiritus tuus iuxta crucem $353,86 r$

$\mathrm{O}$ vos electi sumus namque fragiles et nullius veritatis $654,4 \mathrm{r}$

O vos omnes qui transitis ... Trenorum primo (Lam 1,12). Unde Iohannes de Sancto Geminiano dicit Conveniens est ut sentiat membrum quod sentit caput 153, 84ra

Omne quod movetur necesse. Iste est septimus liber Physicorum in quo philosophus determinat de comparatione motuum 163, 10r

Omne regnum in se divisum desolabitur (Lc 11,17). Pro huius thematis introductione invenio tres scholas scilicet Thebanam, Troianam, Romanam. Prima schola fuit Thebana et in hac pro sui tempore lecta fuit divisio 597, 28ra

Omnes sancti tui quaesumus domine nos ubique laetificent et adiuvent ut dum eorum merita recolimus patrocinia sentiamus 353, 31r

Omnes sunt administratorii spiritus in ministerium missi propter eos qui hereditatem capiunt salutis gloria id est hominis quibus promittitur vita aeterna (Hbr 1,14). Hodie agimus festum omnium angelorum et hoc propter plures causas. Primo quia singulariter omnes honorare non possumus. Isto die omnes honoremus 78, 100va

- Modus est nobilium et aliorum honestorum virorum quod ad filiorum suorum custodiam et instructionem ponunt suos servos $\mathbf{7 8}, 98 \mathrm{va}$

Omnia per ipsum facta sunt et sine ipso factum est nihil. Haec verba scripta (Io 1,3) sic possunt exponi. Omnia scilicet entia a Deo alia. Facta sunt per ipsum id est per verbum Dei. Unde Augustinus sermonem dirigens ad Deum 532, 123r

Omnia scilicet entia a Deo alia. Facta sunt per ipsum id est per verbum Dei. Unde Augustinus sermonem dirigens ad Deum 532, 123r

Omnibus martyribus praefertur. Sic etiam de loco vel eventu Felicis 483, 72r

Omnipotens Deus ex supereffluenti non ex operibus iustitiae quae fecimus 53, 66rb

Omnipotens et misericors Deus qui electos spiritus caelestium gaudiorum $353,7 \mathrm{v}$

Omnipotens et misericors Deus qui hominem ad imaginem tuam formasti et ei angelum corporis et animae custodem $353,6 \mathrm{v}$

Omnipotens et misericors Deus qui omnem animam confitentem et paenitentem 405, 134r

Omnipotens et sempiterne Deus cuius natura bonitas cuius voluntas potentia cuius opus 654, 20v 
Omnipotens mitissime Deus qui sitienti populo fontem 405, 134v

Omnipotens sempiterne Deus confitentibus tibi famulis tuis pro tua pietate relaxa peccata 654, 23r

Omnipotens sempiterne Deus dirige actus nostros in beneplacito tuo 405, 224r; 654, 64v

Omnipotens sempiterne Deus famulos tuos dextera potentiae tuae a cunctis protege periculis 405, 213v

Omnipotens sempiterne Deus maestorum consolatio laborantium fortitudo 405, 125r, 134v

Omnipotens sempiterne Deus ne nos miseros peccatores permittas propter peccata nostra perire 654, 33r

Omnipotens sempiterne Deus qui angelum tuum antequam nasceretur homo et ego nascerer ad custodiendum 353, $11 \mathrm{r}$

Omnipotens sempiterne Deus qui caelestia simul et terrena moderaris 405, 133v

Omnipotens sempiterne Deus qui dedisti famulis tuis in confessione verae fidei aeternae trinitatis gloriam agnoscere 353, 30r, 121r; 405, 216v, 221r

Omnipotens sempiterne Deus qui ex abundantia pietatis tuae et merita supplicum excedis 353, 52r

Omnipotens sempiterne Deus qui facis mirabilia magna solus 405, 133v

Omnipotens sempiterne Deus qui in unitate permanes et in trinitate semper consistis 353, 124r

Omnipotens sempiterne Deus qui nos omnium sanctorum tuorum merita sub una tribuisti celebritate $\mathbf{4 0 5}, \mathbf{2 1 8 v}$

Omnipotens sempiterne Deus qui vivorum dominaris simul et mortuorum omniumque 405, 135r

Omnipotens sempiterne Deus respicere dignare super apostolicam dignitatem 405, 133r

Omnis homo certis sciat ex causis et apertis/quod tres sunt sancti quos Ioseph nomine legi 293, 23r

Omnis motus tendit ad aliquem terminum per debita media 153, 74va

Omnis qui petit accipit etc. (Mt 7,8; Lc 11,10). In verbis istis notandum quod ad impetrandum salutaria quattuor oportet considerare videlicet a quo sit petendum quid sit petendum qualiter sit petendum quando sit petendum 617, $168 \mathrm{v}$

Omnis res per quascumque causas nascitur per easdem et dissolvitur (Decretum Gratiani, p. 2, C. 27, qu. 2, cap. 4). Ea facta quae dubia sunt ut quo animo in meliorem partem interpretemur $\mathbf{6 1 4}, 282 \mathrm{r}$

Omnium magister et dominus Iesus Christus de mundo ascensurus ad patrem 550, 77ra

Opera quae ego facio in nomine patris mei ipsa testimonium perhibent de me (Io 10,25). Pro huius thematis introductione invenio tres scholas scilicet veneficas, angelicas, truffaticas. Prima schola est angelica et in hac legitur magna opera facta fuisse et primo legitur de archangelo Michaele 597, 36vb

Oportet ut extrahantur superfluctuentes humidae primo per flebotomiam 748, 71r

Oremus pro omni gradu ecclesiae. Sacerdotes tui induantur iustitia 405, 132v

Ostendat faciem suam nobis: et misereatur nostri 405, 89r

Ostende nobis domine misericordiam tuam et salutare tuum da nobis $353,41 \mathrm{r}$

Ostendite mihi numisma census (Mt 22,19). Nota praedicatores dicuntur pastores quibus dicetur Iohannes XXI Afferte mihi de piscibus 174, 222ra

Paenitentiam agite ... (Mt 3,2). Aristoteles $5^{\circ}$ Physicorum Omnis motus tendit ad aliquem terminum per debita media 153, 74va

Papa stupor mundi si dixero papa nocenti 327, 1r

Partes orationis quot sunt? Octo. Quae? Devotio lacrimae dulcedo incendium ascensio meditatio contemplatio et languor. Devotio quid est 617, 2v

Parvulus natus est nobis (Is 9,5). Circa nativitatem domini tria notantur. Primo natus describitur secundo nativitatis tempus tertio nativitatis utilitas. De primo sciendum quod fuit natus admirabilis ineffabilis formidabilis venerabilis $\mathbf{6 1 7}, 136 r$

Pastores loquebantur ad invicem Transeamus usque Betlehem et videamus hoc verbum quod factum est etc. (Lc 2,15). Hodiernae diei gaudiosa festivitas nos admonet et accendit aliquid de temporali Christi 53, 52rb

- Notandum quod Octavianus imperator 42 anno imperii sui quia 57 annis regnavit et versus finem valde pacifice 53, 52vb

Pateant aures misericordiae tuae domine precibus supplicantium et ut petentibus desiderata 353, 48r

Pater clarifica nomen tuum (Io 12,28). Pro huius thematis introductione invenio tres scholas scilicet sapientiae, praesentiae, refulgentiae. Prima schola est sapientiae in qua legitur quod sapientium nomen clarificatur per famam in multis locis $\mathbf{5 9 7}$, 39va

Per hoc convivium Veteris Testamenti figuratum est nobis convivium a Christo hodie institutum sacri corporis et sanguinis sui $617,173 \mathrm{v}$

Per magnam misericordiam domini nostri Iesu Christi et per multitudinem miserationum suarum salvet et protegat $654,17 \mathrm{v}$

Per proprium sanguinem introivit semel in sancta aeterna redemptione inventa (Hbr 9,12). Pro huius thematis introductione invenio tres scholas scilicet cordialem, pigmentalem, usualem. Prima est cordialis in qua legitur quod sanguis est summum elementum cordis 597, 35rb 
Percusserunt me et vulneraverunt me custodes murorum (Ct 5,7). In verbis propositis notatur triplex martyrium quod suscipit beatus Bartholomaeus fuit enim fustigatus deinde vivus excoriatus postremum decollatus 617, $183 r$

Perfecta Christi caritas confirmetur in nobis $405,12 \mathrm{v}$

Perpetuum nobis domine tuae miserationis praesta subsidium 353, 10r

Persaepe animadvertens hoc mortale hominum genus iniuriis casibus additum et infinita mortis $\mathbf{7 4 8 , 9 0 \mathrm { v }}$

Pestilentia est mutatio quaedam in aere facta propter admixtionem vaporum corruptorum vel sic est morbus quidem contagiosus 748, 72r

Pestilentiae causa dicitur esse triplex. Nam vel est causa radix superior tantum et haec est superior et caelestis $\mathbf{7 4 8}$, $54 \mathrm{v}$

Petite et accipietis (Io 16,24). Benignitas salvatoris Dei nostri maior est in exaudiendo petitiones filiorum suorum 153, 119vb

- Ex quo dominus noster Iesus Christus in verbis praemissis invitat nos ad orandum tunc hic quaeritur 153, $123 r b$

Petite et accipietis (Lc 11,9). In his verbis notandum est quod sex sunt quae invitant nos ad petendum 617, 169r

Petre amas me. Tu scis domine quia amo te (Io 21,17). Dicit beatus Iohannes in suo evangelio quod dominus interrogavit beatum Petrum de sua dilectione dicens 617, 175v

Petrus apostolus dicit Paenitentiam agite et baptizetur 181, 41rb

Phlebotomia electiva debet fieri parum post ortum solis et post primam et secundam digestionem et superfluitum expulsionem $748,52 \mathrm{v}$

Pietate tua quaesumus domine nostrorum absolve vincula peccatorum $405,132 \mathrm{v}$

Pii esse debemus in parentes in sanguine nobis iniunctos ad necessitatem praecipue autem post debemus esse in Deo 755, 10vb

Piissimus salvator Iesus Christus totiusque consolator Deus omnis suae pietatis tantam humani generis imperitiam et ignaviam necnon infirmitatis $\mathbf{8 5}, 1 \mathrm{r}$

Placeat tibi sancta trinitas hoc obsequium servitutis meae et praesta ut hoc sacrificium 252, 21v

Plebani quia post praelatum maioribus quam ceteri fratres sunt periculis expositi 76, 63v

Plebs ab imatu parit Herodis cruciatu 308, 228va

Plures sunt agri in quibus seminat 177, 44vb

Ponam arcum meum in nubibus caeli et erit signum foederis mei (Gn 9,13). Haec verba possunt exponi de beata Maria Magdalena quae intellegitur per arcum caelestem propter tria. Primo ratione materiae 78, 69vb

Porrige nobis Deus dexteram tuam et per intercessionem sanctissimi Dei genitricis Mariae auxilium nobis supernae virtutis impende $353,153^{\mathrm{I}} \mathrm{r}$

Post considerationem eorum quae pertinent ad mysteria verbi incarnati considerandum est de ecclesiae sacramentis 38, $144 \mathrm{rb}$

Post prooemium in quo breviter edocemur 253, 1ra

Postquam consummati sunt dies octo ut circumcideretur puer vocatum est nomen eius Iesus etc. (Lc 2,21). Ex quo tota Christi vita et conversatio nostra est instructio 53, 63ra

- Sciendum quod Christus die octavo circumcisus est et sanguinem suum fudit 153, 21ra

- Sciendum quod Deus creavit primos parentes iustos iustitia naturali id est sine omni obliquitate 53, 63va

- Solent homines in novo anno munuscula sibi invicem dare 153, 19rb

Postquam locutus est eis Assumptus est in caelum ... (Mc 16,19). Sciendum quod ab origine mundi non fuit tale festum in caelo nec umquam usque post iudicium erit 153, 126ra

Praelatus monasterii qui tam verbo quam exemplo fratribus sibi commissis praeesse debet 76, 54r

Praemissis in nomine Christi librorum tabulis sive capitulorum titulis sequuntur ex eis 52, 4ra

Praesens evangelium mea non indiget expositione quia summa veritas 53, 134va

Praesens evangelium tangit statum Christi tempore pueritiae circa 12 annum 53, 81rb

Praesens Novi Testamenti praecipua festivitas inter ceteras venerabilis toto orbe terrarum 53, 299ra

Praesta quaesumus omnipotens Deus ut familia tua per viam salutis incedat et beati Iohannis praecursoris 405, $217 \mathrm{r}$

Praesta quaesumus omnipotens Deus ut passionum charismatum et gloriae rationalis ac beatificae animae unigeniti filii tui domini nostri Iesu Christi 353, 189v

Praesta quaesumus omnipotens Deus ut qui beati Pangratii martyris tui natalicia colimus 14820, 85v

Praesta quaesumus omnipotens Deus ut qui gloriosos martyres Dionysium socios quam (!) eius fortes in sua confessione cognovimus 405, 219r

Praetende domine fidelibus tuis dexteram caelestis auxilii 405, 207r

Praetende quaesumus domine famulis et famulabus tuis 654, 65r

Praeterea de lege illa vel errore quem cives tuos asseris statuisse videlicet ut si quis teneret per 30 annos 107, 79ra

Praeterea quam divinum officium concernunt $76,53 \mathrm{v}$

Precibus et meritis beatae Marie virginis liberet nos filius eius ab omnibus malis 353, 166r 
Precibus et meritis beatissimae Mariae virginis et omnium sanctorum perducat nos dominus ad regna caelorum $353,134 \mathrm{r}$

Precibus et meritis sanctissimae Dei genitricis virginis Mariae et omnium sanctorum suorum salvet et protegat 405, $14 \mathrm{v}$

Precibus et meritis sanctissimae suae matris salvat et protegat 353, $14 \mathrm{r}$

Presbyter attende capias haec dogmata mente/haec tibi norma datur per quam tua vita regatur 167, 71vb

Presbyter potest supplere missam ab episcopo incohatam si episcopus non poterit propter infirmitatem 155, 13ra

Prima missa est de exaltatione sanctae crucis ... In secunda missa sic domine Iesu Christe qui iudicium innocentis sustinuisti ... In tertia sic domine Iesu Christe qui innocenter et indigne in cruce es conclamatus ... In quarta missa sic domine Iesu Christe per vulnera piissimi corporis et cordis tui ... In quinta sic domine Iesu Christe rex caelorum per sepulturam tuam dignare animam $754,26 \mathrm{v}$

Prima pars praesentis evangelii congruit multum praesenti tempore in quo celebrantur nuptiae et matrimonia 53, $92 \mathrm{vb}$

Prima pronosticorum finis laudabilis medicinae existit cum actor futura in singulis propendit quamvis omnes minime curare possit 453 , VDS

Primo debemus quaerere Christum cum plena cordis conversione 308, 201va

Primo reprobatur superfluitas quia superflua sunt resecanda ab arte id est a iure canonico 155, 49vb

Primum capitulum est quomodo confessor debet considerare conditiones confiteri volentis. Ubi notandum quod confessor sedens ad confessiones audiendas si confiteri volentem non cognoscit quaerat ab eo an sit suus parochianus 606, 1rb

Primum dubium quare confert thyriaca et metridatum cum sint excellentis calefactionis et notum est quod quae augmentant caliditatem in corpore nostro $748,64 \mathrm{v}$

Primus qui hic fuit Ninius idem fabricator fuit Thare ille dedit Abraham. Abraham dedit Ismaelitis 308, 228vb

Prius dictum est de nomine. Nunc dicendum est de hoc vocabulo Maria. Et est notandum quod quattuor genera volatilium solent nidos suos ornare 31, 65va

Prius dictum est quod gratia habet septem efficacias quas in anima facit et quod sunt septem praeparationes quibus homo ad gratiam se disponit 31, 73rb

Prius dictum est quomodo Maria fuit gratiose salutata quod notabatur in hoc verbo Ave 31, 75vb

Pro huius thematis introductione invenio tres scholas angelicae naturae, humanae creaturae, artificialis figurae et in omnibus his legitur forma rapinae. Prima schola est angelicae naturae in qua legitur rapina 597, 40va

Pro huius thematis introductione invenio tres scholas Catonis, Tullii et Senecae. Prima schola est Catonis et quamquam intra illam bona vita legatur tamen inter alia qui ibi leguntur $\mathbf{5 9 7}, 29 \mathrm{vb}$

Pro huius thematis introductione invenio tres scholas scilicet alchimistarum, artistarum, poetarum. In omnibus autem his scholis legitur transfiguratio. Prima schola est alchimistarum 597, 17rb

Pro huius thematis introductione invenio tres scholas scilicet arborum et plantarum, vaporum et nebularum, dolentium animarum. Prima schola est plantarum et arborum in qua talis doctrina legitur quod quando arbores plorant 597, 37rb

Pro huius thematis introductione invenio tres scholas scilicet Belzebub in Babylonia, Iani in Roma, Pharisaeorum in Ierusalem. Prima schola fuit in magna civitate Babyloniae in qua tractabatur 597, 9va

Pro huius thematis introductione invenio tres scholas scilicet caeli, paradisi, mundi. Prima ergo schola fuit caeli. Nam in principio creavit Deus caelum et terram 597, 18vb

Pro huius thematis introductione invenio tres scholas scilicet cordialem, pigmentalem, usualem. Prima est cordialis in qua legitur quod sanguis est summum elementum cordis 597, 35rb

Pro huius thematis introductione invenio tres scholas scilicet dominorum, generatorum, magistrorum. Prima schola fuit dominorum et in ista et in aliis legitur quod omnes intendunt sibi assimilare 597, 27ra

Pro huius thematis introductione invenio tres scholas scilicet elegantiae in naturalibus affluentiae in temporalibus eminentiae in dignitatibus 597, 20ra

Pro huius thematis introductione invenio tres scholas scilicet Eremitarum, Praedicatorum, Minorum. Prima schola est Eremitarum in Aegidio qui videtur velle tenere quod si primus homo non peccasset 597, 7ra

Pro huius thematis introductione invenio tres scholas scilicet extimam, intimam, extrinsecam. Prima schola dicitur extima et haec est excellentiae dignitatis et in hac lego trinitatem 597, 33rb

Pro huius thematis introductione invenio tres scholas scilicet Hebraicam, Graecam et Latinam. Prima schola est Hebraica in qua considero Salomonem facientem iustitiam 597, 8rb

Pro huius thematis introductione invenio tres scholas scilicet internas, alternas, subalternas. Prima est interna et est voluntatis et in hac legitur quod ea quae sunt in homine ipsi voluntati praesenti principaliori et digniori subalternas serviunt $\mathbf{5 9 7}$, 42ra

Pro huius thematis introductione invenio tres scholas scilicet lapidum, herbarum, verborum. Prima ergo schola est lapidum et in illa legitur magna virtus. Nam videmus quod carbunculus 597, 30va

Pro huius thematis introductione invenio tres scholas scilicet mechanicas, trepidas et incredulas. Primo invenio scholas mechanicas et iste sine dubio ut earum opera cognoscantur $\mathbf{5 9 7 , 1 0 v b}$ 
Pro huius thematis introductione invenio tres scholas scilicet mechanicas, piraticas, maleficas. Prima schola est mechanica et haec utitur ligno 597, 43ra

Pro huius thematis introductione invenio tres scholas scilicet motorum, auditorum, bellatorum. Prima est motorum et in illa legitur lux gratiae unde Gen. primo dixit Deus fiat lux et facta est lux 597, 36ra

Pro huius thematis introductione invenio tres scholas scilicet organicam, scientificam, evangelicam. Prima schola dicitur organica et in hac legitur quod quis doctus esse non potest 597, 33va

Pro huius thematis introductione invenio tres scholas scilicet planetae, cometae, monetae. Prima est planetae et in hac legitur vita secundum quod melior est constellatio vel planeta de tanto efficimur levioris vitae 597, 35vb

Pro huius thematis introductione invenio tres scholas scilicet Sardanapalli in Asia, Catilinae in Roma et Attilae in Ungaria. Prima ergo schola est Sardanapalli 597, 22va

Pro huius thematis introductione invenio tres scholas scilicet sapientiae, praesentiae, refulgentiae. Prima schola est sapientiae in qua legitur quod sapientium nomen clarificatur per famam in multis locis $\mathbf{5 9 7}, 39 \mathrm{va}$

Pro huius thematis introductione invenio tres scholas scilicet Thebanam, Troianam, Romanam. Prima schola fuit Thebana et in hac pro sui tempore lecta fuit divisio 597, 28ra

Pro huius thematis introductione invenio tres scholas scilicet urbis fundatorum, in campo bellatorum, in campo clericorum. Prima schola est urbis fundatorum 597, 38rb

Pro huius thematis introductione invenio tres scholas scilicet veneficas, angelicas, truffaticas. Prima schola est angelica et in hac legitur magna opera facta fuisse et primo legitur de archangelo Michaele 597, 36vb

Pro huius thematis introductione invenio tres scholas scilicet vulgaricam, canonicam, theologicam et in his legitur quod nullus possit iudicari $\mathbf{5 9 7}$, 32ra

Pro huius thematis introductione invenio tres scholas scilicet vulgarium, naturalium, moralium. Prima mensuratur experientia secunda ratione tertia discretione $597,2 \mathrm{va}$

Pro huius thematis introductione invenio tres scholas videlicet Origenis, Augustini, Hieronymi. Prima schola est Origenis cuius talis fuit opinio seu doctrina 597, 30rb

Pro huius thematis introductione invenio tres scholas videlicet physicam Avicennae, cyrusicam Galeni, evangelicam Iesu Christi. In prima schola fuit magnus medicus naturalis et in illa legebatur 597, 13rb

Pro huius thematis introductione invenio tres scholas. Prima igitur schola fuit Moysii inesse figurali 597, 1ra

Pro huius thematis introductione invenio tres scholas. Prima schola est agricultorum qui abundat in gratia temporali cum tales fructus terrae et gratiam Dei 597, 16ra

Pro huius thematis introductione invenio tres scilicet olivae in Minerva, lauri in Mercurio, palmae in Marte. Prima schola est olivae in Minerva. Nam ut possum capere ex dictis poetarum oliva consecrata est in nomine Minervae 597, 40vb

Pro huius thematis introductione reperio tres scholas mirificam, munificam, magnificam. Prima schola est mirificum (!) et haec schola est Dei. Prope enim Deus qui fecit mirabilia 597, 32vb

Pro huius thematis introductione reperio tres scholas scilicet elementalem, spiritualem, iudicialem. In his tribus scholis legitur mors. Prima ergo schola est elementalis quia composita originaliter ab his cum omne compositum resolvi $\mathbf{5 9 7}, 34 \mathrm{vb}$

Pro huius thematis introductione tres invenio scholas scilicet Medeae, Dyodonis, Ysiphilae. Prima ergo schola fuit Medeae nam Medea fuit filia Ochis (!) regis qui regnavit in insula Colchide 597, 25va

Pro huius thematis introductione tres scholas invenio scilicet aequitatis, benignitatis, sanctitatis. Prima schola est aequitatis et in hac legitur quod relevetur infirmus 597, 34va

Pro huius thematis introductione tres scholas invenio scilicet examinationis, confessionis, obligationis. Prima schola est examinationis et in ista schola legitur quod reus dato quod omnia sunt allegata et approbata 597, 34ra

Pro huius thematis introductione tres scholas invenio scilicet filiorum, inimicorum, discipulorum. Prima schola est filiorum. In hac considero inter filios primi parentis 597, 29ra

Pro huius thematis introductione tres scholas invenio scilicet Martis, partis, mortis. Prima est Martis. Nam Mars ut pluries dictum est planeta malevolus est et nati sub illo sunt pessimi 597, 36va

Pro huius thematis introductione tres scholas invenio scilicet nuptiarum, victoriarum et scientiarum. Prima ergo fuit nuptiarum et illam invenio in rege Asuero 597, 29rb

Pro huius thematis introductione tres scholas invenio scilicet Polestinoris, Mesabellis, Pignaleonis. Prima schola fuit Polestinoris qui fuit rex cuiusdam insulae 597, 24rb

Pro huius thematis introductione tres scholas invenio scilicet potentiarum, naturarum, grammaticorum. Nam prima est potentiarum et quia habemus plures potentias $\mathbf{5 9 7}, 32 \mathrm{rb}$

Pro huius thematis introductione tres scholas reperio et fortunae, naturae, rationalis creaturae. Prima schola scilicet naturae dicit quod omnia naturalia 597, 6rb

Pro huius thematis introductione tres scholas reperio ethicam seu monasticam, oeconomicam seu familiarem, politicam seu civilem. Prima schola est monastica in qua legitur 597, 14rb

Pro huius thematis introductione tres scholas reperio scilicet Epicureorum, Platonicorum, Hypotheticorum. Sed in omnibus istis scholis doctrina legitur quae secundum aliquam partem merito nobis timorem 597, 5rb 
Pro huius thematis introductione tres scholas reperio scilicet illustrium magnificorum, secunda eloquentium, tertia decipientium et proditorum. Prima schola fuit illustrium etc. 597, 12ra

Pro huius thematis introductione tres scholas reperio scilicet naturae, scripturae, gratiae. Primo dico quod invenio scholam naturae 597, 4ra

Pro huius thematis introductione tres scholas reperio videlicet mundi, carnis, daemonis. Prima schola est mundi in prima legitur apparentia sive existentia 597, 21rb

Pro intellectu dubitatur quale fuit illud desertum ad litteram 53, 174va

Pro intellectu litterae notandum ut narrat Iosephus 13 libro Antiquitatum capitulo 14 regnum Iudaeorum fuit interceptum 481 annis et duos menses a captivitate 53, 71ra

Pro intellectu litterae notandum quod Iohannis 12 dicitur Quando Iudaei iam ex consilio Caiphae 53, 249va

Pro intellectu notandum quod secundum magistrum historiarum Iohannes arguebat Herodem propter Herodiadem quam a fratre suo receperat 53 , 26ra

Pro intellectu notandum sicut habetur Matthaei 14 Postquam Christus transfretavit per mare Tiberiadis venit Capharnaum 53, 237rb

Probet autem seipsum homo ... (1 Cor 11,28). Aristoteles $2^{\circ}$ De anima Simile a simili nutritur sicut patet in cibo digesto a quo corpus nutritur 153, 81rb

Propitiare nobis quaesumus omnipotens pater per unigeniti tui corpus et sanguinem 353, 65r

Propter multiplicationem humani generis Deus specialiter instituit matrimonium 53, 84vb

Prosequendo sermonem iam inceptum tunc sciendum quod quanto caelum aperitur per intensam contritionem 153, $9 \mathrm{rb}$

Protector noster in te sperantium Deus sine quo nihil est validum 353, 54r

Protege domine famulos tuos subsidiis pacis et beatae Mariae virginis patrociniis confidentes 405, 214r, 222r

Protege domine populum tuum et apostolorum tuorum Petri et Pauli et omnium aliorum 353, 31r

Protege domine populum tuum et apostolorum tuorum Petri et Pauli patrocinio confidentem 405, 218r

Publii Ovidii Nasonis poetae vetusta equestris ordinis familia fuit 579, $1 \mathrm{r}$

Puer autem crescebat ... (Lc 2,40). Ex quo in praesenti evangelio fit mentio de puero nobis recenter nato. Tunc pro praesenti sermone tria sunt dicenda. Primo quare Christus parvulus factus est 153, 15vb

- Sicut puer Iesus crevit corporaliter ita et nos crescere debemus spiritualiter 153, 17va

Puer Iesus proficiebat sapientia aetate (Lc 2,52). Praesens evangelium tangit statum Christi tempore pueritiae circa 12 annum 53, 81rb

- Quando diligenter consideramus inaestimabilia divinae bonitatis beneficia nobis exhibita 53, 80va

Pulcherrime Iesu Christe rogo te per illam sacratissimam effusionem pretiosissimi sanguinis tui quo sumus redempti 405, 224r

Puppe saporatus iubet obmutescere natus 308, 228vb

Quadam autem vice venerunt gentiles ut eum tenerent 308, 3rb

Quadam vice antiquus hostis corporalibus eius 308, 54va

Quadam vice cum in spiritu temptatus esset totum mundum laqueis sese invicem 308, 46ra

Quadam vice cum praedicans Felix praedicaret et persecutor 308, 3ra

Quadruplex agitur festum in hac septimana scilicet festum venerationis festum recreationis festum reconciliationis 617, $149 r$

Quae procedunt de ore haec coinquinant hominem (Mt 15,18). Pro huius thematis introductione invenio tres scholas Catonis, Tullii et Senecae. Prima schola est Catonis et quamquam intra illam bona vita legatur tamen inter alia qui ibi leguntur 597, 29vb

Quaecumque solveris super terram erunt soluta et in caelo (Mt 18,18). Pro huius thematis introductione tres scholas invenio scilicet nuptiarum, victoriarum et scientiarum. Prima ergo fuit nuptiarum et illam invenio in rege Asuero 597, 29rb

Quaeritis me et non invenietis (Io 7,34). Pro huius thematis introductione invenio tres scholas scilicet motorum, auditorum, bellatorum. Prima est motorum et in illa legitur lux gratiae unum Gen. primo dixit Deus fiat lux et facta est lux 597, 36ra

Quaeritur primo utrum et Nephiae et Typhones descendunt ad terram ex nubibus 440, 347ra

Quaeritur quis effectus baptismi. Respondetur secundum Thomam in $4^{\circ}$ Pueri quidam in baptismo mundantur 447, IX*ra

Quaeritur utrum angelus in primo instanti creationis fuerit malus actu propriae voluntatis 52, 44ra

Quaestio inter doctores scholasticos solet moveri utrum Deus posset non retribuere mercedem summae beatitudinis creaturae rationali diligenti eum fideliter 597, 43va

Quaestio oritur inter doctores utrum in hac vita possit Deum videre facialiter 597, 44ra

Quaesumus domine pro tua pietate miserere animae famuli tui a contagiis mortalitatis 654, 87r

Quaesumus domine ut animae famuli tui cuius obitus sive diem commemoramus sanctorum tuorum largiri digneris consortium et rorem misericordiae tuae perennis infundere 14820 , 85v 
Quaesumus omnipotens Deus ut beatae et gloriosae semperque virginis Dei genitricis Mariae intercessio gloriosa nos ab omni malo protegat 353, 161r

Quam detestabile sit vitium invidiae et fugiendum patet propter multa mala 53, 240ra

Quamquam nesciatur de homine quoquam an salvetur vel damnetur 153, 127ra

Quamvis de astrolabii compositione tam modernorum quam veterum dicta habeantur 776, 61r

Quamvis divina miseratio multis variisque modis in scripturis sanctis omnis vocare dignata est 617, 63r

Quamvis haeretici miseri mentiantur carnale martyrium esse illicitum eorum tamen falsitas manifeste apparet 153, 32va

Quamvis in nuptiis homines soleant convivia tenere haec autem caute tenenda sunt in Dei timore 53, 92rb

Quamvis multis modis homo serviat Deo et pro peccatis suis satisfaciat 53, 338rb

Quamvis venerandi domini haec pestis tam admirabilis et horrenda a causis superioribus procedat regulantibus et gubernantibus corpora nostra $\mathbf{7 4 8 , 7 1 \mathrm { r }}$

Quando aliquis se cupit ad communem vitam transferre 76, 19r

Quando dignitatem festorum totius anni clarius inspicimus invenimus quod ipsa praesens paschalis sollemnitas 53, 310ra

Quando diligenter consideramus inaestimabilia divinae bonitatis beneficia nobis exhibita 53, 80va

Quando dorsum equi laeditur per sellam 160,1r

Quando enim occurrat festum alicuius sancti tunc consuevimus eius legendam et passionem ut Laurentii Petri etc. Sic enim hodie est flendum 174, 156ra

Quando equus patitur fissuras contra ungulam vulgariter in den fisselen 160, 1r

Quando equus patitur in pedibus defectum 160, $1 \mathrm{r}$

Quando feudum tenet a laico de iudice c. ceterum 145, 314va

Quanta Iudaeis acciderint gravia post temeritatem crucis in Christum scribit magister in Ecclesiastica Historia libro 2o capitulo 6o dicens Primo quidem temporibus Tiberii refert in urbe Roma 166, 52va

Quantum ad praesentem festivitatem possunt haec verba esse matris ecclesiae 617, 172r

Quantum ad statum paenitentiae ostendit autem civitatem iustorum laudabilem duplici respectu 162, 9ra

Quare autem non observamus nostrum ieiunium 52, 39vb

Qui manducat hunc panem vivet in aeternum (Io 6,58) et in evangelio hodiernae lectionis. Magnam hodie et praecipuam carissimi omnique devotione recolendam agimus sollemnitatem ad cuius celebrationem venerandam venerabilis Hugo de Sancto Victore in quodam sermone ipsius sollemnitatis nos devote invitat 174, 166va

- Loquendo de manducatione huius venerabilis sacramenti sciendum quod hoc sacramentum tripliciter sumitur 153, 158va

Qui non est dives et nescit vivere pauper/Ille modum vitae nescit habere suae 165, 42ra

Qui se exaltat humiliabitur (Mt 23,12). Pro huius thematis introductione invenio tres scholas scilicet elegantiae in naturalibus affluentiae in temporalibus eminentiae in dignitatibus 597, 20ra

Quia Christus multa signa fecit in civitatibus Iudaeorum ipsi nihilominus in sua pertinacia permanserunt 53, 156vb

Quia in tentivum (!) passionis Christi et occasio fuit proditio 53, 272va

Quia nativitatem beatae Mariae agimus ideo gaudere debemus quia ipsa est stella 78, 91rb

Quia nullus evangelistarum materiam dominicae passionis plene ac complete conscripsit 756, 1ra

Quia plurimi ob nimiam quandoque accurationem et magnam scriptorum sententiam canones utilis astrolabii declarantes intellegere $\mathbf{7 7 6}, 47 \mathrm{r}$

Quia postillatio verborum evangelii satis patet ex alio sermone facto de eodem. Ideo solummodo dicendum erit 53, $110 \mathrm{vb}$

Quia ut ait Ambrosius in sermone de Quadragesima Ecce nunc tempus acceptabile est in quo confessio a morte animam liberat 53, 197vb

Quia video te diu vacare otio silentio 360,1r

Quicumque esset laesus vel percussus a malitia Mercurii 748, 54rb

Quicumque vult salvus esse ante omnia opus est ut teneat catholicam fidem 190,67rb

Quid agendum sit dum quis habeat aliqua peccata a quibus ille cui confiteatur non potest absolvere dicit beatus Thomas 155, 15ra

Quid etiam de illo monacho commemorem cuius nomen quia adhuc superest 166, 57ra

Quid retribuam domino pro omnibus quae retribuit mihi panem caelestem accipiam de mensa domini 100, 28ra

Quis ex vobis arguet me de peccato etc. ubi supra (Io 8,46). Christus dominus frequenter in suis sermonibus arguit Iudaeis super peccatis suis $\mathbf{5 3}$, 246va

Quidam canonicus ad eum venit et ut ad monachum eum reciperet 308, 59rb

Quidam egregius doctor in sermone publice praedicavit quod quicumque devota intentione infrascriptas missas legeret seu legi disponeret pro anima 754, 26v

Quidam habens uxorem condemnatus de crimine capitali 614, 289v 
Quidam religiosus ordinis Cartusiensis monasterii in Ruremunda in solemnitate purificationis gloriosissimae virginis Mariae in summa missa toto conventu praesente et inspiciente ab exterioribus sensibus $\mathbf{7 5 4}, 11 \mathrm{v}$

Quo abiit dilectus tuus o pulcherrima mulierum $(\mathrm{Ct} 6,1)$. In his verbis tria videnda sunt scilicet quae sit dilecta quis sit dilectus quo et quomodo abiit. Circa primum sciendum quod dilecta est beata virgo 617, 170r

Quo studio et quo affectu a nobis orandus sit Deus 755, 4ra

Quod multum terribile sit extremum iudicium videtur posse trahi ex his quae in proximo sermone dixi 53, 11rb

Quod quilibet homo et maxime Christianus debeat fugere lites et contentiones 53, 246ra

Quodam tempore cum Remigius factus est Remensis archiepiscopus et in domo cuiusdam 308, 33vb

Quomodo hic litteras scit cum non didicerit (Io 7,15). Pro huius thematis introductione invenio tres scholas scilicet organicam, scientificam, evangelicam. Prima schola dicitur organica et in hac legitur quod quis doctus esse non potest 597, 33va

Quoniam apostolica sedes intendit providere negotiis non personis 145, 314va

Quoniam autem natura. Hic incipit tertius liber Physicorum in quo Aristoteles determinat de passionibus 168, 17r

Quoniam frequenter in foro paenitentiali dubitationes circa matrimonium 253, 88rc

Quoniam gloriosus et excelsus Deus de largitate sua medicinam produxit et medicum velut naturae refugium creavit 748, 66v

Quoniam quidem. Iste liber intitulatur liber Physicorum Aristotelis filii Nicometi Graecorum sapientissimi 168, 1r

Quoniam quidem scire et intellegere contingit circa omnes scientias quarum principia sunt aut causae aut elementa 168, $1 \mathrm{r}$

Quoniam te carissime filii Iohannes lacrimas maesto cordis dolore perpetim effundere perspexi 748, 162ra

Quoniam ut ait Galenus septimo therapeuticae methodi auctoritate Platonis opus in aliqua scientia vel arte 748, 74r

Quoniam ut ait Hieronymus sacerdotis officium est respondere de lege et ut dominus dicit per Malachiam prophetam Labia sacerdotis custodiunt sacramentum et legem 447, 1ra

Quoniam velut quattuor paradisi flumina ... Scriptura sacra de duobus agit ... Veteris ac novae legis continentiam considerantibus $532,34 \mathrm{v}$

Recipe lixinii partes tres olei nucum partem unam et valet contra cancrum et lupum et ignem persicum in principio certissimum est $\mathbf{7 4 8}, 54 \mathrm{ra}$

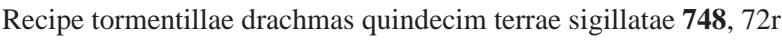

Redde illis mercedem (Mt 20,8). Quaestio inter doctores scholasticos solet moveri utrum Deus posset non retribuere mercedem summae beatitudinis creaturae rationali diligenti eum fideliter 597, 43va

Refert Gregorius in registro. Legitur quod sanctus Augustinus nec cum sorore 308, 14rb

Regem apostolorum dominum venite adoremus 154, $4 \mathrm{r}$

Regem manum. Adoremus dominum 405, 1r

Regulus obnatum stat supplex febre gravatum 308, 228vb

Religiosis atque honestis viris in Christo dilectis fratribus studentibus Neapolim 125, 1ra

Reminiscere miserationum tuarum quaesumus domine et famulos tuos 353, 62r

Repetiturus decretalem [X.3.41.1.] presbyter quae prima sub rubrica de celebratione missarum situatur et ponitur 155, 1ra

Replebimur in bonis domus tuae sanctum est templum tuum mirabile in aequitate Graduale Neocellense I, 324r

Repleti sunt omnes spiritu sancto (Act 2,4). Aristoteles $9^{\circ}$ Metaphysicae Contraria non fiunt in eodem. Cum ergo spiritus sanctus intrat in cor hominis tunc mala et peccata depellit 153, 137ra

- Ex quo iam illis sacris diebus peragitur missio spiritus sancti tunc aliquid de donis spiritus sancti pro praesenti sermone dicendum est 153, 141rb

Respice quaesumus omnipotens et misericors Deus super animas omnium fidelium defunctorum 654, 40r

Respondens Iesus dixit siehe In illo tempore respondens Iesus dixit

Respondit Thomas dixit Deus meus et dominus meus (Io 20,28). Verba praedicta quilibet potest dicere qui digne in hoc sacro tempore communicavit 153, 106ra

Responsorium de ascensione nostri domini 483, 53v

Restat quaerere aliqua circa tertium librum et verum est quod ab antiquo solemus illum totalem librum dividere in quattuor partiales 440, 347ra

Reverendissimo in Christo patri ac domino domino Sebastiano Dei gratia episcopo Brixinensi necnon egregiis eximia doctrina et sapientia eiusdem ecclesiae praelatis ac canonicis Paulus Ursinus philosophus et medicus salutem dicit. Quae vitio nostro non proveniunt quaeque in nostra minime sita sunt 694, $1 \mathrm{v}$

Reverendissimo in Christo patri fratri Hugoni magistro ordinis fratrum Praedicatorum dignissimo ac sacrosanctae paginae professori. Eius subditus frater Alfonsus Bonihominis Hispanus promissam oboedientiam 617, 117r

Reverendo in Christo patri ac domino domino Raimundo divina providentia sanctae sedis Valenciae episcopo servorum devotorum minimus Guido de Monte Rocherii cum devota 550, 1ra 
Reverendo in Christo patri et domino suo domino N. Dei gratia sancti Adriani diaconi cardinalis Laurentius dictus Kycius (!) mereschaltus (!) de Urbe ... Inter cetera animalia quae ad dignitatis humanae solacium 160, 4ra

Rex Assuerus tertio anno imperii sui fecit grande convivium cunctis principibus et pueris suis et vocavit omnem populum qui inventus est in Susia (Est 1,3). Per hoc convivium Veteris Testamenti figuratum est nobis convivium a Christo hodie institutum sacri corporis et sanguinis sui $\mathbf{6 1 7}, 173 \mathrm{v}$

Rex David cooperto capite etc. 2 R. (CAO Nr. 4650). Historia haec est de David quomodo planxit filium suum Absolon. Historia nota est scilicet quid significat 617, 163v

Rex pacificus praemissa salutatione sic pone casum in ista constitutione. Rex pacificus id est dominus noster Iesus Christus 155, 106ara

Rheuma est fluxus humorum ad partes subiectas. Rheumatis autem tres species ab auctoribus distinguuntur 123, $215 \mathrm{v}$

Roma vetus veteres cur (!) te rexere Quirites 579, $14 \mathrm{v}$

Rustica deflenti puero iuraverat olim/Ni taceat rapido quod foret esca lupo $155,155 \mathrm{~V}$

Sacerdos qui sine mortalibus est peccatis et bono proposito si non celebrat missam cum possit et habet copiam celebrandi 167,71 va

Sacramentum mei corporis sumite quo ad fideles et conficite quo ad presbyteros 53, 258rb

Sacratissimam domine dilectissimi filii tui passionis memoriam devote recolentes pro liberatione animarum $\mathbf{6 5 4}$, $43 \mathrm{v}$

Salvator Christus in praesenti evangelio movet singulos homines ad considerandum sua propria opera 53, 130ra

Salvator clementissime qui inter opprobria quae tulisti piae matris anxietatibus compassus fuisti $353,113 \mathrm{v}$

Salvator noster Christus dominus saepius verbis suis nos admonet non solum mala fugere 53, 142rb

Salvator noster Christus dominus sicut omnia in sua passione ostendit ut declararet suam humanitatem 53, 318rb

Sancta Dei genitrix perpetua virgo Maria cum omnibus sanctis et electis diei intercedere dignare $405,127 \mathrm{v}$

Sancta trinitas unus et omnipotens Deus nos quaesumus a peccatorum nostrorum maculis 353, 122v

Sancte Deus sancte fortis sancte et immortalis Deus miserere animabus omnium fidelium defunctorum 405, 220v

Sancti patres primitivi Christianae ecclesiae instituerunt ieiunium fidelibus observandum 53, 176vb

Sancti spiritus corda nostra mundet infusio 353, 39r

Sancti spiritus gratia suffragante de personis 7, 32va

Sanctus Ambrosius eo die missam celebrans super altare 308, 29ra

Sanctus Gregorius in prologo orationis dominicae dicente Praeceptis salutaribus moniti et divina institutione formati audemus dicere 161, 8va

Sanctus Thomas Cantuariensis bonae indolis adolescens cum adhuc in scholis 308, 187vb

Sanctus Udalricus praesul Augustensis cum quandam ecclesiam suae dioecesis dedicare vellet 308, 188va

Sanguinaria id est bursa pastoris sive succus $\mathbf{7 4 8}$, Ir

Sanus fiebat a quacumque detinebatur infirmitate (Io 5,4). Pro huius thematis introductione invenio tres scholas videlicet physicam Avicennae, cyrusicam Galeni, evangelicam Iesu Christi. In prima schola fuit magnus medicus naturalis et in illa legebatur $\mathbf{5 9 7}, 13 \mathrm{rb}$

Sapiens Ecclesiastes 3 (1 und 4) dicit quod omnia tempora tempus habent. Est tempus flendi et tempus ridendi 53, 280rb

Sapientia aeterna splendor gloriae et substantia patris qui universa de nihilo creasti 353, $14 \mathrm{r}$

Scandit montana pia virgo stupet veterana 308, 228rb

Sciendum est quod moderno tempore in Apulia in provincia Capitinate 125, 198va; 165, 71rb

Sciendum primo quod Christus servavit cicatrices vulnerum in suo corpore glorificato 153, 104va

Sciendum quod ab origine mundi non fuit tale festum in caelo nec umquam usque post iudicium erit 153, 126ra

Sciendum quod Christus die octavo circumcisus est et sanguinem suum fudit 153, 21ra

Sciendum quod Christus voluit temptari ut ostenderetur quod nos spiritualiter pugnare oporteret 153, 65rb

Sciendum quod circa praedicta verba tria sunt dicenda. Primo quomodo Deus trahit et vocat hominem 153, 144rb

Sciendum quod Decretum dividitur in tres partes principales. Quarum prima vocatur Distinctiones 614, 273v

Sciendum quod Deus creavit primos parentes iustos iustitia naturali id est sine omni obliquitate 53, 63va

Sciendum quod dicit Haimo Mons in quo Deus sedet caelum intellegitur 153, 37va

Sciendum quod hodie festum trinitatis institutum est ut omnes fideles agnoscant unam simplicem deitatem et trinitatem 153, 147va

Sciendum quod hodierna festivitas inter alia festa dignitatem singularem obtinet 153, 134va

Sciendum quod in caelo sunt solummodo boni in inferno solummodo mali 153, 44va

Sciendum quod per pastorem in praesenti evangelio intelleguntur praelati et per oves intelleguntur subditi 153, $107 \mathrm{vb}$

Sciendum quod plura genera hominum sunt qui dicunt verbis se credere in Deum 153, 115va

Sciendum quod praesens festivitas praecellit alias festivitates in sollemnitate et iucunditate 153, 89va

Sciendum quod secundum dictum Salomonis stultorum infinitus est numerus 153, 99rb 
Sciendum quod sicut Deus arguet peccatores de suis excessibus in futuro 153, 117vb

Sciendum quod sicut Iudaei olim tenuerunt se ad discipulos Christi scilicet separando eos a participatione et communione ipsorum 153, 131vb

Sciendum quod triplex est nativitas naturalis spiritualis et caelestis 153, 150va

Sciens Iesus quia venit hora eius ut transeat ex hoc mundo ad patrem (Io 13,1). Dominus Iesus Christus et magister noster pretiosum nostrae redemptionis pretium 53, 272rb

- Quia in tentivum (!) passionis Christi et occasio fuit proditio 53, 272va

Scire debetis in Christo dilectissimi quod dies hodierna ex salvatoris nostri nativitate nobis redditur gaudiosa 153, 4va

Scire debetis in Christo dilectissimi quod sancta mater ecclesia catholica hodierna die duo nobis tempora repraesentat 153, 48rb

Scito quod talia oportet te praeparare qualia sunt in hostia Quanto maior est festivitas tanto se melius homines praeparare debent $\mathbf{1 7 7}, 75 \mathrm{rb}$

Secundo idem angelus octo officia exercuit circa filium virginis declarandum. Primum erat officium docendi unum Ioseph dubitantem 31, 54ra

Secundum Bedam Satorem istum nullum melius quam Dei filium intelligere possumus 53, 142vb

Secundum Chrysostomum homilia 24 super Matthaeum Ne forte diceret populus apud se 53, 97ra

Secundum dictum Augustini in domo Dei id est in ecclesia quattuor sunt necessaria scilicet grammatica musica computus et ius canonicum. Grammatica ad scripturas sacras intelligendum musica ad laudes Dei decantandum 167, 1ra

Secundum doctores adventus domini agitur per quattuor hebdomadas ad denotandum quod est quadruplex adventus filii Dei 53, 1va

Secundum historiam post mortem Iulii Caesaris qui a poetis commendatur 53, 47vb

Secundum ordinem naturalem in mundo corpora magis conformia in natura sint magis propinqua in situ 31, 79vb

Secundum Originem Iudaei videntes prope esse tempus adventus Messiae 53, 30va

Secundum quod dicit Beda in homilia de Christi transfiguratione ut patet Matthaei 17 Salvator humani generis Christus dominus 53, 238va

Secundum scripturas sanctorum homo per peccatum fit instabilis et mutabilis et despectus 53, 151va

Sed etiam volo quinque verba sensu meo loqui ut et alios instruam (1 Cor 14,19) 155, 15ra

Semen est verbum Dei (Lc 8,11). Est enim semen verbum Dei quod Christus de caelo attulit in terra seminavit 153, $54 \mathrm{ra}$

Semper nos domine martyrum tuorum Nerei et Achillei foveat $14820,85 \mathrm{v}$

Sequere me (Io 21,19). Verba proposita sunt a Christo beato Petro dicta et iam dicuntur cuilibet homini qui vult salvari 153, 11va

Sequere me (Mt 9,9). In illo evangelio duo notantur scilicet dignitas vocantis cum dicitur Sequere me 617, 187Iv

Si alicui plus placuerit praedicare de evangeliis quam de epistolis 174, 1ra

Si per alidadam horariam vis horam diei invenire naturalem poni alidadam super altitudinem mediae diei illius in dorso astrolabii suspensi 776, 71v

Si quis princeps vel rex vel magnus dominus vult destinare nuntium vel legatum ad summum principem vel regem vel dominum magnum pro magna et ardua causa 31,67rb

Si quis revelet peccatum suum sacerdoti non ut paeniteat sed ut consilium et auxilium ab eo recipiat 155, 9va

$\mathrm{Si}$ uxor alicuius viri quia non potest prolem habere timens quod possessio viri ad alios devolveretur 155, 7vb

Si vixeris secundum carnem/morieris morte aeterna 397, VDS

Si volumus amplius scire quod multipliciter est sanctissima virgo domina Maria benedicta inspiciamus 31, 89rb

Sic ambuletis ut abundetis magis prima ad Thessal. 4 (1). Pro huius thematis introductione invenio tres scholas. Prima schola est agricultorum qui abundat in gratia temporali cum tales fructus terrae et gratiam Dei 597, 16ra

Sic comedetis illum renes vestros accingetis calciamenta vestra habebitis in pedibus (Ex 12,11). Haec verba licet ad litteram sint dicta de agno paschali cuius immolatione 53, 251va

- Nunc igitur iuxta praemissa sicut dixi ad contemplationem 53, 252ra

Sic legimus quod unigenitus Dei filius volens [ 153, 156vb

Sic mundo pactum solvit verbo caro factum 308 , 228rb

Sicut apotheca est salubris ita musica delectabilis quia dulcedine sua $\mathbf{7 7 6}, 1 \mathrm{v}$

Sicut auris non potest satiari auditu nec oculus 53, 265va

Sicut credidisti fiat tibi (Mt 8,13). Pro huius thematis introductione invenio tres scholas scilicet vulgarium, naturalium, moralium. Prima mensuratur experientia secunda ratione tertia discretione 597, 2va

Sicut Deus disposuit omnia sapienter sic fidei incrementum et suam humanitatem 53, 70va

Sicut dicit Aristoteles $4^{\circ}$ Ethicorum Terribilissimum omnium terribilium videtur esse mors 153, 154ra

Sicut dicit Bernardus in sermone de epiphania Priusquam appareret Dei humanitas latebat 53, 47va

Sicut dicit Gregorius homilia 2 super evangelia Miracula domini et salvatoris nostri sic accipienda sunt 53, 174ra 
Sicut enim tunc vos scitis, quod mos praedicatorum est in principio sermonum praedicatorum ad beatam virginem recurrere 174, 156 1 ra

Sicut in bello corporali securius pugnatur et citius obtinetur triumphus contra hostes 53, 169rb

Sicut in dominica proxima futura recolitur spiritus sancti missio 153, 129va

Sicut inter virtutes morales quae pertinentes sunt ad mores exteriores praecipue praecipua est gratitudo 53, 156rb

Sicut omnipotens Deus verax est in praemissis Ita et misericors 53, 43rb

Sicut ovis ad occisionem ductus est (Is 53,7). Hodie carissimi dies celebratur insignis et festiva in tanto maioris devotionis affectu a singulis Christi fidelibus est celebranda 174, 163ra

Sicut patrifamilias placet servus qui parate exsequitur suam voluntatem 53, 129va

Sicut puer Iesus crevit corporaliter ita et nos crescere debemus spiritualiter 153, 17va

Sicut tactum est in carta quadam hoc in loco reperta $\mathbf{7 6}, 71^{\mathrm{I}} \mathrm{r}$

Sicut valde consultum est servo procuratori alicuius potentis domini qui numquam rationem fecit 53, 19rb

Signa autem eos qui crediderint. Haec sequentur (Mc 16,17). Quamquam nesciatur de homine quoquam an salvetur vel damnetur 153, 127ra

Signa generalia putridarum eis propria sunt duo ut dicit Averroes 748, Iv

Signum non dabitur ei (Mt 12,39). Pro huius thematis introductione invenio tres scholas scilicet mechanicas, trepidas et incredulas. Primo invenio scholas mechanicas et iste sine dubio ut earum opera cognoscantur 597, $10 \mathrm{vb}$

Simile a simili nutritur sicut patet in cibo digesto a quo corpus nutritur 153, 81rb

Simile est regnum caelorum homini patrifamilias (Mt 20,1). Chrysostomus super Matthaeum homilia 28 Homo Christus paterfamilias cui caeli et pater (recte: terra) una est domus familia 53, 124va

- Dominus Deus creavit hominem immo et totum mundum propter suam bonitatem 53, 124ra

- Ex quo in praesenti evangelio fit mentio de patrefamilias qui conduxit operarios 153, 50ra

- Salvator Christus in praesenti evangelio movet singulos homines ad considerandum sua propria opera 53, 130ra

- Scire debetis in Christo dilectissimi quod sancta mater ecclesia catholica hodierna die duo nobis tempora repraesentat 153, 48rb

- Sicut patrifamilias placet servus qui parate exsequitur suam voluntatem 53, 129va

Similiter autem. Hic est quartus liber Physicorum in quo Aristoteles determinat de passionibus 168, 24v

Simpliciores et minus expertos confessores de modo audiendi 532, $125 \mathrm{r}$

Sinite utraque crescere ... (Mt 13,30). Sciendum quod in caelo sunt solummodo boni in inferno solummodo mali 153, 44va

Sistitur hic domino redimendus turture bino 308, 228va

Sit per te excusabile quod per te gerimus $\mathbf{4 0 5}$, 210r

Solent homines in novo anno munuscula sibi invicem dare $\mathbf{1 5 3}, 19 \mathrm{rb}$

Solus Deus dicitur immortalis quia solus est incommutabilis nam et omnia (recte: anima) moritur dum de ore autem (recte: deserente) Deo de bono in malum mutatur 52, 4ra

Solvite templum hoc et in tribus diebus excitabo illud (Io 2,19). Pro huius thematis introductione invenio tres scholas scilicet extimam, intimam, extrinsecam. Prima schola dicitur extima et haec est excellentiae dignitatis et in hac lego trinitatem $\mathbf{5 9 7}, 33 r b$

Spiritus eius ornavit caelos et obstetricante manu eius eductus est coluber tortuosus (Iob 26,13). Creaturarum consideratio pertinet ad theologos et philosophos 86, 1ra

Spiritus est vapor temperatus genitus ex parte subtiliori sanguinis $\mathbf{7 4 8}, 218 \mathrm{vc}$

Spiritus meus super mel dulcis (Sir 24,27). Ex quo spiritus sanctus est fons totius dulcedinis tunc quaeritur quare Deus quandoque dilectis suis subtrahit in praesenti consuetam gratiam 153, 139ra

Stabat mater dolorosa iuxta crucem lacrimosa dum pendebat filius 353, $162 \mathrm{r}$

Stabunt iusti in magna constantia etc. (Sap 5,1). Circa quem textum est dicendum an sancti in aeterna beatitudine quam habebunt post resurrectionem sedebunt vel stabunt 53, 346vb

Stephanus vidit caelos apertos (Act 7,56). Aristoteles $1^{\circ}$ Ethicorum finis per quem omnia desiderantur et sperantur optimus est 153, 7rb

Stetit angelus iuxta aram templi habens thuribulum aureum in manu sua 353, 3r

Subveniat nobis domine misericordia tua ut ab imminentibus peccatorum nostrorum periculis $353,47 \mathrm{r}$

Subsequens oratio de beata virgine et Dei genitrice Maria continens principaliora ipsius et filii eius gesta $654,117 \mathrm{r}$

Summum constitue rescriptum post aliud consue 145, 1r

Sunt autem septem genera hominum qui Deum non colunt sed idola adorant. Primus genus est de quibus 308, 210ra

Supplicationem servorum tuorum Deus miserator exaudi ut qui in commemoratione sanctae Dei genitricis et virginis Mariae congregamur eius intercessionibus 353, 157v

Suppliciter te Deus pater omnipotens qui es creator omnium rerum 654, 65v 
Surrexit non est hic (Mc 16,6). Quando dignitatem festorum totius anni clarius inspicimus invenimus quod ipsa praesens paschalis sollemnitas 53, 310ra

Tangere qui gaudes meretricem qualiter audes/palmis pollutis regem tractare salutis 167, 72r

Te Deum laudamus te dominum misericordissimum confitemur tuam maximam misericordian semper imploramus $353,42 \mathrm{v}$

Te domine sancte pater omnipotens aeterne Deus supplices deprecamur pro animabus omnium fidelium defunctorum quas ab origine mundi accersiri voluisti $654,36 \mathrm{v}$

Te invocamus te adoramus te laudamus beata trinitas miserere nobis $353,117 \mathrm{r}$

Te lucem veram et lucis auctorem domine deprecamur ut digneris a nobis tenebras depellere vitiorum 405, 92r

Te matrem laudamus te Mariam virginem confitemur 353, 168v

Templum Dei sanctum est quod estis vos si quis autem templum Dei violavit disperdet illum dominus Deus (1 Cor $3,17)$. In verbis istis apostolus duo facit, ostendit enim fidelis animae sanctitatem et exsecratur sanctitatis violatorem 162, 8ra

Templum hoc sanctum ingredientes rex pie exaudi nos domine. Nota tria templa placentia Deo. Primum templum est aureum secundum est eburneum tertium est lapideum 162, 3ra

Tempore pestilentiali si vis ut apostema ex materia venenosa $\mathbf{7 4 8}, 70 \mathrm{v}$

Thales dicit Antiquissimum entium est Deus ingenitum et in aevum. Optimum entium mundus nam opus Dei 155, 144ra

Thomas autem non fuit cum eis quando venit Iesus (Io 20,24). Notandum quod beatus Thomas Christum discipulis apparentibus non vidit quia non fuit cum eis sed post octo dies eum vidit 153, 103va

Tibi dico surge (Lc 7,14). Pro huius thematis introductione tres scholas invenio scilicet aequitatis, benignitatis, sanctitatis. Prima schola est aequitatis et in hac legitur quod relevetur infirmus 597, 34va

Tota summa huius evangelii est quod Christus voluntarie ivit ad desertum locum 53, 170ra

Totam vitam nostram plenam fecit Deus temptationibus et etiam rationabiliter Deus permittit electos suos temptari 53, $164 \mathrm{ra}$

Tradetur enim gentibus ... (Lc 18,32). Ubi sciendum quod passio Christi quae in hodierno evangelio nobis proponitur retrahere nos debet ab illicitis gaudiis huius saeculi 153, 58ra

Transfiguratus est ante eos (Mt 17,2). Pro huius thematis introductione invenio tres scholas scilicet alchimistarum, artistarum, poetarum. In omnibus autem his scholis legitur transfiguratio. Prima schola est alchimistarum 597, $17 \mathrm{rb}$

Translati sumus de morte ad vitam (1 Io 3,14). Nos enim videmus ad sensum quod quando aliqui evaserunt mortem qui fuerunt in bello fortissimo ubi multi mortui fuerunt ad suos dilectos veniunt et dicunt 174, 90vb

Transmutatur autem. In ista parte Aristoteles ponit quintum librum Physicorum in quo Aristoteles determinat de divisione motus $168,39 r$

Tres sunt omnes doctrinae quae ordine habentur etc. Istius libri qui Tegni id est Pars (!) parva dicitur 453, 33v

Tres sunt omnes doctrinae quae ordine habentur. Prima quidem ex finis notione 453, $1 \mathrm{r}$

Triplex causa febrem generat custodit et auget $\mathbf{7 4 8}, 1 \mathrm{r}$

Triplex est rigor scilicet praecedens et est in interpolatis coincidens ex multitudine materiae $\mathbf{7 4 8}, 40 \mathrm{v}$

Tu domine qui nosti corda hominum etc. (Act 1,24). Hodie in ecclesia agitur de duabus personis scilicet de Iuda qui est de honore suo detrusus 78, 35ra

Tu puer propheta altissimi vocaberis praeibis enim ante faciem domini parare vias eius (Lc 1,76). Nota quod est triplex via. Prima in mundum, secunda per mundum, tertia extra mundum. Prima via in mundo (!) est lamentabilis 78, 64vb

Tua nos domine Deus misericordia ab omni surreptione vetustatis 353, 50v

Tui amoris gratia mi Antoni Magliane ad hunc deveni locum 748, 1v

Tulerunt ergo lapides ... (Io 8,59). Aristoteles 8o Ethicorum dicit Vera amicitia habet reamationem. Et quia Christus vere nos dilexit 153, 77ra

Tussis est motus naturalis ex pulmone 123, 218r

Tutela bona confessionis quando confitetur mulier se habere filium spurium inter legitimos. Officii mulier quae partum supponit alienum vel de adulterio concepit 155, 7ra

Ubi sciendum est quod per mare intellegitur praesens mundus et per motum magnum 153, 41va

Ubi sciendum quod passio Christi quae in hodierno evangelio nobis proponitur retrahere nos debet ab illicitis gaudiis huius saeculi 153, 58ra

Ubi sciendum quod seminator est Deus omnipotens qui exiit seminare semen suum id est genus humanum creando $153,51 \mathrm{vb}$

Unde Iohannes de Sancto Geminiano dicit Conveniens est ut sentiat membrum quod sentit caput 153, 84ra 
Unde Iohannes de Sancto Geminiano Videmus enim quod cum animal brutum sentit se vulneratum sollicite quaerit et procurat sanationis remedium 153, 60va

Ure igni sancti spiritus renes nostros et corda nostra domine $654,65 \mathrm{v}$

Urina est colamentum sanguinis et aliorum similiter humorum de naturae quidem actionibus natum 748, 138ra

Usurarius quidam cum crux in quibusdam partibus praedicaretur cum ceteris caecus non ex devotione sed ex importuna circumstantium ammonitione 308, 194va

Usurarius quidam dives nimis diversarum 308, 195rb

Ut in aliis vero dominicis. Propter baptismalia sacramenta in tribus personis 483, 54r

Ut quid Mercuri hic ades galero redimitus et citharam gestans 694, 3r

Ut seriem mente teneas textus doceam te/Est Genesis primus, post Exodus ipse secundus 166, IIv

Ut tuam domine misericordiam consequamur fac nos per intercessionem 654, $15 \mathrm{r}$

Utrum autem factus. Iste est octavus liber Physicorum in quo Aristoteles determinat de perpetuitate motus 163, 15r

Utrum corpus discrasiatum ex generatione et tempore debeat reduci ad temperamentum 453, 54va

Utrum de passionibus et operationibus animatorum ponenda sit scientia distincta a scientia de anima de animalibus et a scientia de plantis $\mathbf{4 4 0}$, 1ra

Utrum habens confessionale a sede apostolica secundum formam consuetam possit sibi rationem istius eligere in confessorem quemcumque sacerdotem non suspensum 155, 14va

Utrum in omni tempore morbi possit fieri evacuatio in febre putrida. Quod sic auctoritate illius aphorismi. Incohantibus morbis etc. 453, 53va

Utrum ratione confessionalis quod dari consuevit possit quis absolvi in casibus episcopalibus a quolibet sacerdote $155,14 \mathrm{vb}$

Utrum religiosus professus et divina praecepta cum substantialibus regulae conservans $\mathbf{7 6}, 11 \mathrm{r}$

Utrum sacerdos in confessione eam absolvere posset cum qua peccavit fornicariae 155, 14vb

Utrum sit possibile umorem vel umores nostri corporis peccare solum in quali. Et arguitur quod non. Primo sic quilibet umor peccans 453 , 143ra

Utrum solus Deus sit adoratione latriae adorandus 165, 131v

Utrum tantum tres sint omnes doctrinae ordinariae. Arguitur quod non. Primo quot sunt quaestiones tot sunt scientiae vel doctrinae $\mathbf{4 5 3}$, 187ra

Utrum usura mortaliter culpabilis sit penes intentionem principaliter mensuralis (!). Arguitur quod non quia usura attenditur penes pactum mutui inter diversas personas contractum ergo non penes intentionem principaliter 447, 207ra

Vado ad eum qui me misit (Io 16,5). Divina dispositione et providentia ab aeterno Deus piissimus disposuit postquam Iudaicus populus 53, 333rb

Vado piscari (Io 21,3). Ex quo hodie est ultima dies celebris praesentis festivitatis paschae et modo homines redire debent ad pristinos labores suos 153, 101ra

Vehementiores fiunt motus aegrium et acta eorum in nocte $\mathbf{7 4 8}$, Iv

Venerabilibus in Christo patribus dominis Dei gratia archiepiscopis et episcopis sedis apostolicae gratiam et communionem habentibus $253,83 \mathrm{v}$

Venerabilis domine N. Vos misistis ad me pro Amigdalis ego deberem nos providere cum Amigdalis ego locutus sum cum domino N. 617, $195 \mathrm{r}$

Venerandae ac praedilectae pater ad satisfaciendum oboedientiae mihi per paternitatem vestram nuper iniunctae sub actu visitatione videlicet ut scribere vobis deberem quid sentiam $754,13 \mathrm{r}$

Venit enim filius hominis quaerere et salvum facere $(\operatorname{Lc} 19,10)$. Hic sumat peccatrix anima confidentiam tripliciter. Quia Christus venit quaesivit et salvum fecit venit nascendo quaesivit praedicando salvum fecit moriendo 162, $7 \mathrm{rb}$

- Ista scribit beatus Lucas et sunt verba nostri salvatoris suam dilectionem quam ad quendam humanum habuit 162, 1ra

Venite mittamus lignum in panem eius (Ier 11,19). Pro huius thematis introductione invenio tres scholas scilicet mechanicas, piraticas, maleficas. Prima schola est mechanica et haec utitur ligno 597, 43ra

Vera amicitia habet reamationem. Et quia Christus vere nos dilexit 153, 77ra

Vera patientia quanta bona et quantas utilitates afferat homini possumus ex diversis scripturis sacris colligere 53, $138 v a$

Verba praedicta quilibet potest dicere qui digne in hoc sacro tempore communicavit 153, 106ra

Verba proposita leguntur in evangelio hodierno et per ea insinuatur nobis gloria praemium omnium sanctorum quorum hodie festivitas celebratur 617, 189r

Verba proposita possunt esse interioris hominis id est animae respondentis ad quaestionem sibi factam $\mathbf{6 1 7}, 171 \mathrm{r}$

Verba proposita sunt a Christo beato Petro dicta et iam dicuntur cuilibet homini qui vult salvari 153, 11va

Verba sunt beati Tobiae ad vocem haedi cuiusdam balantis caprarum 53, 209rb 
Veri praedicatores praecipue quibus non sunt certae elemosinae assignatae libentius vadunt ad eos convertendos qui nondum ad fidem Christi conversi sunt quam ad illos qui iam conversi sunt 155, 16vb

Verus ac pius samaritanus dulcis Iesus qui vinum et oleum fundit 550, 44vb

Videntes stellam gavisi sunt gaudio magno valde etc. (Mt 2,10). Glossa non fuit satis evangelistae dicere gavisi sunt sed addit valde magno gaudio 153 , 25vb

Videte ne furtivus sit reddite eum [...] dominis suis quia non licet vobis edere ex furto aliquid aut contingere (Tb 2,13). Verba sunt beati Tobiae ad vocem haedi cuiusdam balantis caprarum 53, 209rb

Vidi alterum angelum descendentem de caelo amictum nube et iris in capite eius et facies eius sicut sol (Apc 10,1). In verbis istis tria notantur de sancto Bernhardo. Primo sanctitas vitae cum dicitur Vidi alterum angelum descendentem de caelo amictum nube. Primus enim angelus fuit beatus Benedictus 78, 80ra

Vidi civitatem sanctam Ierusalem (Apc 21,2). Dicit beatus Augustinus quod duplex est civitas 162, 8vb

- Quantum ad statum paenitentiae ostendit autem civitatem iustorum laudabilem duplici respectu 162, 9ra

Vidit Iacob in somnis scalam et angelos Dei descendentes et ascendentes per eam $(\mathrm{Gn} 28,12)$. Ait vere dominus est in loco isto et ego nesciebam (Gn 28,16). His verbis possumus quattuor notare. Primo quis sit Iacob secundo quod dormivit tertio quae sit scala quarto quod angelos vidit 162, 3va

Vidit Iacobus scalam a terra usque ad caelum attingentem per quam ascendebant $\mathbf{1 8 1}, 1 \mathrm{r}$

Virorum illustrium praesulum scilicet ac doctorum praeconia (!) sacrosanctam quintae huius distinctionis series continet et declarat nugas nimirum respuens $\mathbf{3 0 8}, 12 \mathrm{rb}$

Vita brevis ars vero longa tempus acutum experimentum vero fallax iudicium autem difficile 453, 39r

Vita brevis ars vero longa tempus acutum. Praetermissis quibusdam superfluis inquisitionibus in principio huius libri 453, 59ra

Vobis datum est nosse mysterium regni Dei (Mt 13,11). Quaestio oritur inter doctores utrum in hac vita possit Deum videre facialiter $\mathbf{5 9 7}$, 44ra

Vor allen dingen ir lieben prüder habt got lieb dar nach den nächsten. Wan die zway gepot synd uns vorderleich gegeben 146, $1 \mathrm{r}$

Vos autem contristabimini (Io 16,20). Hic est dicendum quare Deus permittit aliquos bonos homines ita acerbissime tribulari in praesenti 153, 115rb

Vos estis autem genus electum regale sacerdotium gens sancta etc. (1 Pt 2,9). Haec verba sunt beati Petri ad commendationem et dignitatem sacerdotalem. In verbis praemissis possumus notare triplicem gradum sive excellentiam cuiuslibet sacerdotis. Primo eius dignitatem 597, 58ra

Vos portae pulcherrimae quae in magnam surrexistis altitudinem $654,3 \mathrm{v}$

Wer begert zu ainem donatum aufgenommen werden, der sol vor wissen, daz er nit zu müssichait und rue 76, 73r

Zachaee festinans descende (Lc 19,5). Nota quod quidam Deum recipiunt in domum suam et non in animam quidam in animam et non in domum quidam in animam et in domum quidam nec in animam nec in domum 162, 1va

Zachaeus interpretatur iustus sed quia ille iustus non erat ideo dominum videre non poterat. Sunt autem tres causae quare dominum videre non poterat. Primo propter divitias 162, 4ra

Zamay non spiero de veder vendeta/ de quella falsa lengua maledeta 4 , Iv 


\section{UNVOLLSTÄNDIGE TEXTANFÄNGE (INCIPIT MUTILE)}

] adhuc super corda Iudaeorum positum et ideo non valent videre splendidum legis sensum 483, 39r ] aenigma vel obscuritas sive imperfectio 86, 34ra (aeter)]nitas. Per te sumus redempti summa tu caritas Graduale Neocellense I, 221r

] aqua de floribus fabarum aut aqua furfuris aut aqua $\mathbf{7 4 8}$, Ir

] Aristoteles $2^{\circ}$ Ethicorum cum dicit eam esse non contemplationis gratia. Iste est prologus quem praemittit magister Buridanus libris Ethicorum quo primo innuit primam conclusionem 440, 89ra

] Ausoniis disterminat arva colonis unde apparet Antenorem non ad Italiam venisse 173, 27ra

] caelis et quidcumque solveris super terram erit solutum et in caelis (Mt 16,19) 196, 30[21]r

(ca)]ventes in secretis pariunt et occultant. Feminae onagrorum 171, 1ra

(certa)]minis tendimus. Scrinium cum reliquiis portamus contra daemones 483, 36r

] cognitio rei nisi per speciem eius sed species eventus futuri non potest $\mathbf{8 6}$, 25ra

] consiliis cinctus odiis $327,11 \mathrm{r}$

] contemnens suam velit statuere iustitiae domini non sit subiectus 282, $1 \mathrm{r}$

(cor)]rigebatur quod in ecclesia sua nolebat facere residentiam 253, 84ra

] cur timebo. Tertio dicitur quae impiis et iustis reddenda sunt ibi 19, 1ra

]date cum omnes populi 15063, $125 \mathrm{r}$

] de manu Aegyptii et interfecit eum hasta sua. Haec fecit Banaias filius 20, 1ra

] deficientem et respondent totum ad temperamentum sanitatis 440, 269ra

] Dei dicuntur quia ex praecepto Dei in servitium Dei offeruntur 483, 33r

] Deum ex toto corde et ex tota anima et proximum nostrum sicut nos. Necessaria est ita quia virtus concordiae 146, $6 \mathrm{r}$

] dicitur in Deum peccare 86, 36ra

] eas in sinum Abrahae in lucem sempiternam Graduale Neocellense I, 270r

] ecclesia conficitur et capiti Christo coniungitur 483, 35r

(en)]sis cedit mortique vita succedit ecce vidit Graduale Neocellense II, 98r

] episcopus Brixinensis dilecto nobis in Christo Iohanni scholastici (!) de Isnina salutem in domino. Ecclesiam parochialem sancti [...] usina nostrae dioecesis ad collationem nostram pleno 53, HDS

(epule)]mur in azymis sinceritatis et veritatis Graduale Neocellense I, 163r

] erat cor unum et anima una et nemo dicebat aliquid 190, 31ra

] erectis quasi orans huius exemplum 146, 13ra

] esse scilicet secundum quid aliquas praelationes a Deo non esse 86, 35ra

] esse vestimenta clericorum in quibus nihil notari possit 146, 10r

] est in multis pro nobis constituta 31, 91ra

] Et merito quidem contra eos cum quadam indignatione loquitur qui in Christum dominum 190, 1ra

] et non aedificabis eos. Isti exterminio digni sunt 190, 7ra

] et probatur extra de regula veniens prope prin. Sequitur de manifesto videre 7, 64ra

] etiam Benedictus in eadem significatione 483, $3 \mathrm{r}$

] exercitus in militiam congregatur. Signa militibus per turbas (!) dantur 483, $1 \mathrm{r}$

] facias auxilium tuum a me ad defensionem meam Graduale Neocellense I, 130r

] faciem terrae. Alleluia Graduale Neocellense I, 207r

] faciunt sic victos e contrario voti impotes qui non possunt facere quod volunt 173, 1ra

] facultas et manumittentis 107, 54ra 
] gaudet purpureosque iacit flores 173, 85ra

] Hic Deus meus et honorabo eum Deus patris mei Graduale Neocellense I, 152r

(hu)]militatis gratia Petri petens vestigia 194, 22r

]ia. Benedictus es domine Deus patrum nostrorum Graduale Neocellense I, 219r

] Iam mare transcurri 327, 19r

] In serie dicta $327,14 \mathrm{r}$

] in populo Dei 15063, 84r

] indicas Hermannum VII q. I Quamvis triste et C. de codicillis nec codicillos quod vero supra dictum est 253, 85ra

] infinitum utique (!) in longitudine est et in tempore 163, 26r

] Item agitur scilicet qui $[\ldots]$ non est generatione [...] non est 405, VDS

]ituri sunt qui semper caelestia dilexerunt 190, 15ra

]ma. sed etsi § quocumque quomodo intra diem illam poterit probare laesionem 253, 83ra

] magis ad vindictam pertinet quam ad disciplinam. Caveant ergo fratres ut neminem reprehendant 146, 11r

] malum quia liberum arbitrium per se in bonum ordinatum est $\mathbf{8 6}$, 39ra

(man)]datis tuis quae dilexi Graduale Neocellense II, 64r

] manus baptizandus et perfert fraudes temptatoris fugit persequentum lapides 154, $1 \mathrm{r}$

(ma)]nifestam non quae iudici nec quae alii 107, 81va

] mihi ianuam vitae 15063, $15 \mathrm{r}$

] miracula et in hoc apparebit ipsorum conscientia unde Gregorius 153, 1ra

] Missa legatio dicitur Totum tempus quo Christus mundum intravit 483, 22r

(ne)]mo propheta acceptus est in patria sua $\mathbf{1 7 1}, 16 \mathrm{ra}$

] non erit. Sed illi soli dicant qui dominum timent 190, 39ra

] non omnino sunt certae pronuntiationes neque vitae neque mortis. Curatio rectificetur aer $123,11^{\text {a }} \mathrm{r}$

] non procedit ab ore vestro sed si quis bonus est ad aedificationem fidei ut det gratiam audientibus. Ergo videtur quod etiam alii quam Christo competat esse ecclesiae caput. Propterea Christus ex eo quod praeest ecclesiae non solum dicit caput 38, 1ra

] noster in universa terra iudicia eius 617, VDS

] nugis et ioco ac fabulis vacantes. Nota ad honorem individuae trinitatis 606, 1ra

(ob)]dormiam in morte ne quando dicat inimicus meus Graduale Neocellense I, $87 \mathrm{r}$

] panem invenit sed cum vix ad unius prandii esum tribus personis sufficere videntur Laurentius artifices suos nolens deficere 308 , 1ra

] parenti veteri tu membris fortioribus Graduale Neocellense I, 324r

(Item quod est frater ...)] paternam pietatem non agnoscat ... Quid si aliquis interfecit patrem vel tutorem meum 7, 1ra

] peccati superbia. Prima est enim in peccando ultima remanet in conflictu 146, $8 \mathrm{r}$

(perma)]nens et materia transiens. Permanens est ut in cultello ferrum transiens est ut in pane farina et in vitro 605, 3ra

] per quem videmus signa in populo 440 , urspr. VDS (heute abgelöst)

] poetis plerumque conceditur 173, 136ra

(prae)]clarissima Amen Graduale Neocellense II, 145r

] praeformet capitis (!) naturae 327, $8 \mathrm{r}$

] Prima est certitudo 146, 122ra

(prin)]cipis Pharisaeorum sabbato manducare 15063, 131r

] pullorum evolantium imbecilles 171, 12ra

] quae vulgo dicitur Rothinholus. Horatius in sermone. Licinias (!) soliti impensa (!) prandere coemptas. Lucinium -nii ubi solet candela lucere quia dat lumen et dicitur a luce 106, 1ra

] quaedam forma substantialis ut anima est substantialis forma hominis alia autem et forma accidentalis ut album homini. Prima harum 605, 2ra

] quam commodum oboedientis attenderet. Itaque ut homo super hanc vitam 485, $7 \mathrm{r}$

] quasi torrens praegravemur negotiis curis excitemur innumeris cogitationibus 99, 1ra

] Qui cecidit seseque potens 327, 15r

] quod non quia tantum consequitur per directam 7, 5ra 
] redeundum est ad mansuetudinis lenitatem. Nam pertinax motus facile 146, 12r

(revela)]tionem plurimum addendum fuit. Modum vero divinae cognitionis quam primus ille homo habuisse creditur explicare difficile est excepto eo quod diximus 485, $1 \mathrm{r}$

] rubrum id est per baptismum vel per desertum id est paenitentiam 483, 37r

] salvos faciet eos. Hoc est enim eorum voluntas 190, 63ra

] secundo an excuset peccatum. Ad primum sic proceditur 86, 38ra

] sibi adiudicate ut extra de sententia et re iu. c. Bertoldus in fi. Si autem personali 253, 84va

(si)]cut dixit alleluia 15063, 96r

] simul citant cui oboedire teneatur pro ordinario facit quia eius iurisdictio firmior et antiquior cui specialis non derogat 7,144 ra

] so sy ye meyner bedurffen, ye saliger sy sind. Noch so sol der zarten speis girikait sy nicht uben $146,2 r$

] subiugat. Oppressos a diabolo liberans $483,13 r$

] sumit significans angelum qui Christo resurgente lapidem 483, 19r

] tabernaculorum celebratio ordinati enim $483,64 \mathrm{r}$

]tuum montem Sion. Onus Aegypti. Ecce dominus ascendet super nubem levem 315, 1r

] tuus dolentes quaerebamus te et quid est quod me quaerebatis Graduale Neocellense I, 43r

]um filios Israel et Ioseph Graduale Neocellense I, 54r

] usitata haec enim catholicos et in schismaticos et fideles in haereticos et doctores in adulatores convertit sicut recenter nobis occurrit et nuper exprimato vidistis. Haec enim facultas est illa ancilla Agar de qua scribitur 200, 1ra

]usurarum excommunicatum publice nominatum interdictum et tempus interdicti numquid una vel quadruplici excommunicatione ligabitur 99, 1ra

] verbere et castigatione in ipso initio peccati $146,12^{\mathrm{a}} \mathrm{r}$

(vir)]gine nascitur et per multas passiones in candorem resurrectionis $483,21 \mathrm{r}$

] virum de plebe et claritatem 15063, 65r

] Vocum quae flecti nequeunt 327, $16 \mathrm{r}$

] volentes libro sexto salvis quae dicuntur in sequenti 145, 101va 


\section{VERFASSER UND WERKTITEL}

\section{(Autoren erscheinen in der Regel unter ihrem Vornamen)}

Adam de Aldersbach OCist (gest. ca. 1260): Summula pauperum. Mit Kommentar und Interlinearglossen 167, 1ra Ps.-Aegidius Romanus: Speculum peccatoris s. Ps.-Augustinus

Alanus ab Insulis OCist (frühscholastischer Theologe, gest. 1203): Summa de arte praedicatoria 181

Albertus de Brixia OP (gest. ca. 1314): Summa de officio sacerdotis 447, 1ra

Ps.-Albertus Magnus: Secreta mulierum. Mit Kommentar 155, 123r

Aldobrandinus de Cavalcantibus OP (Prediger, Bischof von Orvieto, gest. 1279): Sermo in dedicatione ecclesiae 162, 8ra

Aldobrandinus de Toscanella (Lektor in Pisa, Pistoia, Siena, Viterbo 1287-1292): Scala fidei 31, 1ra Alexander de Villa Dei (Grammatiker, Mathematiker, gest. ca. 1250): Doctrinale (Fragmente) 52, Fälze

Alfonsus Bonihominis OP (Arabist, gest. 1339) s. Rabbi Samuel

Ambrosius Spiera OSM (ca. 1413-1454/1455): Sermo Fer. 6 in parasceve 174, 156 ra

Anrufung an den hl. Hartmann 293, 23v

Antiphonarium 15063; 139, 154r; 940, 152r

Antonius Guainerius (Arzt aus Pavia, gest. nach 1445):

- Summarium de febribus 748, $1 \mathrm{v}$

- Tractatus de peste et venenis $\mathbf{7 4 8 , 9 0 \mathrm { v }}$

Antonius Volscus: Vita Ovidii 579, 1r (am Rand)

De aqua vitae $\mathbf{7 4 8 , 5 3 r a}$

Argumenta librorum Dictys Cretensis: De Troiani regni excidio cum appendiculis 691

Aristoteles (Philosoph, gest. 322):

- De anima, translatio nova durch Guilelmus de Moerbeke. Mit Kommentar 163, 32r

- Physica, Lib. 6-8, Translatio nova durch Guilelmus de Moerbeke. Mit Kommentar 163, 1r (Forts. von Cod. 168, 46v)

- Physica, Lib. 1-5, Translatio nova durch Guilemus de Moerbeke. Mit Kommentar 168, 1r

- s. auch Iohannes Buridanus

- s. auch Quaestiones secundum Iohannem Buridanum super libros Ethicorum Aristotelis I-V

Arnoldus de Geilhoven CRSA (gest. 1442): Remissorium utriusque iuris (Praefatio) 4, 1ra

Ars notariatus 155, 115ra

Ars praedicandi 155, 139r

Astronomische Texte 776, 47r

Auctoritates (Zitate):

- zu De Anima 597, 57vb

- philosophische 155, 144ra

- verschiedene 308, 225va; 755, 10ra

Augustinus, hl. (Kirchenvater, gest. 430):

- Confessiones 158, 1ra

- Exzerpte 167, 71va

- Sermo 9: De decem chordis 165, 141r

- s. auch Regula s. Augustini

Ps.-Augustinus:

- Auctoritates (Exzerpte) 165, 42ra

- Epistola 18 (ad Cyrillum Hierosolymitanum episcopum de magnificentiis beati Hieronymi) 125, 183vb; 165, 53va

- De praedestinatione Dei 532, 27r

- Sermo 277: De reddendis decimis 155, 16ra

- Speculum peccatoris $\mathbf{8 3}, 52 \mathrm{va}$ 
Augustinus Favaroni OESA (Generalprior, Erzbischof von Nazareth, 1360-1443): Sermones bzw. Interrogationes seu introductiones quadragesimales 597, 43va

Avianus Poeta (röm. Fabeldichter, ca. 4./5. Jh. n. Chr.): Fabeln (Nr. 1-28). Mit Kommentar 155, 155v

Bartholomaeus Brixiensis (Kanonist, 1200-1258): Quaestiones dominicales, De conditionibus appositis, unvollständig 614, $289 \mathrm{v}$

Bartholomaeus a Sancto Concordio OP (Kanonist, gest. 1347): Summa de casibus conscientiae (= Summa Pisanella) 145, 2ra

Beda Venerabilis OSB (Kirchenlehrer, gest. 735): Exzerpte 167, 71va

Ps.-Beda Venerabilis: Termini quartae decimae lunae regulares (Memorialverse zur Berechnung des Osterfestes) $360,26 r$

Beimiarm s. Isaac Iudaeus

Bernardinus Senensis OFM (Prediger) (?): Speculum peccatorum sive amatorum mundi, unvollständig 83, 55va

Bernardus Claraevallensis OCist, hl. (Kirchenlehrer, gest. 1153):

- De gradibus humilitatis et superbiae 282, 1r

- De gratia et libero arbitrio, unvollständig 282, $1 \mathrm{r}$

- Epistola 17 (ad Henricum Senonensem archiepiscopum: De moribus et officio episcoporum) 282, 15r

- s. auch Tractatus super missus est

Ps.-Bernardus Claraevallensis: Speculum peccatoris s. Ps.-Augustinus

Bernardus de Gordonio (Arzt, ca. 1283-1320): Practica seu Lilium medicinae, unvollständig 123, 1r, 215v (Nachtrag), 218r (Nachtrag)

Bernardus Papiensis (Bischof von Faenza und Pavia, gest. 1213): Breviarium Extravagantium sive Compilatio prima Decretalium, unvollständig 107, 1ra

Bernardus Parmensis de Botone (Kanonist, gest. 1266): Casus longi Decretalium (Exzerpte) 155, 106ara

Bibel s. Vetus testamentum

Bonaventura OFM (Kirchenlehrer, gest. 1247) (Bonaventura abbreviatus): Super II Sententiarum 52, 43v

Ps.-Bonaventura:

- Stimulus amoris s. auch Iacobus Mediolanensis

- Tabula a celebrantibus missam consideranda 167, 72r

Bonifatius VIII. (Papst 1294-1303): Regulae iuris 614, 282v

Breviarium Salisburgense 405

Bruno de Segni OSB (Abt von Montecassino, Bischof von Segni, ca. 1048-1123): Expositio in Psalmos, unvollständig 190, 1ra

Caesarius Heisterbacensis OCist (Mönch, 1180-1240): Dialogus miraculorum, Dist. 3, cap. 6 125, 284ra; 308, $126 \mathrm{vb}$

Caesarius Arelatensis, hl. (Bischof von Arles, Kirchenschriftsteller, 469/70-542): Sermo 33 155, 16ra

Canones: Begriffserklärungen (wohl Kompilation aus mehreren Rechtslexika) 155, 18ra

Cedula (Abschrift), Augustiner Chorherrenstift Neustift 76, 71'r

Chalmelli, Raimundus (Arzt, ca. 1334-1398): De pestilentia libri tres, unvollständig 748, 54v

Christophorus Barsisius (Professor der Medizin in Padua 1434-1440): De febrium cognitione et cura 748, 41r

Cicero, Marcus Tullius (röm. Politiker, Anwalt und Philosoph, 106-43 v. Chr.): De officiis 1,22 755, 10rb

Claustrum animae 165, 144rb

Clemens V. (Papst 1305-1314): Constitutiones (Clementinen), unvollständig 99, 1ra

De comparationibus BMV 171, 62ra

Conradus de Brundelsheim (Soccus) OCist (Abt von Heilsbronn, gest. 1321): Sermo in dedicatione ecclesiae 162, $5 \mathrm{rb}$

Conradus de Waldhausen OSACan (Prediger, gest. 1369):

- Flores (Graeculus Piper) secundum Conradum de Waldhausen 177, 1ra

- s. auch Graeculus

Conradus Eberbacensis OCist (Kirchenschriftsteller, Abt von Eberbach, gest. 1221):

- Exordium magnum Cisterciense, Dist. 4 (Auszüge) 125, 261ra, 272rb; 308, 76va, 101rb

- Exordium magnum Cisterciense, Dist. 5 (Auszüge) 125, 272va; 308, 101va, 101vb

Conradus Hirsaugiensis OSB (Mönch in Hirsau, Philosoph, Schriftsteller, Musiker, ca.1070-1150): Dialogus super auctores, unvollständig 360, 1r

Constantinus Africanus (Arzt, um 1010-1057):

- Praefatio 748, 162ra

- s. auch Isaac Iudaeus

Ps.-Cyrillus: Epistola ad Augustinum de miraculis Hieronymi 125, 186va; 165, 55vb 
De ... (anonyme Texte) s. unter dem ersten Substantiv

Declaratio arboris consanguinitatis 155, 105v

Determinatio doctorum universitatis Pragensis de V propositionibus magistri Iohannis Muntzinger 1386 facta $=$ Gutachten der Prager theologischen Fakultät im Rahmen der theologischen Streitigkeiten zw. Johannes Müntzinger und den Dominikanern in Ulm 165, 129r

Dionysius Carthusianus (Theologe, „Doctor ecstaticus“, 1402-1471): Revelatio cuiusdam Carthusiensis in missa $754,11 \mathrm{v}$

Dispositio catholicae fidei, unvollständig 190, 67rb

Divisiones libri tegni Galeni 453, 33v

Donatus, Aelius (Grammatiker, Mitte 4. Jh.) s. Terentius Afer, Publius

Donatus devotionis: De octo partibus orationis, Pars 1 617, $1 \mathrm{r}$

Durantis, Guilelmus (Kanonist, gest. 1296):

- Rationale divinorum officiorum 550, 96ra

- Speculum iudiciale, unvollständig 7, 1ra

Eadmerus Cantuariensis OSB (Bischof von St. Andrews, gest. 1124): De beatitudine coelestis patriae 532, 28v

Ebendorfer, Thomas (Theologe, Rektor der Universität Wien, 1388-1464): Sermones de tempore de evangeliis, pars hiemalis $\mathbf{5 3}, 1 \mathrm{r}$

Ecbertus Schonaugiensis OSB (Theologe, ca. 1120-1184): Soliloquium seu Meditationes 125, 169va (Auszug); $165,139 \mathrm{v}$

Engelschalk, Albertus (Theologe, Rektor der Universität Prag und Wien, ca. 1353-1430) s. Ambrosius Spiera

Engelschalk, Matthias (Magister in Niederaltaich, 15. Jh.): De passione Christi secundum quattuor evangelistas 756

Epistola de visione cuiusdam fratris ordinis Carthusiensis in Ruremunda 754, 13r

Eusebius Caesariensis (Bischof von Caesarea, griechischer Kirchenschriftsteller, gest. 339): Ecclesiasticae Historiae, ins Lat. übersetzt von Rufinus Aquileiensis (Auszüge) 166, 52va

Ps.-Eusebius Caesariensis: Epistola ad beatum Damasum episcopum Portuensem et ad christianissimum Theodosium Romanorum senatorem de morte Hieronymi 125, 170rb; 165, 42va; 182, 1ra

Exempla s. auch Miracula

Expositio orationis dominicae 161, 8va

Expositio super Ave Maria 31, 49ra

Flavius Iosephus (jüdischer Historiker, gest. ca. 100):

- De antiquitatibus (Auszüge) 52, 38vb

- De bello Iudaico (Auszüge) 52, 38vb

- De forma vivendi monachorum 165, $143 \mathrm{va}$

Fragmente:

- philosophischer Traktat 405, VDS

- Psalterium 617, VDS

- Urkunde des Bischofs von Brixen an Johannes, scholasticus aus Isny (de Ysnina) 53, HDS

Franciscus de Zabarellis (Theologe, 1339-1417): De horis canonicis 155, 1ra

Galenus (griechischer Arzt und Philosoph, ca. 130-200):

- Ars parva seu Microtegni, ins Lat. übersetzt von Gerardus Cremonensis 453, 1r

- s. auch Divisiones libri tegni Galeni

Galfredus de Vinosalvo (Grammatiker, gest. um 1210): Poetria nova, unvollständig 327, 1r

Gentilis de Fulgineo (Arzt, Naturphilosoph, gest. 1348): Consilium de peste, Textbeginn 748, 66v

Gerardus Cremonensis (Übersetzer aus dem Arabischen und Griechischen ins Lateinische, gest. 1187) s. Galenus

Gerardus de Vliederhoven OT (Theologe, 2. H. 14. Jh.): Cordiale quattuor novissimorum 125, 125va

Gerson, Iohannes (Theologe, gest. 1429):

- De modo confessionis et absolutionis sacramentalis 755, 8rb

- De modo excommunicationum $755,8 \mathrm{vb}$

- De oratione et suo valore $\mathbf{7 5 4}, 1 \mathrm{r}$

- De probatione spirituum 755, 1ra

Gerson, Iohannes (Theologe, gest. 1429) (?): De iniunctione paenitentiae 755, 9va

Godefridus Altissiodorensis (franz. Zisterzienserabt, Mönch in Clairvaux, ca. 1115/20-1188): Declamationes ex s. Bernardi sermonibus, cap. 25 125, 311rb; 308, 187va

Godefridus Herilacensis OSB (Theologe, 15. Jh.) (= Ps.-Iacobus de Paradiso): Expositio super orationem dominicam, unvollständig 31, 92ra

Godefridus de Trano (Jurist, Kardinaldiakon, gest. ca. 1245): Summa super rubricis Decretalium 253, 1ra 
Graduale 139, 1r; 940, Ir

Graduale Neocellense (2 Bde) (ohne Sign.)

Graeculus (Titelname von lateinischen Predigten um 1300):

- Sermo in annuntiatione BMV 617, 148r

- s. auch Conradus de Waldhausen

Grammatica speculativa s. auch De modis significandi

Gregorius Magnus, hl. (Kirchenlehrer, Papst 590-604):

- Dialogi 83, 1ra; 165, 1ra; 495

- Dialogi, Lib. 1 (Auszüge) 125, 307ra; 308, 177rb

- Dialogi, Lib. 3 (Auszüge) 308, 198va, 200ra

- Dialogi, Lib. 4 (Auszüge) 125, 275va, 302ra, 305rb; 308, 107va, 166rb, 173ra, 199va

- Exzerpte 167, 71va

- XL Homiliae in Evangelia (Auszüge) 125, 288 va; 308, 139va

Ps.-Gregorius Magnus: Dialogi, Lib. 2 (Auszüge) 125, 246vb; 308, 55vb

Grimlaicus (um 900): Regula solitariorum (Auszüge) 125, 280rb, 300va, 301rb, 303va, 310vb; 308, 118ra, 163rb, 164va, 169ra, 186ra

Guarinus Veronensis (Humanist, Übersetzer, 1374-1460): Argumenta Iuvenalis Saturarum 217, 1r

Guido de Monte Rocherii (Pfarrer von Teruel in Aragonien, 14. Jh.): Manipulus curatorum 550, 1ra

Guilelmus de Moerbeke OP (Bischof von Korinth, Übersetzer aus dem Arabischen und Griechischen ins Lateinische, gest. 1286)

- Aristoteles: De anima, translatio nova 163,32r

- Aristoteles: Physica, translatio nova 163, 1r (Lib. 6-8; Forts. von Cod. 168, 46v); 168, 1r (Lib. 1-5)

Guilelmus Malmesburiensis OSB (Historiograph, Bibliothekar, 1080-1142): Gesta regum Anglorum (Auszüge) 125, 213va, 272vb, 282va, 287ra, 287rb; 308, 102ra, 123ra, 133vb, 134va, 136rb

Guilelmus Peraldus OP (Prediger, gest. ca. 1271): Summa de vitiis et virtutibus (Exzerpte) 125, 98ra

Henricus Suso (Mystiker, gest. 1366): Horologium sapientiae 183

Ps.-Henricus de Frimaria: In libros I-IV Sententiarum sive Filia magistri 532, 34v

Herbertus Claraevallensis OCist. (ca. 1168/98):

- De miraculis, Lib. 1 (Auszüge) 125, 279va; 308, 116ra

- De miraculis, Lib. 2 (Auszüge) 125, 250rb, 250va, 272rb, 272va; 308, 60vb, 61rb, 101rb, 101va, 101vb

- De miraculis, Lib. 3 (Auszüge) 125, 216va, 277va, 279vb, 282vb, 284vb; 308, 111va, 116vb, 123vb, 128rb

Herolt, Iohannes OP (Prior und Lektor in Nürnberg, gest. 1468) (Discipulus): Sermones de tempore 153, 1ra

Hieronymus, hl. (Kirchenvater, gest. 420):

- Bibelprologe 20; 204

- Epistola ad Helvidium (Auszüge) 52, 38vb

- Epistola 107 (ad Laetam) (Auszug) 125, 303va; 308, 169rb

Ps.-Hieronymus: Speculum peccatoris s. Ps.-Augustinus

Hippocrates (griechischer Arzt, 460-370 v. Chr.):

- Aphorismi 453,39r

- s. auch Quaestiones in Hippocratis Aphorismos

Historia passionis dni secundum quattuor evangelistas 174, 156 ra

Honorius Augustodunensis (Scholastiker, 12. Jh.):

- Gemma animae, unvollständig 483

- Speculum ecclesiae (Auszüge) 125, 271 I va, 288 $\mathrm{I} r a ; 308,99 v b, 138 v a$

Horatius Flaccus, Quintus (römischer Dichter, 65-8 v. Chr.): Auszüge aus u. a. Ars poetica, Carmina, Epistolae, Sermones 755, 11va

Hugo de Sancto Caro OP (Theologe, Kardinal, gest. 1263): Postilla in Proverbia, unvollständig 156

Ps.-Hugo de Sancto Caro: In libros I-IV Sententiarum sive Filia magistri s. Ps.-Henricus de Frimaria

Hugo de Sancto Victore CRSA (Scholastiker, Mystiker, gest. 1141):

- De orando Deum 755, 4ra

- De sacramentis, Lib. 1, unvollständig 485

Hugo de Sancto Victore (?): Expositio in regulam beati Augustini, unvollständig 142, 7r; 146, 6r

Humbertus de Prulliaco OCist (Abt von Preuilly, gest. 1298): Extractiones super IV librum Sententiarum Petri Lombardi 52, 110v

Humbertus de Romanis OP (Prior in Lyon, gest. 1277): Expositio regulae s. Augustini, unvollständig 146, 13ra

Iacobus Forliviensis (Arzt, Lektor an der Universität Padua, ca. 1360-1414):

- Expositio in Hippocratis Aphorismos 453, 59ra

- Quaestiones primi tegni Galeni 453, 187ra 
Iacobus de Lausanna OP (Prediger, gest. vor 1332): Compendium moralitatum 52, 202ra

Iacobus Mediolanensis OFM (Theologe, Ende 13. Jh.) = Ps.-Bonaventura: Stimulus amoris (Auszug) 125, 161ra; $165,132 \mathrm{v}$

Ps.-Iacobus de Paradiso s. Godefridus Herilacensis

Iacobus de Voragine OP (Prediger, Hagiograph, gest. 1298): Legenda aurea sanctorum, sive Lombardica historia, cap. 35: De ieiunio quattuor temporum 52, 39rb

Innocentius III. (Papst 1198-1216):

- De contemptu mundi, Lib. 2 (Auszüge) 125, 306ra; 308, 174va

- De contemptu mundi, Lib. 3 (Auszüge) 125, 271' $\mathrm{ra}$; 308, 98vb

Iohannes XXI. (Papst 1176-1177) s. Petrus Hispanus

Iohannes XXII. (Papst 955-963): Extravagantes, unvollständig 99, 33vb

Iohannes Andreae (Kanonist, gest. 1348):

- Hieronymianus (Auszüge) 125, 198va; 165, 71rb

- Novella super librum sextum Decretalium, unvollständig 7, 144ra

- Summula quarti libri Decretalium (Summa de sponsalibus et matrimonio) = Überarbeitung von Iohannes de Anguissola: Summa de sponsalibus et matrimoniis 99, 32va

- s. auch Clemens V.

- s. auch Summarium Quaestionum mercurialium

Ps.-Iohannes Andreae: Ordo iudiciarius 155, 118rb

Iohannes de Anguissola s. Iohannes Andreae

Iohannes de Auerbach (Domvikar in Bamberg, Kanonist, 15. Jh.): Processus iudiciarius 155, 51ra

Iohannes Buridanus (Rektor in Paris, ca. 1300-1358):

- Quaestiones super libros Meteororum Aristotelis, unvollständig 440, 269ra

- s. auch Quaestiones secundum Iohannem Buridanum super libros Ethicorum Aristotelis I-V

Iohannes Calderinus (Kanonist, ca. 1300-1365):

- Repertorium utriusque iuris 4, 1ra

- s. auch Arnoldus de Geilhoven

Iohannes Calphurnius (Humanist, Professor in Padua, gest. 1503) s. Terentius Afer, Publius

Iohannes Cassianus (frühchristlicher Schriftsteller, ca. 360-435): Vitae patrum, Lib. 4 (Auszüge) 125, 309ra, 309vb; 165, 104vb; 166, 57ra; 308, 181vb, 183vb

Iohannes Contractus (Korz) OFM (Prediger, 2. H. 14. Jh.): Sermo de s. Andrea 617, 194r

Iohannes de Dambach OP (Theologe, gest. 1372): Tractatus de indulgentiis 161, 1ra

Iohannes de Deo (Kanonist, 13. Jh.): Concordantiae Decretalium et Decretorum 614, 270r

Iohannes Friburgensis OP (Theologe, gest. 1314): Confessionale 532, 125r

Iohannes Guallensis (Wallensis) OFM (Kanonist, gest. 1285 in Paris): Compilatio secunda Decretalium, unvollständig 107, 79ra

Iohannes Ianuensis OP (Theologe, Lexikograph, gest. 1298): Catholicon sive Prosodia, Pars 5: Vocabularium, unvollständig 106

Iohannes Marchesinus OFM (Theologe, gest. vor 1312): Super Psalterio (aus: Mammotrectus super Bibliam) 155, $141 \mathrm{r}$

Iohannes Mesue: Liber aphorismorum 453, 35r

- s. auch Synonyma Rasis

Iohannes de Sancta Sophia (Arzt aus Padua, 2. H. 14. Jh.): Consilium de pestilentia 748, 71r

Iohannes de Tornamira (Arzt in Montpellier, gest. vor 1396): Preservatio et cura apostematum antrosorum pestilentialium $\mathbf{7 4 8}, 69 \mathrm{v}$

Iohannes de Turrecremata (Theologe, 1388-1468): Meditationes 397, 1r

Isaac Iudaeus (= Beimiarm) (Arzt und Philosoph, gest. um 955), ins Lat. übersetzt von Constantinus Africanus (Arzt, um 1018-1087):

- Liber de febribus 748, 162ra

- Liber de urinis 748, 138ra

Isaias mit Glossa ordinaria, unvollständig 315

Isidorus Hispalensis, hl. (Kirchenlehrer, Bischof von Sevilla, gest. 636): De summo bono seu Sententiarum Lib. 1-3 (Exzerpte) 52, 2va

Iuvenalis, Decimus Iunius (röm. Satiriker, ca. 60/90-140): Saturae 217, 1r, 45r (jeweils unvollständig); 755, 11va, 12ra (jeweils Auszüge)

Kempf, Nicolaus OCart (Theologe, Prior von Geirach, Gaming und Pleterje, gest. 1497): Tractatus de proponentibus religionis ingressum et de anno probationis $\mathbf{6 1 7}, 63 \mathrm{r}$

Kanonistische Kurztexte 145, 314va; 155, 6va, 15ra, 16vb, 48ra, 49vb; 614, 273v 
Lacteus liquor, unvollständig 308, 1ra

Lectionarium missae Neocellense 196

Leo OCist. (Prediger, 14. Jh.): Speculum corporis Christi sive Dialogus increduli et ecclesiae de sacramento eucharistiae 617, 150r

Libellus officiorum 76, 53v

Liber anniversariorum Neocellensis 142, 52ra

Liber Horarum 353 (Bd. 1); 654 (Bd. 2)

Liber miraculorum dictus Lacteus s. Sibylla Tiburtina

Liber sermonum „Fons vitae“ 174, 169rb

Marsilius de Inghen (Scholastiker, Magister an der Universität Paris und Heidelberg, ca. 1340-1396): Quaestiones parvorum naturalium Aristotelis 440, 1ra

Martinus V. (Papst 1417-1431): Bulla „Regimini universalis“ 447, X*r

Martinus Oppaviensis OP (Theologe, gest. 1278): Sermo in dedicatione ecclesiae 162, 9vb

Medizinische Rezepte, Anweisungen, Abhandlungen und Notizen: 453, 53va; 748, Ir, 1r, 40v, 52r, 52v, 54ra, 64v, 66r, 69v, 70v, 72r, 212v, 218vc

- zur Heilung von Pferdekrankheiten 160, 1r

Memorialverse:

- De ordine librorum Bibliae 166, IIv

- Berechnung des Osterfestes s. Ps.-Beda Venerabilis

Miracula:

- Miraculum de duobus sociis 125, 311v

- verschiedene: 308, 187vb, 201va

- s. auch Lacteus liquor

- s. auch Sibylla Tiburtina

Missale:

- Missale (festivum) 100

- Missale speciale (Teilmissale) 154, $1 \mathrm{r}$

- De modis significandi (Grammatica speculativa), unvollständig 605, 5va

Mundinus de Leuciis (Arzt, ca. 1270-1326): Anatomia 748, 74r

Müntzinger, Iohannes (Theologe, Rektor der Stadtschulen in Ulm um Rottweil, gest. 1417) s. Quaestio de articulis und s. Determinatio doctorum

Musicae modulationis commendatio 776, $1 \mathrm{r}$

Musiktraktat 776, 13r

Necrologium Neocellense 142, 127ra

Neustift, Augustinerchorherrenstift:

- Kapitelbeschluss von 1653, betreffend die Vigil des Augustinustages in Neustift und die Frage der Abstinenz 76, $74 \mathrm{r}$

- Über die Pfründnerschaft im Kloster, dt. 76, 73r

- Verfügung des Propstes Fortunat Troyer (1678-1707), betreffend die Offizien beim Begräbnis eines Klerikers 726, $74 \mathrm{r}$

- Vermerke über den 1581 verstorbenen Neustifter Propst Augustinus Schbäl (recte: Schabl) und den 1581 zum Propst gewählten Adamus Lang 726, 76r

- Visitationsinstrument (Abschrift), Augustiner Chorherrenstift Neustift 76, 66r

Ps.-Nicolaus de Dinkelsbühl: Speculum artis bene moriendi 754, 18r

Ps.-Nicolaus de Gorran: Postilla in Proverbia s. Hugo de Sancto Caro

Nicolaus Pergamenus (Fabeldichter, 15. Jh.): Dialogus creaturarum (Auszüge) 125, 304va; 308, 171va

Notizen:

- zu De anima 163, 79v

- zu De baptismo 447, IX*ra

- aus Kloster Baumburg (Oberbayern) über die Weihe der dortigen Kirche 293, 22r

- komputistische 617, 195r

- zu Unterschieden zw. der griech. und der lat. Kirche 52, VDS

- verschiedene 52, VDS; 165, 111rb; 167, 72r; 173, 172r; 360, 26r; 397, VDS; 453, VDS; 532, 124v

- zur Verwandtschaft der hl. Maria 293, 23r

- zur Verwendung der Alhidade mit Skizze 776, 71v

- zur Weihe der Kirche zu Seckau 293, 22r 
Odo de Cheriton (englischer Theologe, gest. ca. 1246): Parabolae (Auszüge) 125, 282ra, 297rb; 308, 121va, 156va Ordenshandschriften:

- s. Tabelle mit Auflistung der Ordensgemeinschaften

- s. Neustift, Augustiner Chorherrenstift

Ordinarium missae 252

De ordine librorum Bibliae s. Memorialverse

Ordo baptisterii 726, 71r

Ps.-Origenes: Homilia de s. Maria Magdalena 161, 6ra

Ovidius Naso, Publius (röm. Dichter, 43 v. Chr.-17 n. Chr.):

- Ars amatoria (Auszug) 755, 11vb

- Remedia amoris. Mit zahlreichen Interlinear- und Marginalglossen 579

- s. auch Antonius Volscus

Peregrinus Oppoliensis OP (Prior in Breslau und Ratibor, gest. um 1322): Sermones de sanctis 78, 1ra Persius Flaccus, Aulus (röm. Dichter, 34-62): Saturae, unvollständig 217, 35r

Pestregimen 748, 71r, 72r

Petrus Beneventanus Collivacinus (Kanonist, päpstlicher Notar, gest. 1219/20): Compilatio tertia Decretalium, unvollständig 107, 81ra

Petrus Blesensis (Theologe, 1135-1212): Compendium in Iob 77, 113ra

Petrus Cantor (Magister und Kanonikus an der Kathedralsschule von Notre-Dame in Paris, ca. 1130-1197): Verbum abbreviatum (Auszüge) 125, 304va, 307ra; 308, 171rb, 177ra

Petrus Hispanus (Philosoph, ab 1276 Papst Iohannes XXI., ca. 1210-1277): Tractatus sive Summulae logicales, unvollständig 605, 1ra

Petrus Lombardus (Scholastiker, Bischof von Paris, um 1095-1160):

- Commentarii in Psalmos, unvollständig 19

- s. auch Richardus de Mediavilla

De plebanis 76, 63v

Pomponius Laetus, Iulius (Humanist, 1428-1498): Widmungsbrief zur Sallustedition an Augustinus Maphaeus 780, $1 \mathrm{r}$

Practica contra pestem $\mathbf{7 4 8}, 66 \mathrm{v}$

Processus iudiciarius 614, 150r

- s. auch Iohannes de Auerbach

Prosdocimus de Beldemandis (Mathematiker, Astronom, Musiktheoretiker, gest. 1428): Compositio astrolabii 776, $61 \mathrm{r}$

Ps(eudo-) s. nach dem Namen des jeweiligen Autors

Quadragesimale De schola Christi (48 Predigten) 597, 1ra

Quaestio de articulis Iohannis Müntzinger 165, 131v

Quaestio sollemnis 76, 11r

Quaestiones disputatae de peccato in spiritum sanctum 165, 114r

Quaestiones in Hippocratis Aphorismos, unvollständig 453, 143ra

Quaestiones secundum Iohannem Buridanum super libros Ethicorum Aristotelis I-V, unvollständig 440, 89ra

Rabbi Samuel (11. Jh.): Epistola ad Rabbi Isaac, ins Lat. übersetzt von Alfonsus Bonihominis 617, 117r

Raber, Vigil: Neustifter Wappenbuch ohne Sign.

Radbertus Paschasius OSB (Abt von Corbey, ca. 788-858): De corpore et sanguine dni, cap. 14 125, 278vb; 308, $114 \mathrm{rb}$

Raimundus de Pennaforte OP (Professor des Kirchenrechts in Bologna, gest. 1275):

- Summa de matrimonio (= Summa, Lib. 4) 253, 85ra (unvollständig); 614, 139r

- Summa de paenitentia (= Summa, Lib. 1-3) 614, 1r

Rampegolus, Antonius OESA (ca. 1360-1423): Biblia aurea 125, 1ra

De reemptionibus 447, 208ra

Regimen Sanitatis Salernitanum 748, 1r (sechs Verse), 176ra (vier Verse), 212vb (sechs Verse)

Regula s. Augustini 76, 1r; 142, 1r; 146, 1r (dt., unvollständig)

Regulae iuris civilis (alphabetisch geordnete Sammlung von Rechtssprichwörtern und -regeln [A-U/V]) 614, 275r

Richardus de Mediavilla OFM (Theologe, 1249-1302): Commentarius in Petri Lombardi Sententiarum librum secundum, Prologus 532, $123 \mathrm{r}$

Rituale Neocellense 194; 726; 14820

Robertus Anglicus (Mathematiker in Montpellier, um 1250/71) (?): De astrolabio 776, 47r 
Robertus Holcot OP (Theologe, Lehrer in Cambridge und Oxford, gest. 1349):

- Commentarius in librum Sapientiae, cap. 3 (Exzerpte) 617, 196r

- Postilla super librum sapientiae, unvollständig 200

Rufinus Aquileiensis (frühchristlicher Schriftsteller, ca. 435-510):

- Historia monachorum (= Vitae patrum, Lib. 2) (Auszüge) 125, 305va, 307rb, 309ra, 309va; 165, 75ra; 308, 173va, 177va 182ra

- s. auch Eusebius Caesariensis

Ps.-Rufinus Aquileiensis: Vitae patrum, Lib. 3 = Verba seniorum (Auszüge) 125, 303va, 305ra, 305vb, 307rb, 307va, 308vb, 311rb; 165, 88va; 308, 169ra, 172va, 174rb, 178ra, 187ra

Rusius, Laurentius (Veterinär, 14. Jh.): Marescalcia 160, 2ra

Sallustius Crispus, Gaius (röm. Historiograph, Politiker, $86-35$ v. Ch.):

- De bello Iugurthino 780, 37r

- De coniuratione Catilinae 755, 11vb (Auszug); 780, 2r

De schola Christi s. Quadragesimale De schola Christi

Serapion s. Synonyma Rasis

Serlon de Wilton (englischer Dichter, ca. 1110-1181): Versus 158, IIr

Sermones, anonym:

- Sermo 597, 58ra (unvollständig); 78, 112ra

- Sermones in dedicatione ecclesiae 162, 1ra

- Sermones de epistolis de tempore „Sensatus“. Mit Konkordanz I und II 174, 1ra

- Sermones de sanctis et de tempore $\mathbf{6 1 7}, 134 \mathrm{v}$

- Sermones de tempore 174, 155ra

- s. Liber sermonum „Fons vitae“

Servasanctus de Faenza OFM (gest. um 1300): Sermones 617, 200r

Servius, Maurus Honoratus (röm. Grammatiker, ca. 4./5. Jh.):

- Commentarius in Vergilii Aeneidos, unvollständig 173, 27ra

- Commentarius in Vergilii Bucolica, unvollständig, 173, 1ra

- Commentarius in Vergilii Georgica 173, 3vb

Sibylla Tiburtina (= Liber miraculorum dictus Lacteus) 125, 205ra

Sigbertus Gemblacensis (Chronograph, ca. 1030-1112): Chronica 823 125, 281vb; 308, 121va

Speculum humanae salvationis 166, 1ra

Statius, Publius Papinius (röm. Epiker, 45-96): Thebais II 620 (Federprobe) 173, 172r

Statuta canonicorum regularium sub episcopis Pataviensibus Georgio et Leonhardo (1389-1451) ordinata pro monasteriis BMV in Dürnstein et s. Dorothea (Wien) (sog. „Wiener Statuten”) 76, 17r

Strambotto (ital.) 4, Iv

Sulpicius Severus (frühchristlicher Schriftsteller, um 400):

- Dialogi, Lib. 1 (Auszüge) 125, 283va, 288rb; 308, 125va, 136vb

- Vitae patrum, Lib. 4 (Auszüge) 125, 309ra, 309vb; 165, 104vb; 166, 57ra; 308, 181vb, 183vb

Summarium Quaestionum mercurialium Iohannis Andreae 614, 284r

Synonyma Rasis 748, 213ra

Tabelle mit Auflistung der verschiedenen Ordensgemeinschaften 155, 17va

Tafel zur Berechnung des Osterfestes mit erläuternden Versus de termino paschae (19 Zeilen) 360, 26v

Tancredus Bononiensis (Kanonist, 1185-1236): Ordo iudicarius, unvollständig 253, 83ra, 84ra

Terentius Afer, Publius (röm. Dichter, 195/184-159/158 v. Ch.), mit vereinzelten Auszügen aus dem Kommentar des Iohannes Calphurnius und des Aelius Donatus 755, 10ra

Termini librorum I-V Decretalium 155, 45va

Theobaldus (11. Jh.): Physiologus cum commento 155, 151r

Thomas a Kempis OSA (Theologe, gest. 1471): De imitatione Christi 125, 146ra

Thomas Cantimpratensis OP (Theologe und Naturforscher, 1201-1263): Liber de natura rerum, unvollständig 171, 1ra

Thomas de Aquino OP, hl. (Kirchenlehrer, gest. 1274):

- Catena aurea in Lucam (Exzerpte) 52, 38vb

- Summa theologica, pars 3. Quaestiones de incarnatione dni, unvollständig 38

- Super librum secundum Sententiarum, unvollständig 86

- s. auch Trakate 
Traktate:

- Traktat in enger Anlehnung an: Thomas de Aquino: Super librum quartum Sententiarum 77, 1ra

- Musiktraktat 776, $13 \mathrm{r}$

- de absentis praesentia 532, $1 \mathrm{r}$

- de anthrace 748, 90r

- de asmate 123, 212r

- de confessione, unvollständig 606

- de decem praeceptis 308, 210ra

- de divisionibus in musica 776, 23r

- de febribus 123, $195 \mathrm{r}$

- de sacramentis 85, $1 \mathrm{r}$

- quomodo religiosus proficere possit in religione $617,55 \mathrm{r}$

- super Missus est (Exzerpte aus Bernardus Claraevallensis) 171, 88rb

- über die Legende der 30 Denare, unvollständig 308, 228vb

- De transsubstantiatione $\mathbf{1 6 7}, 71 \mathrm{vb}$

Urkunden:

- Notariatsinstrumente Brixen 1420 und 1446 (jeweils Abklatsch) 550, VD, HD (urspr. Einband lose)

- Urkundenvorlage (anonymisiert) 253, 83v

- s. auch Fragmente

Ursinus, Paulus (Arzt, 1. H. 16. Jh): Dialogus de formidine diluvii instantis anni vigesimi quarti abigenda 694

De usura 447, 207ra

Verba seniorum:

- s. Ps.-Rufinus Aquileiensis: Vitae patrum, Lib. 3

- s. Vitae patrum, Lib. 5

- s. Vitae patrum, Lib. 6

Vergilius Maro, Publius (röm. Dichter, 70-19 v. Chr.): Georgica (Federprobe) 173, 172r

Verse:

- über drei Heilige namens Joseph (34 Verse) 293, 23r

- zu Stationen im Leben Mariens und Jesu 308, 228rb

- de ornamentis filiarum Ierusalem 483, 76v

- de regimine sacerdotis $167,71 \mathrm{vb}$

- de sanctis Iohanne Baptista et Iohanne ev. 52, VDS

- de termino paschae s. Tafel zur Berechnung des Osterfestes

- Versus de titulis librorum Decretalium 145, 1r

- s. auch Regimen Sanitatis Salernitatum

- s. auch Serlon de Wilton

- s. auch Strambotto

- s. auch De transsubstantiatione

- s. auch Vita s. Mariae

Vetus testamentum 20 (unvollständig); 204

Visio Philiberti 308, 189ra

Vita beati Hartmanni episcopi (Brixinensis) 293

Vita s. Mariae post ascensionem Christi versificata 166, 51va

Vitae patrum:

- Lib. 2 s. Rufinus Aquileiensis: Historia monachorum

- Lib. 3 s. Ps.-Rufinus Aquileiensis

- Lib 4 s. Iohannes Cassianus, Sulpicius Severus

- Lib. 5: Verba seniorum 125, 301rb, 302rb, 302vb, 303ra, 303rb, 304rb, 306rb; 308, 164va, 166va, 167va, 168ra, 168vb, 170vb, 184va, 185ra, 185rb, 185vb, 186ra

- Lib. 6: Verba seniorum 125, 305vb, 307rb; 308, 174rb, 178ra, 186rb, 186vb

Vitalis Blesensis (franz. Dichter, 12. Jh.): Geta, unvollständig 327, 20ra

Volgosius, Raphael: Alphabetisches Titelverzeichnis zum Römischen Recht 578, 1ra

Votivmessen und Gebete für Verstorbene 754, 26v

Wernerus de Ellerbach OSB (Abt von St. Blasien, gest. 1126): Deflorationes ss. patrum, Lib. 1, Sermo in rogationibus 125, 288' ra; 308, 138rb

„Wiener Statuten“ s. Statuta 


\section{VORBESITZER, BENÜTZER, AUFTRAGGEBER UND KÄUFER}

Bartolomeo da Cremona 173 (Buchdrucker in Venedig)

Bertholdus (Berchtoldus hospitalis), Hospitaler zu Brixen 7; 99; 253 (Besitzer, Geschenkgeber)

Bertoldus de Saxonia, Präbendar und Arzt in Kloster Neustift 123, Vv; 453; 748, IIIv (Besitzer, Geschenkgeber)

Ebner, Johann (Brixner Domherr, gest. 1460) 4, IIv, 234r, 431va (Besitzer)

Ephensteiner, Petrus 76 (Kopist der Hs. bzw. Schreiber einer Hs. aus dem Jahr 1728)

Führer, Paul Nikolaus 76 (Buchdrucker in Brixen)

Geczenperger, Nikclas 940, HDS

Golser, Georg (Bischof von Brixen 1464-88) 353, IVrb

Härber von Ringelsberg, Lukas (Propst von Neustift 1483-1503) 405 (Auftraggeber, Besitzer)

Helene 578, Ir (Käuferin/Verkäuferin?)

Hermannus (Verwalter des Spitals in Brixen, Propst von Neustift 1200-10) 293 (möglicher Verfasser)

Iacob (Vetter des Pranttner Michel) Nr. 940, HDS

Iohannes, scholasticus aus Isny (de Ysnina) 53, HDS (Adressat einer Urkunde des Bischofs von Brixen)

Konrad II. von Rodank (Propst von Neustift ca. 1180-1200) 293 (möglicher Verfasser)

Lang, Adamus (Propst von Neustift 1581-85) 726, 76r

Mayr (Meyer, Mayer), Caspar 146; 196 (Bibliothekar)

Mérey, Sándor 146; 196

Michel auf Ellen 940, HDS

Neuhauser, Kaspar (Stadtrichter [1494-1501] und bischöflicher Zöllner [1490/92] in Klausen) 353; 654, 202r (Auftraggeber, Besitzer, Geschenkgeber)

Neuhauser, Nikolaus (Kirchpropst [1483/84], Bürgermeister [1488] und Stadtrichter [1492] in Klausen) 353, IIIra Nicolaus Leopoldus, magister ex Insprugga (1511 Lehrer an der Pfarrschule von St. Jakob, Innsbruck, empfängt 1513 in Brixen die niederen Weihen und erhält 1515 Kanonikat, gest. 1535) 167, 1r; 579, 1r (Besitzer)

Nikolaus (Propst des Augustiner Chorherrenstiftes St. Dorothea bei Wien) 76 (Schreiber, aber auch Überlasser der Hs.)

Posch, Augustin I. (Propst von Neustift, 1519-27) 100 (Auftraggeber, Besitzer)

Pranttner, Michel 940, HDS

Reger, Johann 654, A (Buchdrucker in Ulm; Druck möglicherweise Vorlage für Miniaturen)

Rugen(n), Jörg Neustifter Wappenbuch (mögliche Vorlage)

Sacchi, Bartolomeo (Bartolomeo Platina, Bartolomeo Cremonensis) 173 (Notiz am Ende)

Schabl, Augustin II. (Propst von Neustift 1569-81) 353; 654 (Besitzer); 726, 76r

Scheiber, Nikolaus III. (Propst von Neustift 1439-49) Graduale Neocellense I und II (Auftraggeber)

Schobser, Johann 654, A (Buchdrucker in Ulm; Druck möglicherweise Vorlage für Miniaturen)

Schuechl, Narziß 353; 405; 654; 15063, E (Buchbinder)

Schweidnitz, Nicolaus 614, 150r

Servacius Lichtensteyn, de Prussia Graduale Neocellense II, 210v (Buchmaler)

Sprenz, Sebastian (Fürstbischof von Brixen 1521-25) 694 (Widmungsträger)

Steigenberger, Anton (Propst von Neustift 1737-67) 146

Székely, Samuel 146; 196 (Geschenknehmer)

Troyer, Fortunat (Propst von Neustift 1678-1707) 726, 74r

Zeiller, Georg (Gregorius) 146 (Dechant - in der Hs. Gregorius, im Chorherrenverzeichnis: Georg) 


\title{
SCHREIBER, SCHREIBERVERSE UND -SPRÜCHE
}

\author{
Schreiber \\ Chirchmair, Hainricus (de Malhenstorff, möglicherweise identisch mit Kloster Mallersdorf OSB, Diözese \\ Regensburg) 447, 206vb \\ Claghewinter, Rudolph (de Saxonia) 4, 431vb \\ Edlinger, Heinricus 139 (ohne Nennung des Schreibers); 940, 1r \\ Frechen, Nicolaus 167, 71va \\ Fresell, Iacobus (de Scocia) 617, 53r \\ H., F. 14820, 85v \\ Hölzl, Georg (aus Mattighofen) 353 (ohne Nennung des Schreibernamens); 654, 202r \\ Lämpl, Erasmus 617, 134r, 191v \\ Petrus, Nicolaus 145, 313vb \\ Prensteiner, Franciscus 726, 70v \\ R., H. 142, 25vb, 37va \\ Smyt, Laurencius 550, 445ra \\ Stetner, Stephan 100, 38rb, 93rb, 94va, 104ra; 194, 70v \\ Tegedener, Matheus (de Iuterbock) 155, 105r \\ Weinkern, Albertus 614, 261r \\ Zollner, Friedrich Graduale Neocellense I, 325r; Graduale Neocellense II (ohne Nennung des Schreibernamens)
}

\section{Schreiberverse und -sprüche}

Assit ad inceptum sancta Maria meum 165, 114r; 168, 1r

Detur pro penna scriptori pulchra puella (Colophons Nr. 20587. Walther, Proverbia Nr. 5527a) 605, 5rb

Finis adest operis mercedem posco laboris etc. (Colophons Nr. 21270) 52, 4ra, 38va

Finito libro grates Christo referamus 327, 19v

Finito libro sit laus et gloria Christo. Pitet got umb den der daz geschriben hat 532, 122v

Lauda scriptorem donec videas meliorem (Colophons Nr. 22151. Vgl. Walther, Proverbia Nr. 13516a) 605, 5rb

Lex est defuncta ubi iudicis est manus uncta 614, 149v 


\section{ENTSTEHUNGSZEITEN (DATIERUNGEN)}

\section{Jh. 495}

12. Jh. 154 (mit Nachträgen 13. Jh.); 282 (2. Hälfte 12. Jh.); 315; 360; 483 (2. Hälfte)

12./13. Jh. 20; 293; 485 (um 1200)

13. Jh. 19; 86 (wohl Mitte); 107 (1210/34); 327

13./14. Jh. 156 (um 1300); 171; 605; 617, VDS Fragm.

14. Jh. 7 (1. Hälfte); 31; 52, Fälze (Anfang); 52, T. I (Ende); 52, T. II (1396: 270vb), 53 (HDS Fragm.: 2. Hälfte); 99 (1. Hälfte); 161 (Ende); 162 (Ende); 163, T. I (um 1389); 163, T. II (Ende) 168 (9. Jz. 14. Jh.); 253 (1. Hälfte); 293, Makulatureinband; 308; 440, urspr. VDS, heute abgelöst; 532; 606; 617, T. I (7./8. Jz.)

14./15. Jh. 140083 (1400: 52rb); 158 (um 1400); 182 (1400: 16rb); 183 (um 1400)

1. H. 15. Jh. 4 (Anfang); 38; 78 (um 1430/33); 106; 145 (1427: 313vb); 146 (Terminus ante quem 1445); 153 (4. Jz.); 163, T. I (um 1443); 165 (um 1407); 165, T. III (1407: 128v); 166 (1. Jz.); 167 (1419: 71va); 173 (2. Drittel); 177 (um 1430/33); 181 (um 1410); 200 (um 1415/20); 217; 447 (1414: 206vb, IX*ra); 453, T. II-IV (um 1440); 614, T. II (u. a. 1419: 261r); 614, T. III (1. Jz.); 614, T. IV (4. Jz.); 748, T. I-III (um 1440); 748, T. IV (um 1430); Graduale Neocellense I (1442: 325v); Graduale Neocellense II (zw. 1442 und 1446)

2. H. 15. Jh. 53 (1452: 237ra); 76, T. I (um 1450); 76, T. II (6. Jz.); 77 (1465: 106vb, 112vb, 119va); 123 (6. Jz.); 125 (6. Jz. 15. Jh.); 142, T. II (1459: 172v); 155 (7. Jz., u. a. 1463: 105r); 160 (um 1540); 174 (um 1470, u. a. 1472: 151rb); 196 (vor 1482?); 204 (um 1470); 252 (4. Viertel); 353 (um 1496); 397; 440 (um 1450); 550, T. I. (6. Jz.); 453, T. I (1455-1460); 550, T. II (7. Jz., u. a. 1465: 97vb, 445ra); 578 (1480: 10vb); 579 (1491: 14v); 597 (um 1464/65); 617, T. I, II, IV (7. Jz., T. I. u a. 1467: 53r); 617, T. III (6. Jz., u. a. 1455: 134r, 191v); 654 (1496: 202r); 754 (6. Jz.); 755 (6. Jz. und 1481?: 3vb); 756 (1479: 53ra); 780 (Ende); 15063 (mit späteren Zusätzen); 139, T. I (1495/96: 1r bzw. 54v); 139, T. II (Ende); 940 (1490/93: 1r bzw. 2r)

15./16. Jh. 190

16. Jh. 85 (Anfang); 100 (1524/26: 1v, 38rb, 50rb, 50v, 93rb, 94va, 104ra); 142, T. I (1521: 4r, 6v, 22va, 29rb, 43vb); 194 (1507: 70v); 405 (1501: 225r); 691 (Anfang); 694 (1523); 726 (1523: 24v, 40v, 65r, 70r, 70v; mit späteren Zusätzen, u. a. 1687: 74r); 755; 776 (Anfang, u. a. 1502: 12v); 14820 (Anfang, mit späteren Zusätzen, u. a. 1578); Neustifter Wappenbuch (1548/52); Graduale Neocellense I (1512: 324r) 


\section{ENTSTEHUNGSORTE}

Basel 77

Bologna 7; 99; 217

Bologna s. auch Oberitalien

Brixen 53 HDS Fragm.; 550 VD Abklatsch; 578

Brixen s. auch Raum Brixen

Entstehungsort unbestimmt 20; 52 Fälze; 282; 315; 360; 405 VDS Fragm.; 483; 485; 495; 532; 605; 606; 617 VDS Fragm.; 1012

Frankreich Cod. 86 (?); 327 (?)

Frankreich s. auch Nordfrankreich

Italien 173

Neustift s. auch Raum Brixen, Tirol

Neustift 76, T. I; 85 (?); 100; 142; 146, T. I (?); 190 (?); 194; 196; 252 (?); 293; 405 (?); $617 ; 691$ (?); $726 ; 755$ (?); 776 (?); 14820; 15063 (?); Graduale Neocellense I und II

Nordfrankreich (Raum Paris) 19; 107; 156

Oberitalien s. auch Bologna

Oberitalien 4 (Bologna?); 253 (Bologna?); 780 (?)

Paris, Raum Paris s. auch Nordfrankreich

Pfalzen s. Brixen, Diözese

Raum Brixen 78 (Neustift?); 353; 440 urspr. VDS, heute gelöst (?); 550, T. II (u. a. Villanders); 654

Sterzing (?) Neustifter Wappenbuch

Süddeutscher Raum 31 (?); 38 (?); 52 (Tirol?); 83; 106 (?); 123; 125; 145 (Tirol?); 146 (T. I: Neustift?); 158; 160; $161 ; 162 ; 165 ; 166 ; 167 ; 171 ; 182 ; 183 ; 397$ (?); 447; 756

Süddeutsch-österreichischer Raum 308

Schwäbisch-Schweizer Raum 748, T. IV

Tirol 4; 174 (?); 177 (Neustift?); 204 (?); 440 (?); 579 (?); 614; 617 (u. a. Neustift); 694; 754

Umfeld Neustift 154; 155 (u. a. Pfalzen); 139; 940

Wien 76, T. II (St. Dorothea); 163; 168

Wiener Raum 53 (?); 153; 181; 200 (?); 453, T. I, T. II-IV (?); 550, T. I; 579 (?); 597; 748, T. I-III (?); 755 (?) 

ISBN 978-3-7001-8625-0

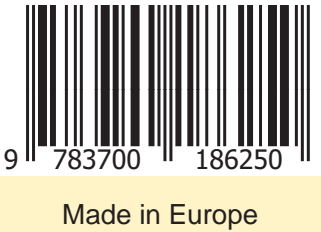

